\section{ABOUT THE OFFICE OF SCIENTIFIC AND TECHNICAL INFORMATION}

The Office of Scientific and Technical Information (OSTI) in Oak Ridge, Tennessee, provides direction for the Department of Energy's scientific and technical information (STI) program and maintains a centralized base of support to assist Departmental elements in planning, developing, and implementing STI activities. DOE-originated and worldwide literature and software on advances in subjects of interest to DOE researchers is collected, processed, and disseminated using computerized databases, publications, and other media.

This information collection containing over three million citations represents a major national resource of scientific and technical information. In addition to information acquired from DOE and its contractors, DOE acquires information through its international partnerships with the International Energy Agency's Energy Technology Data Exchange (ETDE), a consortium comprised of members from Europe, Japan, Canada, and the United States; the International Atomic Energy Agency's International Nuclear Information System, representing 80 countries; bilateral agreements with foreign governments; exchange agreements with other U.S. government agencies; and contracts with private information organizations and professional societies.

The subject scope of this information extends beyond energy, covering basic scientific studies in such areas as radiology, atomic and nuclear physics, radiation and nuclear chemistry, superconductivity, supercomputers, the environment, radioactive waste management, nuclear medicine, and arms control.

Major DOE databases are available within the United States through DIALOG Information Services and STN International and outside the United States through formal governmental exchange agreements. DOE and DOE contractor offices can access the databases online through the Integrated Technical Information System (ITIS) maintained by OSTI.

\section{FOR FURTHER INFORMATION ON THE CIVILIAN RADIOACTIVE WASTE MANAGEMENT PROGRAM}

Contact for the Yucca Mountain Site Characterization Project Office:

Robert M. Nelson, Jr.

Acting Project Manager

Yucca Mountain Site Characterization Project Office

U.S. Department of Energy

P. O. Box 98608

Las Vegas, NV 89193-8608

(7.02) 794-7920

Contact for the Office of Civilian Radioactive Waste

Management:

Ginger P. King

Education and Information Division

Office of Civilian Radioactive Waste Management

U.S. Department of Energy

1000 Independence Avenue, S.W.

Washington, DC 20505

(202) $586-5722$

\section{Yucca Mountain Site Characterization Project Bibliography}

\section{ABOUT THIS BIBLIOGRAPHY}

Following a reorganization of the Office of Civilian Radioactive Waste Management in 1990, the Yucca Mountain Project was renamed Yucca Mountain Site Characterization Project. The title of this bibliography was also changed to Yucca Mountain Site Characterization Project Bibliography. Prior to August 5, 1988, this project was called the Nevada Nuclear Waste Storage Investigations.

This bibliography contains information on this ongoing project that was added to the Department of Energy's Energy Science and Technology Database from January 1, 1992, through December 31, 1993.

The bibliography is categorized by principal project participating organization. Participant-sponsored subcontractor reports, papers, and articles are included in the sponsoring organization's list. Another section contains information about publications on the Energy Science and Technology Database that were not sponsored by the project but have some relevance to it.

Earlier information on this project can be found in the first bibliography DOE/TIC-3406, which covers 1977-1985, and its three supplements DOE/OSTI-3406(Suppl.1), DOE/OSTI-3406(Suppl.2), and DOE/OSTI-3406(Suppl.3), which cover information obtained during 1986-1987, 1988-1989, and 1990-1991, respectively. All entries in the bibliographies are searchable online on the NNW database file. This file can be accessed through the Integrated Technical Information System (ITIS) of the U.S. Department of Energy (DOE).

DOE and DOE contractors can order copies of most Yucca Mountain Site Characterization Project reports and other documents published by the DOE and the principal participant organizations from;

Office of Scientific and Technical Information

P. O. Box 62

Oak Ridge, TN 37831

Persons not affiliated with DOE or DOE contractors can order from:

U.S. Department of Commerce

Technology Administration

National Technical Information Service

Springfield, VA 22161

U.S. Geological Survey reports and maps can be purchased from:

U.S. Geological Survey

Attn: Books and Open-File Reports Section, or Map Distribution Section

Federal Center

P.O. Box 25425

Denver, CO 80225

General information and publications on the national program can be obtained through the Office of Civilian Radioactive Waste Management Toll-Free Infomation System at 1-800-225-NWPA (6972) (or, in Washington, DC, at 488-5513), or by writing to the OCRWM Information Center, P.O. Box 44375, Washington, DC 20026.

Jerry J. Lorenz, YMP Managing Editor Peter M. Stephan, YMP Technical Editor 


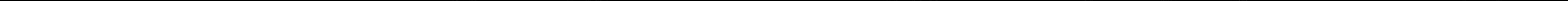




\section{DISCLAIMER}

This report was prepared as an account of work sponsored by an agency of the United States Government. Neither the United States Government nor any agency thereof, nor any of their employees, make any warranty, express or implied, or assumes any legal liability or responsibility for the accuracy, completeness, or usefulness of any information, apparatus, product, or process disclosed, or represents that its use would not infringe privately owned rights. Reference herein to any specific commercial product, process, or service by trade name, trademark, manufacturer, or otherwise does not necessarily constitute or imply its endorsement, recommendation, or favoring by the United States Government or any agency thereof. The views and opinions of authors expressed herein do not necessarily state or reflect those of the United States Government or any agency thereof. 


\section{DISCLAIMER}

Portions of this document may be illegible in electronic image products. Images are produced from the best available original document. 


\section{CONTENTS}

Foreword $\quad$ v

MANAGEMENT OVERVIEW
$\begin{array}{ll}\text { FY } 1992 & \text { vii } \\ \text { FY } 1993 & \text { vii }\end{array}$

PROJECT HISTORY

FY 1992 ix

FY 1993 xiii

BIBLIOGRAPHY WITH ABSTRACTS

Yucca Mountain Site Characterization Project Office 1

CRWMS M\&O, Las Vegas* 21

Los Alamos National Laboratory $\quad 22$

Lawrence Livermore National Laboratory $\quad 30$

Sandia National Laboratories $\quad 46$

$\begin{array}{ll}\text { U.S. Geological Survey } & 78\end{array}$

Related Information $\quad 86$

\section{INDEXES}

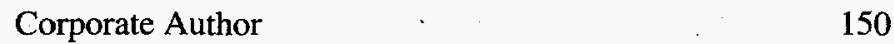

Personal Author $\quad 163$

$\begin{array}{ll}\text { Subject } & 180\end{array}$

Contract Number $\quad 223$

Report Number $\quad 228$

Order Number Correlation $\quad 243$

Key Word in Context 246

*Civilian Radioactive Waste Management System, Management \& Operating Contractor, Las Vegas. 



\section{FOREWORD}

The Nuclear Waste Policy Act of 1982 (NWPA) established a national policy for the safe storage and permanent disposal of spent nuclear fuel and high-level radioactive waste. Congress assigned primary responsibility for development of a radioactive waste management system to the U.S. Department of Energy (DOE). The concept of a deep geologic repository was selected as the safest and most feasible method for permanent disposal of spent fuel from civilian reactors and high-level waste from national defense programs.

The DOE Office of Civilian Radioactive Waste Management (OCRWM) was formed in 1983 to administer the responsibilities delegated to the DOE by the NWPA. In February 1983, the DOE identified Yucca Mountain, in Nye County, Nevada, as one of nine potentially acceptable repository sites. The sites were evaluated to determine their suitability. In May 1986, the number of sites for further consideration was reduced to three: Yucca Mountain; the Hanford Reservation in Washington State; and a site in Deaf Smith County, Texas. At these sites, the DOE planned to conduct site characterization studies, that is, extensive surface-based and underground investigations. The Nuclear Waste Policy Amendments Act of 1987 suspended site studies in Washington and Texas and directed the DOE to characterize only the Yucca Mountain site.

The Yucca Mountain Site Characterization Project Office in Las Vegas, Nevada, formerly the Yucca Mountain Project Office, has local responsibility for the scientific investigations to determine if Yucca Mountain is a suitable repository site. The Yucca Mountain Site Characterization Project (YMP) work force includes scientists from diverse disciplines as well as engineers and support personnel employed by the DOE, other government agencies, national laboratories, and private contractors. The major participants include the U.S. Geological Survey; Lawrence Livermore National Laboratory; Los Alamos National Laboratory; Sandia National Laboratories; MAC Technical Services; Raytheon Services Nevada; Reynolds Electrical \& Engineering Company, Inc.; Science Applications International Corporation; and TRW, Inc.

Yucca Mountain is located about 100 miles northwest of Las Vegas on the Nevada Test Site's southwestern border. The property is administered by the Bureau of Land Management, the U.S. Air Force, and the DOE. The parcels of land designated for the potential repository have been withdrawn from public use to prevent intrusions that might affect the quality of scientific data or future repository performance.
Yucca Mountain is a long, narrow ridge running north and south, with a steep western slope and a more gradual eastern slope. The ridge rises 1,000 to 1,200 feet above the surrounding alluvial flats. The mountain appears to possess several attributes that are desirable for a repository site; an arid environment, a deep static water table, slow hydrologic transport within the water table, and a volcanic tuff formation that would help retard radionuclide movement.

Preliminary data indicate Yucca Mountain is a favorable site, but adverse conditions may exist. Concerns have been raised about potential volcanic activity, faulting, earthquakes, and possible fluctuations in the water table.

Approximately eight more years of site characterization studies are necessary to analyze all factors that could affect the performance of a repository. If the site characterization studies are completed without discovery of any disqualifying conditions, the data gathered would be used to prepare a repository construction and operation application to the U.S. Nuclear Regulatory Commission (NRC). The NRC would then determine whether the proposed site meets strict federal regulations that prohibit a repository from posing a threat to the environment. If the Yucca Mountain site is deemed unsuitable, DOE must suspend site studies and report to Congress accordingly.

The Yucca Mountain Site Characterization Plan (SCP) is a 6,000-page document outlining numerous surface, underground, and climatological studies that must be performed to evaluate the site's suitability. The SCP contains a description of planned activities, information on their priority, and a general schedule for the site characterization program. Individual areas of study are presented in greater detail in separate SCP Study Plans. During site characterization, the DOE must also evaluate environmental and socioeconomic conditions.

Site characterization studies are divided into surface-based investigations and in situ testing. The surface-based program is a series of investigations designed to characterize the surface and subsurface environment throughout the repository study area. For in situ testing, an underground laboratory will be established at the depth of the potential repository horizon to study the processes and phenomena contributing to waste isolation performance and to evaluate how an engineered facility would affect the hydrogeologic environment.

All data gathered during the site characterization process must meet strict quality assurance $(\mathrm{QA})$ requirements to be accepted for NRC licensing. While some of the site 
characterization activities will rely on advanced state-of-theart technology and some of the country's top scientists to gather and analyze data, exemplary scientific work alone is not enough. Project staff and their contractors must follow stringent QA procedures to ensure that all data are verifiable. The NRC will require traceability of all scientific samples; therefore, measures have been implemented to ensure that site characterization activities will produce verifiable data.
The site characterization phase is expected to last until early 2001. At that time, if the site proves to be suitable, the DOE would recommend construction of a repository at Yucca Mountain. If the President approves DOE's recommendation, a formal application for a repository construction license would be submitted to the NRC. Under the current repository development schedule, the Yucca Mountain repository would begin operations in 2010 . 


\section{MANAGEMENT OVERVIEW}

\section{FY 1992}

The U.S. Department of Energy (DOE) was issued a Water Appropriation Permit by the State of Nevada for Well J-13 on the Nevada Test Site. The permit allows the pumping of water for dust suppression, site preparation, and drilling for surface-based testing and Exploratory Studies Facility (ESF) activities.

A 5.6 Richter magnitude earthquake occurred near Yucca Mountain on the morning of June 29, 1992. The epicenter was located approximately $20 \mathrm{~km}(12 \mathrm{mi})$ from the potential repository block. Collection of aftershock information revealed no surface ruptures and aided in understanding the geometry of faults at depth.

The Nuclear Regulatory Commission (NRC) lifted its Objection 2 to the Site Characterization Analysis. In so doing, the NRC determined that the DOE and DOE-participant Quality Assurance (QA) programs were acceptable for implementing site characterization and other quality-related activities.

DOE received approval to start comprehensive surface-based testing and to begin Title II design for the ESF. Design activities were initiated for north portal surface preparation, a tunnel boring machine (TBM) launch chamber, and electrical and water distribution. A separate study determined that there would be no significant impacts on floodplains as a result of ESF activities, and no cumulative impacts.

An extensive Early Site Suitability Evaluation (ESSE) report was completed. The purpose of the report was to provide DOE management with an early assessment of the Yucca Mountain site. On May 7, 1992, DOE conducted a Director's Forum focusing on policy issues related to the ESSE. The forum provided an opportunity for affected governments, Indian Tribes, interested parties, and the public to discuss policy, strategy, plans for site evaluation, and the relationship of the ESSE report to the site evaluation process.

A Total System Performance Assessment of the Yucca Mountain site, which involved an analysis of both expected and unexpected conditions, was conducted. The modeling capabilities of the Yucca Mountain Site Characterization Project (YMP) participants and their ability to generate complementary cumulative distribution functions were tested.

The National Academy of Sciences' National Research Council Panel on Coupled Hydrologic/Tectonic/Hydrothermal Systems at Yucca Mountain released its report entitled
"Ground Water at Yucca Mountain: How High Can It Rise?" The panel concluded that none of the evidence cited as proof of groundwater upwelling in and around Yucca Mountain could be reasonably attributed to that process and that significant water table excursions to the repository design level are not shown by the geologic record.

An Integrated Test Evaluation (ITE) task was initiated to integrate and evaluate the results and recommendations from various studies, performance assessments, and other sources. The purpose of the ITE is to develop recommendations regarding changes in work scope or prioritization in baseline plans. The primary criterion for prioritization is the earliest possible detection of unsuitable conditions for a potential repository at the Yucca Mountain site.

The Office of Civilian Radioactive Waste Management (OCRWM) held a workshop with interested parties, affected governments, and the public to discuss the draft Mission Plan Amendment it issued in September 1991. Responses were provided to 38 parties who submitted approximately 700 comments.

Drilling with the specially designed LM-300 drill rig began. The LM-300 uses dry drilling and coring techniques to avoid contaminating core samples and the in situ environment with drilling fluids. Surface-based excavations continued to provide samples and exposures to aid geologic mapping. Phase I of neutron access drilling on the northeastern edge of the potential repository block was completed. Phase II was begun.

A preliminary draft annotated outline for license application was developed. The purpose of the outline is to provide the NRC with DOE's understanding and interpretation of the regulatory requirements and to allow the NRC to recognize those areas where DOE requires guidance as a potential applicant under 10 CFR Part 60.

Public outreach efforts continued, with Yucca Mountain tours, workshops on the programmatic and technical aspects of the project, and exhibits. The OCRWM international program continued cooperative activities with several countries and international organizations to share advances in technology, science, and public education in nuclear waste disposal.

\section{FY 1993}

Two major program milestones were reached during FY 1993. The first came in November 1992 when OCRWM received approval from the DOE's Energy System Acquisition 
Advisory Board to start construction of an ESF. The second came on April 2, 1993, when excavation began on the ESF North Ramp Starter Tunnel. The Starter Tunnel, completed on September 9, 1993, was excavated with conventional drill and blast techniques to prepare a launch chamber for a TBM that will be used for most of the subsequent excavation.

Geologic mapping was completed to the end of the Starter Tunnel and a consolidated sampling program was conducted to obtain samples for geomechanical and mineralogical analyses. All boreholes for the neutron access program were completed. The large block test and the engineered barrier system field tests moved forward, and hydrologic modeling continued.

Advanced conceptual design of the waste package proceeded with detailed thermal, criticality, and shielding evaluations. The Director of OCRWM ordered a study to evaluate the feasibility of using a multipurpose canister in the Civilian Radioactive Waste Management System. The potential use of such a canister led to consideration of in-drift emplacement to accommodate larger canisters.

The Yucca Mountain Site Characterization Project Office started an issue resolution process to help identify, clarify, and resolve technical and regulatory issues raised during site characterization. Issue resolution is directed toward receiving guidance from the NRC in meeting the requirements of 10 CFR Part 60.

The DOE received a permit from the U.S. Bureau of Land Management for sand and gravel extraction from between Fran Ridge and Fortymile Wash, with the material to be used during ESF site preparation and construction. A point source permit was received from the State of Nevada for dust control for a cone gravel screening plant.

The Nuclear Waste Technical Review Board (NWTRB) issued a "Special Report to Congress and the Secretary of Energy" in March 1993. This report expressed the NWTRB's concerns over the program's deadlines, the need for an integrated overall nuclear waste management plan, and the effectiveness of program management. The project and affiliated contractors held workshops with, and made other presentations to, the NWTRB in response to its concerns expressed in this and other reports.

The Energy Policy Act of 1992 instructed the DOE to evaluate whether its current programs and plans for management of nuclear waste were adequate to deal with volumes or categories that might be generated through new nuclear power plants. Congress also asked the Secretary of Energy to report on additional transportation, interim storage, and geologic repositories needed for these new wastes. A draft report responding to these issues was released in June 1993 for public review and comment.

Public outreach efforts continued. Numerous tours of Yucca Mountain were conducted, and meetings were held in various communities in southern Nevada to update the public and appropriate agency personnel regarding site characterization. The OCRWM international program continued cooperative activities with several countries and international organizations to share advances in technology, science, and public education in nuclear waste disposal. In addition, the international program worked to achieve consensus on common issues and to develop and conduct cooperative activities of mutual benefit. 


\section{PROJECT HISTORY}

\section{FY 1992}

The U.S. Department of Energy (DOE) implemented a comprehensive quality assurance audit program. All participants and the Project Office were audited. In addition, bimonthly quality assurance meetings were held with the Nuclear Regulatory Commission (NRC) to ensure that the NRC is kept informed of the status of the quality assurance program. These meetings provide a forum for the DOE, NRC, Edison Electric Institute, the State of Nevada, and local governments to identify quality assurance issues and participate in their resolution.

As recommended by the Exploratory Studies Facility (ESF) Alternatives Study, ESF requirement documents were revised to provide a two-ramp configuration. The ramp sizing study was completed. Construction began on a new $138 \mathrm{kV}$ power line to provide power to meet ESF ventilation requirements.

The Early Site Suitability Evaluation (ESSE) team reported that presently available evidence continues to support the finding of the Environmental Assessment of Yucca Mountain that the site is suitable for site characterization. The report was reviewed twice, first by Yucca Mountain Site Characterization Project (YMP) technical personnel not involved in preparing the ESSE Report or its evaluations, second by a panel of university faculty and private consultants having minimal previous involvement with the program. The report was made available for public comment.

The Integrated Test Evaluation (ITE) was formally initiated in March 1992. The ITE provides a decision framework for prioritizing the site testing program and evaluating the effectiveness of tests in determining site suitability, regulatory compliance, and scientific confidence.

Work with Federal and State agencies continued to obtain permits and clearance needed for all site characterization activities. Various State of Nevada permits were received and reports were submitted as required to satisfy permit conditions.

The regional meteorology network continued to measure precipitation, temperature, wind, and lightning. The collection gage network was expanded from 104 to 120 gages. Daily weather patterns were monitored and categorized according to the five major weather types of North America. Erosional and depositional features related to severe runoff were studied. Water levels were obtained from observation wells in the subregional groundwater flow system. Precipitation, streamflow, and recharge events were documented. Meteorological monitoring and air quality data acquisition and processing continued. The monitoring focused on acquiring atmospheric dispersion information. Air quality data were reported to the State of Nevada in fulfillment of permit requirements.

Several studies continued to characterize unsaturated-zone infiltration. Laboratory measurements were completed on transects of surface outcrop samples to determine bulk density, porosity, grain density, saturated hydraulic conductivity, and sorptivity. A series of transects characterized horizontal and vertical variability in the nonwelded shardy base of the Tiva Canyon flow unit. A small-scale deterministic model was used to evaluate mechanisms of net infiltration occurring on a small watershed. Large-scale net infiltration processes were evaluated using one-dimensional simulations of USW UZN-55. A preliminary field calibration has been developed from core data from this hole. Sites were selected for artificial infiltration studies, and several types of infiltrometers and sampling schemes were tested and evaluated.

To characterize percolation in the unsaturated zone, a procedure for preserving, handling, and analyzing core samples from Yucca Mountain drill holes was approved and implemented. Prototype testing continued on several laboratory techniques. New test equipment was received, tested, and put into service. Monitoring of three boreholes adjacent to the Hydrologic Research Facility building continued, with sensors at depths of $10,20,30$, and 40 feet producing excellent quality data.

Percolation tests continued on a large, fractured, weldedtuff block from the Tiva Canyon columnar unit. Development of the Moise projection method for fracture profile characterization continued. Prototype testing of Apache Leap Tuff identified the strengths and weaknesses of the equipment and methods proposed for use in the ESF and surfacebased air permeability testing.

In the gaseous-phase movement studies of the unsaturated zone, tests were conducted to determine if thermal infrared surveys could locate fractures that exhaust air due to topographic effects. The surveys indicated that false positive readings were generated by overhanging ledges and loose boulders. The tests indicated that aerial infrared surveys would not be useful in detecting blowing fractures, although a stationary thermal imager focused on one area for a long duration might detect blowing fractures on very cold nights.

Rock-gas samples from USW UZ-1 were analyzed for gas compositions and isotopic data. Batch and column tracer gassorption tests were completed. Batch tests were conducted for the adsorption of tracer gases on Yucca Mountain volcanic 
tuffs and borehole stemming material. Monitoring continued on the injection of trace gas into the drilling air at UE-25UZ\#16. Three sample collection ports were installed on the uphole drilling line to check air leakage.

Pore-water extraction tests were conducted on welded and nonwelded tuff cores and rock chips to determine (1) the relative efficiency of recovering pore water by continuous compression loading rather than stepped loading, (2) the ability to extract pore water from chips as well as from core, and (3) if pore-water chemistry results were similar for all methods. Preliminary analyses show very little difference among the methods.

Studies continued of fluid flow in unsaturated, fractured rock. The flow module of computer program SFIT was used to simulate a hypothetical imbibition experiment into a column of soil with properties taken from the VS2D documentation. Results from this simulation were then used as input to the parameter estimation module of SFIT, permitting investigation into the data producing the most economical and accurate estimates of the soil properties from imbibition experiments. Fracture network simulations of the variability in pressure head and flux distribution in variably saturated fractures were examined as a function of boundary pressure head. The flow model of SFIT does not seem capable of simulating flow problems involving hydraulic properties thought to be reasonable for tuffs. The TOUGH simulator for unsaturated flow in fractured formations was modified to enable analytical computation of matrix imbibition from the fractures.

Four two-dimensional, vertical cross sections through the main fault zones including as many wells as possible were chosen for numerical simulations for site unsaturated-zone modeling. Simulations were performed with the TOUGH2 code using various rock properties and boundary conditions. Results were used to control the accuracy of the threedimensional grid and to evaluate the effect of permeability and porosity contrasts at the boundaries between hydrogeological units and sublayers.

Monitoring of water levels in the saturated zone continued. Four zones in two wells were monitored continuously to detect water-level fluctuations caused by earthquakes and underground nuclear testing. Earthquake-related data were provided to the State of Nevada. Monitoring strain-related pressure responses in wells due to atmospheric loading, earth tides, and seismic events continued. Batch sorption experiments for lithium bromide at the C-hole sites were completed.

Site groundwater and precipitation chemical and isotopic data were compiled and entered into a spreadsheet file to provide a means to assess data suitability at site scale. Work progressed on assembling information relative to the procurement of a downhole data- and sample-collection system. Work continued on the revised potentiometric water level map in the vicinity of Yucca Mountain. Several Geographic Information Systems (GIS) for performing three-dimensional geologic modeling were evaluated. This work contributed to saturated-zone hydrologic system synthesis and modeling.
Data were collected and summarized on chemical, mineralogical, petrographic, mechanical, and hydrologic properties for six potential field-testing locations. These locations may be considered for installation of a shallow mined facility for field-testing of rocks analogous to the tuffaceous beds of Calico Hills. Twenty-nine samples of cuttings from drill hole USW H-5 were analyzed using x-ray diffraction (XRD) to better define the transition from vitric to zeolitic tuff with depth. Trace-element data collected by instrumental neutron activation analysis were used to draw distinctions between drill cores and between calcites above or below the water table.

In studies of the history of mineralogical and geochemical alteration of Yucca Mountain, data collection was completed on trace-element chemistry and microfossil features used to determine whether or not a calcrete sample was of pedogenic origin. Field data were collected and petrographic studies were completed on samples from outcrop sites at Yucca Mountain and Busted Butte that have a bearing on evaluating the hypothesis of upwelling water from depth. Data collection was completed on the effects of dehydration and rehydration on samples from USW G-4 in the lower vitrophyre of the Topopah Spring Member of the Paintbrush Tuff. The loss of water and volatile elements was assessed, and samples were characterized by XRD, infrared spectral analysis, and chemical analysis.

Data collection was completed on the effects of crushing, grinding, sieving, and washing of samples used in batch sorption measurements of cesium, strontium, and neptunium on zeolitized and devitrified tuff. It was found that sorption ratios for all three radionuclides remained essentially the same for tuff size fractions greater than 75 micrometers. For size fractions under 500 micrometers, mineral fractionation could occur during the grinding process. A series of experiments was begun to measure the batch sorption coefficients of neptunium in crushed-tuff samples under a variety of conditions.

Neptunium transport experiments under advective and diffusive conditions to elucidate the migration of neptunium through tuff were completed. These studies were complemented by batch sorption studies designed to identify the minerals in tuff responsible for the sorption of the neptunium. Results indicate that iron and manganese oxides and oxyhydroxides strongly bind neptunium.

The computer code FEHMN was used to generate a threedimensional, finite-element mesh to transport nuclides separately through matrix and fracture materials. A conceptual design was developed for testing radionuclide transport concepts at Yucca Mountain. The design, using a combination of geological, geochemical, geophysical, and hydrological techniques, will enable the determination of flow and solute response over a $10 \times 10 \times 10$ meter block of tuff.

A two-dimensional analysis of gravity profiles across Yucca Mountain relative to deep detachment faults was completed. Strontium isotopic variations within the Topopah Spring welded and lithophysal units from boreholes USW G-4 and 
UE-25a\#1 were further evaluated to assess the utility of strontium isotopic analysis for evaluating stratigraphy within the lithologically monotonous repository horizon. Volcanic units sampled below the water table from boreholes UE$25 \mathrm{JF} \# 3$ and UE-25J\#13 were analyzed for selected trace elements and strontium isotopic compositions. Detailed gravity and magnetic profiles across the Midway Valley area were obtained. These studies are designed to support the seismic transect across Yucca Mountain.

Mapping and measurement of fault parameters along and within the Ghost Dance Fault continued. Structural analysis of exposed parts of the Ghost Dance fault zone in the vicinity of the potential repository block began. Numerous previously unmapped faults were mapped. Fracture data at four bedded-tuff stations and one upper-lithophysal station were collected and analyzed. Validation studies on computer programs that model seismic wave propagation through fractured rock continued. Various combinations of anisotropy were used to model the effect of fracture anisotropy on the vertical seismic profiling $\mathrm{C}$-hole source locations.

In work to develop three-dimensional rock characteristics models, results from the earlier outcrop sampling scoping study provided insight into the spatial distribution of physical rock properties in unsaturated zone units at Yucca Mountain. A set of new geostatistical simulations of hydrologic properties was generated. Lynx GMS software, which offers greatly enhanced, true three-dimensional modeling capabilities, was obtained, and selected data were input into the system.

In climate studies, ostracode samples were collected in New Mexico to develop a method for linking the strontium isotope composition in ostracodes to the saline composition of the host waters. In southern Nevada, the method will help reconstruct mean annual air-temperatures and precipitation. Pollen from aquatic sediments and plant macrofossils from packrat middens were studied for evidence of the type of past vegetation community in the region. The cellulose extracted from woody plant material preserved in packrat middens is expected to provide a stable isotope record that may also be used to reconstruct climate.

Sampling was begun for carbonate-bearing materials in Midway Valley soil pits for geochronological purposes. Data from these samples will help to provide absolute ages for alluvial surfaces identified through Quaternary mapping and establish a time frame for estimating past states of effective moisture. A test plan was developed for the global ice sheet dynamic model to be implemented by the University of Maine.

In Quaternary regional hydrology characterization, paleoflood channels, drainage basins, alluvial fans, and geomorphic surfaces in the Yucca Mountain region were evaluated, and techniques were developed to investigate regional paleoflood features using a geomorphometric approach. Field investigations were conducted at several sites to provide data on the mechanics of hydrologic transport related to past and present floods. Vegetation distribution mapping in the Amargosa Desert continued. Spring and well water samples continued to be an important contributior to the geochemical characterization of groundwater flow systems. Isotopic characterization of groundwater and spring deposits in Crater Flat was completed. Carbonate-rich paleodischarge deposits at the southern end of Crater Flat were studied for uranium-disequilibrium dating.

Data from 1985 through 1991 were compiled to develop a water data management file to support watershed modeling applications using the Precipitation-Runoff Modeling System (PRMS). Data on chloride-ion concentrations from the bulk precipitation collectors and also from periodic grab samples of streamflow were used to compute average concentrations at the various collection sites. These estimates were used in the first step of the chloride-ion balance equations to estimate the average annual sum of all returns to the atmosphere.

Oxygen isotopic data from opaline silica from Trench 14 calcrete and secondary mineralization in Yucca Mountain drill core samples were reviewed to determine formation temperatures for the coexisting calcite in the unsaturated zone. Continued work on the secondary calcite samples from Yucca Mountain indicated that calcites in the unsaturated and saturated zones precipitated from distinctly different fluids. Delicate growth-banding of the unsaturated zone calcite, observed by cold cathode luminescence, indicates that this calcite may record a long history of deposition. Samples previously analyzed for strontium isotopes were analyzed for uranium, thorium, and lead contents as well as lead isotopic compositions.

Hydrologic modeling hardware and operating system software needs were evaluated, and surface-water flow model evaluation continued, as part of the effort to characterize the future regional hydrology due to climate changes. Mapping of drainages, faults, hydrologic basins, water chemistry, and other hydrologic considerations continued. Regional studies to elucidate the mechanism of recharge and discharge continued. A complete structural analysis of the regional study area was conducted in an attempt to evaluate the effects of stress regimes on groundwater fracture flow.

In postclosure tectonics studies, a strategy was developed for calculating the probability of bounding the effects of magmatic disruption on a repository. The stratigraphy of the Lathrop Wells volcanic center was revised using field data from trenching studies and geochemical studies. Paleomagnetic data was evaluated for lava flow units at the Lathrop Wells volcanic center. Geochemical and petrological data for the Crater Flat volcanic field were examined.

All the north ramp ESF test pits were excavated, and the inplace testing was completed. Laboratory investigations tested a range of soil and rock properties, and the data were submitted for use in the surface facilities design process.

Several rock types were tested at eight government and private rock mechanics laboratories. This work supported 
efforts of the Standards Research/Steering Committee of the American Society for Testing Materials (ASTM) for the Interlaboratory Testing Program for Rock Properties to establish measures of precision for published standard ASTM rock property test methods. Axial strain rate experiments were completed on saturated rock samples, and creep experiments were begun on other saturated samples. Studies proceeded on defining the baseline-condition test technique for determining the mechanical properties of fractures. The frictional behavior of artificially produced, relatively smooth, fractures was investigated. To determine the variability of the roughness of natural fracture surfaces, topographies of 17 natural fractures from various rock types including tuff from Yucca Mountain were studied. The time-dependent mechanical properties of fractures were investigated to address long-term stability issues within the potential repository. A study was completed on the effects a hot thermal environment would have on test instrumentation proposed for the in-situ thermomechanical experiments.

Mapping was completed of an exploratory trench across two vegetation lineaments coincident with the mapped trace of the Bow Ridge Fault. Excavation and logging of test pits in Midway Valley was begun. Trenches were excavated at the site of prospective surface facilities. Trench mapping focused on surface faulting events, total vertical dip-slip displacement, and the amount of lateral displacement of Pleistocene colluvial deposits.

In faulting studies, a preliminary study was begun of fault zones in the Rock Valley fault system. Field reconnaissance was conducted to evaluate published and unpublished geologic mapping of a proposed detachment fault in the Bare Mountain area. A structure map of southern Yucca Mountain was prepared from unpublished geologic mapping. Preliminary investigations were made of the Busted Butte exposures of the Paintbrush Canyon fault. Samples of pedogenic carbonate were collected from both buried and relict soils and fault zones in the Busted Butte exposures and Trenches 14C and 14D at Exile Hill. The relationships between recently exposed buried soils and fault-related fractures and veins were examined and sampled for geochronological work at several sites. Surface deformation caused by the Landers earthquake of June 28,1992 , was examined to determine whether similar features, indicative of paleoearthquakes, might be recognizable near Yucca Mountain.

Work continued on models and codes to analyze the responses of jointed rock masses representative of the potential repository site. Work continued on a series of numerical analyses of laboratory experiments designed to evaluate and validate joint models. Studies were conducted on the effects of nonstandard loading conditions on the frictional properties of joints.

Calculations were completed examining the temperature and stress changes at all exploratory access and drift locations planned for construction during site characterization. Twodimensional thermal analyses were run in support of the study on thermal management of the potential repository. Initial design analyses were completed addressing the range of thermal loading that would be appropriate for both indrift and in-borehole emplacement schemes.

The development of a borehole sealing strategy continued. Sealing components were evaluated on the basis of response to seismic loads. Computer codes usable in assessing sealing component performance were identified. Studies were conducted to evaluate water flow through a backfilled drift, thermomechanical and strength requirements for grouted fractures, and seismic analysis of sealing components. Hydrologic analyses were conducted to determine the lateral extent of water flow in a drift from a discrete, waterproducing zone. Gaseous flow analyses were conducted to determine the lateral migration of gaseous flow through backfill. Geochemistry analyses considered alterations of the mineralogy of the Topopah Spring and Calico Hills tuffs. Preliminary temperature and stress change histories were developed assuming various loading conditions.

Conceptual waste package design began for a large-block laboratory test of coupled thermal-hydrologicalmechanical-geochemical-corrosion phenomena. The waste package environment feasibility study continued using a resonant cavity to measure relative humidity in laboratory rock samples. A suite of fracture-matrix flow calculations was conducted to compare primary retardation mechanisms affecting radionuclide transport in fractures. Repository and drift scale hydrothermal model calculations were made to quantitate the impact of repository-heat-driven hydrothermal flow on hydrological performance and the impact of high areal power densities on the ambient hydrothermal system. Calculations were also made to quantitate the ability to discriminate between conduction-dominated heat flow and heat flow that is significantly influenced by far-field convection. Repository thermal calculations using heat conduction models were performed. Several suites of scoping calculations were performed to systematically examine the sensitivity of hydrothermal performance. The impact of low thermal loads on repository-heat-drive refluxing was examined. Work began to examine the impact of repository-heatdriven hydrothermal flow on the hydrology and geochemistry of the saturated zone.

In studies characterizing the spent fuel waste form, a flow through dissolution test was conducted with ATM-105 spent fuel that had been partially oxidized. A series of dissolution measurements was conducted on uranium dioxide pellets. Surface area changes were further investigated using electron spectroscopy for chemical analysis and scanning electron microscopy. Tests revealed the absence of a substantial difference in dissolution rates between oxidized and unoxidized specimens. Dissolution tests on glass waste form continued.

GEMBOCHS programs were used to generate revised suites of thermodynamic data files to support the EQ3/6 geochemical modeling package. The requested set of GEMBOCHS 
parameter screens was generated for inclusion in the YMP Technical Data Base Parameter Dictionary. A guideline was prepared documenting the rationale for the organization of chemical species and reaction in future versions of the EQ3/6 data files. Restructuring was completed for sets of basis and auxiliary basis aqueous species used in $\mathrm{EQ} 3 / 6$ calculations. EQ3/6 user manuals were prepared. Waste package performance assessment model development progressed with completion of the individual software plan for PANDORA version 1.1 and its user manual.

Testing and calibration continued on the flow-through system designed to study the adsorption and hydrology of pore fluid with radionuclide tracers. Microscopic examination of autoradiography film exposed to tuff core wafers and a sample of Climax Stock granite revealed the presence of alpha tracks. Transmission electron microscope and optical microscope analysis of colloids separated from uranium dioxide leach solutions was conducted. Experiments were begun to measure the effect of temperature on the acid/base and uranium adsorptive properties of iron oxide goethite.

Various concepts were evaluated during the advanced conceptual design phase of waste package development. Preliminary waste package criticality and shielding analyses were performed. Thermal conduction calculations for the drift emplacement of robust waste packages are continuing.

Standard probabalistic risk assessment methods were applied to the ESF design to determine the impact of ESF design changes on previous radiological risk evaluations. Results of the study will be used to identify "Items Important To Safety."

Performance assessment code verification continued. LLUVIA-II was modified to allow treatment of dipping layers. LLUVIA-II is being used in determining infiltration limits that may cause significant lateral diversion of water in Yucca Mountain. Evaluation of the modified version of the JACQ3D code on a two-dimensional infiltration problem was completed. Benchmarking was completed to evaluate the applicability of COYOTEII to flow problems.

Experimentation into gravity driven fingering in unsaturated fractures continued. Work continued on the gas permeameter to be used to collect data for testing effective media property models. Experiments progressed to develop scaling laws for saturated and unsaturated systems containing micro-layering and cross-bedding heterogeneities. Efforts continued in the development of $\mathrm{x}$-ray absorption and transmitted light as techniques for measuring moisture content in porous media.

An intermediate-scale caisson experiment was in progress to demonstrate a strategy to validate key geochemical and hydrological assumptions in performance assessment models. Preliminary geochemical characterization of several candidate materials was conducted. The preliminary design assumes the bulk of the caisson contains Wedron 510 sand with a sorbing layer composed of a mixture of sand and powdered limonite. To reduce the confounding influence of disequilibrium with atmospheric carbon dioxide on $\mathrm{pH}$ measurements, a method was developed to carry out batch experiments under carbon dioxide-free conditions. A computer-driven autotitrator was fabricated for the acidimetric and alkalimetric determination of mineral surface hydrolysis constants.

Unsaturated flow analysis continued with completed work on a two-dimensional numerical analysis of a portion of the Yucca Mountain region. NORIA-SP was used to generate a time-dependent flow field. The STAFF2D code was used to calculate flow and transport in the saturated zone for the Total System Performance Assessment. The geometry was set up for two cross sections, one perpendicular and one parallel to the wash where boreholes N54 and N55 are located. Geostatistical simulation of porosity between USWN54 and USW-N55 for the Yucca Mountain INTRAVAL Test Case was successfully demonstrated. A cross-sectional model for the saturated-flow model was constructed.

Several studies involving conceptual model development to identify methods of handling uncertainty of pre-wasteemplacement groundwater travel time progressed or were completed. Tools were developed for data analysis. Progress was made on compiling and interpreting fracture data and transport parameters from currently available site data.

Results were obtained from a set of analyses for the initial total-system performance assessment: groundwater flow, gas flow, human intrusion, and basaltic volcanism. Development of source-term inventories continued using the ORIGEN database. The source terms reflect the changes in isotopic compositions due to reactor type, amount of burnup, and length of decay since discharge from the reactors. Work continued on the development of the total-system simulator platform, WINGZ. These efforts support calculation of an empirical complementary cumulative distribution function.

\section{FY 1993}

The Department of Energy issued the "Quality Assurance Requirements and Description for the Civilian Radioactive Waste Management Program" (QARD), which represents the highest level quality assurance (QA) requirements within the program. The QARD more specifically defined the applicability of the QA program and established a methodology for establishing QA controls based on the importance of items to which a given activity is related. The relative importance is based on considerations of radiological safety and waste isolation.

Construction of the Exploratory Studies Facility (ESF) began on November 30, 1992, with site preparation work. Site preparation included construction of a topsoil storage area, rock storage area, access roads, and a facility pad. Excavation of the 60-meter starter tunnel began on April 2, 1993, and was completed on September 9, 1993. The contract for the 7.6-meter diameter tunnel boring machine (TBM) was awarded on June 4, 1993, with delivery scheduled for April 1994. The ESF design was enhanced to provide reorientation of drifts so 
as to maximize the vertical distance from emplacement drifts to the water table, allow potential repository layouts that avoid having emplacement drifts crossing the Ghost Dance Fault, preserve the conventional rail haulage option in the main drift and Topopah Spring level ramps, and preserve potential repository design flexibility.

Interactions continued with the Nuclear Regulatory Commission and other oversight organizations. A Yucca Mountain Site Characterization Project (YMP) Environmental Audit Program was established in preparation for an Environmental Compliance Audit. Compiling began of a list of data needs to support design, performance assessment, and licensing activities. The Technical Data Parameter Dictionary identifies and defines the data.

In studies to characterize the meteorology for regional hydrology, the precipitation and meteorological monitoring collection gage network was expanded. Automated weatherdata acquisition continued via the weather stations and tipping-bucket precipitation gages, and statistical analysis of data was begun. Monitoring of streamflow and surface-water runoff continued. Hydrochemical sampling was performed in three deep, 2-inch-diameter piezometers in the central Amargosa Desert, and hydraulic testing and hydrochemical sampling were conducted at drillhole USW UZ-14. Soil-moisture measurements and depth-to-water measurements were made regularly in upper Fortymile Wash.

In studies to support regional hydrologic system synthesis and modeling, development of a three-dimensional hydrogeologic framework model of the regional flow system at Yucca Mountain continued. Refinements to a twodimensional finite element mesh of the subregional flow system were made. A series of Geographic Information System maps was developed by synthesizing and interpreting much of the regional hydrogeologic data of the Death Valley region. Present-day discharge areas and previously estimated flux rates were analyzed. A regional potentiometricsurface map of the regional model area using well, spring, and surface hydrography data was developed. Regional water chemistry data were sorted, and basic statistics were run on the basis of lithologic group.

An experimental surficial sampling project was conducted to characterize the hydrologic and physical properties of surficial materials. Bulk samples were collected from the exposed alluvial face at neutron access hole UE-25 UZN \#85. Preliminary map unit descriptions for geomorphic surfaces, depth to bedrock, and soil classification were defined and evaluated. Calibration techniques were developed for all of the probes used with the geophysical logging van. Studies were conducted to collect data needed for the smallscale deterministic model. Deep borehole infiltration processes were investigated by the development of a onedimensional model of USW UZN-55. A prototype ponding/infiltration study was conducted at the UE-25 UZN \#85 neutron access borehole, and a preliminary twodimensional model was developed which contained nine major stratigraphic units. All of these studies contributed to characterization of unsaturated-zone infiltration.
Borehole UE-25 UZ\#16 was completed in March 1993. Core samples from this hole, as well as samples from USW UZN-31 and USW UZN-32, were processed for porosity, bulk density, particle density, and water content in support of the continuing study of the surface-based study of percolation in the unsaturated zone. Rock physical property determinations were completed on all available surface outcrop transect samples. Construction continued on a second permeameter to measure single-phase water or air permeability on densely welded tuff.

Fracture profile characterization continued with the installation of high-resolution imaging equipment and related software. A low-pressure vessel to test single fracture rock cores was fabricated. Measurements were made of water-flow rates through a naturally fractured core at unsaturated conditions. The ponding test on a large, fractured, welded tuff block from the Tiva Canyon columnar unit continued. Monitoring began for perched water in the ESF Starter Tunnel.

Several studies were conducted in support of characterization of gaseous-phase movement in the unsaturated zone. Gasflow data from Borehole USW UZ-6a were collected, tabulated, and analyzed for utilization in the three-dimensional gas-flow and transport model. Gas sampling for gas chromatographic analysis and for isotopic analysis was conducted in boreholes USW-UZ-6, USW UZ-6a, USW UZ-13, and selected neutron access boreholes. A standpipe for measuring air flow direction was designed, constructed, and installed at USW UZ-6a.

The annual gas sampling at borehole USW UZ-1 was conducted in January 1993. Batch-type experiments were conducted to test the sorption and desorption of sulfur hexafluoride and carbon dioxide tracer gases on crushed tuffs of the Tiva Canyon and Yucca Mountain members of the Paintbrush Tuff. Laboratory analyses of gas samples continued. Cores from UE-25 UZ\#16 and USW UZ-14 were tested for pore-water extraction by one-dimensional compression and distillation for water analysis of the pore waters. Pore-water extraction by distillation was accomplished on over 90 cores from various boreholes.

Several activities supported the study of fluid flow in unsaturated, fractured rock. Preliminary work was completed to test the feasibility of deriving fracture porosity from acoustic properties of fractured core. Data on fracture orientation, dip, frequency, density, orientation, and flow rates in differential stress regimes, and fracture characterization at different scales, were compiled. This data will be used as input to fracture network models. An approximate expression for the Warren-Root alpha parameter, which governs the fracture/matrix interflow rate and equilibrium time, was developed.

The decoupling of the numerical code TOUGH was completed, to enable solving unsaturated-zone site modeling problems involving flow only. A study was performed addressing the accuracy of the three-dimensional site-scale 
model with respect to the grid spacing used. New moisture tension permeability and porosity data were received from other unsaturated zone activities. Incorporation continued of structural and material properties data into the site model.

Monitoring of water levels in the saturated zone at Yucca Mountain continued in support of site saturated-zone groundwater flow system characterization. Selected zones in two wells were monitored continuously to detect water-level fluctuations caused by earthquakes and underground nuclear testing. Work continued with expanding the two 3-zone packer systems to three 5-zone packer strings. Wells UE25c\#1, UE-25c\#2, and UE-25c\#3 were instrumented with transducers in an open-hole configuration to collect atmospheric-loading data.

Saturated-zone hydrochemical data from several sources were checked for quality, formatted, and combined with previously entered data to yield a general database. Samples and data were collected at UE-25 UZ\#16. Field data and samples were collected during construction of USW UZ-14. Field data and samples were collected at springs within Death Valley National Monument to provide a hydrochemical and isotopic means of determining relationships, if any, with the geohydrologic system of which Yucca Mountain is a part.

Several modifications were made to the fracture flow and transport code TRINET. Fracture mapping in the Bullfrog Member of the Crater Flat Tuff at Raven Canyon and east of Little Skull Mountain was completed. Outcrop samples of the Crater Flat Tuff were collected and analyzed for bulk density, porosity, and particle density. These studies contributed to saturated-zone hydrologic system synthesis and modeling.

Data were collected and summarized on various chemical, mineralogical, and petrographic studies. Collection of quantitative $x$-ray diffraction data on mineral distribution and their likely modes of interaction with nuclear waste was completed. Preliminary data collection on the chemical composition of fracture calcites at Yucca Mountain was completed. Data collection was completed on the effects of varying humidity on the calibration data obtained for clays and zeolites occurring at Yucca Mountain. Dust samples were collected from natural dust traps at and near Yucca Mountain and from the cyclone on the drilling rig at UE-25 UZ\#16. These samples were characterized using x-ray diffraction and scanning electron microscopy to define natural background dust levels in the Yucca Mountain area.

A study evaluating the use of potassium-argon geochronology in determining the alteration history of the zeolitized portions of Miocene tuffs at Yucca Mountain was completed, and potassium-argon studies of secondary minerals using the electron microprobe and scanning electron microscope continued. Data collection was completed on altered rock at Busted Butte and Yucca Mountain in order to address a concern about hydrothermal processes that could compromise the isolation capability of a potential waste repository. The mineral content of ashed plant roots from the vicinity of Trench 14 was determined.
In batch sorption studies to help characterize site geochemistry, data collection was completed on the study of uranyl interactions in goethite/solution interface. Data collection was completed on a study of radionuclide sorption as it relates to sample grinding, surface area, and water composition. Data collection on atomic force microscopy images of goethite and hematite surfaces was completed.

Speciation measurements were conducted using nuclear magnetic resonance and electronic spectroscopy. Data collection was completed on the study of actinide solubilities and speciations in two Yucca Mountain groundwaters. Model development continued on the determination of speciation information from experimental data.

Data collection was completed for a study on retardation of neptunium by minerals in Yucca Mountain tuffs as a function of groundwater chemistry. Column experiments were completed to determine the rate of neptunium sorption onto tuffs. The hydrologic parameters of solid-tuff columns that will be used to study neptunium transport were determined. Radionuclide migration studies through fractured-tuff samples from borehole USW G-1 were begun. Characterization of the hydrological parameters and mineralogy of a column of fractured tuff from borehole USW G-1 was completed. Data collection was completed on neptunium diffusion and on the diffusion of sorbing and nonsorbing radionuclides in saturated tuff.

Dual permeability models capable of representing flow in both fractures and matrix material were completed for airwater systems for both flow and transport. A method for generating computational meshes for Yucca Mountain flow and transport simulations was developed. A new version of FEHM, which incorporates memory allocation, was completed. Work was also completed on FEHM enhancements that allow two-dimensional triangular elements in threedimensional space. An unstructured-mesh construction tool was used to improve the mesh generation capability of FEHM and to allow the three-dimensional grid of Yucca Mountain to more realistically capture the hydrologic units.

Studies to characterize the vertical and lateral distribution of stratigraphic units within the site area were continued. Geologic cross sections depicting the North Ramp, South Ramp, and main Topopah-level drift alignments of the ESF were completed. Construction of isopach and structural contour maps continued. Updates to the lithostratigraphic model continued. New gravity and ground magnetic data sets obtained in Yucca Wash were reduced to obtain anomaly values. Magnetic susceptibility and magnetometer logs were acquired in boreholes UE-25 UZ\#16 and USW NRG-6.

Stratigraphic- and structural-feature field mapping along the trace of the Ghost Dance fault system continued. Detailed geologic mapping of the northeast corner of the site area continued. Samples from a stratigraphic sequence of Tiva Canyon tuffs were prepared and analyzed for trace element geochemical analysis. Work began on petrographic examination of a suite of rock samples collected from subunits 
within the Tiva Canyon Tuff. X-ray fluorescence analyses of tuff samples from northwestern Yucca Mountain and southern Crater Flat were completed. Conventional and photogrammetrical mapping of the North Ramp Starter Tunnel began, and rock samples were collected. Work continued on the incorporation and integration of the vertical seismic profiling model with rock characteristics.

Studies continued to develop three-dimensional models of rock characteristics at the potential repository site. The adaptive grid algorithm was implemented and applied successfully to the stochastic simulations of the N54/N55 cross section of the medial Paintbrush Tuff sequence. The geostatistical indicator simulation exercise of stochastic sequences of welded versus nonwelded tuff for Yucca Mountain was completed, and the results were incorporated into the ongoing Total System Performance Assessment.

In climate studies, physical and chemical properties data for ostracode species from various sites in the western United States were categorized and analyzed. Modern terrestrial gastropods were collected from different elevations in the Sheep and Spring Mountain ranges to provide shells for stable isotope analysis. Previously collected middens were processed, sorted, and analyzed. Cores were taken from three localities in southern Nevada and sampled for pollen, weight loss, and ostracodes. Carbonate-rich samples from buried soils were collected from several trenches in Midway Valley and outcrop sites in Fortymile Wash. A new suite of playa samples was selected for geochemical and strontium isotopic analysis. Strontium analyses were performed on several precipitation samples gathered from storms at Yucca Mountain.

Flood flow and related precipitation data for the Yucca Mountain/upper Amargosa River watershed were compiled and analyzed in support of the characterization of quaternary regional hydrology. Water samples were collected from wells and springs and were analyzed for major ions and/or strontium isotopes. Plots of hydrochemical data and flow paths were developed for testing groundwater flow system hypotheses. Samples were collected for geochronological studies at spring discharge sites near the southern end of Crater Flat. Pedogenic and spring discharge deposits at Yucca Mountain and vicinity were re-examined in light of the uncertain origins of some of these deposits. Several sites whose groundwater discharge origins are wellestablished were selected for comparison of their physical, morphological, and geochemical features with deposits of a less-certain nature.

At the Lathrop Wells volcanic center, four trenches were excavated and studies were begun to investigate the stratigraphic relationship of the lava flow and pyroclastic surge volcanic units. Statistical analyses of the conventional potassium-argon and argon- 39 and -40 data sets were completed. Paleomagnetic sampling of the lava-flow units and measurement of field magnetic directions of oriented clasts from dissected scoria deposits were completed.
The assembly of new information was begun on radiometric age data from altered rocks and known mineral occurrences in the vicinity of Yucca Mountain. The evaluation of hydrocarbons in the Yucca Mountain region and at the Railroad Valley analog continued. Strontium isotopic data for Paleozoic limestones from Bare Mountain, Striped Hills, Spring Mountains, and ranges in the Indian Springs Valley were compiled and evaluated. These studies contributed to the natural resource assessment of the Yucca Mountain area.

Meteorological monitoring continued at nine sites. A field study for scoping air diffusion measurements in mountain terrain was conducted. Sample collection and analysis continued for air particulate radionuclide concentrations, ambient gamma radiation, ambient radon concentrations, and radionuclide concentrations in surface soil at selected locations.

In the exploration program, a section map of the North Ramp/Bow Ridge fault area was prepared to incorporate the information from boreholes UE-25 NRG\#1, UE-25 NRG\#2, UE-25 NRG\#2A, UE-25 NRG\#2B, UE-25 NRG\#3, and UE-25 RF\#8. Drilling was completed on boreholes UE25 NRG\#44 and UE-25 NRG\#5. The locations for additional North Ramp boreholes designated USW NRG-8a, USW NRG-8b, and USW NRG-8c were identified.

Laboratory testing of core from UE-25 NRG\#1 was completed. Testing of dry-air samples from ten depths between 0.34 and 126.8 meters was completed from ambient to 110 degrees Celsius. Polished thin sections were made on samples from depths 6.8 to 126.8 meters, and mesoscopic descriptions were completed for these samples.

Calibration and calibration verification runs were completed for thermal expansion testing of both large and small samples. Thermal expansion samples in 25.4 millimeter and 101.6 millimeter lengths were machined and inspected. Thermal expansion tests were completed using samples from USW G-1 to establish the maximum heating rate for samples containing tridymite and cristobalite. A small and a large sample from Busted Butte Unit TSw2 were run to establish the thermal expansion behavior for samples that do not contain tridymite and cristobalite.

The mechanical properties of tuff samples from the series of North Ramp geologic drillholes were measured. Timedependent deformation under high temperatures at high and low strain rates was studied. Prototype experiments were completed for future testing of compressive mechanical properties of intact rock at baseline conditions.

Several studies produced data relating to the time-dependent mechanical properties of fractures and the effect of roughness on mechanical properties. Work continued on the development of a computer program to model the dilation, normal stiffness, and shear stiffness of single fractures in rock. Data from fracture topographies were analyzed to quantify the roughness of each surface, the scaling properties, and the degree of mismatch between the two opposing surfaces. 
Surveys for precarious rocks continued in various parts of Nevada and California. The Little Skull Mountain earthquake aftershock studies continued and, as is generally the case, the seismicity rate decreased with time. Earthquake records were compiled and correlations of precarious rocks with maps of historical seismicity in the west were made. A computer code was developed and testing was begun for two-dimensional dynamic stability calculations.

Detailed mapping of trenches and soil test pits in the vicinity of the proposed ESF east of Exile Hill in Midway Valley continued. Lithologic contacts, soil boundaries, sedimentary structures, and potential tectonic structures were mapped. Field mapping and descriptions of existing trenches near the proposed ESF were completed. Bedrock faults exposed in the box cut of the ESF portal were mapped to determine their locations relative to the faults and fractures observed in trenches in the construction area.

A map of Quaternary faults within $100 \mathrm{~km}$ of Yucca Mountain was completed. A verification of mapped faults and lineaments and their relationship to surficial deposits was conducted. Field work was undertaken to characterize fault disruption and history of displacement among faults in Rock Valley. Field work at Calico Hills revealed exposures of Paleozoic stratigraphy and a new, tectonically important breccia unit. Aerial photography interpretation, including photogrammetry, was used to produce a final compilation map of the east of the Beatty quadrangle.

Field mapping of Quaternary faults was completed. Field logs showing stratigraphic units and fault structures were completed for both north and south faces of Trench 8 on the Solitario Canyon fault. Exposure \#4 on the west side of Busted Butte was cleaned of colluvial cover, and stratigraphic and structural contacts were identified and flagged. Stratigraphic units and structures on the outer wall, north side, of Trench 14D on the Bow Ridge fault were cleaned and mapped.

Several studies were conducted in support of preclosure repository performance analyses. Studies continued to reveal the surface characteristics of natural fractures and how to relate these to the frictional data gathered from replicas of the surfaces. Laboratory work continued on experiments involving layered polycarbonate models designed to provide well-controlled experimental data for code validation. A series of experiments was conducted to study the effects of a nonstandard loading condition on the mechanical properties of joints. The manual for JAC3D, a three-dimensional mechanical finite-element code, was completed. Dynamic and quasi-static loading analyses of the North Ramp were performed. Ventilation requirements for repository development were evaluated. Analysis of heat transfer between the waste packages and the surrounding air and rock was performed using the in-drift emplacement mode to represent the worst case scenario for control of drift temperature during the emplacement operations.
Preliminary layouts were made to accommodate the three emplacement modes (vertical, horizontal, and in-drift) and a variety of thermal loads. A study was performed to investigate various types of equipment and shielding that may be used in transporting waste packages from the repository surface facilities to the final underground emplacement areas. The range of equipment investigated included rubbertired, crawler tractor drive, and rail. Power sources considered included diesel and electric schemes.

In studies of thermal loading for the underground facility, thermal loading scenarios were investigated with emphasis on preclosure performance. Four thermal loading scenarios were investigated for input into the Total System Performance Assessment. Near-field thermal calculations, assuming an in-drift emplacement geometry, were carried out. Laboratory-scale experiments were performed to determine the effects of saturation variations on nonisothermal flow in sand. Preliminary numerical simulations using the TOUGH 2 code were conducted to study flow patterns and temperature fields during simulations of the natural convection in a saturated, two-dimensional, porous media.

Work proceeded in the evaluation of Defense Nuclear Agency sealing technologies used in sealing nuclear weapons test facilities at the Nevada Test Site. A proposed strategy was developed for sealing boreholes. The strategy is based on evaluations of the current and planned borehole system, the potential impacts on performance that the borehole system could have, and the technologies available to seal boreholes.

The advanced conceptual design of the waste package continued. Calculations were made in the analytical evaluation of the multipurpose canister. Engineering calculations and bases were developed. The design basis for thermal and criticality evaluations was defined; shielding requirements were developed and evaluated; and material selection criteria development and evaluation of structural response over time were begun. A matrix of waste package design options was compiled.

Efforts continued to refine the coupling of fluid-rock interaction with hydrological properties in the post-emplacement environment. Activities related to definition of equilibrium vs. nonequilibrium domains continued. Models of mineral evolution in the vicinity of waste packages were further developed. Computations have begun in which the dissolution and precipitation kinetics of various silicates are used to bound estimates of the rates at which mineralogical and chemical equilibrium may be achieved in the vicinity of waste packages and in the areas surrounding the altered zone around the potential repository.

Several activities contributed to the studies of the hydrologic properties of the waste package environment. Determination of the moisture retention curves of selected Topopah Spring tuff samples was completed. Work continued on the measurement of electrical resistivity as a function of moisture content using samples from USW GU-3. 
Work continued on the experiment to determine the moisture retention curve and one-dimensional imbibition using USW G-4 core. Work began on the determination of electrical resistivity as a function of water saturation using samples from USW G-4 core. Work continued on the analysis of thermohydrological behavior for a range of thermal loading conditions and hydrological properties. Work continued on an experiment to determine the effect of fracture surface coatings on the imbibition of water into the matrix. Work continued on the hydrothermal calculations of largescale in situ heater tests. The focus of these calculations was to analyze the feasibility of using small thermal probes to determine the thermal conductivity and diffusivity of the rock near the heaters.

In engineered barrier system field tests, a geomechanical numerical simulation of the Large Block test was begun. Specifications were reviewed for several geomechanical diagnostic systems for the Large Block Test, and hydrothermal modeling analysis continued. The model extends downward to the water table, assumed to be at a depth of 568.1 meters.

Design began of a study program to respond to concern about organic materials, including diesel fumes and exhaust, that may be introduced into the ESF. The first series of diesel fuel stability experiments was begun. The GEMBOCHS thermodynamic database that supports the EQ3/6 codes for aqueous species, gases, and solids containing carbon was searched.

Spent fuel waste form characterization studies continued. A test matrix for uranium dioxide spent fuel was completed using aggressive water chemistries with prescribed carbonate/bicarbonate concentrations, high $\mathrm{pH}$ values, oxygen fugacities, and temperatures. Eight uranium dioxide dissolution experiments were completed at temperatures of 50 and 75 degrees Celsius. The oxidation drybath activity on spent fuel at low temperatures continued. Work continued on two long-term, room-temperature dissolution experiments. The oxidation drybath testing activity on spent fuel at temperatures below 200 degrees Celsius continued.

The GEMBOCHS software was transferred to a new server and updated to include equilibrium-constant and reactionenthalpy data from the CHEMVAL-II database. The testing and final preparation of Version 7.2 of the EQ3/6 software was completed, and update packages were distributed to registered users. A new suite of data containing corrections to the thermodynamic data for two magnesium hydroxysulfate minerals was included in the update. Data restructuring was completed to provide a common structure for both EQ3NR and EQ6.

Modeling has been done to determine whether spent fuel cladding breach will occur for a variety of repository configurations. The phenomenon involves the temperature history of the cladding, stress from internal gas pressure, and eventual rupture of the cladding caused by creep. Work continued on the scoping study of cladding temperature history for various drift emplacement heat loadings, and of cladding creep endurance. A summary model of the near-field environment of the waste package is being developed. Work began on documenting the stochastic model for condensate drainage. Work continued on development of a new-generation waste package/engineered barrier system performance assessment code.

In studies to determine radionuclide transport parameters, diffusion experiments continued using single crystals of clinoptilolite saturated with various salts and heated to 85 degrees Celsius. The saw-cut face of as-cut, rinsed in deionized water, and ultrasonically cleaned samples of tuff were examined under the scanning electron microscope to look for fine particles that could be mobilized in flow experiments. A sample of Well UE-25 J\#13 water was analyzed for colloids using light scattering, and samples were prepared for transmission electron microscopy analysis.

Accelerated testing in UE-25 J\#13 water of three candidate waste package materials (Incaloy 825, stainless steel 304, and stainless steel 316) simulated up to 1000 years of service-environment exposure. In this testing, no environmentally assisted cracks formed in the specimens. Slow crack growth rate studies on austenitic alloys continued. Work continued on compiling information on the corrosion and oxidation behavior of carbon steels, cast irons, and lowto-intermediate alloy steels.

Standard probabalistic risk assessment methods were used to evaluate the impact of ESF design changes on previous public radiological risk evaluations and to estimate the level of uncertainty in the assessment results. Rock-fall likelihoods and consequences were estimated from an analysis of mining rock-fall data and underground transportation accident data.

Preliminary experiments investigating the effects of air entrapment on fracture permeability and tracer migration were begun. Experiments were performed to investigate the influence of matrix imbibition on water percolation through unsaturated fractures in the plane normal to the fracture. The geochemical properties of a porous sand and several tracers were characterized to design a caisson experiment for validation of reactive transport models. Chemical analyses of bulk compositions and surface coatings were made of several particle-size fractions. A large-format test chamber for experiments to investigate the effect of matrix imbibition on saturated fracture flow was constructed, and a suite of rock slabs was cut from Topopah Spring tuff for use in these experiments.

Nickel solubility and nickel sorption studies were carried out under carbon dioxide-free conditions. The draft technical procedure for nickel analysis using the graphite-furnace atomic absorption spectrophotometer was revised to reflect improvements in operating procedures and data reduction. Development began on two techniques to carry out in situ 
sorption studies in unsaturated media. A kinetic batch sorption study was run to determine the time dependency of nickel sorption by Wedron 510 sand. Several studies were conducted on lithium and bromine sorption by Wedron 510 sand.

The Total System Performance Assessment (TSPA) combines the effects of the waste package and other engineered barriers and the site to determine the release of radionuclides to the accessible environment due to all significant processes and events. The general scenario to be modeled in the TSPA for 1993 was agreed to be thermally driven condensate interacting with selected waste packages. Several evaluations of total system performance have been conducted.
The Yucca Mountain borehole stratigraphy interpretation needed for the TSPA was completed. A subrepository-scale hydrothermal model was developed to provide hydrologic inputs to TSPA 1993. Basic data acquisition, reduction, and analysis necessary to provide probability distributions for TSPA were completed. Saturated transmissivities, conductivities, and permeabilities were acquired or derived from YMP borehole and laboratory tests and analysis. The fracture parameters, including fracture frequency, spacing, porosity, hydraulic conductivity, air-entry, orientation, and aperture, were completed. A program was written to sample fracture frequency and bulk conductivity distributions to create a distribution of fracture apertures using the cubic law. 


\section{Bibliography With Abstracts}

\section{YUCCA MOUNTAIN SITE CHARACTERIZA- TION PROJECT OFFICE}

1.

(CONF-9112100-1-Vugraphs) GENISES: A GIS Database for the Yucca Mountain Site Characterization Project. Beckett, J. EG and G Energy Measurements, Inc., Las Vegas, NV (United States). [1991]. 12p. Sponsored by USDOE, Washington, DC (United States). DOE Contract AC08-88NV10617. From GENISES: A geographic information system (GIS) database for the Yucca Mountain Site characterization project; Las Vegas, NV (United States); 16 Dec 1991. Order Number DE92007905. Source: OSTI; NTIS; INIS; GPO Dep.

This paper provides a general description of the Geographic Nodal Information Study and Evaluation System (GENISES) database design. The GENISES database is the Geographic Information System (GIS) component of the Yucca Mountain Site Characterization Project Technical Database (TDB). The GENISES database has been developed and is maintained by EG \& G Energy Measurements, Inc., Las Vegas, NV (EG \& G/EM). As part of the Yucca Mountain Project (YMP) Site. Characterization Technical Data Management System, GENISES provides a repository for geographically oriented technical data. The primary objective of the GENISES database is to support the Yucca Mountain Site Characterization Project with an effective tool for describing, analyzing, and archiving geo-referenced data. The database design provides the maximum efficiency in inputfoutput, data analysis, data management and information display. This paper provides the systematic approach or plan for the GENISES database design and operation. The paper also discusses the techniques used for data normalization or the decomposition of complex data structures as they apply to GIS database. ARC/INFO and INGRES files are linked or joined by establishing "relate" fields through the common attribute names. Thus, through these keys, ARC can allow access to normalized INGRES files greatly reducing redundancy and the size of the database.

2 (CONF-920849-1) Technical data management at the Yucca Mountain Site Characterization Project. Statler, J. (Science Applications International Corp., Las Vegas, NV (United States)); Newbury, C.M.; Heitland, G.W. Science Applications International Corp., Las Vegas, NV (United States). [1992]. 12p. Sponsored by USDOE, Washington, DC (United States). DOE Contract AC0887NV10576. From 16. annual Nuclear Information and Records Management Association symposium: shared information - golden gateway to progress; San Francisco, CA (United States); 30 Aug - 2 sep 1992. Order Number DE92018115. Source: OSTI; NTIS; INIS; GPO Dep.

The Department of Energy/Office of Civilian Radioactive waste Management (DOE/OCRWM) is responsible for the characterization of Yucca Mountain, Nevada, to determine its potential as a site of a high-level radioactive waste repository. The characterization of Yucca Mountain encompasses many diverse investigations, both onsite and in laboratories across the country. Investigations are being conducted of the geology, hydrology, mineralogy, paleoclimate, geotechnical properties, and archeology of the area, to name a few. Effective program management requires that data from site investigations be processed, interpreted and disseminated in a timely manner to support model development and validation, repository design, and performance assessment. The Program must also meet regulatory requirements for making the technical data accessible to a variety of external users throughout the life of the Project. Finally, the DOEf OCRWM must make available the data or its description and access location available for use in support of the license application and supporting documentation. To accomplish these objectives, scientific and engineering data, generated by site characterization activities, and technical data, generated by environmental and socioeconomic impact assessment activities, must be systematically identified, cataloged, stored and disseminated in a controlled manner.

3 Current plans to characterize the design basis ground motion at the Yucca Mountain, Nevada, site. Simecka, W.B. (Dept. of Energy, Las Vegas, NV (US)); Grant, T.A.; Voegele, M.D.; Cline, K.M. pp. 176-190 of Dynamic analysis and design considerations for high-level nuclear waste repositories. Hossain, Q.A. (ed.). American Society of Civil Engineers, New York, NY (US) (1993). pp. 443 From American Society of Civil Engineers (ASCE) symposium on dynamic analysis and design considerations, for high-level nuclear waste repositories; San Francisco, CA (United States); 19-20 Aug 1992.

A site at Yucca Mountain Nevada is currently being studied to assess its suitability as a potential host site for the nation's first commercial high level waste repository. The DOE has proposed a new methodology for determining design-basis ground motions that uses both deterministic and probabilistic methods. The role of the deterministic approach is primary. It provides the level of detail needed by design engineers in the characterization of ground motions. The probabilistic approach provides a logical structured procedure for integrating the range of possible earthquakes that contribute to the ground motion hazard at the site. In addition, probabilistic methods will be used as needed to provide input for the assessment of long-term repository performance. This paper discusses the local tectonic environment, potential seismic sources and their associated displacements and ground motions. It also discusses the approach to assessing the design basis earthquake for the surface and underground facilities, as well as selected examples of the use of this type of information in design activities.

4 (CONF-920866-7) Current plans to characterize the design basis ground motion at the Yucca Mountain, Nevada Site. Simecka, W.B. (USDOE Nevada Field Office, Las Vegas, NV (United States)); Grant, T.A.; Voegele, M.D.; Cline, K.M. Science Applications International Corp., Las Vegas, NV (United States); American Society of Civil Engineers, New York, NY (United States). 1992. 10p. Sponsored by USDOE, Washington, DC (United States). DOE Contract AC08-87NV10576. From American 
Society of Civil Engineers (ASCE) symposium on dynamic analysis and design considerations, for high-level nuclear waste repositories; San Francisco, CA (United States); 1920 Aug 1992. Order Number DE93013508. Source: OSTI; NTIS; INIS; GPO Dep.

A site at Yucca Mountain Nevada is currently being studied to assess its suitability as a potential host site for the nation's first commercial high level waste repository. The DOE has proposed a new methodology for determining design-basis ground motions that uses both deterministic and probabilistic methods. The role of the deterministic approach is primary. It provides the level of detail needed by design engineers in the characterization of ground motions. The probabilistic approach provides a logical structured procedure for integrating the range of possible earthquakes that contribute to the ground motion hazard at the site. In addition, probabilistic methods will be used as needed to provide input for the assessment of long-term repository performance. This paper discusses the local tectonic environment, potential seismic sources and their associated displacements and ground motions. It also discusses the approach to assessing the design basis earthquake for the surface and underground facilities, as well as selected examples of the use of this type of information in design activities.

5 (CONF-930408-69) Using QA classification to guide design and manage risk. Lathrop, J. (Strategic Insights, Los Altos, CA (United States)); DeKlever, R.; Petrie, E.H. Raytheon Services Nevada, Las Vegas, NV (United States). 28 Jan 1993. 8p. Sponsored by USDOE, Washington, DC (United States). DOE Contract AC08-91NV10833. From International high-level radioactive waste management conference; Las Vegas, NV (United States); 25-29 Apr 1993. Order Number DE93012990. Source: OSTI; NTIS; INIS; GPO Dep.

Raytheon Services Nevada has developed a classification process based on probabilistic risk assessment, using accidentfimpact scenarios for each system classified. Initial classification analyses were performed for the 20 systems of Package IA of the Exploratory Studies Facility (ESF). The analyses demonstrated a solid, defensible methodological basis for classification which minimizes the use of direct engineering judgment. They provide guidance for ESF design and risk management through the identification of: The critical characteristics of each system that need to be controlled; and the parts of the information base that most need to be further developed through performance assessment or other efforts.

6 (DOE/NV/10576-T4) Yucca Mountain Site Characterization Project Technical Data Catalog: Yucca Mountain Site Characterization Project. USDOE Yucca Mountain Site Characterization Project Office, Las Vegas, NV (United States). 30 Jun 1992. 165p. Sponsored by USDOE, Washington, DC (United States). DOE Contract AC08-87NV10576. Order Number DE92019014. Source: OSTI; NTIS; INIS; GPO Dep.

The June 1, 1985 DOE/NRC Site-Specific Procedural Agreement for Geologic Repository Site Investigation and Characterization Program requires the DOE to develop and maintain a catalog of data which will be updated and provided to the NRC at least quarterly. This catalog is to include a description of the data; the time (date), place, and method of acquisition; and where it may be examined. The Yucca Mountain Site Characterization Project (YMP) Technical Data Catalog is published and distributed in accordance with the requirements of the Site-Specific Agreement. The
YMP Technical Data Catalog is a report based on reference information contained in the YMP Automated Technical Data Tracking System (ATDT). The reference information is provided by Participants for data acquired or developed in support of the YMP. The Technical Data Cataiog is updated quarterly and published in the month following the end of each quarter. This edition of the Technical Data Catalog supersedes the edition dated March 31, 1992.

7 US Environmental Protection Agency Standards 40 CFR 191. Pflum, C.G. (Science Applications International Corp., Las Vegas, NV (United States)); Van Konynenburg, R.A.; Krishna, P. Science Applications International Corp., Las Vegas, NV (United States). 14 Jan 1993. 45p. Sponsored by USDOE, Washington, DC (United States). DOE Contract AC08-87NV10576. Order Number DE94000959. Source: OSTI; NTIS; INIS; GPO Dep.

This paper is about the US Environmental Protection Agency (EPA) "Environmental Standards for the Disposal of Spent Nuclear Fuel, High-Level and Transuranic Wastes," 40 CFR 191. These standards regulate the disposal of radioactive wastes in geologic repositories. Currently, two repository sites are under investigation: The Waste Isolation Pilot Plant (WIPP) site, located near Carisbad, New Mexico, may become the repository for defense-generated transuranic waste (TRU); and the Yucca Mountain site, located near Las Vegas, Nevada, may become the repository for spent reactor fuel and a small amount of reprocessing waste (hereinafter called high-level radioactive waste or $H L W)$. The paper was written for readers who have an interest in 40 CFR 191 but do not have the time or inclination to ponder the technical details.

8 (DOE/NV/10872-8) Identification and characterization of conservative organic tracers for use as hydrologic tracers for the Yucca Mountain Site Characterization Project: Quality Assurance Project Plan: Quarterly technical progress report, January 1, 1993March 31, 1993. Stetzenbach, K.J. Nevada Univ., Las Vegas, NV (United States). Harry Reid Center for Environmental Studies. 25 Feb 1993. 70p. Sponsored by USDOE, Washington, DC (United States). DOE Contract FC0890NV10872. Order Number DE93014228. Source: OSTI; NTIS; INIS; GPO Dep.

Studies continued on organic tracers for use as hydrologic tracers as part of the Yucca Mountain Site Characterization project. This subject report for the quarter 01/01/93 through $03 / 31 / 93$ discusses the following issues: project organization and responsibilities; quality assurance program; design control; procurement document control; instructions, procedures, and drawings; document control; control of purchased items and services; identification and control of items; control of processes; inspection; test control; control of measuring and test equipment; handling, storage, and shipping; inspection, test, and operating status; control of nonconforming items and conditions; corrective action; quality assurance records; audits; software quality assurance; and scientific investigation.

9 hydrologic tracers for the Yucca Mountain Site Characterization Study: Progress report, June 1-December 31, 1990. Stetzenbach, K.J. Nevada Univ., Las Vegas, NV (United States). Environmental Research Center. [1990]. 123p. Sponsored by USDOE, Washington, DC (United 
States). DOE Contract FC08-90NV10872. Order Number DE92014660. Source: OSTI; NTIS; GPO Dep.

Ground water tracers are solutes dissolved in or carried by ground water to delineate flow pathways. Tracers provide information on direction and speed of water movement and that of contaminants that might be conveyed by the water. Tracers can also be used to measure effective porosity, hydraulic conductivity, dispersivity and solute distribution coefficients. For most applications tracers should be conservative, that is, move at the same rate as the water and not sorb to aquifer materials. Tracers must have a number of properties to be functional. Regardless of the desired properties, the chemical and physical behavior of a tracer in ground water and the porous medium under study must be understood. Good estimates of tracer behavior can be obtained from laboratory studies. Studies in this proposal will address tracer properties with analytical method development, static sorption and degradation studies and column transport studies, Mutagenicity tests will be performed on promising candidates. The tracers that will be used for these experiments are fluorinated organic acids and other organic compounds that have the chemical and biological stability necessary to be effective in the Yucca Mountain environment. Special emphasis will be placed on compounds that fluoresce or have very large ultraviolet absorption coefficients for very high analytical sensitivity.

10 (DOE/NV/10872-T3) Identification and charac terization of conservative organic tracers for use as hydrologic tracers for the Yucca Mountain Site Characterization Study: Progress report, January 1, 1991-June 30, 1991. Stetzenbach, K.J. Nevada Univ., Las Vegas, NV (United States). Environmental Research Center. [1991]. 90p. Sponsored by USDOE, Washington, DC (United States). DOE Contract FC08-90NV10872. Order Number DE92014661. Source: OSTI; NTIS; GPO Dep.

Studies continue on the use of organic acids as tracers in hydrology studies of Yucca Mountain. Work performed during this time period has been concentrated in three main areas: the familiarization with, and optimization of, the LCMS hardware and data system; the initial development of soil column test procedures, which are used for evaluation of both the columns themselves and the tracer compounds; and continuation of the batch sorption and degradation stud: ies for the potential tracers. All three of these tasks will continue, as the addition of new tracer compounds, analytical information, and equipment will necessitate further evaluation of existing methods and procedures. Also included in this report is the final report on an information system.

11. (DOE/NV/10872-T4) UNS YMSCP QA support task: Quarterly technical progress report, January 1, 1991-June 30, 1991. Cross-Smiecinski, A.J. Nevada Univ., Las Vegas, NV (United States). Environmental Research Center. $30 \mathrm{Jul}$ 1991. 51p. Sponsored by USDOE, Washington, DC (United States). DOE Contract FC08-9ONV10872. Order Number DE92014662. Source: OSTI; NTIS; GPO Dep.

This report describes a quality assurance program plan for the Yucca Mountain Project. Aspects of the plan include: document control, equipment maintenance and calibration, process control, audits, computer software, and inspections. (CBS)

12 (DOENNV/10872-T10) Report on task assignment No. 3 for the Waste Package Project: Parts A \& B,
ASME pressure vessel codes review for waste package application; Part C, Library search for reliability/fallure rates data on low temperature low pressure piping, containers, and casks with long design lives. Trabia, M.B.; Kiley, M.; Cardle, J.; Joseph, M. Nevada Univ., Las Vegas, NV (United States). Jul 1991. 84p. Sponsored by USDOE, Washington, DC (United States). DOE Contract FC0890NV10872. Order Number DE92014668. Source: OSTI; NTIS; GPO Dep.

The Waste Package Project Research Team, at UNLV, has four general required tasks. Task one is the management, quality assurance, and overview of the research that is performed under the cooperative agreement. Task two is the structural analysis of spent fuel and high level waste. Task three is an American Society of Mechanical Engineers (ASME) Pressure Vessel Code review for waste package application. Finally, task four is waste package labeling. This report includes preliminary information about task three (ASME Pressure Vessel Code review for Waste package Application). The first objective is to compile a list of the ASME Pressure Vessel Code that can be applied to waste package containers design and manufacturing processes. The second objective is to explore the use of these applicable codes to the preliminary waste package container designs. The final objective is to perform a library search for reliability and/or failure rates data on low pressure, low temperature, containers and casks with long design lives.

13 (DOENV/10872-T12) Fingerprinting of ground water by ICP-MS: Progress report, July 1 , 1991December 31, 1991. Stetzenbach, K. Nevada Univ., Las Vegas, NV (United States). Harry Reid Center for Environmental Studies. [1991]. 10p. Sponsored by USDOE, Washington, DC (United States). DOE Contract FCO890NV10872. Order Number DE92014670. Source: OSTI; NTIS; GPO Dep.

The purpose of this project is to investigate the use of $\mathrm{mi}-$ nor constituents of ground water and vadose zone water such as the rare earths and some lighter elements, to delineate ground water flow paths and recharge zones in the Yucca Mountain area. The major piece of equipment required to perform this task is an inductively coupled plasma-mass spectrometer (ICP-MS). This instrument has been purchased and should be delivered in February 1992. During this reporting period, three ICP-MS systems were evaluated the Perkin-Eimer Elan 5000 was chosen. As part of the evaluation process, samples of $\mathrm{J}-13$ water and tuff were prepared and analyzed by each of the competing companies. This gave us the opportunity to make initial observations as to the number of compounds and their concentrations present in the $J-13$ samples. Table 1 lists the results of the analysis of $\mathrm{J}-13$ water. Once the ICP-MS is operational, we will be collecting and analyzing waters from existing wells, springs, and seeps to determine which of these minor chemical constituents will be most helpful in establishing chemical signatures for the ground waters beneath Yucca Mountain.

14 (DOENV/10872-T13) Identification and characterization of conservative organic tracers for use as hydrologic tracers for the Yucca Mountain Site Characterization Study: Progress report, July 1, 1991December 31, 1991. Dombrowski, T.; Stetzenbach, K. Nevada Univ., Las Vegas, NV (United States). Harry Reid Center for Environmental Studies. [1991]. 14p. Sponsored by USDOE, Washington, DC (United States). DOE Contract 
FC08-90NV10872. Order Number DE92014671. Source: OSTI; NTIS; GPO Dep.

Studies continued on organic tracers for use as hydrologic tracers as part of the Yucca Mountain Site Characterization project. Tracers studied include benzoic acids, cinnamic acids, and salicylic acids. The main focus of the work performed during the time period from 07/01/91 to 12/31/91 has been the continuation of (1) LC-MS optimization for tracer identification, (2) batch sorption and degradation studies, (3) neoprene tubing evaluation studies, and (4) soil column evaluation of tracer compounds. All of these areas of research (except perhaps the neoprene tubing evaluation) are ongoing and will continue throughout the coming year.

15 (DOENV/10872-T68) Identification and characterization of conservative organic tracers for use as hydrologic tracers for the Yucca Mountain Site characterization study: Progress report, April 1, 1993-June 30, 1993. Organic Tracer Toxicity Report fluorinated benzoic acids. Dombrowski, T.; Stetzenbach, K. Nevada Univ., Las Vegas, NV (United States). Harry Reid Center for Environmental Studies. [1993]. 33p. Sponsored by USDOE, Washington, DC (United States). DOE Contract FCO890NV10872. Order Number DE93018968. Source: OSTI; NTIS; INIS; GPO Dep.

This report is in two parts one for the fluorinated benzoic acids and one for the fluorinated aliphatic acids. The assumptions made in the report regarding the amount of tracer that will be used, dilution of the tracer during the test and the length of exposure (if any) to individuals drinking the water were made by the authors. These assumptions must really come from the USGS hydrologists in charge of the cwell tracer testing program. Accurate estimates of dilution of the tracer during the test are also important because of solubility limitations of some of the tracers. Three of the difluorobenzoic acids have relatively low solubilities and may not be usable if the dilution estimates are large. The toxicologist that reviewed the document agreed with our conclusion that the fluorinated benzoic and toluic acids do not represent a health hazard if used under the conditions as outlined in the report. We are currently testing 15 of these compounds, and if even if three difluorobenzoic acids cannot be used because of solubility limitations we will still have 12 tracers. The toxicologist felt that the aliphatic fluorinated acids potentially present more of a health risk than the aromatic. This assessment was based on the fact of a known allergic response to halothane anesthetic. This risk, although minimal, is known and he felt that was enough reason to recommend against their use. The authors feel that the toxicologists interpretation of this risk was overly conservative, however, we will not go against his recommendation at this time for the following reasons. First, without the aliphatic compounds we still have 12 to 15 fluorinated aromatic acids which, should be enough for the c-well tests. Second, to get a permit to use aliphatic compounds would undoubtedly require a hearing which could be quite lengthy.

16 (DOENV/10872-T69) Identification of subsurface microorganisms at Yucca Mountain: Fourth quarterly report. Stetzenbach, L.D. Nevada Univ., Las Vegas, NV (United States). Harry Reid Center for Environmental Studies. [1993]. 13p. Sponsored by USDOE, Washington, DC (United States). DOE Contract FCO89ONV10872. Order Number DE93018969. Source: OSTI NTIS; INIS; GPO Dep.

Bacteria isolated from water samples collected in a series of ground water springs have been isolated, enumerated, and identified from twenty six sites. Ten sites were sampled in Death Valley, California and sixteen sites were sampled in Ash Meadows, Nevada. Replicate samples were collected and tested from four locations. All water samples were collected in conjunction with the HRC chemistry group conducting ground water fingerprinting studies. The protocol for collection of samples, as described in the 3rd quarterly report, specified aseptic collection in sterile screw-capped containers and transportation on ice to the HRC microbiology laboratory. All samples were inoculated by spread plating onto R2A (Difco Laboratories, Detroit, MI) bacterial culture medium. the R2A plates were then incubated at $28^{\circ}$ for 5-7 days and colonies wee counted with the aid of a grid template and magnifying lens.

17 (DOE/NV/10872-T84) Quarterly progress report on the DOE Waste Package project at the University of Nevada, Las Vegas, July 1, 1993 through September 30 , 1993. Ladkany, S.G. Nevada Univ., Las Vegas, NV (United States). 1993. 113p. Sponsored by USDOE, Washington, DC (United States). DOE Contract FC08-90NV10872. Order Number DE94002515. Source: OSTI; NTIS; GPO Dep.

Progress reports are presented for the following tasks: overview and progress of waste package project and container design; waste container design considerations (criticality analysis, experimental drift model); waste container alternate design considerations; thermal simulation of high level nuclear waste canister emplacement; structural analysis and design of nuclear waste package canister; robotic manipulation of the nuclear waste container; investigation of stress in a circular tunnel due to overburden \& thermal loading of horizontally placed 21PWR multi-purpose canisters; investigation of faulted tunnel models by combined photoelasticity and finite element analysis; and transport phenomena in the near field.

18 (DOE/OR/21497-1) Thermal impact on host rock of geologic repository: Final report. Mou, ChingHua. South Carolina State Coll., Orangeburg, SC (United States). Mar 1986. 39p. Sponsored by USDOE, Washington, DC (United States). DOE Contract FG05-84OR21497. Order Number DE92013559. Source: OSTI; NTIS; INIS; GPO Dep.

The initial stress of rock was estimated and analyzed based on the geological survey information collected during the site visits. Change in stress and its distribution in the rock due to excavation was investigated and predicted according to the repository geometry. Thermal effects on the magnitude and distribution of stress in rock was also investigated and predicted according to the repository geometry. Thermal effects on the magnitude and distribution of rock stresses were investigated under two different temperature conditions. Emphasis was placed on the development of fractures due to stress concentration at or near the repository openings. Permeability characteristics of host rock were evaluated at three temperature levels. Series of permeability tests were conducted for determining the thermal effect on the hydrological characteristics of rock. The following goals were achieved from this investigation: (1) Better understanding of stress changes in host rock due to repository excavation and thermal impact. (2) Better understanding of the development of rock fractures and its effect on the hydrological characteristics of host rock. (3) To provide the technical information obtained from this study to the Office of Civilian Radioactive Wastes Management (OCRWM) with a hope that it may assist OCRWM in the decision making of 
selecting a repository site. Due to limited time for this research, only one type of host media, granite, was included in the study.

19 (DOE/OSTI-3406-Suppl.2-Add.3) Yucca Mountain Site characterization project bibliography, January-June 1991: An Update: Supplement 2, Addendum 3. Lorenz, J.J.; Stephan, P.M. (eds.). USDOE Office of Scientific and Technical Information, Oak Ridge, TN (United States). Sep 1991. 37p. Sponsored by USDOE, Washington, DC (United States). Order Number DE91014380. Source: OSTI; NTIS; INIS; GPO Dep.

Following a reorganization of the Office of Civilian Radioactive Waste Management in 1990, the Yucca Mountain Project was renamed Yucca Mountain Site Characterization Project. The title of this bibliography was also changed to Yucca Mountain Site Characterization Project Bibliography. Prior to August 5, 1988, this project was called the Nevada Nuclear Waste Storage Investigations. This bibliography contains information on this ongoing project that was added to the Department of Energy's Energy Science and Technology Database from January 1991 through June 1991. The bibliography is categorized by principal project participating organization. Participant-sponsored subcontractor reports, papers, and articles are included in the sponsoring organization's list. Another section contains information about publications on the Energy Science and Technology Database that were not sponsored by the project but have some relevance to it.

20

(DOE/OSTI-3406-Suppl.3) Yucca Mountain Site Characterization Project bibliography, January-June 1991: Supplement 3. USDOE Office of Scientific and Technical Information, Oak Ridge, TN (United States). Jun 1992. 283p. Sponsored by USDOE, Washington, DC (United States). Order Number DE92004874. Source: OSTI; NTIS; INIS; GPO Dep.

Following a reorganization of the Office of Civilian $\mathrm{Ra}$ dioactive Waste Management in 1990, the Yucca Mountain Project was renamed Yucca Mountain Site Characterization Project. The title of this bibliography was also changed to Yucca Mountain Site Characterization Project Bibliography. Prior to August 5,1988 , this project was called the Nevada Nuclear Waste Storage Investigations. This bibliography contains information on this ongoing project that was added to the Department of Energy's Science and Technology Database from January 1, 1990, through December 31, 1991.

21 (DOE/OSTL-3406(Suppl.3)(Add.1)) Yucca Mountain Site characterization project bibliography, January-June 1992: An Update: Supplement 3, Addendum 1. USDOE Office of Scientific and Technical Information, Oak Ridge, TN (United States). Sep 1992. 38p. Sponsored by USDOE, Washington, DC (United States). Order Number DE92016339. Source: OSTI; NTIS; INIS; GPO Dep.

Following a reorganization of the Office of Civilian Radioactive Waste Management in 1990, the Yucca Mountain Project was renamed Yucca Mountain Site Characterization Project. The title of this bibliography was also changed to Yucca Mountain Site Characterization Project Bibliography. Prior to August 5, 1988, this project was called the Nevada Nuclear Waste Storage Investigations. This bibliography contains information on this ongoing project that was added to the Department of Energy's Energy Science and Technology Database from January 1, 1992, through June 30, 1992.
The bibliography is categorized by principal project participating organization. Participant-sponsored subcontractor resorts, papers, and articles are included in the sponsoring organization's list. Another section contains information about publications on the Energy Science and Technology Database that were not sponsored by the project but have some relevance to it.

22 (DOE/OSTI-3406(Suppl.3)(Add.2)) Yucca Mountain Site Characterization Project bibliography, July-December 1992: An update, Supplement 3, Addendum 2: Civilian Radioactive Waste Management Program. USDOE Office of Scientific and Technical Information, Oak Ridge, TN (United States). Apr 1993. 44p. Sponsored by USDOE, Washington, DC (United States). Order Number DE93005637. Source: OSTI; NTIS; INIS; GPO Dep.

Following a reorganization of the Office of Civilian Radioactive Waste Management in 1990, the Yucca Mountain Project was renamed Yucca Mountain Site Characterization Project. The title of this bibliography was also changed to Yucca Mountain Site Characterization Project Bibliography. Prior to August 5, 1988, this project was called the Nevada Nuclear Waste Storage Investigations. This bibliography contains information on this ongoing project that was added to the Department of Energy's Energy Science and Technology Database from July 1, 1992, through December 31 , 1992. The bibliography is categorized by principal project participating organization. Participant-sponsored subcontractor reports, papers, and articles are included in the sponsoring organization's list. Another section contains information about publications on the Energy Science and Technology Database that were not sponsored by the project but have some relevance to it.

23 (DOE/RW/00134-T2) Yucca Mountain Site Characterization Project Technical Data Catalog. USDOE Yucca Mountain Site Characterization Project Office, Las Vegas, NV (United States). 31 Dec 1992. 246p. Sponsored by USDOE, Washington, DC (United States). DOE Contract AC01-91RW00134. Order Number DE93014510. Source: OSTI; NTIS; INIS; GPO Dep.

The June 1, 1985, Department of Energy (DOE)/Nuclear, Regulatory Commission (NRC) Site-Specific Procedural Agreement for Geologic Repository Site Investigation and Characterization Program requires the DOE to develop and maintain a catalog of data which will be updated and provided to the NRC at least quarterly. This catalog is to include a description of the data; the time (date), place, and method of acquisition; and where it may be examined. The Yucca Mountain Site Characterization Project (YMP) Technical Data Catalog is published and distributed in accordance with the requirements of the Site-Specific Agreement. The YMP Technical Data Catalog is a report based on reference information contained in the YMP Automated Technical Data Tracking System (ATDT). The reference information is provided by Participants for data acquired or developed in support of the YMP. The Technical Data Catalog is updated quarterly and published in the month following the end of each quarter. Each new publication of the Technical Data Catalog supersedes the previous edition.

24 (DOE/RW-0293P) DOE's Yucca Mountain studies: What are they? Why are they being done?. USDOE Office of Civilian Radioactive Waste Management, Washington, DC (United States). Dec 1990. 28p. Sponsored by 
USDOE, Washington, DC (United States). Source: OSTI (Free of Charge); INIS.

This booklet is about the disposal of high-level nuclear waste in the United States. It is intended for readers who do not have a technical background. It discusses why scientists and engineers think high-level nuclear waste may be disposed of safely underground. It also describes why Yucca Mountain, Nevada, is being studied and provides basic information about those studies.

25 (DOE/RW-0307P-4) Site characterization progress report: Yucca Mountain, Nevada, October 1, 1990-March 31, 1991: Number 4. USDOE Office of Civilian Radioactive Waste Management, Washington, DC (United States). Oct 1991. 158p. Sponsored by USDOE, Washington, DC (United States). Source: OSTI (Free of Charge); INIS.

In accordance with the requirements of Section 113 (b) (3) of the Nuclear Waste Policy Act of 1982, as amended (NWPA), the US Department of Energy (DOE) has prepared this report on the progress of site characterization activities at Yucca Mountain, Nevada, for the period October 1, 1990, through March 31, 1991. This report is the fourth in a series of reports that are issued at intervais of approximately six months during site characterization. The report covers a number of initiatives to improve the effectiveness of the site characterization program, and covers continued efforts related to preparatory activities, Study Plans, and performance assessment.

26

(DOE/RW-0307P-5) Site characterization progress report: Yucca Mountain, Nevada, April 1, 1991September 30, 1991, Number 5: Nuclear Waste Policy Act (Section 113). USDOE Office of Civilian Radioactive Waste Management, Washington, DC (United States). Jun 1992. 180p. Sponsored by USDOE, Washington, DC (United States). Source: INIS; OSTI (Free of Charge).

The Site Characterization Progress Report of Yucca Mountain (PR) presents brief summaries of the status of site characterization activities and cites the technical reports and research products that provide more detailed information on the activities. The report provides highlights of work started during the reporting period, work in progress, and work completed and documented during the reporting period. In addition, the report is the vehicle for the discussion of changes to the DOE's site characterization program resulting from ongoing collection and evaluation of site information; the development of repository and waste-package designs; the results of performance assessments; and any changes that occur in response to external comments. Information covered includes geochemistry, hydrology, geology, climate, and radiation dose estimate calculations.

27

(DOE/RW-0307P-6) Progress report on the scientific investigation program for the Nevada Yucca Mountain Site, October 1, 1991-March 31, 1992, Number 6. USDOE Office of Civilian Radioactive Waste Management, Washington, DC (United States). Sep 1992. 170p. Sponsored by USDOE, Washington, DC (United States). Order Number DE93005088. Source: OSTI; NTIS; INIS; GPO Dep.

Prepared in accordance with Nuclear Waste Policy Act (Section 113).

In accordance with the requirements of section 113 (b)(3) of the Nuclear Waste Policy Act (NWPA) and 10 CFR $60.18(\mathrm{~g})$, the US Department of Energy (DOE) has prepared this report on the progress of site characterization activities at Yucca Mountain, Nevada, for the period October 1, 1991 , through March 31, 1992. This report is the sixth in a series of reports that are issued at intervals of approximately six months during site characterization. Also included in this report are activities such as public outreach and international programs that are not officially part of site characterization. Information on these activities is provided in order to fully integrate all aspects of the Yucca Mountain studies.

28 (DOE/RW-0307P-7) Site characterization progress report: Yucca Mountain, Nevada, April 1, 1992-September 30, 1992, Number 7. USDOE Office of Civilian Radioactive Waste Management, Washington, DC (United States). Dec 1992. 256p. Sponsored by USDOE, Washington, DC (United States). Source: OSTI (Free of Charge); INIS.

Prepared in accordance with Nuclear Waste Policy Act (Section 113).

In accordance with section 113(b)(3) of the Nuclear Waste Policy Act of 1982, as amended (NWPA), the Department has prepared the seventh in a series of reports on the progress of site characterization at the Yucca Mountain candidate site. The Civilian Radioactive Waste Management Program made significant progress during the reporting period at the Yucca Mountain Site Characterization Project. Several important advances were made in the surfacebased testing program including: initiation of borehole drilling utilizing the new, state-of-the-art LM-300 drill rig which employs dry drilling and coring techniques; neutron access borehole drilling to evaluate infiltration processes; excavations to aid geologic mapping; and trenching in Midway Valley to study Quaternary faulting. A Floodplain Assessment and Statement of Findings was published in the Federal Register which concluded there would be no significant impact nor cumulative impacts on floodplains resulting from Exploratory Studies Facility activities. The Nationa Academy of Sciences' National Research Council released its report entitled "Ground Water at Yucca Mountain: How High Can It Rise?" which concluded that none of the evidence cited as proof of groundwater upwelling in and around Yucca Mountain could be reasonably attributed to that process and that significant water table excursions to the repository design level are not shown by the geologic record. The June 29, 1992, earthquake near Yucca Mountain provided scientists with a wealth of information relevant to understanding the neotectonics of the area and the geometry of faults at depth. Early findings suggest that accelerations recorded were well within proposed design limits for the surface waste handling facilities.

29 (DOE/RW-0313P) Yucca Mountain Site Characterization Project Plan. Gertz, C.P.; Bartlett, J. USDOE Office of Civilian Radioactive Waste Management, Washington, DC (United States). Jan 1992. 71p. Sponsored by USDOE, Washington, DC (United States). Source: OSTI (Free of Charge)

The purpose of this document is to describe the Yucca Mountain Site Characterization Project (YMP) and establish an approved YMP baseline against which overall YMP progress and management effectiveness shall be measured. For the sake of brevity, this document will be referred to as the Project Plan throughout this document. This Project Plan only addresses activities up to the submittal of the repository license application (LA) to the Nuclear Regulatory Commission (NRC). A new Project Plan will be submitted to establish the technical, cost, and schedule baselines for the 
final design and construction phase of development extending through the start of repository operations, assuming that the site is determined to be suitable.

30 (DOE/RW-0345P) DOE's Yucca Mountain studies. USDOE Office of Civilian Radioactive Waste Management, Washington, DC (United States). Education and Information Div.; USDOE Yucca Mountain Site Characterization Project Office, Las Vegas, NV (United States). Dec 1992. 21p. Sponsored by USDOE, Washington, DC (United States). Source: OSTI (Free of Charge); INIS.

This booklet is about the disposal of high-level nuclear waste in the United States. It is for readers who have a general rather than a technical background. It discusses why scientists and engineers think high-level nuclear waste may be disposed of safely underground. It also describes why Yucca Mountain, Nevada, is being studied as a potential repository site and provides basic information about those studies.

31 (DOE/RW-0423) Site characterization progress report: Yucca Mountain, Nevada, October 1, 1992-March 31, 1993, No. 8. USDOE Office of Civilian Radioactive Waste Management, Washington, DC (United States). Aug 1993. 289p. Sponsored by USDOE, Washington, DC (United States). Source: OSTI (Free of Charge); INIS.

In accordance with requirements of Section $113(b)(3)$ of the Nuclear Waste Policy Act of 1982, as amended, and 10 CFR $60.18(\mathrm{~g})$, the US Department of Energy has prepared this report on the progress of site characterization activities at Yucca Mountain, Nevada, for the period October 1, 1992, through March 31, 1993. This report is the eighth in a series issued at intervals of approximately six months during site characterization of Yucca Mountain as a possible site for a geologic repository for the permanent disposal of high-level radioactive waste. Also included in this report are activities such as public outreach and international programs that are not formally part of the site characterization process. Information on these activities is provided to report on all aspects of the Yucca Mountain studies.

32 (DOE/RW-93016760) Yucca Mountain Site Characterization Project: Technical data catalog,(quarterly supplement). USDOE Yucca Mountain Site Characterization Project Office, Las Vegas, NV (United States). 31 Mar 1993. 104p. Sponsored by USDOE, Washington, DC (United States). Order Number DE93016760. Source: OSTI; NTIS; INIS; GPO Dep.

The June 1, 1985, Department of Energy (DOE)/Nuclear Regulatory Commission (NRC) Site-Specific Procedural Agreement for Geologic Repository Site Investigation and Characterization Program requires the DOE to develop and maintain a catalog of data which will be updated and provided to the NRC at least quarterly. This catalog is to include a description of the data; the time (date), place, and method of acquisition; and where it may be examined. The Yucca Mountain Site Characterization Project (YMP) Technical Data Catalog is published and distributed in accordance with the requirements of the Site-Specific Agreement. The YMP Technical Data Catalog is a report based on reference information contained in the YMP Automated Technical Data Tracking System (ATDT). The reference information is provided by Participants for data acquired or developed in support of the YMP. The Technical Data Catalog is updated quarterly and published in the month following the end of each quarter. A complete revision to the Catalog is published at the end of each fiscal year.
33 (DOE/RW-93019729) Yucca Mountain Site Characterization Project Technical Data Catalog (quarterly supplement). USDOE Yucca Mountain Site Characterization Project Office, Las Vegas, NV (United States). 30 Jun 1993. 127p. Sponsored by USDOE, Washington, DC (United States). Order Number DE93019729. Source: OSTI; NTIS; INIS; GPO Dep.

The June 1, 1985, Department of Energy (DOE)/Nuclear Regulatory Commission (NRC) Site-Specific Procedural Agreement for Geologic Repository Site Investigation and Characterization Program requires the DOE to develop and maintain a catalog of data which will be updated and provided to the NRC at least quarterly. This catalog is to include a description of the data; the time (date), place, and method of acquisition; and where it may be examined. The Yucca Mountain Site Characterization Project (YMP) Technical Data Catalog is published and distributed in accordance with the requirements of the Site-Specific Agreement. The YMP Technical Data Catalog is a report based on reference information contained in the YMP Automated Technical Data Tracking System (ATDT). The reference information is provided by Participants for data acquired or developed in support of the YMP. The Technical Data Catalog is updated quarterly and published in the month following the end of each quarter. A complete revision to the Catalog is published at the end of each fiscal year. Supplements to the end-of-year edition are published each quarter. These supplements provide information related to new data items not included in previous quarterly updates and data items affected by changes to previously published reference intormation. The Technical Data Catalog, dated December 31, 1992, should be retained as the baseline document for the supplements until the end-of-year revision is published and distributed in October 1993.

34 (EGG-10617-1194) Three dimensional visualization in support of Yucca Mountain Site characterization activities. Brickey, D.W. EG and G Energy Measurements, Inc., Las Vegas, NV (United States). [1992]. 10p. Sponsored by USDOE, Washington, DC (United States). DOE Contract AC08-88NV10617. (CONF920430-50: 3 . international high level radioactive waste management (IHLRWM) conference, Las Vegas, NV (United States), 12-16 Apr 1992). Order Number DE92007623. Source: OSTI; NTIS; INIS; GPO Dep.

An understanding of the geologic and hydrologic environment for the proposed high-level nuclear waste repository at Yucca Mountain, NV is a critical component of site characterization activities. Conventional methods allow visualization of geologic data in only two or two and a half dimensions. Recent advances in computer workstation hardware and software now make it possible to create interactive three dimensional visualizations. Visualization software has been used to create preliminary two-, two-and-a-half-, and three-dimensional visualizations of Yucca Mountain structure and stratigraphy. The three dimensional models can also display lithologically dependent or independent parametric data. Yucca Mountain site characterization studies that will be supported by this capability include structural, lithologic, and hydrologic modeling, and repository design.

35 (EGG-10617-2127) Yucca Mountain Biological Resources Monitoring Program: Annual report, FY91. $E G$ and $G$ Energy Measurements, Inc., Goleta, CA (United States). Santa Barbara Operations. Jan 1992. 69p. Sponsored by USDOE, Washington, DC (United States). DOE 
Contract AC08-88NV10617. Order Number DE92011449. Source: OSTI; NTIS; INIS; GPO Dep.

The US Department of Energy (DOE) is required by the Nuclear Waste Policy Act of 1982 (as amended in 1987) to study and characterize Yucca Mountain as a possible site for a geologic repository for high-level nuclear waste. During site characterization, the DOE will conduct a variety of geotechnical, geochemical, geological, and hydrological studies to determine the suitability of Yucca Mountain as a repository. To ensure that site characterization activities (SCA) do not adversely affect the Yucca Mountain area, an environmental program has been implemented to monitor and mitigate potential impacts and to ensure that activities comply with applicable environmental regulations. This report describes the activities and accomplishments during fiscal year 1991 (FY91) for six program areas within the Terrestrial Ecosystem component of the YMP environmental program. The six program areas are Site Characterization Activities Effects, Desert Tortoises, Habitat Reclamation, Monitoring and Mitigation, Radiological Monitoring, and Biological Support.

36 (EGG-10617-2195) Yucca Mountain biological resources monitoring program: Annual report FY92. EG and $G$ Energy Measurements, Inc., Goleta, CA (United States). Santa Barbara Operations. Feb 1993. 79p. Sponsored by USDOE, Washington, DC (United States). AC08-88NV10617. Order Number DE93018485. Source: OSTI; NTIS; INIS; GPO Dep.

The US Department of Energy (DOE) is required by the Nuclear Waste Policy Act of 1982 (as amended in 1987) to study and characterize Yucca Mountain as a potential site for a geologic repository for high-level nuclear waste. During site characterization, the DOE will conduct a variety of geotechnical, geochemical, geological, and hydrological studies to determine the suitability of Yucca Mountain as a potential repository. To ensure that site characterization activities (SCA) do not adversely affect the environment at Yucca Mountain, an environmental program has been implemented to monitor and mitigate potential impacts and ensure activities comply with applicable environmental regulations. This report describes the activities and accomplishments of EG\&G Energy Measurements, Inc. (EG\&G/EM) during fiscal year 1992 (FY92) for six program areas within the Terrestrial Ecosystem component of the YMP environmental program. The six program areas are Site Characterization Effects, Desert Tortoises, Habitat Reclamation, Monitoring and Mitigation, Radiological Monitoring, and Biological Support.

37 (LBL-23591) The capillary hysteresis model HYSTR: User's guide. Niemi, A.; Bodvarsson, G.S. Lawrence Berkeley Lab., CA (United States). Nov 1991. 59p. Sponsored by USDOE, Washington, DC (United States). DOE Contract AC03-76SF00098; Al08. 78ET44802. Order Number DE92008106. Source: OSTI; NTIS; INIS; GPO Dep.

The potential disposal of nuclear waste in the unsaturated zone at Yucca Mountain, Nevada, has generated increased interest in the study of fluid flow through unsaturated media. In the near future, large-scale field tests will be conducted at the Yucca Mountain site, and work is now being done to design and analyze these tests. As part of these efforts a capillary hysteresis model has been developed. A computer program to calculate the hysteretic relationship between capillary pressure $\phi$ and liquid saturation $\left(S_{1}\right)$ has been written that is designed to be easily incorporated into any numerical unsaturated flow simulator that computes capillary pressure as a function of liquid saturation. This report gives a detailed description of the model along with information on how it can be interfaced with a transport code. Although the model was developed specifically for calculations related to nuclear waste disposal, it should be applicable to any capillary hysteresis problem for which the secondary and higher order scanning curves can be approximated from the first order scanning curves. HYSTR is a set of subroutines to calculate capillary pressure for a given liquid saturation under hysteretic conditions.

38 (LBL-23592) Incorporation of the capillary hysteresis model HYSTR into the numerical code TOUGH. Niemi, A.; Bodvarsson, G.S.; Pruess, K. Lawrence Livermore National Lab., CA (United States). Nov 1991. 25p. Sponsored by USDOE, Washington, DC (United States). DOE Contract Al08-78ET44802;AC03-76SF00098. Order Number DE92008051. Source: OSTI; NTIS; INIS; GPO Dep.

As part of the work performed to model flow in the unsaturated zone at Yucca Mountain Nevada, a capillary hysteresis model has been developed. The computer program HYSTR has been developed to compute the hysteretic capillary pressure - liquid saturation relationship through interpolation of tabulated data. The code can be easily incorporated into any numerical unsaturated flow simulator. A complete description of HYSTR, including a brief summary of the previous hysteresis literature, detailed description of the program, and instructions for its incorporation into a numerical simulator are given in the HYSTR user's manual (Niemi and Bodvarsson, 1991a). This report describes the incorporation of HYSTR into the numerical code TOUGH (Transport of Unsaturated Groundwater and Heat; Pruess, 1986). The changes made and procedures for the use of TOUGH for hysteresis modeling are documented.

39 (LBL-23593) Preliminary capillary hysteresis simulations for fractured rocks - model development and results of simulations. Niemi, A.; Bodvarsson, G.S. Lawrence Berkeley Lab., CA (United States). Nov 1991. 85p. Sponsored by USDOE, Washington, DC (United States);Department of the Interior; Washington, DC (United States). DOE Contract AC03-76SF00098. Order Number DE93015280. Source: OSTI; NTIS; GPO Dep.

As part of the code development and modeling work being carried out to characterize the flow in the unsaturated zone at Yucca Mountain, Nevada, capillary hysteresis models simulating the history-dependence of the characteristic curves have been developed. The objective of the work has been both to develop the hysteresis models, as well as to obtain some preliminary estimates of the possible hysteresis effects in the fractured rocks at Yucca Mountain given the limitations of presently available data. Altogether three different models were developed based on work of other investigators reported in the literature. In these three models different principles are used for determining the scanning paths: in model (1) the scanning paths are interpolated from tabulated first-order scanning curves, in model (2) simple interpolation functions are used for scaling the scanning paths from the expressions of the main wetting and main drying curves and in model (3) the scanning paths are determined from expressions derived based on the dependent domain theory of hysteresis.

40 (LBL-28914) A gas-phase source term for Yucca Mountain. Zwahlen, E.D.; Lee, W.W.L.; Pigford, T.H.; Chambre, P.L. Lawrence Berkeley Lab., CA (United States). Feb 1990. 10p. Sponsored by USDOE, Washington, 
DC (United States). DOE Contract AC03-76SF00098. (UCBNE-4167). Order Number DE92000645. Source: OSTI; NTIS; INIS; GPO Dep.

We previously presented analyses of gas flow into and out of a partly failed nuclear waste container for various assumed hole sizes and failure times. We also estimated the release rate of ${ }^{14} \mathrm{C}$ by advection and counter-diffusion from the failed container. Here we present an estimate of ${ }^{14} \mathrm{C}$ release rate and cumulative release for hole sizes of one to $300-\mu \mathrm{m}$ and failure at emplacement and 300 years. 4 refs., 4 figs.

41 (LBL-29700, pp. 23-26) Continued development of a semianalytical solution for two-phase fluid and heat flow in a porous medium. Doughty, $C$. (Lawrence Berkeley Lab., CA (United States)); Pruess, K. Lawrence Berkeley Lab., CA (United States). Jun 1991. In Earth Sciences Division annual report 1990. 197p. Order Number DE92000647. Source: OSTI; NTIS; INIS.

Over the past few years the authors have developed a semianalytical solution for transient two-phase water, air, and heat flow in a porous medium surrounding a constantstrength linear heat source, using a similarity variable $\eta=r /$ $\sqrt{ }$ t. Although the similarity transformation approach requires a simplified geometry, all the complex physical mechanisms involved in coupled two-phase fluid and heat flow can be taken into account in a rigorous way, so that the solution may be applied to a variety of problems of current interest. The work was motivated by adverse to predict the thermohydrological response to the proposed geologic repository for heat-generating high-level nuclear wastes at Yucca Mountain, Nevada, in a partially saturated, highly fractured volcanic formation. The paper describes thermal and hydrologic conditions near the heat source; new features of the model; vapor pressure lowering; and the effective-continuum representation of a fractured/porous medium.

42 (LBL-29700, pp. 42-47) Method development and strategy for the characterization of complexly faulted and fractured rhyolitic tuffs, Yucca Mountain, Nevada. Karasaki, K. (Lawrence Berkeley Lab., CA (United States)); Galloway, D. Lawrence Berkeley Lab., CA (United States). Jun 1991. In Earth Sciences Division annual report 1990. 197p. Order Number DE92000647. Source: OSTI; NTIS; INIS.

The planned high-level nuclear waste repository at Yucca Mountain, Nevada, would exist in unsaturated, fractured welded tuff. One possible contaminant pathway to the accessible environment is transport by groundwater infiltrating to the water table and flowing through the saturated zone. Therefore, an effort to characterize the hydrology of the saturated zone is being undertaken in parallel with that of the unsaturated zone. As a part of the saturated zone investigation, there wells-UE-25c\#1, UE-25c\#2, and UE-25c\#3 (hereafter called the c-holes)-were drilled to study hydraulic and transport properties of rock formations underlying the planned waste repository. The location of the c-holes is such that the formations penetrated in the unsaturated zone occur at similar depths and with similar thicknesses as at the planned repository site. In characterizing a highly heterogeneous flow system, several issues emerge. (1) The characterization strategy should allow for the virtual impossibility to enumerate and characterize all heterogeneities. (2) The methodology to characterize the heterogeneous flow system at the scale of the well tests needs to be established. (3) Tools need to be developed for scaling up the information obtained at the well-test scale to the larger scale of the site. In the present paper, the characterization strategy and the methods under development are discussed with the focus on the design and analysis of the field experiments at the c-holes.

43 (LBL-29700, pp. 67-70) TOUGH2: A general-purpose numerical simulator for multiphase nonisothermal flows. Pruess, K. (Lawrence Berkeley Lab., CA (United States)). Lawrence Berkeley Lab., CA (United States). Jun 1991. In Earth Sciences Division annual report 1990. 197p. Order Number DE92000647. Source: OSTI; NTIS; INIS.

Numerical simulators for multiphase fluid and heat flows in permeable media have been under development at Lawrence Berkeley Laboratory for more than 10 yr. Real geofluids contain noncondensible gases and dissolved solids in addition to water, and the desire to model such 'compositional' systems led to the development of a flexible multicomponent, multiphase simulation architecture known as MULKOM. The design of MULKOM was based on the recognition that the mass-and energy-balance equations for multiphase fluid and heat flows in multicomponent systems have the same mathematical form, regardless of the number and nature of fluid components and phases present. Application of MULKOM to different fluid mixtures, such as water and air, or water, oil, and gas, is possible by means of appropriate 'equation-of-state' (EOS) modules, which provide all thermophysical and transport parameters of the fluid mixture and the permeable medium as a function of a suitable set of primary thermodynamic variables. Investigations of thermal and hydrologic effects from emplacement of heatgenerating nuclear wastes into partially water-saturated formations prompted the development and release of a specialized version of MULKOM for nonisothermal flow of water and air, named TOUGH. TOUGH is an acronym for 'transport of unsaturated groundwater and heat' and is also an allusion to the tuff formations at Yucca Mountain, Nevada. The TOUGH2 code is intended to supersede TOUGH. It offers all the capabilities of TOUGH and includes a considerably more general subset of MULKOM modules with added capabilities. The paper briefly describes the simulation methodology and user features.

44 (LBL-29700, pp. 79-83) Modeling studies of gas movement and moisture migration at Yucca Mountain, Nevada. Tsang, Y.W. (Lawrence Berkeley Lab., CA (United States)); Pruess, K. Lawrence Berkeley Lab., CA (United States). Jun 1991. In Earth Sciences Division annual report 1990. 197p. Order Number DE92000647. Source: OSTI; NTIS; INIS.

Modeling studies on moisture redistribution processes that are mediated by gas phase flow and diffusion have been carried out. The problem addressed is the effect of a lowered humidity of the soil gas at the land surface on moisture removal from Yucca Mountain, the potential site for a highlevel nuclear waste repository. At the land surface, humid formation gas contacts much drier atmospheric air. Near this contact, the humidity of the soil gas may be considerably lower than at greater depth, where the authors expect equilibrium with the liquid phase and close to $100 \%$ humidity. The lower relative humidity of the soil gas may be modeled by imposing, at the land surface, an additional negative capillary suction corresponding to vapor pressure lowering according to Kelvin's Equation, thus providing a driving force for the upward movement of moisture in both the vapor and liquid phases. Sensitivity studies show that moisture 
removal from Yucca Mountain arising from the loweredrelative-humidity boundary condition is controlled by vapor diffusion. There is much experimental evidence in the soil literature that diffusion of vapor is enhanced due to pore-level phase change effects by a few orders of magnitude. Modeling results presented here will account for this enhancement in vapor diffusion.

45 (LBL-29700, pp. 87-88) Variation and correlation of hydrologic properties. Wang, J.S.Y. (Lawrence Berkeley Lab., CA (United States)). Lawrence Berkeley Lab., CA (United States). Jun 1991. In Earth Sciences Division annual report 1990. 197p. Order Number DE92000647. Source: OSTI; NTIS; INIS.

Hydrological properties vary within a given geological formation and even more so among different soil and rock media. The variance of the saturated permeability is shown to be related to the variance of the pore-size distribution index of a given medium by a simple equation. This relationship is deduced by comparison of the data from Yucca Mountain, Nevada (Peters et al., 1984), Las Cruces, New Mexico (Wierenga et al., 1989), and Apache Leap, Arizona (Rasmussen et al., 1990). These and other studies in different soils and rocks also support the Poiseuille-Carmen relationship between the mean value of saturated permeability and the mean value of capillary radius. Correlations of the mean values and variances between permeability and pore-geometry parameters can lead us to better quantification of heterogeneous flow fields and better understanding of the scaling laws of hydrological properties.

46 (LBL-29700, pp. 91-92) Sorptivity of rocks and solls of the van -Genuchten-Mualem type. Zimmerman, R.W. (Lawrence Berkeley Lab., CA (United States)); Bodvarsson, G.S. Lawrence Berkeley Lab., CA (United States). Jun 1991. In Earth Sciences Division annual report 1990. 197p. Order Number DE92000647. Source: OSTI; NTIS; INIS.

One hydrological process that will have great relevance to the performance of the proposed underground radioactive waste repository at Yucca Mountain, Nevada, is that of the absorption of water from a water-filled fracture into the adjacent unsaturated rock formation. The rate at which water is imbibed by a rock depends on the hydrological properties of the rock and on the initial saturation (or initial capillary suction) of the formation. The hydrological properties that affect imbibition are the relative permeability function and the capillary pressure function. These functions are often collectively referred to as the 'characteristic functions' of the porous medium. For one-dimensional absorption, it can be shown that, regardless of the details of the characteristic functions, the total amount of water imbibed by the formation, per unit surface area, will be proportional to the square root of the elapsed time. Hence the ability of a rock or soll to imbibe water can be quantified by a parameter known as the sorptivity $S$, which is defined such that the cumulative volumetric liquid influx per unit area is given by $Q=S \sqrt{ }$ t. The paper discusses the simplification of these characteristic functions of porous medium.

47 (LBL-30043) Geotechnical support and topical studies for nuclear waste geologic repositories: Annual report, fiscal year 1989. Lawrence Berkeley Lab., CA (United States). Dec 1990. 186p. Sponsored by USDOE, Washington, DC (United States). DOE Contract ACO376SF00098. Order Number DE94003377. Source: OSTI; NTIS; INIS; GPO Dep.
This multidisciplinary project was initiated in fiscal year 1986. It comprises two major interrelated tasks, technical assistance and topical studies. The present report lists the technical reviews and comments made during the fiscal year 1989 and summarizes the technical progress of the topical studies. The major task was a study of the mechanical, hydraulic, geophysical and geochemical properties of fractures in geologic rock masses. In the area of technical assistance, there were a total of 30 geotechnical support activities, including reviews of 15 study plans (SP) and participation in 5 SP Review Workshops; in-depth multidisciplinary review of 5 Exploratory Shaft Facility (ESF) Study Plans and presentation of results to DOE; preparation and revision of a white paper and proposed work statement on preclosure monitoring and performance confirmation as an outgrowth of a request made by DOE to $L B L$; the hosting of a DOE program review; with DOE's encouragement, preparation of 8 papers for the International High-Level Radioactive Waste Management Conference to be held in April, 1990 in Las Vegas, Nevada; and 5 instances of general technical assistance to DOE. Selected papers will be processed separately for inclusion in the Energy Science and Technology Database.

48 (LBL-30707) Waste-package release rates for site suitability studies. Lee, W.W.L.; Sadeghi, M.M.; Chambre, P.L.; Pigford, T.H. Lawrence Berkeley Lab., CA (United States). Apr 1991. 26p. Sponsored by USDOE, Washington, DC (United States). DOE Contract ACO376SF00098. Order Number DE92009131. Source: OSTI; NTIS; INIS; GPO Dep.

Performance-assessment calculations in support of the site- suitability effort for the Yucca Mountain Project will address radionuclide transport arising from various disruptive scenarios. Here we present release rates of radionuclides from individual waste packages for scenarios involving various postulated forms of water intrusion, including increased infiltration rate as well as rock immediately surrounding an individual waste package becoming saturated with ground water. We examine: (1) effect of increased water infiltration rate on release rates; increases in radionuclide release rates resulting from water filling the annulus between the waste container and the surrounding rock, as well as water saturating the pores and fractures in the rock surrounding the waste package; $(3)$ the effect of flow in fractures in the saturated rock on release rate; and (4) release of radionuclides to the mountain surface resulting from an exploratory borehole shaft intersecting a waste package. The radionuclides considered are Tc-99; 1-129; Cs-135; Np- 237; $\mathrm{Pu}-239,240,242 ;$ and Am-241,243. Release rates are calculated for both the wet-drip bathtub and the wet-continuous water-contact modes, as described in the Working Group 2 report, applying equations as published by Sadeghi, et al., [1990] and as extended in the present report.

49 (LBL-31069) Preliminary calculations of release rates of Tc-99, $1-129$, and $N p-237$ from spent fuel in a potential repository in tuff. Apted, M.J. (Battelle Pacific Northwest Lab., Richland, WA (United States)); O'Connell, W.J.; Lee, K.H.; Maclntyre, A.T.; Ueng, T.-S.; Lee, W.W.L.; Pigford, T.H. Lawrence Berkeley Lab., CA (United States). Jun 1990. 38p. Sponsored by USDOE, Washington, DC (United States). DOE Contract AC03-76SF00098. Order Number DE92009137. Source: OSTI; NTIS; INIS; GPO Dep.

This report presents preliminary calculations of timedependent release rates of selected radionuclides from the engineered barrier system in a potential high-level waste repository in unsaturated tuff, representative of a potential 
repository at Yucca Mountain in southern Nevada. These results are intended for use as preliminary source terms for calculating total system performance. The radionuclides specified for preliminary release-rate calculations are Tc-99, $\mathrm{l}-129, \mathrm{Cs}-135$, and $\mathrm{Np}-237$ for ground-water pathways and C-14 for gaseous release.

$50 \quad(L B L-31181)$ Solubility and speciation studies for nuclear repository performance assessment. Nitsche, H. Lawrence Berkeley Lab., CA (United States). Oct 1990. 9p. Sponsored by USDOE, Washington, DC (United States). DOE Contract AC03-76SF00098. (CONF-9010497-1: Technical workshop on near field performance assessment for high-level waste, Madrid (Spain), 15-17 Oct 1990). Order Number DE92017084. Source: OSTI; NTIS; INIS; GPO Dep.

Solubility and speciation data are important in understanding aqueous radionuclide transport through the geosphere. They define the source term for transport retardation processes such as sorption and colloid formation. Solubility and speciation data are useful in verifying the validity of geochemical codes that are part of the predictive transport models. Radionuclide solubility studies in groundwaters from a repository region will provide limits on radionuclide concentrations in these waters. Meaningful thermodynamically defined solubility studies must satisfy four criteria: (1) solution equilibrium conditions, (2) effective and complete phase separation, (3) a well-defined solid phase, and (4) knowledge of the speciation/oxidation state of the soluble species at equilibrium. Results from solubility and speciation experiments of ${ }^{237} \mathrm{NpO}_{2}{ }^{+},{ }^{239} \mathrm{Pu}^{4+}$, and ${ }^{241} \mathrm{Am}^{3+} \mathrm{Nd}^{3+}$ in $\mathrm{J}-13$ groundwater (from the Yucca Mountain region, Nevada, which is being investigated as a potential high-level nuclear waste disposal site) at three different temperatures $\left(25^{\circ}\right.$, $60^{\circ}$, and $\left.90^{\circ} \mathrm{C}\right)$ and $\mathrm{pH}$ values $(6,7$, and 8.5$)$ are presented.

51 (LBL-31258) Releases from exotic waste packages from partitioning and transmutation. Lee, W.W.L. (Lawrence Berkeley Lab., CA (United States)); Choi, J.S. Lawrence Berkeley Lab., CA (United States). Sep 1991. 10p. Sponsored by USDOE, Washington, DC (United States). DOE Contract AC03-76SF00098; W-7405-ENG-48. (CONF-920430-68: 3. international high level radioactive waste management (IHLRWM) conference, Las Vegas, NV (United States), 12-16 Apr 1992). Order Number DE92009987. Source: OSTI; NTIS; INIS; GPO Dep.

Partitioning the actinides in spent nuclear fuel and transmuting them in actinide-burning liquid-metal reactors has been proposed as a potential method of reducing the public risks from geologic disposal of nuclear waste. To quantify the benefits for waste disposal of actinide burning, we calculate the release rates of key radionuclides from waste packages resulting from actinide burning, and compare them with release rates from LWR spent fuel destined for disposal at the potential repository at Yucca Mountain. The wet-drip water-contact mode has been used. Analytic methods and parameter values are very similar to those used for assessing Yucca Mountain as a potential repository. Once released, the transport characteristics of radionuclides will be largely determined by site geology. For the most important nuclides such as $1-129$ and $T_{c}-99$, which are undiminished by actinide-burning reactors, it is not surprising that actinide burning offers little reduction in releases. For important actinides such as $\mathrm{Np}-237$ and $\mathrm{Pu}$ isotopes, which are reduced in inventory, the releases are not reduced because the release rates are proportional to solubility, rather than inventory.
52 (LBL-31666) Radioelements and their occurrence with secondary minerals in heated and unheated tuff at the Nevada Test Site. Flexser, S.; Wollenberg, H.A. Lawrence Berkeley Lab., CA (United States). Jun 1992. 34p. Sponsored by USDOE, Washington, DC (United States). DOE Contract AC03-76SF00098. (CONF-920430103: 3. international high level radioactive waste management (IHLRWM) conterence, Las Vegas, NV (United States), 12-16 Apr 1992). Order Number DE93007659. Source: OSTI; NTIS; INIS; GPO Dep.

Samples of devitrified welded tuff near and away from the site of a heater test in Rainier Mesa were examined with regard to whole-rock radioelement abundances, microscopic distribution of $\mathrm{U}$, and oxygen isotope ratios. Wholerock $\mathrm{U}$ averages between 4 and $5 \mathrm{ppM}$, and $U$ is concentrated at higher levels secondary opaque minerals as well as in accessory grains. $U$ in primary and secondary sites is most commonly associated with Mn phases, which average $\sim 30$ ppM $U$ in more uraniferous occurrences. This average is consistent and apparently unaffected by proximity to the heater. The Mn phases differ compositionally from Mn minerals in other NTS tuffs, usually containing abundant $\mathrm{Fe}, \mathrm{T}$, and sometimes $\mathrm{Ce}$, and are often poorly crystalline. Oxygen isotope ratios show some depletion in $\delta^{18} O$ in tuff samples very close to the heater; this depletion is consistent with isotopic exchange between the tuff and interstitial water, but it may also reflect original heterogeneity in isotopic ratios of the tuff unrelated to the heater test. Seismic properties of several tuff samples were measured. Significant differences correlating with distance from the heater occur in P-and Swave amplitudes; these may be due to loss of bound water. Seismic velocities are nearly constant and indicate a lack of significant microcracking. The absence of clearer signs of heater-induced $U$ mobilization or isotopic variations may be due to the short duration of the heater test, and to insufficient definition of pre-heater-test heterogeneities in the tuff.

53 (LBL-31799) Design of a three-dimensional site-scale model for the unsaturated zone at Yucca Mountain, Nevada. Wittwer, C.S. (Lawrence Berkeley Lab., CA (United States)); Bodvarsson, G.S.; Chornack, M.P.; Flint, A.L.; Lewis, B.D.; Spengler, R.W.; Flint, L.E.; Rautman, C.A. Lawrence Berkeley Lab., CA (United States). Jan 1992. 9p. Sponsored by USDOE, Washington, DC (United States). DOE Contract ACO3-76SF00098; Al0878ET44802. (CONF-920430-69: 3. international high level radioactive waste management (IHLRWM) conference, Las Vegas, NV (United States), 12-16 Apr 1992). Order Number DE92010459. Source: OSTI; NTIS; INIS; GPO Dep.

A three-dimensional model of moisture flow within the unsaturated zone at Yucca Mountain is being developed. This site-scale model covers an area of about $30 \mathrm{~km}^{2}$ and is bounded by major faults to the east and west. A detailed numerical grid has been developed based on location of boreholes, different infiltration zones, hydrogeological units and their outcrops, major faults, and water level data. Different maps, such as contour maps and isopachs maps, are presented for the different infiltration zones, and for the base of the Tiva Canyon, the Paintbrush, and the Topopah Spring hydrogeological units.

$54 \quad(L B L-31975)$ Semi-analytical treatment of tracture/matrix flow in a dual-porosity simulator for unsaturated fractured rock masses. Zimmerman, R.W.; Bodvarsson, G.S. Lawrence Berkeley Lab., CA (United States). Apr 1992. 7p. Sponsored by USDOE, Washington, DC (United States). DOE Contract AC03-76SF00098. 
(CONF-920430-98: 3. international high level radioactive waste management (IHLRWM) conference, Las Vegas, NV (United States), 12-16 Apr 1992). Order Number DE92017022. Source: OSTI; NTIS; INIS; GPO Dep.

A semi-analytical dual-porosity simulator for unsaturated flow in fractured rock masses has been developed. Fluid flow between the fracture network and the matrix blocks is described by analytical expressions that have been derived from approximate solutions to the imbibition equation. These expressions have been programmed into the unsaturated flow simulator, TOUGH, as a source/sink term. Flow processes are then simulated using only fracture elements in the computational grid. The modified code is used to simulate flow along single fractures, and infiltration into pervasively fractured formations.

55

(LBL-32874) Radionuclide solubility and speciation studies for the Yucca Mountain site characterization project. Nitsche, H.; Roberts, K.; Prussin, T.; Keeney, D.; Carpenter, S.A.; Becraft, K.; Gatti, R.C. Lawrence Berkeley Lab., CA (United States). Dec 1992. 7p. Sponsored by USDOE, Washington, DC (United States). DOE Contract AC03-76SF00098. (CONF-930408-53: International high-level radioactive waste management conference, Las Vegas, NV (United States), 25-29 Apr 1993). Order Number DE93010444. Source: OSTI; NTIS; INIS; GPO Dep.

Yucca Mountain, Nevada, USA, is being investigated for its suitability as a potential site for a geologic nuclear waste repository. As part of the site characterization studies, actinide solubilities and speciations were studied at $\mathrm{pH} 6,7$, and 8.5 at $25^{\circ} \mathrm{C}$ in two different groundwaters from the vicinity of Yucca Mountain. The groundwaters differ substantially in total dissolved carbonate concentration, and to a lesser extent in jonic strength. In the waters with higher carbonate content, the solubilities of neptunium(V) decreased, whereas those americium(III) increased at $25^{\circ} \mathrm{KC}$ and decreased at $60^{\circ} \mathrm{C}$. The solids formed were sodium neptunium carbonates and americium hydroxycarbonates. Plutonium solubilities did not significantly change with changing water composition because the solubility-controlling solids were mostly amorphous Pu(IV) polymers that contained only small amounts of carbonate.

$56 \quad(\mathrm{LBL}-33464)$ An inverse procedure for estimating the unsaturated hydraulic conductivities of volcanic tuffs. Zimmerman, R.W. (Lawrence Berkeley Lab., CA (United States)); Bodvarsson, G.S.; Flint, A.L.; Flint, L.E. Lawrence Berkeley Lab., CA (United States). Jan 1993. 7p. Sponsored by USDOE, Washington, DC (United States). DOE Contract AC03-76SF00098; Al08-78ET44802. (CONF-930408-50: International high-level radioactive waste management conference, Las Vegas, NV (United States), 25-29 Apr 1993). Order Number DE93010421. Source: OSTI; NTIS; INIS; GPO Dep.

A procedure is developed for estimating the hydraulic conductivity function of unsaturated volcanic tuff, using measurements of the sorptivity and capillary pressure functions. The method assumes that the sorptivity is a linear function of the initial saturation, as is suggested by experimental data. The procedure is tested on a vitrified tuff from the Calico Hills unit at Yucca Mountain, and the predicted conductivities are in reasonable agreement with measured values. Further tests of this method are needed to establish whether or not it can be routinely used for conductivity predictions.
57

(LBL-33597) Modeling of strongly heat-driven flow processes at a potential high-level nuclear waste repository at Yucca Mountain, Nevada. Pruess, K.; Tsang, Y. Lawrence Berkeley Lab., CA (United States). Jan 1993. 8p. Sponsored by USDOE, Washington, DC (United States). DOE Contract AC03-76SF00098; AC04-76DP00789. (CONF-930408-59: International high-level radioactive waste management conference, Las Vegas, NV (United States), 25-29 Apr 1993). Order Number DE93010450. Source: OSTI; NTIS; INIS; GPO Dep.

Two complementary numerical models for analyzing highlevel nuclear waste emplacement at Yucca Mountain have been developed. A vertical cross-sectional $(X-Z)$ model permits a realistic representation of hydrogeologic features, such as alternating tilting layers of welded and non-welded tuffs. fault zones, and surface topography. An alternative radially symmetric (R-Z) model is more limited in its ability to describe the hydrogeology of the site, but is better suited to model heat transfer in the host rock. Our models include a comprehensive description of multiphase fluid and heat flow processes, including strong enhancements of vapor diffusion from pore-level phase change effects. The neighborhood of the repository is found to partially dry out from the waste heat. A condensation halo of large liquid saturation forms around the drying zone, from which liquid flows downward at large rates. System response to infiltration from the surface and to ventilation of mined openings is evaluated. The impact of the various flow processes on the waste isolation capabilities of the site is discussed.

58 (LBL-33627) Geohydrologic data and models of Rainier Mesa and their implications to Yucca Mountain. Wang, J.S.Y.; Cook, N.G.W.; Wollenberg, H.A.; Carnahan, C.L.; Javandel, I.; Tsang, C.F. Lawrence Berkeley Lab., CA (United States). Jan 1993. 7p. Sponsored by USDOE, Washington, DC (United States). DOE Contract AC03-76SF00098. (CONF-930408-61: International highlevel radioactive waste management conference, Las Vegas, NV (United States), 25-29 Apr 1993). Order Number DE93010410. Source: OSTI; NTIS; INIS; GPO Dep.

The geohydrologic data collected at Rainier Mesa provide the only extensive observations in tunnels presently available on flow and transport in tuff units similar to those of a potential nuclear waste repository at Yucca Mountain. This information can, therefore, be of great value in planning the Exploratory Studies Facility (ESF) testing in underground drifts at Yucca Mountain. In this paper, we compare the geohydrologic characteristics of tuff units of these two sites and summarize the hydrochemical data indicating the presence of nearly meteoric water in Rainier Mesa tunnels. A simple analytic model is used to evaluate the possibility of propagating transient pulses of water along fractures or faults through the Paintbrush nonwelded tuff unit to reach the tunnel beds below. The results suggest that fast flow could occur without significant mixing between meteoric fracture water and matrix pore water. The implications of these findings on planning for the ESF Calico Hills study at Yucca Mountain are discussed.

$59(\mathrm{LBL}-33660)$ Single fracture aperture patterns: Characterization by slit-island fractal analysis. Cox, B.L.; Wang, J.S.Y. Lawrence Berkeley Lab., CA (United States). Jan 1993. 8p. Sponsored by USDOE, Washington, DC (United States). DOE Contract AC03-76SF00098. (CONF930408-49: International high-level radioactive waste management conference, Las Vegas, NV (United States), 
25-29 Apr 1993). Order Number DE93010413. Source: OSTI; NTIS; INIS; GPO Dep.

Single fracture measurements are difficult to obtain, but they are the only means we have to observe and study natural fracture morphology. The character of the fracture openings (apertures) is often one of the primary factors controlling fluid flow in the fracture. In particular, the shape, distribution, and connectivity of contact areas and flow channels can affect the relative permeability of wetting and non-wetting fluid phases in unsaturated systems. In this paper we use three methods of fractal analysis (the slit-island, the divider, and the variogram) as well as statistical and geostatistical analysis to characterize the geometry of measured fracture apertures obtained from two different fractured rock specimens from the field. One of these is a granitic fracture (crack) of homogeneous lithology and no displacement, the other is a fracture (fault) obtained from a highly altered fault zone, containing striations and slickensides. We discuss the fractal and geostatistical analysis of these two fractures in the context of what information is most helpful for making predictions about fluid flow in single fractures.

(LBL-33661) The role of fault zones in affecting multiphase flow at Yucca Mountain. Tsang, Y.W.; Pruess, K.; Wang, J.S.Y. Lawrence Berkeley Lab., CA (United States). Jan 1993. 8p. Sponsored by USDOE, Washington, DC (United States). DOE Contract ACO376SF00098. (CONF-930408-52: International high-level radioactive waste management conference, Las Vegas, NV (United States), 25-29 Apr 1993). Order Number DE93010431. Source: OSTI; NTIS; INIS; GPO Dep.

Within Yucca Mountain, the potential High Level NuclearWaste Repository site, there are large scale fault zones, most notably the Ghost Dance Fault. The effect of such high-permeability, large scale discontinuities on the flow and transport is a question of concern in assessing the ability of the site to isolate radio-nuclides from the biosphere. In this paper, we present a numerical study to investigate the role of the fault in affecting both the liquid and gas phase flows in the natural state at Yucca Mountain prior to waste emplacement, as well as after the waste emplacement when the fluid flow is strongly heat-driven. Our study shows that if the characteristic curves of the Ghost Dance Fault obey the same relationship between saturated permeability and capillary scaling parameter, as is observed from the measured data of Yucca Mountain welded and nonwelded tuffs. Apache Leap tuffs, and Las Cruces soil, then a large saturated permeability of the Ghost Dance Fault will play little róle in channeling water into the fault, or inenhancing the flow of water down the fault. However, the Fault may greatly enhance the upward gas flow after emplacement of waste. This may have implications on the transport of gaseous radio-nuclides such as $\mathrm{C}^{14}$. The results of this study also focus attention on the need for field measurements of fluid flow in the fault zones.

$61 \quad(L B L-33663)$ Flow and transport in hierarchically fractured systems. Karasaki, K. Lawrence Berkeley Lab., CA (United States). Jan 1993. 6p. Sponsored by USDOE, Washington, DC (United States). DOE Contract AC03-76SF00098. (CONF-930408-48: International highlevel radioactive waste management conference, Las Vegas, NV (United States), 25-29 Apr 1993). Order Number DE93010414. Source: OSTI; NTIS; INIS; GPO Dep.

Preliminary results indicate that flow in the saturated zone at Yucca Mountain is controlled by fractures. A current conceptual model assumes that the flow in the fracture system can be approximately by a three-dimensionally interconnected network of linear conduits. The overall flow system of rocks at Yucca Mountain is considered to consist of hierarchically structured heterogeneous fracture systems of multiple scales. A case study suggests that it is more appropriate to use the flow parameters of the large fracture system for predicting the first arrival time, rather than using the bulk average parameters of the total system.

62 (PNL-7474) Three-dimensional modeling of unsaturated flow in the vicinity of proposed exploratory shaft facilities at Yucca Mountain, Nevada. Rockhold, M.L. (Pacific Northwest Lab., Richland, WA (United States)); Sagar, B.; Connelly, M.P. Pacific Northwest Lab., Richland, WA (United States). Apr 1992. 46p. Sponsored by USDOE, Washington, DC (United States). DOE Contract ACO676RL01830. Order Number DE92012319. Source: OSTI; NTIS; INIS; GPO Dep.

This report describes the results of a study to investigate the influence of proposed exploratory shafts on the moisture distribution within unsaturated, fractured rock at Yucca Mountain, Nevada. The long-term effects of exploratory shatts at Yucca Mountain are important in the estimation of potential waste migration and fate, while short-term effects may be important in the planning and interpretation of tests performed at the site. The PORFLO-3 computer code was used for simulation of moisture flow through the geologic units adjacent to the ESF. Rather than represent fractures as discrete elements, an equivalent continuum was stipulated, in which the fractured units were assigned equivalent or composite hydrologic properties. Explicit treatment of fractures is not feasible because of the extremely large number of fractures contained in the site-scale problem and the difficulties in characterizing and modeling the fracture geometries.

63 (PNL-8444) Preliminary total-system analysis of a potential high-level nuclear waste repository at Yucca Mountain. Eslinger, P.W. (Pacific Northwest Lab., Richland, WA (United States)); Doremus, L.A.; Engel, D.W.; Miley, T.B.; Murphy, M.T.; Nichols, W.E.; White, M.D.; Langford, D.W.; Ouderkirk, S.J. Pacific Northwest Lab., Richland, WA (United States). Jan 1993. 203p. Sponsored by USDOE, Washington, DC (United States). DOE Contract AC06-76RL01830. Order Number DE93007438. Source: OSTI; NTIS; INIS; GPO Dep.

The placement of high-level radioactive wastes in mined repositories deep underground is considered a disposal method that would effectively isolate these wastes from the environment for long periods of time. This report describes modeling performed at PNL for Yucca Mountain between May and November 1991 addressing the performance of the entire repository system related to regulatory criteria established by the EPA in 40 CFR Part 191. The geologic stratigraphy and material properties used in this study were chosen in cooperation with performance assessment modelers at Sandia National Laboratories (SNL). Sandia modeled a similar problem using different computer codes and a different modeling philosophy. Pacific Northwest Laboratory performed a few model runs with very complex models, and SNL performed many runs with much simpler (abstracted) models.

64. (PNL-8636) MSTS - Multiphase Subsurface Transport Simulator theory manual. White, M.D.; Nichols, W.E. Pacific Northwest Lab., Richland, WA (United States). May 1993. 102p. Sponsored by USDOE, Washington, DC 
(United States). DOE Contract AC06-76RL01830. Order Number DE93016342. Source: OSTI; NTIS; INIS; GPO Dep.

The US Department of Energy, through the Yucca Mountain Site Characterization Project Office, has designated the Yucca Mountain site in Nevada for detailed study as the candidate US geologic repository for spent nuclear fuel and high-level radioactive waste. Site characterization will determine the suitability of the Yucca Mountain site for the potential waste repository. If the site is determined suitable, subsequent studies and characterization will be conducted to obtain authorization from the Nuclear Regulatory Commission to construct the potential waste repository. A principal component of the characterization and licensing processes involves numerically predicting the thermal and hydrologic response of the subsurface environment of the Yucca Mountain site to the potential repository over a 10,000-year period. The thermal and hydrologic response of the subsurface environment to the repository is anticipated to include complex processes of countercurrent vapor and liquid migration, multiple-phase heat transfer, multiple-phase transport, and geochemical reactions. Numerical simulators based on mathematical descriptions of these subsurface phenomena are required to make numerical predictions of the thermal and hydrologic response of the Yucca Mountain subsurface environment The engineering simulator called the Multiphase Subsurface Transport Simulator (MSTS) was developed at the request of the Yucca Mountain Site Characterization Project Office to produce numerical predictions of subsurface flow and transport phenomena at the potential Yucca Mountain site. This document delineates the design architecture and describes the specific computational algorithms that compose MSTS. Details for using MSTS and sample problems are given in the "User's Guide and Reference" companion document.

65 (PNL-SA-20324) Simulation of two-phase carbon-14 transport at Yucca Mountain, Nevada. White, M.D.; Freshley, M.D.; Eslinger, P.W. Pacific Northwest Lab., Richland, WA (United States). Feb 1992. 16p. Sponsored by USDOE, Washington, DC (United States). DOE Contract AC06-76RL01830. (CONF-920256-2: National Water Wells Association (NWWA) meeting on solving ground water problems with models, Dallas, TX (United States), 11-13 Feb 1992). Order Number DE92010496. Source: OSTI; NTIS; INIS; GPO Dep.

In support of pacific Northwest Laboratory's (PNL) preliminary total system performance assessment of the proposed high-level nuclear-waste repository at Yucca Mountain, transport of carbon-14 $\left(\mathrm{C}^{14}\right)$ in the unsaturated zone was numerically modeled with the Multiphase Subsurface Transport Simulator (MSTS). Total system performance assessments are being conducted to estimate potential cumulative releases and doses from radionuclides being transported through different pathways to the accessible environment from the proposed waste repository. Transport of radionuclides in the gaseous and liquid phases are pathways through which some of the inventory in the proposed repository could reach the accessible environment. Carbon14 transport in the unsaturated zone at Yucca Mountain was estimated with MSTS by considering two-phase diffusion, advection, phase petitioning, and radioactive decay.Transport results were based on a two-dimensional physical and hydrogeological system that represented an east-west cross section through Yucca Mountain. Carbon-14 source rates from failed repository waste canisters were estimated from the source term modeling subtasks associated with PNL's total system performance assessment of the proposed Yucca Mountain repository. Simulation results included estimates of liquid, gas, heat, and $\mathrm{C}^{14}$ transport within the unsaturated zone at Yucca Mountain. Predictions of $\mathrm{C}^{14}$ distributions surrounding the proposed nuclear waste repository within Yucca Mountain and a brief description of the thermal-hydrogeologic computer code MSTS are presented.

66 (PNL-SA-20329) A demonstration of dose modeling at Yucca Mountain. Miley, T.B.; Eslinger, P.W. Pacific Northwest Lab., Richland, WA (United States). Nov 1992. 7p. Sponsored by USDOE, Washington, DC (United States). DOE Contract AC06-76RL01830. (CONF-92110145: 16. Materials Research Society (MRS) fall meeting, Boston, MA (United States), 30 Nov - 5 dec 1992). Order Number DE93005097. Source: OSTI; NTIS; INIS; GPO Dep.

The U. S. Environmental Protection Agency is currently revising the regulatory guidance for high-level nuclear waste disposal. In its draft form, the guidelines contain dose limits. Since this is likely to be the case in the final regulations, it is essential that the US Department of Energy be prepared to calculate site-specific doses for any potential repository location. This year, Pacific Northwest Laboratory (PNL) has made a first attempt to estimate doses for the potential geologic repository at Yucca Mountain, Nevada as part of a preliminary total-systems performance assessment. A set of transport scenarios was defined to assess the cumulative release of radionuclides over 10,000 years under undisturbed and disturbed conditions at Yucca Mountain. Dose estimates were provided for several of the transport scenarios modeled. The exposure scenarios used to estimate dose in this total-systems exercise should not, however, be considered a definitive set of scenarios for determining the risk of the potential repository. Exposure scenarios were defined for waterborne and surface contamination that result from both undisturbed and disturbed performance of the potential repository. The exposure scenarios used for this analysis were designed for the Hanford Site in Washington. The undisturbed performance scenarios for which exposures were modeled are gas-phase release of ${ }^{14} \mathrm{C}$ to the surface and natural breakdown of the waste containers with waterborne release. The disturbed performance scenario for which doses were estimated is exploratory drilling. Both surface and waterborne contamination were considered for the drilling intrusion scenario.

67 (SAIC-91/8000) Report of early site suitability evaluation of the potential repository site at Yucca Mountain, Nevada: Yucca Mountain Site Characterization Project. Younker, J.L. (Science Applications International Corp., Las Vegas, NV (United States)); Andrews, W.B.; Fasano, G.A.; Herrington, C.C.; Mattson, S.R.; Murray, R.C.; Ballou, L.B.; Revelli, M.A.; Ducharme, A.R.; Shephard, L.E.; Dudley, W.W.; Hoxie, D.T.; HerScience Applications International Corp., Las Vegas, NV (United States). Jan 1992. 419p. Sponsored by USDOE, Washington, DC (United States). DOE Contract AC08-87NV10576. Order Number DE92017680. Source: OSTI; NTIS; INIS; GPO Dep.

This study evaluated the technical suitability of Yucca Mountain, Nevada, as a potential site for a mined geologic repository for the permanent disposal of radioactive waste. The evaluation was conducted primarily to determine early in the site characterization program if there are any features or conditions at the site that indicate it is unsuitable for 
repository development. A secondary purpose was to determine the status of knowledge in the major technical areas that affect the suitability of the site. This early site suitability evaluation (ESSE) was conducted by a team of technical personnel at the request of the Associate Director of the US Department of Energy (DOE) Office of Geologic Disposal, a unit within the DOE's Office of Civilian Radioactive Waste Management. The Yucca Mountain site has been the subject of such evaluations for over a decade. In 1983, the site was evaluated as part of a screening process to identify potentially acceptable sites. The site was evaluated in greater detail and found suitable for site characterization as part of the Environmental Assessment (EA) (DOE, 1986) required by the Nuclear Waste Policy Act of 1982 (NWPA). Additional site data were compiled during the preparation of the Site Characterization Plan (SCP) (DOE, 1988a). This early site suitability evaluation has considered information that was used in preparing both-documents, along with recent information obtained since the EA and SCP were published. This body of information is referred to in this report as "current information" or "available evidence."

68

(SAIC-91/8001) Report of the Peer Review Panel on the early site suitability evaluation of the Potential Repository Site at Yucca Mountain, Nevada: Yucca Mountain Site Characterization Project. Science Applications International Corp., Las Vegas, NV (United States). Jan 1992. 736p. Sponsored by USDOE, Washington, DC (United States). DOE Contract AC08-87NV10576. Order Number DE92017681. Source: OSTI; NTIS; INIS; GPO Dep.

The US Department of Energy (DOE) Yucca mountain Site Characterization Project Office (YMPO) assigned Science Applications International Corporation (SAIC), the Technical and Management Support Services (T\&MSS) contractor to the YmPo, the task of conducting an Early Site Suitability Evaluation (ESSE) of the Yucca mountain site as a potential site for a high-level radioactive waste repository. First, the assignment called for the development of a method to evaluate a single site against the DOE General Guidelines for Recommendation of Sites for Nuclear Waste Repositories, 10 CFR Part 960 . Then, using this method, an evaluation team, the ESSE Core Team, of senior YMP scientists, engineers, and technical experts, evaluated new information obtained about the site since publication of the final Environmental Assessment (DOE, 1986) to determine if new suitability/unsuitability findings could be recommended. Finally, the Core Team identified further information and analyses needed to make final determinations for each of the guidelines. As part of the task, an independent peer review of the ESSE report has been conducted. Expertise was solicited that covered the entire spectrum of siting guidelines in 10 CFR Part 960 in order to provide a complete, in-depth critical review of the data evaluated and cited in the ESSE report, the methods used to evaluate the data, and the conclusions and recommendations offered by the report. Fourteen nationally recognized technical experts (Table 2) served on the Peer Review Panel. The comments from the Panel and the responses prepared by the ESSE Core Team, documented on formal Comment Response Forms, constitute the body of this document.

69 (YMP-91-17) Nevada commercial spent nuclear fuel transportation experience. Science Applications International Corp., Las Vegas, NV (United States); USDOE Yucca Mountain Site Characterization Project Office, Las Vegas, NV (United States). Sep 1991. 22p. Sponsored by
USDOE, Washington, DC (United States). DOE Contract AC08-87NV10576. Order Number DE93017090. Source: OSTI; NTIS; INIS; GPO Dep.

The purpose of this report is to present an historic overview of commercial reactor spent nuclear fuel (SNF) shipments that have occurred in the state of Nevada, and to review the accident and incident experience for this type of shipments. Results show that between 1964 and 1990, 309 truck shipments covering approximately 40,000 miles moved through Nevada; this level of activity places Nevada tenth among the states in the number of truck shipments of SNF. For the same period, 15 rail shipments moving through the State covered approximately 6,500 miles, making Nevada 20 th among the states in terms of number of rail shipments. None of these shipments had an accident or an incident associated with them. Because the data for Nevada are so limited, national data on SNF transportation and the safety of truck and rail transportation in general were also assessed.

70 (YMP-91-19) The Nevada railroad system: Physical, operational, and accident characteristics. USDOE Yucca Mountain Site Characterization Project Office, Las Vegas, NV (United States). Sep 1991. 105p. Sponsored by USDOE, Washington, DC (United States). DOE Contract AC08-87NV10576. Order Number DE93017091. Source: OSTI; NTIS; GPO Dep.

This report provides a description of the operational and physical characteristics of the Nevada railroad system. To understand the dynamics of the rail system, one must consider the system's physical characteristics, routing, uses, interactions with other systems, and unique operational characteristics, if any. This report is presented in two parts. The first part is a narrative description of all mainlines and major branchlines of the Nevada railroad system. Each Nevada rail route is described, including the route's physical characteristics, traffic type and volume, track conditions, and history. The second part of this study provides a more detailed analysis of Nevada railroad accident characteristics than was presented in the Preliminary Nevada Transportation Accident Characterization Study (DOE, 1990).

71 Waste package and engineered barrier system design concepts for the direct disposal of spent fuel in the potential United States repository at Yucca Mountain, Nevada. Harrison, D.J. (Department of Energy, Las Vegas, NV (United States). Yucca Mountain Site Characterization Project Office); Stahl, D. pp. 161-170 of Geological disposal of spent fuel and high level and alpha bearing wastes: Proceedings of an international symposium held in Antwerp, 19-23 October 1992. IAEA, Vienna (Austria) (Apr 1993). [487] of (CONF-9210119-: International symposium on geologic disposal of spent fuel, high-level and alphabearing wastes, Antwerp (Belgium), 19-23 Oct 1992).

The goal of the United States Department of Energy's Yucca Mountain Site Characterization Project (YMP) waste package design programme is to develop a design for a waste package and associated engineered barrier system that meets the applicable regulatory requirements for safe disposal of spent nuclear fuel and solidified high level waste in a geological repository. Attainment of this goal relies on a multibarrier approach, the unsaturated nature of the Yucca Mountain site, consideration of technical alternatives, and the sufficient resolution of technical and regulatory uncertainties. To accomplish this, an iterative system engineering approach will be used. This will involve selection of candidate designs and materials, evaluation of the designs against performance requirements, and then selection of 
one or two preferred designs for further detailed evaluation and final design. The reference design of the waste package described in the YMP Site Characterization Plan is a thin walled, vertical, borehole emplaced package with an air gap between the package and the rock wall. Several design concepts being evaluated during the advanced conceptual design phase of the programme include more robust designs such as small, drift emplaced packages and higher capacity, drift emplaced packages, both partially and totally self-shielded. Metallic as well as ceramic materials are being considered. (author). 4 refs, 5 figs.

72 Repository development and long-term data observation needs in the Yucca Mountain, Nevada site characterization program. Voegele, M.D. (Science Applications International Corp., Las Vegas, NV (United States)); Blanchard, M.B. pp. 35-46 of Long-term observation of the geological environment: needs and techniques. Organisation for Economic Co-Operation and Development, Paris (France) (1993). pp. 214 (CONF-9109268-: OECD/NEA workshop on long-term observation of the geological environment: needs and techniques, Helsinki (Finland), 9-11 Sep 1991).

The development of the site characterization program at the potential high level waste repository site at Yucca Mountain originated from a regulatory basis. This approach resulted in the identification of geotechnical information needed to support a license application, as well as a preliminary identification of information to form the basis for a long-term observation program. The program of site characterization involves surface and subsurface based tests to determine the suitability of the Yucca Mountain site. These test programs will also initiate the program of long-term observations if the site is suitable for a repository. The data from long-term observation programs will generally be used to provide enhanced confidence in the conclusions reached at the several stages of the repository licensing process. 4 refs., 1 tab., 2 figs.

73 Yucca Mountain: Policy, progress and politics. Gertz, C.P. (Site Characterization Project Office, US DOE, Las Vegas, NV (United States)); Larkin, E.L. pp. 155-157 of Proceedings of emerging technologies for hazardous waste management: Volume 1. Tedder, D.W. American Chemical Society, Washington, DC (United States) (1992). pp. 381 (CONF-9209226-: American Chemical Society (ACS) special symposium on emerging technologies in hazardous waste management, Atlanta, GA (United States), 21-23 Sep 1992).

This paper reports on the U.S. Department of Energy's (DOE) office of Civilian Radioactive Waste Management (OCRWM) continuing study of Yucca Mountain, Nevada, to determine the mountain's suitability for isolating high-level nuclear waste. As mandated by the Congress of the United States in the Nuclear Waste Policy Act as amended in 1987, DOE is studying the rocks, climate, and water table at Yucca Mountain to ensure the site is suitable before building a potential repository about 305 meters $(1,000$ feet) underground. The object of the scientific studies is to determine if Yucca Mountain can isolate solid radioactive materials by using natural barriers, such as the mountain itself-and engineered barriers, such as the waste package container, to isolate the waste.

74

Design of a three-dimensional site scale model for the unsaturated zone at Yucca Mountain, Nevada. Wittwer, C.S. (Lawrence Berkeley Lab., CA (United States));
Bodvarsson, G.S.; Chornack, M.P.; Flint, A.L.; Lewis, B.D.; Spengler, R.W.; Flint, L.E.; Rautman, C.A. pp. 263-271 of Proceedings of high level radioactive waste management: Volume 1. American Nuclear Society, La Grange Park, IL (United States) (1992). pp. 2425 (CONF-920430-: 3. international high level radioactive waste management (IHLRWM) conference, Las Vegas, NV (United States), 1216 Apr 1992).

This paper discusses a three-dimensional model of moisture flow within the unsaturated zone at Yucca Mountain which is being developed. The site-scale model covers an area of about $30 \mathrm{~km}^{2}$ and is bounded by major faults to the east and west. A detailed numerical grid has been developed based on locations of boreholes, different infiltration zones, hydrogeological units and their outcrops, major faults, and water level data. Different maps, such as contour maps and isopachs maps, are presented for the different infiltration zones, and for the base of the Tiva Canyon, the Paintbrush, and the Topopah Spring hydrogeological units.

75 Underground exploration at Yucca Mountain. Gertz, C.P. (Yucca Mountain Site Characterization Project Office, U.S. Dept. of Energy, Las Vegas, NV (US)). pp. 478488 of Environmental issues and waste management in energy and minerals production. Yegulalp, T.M.; Kim, K. Battelle Press, Columbus, OH (United States) (1992). pp. 602 (CONF-9008109-: 1. international conference on environmental issues and waste management in energy and minerals production, Secaucus, NJ (United States), 27-29 Aug 1990).

The U.S. Department of Energy (DOE) is preparing to begin work on a facility that is a unique underground structure. We are proposing a mined facility under Yucca Mountain, Nevada, that is unorthodox due to its role in predicting what will occur at the site over the course of 10,000 years. The Yucca Mountain facility will be a first-of-its-kind construction project designed for utting edge subsurface geologic investigations. This paper describes testing programs and other preliminary measures needed for the development of the Yucca Mountain facility.

76 Early evaluation of the suitability of the Yucca Mountain site. Younker, J.L. (Science Applications International Corp., Las Vegas, NV (United States)); Rickertsen, L.D.; Judd, B.R. pp. 517-524 of Proceedings of high level radioactive waste management: Volume 1. American $\mathrm{Nu}$ clear Society, La Grange Park, IL (United States) (1992). pp. 2425 (CONF-920430-: 3. international high level radioactive waste management (IHLRWM) conference, Las Vegas, NV (United States), 12-16 Apr 1992).

This paper evaluates the technical suitability of Yucca Mountain, Nevada, as a potential site for a geologic repository for radioactive waste. The result of this early sitesuitability evaluation is that, in the judgment of the Evaluation Team that conducted the evaluation, the evidence supports a conclusion that the site is not unsuitable. Additional information is needed, however, in specific areas before a recommendation on repository development can be made.

77 Regulatory considerations in design of the exploratory studies facility. Parsons, M.W. (Science Applications International Corp., Las Vegas, NV (United States)); Voegele, M.D. pp. 671-678 of Proceedings of high level radioactive waste management: Volume 1. American Nuclear Society, La Grange Park, IL (United States) (1992). pp. 2425 (CONF-920430-: 3. international high level radioactive 
waste management (IHLRWM) conference, Las Vegas, NV (United States), 12-16 Apr 1992).

The Department of Energy (DOE) has the responsibility for developing a mined geologic repository for the disposal of spent nuclear fuel and other high-level radioactive waste. A site at Yucca Mountain, Nevada had been identified as a potential location of a repository. If a repository is built at Yucca Maintain, it will consist of a system of tunnels and rooms excavated in rock formations approximately 300 meters below the surface. A multiyear site characterization program is to be conducted to investigate whether the Yucca Mountain site is a suitable location of the repository. To assist the DOE in selecting an ESF design, the DOE's Yucca Mountain Site Characterization Project Office (YMPO) undertook an effort to develop the information required to make an informed decision regarding the selection of the preferred configuration for an ESF at Yucca Mountain, NV. The decision process took into account potentially discriminatory regulatory requirements and concerns. These were cross-correlated to the decision factors expressed in influence diagrams. This paper discusses the role of regulatory requirements in the Exploratory Shaft Facilities Alterative Studies decision process. It also discusses related regulatory concerns and the nature of the discrimination between options provided by the regulatory concerns.

78 Variations of hydrological parameters of tuff and soil. Wang, J.S.Y. (Lawrence Berkeley Lab., CA (United States). Earth Sciences Div.). pp. 727-731 of Proceedings of high level radioactive waste management: Volume 1. American Nuclear Society, La Grange Park, IL (United States) (1992). pp. 2425 (CONF-920430-: 3. international high level radioactive waste management (IHLRWM) conference, Las Vegas, NV (United States), 12-16 Apr 1992).

In this paper the saturated and unsaturated flow parameters of Yucca Mountain and Apache Leap tuffs and Las Cruces sol are compared. The saturated permeability generally has large variance, spanning over 2 to 4 orders of magnitude within each medium. Among different media, the mean value of saturated permeability are approximately proportional to the square of capillary radius. The capillary radius is determined by the unsaturated characteristic curve. A simple relationship between the variance of saturated permeability and the variance of pore-size distribution index is deduced from these data sets. These relationships could impose constraints on the choice and scaling of hydrological parameters for fractures, faults, or other units with scanty measurements.

79 The status of Yucca Mountain site characterization activities. Gertz, C.P. (Characterization Project Office, US DOE (US)); Larkin, E.L. pp. 748-750 of Proceedings of high level radioactive waste management: Volume 1 . American Nuclear Society, La Grange Park, IL (United States) (1992). pp. 2425 (CONF-920430-: 3. international high level radioactive waste management (IHLRWM) conference, Las Vegas, NV (United States), 12-16 Apr 1992).

The U.S. Department of Energy (DOE) Office of Civilian Radioactive Waste Management is continuing its studies to determine if Yucca Mountain in Nevada can safely isolate high-level nuclear waste for the next ten thousand years. As mandated by Congress in 1987, DOE is studying the rocks, the climate, and the water table at Yucca Mountain to ensure that the site is suitable before building a repository about 305 meters $(1,000$ feet) below the surface. Yucca Mountain, located 161 kilometers (100 miles) northwest of Las Vegas, lies on the western edge of the Nevada Test Site. Nevada and DOE have been in litigation for almost two years over three environmental permits needed to conduct studies, but recent court decisions have allowed limited work to take place. This paper will examine progress made on the Yucca Mountain Site Characterization Project (YMP) during the past year and continuing into 1992, discuss the complex legal issues that are delaying progress, and describe new site drilling work. Title I and II design work on the underground exploratory studies facility (ESF) also will be discussed.

80 US Department of Energy issue resolution process. Blanchard, M.B. (Yucca Mountain Project, USDOE (US)); Voegele, M.D.; Lugo, M.A. pp. $1062-1066$ of Proceedings of high level radioactive waste management: Volume 1. American Nuclear Society, La Grange Park, IL (United States) (1992). pp. 2425 (CONF-920430-: 3. international high level radioactive waste management (IHLRWM) conference, Las Vegas, NV (United States), 12-16 Apr 1992).

The Nuclear Waste Policy Act of 1982, as amended, charged the U.S. Department of Energy (DOE) with the responsibility to site, license, develop, operate, and close a geologic repository. Part of this involves formal licensing interactions with the U.S. Nuclear Regulatory Commission (NRC), the focus of which is the resolution of licensing issues. This paper discusses the process the DOE plans to implement over the next several years to reach resolution on these licensing issues with the NRC staff in order to expedite the licensing process. While several vehicles exist for resolution of issues, this paper focuses on the use of topical reports submitted by the DOE to the NRC staff and also on the use of rulemaking for selected issues. This process is a refinement and further expansion of the process described in the Site Characterization Plan $(S C P)^{2}$ for the Yucca Mountain site in southern Nevada.

81 Tunnel boring machine applications: Yucca Mountain Exploratory Studies Facility. Bhattacharyya, K.K. (Nuclear Waste Management System, Morrison Knudsen Corp., TRW Environmental Safety Systems, Inc., Las Vegas, NV (US)); McDonald, R.; Saunders, R.S. pp. $1521-$ 1526 of Proceedings of high level radioactive waste management: Volume 1. American Nuclear Society, La Grange Park, IL (United States) (1992). pp. 2425 (CONF920430-: 3. international high level radioactive waste management (IHLRWM) conference, Las Vegas, NV (United States), 12-16 Apr 1992).

This paper reports that characterization of Yucca Mountain for a potential repository requires construction of an underground Exploratory Studies Facility (ESF). Mechanical excavating methods have been proposed for construction of the ESF as they offer a number of advantages over drilling and blasting at the Yucca Mountain site, including; less ground disturbance and therefore a potential for less adverse effects on the integrity of the site, creation of a more stable excavation cross section requiring less ground support, and an inherently safer and cleaner working environment. The tunnel boring machine (TBM) provides a proven technology for excavating the welded and unwelded Yucca Mountain tuffs. The access ramps and main underground tunnels form the largest part of the ESF underground construction work, and have been designed for excavation by TBM.

82 Radioelements and their occurrence with secondary minerals in heated and unheated tuff at the Nevada test site. Flexser, S. (Earth Sciences Div., Lawrence Berkeley Lab., Univ. of California, Berkeley, CA (US)); Wollenberg, H.A. pp. 1593-1598 of Proceedings of 
high level radioactive waste management: Volume 1. American Nuclear Society, La Grange Park, IL (United States) (1992). pp. 2425 (CONF-920430-: 3. international high level radioactive waste management (IHLRWM) conference, Las Vegas, NV (United States), 12-16 Apr 1992).

This paper discusses samples of devitrified welded tuff near and away from the site of a heater test which were examined with regard to whole-rock radioelement abundances, microscopic distribution of $\mathrm{U}$, and oxygen isotope ratios. While-rock $U$ averages $3.7 \mathrm{ppm}$, and $U$ is concentrated at higher levels in primary and secondary opaque minerals as well as in accessory grains. $U$ in secondary sites is most commonly associated with $\mathrm{Mn}$ minerals, which average $\sim 30$ ppm $U$ in more uriniferous occurrences. This average is consistent and apparently unaffected by proximity to the heater. The Mn minerals differ compositionally from Mn minerals in other NTS tuffs, usually containing abundant $\mathrm{Fe}, \mathrm{T}$, and sometimes $\mathrm{Ce}$, and they are intergrown with amorphous material. Oxygen isotope ratios show a depletion in $\delta^{18} \mathrm{O}$ in tuff samples very close to the heater, and this depletion is within the range of values consistent with isotopic exchange between the tuff and included interstitial water. The variation of the isotopic ratios with distance from the heater is similar to the variation of whole-rock interaction induced by heating, but at levels that would have been masked by background or opaque mineral concentrations of $\mathrm{U}$ in the tuff.

83 Science and students: Yucca Mountain Project's educational outreach and public tour programs. Gil, A.V. (SAIC, Las Vegas, NV (US)); Larkin, E.L.; Harle, E. pp. 1819-1825 of Proceedings of high level radioactive waste management: Volume 1. American Nuclear Society, La Grange Park, IL (United States) (1992). pp. 2425 (CONF-920430-: 3. international high level radioactive waste management (IHLRWM) conference, Las Vegas, NV (United States), 12-16 Apr 1992).

Decisions regarding the use of energy, technology, and the environment require a well-educated and science-literate public. This paper reports that one of these decisions involves the problem of nuclear waste disposal. Many Nevadans are uninformed or misinformed about the Yucca Mountain Site Characterization Project (YMP). Mountain Site Characterization Project (YMP). The U.S. Department of Energy (DOE) has an active public outreach program in place that includes educational presentations for schools and a tour program for the public. Results of surveys taken after the tours to Yucca Mountain indicate that participants have learned about the site and the characterization program. In many cases, negative opinions about the YMP have changed.

84 Conservative tracers for the C-well hydraulic testing. Dombrowski, T. (Harry Reid Center for Environmental Studies, Univ. of Nevada, Las Vegas, NV (US)); Coates, G.; Stetzenbach, K.J. pp. 1991-1996 of Proceedings of high level radioactive waste management: Volume 1. American Nuclear Society, La Grange Park, IL (United States) (1992). pp. 2425 (CONF-920430-: 3. international high level radioactive waste management (IHLRWM) conference, Las Vegas, NV (United States), 12-16 Apr 1992).

This paper reports that work is being done to identify and characterize conservative organic tracers for use as groundwater tracers at the $\mathrm{C}$-well complex. An evaluation of the chemical and biological stability of several compounds including fluorinated aliphatic and aromatic acids, fluorinated salicylic acids, and fluorinated cinnamic acids was carried out using tuff samples from the Yucca Mountain area and
$\mathrm{J} 13$ or de-ionized water. Samples were monitored over a 60 day period for any decrease in concentration; the resulting data was evaluated for possible sorption or biological degradation of the candidate compound. The fluorinated benzoic acids show the greatest stability over the 60-day period. All analyses were carried out using an HPLC system, with either a fluorescence detector, a variable wavelength UV-VIS detector, or a quadrupole mass spectrometer.

85 Records Management in support of the licensing process for the high level radioactive waste facility. Sheats, D.G. (Integrated Resources Group, Inc., Metairie, LA (US)). pp. 2083-2087 of Proceedings of high level radioactive waste management: Volume 1. American Nuclear Society, La Grange Park, IL (United States) (1992). pp. 2425 (CONF-920430-: 3. international high level radioactive waste management (IHLRWM) conference, Las Vegas, NV (United States), 12-16 Apr 1992).

This paper reports that the Yucca Mountain project (YMP) is imposing a unique set of requirements of the Records Management (RM) Program. Not only must RM function in the traditional role as archivist, but, in relationship to the Licensing Support System (LSS), perform the function of information Manager. As information Manager, it becomes vitally important that RM fully understand the Licensing Process and the regulatory requirement imposed by the process.

86 Flow to licensing: Technical data tracking and the Licensing Support System (LSS). Statler, J. (Science Applications International Corp., Las Vegas, NV (US)). pp. 2088-2092 of Proceedings of high level radioactive waste management: Volume 1. American Nuclear Society, La Grange Park, IL (United States) (1992). pp. 2425 (CONF920430-: 3. international high level radioactive waste management (IHLRWM) conference, Las Vegas, NV (United States), 12-16 Apr 1992).

The Department of Energy/Office of Civilian Radioactive Waste Management (DOE/OCRWM) is responsible for the characterization of Yucca Mountain, Nevada, to determine if it is a suitable site for the location of the first high-level radioactive waste repository. Site Characterization involves extensive scientific investigations and engineering analyses. The DOEJOCRWM must ensure that traceability is retained between data collected in the course of site characterization and the conclusions based upon that data. The DOE OCRWM must also identify and provide access to the data it generates in a timely manner to facilitate the licensing process. Finally, the DOE/OCRWM must submit the data or its description and access location to the Licensing Support System for use in support of the license application and supporting documentation. This paper reports that the Automated Technical Data Tracking system and its associated Technical Data Information Form meet those needs and provide key links in the licensing process.

87 Management of scientific and engineering data collected during site characterization of a potential high-level waste repository. Newbury, C.M. (US Dept. of Energy, Las Vegas, NV (US)); Heitland, G.W. pp. 20932097 of Proceedings of high level radioactive waste management: Volume 1. American Nuclear Society, La Grange Park, IL (United States) (1992). pp. 2425 (CONF920430-: 3. international high level radioactive waste management (IHLRWM) conference, Las Vegas, NV (United States), 12-16 Apr 1992). 
This paper discusses the characterization of Yucca Mountain as a potential site for a high-level nuclear waste repository encompasses many diverse investigations to determine the nature of the site. Laboratory and on-site investigations are being conducted of the geology, hydrology, mineralogy, paleoclimate, geotechnical properties, and past use of the area, to name a few. Effective use of the data from these investigations requires development of a system for the collection, storage, and dissemination of those scientific and engineering data needed to support model development, design, and performance assessment. The time and budgetary constraints associated with this project make sharing of technical data within the geoscience community absolutely critical to the successful solution of the complex scientific problem challenging us.

88 Implementing the Payments-Equal-To-Taxes (PETT) program in Nevada. Ellis, C.B. (Science Applications International Corp., Las Vegas, NF (US)); Rogers, C.L. pp. 2207-2211 of Proceedings of high level radioactive waste management: Volume 1. American Nuclear Society, La Grange Park, IL (United States) (1992). pp. 2425 (CONF-920430-: 3. international high level radioactive waste management (IHLRWM) conference, Las Vegas, NV (United States), 12-16 Apr 1992).

The Nuclear Waste Policy Act of '1982, as amended (NWPA), contains a unique entitlement provision for local units of government that are affected by the proposed nuclear waste repository at Yucca Mountain, Nevada. The Secretary of Energy is required to make Payments-EqualTo-Taxes (PETT) for the Federal activities associated with the proposed repository. The PETT program is designed to provide affected jurisdictions with the revenue they would have received if the proposed repository sites was being characterized and developed by a private entity rather than the Federal government. The Yucca Mountain Site Characterization Project Office (YMPO) is in the process of implementing the PETT program in Nevada. This paper describes how the YMPO is following the required procedures to implement the PETT program.

89 Radiological environmental monitoring for the Yucca Mountain site. Shenk, K.J. (Technical and Management Support Services Project, Science Applications International Corp., Las Vegas, NV (US)); Prince, J.K.; Sorensen, C.D. pp. 2313-2317 of Proceedings of high level radioactive waste management: Volume 1. American $\mathrm{Nu}$ clear Society, La Grange Park, IL (United States) (1992). pp. 2425 (CONF-920430-: 3. international high level radioactive waste management (IHLRWM) conference, Las Vegas, NV (United States), 12-16 Apr 1992).

This paper discusses the radiological environmental monitoring program for the Yucca Mountain Site Characterization project which is being conducted to provide data in support of fulfiling DOE Orders, and requirements stipulated by the Nuclear Regulatory Commission. Data are being collected concerning many different environmental media such as, air, biota, soil, and water. Additionally, ambient levels of radiation and radon are also being monitored. The variations in the environmental parameters being measured, whose bounds will be characterized by the preoperational studies, will serve as a background in determining whether any impacts occur to the environment during site characterization and beyond, if the site is selected as a repository. The program also provides data necessary to estimate an hypothesized offsite dose to the public.
90 Update on the Yucca Mountain Project site characterization program. Gertz, C.P. (USDOE, Yucca Mountain Project Office (US)); Christy, R.P. pp. 1-5 of Fuel cycle 90 conference. U.S. Council for Energy Awareness, Washington, DC (USA) (1990). vp. of (CONF-900308-: Fuel cycle '90 conference, Nashville, TN (United States), 25-28 Mar 1990).

The U.S. Department of Energy (DOE) is evaluating Yucca Mountain in Nevada to determine if the site would be a safe location for a high-level radioactive waste repository. As mandated by Congress, DOE must study the geology, hydrology, environment and other factors to predict whether a geologic repository about 1,000 feet below Yucca Mountain's surface could isolate high-level waste for 10,000 years. The Yucca Mountain Project has embarked on an broad-based site characterization program designed to examine all factors that could impact the performance of a repository. While there are several site studies under way, an extensive surface-based testing program has not progressed as quickly as originally planned. The DOE is presently involved in litigation with the state of Nevada, which has refused issue environmental permits that are required before new site characterization studies can begin. This paper examines progress made on the Yucca Mountain Project during the past year, discusses studies that are planned in the near-term, and describes the prerequisites that must be resolved before new studies can be initiated.

91 Design considerations for the Yucca Mountain project exploratory shaft facility. Bullock, R.L. Sr. (Fenix and Scisson of Nevada, NV (US)). pp. 8 of Proceedings of the conference on shaft drilling technology. Institute of Shaft Drilling Technology, Parker, CO (United States) (1990). vp. of (CONF-900565-: Conference on shaft drilling technology, Las Vegas, NV (United States), 2-4 May 1990).

This paper reports on the regulatory/requirements challenges of this project which exist because this is the first facility of its kind to ever be planned, characterized, designed, and built under the purview of a U.S. Nuclear Regulatory Agency. The regulations and requirements that flow down to the Architect/Engineer (AVE) for development of the Exploratory Shaft Facility (ESF) design are voluminous and unique to this project. The subsurface design and construction of the ESF underground facility may eventually become a part of the future repository facility and, if so, will require licensing by the Nuclear Regulatory Commission (NRC). The Fenix and Scisson of Nevada-Yucca Mountain Project (FSN-YMP) group believes that all of the UMP design and construction related activities, with good design/ construct control, can be performed to meet all engineering requirements, while following a strict quality assurance program that will also meet regulatory requirements.

92 Stripa: An international cooperative project. Levich, R.A. (Yucca Mountain Project Office, US DOE, Las Vegas, NV (US)); Ferrigan, P.M.; Patera, E.S.; Wilkey, P.L. pp. 67-74 of Excellent and economic nuclear plant performance: NE-Volume 4. Penfield, S.R. Jr. American Society of Mechanical Engineers, New York, NY (United States) (1990). pp. 175 (CONF-9009110-: Joint American Nuclear Society (ANS) Power Division topical meeting and the American Society of Mechanical Engineers (ASME) nuclear energy conference, Newport, RI (United States), 16-20 Sep 1990).

The Nuclear Energy Agency of the Organization for Economic Cooperation and Development sponsors the International Stripa Project. The Stripa. Project is open to participation by all OECD member nations and nine nations 
have participated in the project over its duration. The objectives of the Stripa Project are: to develop techniques for characterizing sites located deep in rock formations that are potentially suitable for the geologic disposal of high-level radioactive wastes; and to evaluate particular engineering design considerations that could enhance the long-term safety of a high-level radioactive waste repository in a geologic medium. The purpose of this paper is to briefly summarize the research conducted at Stripa and discuss the ways in which the technology developed for the Stripa Project has been and will be transferred to the United States Civilian Radioactive Waste Management Program's Yucca Mountain Project.

93 Status of the Yucca Mountain project. Gertz, C.P. (Yucca Mountain Project Office, US DOE, Las Vegas, NV (US)). pp. 197-201 of Proceedings of SPECTRUM ' 90. American Nuclear Society, La Grange Park, IL (United States) (1990). pp. 505 (CONF-900977-: Spectrum '90: American Nuclear Society (ANS) international meeting on radioactive waste technologies, decontamination, and hazardous wastes, Knoxville, TN (United States), 30 Sep - 4 oct 1990).

The US Department of Energy (DOE) is evaluating Yucca Mountain in Nevada to determine if the site would be a safe location for a high-level radioactive waste repository. As mandated by Congress, DOE must study the geology, hydrology, environment and other factors to predict whether a geologic repository about 1,000 feet below Yucca Mountain's surface could isolate high-level waste for 10,000 years. The Yucca Mountain Project has embarked on an broad-based site characterization program designed to examine all factors that could impact the performance of a repository. While there are several site studies under way, an extensive surface-based testing program has not progressed as quickly as originally planned. The DOE is presently involved in litigation with the state of Nevada, which as refused issue environmental permits that are required before new site characterization studies can begin. This paper will examine progress made on the Yucca Mountain Project during the past year, discuss studies that are planned in the near-term, and will describe the prerequisites that must be resolved before new studies can be initiated.

94 On numerical modeling of capillary barriers. Oldenburg, C.M. (Lawrence Berkeley Lab., CA (US)); Pruess, K. Water Resources Research (United States); 29(4): 1045-1056 (Apr 1993). DOE Contract AC0376 SF00098.

Because of their ability to protect underground regions from wetting by downward infiltration, capillary barriers have been objects of considerable interest. A capillary barrier consists of a layer of fine soil overlying a layer of coarse soil. In unsaturated conditions, infiltrating water may be held in the fine medium by capillary force and resist moving into the coarse layer. If the contact is tilted, infiltrating water in the fine layer will build up and flow downdip along the contact, a process known as capillary diversion. Capillary barriers occur naturally or can be created artifically. Recently progress has been made in the theoretical, laboratory, and field study of capillary barriers. Because of the potential significance of capillary barriers on important questions of hazardous waste isolation, and in light of intriguing results of laboratory and field experiments of capillary barriers as well as the simple theoretical results, numerical experiments are presented of an idealized field-scale capillary barrier system with the objective of further understanding the behavior of capillary barriers. An additional objective is the evaluation of the accuracy with which numerical methods can be expected to model the full complement of complicated flow processes associated with the potential high-level nuclear waste repository at Yucca Mountain. To this end, different mobility weighting schemes and grid orientation effects in the flow in the model capillary barrier system are investigated.

95 Classification and grading of design products for the Yucca Mountain project. DeKlever, R.C. (Raytheon Services Nevada, Las Vegas (United States)); Bullock, R.L.; Verna, B.J. Transactions of the American Nuclear Society (United States); 68: 79-81 (1993). (CONF-930601-: American Nuclear Society (ANS) annual meeting, San Diego, CA (United States), 20-24 Jun 1993).

The US Department of Energy faces some unique challenges in its site characterization effort to determine if Yucca Mountain is suitable to house this nation's first high-level radioactive waste repository. Facilities are being designed and constructed for both surface-based testing (SBT), which includes drilling a number of test holes and excavating trenches and test pits into the mountain, and the Exploratory Studies Facility (ESF), which will be an extensive underground test laboratory. During construction and testing, the Yucca Mountain Project (YMP) must ensure that the ability to safely store waste for $10,000 \mathrm{yr}$ is not compromised. The YMP has initiated a determination of "important to waste isolation" (ITWI) effort to determine which items and activities are important to the gathering of valid test data and which could have an effect on the natural barriers. Concerns include the potential effects of changing the site's normal water patterns, introducing toreign materials, damaging the unexcavated rock, etc. The project has now entered into the phase in which the design organizations perform detailed QA classification analyses on their designs and a YMP assessment team reviews those analyses. Raytheon Services Nevada has been responsible for designing, classifying, and grading SBT and the initial ESF systems.

96 Site studies continue at Yucca Mountain in the US. Gertz, C.P. (USDOE Nevada Operations Office, Las Vegas, NV (United States)); Larkin, E.L. Nuclear Engineering International (Incorporates Nuclear Power) (United Kingdom); 37(455): 45-47 (Jun 1992).

The US DoE's Office of Civilian Radioactive Waste Management is continuing its studies to determine if Yucca Mountain in Nevada can safely isolate high-level nuclear waste for the next 10000 years. Its studies will look into the rocks, climate, and water table to ensure that the site is suitable for a below-surface repository. (author).

97 Dependence of actinide solubility and speciation on carbonate concentration and ionic strength in groundwater. Nitsche, H. (Lawrence Berkeley Lab., CA (United States). Earth Sciences Div.); Mueller, A.; Standifer, E.M.; Deinhammer, R.S.; Becraft, K.; Prussin, T.; Gatti, R.C. Radiochimica Acta (Germany); 58-59(pt.1): 27-32 (1992). (CONF-9110152-: 3 . international conference on chemistry and migration behaviour of actinides and fission products in the geosphere (MIGRATION-3), Jerez de la Frontera (Spain), 21-25 Oct 1991).

Yucca Mountain, Nevada, USA, is being investigated for its potential suitability as a geologic nuclear waste repository. As part of the site characterization studies, actinide solubilities and speciations were studied at $\mathrm{pH} 6,7$, and 8.5 in two different groundwaters coming from the vicinity of 
Yucca Mountain. The groundwaters differ substantially in total dissolved carbonate concentration, and to a lesser extent in ionic strength. The solubilities of neptunium( $V$ ) decreased, whereas those of americium(III) increased in the water with the higher carbonate content. The solids formed were sodium neptunium carbonates and americium hydroxycarbonates. Plutonium solubilities did not significantly change with changing water composition, because the solubilitycontrolling solids were mostly amorphous $\mathrm{Pu}(\mathrm{IV})$ polymers that contained only small amounts of carbonate. (orig.).

98 U.S. strategy for evaluating the Yucca Mountain, Nevada site. Gertz, C.P. (USDOE Nevada Operations Office, Las Vegas, NV (United States)); Younker, J.L.; Rickertsen, L. Radioactive Waste Management and the Nuclear Fuel Cycle (Switzerland); 12(1-4): $77-85$ (1991). (CONF8806517-: Nuclear waste management 1988: perspectives on national and international programs and technology, San Diego, CA (United States), 12-16 Jun 1988).

The plan for site characterization at the Yucca Mountain site emphasizes investigations to gain more information about the flow characteristics of the unsaturated zone, about the geochemistry that could retard radionuclide transport and the saturated zone characteristics, about unlikely processes and events that could disrupt the site, and about preclosure radiation safety and the effects of seismicity on surface and underground facilities. In general, the U.S. Department of Energy (DOE) will place emphasis during the site characterization phase on developing a full understanding of those site and engineered features that are expected to make largest contribution to satisfying the regulatory requirements, which were developed by the U.S. Nuclear Regulatory Commission (NRC) and the U.S. Environment Protection Agency (EPA) to protect the public health and safety. (author) 2 figs., 3 refs.

99 Plans for characterization of the potential geologie repository site at Yucca Mountain, Nevada. Dobson, D.C. (US DOE, Las Vegas, NV (US)); Blanchard, M.B.; Voegele, M.D.; Younker, J.L. Proceedings of the American Power Conference (United States); 53: 689-693 (1991). (CONF-9104106-: 53. annual American power conference, Chicago, IL (United States), $29 \mathrm{Apr}-1$ may 1991).

This paper provides a summary of the regulatory background for the U.S. geologic repository program, describing the history of the congressional actions that established the program and the allocation of responsibilities within the program. The current status of actions by the U.S. Department of Energy (DOE) to investigate a potential repository site, located at Yucca Mountain in Nye County, Nevada is then reviewed. The U.S. Nuclear Regulatory Commission has provided guidance to the DOE for characterizing potential repository sites and the DOE's approach to implementing that guidance is described.

\section{CRWMS M\&O, LAS VEGAS}

100 (CONF-930408-8) Yucca Mountain Exploratory Studies Facilities: Construction status: Extended summary. Allan, J. (Morrison-Knudsen Corp. (United States)); Leonard, T.M. Reynolds Electrical and Engineering Co., Inc., Las Vegas, NV (United States). Sep 1992. 4p. Sponsored by USDOE, Washington, DC (United States). DOE Contract AC08-89NV10630. From International high-level radioactive waste management conference; Las Vegas, NV
(United States); 25-29 Apr 1993. Order Number DE93005704. Source: OSTI; NTIS; INIS; GPO Dep.

This paper discusses the progress to date on, the construction planning development of the Yucca Mountain Site Characterization Project Exploratory Studies Facilities (ESF).

101 (DOE/RW/00134-T1) Yucca Mountain Site Characterization Project technical data catalog: Yucca Mountain Site Characterization Project. USDOE Yucca Mountain Site Characterization Project Office, Las Vegas, NV (United States). 30 Sep 1992. 209p. Sponsored by USDOE, Washington, DC (United States). DOE Contract AC01-91AW00134. Order Number DE93003685. Source: OSTI; NTIS; INIS; GPO Dep.

The June 1, 1985, Department of Energy (DOE)/Nuclear Regulatory Commission (NRC) Site-Specific Procedural Agreement for Geologic Repository Site Investigation and Characterization Program requires the DOE to develop and maintain a catalog of data which will be updated and provided to the NRC at least quarterly. This catalog is to include a description of the data; the time (date), place, and method of acquisition; and where it may be examined. The Yucca Mountain Site Characterization Project (YMP) Technical Data Catalog is published and distributed in accordance with the requirements of the Site-Specific Agreement. The YMP Technical Data Catalog is a report based on reference information contained in the YMP Automated Technical Data Tracking System (ATDT). The reference information is provided by Participants for data acquired or developed in support of the YMP. The Technical Data Catalog is updated quarterly and published in the month following the end of each quarter. Each new publication of the Technical Data Catalog supersedes the previous edition.

102 (DOE/RW/00134-T4) A comparative application of the Repository Integration Program (RIP) to Total System Performance Assessment, 1991. INTERA, Inc., Las Vegas, NV (United States). 16 Jul 1993. 276p. Sponsored by USDOE, Washington, DC (United States). DOE Contract AC01-91RW00134. Order Number DE93017134. Source: OSTI; NTIS; INIS; GPO Dep.

During Fiscal Year (FY) 1991 and FY 1992, Sandia National Laboratory and Battelle Pacific Northwest Laboratory were assigned the responsibility to generate initial Total System Performance Assessments (TSPAs) of the Yucca Mountain site. The analyses performed by these organizations (called TSPA-1991) are reported in Barnard et al(1992) and Eslinger et at. (1993). During this same time period, Golder Associates Inc. was assigned the task of generating a model capable of analyzing the total system performance of a high-level radioactive waste repository. The developed model, called Repository Integration Program (RIP), is documented in Kossik and Hachey (1993), Miller et al. (1993), and Golder Associates Inc. (1993). In FY 1993, the Civilian Radioactive Waste Management System Contractor was assigned the responsibility to plan, coordinate, and contribute to the second iteration of TSPA-2. Prior to initiating the next TSPA iteration, it was decided that it would be valuable to evaluate the applicability of RIP for use in this iteration. Therefore, analyses were conducted to compare the results generated by RIP to those reported in TSPA-1991. In particular, the aim was to generate a RIP input data set as equivalent as possible to that documented in Barnard et al. (1992) and to analyze the total system performance (as well as the performance of the individual subsystem components 
of the waste package/Engineered Barrier System (EBS), unsaturated gaseous flow and transport, unsaturated aqueous flow and transport, saturated flow and transport, and disruptive processes/events). The performance measure for comparison with the results of TSPA-1991 is the cumulative release of radionuclides to the accessible environment over a 10,000-year period following closure normalized to the US Environmental Protection Agency (EPA) release limits specified in 40 CFR 191.

\section{LOS ALAMOS NATIONAL LABORATORY}

103 (LA-12062-MS-Rev.1) FEHMN 1.0: Finite element heat and mass transfer code: Revision 1. Zyvoloski, G.; Dash, Z.; Kelkar, S. Los Alamos National Lab., NM (United States). May 1992. 113p. Sponsored by USDOE, Washington, DC (United States). DOE Contract W7405-ENG-36. Order Number DE92013998. Source: OSTI; NTIS; INIS; GPO Dep.

A computer code is described which can simulate nonisothermal multi-phase multicomponent flow in porous media. It is applicable to natural-state studies of geothermal systems and groundwater flow. The equations of heat and mass transfer for multiphase flow in porous and permeable media are solved sing the finite element method. The permeability and porosity of the medium are allowed to depend on pressure and temperature. The code also has provisions for movable air and water phases and noncoupled tracers; that is, tracer solutions that do not affect the heat and mass transfer solutions. The tracers can be passive or reactive. The code can simulate two-dimensional, two-dimensional radial, or three-dimensional geometries. A summary of the equations in the model and the numerical solution procedure are provided in this report. A user's guide and sample problems are also included. The FEHMN (Finite Element Heat and Mass Nuclear) code, described in this report, is a version of FEHM (Finite Element Heat and Mass, Zyvoloski et al., 1988) developed for the Yucca Mountain Site Characterization Project (YMP). The main use of FEHMN will be to assist in the understanding of flow fields in the saturated zone below the potential Yucca Mountain repository.

104 (LA-12325-C) Proceedings of the DOENucca Mountain Site Characterization. Project Radionuclide Adsorption Workshop at Los Alamos National Laboratory, September 11-12, 1990. Canepa, J.A. Los Alamos National Lab., NM (United States). Aug 1992. 238p. Sponsored by USDOE, Washington, DC (United States). DOE Contract W7405-ENG-36. (CONF-9009350-: DOEYucca Mountain site characterization project radionuclide adsorption workshop, Los Alamos, NM (United States), 11-12 Sep 1990). Order Number DE92041241. Source: OSTI; NTIS; INIS; GPO Dep.

Los Alamos National Laboratory hosted a workshop on radionuclide adsorption for the Department of Energy (DOE)/ Yucca Mountain Site Characterization Project on September 11 and 12, 1990. The purpose of the workshop was to respond to a recommendation by the Nuclear Waste Technical Review Board that the DOE organize a radionuclide adsorption workshop to be attended by the DOE and its contractors involved in the measurement and modeling of such adsorption. The workshop would have two general purposes: (a) to determine the applicability of available radionuclide adsorption data on tuff and models for predicting such adsorption under existing and postclosure conditions at Yucca Mountain and (b) to establish what additional radionuclide adsorption research and model development are needed. Individual projects are processed separately for the databases.

105 (LA-12325-C, pp. 9-40) A strategy for the derivation and use of sorption coefficients in performance assessment calculations for the Yucca Mountain site. Meijer, A. (Los Alamos National Lab., NM (US)). Los Alamos National Lab., NM (United States). Aug 1992. (CONF-9009350-: DOEYucca Mountain site characterization project radionuclide adsorption workshop, Los Alamos, NM (United States), 11-12 Sep 1990). In Proceedings of the DOE/Yucca Mountain Site Characterization Project Radionuclide Adsorption Workshop at Los Alamos National Laboratory, September 11-12, 1990. 238p. Order Number DE92041241. Source: OSTI; NTIS; INIS.

Chemical understanding of the reactions by which radionuclides could sorb onto solid surfaces in Yucca Mountain is not well developed at the present time nor are the controls on these mechanisms well defined. The chemical interactions of radionuclides with the host rock of the repository must be quantified. This paper presents a strategy for quantifying these interactions for the Yucca Mountain site. The strategy recognizes that minimum values exist for sorption coefficients for radionuclides in the emplaced waste that provide adequate barriers to transport relative to the regulatory limits. For example, preliminary transport calculations suggest that a minimum $\mathrm{K}_{d}$ value of $100 \mathrm{ml} / \mathrm{g}$ should provide an adequate sorption barrier for many of the radionuclides to be placed in the repository. This economizes the experimental work required to address the sorption barrier for these radionuclides in that this work must only show that a $K_{d}$ value of at least $100 \mathrm{~m} / \mathrm{g}$ will be achieved under any credible scenario. If the major (i.e., most abundant) mineral phase that has the lowest sorption potential shows a sorption coefficient of at least $100 \mathrm{ml} / \mathrm{g}$ under the least favorable conditions for these elements, this value could be used in all transport scenarios. If this mineral phase does not have sufficient sorption potential, the (major) phase with the next lowest sorption potential could be evaluated and so on. Unfortunately, for some radionuclides (i.e., U, Np, C, I, Se, and $T c$ ), the minimum $K_{d}$ approach is clearly inadequate. Out of this group, the elements $C$, l,and Tc will likely not have a significant sorption barrier during ground water flow. For $U$, $\mathrm{Np}$, and $\mathrm{Se}$, the proposed strategy is to first identify the mineral and/or water compositional parameters that are most critical to their sorption behavior. This information can be obtained from pure mineral and whole-rock sorption studies. 48 refs., 7 figs., 3 tabs.

106 (LA-12325-C, pp. 91-109) Radionuclide migration laboratory studies for validation of batch-sorption data. Triay, I.R. (Los Alamos National Lab., NM (United States)); Mitchell, A.J.; Ott, M.A. Los Alamos National Lab., NM (United States). Aug 1992. (CONF-9009350-: DOENucca Mountain site characterization project radionuclide adsorption workshop, Los Alamos, NM (United States), 11-12 Sep 1990). In Proceedings of the DOENucca Mountain Site Characterization Project Radionuclide Adsorption Workshop at Los Alamos National Laboratory, September 11-12, 1990. 238p. Order Number DE92041241. Source: OSTI; NTIS; INIS.

To validate batch-sorption transport models of sorbing and non-sorbing radionuclides, the authors conducted advective and diffusive migration experiments in the laboratory using columns of saturated crushed, intact, and fractured tuff from Yucca Mountain, Nevada, and pure mineral separates. For 
crushed tuff and pure minerals separates, batch-sorption coefficients agree with those they obtained under flowing conditions for alkaline and alkaline earth elements; for actinides, they found a smaller sorption coefficient caused by elution of a small fraction of the actinides. Studies of solidtuff columns indicate that batch-sorption coefficients will fit elution data of alkaline and alkaline earth elements provided that they have a detailed characterization of the hydrologic properties of the tuff. Studies of fractured-tuff columns indicate good agreement between fracture transport models and elution of nonsorbing radionuclides. Diffusion is one of the most important retardation mechanisms in fractured media; their studies indicate that the diffusion coefficient for nonsorbing radionuclides into saturated Yucca Mountain tuff is approximately $10^{-6} \mathrm{~cm}^{2} / \mathrm{s}$. Coefficients of diffusion of the sorbing radionuclides into saturated tuff could not be fit, assuming reversible, instantaneous, and linear sorption. The authors believe that conservative transport modelling calculations will result from fitting the batch-sorption coefficient and the diffusion coefficient for tritiated water. Their validation strategy, which begins with laboratory transport experiments on columns of crushed Yucca Mountain tuff to study the effects of kinetics of speciation, mass transfer kinetics, or non-linear, non-reversible, or non-instantaneous sorption, is presented. When the differences between batchsorption data and the results of their crushed-tuff column experiments are resolved, the next level of complexity will be tackled. 20 refs., 10 figs., 2 tabs.

107 (LA-12376-MS) A summary and discussion of hydrologic data from the Calico Hills nonwelded hydrogeologic unit at Yucca Mountain, Nevada. Loeven, C. Los Alamos National Lab., NM (United States). Jan 1993. 107p. Sponsored by USDOE, Washington, DC (United States). DOE Contract W-7405-ENG-36. Order Number DE93006097. Source: OSTI; NTIS; INIS; GPO Dep.

This report is a summary of available hydrologic data from in situ and laboratory testing of the Calico Hills nonwelded hydrogeologic unit, including hydraulic conductivity, porosity, saturation, pore-size distribution and parameters from curvefits to pressure-saturation data. Sample statistics of hydraulic conductivity, porosity and saturation data for vitric, devitrified and zeolitic tuffs are presented and discussed. While a high degree of variability is observed in both laboratory and in situ hydraulic conductivity measurements, uncertainties arising from differences in size of laboratory test samples, sample handling, test procedures and insufficient number of samples point to the need for additional data of specific types to adequately characterize the unit. Hydrologic issues related to transport analysis in the Calico Hills nonwelded hydrogeologic unit at Yucca Mountain are discussed together with recommendations for future work. The compiled data are included as an appendix.

108 (LA-12542-MS) Geologic evaluation of six nonwelded tuff sites in the vicinity of Yucca Mountain, Nevada for a surface-based test facility for the Yucca Mountain Project. Broxton, D.E. (Los Alamos National Lab., NM (United States)); Chipera, S.J.; Byers, F.M. Jr.; Rautman, C.A. Los Alamos National Lab., NM (United States). Oct 1993. 83p. Sponsored by USDOE, Washington, DC (United States). DOE Contract W-7405-ENG-36. Order Number DE94000698. Source: OSTI; NTIS; INIS; GPO Dep.

Outcrops of nonwelded tuff at six locations in the vicinity of Yucca Mountain, Nevada, were examined to determine their suitability for hosting a surface-based test facility for the Yucca Mountain Project. Investigators will use this facility to test equipment and procedures for the Exploratory Studies Facility and to conduct site characterization field experiments. The outcrops investigated contain rocks that include or are similar to the tuffaceous beds of Calico Hills, an important geologic and hydrologic barrier between the potential repository and the water table. The tuffaceous beds of Calico Hills at the site of the potential repository consist of both vitric and zeolitic tuffs, thus three of the outcrops examined are vitric tuffs and three are zeolitic tuffs. New data were collected to determine the lithology, chemistry, mineralogy, and modal petrography of the outcrops. Some preliminary data on hydrologic properties are also presented. Evaluation of suitability of the six sites is based on a comparison of their geologic characteristics to those found in the tuffaceous beds of Calico Hills within the exploration block.

109 (LA-12562-MS) Measured solubilities and speciations of neptunium, plutonium, and americium in a typical groundwater $(\mathrm{J}-13)$ from the Yucca Mountain region: Milestone report 3010-WBS 1.2.3.4.1.3.1. Nitsche, H. (and others); Gatti, R.C.; Standifer, E.M. Los Alamos National Lab., NM (United States); Lawrence Berkeley Lab., CA (United States). Jul 1993. 127p. Sponsored by USDOE, Washington, DC (United States). DOE Contract W-7405ENG-36 ; AC03-76SF00098. Order Number DE94001566. Source: OSTI; NTIS; INIS; GPO Dep.

Solubility and speciation data are important in understanding aqueous radionuclide transport through the geosphere. They define the source term for transport retardation processes such as sorption and colloid formation. Solubility and speciation data are useful in verifying the validity of geochemical codes that are part of predictive transport models. Results are presented from solubility and speciation experiments of ${ }^{237} \mathrm{NpO}_{2}{ }^{+},{ }^{239} \mathrm{Pu}^{4+},{ }^{241} \mathrm{Am}^{3+} \mathrm{Nd}^{3+}$, and ${ }^{243} \mathrm{Am}^{3+}$ in $\mathrm{J}-13$ groundwater (from the Yucca Mountain region, Nevada, which is being investigated as a potential high-level nuclear waste disposal site) at three different temperatures $\left(25^{\circ}\right.$, $60^{\circ}$, and $90^{\circ} \mathrm{C}$ ) and $\mathrm{pH}$ values $(5.9,7.0$, and 8.5$)$. The solubility-controlling steady-state solids were identified and the speciation and/or oxidation states present in the supernatant solutions were determined. The neptunium solubility decreased with increasing temperature and $\mathrm{pH}$. Plutonium concentrations decreased with increasing temperature and showed no trend with $\mathrm{pH}$. The americium solutions showed no clear solubility trend with increasing temperature and increasing $\mathrm{pH}$.

110 (LA-12564-MS) Kinetics of silica-phase transitions. Duffy, C.J. Los Alamos National Lab., NM (United States). Jul 1993. 23p. Sponsored by USDOE, Washington, DC (United States). DOE Contract W-7405-ENG-36. Order Number DE93016231. Source: OSTI; NTIS; INIS; GPO Dep.

In addition to the stable silica polymorph quart, several metastable silica phases are present in Yucca Mountain. The conversion of these phases to quart is accompanied by volume reduction and a decrease in the aqueous silica activity, which may destabilize clinoptilolite and mordenite. The primary reaction sequence for the silica phases is from opal or glass to disordered opal-CT, followed by ordering of the opal-CT and finally by the crystallization of quartz. The ordering of opal-CT takes place in the solid state, whereas the conversion of opal-CT takes place through dissolutionreprecipitation involving the aqueous phase. It is proposed that the rate of conversion of opal-CT to quartz is controlled by diffusion of defects out of a disordered surface layer formed on the crystallizing quartz. The reaction rates are observed to be dependent on temperature, pressure, degree 
of supersaturation, and $\mathrm{pH}$. Rate equations selected from the literature appear to be consistent with observations at Yucca Mountain.

111 (LA-12708-MS) Preliminary conceptual model for mineral evolution in Yucca Mountain. Duffy, C.J. Los Alamos National Lab., NM (United States). Dec 1993. 47p. Sponsored by USDOE, Washington, DC (United States). DOE Contract W-7405-ENG-36. Order Number DE94003899. Source: OSTI; NTIS; INIS; GPO Dep.

A model is presented for mineral alteration in Yucca Mountain, Nevada, that suggests that the mineral transformations observed there are primarily controlled by the activity of aqueous silica. The rate of these reactions is related to the rate of evolution of the metastable silica polymorphs opalCT and cristobalite assuming that $a_{S_{i O}}$ is ix fixed at the equilibrium solubility of the most soluble silica polymorph present. The rate equations accurately predict the present depths of disappearance of opal-CT and cristobalite. The rate equations have also been used to predict the extent of future mineral alteration that may result from emplacement of a high-level nuclear waste repository in Yucca Mountain. Relatively small changes in mineralogy are predicted, but these predictions are based on the assumption that emplacement of a repository would not increase the $\mathrm{pH}$ of water in Yucca Mountain nor increase its carbonate content. Such changes may significantly increase mineral alteration. Some of the reactions currently occurring in Yucca Mountain consume $\mathrm{H}^{+}$and $\mathrm{CO}_{3}{ }^{2-}$. Combining reaction rate models for these reactions with water chemistry data may make it possible to estimate water flux through the basal vitrophyre of the Topopah Spring Member and to help confirm the direction and rate of flow of groundwater in Yucca Mountain.

112 (LA-SUB-93-51) The Lathrop Wells volcanic center: Status of field and geochronology studies. Crowe, B. (Los Alamos National Lab., Las Vegas, NV (United States)); Morley, R.; Wells, S.; Geissman, J.; McDonald, E.; McFadden, L.; Perry, F.; Murrell, M.; Poths, J.; Forman, S. Los Alamos National Lab., NM (United States). [1993]. 16p. Sponsored by USDOE, Washington, DC (United States). DOE Contract W-7405-ENG-36. Order Number DE93008917. Source: OSTI; NTIS; INIS; GPO Dep.

The Lathrop Wells volcanic center is located $20 \mathrm{~km}$ south of the potential Yucca Mountain site, at the south end of the Yucca Mountain range. It has long been recognized as the youngest basalt center in the region. However, determination of the age and eruptive history of the center has proven problematic. The purpose of this paper is to describe the status of field and geochronology studies of the Lathrop Wells center. Our perspective is that it is critical to assess all possible methods for obtaining cross-checking data to resolve chronology and field problems. It is equally important to consider application of the range of chronology methods available in Quaternary geologic research. Such an approach seeks to increase the confidence in data interpretations through obtaining convergence among separate isotopic, radiogenic, and age-correlated methods. Finally, the assumptions, strengths, and weaknesses of each dating method need to be carefully described to facilitate an impartial evaluation of results.

113 (LA-SUB-93-217) Summary report on the evaluation of a 1977-1985 edited sorption data base for isotherm modeling. Polzer, W.L. (Los Alamos National Lab., NM (United States)); Beckman, R.J.; Fuentes, H.R.; Yong, C.; Chan, P.; Rao, M.G. Los Alamos National Lab.,
NM (United States); Texas Univ., El Paso, TX (United States); Howard Univ., Washington, DC (United States). [1993]. 278p. Sponsored by USDOE, Washington, DC (United States). DOE Contract W-7405-ENG-36. Order Number DE93040572. Source: OSTI; NTIS; INIS; GPO Dep.

Sorption data bases collected by Los Alamos National Laboratory (LANL) from 1977 to 1985 for the Yucca Mountain Project.(YMP) have been inventoried and fitted with isotherm expressions. Effects of variables (e.g., particie size) on the isotherm were also evaluated. The sorption data are from laboratory batch measurements which were not designed specifically for isotherm modeling. However a limited number of data sets permitted such modeling. The analysis of those isotherm data can aid in the design of future sorption experiments and can provide expressions to be used in radionuclide transport modeling. Over $1200 \mathrm{ex}$ perimental observations were inventoried for their adequacy to be modeled $b$ isotherms and to evaluate the effects of variables on isotherms. About $15 \%$ of the observations provided suitable data sets for modeling. The data sets were obtained under conditions that include ambient temperature and two atmospheres, air and $\mathrm{CO}_{2}$.

114 (LA-UR-91-3236) A suggested approach toward measuring sorption and applying sorption data to repository performance assessment. Rundberg, R.S. Los Alamos National Lab., NM (United States). [1991]. 23p. Sponsored by USDOE, Washington, DC (United States). DOE Contract W-7405-ENG-36: (CONF-9110263-1: Nuclear Energy Agency (NEA) sorption workshop, Interlacken (Switzerland), 21 Oct 1991). Order Number DE92002462. Source: OSTI; NTIS; INIS; GPO Dep.

The sorption of radioisotopes in relation to geologic disposal of radioactive wastes is discussed. Properties of the radioactive materials, rocks, and minerals, and the chemistry involved are described. 51 refs., 12 figs. CBS

115 (LA-UR-91-3747) A strategy for the derivation and use of sorption coefficients in performance assessment calculations for the Yucca Mountain site. Meijer, A. Los Alamos National Lab., NM (United States). [1990]. 62p. Sponsored by USDOE, Washington, DC (United States). DOE Contract W-7405-ENG-36. (CONF-9009454-1) Sorption workshop, Los Alamos, NM (United States), 23 Sep 1990). Order Number DE92003794. Source: OSTI; NTIS; INIS; GPO Dep.

The chemical interactions of dissolved radionuclides with mineral surfaces along flowpaths from the proposed repository to the accessible environment around Yucca Mountain constitute one of the potential barriers to radionuclide migration at the site. Our limited understanding of these interactions suggests their details will be complex and will involve control by numerous chemical and physical parameters. It appears unlikely that we will understand all the details of these reactions or obtain all the site data required to evaluate each of them in the time available for site characterization. Yet, performance assessment calculations will require some form of coupling of chemical interaction models will hydrologic flow models for the site. Clearly, strategies will be needed to bound the problem without compromising the reliability of the performance assessment calculations required for site suitability analysis. The main purpose of this paper is to describe such a strategy. 39 refs., 7 figs., 5 tabs.

116 (LA-UR-91-4035) Natural gels in the Yucca Mountain Area, Nevada, USA. Levy, S.S. Los Alamos National Lab., NM (United States). [1991]. 12p. Sponsored by 
USDOE, Washington, DC (United States). DOE Contract W-7405-ENG-36. (CONF-911109-5: Fall meeting of the European Materials Research Society (EMRS), Strasbourg (France), 5-8 Nov 1991). Order Number DE92005058. Source: OSTI; NTIS; INIS; GPO Dep.

Relict gels at Yucca Mountain include pore- and fracturefillings of silica and zeolite related to diagenetic and hydrothermal alteration of vitric tuffs. Water-rich free gels in fractures at Rainier Mesa consist of smectite with or without silica-rich gel fragments. Gels are being studied for their potential role in transport of radionuclides from a nuclearwaste repository.

117 (LA-UR-91-4041) Physical processes and effects of magmatism in the Yucca Mountain region. Valentine, G.A. (Los Alamos National Lab., NM (United States)); Crowe, B.M.; Perry, F.V. Los Alamos National Lab., NM (United States). [1991]. 36p. Sponsored by USDOE, Washington, DC (United States). DOE Contract W-7405ENG-36. (CONF-920430-10: 3. international high level radioactive waste management (IHLRWM) conference, Las Vegas, NV (United States), 12-16 Apr 1992). Order Number DE92005056. Source: OSTI; NTIS; INIS; GPO Dep.

This paper describes initial studies related to the effects of volcanism on performance of the proposed Yucca Mountain radioactive waste repository, and to the general processes of magmatism in the Yucca Mountain region. Volcanism or igneous activity can affect the repository performance by ejection of waste onto the earth's surface (eruptive effects), or by subsurface effects of hydrothermal processes and attered hydrology if an intrusion occurs within the repository block. Initial, conservative calculations of the volume of waste that might be erupted during a small-volume basaltic eruption (such as those which occurred in the Yucca Mountain region) indicate that regulatory limits might be exceeded. Current efforts to refine these calculations, based upon field studies at analog sites, are described. Studies of subsurface effects are just beginning, and are currently focused on field studies of intrusion properties and contact metamorphism at deeply eroded analog sites. General processes of magmatism are important for providing a physical basis for predictions of future volcanic activity. Initial studies have focused on modeling basaltic magma chambers in conjunction with petrographic and geochemical studies. An example of the thermal-fluid dynamic evolution of a small basaltic sill is described, based on numerical simulation. Quantification of eruption conditions can provide valuable information on the overall magmatic system. We are developing quantitative methods for mapping pyroclastic facies of small basaltic centers and, in combination with two-phase hydrodynamic simulation, using this information to estimate eruption conditions. Examples of such hydrodynamic simulations are presented, along with comparison to an historical eruption in Hawaii.

118 (LA-UR-92-26) Radionuclide migration laboratory studies for validation of batch sorption data. Triay, I.R.; Mitchell, A.J.; Ott, M.A. Los Alamos National Lab., NM (United States). [1991]. 21p. Sponsored by USDOE, Washington, DC (United States). DOE Contract W-7405-ENG-36. (CONF-9109344-1: Sorption workshop, Los Alamos, NM (United States), 18-22 Sep 1991). Order Number DE92007425. Source: OSTI; NTIS; INIS; GPO Dep.

Advective and diffusive migration experiments (within the Dynamic Transport Column Experiments and Diffusion Studies of the Yucca Mountain Site Characterization Project) involve utilizing crushed material, intact, and fractured tuff in order to test and improve (if necessary) transport models by experimentally observing the migration of sorbing and nonsorbing radionuclides on a laboratory scale. Performing a validation of the sorption data obtained with batch techniques (within the Batch Sorption Study) is an integral part of the mission of the Dynamic Transport Column Experiments and Diffusion Studies. In this paper the work scope of the radionuclide migration laboratory experiments (as they apply to validation of batch sorption data) is reviewed.

119 (LA-UR-92-329) Geochemical evidence for waning magmatism and polycyclic volcanism at Crater Flat, Nevada. Perry, F.V. (New Mexico Univ., Albuquerque, NM (United States). Dept. of Geology); Crowe, B.M. Los Alamos National Lab., NM (United States). [1991]. 11p. Sponsored by USDOE, Washington, DC (United States). DOE Contract W-7405-ENG-36. (CONF-920430-52: 3. international high level radioactive waste management (IHLRWM) conference, Las Vegas, NV (United States), 1216 Apr 1992). Order Number DE92007420. Source: OSTI; NTIS; GPO Dep.

Petrologic and geochemical studies of basaltic rocks in the Yucca Mountain region are currently focused on understanding the evolution of volcanism in the Crater Flat volcanic field and the mechanisms of polycyclic volcanism at the Lathrop Wells volcanic center, the youngest center in the Crater Flat volcanic field. Geochemical and petrologic data indicate that the magma chambers which supplied the volcanic centers in Crater Flat became situated at greater crustal depths as the field evolved. Deep magma chambers may be related to a waning magma flux that was unable to sustain upper crystal magma conduits and chambers. Geochemical data from the Lathrop Wells volcanic center indicate that eruptive units identified from field and geomorphic relationships are geochemically distinct. The geochemical variations cannot be explained by fractional crystallization of a single magma batch, indicating that several magma batches were involved in the formation of the Lathrop Wells center. Considering the low magma flux in the Yucca Mountain region in the Quaternary, the probability of several magma batches erupting essentially simultaneously at Lathrop Wells in considered remote. It is more likely that the Lathrop Wells center was formed by a series of eruptions that took place over many thousands of years. The geochemical data from Lathrop Wells is consistent with the concept of a complex, polycyclic volcano, which was originally proposed based on geomorphic and soil-development data.

120 (LA-UR-92-377) Recurrence models of volcanic events: Applications to volcanic risk assessment. Crowe, B.M. (Los Alamos National Lab., Las Vegas, NV (United States)); Picard, R.; Valentine, G.; Perry, F.V. Los Alamos National Lab., NM (United States). [1992]. 13p. Sponsored by USDOE, Washington, DC (United States). DOE Contract W-7405-ENG-36. (CONF-920430-64: 3 . international high level radioactive waste management (IHLRWM) conference, Las Vegas, NV (United States), 12$16 \mathrm{Apr}$ 1992). Order Number DE92008443. Source: OSTI; NTIS; INIS; GPO Dep.

An assessment of the risk of future volcanism has been conducted for isolation of high-level radioactive waste at the potential Yucca Mountain site in southern Nevada. Risk used in this context refers to a combined assessment of the probability and consequences of future volcanic activity. Past studies established bounds on the probability of magmatic disruption of a repository. These bounds were revised as additional data were gathered from site characterization 
studies. The probability of direct intersection of a potential repository located in an eight $\mathrm{km}^{2}$ area of Yucca Mountain by ascending basalt magma was bounded by the range of $10^{-8}$ to $10^{-10} \mathrm{yr}^{-12}$. The consequences of magmatic disruption of a repository were estimated in previous studies to be limited. The exact releases from such an event are dependent on the strike of an intruding basalt dike relative to the repository geometry, the timing of the basaltic event relative to the age of the radioactive waste and the mechanisms of release and dispersal of the waste radionuclides in the accessible environment. The combined low probability of repository disruption and the limited releases associated with this event established the basis for the judgement that the risk of future volcanism was relatively low. It was reasoned that that risk of future volcanism was not likely to result in disqualification of the potential Yucca Mountain site.

121 (LA-UR-92-461) Preliminary assessment of clinoptilolite K/Ar results from Yucca Mountain, Nevada: A potential high-level radioactive waste repository site. WoldeGabriel, G.; Bish, D.L.; Broxton, D.E.; Chipera, S.J. Los Alamos National Lab., NM (United States). [1992]. 5p. Sponsored by USDOE, Washington, DC (United States). DOE Contract W-7405-ENG-36. (CONF-920761-1: 7. water-rock interaction conference, Park City, UT (United States), 9-23 Jul 1992). Order Number DE92008473. Source: OSTI; NTIS; INIS; GPO Dep.

At Yucca Mountain, evidence for at least three distinct temporal groups of clinoptilolites can be delineated from the preliminary K/Ar dates (2-3 Ma; 4-5 Ma; 7-11 Ma). The older $\mathrm{K} / \mathrm{Ar}$ dates that are similar to published illite/smectite ages (9-12 Ma) may be crystallization ages, whereas the younger dates probably represent continued diagenetic reactions of older clinoptilolites with percolating fluids. The $\mathrm{K} /$ Ar dates increase with depth, suggesting minimal argon loss in the deeper samples. Internal consistency of the clinoptilolite $\mathrm{K} / \mathrm{Ar}$ results at different levels within the drill holes suggest that dating of K-rich zeolites may provide useful information for assessing the zeolitization at Yucca Mountain. Variations in the KJAr dates are probably related to Ar loss during dissolution of older clinoptilolites and to contamination by finely crystalline feldspars.

122 (LA-UR-92-534) The Lathrop Wells volcanic center: Status of field and geochronology studies. Crowe, B. (Los Alamos National Laboratory, Las Vegas, NV (United States)); Morley, R.; Welis, S.; Geissman, J.; McDonald, E.; McFadden, L.; Perry, F.; Murrell, M.; Poths, J.; Forman, S. Los Alamos National Lab., NM (United States). [1992]. 18p. Sponsored by USDOE, Washington, DC (United States). DOE Contract W-7405-ENG-36. (CONF920430-65: 3. international high level radioactive waste management (IHLRWM) conference, Las Vegas, NV (United States), 12-16 Apr 1992). Order Number DE92008492. Source: OSTI; NTIS; INIS; GPO Dep.

The purpose of this paper is to describe the status of field and geochronology studies of the Lathrop Wells volcanic center. Our perspective is that it is critical to assess all possible methods for obtaining cross-checking data to resolve chronology and field problems. It is equally important to consider application of the range of chronology methods available in Quaternary geologic research. Such an approach seeks to increase the confidence in data interpretations through obtaining convergence among separate isotopic, radiogenic, and age-correlated methods. Finally, the assumptions, strengths, and weaknesses of each dating method need to be carefully described to facilitate an impartial evaluation of results. The paper is divided into two parts. The first part describes the status of continuing field studies for the volcanic center for this area south of Yucca Mountain, Nevada. The second part presents an overview of the preliminary results of ongoing chronology studies and their constraints on the age and stratigraphy of the Lathrop Wells volcanic center. Along with the chronology data, the assumptions, strengths, and limitations of each methods are discussed.

123 (LA-UR-92-537) Chemical changes associated with zeolitization of the tuffaceous beds of Calico Hills at Yucca Mountain, Nevada. Broxton, D.E. Los Alamos National Lab., NM (United States). [1992]. 7p. Sponsored by USDOE, Washington, DC (United States). DOE Contract W7405-ENG-36. (CONF-920761-2: 7. water-rock interaction conference, Park City, UT (United States), 9-23 Jul 1992). Order Number DE92008440. Source: OSTI; NTIS; INIS; GPO Dep.

The chemistry of the tuffaceous beds of Calico Hills was examined in samples collected over a $100^{2} \mathrm{~km}$ area south of the Timber Mountain-Oasis Valley caldera complex to determine regional geochemical patterns during zeolitization. Samples of 58 vitric and zeolitic tuffs were analyzed for 48 elements by a combination of $x$-ray fluorescence, atomic absorption spectrophotometry, and neutron activation analysis. Major and trace element concentrations for zeolitic tuffs vary significantly from those for vitric tuffs. Complex, geographically-controlled patterns of elemental enrichment and depletion in the zeolitic tuffs are found for $\mathrm{Na}, \mathrm{K}, \mathrm{Ca}$, $\mathrm{Mg}, \mathrm{U}, \mathrm{Rb}, \mathrm{Sr}, \mathrm{Ba}$ and $\mathrm{Cs}$. Vitric and zeolitic tuffs generally have the same $\mathrm{SiO}_{2}$ contents on an anhydrous basis, but minor net silica gain or loss has occurred in some samples. Zeolitic tuffs from the northern part of the study area, adjacent to the caldera complex, are notably $\mathrm{K}$-rich and $\mathrm{Na}$ - and U-poor compared to zeolitic tuffs to the south. The compositions of the K-rich zeolitic tuffs are similar to those found in other areas of the western US where volcanic rocks are affected by potassium metasomatism. Alteration of vitric tuffs took place in an open chemical system and geographic control of major element compositions probably reflects regional variations in groundwater chemistry during alteration. The Krich zeolitic tuffs in the northern part of the study area were probably altered by hydrothermal fluids whereas tuffs further south were altered by lower-temperature groundwaters.

124 (LA-UR-92-1194) Water-rock interactions and the pH stability of groundwater from Yucca Mountain, Nevada. Ebinger, M.H. Los Alamos National Lab., NM (United States). [1992]. 5p. Sponsored by USDOE, Washington, DC (United States). DOE Contract W-7405-ENG-36. (CONF-920761-13: 7. water-rock interaction conference, Park City, UT (United States), 9-23 Jul 1992). Order Number DE92013548. Source: OSTI; NTIS; INIS; GPO Dep.

Titrations of acidic solutions in waters from the tuff and carbonate aquifers at Yucca Mountain were simulated using the geochemical codes PHREEQE and EQ3/6. The simulations tested $\mathrm{pH}$ stability of the waters in the presence of different minerals and in their absence. Two acidic solutions, $10^{-4} \mathrm{HCl}$ and $10^{-4} \mathrm{M} \mathrm{UO} \mathrm{O}_{2}\left(\mathrm{NO}_{3}\right)_{2}$, were titrated in to the water. Little $\mathrm{pH}$ and/or compositional change resulted in the groundwater when the $\mathrm{HCl}$ solution was titrated, but significant $\mathrm{pH}$ and $\mathrm{CO}_{2}$ fugacity changes were observed when $\mathrm{UO}_{2}\left(\mathrm{NO}_{3}\right)_{2}$ was titrated. Water interactions with alkali feldspar, quartz or cristobalite, and $\mathrm{Ca}$-smectite buffered the $\mathrm{pH}$ and compositional changes in the carbonate water and 
decreased the magnitude of $\mathrm{pH}$ and compositional changes when small volumes of $\mathrm{UO}_{2}\left(\mathrm{NO}_{3}\right)_{2}$ added to the tuffaceous waters.

125 (LA-UR-92-3549) Surface-discharging hydrothermal systems at Yucca Mountain: Examining the evidence. Levy, S.S. Los Alamos National Lab., NM (United States). [1992]. 7p. Sponsored by USDOE, Washington, DC (United States). DOE Contract W-7405-ENG-36. (CONF921101-6: 16. Materials Research Society (MRS) fall meeting, Boston, MA (United States), 30 Nov - 5 dec 1992). Order Number DE93003790. Source: OSTI; NTIS; INIS; GPO Dep.

This paper discusses exposures of altered rock that have been thought to form by recent discharge of water from depth. They were examined to address a concern that hydrothermal processes could compromise the isolation capability of a potential high-level nuclear waste repository at Yucca Mountain. Suspected hot-spring and hydrothermalvent deposits are more likely the products of infiltration of meteoric water into newly deposited and still-hot pyroclastic flows >12 Myr ago.

126 (LA-UR-93-0071) Transport of neptunium through Yucca Mountain tuffs. Triay, I.R.; Robinson, B.A.; Mitchell, A.J.; Overly, C.M.; Lopez, R.M. Los Alamos National Lab., NM (United States). [1993]. 9p. Sponsored by USDOE, Washington, DC (United States). DOE Contract W7405-ENG-36. (CONF-9211191-1: Materials Research Society meeting, Austin, TX (United States), 30 Nov 1992). Order Number DE93007338. Source: OSTI; NTIS; INIS; GPO Dep.

Neptunium has a high solubility in groundwaters from Yucca Mountain [1]. Uranium in nuclear reactors produces ${ }^{237} \mathrm{~Np}$ which has a half-life of $2.14 \times 10^{6}$ years. Consequently, the transport of ${ }^{237} \mathrm{~Np}$ through tuffs is of major importance in assessing the performance of a high-level nuclear waste repository at Yucca Mountain. The objective of this work is to determine the amount of $\mathrm{Np}$ retardation that is provided by the minerals in Yucca Mountain tuffs as a function of groundwater chemistry.

127 (LA-UR-93-270) Dependence of radionuclide sorption on sample grinding, surface area, and water composition. Rogers, P.S.Z.; Meijer, A. Los Alamos National Lab., NM (United States). [1993]. 8p. Sponsored by USDOE, Washington, DC (United States). DOE Contract W7405-ENG-36. (CONF-930408-18: International high-level radioactive waste management conference, Las Vegas, NV (United States), 25-29 Apr 1993). Order Number DE93007371. Source: OSTI; NTIS; INIS; GPO Dep.

In its 1987 technical position paper, "Determination of Radionuclide Sorption for High-Level Nuclear Waste Repositories", the Nuclear Regulatory Commission (NRC) review panel delineated several studies needed to show that experimental sorption coefficients could accurately model radionuclide sorption behavior along release pathways. In particular, they focused on the potential problems involved with the use of crushed rock samples, stating "If crushed solids are used, it is essential to show that laboratory experiments involving sorption on crushed solids are relevant to the repository site. The surfaces of crushed material may be significantly different from the surfaces of intact material, both porous and fractured. Grinding may expose the surfaces of solid phases different from those which groundwater would contact in a repository and/or may change the reactivity of the same mineral surfaces with dissolved radionuclides. The surface of crushed minerals can be enriched in certain elements by factors of two and three relative to the bulk composition. The experiments reported here were performed in direct response to the NRC technical position paper.

128 (LA-UR-93-436) Neptunium retardation with tuffs and groundwaters from Yucca Mountain. Triay, I.R.; Robinson, B.A.; Lopez, R.M.; Mitchell, A.J.; Overly, C.M. Los Alamos National Lab., NM (United States). [1993]. 6p. Sponsored by USDOE, Washington, DC (United States). DOE Contract W-7405-ENG-36. (CONF-930408-20: International high-level radioactive waste management conference, Las Vegas, NV (United States), 25-29 Apr 1993). Order Number DE93007324. Source: OSTI; NTIS; INIS; GPO Dep.

The retardation of neptunium was studied using batch sorption and column techniques. Pure mineral separates, tuffs and groundwaters from Yucca Mountain were used for these experiments. Our results indicate that Np sorption increases rapidly as the $\mathrm{pH}$ of the water increases in cases where surface complexation is thought $w$ be the dominant sorption mechanism. Oxide minerals (such as hematite) sorb $\mathrm{Np}$ strongly; therefore, these minerals even at trace levels in Yucca Mountain tuffs can result in significant Np retardation. Neptunium in groundwaters from Yucca Mountain exhibited a significant amount of sorption onto quartz. Neptunium sorption onto quartz is important because of the large quantity of silica in the tuffs. Elution of neptunium solutions in groundwater through columns made of crushed tuff yielded sorption coefficients that agree with the sorption results obtained using batch sorption techniques. Agreement between batch and column experiments indicates a neptunium sorption mechanism that is linear, reversible, and instantaneous.

129 (LA-UR-93-437) Diffusion of sorbing and nonsorbing radionuclides. Triay, I.R.; Birdsell, K.H.; Mitchell, A.J.; Ott, M.A. Los Alamos National Lab., NM (United States). [1993]. 7p. Sponsored by USDOE, Washington, DC (United States). DOE Contract W-7405-ENG-36. (CONF930408-21: International high-level radioactive waste management conference, Las Vegas, NV (United States), 25-29 Apr 1993). Order Number DE93007323. Source: OSTI; NTIS; INIS; GPO Dep.

Diffusion is considered one of the most important retardation mechanisms in fractured media. The diffusion experiments conducted involved solid tuff and groundwater from Yucca Mountain. The uptake of radionuclides by the tuff was studied utilizing containers made of tuff in the form of beakers. The solution containing the radionuclides of interest was placed in the tuff beaker cavity and the uptake of the radionuclides by the tuff was measured as a function of time. Our results indicate that the diffusion coefficient for nonsorbing radionuclides into saturated Yucca Mountain tuff is on the order of $10^{-6} \mathrm{~cm}^{2} / \mathrm{s}$. Large anions, such as pertechnetate are excluded from tuff pores and their diffusion coefficients are on the order of $10^{-7} \mathrm{~cm}^{2} / \mathrm{s}$. Comparison of the predictions for the uptake of sorbing radionuclides by the tuff with the actual data obtained indicates that conservative transport calculations will result from predicting diffusion using the batch sorption coefficient for the sorbing radionuclide and the diffusion coefficient obtained for tritiated water.

130 (LA-UR-93-690) The quality assurance liaison: Combined technical and quality assurance support. Bolivar, S.L. (Los Alamos National Lab., NM (United States)); Day, J.L. Los Alamos National Lab., NM (United States). 
[1993]. 8p. Sponsored by USDOE, Washington, DC (United States). DOE Contract W-7405-ENG-36. (CONF-93061141: 17. annual Rocky Mountain quality conference, Denver, CO (United States), 6-8 Jun 1993). Order Number DE93008725. Source: OSTI; NTIS; INIS; GPO Dep.

This paper describes the role of the quality assurance liaison, the responsibilities of this position, and the evolutionary changes in duties over the last six years. The role of the quality assurance liaison has had a very positive impact on the Los Alamos Yucca Mountain Site Characterization (YW) quality assurance program. Having both technical and quality assurance expertise, the quality assurance liaisons are able to facilitate communications with scientists on quality assurance issues and requirements, thereby generating greater productivity in scientific investigations. The quality assurance liaisons help ensure that the scientific community knows and implements existing requirements, is aware of new or changing regulations, and is able to conduct scientific work within Project requirements. The influence of the role of the quality assurance liaison can be measured by an overall improvement in attitude of the staff regarding quality assurance requirements and improved job performance, as well as a decrease in deficiencies identified during both internal and external audits and surveillances. This has resulted in a more effective implementation of quality assurance requirements.

131 (LA-UR-93-2254) K/AR dating of clinoptilolite, mordenite, and associated clays from Yucca Mountains, Nevada. WoldeGabriel, G. Los Alamos National Lab., NM (United States). [1993]. 26p. Sponsored by USDOE, Washington, DC (United States). DOE Contract W-7405-ENG-36. (CONF-9306100-3: Zeolite 93: 4th international conference on the occurrence, properties, and utilization of natural zeolites, Boise, ID (United States), 20-28 Jun 1993). Order Number DE93016563. Source: OSTI; NTIS; INIS; GPO Dep.

Zeolites are abundant in the geologic record in both continental and marine environments. The purpose of the present study is to evaluate the utility of K-bearing zeolites for dating by the KAr method to determine the time of zeolite diagenesis at Yucca Mountain, Nevada (Fig. 1). At Yucca Mountain, K-rich clinoptilolite and possibly mordenite are the only potentially KAr dateable secondary minerals present in the zeolite-rich tuffs except for some illite/smectites $(\geq 10 \%$ illite layers) associated with these minerals. Direct dating of $\mathrm{K}$ rich clinoptilolite, the most abundant zeolite in the altered tuffs, is important to delineate zeolite chronology as part of the site characterization of Yucca Mountain.

132 (LA-UR-93-2326) The importance of zeolites in the potential high-level radioactive waste repository at Yucca Mountain, Nevada. Vaniman, D.T.; Bish, D.L. Los Alamos National Lab., NM (United States). 1993. 24p. Sponsored by USDOE, Washington, DC (United States). DOE Contract W-7405-ENG-36. (CONF-9306100-2: Zeolite 93: 4th international conference on the occurrence, properties, and utilization of natural zeolites, Boise, ID (United States), 20-28 Jun 1993). Order Number DE93016459. Source: OSTI; NTIS; GPO Dep.

Zeolitic rocks play an important role in retarding the migration of radionuclides that occur in solution as simple cations ( $\mathrm{Cs}, \mathrm{Sr}, \mathrm{Ba}$ ). However, the interaction of zeolites with complex transuranic species in solution provides little if any advantage over other common silicate minerals. The most important consequences of zeolite occurrences near a high-level radioactive waste repository environment are likely to be their response to thermal loading and their impact on site hydrology. Partial zeolite dehydration during the early thermal pulse from the repository and rehydration as the repository slowly cools can have an important impact on the water budget of a repository in unsaturated rocks, provided that the long-term heating does not result in zeolite destabilization.

133 (LA-UR-93-2761) Equilibrium modeling of the formation of zeolites in fractures at Yucca Mountain, Nevada. Chipera, S.J.; Bish, D.L.; Carlos, B.A. Los Alamos National Lab., NM (United States). [1993]. 28p. Sponsored by USDOE, Washington, DC (United States). DOE Contract W-7405-ENG-36. (CONF-9306100-4: Zeolite 93: 4th international conference on the occurrence, properties, and utilization of natural zeolites, Boise, ID (United States), 2028 Jun 1993). Order Number DE93018290. Source: OSTI; NTIS; INIS; GPO Dep.

Yucca Mountain, in southern Nevada, is currently being investigated to determine its suitability to host the first US high-level nuclear waste repository. One of the reasons that Yucca Mountain was chosen for study is the presence of thick sequences of zeolite-rich horizons. In as much as fractures may serve as potential pathways for aqueous transport, the minerals that line fractures are of particular interest. Zeolites are common in fractures at Yucca Mountain and consist mainly of clinoptilolite/heulandite and mordenite although sporadic occurrences of chabazite, erionite, phillipsite, and stellrite have been identified using $X$-ray powder diffraction. To understand better the conditions under which the obsenved zeolite species were formed, thermodynamic data were estimated and calculations of $\log \mathrm{a}\left(\left(\mathrm{K}^{+}\right)^{2} / \mathrm{Ca}^{++}\right)$ versus log a $\left(\left(\mathrm{Na}^{+}\right)^{2} / \mathrm{Ca}^{++}\right)$were conducted at various temperatures and silica activities. Using present-day Yucca Mountain water chemistries as a lower constraint on silica activity, clinoptilolite/heulandite and mordenite are still the zeolite species that would form under present conditions.

134 (LA-UR-93-2882) Distribution and chemistry of fracture-lining zeolites at Yucca Mountain, Nevada. Carlos, B.; Chipera, S.; Bish, D.; Raymond, R. Los Alamos National Lab., NM (United States). [1993]. 38p. Sponsored by USDOE, Washington, DC (United States). DOE Contract W-7405-ENG-36. (CONF-9306100-6: Zeolite 93: 4th international conference on the occurrence, properties, and utilization of natural zeolites, Boise, ID (United States), 2028 Jun 1993). Order Number DE93040090. Source: OSTI; NTIS; INIS; GPO Dep.

Yucca Mountain, a > 1.5-km thick sequence of tuffs and subordinate lavas in southwest Nevada, is being investigated as a potential high-level nuclear waste repository site. Fracture-lining minerals are possible sources of information on past transport within the tuffs, and they may act as natural barriers to radionuclide migration along the fractures. Cores from several drill holes were examined to determine the distribution and chemistry of zeolite minerals in fractures. Fracture-lining minerals in the Paintbrush Tuff are highly variable in distribution, both vertically and laterally across the mountain, with mordenite, heulandite, and stellerite widespread in fractures even though the tuff matrix is generally devitrified and not zeolitic. Where heulandite occurs as both tabular and prismatic crystals in the same fracture, the two morphologies have different compositions, suggesting multiple episodes of zeolite formation within the fractures. In contrast to the Paintbrush Tuff, fractures in the Calico Hills Formation and the Crater Flat Tuff generally contain abundant clinoptilolite and mordenite only where the 
matrix is zeolitic, although mordenite does occur as fracture linings in some devitrified intervals of the Crater Flat Tuff as well. The fracture-lining zeolites correlate with the degree of alteration of the zeolitic tuffs, with clinoptilolite plus mordenite in tuffs containing clinoptilolite, and analcime in fractures limited to tuff intervals containing anaicime. These data suggest that fracture-lining zeolite formation may have been coincident with the original alteration of the tuffs.

135 (LA-UR-93-3299) Effects of magmatic processes on the potential Yucca Mountain repository: Field and computational studies. Valentine, G.A.; Groves, K.R.; Gable, C.W.; Perry, F.V.; Crowe, B.M. Los Alamos National Lab., NM (United States). [1993]. 27p. Sponsored by USDOE, Washington, DC (United States). DOE Contract W-7405-ENG-36. (CONF-9309228-2: Focus 93: site characterization and model validation, Las Vegas, NV (United States), 26-29 Sep 1993). Order Number DE94000896. Source: OSTI; NTIS; INIS; GPO Dep.

Assessing the risk of future magmatic activity at a potential Yucca Mountain radioactive waste repository requires, in addition to event probabilities, some knowledge of the consequences of such activity. Magmatic consequences are divided into an eruptive component, which pertains to the possibility of radioactive waste being erupted onto the surface of Yucca Mountain, and a subsurface component, which occurs whether there is an accompanying eruption or not. The subsurface component pertains to a suite of processes such as hydrothermal activity, changes in country rock properties, and long term alteration of the hydrologic flow field which change the waste isolation system. This paper is the second in a series describing progress on studies of the effects of magmatic activity. We describe initial results of field analog studies at small volume basaltic centers where detailed measurements are being conducted of the amount of wall rock debris that can be erupted as a function of depth in the volcanic plumbing system. Constraints from field evidence of wall rock entrainment mechanisms are also discussed. Evidence is described for a mechanism of producing subhorizontal sills versus subvertical dikes, an issue that is important for assessing subsurface effects. Finally, new modeling techniques, which are being developed in order to capture the three dimensional complexities of real geologic situations in subsurface effects, are described.

136 (LA-UR-93-3505) Simulation modeling of the probability of magmatic disruption of the potential Yucca Mountain Site. Crowe, B.M. (Los Alamos National Lab., NM (United States)); Perry, F.V.; Valentine, G.A.; Wallmann, P.C.; Kossik, R. Los Alamos National Lab., NM (United States). [1993]. 11p. Sponsored by USDOE, Washington, DC (United States). DOE Contract W-7405-ENG-36. (CONF-9309228-6: Focus 93: site characterization and model validation, Las Vegas, NV (United States), 26-29 Sep 1993). Order Number DE94002599. Source: OSTI; NTIS; INIS; GPO Dep.

The first phase of risk simulation modeling was completed for the probability of magmatic disruption of a potential repository at Yucca Mountain. E1, the recurrence rate of volcanic events, is modeled using bounds from active basaltic volcanic fields and midpoint estimates of $\mathrm{E} 1$. The cumulative probability curves for $\mathrm{El}$ are generated by simulation modeling using a form of a triangular distribution. The $50 \%$ estimates are about 5 to $8 \times 10^{8}$ events $\mathrm{yr}^{-1}$. The simulation modeling shows that the cumulative probability distribution for $E 1$ is more sensitive to the probability bounds then the midpoint estimates. The E2 (disruption probability) is modeled through risk simulation using a normal distribution and midpoint estimates from multiple alternative stochastic and structural models. The $50 \%$ estimate of E2 is $4.3 \times 10^{-3}$ The probability of magmatic disruption of the potential Yucca Mountain site is $2.5 \times 10^{-8} \mathrm{yr}^{-1}$. This median estimate decreases to $9.6 \times 10^{-9} \mathrm{yr}^{-1}$ if $\mathrm{E}_{1}$ is modified for the structural models used to define E2. The Repository Integration Program was tested to compare releases of a simulated repository (without volcanic events) to releases from time histories which may include volcanic disruptive events. Results show that the performance modeling can be used for sensitivity studies of volcanic effects.

137 The Lathrop Wells volcanic center: Status of field and geochronology studies. Crowe, B. (Los Alamos National Lab., Las Vegas, NV (US)); Morley, R. pp. 1997. 2013 of Proceedings of high level radioactive waste management: Volume 1. American Nuclear Society, La Grange Park, IL (United States) (1992). pp. 2425 (CONF920430-: 3. international high level radioactive waste management (IHLRWM) conference, Las Vegas, NV (United States), 12-16 Apr 1992).

The Lathrop Wells volcanic center is located $20 \mathrm{~km}$ south of the potential Yucca Mountain site, at the south end of the Yucca Mountain range. This paper discusses a detailed Study Plan which was prepared describing planned geochronology and field studies to assess the chronology of the Lathrop Wells volcanic center and other Quaternary volcanic centers in the region. A paper was published discussing the geomorphic and soil evidence for a late Pleistocene or Holoceno age for the main cone of the center. The purpose of this paper was to expose the ideas concerning the age of the Lathrop Wells center to scientific scrutiny. Additionally, field evidence was described suggesting the Lathrop Wells center may have formed from multiple eruptive events with significant intervals of no activity between events. This interpretation breaks with established convention in the volcanological literature that small volume basalt centers are monogenetic.

138 Physical processes and effects of magmatism in the Yucca Mountain region. Valentine, G.A. (MS F665, EES-5, Los Alamos National Lab., Los Alamos, NM (US)); Crowe, B.M.; Perry, F.V. pp. 2014-2024 of Proceedings of high level radioactive waste management: Volume 1. American Nuclear Society, La Grange Park, IL (United States) (1992). pp. 2425 (CONF-920430-: 3. international high level radioactive waste management (IHLRWM) conference, Las Vegas, NV (United States), 12-16 Apr 1992).

Initial studies related to the effects of volcanism on performance of the potential Yucca Mountain radioactive waste repository, and to the general processes of magmatism in the Yucca Mountain region, are described. Volcanism or igneous activity can affect the repository performance by ejection of waste onto the earth's surface (eruptive effects), or by subsurface effects of hydrothermal processes and altered hydrology if an intrusion occurs within the repository block. Initial, conservative calculations of the volume of waste that might be erupted during a small-volume basaltic eruption (such as those which have occurred in the Yucca Mountain region) indicate that regulatory limits might be exceeded. Current efforts to refine these calculations, based upon field studies at analog sites, are described. In this paper an example of the thermal-fluid dynamic evolution of a small basaltic sill is described, based on numerical simulation. Quantification of eruption conditions can provide valuable information on the overall magmatic system. The 
authors are developing quantitative methods for mapping pyroclastic facies of small basaltic centers and in combination with two-phase hydrodynamic simulation, using this information to estimate eruption conditions. Examples of such hydrodynamic simulations are presented, along with comparison to an historical eruption in Hawail.

139 Recurrence models of volcanic events: Applications to volcanic risk assessment. Picard, R. (Los Alamos National Lab., Las Vegas, NV (US)); Valentine, G.; Crowe, B.M.; Perry, F.V. pp. 2344-2355 of Proceedings of high level radioactive waste management: Volume 1. American Nuclear Society, La Grange Park, IL (United States) (1992). pp. 2425 (CONF-920430-: 3. international high level radioactive waste management (IHLRWM) conference, Las Vegas, NV (United States), 12-16 Apr 1992).

An assessment of the risk of future volcanism has been conducted for isolation of high-level radioactive waste at the potential Yucca Mountain site in southern Nevada. Volcanism studies for the Yucca Mountain Site Characterization Project have progressed to a sufficient degree that it is now prudent to work toward concluding aspects of the work. An advantage of a probabilistic approach to volcanic risk is that it assigns a structured formalism to the problem. This formalism subdivides a complex issue into logical sections. The significance of uncertainty or differences in scientific opinion concerning volcanism issues can be tested for each section of a probabilistic problem. The perspective for making judgement of significance for volcanism studied are the regulatory requirements for assessing the suitability of the potential Yucca Mountain site. This paper attempts to begin the process of helping establish the probabilistic framework for making those judgement. There are three objectives. First, the authors describe the tripartite probability used to define the risk of volcanism and the geologic assumptions required for the probability model. Second, the authors examine and define the first part of this probability, the recurrence of volcanic events. Studies are reviewed from the volcanological literature where time-volume behavior of volcanic centers and fields have been evaluated. These evaluations include both conventional statistical analysis of time-series of volcanic events and applications using newly developing concepts of fractal analysis and deterministic chaos. Third, the authors tabulate past calculations and derive new values for the recurrence of volcanic events using a simple Poison model.

140 Geochemical evidence for waning magmatism and polycyclic volcanism at Crater Flat, Nevada. Perry, F.V. (Dept. of Geology, Univ. of New Mexico, Albuquerque, NM (US)); Crowe, B.M. pp. 2356-2365 of Proceedings of high level radioactive waste management: Volume 1. American Nuclear Society, La Grange Park, IL (United States) (1992). pp. 2425 (CONF-920430-: 3. international high level radioactive waste management (IHLRWM) conference, Las Vegas, NV (United States), 12-16 Apr 1992).

This paper reports that petrologic and geochemical studies of basaltic rocks in the Yucca Mountain region are currently focused on understanding the evolution of volcanism in the Crater Flat volcanic field and the mechanisms of polycyclic volcanic field and the mechanisms of polycyclic volcanism at the Lathrop Wells volcanic center, the youngest center in the Crater Flat volcanic field. Geochemical and petrologic data indicate that the magma chambers which supplied the volcanic centers at Crater Flat became situated at greater crustal depths as the field evolved. Deep magma chambers may be related to a waning magma flux that was unable to sustain upper crustal magma conduits and chambers. Geochemical data from the Lathrop Wells volcanic center indicate that eruptive units identified from field and geomorphic relationships are geochemically distinct. The geochemical variations cannot be explained by fractional crystallization of a single magma batch, indicating that several magma batches were involved in the formation of the Lathrop Wells center. Considering the low magma flux in the Yucca Mountain region in the Quaternary, the probability of several magma batches erupting essentially simultaneously at Lathrop Wells is considered remote.

141 An evaluation of lithium sorption isotherms and their application to ground-water transport. Newman, B.D. (Univ. of Texas, El Paso (United States)); Fuentes, H.R.; Polzer, W.L. Ground Water (United States); 29(6): 818-824 (Nov-Dec 1991).

Batch adsorption and desorption equilibrium experiments were used to evaluate lithium sorption on crushed tuff in contact with ground water. The laboratory studies were conducted in support of saturated zone characterization field tests to be performed near Yucca Mountain, Nevada. These studies included equilibrium experiments conducted at $38 \mathrm{C}$ (expected subsurface temperature) for a 1 - to $2,000-\mathrm{mg} / 1$ range of initial lithium solution concentrations. Data from the equilibrium experiments were used in the evaluation of Linear, Langmuir, Freundlich, and Modified Freundlich isotherm expressions. Comparisons of adsorption and desorption isotherms showed that lithium adsorption was reversible for solution concentrations up to $150 \mathrm{mg} / \mathrm{l}$. This conclusion was based on F-test comparisons of predicted adsorption and desorption data from Langmuir isotherms. Lithium sorption was best represented by the nonlinear isotherms where the Langmuir gave the best fit followed by the Modified Freundlich and Freundlich. When these isotherms were used in a one-dimensional, column adsorption transport code, differences occurred in the predicted breakthrough curves. The transport results showed differences of as much as a factor of five in the time of arrival of lithium for the various isotherms depending on the influent concentration chosen. The differences in the simulation breakthrough curves indicate the importance of isotherm selection. Statistical discrimination and column experiments are suggested as better evaluations of isotherms that are to be incorporated into field-scale transport simulations.

\section{LAWRENCE LIVERMORE NATIONAL LAB- ORATORY}

142 (AECL-10121, pp. 87-107) Evaluation of copper, aluminum bronze, and copper-nickel container material for the Yucca mountain project. Kass, J. (Lawrence Livermore National Lab., CA (United States)). Atomic Energy of Canada Ltd., Pinawa, MB (Canada). Whiteshell Nuclear Research Establishment. Jan 1990. (CONF-8802159-: Workshop on waste container corrosion, Winnipeg (Canada), 9-10 Feb 1988). In Proceedings of a workshop on corrosion of nuclear fuel waste containers. 324p. Order Number DE92606369. Source: OSTI; NTIS (US Sales Only); INIS.

Copper, 70 percent aluminum bronze, and 70/30 coppernickel were evaluated as potential waste-packaging materials as part of the Yucca Mountain Project. The proposed waste repository site is under a desert mountain in 
southern Nevada. The expected temperatures at the container surface are higher than at other sites, about $250 \mathrm{C}$ at the beginning of the containment period; they could fall below the boiling point of water during this period, but will be exposed to very little water, probably less than $5 \mathrm{l} / \mathrm{a}$. Initial gamma flux will be $10^{4} \mathrm{rad} / \mathrm{h}$, and no significant hydrostatic or lithostatic pressure is expected. Packages will contain PWR or BWR fuel, or processed-glass waste. Three copper alloys are being considered for containers: oxygen-free copper (CDA 102); 7 percent aluminum bronze (CDA 613); and 70/30 copper-nickel (CDA 715). Phase separation due to prolonged thermal exposure could be a problem for the two alloys, causing embrittlement. The reduction of internal oxides present in pure copper by hydrogen could cause mechanical degradation. Corrosion and oxidation rates measured for the three materials in well water with and without gamma irradiation at flux rates about ten times higher than those expected were all quite small. The corrosion/oxidation rates for CDA715 show a marked increase under irradiation, but are still acceptable. In the presence of ammonia and other nitrogen-bearing species stress corrosion cracking (SCC) is a concern. Welded U-bend specimens of all three materials have been tested for up to $10000 \mathrm{~h}$ in highly irradiated environments, showing no SCC. There was some alloy segregation in the Al bronze specimens. The investigators believe that corrosion and mechanical properties will not present problems for these materials at this site. Further work is needed in the areas of weld inspection, welding techniques, embrittlement of weld metal, the effects of dropping the containers during emplacement, and stress corrosion cracking.

143

(ANL-91/36) Parametric effects on glass reaction in the unsaturated test method. Woodland, A.B.; Bates, J.K.; Gerding, T.J. Argonne National Lab., IL (United States). Dec 1991. 130p. Sponsored by USDOE, Washington, DC (United States). DOE Contract W-31109-ENG-38. Order Number DE92007578. Source: OSTI; NTIS; INIS; GPO Dep.

The Unsaturated Test Method has been applied to study glass reaction under conditions that may be present at the potential Yucca Mountain site, currently under evaluation for storage of reprocessed high-level nuclear waste. The results from five separate sets of parametric experiments are presented wherein test parameters ranging from water contact volume to sensitization of metal in contact with the glass were examined. The most significant effect was observed when the volume of water, as controlled by the water inject volume and interval period, was such to allow exfoliation of reacted glass to occur. The extent of reaction was also influenced to a lesser extent by the degree of sensitization of the $304 \mathrm{~L}$ stainiess steel. For each experiment, the release of cations from the glass and alteration of the glass were examined. The major alteration product is a smectite clay that forms both from precipitation from solution and from in-situ alteration of the glass itself. It is this clay that undergoes exfoliation as water drips from the glass. A comparison is made between the results of the parametric experiments with those of static leach tests. In the static tests the rates of release become progressively reduced through 39 weeks while, in contrast, they remain relatively constant in the parametric experiments for at least 300 weeks. This differing behavior may be attributable to the dripping water environment where fresh water is periodically added and where evaporation can occur.
144

(ANL/CP-72981) Progress in assessing the effect of lonizing radiation on the anticipated waste package environment at the Yucca Mountain potential repository site. Reed, D.T. Argonne National Lab., IL (United States). [1991]. 11p. Sponsored by USDOE, Washington, DC (United States). DOE Contract W-31109-ENG-38 ; W-7405-ENG-48. (CONF-910945-6: Focus '91: nuclear waste packaging, Las Vegas, NV (United States), 29 Sep 4 oct 1991). Order Number DE92004722. Source: OSTI; NTIS; INIS; GPO Dep.

Progress in establishing the effect of ionizing radiation on the expected air/water vapor waste package environment is summarized. This work was performed at Argonne National Laboratory (ANL) in support of the Yucca Mountain Site Characterization Project. The radiolytic issues that have been identified are presented. Long-term gamma experiments with gas compositions ranging from dry air to high-humidity air were completed. The predominant nitrogen fixation products in all air-like systems studied were nitrogen dioxide and nitric acid. Yields between 0.8 and 2.3 molec/ $100 \mathrm{eV}$ have been measured. Ammonia formation, although not predominant, was also observed at temperature below $100^{\circ} \mathrm{C}$. The ammonia yields were low, and the concentration did not build up with increased absorbed dose. The status of the issues identified is given.

145 (ANL/CP-75242) Crack-growth-rate testing of candidate waste container materials. Park, J.Y.; Shack, W.J.; Diercks, D.R. Argonne National Lab., IL (United States). [1991]. 7p. Sponsored by USDOE, Washington, DC (United States); Lawrence Livermore National Lab., CA (United States). DOE Contract W-31109-ENG-38. (CONF910945-7: Focus '91: nuclear waste packaging, Las Vegas, NV (United States), 29 Sep - 4 oct 1991). Order Number DE92007369. Source: OSTI; NTIS; INIS; GPO Dep.

Fracture-mechanics crack growth tests were conducted on 25.4-mm-thick compact tension specimens of Types $304 \mathrm{~L}$ and $316 \mathrm{~L}$ stainiess steel (SS) and Incoloy 825 at $93^{\circ} \mathrm{C}$ and 1 atmosphere of pressure is simulated $\mathrm{J}-13$ well water, which is representative of the groundwater at the Yucca Mountain site in Nevada that is proposed for a high-level nuclear waste repository. Crack growth rates were measured under various load conditions: load ratios $(R)$ of $0.5-1.0$, frequencies of $10^{-3}-1 \mathrm{~Hz}$, rise times of $1-1000 \mathrm{~s}$, and peak stress intensities of $25-40 \mathrm{MPa} \cdot \mathrm{m}^{1 / 2}$. The measured crack growth rates are bounded by the predicted rates from the current ASME Section XI correlation for fatigue crack growth rates of austenitic stainless steel in air. Environmentally accelerated crack growth was not evident in any of the three materials under the test conditions investigated.

146 (ANL/MCT/CP-75243) Crack growth behavior of candidate waste container materials in simulated underground water. Park, J.Y.; Shack, W.J.; Diercks, D.R. Argonne National Lab., IL (United States). [1992]. 16p. Sponsored by USDOE, Washington, DC (United States). DOE Contract W-31109-ENG-38. (CONF-921119-3: American Society for Testing and Materials (ASTM) symposium on application of accelerated corrosion tests to life prediction of materials, Miami, FL (United States), 16-17 Nov 1992). Order Number DE93008648. Source: OSTI; NTIS; INIS; GPO Dep.

Fracture-mechanics crack growth tests were conducted on 25.4-mm-thick compact tension specimens of Types $304 \mathrm{~L}$ and $316 \mathrm{~L}$ Stainless steel and Incoloy 825 at $93^{\circ} \mathrm{C}$ and 1 atmosphere of pressure in simulated $\mathrm{J}-13$ well water, which is representative of the groundwater at the Yucca 
Mountain site in Nevada that is proposed for a high-level nuclear waste repository. Crack growth rates were measured under various load conditions: load ratios of $0.2-1.0$, frequencies of $2 \times 10^{-4}-1 \mathrm{~Hz}$, rise times of $1-5000 \mathrm{~s}$, and peak stress intensities of $25-40 \mathrm{MPa} \cdot \mathrm{m}^{\frac{1}{2}}$. The measured crack growthrates are bounded by the predicted rates from the current ASME Section 11 correlation for fatigue crack growth rates of austenitic stainless steel in air. Environmentally accelerated crack growth was not evident in any of the three materials under the test conditions investigated.

147 (ESTSC-000324SUNOOOO) EQ3/6 V7.0: Geochemical Modeling of Aqueous Systems. Wolery, T.J. (Lawrence Livermore National Lab., CA (United States)). Lawrence Livermore National Lab., CA (United States). 10 Dec 1990. Sponsored by USDOE, Washington, DC (United States). DOE Contract W-7405-ENG-48. Source: ESTSC; Lawrence Livermore National Lab.

Description: SUN; UNIX, GENERALLY SPEAKING. VMS ANANSI FORTRAN 77. EQ3NR input files end in .3i, EQ6 input files end in .6i. This is a recommended convention, and it is required in order to run these codes using the RUNEQ36 script. The data file names have the form exemplified by data0.comR10. Here com is one of the five data file descriptors and R10 is a stage number(a configuration control identifier). This general form is required to run the RUNEQPT script. Text files in the package end in .txt. FORTRAN source files end in .fsc. The EQLIB library which is part of the package, supports the EQPT,EQ3NR and EQ6 codes.

EQ3/6 is a software package for geochemical modeling of aqueous systems. This description pertains to version 7.0. The major components of the package include: EQ3NR a speciation-solubility code; EQ6, a reaction path code which models water/rock interaction or fluid mixing in either a pure reaction progress mode or a time mode; EQPT, a data file preprocessor; EQLIB, a supporting software library; and five supportingthermodynamic data files. The software deals with the concepts of thermodynamic equilibrium, thermodynamic disequilibrium, and reaction kinetics. The five supporting data files contain both standard state and activity coefficient-related data. Three support the use of the Davies or B-dot equations for the activity coefficients; the other two support the use of Pitzes's equations. The temperature range of the thermodynamic data on the data files varies from 25 degrees $C$ only to $0-300$ degrees $C$. EQ3NR is useful for analyzing groundwater chemistry data, calculating solubility limits, and determining whether certain reactions are in states of partial equilibrium or disequilibrium. It is also required to initialize an EQ6 calculation. EQ6 models the consequences of reacting an aqueous solution with a specified set of reactants. It can also model fluid mixing and the effects of changes in temperature. This code operates in a pure reaction progress frame (e.g., makes equilibrium step calculations with no time variable) or in a time frame.

148 (ESTSC-000324SUNO001) EQ3/6 V7.1: Geochemical Modeling of Aqueous Systems. Wolery, T.J. (Lawrence Livermore National Lab., CA (United States)). Lawrence Livermore National Lab., CA (United States). 1 Sep 1992. Sponsored by USDOE, Washington, DC (United States). DOE Contract W-7405-ENG-48. Source: ESTSC; Lawrence Livermore National Lab.

Description: SUN; UNIX, GENERALLY SPEAKING. VMS ANANSI FORTRAN 77; 23.5 DISKETTES. EQ3NR input files end in .3i, EQ6 input files end in .6i. This is a recommended convention, and it is required in order to run these codes using the RUNEQ36 script. The data file names have the form exemplified by data0.comR10. Here com is one of the five data file descriptors and R10 is a stage number(a configuration control identifier). This general form is required to run the RUNEQPT script. Text files in the package end in .txt. FORTRAN source files end in .tsc. The EQLIB library which is part of the package, supports the EQPT,EQ3NR and EQ6 codes.

EQ3/6 is a software package for geochemical modeling of aqueous systems. This description pertains to version 7.1 . It differs from version 7.0 in that a number of bugs have been fixed, most of which pertain to portability. It also contains a newer set of supporting data files. The major components of the package include: EQ3NR a speciation-solubility code; EQ6, a reaction path code which models water/rock interaction or fluid mixing in either a pure reaction progress mode or a time mode; EQPT, a data file preprocessor; EQLIB, a supporting software library; and five supporting thermodynamic data files. The software deals with the concepts of thermodynamic equilibrium, thermodynamic disequilibrium, and reaction kinetics. The five supporting data files contain both standard state and activity coefficient-related data. Three support the use of the Davies or B-dot equations for the activity coefficients; the other two support the use of Pitzes's equations. The temperature range of the thermodynamic data on the data files varies from 25 degrees $C$ only to 0 300 degrees C. EQPT is a data file preprocessor. EQ3NR is a speciation solubility code that is useful for analyzing groundwater chemistry data, calculating solubility limits, and determining whether certain reactions are in states of partial equilibrium or disequilibrium. It is also required to initialize an EQ6 calculation. EQ6 is a reaction-path code. It models the consequences of reacting an aqueous solution with a specified set of reactants. It can also model fluid mixing and the effects of changes in temperature. This code operates in a pure reaction progress frame (e.g., makes equilibrium step calculations with no time variable) or in a time frame.

149 (LA-12325-C, pp. 75) Modeling cation exchange using EQ3/6. Viani, B. (Lawrence Livermore National Lab., CA (US)); Bruton, C.; Bourcier, B. Los Alamos National Lab., NM (United States). Aug 1992. (CONF-9009350-: DOE/Yucca Mountain site characterization project radionuclide adsorption workshop, Los Alamos, NM (United States), 11-12 Sep 1990). In Proceedings of the DOE Yucca Mountain Site Characterization Project Radionuclide Adsorption Workshop at Los Alamos National Laboratory, September 11-12, 1990. 238p. Order Number DE92041241. Source: OSTI; NTIS; INIS.

Geochemical modeling codes must be able to predict solid-solution and ion-exchange behavior of zeolites and smectites in order to design and assess strategies for containing and cleaning up toxic and/or radioactive wastes. Cation-exchange and solid-solution models have been implemented in the EQ3/6 geochemical modeling package and used to predict the composition of clinoptilolite under a variety of conditions. Published free energies of cation exchange on clinoptilolite at $25^{\circ} \mathrm{C}$ were combined with the calorimetric data for clinoptilolite to derive free energies of formation of the component end members of a solid solution in which mixing is allowed only on the exchange site. The solid-solution model and component end-member data were incorporated into EQ3/6 and its data base. An option to treat cation exchange independently of the solid-solution model was also developed and implemented in EQ3/6. This option allows the user to model mixed-phase exchangers, multisite exchangers, and systems in which the exchanger is not in 
overall equilibrium with the solution. Two "ideal" cationexchange conventions [Vanselow (mole fraction) and Gapon (equivalent fraction)] are currently implemented in the code. A description of the cation-exchange models and their implementation into EQ3/6 is presented, and the relationship between the exchange formalisms and the solid-solution models is discussed. The advantages and limitations of the models and currently available thermodynamic data are addressed by comparing cation-exchange compositions of clinoptilolites with (1) published binary exchange data; (2) compositions of coexisting clinoptilolites and formation waters at Yucca Mountain; and (3) experimental sorption isotherms of $\mathrm{Cs}$ and $\mathrm{Sr}$ on zeolitized tuff.

150 (LLNL-94001185) Bibliography of Yucca Mountain Project (YMP) publications at Lawrence Livermore National Laboratory (January 1978 through September 1993). Lawrence Livermore National Lab., CA (United States). Oct 1993. 71p. Sponsored by USDOE, Washington, DC (United States). DOE Contract W-7405-ENG-48. Order Number DE94001185. Source: OSTI; NTIS; INIS; GPO Dep.

This report consists of a listing of research projects pertaining to the Yucca Mountain Project.

151 (PNL-5109-104) Characterization of spent fuel approved testing material-ATM-104. Guenther, R.J.; Blahnik, D.E.; Jenquin, U.P.; Mendel, J.E.; Thomas, L.E.; Thornhill, C.K. Pacific Northwest Lab., Richland, WA (United States). Dec 1991. 415p. Sponsored by USDOE, Washington, DC (United States). DOE Contract AC06-76RL01830. Order Number DE92006636. Source: OSTI; NTIS; INIS; GPO Dep.

The characterization data obtained to date are described for Approved Testing Material 104 (ATM-104), which is spent fuel from Assembly D047 of the Calvert Cliffs Nuclear Power Plant (Unit 1), a pressurized-water reactor. This report is one in a series being prepared by the Materials Characterization Center at Pacific Northwest Laboratory (PNL) on spent fuel ATMs. The ATMs are receiving extensive examinations to provide a source of well-characterized spent fuel for testing in the US Department of Energy Office of Civilian Radioactive Waste Management (OCRWM) Program. ATM-104 consists of 128 full-length irradiated fuel rods with rod-average burnups of about $42 \mathrm{MWd} / \mathrm{kgM}$ and expected fission gas release of about $1 \%$. A variety of analyses were performed to investigate cladding characteristics, radionuclide inventory, and redistribution of fission products. Characterization data include (1) fabricated fuel design, irradiation history, and subsequent storage and handling history; (2) isotopic gamma scans; (3) fission gas analyses; (4) ceramography of the fuel and metallography of the cladding; (5) special fuel studies involving analytical transmission electron microscopy (AEM) and electron probe microanalyses (EPMA); (6) calculated nuclide inventories and radioactivities in the fuel and cladding; and (7) radiochemical analyses of the fuel and cladding.

152 (PNL-5109-105) Characterization of spent fuel approved testing material-ATM-105. Guenther, R.J.; Blahnik, D.E.; Campbell, T.K.; Jenquin, U.P.; Mendel, J.E.; Thomas, L.E.; Thornhill, C.K. Pacific Northwest Lab., Richland, WA (United States). Dec 1991. 364p. Sponsored by USDOE, Washington, DC (United States). DOE Contract AC06-76RL01830. Order Number DE92007036. Source: OSTI; NTIS; INIS; GPO Dep.

The characterization data obtained to data are described for Approved Testing Material 105 (ATM-105), which is spent fuel from Bundles CZ346 and CZ348 of the Cooper Nuclear Power Plant, a boiling-water reactor. This report is one in a series being prepared by the Materials Characterization Center at Pacific Northwest Laboratory (PNL) on spent fuel ATMs. The ATMs are receiving extensive examinations to provide a source of well-characterized spent fuel for testing in the US Department of Energy Office of Civilian Radioactive Waste Management (OCRWM) Program. ATM-105 consists of 88 full-length irradiated fuel rods with rodaverage burnups of about $2400 \mathrm{GJ} / \mathrm{kgM}$ (28 MWd/kgM) and expected fission gas release of about $1 \%$. Characterization data include (1) descriptions of as-fabricated fuel design, irradiation history, and subsequent storage and handling; (2) isotopic gamma scans; (3) fission gas analyses; (4) ceramography of the fuel and metallography of the cladding; (5) special fuel studies involving analytical transmission electron microscopy (AEM); (6) calculated nuclide inventories and radioactivities in the fuel and cladding; and (7) radiochemical analyses of the fuel and cladding. Additional analyses of the fuel are being conducted and will be included in planned revisions of this report.

153 (PNL-7581) SUMO, System performance assessment for a high-level nuclear waste repository: Mathematical models. Eslinger, P.W.; Miley, T.B.; Engel, D.W.; Chamberlain, P.J. II. Pacific Northwest Lab., Richland, WA (United States). Sep 1992. 178p. Sponsored by USDOE, Washington, DC (United States). DOE Contract AC06-76RL01830. Order Number DE92041231. Source: OSTI; NTIS; INIS; GPO Dep.

Following completion of the preliminary risk assessment of the potential Yucca Mountain Site by Pacific Northwest Laboratory (PNL) in 1988, the Office of Civilian Radioactive Waste Management (OCRWM) of the US Department of Energy (DOE) requested the Performance Assessment Scientific Support (PASS) Program at PNL to develop an integrated system model and computer code that provides. performance and risk assessment analysis capabilities for a potential high-level nuclear waste repository. The system model that has been developed addresses the cumulative radionuclide release criteria established by the US Environmental Protection Agency (EPA) and estimates population risks in terms of dose to humans. The system model embodied in the SUMO (System Unsaturated Model) code will also allow benchmarking of other models being developed for the Yucca Mountain Project. The system model has three natural divisions: (1) source term, (2) far-field transport, and (3) dose to humans. This document gives a detailed description of the mathematics of each of these three divisions. Each of the governing equations employed is based on modeling assumptions that are widely accepted within the scientific community.

154 (PNL-7847) AREST user's guide, PC version. Buxbaum, M.E. (Boeing Computer Senvices Co., Richland, WA (United States)); Engel, D.W. Pacific Northwest Lab., Richland, WA (United States). Nov 1991. 96p. Sponsored by USDOE, Washington, DC (United States). DOE Contract AC06-76RL01830. Source: OSTI (requests by US Government Agencies and Their Contractors). Other requestors should be directed to Battelle Memorial Inst., Richland, WA.

The AREST code implements the Analytical REpository Source-Term model for the evaluation of radionuclide release from the engineered barrier system of an underground high level nuclear waste repository. Development of the AREST code has been funded by the US Department of Energy (DOE) Office of Civilian Radioactive Waste Management 
(OCRWM). This model has historically been run on VAX and SUN workstation platforms. With the advent of more powerful PCs and the development of advanced graphical user interfaces for PCs, the latest version of AREST was ported to PCs running OS/2. The purpose of this user's guide is to explain and illustrate the use of the Microsoft OS/2 Presentation Manager (PM) (Microsoft Corp., 1989) interface to the model. The performance models and assumptions for the AREST model have already been described in detail.

155 (PNL-8081) An example postclosure risk assessment using the potential Yucca Mountain Site. Doctor, P.G.; Eslinger, P.W.; Elwood, D.M.; Engel, D.W.; Freshley, M.D.; Liebetrau, A.M.; Reimus, P.W.; Strenge, D.L.; Tanner, J.E.; Van Luik, A.E. Pacific Northwest Lab., Richland, WA (United States). May 1992. 299p. Sponsored by USDOE, Washington, DC (United States). DOE Contract AC06-76RL01830. Order Number DE92014614. Source: OSTI; NTIS; INIS; GPO Dep.

The risk analysis described in this document was performed for the US Department of Energy's (DOE) Office of Civilian Radioactive Waste Management (OCRWM) over a 2-year time period ending in June 1988. The objective of Pacific Northwest Laboratory's (PNL) task was to demonstrate an integrated, though preliminary, modeling approach for estimating the postclosure risk associated with a geologic repository for the disposal of high-level nuclear waste. The modeling study used published characterization data for the proposed candidate site at Yucca Mountain, Nevada, along with existing models and computer codes available at that time. Some of the site data and conceptual models reported in the Site Characterization Plan published in December 1988, however, were not yet available at the time that PNL conducted the modeling studies.

156 (PNL-8327) Thermal analysis of Yucca Mountain commercial high-level waste packages. Altenhofen, M.K. (Altenhofen (M.K.), Richland, WA (United States)); Eslinger, P.W. Pacific Northwest Lab., Richland, WA (United States). Oct 1992. 27p. Sponsored by USDOE, Washington, DC (United States). DOE Contract AC06-76RL01830. Order Number DE93001775. Source: OSTI; NTIS; INIS; GPO Dep.

The thermal performance of commercial high-level waste packages was evaluated on a preliminary basis for the candidate Yucca Mountain repository site. The purpose of this study is to provide an estimate for waste package component temperatures as a function of isolation time in tuff. Several recommendations are made concerning the addjtional information and modeling needed to evaluate the thermal performance of the Yucca Mountain repository system.

157

(PNL-SA-22264) AREST: The next generation. Engel, D.W. (Pacific Northwest Lab., Richland, WA (United States)); McGrail, B.P.; Eslinger, P.W.; Altenhofen, M.K. Pacific Northwest Lab., Richland, WA (United States). Apr 1993. 7p. Sponsored by USDOE, Washington, DC (United States). DOE Contract AC06-76RL01830. (CONF-93040870: International high-level radioactive waste management conference, Las Vegas, NV (United States), 25-29 Apr 1993). Order Number DE93013165. Source: OSTI; NTIS; INIS; GPO Dep.

Simple mass transport models using constant boundary conditions at the waste form surface and at the host rock boundary do not always result in realistic predictions of the performance of an underground repository for the disposal of high-level radioactive waste. What is needed is a model that couples the important processes that can not be modeled independently, including (1) thermal modeling, (2) geochemical modeling, (3) containment degradation, (4) waste form dissolution, and (5) radionuclide transport. Such a model is being developed by modifying the AREST code.

158 (SKB-TR-91-59, pp. 67-75) Solubility and speciation studies for nuclear repository performance assessment. Nitsche, H. (Lawrence Berkeley Laboratory, Berkeley, CA (USA)). Swedish Nuclear Fuel and Waste Management Co., Stockholm (Sweden). Dec 1991. (CONF9010497-: Technical workshop on near field performance assessment for high-level waste, Madrid (Spain), 15-17 Oct 1990). In Proceedings from the technical workshop on nearfield performance assessment for high-level waste. $190 \mathrm{p}$. Order Number DE92644559. Source: OSTI; NTIS; INIS.

Solubility and speciation data are important in understanding aqueous radionuclide transport through the geosphere. They define the source term for transport retardation processes such as sorption and colloid formation. Solubility and speciation data are useful in verifying the validity of geochemical codes that are part of predictive transport models. Radionuclide solubility studies in groundwaters from a repository region will provide limits on radionuclide concentrations in these waters. Meaningful thermodynamically defined solubility studies must satisfy four criteria: (1) solution equilibrium conditions, (2) effective and complete phase separation, (3) a well-defined solid phase, and (4) knowledge of the speciation/oxidation state of the soluble species at equilibrium. Results from solubility and speciation experiments of ${ }^{237} \mathrm{NpO}^{+}{ }_{2}{ }^{239} \mathrm{Pu}^{4+}$, and ${ }^{241} \mathrm{Am}^{3+} \mathrm{Nd}^{3+}$ in $\mathrm{J}-13$ groundwater (from the Yucca Mountain region, Nevada, which is being investigated as a potential high-level nuclear waste disposal site) at three different temperatures (25 degrees, 60 degrees, and 90 degrees $C$ ) and $\mathrm{pH}$ values $(6,7$, and 8.5 ) are presented. (au) (3 refs., 3 figs.).

159 (UCID-21414-Rev.1) Thermal performance of a buried nuclear waste storage container storing a hybrid mix of PWR and BWR spent fuel rods: Revision 1. Johnson, G.L. Lawrence Livermore National Lab., CA (United States). Nov 1991. 105p. Sponsored by USDOE, Washington, DC (United States). DOE Contract W-7405-ENG-48. Order Number DE92004466. Source: OSTI; NTIS; INIS; GPO Dep.

Lawrence Livermore National Laboratory will design, model, and test nuclear waste packages for use at the Nevada Nuclear Waste Storage Repository at Yucca Mountain, Nevada. One such package would store tightly packed spent fuel rods from both pressurized and boiling water reactors. The storage container provides the primary containment of the nuclear waste and the spent fuel rod cladding provides secondary containment. A series of transient conduction and radiation heat transfer analyses was run to determine for the first $1000 \mathrm{yr}$ of storage if the temperature of the tuff at the borehole wall ever falls below $97^{\circ} \mathrm{C}$ and whether the cladding of the stored spent fuel ever exceeds $350^{\circ} \mathrm{C}$. Limiting the borehole to temperatures of $97^{\circ} \mathrm{C}$ or greater helps minimize corrosion by assuring that no condensed water collects on the container. The $350^{\circ} \mathrm{C}$ cladding limit minimizes the possibility of creep- related failure in the spent fuel rod cladding. For a series of packages stored in a $8 \times 30 \mathrm{~m}$ borehole grid where each package contains 10-yr-old spent fuel rods generating $4.74 \mathrm{~kW}$ or more, the borehole wall stays above $97^{\circ} \mathrm{C}$ for the full 10000 $\mathrm{yr}$ analysis period. For the $4.74-\mathrm{kW}$ load, the peak cladding temperature rises to just below the $350^{\circ} \mathrm{C}$ limit about 4 years 
after emplacement. If the packages are stored using the spacing specified in the Site Characterization Plan $(15 \mathrm{ft} \times$ $126 \mathrm{ft}$ ), a maximum of $4.1 \mathrm{~kW}$ per container may be stored. If the $0.05-\mathrm{m}$-thick void between the container and the borehole wall is filled with loosely packed bentonite, the peak cladding temperature rises more than $40^{\circ} \mathrm{C}$ above the allowed cladding limit. In all cases the dominant heat transfer mode between container components is thermal radiation.

160 (UCID-21756) Corrosion models for predictions of performance of high-level radioactive-waste containers. Farmer, J.C. (Lawrence Livermore National Lab., CA (United States)); McCright, R.D.; Gdowski, G.E. Lawrence Livermore National Lab., CA (United States). 1 Nov 1991. 41p. Sponsored by USDOE, Washington, DC (United States). DOE Contract W-7405-ENG-48. Order Number DE92004467. Source: OSTI; NTIS; INIS; GPO Dep.

The present plan for disposal of high-level radioactive waste in the US is to seal it in containers before emplacement in a geologic repository. A proposed site at Yucca Mountain, Nevada, is being evaluated for its suitability as a geologic repository. The containers will probably be made of either an austenitic or a copper-based alloy. Models of alloy degradation are being used to predict the long-term performance of the containers under repository conditions. The models are of uniform oxidation and corrosion, localized corrosion, and stress corrosion cracking, and are applicable to worst-case scenarios of container degradation. This paper reviews several of the models.

161 (UCID-21863) Cost estimate of high-level radioactive waste containers for the Yucca Mountain Site Characterization Project. Russell, E.W. (Lawrence Livermore National Lab., CA (United States)); Clarke, W.; Domian, H.A.; Madson, A.A. Lawrence Livermore National Lab., CA (United States). Aug 1991. 234p. Sponsored by USDOE, Washington, DC (United States). DOE Contract W7405-ENG-48. Order Number DE92004628. Source: OSTI; NTIS; INIS; GPO Dep.

Includes 4 sheets of microfice supplements.

This report summarizes the bottoms-up cost estimates for fabrication of high-level radioactive waste disposal containers based on the Site Characterization Plan Conceptual Design (SCP-CD). These estimates were acquired by Babcock and Wilcox (B\&S) under sub-contract to Lawrence Livermore National Laboratory (LLNL) for the Yucca Mountain Site Characterization Project (YMP). The estimates were obtained for two leading container candidate materials (Alloy 825 and CDA 715), and from other three vendors who were selected from a list of twenty solicited. Three types of container designs were analyzed that represent containers for spent fuel, and for vitrified high-level waste (HLW). The container internal structures were assumed to be AISI-304 stainless steel in all cases, with an annual production rate of 750 containers. Subjective techniques were used for estimating QAVQ costs based on vendor experience and the specifications derived for the LLNL-YMP Quality Assurance program. In addition, an independent QAVC analysis is reported which was prepared by Kasier Engineering. Based on the cost estimates developed. LLNL recommends that values of $\$ 825 \mathrm{~K}$ and $\$ 62 \mathrm{~K}$ be used for the 1991 TSLCC for the spent fuel and HLW containers, respectively. These numbers represent the most conservative among the three vendors, and are for the high-nickel anstenitic steel (Alioy 825). 6 rets., 7 figs.
162 (UCRL-101693) Prototype heater test of the environment around a simulated waste package. Ramirez, A.L.; Buscheck, T.A.; Carlson, R.; Daily, W.; Latorre, V.R.; Lee, K; Lin, Wunan, Mao, Nai-hsien; Towse, D.; Ueng, Tzou-Shin; Watwood, D. Lawrence Livermore $\mathrm{Na}$ tional Lab., CA (United States). [1991]. 12p. Sponsored by USDOE, Washington, DC (United States). DOE Contract W7405-ENG-48. Order Number DE92005396. Source: OSTI; NTIS; INIS; GPO Dep.

This paper presents selected results obtained during the 301 day duration of the Prototype Engineered Barrier System Field Test (PEBSFT) performed in G-Tunnel within the Nevada Test Site. The test described is a precursor to the Engineered Barrier Systems Fieid Tests (EBSFT) planned for the Exploratory Shaft Facility in Yucca Mountain. The EBSFT will consist of in situ tests of the geohydrologic and geochemical environment in the near field (within a few meters) of heaters emplaced in welded tuff to simulate the thermal effects of waste packages. The paper discusses the evolution of hydrothermal behavior during the prototype test, including rock temperatures, changes in rock moisture content, air permeability of fractures and gas-phase humidity in the heater borehole.

163 (UCRL-ID-105340) A scoping study of water table excursions induced by seismic and volcanic events. Carrigan, C.R. (Lawrence Livermore National Lab., CA (United States)); King, G.C.P.; Barr, G.E. Lawrence Livermore National Lab., CA (United States). Nov 1990. 62p. Sponsored by USDOE, Washington, DC (United States). DOE Contract W-7405-ENG-48. Order Number DE92012395. Source: OSTI; NTIS; GPO Dep.

We develop conservative models of water table response to displacements just beneath the water table simulating (1) shallow intrusion of a dike and (2) high level slip on a normal fault locked at the end. For matrix flow, we fine local water table excursions of under $10 \mathrm{~m}$. in cases of isotropic permeability which includes dike inflation of $4 \mathrm{~m}$ and fault slips corresponding to earthquakes having a moment magnitude of 7.4. Even for enhancements of vertical permeability up to $10^{4}: 1$, excursions did not exceed $15 \mathrm{~m}$ which implies that pumping is strongly volume limited. We also present an analysis of upward directed flow in cracks for the case of earthquake induced pore pressure changes. For matrix properties characteristic of the Calico Hills (vitric) formation and a crack distribution bounding the potential flow capacity of published data, we estimate an upper bound of 0.25 cu $m$. of ground water per $m$. of fault length as the amount capable of being pumped to a level $250 \mathrm{~m}$. above the normal water table. While the presence of even larger fractures than assumed might carry more ground water to that level an absolute upper limit of less than $50 \mathrm{cu}$. $\mathrm{m}$. per $\mathrm{m}$. of fault length is available to be pumped assuming a value $n=0.46$ for the rock porosity. For less porous rocks typical of the Topopah Spring or Tiva Canyon formations $(n \approx 0.10)$ the upper limit may be reduced to less than $10 \mathrm{cu}$. $m$. per $m$. of fault length. This upper limit depends only upon strain, the height of pumping above the water table and the formation porosity.

164 (UCRL-ID-107289) Estimating the time for dissolution of spent fuel exposed to unlimited water. Leider, H.R.; Nguyen, S.N.; Stout, R.B.; Weed, H.C. Lawrence Livermore National Lab., CA (United States). Dec 1991. 13p. Sponsored by USDOE, Washington, DC (United States). DOE Contract W-7405-ENG-48. Order Number DE92006660. Source: OSTI; NTIS; INIS; GPO Dep. 
The release of radionuclides from spent fuel cannot be precisely predicted at this point because a satisfactory dissolution model based on specific chemical processes is not yet available. However, preliminary results on the dissolution rate of $\mathrm{UO}_{2}$ and spent fuel as a function of temperature and water composition have recently been reported. This information, together with data on fragment size distribution of spent fuel, are used to estimate the dissolution response of spent fuel in excess flowing water within the framework of a simple model. In this model, the reaction/dissolution front advances linearly with time and geometry is preserved. This also estimates the dissolution rate of the bulk of the fission products and higher actinides, which are uniformly distributed in the $\mathrm{UO}_{2}$ matrix and are presumed to dissolve congruently. We have used a fuel fragment distribution actually observed to calculate the time for total dissolution of spent fuel. A worst-case estimate was also made using the initial (maximum) rate of dissolution to predict the total dissolution time. The time for total dissolution of centimeter size particles is estimated to be $5.5 \times 10^{4}$ years at $25^{\circ} \mathrm{C}$.

165 (UCRL-ID-108153) Physical limits on steam generation by radioactive decay heat. Chesnut, D.A. Lawrence Livermore National Lab., CA (United States). Dec 1991. 7p. Sponsored by USDOE, Washington, DC (United States). DOE Contract W-7405-ENG-48. Order Number DE92004468. Source: OSTI; NTIS; INIS; GPO Dep.

This report briefly discusses the possibilities that flood water contacting the hot radioactive waste and rock at Yucca Mountain could produce enough steam to lift the top of the mountain off the repository.

166 (UĊRL-ID-108330) Survey of degradation modes of four nickel-chromium-molybdenum alloys. Gdowski, G.E. (KMI Energy Services, Livermore, CA (United States)). Lawrence Livermore National Lab., CA (United States). Mar 1991. 67p. Sponsored by USDOE, Washington, DC (United States). DOE Contract W-7405-ENG-48. Order Number DE92004469. Source: OSTI; NTIS; INIS; GPO Dep.

This report examines the degradation modes of four $\mathrm{Ni}$ $\mathrm{Cr}-\mathrm{Mo}$ alloys under conditions relevant to the Yucca Mountain Site Characterization Project (YMP). The materials considered are Alloys $\mathrm{C}-276, \mathrm{C}-4, \mathrm{C}-22$, and 625 because they have desirable characteristics for the conceptual design (CD) of the high-level radioactive-waste containers presented in the YMP Site Characterization Plan (SCP). The types of degradation covered in this report are general corrosion; localized corrosion, including pitting and crevice corrosion; stress corrosion cracking in chloride environments; hydrogen embrittlement (HE); and undesirable phase transformations due to a lack of phase stability. Topics not specifically addressed are welding concerns and microbiological corrosion. The four $\mathrm{Ni}-\mathrm{Cr}$-Mo alloys have excellent corrosion resistance in chloride environments such as seawater as well as in more aggressive environments. They have significantly better corrosion resistance than the six materials considered for the CD waste container in the YMP SCP. (Those six materials are Types $304 \mathrm{~L}$ and $3161 \mathrm{~L}$ stainless steels, Alloy 825 , unalloyed copper, $\mathrm{Cu}(70)-\mathrm{Ni}(30)$, and $7 \%$ aluminum bronze.) In seawater, the $\mathrm{Ni}$-Cr-Mo alloys have negligible general corrosion rates and show little evidence of localized corrosion. The four base materials of these alloys are expected to have nearly indistinguishable corrosion resistance in the YMP environments. The strength requirements of the SCP-CD waste container are met by these materials in the annealed condition; in this condition, they are highly resistant to HE. Historically, $\mathrm{HE}$ has been noted when these materials have been strengthened (coldworked) and used in sour gas $\left(\mathrm{H}_{2} \mathrm{~S}\right.$ and $\left.\mathrm{CO}_{2}\right)$ well service conditions that are not expected for the YMP. Metallurgical phase stability may be a concern under conditions favoring (1) the formation of intermetallics and carbides, and (2) microstructural ordering.

167 (UCRL-ID-109215) Diffusion releases through one and two finite planar zones from a nuclear waste package. Ueng, Tzou-Shin; O'Connell, W.J. Lawrence Livermore National Lab., CA (United States). Jul 1992. 22p. Sponsored by USDOE, Washington, DC (United States). DOE Contract W-7405-ENG-48. Order Number DE92016744. Source: OSTI; NTIS; INIS; GPO Dep.

For a radioactive waste package emplacement in a potential repository, a partially saturated rock rubble zone may act more as a diffusive barrier than as a pathway to release. We approximate the diffusive transport from the waste packaging using one-dimensional one- and two-barrier geometries. When the effective diffusion coefficient in the first zone is several orders of magnitude lower than that in the host rock, then the two-zone geometry can be approximately by a onezone problem, keeping only the narrow rubble zone. When the effective diffusion coefficients in the two zones are comparable, or there is an additional barrier, then a two-zone (both of finite extent) approach is adopted. We present solutions for the diffusion response in the two planar geometries for three input cases: a pulse transient input, a steady input rate, and a constant concentration at the source. The solutions have algebraic key elements allowing identification of sensitive factors. For the one-zone case, dimensionless parameters allow plotting of the family of transient response solutions on a single graph. Comparisons with several problems analyzed by others, and on problems where the one-zone and two-zone analyses should give comparable results, support verification of the method.

168 (UCRL-ID-109921) Modeling fluid-rock interaction at Yucca Mountain, Nevada: A progress report, April 15, 1992. Viani, B.E.; Bruton, C.J. Lawrence Livermore National Lab., CA (United States). Aug 1992. 72p. Sponsored by USDOE, Washington, DC (United States). DOE Contract W-7405-ENG-48. Order Number DE92041080. Source: OSTI; NTIS; INIS; GPO Dep.

Volcanic rocks at Yucca Mountain, Nevada aie being assessed for their suitability as a potential repository for high-level nuclear waste. Recent progress in modeling fluidrock interactions, in particular the mineralogical and chemical changes that may accompany waste disposal at Yucca Mountain, will be reviewed in this publication. In Part 1 of this publication, "Geochemical Modeling of ClinoptiloliteWater Interactions," solid-solution and cation-exchange models for the zeolite clinoptilolite are developed and compared to experimental and field observations. At Yucca Mountain, clinoptilolite which is found lining fractures and as a major component of zeolitized tuffs, is expected to play an important role in sequestering radionuclides that may escape from a potential nuclear waste repository. The solidsolution and ion-exchange models were evaluated by comparing predicted stabilities and exchangeable cation distributions of clinoptilolites with: (1) published binary exchange data; (2) compositions of coexisting clinoptilolites and formation waters at Yucca Mountain; (3) experimental sorption isotherms of $\mathrm{Cs}$ and $\mathrm{Sr}$ on zeolitized tuff, and (4) high temperature experimental data. Good agreement was found between predictions and expertmental data, especially for binary exchange and $\mathrm{Cs}$ and $\mathrm{Sr}$ sorption on clinoptilolite. 
Part 2 of this publication, "Geochemical Simulation of FluidRock Interactions at Yucca Mountain," describes preliminary numerical simulations of fluid-rock interactions at Yucca Mountain. The solid-solution model developed in the first part of the paper is used to evaluate the stability and composition of clinciptilolite and other minerals in the host rock under ambient conditions and after waste emplacement.

169 (UCRL-ID-111624) Modeling pitting corrosion damage of high-level radioactive-waste containers, with emphasis on the stochastic approach. Henshall, G.A.; Halsey, W.G.; Clarke, W.L.; McCright, R.D. Lawrence Livermore National Lab., CA (United States). Jan 1993. 64p. Sponsored by USDOE, Washington, DC (United States). DOE Contract W-7405-ENG-48. Order Number DE93007743. Source: OSTI; NTIS; INIS; GPO Dep.

Recent efforts to identify methods of modeling pitting corrosion damage of high-level radioactive-waste containers are described. The need to develop models that can provide information useful to higher level system performance assessment models is emphasized, and examples of how this could be accomplished are described. Work to date has focused upon physically-based phenomenological stochastic models of pit initiation and growth. These models may provide a way to distill information from mechanistic theories in a way that provides the necessary information to the less detailed performance assessment models. Monte Carlo implementations of the stochastic theory have resulted in simulations that are, at least qualitatively, consistent with a wide variety of experimental data. The effects of environment on pitting corrosion have been included in the model using a set of simple phenomenological equations relating the parameters of the stochastic model to key environmental variables. The results suggest that stochastic models might be useful for extrapolating accelerated test data and for predicting the effects of changes in the environment on pit initiation and growth. Preliminary ideas for integrating pitting. models with performance assessment models are discussed. These ideas include improving the concept of container "failure", and the use of "rules-of-thumb" to take information from the detailed process models and provide it to the higher level system and subsystem models. Finally, directions for future work are described, with emphasis on additional experimental work since it is an integral part of the modeling process.

170 (UCRL-ID-111979) Post-closure performance assessment of waste packages for the Yucca Mountain Project. O'Connell, W.J.; Ueng, T.S.; Lewis, L.C. Lawrence Livermore National Lab., CA (United States). Oct 1993. 93p. Sponsored by USDOE, Washington, DC (United States). DOE Contract W-7405-ENG-48. Order Number DE93041100. Source: OSTI; NTIS; INIS; GPO Dep.

This report details a system model of some core features of the performance of waste packages for the permanent disposal of spent nuclear fuel at the Yucca Mountain Site. The model is realized in the prototype computer program PANDORA-1.1. The PANDORA system model links processes leading to possible release of radionuclides from the waste package. The PANDORA submodels are being developed for processes and conditions specific to this potential repository site, notably the comparatively dry location in an arid area and well above the groundwater table, and the rock medium of porous partially welded tuff.

171 (UCRL-ID-112036) Scientific investigation plan for initial engineered barrier system field tests. Wunan
Lin. Lawrence Livermore National Lab., CA (United States). Feb 1993. 37p. Sponsored by USDOE, Washington, DC (United States). DOE Contract W-7405-ENG-48. Order Number DE93008756. Source: OSTI; NTIS; INIS; GPO Dep.

The purpose of this Scientific Investigation Plan (SIP) is to describe tests known as Initial Engineered Barrier System Field Tests (IEBSFT) and identified by Work Breakdown Structure as WBS 1.2.2.2.4. The IEBSFT are precursors to the Engineered Barrier System Field Test (EBSFT), WBS 1.2.2.2.4, to be conducted in the Exploratory Study Facility (ESF) at Yucca Mountain. The EBSFT and IEBSFT are designed to provide information on the interaction between waste packages (simulated by heated containers) and the surrounding rock mass, its vadose water, and infiltrated water. Heater assemblies will be installed in drifts or boreholes openings and heated to measure moisture movement during heat-up and subsequent cool-down of the rock mass. In some of the tests, infiltration of water into the heated rock mass will be studied. Throughout the heating and cooling cycle, instruments installed in the rock will monitor such parameters as temperature, moisture content, concentration of some chemical species, and stress and strain. Rock permeability measurements, rock and fluid (water and gas) sampling, and fracture pattern measurements will also be made before and after the test.

172 (UCRL-ID-112058) Selection of candidate container materials for the conceptual waste package design for a potential high level nuclear waste repository at Yucca Mountain. Van Konynenburg, R.A. (Lawrence Livermore National Lab., CA (United States)); Halsey, W.G.; McCright, R.D.; Clarke, W.L. Jr.; Gdowski, G.E. Lawrence Livermore National Lab., CA (United States). Feb 1993. 135p. Sponsored by USDOE, Washington, DC (United States). DOE Contract W-7405-ENG-48. Order Number DE93008757. Source: OSTI; NTIS; INIS; GPO Dep.

Preliminary selection criteria have been developed, peerreviewed, and applied to a field of 41 candidate materials to choose three alloys for further consideration during the advanced conceptual design phase of waste package development for a potential high level nuclear waste repository at Yucca Mountain, Nevada. These three alloys are titanium grade 12, Alloy $\mathrm{C}-4$, and Alloy 825 . These selections are specific to the particular conceptual design outlined in the Site Characterization Plan. Other design concepts that may be considered in the advanced conceptual design phase may favor other materials choices.

173 (UCRL-ID-112432) Technical basis and programmatic requirements for laboratory study of hydrological properties of the near-field environment. Lin, W. Lawrence Livermore National Lab., CA (United States). Oct 1993. 50p. Sponsored by USDOE, Washington, DC (United States). DOE Contract W-7405-ENG-48. Order Number DE94001854. Source: OSTI; NTIS; INIS; GPO Dep.

This document contains the technical basis and programmatic requirements for a study plant governs laboratory study of hydrological properties of the near-field environment of a nuclear waste repository. The Study Plan (SP), known as "Near-Field Environment Hydrological Properties (NFEHP)," will be reviewed by Yucca Mountain Site Characterization Project Office (YMPO) of the United States Department of Energy (DOE). The final version of the SP may be different from this document. The SP is identified by Work Breakdown Structure (WBS) as WBS 1.2.2.2.2. This study is described in Section 8.3.4.2.4.1 of the Site Characterization Plant (SCP). The purpose and objective of the 
Near-Field Environment Hydrological Properties study are to understand, at the laboratory scale, hydrological processes expected to occur within the near field of nuclear waste repository after waste package emplacement.

174 (UCRL-ID-112433) Technical basis and programmatic requirements for Engineered Barrier System Field Tests. Lin, Wunan. Lawrence Livermore National Lab., CA (United States). Nov 1992. 38p. Sponsored by USDOE, Washington, DC (United States). DOE Contract W-7405ENG-48. Order Number DE93017958. Source: OSTI; NTIS; INIS; GPO Dep.

The purpose of this study plant is to describe tests known as Engineered Barrier System Field Tests (EBSFT), which are to be conducted in the Exploratory Study Facility (ESF) at Yucca Mountain, Nevada. The EBSFT is designed to provide information on the interaction between waste packages (simulated by heated containers), the surrounding rock mass, and its vadose water. The Yucca Mountain site is being characterized to determine its suitability as a potential deep geological repository for high-level nuclear waste. Water is the main medium by which radioactive nuclides travel to the accessible environment. Therefore, the movement of water over the approximate 10,000-year lifetime required for radioactive nuclide decay must be understood. Development of a repository and emplacement of nuclear wastes impose stress loadings on the repository rock mass. The stress loadings include (1) thermal energy and irradiation from the waste packages, and (2) mechanical stress due to the mining of openings, and the transporting of waste canisters. The influence $f$ the thermal stress may extend to all lithological units, including the saturated zone under the ground water table, in Yucca Mountain. In general, the purpose of this study is to investigate the movement of water in the rock mass under the influence of the thermal loading of the waste packages. Specifically, the study will investigate heat flow mechanism, relationship between boiling and dry-out, and the rewetting of the dry-out region when the repository is cooled down.

175 (UCRL-ID-112834) Technical basis and programmatic requirements for large block testing of coupled thermal-mechanical-hydrological-chemical processes. Lin, Wunan. Lawrence Livermore National Lab., CA (United States). Sep 1993. 41p. Sponsored by USDOE, Washington, DC (United States). DOE Contract W-7405ENG-48. Order Number DE93040441. Source: OSTI; INIS; NTIS; GPO Dep.

This document contains the technical basis and programmatic requirements for a scientific investigation plan that governs tests on a large block of tuff for understanding the coupled thermal- mechanical-hydrological-chemical processes. This study is part of the field testing described in Section 8.3.4.2.4.4.1 of the Site Characterization Plan (SCP) for the Yucca Mountain Project. The first, and most important objective is to understand the coupled TMHC processes in order to develop models that will predict the performance of a nuclear waste repository. The block and fracture properties (including hydrology and geochemistry) can be well characterized from at least five exposed surfaces, and the block can be dismantled for post-test examinations. The second objective is to provide preliminary data for development of models that will predict the quality and quantity of water in the near-field environment of a repository over the current 10,000 year regulatory period of radioactive decay. The third objective is to develop and evaluate the various measurement systems and techniques that will later be employed in the Engineered Barrier System Field Tests (EBSFT).

176 (UCRL-ID-113383) Chemical and mineralogical concerns for the use of man-made materials in the postemplacement environment. Meike, A. Lawrence Livermore National Lab., CA (United States). 16 Jan 1993. 12p. Sponsored by USDOE, Washington, DC (United States). DOE Contract W-7405-ENG-48. Order Number DE93019212. Source: OSTI; NTIS; INIS; GPO Dep.

In a radioactive waste repository, materials will be introduced for a variety of reasons. Some materials such as metals, bonding agents, and concrete will serve as active parts of the designed engineered barrier system (EBS). Other materials will be introduced to serve a number of purposes that include any or all of the following: surveillance (thermocouples, gauges), construction and operation (drilling rigs, roadbeds, exhaust fumes, chemical toilets, concrete, grout, rebar), lubrication (petroleum-based products, rope dressing) and other functions. Water chemistry will directly affect the corrosion of containers, the dissolution of spent fuel and waste glass and the concentration of dissolved or suspended radionuclides in water that exits breached containers. To predict the water quality requires a knowledge of the dissolution kinetics of the phases present in man-made materials, and the precipitation kinetics of product phases. The chemical evolution of man-made materials of interest to the Yucca Mountain project are by and large not presently known. Prediction of the long-term behavior $(10,000$ years) required of the modeling efforts is an additional layer of complexity that is not addressed by current models of water chemistry. Man-made modifications to the environment may significantly alter the thermal, chemical and radionuclide transportation attributes of the natural environment that are presently being considered in order to determine a waste package design. The specific chemical concerns addressed here are: solubility and stability of solid phases; liquid and gas phase stability; long term effects; radiolysis effects; colloids; and interactions between manmade material, rock, and $\mathrm{J}-13$ or concentrated J-13 water. The report concludes with recommendations.

177

(UCRL-ID-114148) Rationale for determining MCC spent fuel acquisitions. Marschman, S.C. (Pacific Northwest Lab., Richland, WA (United States)); Einziger, R.E.; Stout, R.B. Lawrence Livermore National Lab., CA (United States). Jun 1993. 16p. Sponsored by USDOE, Washington, DC (United States). DOE Contract W-7405ENG-48. Order Number DE94000351. Source: OSTI; NTIS; INIS; GPO Dep.

The Yucca Mountain Site Characterization Project of the US Department of Energy (DOE) is investigating the suitability of the Topopah Spring Tuff at Yucca Mountain, Nevada, for use as a disposal site for spent nuclear fuel and other high-level waste forms. The performance of the high-level waste forms and the engineered barrier system at the site must be shown to comply with the requirements in $10 \mathrm{CFR}$ 60. Lawrence Livermore National Laboratory (LLNL) has the responsibility for determining the performance of the US commercial reactor spent nuclear fuels under potential repository conditions. Pacific Northwest Laboratory (PNL) performs testing of these highly radioactive materials in support of the LLNL program. This report summarizes the rationale for selecting additional spent fuels that should be acquired to support the LLNL and PNL testing programs. 
These programs have identified specific attributes that may affect spent fuel behavior in a repository.

178 (UCRL-JC-106693) Temperature measurements from a horizontal heater test in G-Tunnel. Lin, Wunan; Ramirez, A.L.; Watwood, D. Lawrence Livermore National Lab., CA (United States). Oct 1991. 19p. Sponsored by USDOE, Washington, DC (United States). DOE Contract W-7405-ENG-48. (CONF-910945-14: Focus '91: nuclear waste packaging, Las Vegas, NV (United States), 29 Sep - 4 oct 1991). Order Number DE92014889. Source: OSTI; NTIS; INIS; GPO Dep.

A horizontal heater test was conducted in G-Tunnel, Nevada Test Site, to study the hydrothermal response of the rock mass due to a thermal loading. The results of the temperature measurements are reported here. The measured temperatures agree well with a scoping calculation that was performed using a model which investigates the transport of water, vapor, air, and heat in fractured porous media. Our results indicate that the temperature field might be affected by the initial moisture content of the rock, the fractures in the rock, the distance from the free surface of the alcove wall, and the temperature distribution on the heater surface. Higher initial moisture content, higher fracture density, and cooling from the alcove wall tend to decrease the measured temperature. The temperature on top of the horizontal heater can was about $30^{\circ} \mathrm{C}$ greater than at the bottom throughout most of the heating phase, causing the rock temperatures above the heater to be greater than those below. Along a radius from the center of the heater, the heating created a dry zone, followed by a boiling zone and condensation zone. Gravity drainage of the condensed water in the condensation zone had a strong effect on the boiling process in the test region. The temperatures below and to the side of the heater indicated a region receiving liquid drainage from an overlying region of condensation. We verified that a thermocouple in a thin-wall tubing measures the same temperature as one grouted in a borehole.

179 (UCRL-JC-106703) Field air injection tests to determine the effect of a heat cycle on the permeability of welded tuff. Lee, K.H.; Ueng, Tzou-Shin. Lawrence Livermore National Lab., CA (United States). Oct 1991. 15p. Sponsored by USDOE, Washington, DC (United States). DOE Contract W-7405-ENG-48. (CONF-910945-13: Focus '91: nuclear waste packaging, Las Vegas, NV (United States), 29 Sep - 4 oct 1991). Order Number DE92014888. Source: OSTI; NTIS; INIS; GPO Dep.

As part of a series of prototype tests conducted in preparation for site characterization at Yucca Mountain, air-injection tests were conducted in the welded tuffs in G-Tunnel at the Nevada Test Site. The objectives were to characterize the permeability of the highly fractured tuff around a horizontal heater emplacement borehole, and to determine the effect of a heating and cooling cycle on the rock-mass permeability. Air was injected into packed-off intervals along the heater borehole. The bulk permeability of the rock adjacent to the test interval was computed from the air-flow rate, temperature, and pressure at steady state. The permeability varied from a minimum of $0.08 \mathrm{D}$ to a maximum of over 144 D. Higher permeabilities seemed to correlate spatially with the mapped fractures. The rock was then heated for a period of 6.5 months with an electrical-resistive heater installed in the borehole. After heating, the rock was allowed to cool down to the ambient temperature. the highest borehole wall temperature measured was $242^{\circ} \mathrm{C}$. Air injection tests were repeated following the heating and cooling cycle, and the results showed significant increases in bulk permeability ranging from 10 to $1830 \%$ along the borehole.

180 (UCRL-JC-106752) Thermocouple psychrometer measurements of in situ water potential changes in heated welded tuff. Mao, Nai-hsien (Lawrence Livermore National Lab., CA (United States)); Wang, H.F. Lawrence Livermore National Lab., CA (United States). Oct 1991. 21 p. Sponsored by USDOE, Washington, DC (United States). DOE Contract W-7405-ENG-48. (CONF-910945-11: Focus '91: nuclear waste packaging, Las Vegas, NV (United States), 29 Sep - 4 oct 1991). Order Number DE92014884. Source: OSTI; NTIS; INIS; GPO Dep.

Ten thermocouple psychrometers (TCPs) to measure water potential (WP) were installed in three holes in G-Tunnel at the Nevada Test Site as part of the Prototype Engineered Barrier System Field Tests. We calibrated the TCPs in $\mathrm{NaCl}$ solutions up to $80^{\circ} \mathrm{C}\left(176^{\circ} \mathrm{F}\right)$ in the laboratory. In two holes, we used rubber sleeves and packers to house TCPs, and in the third hole, we used foam. All three holes were grouted behind the TCP assemblages. The initial moisture condition indicated by TCP data was about $99.5 \%$ relative humidity or a WP of about -5 bar. This corresponded to $15.4 \mathrm{~g} / \mathrm{m}^{3}$ of water in the air near the borehole wall, which was much wetter than we expected. A drying and re-wetting cycle peaked at about day 140 with a WP of -65 bar in borehole P3, located below the heater. A similar cycle but reduced in scale was found at about day 175 with a WP of -45 bar in borehole $\mathbf{P 2}$, above the heater. This difference is drying behavior above and below the heater was also observed from neutron data and was explained as a gravity effect.

181 (UCRL-JC-106758) Demands placed on waste package performance testing and modeling by some general results on reliability analysis. Chesnut, D.A. Lawrence Livermore National Lab., CA (United States). Sep 1991. 10p. Sponsored by USDOE, Washington, DC (United States). DOE Contract W-7405-ENG-48. (CONF-91094515: Focus '91: nuclear waste packaging, Las Vegas, NV (United States), 29 Sep - 4 oct 1991). Order Number DE92016156. Source: OSTI; NTIS; INIS; GPO Dep.

Waste packages for a US nuclear waste repository are required to provide reasonable assurance of maintaining substantially complete containment of radionuclides for 300 to 1000 years after closure. The waiting time to failure for complex failure processes affecting engineered or manufactured systems is often found to be an exponentiallydistributed random variable. Assuming that this simple distribution can be used to describe the behavior of a hypothetical single barrier waste package, calculations presented in this paper show that the mean time to failure (the only parameter needed to completely specify an exponential distribution) would have to be more than 107 years in order to provide reasonable assurance of meeting this requirement. With two independent barriers, each would need to have a mean time to failure of only $10^{5}$ years to provide the same reliability. Other examples illustrate how multiple barriers can provide a strategy for not only achieving but demonstrating regulatory compliance.

182 (UCRL-JC-106759) The Impact of episodic nonequilibrium fracture-matrix flow on geological repository performance. Buscheck, T.A.; Nitao, J.J.; Chestnut, D.A. Lawrence Livermore National Lab., CA (United States). 29 Oct 1991. 12p. Sponsored by USDOE, Washington, DC 
(United States). DOE Contract W-7405-ENG-48. (CONF910945-5: Focus '91: nuclear waste packaging, Las Vegas, NV (United States), 29 Sep - 4 oct 1991). Order Number DE92004673. Source: OSTI; NTIS; INIS; GPO Dep.

Adequate representation of fracture-matrix interaction during episodic infiltration events is crucial in making valid hydrological predictions of repository performance at Yucca Mountain. Various approximations have been applied to represent fracture-matrix flow interaction, including the Equivalent Continuum Model (ECM), which assumes capillary equilibrium between fractures and matrix, and the Fracture-Matrix Model (FMM), which accounts for nonequilibrium fracture-matrix flow. We analyze the relative impact of matrix imbibition on episodic nonequilibrium fracturematrix flow for the eight major hydrostratigraphic units in the unsaturated zone at Yucca Mountain. Comparisons are made between ECM and FMM predictions to determine the applicability of the ECM. The implications of nonequilibrium fracture-matrix flow on radionuclide transport are also discussed.

183 (UCRL-JC-106916) Engineered barrier system and waste package design concepts for a potential geologic repository at Yucca Mountain. Short, D.W.; Ruffner, D.J.; Jardine, L.J. Lawrence Livermore National Lab., CA (United States). Oct 1991. 13p. Sponsored by USDOE, Washington, DC (United States). DOE Contract W-7405ENG-48. (CONF-910945-4: Focus '91: nuclear waste packaging, Las Vegas, NV (United States), 29 Sep - 4 oct 1991). Order Number DE92004657. Source: OSTI; NTIS; INIS; GPO Dep.

We are using an iterative process to develop preliminary concept descriptions for the Engineered Barrier System and waste-package components for the potential geologic repository at Yucca Mountain. The process allows multiple design concepts to be developed subject to major constraints, requirements, and assumptions. Involved in the highly interactive and interdependent steps of the process are technical specialists in engineering, metallic and nonmetallic materials, chemistry, geomechanics, hydrology, and geochemistry. We have developed preliminary design concepts that satisfy both technical and nontechnical (e.g., programmatic or policy) requirements.

184 (UCRL-JC-106918) A preliminary guidebook for identifying stratigraphic contacts at the Nevada Test Site. Pawloski, G.A. (Lawrence Livermore National Lab., CA (United States)); McKague, H.L.; Wagoner, J.L.; McKinnis, W.B. Lawrence Livermore National Lab., CA (United States). Jan 1992. 24p. Sponsored by USDOE, Washington, DC (United States). DOE Contract W-7405-ENG-48. (CONF-9109114-10: 6. symposium on containment of underground nuclear explosions, Reno, NV (United States), 24-26 Sep 1991). Order Number DE92008074. Source: OSTI; NTIS; INIS; GPO Dep.

Lithologic variation, regional depositional trends, and the lack of written guidelines have resulted in inconsistencies in the recognition of stratigraphic contacts in drill holes at the Nevada Test.Site (NTS). Stratigraphic identification, based on mineralogy of discrete samples, can be augmented by geophysical logs and downhole movies to more accurately and consistently locate contacts between units. Criteria are established for locating the base of the Pahute Mesa ashflow tuff, the top of the Ammonia Tanks ash-flow tuff, the top of the Ammonia Tanks bedded tuff, and the top and the base of the Rainier Mesa Tuff.
185 (UCRL-JC-107920) The impact of episodic nonequilibrium fracture-matrix flow on repository performance at the potential Yucca Mountain site. Buscheck, T.A.; Nitao, J.J.; Chesnut, D.A. Lawrence Livermore National Lab., CA (United States). Nov 1991. 12p. Sponsored by USDOE, Washington, DC (United States). DOE Contract W-7405-ENG-48. (CONF-911109-4: Fall meeting of the European Materials Research Society (EMRS), Strasbourg (France), 5-8 Nov 1991). Order Number DE92002764. Source: OSTI; NTIS; INIS; GPO Dep.

Adequate representation of fracture-matrix interaction during episodic infiltration events is crucial in making valid hydrological predictions of repository performance at Yucca Mountain. Approximations have been applied to represent fracture-matrix flow interaction, including the Equivalent Continuum Model, which assumes capillary equilibrium between fractures and matrix, and the Fracture-Matrix Model, which accounts for nonequilibrium fracture-matrix flow and transport for the eight major hydrostratigraphic units in the unsaturated zone at Yucca Mountain. 18 refs., 6 figs., 3 tabs.

186 (UCRL-JC-107985) Fabrication and closure development of nuclear waste disposal containers for the Yucca Mountain Project: Status report. Domian, H.A. (Babcock and Wilcox Co., Alliance, OH (United States)); Robitz, E.S.; Conrardy, C.C.; LaCount, D.F.; McAninch, M.D.; Fish, R.L.; Russell, E.W. Lawrence Livermore National Lab., CA (United States). Sep 1991. 11p. Sponsored by USDOE, Washington, DC (United States). DOE Contract W-7405ENG-48. (CONF-910945-16: Focus '91: nuclear waste packaging, Las Vegas, NV (United States), 29 Sep - 4 oct 1991). Order Number DE93007507. Source: OSTI; NTIS; INIS; GPO Dep.

In GFY 89, a project was undenway to determine and demonstrate a suitable method for fabricating thin-walled monolithic waste containers for service within the potential repository at Yucca Mountain. A concurrent project was undenway to determine and. demonstrate a suitable closure process for these containers after they have been filled with high-level nuclear waste. Phase 1 for both the fabrication and closure projects was a screening phase in which candidate processes were selected for further laboratory testing in Phase 2. This report describes the final results of the Phase 1 efforts. It also describes the preliminary results of Phase 2 efforts.

187 (UCRL-JC-109216) The implications of episodic nonequilibrium fracture-matrix flow on site suitability and total system performance. Nitao, J.J.; Buscheck, T.A.; Chesnut, D.A. Lawrence Livermore National Lab., CA (United States). Apr 1992. 26p. Sponsored by USDOE, Washington, DC (United States). DOE Contract W7405-ENG-48. (CONF-920430-95: 3. international high level radioactive waste management (IHLRWM) conference, Las Vegas, NV (United States), 12-16 Apr 1992). Order Number DE92014807. Source: OSTI; NTIS; INIS; GPO Dep.

We apply our work on fracture- and matrix-dominated flow to develop a conceptual model of hydrological flow processes in the unsaturated zone at Yucca Mountain. The possibility of fracture-dominated flow is discussed, and various deductions are made on its impact on natural and total system performance, site characterization activities, and site suitability determination. zone at Yucca Mountain: The beginning of a testing 
strategy. Chesnut, D.A. Lawrence Livermore National Lab., CA (United States). 8 Jan 1992. 15p. Sponsored by USDOE, Washington, DC (United States). DOE Contract W-7405ENG-48. (CONF-920430-67: 3. international high level radioactive waste management (IHLRWM) conference, Las Vegas, NV (United States), 12-16 Apr 1992). Order Number DE92008930. Source: OSTI; NTIS; INIS; GPO Dep.

The concept of a disturbed zone surrounding the mined openings of a potential geologic repository for high-level radioactive waste was introduced by the US Nuclear Regulatory Commission (NRC) as a region to be excluded for determining groundwater travel time to the accessible environment, but to be included for determining the impact of underground construction and radioactive decay heat on groundwater movement and radionuclide transport for total system performance analysis. This paper explores both the regulatory and technical necessity for characterizing and modeling a larger region - the altered zone - within which the temperature is increased significantly by heat from the high-level waste. Particular attention is given to addressing the effects of heterogeneity on groundwater flux and travel time, showing how these effects might be modeled simply on a macroscopic scale, and outlining its parameters. The effect of uncertainty in the parameter values on the performance of a potential repository can then be easily handled by probabilistic analysis.

189 (UCRL-JC-109232) The impact of thermal loading on repository performance at Yucca Mountain. Buscheck, T.A.; Nitao, J.J. Lawrence Livermore National Lab., CA (United States). 15 Jan 1992. 15p. Sponsored by USDOE, Washington, DC (United States). DOE Contract W7405-ENG-48. (CONF-920430-60: 3. international high level radioactive waste management (IHLRWM) conference, Las Vegas, NV (United States), 12-16 Apr 1992). Order Number DE92008080. Source: OSTI; NTIS; INIS; GPO Dep.

In the unsaturated zone at Yucca Mountain, liquid flow along preferential fracture pathways is the only credible mechanism capable of bringing water to waste packages and transporting radionuclide to the water table. Three categories of features or mechanisms will mitigate the impact of flow along preferential fracture pathways: (1) discontinuity in fracture pathways, (2) liquid-phase dispersion in fracture networks, and (3) fracture-matrix interaction. For repository areal power densities (APDs) that are too low to result in significant boiling or rock dry-out effects, the primary mode of fracture-matrix interaction is matrix imbibition. For high APDs, boiling and enhanced matrix imbibition due to rock dry-out significantly add to the capacity of the unsaturated zone to retard fracture-dominated flow. With the use of $\mathrm{V}$ TOUGH code, hydrothermal flow calculations are made for a range of APDs and spent fuel ages. For APD $>20 \mathrm{~kW} / \mathrm{acre}$, repository-heat-generated flow of vapor and liquid in fractures is found to dominate the ambient hydrological system. For high APDs, boiling conditions can persist for $10,000 \mathrm{yr}$ or longer and rock-dry benefits for at least 100,000 yr.

190 (UCRL-JC-109952) Modeling ion exchange in clinoptilolite using the EQ3/6 geochemical modeling code. Viani, B.E.; Bruton, C.J. Lawrence Livermore National Lab., CA (United States). Jun 1992. 5p. Sponsored by USDOE, Washington, DC (United States). DOE Contract W7405-ENG-48. (CONF-920761-14: 7. water-rock interaction conference, Park City, UT (United States), 9-23 Jul 1992). Order Number DE92017439. Source: OSTI; NTIS; INIS; GPO Dep.
Assessing the suitability of Yucca Mtn., NV as a potential repository for high-level nuclear waste requires the means to simulate ion-exchange behavior of zeolites. Vanselow and Gapon convention cation-exchange models have been added to geochemical modeling codes EQ3NR/EQ6, allowing exchange to be modeled for up to three exchangers or a single exchanger with three independent sites. Solidsolution models that are numerically equivalent to the ion-exchange models were derived and also implemented in the code. The Gapon model is inconsistent with experimental adsorption isotherms of trace components in clinoptilolite. $A$ one-site Vanselow model can describe adsorption of $C_{s}$ or Sr on clinoptilolite, but a two-site Vanselow exchange model is necessary to describe $\mathrm{K}$ contents of natural clinoptilolites.

191 (UCRL-JC-110677) Engineered barrier environment, Yucca Mountain. Wilder, D.G. Lawrence Livermore National Lab., CA (United States). Feb 1993. 7p. Sponsored by USDOE, Washington, DC (United States). DOE Contract W-7405-ENG-48. (CONF-930601-6: American Nuclear Society (ANS) annual meeting, San Diego, CA (United States), 20-24 Jun 1993). Order Number DE93009070. Source: OSTI; NTIS; INIS; GPO Dep.

The US Department of Energy is studying the suitability of Yucca Mountain (YM) as a potential nuclear waste repository site. Environmental conditions are important to engineered barrier system (EBS) design, materials testing, selection, design criteria, waste-form characterization, and performance assessment. Yucca Mountain is located in uninhabited desert which results in an environmental framework (unsaturated conditions, and sorptive properties of the rock materials) that is generally favorable for waste disposal. However, waste package (WP) and engineered barrier system (EBS) design concepts, including materials testing and selection, design criteria development, waste-form characterization, and performance assessments all require a specific and detailed understanding of the environmental conditions that will interact with the WP/EBS. Environmental conditions assessments from a series of laboratory and modeling studies have been conducted which provide the current understanding of the near-field environmental conditions at $Y M$ that not only exist now but will exist in the future. Because the environmental conditions can change with time, emphasis of the investigations were on processes and changed (not ambient) conditions.

192 (UCRL-JC-111652) Alternative strategies: A means for saving money and time on the Yucca Mountain Project. Wilder, D.G. Lawrence Livermore National Lab., CA (United States). Jan 1993. 15p. Sponsored by USDOE, Washington, DC (United States). DOE Contract W7405-ENG-48. (CONF-930408-25: International high-level radioactive waste management conference, Las Vegas, NV (United States), 25-29 Apr 1993). Order Number DE93008021. Source: OSTI; NTIS; INIS; GPO Dep.

The United States Department of Energy (DOE) is undertaking studies to determine the suitability of Yucca Mountain (YM) as a potential site for disposal of high level nuclear waste. Yucca Mountain is located in an arid environment. Many processes that could contribute to mobilization of radionuclides are either absent or minimized in a dry site. Therefore, Yucca Mountain should have the potential of being a veryfavorable site for disposal of waste. The determination of suitability has no precedence, and the characterization of an and site is complex, requiring intensive studies to determine suitability. The studies undertaken by the Yucca Mountain Site Characterization Project (YMP) 
are very costly. By a process called performance allocation, the YMP determined strategies to satisfy regulations or meet performance while minimizing costs and schedules. Those involved recognized that allocations should be reviewed as additional information became available. The allocation has not been reviewed nor revised since the initial allocation in the Site Characterization Plan (SCP). The purpose of this paper is to outline alternative allocations that the author feels should be considered based on the additional information that is available at this time.

193 (UCRL-JC-112435) Drift emplaced waste package thermal response. Ruffner, D.J. (Lawrence Livermore National Lab., CA (United States)); Johnson, G.L.; Platt, E.A.; Blink, J.A.; Doering, T.W. Lawrence Livermore National Lab., CA (United States). Jan 1993. 17p. Sponsored by USDOE, Washington, DC (United States). DOE Contract W-7405-ENG-48. Order Number DE93008020. Source: OSTI; NTIS; INIS; GPO Dep.

Thermal calculations of the effects of radioactive waste decay heat on the I repository at Yucca Mountain, Nevada have been conducted by the Yucca Mountain Site Characterization Project (YMP) at Lawrence Livermore National Laboratory (LLNL) in conjunction with the B\&W Fuel Company. For a number of waste package spacings, these 3D transient calculations use the TOPAZ3D code to predict drift wall temperatures to 10,000 years following emplacement. Systematic tcniperature variation occurs as a function of fuel age at emplacement and Areal Mass Loading (AML) during the first few centuries after emplacement. After about 1000 years, emplacement age is not a strong driver on rock temperature; AML has a larger impact. High AMLs occur when large waste packages are emplaced end-tocnd in drifts. Drift emplacement of equivalent packages results in lower rock teniperatures than borehole emplacement. For an emplacement scheme with $50 \%$ of the drift length occupied by packages, an AML of $138 \mathrm{MTU}$ /acre is about three times higher than the Site Characterization Plan-Conceptual Design (SCP-CD) value. With this higher AML (requiring only $1 / 3$ of the SCP-CD repository footprint), peak drift wall temperatures do not exceed $160^{\star} \mathrm{C}$, but rock temperatures excetd the boiling point of water for about 3000 years. These TOPAZ3D results live been compared with reasonable agreement with two other computer codes.

194 (UCRL-JC-112444) The analysis of repositoryheat-driven hydrothermal flow at Yucca Mountain. Buscheck, T.A.; Nitao, J.J. Lawrence Livermore National Lab., CA (United States). Jan 1993. 21p. Sponsored by USDOE, Washington, DC (United States). DOE Contract W7405-ENG-48. (CONF-930496-3: High-level radioactive waste management, Las Vegas, NV (United States), 25-29 Apr 1993). Order Number DE93009062. Source: OSTI; NTIS; INIS; GPO Dep.

To safely and permanently store high-level nuclear waste, the potential Yucca Mountain repository site must mitigate the release and transport of radionuclides for tens of thousands of years. In the failure scenario of greatest concern, water would contact the waste package (WP), accelerate its failure rate, and eventually transport radionuclides to the water table. In a concept called the "extended-dry repository," decay heat arising from radioactive waste extends the time before liquid water can contact a WP. Recent modeling and theoretical advances in nonisothermal, multiphase fracture-matrix flow have demonstrated (1) the critical importance of capillary pressure disequilibrium between fracture and matrix flow, and (2) that radioactive decay heat plays a dominant role in the ability of the engineered and natural barriers to contain and isolate radionuclides. Our analyses indicate that the thermo-hydrological performance of both the unsaturated zone (UZ) and saturated zone (SZ) will be dominated by repository-heat-driven hydrothermal flow for tens of thousands of years. For thermal loads resulting in extended-dry repository conditions, UZ performance is primarily sensitive to the thermal properties and thermal loading conditions and much less sensitive to the highly spatially and temporally variable ambient hydrologic properties and conditions. The magnitude of repository-heat-driven buoyancy flow in the $S Z$ is far more dependent on the total mass of emplaced spent nuclear fuel (SNF) than on the details of SNF emplacement, such as the Areal Power Density [(APD) expressed in kill/acre] or SNF age.

195 (UCRL-JC-112445) Large-scale in situ heater tests for hydrothermal characterization at Yucca Mountain. Buscheck, T.A.; Wilder, D.G.; Nitao, J.J. Lawrence Livermore National Lab., CA (United States). Jan 1993. 42p. Sponsored by USDOE, Washington, DC (United States). DOE Contract W-7405-ENG-48. (CONF-930408-26: International high-level radioactive waste management conference, Las Vegas, NV (United States), 25-29 Apr 1993). Order Number DE93008022. Source: OSTI; NTIS; INIS; GPO Dep.

To safely and permanently store high-level nuclear waste, the potential Yucca Mountain repository site must mitigate the release and transport of radionuclides for tens of thousands of years. In the failure scenario of greatest concern, water would contact a waste package, accelerate its failure rate, and eventually transport radionuclides to the water table. Our analyses indicate that the ambient hydrological system will be dominated by repository-heat-driven hydrothermal flow for tens of thousands of years. In situ heater tests are required to provide an understanding of coupled geomechanical-hydrothermal-geochemical behavior in the engineered and natural barriers under repository thermal loading conditions. In situ heater tests have been included in the Site Characterization Plan in response to regulatory requirements for site characterization and to support the validation of process models required to assess the total systems performance at the site. Because of limited time, some of the in situ tests will have to be accelerated relative to actual thermal loading conditions. We examine the tradeoffs between the limited test duration and generating hydrothermal conditions applicable to repository performance during the entire thermal loading cycle, including heating (boiling and dry-out) and cooldown (re-wetting). For in situ heater tests to be applicable to actual repository conditions, a minimum heater test duration of 6-7 yr (including 4 yr of full-power heating) is required.

196 (UCRL-JC-112825) Single-hole in situ thermal probe for hydrothermal characterization at Yucca Mountain. Danko, G. (Nevada Univ., Reno, NV (United States). Mackay School of Mines); Buscheck, T.A. Lawrence Livermore National Lab., CA (United States). Jan 1993. 13p. Sponsored by USDOE, Washington, DC (United States). DOE Contract W-7405-ENG-48; FCO8-90NV10891. (CONF930496-2: High-level radioactive waste management, Las Vegas, NV (United States), 25-29 Apr 1993). Order Number DE93009063. Source: OSTI; NTIS; INIS; GPO Dep.

The REKA thermal probe method, which uses a single borehole to measure in situ rock thermophysical properties and provides for efficient and low-cost site characterization, 
is analyzed for its application to hydrothermal system characterization. It is demonstrated throughout the evaluation of several temperature fields obtained for different thermal zones that the REKA method can be applied to simultaneously determine (1) two independent thermophysical properties, i.e., heat conductivity and thermal diffusivity and (2) a set of heat transport parameters, which can be used to characterize the behavior of a hydrothermal system. Based on the direct physical meaning of these transport parameters, the components of the heat transport mechanism in a given time and location of the hydrothermal system can be described. This evaluation can be applied to characterizing and quantifying in situ rock dry-out and condensate shedding at the proposed repository site.

197 (UCRL-JC-114783) Coupled

hydrogeochemical processes and their significance for Yucca Mountain Site Characterization. Glassley, W. Lawrence Livermore National Lab., CA (United States). Sep 1993. 7p. Sponsored by USDOE, Washington, DC (United States). DOE Contract W-7405-ENG-48. (CONF-9309228-4: Focus 93: site characterization and model validation, Las Vegas, NV (United States), 26-29 Sep 1993). Order Number DE94002011. Source: OSTI; NTIS; INIS; GPO Dep.

Geochemical processes can results in changes in hydrological properties and processes via modification of pore and fracture volumes. Coupling of these processes must be taken into account when modeling repository evolution. Preliminary calculations have been carried out to determine the distribution of equilibrium vs kinetically controlled recrystallization domains in the repository block, and what the magnitude of resulting changes in porosity may be. The results suggest that equilibrium may be achieved for most of the hydrological regimes that may develop, except within fractures a few tens of meters from emplacement drifts. Preliminary models suggest total change in porosity may be ca. twenty percent in equilibrium-dominated regimes.

198 (UCRL-LR-107476-Vol.1) Preliminary near-field environment report: Volume 1, Technical bases for EBS design. Wilder, D.G. Lawrence Livermore National Lab., CA (United States). Apr 1993. 48p. Sponsored by USDOE Washington, DC (United States). DOE Contract W-7405ENG-48. Order Number DE93014854. Source: OSTI; NTIS; INIS; GPO Dep.

The United States Department of Energy (DOE) is investigating the suitability of Yucca Mountain as a potential site for the nation's first high-level nuclear waste repository. The site is located about $120 \mathrm{~km}$ northwest of Las Vegas, Nevada, in an area of uninhabited desert (Fig. 1). Lawrence Livermore National Laboratory (LLNL) is a Yucca Mountain Site Characterization Project (YMP) participant and is responsible for the development of waste package (WP) and engineered barrier system (EBS) design concepts, including materials testing and selection, design criteria development, waste-form characterization, performance assessments, and near-field environment (NFE) characterization.

199 (UCRL-LR-107476-Vol.2) Preliminary near-field environment report: Volume 2, Scientific overview of near-field environment and phenomena. Wilder, D.G. Lawrence Livermore National Lab., CA (United States). Apr 1993. 122p. Sponsored by USDOE, Washington, DC (United States). DOE Contract W-7405-ENG-48. Order Number DE93014855. Source: OSTI; NTIS; INIS; GPO Dep.
The Yucca Mountain Site Characterization Project Office (YMPO) of the Department of Energy's Office of Civilian Radioactive Waste Management Program is conducting a broad range of studies to determine the suitability of Yucca Mountain, Nevada, as the site for a potential nuclear-waste repository. The potential repository horizon is in the unsaturated zone, well above the saturated rock units. The major advantages of unsaturated conditions are that container corrosion, waste-form leaching, and radionuclide transport mechanisms are minimized due to the lack of contact between liquid water and the waste package (WP). The design and performance of the WP and the engineered barrier system (EBS) will be dependent on the geomechanical, hydrologic, and geochemical conditions over time in the rock forming the near-field environment (NFE). Whereas the purpose of Vol. 1 of this report (Technical Bases for EBS Design") is to provide technical information on the NFE that is needed for future repository design decisions, the purpose of this volume is to document the scientific and engineering data, models, and approaches that were used to gather that information, thus enabling scientists and engineers to determine the validity of the information provided in Vol. 1. This is of particular importance since there is only limited data and experience with these types of engineered systems, especially in unsaturated rock masses, and very little data or understanding of engineering system performance at the temperatures that will likely result from waste emplacement. It is important, therefore, to have an understanding of the physical processes (a mechanistic understanding) in addition to the statistical distributions of the environmental conditions. This volume consists of eight sections divided by area of study, and a final section summarizing the results of field tests performed at G-Tunnel at the Nevada Test Site (NTS) near Yucca Mountain.

200 (UCRL-MA-110662-Pt.1) EQ3/6, a software package for geochemical modeling of aqueous systems: Package overview and installation guide (Version 7.0). Wolery, T.J. Lawrence Livermore National Lab., CA (United States). 14 Sep 1992. 70p. Sponsored by USDOE, Washington, DC (United States). DOE Contract W-7405-ENG-48. Order Number DE93003359. Source: OST); INIS; NTIS (documentation only); ESTSC (complete software package), P.O. Box 1020, Oak Ridge, TN 37831-1020; GPO Dep.

$E Q 3 / 6$ is a software package for geochemical modeling of aqueous systems. This repont describes version 7.0. The major components of the package include: EQ3NR, a speciation-solubility code; EQ6, a reaction path code which models water/rock interaction or fluid mixing in either a pure reaction progress mode or a time mode; EQPT, a data file preprocessor, EQLIB, a supporting software library; and five supporting thermodynamic data files. The software deals with the concepts of thermodynamic equilibrium, thermodynamic disequilibrium, and reaction kinetics. The five supporting data files contain both standard state and activity coefficient-related data. Three support the use of the Davies or B-dot equations for the activity coefficients; the other two support the use of Pitzer's equations. The temperature range of the thermodynamic data on the data files varies from $25^{\circ} \mathrm{C}$ only to $0-300^{\circ} \mathrm{C}$. EQPT takes a formatted data file (a data 0 file) and writes an unformatted near-equivalent called a datal file, which is actually the form read by EQ3NR and EQ6. EQ3NR is useful for analyzing groundwater chemistry data, calculating solubility limits, and determining whether certain reactions are in states of partial equilibrium or disequilibrium. It is also required to initialize an EQ6 calculation. EQ6 models the consequences of reacting an 
aqueous solution with a set of reactants which react irreversibly. It can also model fluid mixing and the consequences of changes in temperature. This code operates both in a pure reaction progress frame and in a time frame.

201 (UCRL-MA-110662-Pt.2) EQPT, a data file preprocessor for the EQ3/6 software package: User's guide and related documentation (Version 7.0): Part 2. Daveler, S.A.; Wolery, T.J. Lawrence Livermore National Lab., CA (United States). 17 Dec 1992. 96p. Sponsored by USDOE, Washington, DC (United States). DOE Contract W-7405ENG-48. Order Number DE93005826. Source: OSTI; NTIS INIS; GPO Dep.

EQPT is a data file preprocessor for the EQ3/6 software package. EQ3/6 currently contains five primary data files, called datao files. These files comprise alternative data sets. These data files contain both standard state and activity coefficient-related data. Three (com, sup, and nea) support the use of the Davies or B-dot equations for the activity coefficients; the other two (hmw and pit) support the use of Pitzer's $(1973,1975)$ equations. The temperature range of the thermodynamic data on these data files varies from $25^{\circ} \mathrm{C}$ only to $0-300^{\circ} \mathrm{C}$. The principal modeling codes in EQ3/ 6, EQ3NR and EQ6, do not read a dataO file, however. Instead, these codes read an unformatted equivalent called a data1 file. EQPT writes a datal file, using the corresponding data0 file as input. In processing a data0 file, EQPT checks the data for common errors, such as unbalanced reactions. It also conducts two kinds of data transformation. Interpolating polynomials are fit to data which are input on temperature adds. The coefficients of these polynomials are then written on the datal file in place of the original temperature grids. A second transformation pertains only to data files tied to Pitzer's equations. The commonly reported observable Pitzer coefficient parameters are mapped into a set of primitive parameters by means of a set of conventional relations. These primitive form parameters are then written onto the datal file in place of their observable counterparts. Usage of the primitive form parameters makes it easier to evaluate Pitzer's equations in EQ3NR and EQ6. EQPT and the other codes in the EQ3/6 package are written in FORTRAN 77 and have been developed to run under the UNIX operating system on computers ranging from workstations to supercomputers.

202 (UCRL-MA-110662-Pt.3) EQ3NR, a computer program for geochemical aqueous speciation-solubility calculations: Theoretical manual, user's guide, and related documentation (Version 7.0): Part 3. Wolery, T.J. Lawrence Livermore National Lab., CA (United States). 14 Sep 1992. 259p. Sponsored by USDOE, Washington, DC (United States). DOE Contract W-7405-ENG-48. Order Number DE93005827. Source: OSTI; NTIS; INIS; GPO Dep.

EQ3NR is an aqueous solution speciation-solubility modeling code. It is part of the EQ3/6 software package for geochemical modeling. It computes the thermodynamic state of an aqueous solution by determining the distribution of chemical species, including simple ions, ion pairs, and complexes, using standard state thermodynamic data and various equations which describe the thermodynamic activity coefficients of these species. The input to the code describes the aqueous solution in terms of analytical data, including total (analytical) concentrations of dissolved components and such other parameters as the $\mathrm{pH}, \mathrm{pHCl}$, Eh, pe, and oxygen fugacity. The input may also include a desired electrical balancing adjustment and various constraints which impose equilibrium with special pure minerals, solid solution end-member components (of specified mole fractions), and gases (of specified fugacities). The code evaluates the degree of disequilibrium in terms of the saturation index $(S I=\log Q / K)$ and the thermodynamic affinity $(A=-2.303 R T \log Q / K)$ for various reactions, such as mineral dissolution or oxidation-reduction in the aqueous solution itself. Individual values of Eh, pe, oxygen fugacity, and Ah (redox affinity) are computed for aqueous redox couples. Equilibrium fugacities are computed for gas species. The code is highly flexible in dealing with various parameters as either model inputs or outputs. The user can specify modification or substitution of equilibrium constants at run time by using options on the input file.

203 (UCRL-MA-110662-Pt.4) EQ6, a computer program for reaction path modeling of aqueous geochemical systems: Theoretical manual, user's guide, and related documentation (Version 7.0): Part 4. Wolery, T.J.; Daveler, S.A. Lawrence Livermore National Lab., CA (United States). 9 Oct 1992. 349p. Sponsored by USDOE, Washington, DC (United States). DOE Contract W-7405ENG-48. Order Number DE93007118. Source: OSTI; INIS; NTIS (documentation only); ESTSC (complete software package), P.O. Box 1020, Oak Ridge, TN 37831-1020; GPO Dep.

EQ6 is a FORTRAN computer program in the EQ3/6 software package (Wolery, 1979). It calculates reaction paths (chemical evolution) in reacting water-rock and water-rockwaste systems. Speciation in aqueous solution is an integral part of these calculations. EQ6 computes models of titration processes (including fluid mixing), irreversible reaction in closed systems, irreversible reaction in some simple kinds of open systems, and heating or cooling processes, as well as solve "single-point" thermodynamic equilibrium problems. A reaction path calculation normally involves a sequence of thermodynamic equilibrium calculations. Chemical evolution is driven by a set of irreversible reactions (i.e., reactions out of equilibrium) and/or changes in temperature and/or pressure. These irreversible reactions usually represent the dissolution or precipitation of minerals or other solids. The code computes the appearance and disappearance of phases in solubility equilibrium with the water. It finds the identities of these phases automatically. The user may specify which potential phases are allowed to form and which are not. There is an option to fix the fugacities of specified gas species, simulating contact with a large external reservoir. Rate laws for irreversible reactions may be either relative rates or actual rates. If any actual rates are used, the calculation has a time frame. Several forms for actual rate laws are programmed into the code. EQ6 is presently able to model both mineral dissolution and growth kinetics.

204 The implications of episodic nonequilibrium fracture-matrix flow on site suitability and total system performance. Nitao, J.J. (Earth Sciences Dept., Lawrence Livermore National Lab., Livermore, CA (US)); Buscheck, T.A.; Chesnut, D.A. pp. 279-296 of Proceedings of high level radioactive waste management: Volume 1. American Nuclear Society, La Grange Park, IL (United States) (1992). pp. 2425 (CONF-920430-: 3. international high level radioactive waste management (IHLRWM) conference, Las Vegas, NV (United States), 12-16 Apr 1992).

In this paper the authors apply their work on fracture- and matrix-dominated flow to develop a conceptual model of hydrological flow processes in the unsaturated zone at Yucca Mountain. The possibility of fracture-dominated flow is discussed, and various deductions are made on its impact on 
natural and total system performance, site characterization activities, and site suitability determination.

205 The impact of thermal loading on repository performance at Yucca Mountain. Buscheck, T.A. (Earth Sciences Dept., Livermore National Lab., Livermore, CA (US)); Nitao, J.J. pp. 1003-1017 of Proceedings of high level radioactive waste management: Volume 1. American Nuclear Society, La Grange Park, IL (United States) (1992). pp. 2425 (CONF-920430-: 3. international high level radioactive waste management (IHLRWM) conference, Las Vegas, NV (United States), 12-16 Apr 1992).

This paper reports that in the unsaturated zone at Yucca Mountain, liquid flow along preferential fracture pathways is the only credible mechanism capable of bringing water to waste packages and transporting radionuclides to the water table. Three categories of features or mechanisms will mitigate the impact of flow along preferential fracture pathways: discontinuity in fracture pathways, liquid-phase dispersion in fracture networks, and fracture-matrix interaction. For repository areal power densities (APDs) that are too low to result in significant boiling or rock dry-out effects, the primary mode of fracture-matrix interaction is matrix imbibition. For high APDs, boiling and enhanced matrix imbibition due to rock dry-out significantly add to the capacity of the unsaturated zone to retard fracture-dominated flow.

206 Characterizing the altered zone at Yucca Mountain: The beginning of a testing strategy. Chesnut, D.A. (Earth Sciences Dept., Lawrence Livermore National Lab., Livermore, CA (US)). pp. 1026-1039 of Proceedings of high level radioactive waste management: Volume 1. American Nuclear Society, La Grange Park, IL (United States) (1992). pp. 2425 (CONF-920430-: 3. international high level radioactive waste management (IHLRWM) conference, Las Vegas, NV (United States), 12-16 Apr 1992).

The concept of a disturbed zone surrounding the mined openings of a potential geologic repository for high-level radioactive waste was introduced by the U.S. Nuclear Regulatory Commission (NRC) as a region to be excluded for determining groundwater travel time to the accessible environment, but to be included for determining the impact of underground construction and radioactive decay heat on groundwater movement and radionuclide transport for total system performance analysis. This paper explores both the regulatory and technical necessity for characterizing and modeling a larger region the altered zone within which the temperature is increased significantly by heat from the highlevel waste. Particular attention is given to addressing the effects of heterogeneity on groundwater flux and travel time, showing how these effects might be modeled simply on a macroscopic scale, and outlining several possibilities for testing the model and obtaining its parameters. The effect of uncertainty in the parameter values on the performance of a potential repository can then be easily handled by probabilistic analysis.

207 Releases from exotic waste packages from partitioning and transmutation. Lee, W.W.L. (Lawrence Livermore National Lab., Univ. of California, Livermore, CA (US)); Choi, J.S. pp. 1387-1396 of Proceedings of high level radioactive waste management: Volume 1. American $\mathrm{Nu}$ clear Society, La Grange Park, IL (United States) (1992). pp. 2425 (CONF-920430-: 3. international high level radioactive waste management (IHLRWM) conference, Las Vegas, NV (United States), 12-16 Apr 1992).
This paper reports that partitioning the actinides in spent nuclear fuel and transmuting them in actinide-burning liquidmetal reactors has been proposed as a potential method of reducing the public risks from geologic disposal of nuclear waste. To quantify the benefits for waste disposal of actinide burning, the authors calculate the release rates of key radionuclides form waste packages resulting from actinide burning, and compare them with release rates from LWR spent fuel designed for disposal at the potential repository at Yucca Mountain. The wet-drip water-contact mode has been used. Analytic methods and parameter values are very similar to those used for assessing Yucca Mountain as a potential repository. Once released, the transport characteristics of radionuclides will be largely determined by site geology. For the most important nuclides such as I-129 and Tc-99, which are undiminished by actinide-burning reactors, it is not surprising that actinide burning offers little reduction in releases. For important actinides such as Np-237 and $\mathrm{Pu}$ isotopes, which are reduced in inventory, the releases are not reduced because the release rates are proportional to solubility, rather than inventory.

208 Potential increases in natural radon emissions due to heating of the Yucca Mountain rock mass. Pescatore, C. (Brookhaven National Lab., Upton, NY (US)); Sullivan, T.M. pp. 1599-1606 of Proceedings of high level radioactive waste management: Volume 1 . American Nuclear Society, La Grange Park, IL (United States) (1992). pp. 2425 (CONF-920430-: 3. international high level radioactive waste management (IHLRWM) conference, Las Vegas, NV (United States), 12-16 Apr 1992).

This paper reports on the heating of the rock mass by the spent fuel in the proposed repository at Yucca Mountain which will cause extra amounts of natural radon to diffuse into the fracture system and to migrate faster to the accessible environment. Inideed, free-convection currents due to heating will act to shorten the radon travel times and will cause large releases than would be possible under undisturbed conditions. To estimate the amount of additional radon released due to heating of the Yucca Mountain rock mass, we obtain and expression for the release enhancement factor, $E$. This factor is defined as the ratio between the total flux of radon at the surface of the mountain before and after closure of the repository assuming the only cause of disturbance to be the heating of the rock mass. With appropriate approximations and using a heat load representative of that expected at Yucca Mountain, the present calculations indicate that the average enhancement factor over the first 10,000 years will be 4.5 as a minimum. These calculations are based on the assumption that barometric pumping does not significantly influence radon release. The latter assumption will need to be substantiated.

209 Radionuclide distribution in LWR spent fuel. Guenther, R.J. (Pacific Northwest Lab., Richland, WA (United States)); Blahnik, D.E.; Thomas, L.E.; Baldwin, D.L.; Mendel, J.E. pp. 120-123 of Proceedings of SPECTRUM '90. American Nuclear Society, La Grange Park, IL (United States) (1990). pp. 505 DOE Contract AC06-76RL01830. (CONF-900977-: Spectrum '90: American Nuclear Society (ANS) international meeting on radioactive waste technologies, decontamination, and hazardous wastes, Knoxville, TN (United States), 30 Sep - 4 oct 1990).

The Materials Characterization Center (MCC) at Pacific Northwest Laboratory (PNL) provides well-characterized spent fuel from light-water reactors (LWRs) for use in laboratory tests relevant to nuclear waste disposal in the proposed 
Yucca Mountain repository. Interpretation of results from tests on spent fuel oxidation, dissolution, and cladding degradation requires information on the inventory and distribution of radionuclides in the initial test materials. This paper summarizes results that help define the ${ }^{14} \mathrm{C}$ inventory and distribution in cladding, the gap and grain boundary inventory of radionuclides in fuels with different FGRs, and the structure and radionuclide inventory of the fuel rim region within a few hundred micrometers from the fuel edge.

210 Uncertainty analyses of unsaturated zone travel time at Yucca Mountain. Nichols, W.E. (Pacific Northwest labs., Richland, WA (US)); Freshley, M.D. Ground Water (United States); 31(2): 293-301 (Mar-Apr 1993). DOE Contract AC06-76RL01830.

Uncertainty analysis method can be applied to numerical models of ground-water flow to estimate the relative importance of physical and hydrologic input variables with respect to ground-water travel time. Monte Carlo numerical simula: tions of unsaturated flow in the Calico Hills nonwelded zeolitic ( $\mathrm{CHnz}$ ) layer at Yucca Mountain, Nevada, indicate that variability in recharge, and to a lesser extent in matrix porosity, explains most of the variability in predictions of water travel time through the unsaturated zone. Variations in saturated hydraulic conductivity and unsaturated curve-fitting parameters were not statistically significant in explaining variability in water travel time through the unsaturated $\mathrm{CHnz}$ unit. The results of this study suggest that the large uncertainty associated with recharge rate estimates for the Yucca Mountain site is of concern because the performance of the potential repository would be more sensitive to uncertainty in recharge than to any other parameter evaluated. These results are not exhaustive because of the limited site characterization data available and because of the preliminary nature of this study, which is limited to a single stratigraphic unit, one dimension, and does not account for fracture flow or other potential fast pathways at Yucca Mountain.

211 Potential for water-table excursions induced by seismic events at Yucca Mountain, Nevada. Carrigan, C.R. (Lawrence Livermore National Lab., CA (United States)); King, G.C.P.; Barr, G.E.; Bixler, N.E. Geology (United States); 19(12): 1157-1160 (Dec 1991).

The possibility that 100-200 m changes in water-table elevation can be mechanically induced by earthquakes is a consideration in site studies of a potential high-level nuclear waste repository at Yucca Mountain, Nevada. However, numerical simulations of tectonohydrologic coupling involving earthquakes typical of the Basin and Range province produce $2-3 \mathrm{~m}$ excursions of a water table that is $500 \mathrm{~m}$ below the land surface. Even displacements corresponding to extraordinary seismic events drive water-table excursions of less than $20 \mathrm{~m}$. Flow resulting from earthquake-induced pore-pressure fields below the water table tends to be mainly horizontal; vertical flows that cause changes of the level of the water table are secondary. Strongly anisotropic permeability, intended to enhance vertical flow within fault zones, only doubles water-table rise in the models considered. These simulations of water-table rise compare well with observations following large earthquakes in the Basin and Range. The authors' models suggest that exceptional hydrologic and/or tectonic conditions would be required to produce substantially larger water-table rises.

\section{SANDIA NATIONAL LABORATORIES}

212 (BNL-45042) Potential increases in natural radon emissions due to heating of the Yucca Mountain rock mass. Pescatore, C.; Sullivan, T.M. Brookhaven National Lab., Upton, NY (United States). [1992]. 8p. Sponsored by USDOE, Washington, DC (United States). DOE Contract AC02-76CH00016. (CONF-920430-51: 3. international high level radioactive waste management (IHLRWM) conference, Las Vegas, NV (United States), 12-16 Apr 1992). Order Number DE92007610. Source: OSTI; NTIS; INIS; GPO Dep.

Heating of the rock mass by the spent fuel in the proposed repository at Yucca Mountain will cause extra amounts of natural radon to diffuse into the fracture system and to migrate faster to the accessible environment. Indeed, free-convection currents due to heating will act to shorten the radon travel times and will cause larger releases than would be possible under undistributed conditions. To estimate the amount of additional radon released due to heating of the Yucca Mountain rock mass, we obtain an expression for the release enhancement factor, $E$. This factor is defined as the ratio between the total flux of radion at the surface of the mountain before and after closure of the repository assuming the only cause of disturbance to be the heating of the rock mass. With appropriate approximations and using a heat load representative of that expected at Yucca Mountain, the present calculations indicate that the average enhancement factor over the first 10,000 years will be 4.5 as a minimum. These calculations are based on the assumption that barometric pumping does not significantly influence radion release. The latter assumption will need to be substantiated.

213 Design of underground repository openings in hard rock to accommodate vibratory ground motions. Hardy, M.P. (J.F.T. Agapito and Associates, Inc., Grand Junction, CO (US)); Bauer, S.J. pp. 210-227 of Dynamic analysis and design considerations for high-level nuclear waste repositories. Hossain, Q.A. (ed.). American Society of Civil Engineers, New York, NY (US) (1993). pp. 443 DOE Contract AC04-76DP00789. From American Society of Civil Engineers (ASCE) symposium on dynamic analysis and design considerations, for high-level nuclear waste repositories; San Francisco, CA (United States); 19-20 Aug 1992.

A methodology and preliminary application for designing repository openings to withstand vibratory ground motions is presented. The methodology first establishes the design basis ground motion based on the usage category, performance goals, and hazard exceedance guidelines and incorporates those motions into the more general drift design methodology. The repository drift design methodology includes the effects of the in situ stresses and the thermal loads generated from the heat released from the nuclear waste packages. Empirical and analytical methods for design for seismic loading are reviewed, and it is concluded that analytical methods provide the only means method to adequately incorporate the effects of seismic and thermal loads on design. Quasi-static and dynamic analysis methods are discussed. The example application to the potential repository at the Yucca Mountain site illustrates, by using the quasi-static method, that the seismic loads in combination with the thermal loads can be significant in the design of the ground support/reinforcement system in some locations. Under present expected conditions, the seismic loads themselves are not excessive and can be accommodated in the 
design by available ground support/reinforcement systems. However, in the waste emplacement drift where the thermal loads are high, the potential and additional seismic loads couid require novel ground supportreinforcement designs and maintenance.

\section{Seismic design of circular-section concrete-} lined underground openings-Preclosure performance considerations for the Yucca Mountain site. Richardson, A.M. (J.F.T. Agapito and Associates, Inc., Grand Junction, CO (US)); Blejwas, T.E. pp. 243-262 of Dynamic analysis and design considerations for high-level nuclear waste repositories. Hossain, Q.A. (ed.). American Society of Civil Engineers, New York, NY (US) (1993). pp. 443 DOE Contract AC04-76DP00789. From American Society of Civil Engineers (ASCE) symposium on dynamic analysis and design considerations, for high-level nuclear waste repositories; San Francisco, CA (United States); 19-20 Aug 1992.

Yucca Mountain, the potential site of a repository for highlevel radioactive waste, is situated in a region of natural and man-made seismicity. Underground openings excavated at this site must be designed for worker safety in the seismic environment anticipated for the preclosure period. This includes accesses developed for site characterization regardless of the ultimate outcome of the repository siting process. Experience with both civil and mining structures has shown that underground openings are much more resistant to seismic effects than surface structures, and that even severe dynamic strains can usually be accommodated with proper design. This paper discusses the design and performance of lined openings in the seismic environment of the potential site. The types and ranges of possible ground motions (seismic loads) are briefly discussed. Relevant historical records of underground opening performance during seismic loading are reviewed. Simple analytical methods of predicting liner performance under combined in situ, thermal, and seismic loading are presented, and results of calculations are discussed in the context of realistic performance requirements for concrete-lined openings for the preclosure period. Design features that will enhance liner stability and mitigate the impact of the potential seismic load are reviewed. The paper is limited to preclosure performance concerns involving worker safety because present decommissioning plans specify maintaining the option for liner removal at seal locations, thus decoupling liner design from repository postclosure performance issues.

215 Seismic considerations in sealing a potential high-level radioactive waste repository. Fernandez, J.A. (Sandia National Labs., Albuquerque, NM (US)); Richardson, A.M.; Lin, Ming. pp. 263-285 of Dynamic analysis and design considerations for high-level nuclear waste repositories. Hossain, Q.A. (ed.). American Society of Civil Engineers, New York, NY (US) (1993). pp. 443 DOE Contract AC04-76DP00789. From American Society of Civil Engineers (ASCE) symposium on dynamic analysis and design considerations, for high-level nuclear waste repositories; San Francisco, CA (United States); 19-20 Aug 1992.

The potential repository system is intended to isolate highlevel radioactive waste at Yucca Mountain according the performance objective-10 CFR 60.112 . One subsystem that may contribute to achieving this objective is the sealing subsystem. This subsystem is comprised of sealing components in the shatts, ramps, underground network of drifts, and the exploratory boreholes. Sealing components can be rigid, as in the case of a shaft seal, or can be more compressible, as in the case of drift fill comprised of mined rockfill. This paper presents the preliminary seismic response of discrete sealing components in welded and nonwelded tuff. Special consideration is given to evaluating the stress in the seal, and the behavior of the interface between the seal and the rock. The seismic responses are computed using both static and dynamic analyses. Also presented is an evaluation of the maximum seismic response encountered by a drift seal with respect to the angle of incidence of the seismic wave. Mitigation strategies and seismic design considerations are proposed which can potentially enhance the overall response of the sealing component and subsequently, the performance of the overall repository system.

216 (DOENV/10576-T5) Technical data base quarterly report, April-June 1992: Yucca Mountain Site Characterization Project. Sandia National Labs., Albuquerque, NM (United States); EG and G Energy Measurements, Inc., Las Vegas, NV (United States); Lawrence Livermore National Lab., CA (United States). [1992]. 275p. Sponsored by USDOE, Washington, DC (United States). DOE Contract AC08-87NV10576; AC04-76DP00789; W-7405-ENG-48 ; AC08-83NV10282. Order Number DE92019615. Source: OSTI; NTIS; GPO Dep.

The acquisition and development of technical data are activities that provide the information base from which the Yucca mountain Site will be characterized and may $P$ ventually be licensed as a high-level waste repository. The Project Technical Data Base (TDB) is the repository for the regional and site-specific technical data required in intermediate and license application analyses and models. The TDB Quarterly Report provides the mechanism for identifying technical data currently available from the Project TDB. Due to the variety of scientific information generated by YMP activities, the Project TDB consists of three components, each designed to store specific types of data. The Site and Engineering Properties Data Base (SEPDB) maintains technical data best stored in a tabular format. The Geographic Nodal Information Study and Evaluation System (GENISES), which is the Geographic Information System (GIS) component of the Project TDB, maintains spatial or map-like data. The Geologic and Engineering Materials Bibliography of Chemical Species (GEMBOCHS) data base maintains thermodynamic/geochemical data needed to support geochemical reaction models involving the waste package and repository geochemical environment. Each of these data bases are addressed independently within the TDB Quarterly Report.

217 (SAND-85-0004) Total System Performance Assessment Code (TOSPAC): Volume 2, User's guide: Yucca Mountain Site Characterization Project. Gauthier, J.H. (Spectra Research Inst., Albuquerque, NM (United States)); Dudley, A.L; Skinner, L.H.; Wilson, M.L.; Peters, R.R. Sandia National Labs., Albuquerque, NM (United States). Jul 1992. 320p. Sponsored by USDOE, Washington, DC (United States). DOE Contract AC04-76DP00789. Order Number DE92019324. Source: OSTI; NTIS; INIS; GPO Dep.

TOSPAC is a computer program that calculates partially saturated groundwater flow with the transport of watersoluble contaminants. TOSPAC Version 1 is restricted to calculations involving one-dimensional, vertical columns of one or more media. TOSPAC was developed to help answer questions surrounding the burial of toxic wastes in arid regions. Burial of wastes in arid regions is attractive because of generally low population densities and little groundwater flow, in the unsaturated zone, to disturb the waste. TOSPAC helps to quantify groundwater flow and the spread of contamination, offering an idea of what could happen in the 
distant future. Figure 1.1 illustrates the problem TOSPAC was designed to investigate. For groundwater flow, TOSPAC can provide saturations, velocities, and and travel tunes for water in the rock matrix or the fractures in the unsaturated zone. TOSPAC can determine how hydrologic conditions vary when the rate of infiltration changes. For contaminant transport, TOSPAC can compute how much of a contaminant is dissolved in the water and how it is distributed. TOSPAC can determine how fast the solute is moving and the shape of the concentration front. And TOSPAC can be used to investigate how much of the contaminant remains in the inventory of a repository, how much is adsorbed onto the soil or rock matrix, and how much reaches the water table. Effective use of TOSPAC requires knowledge in a number of diverse disciplines, including real groundwater flow and transport, the mathematical models of groundwater flow and transport, real-world data required for the models, and the numerical solution of differential equations. Equally important is a realization of the limitations intrinsic to a computer model of complex physical phenomena. This User's Guide not only describes the mechanics of executing TOSPAC on a computer, but also examines these other topics.

218 (SAND-86-7006) An evaluation of the seismic Ity of the Nevada Test Site and vicinity: Yucca Mountain Site Characterization Project. Vortman, L.J. Sandia National Labs., Albuquerque, NM (United States). Dec 1991. 237p. Sponsored by USDOE, Washington, DC (United States). DOE Contract AC04-76DP00789. Order Number DE92004787. Source: OSTI; NTIS; INIS; GPO Dep.

Two USGS catalogs of earthquakes in the Southern Great Basin were edited to remove man-made seisms. Editing reduced 11,988 entries to 8,161 . Known location of underground nuclear explosions provided an opportunity to assess location accuracy showing that accuracy differed according to the source of earthquake data. No evidence was found of explosions triggering earthquakes distant from the working points. Relationships are developed between earthquake magnitude and explosion yield for explosions at Pahute Mesa and Yucca Flat. Comparison of the number of underground nuclear explosions with the number of earthquakes of comparable magnitude shows the former exceeds the latter when magnitude is greater than four. Edited catalogs are recommended for hazard analysis relative to repository siting because unedited catalogs tend to greatly exaggerate seismicity of the region.

219 (SAND-87-1305) JAC3D - A three-dimensional finite element computer program for the nonlinear quasi-static response of solids with the conjugate gradient method: Yucca Mountain Site Characterization Project. Biffle, J.H. Sandia National Labs., Albuquerque, NM (United States). Feb 1993. 132p. Sponsored by USDOE, Washington, DC (United States). DOE Contract AC04-76DP00789. Order Number DE93015729. Source: OSTI; NTIS; INIS; GPO Dep.

$J A C 3 D$ is a three-dimensional finite element program designed to solve quasi-static nonlinear mechanics problems. $A$ set of continuum equations describes the nonlinear mechanics involving large rotation and strain. A nonlinear conjugate gradient method is used to solve the equation. The method is implemented in a three-dimensional setting with various methods for accelerating convergence. Sliding interface logic is also implemented. An eight-node Lagrangian uniform strain element is used with hourglass stiffness to control the zero-energy modes. This report documents the elastic and isothermal elastic-plastic material model. Other material models, documented elsewhere, are also available. The program is vectorized for efficient performance on Cray computers. Sample problems described are the bending of a thin beam, the rotation of a unit cube, and the pressurization and thermal loading of a hollow sphere.

220 (SAND-87-2380) Statistical analysis of hydrologic data for Yucca Mountain: Yucca Mountain Site Characterization Project. Rutherford, B.M.; Hall, I.J.; Peters, R.R.; Easterling, R.G.; Klavetter, E.A. Sandia National Labs., Albuquerque, NM (United States). Feb 1992. 273p. Sponsored by USDOE, Washington, DC (United States). DOE Contract AC04-76DP00789. Order Number DE92010759. Source: OSTI; NTIS; INIS; GPO Dep.

The geologic formations in the unsaturated zone at Yucca Mountain are currently being studied as the host rock for a potential radioactive waste repository. Data from several drill holes have been collected to provide the preliminary information needed for planning site characterization for the Yucca Mountain Project. Hydrologic properties have been measured on the core samples and the variables analyzed here are thought to be important in the determination of groundwater travel times. This report presents a statistical analysis of four hydrologic variables: saturated-matrix hydraulic conductivity, maximum moisture content, suction head, and calculated groundwater travel time. It is important to modelers to have as much information about the distribution of values of these variables as can be obtained from the data. The approach taken in this investigation is to (1) identify regions at the Yucca Mountain site that, according to the data, are distinctly different; (2) estimate the means and variances within these regions; (3) examine the relationships among the variables; and (4) investigate alternative statistical methods that might be applicable when more data become available. The five different functional stratigraphic units at three different locations are compared and grouped into relatively homogeneous regions. Within these regions, the expected values and variances associated with core samples of different sizes are estimated. The results provide a rough estimate of the distribution of hydrologic variables for small core sections within each region.

221 (SAND-87-2777) Retrieval strategy report for a potential high-level nuclear waste repository: Yucca Mountain Site Characterization Project. Flores, R. Sandia National Labs., Albuquerque, NM (United States). Dec 1991. 521p. Sponsored by USDOE, Washington, DC (United States). DOE Contract AC04-76DP00789. Order Number DE92005385. Source: OSTI; NTIS; INIS; GPO Dep.

In federal laws, regulations, and departmental directives, the US Congress, the Nuclear Regulatory Commission, and the US Department of Energy have developed criteria for retrievability of waste emplaced in a geologic repository for high-level radioactive waste. In response to these criteria, the Yucca Mountain Project has included in the design of the potential repository at Yucca Mountain the option to retrieve emplaced waste as a planned contingency operation. This report presents a Project strategy for maintaining retrievability. It includes descriptions of repository and equipment designs; the operations during waste emplacement, post-emplacement, and retrieval; and expected repository conditions (normal and abnormal). Retrieval-related regulations and requirements are presented and discussed as a basis for evaluating the designs and operations plans. The report concludes with discussions of retrieval strategy implementation, which includes determining which equipment and 
operations demonstrations are necessary or required and plans for future work. 78 figs., 34 tabs.

\begin{tabular}{|c|c|c|}
\hline 22 & $\begin{array}{l}\text { (SAND-87-2778) } \\
\text { evaluations: }\end{array}$ & $\begin{array}{c}\text { G-tunnel } \\
\text { Yucca }\end{array}$ \\
\hline
\end{tabular}
Characterization Project. Zimmerman, R.M. (Sandia National Labs., Albuquerque, NM (United States)); Sifre-Soto, C.; Mann, K.L.; Bellman, R.A. Jr.; Luker, S.; Dodds, D.J. Sandia National Labs., Albuquerque, NM (United States). Apr 1992. 99p. Sponsored by USDOE, Washington, DC (United States). DOE Contract AC04-76DP00789. Order Number DE92015393. Source: OSTI; NTIS; INIS; GPO Dep.

Designers and analysts of radioactive waste repositories must be able to predict the mechanical behavior of the host rock. Sandia National Laboratories elected to conduct a development program to enhance mechanical-type measurements. The program was focused on pressurized slot testing and featured (1) development of an improved method to cut slots using a chain saw with diamond-tipped cutters, (2) measurements useful for determining in situ stresses normal to slots, (3) measurements applicable for determining the in situ modulus of deformation parallel to a drift surface, and (4) evaluations of pressurized slot strength testing results and methods. This report contains data interpretation and evaluations. Included are recommendations for future efforts. This third report contains the interpretations of the testing with emphasis on the measurement results as they apply to describing rock behavior. In particular, emphases are placed on (1) normal stress determinations using the flatjack cancellation (FC) method, (2) modulus of deformation determinations, and (3) high pressure investigations. Most of the material in the first two reports is not repeated here. Appropriate data are repeated in tabular form.

223 (SAND-87-7075) HEFF-A user's manual and guide for the HEFF code for thermal-mechanical analysis using the boundary-element method: Version 4.1: Yucca Mountain Site Characterization Project. St. John, C.M. (Agapito (J.F.T.) and Associates, Inc., Grand Junction, CO (United States)); Sanjeevan, K. Sandia National Labs., Albuquerque, NM (United States); Agapito (J.F.T.) and Associates, Inc., Grand Junction, CO (United States). Dec 1991. 164p. Sponsored by USDOE, Washington, DC (United States). DOE Contract AC04-76DP00789. Order Number DE92007216. Source: OSTI; NTIS; INIS; GPO Dep.

The HEFF Code combines a simple boundary-element method of stress analysis with the closed form solutions for constant or exponentially decaying heat sources in an infinite elastic body to obtain an approximate method for analysis of underground excavations in a rock mass with heat generation. This manual describes the theoretical basis for the code, the code structure, model preparation, and step taken to assure that the code correctly performs its intended functions. The material contained within the report addresses the Software Quality Assurance Requirements for the Yucca Mountain Site Characterization Project. 13 refs., 26 figs., 14 tabs.

224 (SAND-87-7082) Effects of a potential drop of a shipping cask, a waste container, and a bare fuel assembly during waste-handling operations: Yucca Mountain Site Characterization Project. Wu, C.L. (Bechtel National, Inc., San Francisco, CA (United States)); Lee, J.; Lu, D.L.; Jardine, L.J. Sandia National Labs., Albuquerque, NM (United States); Bechtel National, Inc., San Francisco, CA (United States). Dec 1991. 145p. Sponsored by USDOE, Washington, DC (United States). DOE Contract
AC04-76DP00789. Order Number DE92006828. Source: OSTI; NTIS; INIS; GPO Dep.

This study investigates the effects of potential drops of a typical shipping cask, waste container, and bare fuel assembly during waste-handling operations at the prospective Yucca Mountain Repository. The waste-handling process (one stage, no consolidation configuration) is examined to estimate the maximum loads imposed on typical casks and containers as they are handled by various pieces of equipment during waste-handling operations. Maximum potential drop heights for casks and containers are also evaluated for different operations. A nonlinear finite-element model is employed to represent a hybrid spent fuel container subject to drop heights of up to $30 \mathrm{ft}$ onto a reinforced concrete floor. The impact stress, strain, and deformation are calculated, and compared to the failure criteria to estimate the limiting (maximum permissible) drop height for the waste container. A typical Westinghouse $17 \times 17$ PWR fuel assembly is analyzed by a simplified model to estimate the energy absorption by various parts of the fuel assembly during a $30 \mathrm{ft}$ drop, and to determine the amount of kinetic energy in a fuel pin at impact. A nonlinear finite-element analysis of an individual fuel pin is also performed to estimate the amount of fuel pellet fracture due to impact. This work was completed on May 1990.

$\begin{array}{llll}225 & \text { (SAND-88-0585) G-Tunnel pressurized slot- } \\ \text { testing preparations: } & \text { Yucca Mountain Site }\end{array}$ Characterization Project. Zimmerman, R.M. (Sandia National Labs., Albuquerque, NM (United States)); Sifre-Soto, C.; Mann, K.L.; Bellman, R.A. Jr.; Luker, S.; Dodds, D.J. Sandia National Labs., Albuquerque, NM (United States). Apr 1992. 65p. Sponsored by USDOE, Washington, DC (United States). DOE Contract AC04-76DP00789. Order Number DE92014170. Source: OSTI; NTIS; INIS; GPO Dep.

Designers and analysts of radioactive waste repositories must be able to predict the mechanical behavior of the host rock. Sandia National laboratories elected to conduct a development program on pressurized slot testing and featured (1) development of an improved method to cut slots using a chain saw with diamond-tipped cutters, (2) measurements useful for determining in situ stresses normal to slots, (3) measurements applicable for determining the in situ modulus of deformation parallel to a drift surface, and (4) evaluations of the potentials of pressurized slot strength testing. This report describes the preparations leading to the measurements and evaluations.

226 (SAND-88-0810) Preliminary numerical modeling for the G-Tunnel welded tuff mining experiment: Yucca Mountain site characterization project. Johnson, R.L.; Bauer, S.J. Sandia National Labs., Albuquerque, NM (United States). Sep 1991. 48p. Sponsored by USDOE, Washington, DC (United States). DOE Contract AC0476DP00789. Order Number DE92000944. Source: OSTI; NTIS; INIS; GPO Dep.

Yucca Mountain, located in Southern Nevada, is to be considered as a potential site for a nuclear waste repository. Located in Rainier Mesa on the Nevada Test Site, G-Tunnel has been the site of a series of experiments, part of whose purpose is to evaluate measurement techniques for rock mechanics before testing in the Exploratory Shaft. Rainier Mesa is composed of welded and nonwelded tuffs that have thermal and mechanical properties and stress states similar to those of tuffs expected to be encountered at Yucca Mountain. A series of finite element calculations were performed 
to aid in designing instrumentation for the experiments in $\mathrm{G}$ Tunnel and later to correlate with measured data. In this report are presented the results of the preliminary finite element calculations performed in conjunction with experimental measurements of drift convergence, or closure, and rock mass relaxation zones made before, during, and after completing the welded tuff mining experiment in G-Tunnel. Tape extensometer measurements of drift convergences and measurements determined by multiple point borehole extensometers are compared with corresponding calculated values using linear elastic and jointed rock material models. 9 refs., 25 figs., 7 tabs.

227 (SAND-88-1331) G-Tunnel Welded Tuff Mining Experiment instrumentation evaluations: Yucca Mountain Site Characterization Project. Zimmerman, R.M. (Sandia National Labs., Albuquerque, NM (United States)); Bellman, R.A. Jr.; Mann, K.L.; Thompson, T.W. Sandia National Labs., Albuquerque, NM (United States). Apr 1992. 108p. Sponsored by USDOE, Washington, DC (United States). DOE Contract AC04-76DP00789. Order Number DE92013768. Source: OSTI; NTIS; INIS; GPO Dep.

Designers and analysts of radioactive waste repositories must be able to predict the mechanical behavior of the host rock. Sandia National Laboratory has conducted a mine-by experiment in welded tuff so that information could be obtained regarding the response of the rock to a drill and blast excavation process, where smooth-blasting techniques were used. This report describes the results of the evaluations of nine different instrument or measurement systems used in conjunction with these mining activities.

228 (SAND-88-1581) Linear thermal expansion data for tuffs from the unsaturated zone at Yucca Mountain, Nevada: Yucca Mountain Site Characterization Project. Schwartz, B.M.; Chocas, C.S. Sandia National Labs., Albuquerque, NM (United States). Jul 1992. 146p. Sponsored by USDOE, Washington, DC (United States). DOE Contract AC04-76DP00789. Order Number DE92018930. Source: OSTI; NTIS; INIS; GPO Dep.

Experiment results are presented for linear thermal expansion measurements on tuffaceous rocks from the unsaturated <one at Yucca Mountain, Nevada. Data were obtained both with and without confining pressure. The accuracy of the unconfined data collected between 50 and $250^{\circ} \mathrm{C}$ is better than 1.8 percent, with the precision better than 4.5 ;percent. The accuracy of the unconfined data collected between ambient temperature and $50^{\circ} \mathrm{C}$ and is approximately 11 percent deviation from the true value, with a precision of 12 percent of the mean value. Because of experiment design and the lack of information related calibrations, the accuracy and precision of the confined thermal expansion measurements could not be determined.

229

(SAND-88-2730) TOSPAC calculations in support of the COVE 2A benchmarking activity: Yucca Mountain Site Characterization Project. Gauthier, J.H. (Spectra Research Inst., Albuquerque, NM (United States)); Zieman, N.B.; Miller, W.B. Sandia National Labs., Albuquerque, NM (United States); Spectra Research Inst., Albuquerque, NM (United States). Oct 1991. 200p. Sponsored by USDOE, Washington, DC (United States). DOE Contract AC04-76DP00789. Order Number DE92003588. Source: OSTI; NTIS; INIS; GPO Dep.

The purpose of the the Code Verification (COVE) $2 A$ benchmarking activity is to assess the numerical accuracy of several computer programs for the Yucca Mountain Site
Characterization Project of the Department of Energy. This paper presents a brief description of the computer program TOSPAC and a discussion of the calculational effort and results generated by TOSPAC for the COVE 2A problem set. The calculations were performed twice. The initial calculations provided preliminary results for comparison with the results from other COVE 2A participants. TOSPAC was modified in response to the comparison and the final calculations included a correction and several enhancements to improve efficiency. 8 refs.

230 (SAND-88-3032) Prediction of Pseudo relative velocity response spectra at Yucca Mountain for underground nuclear explosions conducted in the Pahute Mesa testing area at the Nevada testing site: Yucca Mountain Site Characterization Project. Phillips, J.S. Sandia National Labs., Albuquerque, NM (United States). Dec 1991. 214p. Sponsored by USDOE, Washington, DC (United States). DOE Contract AC04-76DP00789. Order Number DE92006613. Source: OSTI; NTIS; INIS; GPO Dep.

The Yucca Mountain Site Characterizatiôn Project (YMP), managed by the Office of Geologic Disposal of the Office of Civilian Radioactive Waste Management of the US Department of Energy, is examining the feasibility of siting a repository for commercial, high-level nuclear wastes at Yucca Mountain on and adjacent to the Nevada Test Site (NTS). This work, intended to extend our understanding of the ground motion at Yucca Mountain resulting from testing of nuclear weapons on the NTS, was funded by the Yucca Mountain project and the Military Applications Weapons Test Program. This report summarizes one aspect of the weapons test seismic investigations conducted in FY88. Pseudo relative velocity response spectra (PSRV) have been calculated for a large body of surface ground motions generated by underground nuclear explosions. These spectra have been analyzed and fit using multiple linear regression techniques to develop a credible prediction technique for surface PSRVs. In addition, a technique for estimating downhole PSRVs at specific stations is included. A data summary, data analysis, prediction development, prediction evaluation, software summary and FORTRAN listing of the prediction technique are included in this report.

231 (SAND-88-3164) Calculation of experiment uncertainty in laboratory determination of several geoengineering properties of tuffs from Yucca Mountain, Nevada: Yucca Mountain Site Characterization Project. Nimick, F.B.; Schwartz, B.M.; Price, R.H. Sandia National Labs., Albuquerque, NM (United States). Nov 1991. 39p. Sponsored by USDOE, Washington, DC (United States). DOE Contract AC04-76DP00789. Order Number DE92003612. Source: OSTI; NTIS; INIS; GPO Dep.

A method for estimating the precision and accuracy of measured parameters is described. Examples of application of the estimating method are presented for density, porosity, compressive strength, Young's modulus, Poisson's ratio, and thermal expansion. With the exception of the coefficient of linear thermal expansion, all laboratory data for these properties for tuff samples appear to have reasonable experiment uncertainties. Uncertainties in the thermalexpansion coefficients may be as high as $39 \%$ of the values, although most uncertainties for the coefficients are probably $\leq 2 \%$. 4 refs., 1 fig., 15 tabs.

232 (SAND-88-7051) Probable maximum flood control: Yucca Mountain Site Characterization Project. DeGabriele, C.E. (Bechtel National, Inc., San Francisco, CA 
(United States)); Wu, C.L. Sandia National Labs., Albuquerque, NM (United States); 'Bechtel National, Inc., San Francisco, CA (United States). Nov 1991. 59p. Sponsored by USDOE, Washington, DC (United States). DOE Contract AC04-76DP00789. Order Number DE92017282. Source: OSTI; NTIS; INIS; GPO Dep.

This study proposes preliminary design concepts to protect the waste-handling facilities and all shaft and ramp entries to the underground from the probable maximum flood (PMF) in the current design configuration for the proposed Nevada Nuclear Waste Storage Investigation (NNWSI) repository protection provisions were furnished by the United States Bureau of Reclamation (USSR) or developed from USSR data. Proposed flood protection provisions include site grading, drainage channels, and diversion dikes. Figures are provided to show these proposed flood protection provisions at each area investigated. These areas are the central surface facilities (including the waste-handling building and waste treatment building), tuff ramp portal, waste ramp portal, men-and-materials shaft, emplacement exhaust shaft, and exploratory shafts facility.

233 (SAND-88-7054) Processes, mechanisms, parameters, and modeling approaches for partially saturated flow in soil and rock media: Yucca Mountain Site Characterization Project. Wang, J.S.Y. (Lawrence Berkeley Lab., CA (United States)); Narasimhan, T.N. Sandia National Labs., Albuquerque, NM (United States); Lawrence Berkeley Lab., CA (United States). Jun 1993. 284p. Sponsored by USDOE, Washington, DC (United States). DOE Contract AC04-76DP00789. (LBL-26224). Order Number DE93018768. Source: OSTI; NTIS; INIS; GPO Dep.

This report discusses conceptual models and mathematical equations, analyzes distributions and correlations among hydrological parameters of soils and tuff, introduces new path integration approaches, and outlines scaling procedures to model potential-driven fluid flow in heterogeneous media. To properly model the transition from fracture-dominated flow under saturated conditions to matrix-dominated flow under partially saturated conditions, characteristic curves and permeability functions for tractures and matrix need to be improved and validated. Couplings from two-phase flow, heat transfer, solute transport, and rock deformation to liquid flow are also important. For stochastic modeling of alternating units of welded and nonwelded tuff or formations bounded by fault zones, correlations and constraints on average values of saturated permeability and air entry scaling factor between different units need to be imposed to avoid unlikely combinations of parameters and predictions. Large-scale simulations require efficient and verifiable numerical algorithms. New path integration approaches based on postulates of minimum work and mass conservation to solve flow geometry and potential distribution simultaneously are introduced. This verifiable integral approach, together with fractal scaling procedures to generate statistical realizations with parameter distribution, correlation, and scaling taken into account, can be used to quantify uncertainties and generate the cumulative distribution function for groundwater travel times.

234 (SAND-88-7061) Preclosure radiological safety analysis for accident conditions of the potential Yucca Mountain Repository: Underground facilities: Yucca Mountain Site Characterization Project. Ma, C.W. (Bechtel National, Inc.; San Francisco, CA (United States)); Sit, R.C.; Zavoshy, S.J.; Jardine, L.J.; Laub, T.W. Sandia National Labs., Albuquerque, NM (United States); Bechtel
National, Inc., San Francisco, CA (United States). Jun 1992. 158p. Sponsored by USDOE, Washington, DC (United States). DOE Contract AC04-76DP00789. Order Number DE92017362. Source: OSTI; NTIS; INIS; GPO Dep.

This preliminary preclosure radiological safety analysis assesses the scenarios, probabilities, and potential radiological consequences associated with postulated accidents in the underground facility of the potential Yucca Mountain repository. The analysis follows a probabilistic-riskassessment approach. Twenty-one event trees resulting in 129 accident scenarios are developed. Most of the scenarios have estimated annual probabilities ranging from $10^{-11}$ / yr to $10^{-5} / y r$. The study identifies 33 scenarios that could result in offsite doses over $50 \mathrm{mrem}$ and that have annual probabilities greater than $10^{-8} / \mathrm{yr}$. The largest offsite dose is calculated to be $220 \mathrm{mrem}$, which is less than the $500 \mathrm{mrem}$ value used to define items important to safety in 10 CFR 60 . The study does not address an estimate of uncertainties, therefore conclusions or decisions made as a result of this report should be made with caution.

235 (SAND-88-7065) Documentation and verification of the SHAFT code: Yucca Mountain Site Characterization Project. St.John, C.M. (Agapito (J.F.T.) and Associates, Inc., Grand Junction, CO (United States)). Sandia National Labs., Albuquerque, NM (United States); Agapito (J.F.T.) and Associates, Inc., Grand Junction, CO (United States). Dec 1991. 173p. Sponsored by USDOE, Washington, DC (United States). DOE Contract AC0476DP00789. Order Number DE92004786. Source: OST1; NTIS; INIS; GPO Dep.

The SHAFT code incorporates equations to compute stresses in a shaft liner when the rock through which a shaft passes is subject to known three-dimensional states of stress or strain. The deformation modes considered are hoop deformation, axial deformation, and shear on a plane normal to the shaft axis. Interaction between the liner and the soil and rock is considered, and it is assumed that the liner is in place before loading is applied. This code is intended to be used interactively but creates a permanent record complete with necessary quality assurance information. The code has been carefully verified for the case of generalized plane strain, in which an arbitrary axial strain can be defined. It may also be used for plane stress analysis. Output is given in the form of stresses at selected sample points in the linear and the rock and a simple graphical representation of the distribution of stress through the liner. 12 figs., 13 tabs.

236 (SAND-88-7124) Waste package emplacement borehole option study: Yucca Mountain Site Characterization Project. Streeter, W.S. (Parsons, Brinckerhoff, Quade and Douglas, Inc., San Francisco, CA (United States)). Sandia National Labs., Albuquerque, NM (United States); Parsons, Brinckerhoff, Quade and Douglas, Inc., San Francisco, CA (United States). Mar 1992. 58p. Sponsored by USDOE, Washington, DC (United States). DOE Contract AC04-76DP00789. Order Number DE92013459. Source: OSTI; NTIS; INIS; GPO Dep.

This study evaluates the cost and thermal effects of various waste package emplacement configurations that differ in emplacement orientation, number of containers per borehole, and standoff distance at the potential Yucca Mountain nuclear waste repository. In this study, eight additional alternatives to the vertical and horizontal orientation options presented in the Site Characterization Plan Conceptual 
behavior for both joint sets. Because nonlinear behavior is allowed for both joint sets, a great many cases must be considered to fully describe the joint shear behavior of the jointed medium. An extensive set of equations is required to describe the joint shear stress and slip displacements that can occur for all the various cases. This report examines possible methods for simplifying this set of equations so that the model can be implemented efficiently form a computational standpoint. The shear model must be examined carefully to obtain a computationally efficient implementation that does not lead to numerical problems. The application to fractures in rock is discussed. 5 refs., 4 figs.

246 (SAND-89-7002) Preclosure radiological safety analysis for the exploratory shaft facilities: Yucca Mountain Site Characterization Project. Ma, C.W. (Bechtel National, inc., San Francisco, CA (United States)); Miller, D.D.; Jardine, L.J. Sandia National Labs., Albuquerque, NM (United States); Bechtel National, Inc., San Francisco, CA (United States). Jun 1992. 111p. Sponsored by USDOE, Washington, DC (United States). DOE Contract AC0476DP00789. Order Number DE92017360. Source: OSTI; NTIS; INIS; GPO Dep.

This study assesses which structures, systems, and components of the exploratory shaft facility (ESF) are important to safety when the ESF is converted to become part of the operating waste repository. The assessment follows the methodology required by DOE Procedure AP-6.10Q. Failures of the converted ESF during the preclosure period have been evaluated, along with other underground accidents, to determine the potential offsite radiation doses and associated probabilities. The assessment indicates that failures of the ESF will not result in radiation doses greater than 0.5 rem at the nearest unrestricted area boundary. Furthermore, credible accidents in other underground facilities will not result in radiation doses larger than 0.5 rem, even if any structure, system, or component of the converted ESF fails at the same time. Therefore, no structure, system, or component of the converted ESF is important to safety.

247 (SAND-89-7007) Transportation cask decontamination and maintenance at the potential Yucca Mountain repository: Yucca Mountain Site characterizatjon project. Hartman, D.J. (Bechtel National, Inc., San Francisco, CA (United States)); Miller, D.D.; Hill, R.R. Sandia National Labs., Albuquerque, NM (United States); Bechtel National, Inc., San Francisco, CA (United States). Apr 1992. 145p. Sponsored by USDOE, Washington, DC (United States). DOE Contract AC04-76DP00789. Order Number DE92013055. Source: OSTI; NTIS; INIS; GPO Dep.

This study investigates spent fuel cask handling experience at existing nuclear facilities to determine appropriate cask decontamination and maintenance operations at the potential Yucca Mountain repository. These operations are categorized as either routine or nonroutine. Routine cask decontamination and maintenance tasks are performed in the cask preparation area at the repository. Casks are taken offline to a separate cask maintenance area for major nonroutine tasks. The study develops conceptual designs of the cask preparation area and cask maintenance area. The functions, layouts, and major features of these areas are also described.

248 (SAND-89-7008) Effects of various radiation source characteristics on shielding requirements at the potential Yucca Mountain repository. Smith, D.W. (Bechtel National, Inc., San Francisco, CA (United States)); Miller,
D.D.; Hill, R.R. Sandia National Labs., Albuquerque, NM (United States); Bechtel National, Inc., San Francisco, CA (United States). Feb 1992. 207p. Sponsored by USDOE, Washington, DC (United States). DOE Contract AC0476DP00789. Order Number DE92010359. Source: OSTI; NTIS; INIS; GPO Dep.

This radiation shielding study provides dose rate information that can be used to estimate required shielding thicknesses for different repository configurations, including various hot cells and vaults in the waste-handling building. the boreholes in the underground emplacement area, and the transter casks. The study determines gamma and neutron source strengths for various waste types and source geometries representative of conditions at the repository and determines dose rates as a function of shielding thickness for selected materials.

249 (SAND-89-7018) Conceptual, experimental and computational approaches to support performance assessment of hydrology and chemical transport at Yucca Mountain: Yucca Mountain Site Characterization Project. Narasimhan, T.N. (Lawrence Berkeley Lab., CA (United States)); Wang, J.S.Y. Sandia National Labs., Albuquerque, NM (United States); Lawrence Berkeley Lab., CA (United States). Jul 1992. 125p. Sponsored by USDOE, Washington, DC (United States). DOE Contract AC0476DP00789 ; AC03-76SF00098. (LBL-28613). Order Number DE92018938. Source: OST!; NTIS; INIS; GPO Dep.

The authors of this report have been participating in the Sandia National Laboratory's hydrologic performance assessment of the Yucca Mountain, Nevada, since 1983. The scope of this work is restricted to the unsaturated zone at Yucca Mountain and to technical questions about hydrology and chemical transport. The issues defined here are not to be confused with the elaborate hierarchy of issues that forms the framework of the US Department of Energy plans for characterizing the site (DOE, 1989). The overall task of hydrologic performance assessment involves issues related to hydrology, geochemistry, and energy transport in a highly heterogeneous natural geologic system which will be perturbed in a major way by the disposal activity. Therefore, a rational evaluation of the performance assessment issues must be based on an integrated appreciation of the aforesaid interacting processes. Accordingly, a hierarchical approach is taken in this report, proceeding from the statement of the broad features of the site that make it the site for intensive studies and the rationale for disposal strategy, through the statement of the fundamental questions that need to be answered, to the identification of the issues that need resolution. Having identified the questions and issues, the report then outlines the tasks to be undertaken to resolve the issues. The report consists essentially of two parts. The first part deals with the definition of issues summarized above. The second part summarizes the findings of the authors between 1983 and 1989 under the activities of the former Nevada Nuclear Waste Storage Investigations (NNWSI) and the current YMP.

250 (SAND-89-7023) Documentation and verifica tion of STRES3D, Version 4.0: Yucca Mountain Site Characterization Project. Asgian, M.I. (Agapito (J.F.T.) and Associates, Inc., Grand Junction, CO (United States)); St. John, C.M.; Hardy, M.P.; Goodrich, R.R. Sandia National Labs., Albuquerque, NM (United States); Agapito (J.F.T.) and Associates, inc., Grand Junction, CO (United States). Dec 1991. 235p. Sponsored by USDOE, Washington, DC 
(United States). DOE Contract AC04-76DP00789. Order Number DE92004785. Source: OSTI; NTIS; INIS; GPO Dep.

STRES3D is a thermomechanical analysis code for predicting transient temperatures, stresses and displacements in an infinite and semi-infinite, conducting, homogeneous, elastic medium. The heat generated at the sources can be constant or decay exponentially with time. Superposition is used to integrate the effect of heat sources distributed in space and time to simulate the thermomechanical effect of placement of heat generating nuclear waste canisters in an underground repository. Heat sources can be defined by point, lines or plates with numerical integration of the kernal point source solution used to develop the line and plate sources. STRES3D is programmed using FORTRAN77 and is suitable for use on micro or larger computer systems.

251 (SAND-89-7024) Identification of structures, systems, and components important to safety at the potential repository at Yucca Mountain: Yucca Mountain Site Characterization Project. Hartman, D.J. (Bechtel National, Inc., San Francisco, CA (United States)); Miller, D.D.; Klamerus, L.J. Sandia National Labs., Albuquerque, NM (United States); Bechtel National, Inc., San Francisco, CA (United States). Oct 1991. 110p. Sponsored by USDOE, Washington, DC (United States). DOE Contract ACO476DP00789. Order Number DE92003946. Source: OSTI; NTIS; INIS; GPO Dep.

This study recommends which structures, systems, and components of the potential repository at Yucca Mountain are important to safety. The assessment was completed in April 1990 and uses the reference repository configuration in the Site Characterization Plan Conceptual Design Report and follows the methodology required at that time by DOE Procedure AP6.10-Q. Failures of repository items during the preclosure period are evaluated to determine the potential offsite radiation doses and associated probabilities. Items are important to safety if, in the event they fail to perform their intended function, an accident could result which causes a dose commitment greater than 0.5 rem to the whole body or any organ of an individual in an unrestricted area. This study recommends that these repository items include the structures that house spent fuel and high-level waste, the associated filtered ventilation exhaust systems, certain waste- handling equipment, the waste containers, the waste treatment building structure, the underground waste transporters, and other items listed in this report. This work was completed April 1990. 27 refs., 7 figs., 9 tabs.

252 (SAND-90-0018C) Preliminary drift design analyses for nuclear waste repository in tuff. Hardy, M.P. (Agapito (J.F.T.) and Associates, Inc., Grand Junction, CO (United States)); Brechtel, C.E.; Goodrich, R.R.; Bauer, S.J. Sandia National Labs., Albuquerque, NM (United States). 30 Jan 1990. 8p. Sponsored by USDOE, Washington, DC (United States). DOE Contract AC04-76DP00789. (CONF-900646-12: 31. US symposium on rock mechanics, Golden, CO (United States), 18-20 Jun 1990). Order Number DE92003144. Source: OSTI; NTIS; INIS; GPO Dep.

The Yucca Mountain Project (YMP) is examining the feasibility of siting a repository for high-level nuclear waste at Yucca Mountain, on and adjacent to the Nevada Test Site (NTS). The proposed repository will be excavated in the Topopah Spring Member, which is a moderately fractured, unsaturated, welded tuff. Excavation stability will be required during construction, waste emplacement, retrieval (if required), and closure to ensure worker safety. The subsurface excavations will be subject to stress changes resulting from thermal expansion of the rock mass and seismic events associated with regional tectonic activity and underground nuclear explosions (UNEs). Analyses of drift stability are required to assess the acceptable waste emplacement density, to design the drift shapes and ground support systems, and to establish schedules and cost of construction. This paper outlines the proposed methodology to assess drift stability and then focuses on an example of its application to the YMP repository drifts based on preliminary site data. Because site characterization activities have not begun, the database currently lacks the extensive site-specific field and laboratory data needed to form conclusions as to the final ground support requirements. This drift design methodology will be applied and refined as more site-specific data are generated and as analytical techniques and methodologies are verified during the site characterization process.

253 (SAND-90-2261) Research program to develop and validate conceptual models for flow and transport through unsaturated, fractured rock: Yucca Mountain Site Characterization Project. Glass, R.J.; Tidwell, V.C. Sandia National Labs., Albuquerque, NM (United States). Sep 1991. 63p. Sponsored by USDOE, Washington, DC (United States). DOE Contract AC04-76DP00789. Order Number DE92004301. Source: OSTI; NTIS; INIS; GPO Dep.

As part of the Yucca Mountain Project, our research program to develop and validate conceptual models for flow and transport through unsaturated fractured rock integrates fundamental physical experimentation with conceptual model formulation and mathematical modeling. Our research is directed toward developing and validating macroscopic, continuum-based models and supporting effective property models because of their widespread utility within the context of this project. Success relative to the development and validation of effective property models is predicted on a firm understanding of the basic physics governing-flow through fractured media, specifically in the areas of unsaturated flow and transport in a single fracture and fracture-matrix interaction.

254 (SAND-90-2491) Summary and evaluation of existing geological and geophysical data near prospective surface facilities in Midway Valley, Yucca Mountain Project, Nye County, Nevada: Yucca Mountain Site Characterization Project. Gibson, J.D. (Sandia National Labs., Albuquerque, NM (United States)); Swan, F.H.; Wesling, J.R.; Bullard, T.F.; Perman, R.C.; Angell, M.M.; DiSilvestro, L.A. Sandia National Labs., Albuquerque, NM (United States). Jan 1992. 282p. Sponsored by USDOE, Washington, DC (United States). DOE Contract ACO476DP00789. Order Number DE92016673. Source: OSTI; NTIS; INIS; GPO Dep.

Midway Valley, located at the eastern base of the Yucca Mountain in southwestern Nevada, is the preferred location of the surface facilities for the potential high-level nuclear waste repository at Yucca Mountain. One goal in siting these surface facilities is to avoid faults that could produce relative displacements in excess of $5 \mathrm{~cm}$ in the foundations of the waste-handling buildings. This study reviews existing geologic and geophysical data that can be used to assess the potential for surface fault rupture within Midway Valley. Dominant tectonic features in Midway Valley are northtrending, westward-dipping normal faults along the margins of the valley: the Bow Ridge fault to the west and the Paintbrush Canyon fault to the east. Published estimates of average Quaternary slip rates for these faults are very low but the age of most recent displacement and the amount of 
Order Number DE93004386. Source: OSTI; NTIS; INIS; GPO Dep.

Sequential indicator simulation (SIS) is a geostatistical technique designed to aid in the characterization of uncertainty about the structure or behavior of natural systems. This report discusses a simulation experiment designed to study the quality of uncertainty bounds generated using SIS. The results indicate that, while SIS may produce reasonable uncertainty bounds in many situations, factors like the number and location of available sample data, the quality of variogram models produced by the user, and the characteristics of the geologic region to be modeled, can all have substantial effects on the accuracy and precision of estimated confidence limits. It is recommended that users of SIS conduct validation studies for the technique on their particular regions of interest before accepting the output uncertainty bounds.

265 (SAND-91-0790) Estimation of the limitations for surficial water addition above a potential high level radioactive waste repository at Yucca Mountain, Nevada: Yucca Mountain Site Characterization Project. Fewell, M.E.; Sobolik, S.R.; Gauthier, J.H. Sandia National Labs., Albuquerque, NM (United States). Jan 1992. 70p. Sponsored by USDOE, Washington, DC (United States). DOE Contract AC04-76DP00789. Order Number DE92008454. Source: OSTI; NTIS; INIS; GPO Dep.

The Yucca Mountain Site Characterization Project is studying Yucca Mountain in southwestern Nevada as a potential site for a high-level nuclear waste repository. Site characterization includes surface-based and underground testing. Analyses have been performed to design site characterization activities with minimal impact on the ability of the site to isolate waste, and on tests performed as part of the characterization process. One activity of site characterization is the construction of an Exploratory Studies Facility, consisting of underground shafts, drifts, and ramps, and the accompanying surface pad facility and roads. The information in this report addresses the following topics: (1) a discussion of the potential effects of surface construction water on repository-performance, and on surface and underground experiments; (2) one-dimensional numerical calculations predicting the maximum allowable amount of water that may infiltrate the surface of the mountain without affecting repository performance; and (3) two-dimensional numerical calculations of the movement of that amount of surface water and how the water may affect repository performance and experiments. The results contained herein should be used with other site data and scientific/ engineering judgement in determining controls on water usage at Yucca Mountain. This document contains information that has been used in preparing Appendix 1 of the Exploratory Studies Facility Design Requirements document for the Yucca Mountain Site Characterization Project.

266 (SAND-91-0791) Movement of shaft and drift construction water in Yucca Mountain, Nevada: An extended study: Yucca Mountain Site Characterization Project. Sobolik, S.R.; Fewell, M.E.; Eaton, R.R. Sandia National Labs., Albuquerque, NM (United States). Dec 1991. 73p. Sponsored by USDOE, Washington, DC (United States). DOE Contract AC04-76DP00789. Order Number DE92006614. Source: OSTI; NTIS; INIS; GPO Dep.

The Yucca Mountain Site Characterization Project is studying Yucca Mountain in southwestern Nevada as a potential site for a high-level nuclear waste repository. Site characterization includes surface-based and underground testing. Analyses have been performed to design site characterization activities with minimal impact on the ability of the site to isolate waste, and on tests performed as part of the characterization process. One activity of site characterization is the construction of an Exploratory Studies Facility, for which many design options are being considered, including shafts, drifts, and ramps. The information in this report pertains to: (1) engineering calculations of the potential distribution of residual water from constructing the shafts and drifts; (2) numerical calculations predicting the movement of residual construction water from the shaft and drift walls into the rock; and (3) numerical calculations of the movement of residual water and how the movement is affected by ventilation. This document contains information that has been used in preparing Appendix 1 of the Exploratory Studies Facility Design Requirements document for the Yucca Mountain Project.

267 (SAND-91-0792) Estimation of the impact of water movement from sewage and settling ponds near a potential high level radioactive waste repository in Yucca Mountain, Nevada: Yucca Mountain Site Characterization Project. Sobolik, S.R.; Fewell, M.E. Sandia National Labs., Albuquerque, NM (United States). Feb 1992. 60p. Sponsored by USDOE, Washington, DC (United States). DOE Contract AC04-76DP00789. Order Number DE92010761. Source: OSTI; NTIS; INIS; GPO Dep.

The Yucca Mountain Site Characterization Project is studying Yucca Mountain in southwestern Nevada as a potential site for a high-level nuclear waste repository. Site characterization includes surface-based and underground testing. Analyses have been performed to design site characterization activities with minimal impact on the ability of the site to isolate waste, and on tests performed as part of the characterization process. One activity of site characterization is the construction of an Exploratory Studies Facility, which may include underground shafts, dritts, and ramps, and the accompanying ponds used for the storage of sewage water and muck water removed from construction operations. The information in this report pertains to the twodimensional numerical calculations modelling the movement of sewage and settling pond water, and the potential effects of that water on repository performance and underground experiments. This document contains information that has been used in preparing Appendix I of the Exploratory Studies Facility Design Requirements document (ESF DR) for the Yucca Mountain Site Characterization Project.

268 (SAND-91-0894) Anisotropy of the Topopah Spring Member Tuff. Martin, R.J. III (New England Research, Inc., White River Junction, VT (United States)); Boyd, P.J.; Haupt, R.W.; Price, R.H. Sandia National Labs., Albuquerque, NM (United States). Jul 1992. 39p. Sponsored by USDOE, Washington, DC (United States). DOE Contract AC04-76DP00789. Order Number DE92017356. Source: OSTI; NTIS; INIS; GPO Dep.

Mechanical properties of the tuffaceous rocks within Yucca Mountain are needed for near and far-field modeling of the potential nuclear waste repository. If the mechanical properties are significantly anisotropic (i.e., direction-dependent), a more complex model is required. Relevant data from tuffs tested in earlier studies indicate that elastic and strength properties are anisotropic. This scoping study confirms the elastic anisotropy and concludes some tuffs are transversely isotropic. An approach for sampling and testing the rock to determine the magnitude of the anisotropy is proposed. 
269 (SAND-91-1493) Equivalent Energy Density concept: A preliminary reexamination of a technique for equating thermal loads: Yucca Mountain Site Characterization Project. Ryder, E.E. Sandia National Labs., Albuquerque, NM (United States). Aug 1992. 111p. Sponsored by USDOE, Washington, DC (United States). DOE Contract AC04-76DP00789. Order Number DE93000844. Source: OSTI; NTIS; INIS; GPO Dep.

Historical and projected inventories of spent fuel from commercial light-water nuclear reactors exhibit diverse decay characteristics and ages. This report summarizes a preliminary reexamination of a method for determining equivalent thermal loads for the range of spent fuel expected at a potential underground repository. The method, known at the Equivalent Energy Density (EED) concept, bases its equivalence criteria on the assumption that a given waste will produce worst-case thermomechanical effects equal to worst-case thermomechanical effects produced by a baseline waste, provided that the thermal energy deposited in the host rock over a specified deposition period is the same for both waste descriptions. To test this assumption, temperature histories at representative locations within the host rock were calculated using layouts defined by the EED concept and four deposition periods $(20,50,100$, and 300 years). It was found that the peak temperatures at nearfield locations were best matched by the shorter deposition periods of 20 and 50 years. However, due to the sensitivity of the near-field environment to short-term canister-tocanister interactions, caution, should be used when choosing a near-field deposition period. At the location chosen to represent the far-field, a 300-year deposition period provided reasonable correspondence of peak temperature responses for all waste descriptions examined.

270 (SAND-91-1676C) Analysis of slot cutting methods for the Yucca Mountain heated block test using a compliant-joint model. Chen, E.P.; Costin, L.S. Sandia National Labs., Albuquerque, NM (United States). [1991]. 8p. Sponsored by USDOE, Washington, DC (United States). DOE Contract AC04-76DP00789. (CONF-9206333: International Society for Rock Mechanics fractured and jointed rock masses conference, Lake Tahoe, CA (United States), 3-5 Jun 1992). Order Number DE92016083. Source: OSTI; NTIS; INIS; GPO Dep.

Pretest analysis of a heated block test, proposed for the Exploratory Studies Facility at Yucca Mountain, Nevada, was conducted in this investigation. Specifically, the study focuses on the evaluation of the various designs to drill holes and cut slots for the block. The thermal/mechanical analysis was based on the finite element method and a compliant-joint rock-mass constitutive model. Based on the calculated results, relative merits of the various test designs are discussed.

271 (SAND-91-1730C) A study of discrete and continuum joint modeling techniques. Jung, J.; Brown, S.R. Sandia National Labs., Albuquerque, NM (United States). [1992]. 8p. Sponsored by USDOE, Washington, DC (United States). DOE Contract AC04-76DP00789. (CONF-9206331: International Society for Rock Mechanics fractured and jointed rock masses conference, Lake Tahoe, CA (United States), 3-5 Jun 1992). Order Number DE92012631. Source: OSTI; NTIS; INIS; GPO Dep.

This paper presents the results of a numerical and experimental study in which finite element and discrete element techniques were used to analyze a layered polycarbonate plate model subjected to uniaxial compression. Also, the two analysis techniques were used to compute the response of an eight meter diameter drift in jointed-rock. The drift was subjected to in-situ and far-field induced thermal stresses. The finite element analyses used a continuum rock model to represent the jointed-rock. A comparison of the analyses showed that the finite element continuum joint model consistently predicted less joint slippage than did the discrete element analyses, although far-field displacements compared well.

272 (SAND-91-1788C) Uncertainty and sensitivity results for pre-waste-emplacement groundwater travel time. Kaplan, P.G. Sandia National Labs., Albuquerque, NM (United States). 13 Dec 1991. 4p. Sponsored by USDOE, Washington, DC (United States). DOE Contract AC0476DP00789. (CONF-920430-13: 3. international high level radioactive waste management (IHLRWM) conference, Las Vegas, NV (United States), 12-16 Apr 1992). Order Number DE92005182. Source: OSTI; NTIS; INIS; GPO Dep.

Uncertainty and sensitivity analyses for pre-wasteemplacement groundwater travel time were conducted. Although preliminary, a number of interesting results were obtained. Uncertainty in the groundwater travel time statistics, as measured by the coefficient of variation, increases and then decreases as the modeled system transitions from matrix-dominated to fracture-dominated flow. The uncertainty analysis also suggests that the median, as opposed to the mean, may be a better indicator of performance with respect to the regulatory criterion. The sensitivity analysis shows a strong correlation between an effective fracture property, fracture porosity, and failure to meet the regulatory pre-waste-emplacement groundwater travel time criterion of 1000 years.

273 (SAND-91-1891C) Estimating the consequences of significant fracture flow at Yucca Mountain. Gauthier, J.H. (Spectra Research Inst., Albuquerque, NM (United States)); Wilson, M.L.; Lauffer, F.C. Sandia National Labs., Albuquerque, NM (United States). 11 Dec 1991. 16p. Sponsored by USDOE, Washington, DC (United States). DOE Contract AC04-76DP00789. (CONF-920430-9: 3. international high level radioactive waste management (IHLRWM) conference, Las Vegas, NV (United States), 1216 Apr 1992). Order Number DE92004889. Source: OSTI; NTIS; INIS; GPO Dep.

A simple model is proposed for investigating the possibility of significant fracture flow at Yucca Mountain, Nevada. The model allows an estimate of the number of flowing fractures at Yucca Mountain based on the size of the fractures and the yearly volume of infiltrating water. Given the number of flowing fractures, the number of waste containers they contact is estimated by a geometric argument. Preliminary results indicate that the larger the flowing fractures, the lower the releases of radionuclides. Also, even with significant fracture flow, releases could be well below the limits set by the Environmental Protection Agency.

274 (SAND-91-1925C) Deterministic geologic processes and stochastic modeling. Rautman, C.A. (Sandia National Labs., Albuquerque, NM (United States)); Flint, A.L. Sandia National Labs., Albuquerque, NM (United States). [1991]. 9p. Sponsored by USDOE, Washington, DC (United States). DOE Contract AC04-76DP00789; Al0878ET44802. (CONF-920430-30: 3. international high level radioactive waste management (IHLRWM) conference, Las Vegas, NV (United States), 12-16 Apr 1992). Order Number DE92005457. Source: OSTI; NTIS; INIS; GPO Dep. 
Recent outcrop sampling at Yucca Mountain, Nevada, has produced significant new information regarding the distribution of physical properties at the site of a potential high-level nuclear waste repository. Consideration of the spatial distribution of measured values and geostatistical measures of spatial variability indicates that there are a number of widespread deterministic geologic features at the site that have important implications for numerical modeling of such performance aspects as ground water flow and radionuclide transport. These deterministic features have their origin in the complex, yet logical, interplay of a number of deterministic geologic processes, including magmatic evolution; volcanic eruption, transport, and emplacement; postemplacement cooling and alteration; and late-stage (diagenetic) alteration. Because of geologic processes responsible for formation of Yucca Mountain are relatively well understood and operate on a more-or-less regional scale, understanding of these processes can be used in modeling the physical properties and performance of the site. Information reflecting these deterministic geologic processes may be incorporated into the modeling program explicitly, using geostatistical concepts such as soft information, or implicitly, through the adoption of a particular approach to modeling. It is unlikely that any single representation of physical properties at the site will be suitable for all modeling purposes. Instead, the same underlying physical reality will need to be described many times, each in a manner conducive to assessing specific performance issues.

275

(SAND-91-1926C) Modulus dispersion and attenuation in tuff and granite. Haupt, R.W. (New England Research, inc., White River Junction, VT (United States)); Martin, R.J. III; Tang, X.; Dupree, W.J.; Price, R.H. Sandia National Labs., Albuquerque, NM (United States). 23 Dec 1991. 13p. Sponsored by USDOE, Washington, DC (United States). DOE Contract AC04-76DP00789. (CONF-9206343: 33. US symposium on rock mechanics, Santa $\mathrm{Fe}$, NM (United States), 3-10 Jun 1992). Order Number DE92005459. Source: OSTI; NTIS; INIS; GPO Dep.

The effects of loading frequency, strain amplitude, and saturation on elastic moduli and attenuation have been measured in samples of the Topopah Spring Member welded tuff. Four different laboratory techniques have been used to determine Young's modulus and extensional wave attenuation at frequencies ranging from $10^{-2}$ to $10^{6} \mathrm{~Hz}$. The results are compared with data acquired for Sierra White granite under the same conditions. The modulus and attenuation in room dry samples remain relatively constant over frequency. Frequency dependent attenuation and modulus dispersion are observed in the saturated samples and are attributed to fluid flow and sample size. The properties of tuff were independent of strain amplitude in room dry and saturated conditions.

276 (SAND-91-1927C) An overview of the Yucca Mountain Global/Regional Climate Modeling Program. Sandoval, R.P. (Sandia National Labs., Albuquerque, NM (United States)); Behl, Y.K.; Thompson, S.L. Sandia National Labs., Albuquerque, NM (United States). 10 Jan 1992. $8 p$. Sponsored by USDOE, Washington, DC (United States). DOE Contract AC04-76DP00789. (CONF-920430-40: 3 . international high level radioactive waste management (IHLRWM) conference, Las Vegas, NV (United States), $12-$ $16 \mathrm{Apr} 1992$ ). Order Number DE92006807. Source: OSTl; NTIS; INIS; GPO Dep.
The US Department of Energy (DOE) has developed a site characterization plan (SCP) to collect detailed information on geology, geohydrology, geochemistry, geoengineering, hydrology, climate, and meteorology (collectively referred to as "geologic information") of the Yucca Mountain site. This information will be used to determine if a mined geologic disposal system (MGDS) capable of isolating high-level radioactive waste without adverse effects to public health and safety over 10,000 years, as required by regulations 40 CFR Part 191 and 10 CFR Part 60, could be constructed at the Yucca Mountain site. Forecasts of future climates conditions for the Yucca Mountain area will be based on both empirical and numerical techniques. The empirical modeling is based on the assumption that future climate change will follow past patterns. In this approach, paleclimate records will be analyzed to estimate the nature, timing, and probability of occurrence of certain climate states such as glacials and interglacials over the next 10,000 years. For a given state, key climate parameters such as precipitation and temperature will be assumed to be the same as determined from the paleoclimate data. The numerical approach, which is the primary focus of this paper, involves the numerical solution of basic equations associated with atmospheric motions. This paper describes these equations and the strategy for solving them to predict future climate conditions around Yucca Mountain.

277 (SAND-91-1958C) Summary of the Exploratory Studies Facility Alternatives Study: Draft. Costin, L.S.; Dennis, A.W.; Stevens, A.L. Sandia National Labs., Albuquerque, NM (United States). 5 Dec 1991. 11p. Sponsored by USDOE, Washington, DC (United States). DOE Contract AC04-76DP00789. (CONF-920430-34-Draft: 3. international high level radioactive waste management (IHLRWM) conference, Las Vegas, NV (United States), 12-16 Apr 1992). Order Number DE92006554. Source: OSTI; NTIS; INIS; GPO Dep.

This paper presents a summary of the conduct and findings of the Exploratory Studies Facility Alternatives Study (ESF-AS). The Exploratory Studies Facility (ESF) is being planned for use in the characterization of a site for a potential high-level nuclear waste repository at Yucca Mountain, NV. The purpose of the ESF-AS were to identify and rank order ESF-repository options and to improve understanding of the favorable or unfavorable features of the ESF design. The analysis resulted in the ranking of 34 options, in accordance with the extent to which each option could achieve the objectives. Additional findings regarding design features that were identified as key elements in an option's ability to provide good overall performance are also discussed.

278 (SAND-91-1982C) Fault stress analysis for the Yucca Mountain Site Characterization Project. Bauer, S.J. (Sandia National Labs., Albuquerque, NM (United States)); Hardy, M.P.; Goodrich, R.; Lin, M. Sandia National Labs., Albuquerque, NM (United States). 11 Dec 1991. 22p. Sponsored by USDOE, Washington, DC (United States). DOE Contract AC04-76DP00789. (CONF-920430-5: 3 . international high level radioactive waste management (IHLRWM) conference, Las Vegas, NV (United States), 1216 Apr 1992). Order Number DE92004895. Source: OSTI; NTIS; INIS; GPO Dep.

An understanding of the state of stress on faults is important for pre- and postclosure performance considerations for the potential high-level radioactive waste repository at Yucca Mountain. This paper presents the results of threedimensional numerical analyses that provide estimates of 
the state of stress through time $(10,000$ years) along three major faults in the vicinity of the potential repository due to thermal stresses resulting from waste emplacement. It was found, that the safety factor for slip close to the potential repository increases with time after waste emplacement. Possible fault slip is predicted above and below the potential repository for certain loading conditions and times. In general, thermal loading reduces the potential for slip in the vicinity of the potential repository.

279 (SAND-91-1983C) X-ray and visible light transmission as two-dimensional, full-field moisture-sensing techniques: A preliminary comparison. Tidwell, V.C.; Glass, R.J. Sandia National Labs., Albuquerque, NM (United States). 21 Jan 1992. 12p. Sponsored by USDOE, Washington, DC (United States); Environmental Protection Agency, Washington, DC (United States). DOE Contract ACO476DP00789. Grant R81-2919-01-0. (CONF-920430-43: 3. international high level radioactive waste management (IHLRWM) conference, Las Vegas, NV (United States), $12-$ $16 \mathrm{Apr}$ 1992). Order Number DE92006836. Source: OSTI; NTIS; INIS; GPO Dep.

Two independent high-resolution moisture-sensing techniques, $x$-ray absorption and light transmission, have been developed for use in two-dimensional, thin-slab experimental systems. The techniques yield full-field measurement capabilities with exceptional resolution of moisture content in time and space. These techniques represent powerful tools for the experimentalist to investigate processes governing unsaturated flow and transport through fractured and nonfractured porous media. Evaluation of these techniques has been accomplished by direct comparison of data obtained by means of the $\mathrm{x}$-ray and light techniques as well as comparison with data collected by gravimetric and gamma-ray densitometry techniques. Results show excellent agreement between data collected by the four moisture-content measurement techniques. This program was established to support the Yucca Mountain Site Characterization Project.

\section{0}

(SAND-91-1984C) Field research program for unsaturated flow and transport experimentation. Tidwell, V.C.; Rautman, C.A.; Glass, R.J. Sandia National Labs., Albuquerque, NM (United States). [1992]. 6p. Sponsored by USDOE, Washington, DC (United States). DOE Contract AC04-76DP00789. (CONF-920430-19: 3. international high level radioactive waste management (IHLRWM) conference, Las Vegas, NV (United States), 12-16 Apr 1992). Order Number DE92005322. Source: OSTI; NTIS; INIS; GPO Dep.

As part of the Yucca Mountain Site Characterization Project, a field research program has been developed to refine and validate models for flow and transport through unsaturated fractured rock. Validation of these models within the range of their application for performance assessment requires a more sophisticated understanding of the processes that govern flow and transport within fractured porous media than currently exists. In particular, our research is prioritized according to understanding and modeling processes that, if not accurately incorporated into performance assessment models, would adversely impact the project's ability to evaluate repository performance. For this reason, we have oriented our field program toward enhancing our understanding of scaling processes as they relate to effective media property modeling, as well as to the conceptual modeling of complex flow and transport phenomena.
281 (SAND-91-2010C) Use of Wingz spreadsheet as an Interface to total-system performance assessment. Chambers, W.F.; Treadway, A.H. Sandia National Labs., Albuquerque, NM (United States). [1992]. 5p. Sponsored by USDOE, Washington, DC (United States). DOE Contract AC04-76DP00789. (CONF-920430-15: 3. international high level radioactive waste management (IHLRWM) conference, Las Vegas, NV (United States), 12-16 Apr 1992). Order Number DE92005179. Source: OSTI; NTIS; INIS; GPO Dep.

A commercial spreadsheet has been used as an interface to a set of simple models to simulate possible nominal flow and failure scenarios at the potential high-tevel nuclear waste repository at Yucca Mountain, Nevada. Individual models coded in FORTRAN are linked to the spreadsheet. Complementary cumulative probability distribution functions resulting from the models are plotted through scripts associated with the spreadsheet. All codes are maintained under a source code control system for quality assurance. The spreadsheet and the simple models can be run on workstations, PCs, and Macintoshes. The software system is designed so that the FORTRAN codes can be run on several machines if a network environment is available.

282 (SAND-91-2029C) Comparison of two conceptual models of flow using the TSA. Wilson, M.L. Sandia National Labs., Albuquerque, NM (United States). [1992]. 9p. Sponsored by USDOE, Washington, DC (United States). DOE Contract AC04-76DP00789. (CONF-920430-8: 3. international high level radioactive waste management (IHLRWM) conference, Las Vegas, NV (United States), 1216 Apr 1992). Order Number DE92004890. Source: OSTI; NTIS; INIS; GPO Dep.

As part of the performance-assessment task for the potential repository site at Yucca Mountain, Nevada, Sandia National Laboratories is developing a set of programs called the Total-System Analyzer (TSA). The TSA is one of the tools being used in the current effort to provide a systematic preliminary estimate the total-system performance of the Yucca Mountain site. The purposes of this paper are twofold: (1) to describe capabilities that have been added to the TSA in the last year; and (2) to present a comparison of two conceptual models of unsaturated-zone flow and transport, in terms of the performance measure specified by the Environmental Protection Agency (EPA) in 40 CFR Part 191. The conceptual-model comparison is intended to demonstrate the new TSA capabilities and at the same time shed some light on the performance implications of fracture flow at Yucca Mountain. Unsaturated fracture flow is not yet well understood, and it is of great importance in determining the performance of Yucca Mountain.

283 (SAND-91-2030C) Wetted-region structure in horizontal unsaturated fractures: Water entry through the surrounding porous matrix. Glass, R.J. (Sandia National Labs., Albuquerque, NM (United States)); Norton, D.L. Sandia National Labs., Albuquerque, NM (United States). 11 Dec 1991. 24p. Sponsored by USDOE, Washington, DC (United States). DOE Contract AC04-76DP00789. Order Number DE92005180. Source: OSTI; NTIS; INIS; GPO Dep.

Small-scale processes that influence wetted structure within the plane of a horizontal fracture as the fracture wets or drains through the matrix are investigated. Our approach integrates both aperture-scale modeling and physical experimentation. Several types of aperture-scale models have been defined and implemented. A series of physical experimental systems that allow us to measure wetted-region 
structure as a function of system parameters and water pressure head in analogue fractures also have been designed. In our preliminary proof-of-concept experiment, hysteresis is clearly evident in the measured saturation/ pressure relation, as is the process of air entrapment, which causes a reduction in the connected areas between blocks and the wetted region available for flow in the plane of the fracture. A percolation threshold where the system is quickly spanned, allowing fluid conduction in the fracture plane, is observed which is analogous to that found in the aperturescale models. A fractal wetted and entrapped-region structure is suggested by both experiment and modeling. This structure implies that flow tortuosity for both flow in the fracture and for inter-block fluid transfer is a scaledependent function of pressure head.

284 (SAND-91-2056C) Yucca Mountain Project total-system performance assessment preliminary analyses: Overview: Draft. Barnard, R.W.; Dockery, H.A. Sandia National Labs., Albuquerque, NM (United States). 19 Dec 1991. 16p. Sponsored by USDOE, Washington, DC (United States). DOE Contract AC04-76DP00789. (CONF920430-20-Draft: 3. international high level radioactive waste management (IHLRWM) conference, Las Vegas, NV (United States), 12-16 Apr 1992). Order Number DE92005320. Source: OSTI; NTIS; INIS; GPO Dep.

Sandia National Laboratories and Pacific Northwest Laboratory have produced a coordinated initial total-system performance assessment analysis for the potential repository at Yucca Mountain. Analyses included radionuclide transport via groundwater and gas flow, human intrusion, tectonism, and basaltic igneous intrusion. Both abstracted and detailed calculations were used for the analyses. Probabilistic release distributions were calculated for the individual components, and a combined distribution for the overall behavior of the system was constructed. Results from the analyses using abstracted models indicate that this method produces reasonable outcomes based on our current understanding of the site.

285 (SAND-91-2098C) Design of an intermediatescale experiment to validate unsaturated- zone transport models. Siegel, M.D.; Hopkins, P.L.; Glass, R.J.; Ward, D.B. Sandia National Labs., Albuquerque, NM (United States). 18 Dec 1991. 31p. Sponsored by USDOE, Washington, DC (United States). DOE Contract ACO476DP00789. (CONF-920430-16: 3. international high leve radioactive waste management (IHLRWM) conference, Las Vegas, NV (United States), 12-16 Apr 1992). Order Number DE92005319. Source: OSTI; NTIS; INIS; GPO Dep.

An intermediate-scale experiment is being carried out to evaluate instrumentation and models that might be used for transport-model validation for the Yucca Mountain Site Characterization Project. The experimental test bed is a $6-\mathrm{m}$ high $\times$ 3-m diameter caisson filled with quartz sand with a sorbing layer at an intermediate depth. The experiment involves the detection and prediction of the migration of fluid and tracers through an unsaturated porous medium. Pre-test design requires estimation of physical properties of the porous medium such as the relative permeability, saturation pressure relations, porosity, and saturated hydraulic conductivity as well as geochemical properties such as surface complexation constants and empircial $K_{d}$ 'S. The pre-test characterization data will be used as input to several computer codes to predict the fluid flow and tracer migration. These include a coupled chemical-reaction/transport model, a stochastic model, and a deterministic model using retardation factors. The calculations will be completed prior to elution of the tracers, providing a basis for validation by comparing the predictions to observed moisture and tracer behavior.

286 (SAND-94-2176C) Proposed sealing field tests for a potential high-level radioactive waste repository in unsaturated tuff. Fernandez, J.A. (Sandia National Labs., Albuquerque, NM (United States)); Case, J.B.; Tyburski, J. Sandia National Labs., Albuquerque, NM (United States). 6 Jan 1992. 8p. Sponsored by USDOE, Washington, DC (United States). DOE Contract AC04-76DP00789. (CONF920430-37: 3 . international high level radioactive waste management (IHLRWM) conference, Las Vegas, NV (United States), 12-16 Apr 1992). Order Number DE92006526. Source: OSTI; NTIS; INIS; GPO Dep.

This paper contains a general description of the field tests proposed for the Yucca Mountain Site Characterization Project repository sealing program. The tests are intended to resolve various performance and emplacement concerns associated with sealing components. Ten discrete tests are proposed to address these concerns. These tests are divided into two categories - simple and complex tests. The simple tests are: the small-scale in situ tests: the intermediate-scale borehole seal tests; the fracture grouting tests; the surface backfill tests; and the grouted rock mass tests. The complex tests are the seepage control tests; in situ backfill tests; in situ bulkhead tests; large-scale shaft seal tests; and remote borehole seal tests. These tests are proposed to be performed in welded and nonwelded tuff environments. The final selection of sealing tests will depend on the nature of the geologic and hydrologic conditions encountered during the development of the exploratory studies facility. Some tests may be performed before license application and some after license application.

287 (SAND-91-2177C) Supporting hydration calculations for small- to large-scale seal tests in unsaturated tuff. Case, J.B. (I. T. Corp., Albuquerque, NM (United States)); Tyburski, J.R.; Fernandez, J.A. Sandia National Labs., Albuquerque, NM (United States). 6 Jan 1992. 8p. Sponsored by USDOE, Washington, DC (United States). DOE Contract AC04-76DP00789. (CONF-920430-36: 3. international high level radioactive waste management (IHLRWM) conference, Las Vegas, NV (United States), 12$16 \mathrm{Apr}$ 1992). Order Number DE92006527. Source: OST!; NTIS; INIS; GPO Dep.

The design of cementitious repository seals requires an understanding of cement hydration effects in developing a tight interface zone between the rock and the seal. For this paper, a computer code, SHAFT.SEAL, is used to model early-age cement hydration effects and performs thermal and thermomechanical analysis of cementitious seals. The model is described, and then used to analyze for the effects of seal size, rock temperature and placement temperature. The model results assist in selecting the instrumentation necessary for progressive evaluation of seal components and seal-system tests. Also, the results identify strategies for seal emplacement for a series of repository seal tests for the Yucca Mountain Site Characterization Project (YMP).

288 (SAND-91-2217C) Applications of performance assessment in support of the Exploratory Studies Facility (ESF) design. Fewell, M.E.; Sobolik, S.R.; Gauthier, J.H.; Shephard, L.E.; Costin, L.S. Sandia National Labs., Albuquerque, NM (United States). [1992]. 7p. Sponsored by 
USDOE, Washington, DC (United States). DOE Contract AC04-76DP00789. (CONF-920430-38: 3. international high level radioactive waste management (IHLRWM) conference, Las Vegas, NV (United States), 12-16 Apr 1992). Order Number DE92006741. Source: OSTI; NTIS; INIS; GPO Dep.

Performance assessments (PA) are an integral part of the exploratory studies facility (ESF) design effort currently underway as part of the Yucca Mountain Site Characterization Program. These assessments are part of an interdisciplinary effort that requires input from ESF design, construction, operation, and testing as well as from performance assessment personnel to make judgments about the effects of ESF construction, operation, and testing on the ability of the repository to isolate waste and on tests conducted in the ESF. These judgments lead to the formulation of controls or limitations that when imposed will provide reasonable assurance that the ESF will not degrade the ability of the site to isolate high-level radioactive waste or interfere with tests. PA draws from a knowledge base, which includes interpretations of the results of specific analyses in the areas of fluid flow, geochemistry and materials, thermal mechanical, and total systems. The process for applying performance assessments to support the design and construction of the ESF is outlined. In addition, the role of performance assessment is illustrated by describing two controls on the use of water at Yucca Mountain and the two PA analyses on which these controls are based.

289 (SAND-91-2252C) Developing a functioning visualization and analysis system for performance assessment. Jones, M.L. Sandia National Labs., Albuquerque, NM (United States). [1992]. 6p. Sponsored by USDOE, Washington, DC (United States). DOE Contract ACO476DP00789. (CONF-920430-12: 3. international high level radioactive waste management (IHLRWM) conference, Las Vegas, NV (United States), 12-16 Apr 1992). Order Number DE92005183. Source: OSTI; NTIS; INIS; GPO Dep.

Various commercial software packages and customized programs provide the ability to analyze and visualize the geology of Yucca Mountain. Starting with sparse, irregularly spaced data a series of gridded models has been developed representing the thermal/mechanical units within the mountain. Using computer aided design (CAD) sottware and scientific visualization software, the units can be manipulated, analyzed, and graphically displayed. The outputs are typically gridded terrain models, along with files of threedimensional coordinates, distances, and other dimensional values. Contour maps, profiles, and shaded surfaces are the output for visualization.

290 (SAND-91-2416) LLUVIA-Il: A program for twodimensional, transient flow through partially saturated porous media: Yucca Mountain Site Characterization Project. Eaton, R.R.; Hopkins, P.L. Sandia National Labs., Albuquerque, NM (United States). Aug 1992. 53p. Sponsored by USDOE, Washington, DC (United States). DOE Contract AC04-76DP00789. Order Number DE93001349. Source: OSTI; NTIS; INIS; GPO Dep.

LLUVIA-II is a program designed for the efficient solution of two- dimensional transient flow of liquid water through partially saturated, porous media. The code solves Richards equation using the method-of-lines procedure. This document describes the solution procedure employed, input data structure, output, and code verification.

291 (SAND-91-2499C) Preclosure seismic hazards and their impact on site suitability of Yucca Mountain,
Nevada. Gibson, J.D. Sandia National Labs., Albuquerque, NM (United States). 7 Jan 1992. 8p. Sponsored by USDOE, Washington, DC (United States). DOE Contract AC0476DP00789. (CONF-920430-35: 3. international high level radioactive waste management (IHLRWM) conference, Las Vegas, NV (United States), 12-16 Apr 1992). Order Number DE92006553. Source: OSTI; NTIS; INIS; GPO Dep.

This paper presents an overview of the preclosure seismic hazards and the influence of these hazards on determining the suitability of Yucca Mountain as a national high-level nuclear-waste repository. Geologic data, engineering analyses, and regulatory guidelines must be examined collectively to assess this suitability. An environmental assessment for Yucca Mountain, written in 1986, compiled and evaluated the existing tectonic data and presented arguments to satisfy, in part, the regulatory requirements that must be met if the Yucca Mountain site is to become a national waste repository. Analyses have been performed in the past five years that better quantify the local seismic hazards and the possibility that these hazards could lead to release of radionuclides to the environment. The results from these analyses increase the confidence in the ability of Yucca Mountain and the facilities that may be built there to function satisfactorily in their role as a waste repository. Uncertainties remain, however, primarily in the input parameters and boundary conditions for the models that were used to complete the analyses. These models must be validated and uncertainties reduced before Yucca Mountain can qualify as a viable high-level nuclear waste repository.

292 (SAND-91-2685C) The hydrothermal stability of cement sealing materials in the potential Yucca Mountain high level nuclear waste repository. Krumhansl, J.L. (Sandia National Labs., Albuquerque, NM (United States)); Hinkebein, T.E.; Myers, J. Sandia National Labs., Albuquerque, NM (United States). 26 Nov 1991. 7p. Sponsored by USDOE, Washington, DC (United States). DOE Contract AC04-76DP00789. (CONF-911202-10: Annual fall meeting of the Materials Research Society (MRS), Boston, MA (United States), 2-6 Dec 1991). Order Number DE92004480. Source: OSTI; NTIS; INIS; GPO Dep.

Cementitious materials, together with other materials, are being considered to seal a potential repository at Yucca Mountain. A concern with cementitious materials is the chemical and mineralogic changes that may occur as these materials age while in contact with local ground waters. A combined theoretical and experimental approach was taken to determine the ability to theoretically predict mineralogic changes. The cementitious material selected for study has a relatively low Ca:Si ratio approaching that of the mineral tobermorite. Samples were treated hydrothermally at $200^{\circ} \mathrm{C}$ with water similar to that obtained from the $\mathrm{J}-13$ well on the Nevada Test Site. Post-test solutions were analyzed for $\mathrm{pH}$ as well as dissolved $\mathrm{K}, \mathrm{Na}, \mathrm{Ca}, \mathrm{Al}$, and $\mathrm{Si}$. Solid phases formed during these experiments were characterized by scanning electron microscopy and $X$ - ray diffraction. These findings were compared with predictions made by the geochemical modeling code EQ3NR/E06. It was generally found that there was good agreement between predicted and experimental results.

293 (SAND-91-2795) TSPA 1991: An initial totalsystem performance assessment for Yucca Mountain: Yucca Mountain Site Characterization Project. Barnard, R.W. (Sandia National Labs., Albuquerque, NM (United States)); Wilson, M.L.; Dockery, H.A.; Kaplan, P.G.; Eaton, R.R.; Bingham, F.W.; Gauthier, J.H.; Robey, T.H. Sandia 
25-29 Apr 1993). Order Number DE93006753. Source: OSTI; NTIS; INIS; GPO Dep.

As a follow-on to Sandia's 1991 preliminary total-system performance assessment of the Yucca Mountain site, this paper presents results of some sensitivity analyses that were done using results from the 1991 study. Two conceptual models of unsaturated-zone flow and transport at Yucca Mountain were included in the study, including both aqueous and gaseous releases. The sensitivities are quite different for the two models. For the composite-porosity model, the results are most sensitive to groundwater percolation flux, gaseous transport time, container lifetime, and fuel-matrix-alteration rate. For the weeps model, the results are most sensitive to parameters used to characterize fracture flow (fracture aperture and fracture connectivity) and infiltration (percolation flux and weep-episode factor).

320 (SAND-92-2670C) Investigation of fracturematrix interaction: Preliminary experiments in a simple system. Foltz, S.D. (New Mexico Univ., Albuquerque, NM (United States). Dept. of Physics and Astronomy); Tidwell, V.C.; Glass, R.J.; Sobolik, S.R. Sandia National Labs., Albuquerque, NM (United States). [1992]. 30p. Sponsored by USDOE, Washington, DC (United States). DOE Contract AC04-76DP00789. (CONF-930408-65: international highlevel radioactive waste management conference, Las Vegas, NV (United States), 25-29 Apr 1993). Order Number DE93011580. Source: OSTI; NTIS; INIS; GPO Dep.

Paramount to the modeling of unsaturated flow and transport through fractured porous media is a clear understanding of the processes controlling fracture-matrix interaction. As a first step toward such an understanding, two preliminary experiments have been performed to investigate the influence of matrix imbibition on water percolation through unsaturated fractures in the plane normal to the fracture. Test systems consisted of thin slabs of either tuff or an analog material cut by a single vertical fracture into which a constant fluid flux was introduced. Transient moisture content and solute concentration fields were imaged by means of $x$-ray absorption. Flow fields associated with the two different media were significantly different owing to differences in material properties relative to the imposed flux. Richards' equation was found to be a valid means of modeling the imbibition of water into the tuff matrix from a saturated fracture for the current experiment.

321 (SAND-92-2671C) Recent developments in stochastic modeling and upscaling of hydrologic properties in tuff. Rautman, C.A. (Sandia National Labs., Albuquerque, NM (United States)); Robey, T.H. Sandia National Labs., Albuquerque, NM (United States). [1992]. 10p. Sponsored by USDOE, Washington, DC (United States). DOE Contract AC04-76DP00789. (CONF-930408-37: International highlevel radioactive waste management conference, Las Vegas, NV (United States), 25-29 Apr 1993). Order Number DE93008358. Source: OSTI; NTIS; INIS; GPO Dep.

A set of detailed geostatistical simulations of porosity has been produced for a layered stratigraphic sequence of welded and nonwelded volcanic tuffs at Yucca Mountain, Nevada. The simulations are produced using a composite. model of spatial continuity and they are highly conditioned to abundant drill hole (core) information. A set of derivative simulations of saturated hydraulic conductivity has been produced, in the absence of conditioning data, using a cross-variable relationship developed from similar data elsewhere. The detailed simulations reproduce both the major stratigraphic units and finer scale layering indicated by the drill hole data. These simulations have been scaled up several order of magnitude to represent block-scale effective hydrologic properties suitable for use in numerical modeling of groundwater flow and transport. The upscaling process involves the reformulation of a previously reported method that iteratively adapts an initial arbitrary grid to "homogenize" the detailed hydraulic properties contained within the adjusted cell limits and to minimize the size of cell in highiy heterogeneous regions. Although the computation of the block-effective property involves simple numerical averaging, the blocks over which these averages are computed are relatively homogeneous, which reduces the numerical difficulties involved in averaging non-additive properties, such as permeability. The entire process of simulation and upscaling is rapid and computationally efficient compared with alterative techniques. It is thus suitable for the Monte Carlo evaluation of the uncertainty in site characterization as it affects the results of groundwater flow and transport calculations.

322 (SAND-92-2672C) Numerical methods for fluid flow in unsaturated heterogeneous tuff. Robey, T.H. (Spectra Research Inst., Albuquerque, NM (United States)). Sandia National Labs., Albuquerque, NM (United States). [1992]. 9p. Sponsored by USDOE, Washington, DC (United States). DOE Contract AC04-76DP00789. (CONF-93040812: International high-level radioactive waste management conference, Las Vegas, NV (United States), 25-29 Apr 1993). Order Number DE93006783. Source: OSTI; NTIS; INIS; GPO Dep.

A numerical approach for modeling unsaturated flow is developed for heterogeneous simulations of fractured tuff generated using a geostatistical method. Cross correlations of hydrologic properties and upscaling of moisture retention cunves is discussed. The approach is demonstrated for a study of infiltration at Yucca Mountain.

323

(SAND-92-2739C) Scale dependence of effective media properties. Tidwell, V.C.; VonDoemming, J.D.; Martinez, K. Sandia National Labs., Albuquerque, NM (United States). [1992]. 15p. Sponsored by USDOE, Washington, DC (United States). DOE Contract AC0476DP00789. (CONF-930408-29: International high-level radioactive waste management conference, Las Vegas, NV (United States), 25-29 Apr 1993). Order Number DE93008408. Source: OSTI; NTIS; INIS; GPO Dep.

For problems where media properties are measured at one scale and applied at another, scaling laws or models must be used in order to define effective properties at the scale of interest. The accuracy of such models will play a critical role in predicting flow and transport through the Yucca Mountain Test Site given the sensitivity of these calculations to the input property fields. Therefore, a research programhas been established to gain a fundamental understanding of how properties scale with the aim of developing and testing models that describe scaling behavior in a quantitative-manner. Scaling of constitutive rock properties is investigated through physical experimentation involving the collection of suites of gas permeability data measured over a range of discrete scales. Also, various physical characteristics of property heterogeneity and the means by which the heterogeneity is measured and described are systematically investigated to evaluate their influence on scaling behavior. This paper summarizes the approach that isbeing taken toward this goal and presents the results of a scoping study that was conducted to evaluate the feasibility of the proposed research. 
324 (SAND-92-2762) Use of the iterative solution method for coupled finite element and boundary element modeling: Yucca Mountain Site Characterization Project. Koteras, J.R. Sandia National Labs., Albuquerque, NM (United States). Jul 1993. 40p. Sponsored by USDOE, Washington, DC (United States). DOE Contract ACO476DP00789. Order Number DE93018682. Source: OSTI; NTIS; INIS; GPO Dep.

Tunnels buried deep within the earth constitute an important class geomechanics problems. Two numerical techniques used for the analysis of geomechanics problems, the finite element method and the boundary element method, have complementary characteristics for applications to problems of this type. The usefulness of combining these two methods for use as a geomechanics analysis tool has been recognized for some time, and a number of coupling techniques have been proposed. However, not all of them lend themselves to efficient computational implementations for large-scale problems. This report examines a coupling technique that can form the basis for an efficient analysis tool for large scale geomechanics problems through the use of an iterative equation solver.

325 (SAND-92-2784C) Scenario development for performance assessment: Some questions for the nearfield modelers. Barr, G.E.; Barnard, R.W. Sandia National Labs., Albuquerque, NM (United States). [1992]. 12p. Sponsored by USDOE, Washington, DC (United States). DOE Contract AC04-76DP00789. (CONF-930408-27: International high-level radioactive waste management conference, Las Vegas, NV (United States), 25-29 Apr 1993). Order Number DE93008410. Source: OSTI; NTIS; INIS; GPO Dep.

In an attempt to achieve completeness and consistency, the performance-assessment analyses developed by the Yucca Mountain Project are tied to scenarios described in event trees. Development of scenarios requires describing the constituent features, events, and processes in detail. Several features and processes occurring at the waste packages and the rock immediately surrounding the packages (i.e., the near field) have been identified: the effects of radiation on fluids in the near-field rock, the pathdependency of rock-water interactions, and the partitioning of contaminant transport between colloids and solutes. This paper discusses some questions regarding these processes that the near-field performance-assessment modelers will need to have answered to specify those portions of scenarios dealing with the near field.

326 (SAND-92-2790C) Small-scale behavior of single gravity-driven fingers in an initially dry fracture. Nicholl, M.J.; Glass, R.J.; Nguyen, H.A. Sandia National Labs., Albuquerque, NM (United States). [1992]. 30p. Sponsored by USDOE, Washington, DC (United States). DOE Contract AC04-76DP00789. (CONF-930408-17: international high-level radioactive waste management conference, Las Vegas, NV (United States), 25-29 Apr 1993). Order Number DE93006765. Source: OSTI; NTIS; INIS; GPO Dep.

Experiments investigating the behavior of individual, gravity-driven fingers in an initially dry, rough-walled analog fracture are presented. Fingers were initiated from constant flow to a point source. Finger structure is described in detail; specific phenomena observed include: desaturation behind the finger-tip, variation in finger path, intermittent flow structures, finger-tip bifurcation, and formation of dendritic sub-fingers. Measurements were made of finger-tip velocity, finger width, and finger-tip length. Non-dimensional forms of the measured variables are analyzed relative to the independent parameters, flow rate and gravitational gradient.

327 (SAND-92-2791C) Wetting front instability in an initially wet unsaturated fracture. Nicholl, M.J.; Glass, R.J.; Nguyen, H.A. Sandia National Labs., Albuquerque, NM (United States). [1992]. 28p. Sponsored by USDOE, Washington, DC (United States). DOE Contract AC0476DP00789. (CONF-930408-28: International high-level radioactive waste management conference, Las Vegas, NV (United States), 25-29 Apr 1993). Order Number DE93008409. Source: OSTI; NTIS; INIS; GPO Dep.

Experimental results exploring gravity-driven wetting front instability in a pre-wetted, rough-walled analog fracture are presented. Initial conditions considered include a uniform moisture field wetted to field capacity of the analog fracture and the structured moisture field created by unstable infiltration into an initially dry fracture. As in previous studies performed under dry initial conditions, instability was found to result both at the cessation of stable infiltration and at flux lower than the fracture capacity under gravitational driving force. Individual fingers were faster, narrower, longer, and more numerous than observed under dry initial conditions. Wetting fronts were found to follow existing wetted structure, providing a mechanism for rapid recharge and transport.

328 (SAND-92-2792C) Modeling gravity-driven fingering in rough-walled fractures using modified percolation theory. Glass, R.J. Sandia National Labs., Albuquerque, NM (United States). [1992]. 11p. Sponsored by USDOE, Washington, DC (United States). DOE Contract AC04-76DP00789. (CONF-930408-44: International highlevel radioactive waste management conference, Las Vegas, NV (United States), 25-29 Apr 1993). Order Number DE93009636. Source: OSTI; NTIS; INIS; GPO Dep.

Pore scale invasion percolation theory is modified for imbibition of.wetting fluids into fractures. The effects of gravity, local aperture field geometry, and local in-plane air/water interfacial curvatureare included in the calculation of aperture filling potential which controls wetted structure growth within the fracture. The inclusion of gravity yields fingers oriented in the direction of the gravitational gradient. These fingers widen and tend to meander and branch more as the gravitational gradient decreases. In-plane interfacial curvature also greatly affects the wetted structure in both horizontal and nonhorizontal fractures causing the formation of macroscopic wetting fronts. The modified percolation model is used to simulate imbibition into an analogue rough-walled fracture where both fingering and horizontal imbibition experiments were previously conducted. Comparison of numerical and experimental results showed reasonably good agreement. This process oriented physical and numerical modeling is-a necessary step toward including gravity-driven fingering in models of flow and transport through unsaturated, fractured rock.

329 (SAND-92-2826C) Rock mass mechanical property estimation strategy for the Yucca Mountain Site Characterization Project. Lin, M. (Agapito (J.F.T.) and Associates, Inc., Grand Junction, CO (United States)); Brechtel, C.E.; Hardy, M.P.; Bauer, S.J. Sandia National Labs., Albuquerque, NM (United States). [1992]. 13p. Sponsored by USDOE, Washington, DC (United States). DOE Contract AC04-76DP00789. (CONF-930408-13: International high-level radioactive waste management conference, Las Vegas, NV (United States), 25-29 Apr 1993). Order Number DE93006771. Source: OSTI; NTIS; INIS; GPO Dep. 
This paper presents a method of estimating the rock mass properties for the welded and nonwelded tutfs based on currently available information on intact rock and joint characteristics at the Yucca Mountain site. Variability of the expected ground conditions at the potential repository horizon (the TSw2 thermomechanical unit) and in the Calico Hills nonwelded tuffs is accommodated by defining five rock mass quality categories in each unit based upon assumed and observed distributions of the data.

330 (SAND-92-2827C) Instrumentation requirements for the ESF thermomechanical experiments. Pott, J. (Sandia National Labs., Albuquerque, NM (United States)); Brechtel, C.E. Sandia National Labs., Albuquerque, NM (United States). [1992]. 8p. Sponsored by USDOE, Washington, DC (United States). DOE Contract AC04760P00789. (CONF-930408-14: International high-level radioactive waste management conference, Las Vegas, NV (United States), 25-29 Apr 1993). Order Number DE93006770. Source: OSTI; NTIS; INIS; GPO Dep.

In situ thermomechanical experiments are planned as part of the Yucca Mountain Site Characterization Project that require instruments to measure stress and displacement at temperatures that exceed the typical specifications of existing geotechnical instruments. A high degree of instrument rellability will also be required to satisfy the objectives of the experiments, therefore a study was undertaken to identify areas where improvement in instrument performance was required. A preliminary list of instruments required for the experiments was developed, based on existing test planning and analysis. Projected temperature requirements were compared to specifications of existing instruments to identify instrumentation development needs. Different instrument technologies, not currently employed in geotechnical instrumentation, were reviewed to identify potential improvements of existing designs for the high temperature environment. Technologies with strong potentials to improve instrument performance with relatively high reliability include graphite fiber composite materials, fiber optics, and video imagery.

331 (SAND-92-2828C) A working definition of scenario and a method of scenario construction. Barr, G.E.; Dunn, E. Sandia National Labs., Albuquerque, NM (United States). [1992]. 6p. Sponsored by USDOE, Washington, DC (United States). DOE Contract AC04-76DP00789. (CONF930408-11: International high-level radioactive waste management conference, Las Vegas, NV (United States), 25-29 Apr 1993). Order Number DE93006782. Source: OSTI; NTIS; INIS; GPO Dep.

The event-tree method of scenario construction has been chosen for the Yucca Mountain performance assessment. Its applicability and suitability to the problem are discussed and compared with those of the Nuclear Regulatory Commission (NRC) method. The event-tree method is appropriate for an incompletely characterized site, where there must be an evolving understanding, over time, of the processes at work, for a site that may require analysis of details in specific context, and when the scenario functions to guide site characterization. Anticipating the eventual requirement for using the NRC method, we show that the event-tree method can be translated to the NRC format after final scenario screening.

332 (SAND-92-2838C) Comparison of predicted far-field temperatures for discrete and smeared heat sources. Ryder, E.E. Sandia National Labs., Albuquerque,
NM (United States). 16 Dec 1992. 7p. Sponsored by USDOE, Washington, DC (United States). DOE Contract AC04-76DP00789. (CONF-930408-31: International highlevel radioactive waste management conference, Las Vegas, NV (United States), 25-29 Apr 1993). Order Number DE93008406. Source: OSTI; NTIS; INIS; GPO Dep.

A fundamental concern in the design of the potential repository at Yucca Mountain. Nevada is the response of the host rock to the emplacement of heat-generating waste. The thermal perturbation of the rock mass has implications regarding the structural, hydrologic. and geochemical performance of the potential repository. The phenomenological coupling of many of these performance aspects makes repository thermal modeling a difficult task. For many of the more complex, coupled models, it is often necessary to reduce the geometry of the potential repository to a smeared heat-source approximation. Such simplifications have impacts on induced thermal profiles that in turn may influence other predicted responses through one- or two-way thermal couplings. The effect of waste employment layout on hostrock thermal was chosen as the primary emphasis of this study. Using a consistent set of modeling and input assumptions, far-field thermal response predictions made for discrete-source as well as plate source approximations of the repository geometry. Input values used in the simulations are consistent with a design-basis a real power density (APD) of $80 \mathrm{~kW} /$ acre as would be achieved assuming a 2010 emplacement start date, a levelized receipt schedule, and a limitation on available area as published in previous design studies. It was found that edge effects resulting from general repository layout have a significant influence on the shapes and extents of isothermal profiles, and should be accounted for in far-field modeling efforts.

333 (SAND-92-7344C) The results of near-field thermal and mechanical calculations of thermal loading schemes. Holland, J.F. (Technadyne Engineering Consultants, Inc., Albuquerque, NM (United States)). Sandia National Labs., Albuquerque, NM (United States). [1992]. 6p. Sponsored by USDOE, Washington, DC (United States). DOE Contract AC04-76DP00789. (CONF-930408-40: International high-level radioactive waste management conference, Las Vegas, NV (United States), 25-29 Apr 1993). Order Number DE93008412. Source: OSTI; NTIS; INIS; GPO Dep.

Two waste emplacement schemes,borehole and in-drift are under evaluation as potential repository drift geometries for the Yucca Mountain Site Characterization Project Calculations were performed to examinethe systems implications of various thermal loadings on the near- and far-field repository environments. Ms paper reports the results of two-dimensional finite element analyses of the near-field thermal and structural response of the potential repository. Thermal calculations were run to 1000 years and mechanical calculations were run to 75 years. the time when the drifts will be backfilled. Local areal power densities (LAPDs) of 57,80 , and $100 \mathrm{~kW} /$ acre were used in the calculations. Both emplacement schemes meet current near-field thermal performance goals for all loadings examined. The mechanical calculations predict no intact rock failure, limited joint slippage around the drifts, and closure of apertures for vertical fractures above and below the drifts.

334 (SAND-93-0039C) Preliminary characterization of materials for a reactive transport model validation experiment. Siegel, M.D.; Ward, D.B.; Cheng, W.C.; Bryant, 
C.; Chocas, C.S.; Reynolds, C.G. Sandia National Labs., Albuquerque, NM (United States). [1993]. 21p. Sponsored by USDOE, Washington, DC (United States). DOE Contract AC04-76DP00789: (CONF-930408-30: International highlevel radioactive waste management conference, Las Vegas, NV (United States), 25-29 Apr 1993). Order Number DE93008407. Source: OSTI; NTIS; INIS; GPO Dep.

The geochemical properties of a porous sand and several tracers $(\mathrm{Ni}, \mathrm{Br}$, and $\mathrm{Li}$ ) have been characterized for use in a caisson experiment designed to validate sorption models used in models of inactive transport. The surfaces of the sand grains have been examined by a combination of techniques including potentiometric titration, acid leaching, optical microscopy, and scanning electron microscopy with energy-dispersive spectroscopy. The surface studies indicate the presence of small amounts of carbonate, kaolinite and iron-oxyhydroxides. Adsorption of nickel, lithium and bromide by the sand was measured using batch techniques. Bromide was not sorbed by the sand. A linear $\left(K_{d}\right)$ or an isotherm sorption model may adequately describe transport of $\mathrm{Li}$; however, a model describing the changes of $\mathrm{pH}$ and the concentrations of other solution species as a function of time and position within the caisson and the concomitant effects on $\mathrm{Ni}$ sorption may be required for accurate predictions of nickel transport.

335 (SAND-93-1109C) An approach to validation of thermomechanical models. Costin, L.S. (Sandia National Labs., Albuquerque, NM (United States)); Hardy, M.P.; Brechtel, C.E. Sandia National Labs., Albuquerque, NM (United States). [1993]. 6p. Sponsored by USDOE, Washington, DC (United States). DOE Contract AC04-76DP00789. (CONF-9309228-1: Focus 93: site characterization and model validation, Las Vegas, NV (United States), 26-29 Sep 1993). Order Number DE93018826. Source: OSTI; NTIS; GPO Dep.

Thermomechanical models are being developed to support the design of an Exploratory Studies Facility (ESF) and a potential high-level nuclear waste repository at Yucca Mountain, Nevada. These models are used for preclosure design of underground openings, such as access drifts, emplacement drifts, and waste emplacement boreholes; and in support of postclosure issue resolution relating to waste canister performance, disturbance of the hydrological properties of the host rock, and overall system performance assessment. For both design and performance assessment, the purpose of using models in analyses is to better understand and quantify some phenomenon or process. Therefore, validation is an important process that must be pursued in conjunction with the development and application of models. The Site Characterization Plan (SCP) addressed some general aspects of model validation, but no specific approach has, as yet, been developed for either design or performance assessment models. This paper will discuss a proposed process for thermomechanical model validation and will focus on the use of laboratory and in situ experiments as part of the validation process. The process may be generic enough in nature that it could be applied to the validation of other types of models, for example, models of unsaturated hydrologic flow.

336

(SAND-93-1415C) Analysis of releases due to drilling at the potential Yucca Mountain repository. Barnard, R.W. Sandia National Labs., Albuquerque, NM (United States). [1993]. 4p. Sponsored by USDOE, Washington, DC (United States). DOE Contract AC0476DP00789. (CONF-931160-8: American Nuclear Society
(ANS) winter meeting, San Francisco, CA (United States), 14-18 Nov 1993). Order Number DE93017656. Source: OSTI; NTIS; INIS; GPO Dep.

Human Instrusion into the potential repository at Yucca Mountain, Nevada, was modeled in the Total-System Performance Assessment ("TSPA-91") recently completed for the Yucca Mountain Site Characterization Project Office of the DOE. The scenario model assumed that the repository would be penetrated at random locations by a number of boreholes drilled using twentieth-century rotary drilling techniques.

337 (SAND-93-7005C) Implications of stability analysis for heat transfer at Yucca Mountain. Ross, B. (Disposal Safety, Inc., Washington, DC (United States)); Yiqiang Zhang; Ning Lu. Sandia National Labs., Albuquerque, NM (United States). [1993]. 6p. Sponsored by USDOE, Washington, DC (United States). DOE Contract AC04-76DP00789. (CONF-930408-39: International highlevel radioactive waste management conference, Las Vegas, NV (United States), 25-29 Apr 1993). Order Number DE93008355. Source: OSTI; NTIS; INIS; GPO Dep.

An analytical solution has been obtained to the stability problem for an infinite horizontal layer of gas with Its humidity constrained to $100 \%$. Latent heat transfer makes convective heat transfer much more Important for this moist gas than for a dry gas. The critical Rayleigh number for the onset of convective flow in the moist gas, with a lower noflow boundary at $97^{\circ} \mathrm{C}$ and an upper no-flow boundary at $27^{\circ} \mathrm{C}$, is 0.18 , much less than the value of $4 \mathrm{~m}^{2}$ for a dry gas. Although the heat source at Yucca Mountain will be finite in extent, the solution for an infinite horizontal layer still gives a useful criterion for the qualitative importance of convective heat transfer. The critical Rayleigh number of 0.18 corresponds to a permeability of $4 \times 10^{-12} \mathrm{~m}^{2}$ if other parameters ate given values measured at Yucca Mountain. This value falls roughly in the middle of the range of measured permeabilities. The analysis also gives a time constant for the onset of convection, which at twice the critical Rayleigh number is $1000 \mathrm{yr}$. Thus convection will probably make an important contribution, to host transfer at Yucca Mountain if the rock permeability falls in the upper portion of the range of measurements to date, but only at times after a few hundred or thousand years.

338 (SAND-93-7013C) The most likely groundwater flux through the unsaturated tuff matrix at USW H-1. Gauthier, J.H. (Spectra Research Inst., Albuquerque, NM (United States)). Sandia National Labs., Albuquerque, NM (United States). [1993]. 8p. Sponsored by USDOE, Washington, DC (United States). DOE Contract AC0476DP00789. (CONF-930408-15: International high-level radioactive waste management conference, Las Vegas, NV (United States), 25-29 Apr 1993). Order Number DE93006755. Source: OSTI; NTIS; INIS; GPO Dep.

Using a probabilistic inverse method, an estimate is made of the groundwater flux through the unsaturated tuff matrix at drill hole USW $\mathrm{H}-1$ in Yucca Mountain. The most likely flux is found to be between 0 and $0.1 \mathrm{~mm} / \mathrm{yr}$-virtually a hydrostatic condition. This result is consistent at all elevations where in-situ data are available, including the upper nonwelded strata. This study has implications for flow-model validation and future data collection.

339 The hydrothermal stability of cement sealing materials in the potential Yucca Mountain high level nuclear waste repository. Krumhansl, J.L. (Sandia National 
Labs., Albuquerque, NM (United States)); Hinkebein, T.E.; Myers, J. pp. 105-110 of Proceedings of advanced cementitious systems: Mechanisms and properties. Volume 245 . Glasser, F.P.; Pratt, P.L.; Mason, T.O.; Young, J.F.; McCarthy, G.J. Materials Research Society, Pittsburgh, PA (United States) (1992). pp. 369 (CONF-911202-: Annual fall meeting of the Materials Research Society (MRS), Boston, MA (United States), 2-6 Dec 1991).

This paper reports that cementitious materials, together with other materials, are being considered to seal a potential repository at Yucca Mountain. a concern with cementitious materials is the chemical and mineralogic changes that may occur as these materials age while in contact with local ground waters. A combined theoretical and experimental approach was taken to determine the ability to theoretically predict mineralogic changes. The cementitious material selected for study has a relatively low Ca:Si ratio approaching that of the mineral tobermorite.

340 Use of Wingz spreadsheet as an interface to total-system performance assessment. Chambers, W.F. (Sandia National Labs., Albuquerque, NM (United States)) Treadway, A.H. pp. $489-493$ of Proceedings of high level radioactive waste management: Volume 1. American Nuclear Society, La Grange Park, IL (United States) (1992). pp. 2425 DOE Contract AC04-76DP00789. (CONF-920430-: 3. international high level radioactive waste management (IHLRWM) conference, Las Vegas, NV (United States), 1216 Apr 1992).

This paper discusses a commercial spreadsheet used as an interface to a set of simple models to simulate possible nominal flow and failure scenarios at the potential high-level nuclear waste repository at Yucca Mountain, Nevada. Individual models coded in FORTRAN are linked to the spreadsheet. Complementary cumulative probability distribution functions resulting from the models are plotted through scripts associated with the spreadsheet. All codes are maintained under a source code control system for quality assurance. The spreadsheet and the simple models can be run on workstations, PCs, and Macintoshes. The software system is designed so that the FORTRAN codes can be run on several machines if a network environment is available.

341 Summary of the exploratory studies facility alternative study. Costin, L.S. (Sandia National Labs., Albuquerque, NM (United States)); Dennis, A.W.; Stevens, A.L. pp. 643-649 of Proceedings of high level radioactive waste management: Volume 1. American Nuclear Society, La Grange Park, IL (United States) (1992). pp. 2425 (CONF-920430-: 3. international high level radioactive waste management (IHLRWM) conference, Las Vegas, NV (United States), 12-16 Apr 1992).

This paper presents a summary of the conduct and findings of the Exploratory Studies Facility Alternatives Study (ESF-AS). The Exploratory Studies Facility (ESF) is being planned for use in the characterization of a site for a potential high-level nuclear waste repository at Yucca Mountain, NV. The purposes of the ESF-AS were to identify the rank order ESF-repository options and to improve understanding of the favorable or unfavorable features of the ESF design. The analysis resulted in the ranking of 34 options, in accordance with the extend to which each option could achieve the objectives. Additional findings regarding design features that were identified as key elements in an option's ability to provide good overall performance are also discussed.
342 A decision analysis of an exploratory studies facility. Merkhofer, M.W. (Applied Decision Analysis, Inc., Menlo Park, CA (United States)); Gnirk, P. pp. 650-656 of Proceedings of high level radioactive waste management: Volume 1. American Nuclear Society, La Grange Park, IL (United States) (1992). pp. 2425 Sponsored by National Science Foundation, Washington, DC (United States). Grant SES-8722589. (CONF-920430-: 3. international high level radioactive waste management (IHLRWM) conference, Las Vegas, NV (United States), 12-16 Apr 1992).

This paper reports that an Exploratory Studied Facility (ESF) is planned to support the characterization of a potential site for a high-level nuclear waste repository at Yucca Mountain, NV. The selection of a design for the ESF is a critical characterization decision because the ESF design may affect the accuracy of characterization testing an constrains subsequent repository design. To assist the design process, a comparative evaluation was conducted to rank 34 alternative ESF-repository designs. The evaluation relied on techniques from formal decision analysis, including decision trees and multiattribute utility analysis (MUA). The results helped to identify favorable design features and enabled the Department of Energy to adopt an improved ESF design.

343 Quantification of uncertain outcomes from site characterization: Insights from the ESF-AS. Boyle, W.J. (RE/SPEC Inc., Rapid City, SD (US)); Parrish, D.K.; Beccue, P.C. pp. 657-664 of Proceedings of high level radioactive waste management: Volume 1. American Nuclear Society, La Grange Park, IL (United States) (1992). pp. 2425 (CONF-920430-: 3. international high level radioactive waste management (IHLRWM) conference, Las Vegas, NV (United States), 12-16 Apr 1992).

This paper reports that as part of the Exploratory Studies Facility Alternatives Study (ESF-AS), the uncertain outcomes from site characterization were quantified using a probabilistic tree known as Nature's Tree. Nature's Tree distinguished the true characteristics of the Yucca Mountain site from the perceived characteristics deduced from testing. Bayesian probabilistic calculations converted probabilities in Nature's tree to the probabilistic estimates required for the comparative analysis of Exploratory Studies Facility-repository options. Experts on characterization testing explicitly addressed several site characterization issues that are considered implicitly in many site characterization programs.

344 Applications of performance assessment in support of the exploratory studies facility (ESF) design. Fewell, M.E. (Sandia National Labs., Albuquerque, NM (United States)); Sobolik, S.R.; Gauthier, J.H.; Shephard, L.E.; Costin, L.S. pp. 665-670 of Proceedings of high level radioactive waste management: Volume 1. American $\mathrm{Nu}$ clear Society, La Grange Park, IL (United States) (1992). pp. 2425 (CONF-920430-: 3. international high level radioactive waste management (IHLRWM) conference, Las Vegas, NV (United States), 12-16 Apr 1992).

Performance assessment (PA) are an integral part of the ESF design effort currently underway as part of the Yucca Mountain Site Characterization Program. These assessments are part of an interdisciplinary effort that requires input from ESF design, construction, operation, and testing as well as from performance assessment personnel to make judgments about the effects of ESF construction, operation, and testing on the ability of the repository to isolate waste and on tests conducted in the ESF. These judgments lead to the formulation of controls or limitations that when imposed will provide reasonable assurance that the ESF will 
not degrade the ability of the site to isolate high-level radioactive waste or interfere with tests. PA draws from the knowledge base, which includes interpretations of the results of specific analyses in the areas of fluid flow, geochemistry and materiais, thermal mechanical, and total systems. In this paper, this process for applying performance assessments to support the design and construction of the ESF is outlined. In addition, the role of performance assessment is illustrated by describing two controls on the use of water at Yucca Mountain and the two PA analyses on which these controls are based.

345 Field research program for unsaturated flow and transport experimentation. Tidwell, V.C. (Sandia National Labs., Albuquerque, NM (United States)); Rautman, C.A.; Glass, R.J. pp. 704-709 of Proceedings of high level radioactive waste management: Volume 1. American Nuclear Society, La Grange Park, IL (United States) (1992). pp. 2425 DOE Contract AC04-76DP00789. (CONF-920430: 3 . international high level radioactive waste management (IHLRWM) conference, Las Vegas, NV (United States), 12 16 Apr 1992).

This paper reports that as part of the Yucca Mountain Site Characterization Project, a field research program has been developed to refine and validate program has been developed to refine and validate models for flow and transport through unsaturated fractured rock. Validation of these models within the range of their application for performance assessment requires a more sophisticated understanding of the processes that govern flow and transport within fractured porous media than currently exists. In particular, the authors' research is prioritized according to understanding and modeling process that, if not accurately incorporated into performance assessment model, would adversely impact the project's ability to evaluate repository performance. For this reason, the authors have oriented our field program toward enhancing our understanding of scaling processes as they relate to effective media property modeling, as well as the to the conceptual modeling of complex flow and transport phenomena.

346 Developing a functioning visualization and analysis system for performance assessment. Jones, M.L. (Sandia National Labs., Albuquerque, NM (United States)). pp. 846-851 of Proceedings of high level radioactive waste management: Volume 1. American Nuclear Society, La Grange Park, IL (United States) (1992). pp. 2425 DOE Contract AC04-76DP00789. (CONF-920430-: 3. international high level radioactive waste management (IHLRWM) conference, Las Vegas, NV (United States), 12-16 Apr 1992).

This paper reports that various commercial software packages and customized programs provide the ability to analyze and visualize the geology of Yucca Mountain. Starting with sparse, irregularly spaced data a series of gridded terrain models has been developed representing the thermal/ mechanical units within the mountain. Using computer aided design (CAD) sottware and scientific visualization software, the units can be manipulated, analyzed, and graphically displayed. The outputs are typically gridded terrain models, along with files of three-dimensional coordinates, distances, and other dimensional values. Contour maps, profiles, and shaded surfaces are the output for visualization.

347 Yucca Mountain project total-system performance assessment preliminary analyses: Overview. Barnard, R.W. (Sandia National Labs., Albuquerque, NM (United States)); Dockery, H.A. pp. $874-881$ of Proceedings of high level radioactive waste management: Volume 1. American Nuclear Society, La Grange Park, IL (United States) (1992). pp. 2425 DOE Contract AC04-76DP00789. (CONF-920430-: 3. international high level radioactive waste management (IHLRWM) conference, Las Vegas, NV (United States), 12-16 Apr 1992).

This paper reports that Sandia National Laboratories and Pacific Northwest Laboratory have produced a coordinated initial total-system performance assessment analysis for the potential repository at Yucca Mountain. Analyses included radionuclide transport via groundwater and gas flow, human intrusion, tectonism, and basaltic igneous intrusion. Both abstracted and detailed calculations were used for the analyses. Probabilistic release distributions were calculated for the individual components, and a combined distribution for the overall behavior of the system was constructed. Results from the analyses using abstracted models indicate that this method produces reasonabie outcomes based on the authors' current understanding of the site.

348 Estimating the consequences of significant fracture flow at Yucca Mountain. Gauthier, J.H. (Spectra Research Inst., Albuquerque, NM (United States)); Wilson, M.L.; Lauffer, F.C. pp. 891-898 of Proceedings of high level radioactive waste management: Volume 1. American Nuclear Society, La Grange Park, IL (United States) (1992). pp. 2425 DOE Contract AC04-76DP00789. (CONF-920430: 3. international high level radioactive waste management (IHLRWM) conference, Las Vegas, NV (United States), 1216 Apr 1992).

In this paper a simple model is proposed for investigating the possibility of significant fracture flow at Yucca Mountain, Nevada. The model allows an estimate of the number of flowing fractures at Yucca Mountain based on the size of the fractures and the yearly volume of infiltrating water. Given the number of flowing fractures, the number of waste containers they contact is estimated by a geometric argument. Preliminary results indicate that the larger the flowing fractures, the lower the releases of radionuclides. Also, even with significant fracture flow, releases could be well below the limits set by the Environmental Protection Agency.

349 Preclosure seismic hazards and their impact on site suitability of Yucca Mountain, Nevada. Gibson, J.D. (Sandia National Labs., Albuquerque, NM (United States)). pp. 1151-1158 of Proceedings of high level radioactive waste management: Volume 1. American Nuclear Society, La Grange Park, IL (United States) (1992). pp. 2425 DOE Contract AC04-76DP00789. (CONF-920430-: 3. international high level radioactive waste management (IHLRWM) conference, Las Vegas, NV (United States), 12-16 Apr 1992).

This paper presents an overview of the preclosure seismic hazards and the influence of these hazards on determining the suitability of Yucca Mountain as a national high-level nuclear-waste repository. Geologic data, engineering analyses, and regulatory guidelines must be examined collectively to assess this suitability. An environmental assessment for Yucca Mountain, written in 1986, compiled and evaluated the existing tectonic data and presented arguments to satisfy, in part, the regulatory requirements that must be met if the Yucca Mountain site is to become a national waste repository. Analyses have been performed in the past five years that better quantify the local seismic hazards and the possibility that these hazards could lead to release of radionuclides to the environment. The results from these analyses increase the confidence in the ability of Yucca Mountain and the facilities that may be built there to 
function satisfactorily in their role as a waste repository. Uncertainties remain, however, primarily in the input parameters and boundary conditions for the models that were used to complete the analyses. These models must be validated and uncertainties reduced before Yucca Mountain can qualify as a viable high-level nuclear-waste repository.

350 An overview of the Yucca Mountain global/ regional climate modeling program. Sandoval, R.P. (Sandia National Labs., Albuquerque, NM (United States)); Behl, Y.K.; Thompson, S.L. pp. 1188-1195 of Proceedings of high level radioac tive waste management: Volume 1. American Nuclear Society, La Grange Park, IL (United States) (1992). pp. 2425 (CONF-920430-: 3. international high level radioactive waste management (IHLRWM) conference, Las Vegas, NV (United States), 12-16 Apr 1992).

The U.S. Department of Energy (DOE) has developed a site characterization plan (SCP) to collect detailed information on geology, geohydrology, geochemistry, geoengineering, hydrology, climate, and meteorology (collectively referred to as geologic information) of the Yucca Mountain site. Forecasts of future climate conditions for the Yucca Mountain area will be based on both empirical and numerical techniques. The empirical modeling is based on the assumption that future climate change wil follow past patterns. The numerical approach, which is the primary focus of this paper involves the numerical solution of basic equations associated with atmospheric motions. This paper describes these equations and the strategy for solving them to predict future climate conditions around Yucca Mountain.

351 Performance-assessment comparisons for a repository containing LWR spent fuel or partitioned/ transmutted nuclear waste. Barnard, R.W. (Sandia National Lab., System Performance Assessment, Division 6312, Albuquerque, NM (US)); Lee, W.W.L. pp. 1397-1403 of Proceedings of high level radioactive waste management: Volume 1. American Nuclear Society, La Grange Park, IL (United States) (1992). pp. 2425 DOE Contract AC0476DP00789. (CONF-920430-: 3. international high level radloactive waste management (IHLRWM) conference, Las Vegas, NV (United States), 12-16 Apr 1992).

This paper describes one component of the total-system performance assessment analyses being performed for a potential geologic repository containing partitioned and/or transmuted waste. An analysis of the releases of radionuclides at the earth's surface due to human intrusion is presented here. The results are compared with other totalsystem performance assessments for the potential Yucca Mountain repository containing light-water-reactor spent fuel. Although most of the releases from a repository containing partitioned/transmuted waste are lower than those from a repository containing conventional spent fuel, the maximum releases are not significantly different.

352 TBM performance prediction in Yucca Mountain welded tuff from linear cutter tests. Gertsch, R. (Earth Mechanics inst., Dept. of Mining Engineering, Colorado School of Mines, Golden, CO (US)); Ozdemir, L.; Gertsch, L. pp. 1516-1520 of Proceedings of high level radioactive waste management: Volume 1. American Nuclear Society, La Grange Park, IL (United States) (1992). pp. 2425 (CONF-920430-: 3. international high level radioactive waste management (IHLRWM) conference, Las Vegas, NV (United States), 12-16 Apr 1992).

This paper discusses performance prediction which were developed for tunnel boring machines operating in welded tuff for the construction of the experimental study facility and the potential nuclear waste repository at Yucca Mountain. The predictions were based on test data obtained from an extensive series of linear cutting tests performed on samples of Topopah String welded tuff from the Yucca Mountain Project site. Using the cutter force, spacing, and penetration data from the experimental program, the thrust, torque, power, and rate of penetration were estimated for a $25 \mathrm{ft}$ diameter tunnel boring machine (TBM) operating in welded tuff. The result show that the Topopah Spring weided tuff (TSw2) can be excavated at relatively high rates of advance with state-of-the-art TBMs. The result also show, however, that the TBM torque and power requirements will be higher than estimated based on rock physical properties and past tunneling experience in rock formations of similar strength.

353 Deterministic geologic processes and stochastic modeling. Rautman, C.A. (Sandia National Lab., Albuquerque, NM (US)); Flint, A.L. pp. $1617-1624$ of Proceedings of high level radioactive waste management: Volume 1. American Nuclear Society, La Grange Park, IL (United States) (1992). pp. 2425 (CONF-920430-: 3. international high level radioactive waste management (IHLRWM) conference, Las Vegas, NV (United States), 1216 Apr 1992).

This paper reports that recent outcrop sampling at Yucca Mountain, Nevada, has produced significant new information regarding the distribution of physical properties at the site of a potential high-level nuclear waste repository, consideration of the spatial variability indicates that her are a number of widespread deterministic geologic features at the site that have important implications for numerical modeling of such performance aspects as ground water flow and radionuclide transport. Because the geologic processes responsible for formation of Yucca Mountain are relatively well understood and operate on a more-or-less regional scale, understanding of these processes can be used in modeling the physical properties and performance of the site. Information reflecting these deterministic geologic processes may be incorporated into the modeling program explicitly using geostatistical concepts such as soft information, or implicitly, through the adoption of a particular approach to modeling.

354 Design of an intermediate-scale experiment to validate unsaturated-zone transport models. Siegel, M.D. (Sandia National Lab., Albuquerque, NM (US)); Hopkins, P.L.; Glass, R.J.; Ward, D.B. pp. 1972-1984 of Proceedings of high level radioactive waste management: Volume 1. American Nuclear Society, La Grange Park, IL (United States) (1992). pp. 2425 (CONF-920430-: 3. international high level radioactive waste management (IHLRWM) conference, Las Vegas, NV (United States), 12-16 Apr 1992).

This paper discusses an intermediate-scale experiment that is being carried out to evaluate instrumentation and models that might be used for transport-model validation for the Yucca Mountain Site Characterization Project. The experimental test bed is a $6-\mathrm{m}$ high $\times 3-\mathrm{m}$ diameter caisson filled with quartz sand with a sorbing layer at an intermediate depth. The experiment involves the detection and prediction of the migration of fluid and tracers through an unsaturated porous medium. Pre-test design and materiais characterization require estimation of physical properties of the porous medium such as the relative permeability, saturation/pressure relations, porosity, and saturated hydraulic conductivity as well as geochemical properties such as surface complexation constants and empirical $K_{d}$ 's. The pretest characterization data will be used as input to several 
computer codes to predict the fluid flow and tracer migration. These include a coupled chemical-reaction/transport model, a stochastic model, and a deterministic model using retardation factors. The calculations will be completed prior to elution of the tracers, providing a basis for validation by comparing the predictions of observed moisture and tracer behavior.

355 Fault stress analysis for the Yucca Mountain site characterization project. Bauer, S.J. (Sandia National Lab., Performance Assessment Applications Div. 6313, Albuquerque, NM (US)); Hardy, M.P.; Goodrich, R.; Lin, M. pp. 2267-2277 of Proceedings of high level radioactive waste management: Volume 1. American Nuclear Society, La Grange Park, IL (United States) (1992). pp. 2425 DOE Contract AC04-76DP00789. (CONF-920430-: 3. international high level radioactive waste management (IHLRWM) conference, Las Vegas, NV (United States), 12-16 Apr 1992).

An understanding of the state of stress on faults is important for pre- and post-closure performance considerations for the potential high-level radioactive waste repository at Yucca Mountain. This paper presents the results of threedimensional numerical analyses that provide estimates of the state of stress through time $(10,000$ years) along three major faults in the vicinity of the potential repository due to thermal stresses resulting from waste emplacement. it was found, that the safety factor for slip close to the potential repository increases with time after waste emplacement. Possible fault slip is predicted above and below the potential repository for certain loading conditions and times. In general, thermal loading reduces the potential for slip in the vicinity of the potential repository.

356 Proposed sealing field tests for a potential high-level radioactive waste repository in unsaturated tuff. Fernandez, J.A. (Sandia National Lab., Geoscience Assessment and Validation, Albuquerque, NM (US)); Case, J.B.; Tyburski, J. pp. 2290-2297 of Proceedings of high level radioactive waste management: Volume 1. American Nuclear Society, La Grange Park, IL (United States) (1992). pp. 2425 DOE Contract AC04-76DP00789. (CONF-920430: 3 . international high level radioactive waste management (IHLRWM) conference, Las Vegas, NV (United States), 1216 Apr 1992).

This paper contains a general description of the field tests proposed for the Yucca Mountain Site Characterization Project repository sealing program. The tests are intended to resolve various performance and emplacement concerns associated with sealing components. Ten discrete tests are proposed to address these concerns. These tests are divided into two categories - simple and complex tests. The simple tests are: the small-scale in situ tests; the intermediate-scale borehole seal tests; the fracture grouting tests; the surface backfill tests; and the grouted rock mass tests. The complex tests are the seepage control tests; in situ backfill tests; in situ bulkhead tests; large-scale shaft seal tests; and remote bore-hole seal tests. These tests are proposed to be performed in welded and nonwelded tuff environments. The final selection of sealing tests will depend on the nature of the geologic and hydrologic conditions encountered during the development of the exploratory studies facility. Some tests may be performed before license application and some after license application.

357 Supporting hydration calculátions for small- to large-scale seal tests in unsaturated tuff. Tyburski, J.R. (IT Corp., Albuquerque, NM (US)); Case, J.B.; Fernandez,
J.A. pp. 2298-2305 of Proceedings of high level radioactive waste management: Volume 1. American Nuclear Society, La Grange Park, IL (United States) (1992). pp. 2425 DOE Contract AC04-76DP00789. (CONF-920430-: 3. international high level radioactive waste management (IHLRWM) conference, Las Vegas, NV (United States), 12-16 Apr 1992).

The design of cementitious repository seals requires an understanding of cement hydration effects in developing a tight interface zone between the rock and the seal. For this paper, a computer code, SHAFT.SEAL, is used to model early-age cement hydration effects and performs thermal and thermomechanical analysis of cementitious seals. The model is described, and then used to analyze for the effects of seal size, rock temperature and placement temperature. The model results assist in selecting the instrumentation necessary for progressive evaluation of seal components and seal-system tests. Also, the results identify strategies for seal emplacement for a series of repository seal tests for the Yucca Mountain Site Characterization Project (YMP).

358 Laboratory research program to aid in developing and testing the validity of conceptual models for flow and transport through unsaturated porous media. Glass, R.J. (Sandia National Labs., Albuquerque, NM (US)). pp. 275-283 of Safety Assessment of Radioactive Waste Repositories. Organisation for Economic Co-operation and Development, Paris (FR) (1991). pp. 668 Contract DE-AC 04-76DP00789. (CONF-9005117-: GEOVAL '90, Stockholm (Sweden), 14-17 May 1990).

As part of the Yucca Mountain Project, a laboratory research program is being developed at Sandia National Laboratories that will integrate fundamental physical experimentation with conceptual model formulation and mathematical modeling and aid in subsequent model validation for unsaturated zone water and contaminant transport. Experimental systems are being developed to explore flow and transport processes and assumptions of fundamental importance to various conceptual models. Experimentation will run concurrently in two types of systems: fractured and nonfractured tuffaceous systems; and analogue systems having specific characteristics of the tuff systems but designed to maximize experimental control and resolution of data measurement. Areas in which experimentation currently is directed include infiltration flow instability, water and solute movement in unsaturated fractures, fracture-matrix interaction, and scaling laws to define effective large-scale properties for heterogeneous, fractured media. 16 refs..

359 A conceptual design for a nuclear waste repository at the Yucca Mountain site. Hunter, T.O. (Sandia National Labs., Albuquerque, NM (United States)); Stevens, A.L. pp. 203-204 of Proceedings of SPECTRUM '90. American Nuclear Society, La Grange Park, IL (United States) (1990). pp. 505 DOE Contract AC04-76DP00789. (CONF900977-: Spectrum '90: American Nuclear Society (ANS) international meeting on radioactive waste technologies, decontamination, and hazardous wastes, Knoxville, TN (United States), 30 Sep - 4 oct 1990).

The Yucca Mountain Project has recently completed a conceptual design for a nuclear waste repository at the Yucca Mountain site. This conceptual design provides a reference configuration to be used during the site characterization program to evaluate the suitability of that site for a repository. The surface and underground facilities have been designed to account for the unique topographic, structural, and hydrologic setting at Yucca Mountain. This allows 
inclined ramps to be used for access to the underground facilities and for the repository to be located in the unsaturated zone above the water table. Subsequent design activities will provide for more detailed specification of design features and operational modes for the repository facilities. This paper will summarize the basic features of the conceptual design and relate those features to the site characterization program for the Yucca Mountain site.

360 Preliminary postclosure risk assessment Yucca mountain, Nevada, candidate repository site. Eslinger, P.W. (Battelle Pacific Northwest Lab. Richland, WA (US)); Doctor, P.G.; Elwood, D.M.; Engel, D.W.; Freshley, M.D.; Liebetrau, A.M.; Reimus, P.W.; Strenge, D.L.; Tanner, J.E.; Van Luik, A.E. pp. 221-228 of Proceedings of the Symposium on safety assessment of radioactive waste repositories. Organisation for Economic Co-operation and Development, Paris (FR) (1990). pp. 1024 (In FR, EN). (CONF-891008-: International symposium on safety assessment of radioactive waste repositories, Paris (France), 9-13 Oct 1989).

A study was conducted by the Pacific Northwest Laboratory for the U.S. Department of Energy to estimate the postclosure risk, in terms of population health effects, of a proposed high-level nuclear waste repository at Yucca Mountain, Nevada. The risk estimates cover a time span of 1 million years following repository closure. Representative disruptive and intrusive events were selected and evaluated in addition to expected conditions. The estimates were generated assuming spent fuel as the waste form and included all important nuclides from inventory, half-life and dose perspectives. The base case results yield an estimate of 36 health effects over the first million years of repository operation. The doses attributed to the repository corresponds to about 0.1 percent of the doses received from natural background radiation. 16 refs., 1 fig..

\section{U.S. GEOLOGICAL SURVEY}

361 (CONF-8904440-1) Characterization of liquidwater percolation in tuffs in the unsaturated zone, Yucca Mountain, Nye County, Nevada. Kume, J.; Rousseau, J.P. Geological Survey, Lakewood, CO (United States). Water Resources Div. [1989]. 5p. Sponsored by USDOE, Washington, DC (United States). DOE Contract A108-92NV10874. From F.D. Holland, Jr. North Dakota geological survey symposium; Grand Forks, ND (United States); 14-15 Apr 1989. Order Number DE92019173. Source: OSTI; NTIS; INIS; GPO Dep.

A surface-based borehole investigation currently (1989) is being done to characterize liquid-water percolation in tuffs of Miocene age in the unsaturated zone beneath Yucca Mountain, Nye County, Nevada Active in-situ testing and passive in-situ monitoring will be used in this investigation to estimate the present-day liquid-water percolation (flux). The unsaturated zone consists of a gently dipping sequence of fine-grained, densely fractured, and mostly welded ash-flow tuffs that are interbedded with fine-grained, slightly fractured, non-welded ash-flow and ash-fall tuffs that are partly vitric and zeolitized near the water table. Primary study objectives are to define the water potential field within the unsaturated zone and to determine the in-situ bulk permeability and bulk hydrologic properties of the unsaturated tuffs. Borehole testing will be done to determine the magnitude and spatial distribution of physical and hydrologic properties of the geohydrologic units, and of their water potential fields. The study area of this investigation is restricted to that part of Yucca Mountain that immediately overlies and is within the boundaries of the perimeter drift of a US Department of Energy proposed mined, geologic, high-level radioactive-waste repository. Vertically, the study area extends from near the surface of Yucca Mountain to the underlying water table, about 500 to 750 meters below the ground surface. The average distance between the proposed repository and the underiying water table is about 205 meters.

362 (CONF-920307-89) Does localized recharge occur at a discharge area within the ground-water flow system of Yucca Mountain, Nevada?. Czarnecki, J.B. (Geological Survey, Denver, CO (United States)); Kroitoru, L.; Ronen, D.; Magaritz, M. Geological Survey, Denver, CO (United States). [1992]. 7p. Sponsored by USDOE, Washington, DC (United States). DOE Contract Al08-92NV10874. From Waste management '92; Tucson, AZ (United States); 1-5 Mar 1992. Order Number DE92040807. Source: OSTI; NTIS; INIS; GPO Dep.

Studies done in 1984, at a central site on Franklin Lake playa (also known as Alkali Flat, a major discharge area of the ground-water flow system that includes Yucca Mountain, Nevada, the potential site of a high-level nuclear-waste repository) yieid limited hydraulic-head and hydrochemical data from a 3-piezometer nest which indicated a slightly downward hydraulic gradient $(-0.02)$ and decreasing concentration of dissolved solids with increasing depth. Hydraulic-head measurements in June, 1989 made at the piezometer nest showed a substantially larger downward gradient $(-0.10)$ and a 0.83 -meter higher water level in the shallowest piezometer ( 3.29 meters deep), indicating the possibility of localized recharge. during the period of September-November, 1989, a multilevel sampler was used to obtain detailed hydrochemical profiles of the uppermost 1. $5 \mathrm{~m}$ of the saturated zone.

363

(CONF-920761-15) A preliminary study of the chemistry of pore water extracted from tuff by onedimensional compression. Kharaka, Y.K. (Geological Survey, Menlo Park, CA (United States)); Maest, A.S. (eds.); Peters, C.A.; Yang, I.C.; Higgins, J.D.; Burger. Geological Survey, Denver, CO (United States). [1992]. 6p. Sponsored by USDOE, Washington, DC (United States). DOE Contract Al08-92NV10874. From 7. water-rock interaction conference; Park City, UT (United States); 9-23 Jul 1992. Order Number DE92040952. Source: OSTI; NTIS; INIS; GPO Dep.

A specially designed and fabricated one-dimensional com. pression cell is being used to extract water from nonwelded and densely welded tuffs having degrees of saturation greater than 16 and 37 percent respectively. Chemical analyses of pore water obtained at increasing pressures are used to evaluate possible changes in chemistry caused by compression. The extracted pore water varies form a calcium chloride type to a sodium bicarbonate type. The mean concentration of dissolved ions generally decreases during compression. The relative abundance of the major cations varies little with increasing pressure. Possible causes of the pore-water-chemistry changes include: (1) dilution of pore water by low ionic strength adsorbed water from zeolites and clays; (2) dissolution reactions caused by the increase in dissolved carbon dioxide concentrations that may result from pressurization; (3) membrane filtration by zeolites and clays; and (4) ion exchange with the zeolites and clays.

364 Tectonic characterization of a potential highlevel nuclear waste repository at Yucca Mountain, 
Nevada. Whitney, J.W. (Geological Survey, Denver, CO (US)); O'Leary, D.W. pp. 85-96 of Dynamic analysis and design considerations for high-level nuclear waste repositories. Hossain, Q.A. (ed.). American Society of Civil Engineers, New York, NY (US) (1993). pp. 443 From American Society of Civil Engineers (ASCE) symposium on dynamic analysis and design considerations, for high-level nuclear waste repositories; San Francisco, CA (United States); 19-20 Aug 1992.

Tectonic characterization of a potential high-level nuclear waste repository at Yucca Mountain, Nevada, is needed to assess seismic and possible volcanic hazards that could affect the site during the preclosure (next 100 years) and the behavior of the hydrologic system during the postclosure (the following 10,000 years) periods. Tectonic characterization is based on assembling mapped geological structures in their chronological order of development and activity, and interpreting their dynamic interrelationships. Addition of mechanistic models and kinematic explanations for the identified tectonic processes provides one or more tectonic models having predictive power. Proper evaluation and application of tectonic models can aid in seismic design and help anticipate probable occurrence of future geologic events of significance to the repository and its design.

365 Preliminary report: The Little Skull Mountain earthquake, June 29, 1992. Anderson, J.G. (Univ. of Nevada, Reno, NV (US)); Brune, J.N.; Polo, D. de; Savage, M.K.; Sheehan, A.F.; Smith, K.D.; Gomberg, J.; Harmsen, S.C. pp. $162-175$ of Dynamic analysis and design considerations for high-level nuclear waste repositories. Hossain, Q.A. (ed.). American Society of Civil Engineers, New York, NY (US) (1993). pp. 443 From American Society of Civil Engineers (ASCE) symposium on dynamic analysis and design considerations, for high-level nuclear waste repositories; San Francisco, CA (United States); 19-20 Aug 1992.

The Little Skull Mountain earthquake occurred about 20 $\mathrm{km}$ from the potential high level nuclear repository at Yucca Mountain. The magnitude was 5.6, and the focal mechanism indicates normal faulting on a northeast trending structure. There is evidence that the earthquake was triggered by the magnitude $\mathrm{M}_{\mathrm{S}}=7.5$ earthquake in Landers, California, which occurred less than 24 hours earlier. Preliminary locations of the hypocenter and several aftershocks define an $\mathrm{L}$ shaped pattern near the southern boundary of the Nevada Test Site. One arm trends to the northeast beneath Little Skull Mountain, and a shorter, more diffuse zone trends to the southeast. The aftershocks are mostly located at depths between $7 \mathrm{~km}$ and $11 \mathrm{~km}$, and may suggest a southeast dipping plane. There is no clear correlation with previously mapped surface faulting. The strongest recorded acceleration is about $0.21 \mathrm{~g}$ at Lathrop Wells, Nevada, $15 \mathrm{~km}$ from the epicenter. An extensive network of aftershock recorders was installed by the Seismological Laboratory, University of Nevada, Reno, by the US Geological Survey, Golden, Colorado, and by Lawrence Livermore Laboratory, Livermore, California. Aftershock experiments are ongoing as of November, 1992, and include experiments to improve location, depth, focal mechanism, and stress drop, study basin and ridge response near the epicenter and at Midway Valley, and study response of a tunnel at Little Skull Mountain. Analysis of this data, which includes thousands of aftershocks, has only begun.

366 (NUREG/CP-0040, pp. 43-53) Does the wind blow through Yucca Mountain?. Weeks, E.P. (Geological Survey, Denver, CO (US)). Nuclear Regulatory Commission,
Washington, DC (United States). Div. of Regulatory Applications; Southwest Research Inst., San Antonio, TX (United States). Center for Nuclear Waste Regulatory Analyses; Arizona Univ., Tucson, AZ (United States). Dept. of Hydrology and Water Resources. Jun 1993. (CONF-9101106-: 5. flow and transport through unsaturated fractured rock related to high-level radioactive waste disposal, Tucson, AZ (United States), 7-10 Jan 1991). In Proceedings of workshop 5: Flow and transport through unsaturated fractured rock - related to high-level radioactive waste disposal. $238 \mathrm{p}$. Source: OSTI; NTIS; INIS; GPO.

Beginning in February 1986, substantial net discharge of rock gas has been obsenved from a well located on the crest of Yucca Mountain that taps unsaturated fractured rock. Until recently, this net discharge was attributed entirely to a density contrast between slightly geothermally heated water vapor saturated rock gas and cooler, much drier atmospheric air. However, the net discharge is too large to be explained by the temperature and water vapor induced density contrast alone. A portion of this excess flow is now attributed to a wind effect. Hypothetically, as the wind blows against the mountain, the pressure increases along the flank due to a bluff or form-drag effect, and decreases at its crest due to an airfoil effect. This paper further examines the possibility of a wind effect on airflow from wells on Yucca Mountain. 9 refs., 3 figs., 1 tab.

367 (NUREG/CP-0040, pp. 184-188) The composition and $\mathrm{CO}_{2}$ carbon isotope signature of gases from borehole USW UZ-6, Yucca Mountain, Nevada. Thorstenson, D.C. (Geological Survey National Center, Reston, VA (US)). Nuclear Regulatory Commission, Washington, DC (United States). Div. of Regulatory Applications; Southwest Research Inst., San Antonio, TX (United States). Center for Nuclear Waste Regulatory Analyses; Arizona Univ., Tucson, AZ (United States). Dept. of Hydrology and Water Resources. Jun 1993. (CONF-9101106-: 5. flow and transport through unsaturated fractured rock related to high-level radioactive waste disposal, Tucson, AZ (United States), 7-10 Jan 1991). In Proceedings of workshop 5: Flow and transport through unsaturated fractured rock - related to high-level radioactive waste disposal. 238p. Source: OSTI; NTIS; INIS; GPO.

The monitoring of gas composition and/or flow at a number of unsaturated-zone boreholes at Yucca Mountain has been carried out since 1983 by the USGS. This paper reports the first depth profile of $13 \mathrm{C}$ and $14 \mathrm{C}$ (from CO2) form the deepest of these boreholes, USW UZ-6. Much of the significance of the data from UZ-6 lies in its relation to data already obtained from other UZ boreholes. 7 refs., 3 figs., 1 tab.

368 (NUREG/CP-0040, pp. 230-232) Technical issues related to groundwater flow and radionuclide transport in unsaturated fractured rock. Stuckless, J.S.; Murphy, W.M.; Arredondo, A.; Freeze, A.; Meijer, A.; Phillips, F.; Richards, K.; Stiffler, P. Nuclear Regulatory Commission, Washington, DC (United States). Div. of Regulatory Applications; Southwest Research Inst., San Antonio, TX (United States). Center for Nuclear Waste Regulatory Analyses; Arizona Univ., Tucson, AZ (United States). Dept. of Hydrology and Water Resources. Jun 1993. (CONF9101106-: 5. flow and transport through unsaturated fractured rock related to high-level radioactive waste disposal, Tucson, AZ (United States), 7-10 Jan 1991). In 
Proceedings of workshop 5: Flow and transport through unsaturated fractured rock - related to high-level radioactive waste disposal. 238p. Source: OSTI; NTIS; INIS; GPO.

Six high priority issues selected from over twenty technical subjects compiled by the group are summarized in this report. They include: regional distribution of chemical and isotopic tracers in deep vadose environments; detailed isotopic data base for comparison with model results; development of isotopic techniques for constraining ground water flow in unsaturated media; investigation of the significance of fracture coating for radionuclide transport in unsaturated media; radionuclide speciation and solubilities in aqueous solutions; appropriate mathematical formulation for radionuclide retardation. No judgement of relative priority is intended by the order of presentation. Technical issues tocus primarily on the Yucca Mountain, Nevada proposed repository environment.

369 (USGS-BULL-1991) Late quaternary faulting along the Death Valley-Furnace Creek fault system, Callfornia and Nevada. Brogan, G.E. (Geological Survey, Denver, CO (United States)); Kellogg, K.S.; Terhune, C.L.; Slemmons, D.B. Geological Sunvey, Denver, CO (United States). [1991]. 67p. Sponsored by USDOE, Washington, DC (United States). DOE Contract A108-92NV10874. Source: U.S. Geological Society, Books and OFR Section, Federal Center, Box 25425, Denver, CO 80225.

The Death Valley-Furnace Creek fault system, in California and Nevada, has a variety of impressive late Quaternary neotectonic features that record a long history of recurrent earthquake-induced faulting. Although no neotectonic features of unequivocal historical age are known, paleoseismic features from multiple late Quaternary events of surface faulting are well developed throughout the length of the system. Comparison of scarp heights to amount of horizontal offset of stream channels and the relationships of both scarps and channels to the ages of different geomorphic surfaces demonstrate that Quaternary faulting along the northwest-trending Furnace Creek fault zone is predominantly right lateral, whereas that along the north-trending Death Valley fault zone is predominantly normal. These observations are compatible with tectonic models of Death Valley as a northwest- trending pull-apart basin.

370 (USGS/MAP/GP-1001) Geophysical logs and core measurements from forty boreholes at Yucca Mountain, Nevada. Nelson, P.H.; Muller, D.C.; Schimschal, U.; Kibler, J.E. Geological Survey, Washington, DC (United States). [1991]. 399p. Sponsored by USDOE, Washington, DC (United States);Geological Survey, Reston, VA (United States). DOE Contract AlO8-78ET44802. Source: U.S.G.S. Open File Service, Box 25425-Denver Federal Center, Denver, CO 80225 .

A data base of geophysical logs and core measurements acquired in boreholes at Yucca Mountain, Nevada, has been established. We used this data set to generate log plots from 40 boreholes at a scale of $1: 1200$ for reference and for correlation. Log headers summarize the drilling and logging sequence. We describe the logging tools, the sources of core data, and the editing procedures. We illustrate the adverse effects of casing on the gamma-ray log, of borehole rugosity on the density log, and of borehole diameter and fluid resistivity on the resistivity logs. Welding and alteration of the tuffs are the dominant geological controls on the response of the density, velocity, neutron, and resistivity logs. Density, resistivity, gamma-ray, and, in particular, the magnetic-field logs are useful for correlation of stratigraphy and alteration. A few zones in which the matrix is moderately permeable have produced log responses indication invasion of the rock by drilling fluid. Readings from the density log were confirmed with core measurements. It appears that the epithermal-neutron and dielectric-permittivity logs can be used to estimate water content providing calibration methods are established. 82 refs., 30 figs., 6 tabs.

371 (USGS-OFR-89-567A) TURBOSEIS-An interactive program for constructing and editing models of seismic refraction traveltime data using a color-graphics terminal. Chuchel, B.A. Geological Survey, Menio Park, CA (United States). 1989. 82p. Sponsored by USDOE, Washington, DC (United States). DOE Contract Al08-78ET44802. Order Number DE92003698. Source: OSTI; NTIS; US Geological Survey, Books and Open-File Reports Section, Box 25425, Federal Center, Denver, CO 80225; GPO Dep.

TURBOSEIS is a FORTRAN computer program designed to assist the user in interactively developing seismic refraction traveltime curves (modeis), to evaluate the number of refracting horizons at depth in a study area. TURBOSEIS allows one to generate a detailed traveltime curve for each of these layers that can then be input into the programs of Ackermann (Ackermann and other 1986) for inversion of the velocity distribution as a function of depth. This report describes the mechanics of using the program to enter and manipulate the "model."

372 (USGS-OFR-90-369) Geohydrologic data from test holes UE-25 UZ \#4 and UE-25 UZ \#5, Yucca Mountain Area, Nye County, Nevada. Loskot, C.L.; Hammermeister, D.P. Geological Survey, Denver, CO (United States). [1992]. 56p. Sponsored by Department of the Interior, Washington, DC (United States). DOE Contract AlO8-78ET44802. Order Number DE93004285. Source: OSTI; NTIS; GPO Dep.

Data collected to determine the hydraulic characteristics of rocks penetrated by test holes UE-25 UZ No. 4 and UE$25 \mathrm{UZ}$ No. 5 are presented. These test holes are part of a series of test holes drilled in and near the southwestern part of the Nevada Test Site in an investigation conducted by the US Geological Survey in cooperation with the US Department of Energy. This investigation is part of the Yucca Mountain Project Branch, Hydrologic Investigations Program (formerly Nevada Nuclear Waste Storage Investigations) to determine the suitability of this site for storage of high-level radioactive wastes in an underground mined repository. Data on drilling operations, lithology, coring, and laboratory analyses of hydrologic characteristics of core and cuttings samples are included in this report.

373 (USGS-OFR-90-474) Results of rock property measurements made on core samples from Yucca Mountain boreholes, Nevada Test Site, Nevada: Part 1, Boreholes UE25A-4, -5, -6, and -7; Part 2, Borehole UE25PNo.1. Anderson, L.A. Geological Survey, Denver, CO (United States). 1991. 43p. Sponsored by USDOE, Washington, DC (United States). DOE Contract Al08-78ET44802. Order Number DE92005486. Source: OSTI; NTIS; INIS; USGS Books and Open-File Reports Section, Box 25425 Federal Center, Denver, CO 80225; GPO Dep.

Laboratory measurements of resistivity, bulk and grain density, porosity, compressional sonic velocity, water permeability, magnetic susceptibility, and remanent magnetization were made on core samples from Yucca Mountain boreholes located in Drill Hole Wash at the Nevada Test Site. The samples are representative of lithologic variations 
to be found in the Tiva Canyon, Yucca Mountain, Pah Canyon, and the upper Topopah Spring Members of the Paintbrush Tuff. Boreholes penetrated to a depth of approximately 152 meters $(500 \mathrm{ft}$.). The Paintbrush Tuff consists primarily of nonwelded to densely welded rhyolitic ash-flow tuff with relatively thin beds of ash-fall tuff typically separating each Member. Resistivity and bulk density measurements were made on samples containing natural pore waters and repeated following resaturation with local tap water. Density comparisons indicate the samples to be undersaturated in their natural environment as expected in that the boreholes did not intersect the water table.

374 (USGS-OFR-91-105) Aeromagnetic map of the Beatty quadrangle, Nevada-California. Glen, J.M.; Ponce, D.A. Geological Survey, Menlo Park, CA (United States). 1991. 18p. Sponsored by USDOE, Washington, DC (United States). DOE Contract Al08-78ET44802. Source: OSTI; INIS; US Geological Survey, Books and Open-File Reports Section, Federal Center, Box 25425, Denver, CO 80225 0425.

An aeromagnetic map of the Beatty Quadrangle, Nevada-California has been prepared from six separate aeromagnetic surveys. This report contains the map. $(\mathrm{JL})$

375

(USGS-OFR-91-125) US Geological Survey Committee for the Advancement of Science in the Yucca Mountain Project symposium on "Fractures, Hydrology, and Yucca Mountain": Abstracts and summary. Gomberg, J. (ed.). Geological Survey, Denver, CO (United States). 1991. 39p. Sponsored by USDOE, Washington, DC (United States). DOE Contract Al08-92NV10874. (CONF9009542-Absts.: US Geological Survey Committee for the advancement of science conference on fractures, hydrology, and Yucca Mountain, Denver, CO (United States), 13-14 Sep 1990). Order Number DE94000437. Source: OSTI; NTIS; INIS; GPO Dep.

The principal objective of this symposium is to review the available information on fractured/faulted terrains in terms of a coherent hydrogeologic model of ground-water fluid flow and transport, particularly as it pertains to the Yucca Mountain region. This review addresses the influence and significance of fractures on ground-water flow and the transport of conservative-species solutes within the context of the hydrogeologic setting of the Yucca Mountain area. The relations between fluid flow and fractured or faulted host rock are examined integrally from information on geologic, seismologic, hydrologic, and geomechanical properties of the system. The development of new hydrogeologic approaches that incorporate information from this integrated database are contrasted with more standard approaches toward understanding flow in fractured resenvoirs. Ground-water flow in both the unsaturated zone and the saturated zone are considered. The application of various models of flow is addressed, examples include porous-media equivalent and discontinuum fracture-network models. Data and interpretations from the Yucca Mountain area are presented to establish a context for information exchange. The symposium includes discussions relevant to technical considerations for characterizing the Yucca Mountain area hydrogeology. On the basis of these discussions, CASY has compiled this document in order to formally summarize the proceedings and communicate recommendations for future directions of research and investigation.

376 (USGS-OFR-91-367) Seismicity and focal mechanisms for the Southern Great Basin of Nevada and California in 1990. Harmsen, S.C. Geological Survey, Denver, CO (United States). 1991. 103p. Sponsored by Department of the Interior, Washington, DC (United States). DOE Contract Al08-78ET44802. Order Number DE92011869. Source: OSTI; NTIS; GPO Dep.

For the calendar year 1990, the Southern Great Basin seismic network (SGBSN) recorded about 1050 earthquakes in the SGB, as compared to 1190 in 1989. Local magnitudes, $M_{L}$, ranged from 0.0 for various earthquakes to 3.2 for an earthquake on April 3, 1990 5:47:58 UTC, $37.368^{\circ}$ North, $117.358^{\circ}$ West, Mud Lake, Nevada quadrangle. $95 \%$ of those earthquakes have the property, $M_{L} \leq 2.4$. Within a $10 \mathrm{~km}$ radius of the center of Yucca Mountain, the site of a potential national, high-level nuclear waste repository, one earthquake with $\mathrm{M}_{\mathrm{L}}=0.6$ was recorded at 40 -Mile Wash. The estimated depth of focus of this earthquake is $3.8 \mathrm{~km}$ below sea level. Other, smaller events may have also occurred in the immediate vicinity of Yucca Mountain, but would have been below the detection threshold $\left(M_{L} \approx 0.0\right.$ at Yucca Mountain). Focal mechanisms are computed for seventeen earthquakes in the Nevada Test Site (NTS) and in the SGB west of the NTS for the year 1990. Solutions are mostly strike-slip, although normal slip is observed for a hypocenter at Stonewall Flat, Nevada, and reverse slip is observed for a hypocenter at Tucki Mountain, California. The average direction of the focal mechanism P-axes is North $47^{\circ}$ East, with nearly horizontal inclination, and the average direction of the T-axes is North $42^{\circ}$ West, with nearly horizontal inclination, consistent with a regional tectonic model of active northwest extension during the Holocene epoch.

377 (USGS-OFR-91-478) Simulated water-level declines caused by withdrawals from wells $J-13$ and $\downarrow-12$ near Yucca Mountain, Nevada. Czarnecki, J.B. Geological Survey, Denver, CO (United States). 1992. 20p. Sponsored by Department of the Interior, Washington, DC (United States). DOE Contract Al08-92NV10874. Order Number DE93004286. Source: OSTI; NTIS; GPO Dep.

Simulations were done to examine the effects of groundwater withdrawals from wells $\mathrm{J}-13$ and $\mathrm{J}-12$ near Yucca Mountain, Nevada. These simulations were done using a two-dimensional finite-element model of the subregional groundwater flow system of Yucca Mountain and vicinity. Eight different withdrawal rates ranging from 36 gallons per minute (the minimum average for well $\mathrm{J}-13$ ) to 1,390 gallons per minute (the maximum for both $\mathrm{J}-13$ and $\mathrm{J}-12$ combined) were used in conjunction with specific-yield values of 0.001 , 0.005 , and 0.01 . Drawdown was analyzed for each withdrawal rate by plotting contours of drawdown after 10 years of simulated withdrawals, and by plotting drawdown as a function of time for model locations corresponding to well $\mathrm{J}$ 13 , well $\mathrm{J}-12$, one-half mile south of well $\mathrm{J}-12,2$ miles north of the town of Amargosa Valley, and about 5 miles northwest of the Ash Meadows area. Because the range in simulated withdrawal rate was large, the range in resultant drawdown was correspondingly large. The simulated drawdowns after 10 years for the withdrawal rate of 90 gallons per minute from well $\mathrm{J}-13$, based on a specific yield of 0.01 (which was considered to be a minimum value for the aquifer system) were 0.95 foot at well $J-13,0.53$ foot at Amargosa Valley, and 0.16 foot northwest of Ash Meadows.

378 (USGS-OFR-91-493) Water levels in continuously monitored wells in the Yucca Mountain area, Nevada, 1985-88. Luckey, R.R.; Lobmeyer, D.H.; Burkhardt, D.J. Geological Survey, Denver, CO (United States). 1993. 252p. Sponsored by USDOE, Washington, 
DC (United States). DOE Contract A108-92NV10874. Order Number DE93017415. Source: OSTI; NTIS; INIS; GPO; US Geological Survey, Books and Open-Flle Reports Section, Box 25425, Mail Stop 517, Federal Center, Denver, CO 80225-0425; GPO Dep.

Water levels have been monitored hourly in 15 wells completed in 23 depth intervals in the Yucca Mountain area, Nevada. Water levels were monitored using pressure transducers and were recorded by data loggers. The pressure transducers were periodically calibrated by raising and lowering them in the wells. The water levels were normally measured at approximately the same time that the transducers were calibrated. Where the transducer output appeared reasonable, it was converted to water levels using the calibrations and manual water- level measurements. The amount of transducer output that was converted to water levels ranged from zero for several intervals to about 98 percent for one interval. Fourteen of the wells were completed in Tertiary volcanic rocks and one well was completed in $\mathrm{Pa}$ leozoic carbonate rocks. Each well monitored from one to four depth intervals. Water-level fluctuation caused by barometric pressure changes and earth tides were observed.

379 (USGS-OFR-91-572) Seismicity and focal mechanisms for the southern Great Basin of Nevada and California: 1987 through 1989. Harmsen, S.C.; Bufe, C.G. Geological Survey, Denver, CO (United States). [1991]. 214p. Sponsored by USDOE, Washington, DC (United States). DOE Contract Al08-92NV10874. Order Number DE92014882. Source: OSTI; NTIS; GPO Dep.

For the calendar year 1987, the southern Great basin seismic network (SGBSN) recorded about 820 earthquakes in the southern Great Basin (SGB). Local magnitudes ranged from 0.2 to 4.2 (December $30,1987,22: 50: 42$ UTC at Hot Creek Valley). Five earthquakes epicenters in 1987 within the detection threshold of the seismic network are at Yucca Mountain, the site of a potential national, high-level nuclear waste repository. The maximum magnitude of those five earthquakes is 1.1 , and their estimated depths of focus ranged from 3.1 to $7.6 \mathrm{~km}$ below sea level. For the calendar year 1988, about $1280 \mathrm{SGB}$ earthquakes were catalogued, with maximum magnitude-4.4 for an Owens Valley, California, earthquake on July 5, 1988. Eight earthquake epicenters in 1988 are at Yucca Mountain, with depths ranging from three to $12 \mathrm{~km}$ below sea level, and maximum magnitude 2.1. For the calendar year 1989, about 1190 $S G B$ earthquakes were located and catalogued, with maximum magnitude equal to 3.5 for earthquake about ten miles north of Las Vegas, Nevada, on January 9. No Yucca Mountain earthquakes were recorded in 1989. An earthquake having a well-constrained depth of about $30 \mathrm{~km}$ below sea level was observed on August 21, 1989, in eastern Nevada Test Site (NTS).

380 (USGS-OFR-91-620) Geophysical characterization of mineral and energy resources at Yucce Mountain and vicinity, Nevada. Langenheim, V.E. (Geological Survey, Menio Park, CA (United States)); Oliver, H.W.; Hoover, D.B. Geological Survey, Menlo Park, CA (United States). 1991. 8p. Sponsored by USDOE, Washington, DC (United States). DOE Contract AI08-78ET44802. Order Number DE92012265. Source: OSTI; NTIS; GPO Dep.

This report was prepared for the Yucca Mountain Project (Department of Energy) as part of the study of the mineral and energy resource potential of the site (Activity 8.3.1.9.2.1.5) under the Human Interference part of the program. Most of the 1991 geophysical scoping activities in the
Mineral Resources Study were involved with the acquisition and evaluation of existing data. This report presents an overview of how geophysical data (existing and planned) will aid in the evaluation of the potential for mineral and energy resource potential at Yucca Mountain and vicinity.

381 (USGS-OFR-91-623) Photogeologic and kinematic analysis of lineaments at Yucca Mountain, Nevada: Implications for strike-slip faulting and oroclinal bending. O'Neill, J.M.; Whitney, J.W.; Hudson, M.R. Geological Survey, Denver, CO (United States). 1992. 45p. Sponsored by USDOE, Washington, DC (United States). DOE Contract Al08-92NV10874; Al08-78ET44802. Order Number DE93009873. Source: OSTI; NTIS; INIS; GPO Dep.

The main structural grain at Yucca Mountain, as seen from aerial photographs, is a pronounced north-trending linear fabric defined by parallel east-tilted fault-block ridges. The ridges are bounded on the west by normal faults that are easily recognizable on aerial photographs, mainly as isolated, colinear scarps in alluvium and as offset bedrock units. AH ridge-bounding to adjacent faults, most commonly by short northwest-trending fault splays. The generally north-trending high-angle faults primarily display down-tothe-west normal offset, but also have an auxiliary component of left-lateral slip. Left-lateral slip is indicated by offset stream channels, slickenlines, and en echelon fault splays that are structurally linked, commonly by pull-apart grabens. These grabens, best seen on low-sun angle aerial photographs, rangefrom tens of meters to more than 3 kilometers wide. The smallest pull-apart zones are well developed along the Windy Wash and Solitario Canyon faults on the west side of Yucca Mountain; the largest of these features is interpreted to structurally link the Bow Ridge and Solitario Canyon faults in the north-central part of Yucca Mountain; the pronounced northwest-trending drainage system in this part of Yucca Mountain appears to be controlled by tension fractures related to left-lateral strike-slip movement on these north-trending faults. Midway Valley, directly east of this pull-apart graben, may also owe its origin, in part, to a pull-apart mechanism.

382 (USGS/OFR-92-28) Borehole and geohydrologic data for test hole USW UZ-6, Yucca Mountain area, Nye County, Nevada. Whitfield, M.S. Jr. (Geological Survey, Denver, CO (United States)); Loskot, C.L.; Cope, C.M. Geological Survey, Denver, CO (United States). 1993. $40 p$. Sponsored by USDOE, Washington, DC (United States);Department of the Interior, Washington, DC (United States). DOE Contract AIO8-78ET44802. Source: OSTI; INIS; US Geological Survey, Books and Open-File Reports Section, Federal Center, Box 25425, Denver, CO 80225 (United States).

Test hole USW UZ-6, located 1.8 kilometers west of the Nevada Test Site on a major north-trending ridge at Yucca Mountain, was dry drilled in Tertiary tuff to a depth of 575 meters. The area near this site is being considered by the US Department of Energy for potential construction of a high-level, radioactive-waste repository. Test hole USW UZ6 is one of seven test holes completed in the unsaturated zone as part of the US Geological Survey's Yucca Mountain Project to characterize the potential repository site. Data pertaining to borehole drilling and construction, lithology of geologic units penetrated, and laboratory analyses for hydrologic characteristics of samples of drill-bit cuttings are included in this report. 
383 (USGS-OFR-92-137) Earthquake-induced water-level fluctuations at Yucca Mountain, Nevada, April 1992. O'Brien, G.M. Geological Survey, Denver, CO (United States). [1992]. 10p. Sponsored by USDOE, Washington, DC (United States). DOE Contract Al08-92NV10874. Order Number DE92019280. Source: OSTI; NTIS; INIS; GPO; GPO Dep.

This report presents earthquake-induced water-level and fluid- pressure data for well USW H-5 during April 1992. Well USW H-5 is located in the Yucca Mountain area, Nevada. On April 22,1992 a 6.2-magnitude earthquake occurred in southern California which caused a maximum fluid-pressure change of approximately 50 centimeters in well USW H-5. Within 18 hours on April 25-26, 1992, three major earthquakes occurred in northern California. The water-level responses to these earthquakes were detected in well USW $H-5$. The maximum water-level fluctuation from the northern California earthquakes was in excess of $52.5 \mathrm{~cm}$.

384 (USGS-OFR-92-340) Seismicity and focal mechanisms for the southern Great Basin of Nevada and California in 1991. Harmsen, S.C. Geological Survey, Denver, CO (United States). 1993. 105p. Sponsored by USDOE, Washington, DC (United States). DOE Contract Al08-92NV10874. Order Number DE93009824. Source: OSTI; NTIS; INIS; U.S. Geological Survey, Books and Open-File Reports Section, Federal Center, Box 25425, Denver, CO 80225; GPO Dep.

For calendar year 1991, the southern Great Basin seismic network (SGBSN) recorded 980 earthquakes in the SGB, as compared to 1050 in 1990 . Local magnitudes, $M_{L}$, ranged from 0.0 for several earthquakes in the southern Nevada Test Site to 4.1 for a strike-slip earthquake in the Lower Pahranagat Lake SW quadrangle on March 10, 1991. No felt reports or damage reports were filed with the National Earthquake Information Center (NEIC) for Southern Great Basin (SGB) earthquakes of 1991, although public agencies were canvassed following three of the largest of them. Within a $10-\mathrm{km}$ radius of the site of a potential national, high-level nuclear-waste repository near the center of Yucca Mountain, Nevada, no earthquakes were detected, although three earthquakes, with duration magnitudes between 0.8 and 1.1 , were recorded in the Claim Canyon Cauldron segment south of Timber Mountain and $10+\mathrm{km}$ north of the potential repository site. This report examines the seismicity of the region in the vicinity of Yucca Mountain.

385 (USGS-OFR-92-343) Gravity and magnetic data of Fortymile Wash, Nevada Test Site, Nevada. Ponce, D.A. (Geological Survey, Menlo Park, CA (United States)); Kohrn, S.B.; Waddell, S. Geological Survey, Menlo Park, CA (United States). 1992. 34p. Sponsored by USDOE, Washington, DC (United States). DOE Contract Al08-78ET44802. Order Number DE93012727. Source: OSTI; NTIS; INIS; GPO Dep.

Gravity and ground magnetic data collected along six traverses across Fortymile Wash, in the southwest quadrant of the Nevada Test Site suggest that there are no significant vertical offsets below Fortymile Wash. The largest gravity and magnetic anomaly, in the vicinity of Fortymile Wash, is produced by the Paintbrush fault, on the west flank of Fran Ridge. Inferred vertical offset is about $250 \pm 60 \mathrm{~m} \mathrm{(800 \pm}$ $200 \mathrm{ft}$ ). Geophysical data indicate that the fault is about 300 $\mathrm{m}(1,000 \mathrm{ft})$ east of its mapped, but concealed location. North of Busted Butte, near Fran Ridge, geophysical data do not preclude the existence of small vertical offsets bounding Fortymile Wash. However, gravity and magnetic profiles south of Busted Butte show little correlation to those to the north and suggest that vertical offsets, comparable in size to the Paintbrush fault, are not present. Density profiling, a technique used to determine the average density of small topographic features, suggests that the density of near-surface material in the vicinity of Fortymile Wash is 1.80 to $2.00 \mathrm{~g} / \mathrm{cm}^{3}$.

\section{6}

(USGS-OFR-92-490) Proposed algorithm for determining the delta intercept of a thermocouple psychrometer curve. Kurzmack, M.A. Geological Survey, Denver, CO (United States). 1993. 10p. Sponsored by USDOE, Washington, DC (United States). DOE Contract Al08-92NV10874. Order Number DE93016278. Source: OSTI; NTIS; INIS; U.S. Geological Survey, Box 25425, MS 517, Denver Federal Center, Denver, CO 80225-0425 (US); GPO Dep.

The USGS Hydrologic Investigations Program is currently developing instrumentation to study the unsaturated zone at Yucca Mountain in Nevada. Surface-based boreholes up to 2,500 feet in depth will be drilled, and then instrumented in order to define the water potential field within the unsaturated zone. Thermocouple psychrometers will be used to monitor the in-situ water potential. An algorithm is proposed for simply and efficiently reducing a six wire thermocouple psychrometer voltage output curve to a single value, the delta intercept. The algorithm identifies a plateau region in the psychrometer curve and extrapolates a linear regression back to the initial start of relaxation. When properly conditioned for the measurements being made, the algorithm results in reasonable results even with incomplete or noisy psychrometer curves over a 1 to 60 bar range.

387 (USGS-OFR-92-572) Assessment of geophysical logs from borehole USW G-2, Yucca Mountain, Nevada. Nelson, P.H. (Geological Survey, Denver, CO (United States)); Schimschal, U. Geological Survey, Denver, CO (United States). 1993. 34p. Sponsored by USDOE, Washington, DC (United States), DOE Contract Al0892NV10874. Order Number DE93013189. Source: OSTI; NTIS; INIS; GPO; U.S. Geological Survey, Books and Open File Reports Section, Federal Center, Box 25425, Denver, CO 80225; GPO Dep.

Commercial logging contractors, Western Atlas, Schlumberger, and Edcon obtained borehole geophysical logs at the site of a potential high level nuclear waste repository at Yucca Mountain, Nevada. Drill hole USW-G2 was picked for this test of suitable logging tools and logging technology, both representing state-of-the-art technology by these commercial companies. Experience gained by analysis of existing core data and a variety of logs obtained earlier by Birdwell and Dresser Atlas served as a guide to a choice of logs to be obtained. Logs were obtained in water-filled borehole in zeolitized tuff (saturated zone) and in air-filled borehole largely in unaltered welded tuff (unsaturated zone).

388 (USGS-OFR-93-73) Earthquake-induced waterlevel fluctuations at Yucca Mountain, Nevada, June 1992. O'Brien, G.M. Geological Survey, Denver, CO (United States). 1993. 12p. Sponsored by USDOE, Washington, DC (United States). DOE Contract Al08-92NV10874. Order Number DE93016279. Source: OSTI; NTIS; INIS; U.S. Geological Survey, Box 25425, MS 517, Denver Federal Center, Denver, CO 80225-0425 (US); GPO Dep.

This report presents earthquake-induced water-level and fluid-pressure data for wells in the Yucca Mountain area, Nevada, during June 1992. Three earthquakes occurred 
which caused significant water-level and fluid-pressure responses in wells. Wells USW H-5 and USW H-6 are continuously monitored to detect short-term responses caused by earthquakes. Two wells, monitored hourly, had significant, longer-term responses in water level following the earthquakes. On June 28, 1992, a 7.5-magnitude earthquake occurred near Landers, California causing an estimated maximum water-level change of 90 centimeters in well USW H-5. Three hours later a 6.6-magnitude earthquake occurred near Big Bear Lake, California; the maximum water-level fluctuation was 20 centimeters in well USW H-5. A 5.6magnitude earthquake occurred at Little Skull Mountain, Nevada, on June 29, approximately 23 kilometers from Yucca Mountain. The maximum estimated short-term waterlevel fluctuation from the Little Skull Mountain earthquake was 40 centimeters in well USW H-5. The water level in well UE-25p \#1, monitored hourly, decreased approximately 50 centimeters over 3 days following the Little Skull Mountain earthquake. The water level in UE-25p \#1 returned to preearthquake levels in approximately 6 months. The water level in the lower interval of well USW H-3 increased 28 centimeters following the Little Skull Mountain earthquake. The Landers and Little Skull Mountain earthquakes caused responses in 17 intervals of 14 hourly monitored wells, however, most responses were small and of short duration. For several days following the major earthquakes, many smaller magnitude aftershocks occurred causing measurable responses in the continuously monitored wells.

389 (USGS-OFR-93-438) Streamflow and selected precipitation data for Yucca Mountain and vicinity, Nye County, Nevada, water years 1983-85. Pabst, M.E.; Beck, D.A.; Glancy, P.A.; Johnson, J.A. Geological Survey, Carson City, NV (United States). 1993. 70p. Sponsored by USDOE, Washington, DC (United States). DOE Contract Al08-78ET44802 ; Al08-92NV10874. Order Number DE94003607. Source: OSTI; NTIS; INIS; GPO Dep.

Streamflow and precipitation data collected at and near Yucca Mountain, Nevada, during water years 1983-85, are presented in this report. The data were collected and compiled as part of the studies the US Geological Survey is making, in cooperation with the US Department of Energy, to characterize surface-water hydrology in the Yucca Mountain area. Streamflow data include daily mean discharges and peak discharges at 4 complete-record gaging stations and peak discharges at 10 crest-stage, partial-record stations and 12 miscellaneous sites. Precipitation data include cumulative totals at 12 stations maintained by the US Geological Survey and daily totals at 17 stations maintained by the Weather Service Nuclear Support Office, National Oceanic and Atmospheric Administration.

390 (USGSNRIR-89-4025) Geohydrology of rocks penetrated by test well USW H-6, Yucca Mountain, Nye County, Nevada. Craig, R.W. (Geological Survey, Denver, CO (United States)); Reed, R.L. Geological Survey, Denver, CO (United States); Fenix and Scisson, Inc., Tulsa, OK (United States). [1991]. 40p. Sponsored by USDOE, Washington, DC (United States). DOE Contract AI08-78ET44802. Order Number DE92003375. Source: OSTI; NTIS; INIS; US Geological Survey, Books and Open-File Reports Section, Box 250425, Mail Stop 517, Federal Center, Denver, CO 80225-0425; GPO Dep.

Test well USW H-6 is one of several wells drilled in the Yucca Mountain area near the southwestern part of the Nevada Test Site for investigations related to isolation of high-level nuclear waste. This well was drilled to a depth of
1,220 meters. Rocks penetrated are predominantly ash-flow tuffs of Tertiary age, with the principal exception of dacitic(?) lave penetrated at a depth from 877 to 1,126 meters. The composite static water level was about 526 meters below the land surface; the hydraulic head increased slightly with depth. Most permeability in the saturated zone is in two fractured intervals in Crater Flat Tuff. Based on well-test data using the transitional part of a dual-porosity solution, an interval of about 15 meters in the middle part of the Bullfrog Member of the Crater Flat Tuff has a calculated transmissivity of about 140 meters squared per day, and an interval of about 11 meters in the middle part of the Tram Member of the Crater Flat Tuff has a calculated transmissivity of about 75 meters squared per day. The upper part of the Bulffrog Member has a transmissivity of about 20 meters squared per day. The maximum likely transmissivity of any rocks penetrated by the test well is about 480 meters squared per day, based on a recharge-boundary model. The remainder of the open hole had no detectable production. Matrix hydraulic conductivity ranges from less than $5 \times 10^{-5}$ to $1 \times$ $10^{-3}$ meter per day. Ground water is a sodium bicarbonate type that is typical of water from tuffaceous rock of southern Nevada. The apparent age of the water is about 14,6000 years. 29 refs., 26 figs., 5 tabs.

391 Flow and transport through unsaturated rock: Data from two test holes, Yucca Mountain, Nevada. Yang, I.C. (Geological Survey, Denver, CO (United States)). pp. 732-737 of Proceedings of high level radioactive waste management: Volume 1. American Nuclear Society, La Grange Park, IL (United States) (1992). pp. 2425 (CONF920430-: 3. international high level radioactive waste management (IHLRWM) conference, Las Vegas, NV (United States), 12-16 Apr 1992).

This paper reports that tritium data for unsaturated-zone water from test holes UE-25 UZ No. 4 and UE-25 UZ No. 5 , Yucca Mountain, Nevada, indicated concentration inversions at several depths. Chemical-composition inversions and large differences in ${ }^{14} \mathrm{C}$ in the ground-water from these holes also were observed in the deeper strata. These abrupt changes are attributed to preferential flow paths.

392 Paleohydrologic implications of the stable isotopic composition of secondary calcite within the tertiary volcanic rocks of Yucca Mountain, Nevada. Whelan, J.F. (US Geological Survey, Denver, CO (US)); Stuckless, J.S. pp. 1572-1581 of Proceedings of high level radioactive waste management: Volume 1. American Nuclear Society, La Grange Park, IL (United States) (1992). pp. 2425 (CONF-920430-: 3. international high level radioactive waste management (IHLRWM) conference, Las Vegas, NV (United States), 12-16 Apr 1992).

This paper reports on calcite oxide occurs within Yucca Mountain as late-stage sparry druse in lithophysal cavities and on tracture surfaces within the unsaturated zone, and deep in the tuff section as veins and as cements that line secondary porosity and replace phenocrysts. Calcite sampled trom drill holes USW G-1, USW G-2, USW G-3/GU-3, USW G-4 UE25 a No. 1, UE25 b No. 1, and UE25 p No. 1 has $\delta^{18} \mathrm{O}$ values that range from 4.2 to $20.3 \%$ and $\delta^{3} \mathrm{C}$ values that range from -9.5 to $4.4 \%$. Calcite $\delta^{18} \mathrm{O}$ values decrease regularly with depth and are generally consistent with gentle warning of the ground waters along regional geothermal gradients. In the saturated zone, calcite $\delta^{13} \mathrm{C}$ values generally range from -2 to $3 \%$. These values are similar to those of the rocks and waters of the Paleozoic 
aquifer that underlies the volcanic section and suggest the isotopically heavy calcite in the saturated zone precipitated from upward leakage of Paleozoic aquifer waters. The simplest interpretation of the data suggests that past water table elevations might be reconstructed from the $\delta^{13} \mathrm{C}$ values of secondary calcite. Possible alternative explanations of the outlying data are: light $\delta^{13} \mathrm{C}$ values in the saturated zone record times during which, or locations where, descending waters carried $\mathrm{HCO}_{3}$ of soil zone derivation into the upper levels of the saturated zone; and heavy $\delta^{13} \mathrm{C}$ values in the unsaturated record calcite precipitation from descending fluids of soil zone origin that had become ${ }^{13} \mathrm{C}$ enriched by loss of $\mathrm{CO}_{2}$ during descent.

393 Strontium isotope geochemistry of calcite tracture fillings in deep core, Yucca Mountain, Nevada: A progress report. Peterman, Z.E. (US Geological Survey, Denver, CO (US)); Stuckless, J.S.; Marshall, B.D.; Mahan, S.A.; Futa, K. pp. 1582-1586 of Proceedings of high level radioactive waste management: Volume 1. American Nuclear Society, La Grange Park, IL (United States) (1992). pp. 2425 (CONF-920430-: 3. international high level radioactive waste management (IHLRWM) conference, Las Vegas, NV (United States), 12-16 Apr 1992).

This paper reports on the variation of ${ }^{87} \mathrm{SR} /{ }^{86} \mathrm{Sr}$ in calcite fracture fillings as a function of depth which has been determined using samples from five boreholes at Yucca Mountain. The data group into three discrete populations. Within $400 \mathrm{~m}$ of the present-day land surface, the distribution of ${ }^{87} \mathrm{Sr} /{ }^{86} \mathrm{Sr}$ for calcite fracture fillings is similar to that of calcretes and near-surface veins suggesting an origin by infiltrating meteoric water. Veins within a $100-\mathrm{m}$ zone immediately about the modern water table have ${ }^{87} \mathrm{Sr} /{ }^{86} \mathrm{Sr}$ values similar to those of ground water from the Cenozoic volcanic aquifer suggesting a past connection between the two through aqueous diffusion or a higher water level. ${ }^{87} \mathrm{Sr} /{ }^{86} \mathrm{Sr}$ values for calcite fracture fillings below the water table are low (mean = $0.70909 \pm 0.00038$ ) and similar to those of the host rocks. The surficial calcites and those in the vadose zone are clearly unrelated to the deep calcite fracture fillings.

394 Teleseismic tomography of the Yucca Mountain region: Volcanism and tectonism. Evans, J.R. (US Geological Survey, Menlo Park, CA (US)); Smith, M. III. pp. 2372-2380 of Proceedings of high level radioactive waste management: Volume 1. American Nuclear Society, La Grange Park, IL (United States) (1992). pp. 2425 (CONF920430-: 3. international high level radioactive waste management (IHLRWM) conference, Las Vegas, NV (United States), 12-16 Apr 1992).

In this paper the authors use teleseismic tomography of compressional phases in the Yucca Mountain site area and region to delineate any extant magma systems and to map tectonic structures that might affect a potential nuclear waste repository. The authors observe an upper-mantle high-velocity anomaly beneath the Miocene Silent Canyon caldera. If this anomaly is related to southwestern Nevada volcanic field (SWNVF) volcanism, it may represent cooled residuum from the volume that once delivered heat to that system. hence, the SWNVF appears dead at its roots. A large volume of low-velocity upper mantle adjacent to this high may be any of several things, including partial melt. If the latter, it represents a large heat source for possible volcanism near the site area. The authors can rule out large, mature, silicic magma chambers in the crust near Yucca
Mountain, but do reveal a weak columnar low-velocity feature. This low-velocity object may be interpreted variously, one way being local heating of the crust. Lastly, the east boundary of the Crater Flat depression falls very near or beneath the repository block and should be evaluated further.

395 Method development and strategy for the characterization of complexly faulted and fractured rhyolitic tuffs, Yucca Mountain, Nevada, USA. Karasaki, K. (Lawrence Berkeley Lab., CA (US)); Galloway, D. pp. 197210 of Disposal of Radioactive Waste. Organisation for Economic Co-Operation and Development, Paris (FR) (1991). pp. 334 (CONF-9010214-: Nuclear Energy Agency (NEA) workshop on flow heterogeneity and site evaluation, Paris (France), 22-24 Oct 1990).

Field experimental and analytical methods development is undenway to define the hydraulic and transport properties of a thick saturated zone that underlies the planned high level nuclear waste repository at Yucca Mountain, Nevada. The characterization strategy for the highly heterogeneous hydrology is that of hypothesis testing and confidence building. Three test wells, the UE-25c-holes, have been drilled and preliminary data have been collected. Hydro-mechanical analyses indicate formation fluid at depth is hydraulically well connected to the water table. Preliminary hydraulic tests indicate highly localized, fracture-controlled transmissivity. Cross-hole seismic tomography is planned to assess the between-hole structure of fractures and faults. Multi-level cross-hole hydraulic interference and tracer tests are planned using up to 5 packed-off zones in each of the choles to assess the hydraulic conductivity and transport structure in a crude tomographic tashion. An equivalent discontinuum model conditioned with the observed hydraulic measurements will be applied to interpret the hydraulic test responses. As an approach to the scale-up problem the tests will be designed and analyzed to examine the hypothesis that the flow system may be represented by fractal geometry. 4 figs.; 12 refs.

396 Hydrologic modeling and field testing at Yucca mountain, Nevada. Hoxie, D.T. (Geological Survey, Denver, CO (US)). pp. 266-274 of Safety Assessment of Radioactive Waste Repositories. Organisation for Economic Co-operation and Development, Paris (FR) (1991). pp. 668 (CONF-9005117-: GEOVAL '90, Stockholm (Sweden), 1417 May 1990)

Yucca Mountain, Nevada, is being evaluated as a possible site for a mined geologic repository for the disposal of high-level nuclear waste. The repository is proposed to be constructed in fractured, densely welded tuff within the thick (500 to 750 meters) unsaturated zone at the site. Characterization of the site unsaturated-zone hydrogeologic system requires quantitative specification of the existing state of the system and the development of numerical hydrologic models to predict probable evolution of the hydrogeologic system over the lifetime of the repository. To support development of hydrologic models for the system, a testing program has been designed to characterize the existing state of the system, to measure hydrologic properties for the system and to identify and quantify those processes that control system dynamics. 12 refs.

397 The influence of scale on calculated sorptivity values from imbibition experiments on welded and nonwelded tuff. Flint, A.L. (U.S. Geological Survey, Mercury, NV (US)); Richards, K.A.; Flint, L.E. pp. 279-294 of Disposal 
of Radioactive Waste. Organisation for Economic Cooperation and Development, Paris (FR) (1991). pp. 334 (CONF-9010214-: Nuclear Energy Agency (NEA) workshop on flow heterogeneity and site evaluation, Paris (France), 22-24 Oct 1990).

Imbibition experiments were conducted on welded and nonwelded volcanic tuffs to determine the influence of sample size on the calculation of Philip's sorptivity parameter at four different scales. Rock cores, 3.2 and $6.1 \mathrm{~cm}$ in diameter by an average of $5 \mathrm{~cm}$ long, were used in two laboratory scale experiments. A horizontal borehole, $10 \mathrm{~cm}$ in diameter by $10 \mathrm{~m}$ long, was used for the two field scale experiments. Imbibition into the entire borehole was the largest scale experiment and neutron log data collected before and after the imbibition experiment yielded the intermediate scale data. The two sizes of core exhibited virtually the same sorptivity and either could be used to predict the results of the borehole scale experiment as long as the number of samples was large enough to represent the spatial heterogeneity. Core samples could be used to predict the neutron log data only if the unique system geometry was known and accounted for a priori. The neutron log data could be used to predict the results at the borehole scale but could not be used to predict the results of the core samples due to the spatial heterogeneity and the larger sampling volume. 6 figs.; 2 tabs.; 13 refs.

398 Seismic reflection profiling across Tertiary extensional structures in the eastern Amargosa Desert, southern Nevada, Basin and Range province. Brocher, T.M. (Geological Sunvey, Menlo Park, CA (US)); Hart, P.E.; Carr, M.D.; Fox, K.F. Jr. Geological Society of America, Bulletin (United States); 105(1): 30-46 (Jan 1993).

Outcrops, shallow well control, and coincident geophysical surveys are used to interpret a seismic reflection profile in the Amargosa Desert, within the Basin and Range province, of southern Nevada. The east-west - trending, $27-\mathrm{km}-\mathrm{long}$ seismic line crosses all or parts of three Tertiary subbasins, revealing that basin growth occurred by progressive shifts of basin-bounding faults. The reflection line images Tertiary strata that is rotated by steeply dipping listric faults and that noses into normal faults. A shallow (less than 100 to $200 \mathrm{~m}$ deep), laterally continuous, flat-lying, low-frequency reflector, interpreted as a Tertiary basalt flow, suggests that little vertical deformation has occurred within the easternmost of the small Tertiary basins since the eruption of the flow about 10 million years ago. Moderately dipping reflections within the pre-Tertiary bedrock may image Mesozoic thrust faults. The reflection data indicate that, whereas the top of the reflective lower crust shallows to the west, possibly in the direction of increasing crustal extension, the Moho is relatively flat between 30 and $33 \mathrm{~km}$ deep. Apparent bright-spot reflections from the lower crust are interpreted as evidence for ductile shearing of the lower crust, not for active magma chambers. Doming of the lower crust resembles that observed elsewhere in the Basin and Range province and is consistent with ductile flow in the lower crust. 70 refs., 15 figs., 2 tabs.

$399{ }^{40} \mathrm{Ar} /{ }^{39} \mathrm{Ar}$ age of the Lathrop Wells Volcanic Center, Yucca Mountain, Nevada. Turrin, B.D. (Geological Survey, Menlo Park, CA (United States)); Champion, D.; Fleck, R.J. Science (Washington, D.C.) (United States); 253(5020): 654-657 (9 Aug 1991).

Paleomagnetic and Ar/Ar analyses from the Lathrop Wells volcanic center, Nevada, indicate that two eruptive events have occurred there. The ages $(136 \pm 8$ and $141 \pm 9$ thousand years ago) for these two events are analytically indistinguishable. The small angular difference $\left(4.7^{\circ}\right)$ between the paleomagnetic directions from these two events suggests they differ in age by only about 100 years. These ages are consistent with the chronology of the surficial geological units in the Yucca Mountain area. These results contradict earlier interpretations of the cinder-cone geomorphology and soil-profile data that suggest that at least five temporally discreet eruptive events occurred at Lathrop Wells approximately 20,000 years ago.

\section{RELATED INFORMATION}

400 (AD-A-262251/2/XAB) High-level nuclear waste disposal: Policy and prognosis. Research report, August 1991-April 1992. Bouton, E.H. Industrial Coll. of the Armed Forces, Washington, DC (United States). Apr 1992. 43p. (NDU-ICAF-92-S9). Source: NTIS Prices: PC A03/MF A01.

The US government's effectiveness in achieving a solution to the country's high level radioactive waste disposal problem will have profound effects on both near term and long run policy and societal objectives. It is clear that the present adversarial climate surrounding the issue has produced delays and disruptions in the DOE's schedule for activating a permanent geologic disposal facility. Acerbic debate in both chambers on Capitol Hill, extensive litigation that has run several times through the entire court system including the U.S. Supreme Court, and significant added costs borne by taxpayers and utility ratepayers have characterized the flight.

401 (ANL-91/42) Nuclear technology programs: Semiannual progress report, October 1989-March 1990. Harmon, J.E. (ed.). Argonne National Lab., IL (United States). Jan 1992. 209p. Sponsored by USDOE, Washington, DC (United States). DOE Contract W-31109-ENG-38. Order Number DE92013641. Source: OSTI; NTIS; INIS; GPO Dep.

This document reports on the work done by the Nuclear Technology Programs of the Chemical Technology Division, Argonne National Laboratory, in the period October 1989 March 1990. These programs involve R\&D in three areas: applied physical chemistry, separation science and technology, and nuclear waste management. The work in applied physical chemistry includes investigations into the processes that control the release and transport of fission products under accident-like conditions, the thermophysical properties of metal fuel and blanket materials of the Integral Fast Reactor, and the properties of selected materials in environments simulating those of fusion energy systems. In the area of separation science and technology, the bulk of the effort is concerned with developing and implementing processes for the removal and concentration of actinides from waste streams contaminated by transuranic elements. Another effort is concerned water waste stream generated in production of 2,4,6-trinitrotoluene. In the area of waste management, investigations are underway on the performance of materials in projected nuclear repository conditions to provide input to the licensing of the nation's high-level waste repositories.

402 (ANL-92-9) ANL Technical Support Program for DOE Environmental Restoration and Waste Management: Annual report, October 1990-September 1991. Bates, J.K. (Argonne National Lab., IL (United States)); 
Bradley, C.R.; Buck, E.C.; Cunnane, J.C.; Dietz, N.L.; Ebert, W.L.; Emery, J.W.; Feng, X.; Gerding, T.J.; Gong, M.; Hoh, J.C.; Mazer, J.J.; Wronkiewicz, D.J.; Bourcier, W.L.; Morgan, L.E.; Nielsen, JArgonne National Lab., IL (United States); Lawrence Livermore National Lab., CA (United States). Mar 1992. 149p. Sponsored by USDOE, Washington, DC (United States). DOE Contract W-31109-ENG-38. Order Number DE92011753. Source: OSTI; NTIS; INIS; GPO Dep.

This report provides an overview of progress during FY 1991 for the Technical Support Program that is part of the ANL Technology Support Activity for DOE, Environmental Restoration and Waste Management (EM). The purpose is to evaluate, before hot start-up of the Defenses Waste Processing Facility (DWPF) and the West Valley Demonstration Project (WVDP), factors that are likely to affect glass reaction in an unsaturated environment typical of what may be expected for the candidate Yucca Mountain repository site. Specific goals for the testing program include the following: (1) to review and evaluate available information on parameters that will be important in establishing the long-term performance of glass in a repository environment; (2) to perform testing to further quantify the effects of important variables where there are deficiencies in the available data; and $(3)$ to initiate long-term testing that will bound glass performance under a range of conditions applicable to repository disposal.

403 (ANL-92/28) Stress corrosion cracking of candidate waste container materials: Final report. Park, J.Y. (Argonne National Lab., IL (United States)); Maiya, P.S.; Soppet, W.K.; Diercks, D.R.; Shack, W.J.; Kassner, T.F. Argonne National Lab., IL (United States); Lawrence Livermore National Lab., CA (United States). Jun 1992. 76p. Sponsored by USDOE, Washington, DC (United States). DOE Contract W-31109-ENG-38. Order Number DE92019239. Source: OSTI; NTIS; INIS; GPO Dep.

Six alloys have been selected as candidate container materials for the storage of high-level nuclear waste at the proposed Yucca mountain site in Nevada. These materials are Type 304L stainless steel (SS). Type 316L SS, Incoloy 825, phosphorus-deoxidized $\mathrm{Cu}, \mathrm{Cu}-30 \% \mathrm{Ni}$, and $\mathrm{Cu}-7 \% \mathrm{Al}$. The present program has been initiated to determine whether any of these materials can survive for 300 years in the site environment without developing through-wall stress corrosion cracks. and to assess the relative resistance of these materials to stress corrosion cracking (SCC)-A series of slow-strain-rate tests (SSRTs) and fracture-mechanics crack-growth-rate (CGR) tests was performed at $93^{\circ} \mathrm{C}$ and 1 atm of pressure in simulated $J-13$ well water. This water is representative, prior to the widespread availability of unsaturated-zone water, of the groundwater present at the Yucca Mountain site. Slow-strain-rate tests were conducted on 6.35-mm-diameter cylindrical specimens at strain rates of $10^{-7}$ and $10^{-8} \mathrm{~s}^{-1}$ under crevice and noncrevice conditions. All tests were interrupted after nominal elongation strain of $1-4 \%$. Scanning electron microscopy revealed some crack initiation in virtually all the materials, as well as weldments made from these materials. A stress- or strainratio cracking index ranks these materials, in order of increasing resistance to SCC, as follows: Type 304 SS < Type $316 \mathrm{~L}$ SS $<$ Incoloy $825<\mathrm{Cu}-30 \% \mathrm{Ni}<\mathrm{Cu}$ and $\mathrm{Cu}$ $7 \% \mathrm{Al}$. Fracture-mechanics CGR tests were conducted on 25.4-mm-thick compact tension specimens of Types 304L and $316 \mathrm{~L}$ stainless steel (SS) and Incoloy 825 . Crack-growth rates were measured under various load conditions: load ratios $M$ of $0.5-1.0$, frequencies of $10^{-3}-1 \mathrm{~Hz}$, rise nines of $1-1000 \mathrm{~s}$, and peak stress intensities of 25-40 MPa.m ${ }^{1 / 2}$.

\section{4 (ANL-92/44) Nuclear Technology Programs} semiannual progress report, October 1990-March 1991. Argonne National Lab., IL (United States). Dec 1992. 163p. Sponsored by USDOE, Washington, DC (United States). DOE Contract W-31109-ENG-38. Order Number DE93007744. Source: OSTI; NTIS; GPO Dep.

This document reports on the work done by the Nuclear Technology Programs of the Chemical Technology Division, Argonne National Laboratory, in the period October 1990March 1991. These programs involve R\&D in three areas: applied physical chemistry, separation science and technology, and nuclear waste management. The work in applied physical chemistry includes investigations into the processes that control the release and transpose of fission products under accident-like conditions in a light water reactor, the thermophysical properties of the metal fuel in the Integral Fast Reactor, and the properties of selected materials in environments simulating those of fusion energy systems. In the area of separation science and technology, the bulk of the effort is concerned with developing and implementing processes for the removal and concentration of actinides from waste streams contaminated by transuranic elements. In the area of waste management, investigations are underway on the performance of materials in projected nuclear repository conditions to provide input to the licensing of the nation's high-level waste repositories.

405 (ANL-93/13) ANL technical support program for DOE Environmental Restoration and Waste Management: Annual report, October 1991-September 1992. Bates, J.K. (Argonne National Lab., IL (US)); Bradley, C.R.; Buck, E.C.; Cunnane, J.C.; Dietz, N.L.; Ebert, W.L.; Emery, J.W.; Feng, X.; Gerding, T.J.; Gong, M.; Hoh, J.C.; Mazer, J.J.; Wronkiewicz, D.J.; Bourcier, W.L.; Morgan, L.E.; Newton, L.; Nielsen,.Argonne National Lab., IL (United States). May 1993. 212p. Sponsored by USDOE, Washington, DC (United States). DOE Contract W-31109-ENG-38. Order Number DE93018116. Source: OSTI; NTIS; INIS; GPO Dep.

A program was established for DOE Environmental Restoration and Waste Management (EM) to evaluate factors that are anticipated to affect waste glass reaction during repository disposal, especially in an unsaturated environment typical of what may be expected for the proposed Yucca Mountain repository site. This report covers progress in FY 1992 on the following tasks: 1. A compendium of the characteristics of high-level nuclear waste borosilicate glass has been written. 2. A critical review of important parameters that affect the reactivity of glass in an unsaturated environment is being prepared. 3. A series of tests has been started to evaluate the reactivity of fully radioactive glasses in a high-level waste repository environment and compare it to the reactivity of synthetic, nonradioactive glasses of similar composition. 4. The effect of radiation upon the durability of waste glasses at a high glass surface area-to-liquid volume (SAN) ratio and a high gas-to-liquid volume ratio will be assessed. These tests address both vapor and high SA $V$ liquid conditions. 5. A series of tests is being performed to compare the extent of reaction of nuclear waste glasses at various SAN ratios. Such differences in the SAN ratio may significantly affect glass durability. 6. A series of natural analogue tests is being analyzed to demonstrate a meaningful relationship between experimental and natural alteration conditions. 7. Analytical electron microscopy (AEM), infrared 
spectroscopys and nuclear resonant profiling are being used to assess the glass/water reaction pathway by identifying intermediate phases that appear on the reacting glass. Additionally, colloids from the leach solutions are being studied using AEM. 8. A technical review of AEM results is being provided. 9. A study of water diffusion involving nuclear waste glasses is being performed. 10. A mechanistically based model is being developed to predict the performance of glass over repository-relevant time periods.

406 (ANL/CMT/CP-76238) The reaction of SRL 202 glass in J-13 and DIW. Ebert, W.L.; Bates, J.K.; Buck, E.C. Argonne National Lab., IL (United States). [1992]. 9p. Sponsored by USDOE, Washington, DC (United States). DOE Contract W-31109-ENG-38. (CONF-921101-71: 16. Materials Research Society (MRS) fall meeting, Boston, MA (United States), 30 Nov - 5 dec 1992). Order Number DE93006405. Source: OSTI; NTIS; INIS; GPO Dep.

Static leach tests were performed in both $304 \mathrm{~L}$ stainless steel and Tefion vessels using a synthetic high-level waste glass with either deionized water (DIW) or a tuff groundwater solution as the leachant to assess the effects of the vessel and the initial leachant composition on the extent and nature of the glass reaction. The tests were performed using monolith samples at $340 \mathrm{~m}^{-1}$ and crushed samplesat 2000 $\mathrm{m}^{-1}$ for times up to 1 year. The results show less silicon is released from the glass into the groundwater solution than into DIW at both high and low glass surface area/leachant volume ratios (SAN), but the alkali metal and boron releases are not affected by the leachant used. Tests performed in a stainless steel vessel resulted in slightly lower leachate $\mathrm{pH}$ values, but similar reaction rates to those performed in a Teflon vessel, as measured by the boron release. Blank tests with DIW or EJ-13 in the vessels showed the Teflon vessels to release small amounts of fluoride (1 to $2 \mathrm{ppm}$ ) and to acidify the DIW slightly $(4.0<\mathrm{pH}<5.6)$. The $\mathrm{pH}$ values of blank tests with EJ- 13 increased from 8.2 to about 8.6 in steel and to about 9.2 in Teflon vessels. The slightly higher $\mathrm{pH}$ values attained in Tefion vessels are attributed to outgassing of $\mathrm{CO}_{2}$ during the test.

407 (ANLCMT/CP-76240) Effects of radiation exposure on glass alteration in a steam environment. Wronkiewicz, D.J. (Argonne National Lab., IL (United States)); Bates, J.K.; Tani, B.S.; Wang, L.M. Argonne National Lab., IL (United States). [1992]. 9p. Sponsored by USDOE, Washington, DC (United States). DOE Contract W31109-ENG-38. (CONF-921101-76: 16. Materials Research Society (MRS) fall meeting, Boston, MA (United States), 30 Nov - 5 dec 1992). Order Number DE93006419. Source: OSTI; NTIS; INIS; GPO Dep.

Several Savannah River Plant (SRL) glass compositions were reacted in steam at temperatures of 150 to $200^{\circ} \mathrm{C}$. Half of the tests utilized actinide-doped monoliths and were exposed to an external ionizing gamma source, while the remainder were doped only with $U$ and reacted without gamma exposure. All glass samples readily reacted to form secondary mineral phases within the first week of testing. An in situ layer of smectite initially developed on nonirradiated SRL 202 glass test samples. After 21 days, a thin layer of illite was precipitated from solution onto the smectite layer. A number of alteration products including zeolite, Casilicate, and alkali or alkaline earth uranyl silicate phases were also distributed over most sample surfaces. In the irradiated SRL 202 glass tests, up to three layers enveloped rounded, and sometimes fractured, glass cores. After 35 to 56 days these remnant cores were replaced by a mottled or banded Fe- and Si-rich material. The formation of some secondary mineral phases also has been accelerated in the irradiated tests, and in some instances, the irradiated environment may have led to the precipitation of a different suite of minerals. The alteration layer(s) developed at rates of 2.3 and $32 \mu \mathrm{m} /$ day for the nonirradiated and irradiated SRL 202 glasses, respectively, indicating that layer development is accelerated by a factor of $\sim 10$ to $15 X$ due to radiation exposure under the test conditions.

408 (ANLCMT/CP-79779) Elements present in leach solutions from unsaturated spent fuel tests. Finn, P.A.; Bates, J.K.; Hoh, J.C.; Emery, J.W.; Hatenrichter, L.D.; Buck, E.C.; Gong, M. Argonne National Lab., IL (United States). 1993. 9p. Sponsored by USDOE, Washington, DC (United States). DOE Contract W-31109-ENG-38. (CONF931108-3: Fall meeting of the Materials Research Society (MRS), Boston, MA (United States), 29 Nov - 3 dec 1993). Order Number DE94001458. Source: OSTI; NTIS; INIS; GPO Dep.

Preliminary results for the composition of the leachate from unsaturated tests at $90^{\circ} \mathrm{C}$ with spent fuel for $55-134$ days with $\mathrm{J-13}$ groundwater are reported. The $\mathrm{pH}$ of the leachate solutions was found to be acidic, ranging from 4 to 7. The actinide concentrations were $10^{5}$ greater than those reported for saturated spent fuel tests in which the leachate $\mathrm{pH}$ was 8. We also found that most species in the leachate were present as colloids containing both americium and curium. The presence of actinides in a form not currently included in repository radionuclide transport models provides information that can be used in spent fuel reaction modeling, the performance assessment of the repository and the design of the engineering barrier system. This report was prepared as part of the Yucca Mountain Site Characterization Project

409 (ANL/CP-74094) A forecasting model of gaming revenues in Clark County, Nevada. Edwards, $B$. (Argonne National Lab., IL (United States)); Bando, A.; Bassett, G.; Rosen, A.; Carlson, J.; Meenan, C. Argonne National Lab., IL (United States). [1992]. 7p. Sponsored by USDOE, Washington, DC (United States). DOE Contract W31109-ENG-38. (CONF-920430-72: 3. international high level radioactive waste management (IHLRWM) conference, Las Vegas, NV (United States), 12-16 Apr 1992). Order Number DE92010900. Source: OSTI; NTIS; INIS; GPO Dep.

This paper describes the Western Area Gaming and Economic Response Simulator (WAGERS), a forecasting model that emphasizes the role of the gaming industry in Clark County, Nevada. It is designed to generate forecasts of gaming revenues in Clark County, whose regional economy is dominated by the gaming industry, an identify the exogenous variables that affect gaming revenues. This model will provide baseline forecasts of Clark County gaming revenues in order to assess changes in gaming related economic activity resulting from future events like the siting of a permanent high-level radioactive waste repository at Yucca Mountain.

410 (ANL/CP-75280) Perceived risk impacts from siting hazardous waste facilities. Hemphill, R.C. (Argonne National Lab., IL (United States)\}; Edwards, B.K.; Bassett, G.W. Jr. Argonne National Lab., IL (United States). [1992]. $5 p$. Sponsored by USDOE, Washington, DC (United States). DOE Contract W-31109-ENG-38. (CONF-9208101-1: International high-level radioactive waste management conference, Las Vegas, NV (United States), 12-16 Aug 
1992). Order Number DE92016737. Source: OSTI; NTIS; INIS; GPO Dep.

This paper describes methods for evaluating perceptionbased economic impacts resulting from siting hazardous waste facilities. Socioeconomic impact analysis has devoted increasing attention to the potential implications of changed public perceptions of risk due to an activity or situation. This contrasts with traditional socioecconomic impact analysis, which has been limited to measuring direct and indirect consequences of activities, e.g., the employment effects of placing a military base in a specified location. Approaches to estimating economic impacts due to changes in public perceptions are ex ante or ex post. The former predict impacts prior to the construction and operation of a facility, while the later is based on impacts that become evident only when the facility is up and running. The theoretical foundations and practical requirements for demonstrating impacts, resulting from the siting of a hazardous facility are described. The theoretical rationale supporting the study of perceived risk research is presented along with discussion of problems that arise in demonstrating the existence and measuring the quantitative importance of economic impacts due to changes in perceived risk. The high-level nuclear waste facility being considered in Nevada is presented as an example in which there is potential for impacts, but where the link between perceived risk and economic conditions has not yet been developed.

\section{1 (ANLCP-76140) Dual-energy neutron tomog-} raphy of water in rock using the Argonne IPNS. Rhodes, E.; Kupperman, D.S.; Hitterman, R.L. Argonne National Lab., IL (United States). [1992]. 6p. Sponsored by USDOE, Washington, DC (United States). DOE Contract W-31109ENG-38. (CONF-9205157-4: 4. world conference on neutron radiography, San Francisco, CA (United States), 1114 May 1992). Order Number DE92015186. Source: OSTI; NTIS; INIS; GPO Dep.

In dual-energy hydrogen imaging, the increase in hydrogen neutron cross-section at subthermal neutron energies is used to enhance the imaging of small amounts of hydrogen against a background of other absorbing materials by subtracting a tomographic image obtained for higher energy neutrons from that obtained for subthermal neutrons (picking energies such that the other absorbing materials have nearly the same cross-sections at both energies). This technique was used to provide dual-energy imaging of water in tuffaceous rock, with the goal being to track water flow through porous rock for site risk analysis of permanent disposal of radwaste. A feasibility experiment was conducted at the IPNS facility with coarse spatial resolution, yielding promising results.

\section{2}

(ANL/CP-76305) Should high-level nuclear waste be disposed of at geographically dispersed sites?. Bassett, G.W. Jr. (Chicago Univ., IL (United States). Dept. of Economics); Hemphill, R.; Kohout, E. Argonne National Lab., IL (United States). [1992]. 6p. Sponsored by USDOE, Washington, DC (United States). DOE Contract W31109-ENG-38. (CONF-920464-4: 23. annual Pittsburgh conference on modeling and simulation, Pittsburgh, PA (United States), 30 Apr - 1 may 1992). Order Number DE92016399. Source: OSTI; NTIS; INIS; GPO Dep.

Consideration of the technical feasibility of Yucca Mountain in Nevada as the site for a high-level nuclear waste repository has led to an intense debate regarding the economic, social, and political impacts of the repository. Impediments to the siting process mean that the nuclear waste problem is being resolved by adhering to the status quo, in which nuclear waste is stored at scattered sites near major population centers. To assess the merits of alternative siting strategies-including both the permanent repository and the status quo- we consider the variables that would be included in a model designed to select (1) the optimal number of disposal facilities, (2) the types of facilities (e.g., permanent repository or monitored retrievable facility), and (3) the geographic location of storage sites. The objective function in the model is an all-inclusive measure of social cost. The intent of the exercise is not to demonstrate the superiority of any single disposal strategy; uncertainties preclude a conclusive proof of optimality for any of the disposal options. Instead, we want to assess the sensitivity of a variety of proposed solutions to variations in the physical, economic, political, and social variables that influence a siting strategy.

413 (ANL/EAIS/CP-78642) Managing nuclear waste: Social and economic impacts. Hemphill, R.C. (Argonne National Lab., IL (United States)); Bassett, G.W. Jr. Argonne National Lab., IL (United States); Chicago Univ., IL (United States). Dept. of Economics. [1993]. 5p. Sponsored by USDOE, Washington, DC (United States). DOE Contract W-31109-ENG-38. (CONF-930408-54: International highlevel radioactive waste management conference, Las Vegas, NV (United States), 25-29 Apr 1993). Order Number DE93009953. Source: OSTI; NTIS; INIS; GPO Dep.

Recent research has focused on perceptions of risk dominant source of economic impacts due to siting a high level radioactive waste facility. This article addresses the social and economic considerations involved with the issue of risk perception and other types of negative imagery. Emphasis is placed on ways of measuring the potential for economic effects resulting from perceptions prior to construction and operation of a HLW facility. We describe the problems in arriving at defensible estimates of economic impacts. Our review has found that although legal and regulatory bases may soon allow inclusion of these impacts in EIS and for compensation purposes, credible scientific methods do not currently exist for predicting the existence or magnitude of changes in economic decision-making. Policy-makers should recognize the potential for perception-based economic impacts in determining the location and means of managing radioactive waste; but, they also need be cognizant of the current limitations of quantitative estimates of impacts in this area.

414 (ANLEAIS/TM-41) The role of amenities and other factors in influencing the location of nonmanufacturing industry in the United States. Allison, T. (Argonne National Lab., IL (United States). Environmental Assessment and Information Sciences Div.); Calzonetti, F.J. Argonne National Lab., IL (United States). Environmental Assessment and Information Sciences Div. Jul 1990. 68p. Sponsored by USDOE, Washington, DC (United States). DOE Contract W-31109-ENG-38. Order Number DE92009745. Source: OSTI; NTIS; GPO Dep.

Consumer and producer services, the latter in particular, are expected to become an important means of diversification and employment growth to the economy of Nevada. It has been suggested that the siting of the nuclear waste repository at Yucca Mountain, Nevada, will lead to a significant reduction in the amenity value of the state and, consequently, the ability of the state to attract these nonmanufacturing industries. This report reviews the literature dealing with factors important to the location of services, with an emphasis on producer services, to determine 
whether amenities, which have been shown to be an important locational consideration for some manufacturing firms, similarly affect the location of services. The report finds little substantive evidence to link amenities with the location of service firms, although the process by which these firms' locations are chosen is not well understood. Research in this area is comparatively recent, and although a number of theories of service location have been developed, the majority of research is exploratory in scope.

415 (ANL/EAIS/TM-85) Socioeconomic assessment guidance repor: Determining the effects of amenity characteristics on business location decisions. Allison, T. Argonne National Lab., IL (United States). Environmental Assessment and Information Sciences Div. Feb 1993. 46p. Sponsored by USDOE, Washington, DC (United States). DOE Contract W-31109-ENG-38. Order Number DE93011790. Source: OSTI; NTIS; INIS; GPO Dep.

Evaluating perception-based impacts of hazardous waste facilities has become an increasingly important part of socioeconomic impact assessments in recent years. One area of discussion has been the potential effect of risk perceptions on business location decision making. This report evaluates the importance of environmental amenities (broadly defined to include natural, cultural, and recreational features; environmental quality; and other indexes of quality of life) with respect to decisions on locating both manufacturing and business service activities. It discusses the major theoretical and empirical issues that arise in attempting to determine the effects of environmental amenities on the location choices for businesses and business activities. This discussion is followed by a survey of major findings from the academic literature and a review of research by the state of Nevada. A number of recommendations for further research are also provided to help the US Department of Energy's Office of Civilian Radioactive Waste Management better understand the importance of perception-based impacts in business location decision making and estimate the scale of socioeconomic impacts that would result from siting a highlevel waste repository in Nevada.

416 (ANL/EAIS/TM-87) Methodologies for selecting industrles for regions and communities: $A$ critical evaluation of the Las Vegas target industry analysis. Allison, T. Argonne National Lab., IL (United States). Environmental Assessment and Information Sciences Div. Mar 1992. $36 \mathrm{p}$. Sponsored by USDOE, Washington, DC (United States). DOE Contract W-31109-ENG-38. Order Number DE93009908. Source: OSTI; NTIS; GPO Dep.

This report evaluates recent research conducted by a contractor for the state of Nevada. The research was designed to identify industries for which the Las Vegas area might provide competitive locations for new and expansion investment; it made use of target industry analysis (TIA) to identify specific industries that might be part of the future economy of the region and thus provide a baseline for assessing the impact of the Yucca Mountain repository project. This report briefly describes three TIA approaches - the conventional simple screening approach, simultaneous approach, and an alternative hybrid approach - and analytical hierarchy modeling, which is another industry selection methodology. It evaluates the data, methodology, and findings of the state of Nevada study, and it also discusses additional measures of locational advantage and economic development that were not considered in the study. The report then examines how industries search for new locations and reviews methodologies that assess the-predictability of industries choosing particular locations. The report concludes that, although the state of Nevada study provides a general impression of industries likely to locate in the Las Vegas area, the relatively simplistic TIA approach it uses and the additional refinements still needed to make TIA an accurate predictor of future economic structure cast some doubt on the validity of the research findings.

417 (ANL/EAIS/TM-92) Empirical investigation of the effect of amenities and other factors on business location decisions. Calzonetti, F.J. (West Virginia Univ., Morgantown, WV (United States)); Allison, T. Argonne National Lab., IL (United States). Environmental Assessment and Information Sciences Div. Feb 1993. 62p. Sponsored by USDOE, Washington, DC (United States). DOE Contract W31109-ENG-38. Order Number DE93011910. Source: OSTI; NTIS; INIS; GPO Dep.

The impacts that risk perceptions have on those deciding whether to locate a business activity in an area likely to host a nuclear waste facility have become an important consideration in analyses that deal with choosing a site for nuclear waste facilities. This report presents empirical evidence on the importance of environmental amenities and disamenities in business location decisions gathered from surveys and intenviews of owners and managers of manufacturing and producer senvice establishments in Colorado and Utah. Results show that amenities are a much more important consideration for producer service establishments than for manufacturing establishments. Policies of host communities to offset the loss of business establishments that could result from risk perceptions associated with nuclear waste facilities should therefore take into account how sensitive the business activities that are present or likely to locate in the area are to environmental amenities.

418 (ANL/EAIS/TM-93) Technical evaluation of avaliable state of Nevada survey instruments. Argonne National Lab., IL (United States). Environmental Assessment and Information Sciences Div. Feb 1993. $99 \mathrm{p}$. Sponsored by USDOE, Washington, DC (United States). DOE Contract W-31109-ENG-38. Order Number DE93012873. Source: OSTI; NTIS; INIS; GPO Dep.

Argonne National Laboratory (ANL) is reviewing the survey research studies completed by Mountain West Research (1987-1989) for the state of Nevada's Nuclear Waste Project Office. In this research, 14 survey instruments were used to seek data on whether perceptions of risk could be associated with the possible siting of a high-level radioactive waste repository in Nevada and could be a dominant source of potential, significant, adverse economic impacts. This report presents results from phase 1 of the review, in which ANL contracted with the National Opinion Research Center (NORC) at the University of Chicago to evaluate the technical merits of the nine survey instruments that ANL had been able to acquire. The scope of NORC's work was limited to rating the questions and stating their strengths and weaknesses. NORC concluded that the surveys could provide valuable data about risk perceptions and potential behavioral responses. NORC identified a few minor problems with a number of questions and the calculated response rates but claimed these problems would probably not have any major biasing effect. The NORC evaluation would have been more complete if the terms used in the questionnaires had been defined, all survey instruments had been acquired, and all data had been made available to the public. 
419 (CEA-CONF-11515) Hydrogeology and migration in the remote field. Blanc, P.L. (CEA Centre d'Etudes de Fontenay-aux-Roses, 92 (France). Inst. de Protection et de Surete Nucleaire); Escalier des Orres, P.; Gurban, I.; Ledoux, E; Raimbault, L. CEA Centre d'Etudes de Fontenay-aux-Roses, 92 (France). Inst. de Protection et de Surete Nucleaire, 1991. 17p. (In French). (CONF-9111329-: SFEN meeting on Oklo phenomenon, Paris (France), 28 Nov 1991). Order Number DE94603017. Source: OSTI; NTIS (US Sales Only); INIS.

This paper gives the main data on Oklo - Okelobondo site: hydrogeology, stratigraphy, geologic fractures, hydrochemical data. Then the results of computerized simulations of convective - dispersive transport with the help of METIS code (Modelling of flows and mass transfer with interaction in saturated medium) are described. 7 refs., 7 figs.

420 Technical evaluations necessary for determining site suitabllity for a high-level waste repository. Bartlett, J.W. pp. 1-8 of Dynamic analysis and design considerations for high-level nuclear waste repositories. Hossain, Q.A. (ed.). American Society of Civil Engineers, New York, NY (US) (1993). pp. 443 From American Society of Civil Engineers (ASCE) symposium on dynamic analysis and design considerations, for high-level nuclear waste repositories; San Francisco, CA (United States); 19-20 Aug 1992.

Congress, under the Nuclear Waste Policy Act of 1982, as amended, has charged the Department of Energy with the responsibility for safely and permanently disposing of high-level radioactive waste, which consists of spent fuel from commercial nuclear generating stations and waste from reprocessing activities. Under the direction of this law, the Department is currently evaluating the suitability of a potential underground repository at Yucca Mountain, Nevada, approximately 90 miles northwest of Las Vegas. To ensure long-term safe performance of a potential repository system at Yucca Mountain, the Department must fully understand the seismotectonic regime. This understanding will allow us to predict the locations and consequences of seismic events, and to develop designs that appropriately respond to the seismic regime at Yucca Mountain. There are essentially four ways in which seismicity could significantly impact the performance of the repository system: by changing the ground-water regime, either through opening new flow pathways, or by closing existing flow pathways; by disturbing surface waste handling buildings; by disturbing underground openings, such as shafts, drifts, and tunnels; or finally by disturbing the engineered barrier system. The Department is currently conducting a number of seismic and tectonic investigations aimed at describing the nature of the seismic processes currently operating in the Yucca Mountain region, as well as developing a history of faulting that has occurred during the past 14 million years.

421 Assessment of the potential for tectonic fault rupture for high-level nuclear waste repositories. Swan, F.H. (Geomatrix Consultants, Inc., San Francisco, CA (US)); Stepp, J.C.; McGuire, R.K. pp. 55-74 of Dynamic analysis and design considerations for high-level nuclear waste repositories. Hossain, Q.A. (ed.). American Society of Civil Engineers, New York, NY (US) (1993). pp. 443 From American Society of Civil Engineers (ASCE) symposium on dynamic analysis and design considerations, for high-level nuclear waste repositories; San Francisco, CA (United States); 19-20 Aug 1992.

Active faults that extend to or near the Earth's surface may threaten the safety of engineered structures. The threat can be mitigated by appropriate siting and design, which requires understanding of the characteristics and magnitude of the faulting hazard based on detailed site investigations and assessment of the characteristics of faulting that has occurred under the present tectonic regime in the site area. Both deterministic and probabilistic approaches are used to assess hazards due to fault rupture for engineering design. A combined probabilistic-deterministic approach provides the broadest perspective both for evaluating the potential fault rupture hazard and for selecting design criteria, which may differ among the various components of the repository depending on their function and importance to safety. Probabilistic analyses that explicitly incorporates uncertainties in parameters that characterize fault activity, the nature and amount of deformation, and the likelihood of occurrence, as well as uncertainties in the analytical methods, enables reasonable design parameters to be selected and the identification of the input parameters and analytical methods that dominate the hazard. Deterministic analyses can then be made to examine in detail those factors that dominate the fault rupture hazard.

422 Geometric models of faulting at Yucca Mountain. Young, S.R. (Southwest Research Inst., San Antonio, TX (US). Center for Nuclear Waste Regulatory Analyses); Stirewalt, G.L.; Morris, A.P. Pp. 97-117 of Dynamic analysis and design considerations for high-level nuclear waste repositories. Hossain, Q.A. (ed.). American Society of Civil Engineers, New York, NY (US) (1993). Pp. 443 From American Society of Civil Engineers (ASCE) symposium on dynamic analysis and design considerations, for high-level nuclear waste repositories; San Francisco, CA (United States); 19-20 Aug 1992.

Yucca Mountain, Nevada, is currently being studied as a potential site for a geologic repository of high-level radioactive waste. Alternative conceptual tectonic models are expected to be used by the US Department of Energy (DOE) to fulfill part of the requirement of 10 CFR Part 60 to describe and assess subsurface conditions, and to evaluate conditions that may be potentially favorable or adverse to effective waste isolation. Effective assessment of risk due to geologic hazards such as fault rupture, earthquake seismicity, and volcanic eruptions will involve the use of tectonic and structural geologic models of Yucca Mountain. Estimation of the effects of fault movement and associated distributed deformation on fracture patterns, and potential concomitant changes in bulk hydrogeologic properties, requires knowledge of fault geometry and displacement. Yucca Mountain is located in a tectonically active region, and has a recent geological history of extensional tectonic deformation. Geometric models of faults at Yucca Mountain, as described in this paper, suggest that individual fault segments may be curved at depth and flatten into a regional low-angle detachment fault surface at a depth of approximately 7 to $8 \mathrm{kms}$. Magnitude and recurrence of earthquake seismicity in the Great Basin region is strongly dependent on fault geometry. Discrimination between planar and listric fault styles is critical to assessment of earthquake seismic risk. The modeled fault system suggests that distributive displacement is probably characteristic of the Yucca Mountain fault system.

423 Estimation of near-regional seismic ground motion from underground nuclear explosion tests. Bennett, T.J. (S-Cubed, Reston, VA (US)); Murphy, J.R. pp. 191-205 of Dynamic analysis and design considerations for high-level nuclear waste repositories. Hossain, Q.A. (ed.). American Society of Civil Engineers, New York, NY (US) (1993). pp. 
443 From American Society of Civil Engineers (ASCE) symposium on dynamic analysis and design considerations, for high-level nuclear waste repositories; San Francisco, CA (United States); 19-20 Aug 1992.

A problem unique to the location of a nuclear waste repository adjacent to the Nevada Test Site is the assessment of seismic ground motion from potential underground nuclear explosion tests for use in the facility design. Although the problem is unique, it is not new. For more than 30 years the Department of Energy and its predecessor, the Atomic Energy Commission, have maintained a program for predicting and monitoring vibratory ground motion from underground nuclear detonations for use in assuring the safety of structures in the surrounding region. Over the course of the monitoring effort, ground motion measurements have been collected at ranges from less than $1 \mathrm{~km}$ to more than $100 \mathrm{~km}$ for hundreds of nuclear explosions covering yields from less than 1 to 1,000 kilotons in a variety of emplacement media. The ground motion prediction scheme which has evolved from this program utilizes a combination of empirical and analytical elements. This scheme takes into account (1) source factors including explosion yield, depth of burial, physical medium properties and geometrical configuration of multiples, (2) transmission path factors including distance, crustal structure and propagation properties such as attenuation, and (3) recording site response based on local structure, soil properties and seismic wave type. Prediction relations based on this past experience can be used to estimate vibratory ground motion and an associated uncertainty at the Yucca Mountain site from potential future nuclear explosions in different test areas at NTS.

424 Options for dynamic analyses of underground facilities. Chowdhury, A.H. (Southwest Research Inst., San Antonio, TX (US). Center for Nuclear Waste Regulatory Analyses); Hsiung, Suimin; Ahola, M.P. pp. 286-301 of Dynamic analysis and design considerations for high-level nuclear waste repositories. Hossain, Q.A. (ed.). American Society of Civil Engineers, New York, NY (US) (1993). pp. 443 From American Society of Civil Engineers (ASCE) symposium on dynamic analysis and design considerations, for high-level nuclear waste repositories; San Francisco, CA (United States); 19-20 Aug 1992.

Continuum and discontinuum modeling techniques for conducting dynamic analysis of underground facilities of geologic repository are discussed. Compared with continuum analysis, the discontinuum analysis is relatively new and is most applicable to problems in which the deformation of the system is primarily a result of deformation or slip along the discontinuities.

425 Dynamic response of tunnels in jointed rocks. Heuze, F.E. (Lawrence Livermore National Lab., CA (US)); Shaffer, R.J.; Walton, O.R.; Maddix, D.M. pp. $302-310$ of Dynamic analysis and design considerations for high-level nuclear waste repositories. Hossain, Q.A. (ed.). American Society of Civil Engineers, New York, NY (US) (1993). pp. 443 DOE Contract W-7405-ENG-48. From American Society of Civil Engineers (ASCE) symposium on dynamic analysis and design considerations, for high-level nuclear waste repositories; San Francisco, CA (United States); 19. 20 Aug 1992.

The current proposed site for an underground nuclear waste repository is at Yucca Mountain, Nevada. The host rock is a jointed tuff. The question is: how will the repository behave under strong earthquake motion. The basic requirement for analysis is an ability to follow the dynamic motion of a multiplicity of discrete particles, i.e., rock blocks separated by joints and faults. The authors describe the application of the discrete element method (DEM) to the dynamic analysis of the response of tunnels in jointed rocks to earthquake loading. In situations where large motions of many blocks and collapse occur, the discontinuum-based DEM approach appears superior to other methods of analysis.

426 Optimal cost basis for seismic design. Hadjian, A.H. (Bechtel Corp., Norwalk, CA (US)). pp. 358-372 of Dynamic analysis and design considerations for high-level nuclear waste repositories. Hossain, Q.A. (ed.). American Society of Civil Engineers, New York, NY (US) (1993). pp. 443 From American Society of Civil Engineers (ASCE) symposium on dynamic analysis and design considerations, for high-level nuclear waste repositories; San Francisco, CA (United States); 19-20 Aug 1992.

The paper summarizes a methodology for establishing seismic design levels based on a cost-benefit assessment. The methodology requires the development of costs and benefits for varying design levels of vibratory ground motion and surface fault displacements. The optimum design level for a given structure is that which gives the minimum total direct and earthquake consequence costs. The example used is the surface facilities of the proposed high-level waste repository at Yucca Mountain, Nevada.

427 Geotechnical instrumentation for repository shafts. Lentell, R.L. (AWD Technologies, Inc., Boise, ID (US)); Byrne, J. pp. 401-413 of Dynamic analysis and design considerations for high-level nuclear waste repositories. Hossain, Q.A. (ed.). American Society of Civil Engineers, New York, NY (US) (1993). pp. 443 From American Society of Civil Engineers (ASCE) symposium on dynamic analysis and design considerations, for high-level nuclear waste repositories; San Francisco, CA (United States); 19-20 Aug 1992.

The US Congress passed the Nuclear Waste Policy Act in 1980, which required that three distinctly different geologic media be investigated as potential candidate sites for the permanent disposal of high-level nuclear waste. The three media that were selected for study were basalt (WA), salt (TX, LA, MS, UT), and tuff (NV). Preliminary Exploratory Shaft Facilities (ESF) designs were prepared for seven candidate salt sites, including bedded and domal salt environments. A bedded-salt site was selected in Deaf Smith County, TX for detailed site characterization studies and ESF Final Design. Although Congress terminated the Salt Repository Program in 1988, Final Design for the Deaf Smith ESF was completed, and much of the design rationale can be applied to subsequent deep repository shafts. This paper presents the rationale for the geotechnical instrumentation that was designed for construction and operational performance monitoring of the deep shafts of the in-situ test facility. The instrumentation design described herein can be used as a general framework in designing subsequent instrumentation programs for future high-level nuclear waste repository shafts.

428 (CONF-921082-2) Estimating the water table under the Radioactive Waste Management Site in Area 5 of the Nevada Test Site: The Dupuit-Forcheimer approximation. Lindstrom, F.T.; Barker, L.E.; Cawlfield, D.E.; Daffern, D.D.; Dozier, B.L.; Emer, D.F.; Strong, W.R. Reynolds Electrical and Engineering Co., Inc., Las Vegas, NV (United States). [1992]. 26p. Sponsored by USDOE, 
Washington, DC (United States). DOE Contract AC0889NV10630. From American Institute of Hydrology; Portland, OR (United States); 17-22 Oct 1992. Order Number DE92013506. Source: OSTI; NTIS; INIS; GPO Dep.

To adequately manage the low level nuclear waste (LLW) repository in Area 5 of the Nevada Test Site (NTS), a knowledge of the water table under the site is paramount. The estimated thickness of the arid intermountain basin alluvium is roughly 900 feet. Very little reliable water table data for Area 5 currently exists. The Special Projects Section of the Reynolds Electrical \& Engineering Co., Inc. Waste Management Department is currently formulating a long-range drilling and sampling plan in support of a Resource Conservation Recovery Act (RCRA) Part $B$ permit waiver for groundwater monitoring and liner systems. An estimate of the water table under the LLW repository, called the Radioactive Waste Management Site (RWMS) in Area 5, is needed for the drilling and sampling plan. Very old water table elevation estimates at about a dozen widely scattered test drill holes, as well as water wells, are available from declassified US Goological Survey, Lawrence Livermore National Laboratory, and Los Alamos National Laboratory drilling logs. A three-dimensional steady-state water-flow equation for estimating the water table elevation under a thick, very dry vadose zone is developed using the Dupuit assumption. A prescribed positive vertical downward infiltration/evaporation condition is assumed at the atmosphere/soil interface. An approximation to the square of the elevation head, based upon multivariate cubic interpolation methods, is introduced. The approximate is forced to satisfy the governing elliptic (Poisson) partial differential equation over the domain of definition. The remaining coefficients are determined by interpolating the water table at eight "boundary point." Several realistic scenarios approximating the water table under the RWMS in Area 5 of the NTS are discussed.

429 (CONF-930496-1) Rellability modeling of an engineered barrier system. Ananda, M.M.A.; Singh, A.K.; Flueck, J.A. Nevada Univ., Las Vegas, NV (United States). [1993]. 5p. Sponsored by USDOE, Washington, DC (United States). DOE Contract FC08-90NV10872. From High-level radioactive waste management; Las Vegas, NV (United States); 25-29 Apr 1993. Order Number DE93008149. Source: OSTI; NTIS; INIS; GPO Dep.

The Weibull distribution is widely used in reliability literature as a distribution of time to failure, as it allows for both increasing failure rate (IFR) and decreasing failure rate (DFR) models. It has also been used to develop models for an engineered barrier system (EBS), which is known to be one of the key components in a deep geological repository for high level radioactive waste (HLW). The EBS failure time can more realistically be modelled by an IFR distribution, since the failure rate for the EBS is not expected to decrease with time. In this paper, an IFR distribution is used to develop a reliability model for the EBS.

430 (CONF-9304190-1) Word images as policy instruments: Lessons from the Yucca Mountain Controversey. Conary, J.S.; Soden, D.L.; Carns, D.E. Nevada Univ., Las Vegas, NV (United States). [1993]. 41p. Sponsored by USDOE, Washington, DC (United States). DOE Contract FC08-90NV10872. From Western Social Science Association meeting; Corpus Christi, TX (United States); 20 24 Apr 1993. Order Number DE93019282. Source: OSTI; NTIS; INIS; GPO Dep.

A study is described which explores word images which have developed about nuclear issues by Nevadans. The study is based on results of a survey conducted regarding issues related to the Yucca Mountain repository.

431 (DOE/CH/10324-T20) Rail abandonments in the South and their effect on NWPA rail shipments. Southern States Energy Board, Norcross, GA (United States). Feb 1988. 36p. Sponsored by USDOE, Washington, DC (United States). DOE Contract FC01-87CH10324. Order Number DE93016317. Source: OSTI; NTIS; INIS; GPO Dep.

The railroad industry will have a very critical role in the eventual shipping of commercial spent fuel and defense high-level waste as provided under the Nuclear Waste Policy Act of 1982 and the 1987 amendments. The transport of spent fuel is expected to be accomplished by rail from 19 of the South's 27 reactor sites to the proposed Yucca Mountain repository or possible monitored retrievable storage facility. The decline in total track availability, however, could significantly impact the federal government's transportation program. Particularly the situation of continuing abandonments may limit rail opportunities at numerous reactor locations. Commercial nuclear reactor sites have the unfortunate problem of not being located on Class I railroad mainine tracks. The reactor sites are generally located in areas with limited rail traffic and thus vulnerable to rail abandonment procedures. The general deregulation of the railroad industry under the Staggers Act of 1980 also assisted in making rail abandonment, through the Interstate Commerce Commission, a rather simple and quick process. The effects of deregulation, however, have provided alternatives to abandonment. In particular, the Staggers Act has led to an enormous surge in the growth of short line and regional railroads. Such railroads have been able to effectively operate rail lines which Class I railroads found unprofitable. The short lines and regionals were also encouraged to competitively negotiate contracts directly with shippers. While these railroads may help reduce the number of abandonment applications, they may also represent higher shipping costs. The South has experienced a great number of abandonments since the 1960's. Many of the abandonments have been significant in length and have affected areas near nuclear plants expected to ship by rail.

432 (DOE/CH/10378-10) RE/SPEC Inc. technical support to the Repository Technology Program: Summary of activities for September 1, 1988-June 30, 1992. Wagner, R.A. RE/SPEC, Inc., Rapid City, SD (United States). Jun 1992. 56p. Sponsored by USDOE, Washington, DC (United States). DOE Contract AC02-89CH10378. Order Number DE93006069. Source: OSTI; NTIS; INIS; GPO Dep.

This report presents a summary of all RE/SPEC Inc. technical support activities to the Repository Technology Program (RTP) from September 1, 1988, through June 30, 1992. The RE/SPEC Inc. activities are grouped into the following categories: project management, project quality assurance (QA), performance assessment (PA), support of the Office of Civilian Radioactive Waste Management (OCRWM) through technical reviews and general assistance, participation in the Department of Energy (DOE) International Program, and code evaluation and documentation.

433 (DOE/FTR-93010640) [Symposium for the STRIPA Project]: Foreign trip report, October 10-17, 1992. Barr, G.E.; Dockery, H.A.; Hunter, T.O. Sandia National Labs., Albuquerque, NM (United States). 21 Dec 1992. 9p. Sponsored by USDOE, Washington, DC (United States). DOE Contract AC04-76DP00789. Order Number 
DE9301'0640. Source: OSTI; NTIS (US Sales Only); GPO Dep.

The STRIPA mine has been used since the 1970 s for basic research projects related to the containment of radioactive waste. This research, initiated as a joint effort with the US, and later expanded to include other countries with similar interests, was aimed at setting standards for developing techniques and tools to characterize and construct radioactive waste repositories. Of particular interest to the US effort have been the studies directed at understanding fluid flow through fractured media. Another important goals was the establishment of an international forum to perform joint research for a common understanding of natural processes. Information from the STRIPA project has been transferred to the Aspoe facility. Future experimentation and calculational modering at Aspoe is expected to extend basic principles developed from the STRIPA experience. The purpose of this trip was to attend the fourth and last symposium for the STRIPA Project. Dr. Barr was the US representative to the Task Force on Fracture Flow Modeling, one of the integral components of the project. Dr. Hunter was the US representative on the Technical Steering Group, providing guidance for this project. Since the work of this project has been and is being well-reported in documents from SKB, this report focuses solely on those new items and interpretations presented by the principal investigators. Excavation effects were not properly accounted for and their inclusion is both calculationally and experimentally incomplete; this problem is discussed. A more subtle goal is transfer of techniques developed at STRIPA to other projects. Some suggestions and opinions are offered for application to Yucca Mountain.

434 (DOE/FTR-93014804) Travel to France to report on Waste Management projects at WIPP and Yucca Mountain: Foreign trip report, February 2-8, 1992. Anderson, D.R. Sandia National Labs., Albuquerque, NM (United States). 6 Apr 1992. 284p. Sponsored by USDOE, Washington, DC (United States). DOE Contract AC0476DP00789. Order Number DE93014804. Source: OSTI; NTIS (US Sales Only); GPO Dep.

In attendance at the Performance Assessment, Advisory Group (PAAG) meeting in Paris were the OECD/NEA Radiation Protection and Waste Management Division staff, and the NEA Data Bank staff. Twelve nations were represented, as well as the Commission of the European Communities (CEC) and the International Atomic Energy Agency (IAEA). An attendance list is attached (Annex 1). Because this was the first PAAG meeting in 18 months, the entire agenda (Annex 2) was taken up by progress reports on various PAAG-sponsored and PAAG-related activities. As per the PAAG charger, recommendations for follow-on work were made as part of the review of on going work. Notable among recommendations were: (1) that the PSACOIN Level 2 Exercise, a code intercomparison study, should go forward as planned, (2) that a one-day topical discussion on Conceptual Model Uncertainty (CMU) is to be part of the next PAAG meeting, and (3) that the results of that topical discussion will be factored into a full Workshop addressing this topic, and may lead to the formation of a CMU Working Group. A number of nations reported progress and changes in their radioactive waste disposal programs. A highlight is the recent licensing of a geologic disposal system for intermediate level waste in Finland, which now beings to accept waste. Texts of presentations are attached as Annexes 26-46.

435 (DOE/FTR-93014980) Travel to France to attend and participate in the Technical Workshop on
Near-Field Performance Assessment: Foreign trip report, May 9-16, 1993. Barnard, R.W. Sandia National Labs., Albuquerque, NM (United States). 3 Jun 1993. 11p. Sponsored by USDOE, Washington, DC (United States). DOE Contract AC04-76DP00789. Order Number DE93014980. Source: OSTI; NTIS (US Sales Only); GPO Dep.

The workshop addressed the properties and processes that affect the engineered-barrier system and near field of a high-level nuclear-waste repository. Working groups developed recommendations for what should and could be done to better understand these processes, and identified what areas were common to the various participants" programs. Although the European programs all differ from the Yucca Mountain Project in the nature of the geological environment, areas common to afl programs were found. These include: development of scenarios for pre-emplacement alterations to the near field; investigation of radiolytic and chemical alterations to the waste form; development of models for the effects of waste-package corrosion products on transport and retardation; and development of scenarios that link near-field and far-field processes. US Participation in the workshop was worthwhile, although US interests could not be fully represented because of a lack of participants.

436 (DOE/FTR-93015807) Travel to Switzerland for performance assessments for both the low- and intermediate-level and high-level radioactive waste disposal programs being managed and implemented by NAGRA: Foreign trip report, May 2-9, 1993. Van Luik, A.E. INTERA, Inc., Las Vegas, NV (United States). 9 Jun 1993. 14p. Sponsored by USDOE, Washington, DC (United States). DOE Contract AC01-91RW00134. Order Number DE93015807. Source: OSTI; NTIS (US Sales Only); GPO Dep.

The traveler was asked to participate in this PAAG Core Group meeting by the Yucca Mountain Site Characterization Project Office (the Project Office). A request had been received by the Project Office to send a representative, and recommending that it be the traveler since he has been a working member of the PAAG since 1985. The Core Group serves at the convenience of the PAAG Chairman. The primary purpose of the Core Group meeting is to set the agenda for the next full PAAG meeting and draw up the recommendations for actions that are to be presented to the full PAAG. An auxiliary purpose of this travel was to obtain information on recent performance assessment development at NAGRA. Discussions were held regarding progress in performance assessments for both the low- and intermediate-level, and high-level radioactive waste disposal programs being managed and implemented by NAGRA. It is expected that the official announcement of a preferred lowand intermediate-level waste disposal site, for further characterization, is to be made in June 1993.

437 (DOENV-354) Hydrology/Radionuclide Migration Program and related research activities: FY 1986 progress report, October 1, 1985-September 30, 1986. Jones, M.A. (comp.). Nevada Univ., Reno, NV (United States). Desert Research Inst. Feb 1992. 186p. Sponsored by USDOE, Washington, DC (United States). DOE Contract AC08-85NV10384, Order Number DE92017984. Source: OSTI; NTIS; INIS; GPO Dep.

This report presents the results of technical studies conducted under the Hydrology/Radionuclide Migration Program (HRMP) at the Nevada Test Site (NTS) for the period of October 1, 1985 through September 30, 1986. The HRMP was initiated in 1973 as the Radionuclide Migration Program to 
study and better understand the hydrologic systems of the NTS and potential movement and rates of movement of radionuclides and other contaminants injected into these systems by underground nuclear testing.

438 (DOENV/10461-T41) The Timber Mountain magmato-thermal event: An intense widespread culmination of magmatic and hydrothermal activity at the southwestern Nevada volcanic field. Jackson, M.R. Jr. Nevada Univ., Reno, NV (United States). May 1988. 53p. Sponsored by USDOE, Washington, DC (United States). DOE Contract FG08-85NV10461. Order Number DE92017913. Source: OSTI; NTIS; INIS; GPO Dep.

Eruption of the Rainier Mesa and Ammonia Tanks Members Timber Mountain Tuff at about 11.5 and $11.3 \mathrm{Ma}$, respectively, resulted in formation of the timber Mountain (TM) caldera; new K-Ar ages show that volcanism within and around the TM caldera continued for about 1 m.y. after collapse. Some TM age magmatic activity took place west and southeast of the TM caldera in the Beatty - Bullfrog Hills and Shoshone Mountain areas, suggesting that volcanic activity at the TM caldera was an intense expression of an areally extensive magmatic system active from about 11.5 to $10 \mathrm{Ma}$. Epithermal $\mathrm{Au}-\mathrm{Ag}, \mathrm{Hg}$ and fluorite mineralization and hydrothermal alteration are found in both within and surrounding the Timber Mountain - Oasis Valley caldera complex. New K-Ar ages date this hydrothermal activity between about 13 and $10 \mathrm{Ma}$, largely between about 11.5 and $10 \mathrm{Ma}$, suggesting a genetic relation of hydrothermal activity to the TM magmatic system.

439 (DOE/NV/10630-28-Add.1) Addendum to environmental monitoring plan Nevada Test Site and support facilities. Reynolds Electrical and Engineering Co., Inc., Las Vegas, NV (United States). Nov 1992. 75p. Sponsored by USDOE, Washington, DC (United States). DOE Contract AC08-89NV10630. Order Number DE93011044. Source: OSTI; NTIS; INIS; GPO Dep.

This 1992 Addendum to the "Environmental Monitoring Plan Nevada Test Site and Support Facilities - 1991," Report No. DOE/NV/1 0630-28 (EMP) applies to the US Department of Energy's (DOE's) operations on the Continental US (including Amchitka Island, Alaska) that are under the purview of the DOE Nevada Field Office (DOE/NV). The primary purpose of these operations is the conduct of the nuclear weapons testing program for the DOE and the Department of Defense. Since 1951, these tests have been conducted principally at the Nevada Test Site (NTS), which is located approximately 100 miles northwest of Las Vegas, Nevada. In accordance with DOE Order 5400.1, this 1992 Addendum to the EMP brings together, in one document, updated information and/or new sections to the description of the environmental activities conducted at the NTS by user organizations, operations support contractors, and the US Environmental Protection Agency (EPA) originally published in the EMP. The EPA conducts both the offsite environmental monitoring program around the NTS and post-operational monitoring efforts at non-NTS test locations used between 1961 and 1973 in other parts of the continental US All of these monitoring activities are conducted under the auspices of the DOENV, which has the stated policy of conducting its operations in compliance with both the letter and the spirit of applicable environmental statutes, regulations, and standards.

440 (DOE/NV/10630-49) Evaluation of environmental monitoring thermoluminescent dosimeter locations.
Kinnison, R. Reynolds Electrical and Engineering Co., Inc., Las Vegas, NV (United States). Dec 1992. 40p. Sponsored by USDOE, Washington, DC (United States). DOE Contract AC08-89NV10630. Order Number DE93006179. Source: OSTI; NTIS; INIS; GPO Dep.

Geostatistics, particularly kriging, has been used to assess the adequacy of the existing NTS thermoluminescent dosimeter network for determination of environmental exposure levels. (Kriging is a linear estimation method that results in contour plots of both the pattern of the estimated gamma radiation over the area of measurements and also of the standard deviations of the estimated exposure levels.) Even though the network was not designed as an environmental monitoring network, ft adequately serves this function in the region of Pahute and Rainier Mesas.. The Yucca Flat network is adequate only if a reasonable definition of environmental exposure levels is required; $R$ is not adequate for environmental monitoring in Yucca Fiat if a coefficient of variation of 10 percent or less is chosen as the criterion for network design. A revision of the Yucca Flat network design should be based on a square grid pattern with nodes 5000 feet (about one mile) apart, if a 10 percent coefficient of variation criterion is adopted. There were insufficient data for southern and western sections of the NTS to perform the geostatistical analysis. A very significant finding was that a single network design cannot be used for the entire NTS, because different areas have different variograms. Before any design can be finalized, the NTS management must specify the exposure unit area and coefficient of variation that are to be used as design criteria.

441 (DOE/NV/10845-8) Hydrogeologic characterization of wells HTH-1, UE18r, UE6e, and HTH-3, Nevada Test Site. Lyles, B.F.; McKay, W.A.; Chapman, J.B.; Tyler, S.W. Nevada Univ., Reno, NV (United States). Water Resources Center. Jun 1991. 73p. Sponsored by USDOE, Washington, DC (United States). DOE Contract AC089ONV10845. Order Number DE92017988. Source: OSTI; NTIS; INIS; GPO Dep.

Monitoring for the migration of contaminants in groundwater or for the proper design of nuclear test emplacement holes at the Nevada Test Site (NTS) requires proper placement and completion of monitoring wells. This is only possible if the hydrogeologic system is understood in a regional and local context, necessitating data from existing wells and boreholes. Though the NTS Groundwater Characterization Project will be drilling welis, their great expense limits the number of new wells. However, there are many existing boreholes and wells on the NTS which have not been completely evaluated hydrologically. Some of these are incorporated in the Long Term Hydrologic Monitoring Program (LTHMP) of the US Environmental Protection Agency (EPA), others are related to the testing programs. In all cases, additional site investigation in necessary to properly interpret the hydrogeologic data from these wells. Monitoring wells on the NTS are poorly characterized with regard to aquifers penetrated, vertical hydraulic gradients, and vertical variations in water quality. One of the goals of the well validation program was to gain a thorough understanding of the parameters needed to interpret the source and fate potential hazardous and radioactive substances that may be detected in these wells in the future. One of the most critical parameters for monitoring is the knowledge of what aquifer or geologic unit is being sampled when a water sample is collected. Pumped water samples are weighted most heavily to the water quality of the most productive (highest transmissivity) aquifer penetrated by the well. 
442 (DOENV/10845-14) Community Radiation Monitoring Program: Annual report, October 1, 1990 September 30, 1991. Cooper, E.N.; McArthur, R.D. Nevada Univ., Reno, NV (United States). Water Resources Center. Jun 1992. 58p. Sponsored by USDOE, Washington, DC (United States). DOE Contract AC08-90NV10845. Order Number DE93000385. Source: OSTI; NTIS; GPO Dep.

Publication No. 45095.

The Community Radiation Monitoring Program is a cooperative effort between the US Department of Energy (DOE) the US Environmental Protection Agency (EPA), the Desert Research Institute (DRI), a division of the University and Community College System of Nevada, and the Nuclear Engineering Laboratory of the University of Utah ( $U$ of $U$ ). This eleventh year of the program began in the summer of 1991 and the work continues as an integral part of the DOE. sponsored long-term offsite radiological monitoring effort that has been conducted by EPA and its predecessors since the inception of nuclear testing at the Nevada Test Site (NTS). The primary objectives of this program are still to increase the understanding by the people who live in the area surrounding the NTS of the activities for which the DOE is responsible, to enhance the performance of radiological sampling and monitoring, and to inform all concerned of the results of those efforts. One of the primary methods used to improve the communication link with the potentially impacted area has been the hiring and training of local citizens as Managers and program representatives in 19 communities adjacent to and downwind from the NTS. These Managers, active science teachers wherever possible, have succeeded, through their training, experience, community standing, and effort, in becoming a very visible, able and valuable asset in this link.

443 (DOENV/10845-15) Estimates of potential radionuclide migration at the Bullion site. Brikowski, T.H. Nevada Univ., Reno, NV (United States). Water Resources Center. Apr 1992. 33p. Sponsored by USDOE, Washington, DC (United States). DOE Contract AC08-90NV10845. Order Number DE93003157. Source: OSTI; NTIS; INIS; GPO Dep.

The Bullion site in Area 20 of the Nevada Test Site has been selected for an intensive study of the hydrologic consequences of underground testing, including subsequent radionuclide migration. The bulk of the chimney and cavity lie in zeolitized tuffs of low hydraulic conductivity, while the base of the cavity may extend downward into more conductive rhyolite flows. A mathematical analog to the Bullion setting is used here to estimate expected radionuclide migration rates and concentrations. Because of a lack of hydrologic data at the site, two contrasting scenarios are considered. The first is downward-transport, in which downward hydraulic gradients flush chimney contents into the conductive underlying units, enhancing migration. The other is upward-transport, in which upward gradients tend to drive chimney contents into the low-conductivity zeolitized tuffs, discouraging migration. In the downward-transport scenario, radionuclide travel times and concentrations are predicted to be similar to those encountered at Cheshire, requiring approximately 10 years to reach a proposed well $300 \mathrm{~m}$ downgradient. The upward transport scenario yields predicted travel times on the order of 2,000 years to the downgradient well. The most likely scenario is a combination of these results, with vertical movement playing a limited role. Radionuclides injected directly into the rhyolites should migrate laterally very quickly, with travel times as in the downward-transport scenario. Those in the zeolitized tuffwalled portion of the chimney should migrate extremely slowly, as in the upward-transport scenario.

444 (DOE/NV/10845-16) Groundwater chemistry at the Nevada Test Site: Data and preliminary interpretations. Chapman, J.B.; Lyles, B.F. Nevada Univ., Reno, NV (United States). Water Resources Center. Mar 1993. 48p. Sponsored by USDOE, Washington, DC (United States). DOE Contract AC08-90NV10845. Order Number DE93017131. Source: OSTI; NTIS; GPO Dep.

The interpretation of chemical analyses of groundwater collected at and near the Nevada Test Site (NTS) has been vital in developing conceptual models of groundwater flow in the area. These conceptual modeis are tested using recent chemical data generated by the Desert Research Institute, as well as historic analyses from the US Geological Survey. A total of 81 wells are represented by analyses from 1957 to 1990 , with generally excellent agreement between repeat samples from the same location. As identified by previous workers, three hydrochemical facies are represented by the samples: $\mathrm{Ca}-\mathrm{Mg}-\mathrm{HCO}_{3}$ water in carbonate rocks or alluvium derived from carbonates, $\mathrm{Na}-\mathrm{K}-\mathrm{HCO}$, water in volcanic rocks and alluvium derived from volcanic rocks, and a mixed fades found in many carbonate and alluvium water samples, and some volcanic waters. There is a general lack of lateral continuity in chemical characteristics along presumed flowpaths within each hydrologic unit (alluvium, carbonate, and volcanic). Though a lack of continuity between basins on the east side of the NTS was expected for water in alluvial and volcanic units due to the absence of interbasin flow, chemical differences observed within individual basins suggest a dominance of vertical over lateral flow. Groundwater in volcanic materials on the east side of Yucca and Frenchman Flats and on the west side of Pahute Mesa and Yucca Mountain has a nearly pure $\mathrm{Na}-\mathrm{K}-\mathrm{HCO}$ signature that reflects contact with primarily volcanic material. Groundwater in volcanic units in the middle of the NTS and on the east side of Pahute Mesa contains a higher proportion of $\mathrm{Ca}, \mathrm{Mg}$, $\mathrm{Cl}$, and $\mathrm{SO}_{4}$ than the other volcanic waters and indicates the contribution of water from the upper carbonate aquifer and/ or hydrothermally altered regions.

445 (DOENV/10872-T57) Heat pipe effect in porous medium. Joseph, M. Nevada Univ., Las Vegas, NV (United States). Dept. of Civil and Environmental Engineering. Dec 1992. 97p. Sponsored by USDOE, Washington, DC (United States). DOE Contract FC08-90NV10872. Order Number DE93014243. Source: OSTI; NTIS; INIS; GPO Dep.

In this thesis a parametric study of the thermal and hydrologic characteristics of the fractured porous tuffs at Yucca Mountain, Nevada was conducted. The effects of different fracture and matrix properties including permeability, thermal conductivity, specific heat, porosity, and tortuosity on heat pipe performance in the vicinity of the waste package were observed. Computer simulations were carried out using TOUGH code on a Cray YMP-2 supercomputer. None of the fracture parameters affected the heat pipe performance except the mobility of the liquid in the fracture. Matrix permeability and thermal conductivity were found to have significant effect on the heat pipe performance. The effect of mass injection was studied for liquid water and air injected at the fracture boundary. A high rate of mass injection was required to produce any effect on the heat pipe. The fracture-matrix equilibrium is influenced by the matrix permeability and the matrix thermal conductivity. 
446 (DOE/OR/00033-T484) Effects of actinide burning on waste disposal at Yucca Mountain. Hirschfelder, J. (California Univ., Berkeley, CA (United States)). Oak Ridge Inst. for Science and Education, TN (United States); California Univ., Berkeley, CA (United States). [1992]. $113 p$. Sponsored by USDOE, Washington, DC (United States). DOE Contract AC05-760R00033. Order Number DE92016228. Source: OSTI; NTIS; INIS; GPO Dep.

Release rates of 15 radionuclides from waste packages expected to result from partitioning and transmutation of Light-Water Reactor (LWR) and Actinide-Burning LiquidMetal Reactor (ALMR) spent fuel are calculated and compared to release rates from standard LWR spent fuel packages. The release rates are input to a model for radionuclide transport from the proposed geologic repository at Yucca Mountain to the water table. Discharge rates at the water table are calculated and used in a model for transport to the accessible environment, defined to be five kilometers from the repository edge. Concentrations and dose rates at the accessible environment from spent fuel and wastes from reprocessing, with partitioning and transmutation, are calculated. Partitioning and transmutation of LWR and ALMR spent fuel reduces the inventories of uranium, neptunium, plutonium, americium and curium in the high-level waste by factors of 40 to 500 . However, because release rates of all of the actinides except curium are limited by solubility and are independent of package inventory, they are not reduced correspondingly. Only for curium is the repository release rate much lower for reprocessing wastes.

447 (DOE/OR/00033-T487) Environmental monitoring for uranium and neptunium at Yucca Mountain using Epithermal Neutron Activation Analysis. Riggle, K. (Missouri Univ., Columbia, MO (United States)). Oak Ridge Inst. for Science and Education, TN (United States); Missouri Univ., Columbia, MO (United States). May 1992. 109p. Sponsored by USDOE, Washington, DC (United States). DOE Contract AC05-760R00033. Order Number DE92041032. Source: OSTI; NTIS; INIS; GPO Dep.

Epithermal Neutron Activation Analysis (ENAA) is investigated as an analysis method for uranium and neptunium in environmental samples from Yucca Mountain. The design and construction of a facility for this technique are described. Theoretical improvement in sensitivity for ENAA over thermal NAA (TNAA) is discussed and compared to experimental results for different sample types. Uranium is analyzed in eight different sample matrices, including samples from Yucca Mountain. Neptunium has been studied only in AGV-1 Granite. As predicted by theory, uranium shows a high experimental sensitivity improvement factor (average $=7.76$ ), while neptunium has a factor of only 0.49 . Detection limits for uranium using ENAA range from 6 to 52 ppb by weight (2.6 to $17 \mathrm{ng}$ in sample) for the different matrices. Neptunium shows a detection limit of $57 \mathrm{ppb}$ by weight (6.2 $\mathrm{ng}$ in sample) in AGV-1 Granite using ENAA. Using TNAA, neptunium can be analyzed to $35 \mathrm{ppB}$ by weight ( $3.4 \mathrm{ng}$ in sample).

448 (DOE/OR/21555-T2) Monitored retrievable storage of spent nuclear fuel: Transportation studies: Draft. Bronzini, M.S. (Tennessee Univ., Knoxville, TN (United States). Transportation Center); Middendorf, D.P.; Kinnison, H.A.; Miller, A.J. Jr.; Harrison, G.I.; Stammer, R.E. Jr.; Thackston, E.L.; Bowlby, W.; Huddleston, B. Tennessee Safe Growth Team, Nashville, TN (United States); Tennessee Univ., Knoxville, TN (United States). Transportation Center; Vanderbilt Univ., Nashville, TN (United States).
Dept. of Civil and Environmental Engineering. 20 Oct 1986. 350p. Sponsored by USDOE, Washington, DC (United States). DOE Contract FG05-85OR21555. Order Number DE92011923. Source: OSTI; NTIS; GPO Dep.

The US Department of Energy (DOE) is preparing a proposal to Congress (1) to site in Tennessee a Monitored Retrievable Storage (MRS) facility for handling spent nuclear fuel. The MRS would gather spent fuel from all (or only Eastern) reactors, consolidate and repackage it, and send it on to the first nuclear waste permanent repository, which presumably will be located at a site in the West. Three repository sites have been recommended for detailed characterization studies-Deaf Smith Canyon, Texas; Yucca Mountain, Nevada; and Hanford, Washington. Sites recommended for the MRS are in Oak Ridge and Hartsville, Tennessee. (2) The purpose of this study was to estimate the transportation impacts of moving spent nuclear fuel, both with and without the proposed MRS facility. In order to make a fair comparison, the systems considered include measures to reduce transportation requirements, again with and without the MRS. Thus the study objective might be stated more broadly as "to estimate the transportation impacts of alternative systems for moving spent nuclear fuel from reactors to a repository." The purpose of making these impact estimates was to clarify the comparison between alternatives, rather than to determine their precise impacts or recommend any one of them. Both national and state level impacts were of concern.

449 (DOE/RW-0253-Rev.2) Program cost and schedule baseline: Revision 2. USDOE Office of Civilian Radioactive Waste Management, Washington, DC (United States). Nov 1991. 55p. Sponsored by USDOE, Washington, DC (United States). Source: OSTI (Free of Charge).

The purpose of this document is to establish quantitative expressions of proposed costs and schedule to serve as a basis for measurement of the Radioactive Waste Management Program performance. It identifies the components of the Program Cost and Schedule Baseline (PCSB) that will be subject to change control by the Executive Level (Level 0) and Program (Level 1) Change Control Boards (CCBs) and establishes their baseline values. This document also details PCSB reporting, monitoring, and corrective action requirements. The Program technical baseline contained in the Waste Management System Description (WMSD) and the Waste Management System Requirements (WMSR) documents provides the technical basis for the PCSB. The PCSB establishes baseline values for the Yucca Mountain Site Characterization Project cost and schedule through submittal of the license application to the Nuclear Regulatory Commission (NRC).

450 (DOE/RW-0253-Rev.3) Office of Civilian Radioactive Waste Management Program Cost and Schedule Baseline: Revision 3. USDOE Office of Civilian Radioactive Waste Management, Washington, DC (United States). Sep 1992. 53p. Sponsored by USDOE, Washington, DC (United States). Source: OSTI (Free of Charge); INIS.

The purpose of this document is to establish quantitative expressions of proposed costs and schedule to serve as a basis for measurement of program performance. It identifies the components of the Program Cost and Schedule Baseline (PCSB) that will be subject to change control by the Executive (Level 0) and Program (Level 1) Change Control Boards (CCBS) and establishes their baseline values. This document also details PCSB reporting, monitoring, and corrective action requirements. The Program technical baseline 
contained in the Waste Management System Description (WMSD), the Waste Management System Requirements (WMSR), and the Physical System Requirements documents provide the technical basis for the PCSB. Changes to the PCSB will be approved by the Pregrain Change Control Board (PCCB)In addition to the PCCB, the Energy System Acquisition Advisory Board Baseline CCB (ESAAB BCCB) will perform control functions relating to Total Project Cost (TPC) and major schedule milestones for the Yucca Mountain Site Characterization Project and the Monitored Retrievable Storage (MRS) Project.

451 (DOE/RW-0268P-Rev.2) Waste Management System Requirements Document: Volume 4, MGDs, Revision 2. USDOE Office of Civilian Radioactive Waste Management, Washington, DC (United States). Feb 1992. 19p. Sponsored by USDOE, Washington, DC (United States). Source: OSTI; INIS.

This DCP establishes an interim plan for the Office of Civilian Radioactive Waste Management (OCRWM) technical baseline until the results of the OCRWM Document Hierarchy Task Force can be implemented. This plan is needed to maintain continuity in the Program for ongoing work in the areas of Waste Acceptance, Transportation, Monitored Retrievable Storage (MRS) and Yucca Mountain Site Characterization.

452 (DOE/RW-0306P-3) USDOE Office of Civilian Radioactive Waste Management quarterly report on program cost and schedule: Fourth Quarter, FY 1991. USDOE Office of Civilian Radioactive Waste Management, Washington, DC (United States). [1991]. 17p. Sponsored by USDOE, Washington, DC (United States). Source: OSTI (Free of Charge).

This report is intended to provide a summary of the cost and schedule performance for the Civilian Radioactive Waste Management Program. Historical and current cost profiles (extracted from the DOE Financial Information System) are presented for each of the major program elements. Also included in this report are the program schedule baseline, the status of near-term program milestones and the status of the Nuclear Waste Fund revenues and disbursements. In particular, cost profile for the Yucca Mountain Site Characterization Project is given. This report includes data through September 1991.

453 (DOE/RW-0318) Strategic principles workshops: Discusslon drafts and workshop notes. USDOE Office of Civilian Radioactive Waste Management, Washington, DC (United States). Sep 1991. 273p. Sponsored by USDOE, Washington, DC (United States). Source: INIS; OSTI (Free of Charge).

The Office of Civilian Radioactive Waste-Management in the Department of Energy (DOE) is responsible for disposing of this nation's spent fuel and high-level radioactive waste in a manner that protects the health and safety of the public and the quality of the environment. Although embodied in the Federal repository program that began with studies in the late 1950 s, this mission was explicitly established by the Nuclear Waste Policy Act of 1982 and reaffirmed by the Nuclear Waste Policy Amendments Act of 1987. To fulfill our mission, we are developing a waste management system consisting of a geologic repository for permanent disposal deep beneath the surface of the earth, a facility for monitored retrievable storage, and a system for transporting the waste. This discussion draft was developed to help involve parties affected by or interested in the wastemanagement program in the formulation of the basic principles on which the program will be based. It reviews existing objectives, policies, and strategic principles under which the system is currently being developed. Then discussed are issues of strategic importance for which additional strategic principles may be needed. For these issues in particular, views from affected and interested parties is solicited, but comments regarding alternative approaches to the issues presented as well as suggestions for additional issues will also be welcome. Finally, background information on the waste-management program pertinent to the issues discussion is presented.

454 (DOE/RW-0335P(1992)) Annual report to Congress. USDOE Office of Civilian Radioactive Waste Management, Washington, DC (United States). Mar 1992. 90p. Sponsored by USDOE, Washington, DC (United States). Source: OSTI (Free of Charge).

This is the eighth annual report submitted by the Office of Civilian Radioactive Waste Management (OCRWM) to Congress. It covers activities and expenditures during Fiscal Year 1991, which ended September 30, 1991. Chapter 1 of this report describes OCRWM's mission and objectives. Chapters 2 through 8 cover the following topics: earning public trust and confidence; geological disposal; monitored retrieval storage; transportation; systems integration and regulatory compliance; international programs; and program management. Financial statements for the Nuclear Waste Fund are presented in Chapter 9.

455 (DOE/RW-0349P) US Department of Energy Office of Civilian Radioactive Waste Management quarterly report on program cost and schedule: First quarter, FY 1992. USDOE Office of Civilian Radioactive Waste Management, Washington, DC (United States). [1992]. 25p. Sponsored by USDOE, Washington, DC (United States). Source: OSTI (Free of Charge).

This report is intended to provide a summary of the cost and schedule performance for the Civilian Radioactive Waste Management Program. Historical current cost profiles (extracted from the DOE Financial Information System) are presented for each of the major program elements. Also included in this report are the program schedule baseline, the status of near-term program milestones and the status of the Nuclear Waste Fund revenues and disbursements. This report includes data through December 1991.

456 (DOE/RW-0354P) 1991 OCRWM bulletin compilation and index. USDOE Office of Civilian Radioactive Waste Management, Washington, DC (United States). May 1992. 85p. Sponsored by USDOE, Washington, DC (United States). Source: INIS; OSTI (Free of Charge).

The OCRWM Bulletin is published by the Department of Energy, Office of Civilian Radioactive Waste Management, to provide current information about the national program for managing spent fuel and high-level radioactive waste. The document is a compilation of issues from the 1991 calendar year. A table of contents and an index have been provided to reference information contained in this year's Bulletins.

457 (DOE/RW-0365P) Quarterly report on program cost and schedule: Second quarter FY 1992. USDOE Office of Civilian Radioactive Waste Management, Washington, DC (United States). [1992]. 25p. Sponsored by USDOE, Washington, DC (United States). Source: OSTI (Free of Charge). 
This report is intended to provide a summary of the cost and schedule performance for the Civilian Radioactive Waste Management Program. Historical and current cost profiles (extracted from the DOE Financial Information System) are presented for each of the major program elements. Also included in this report are the program schedule baseline, the status of near-term program milestones and the status of the Nuclear Waste Fund revenues and disbursements. This report includes data through March 1992.

458 (DOE/RW-0370) Quarterly report on program cost and schedule, third quarter FY 1992. USDOE Office of Civilian Radioactive Waste Management, Washington, DC (United States). [1992]. 25p. Sponsored by USDOE, Washington, DC (United States). Source: OSTI (Free of Charge).

This report is intended to provide a summary of the cost and schedule performance for the civilian Radioactive Waste Management Program. Historical and current cost profiles (extracted from the DOE Financial information System) are presented for each of the major program elements. Also included in this report are the program schedule baseline, the status of near-term program milestones and the status of the Nuclear Waste Fund revenues and disbursements. This report includes data through June 1992.

459 (DOE/RW-0380P) Quarterly report on program cost and schedule, fourth quarter FY 1992. USDOE Office of Civilian Radioactive Waste Management, Washington, DC (United States). [1992]. 30p. Sponsored by USDOE, Washington, DC (United States). Source: OSTI (Free of Charge).

This report is intended to provide a summary of the cost and schedule perform for the Civilian Radioactive Waste Management Program. Historical and current cost profiles (extracted from the DOE Financial Information System) are presented for each of the major program elements. Also included in this report are the program schedule baseline, the status of near-term program milestones and the status of the Nuclear Waste Fund revenues and disbursements. This report includes data through September 1992.

460 (DOE/RW-0422) Annual report to Congress, FY 1992. USDOE Office of Civilian Radioactive Waste Management, Washington, DC (United States). Jul 1993. 97p. Sponsored by USDOE, Washington, DC (United States). Source: OSTI (Free of Charge); INIS.

The Office of Civilian Radioactive Waste Management (OCRWM) is responsible for disposing of the Nation's spent nuclear fuel from civilian nuclear power reactors and highlevel radioactive waste from its defense activities in a cost-effective manner that protects the health and safety of the public and workers and the quality of the environment. To accomplish this mission OCRWM is developing a waste management system consisting of a geologic repository, a facility for monitored retrievable storage, and a system for transporting the waste. This is the ninth annual report submitted by the OCRWM to Congress. The OCRWM submits this report to inform Congress of its activities and expenditures during fiscal year 1992 (October 1, 1991 through September 30, 1992).

461 (EPRI-TR-100384) Demonstration of a riskbased approach to high-level waste repository evaluation, Phase 2. McGuire, R.K. (Risk Engineering, Inc., Golden, CO (United States)). Electric Power Research Inst., Palo Alto, CA (United States); Risk Engineering, Inc., Golden, CO (United States). OMay 1992. 268p. Sponsored by Electric Power Research Inst., Palo Alto, CA (United
States). Source: EPRI Distribution Center, 207 Coggins Drive, PO Box 23205, Pleasant Hill, CA 94523.

This project develops and applies a probability-based methodology to assess the performance of high-level nuclear waste repositories. The particular method is an extension of the methodology demonstrated previously under Phase 1 of this project. Under the current application, aqueous and gaseous pathways for release of radionuclides are considered, as are possible releases induced by inadvertent human intrusion and by volcanic occurrences. Individual experts in the relevant scientific and engineering fields designate the inputs (and their uncertainties) for the analysis. These inputs are aggregated using the logic tree format so that calculations of levels of release for thirteen radionuclides can be made for all possibie combinations of assumed input valves. The probability distribution of releases reflects the uncertainties in inputs designated by the expert in each field. The methodology is applied to proposed repository at Yucca Mountain, Nevada. The application indicates that, for high levels of possible release, the largest quantities of nuclides will escape the repository by aqueous pathways. Gaseous release of ${ }^{14} \mathrm{C}$ may occur but will be important relative to releases by aqueous pathways only at lower leveis of total release. Volcanic disturbances, earthquakes, and inadvertent human intrusion do not led to large releases. Sensitivity studies for aqueous pathways indicate that critical factors affecting large release are amount of groundwater infiltration, solubilities of radioelements and dissolution rate of the waste matrix, lateral diversion of the groundwater flow around the repository, characteristics of the engineered barrier system, and coupling between fracture and matrix flow.

462 (EPRI-TR-101257, pp. 35-38) Session II: Gas pathway. Ramspott, L. (Lawrence Livermore National Laboratory, CA (United States)). Electric Power Research Inst., Palo Alto, CA (United States); Rogers and Associates Engineering Corp., Salt Lake City, UT (United States). Mar 1993. In Proceedings: EPRI Workshop 2 - Technical basis for EPA HLW disposal criteria. 684p. Source: EPRI Distribution Center, 207 Coggins Drive, PO Box 23205, Pleasant Hill, CA 94523.

This session of the EPA Workshop 2, Technical Basis for EPA HLW Disposal Criteria, focused on the significance of gaseous transport of radionuclide releases. The basis of the cumulative curie release limit set for carbon-14, the principle nuclide of concern with respect to gaseous transport, is not inconsistent with the limits set for the nuclides. It was pointed out that radionuclides released through gaseous wastes affect the world-wide population while radionuclides released to the water supply affect only localized populations. This argument was used to justify a modification to the carbon-14 release limit.

463 (EPRI-TR-101257, pp. 129-133) Reasonableness of human intrusion provisions in EPA's HLW standard. Channell, J. Electric Power Research inst., Palo Alto, CA (United States); Rogers and Associates Engineering Corp., Salt Lake City, UT (United States). Mar 1993. In Proceedings: EPRI Workshop 2 - Technical basis for EPA HLW disposal criteria. 684p. Source: EPRI Distribution Center, 207 Coggins Drive, PO Box 23205, Pleasant Hill, CA 94523.

This paper reviews the question of whether human intrusion should be included in the Environmental Protection Agency High Level Waste Standard or be considered differently from natural events. The four categories of human 
intrusion assumptions considered are (1) inadvertent and intermittent intrusion by exploratory drilling for resources; (2) maximum frequency of inadvertent intrusion into repository need not be greater that 30 boreholes/square $\mathrm{km}$ of repository area per $10,000 \mathrm{yr}$. in sedimentary rock formations or more than 3 boreholes/square $\mathrm{km}$ for other geologic formations; (3) the amount of water released directly to the surface need not be greater than that which would promptly flow through a newly created borehole by artesian flow or 200 cubic meters of water if available to be pumped; and (4) sealing of a human intrusion borehole would result in a borehole with a permeability no greater than that of a typical borehole filled by the soil or gravel naturally over a period of time.

464 (EUR-14690, pp. 135-142) Oklo - natural analogue for transfer processes in a geological repository: present status of the programme. Chapuis, A.M. (CEA Centre d'Etudes de Fontenay-aux-Roses, 92 (France). Inst. de Protection et de Surete Nucleaire); Blanc, P.L. Commission of the European Communities, Luxembourg (Luxembourg). 1993. (CONF-9204265-: Migration of radionuclides in the geosphere meeting, Brussels (Belgium), 9-10 Apr 1992). In Migration of radionuclides in the geosphere. 183p. Order Number DE94604138. Source: OSTI; NTIS (US Sales Only); INIS.

The uranium ore body in Oklo is a unique subject in the world, as natural fission reactions occurred there two billion years ago. It provides opportunities for the study of natural analogy with deep radioactive waste disposal, specially radionuclide mass transfer processes to the surface. The ongoing program is co-funded by the CEC, and it involves several directorates in the CEA, that is to say the IPSN, plus DTA and DCC. Other, non-CEC agencies also take part in the studies, such as SKB (Sweden), AECL and ONTARIOHYDRO (Canada). It can be subdivided into several different tasks: 1. In situ sampling, in close collaboration with the mining company (C.O.M.U.F., Compagnie des Mines d'Uranium de Franceville, Mounana, Gabon). 2. Study and characterization of the source term (mostly in CEA laboratories). 3. Studies on the geochemical systems ruling the migrations, implying collaboration between CEA laboratories and other institutions: CREGU (Centre de Recherches sur la Geologie des matieres premieres minerales et energetiques, formerly 'de I'Uranium', Nancy), Centre de Geochimie de la surface (CNRS, Strasbourg), and Ecole Nationale Superieure des Mines de Paris (ENSMP, Centre de Geologie Generale et Miniere and Centre d'Informatique Geologique, Fontainebleau). 4. Modelling: Part of the modelling will take place in each laboratory involved, but the final coupling of models will be the responsibility of IPSN and ENSMP. 1 fig.

465 (EUR-14690, pp. 143-151) Okelobondo Uranium deposit: Regional context, stratigraphy, sedimentology, tectonic and mineralization. Ango, A.M. (Compagnie Miniere de l'Ogooue, Moanda (Gabon)). Commission of the European Communities, Luxembourg (Luxembourg). 1993. (In French). (CONF-9204265-: Migration of radionuclides in the geosphere meeting. Brussels (Belgium), 9-10 Apr 1992). In Migration of radionuclides in the geosphere. 183p. Order Number DE 94604138 . Source: OSTI; NTIS (US Sales Only); INIS.

This paper describes briefly the geology of Okelobondo uranium deposit (Gabon) and gives the study prospects of natural reactor phenomenon which depends of the operating progress state. Oklo phenomenon is considered as the best natural analogue for the study of radionuclide migration. 3 figs.

466 (GAO/RCED-91-07) Nuclear waste: Quality assurance auditors need access to employee records. General Accounting Office, Washington, DC (United States). Resources, Community and Economic Development Div. Jan 1991. 25p. Source: US General Accounting Office, P.O. Box 6015, Gaithersburg, MD 20877 (United States).

Concerns were expressed about whether the Privacy Act of 1974 (5 U.S.C. 552a) could hamper the ability of the Department of Energy (DOE) to verify the proficiency of both DOE and contractor employees who characterize (investigate) Yucca Mountain, Nevada, as a potential site for a nuclear waste repository. That act generally provides restrictions on what information about private individuals a federal agency may maintain in a system of records, and prohibits the agency's disclosure of such information unless certain statutory conditions for disclosures are met. The Nuclear Regulatory Commission (NRC), which must approve any of DOE's future applications for authorization to construct a repository at the Yucca Mountain site, requires a quality assurance program to meet prescribed quality standards, which include ensuring that studies of the site are performed by qualified employees. This program would entail verification of the training and qualification of DOE and contractor employees. This paper reviews (1) DOE's efforts to identify and resolve the implications of the Privacy Act for DOE's quality assurance program and (2) the ways in which the delay in resolving Privacy Act issues may have affected preliminary work on the Yucca Mountain project.

467 (GAO/RCED-91-55) Nuclear waste: Quarterly report as of March 31, 1990. General Accounting Office, Washington, DC (United States). Resources, Community and Economic Development Div. Feb 1991. 28p. Source: US General Accounting Office, P.O. Box 6015, Gaithersburg, MD 20877 (United States).

This is GAO's final quarterly report on DOE's implementation of the Nuclear Waste Policy Act of 1982. It discusses public comments received by DOE on the Secretary of Energy's November 1989 report to Congress, which assessed the civilian nuclear waste program; uncertainties about the criteria DOE would use to identify the presence of unsuitable site conditions early in the investigation of Yucca Mountain; and the way in which DOE's near-term site investigation plans could be affected by the state of Nevada's refusal to allow DOE access to the Yucca Mountain site.

468 (GAO/RCED-92-157) Nuclear waste: Questionable uses of program funds at Lawrence Livermore Lab. General Accounting Office, Washington, DC (United States). Resources, Community and Economic Development Div. May 1992. 20p. Source: US General Accounting Office, P.O. Box 6015, Gaithersburg, MD 20877 (United States).

The Nuclear Waste Policy Act of 1982, as amended in 1987, directed the Secretary of Energy to, among other things, investigate Yucca Mountain, Nevada, as a potential site for permanently disposing of highly radioactive wastes in an underground repository. In April 1991, the authors testified on Yucca Mountain project expenditures before your Subcommittee. Because of the significance of the authors findings regrading DOE's program management and expenditures, you asked the authors to continue reviewing program expenditures in depth. As agreed with your office, the authors reviewed the expenditures of project funds made available to the Department of Energy's (DOE) 
Lawrence Livermore National Laboratory, which is the lead project contractor for developing a nuclear waste package that wold be used for disposing of nuclear waste at Yucca Mountain. This report discusses the laboratory's use of nuclear waste funds to support independent research projects and to manage Yucca Mountain project activities. It also discusses the laboratory's project contracting practices.

469 (GAO/T-RCED-91-37) Nuclear waste: DOE expenditures on the Yucca Mountain Project. General Accounting Office, Washington, DC (United States). Resources, Community and Economic Development Div. Apr 1991. 13p. Source: US General Accounting Office, P.O. Box 6015, Gaithersburg, MD 20877 (United States).

This book discusses the Department of Energy's (DOE) use of funds appropriated for the scientific investigation of Yucca Mountain, Nevada. These investigations are needed to obtain a Nuclear Regulatory Commission (NRC) license to construct and operate the site as a nuclear waste repository. DOE had planned to begin these investigations of the site, including constructing an exploratory shaft facility in the $1988-90$ time frame. Although DOE spent almost $\$ 500$ million on the Yucca Mountain project in those 3 years, the specific investigations needed for licensing have not begun. This testimony presents the results of a review of Yucca Mountain project costs for fiscal years 1988 through 1990. It is limited to an analysis of summary cost reports, supplemented by discussions with project officials, and reviews of selected project records.

470 (INIS-XN-393) The international hydrocoin project - Groundwater hydrology modelling strategies for performance assessment of nuclear waste disposal. Nuclear Energy Agency, 75 - Paris (France). 1991. [336p.] Order Number DE93609565. Source: OSTI; NTIS (US Sales Only); INIS.

The international cooperation project HYDROCOIN for studying groundwater flow modelling in the context of radioactive waste disposal was initiated in 1984. Thirteen organisations from ten countries and two international organisations have participated in the project which has been managed by the Swedish Nuclear Power Inspectorate, SKI. This report summarises the results from the third phase of HYDROCOIN, Level 3, which has addressed the issues of uncertainty and sensitivity analysis of groundwater flow problems and how uncertainties affect the modelling results. Seven test cases were selected for the project, representing a variety of flow situations in different media, as well as variety of temporal and spatial scales. These test cases were tackled by the participating organisations (Project Teams) using a number of different codes. An overview of the methodologies used in uncertainty and sensitivity analysis is given. Results from the various Teams attempting the Test Cases are presented and conclusions are drawn as to the applicability of the results obtained to the test cases being analysed as well as the general applicability of the results. The importance of making uncertainty and sensitivity analysis as part of a performance analysis of the safety of a nuclear waste repository is stressed. The conclusion is drawn that the HYDROCOIN Level 3 study has greatly contributed to the understanding of these issues. 42 refs., 159 figs., 61 tabs.

471 (INIS-XN-415) The International INTRAVAL project. Phase 1 test cases. Nuclear Energy Agency, 75 Paris (France). 1992. [157p.] Order Number DE93609566. Source: OSTI; NTIS (US Sales Only); INIS.
This report contains a description of the test cases adopted in Phase 1 of the international cooperation project INTRAVAL. Seventeen test cases based on bench-scale experiments in laboratory, field tests and natural analogue studies, have been included in the study. The test cases are described in terms of experimental design and types of available data. In addition, some quantitative examples of available data are given as well as references to more extensive documentation of the experiments on which the test cases are based. Fithteen test cases examples are given: 1 Mass transfer through clay by diffusion and advection. 2 Uranium migration in crystalline bore cores, small scale pressure infiltration experiments. 3 Radionuclide migration in single natural fractures in granite. 4 Tracer tests in a deep basalt flow top. 5 Flow and tracer experiment in crystalline rock based on the Stripa 3-D experiment. 6 Tracer experiment in a fracture zone at the Finnsjon research area. 7 Synthetic data base, based on single fracture migration experiments in Grimsel rock laboratory. 8 Natural analogue studies at Pocos de Caldas, Minais Gerais, Brazil. Redoxtront and radionuclide movement in an open pit uranium mine. 9 Natural analogue studies at the Koongarra site in the Alligator Rivers area of the Northern Territory, Australia. 10 Large block migration experiments in a block of crystalline rock. 11 Unsaturated flow and transport experiments performed at Las Cruces, New Mexico. 12 Flow and transport experiment in unsaturated fractured rock performed at the Apache Leap Tuff site, Arizona. 13 Experiments in partially saturated tuffaceous rocks performed in the G-tunnel underground facility at the Nevada Test site, USA. 14 Experimental study of brine transport in porous media. 15 Groundwater flow in the vicinity of the Gorleben Salt Dome, Federal Republic of Germany.

472 (INIS-XN-418) The International INTRAVAL project. Phase 1, case 7. The Pocos de Caldas natural analogue: studies of redox front movement. Chapman, N. (ed.). Nuciear Energy Agency, 75 - Paris (France). 1992. [73p.] Order Number DE93609569. Source: OSTI; NTIS (US Sales Only); INIS.

The study of natural analogues is an important means of validating models of the geochemical processes affecting radionuclide behaviour. This test case, which is one aspect taken from the much broader geochemical studies carried out in the Pocos de Caldas Project, concerns the nature and behaviour of redox fronts, such as might be generated in the near-field of a spent-fuel repository. A redox front is potentially important in terms of the movements and speciation of certain radionuclides close to the waste package. The natural redox fronts in Osamu Utsumi uranium mine display many of the features which may occur in a repository, and influence the movement of natural series radionuclides, and other elements, through the rock/groundwater system. This report, describes the geological, hydrogeological and geochemical nature of the site, and of the redox fronts. Emphasis is placed on the mineralogy of the fronts, and the concentration profiles of various elements across them. The project involved a number of different modelling approaches which attempted to describe the generation and movement of the fronts through the rock. These included mass balance, reaction-diffusion models, fissure flow models, thermodynamic models, and kinetic models. 21 refs., 36 figs., 1 tab.

473 (INIS-XN-428) The International INTRAVAL project. Phase 1 case 8: The Alligator rivers natural analogue. Duerden, P. (ed.). Nuclear Energy Agency, 75 - 
Paris (France); Swedish Nuclear Power Inspectorate, Stockholm (Sweden). 1992. [215p.] Order Number DE93618121. Source: OSTI; NTIS (US Sales Only); INIS.

INTRAVAL is an international coordinated research program for predicting the potential radionuclide migration in the geosphere with the use of mathematical models. Such models are used to help assess the long-term safety of radioactive waste disposal systems. The objective of the Aliigator Rivers Analogue Project (ARAP) is to identify and study long-term processes that have been significant in the development of the uranium dispersion zone at the Koongarra uranium ore deposit in the Northern Territory of Australia. This report includes a description of the site geology and gives an outline of the experimental programs, which are aimed to study the hydrogeology and geochemistry of the system, and the distribution of uranium and its daughter radionuclides in the rock strata. The extensive databases that have resulted from these studies have been used to develop and test hydrological, geochemical and transport models. A good basis has been established for modelling the transport of radionuclides in the porous, weathered zone of the Koongarra uranium deposit and its surroundings. A number of preliminary transport, hydrology and geochemical modelling reports are given, with the Koongarra databases also being used to test a Performance Assessment model. The possible application of scenario de. velopment procedures to the Koongarra site is discussed. 106 refs., 67 figs., 28 tabs.

474 (JAB-10733-TM6) Processed seismic motion records from Little Skull Mountain, Nevada earthquake of June 29, 1992, recorded at stations in southern Nevada. Lum, P.K.; Honda, K.K. URS/John A. Blume and Associates, Engineers, San Francisco, CA (United States). [1992]. 206p. Sponsored by USDOE, Washington, DC (United States). DOE Contract AC08-89NV10733. Order Number DE93005849. Source: OSTI; NTIS; GPO Dep.

For complete package including technical report and $8 \mathrm{~mm}$ data file, Order No. DE93013314.

As part of the contract with the US Department of Energy, Nevada Field Office (DOENV), URS/John A. Blume \& Associates, Engineers (URS/Blume) maintains a network of seismographs in southern Nevada to monitor the ground motion generated by the underground nuclear explosions (UNEs) at the Nevada Test Site (NTS). The seismographs are located in the communities surrounding the NTS and the Las Vegas valley. When these seismographs are not used for monitoring the UNE generated motions, a limited number of seismographs are maintained for monitoring motion generated by other than UNEs (e.g. motion generated by earthquakes, wind, blast). During the subject earthquake of June 29,1992 , a total of 20 of these systems recorded the earthquake motions. This report contains the recorded data.

475 (JAB-10733-TMB) Processed seismic motion records from Little Skull Mountain, Nevada earthquake aftershocks of July 5, 1992 and September 13, 1992, recorded at seismic stations in southern Nevada. Lum, P.K.; Honda, K.K. URS/John A. Blume and Associates, Engineers, San Francisco, CA (United States). Apr 1993. 187p. Sponsored by USDOE, Washington, DC (United States). DOE Contract AC08-89NV10733. Order Number DE93018073. Source: OSTI; NTIS; GPO Dep.

For complete package including technical report and $8 \mathrm{~mm}$ data file order DE93018074.
As part of the contract with the US Department of Energy, Nevada Field Office (DOE/NV), URS/John A. Blume \& Associates, Engineers (URS/Blume) maintains a network of seismographs in southern Nevada to monitor the ground motion generated by the underground nuclear explosions (UNEs) at the Nevada Test Site (NTS). The seismographs are located in the communities surrounding the NTS and the Las Vegas valley. When these seismographs are not used for monitoring the UNE generated motions, a limited number of seismographs are maintained for monitoring motion generated by other than UNEs (e.g. motion generated by earthquakes, wind, blast). During the subject earthquake aftershocks of July 5 and September 13,1992, a total of 20 of these systems recorded the earthquake motions. This report contains the recorded data.

476 (JAERI-M-91-118) Experimental method for determining distribution coefficients of TRU nuclides for evaluating their migration behaviors. Tanaka, Tadao (Japan Atomic Energy Research Inst., Tokai, lbaraki (Japan). Tokai Research Establishment); Kamiyama, Hideo. Japan Atomic Energy Research Inst., Tokyo (Japan). Aug 1991. 19p. (In Japanese). Order Number DE92750952. Source: OSTI; NTIS (US Sales Only); INIS.

Distribution coefficients of americium and plutonium were measured by batch experiments for typical geological formations at Shimokita area in Aomori prefecture, sand stone, tuff rock and sandy soil. The distribution coefficients of both nuclides were largely affected by $\mathrm{pH}$ of the used synthetic ground water as well as by the separating condition of solidliquid phase. It has been shown that their distribution coefficients are varied by their transfer route among geological formations, since their chemical species, which can move through a certain geological formation, are depending on its pore size and the $\mathrm{pH}$ of infiltrating water in it. It was concluded that consideration on the structure of geological formations and their physico-chemical properties shouid be taken in the measurement of effective distribution coefficients for evaluating the migration behavior of TRU nuclides. (author).

477 (JAERI-M-93-023) Natural analogue studies: Mineral alteration and uranium migration. Murakami, Takashi (Japan Atomic Energy Research Inst., Tokai, Ibaraki (Japan). Tokai Research Establishment). Japan Atomic Energy Research Inst., Tokyo (Japan). Feb 1993. 25p. (In Japanese). Order Number DE93797600. Source: OSTI; NTIS; INIS.

The Alligator Rivers Analogue Project, an international project, was carried out from 1987 to 1992 using the Koongarra uranium ore deposit in northern Australia as a site. This report reviews the papers, published during that period, concerning 'mineral alteration and uranium migration'. The analyses of rocks and model calculations established that the uranium migration has been affected by the mineral alteration. (author).

478 (LA-12301-MS) Colloid research for the Nevada Test Site. Bryant, E.A. Los Alamos National Lab., NM (United States). May 1992. 34p. Sponsored by USDOE, Washington, DC (United States). DOE Contract W-7405ENG-36. Order Number DE92011870. Source: OSTI; NTIS; INIS; GPO Dep.

Research is needed to understand the role of particulates in the migration of radionuclides away from the sites of nuclear tests at the Nevada Test Site. The process of testing itself may produce a reservoir of particles to serve as vectors 
for the transport of long-lived radionuclides in groundwater. Exploratory experiments indicate the presence of numerous particulates in the vicinity of the Cambric test but a much lower loading in a nearby well that has been pumped continuously for 15 years. Recent groundwater colloid research is briefly reviewed to identify sampling and characterization methods that may be applicable at the Nevada Test Site.

479 (LA-12325-C, pp. 41-42) Sorption and porosity heterogeneity: Effects on radionuclide transport. Buchholtz-ten Brink, M. (Lawrence Livermore National Lab., CA (US)). Los Alamos National Lab., NM (United States). Aug 1992. DOE Contract W-7405-ENG-48. (CONF9009350-: DOENucca Mountain site characterization project radionuclide adsorption workshop, Los Alamos, NM (United States), 11-12 Sep 1990). In Proceedings of the DOEY Yucca Mountain Site Characterization Project Radionuclide Adsorption Workshop at Los Alamos National Laboratory, September 11-12, 1990. 238p. Order Number DE92041241. Source; OSTI; NTIS; INIS.

Diffusive transport rates for aqueous species in porous media are a function of the molecular diffusion rate in solution for the species of interest, any change in its concentration in solution due to sorption or reaction, and the tortuosity of the material's pore structure. Diffusion rates can be easily predicted when these factors are constant; however, this is not the case for heterogeneous natural materials and the complex solutions derived from many hazardous wastes. When fluid flow is also present, the transport of hazardous materials in heterogeneous geological materials becomes even more difficult to predict. For actinide elements, the coexistence of multiple oxidation states, colloidal species, and numerous complexes in ground- or waste-water solutions suggests that a range also exists for molecular diffusivity, reactivity, and sorptivity. The physical structure of Topopah Spring tuff, and other rocks, often includes void spaces on scales from grain boundaries and intergranular pore spaces to fractures that are centimeters in width. Movement of aqueous species within the rock then depends on the effective length of the voids and their interconnectedness. Void spaces may be filled with secondary phases and fractures lined with precipitates. Differing sorptive mechanisms can also result in large differences between minerals or aqueous species for reversibility and kinetics of sorption. The author measured diffusive transport of ${ }^{235} \mathrm{U},{ }^{238} \mathrm{U}$, and ${ }^{239} \mathrm{Pu}$ tracers in groundwater within saturated tuff rocks on spacial scales from $0.1 \mu \mathrm{m}$ to $\mathrm{cm}$. She found that regions of greater actinide concentration and faster transport are associated with either greater porosity, identifiable micro-fractures, or concentrations of specific elements such as $\mathrm{Li}$. She also found that addition of sodium bicarbonate to solution increased the apparent diffusivity by one to two orders of magnitude and increased the abundance of colloidal sized particles. 2 refs.

480 (LA-12325-C, pp. 43-74) Current adsorption models and open issues pertaining to performance assessment. Serne, R.J. (Pacific Northwest Lab., Richland, WA (US)). Los Alamos National Lab., NM (United States). Aug 1992. (CONF-9009350-: DOE Yucca Mountain site characterization project radionuclide adsorption workshop, Los Alamos, NM (United States), 11-12 Sep 1990). In Proceedings of the DOEYucca Mountain Site Characterization Project Radionuclide Adsorption Workshop at Los Alamos National Laboratory, September 11-12, 1990. 238p. Order Number DE92041241. Source: OSTI; NTIS; INIS.
Recently several articles have been published that question the appropriateness of the distribution coefficient $\left(R_{d}\right)$ concept to quantify radionuclide migration. Several distinct issues are raised by various critics. In this paper the author provides some perspective on issues surrounding the modeling of nuclide retardation. The first section defines adsorption terminology and discusses various adsorption processes. The next section describes five commonly used adsorption conceptual models, specifically emphasizing what attributes that effect adsorption are explicitly accommodated in each model. The author also reviews efforts to incorporate each adsorption model into performance assessment transport computer codes. The five adsorption conceptual models are (1) the constant $R_{d}$ model, (2) the parametric $R_{d}$ model, (3) isotherm adsorption models, (4) mass action adsorption models, and (5) surface complexation with electrostatics models. The final section discusses the adequacy of the distribution ratio concept, the adequacy of transport calculations that rely on constant retardation factors and the status of incorporating sophisticated adsorption models into transport codes. 86 refs., 1 tab.

481 (LA-12325-C, pp. 77-90) Sorption of cesium and strontium by zeolite single crystals. Burns, R.G. (Massachusetts Inst. of Technology, Cambridge (United States)); Wood, V.M.; Morgenstein, M.E. Los Alamos National Lab., NM (United States). Aug 1992. (CONF. 9009350-: DOEYucca Mountain site characterization project radionuclide adsorption workshop, Los Alamos, NM (United States), 11-12 Sep 1990). In Proceedings of the DOEYucca Mountain Site Characterization Project Radionuclide Adsorption Workshop at Los Alamos National Laboratory, September 11-12, 1990. 238p. Order Number DE92041241. Source: OSTI; NTIS; INIS.

The aspect ratios of crystals of platey clinoptilolite and fibrous mordenite observed in mineral assemblages coating fractures through tuffs at Yucca Mountain, Nevada, influence the sorption properties of these two zeolites. The crystallographic dependencies of cation exchange reactions have been demonstrated in clinoptilolite by reacting $\mathrm{CsCl}$ with oriented single crystals mounted on (100), (010), (001) and (101) faces. Competing cation exchange reactions involving $\mathrm{Cs}^{+}, \mathrm{Sr}^{2+}$ and $\mathrm{Ba}^{2+}$, as well as $\mathrm{Cs}^{+}$in $\mathrm{NaCl}$ or $\mathrm{NaHCO}_{3}$ solutions, were performed on the oriented zeolite crystals. Reactions were carried out at $60^{\circ} \mathrm{C}$ for 1 to 8 weeks in a shaking water bath with dissolved metal chloride solutions ranging in concentrations from $1 \mathrm{M}$ to $10^{-4} \mathrm{M}$. Electron microprobe analyses were performed on the surfaces of the reacted zeolite crystals. In clinoptilolite, cation exchange is initially retarded on (010) faces which are nominal to the one direction (parallel to the b-axis) along which channels do not exist in the clinoptilolite structure. This orientation effect was particularly severe for $\mathrm{Sr}$, concentrations of which on (010) faces remained $90 \%$ lower than values measured on other crystal faces even when reaction times exceeded 2 months. In competition with $\mathrm{Sr}$ and $\mathrm{Ba}$, the uptake of $\mathrm{Cs}$ into clinoptilolite was lowered significantly (and vice versa for $\mathrm{Ba}$ and $\mathrm{Sr}$ ), particularly in the presence of $\mathrm{Ba}$. The addition of $1 \mathrm{M}$ $\mathrm{NaCl}$ did not significantly affect the relative concentrations of these competing cations in reacted zeolite crystals. In $\mathrm{NaHCO}_{3}$ solutions, however, the $\mathrm{Cs}$ uptake was lowered significantly. Although clinoptilolite has a very high selectivity for $\mathrm{Cs}^{+}$compared to other cations, competition with $\mathrm{Sr}^{2+}$ and $\mathrm{Ba}^{2+}$ reduces the concentration of $\mathrm{Cs}^{+}$exchanged into this zeolite. 31 refs., 11 figs. 
482 (LA-12325-C, pp. 111-123) Transport of reactive tracers by unsaturated flow using field and column experiments. Porro, I. (Idaho National Engineering Lab., Idaho Falls (US)); Wierenga, P.J. Los Alamos National Lab., NM (United States). Aug 1992. (CONF-9009350-: DOE/Yucca Mountain site characterization project radionuclide adsorption workshop, Los Alamos, NM (United States), 11-12 Sep 1990). In Proceedings of the DOENucca Mountain Site Characterization Project Radionuclide Adsorption Workshop at Los Alamos National Laboratory, September 11-12, 1990. 238p. Order Number DE92041241. Source: OSTI; NTIS; INIS.

Tracer experiments have been conducted in the laboratory as well as in the field, but few experiments have been performed to verify how well laboratory determined transport parameters can be used for field scale predictions. This study deals with the measurement and prediction of tritium, chromium and boron movement through unsaturated laboratory soil columns (diameter $5 \mathrm{~cm}$, length $30 \mathrm{~cm}$ ), through a field column (diameter $92 \mathrm{~cm}$, length $600 \mathrm{~cm}$ ); and through an undisturbed field profile (down to $600 \mathrm{~cm}$ ). Laboratory determined dispersivity values were approximately $1 / 5$ the value for the field column. Retardation factors were similar in both size columns, but a first-order irreversible rate coefficient used in the prediction of chromium transport was an order of magnitude larger in the laboratory column than in the field column, making predictions of chromium transport in the field column based on laboratory column data erroneous. With dispersivities determined in the field column, laboratory column parameters could be used to accurately predict field column boron break-through curves. The models and parameters used in the predictions will be used to describe boron and chromium movement in the field profile. 19 refs., 5 figs.

483 (LA-12325-C, pp. 125-175) Transport in unsaturated flow systems using centrifuge techniques. Conca, J. (Washington State Univ., Richland (US)). Los Alamos National Lab., NM (United States). Aug 1992. (CONF9009350-: DOE/Yucca Mountain site characterization project radionuclide adsorption workshop, Los Alamos, NM (United States), 11-12 Sep 1990). In Proceedings of the DOENucca Mountain Site Characterization Project Radionuclide Adsorption Workshop at Los Alamos National Laboratory, September 11-12, 1990. 238p. Order Number DE92041241. Source: OSTI; NTIS; INIS.

This report is a compilation of results from investigations on unsaturated flow and diffusion using the Unsaturated Flow Apparatus (UFA) in combination with other techniques at the Washington State University Tri-Cities Earth and Environmental Sciences Laboratory. These results bear directly on the goals of the Radionuclide Adsorption Workshop concerning experimental determination of unsaturated transport properties as stated in the First Report to the US congress and the US Department of Energy from the Nuclear Waste Technical Review Board. Transport parameters (diffusion coefficients, $D(\theta)$, hydraulic conductivities, $K(\theta)$, and retardation factors, $R_{t}$ ) have been experimentally determined in unsaturated gravel, soil, bentonite and whole rock over a wide range of water contents in order to construct relationships of water content to each parameter for use in modeling of flow and transport in the near-field, far-field, and backfill environments. Once the water content was fixed at the target value and the system had achieved hydraulic steady-state, transport parameters were determined from associated methods, e.g., (1) the electrical conductivity of the sample was measured using a $1 \mathrm{kHz}$ conductivity bridge and the diffusion coefficient calculated from the electrical conductivity using the Nernst-Einstein equation; (2) hydraulic conductivity was determined from the driving force and flux density; (3) the effluent was monitored/collected/ analyzed for chemical interactions and retardation effects. These parameters have been investigated on different samples over the past two years since construction of the UFA. Project goals and specific milestones have resulted in diffusion coefficients of unsaturated gravel and soil being the most extensively studied parameter, but the UFA was originally designed to determine retardation factors and transient chemical interactions in unsaturated tuff. 35 refs., 20 figs.

484 (LA-12325-C, pp. 177-186) Unsaturated transport of inorganic cations in undisturbed soll columns. Jardine, P.M. (Oak Ridge National Lab., TN (US)); Jacobs, G.K. Los Alamos National Lab., NM (United States). Aug 1992. DOE Contract AC05-84OR21400. (CONF-9009350-: DOE Yucca Mountain site characterization project radionuclide adsorption workshop, Los Alamos, NM (United States), 11-12 Sep 1990). In Proceedings of the DOEMucca Mountain Site Characterization Project Radionuclide Adsorption Workshop at Los Alamos National Laboratory, September 11-12, 1990. 238p. Order Number DE92041241. Source: OSTI; NTIS; INIS.

The unsaturated transport of $\mathrm{Sr}$, Co, and $\mathrm{Ca}$ were studied in undisturbed soil columns $(14 \times 40 \mathrm{~cm})$ of saprolitic shale to evaluate the significance of time-dependent mass transfer and multispecies competitive exchange during transport. Observed breakthrough curves (BTCs) for $\mathrm{Sr}$ and $\mathrm{Co}$ were delayed relative to nonreactive $\mathrm{Br} B T C$ indicating that the former tracers were adsorbed by the soil. Effluent concentrations of $\mathrm{Sr}$ and $\mathrm{Co}$ were modeled with the classical convective- dispersive (CD) equation and nonequilibrium mass transfer considerations did not appear necessary. Cation exchange equilibria relationships obtained from both shake batch and miscible displacement methods adequately described the thermodynamic processes which were prevalent during transport. These results suggest that the preferential transport of a reactive tracer is negligible for the realistic unsaturated conditions used in this study, and that the massive saprolite within the soil is a chemically active constituent during transport of reactive solutes. The implications of these findings for modeling in-situ subsurface contaminant transport are discussed. 7 refs., 9 figs.

485 (LA-12325-C, pp. 187-224) Sensitivity analysis of integrated radionuclide transport based on a threedimensional geochemical/geophysical model. Birdsell, K.H. (Los Alamos National Lab., NM (US)); Campbell, K.; Eggert, K.G.; Travis, B.J. Los Alamos National Lab., NM (United States). Aug 1992. (CONF-9009350-: DOENucca Mountain site characterization project radionuclide adsorption workshop, Los Alamos, NM (United States), 11-12 Sep 1990). In Proceedings of the DOEYucca Mountain Site Characterization Project Radionuclide Adsorption Workshop at Los Alamos National Laboratory, September 11-12, 1990. 238p. Order Number DE92041241. Source: OSTI; NTIS; INIS.

This report presents preliminary transport calculations for radionuclide movement at Yucca Mountain. These calculations are used to study the sensitivity of radionuclide migration to uncertainties in several factors that affect transport through porous media. These factors include spatial distribution of sorption coefficients, recharge rate, dispersivity length scale, radionuclide species, and source term. The simulations were run with TRACRN (Travis and Birdsell), a 
finite-difference porous flow and radionuclide transport code developed for the Yucca Mountain Site Characterization Project. Approximately 30,000 nodes are used to represent the unsaturated and saturated zones underlying the potential repository in three dimensions. Transport calculations for ${ }^{99} \mathrm{Tc},{ }^{135} \mathrm{Cs}$, and ${ }^{129} \mathrm{I}$ are presented. Calculations such as these are used to study the effectiveness of the site's geochemical barriers at a mechanistic level, to determine the sensitivity of radionuclide transport to various transport mechanisms and parameters, and to help guide the geochemical site characterization program. 12 refs., 41 figs., 1 tab.

486 (LA-12325-C, pp. 225-235) Selected issues on geochemical transport modeling for high-level nuclear waste repository. Nguyen, V.V. (EWA, Inc., Minneapolis, MN (US)); Ghanem, G.V.A. Los Alamos National Lab., NM (United States). Aug 1992. (CONF-9009350-: DOEYucca Mountain site characterization project radionuclide adsorption workshop, Los Alamos, NM (United States), 11-12 Sep 1990). In Proceedings of the DOENucca Mountain Site Characterization Project Radionuclide Adsorption Workshop at Los Alamos National Laboratory, September 11-12, 1990. 238p. Order Number DE92041241. Source: OSTl; NTIS; INIS.

This paper presents a brief summary of selected geochemical transport modeling issues facing site characterization for high-level nuclear waste repository. The major concerns focus on solubility, sorption, thermodynamic data bases, and other geochemical parameters needed to ensure that NRC and EPA requirements regarding long-term waste isolation are met. Several geochemical transport modeling assumptions currently being used and code limitations are also discussed. Future modeling efforts are recommended to include rational formulations based on conservation laws and constitutive theory for reactive chemical transport problems in porous/fractured media. As a companion to deterministic approaches, uncertainty analysis has been proposed to address (1) spatial variability in data bases which are prone to errors, and (2) simplified models of the random spatial processes. It is expected that the conjunctive deterministic and stochastic modeling will help organize the geochemical data acquisition process, reduce the uncertainty associated with transport modeling results, and resolve basic issues related to site suitability and repository performance. 7 refs.

487 (LA-12325-C, pp. 237-238) Evaluation of potential hydrologic tracers in tuffs from Yucca Mountain, Nevada. Bowman, R.S. (New Mexico Inst. of Mining and Technology, Socorro (US)). Los Alamos National Lab., NM (United States). Aug 1992. (CONF-9009350-: DOENucca Mountain site characterization project radionuclide adsorption workshop, Los Alamos, NM (United States), 11-12 Sep 1990). In Proceedings of the DOEYucca Mountain Site Characterization Project Radionuclide Adsorption Workshop at Los Alamos National Laboratory, September 11-12, 1990. 238p. Order Number DE92041241. Source: OSTI; NTIS; INIS

Laboratory column studies were performed on five lithologically different crushed volcanic tuff samples from the proposed high-level nuclear waste repository site at Yucca Mountain, Nevada, to evaluate bromide, iodide, and borate as potential groundwater tracers at Yucca Mountain. The studies consisted of an experimental portion and a modeling portion. In the experimental portion, solutions containing tritium, bromide, iodide, and borate were leached through the packed columns under both saturated and unsaturated flow conditions. In addition, four fluorobenzoate tracers and ${ }^{18} \mathrm{O}$ enriched water were added during one of the unsaturated flow experiments as additional tracers. Effluent fractions were collected and analyzed for tracer concentrations and other hydrochemical characteristics. In the modeling portion, the experimental results for tritium were simulated using a flow and transport model, which is operable on USGS computers. 1 ref.

488 (LA-12460-MS) Geology, drilling, and some hydrologic aspects of seismic hazards program core holes, Los Alamos National Laboratory, New Mexico. Gardner, J.N. (Los Alamos National Lab., NM (United States)); Kolbe, T.; Chang, S. Los Alamos National Lab., NM (United States). Jan 1993. 19p. Sponsored by USDOE, Washington, DC (United States). DOE Contract W-7405ENG-36. Order Number DE93011473. Source: OSTI; NTIS; GPO Dep.

As part of the Los Alamos National Laboratory's Seismic Hazards Investigations Program, we have cored four holes, as follows: SHB-1 at TA-55 to 700 feet; SHB-2 at TA-3 to 200 feet; SHB-3 at TA-16 to 860 feet; and, SHB-4 at TA-18 to 200 feet. In that the near-surface seismic velocity structure of the holes is the subject of other reports, we describe here the lithologies, general aspects of drilling, and some hydrologic implications of the core holes. All four holes penetrated variably welded Tshirege Member of the Bandelier Tuff. Beneath two deeper holes encountered thick sequences of epiclastic sands and gravels, with minor interbeds of Cerro Toledo Rhyolite, on top of the dominantly nonwelded Otowi Member of the Bandelier Tutf. Beneath the Otowi was basalt at TA-55 and Puye Formation sands and gravels at TA-16. Two of the core holes (SHB-3 at TA16 and SHB-4 at TA-18) appear to have encountered groundwater. The holes were all continuously cored with conventional wireline diamond coring techniques. Maintaining high percentage core recovery in nonwelded tuff and loose formations with air as the circulating fluid proved impossible. Light muds, however, improved recovery in these zones considerably. A variety of bits were tested, but none yieided consistent results in the alternating hard and soft rock conditions found beneath the Laboratory.

489 (LA-12522-C, pp. 23-39) Fission product studles in the symmetric mass region. De Laeter, J.R. (Curtin Univ. of Technology, Perth (AU)); Rosman, K.J.R.; Loss, R.D. Los Alamos National Lab., NM (United States). May 1993. (CONF-9105216-: Symposium on inorganic mass spectrometry, Durango, CO (United States), 7-9 May 1991). In Proceedings of the Altred $O$. Nier symposium on inorganic mass spectrometry. 268p. Order Number DE93014376. Source: OSTI; NTIS; INIS.

Fission yields can be determined by radiochemical or mass spectrometric techniques. Mass spectrometry can provide more accurate data, particularly in the symmetric mass region where the probability of fission is low and uncertainties in isometric ratios occur. Fine structure in the mass distribution can usually only be determined by mass spectrometry. Many of the elements in the valley of symmetry have high ionization potentials and are therefore difficult to measure by solid source mass spectrometry. Analytical techniques have been developed to provide the sensitivity required to measure the small sample sizes available in fission product studies. Cumulative fission yields for ruthenium, palladium, cadmium, tin, and tellurium have been 
measured by mass spectrometry for the thermal and epicadmium fission of ${ }^{233} \mathrm{U}$ and for thermal and epicadmium fission of ${ }^{239} \mathrm{Pu}$. These fission yields, which span the mass range $101 \leq A \leq 130$, can be combined to give a mass yield curve for ${ }^{235} \mathrm{U}$ in the valley region, which is symmetrical about $A=116.8$ and exhibits fine structure in the mass 113 to 114 region. Fine structure in ${ }^{233} U$ is also present at mass 111. Mass spectrometric determinations of the fission yields of uranium ore at the Oklo mine site in Gabon enable the nuclear parameters of this natural reactor to be evaluated. This in turn enables the amounts of fission products produced in the reactor zone and the surrounding rocks enables an assessment to be made of the efficiency of this geological repository for containing radioactive waste. The elemental abundances can be determined by isotope dilution mass spectrometry. Unfortunately, the paucity of good fission yield data available for ${ }^{238} \mathrm{U}$ by fast neutrons is a severe constraint in this evaluation.

490 (LA-SUB-93-64) Boron adsorption on hematite and clinoptilolite. Gainer, G.M. Los Alamos National Lab. NM (United States); Texas Univ., El Paso, TX (United States). [1993]. 124p. Sponsored by USDOE, Washington, DC (United States). DOE Contract W-7405-ENG-36. Order Number DE93008920. Source: OSTI; NTIS (documentation only); ESTSC (complete software package), P.O. Box 1020 , Oak Ridge, TN 37831-1020; INIS; GPO Dep.

Thesis submitted by G.M. Gainer to University of Texas, El Paso, Texas.

This thesis describes experiments performed to determine the suitability of boron as a potential reactive tracer for use in saturated-zone $\mathrm{C}$-well reactive tracer studies for the Yucca Mountain Project (YMP). Experiments were performed to identify the prevalent sorption mechanism of boron and to determine adsorption of boron on hematite and clinoptilolite as a function of $\mathrm{pH}$. These minerals are present in the Yucca Mountain tuff in which the C-well studies will be conducted. Evaluation of this sorption mechanism was done by determining the equilibration time of boron-mineral suspensions, by measuring changes in equilibrium to titrations, and by measuring electrophoretic mobility. Experiments were performed with the minerals suspended in $\mathrm{NaCl}$ electrolytes of concentrations ranging from $0.1 \mathrm{~N} \mathrm{NaCl}$ to 0.001 $\mathrm{N} \mathrm{NaCl}$. Experimentalconditions included $\mathrm{pH}$ values between 3 and 12 and temperature of about $38^{\circ} \mathrm{C}$.

491 (LA-SUB-93-83) Characterization of flow in fractured tuff using computerized tomography. Felice, C.W. (Terra Tek, Inc., Salt Lake City, UT (United States)); Sharer, J.C. Los Alamos National Lab., NM (United States); Terra Tek, Inc., Salt Lake City, UT (United States). Sep 1991. 40p. Sponsored by USDOE, Washington, DC (United States). DOE Contract W-7405-ENG-36. (TR-92-27). Order Number DE93008910. Source: OSTI; NTIS; INIS; GPO Dep.

The objective of this effort was to demonstrate TerraTek's capability to use $X$-ray computerized tomography (CT) to observe fluid flow down a fracture and rock matrix imbibition in a sample of Bandelier tuff. To accomplish the objective, a tuff sample $152.4 \mathrm{~mm}$ long and $50.8 \mathrm{~mm}$ in diameter was prepared. A portion of the sample was artificially fractured and coupled to a section of matrix material so that the fracture was not exposed. Water was flowed through the sample at five flow rates and CT scanning performed at set intervals during the flow. Cross sectional images and longitudinal reconstructions were built and saturation profiles calculated for the sample at each time interval at each flow rate. The results showed that for the test conditions, the fracture was not a primary pathway of fluid flow down the sample. Fluid flow was governed by the high imbibition capability of the rock matrix material.

492 (LA-SUB-93-118) Laboratory analysis of hydraulic properties of volcanic tuff samples. Los Alamos National Lab., NM (United States); Stephens (Daniel B.) and Associates, Inc., Albuquerque, NM (United States). 4 Dec 1991. 82p. Sponsored by USDOE, Washington, DC (United States). DOE Contract W-7405-ENG-36. Order Number DE93012082. Source: OSTI; NTIS; GPO Dep.

Daniel B. Stephens and Associates, Inc. (DBS\&A) was requested by LANL to perform laboratory analysis for properties of Tuff samples, as outlined in Subcontract No. 9XT1-X1785-1. The scope of work included conducting the following tasks Sample preparation; Dry bulk density and calculated porosity; Saturated hydraulic conductivity; Moisture characteristics; Air permeability; and Particle density.

493

(LA-SUB-93-185) Colloid transport codenuclear user's manual. Jain, R. (New Mexico Univ., Albuquerque, NM (United States)). Los Alamos National Lab., NM (United States); New Mexico Univ., Albuquerque, NM (United States). 3 Apr 1992. 84p. Sponsored by USDOE, Washington, DC (United States). DOE Contract W. 7405-ENG-36. Order Number DE93018276. Source: OSTI; NTIS; INIS; GPO Dep.

This report describes the CTCN computer code, designed to solve the equations of transient colloidal transport of radionuclides in porous and fractured media. This Fortran 77 package solves systems of coupled nonlinear differential equations with a wide range of boundary conditions. The package uses the Method of Lines technique with a special section which forms finite-difference discretizations in up to four spatial dimensions to automatically convert the system into a set of ordinary differential equations. The CTCN code then solves these equations using a robust, efficient ODE solver. Thus CTCN can be used to solve population balance equations along with the usual transport equations to model colloid transport processes or as a general problem solver to treat up to four-dimensional differential systems.

494 (LA-SUB-93-231) CTCN: Colloid transport code - nuclear: A user's manual. Jain, R. Los Alamos National Lab., NM (United States). [1993]. 33p. Sponsored by USDOE, Washington, DC (United States). DOE Contract W-7405-ENG-36. Order Number DE93040570. Source: OSTI; NTIS; INIS; GPO Dep.

This report describes the CTCN computer code, designed to solve the equations of transient colloidal transport of radionuclides in porous and fractured media. This Fortran 77 package solves systems of coupled nonlinear differentialalgebraic equations with a wide range of boundary conditions. The package uses the Method of Lines technique with a special section which forms finite-difference discretizations in up to four spatial dimensions to automatically convert the system into a set of ordinary differential equations. The CTCN code then solves these equations using a robust, efficient ODE solver. Thus CTCN can be used to solve population balance equations along with the usual transport equations to model colloid transport processes or as a general problem solver to treat up to four-dimensional differential-algebraic systems.

495 (LA-SUB-93-256) Neptunium(V) sorption on quartz and albite in aqueous suspension: Annual progress report. Kohler, M. (Stanford Univ., CA (United States). Dept. of Civil Engineering); Leckie, J.O. Los Alamos 
National Lab., NM (United States); Stanford Univ., CA (United States). Dept. of Civil Engineering. Oct 1991. 35p. Sponsored by USDOE, Washington, DC (United States). DOE Contract W-7405-ENG-36. Order Number DE93040587. Source: OSTI; NTIS; INIS; GPO Dep.

The behavior of neptunium in the subsurface environment is of interest since neptunium isotopes are included in nuclear waste. Previous work investigated the sorption behavior of $\mathrm{Np}$ onto $\alpha-\mathrm{Fe}_{2} \mathrm{O}_{3}$ (hematite), an accessory mineral of the Yucca Mountain repository. The work reported herein involves the much more abundant silicate minerals quartz and albite, and is a logical continuation of the ongoing task. In previous work increased sorption was observed in systems containing hematite and EDTA, a ligand which acts as a surrogate for organic complexing agents. In addition, increased partial pressures of $\mathrm{CO}_{2}$ are common in many ground waters and the effects of carbonate on sorption of radionuclides have to be studied as well. At concentration levels of $10^{-7} \mathrm{M}, \mathrm{Np}(\mathrm{V})$ does not adsorb strongly on quartz and albite up to $\mathrm{pH}$ values of approximately 9 at solid/ solution ratios of 30 to $40 \mathrm{~g} /$. Significant adsorption (> 20\%) occurs on both minerals only at $\mathrm{pH}>9$. Pretreatment of albite affects the sorption behavior of this mineral at $\mathrm{pH}>9$, possibly due to the formation of secondary mineral phases at the albite surface. EDTA does not adsorb on quartz at concentrations of $10^{-6} \mathrm{M}$. In the presence of $50{ }_{\mu} \mathrm{M}$ EDTA, $\mathrm{Np}(\mathrm{V})$ sorption seems to be restricted. EDTA at the $10^{-6} \mathrm{M}$ level adsorbs onto albite to an appreciable degree at $\mathrm{pH}$ values < 7.5. One $\mu \mathrm{M}$ EDTA has no effect on $\mathrm{Np}(\mathrm{V})$ adsorption onto albite. Carbonate species adsorb on quartz and albite, both cases showing a maximum in sorption at $\mathrm{pH} 6.5$ to 7 where $\mathrm{HCO}_{3}{ }^{-}$is the predominant solution species.

496 (LA-UR-92-2577) Preliminary modeling of moisture movement in the tuff beneath Mortandad Canyon, Los Alamos National Laboratory. Geddis, A.M. (Arizona Univ., Tucson, AZ (United States). Dept. of Hydrology). Los Alamos National Lab., NM (United States). 5 . Aug 1992. 69p. Sponsored by USDOE, Washington, DC (United States). DOE Contract AC05-76OR00033. Order Number DE94000628. Source: OSTI; NTIS; INIS; GPO Dep.

An area of upper/middle Mortandad Canyon on the Los Alamos National Laboratory is modeled in cross-section. UNSAT2, a finite element model (FEM) is used to predict moisture movement. Hydraulic characteristics of the tuff are described by van Genuchten parameters determined from laboratory tests on cores taken from a borehole within the cross-section. Material properties are distributed horizontal planar in space to cover the solution domain with required initial conditions. An estimate of seepage flux from a thin perched alluvial aquifer into the upper surface of the tuff is taken from a lumped parameter model. Moisture redistribution for a ponded boundary condition and a larger flux is investigated. A composite simulation using material properties from two separate coreholes is also evaluated.

497 (LBL-29700, pp. 89-90) Geological problems in radioactive waste isolation - A world wide review. Witherspoon, P.A. (Lawrence Berkeley Lab., CA (United States)). Lawrence Berkeley Lab., CA (United States). Jun 1991. In Earth Sciences Division annual report 1990. 197p. Order Number DE92000647. Source: OSTI; NTIS; INIS.

The problem of isolating radioactive wastes from the biosphere presents specialists in the earth sciences with some of the most complicated problems they have ever encountered. This is especially true for high-level waste (HLW), which must be isolated in the underground and away from the biosphere for thousands of years. The most widely accepted method of doing this is to seal the radioactive materials in metal canisters that are enclosed by a protective sheath and placed underground in a repository that has been carefully constructed in an appropriate rock formation. Much new technology is being developed to solve the problems that have been raised, and there is a continuing need to publish the results of new developments for the benefit of all concerned. Table 1 presents a summary of the various formations under investigation according to the reports submitted for this world wide review. It can be seen that in those countries that are searching for repository sites, granitic and metamorphic rocks are the prevalent rock type under investigation. Six countries have developed underground research facilities that are currently in use. All of these investigations are in saturated systems below the water table, except the United States project, which is in the unsaturated zone of a fractured tuff.

498 (LBL-29700, pp. 122-123) Studies of the mobility of uranium and thorium in Nevada Test Site tuff. Wollenberg, H.A. (Lawrence Berkeley Lab., CA (United States)); Flexser, S.; Smith, A.R. Lawrence Berkeley Lab., CA (United States). Jun 1991. In Earth Sciences Division annual report 1990. 197p. Order Number DE92000647. Source: OSTI; NTIS; INIS.

Hydro-geochemical processes must be understood if the movement of radionuclides away from a breached radioactive waste canister is to be modeled and predicted. In this respect, occurrences of uranium and thorium in hydrothermal systems are under investigation in tuff and in rhyolitic tuff that was heated to simulate the effects of introduction of radioactive waste. In these studies, high-resolution gamma spectrometry and fission-track radiography are coupled with observations of alteration mineralogy and thermal history to deduce the evidence of, or potential for movement of, $U$ and Th in response to the thermal environment. Observations to date suggest that $U$ was mobile in the vicinity of the heater but that localized reducing environments provided by $\mathrm{Fe}-\mathrm{Ti}$ Mn-oxide minerals concentrated $U$ and thus attenuated its migration.

499 (LBL-33662) The Nagra-DOE Cooperative Project. Long, J.C.S. (Lawrence Berkeley Lab., CA (United States)); Levitch, R.A.; Zuidema, P. Lawrence Berkeley Lab., CA (United States). [1993]. 6p. Sponsored by USDOE, Washington, DC (United States);Swiss National Cooperative for the Storage of Nuclear Waste, Baden (Switzerland). DOE Contract AC03-76SF00098. (CONF-930408-51: International high-level radioactive waste management conference, Las Vegas, NV (United States), 25-29 Apr 1993). Order Number DE93010432. Source: OSTI; NTIS; INIS; GPO Dep.

The Nagra-DOE Cooperative (NDC-1) research program was sponsored by the US Department of Energy (DOE) through the Lawrence Berkeley Laboratory ( $L B L)$, and the Swiss Nationale Genossenschaft fuer die Lagerung radioaktiver Abfaella (Nagra). Scientists participating in this project explored the geological, geophysical, hydrological, geochemical, and structural effects anticipated from the use of a rock mass as a geologic repository for nuclear waste. Six joint tasks were defined and are described briefly below. Tasks $1,2,3$ and 5 were concerned with the characterization of fractured rock. Task 5 in particular was focused on investigations at the Grimsel Underground Laboratory in the Swiss Alps. Tasks 2 and 6 focused on the phenomenology associated with storing radioactive waste underground. 
500 (NAGRA-NTB-90-19) The regional geology, mineralogy and geochemistry of the Pocos de Caldas alkaline caldera complex, Minas Gerais, Brazil. Schorscher, H.D. (Sao Paulo Univ., SP (Brazil). Inst. de Geociencias); Shea, M.E. Nationale Genossenschaft fuer die Lagerung Radioaktiver Abfaelle (NAGRA), Baden (Switzerland). Jan 1991. 47p. (SKB-TR-90-10; UK-DOE-WR-90-041.). Source: Available from Nagra, $\mathrm{CH}-5401$ Baden, Switzerland.

Pocos de Caldas Report No. 1.

The Pocos de Caldas alkaline complex, the largest in South America, is circular-shaped with a mean diameter of about $33 \mathrm{~km}$. It is one of the Mesozoic alkaline occurrences of south-eastern Brazil that developed from the Upper Jurassic onwards, during continental break-up and drift. It comprises a suite of alkaline volcanic and plutonic rocks (mainly phonolites and nepheline syenites) with normal background amounts of $\mathrm{U}$, Th and rare-earth elements (REEs). The evolutionary history began with major early volcanism involving ankaratrites, phonolite lavas and volcanoclastics, followed by caldera subsidence and nepheline syenite intrusions forming minor ring dykes, various intrusive bodies and circular structures. Finally, eudialyte nepheline syenites and phonolites, strongly enriched in incompatible elements, were emplaced. The regional rock studies were focussed on the 'status quo' properties of the intermediate nephelinic suite with respect to the subsequent more local hydrothermal and final weathering-related processes. They included petrographic, mineralogical, goeochemical and isotopic studies, in addition to petrophysical parameters. Results showed very little variation for the studied intrusive, subvolcanic nepheline syenites and phonolites. The lack of a major differentiated series may be seen as an argument for a short emplacement history of the intermediate nephelinic suite. Previous and present radiometric age measurements suggest a time span of about $15 \mathrm{Ma}$ for emplacement, much too long if compared to modern volcanoes. The end of the magmatic and hydrothermalmineralizing events is likely fixed by the Ar-Ar dating of an unmineralized lamprophyre dyke intrusion at the site of the uranium mine (76 Ma). (author) 8 figs., 6 tabs., 73 refs.

501 (NAGRA-NTB-90-20) Mineralogy, petrology and geochemistry of the Pocos de Caldas analogue study sites, Minas Gerais, Brazil. I. Osamu Utsumi uranium mine: Pocos de Caldas Report No. 2. Waber, N. (Bern Univ., Mineralogisch-Petrographisches Inst., Bern (Switzerland)); Peters, T.; Schorscher, H.D. Nationale Genossenschaft fuer die Lagerung Radioaktiver Abfaelle (NAGRA), Baden (Switzerland). Jan 1991. [527p.] Source: Available from Nagra, $\mathrm{CH}-5430$ Wettingen, Switzerland.

The lithology of the Osamu Utsumi mirie is composed mainly of a sequence of volcanic and subvolcanic phonolites and nepheline syenite intrusions similar to those of the Pocos de Caldas caldera complex; volcanic breccia pipes about $80 \mathrm{~m}$ in diameter also occur, characterised by U-Th$\mathrm{Zr}$-REE mineralisation concentrated in the matrix. A strong hydrothermal alteration, related to the formation of the breccias, has resulted in the potassic alteration and pyritisation of the phonolites and syenites, with a low-grade mineralisation of disseminated pitchblende. The potassic alteration has transformed all feldspars into pure potash feldspars, nepheline into illite and kaolinite, and clinopyrexenes, which are the primary REE-bearers, into mixtures of $\mathrm{TiO}_{2}$-rich minerals, clay minerals and pyrite. The enrichment of $K, S, U$, $\mathrm{Th}, \mathrm{Pb}, \mathrm{Rb}, \mathrm{Ba}$ and $\mathrm{Mo}$ was accompanied by a strong de. pletion in $\mathrm{Ca}, \mathrm{Na}, \mathrm{Mg}$ and $\mathrm{Sr}$. Fluid inclusion data indicate temperatures around $250^{\circ} \mathrm{C}$ and a $\mathrm{KCl}-\mathrm{H}_{2} \mathrm{O}$ mixture with approximately $7 \mathrm{wt} \% \mathrm{KCl}$ for the hydrothermal fluids. For fluids in the breccia pipes that transported additional $\mathrm{Zr}, \mathrm{Hf}$ and $F$, the inclusions indicate boiling and give temperatures of $210^{\circ} \mathrm{C}$ with $40-45 \mathrm{wt} . \% \mathrm{KCl}$ for a $\mathrm{KCl}-\mathrm{NaCl}-\mathrm{H}_{2} \mathrm{O}$ brine containing $\mathrm{FeSO}_{4}$ and $\mathrm{KF}$. Ultramafic dykes (dated to 76 Ma) with carbonatitic affiliation put a younger age limit on the hydrothermal event. (author) figs., tabs., refs.

502 (NAGRA-NTB-90-21) Mineralogy, petrology and geochemistry of the Pocos de Caldas analogue study sites, Minas Gerais, Brazil: II. Morro do Ferro. Waber, M. (Bern Univ., Mineralogisch-Petrographisches Inst., Switzerland (Switzerland)). Nationale Genossenschaft fuer die Lagerung Radioaktiver Abfaelle (NAGRA), Baden (Switzerland). Jan 1991. 120p. (SKB-TR-90-12; UK-DOEWR-90-043.). Source: Available from Nagra, CH-5430 Wettingen, Switzerland.

Pocos de Caldas Report No. 3.

The thorium-rare-earth element deposit at Morro do Ferro is of supergene origin and was formed under lateritic weathering conditions. The ore body forms shallow NW-SE elongated argillaceous lenses that extend from the top of the hill downwards along its south-eastern slope. The deposit is capped by a stockwork of magnetite veins which have protected the underlying, highly argillaceous host rock from excessive erosion. The surrounding country rocks comprise a sequence of subvolcanic phonolite intrusions that have been strongly altered by hydrothermal and supergene processes. From petrological, mineralogical and geochemical studies and mass balance calculations, it is inferred that the highly weathered host rock was originally carbonatic in composition and was initially enhanced in thorium and rareearth elements compared to the surrounding silicate rocks. Intrusion of the carbonatite produced fenitic alteration of the surrounding phonolites, consisting of an early potassic alteration followed by a vein-type Th-REE mineralization with associated fluorite, carbonate, pyrite and zircon. Subsequent lateritic weathering has completely destroyed the carbonatite, forming a residual supergene enrichment of Th and REEs. Initial weathering of the carbonatite leading to solutions enriched in carbonate and phosphate may have appreciably restricted the dissolution of the primary Th-REE phases. Strongly oxidic weathering has resulted in a fractionation between cerium and the other light rare-earth elements. $\mathrm{Ce}^{3+}$ is oxidized to $\mathrm{Ce}^{4+}$ and retained together with thorium by secondary mineral formation and adsorption on poorly orystalline iron- and aluminium-hydroxides. In contrast, the trivalent LREEs are retained to a lesser degree and are thus more available for secondary mineral formation and adsorption at greater depths down the weathering column. (author) figs., tabs., 60 refs.

503 (NAGRA-NTB-90-22) Isotopic geochemical characterization of selected nepheline syenites and phonolites from the Pocos de Caldas alkaline complex, Minas Gerais, Brazil. Shea, M.E. (Chicago Univ., IL (United States). Dept. of Geophysical Sciences). Nationale Genossenschaft fuer die Lagerung Radioaktiver Abfaelle (NAGRA), Baden (Switzerland). Jan 1991. 63p. (SKB-TR90-13; UK-DOE-WR-90-048). Source: Available from Nagra, CH-5401 Baden, Switzerland.

Pocos de Caldas Report No. 4.

This paper presents and discusses the isotopic data from the hydrothermal studies of the Pocos de Caldas Natural Analogue Project. The purpose of this study was to elucidate the mass transport of relevant elements and isotopes 
associated with hydrothermal mineralization and alteration at the Osamu Utsumi uranium mine, particularly as applicable to radwaste isolation concerns in the U.S. nuclear waste program. Research efforts were focussed on studying the thermal, chemical and hydrologic nature of the paleohydrothermal regime associated with a breccia pipe at the Osamu Utsumi mine, and related to the geochemical, geochronological and petrological characterization studies of unaltered regional nepheline syenite and phonolite. (author) 16 figs., 7 tabs., 45 refs.

504

(NAGRA-NTB-90-25) Natural radionuclide and stable element studies of rock samples from the Osamu Utsumi mine and Morro do Ferro analogue study sites, Pocos de Caldas, Brazil. MacKenzie, A.B. (Scottish Universities Research and Reactor Centre, Glasgow (United Kingdom)); Scott, R.D.; Linsalara, P.; Miekeley, N.; Osmond, J.K.; Curtis, D.B. Nationale Genossenschaft fuer die Lagerung Radioaktiver Abfaelle (NAGRA), Baden (Switzerland). Jan 1991. 198p. (SKB-TR-90-16; UK-DOEWR-90-041.). Source: Available from Nagra, $\mathrm{CH}-5401$ Baden, Switzerland.

Pocos de Caldas Report No. 7.

This report describes a study of the distribution and behaviour of natural radionuclides and selected stable elements at the Pocos de Caldas natural analogue study sites. At the Osamu Utsumi mine, the study was focussed upon investigation of the behaviour of natural decay series radionuclides and stable elements at the redox fronts which exist in the mine. Uranium nodules from the mine were also analyzed for natural decay series radionuclides in order to characterize their ages and growth rates, and for natural plutonium. At Morro do Ferro, the objective was to provide additional information on the geochemical behaviour of thorium, uranium and the light rare-earth elements and to relate this to the groundwater flow pattern in an attempt zu evaluate the degree of mobilization of these species. A summary review of those aspects of the geochemistry of natural decay series radionuclides relevant to the interpretation of radioactive disequilibrium is provided along with a detailed treatment of mathematical modeling of natural decay series disequilibria in rock-water interactions. The overall study comprised a number of discrete subprojects carried out in five different laboratories and each of these is described in detail. In addition to constituing a self-contained study, the results and conclusions of this work were also used as an input for modelling studies and other aspects of this integrated research programme. (author) figs., tabs., refs.

505 (NAGRA-NTB-90-26) Natural series radionuclide and rare-earth element geochemistry of waters from the Osamu Utsumi mine and Morro do Ferro analogue study sites, Pocos de Caldas, Brazil. Miekeley, N. (Pontificia Univ. Catolica do Rio de Janeiro, RJ (Brazil). Dept. de Quimica); Coutinho de Jesus, H.; Porto da Silveira, C.L.; Linsalata, P.; Morse, R.; Osmond, K. Nationale Genossenschaft fuer die Lagerung Radioaktiver Abfaelle (NAGRA), Baden (Switzerland). Jan 1991. 90p. (SKB-TR90-17; UK-DOE-WR-90-048.). Source: Available from Nagra, CH-5430 Wettingen, Switzerland.

Pocos de Caldas Report No. 8.

Data are presented on natural series radionuclides and rare-earth elements in prefiltered near-surface and deep groundwaters from the Osamu Utsumi uranium mine and Morro do Ferro analogue study sites. In the Osamu Utsumi uranium mine, very high concentrations of uranium were measured in near-surface waters. In deep groundwaters concentrations of this elements are typically between 3 and $10 \mu \mathrm{g} /$. The reduced concentrations of uranium in the Morro do Ferro host rock are reflected in the considerably lower concentrations of this element in waters from this environment. The concentrations of ${ }^{232} \mathrm{Th}$ in groundwaters from both sites are very low and generally $<0.1 \mu \mathrm{g} /$. However, they can be higher, by a factor of 100 or more, in superficial waters rich in humic compounds or acidic in character. Pronounced disequilibria were measured between ${ }^{234} \mathrm{U}$ and ${ }^{238} \mathrm{U}$ isotopic activities in groundwaters which are characterised by an excess of ${ }^{234} \mathrm{U}$ due to preferential leaching of this isotope and/or recoil effects. The ${ }^{234} \mathrm{U} /{ }^{238} \mathrm{U}$ activity ratio is lower in the superficial waters than it is in the deeper groundwaters. This is because, in moving towards the surface, the groundwater picks up a greater, nen-fractionating leach component of uranium in the zone of higher redox potential. Due to the extremely low solubility of thorium and its strong tendency to sorb on suspended particles, the ${ }^{230} \mathrm{Th}$ ${ }^{234} \mathrm{U}$ activity ratios in groundwaters are also very low. Rareearth element concentrations in groundwaters from both sites are typically in the range between $1-50 \mu \mathrm{g} / \mathrm{l}$ for the light rare-earth elements and $0.001-0.1 \mu \mathrm{g} / \mathrm{f}$ for the heavy rareearth elements, but can be much higher in surface waters with high complexation capacities, as observed for thorium. The chondrite-normalised distribution patterns of the REEs in water samples are similar to those observed in the bedrock, indicating congruent dissolution and sorption of these elements.

506 (NAGRA-NTB-90-27) Chemical and physical characterisation of suspended particles and colloids in waters from the Osamu Utsumi mine and Morro do Ferro analogue study sites, Pocos de Caldas, Brazil. Miekeley, N. (Pontificia Univ. Catolica do Rio de Janeiro, RJ (Brazil). Dept. de Quimica); Coutinho de Jesus, H.; Porto da Silveira, C.L.; Degueldre, C. Nationale Genossenschaft fuer die Lagerung Radioaktiver Abfaelle (NAGRA), Baden (Switzerland). Jan 1991. 87p. (SKB-TR-90-18; UK-DOEWR-90-049.). Source: Available from Nagra, $\mathrm{CH}-5401$ Baden, Switzerland.

Pocos de Caldas Report No. 9.

Data are presented on suspended particles and colloids in groundwaters from the Osamu Utsumi mine and the Morro do Ferro analogue study sites. Cross-flow ultrafiltration with membranes of different pore sizes $(450 \mathrm{~nm}$ to $1.5 \mathrm{~nm}$ ) was used to prepare colloid concentrates and ultrafiltrates for analyses of major and trace elements and $U$ - and Thisotopic compositions. Additional characterisation of colloidal and particulate material was performed by ESCA, SEM and $X$-ray diffraction. The results obtained indicate the presence of low concentrations ( $<1 \mathrm{mg} / 1)$ of colloids $(1.5-450 \mathrm{~nm}$ ) in these waters, composed mainly of iron/organic species. Minor amounts of $\mathrm{U}$ and some other trace elements $\mathrm{CSi}, \mathrm{Ca}$, $\mathrm{Mg}, \mathrm{Cu}, \mathrm{Zn}, \mathrm{Pb}$ and occasionally $\mathrm{Zr}$ and $\mathrm{Sn}$ ) and significant amounts of $T h$ and REEs were associated with these colloids. U-isotopic measurements indicate element exchange equilibrium between aqueous, colloidal and suspended particle phases. Suspended particles $(>450 \mathrm{~nm}$ ) in the waters show the same trends as the colloids with respect to $U$, Th and REE associations, but elemental concentrations were typically higher by the factor of 1,000 or more. Calculated association ratios (in $\mathrm{ml} . \mathrm{g}^{-1}$ ) are in the order of $10^{4}$ to $10^{5}$ for $U, 10^{5}$ to $10^{6}$ for the REEs and $10^{6}$ to $10^{7}$ for Th. In waters with low $\mathrm{pH}$ and high suiphate content, these ratios are considerably lower. Due to the low concentrations of suspended particles in groundwaters from the Osamu Utsumi 
U-mine (<0.5 $\mathrm{mg} / \mathrm{l})$, these particles carry only a minor amount of $U$ and REEs, but a significant fraction of Th. The suspended particle load in groundwaters from the Morro do Ferro environment is higher than in those from the mine by a factor of 5 to 10 . This suggests that $U$ and the REEs could be transported predominantly by particulate matter. However, there is chemical and mineralogical evidence that these particles have a low capacity for migration. (author) 24 figs., 9 tabs., 46 refs.

507

(NAGRA-NTB-90-29) Testing of geochemical models in the Pocos de Caldas analogue study. Bruno, J. (Royal Inst. of Tech., Dept. of Inorganic Chemistry, Stockholm (Sweden)); Sandino, A.; Cross, J.E.; Eikenberg, J.; McKinley, I.G.; Read, D.; Sellin, P. Nationale Genossenschaft fuer die Lagerung Radioaktiver Abfaelle (NAGRA), Baden (Switzerland). Jan 1991. 82p. (SKB-TR-90-20; UKDOE-WR-90-051.). Source: Available from Nagra, $\mathrm{CH}-5401$ Baden, Switzerland.

Pocos de Caldas Report No. 11.

In order to test the geochemical models used in repository performance assessment, modelling groups were provided with selected major element analyses of Pocos de Caldas groundwaters and asked to predict 'blind' the solubility, speciation and limiting solid for a number of trace elements. This report documents these predictions and compares them to field analyses. These tests illustrate particular strengths and weaknesses in current models/databases and allow recommendations for amendments/improvements to be made. (author) figs., tabs., 16 refs.

508 (NAGRA-NTB-90-30) Testing models of redox front migration and geochemistry at the Osamu Utsumi mine and Morro do Ferro analogue study sites, Pocos de Caldas, Brazil. Cross, J.E. (UKAEA Harwell Lab. (United Kingdom). Chemistry Div.); Haworth, A.; Lichtner, P.C.; McKinley, I.G. (ed.). Nationale Genossenschaft fuer die Lagerung Radioaktiver Abfaelle (NAGRA), Baden (Switzerland). Jan 1991. 88p. (SKB-TR-90-21; UK-DOEWR-90-052.). Source: Available trom Nagra, $\mathrm{CH}-5401$ Baden, Switzerland.

Pocos de Caldas Report No. 12.

Redox fronts occur at a number of locations in repository systems and models have been established to describe their chemical evolution and spatial development. Such models can be tested against detailed observations of the welldeveloped redox fronts at the Osamu Utsumi mine. Simple calculations can explain the formation of redox fronts in very general terms but greatly simplify the processes known to be occuring at such fronts. Coupled transport/chemistry models can provide a better simulation of the fronts, but these are primarily interpretative models which have not yet displayed any convincing predictive abilities. They tend to be rather poor, in particular in simulating trace element chemistry in either solution or solid phases. Interpretative modelling of microbial activity, natural series profiles and trace element distributions gives strong indications of the reasons for the limitations of the chemical modeling. The role of microbial catalysis seems to be very significant in such systems, particularly affecting the redox chemistry of sulphur. Natural series measurements indicate very slow redox front movement at particular sites which could be due to precipitation processes limiting accessible porosity, a point not considered in any of the models. Finally, the trace element distributions strongly suggest immobilisation of many elements as co-precipitates or solid solutions in secondary iron minerals, again a process not considered by current models. (author) 31 figs., 8 tabs., 43 refs.

509 (NAGRA-NTB-90-32) Geochemical modelling of water-rock interactions at the Osamu Utsumi mine and Morro do Ferro analogue study sites, Pocos de Caldas, Brazil. Nordstrom, D.K. (Geological Survey, Menlo Park, CA (USA)); Puigdomenech, I.; McNutt, R.H. Nationale Genossenschaft fuer die Lagerung Radioaktiver Abfaelle (NAGRA), Baden (Switzerland). 1990. 42p. (SKB-TR-90-23; UK-DOE-WR-90-054.). Source: Available from Nagra, $\mathrm{CH}-$ 5401 Baden, Switzerland.

Pocos de Caldas Report No. 14.

Geochemical processes involving water-rock interactions have been modelled using groundwater composition, mineralogical data, ion plots and computations of speciation, non-thermodynamic mass balance and thermodynamic mass transfer for two natural analogue sites near Pocos de Caldas, Brazil: the Osamu Utsumi mine and Morro do Ferro. The main rock type is an alkaline igneous complex composed of volcanic and sub-volcanic phonolites that have been hydrothermally altered and highly weathered. This altered rock mass grades from a laterite at the surface to a saprolite and finally to unweathered, hydrothermally altered bedrock at depth. The mine site contains high concentrations of uranium and Morro do Ferro contains high concentrations of thorium and rare-earths. The reaction models can reproduce the water chemistry and mineral occurences and they were validated by predicting the masses of minerals precipitated and the $\mathrm{pH}$ of the final water. The model computations can also reproduce the $\mathrm{pH}$ and iron concentrations of the water samples during $\mathrm{CO}_{2}$ degassing and iron(II) oxidation from exposure to air. The results from the geochemical reaction models reveal that the dominant processes are production of $\mathrm{CO}_{2}$ in the soil zone through aerobic decay of organic matter, dissolution of fluorite, calcite, K-feldspar, albite and manganese oxides, oxidation of pyrite and sphalerite and precipitation of ferric oxides, silica and kaolinite. Recharge waters are undersaturated with respect to barite and discharging waters and deeper groundwaters are saturated to supersaturated with respect to barite, demonstrating a strong equilibrium solubility control. Strontium isotope data demonstrate that sources other than calcium-bearing minerals are required to account for the dissolved strontium in the ground. These may include $\mathrm{K}$ feldspar, smectite-chlorite mixed-layer clays and goyazite. (author) 24 figs., 4 tabs., 18 refs.

510 (NAGRA-NTB-90-33) The Pocos de Caldas project: summary and implications for radioactive waste management: Pocos de Caldas report no. 15. Chapman, N.A. (INTERA Sciences, Geosciences Group, Melton Mowbray (United Kingdom)); McKinley, I.G.; Shea, M.E.; Smellie, J.A.T. Nationale Genossenschaft fuer die Lagerung Radioaktiver Abfaelle (NAGRA), Baden (Switzerland). Jan 1991. 158p. (SKB-TR-90-24; UK-DOEWR-90-055.). Source: Available from Nagra, $\mathrm{CH}-5430$ Wettingen, Switzerland.

This report provides an overview of the Pocos de Caldas natural analogue study, aspects of which have been described in the previous 14 reports of this series. The first part of this report provides the historical background to the project, describes the research programme developed at the Osamu Utsumi and Morro do Ferro sites and summarises the main findings of the geological, hydrologic and geochemical characterisation work. This is followed by reviews of the four analogue sub-projects - testing geochemical 
models of trace element solubility and speciation, evaluation of models of redox front development and movement, examining the role of natural colloids as a vector for transport of trace elements and appraisal of a modelling approach to quantifying hydrothermal alteration and solute transport processes. Finally, the direct implications of the project to radioactive waste management are discussed along with some valuable spin-off which was identified. Such a large multidisciplinary study proved a very valuable focus for forging contacts between specialists from different disciplines in a manner closely analogous to that required for an integrated site assessment. The iterative development of the modellers' wish lists and the field/lab analytical programme was a key to the success of this project and provides guidelines for site-specific performance assessment. (author) figs., tabs., 26 refs.

511 (NRC-93003273) Ground water of Yucca Mountain: How high can it rise?: Final report. National Research Council, Washington, DC (United States). Panel on Coupled Hydrologic/Tectonic/Hydrothermal Systems at Yucca Mountain. 1992. 231p. Sponsored by USDOE, Washington, DC (United States). DOE Contract ACO188RW00142. Order Number DE93003273. Source: OSTI; NTIS; INIS; GPO Dep.

This report describes the geology, hydrology, and possible rise of the water tables at Yucca Mountain. The possibilities of rainfall and earthquakes causing flooding is discussed.

512 (NUREG-1327) Initial demonstration of the NRC's capability to conduct a performance assessment for a High-Level Waste Repository. Codell, R.; Eisenberg, N.; Fehringer, D.; Ford, W.; Margulies, T.; MoCartin, T.; Park, J.; Randall, J. Nuclear Regulatory Commission, Washington, DC (United States). May 1992. 170p. Sponsored by Nuclear Regulatory Commission, Washington, DC (United States). Source: OSTI; NTIS; INIS; GPO.

In order to better review licensing submittals for a HighLevel Waste Repository, the US Nuclear Regulatory Commission staff has expanded and improved its capability to conduct performance assessments. This report documents an initial demonstration of this capability. The demonstration made use of the limited data from Yucca Mountain, Nevada to investigate a small set of scenario classes. Models of release and transport of radionuclides from a repository via the groundwater and direct release pathways provided preliminary estimates of releases to the accessible environment for a 10,000 year simulation time. Latin hypercube sampling of input parameters was used to express results as distributions and to investigate model sensitivities. This methodology demonstration should not be interpreted as an estimate of performance of the proposed repository at Yucca Mountain, Nevada. By expanding and developing the NRC staff capability to conduct such analyses, NRC would be better able to conduct an independent technical review of the US Department of Energy (DOE) licensing submittals for a high-level waste (HLW) repository. These activities were divided initially into Phase 1 and Phase 2 activities. Additional phases may follow as part of a program of iterative performance assessment at the NRC. The NRC staff conducted Phase 1 activities primarily in CY 1989 with minimal participation from NRC contractors. The Phase 2 activities were to involve NRC contractors actively and to provide for the transfer of technology. The Phase 2 activities are scheduled to start in CY 1990, to allow Sandia National Laboratories to complete development and transfer of computer codes and the Center for Nuclear Waste Regulatory Analyses (CNWRA) to be in a position to assist in the acquisition of the codes.

513 (NUREG/CP-0040, pp. 8-13) Hydrogeologic issues at Yucca Mountain: Findings of a DOE peer review team. Freeze, R.A. (Univ. of British Columbia (CA)). Nuclear Regulatory Commission, Washington, DC (United States). Div. of Regulatory Applications; Southwest Research Inst., San Antonio, TX (United States). Center for Nuclear Waste Regulatory Analyses; Arizona Univ., Tucson, AZ (United States). Dept. of Hydrology and Water Resources. Jun 1993. (CONF-9101106-: 5. flow and transport through unsaturated fractured rock related to high-level radioactive waste disposal, Tucson, AZ (United States), 7-10 Jan 1991). In Proceedings of workshop 5: Flow and transport through unsaturated fractured rock - related to high-level radioactive waste disposal. 238p. Source: OSTI; NTIS; INIS; GPO.

The peer review team (PRT) evaluated work done within the Yucca Mountain Project to develop an understanding of unsaturated zone hydrology at the Yucca Mountain sites, and to provide recommendations to DOE regarding unsaturated zone hydrological investigations at Yucca Mountain. The PRT was specifically asked to consider: matrix flow; fracture flow; gaseous flow; the presence and effectiveness of capillary barriers; the presence and effectiveness of fracture barriers; and saturated-unsaturated ground water travel times. The PRT deliberations emphasize the natural hydrogeological system rather than the response of this system to the emplacement of the repository. Twenty-four conclusions and recommendations were reached. Among the programmatic issues were: need for improved program integration and interagency communication; need for project prioritization procedures within the project; negative impacts of the current quality assurance environment; need for closer coordination of construction activities and research activities so as to prevent undue site disturbance. This paper discusses the additional technical issues raised in the report, including both the unsaturated zone and the saturated zone, with a primary emphasis on the unsaturated zone. 8 refs.

514 (NUREG/CP-0040, pp. 27-36) Nonequilibrium fracture-matrix flow during episodic infiltration events in Yucca Mountain. Buscheck, T.A. (Lawrence Livermore National Lab., NM (US)); Nitao, J.J. Nuclear Regulatory Commission, Washington, DC (United States). Div. of Regulatory Applications; Southwest Research Inst., San Antonio, TX (United States). Center for Nuclear Waste Regulatory Analyses; Arizona Univ., Tucson, AZ (United States). Dept. of Hydrology and Water Resources. Jun 1993. Contract W7405-Eng-48. (CONF-9101106-: 5. flow and transport through unsaturated fractured rock related to high-level radioactive waste disposal, Tucson, AZ (United States), 7-10 Jan 1991). In Proceedings of workshop 5: Flow and transport through unsaturated fractured rock - related to high-level radioactive waste disposal. 238p. Source: OSTI; NTIS; INIS; GPO.

This report examines the impact of nonequilibrium fracture-matrix flow on episodic infiltration events in Yucca Mountain. For both the FMMM and ECM calculations, a ponded boundary condition is maintained at the repository horizon until the liquid front has broken through to the water table. The relative impact of matrix imbibition is examined for the five major hydrostratigraphic units between the repository horizon and the water table. The question of what sequencing of infiltration events gives rise to episodic behavior versus behavior which may be time-aggregated is 
aiso addressed. The implications of nonequilibrium fracturematrix flow on radionuclide transport are briefly discussed. 19 refs., 7 figs., 5 tabs.

515 (NUREG/CP-0040, pp. 54-63) Nonisothermal hydrologic transport study at the Apache Leap Tuff site. Rasmussen, T.C. Nuclear Regulatory Commission, Washington, DC (United States). Div. of Regulatory Applications; Southwest Research Inst., San Antonio, TX (United States). Center for Nuclear Waste Regulatory Analyses; Arizona Univ., Tucson, AZ (United States). Dept. of Hydrology and Water Resources. Jun 1993. (CONF-9101106-: 5. flow and transport through unsaturated fractured rock related to highlevel radioactive waste disposal, Tucson, AZ (United States), 7-10 Jan 1991). In Proceedings of workshop 5: Flow and transport through unsaturated fractured rock - related to high-level radioactive waste disposal. $238 p$. Source: OSTI; NTIS; INIS; GPO.

A field-scale heater test is proposed for investigating coupled hydrologic, thermal, and mechanical processes in unsaturated fractured rock related to the disposal of highlevel radioactive waste in an underground repository. Observations of fluid flow and solute transport in nonisothermal, unsaturated, tractured rock under controlled, experimental conditions are limited, and the proposed experiment will provide data sets for use in verifying conceptual and computer models related to HLW isolation in an environment where substantial quantities of heat energy are produced by HLW. Previous nonisothermal experiments with tuff have demonstrated the need for. additional field scale experiments conducted under controlled initial and boundary conditions using more sophisticated and reliable monitoring systems. 8 figs., 1 tab.

516 (NUREG/CP-0040, pp. 64-68) Apache leap watershed study. Anderson, I. Nuclear Regulatory Commission, Washington, DC (United States). Div. of Regulatory Applications; Southwest Research Inst., San Antonio, TX (United States). Center for Nuclear Waste Regulatory Analyses; Arizona Univ., Tucson, AZ (United States). Dept. of Hydrology and Water Resources. Jun 1993. (CONF9101106-: 5. flow and transport through unsaturated fractured rock related to high-level radioactive waste disposal, Tucson, AZ (United States), 7-10 Jan 1991). In Proceedings of workshop 5: Flow and transport through unsaturated fractured rock - related to high-level radioactive waste disposal. 238p. Source: OSTI; NTIS; INIS; GPO.

The fate of rainfall once it reaches the ground surface is an important characterization parameter since precipitation is an important source term for flow of water through the subsurface. This study provides data sets which will allow estimates of the potential for infiltration, deep percolation, and recharge as the result of rainfall. 3 figs., 1 tab.

517 (NUREG/CP-0040, pp. 69-71) Pneumatic permeability measurements in a fractured, partially saturated environment. Guzman, A.; Sully, M.; Neuman, S.; Lohrstorfer, C. Nuclear Regulatory Commission, Washington, DC (United States). Div. of Regulatory Applications; Southwest Research Inst., San Antonio, TX (United States). Center for Nuclear Waste Regulatory Analyses; Arizona Univ., Tucson, AZ (United States). Dept. of Hydrology and Water Resources. Jun 1993. (CONF-9101106-: 5, flow and transport through unsaturated fractured rock related to highlevel radioactive waste disposal, Tucsion, AZ (United States), 7-10 Jan 1991). In Proceedings of workshop 5:
Flow and transport through unsaturated fractured rock - related to high-level radioactive waste disposal. 238p. Source: OSTI; NTIS; INIS; GPO.

In the context of underground disposal of high-level radioactive wastes, the hydraulic conductivity of the host environment is an extremely important parameter. The research task of the authors addresses the technical design of instrumentation and the theoretical aspects of air flow through fractured, unsaturated rocks. Determinations of the pneumatic permeability are being conducted at different scales in selected boreholes located in unsaturated tuff at the Apache Leap Tuff site. 1 fig.

518 (NUREG/CP-0040, pp. 79-83) Field testing the effectiveness of pumping to remove sulfur hexafluoride traced drilling air from a prototype borehole near superior, Arizona. Peters, C.A. (Denver Federal Center, Lakewood, CO (US)); Striffler, P.; Yang, I.C.; Ferarese, J. Nuclear Regulatory Commission, Washington, DC (United States). Div. of Regulatory Applications; Southwest Research Inst., San Antonio, TX (United States). Center for Nuclear Waste Regulatory Analyses; Arizona Univ., Tucson, AZ (United States). Dept. of Hydrology and Water Resources. Jun 1993. (CONF-9101106-: 5. flow and transport through unsaturated fractured rock related to high-level radioactive waste disposal, Tucson, AZ (United States), 7-10 Jan 1991). In Proceedings of workshop 5: Flow and transport through unsaturated fractured rock - related to high-level radioactive waste disposal. $238 \mathrm{p}$. Source: OSTI; NTIS; INIS; GPO.

The US Geological Survey (USGS), Department of the Interior is conducting studies at Yucca Mountain, Nevada, to provide hydrologic, hydrochemical, and geologic information to evaluate the suitability of Yucca Mountain for development as a high-level nuclear-waste repository. The USGS unsaturated-zone hydrochemistry study involves the collection of gas and water samples from the unsaturated zone for chemical and isotopic analyses. Results from these analyses will aid in the understanding of the movement of gas and water in the rock units at Yucca Mountain. A prototype borehole designated USW UZP5 was drilled by the US Department of Energy, Yucca Mountain Site Characterization Project Office (DOE, YMSCPO) in June 1990 in the Apache Leap Tuff of southcentral Arizona. The hole was dry drilled with air using sulfur hexafluoride $\left(S_{6}\right)$ as a tracer. This drilling method simulated that which will be used to drill boreholes for the collection of gas and water samples at Yucca Mountain. The purpose of tracing the drilling air is to quantify its removal by pumping, prior to sampling of in situ gases. The objectives of our work in Arizona were to: (1) Determine the amount of time and the pumping rates required to remove the $S_{6}$-enriched drilling air without inducing additional atmospheric contamination; (2) collect core samples for uniaxial compression to determine the amount of $\mathrm{SF}_{6}$ gas that penetrated the core during drilling; (3) test the effectiveness of the $\mathrm{SF}_{6}$ injection and sampling system; (4) test the installation and effectiveness of the prototype packer system; and (5) test the effectiveness of several core sealing methods. 1 fig., 1 tab.

519 (NUREG/CP-0040, pp. 88-100) Characterization of rock hydrologic properties using model verification. Flint, A.L. (Geological Survey, Mercury, NV (US)); Richards, K.A.; Flint, L.E. Nuclear Regulatory Commission, Washington, DC (United States). Div. of Regulatory Applications; Southwest Research Inst., San Antonio, TX (United States). Center for Nuclear Waste Regulatory Analyses; Arizona 
Univ., Tucson, AZ (United States). Dept. of Hydrology and Water Resources. Jun 1993. (CONF-9101106-: 5. flow and transport through unsaturated fractured rock related to highlevel radioactive waste disposal, Tucson, $A Z$ (United States), 7-10 Jan 1991). In Proceedings of workshop 5: Flow and transport through unsaturated fractured rock - related to high-level radioactive waste disposal. $238 \mathrm{p}$. Source: OSTI; NTIS; INIS; GPO.

Model simulation of imbibition is proposed as a technique to test the adequacy of moisture characteristic and relative permeability data and the ability of the Brooks and Corey and van Genuchten equations to represent that data. The moisture characteristic data was collected using pressure plate, gas drive and submersible pressure outflow cell techniques. The relative permeability data was collected using centrifuge and gas drive techniques. The various relative permeability and moisture characteristic equations were used in a numerical flow simulator to model a laboratory imbibition experiment under two different initial conditions $(5 \%$ and $46.6 \%$ saturation). For the one core tested, the sorption data from the submersible pressure outflow cell composited with the dry end of the centrifuge moisture characteristic curve and the gas drive relative permeability data using the Brooks and Corey equation proved the best fit for modeling imbibition. 10 rets., 6 figs., 2 tabs.

520 (NUREG/CP-0040, pp. 101-115) Numerical and laboratory investigations of transient and steady-state flow in a fractured core. Kwicklis, E.M. (Geological Survey, Lakewood, CO (US)); Thamir, F.; Healy, R.W.; Boughton, C.J.; Anderton, S. Nuclear Regulatory Commission, Washington, DC (United States). Div. of Regulatory Applications; Southwest Research Inst., San Antonio, TX (United States). Center for Nuclear Waste Regulatory Analyses; Arizona Univ., Tucson, AZ (United States). Dept. of Hydrology and Water Resources. Jun 1993. (CONF-9101106-: 5. flow and transport through unsaturated fractured rock related to highlevel radioactive waste disposal, Tucson, AZ (United States), 7-10 Jan 1991). In Proceedings of workshop 5: Flow and transport through unsaturated fractured rock - related to high-level radioactive waste disposal. $238 \mathrm{p}$. Source: OSTI; NTIS; INIS; GPO.

An improved understanding of the ability of fractures to transmit water at matric potentials less than zero is essential for evaluating the ability of the rocks of Yucca Mountain, Nevada, to safely isolate nuclear waste. Numerical and experimental investigations of this subnuclear waste. Numerical and experimental investigations of this subject will help substantiate flux estimates of both liquid water and water vapor at Yucca Mountain, aid in assessing the effectiveness of capillary barriers at the contact between nonwelded and fractured welded units, and may provide insight as to the manner in which flow may become concentrated along specific pathways through a network of fractures under conditions of partial saturation. This paper summarizes some of the numerical and laboratory investigations that have been conducted at the US Geological Survey in Denver on a core of welded tuff containing a single fracture parallel to the core axis. The objectives of these investigations were to (1) explore the possibility that the unsaturated hydrologic properties of a fracture could be estimated by applying inverse techniques to the results of transient imbibition experiments, and (2) evaluate the accuracy of estimates of unsaturated fracture hydrologic properties derived from transient tests or numerical modeling through direct steady-state measurements. The core examined in these experiments is $0.0699 \mathrm{~m}$ long and has a radius of $0.0208 \mathrm{~m}$. It was obtained from the "columnar zone" of the Tiva Canyon member of the Paintbrush Tuff near Wren Wash on Yucca Mountain. 10 refs., 12 figs.

521 (NUREG/CP-0040, pp. 116-125) Ground water flow through unsaturated fractured rock research needs. Ford, W. (Nuclear Regulatory Commission, Washington, DC (US)). Nuclear Regulatory Commission, Washington, DC (United States). Div. of Regulatory Applications; Southwest Research Inst., San Antonio, TX (United States). Center for Nuclear Waste Regulatory Analyses; Arizona Univ., Tucson, AZ (United States). Dept. of Hydrology and Water Resources. Jun 1993. (CONF-9101106-: 5. flow and transport through unsaturated fractured rock related to high-level radioactive waste disposal, Tucson, AZ (United States), 7-10 Jan 1991). In Proceedings of workshop 5: Flow and transport through unsaturated fractured rock - related to high-level radioactive waste disposal. $238 \mathrm{p}$. Source: OSTI; NTIS; INIS; GPO.

This report presents: (1) a discussion of unsaturated fractured rock flow concepts; (2) a summary of unsaturated fractured rock flow modeling methods; and (3) a discussion of scientific investigations that may be needed to build confidence in the numerical modeling of ground water flow through unsaturated fractured rock. At the present time few experiments have been identified that test the concepts of unsaturated flow in fractured rock. Further, neither the continuum, discrete fracture network, nor the stochastic analytic modeling approaches to modeling ground water flow through unsaturated rock have been tested against either laboratory or field experiments. 17 refs.

522 (NUREG/CP-0040, pp. 130-141) Use of a submersible pressure outflow cell for determination of moisture characteristic curves on rock core. Flint, L.E. (Fenix and Scisson, Inc., Mercury, NV (US)); Fint, A.L. Nuclear Regulatory Commission, Washington, DC (United States). Div. of Regulatory Applications; Southwest Research Inst., San Antonio, TX (United States). Center for Nuclear Waste Regulatory Analyses; Arizona Univ., Tucson, AZ (United States). Dept. of Hydrology and Water Resources. Jun 1993. (CONF-9101106-: 5. flow and transport through unsaturated fractured rock related to high-level radioactive waste disposal, Tucson, $A Z$ (United States), 7-10 Jan 1991). In Proceedings of workshop 5: Flow and transport through unsaturated fractured rock - related to high-level radioactive waste disposal. 238p. Source: OSTI; NTIS; INIS; GPO.

A simple device for developing moisture characteristic data curves, the submersible pressure outflow cell, was modified for application to rock core at matric potentials of 0 to -0.5 megapascals (MPa) and possibly to $-1.0 \mathrm{Mpa}$. An automated system was developed to continuously and simultaneously collect data from many cells, obtain sorption and desorption characteristic curves to provide hysteretic information, and data from multi-step outflow experiments. The latter can be used to estimate unsaturated hydraulic conductivity. The system has resolved many of the problems inherent in standard measurement techniques. Model simulation of imbibition using the hysteretic data collected are in close agreement with laboratory measurements of imbibition, data collected are in close agreement with laboratory measurements of imbibition, suggesting the moisture characteristic data correctly describes the core properties.19 refs., 4 figs. 
523 (NUREG/CP-0040, pp. 147-152) Modeling hydrothermal flow in variably saturated, fractured, welded tuff during the prototype engineered barrier system field test of the Yucca Mountain Project. Buscheck, T.A. (Lawrence Livermore National Lab., CA (US)); Nitao, J.J. Nuclear Regulatory Commission, Washington, DC (United States). Div. of Regulatory Applications; Southwest Research Inst., San Antonio, TX (United States). Center for Nuclear Waste Regulatory Analyses; Arizona Univ., Tucson, AZ (United States). Dept. of Hydrology and Water Resources. Jun 1993. Contract W-7405-Eng-48. (CONF9101106-: 5. flow and transport through unsaturated fractured rock related to high-level radioactive waste disposal, Tucson, AZ (United States), 7-10 Jan 1991). In Proceedings of workshop 5: Flow and transport through unsaturated fractured rock - related to high-level radioactive waste disposal. 238p. Source: OSTI; NTIS; INIS; GPO.

The Yucca Mountain Project (YMP) of the US Department of Energy (DOE) is investigating the suitability of the tuffaceous rocks occurring in the unsaturated zone at Yucca Mountain, Nevada for nuclear waste storage. The Engineered Barrier System Field Tests (EBSFT) will be conducted within the Topopah Spring member of the Paintbrush Tuff at Yucca Mountain, primarily to examine the thermohydrological response of the repository environment of thermal loading from waste packages (Yow, 1985). The Prototype Engineered Barrier System Field Test (PEBSFT) was carried out by Ramirez and others $(1989,1990)$ in G-Tunnel complex of the Nevada Test Site to test and evaluate components of the geophysical instrumentation network and to support the validation of thermohydrological models. This report describes the modeling of the PEBSFT carried out by Buscheck and Nitao (1990) with the V-TOUGH code (Nitao, 1989) which is a modified version of the TOUGH code (Pruess, 1987). 7 refs., 5 figs., 2 tabs.

524 (NUREG/CP-0040, pp. 153-160) A survey of hydrothermal modeling related to Yucca Mountain. Wescott, R.G. (Nuclear Regulatory Commission, Washington, DC (US)). Nuclear Regulatory Commission, Washington, DC (United States). Div. of Regulatory Applications; Southwest Research Inst., San Antonio, TX (United States). Center for Nuclear Waste Regulatory Analyses; Arizona Univ., Tucson, AZ (United States). Dept. of Hydrology and Water Resources. Jun 1993. (CONF-9101106-: 5. flow and transport through unsaturated fractured rock related to high-level radioactive waste disposal, Tucson, $A Z$ (United States), 7-10 Jan 1991). In Proceedings of workshop 5: Flow and transport through unsaturated fractured rock - re. lated to high-level radioactive waste disposal. $238 \mathrm{p}$. Source: OSTI; NTIS; INIS; GPO.

Present design requirements call for the emplacement of approximately 62,000 metric tons of commercial reactor spent fuel and 8,000 metric tons of Defense and West Valley vitrified high level waste in a geologic repository (USDOE, 1988). The proposed underground repository at Yucca Mountain will cover an area of over two square miles and will have a design areal thermal power density of 57 kilowatts per acre. Most of the initial decay heat is due to fission products, however long lived actinides and daughter elements will provide significant thermal output after the fission products have decayed to a steady but much lower thermal output level (USNRC, 1983). Depending on the container loadings and emplacement configuration, temperatures in excess of $100 \mathrm{deg} . C$ can occur in the emplacement media and significantly higher temperatures can occur in the waste package. In that the host rock is partially saturated, water can significantly affect heat transfer near the waste package and possibly beyond the repository as well. The purpose of this paper is to present a survey of various efforts involving hydrothermal modeling for the high-level waste repository at Yucca Mountain. These efforts are discussed according to the size or distance scale of modeling supported. The conclusion section presents the author's views as to how these various efforts may be used. Data and information needs are also outlined. 35 refs.

525 (NUREG/CP-0040, pp. 169-178) Flow through nonhomogeneous porous media. Eaton, R.R. (Sandia National Laboratories, Albuquerque, NM (US)); Dykhuizen, R.C.; Hansen, K.M. Nuclear Regulatory Commission, Washington, DC (United States). Div. of Regulatory Applications; Southwest Research Inst., San Antonio, TX (United States). Center for Nuclear Waste Regulatory Analyses; Arizona Univ., Tucson, AZ (United States). Dept. of Hydrology and Water Resources. Jun 1993. DOE Contract AC0476DP00789. (CONF-9101106-: 5. flow and transport through unsaturated fractured rock related to high-level radioactive waste disposal, Tucson, AZ (United States), 7-10 Jan 1991). In Proceedings of workshop 5: Flow and transport through unsaturated fractured rock - related to high-level radioactive waste disposal. 238p. Source: OSTl; NTIS; INIS; GPO.

Modeling studies were conducted to determine the effect of material heterogeneities on the flow of water through rock. Multiple numerical calculations were made using random variations in spatial distributions of material properties. The results of these material variations on flow resistance, mechanical dispersion, and channeling were determined. Computed results were compared with a linear analytical model. Good agreement was obtained in the majority of the flow cases investigated. 12 refs., 7 figs.

526 (NUREG/CP-0040, pp. 179-183) Evaluation of tracers for hydrologic studies at Yucca Mountain. Bowman, R.S. (New Mexico Insti. of Mining and Technology, Socorro (US)); Gross, G.W.; Liddle, R.L. Nuclear Regulatory Commission, Washington, DC (United States). Div. of Regulatory Applications; Southwest Research Inst., San Antonio, TX (United States). Center for Nuclear Waste Regulatory Analyses; Arizona Univ., Tucson, AZ (United States). Dept. of Hydrology and Water Resources. Jun 1993. (CONF. 9101106-: 5. flow and transport through unsaturated fractured rock related to high-level radioactive waste disposal, Tucson, AZ (United States), 7-10 Jan 1991). In Proceedings of workshop 5: Flow and transport through unsaturated fractured rock - related to high-level radioactive waste disposal. 238p. Source: OSTI; NTIS; INIS; GPO.

In order to individually label different water inputs during site characterization and construction of a repository at Yucca Mountain, as many as 30 unique chemical tracers may be required. Only a handful of tracers has been proven suitable for investigations under a broad range of hydrologic and geochemical conditions. An effective tracer is nonreactive, i.e., it is not significantly sorbed nor transformed chemically during the time frame of interest, and it is present naturally at low levels or not at all. Other considerations in choosing a tracer include ease of quantitation, detection limit, environmental hazards, and cost. Tracers to be used under unsaturated conditions must be nonvolatile. Due to the need for more proven tracers for testing at Yucca Mountain (and for hydrological investigations in general), a series of laboratory experiments was performed to evaluate some new and/or little-utilized water tracers. The tracers tested 
included bromide, iodide, borate, and four fluorinated derivatives of benzoic acid. The emphasis was on testing tracers which could be used under unsaturated as well as saturated conditions. A complete report on the experiments described below (Bowman et al., 1990) is available from the senior author or from the US Geological Suney. 5 refs., 2 figs., 1 tab.

527 (NUREG/CP-0114-Vol.1, pp. 259-279) Development and evaluation of a performance assessment methodology for analyzing the safety of a geologic repository for high-level radioactive waste. McCartin, T.J. (Nuclear Regulatory Commission, Washington, DC (United States)); Randall, J.D.; Margulies, T.S. Nuclear Regulatory Commission, Washington, DC (United States). Office of Nuclear Regulatory Research; Brookhaven National Lab., Upton, NY (United States). Apr 1991. (CONF-9010185Vol.1: 18. water reactor safety information meeting, Rockville, MD (United States), 22-24 Oct 1990). in Eighteenth water reactor safety information meeting. Proceedings: Volume 1. 672p. Source: OSTI; NTIS; INIS; GPO.

A performance assessment methodology has been developed to aid in the evaluation of the safety of deep geologic disposal of high-level radioactive waste (HLW). The methodology consists of procedures for selecting and screening scenarios, computer programs for estimating consequences, and techniques for sensitivity and uncertainty analyses. The long-term predictions made in HLW performance place a significant reliance on the models used to make the estimates. The NRC is conducting laboratory and field experiments as well as participating in international model validation projects to build confidence in the models. Current and past efforts in the development of the performance assessment methodology have concentrated on the hydrologic models for fluid flow and radionuclide transport. Future work will need to consider models of waste package iailure, models of radionuclide release from HLW (source term models), and models that describe engineered barrier system performance.

528 (NUREG/CR-4735-Vol.7) Evaluation and compilation of DOE waste package test data: Biannual report, February 1989-July 1989: Volume 7. Interrante, C.G. (Nuclear Regulatory Commission, Washington, DC (United States). Div, of High-Level Waste Management); Fraker, A.C.; Escalante, E. Nuclear Regulatory Commission, Washington, DC (United States). Div. of High-Level Waste Management; National Inst. of Standards and Technology (IMSE), Gaithersburg, MD (United States). Metallurgy Div. Dec 1991. 118p. Sponsored by Nuclear Regulatory Commission, Washington, DC (United States). Source: OSTI; NTIS; INIS; GPO.

This report summarizes evaluations by the National Institute of Standards and Technology (NIST) of Department of Energy (DOE) activities on waste packages designed for containment of radioactive high-level nuclear waste (HLW) for the six-month period, February through July 1989. This includes reviews of related materials research and plans, information on the Yucca Mountain, Nevada disposal site activities, and other information regarding supporting research and special assistance. Outlines for planned interpretative reports on the topics of aqueous corrosion of copper, mechanisms of stress corrosion cracking and internal failure modes of Zircaloy cladding are included. For the publications reviewed during this reporting period, short discussions are given to supplement the completed reviews and evaluations. Included in this report is an overall review of a 1984 report on glass leaching mechanisms, as well as reviews for each of the seven chapters of this report.

529 (NUREG/CR-4735-Vol.8) Evaluation and compilation of DOE waste package test data: Volume 8: Biannual report, August 1989-January 1990. Interrante, C.G. (Nuclear Regulatory Commission, Washington, DC (United States). Div. of High-Level Waste Management); Fraker, A.C.; Escalante, E. Nuclear Regulatory Commission, Washington, DC (United States). Div. of High-Level Waste Management; National Inst. of Standards and Technology (MSEL), Gaithersburg, MD (United States). Metaliurgy Div. Jun 1993. 103p. Sponsored by Nuclear Regulatory Commission, Washington, DC (United States). Source: OSTI; NTIS; INIS; GPO.

This report summarizes evaluations by the National Institute of Standards and Technology (NIST) of some of the Department of Energy (DOE) activities on waste packages designed for containment of radioactive high-level nuclear waste (HLW) for the six-month period, August 1989-January 1990. This includes reviews of related materials research and plans, information on the Yucca Mountain, Nevada disposal site activities, and other information regarding supporting research and special assistance. Short discussions are given relating to the publications reviewed and complete reviews and evaluations are included. Reports of other work are included in the Appendices.

530 (NUREG/CR-5685) Sealing performance of bentonite and bentonite/crushed rock borehole plugs. Ouyang, S. (Arizona Univ., Tucson, AZ (United States). Dept. of Mining and Geological Engineering); Daemen, J.J.K. Nuclear Regulatory Commission, Washington, DC (United States). Div. of Regulatory Applications; Arizona Univ., Tucson, AZ (United States). Dept. of Mining and Geological Engineering. Jul 1992. 315p. Sponsored by Nuclear Regulatory Commission, Washington, DC (United States). Source: OSTI; NTIS; GPO.

This study includes a systematic investigation of the sealing performance of bentonite and bentonite/crushed rock plugs. American Colloid C/S granular bentonite and crushed Apache Leap tuff have been mixed to prepare samples for laboratory flow testing. Bentonite weight percent and crushed tuff gradation are the major variables studied. The sealing performance assessments include high injection pressure flow tests, polyaxial flow tests, high temperature flow tests, and piping tests. The results indicate that a composition to yield a permeability lower than $5 \times 10^{-8} \mathrm{~cm} / \mathrm{s}$ would have at least $25 \%$ bentonite by weight mixed with well-graded crushed rock. Hydraulic properties of the mixture plugs may be highly anisotropic if significant particle segregation occurs during sample installation and compaction. Temperature has no significant effect on the sealing performance within the test range from room temperature to $600^{\circ} \mathrm{C}$. Piping damage to the sealing performance is small if the maximum hydraulic gradient does not exceed 120 and 280 for samples with a bentonite content of 25 and $35 \%$, respectively. The hydraulic gradients above which flow of bentonite may take place are deemed critical. Analytical work includes the introduction of bentonite occupancy percentage and water content at saturation as two major parameters for plug design. A permeability model is developed for the prediction of permeability in clays, especially in view of the difficulties in obtaining this property experimentally. A piping model is derived based on plastic flow theory. This piping model permits the estimation of critical hydraulic gradients at which flow of bentonite takes place. The model can 
also be used to define the maximum allowable pore diameter of a protective filter layer.

531 (NUREG/CR-5687) Borehole stability in densely welded tuffs. Fuenkajorn, K. (Arizona Univ., Tucson, AZ (United States). Dept. of Mining and Geological Engineering); Daemen, J.J.K. Nuclear Regulatory Commission, Washington, DC (United States). Div. of Regulatory Applications; Arizona Univ., Tucson, AZ (United States). Dept. of Mining and Geological Engineering. Jul 1992. 59p. Sponsored by Nuclear Regulatory Commission, Washington, DC (United States). Source: OSTI; NTIS; INIS; GPO.

The stability of boreholes, or more generally of underground openings (i.e. including shafts, ramps, drifts, tunnels, etc.) at locations where seals or plugs are to be placed is an important consideration in seal design for a repository (Juhlin and Sandstedt, 1989). Borehole instability or borehole breakouts induced by stress redistribution could negate the effectiveness of seals or plugs. Breakout fractures along the wall of repository excavations or exploratory holes could provide a preferential flowpath for groundwater or gaseous radionuclides to bypass the plugs. After plug installation, swelling pressures exerted by a plug could induce radial cracks or could open or widen preexisting cracks in the rock at the bottom of the breakouts where the tangential compressive stresses have been released by the breakout process. The purpose of the work reported here is to determine experimentally the stability of a circular hole in a welded tuff sample subjected to various external boundary loads. Triaxial and biaxial borehole stability tests have been performed on densely welded Apache Leap tuff samples and Topopah Spring tuff samples. The nominal diameter of the test hole is 13.3 or $14.4 \mathrm{~mm}$ for triaxial testing, and 25.4 $\mathrm{mm}$ for biaxial testing. The borehole axis is parallel to one of the principal stress axes. The boreholes are drilled through the samples prior to applying external boundary loads. The boundary loads are progressively increased until breakouts occur or until the maximum load capacity of the loading system has been reached. 74 refs.

532 (NUREG/CR-5708) Potentiodynamic polarization studies on candidate container alloys for the Tuff Repository. Thompson, N.G. (Cortest Columbus Technologies, OH (United States)); Beavers, J.A.; Durr, C.L. Nuclear Regulatory Commission, Washington, DC (United States). Div. of Regulatory Applications; Cortest Columbus Technologies, Inc., OH (United States). Jan 1992. 273p. Sponsored by Nuclear Regulatory Commission, Washington, DC (United States). Source: OSTI; NTIS; INIS; GPO.

Cortest Columbus Technologies, Inc. (CC Technologies) is investigating the long-term performance of container materials used for high-level radioactive waste packages. This information is being developed for the Nuclear Regulatory Commission to aid in their assessment of the Department of Energy's application to construct a geologic repository for disposal of high-level radioactive waste. This report summarizes the results of cyclic-potentiodynamic-polarization (CCP) studies performed on candidate container materials for the Tutf Repository. The CPP technique was used to provide an understanding of how specific variables such as environmental composition, temperature, alloy composition, and welding affect both the general- and localized-corrosion behavior of two copper-base and two $\mathrm{Fe}-\mathrm{Cr}-\mathrm{Ni}$ alloys in simulated repository environments. A statistically-designed test solution matrix was formulated, based on an extensive search of the literature, to evaluate the possible range of environmental species that may occur in the repository over the life of the canister. Forty-two CPP curves were performed with each alloy and the results indicated that several different types of corrosion were possible. The copper-base alloys exhibited unusual CCP behavior in that hysteresis was not always associated with pitting. The effects of temperature on the corrosions behavior were evaluated in two types of tests; isothermal tests at temperatures from $50^{\circ} \mathrm{C}$ to $90^{\circ} \mathrm{C}$ and heat-transfer tests where the solution was maintained at $50^{\circ} \mathrm{C}$ and the specimen was internally heated to $90^{\circ} \mathrm{C}$. In the isothermal test, CPP curves were obtained with each alloy in simulated environments at $50^{\circ} \mathrm{C}, 75^{\circ} \mathrm{C}$, and $90^{\circ} \mathrm{C}$. The results of these CCP experiments indicated that no systematic trends were evident for the environments tested. Lastly, the effects of welding on the corrosion behavior of the alloys in simulated environments were examined.

533

(NUREG/CR-5710) Stress-corrosion-cracking studies on candidate container alloys for the Tuff Repository. Beavers, J.A. (Cortest Columbus Technologies, Inc., OH (United States)); Durr, C.L. Nuclear Regulatory Commission, Washington, DC (United States). Div. of Regulatory Applications; Cortest Columbus Technologies, Inc., $\mathrm{OH}$ (United States). May 1992. 111p. Sponsored by Nuclear Regulatory Commission, Washington, DC (United States). Source: OSTI; NTIS; INIS; GPO.

Cortest Columbus Technologies, Inc. (CC Technologies) investigated the long-term performance of container materials used for high-level waste package as part of the information needed by the Nuclear Regulatory Commission (NRC) to assess the Department of Energy's application to construct to geologic repository for high-level radioactive waste. At the direction of the NRC, the program focused on the Tuff Repository. This report summarizes the results of Stress-Corrosion-Cracking (SCC) studies performed in Tasks 3,5, and 7 of the program. Two test techniques were used; U-bend exposures and Slow-Strain-Rate (SSR) tests. The testing was periormed on two copper-base alloys (Alloy CDA 102 and Alloy CDA 175) and two Fe-Cr-Ni alloys (Alloy $304 \mathrm{~L}$ and Alloy 825 ) in simulated $\mathrm{J}-13$ groundwater and other simulated solutions for the Tuff Repository. These solutions were designed to simulate the effects of concentration and irradiation on the groundwater composition. All $\mathrm{SCC}$ testing on the Fe-Cr-Ni Alloys was performed on solution-annealed specimens and thus issues such as the effect of sensitization on SCC were not addressed.

534 (NUREG/CR-5880) Nonisothermal hydrologic transport experimental plan. Rasmussen, T.C.; Evans, D.D. Nuclear Regulatory Commission, Washington, DC (United States). Div. of Regulatory Applications; Arizona Univ., Tucson, AZ (United States). Dept. of Hydrology and Water Resources. Sep 1992. 48p. Sponsored by Nuclear Regulatory Commission, Washington, DC (United States). Source: OSTI; NTIS; INIS; GPO.

A field heater experimental plan is presented for investigating hydrologic transport processes in unsaturated fractured rock related to the disposal of high-level radioactive waste (HLW) in an underground repository. The experimental plan provides a methodology for obtaining data required for evaluating conceptual and computer modeis related to HLW isolation in an environment where significant heat energy is produced. Coupled-process models are currently limited by the lack of validation data appropriate for field scales that incorporate relevant transport processes. Presented in this document is a discussion of previous nonisothermal experiments. Processes expected to dominate 
heat-driven liquid, vapor, gas, and solute flow during the experiment are explained, and the conceptual model for nonisothermal flow and transport in unsaturated, fractured rock is described. Of particular concern is the ability to confirm the hypothesized conceptual model specifically, the establishment of higher water saturation zones within the host rock around the heat source, and the establishment of countercurrent flow conditions within the host rock near the heat source. Field experimental plans are presented using the Apache Leap Tuff Site to illustrate the implementation of the proposed methodology. Both small-scale preliminary experiments and a long-term experiment are described.

535 (NUREG/CR-5890) Regional groundwater modeling of the saturated zone in the vicinity of Yucca Mountain, Nevada: Iterative Performance Assessment, Phase 2. Ahola, M. (Southwest Research Inst., San Antonio, TX (United States). Center for Nuclear Waste Regulatory Analyses); Sagar, B. Nuclear Regulatory Commission, Washington, DC (United States). Div. of High-Level Waste Management; Southwest Research Inst., San Antonio, TX (United States). Center for Nuclear Waste Regulatory Analyses. Oct 1992. 59p. Sponsored by Nuclear Regulatory Commission, Washington, DC (United States). (CNWRA-92-001). Source: OSTI; NTIS; INIS; GPO.

Results of groundwater modeling of the saturated zone in the vicinity of Yucca Mountain are presented. Both a regional $(200 \times 200 \mathrm{~km})$ and subregional $(50 \times 50 \mathrm{~km})$ model were used in the analyses. Simulations were conducted to determine the impact of various disruptive that might take place over the life span of a proposed Yucca Mountain geologic conditions repository on the groundwater flow field, as well as changes in the water-table elevations. These conditions included increases in precipitation and groundwater recharge within the regional model, changes in permeability of existing hydrogeologic barriers, a:nd the vertical intrusion of volcanic dikes at various orientations through the saturated zone. Based on the regional analysis, the rise in the water-table under Yucca Mountain due to various postulated conditions ranged from only a few meters to 275 meters. Results of the subregional model analysis, which was used to simulate intrusive dikes approximately 4 kilometers in length in the vicinity of Yucca Mountain, showed water-table rises ranging from a few meters to as much as 103 meters. Dikes oriented approximately north-south beneath Yucca Mountain produced the highest water-table rises. The conclusions drawn from this analysis are likely to change as more site-specific data become available and as the assumptions in the model are improved.

536 (NUREG/CR-5917-Vol.1) Sensitivity and uncertainty analyses applied to one-dimensional radionuclide transport in a layered fractured rock: MULTFRAC -Analytic solutions and local sensitivities: Phase 2, Iterative performance assessment: Volume 1. Gureghian, A.B. (Southwest Research Inst., San Antonio, TX (United States). Center for Nuclear Waste Regulatory Analyses); Wu, Y.T.; Sagar, B.; Codell, R.A. Nuclear Regulatory Commission, Washington, DC (United States). Div. of High-Level Waste Management; Southwest Research Inst., San Antonio, TX (United States). Center for Nuclear Waste Regulatory Analyses. Dec 1992. 131p. Sponsored by Nuclear Regulatory Commission, Washington, DC (United States). (CNWRA-91-010-Vol.1). Source: OSTI; NTIS; INIS; GPO.

Includes 1 sheet of microfiche supplement.

Exact analytical solutions based on the Laplace transforms are derived for describing the one-dimensional space-time-dependent, advective transport of a decaying species in a layered, saturated rock system intersected by a planar fracture of varying aperture. These solutions, which account for advection in fracture, molecular diffusion into the rock matrix, adsorption in both fracture and matrix, and radioactive decay, predict the concentrations in both fracture and rock matrix and the cumulative mass in the fracture. The solute migration domain in both fracture and rock is assumed to be semi-infinite with non-zero initial conditions. The concentration of each nuclide at the source is allowed to decay either continuously or according to some periodical fluctuations where both are subjected to either a step or band release mode. Two numerical examples related to the transport of Np-237 and $\mathrm{Cm}-245$ in a five-layered system of fractured rock were used to verify these solutions with several well established evaluation methods of Laplace inversion integrals in the real and complex domain. In addition, with respect to the model parameters, a comparison of the analytically derived local sensitivities for the concentration and cumulative mass of Np-237 in the fracture with the ones obtained through a finite-difference method of approximation is also reported.

537 (NUREG/CR-6021) A literature review of coupled thermal-hydrologic-mechanical-chemical processes pertinent to the proposed high-level nuclear waste repository at Yucca Mountain. Manteufel, R.D. (Southwest Research Inst., San Antonio, TX (United States). Center for Nuclear Waste Regulatory Analyses); Ahola, M.P.; Turner, D.R.; Chowdhury, A.H. Nuclear Regulatory Commission, Washington, DC (United States). Div. of HighLevel Waste Management; Southwest Research Inst., San Antonio, TX (United States). Center for Nuclear Waste Regulatory Analyses. Jul 1993. 226p. Sponsored by Nuclear Regulatory Commission, Washington, DC (United States). (CNWRA-92-011). Source: OSTI; NTIS; INIS; GPO.

A literature review has been conducted to determine the state of knowledge available in the modeling of coupled thermal $(T)$, hydrologic $(H)$, mechanical $(M)$, and chemical (C) processes relevant to the design and/or performance of the proposed high-level waste (HLW) repository at Yucca Mountain, Nevada. The review focuses on identifying coupling mechanisms between individual processes and assessing their importance (i.e., if the coupling is either important, potentially important, or negligible). The significance of considering THMC-coupled processes lies in whether or not the processes impact the design and/or performance objectives of the repository. A review, such as reported here, is useful in identifying which coupled effects will be important, hence which coupled effects will need to be investigated by the US Nuclear Regulatory Commission in order to assess the assumptions, data, analyses, and conclusions in the design and performance assessment of a geologic reposit". Although this work stems from regulatory interest in the design of the geologic repository, it should be emphasized that the repository design implicitly considers all of the repository performance objectives, including those associated with the time after permanent closure. The scope of this review is considered beyond previous assessments in that it attempts with the current state-of-knowledge) to determine which couplings are important, and identify which computer codes are currently available to model coupled processes.

538 (NWPO-GR-1) Report of the State of Nevada Commission on Nuclear Projects. Nevada Nuclear Waste Project Office, Carson City, NV (United States); Nevada Commission on Nuclear Projects, Carson City, NV (United 
States). Dec 1990. 107p. Sponsored by USDOE, Washington, DC (United States). DOE Contract FG08-85NV10461. Order Number DE92017833. Source: OSTI; NTIS; INIS; GPO Dep.

This third biennial Report of the Nevada Commission on Nuclear Projects has been prepared in fulfillment of the requirements of NRS 459.0092, which stipulates that the Commission shall report to the Governor and Legislature on any matter relating to radioactive waste disposal the Commission deems appropriate and advise and make recommendations on the policy of the State concerning nuclear waste disposal projects. Chapter One of the Report presents a brief overview of the Commission's functions and statutory charges. It also contains a summary of developments which have affected the overall nuclear waste disposi issue since the last Commission Report was published in November, 1988. Chapter Two contains a synthesis of Commission activities and reports on the findings of the Commission relative to the geotechnical, environmental, socioeconomic, transportation, intergovernmental and legal aspects of federal and State nuclear waste program efforts.

539 (NWPO-GR-15) Yucca Mountain program summary of research and technical review activities, July 1988-June 1989. Nevada Nuclear Waste Project Office, Carson City, NV (United States); Nevada Univ., Las Vegas, NV (United States). Desert Research Inst.; Nevada Univ., Reno, NV (United States). Desert Research Inst. Nov 1989. 95p. Sponsored by USDOE, Washington, DC (United States). DOE Contract FG08-85NV10461. Order Number DE92017893. Source: OSTI; NTIS; INIS; GPO Dep.

The Desert Research Institute (DRI), through its Water Resources Center (WRC), since 1984 has supported the State of Nevada Nuclear Waste Project Office's activities related to the proposed high-level radioactive waste repository at Yucca Mountain on the Nevada Test Site (NTS). This effort is directed at providing the State Office with an unbiased evaluation of the Yucca Mountain Project (YMP) investigations performed by the US Department of Energy (DOE) and the Nuclear Regulatory Commission (NRC). The overall objective is to determine independently whether or not the site meets the performance criteria defined by the Nuclear Waste Policy Act of 1982 and amendments for isolating and containing the wastes during emplacement and the proposed life of the repository. A particularly important area of concern with the proposed repository is the site's hydrology. The faculty of the DRI have long been involved with research throughout the State and have particular expertise in groundwater studies related to radionuclide migration and hydrologic safety of underground nuclear testing by DOE and predecessor agencies. In addition, we utilize laboratory personnel for chemical and isotopic analyses in both of the DRI-WMC water chemistry laboratories.

540 (NWPO-GR-16) Geothermal evaluation and analysis of the Yucca Mountain Repository, Nevada: Final report, July 1, 1989-December 31, 1989. Nevada Nuclear Waste Project Office, Carson City, NV (United States); Nevada Univ., Reno, NV (United States). Div. of Earth Sciences. 17 Jun 1989. 23p. Sponsored by USDOE, Washington, DC (United States). DOE Contract FGO885NV10461. Order Number DE92017904. Source: OSTI; NTIS; INIS; GPO Dep.

This is the final report on the geothermal analysis and evaluation for the proposed nuclear waste repository at Yucca Mountain, for the period of July 1, 1989 to December 31,1989 . Heat flow values were derived by measuring the thermal conductivities of samples taken from selected exploratory wells. Temperature gradients are recorded from the same wells. By using computer generated contour maps of the area, another interpretation of the heat-flow can be derived. Results of the mapping do not coincide with the past observations of the data. Another method used to evaluate the heat-flow of Yucca Mountain was to compare the temperature-depth relationship of the area. (MB)

541 (NWPO-GR-20) Center for Volcanic and Tectonic Studies, Department of Geoscience annual report, October 1, 1989-September 30, 1990. Smith, E.I. (Nevada Univ., Las Vegas, NV (United States). Center for Volcanic and Tectonic Studies). Nevada Nuclear Waste Project Office, Carson City, NV (United States); Nevada Univ., Las Vegas, NV (United States). Center for Volcanic and Tectonic Studies. 1 Nov 1990. 168p. Sponsored by USDOE, Washington, DC (United States). DOE Contract FG08-85NV10461. Order Number DE92017912. Source: OSTI; NTIS; INIS; GPO Dep.

This report summarizes our activities during the period October 1, 1989 to September 30, 1990. Our goal was to develop an understanding of late-Miocene and Pliocene volcanism in the Great Basin by studying Pliocene volcanoes in the vicinity of the proposed high-level nuclear waste repository at Yucca Mountain. Nevada. Field studies during this period concentrated on the Quaternary volcanoes in Crater Flat, Yucca Mountain, Fortification Hill, at Buckboard Mesa and Sleeping Butte, and in the Reveille Range. Also, a study was initiated on structurally disrupted basaltic rocks in the northern White Hills of Mohave County, Arizona. As well as progress reports of our work in Crater Flat, Fortification Hill and the Reveille Range, this paper also includes a summary of model that relates changing styles of Tertiary extension to changing magmatic compositions, and a summary of work being done in the White Hills, Arizona. In the Appendix, we include copies of published papers not previously incorporated in our monthly reports.

542 (NWPO-GR-24-Vol.1) Evaluation of the geologic relations and seismotectonic stability of the Yucca Mountain area, Nevada Nuclear Waste Site Investigation (NNWSI): Final report, January 1, 1987-June 30, 1988: Volume 1. Nevada Nuclear Waste Project Office, Carson City, NV (United States); Nevada Univ., Reno, NV (United States). Center for Neotectonic Studies. Oct 1988 393p. Sponsored by USDOE, Washington, DC (United States). DOE Contract FG08-85NV10461. Order Number DE92017901. Source: OSTI; NTIS; INIS; GPO Dep.

This report provides a summary of progress for the project "Evaluation of the Geologic Relations and Seismotectonic Stability of the Yucca Mountain Area, Nevada Nuclear Waste Site Investigation (NNWSI)" for the eighteen month period of January 1, 1987 to June 10, 1988. This final report was preceded by the final report for the initial six month period, July 1, 1986 to December 31, 1986 (submitted on January 25, 1987, and revised in June 1987.) Quaternary Tectonics, Geochemical, Mineral Deposits, Vulcanic Geology, Seismology, Tectonics, Neotectonics, Remote Sensing, Geotechnical Assessments, Geotechnical Rock Mass Assessments, Basinal Studies, and Strong Ground Motion.

543 (NWPO-GR-24-Vol.2) Evaluation of the geologic relations and seismotectonic stability of the Yucca Mountain Area, Nevada Nuclear Waste Site Investigation (NNWSI): Volume 2, Final report, October 1988. Peppin, W.A. Nevada Univ., Reno, NV (United States). Center for Neotectonic Studies. [1988]. 257p. Sponsored by USDOE, 
Washington, DC (United States). DOE Contract FG0885NV10461. Order Number DE92017902. Source: OSTl; NTIS; INIS; GPO Dep.

This document describes activities for the year ending 30 June 1988 by staff members of the Seismological Laboratory in support of the Yucca Mountain site assessment program. Activities during the year centered largely around acquisition of equipment to be used for site assessment and around a review of the draft site characterization plan for Yucca Mountain. Due to modifications in the scheduling and level of funding, this work has not progressed as originally anticipated. The report describes progress in seven areas, listed in approximate order of significance to the Yucca Mountain project. These are: (1) equipment acquisition, (2) review of the draft site characterization plan, (3) studies of earthquake sequence related to the tectonic problems at Yucca Mountain, (4) a review of the work of Szymanski in relation to Task 4 concerns, (5) coordination meetings with USGS, DOE, and NRC personnel, (6) studies related to Yucca Mountain, and (7) other studies.

544 (NWPO-SE-026-90) Native Americans and Yucca Mountain: A summary report. Fowler, C.S. Nevada Nuclear Waste Project Office, Carson City, NV (United States). Sep 1990. 305p. Sponsored by USDOE, Washington, DC (United States). DOE Contract FG08-85NV10461. Order Number DE92017730. Source: OSTI; NTIS; INIS; GPO; GPO Dep.

This report summarizes data collected between September 1986 and September 1988 relative to Native American concerns involving the potential siting of a high-level nuclear waste repository at Yucca Mountain, Nevada. The data were collected from Western Shoshone and Southern Paiute people upon whose aboriginal lands the repository potentially is to be located. Western Shoshone people involved in the study were those resident or affiliated with reservation communities at Yomba and Duckwater, Nevada, and Death Valley, California. Southern Paiute people were at reservation communities at Moapa and Las Vegas. Additional persons of Western Shoshone and Southern Paiute descent were interviewed at Beatty, Tonapah, Caliente, Pahrump, and Las Vegas, Nevada. The work was part of a larger project of socioeconomic studies for the State of Nevada's Nuclear Waste Projects office, conducted by Mountain West of Phoenix, Arizona.

545 (NWPO-SE-036-87) Yucca Mountain socioeco. nomic project report on the 1987 risk perception telephone surveys. Kunreuther, H. (Pennsylvania Univ., Philadelphia, PA (United States). Wharton School of Finance and Commerce); Slovic, P.; Nigg, J.; Desvousges, W.H. Nevada Nuclear Waste Project Office, Carson City, NV (United States); Pennsylvania Univ., Philadelphia, PA (United States). Wharton School of Finance and Commerce; Decision Research, Eugene, OR (United States); Arizona State Univ., Tempe, AZ (United States); Research Triangle inst., Research Triangle Park, NC (United States). Sep 1987. 193p. Sponsored by USDOE, Washington, DC (United States). DOE Contract FG08-85NV10461. Order Number DE92017735. Source: OSTI; NTIS; INIS; GPO Dep.

The measurement of the risk-related impacts from the siting of a high-level nuclear waste (HLNW) repository represents a new and important addition to conventional socioeconomic impact studies. In particular, the driving forces behind these impacts are the risks people perceive to be associated with the repository. Measuring the risk impacts requires a complementary set of approaches, of which, risk surveys are the cornerstone.a The purpose of these surveys is to provide scientifically defensible measures of the riskrelated impacts. The risk surveys follow directly from a conceptual framework of how the HLNW repository affects peoples' perceptions and, ultimately, their behaviors. These surveys describe and measure: Characteristics of individuals, Risks people perceive from the HLNW repository, Views, or mind sets, they form about the HLNW repository, Changes in behaviors-e.g., changes in retirement decisions or industrial relocations-induced by the location of the repository, and Changes in well-being of Nevada citizens, if the repository were located at Yucca Mountain.

546 (NWPO-SE-037-91) Yucca Mountain Socioeconomic Project: The 1991 Nevada State telephone survey: Key findings. Flynn, J.H.; Mertz, C.K.; Slovic, P. Nevada Nuclear Waste Project Office, Carson City, NV (United States), May 1991. 35p. Sponsored by USDOE, Washington, DC (United States). DOE Contract FG0885NV10461. Order Number DE92017712. Source: OSTI; NTIS; INIS; GPO Dep.

The 1991 Nevada State Telephone Survey was implemented by Decision Research on behalf of the State of Nevada, Agency for Nuclear Projects/Nuclear Waste Project Office (NWPO) as part of an ongoing socioeconomic impact assessment study. The scope of this survey was considerably smaller than a previous survey conducted in 1989 and focused more upon public evaluations of the Yucca Mountain repository program and the trust Nevadans currently addressing the siting issues. In order to provide place in key public officials who are Longitudinal data on the repository program, the 1991 questionnaire consisted of questions that were used in the 1989 NWPO survey which was conducted by Mountain West Research. As a result, the findings from this survey are compared with analogous items from the 1989 survey, and with the results from a survey commissioned by the Las Vegas Review-Journal and reported in their issue of October 21,1990 . The Review-Journal survey was conducted by Bruce Merri11 of the Arizona State University Media Research Center. A more complete comparison of the 1989 and 1991 surveys sponsored by NWPO is possible since the researchers at Decision Research had access to both these databases. The only source of information for the Review-Journal findings was the articles published in the Fall, 1990. The findings of the 1991 survey show that Nevadans oppose the federal government attempts to locate a high-level radioactive waste repository at Yucca Mountain. They support a policy of opposition on the part of Nevada officials. They believe that Nevadans should have the final say in whether to accept the repository or not, and they reject the proposition that benefits from the repository program will outweigh the harms. These findings are very similar to survey results from 1989 and 1990 and once again demonstrate very widespread public opposition by Nevadans to the current federal repository program.

547 (NWPO-SE-038-91) Southern Nevada residents' views about the Yucca Mountain high-level nuclear waste repository and related issues: $A$ comparative analysis of urban and rural survey data. Krannich, R.S. (Utah State Univ., Logan, UT (United States)); Little, R.L.; Mushkatel, A.; Pijawka, K.D.; Jones, P. Nevada Nuclear Waste Project Office, Carson City, NV (United States). Oct 1991. 137p. Sponsored by USDOE, Washington, DC (United States). DOE Contract FG08-85NV10461. Order Number DE92017676. Source: OSTI; NTIS; INIS; GPO Dep. 
two separate surveys were undertaken in 1988 to ascertain southern Nevadans' views about the Yucca Mountain repository and related issues. The first of these studies focused on the attitudes and perceptions of residents in the Las Vegas metropolitan area. The second study addressed similar issues, but focused on the views of residents in six rural communities in three counties adjacent to the Yucca Mountain site. However, parallel findings from the two data sets have not been jointly analyzed in order to identify ways in which the views and orientations of residents in the rural and urban study areas may be similar or different. The purpose of this report is to develop and present a comparative assessment of selected issues addressed in the rural and urban surveys. Because both urban and rural populations would potentially be impacted by the Yucca Mountain repository, such an analysis will provide important insights into possible repository impacts on the well-being of residents throughout southern Nevada.

548 (NWPO-SE-039-91-Vol.1) Native Americans and Yucca Mountain: A revised and updated summary report on research undertaken between 1987 and 1991: Volume 1. Fowler, C.S. (Cultural Resources Consultants Ltd., Reno, NV (United States)). Nevada Nuclear Waste Project Office, Carson City, NV (United States); Cultural Resources Consultants Ltd., Reno, NV (United States). 15 Oct 1991. 210p. Sponsored by USDOE, Washington, DC (United States). DOE Contract FG08-85NV10461. Order Number DE92017713. Source: OSTI; NTIS; INIS; GPO Dep.

This report summarizes data collected between September 1986 and September 1988 relative to Native American concerns involving the potential siting of a high-level nuclear waste repository at Yucca Mountain, Nevada. The data were collected from Western Shoshone and Southern Paiute people upon whose aboriginal lands the repository potentially is to be located. Western Shoshone people involved in the study were those resident or affiliated with reservation communities at Yomba and Duckwater, Nevada, and Death Valley, California. Southern Paiute people were at reservation communities at Moapa and Las Vegas. Additional persons of Western Shoshone and Southern Paiute descent were intenviewed at Beatty, Tonopah, Caliente, Pahrump, and Las Vegas, Nevada. The work was part of a larger project of socioeconomic studies for the State of Nevada's Nuclear Waste Projects office, conducted by Mountain West of Phoenix, Arizona.

549 (NWPO-SE-039-91-Vol.2) Native Americans and Yucca Mountain: A revised and updated summary report on research undertaken between 1987 and 1991 : Volume 2. Fowler, C.S. (Cultural Resources Consultants Ltd., Reno, NV (United States)). Nevada Nuclear Waste Project Office, Carson City, NV (United States); Cultural Resources Consultants Ltd., Reno, NV (United States). 15 Oct 1991. 176p. Sponsored by USDOE, Washington, DC (United States). DOE Contract FG08-85NV10461. Order Number DE92017714. Source: OSTI; NTIS; INIS; GPO Dep.

This report consists of Yucca Mountain Project bibliographies. It is the appendix to a report that summarizes data collected between September 1986 and September 1988 relative to Native American concerns involving the potential siting of a high-level nuclear waste repository at Yucca Mountain, Nevada. The data were collected from Western Shoshone and Southern Paiute people upon whose aboriginal lands the repository potentially is to be located. Western Shoshone people involved in the study were those resident or affiliated with reservation communities at Yomba and
Duckwater, Nevada, and Death Valley, California. Southern Paiute people were at reservation communities at Moapa and Las Vegas. Additional persons of Western Shoshone and Southern Paiute descent were interviewed at Beatty, Tonopah, Caliente, Pahrump, and Las Vegas, Nevada. The work was part of a larger project of socioeconomic studies for the State of Nevada's Nuclear Waste Projects office, conducted by Mountain West of Phoenix, Arizona.

550 (NWPO-SE-040-91) Socioeconomic profiles of Native American communities: Las Vegas Tribes of Paiute Indians. Rusco, M.K. (Cultural Resources Consultants, Ltd. Reno Nevada (United States)). Nevada Nuclear Waste Project Office, Carson City, NV (United States). Oct 1991. 76p. Sponsored by USDOE, Washington, DC (United States). DOE Contract FG08-85NV10461. Order Number DE92017733. Source: OSTI; NTIS; INIS; GPO Dep.

The Las Vegas Colony is located in northwest Las Vegas, Clark County, Nevada. With the Snow Mountain Reservation, a 3,840 US 95 , it forms the land base for the Las Vegas Tribe of Paiute Indians. This report describes data collected in 1987 and 1988 during several visits to the Colony. Socioeconomic data were collected during a houseto-house census and during the administration of a formal questionnaire to a sample of ten Colony residents. Visits to the Colony in 1990 and 1991 enabled us to confirm the current reliability of some of these data and to make changes where necessary. Respondents were also given an opportunity to express concerns about the proposed radioactive waste facility at Yucca Mountain.

551 (NWPO-SE-041-91) Socioeconomic profiles of native American communities: Yomba Shoshone Reservation. Hamby, M. (Cultural Resources Consultants Ltd., Reno, NV (United States)); Rusco, E. Nevada Nuclear Waste Project Office, Carson City, NV (United States); Cultural Resources Consultants Ltd., Reno, NV (United States). Oct 1991. 126p. Sponsored by USDOE, Washington, DC (United States). DOE Contract FG08-85NV10461. Order Number DE92017578. Source: OSTI; NTIS; INIS; GPO Dep.

This report was written by the State of Nevada Agency for Nuclear Projects/Nuclear Waste Project Office. This office oversees the nuclear waste activities for the proposed Yucca Mountain high-level waste facility for the state of Nevada. The Yomba Shoshone Reservation socio-economic profile was the basis of this paper. It describes the life and current status of the Shoshone Indians. Population, utilities, education and social services of the Shoshone are examples of the topics which are discussed. It is intended as base-line information only. It eventually summarizes and compares data from the public opinion of the Shoshone about the high level waste repository at Yucca Mountain. (MB)

552 (NWPO-SE-042-91) Socioeconomic profiles of native American communities: Duckwater Shoshone Reservation. Hamby, M. (Cultural Resources Consultants Ltd., Reno, NV (United States)). Nevada Nuclear Waste Project Office, Carson City, NV (United States); Cultural Resources Consultants Ltd., Reno, NV (United States). Oct 1991. 97p. Sponsored by USDOE, Washington, DC (United States). DOE Contract FG08-85NV10461. Order Number DE92017705. Source: OSTI; NTIS; INIS; GPO Dep.

This report presents socioeconomic aspects of Native Americans of the Duckwater Shoshone Reservation. A survey is included concerning their views on the proposed Yucca Mountain waste repository. (CBS) 
553

(NWPO-SE-043-91) Native Americans and state and local governments. Rusco, E.R. (Cultural Resources Consultants, Ltd. Reno, Nevada (United States)). Nevada Nuclear Waste Project Office, Carson City, NV (United States). Oct 1991. 52p. Sponsored by USDOE, Washington, DC (United States). DOE Contract FG0885NV10461. Order Number DE92017732. Source: OSTI; NTIS; INIS; GPO Dep.

Native Americans' concerns arising from the possibility of establishment of a nuclear repository for high level wastes at Yucca Mountain fall principally into two main categories. First, the strongest objection to the repository comes from traditional Western Shoshones. Their objections are based on a claim that the Western Shoshones still own Yucca Mountain and also on the assertion that putting high level nuclear wastes into the ground is a violation of their religious views regarding nature. Second, there are several reservations around the Yucca Mountain site that might be affected in various ways by building of the repository. There is a question about how many such resenvations there are, which can only be decided when more information is available. This report discusses two questions: the bearing of the continued vigorous assertion by traditionalist Western Shoshones of their land claim; and the extent to which Nevada state and local governments are able to understand and represent Indian viewpoints about Yucca Mountain.

554 (NWPO-SE-044-91) A structural model analysis of public opposition to a high-level radioactive waste facility. Flynn, J. (Nevada Nuclear Waste Project Office, Carson City, NV (United States)); Mertz, C.K.; Slovic, P.; Burns, W. Nevada Nuclear Waste Project Office, Carson City, NV (United States). Sep 1991. 33p. Sponsored by USDOE, Washington, DC (United States). DOE Contract FG08-85NV10461. Order Number DE92017731. Source: OSTI; NTIS; INIS; GPO Dep.

Studies show that most Nevada residents and almost all state officials oppose the proposed high-level radioactive waste repository project at Yucca Mountain. Surveys of the public show that individual citizens view the Yucca Mountain repository as having high risk; nuclear experts, in contrast, believe the risks are very low. Policy analysts have suggested that public risk perceptions may be reduced by better program management, increased trust in the federal government, and increased economic benefits for accepting a repository. The model developed in this study is designed to examine the relationship between public perceptions of risk, trust in risk management, and potential economic impacts of the current repository program using a confirmatory multivariate method known as covariance structure analysis. The results indicate that perceptions of potential economic gains have little relationship to opposition to the repository. On the other hand, risk perceptions and the level of trust in repository management are closely related to each other and to opposition. The impacts of risk perception and trust in management on opposition to the repository result from a combination of their direct influences as well as their indirect influences operating through perceptions that the repository would have serious negative impacts on the state's economy due to stigmatization and reduced tourism.

555 (NWPO-SE-045-92) Social impacts of hazardous and nuclear facilities and events: Implications for Nevada and the Yucca Mountain high-level nuclear waste repository: [Final report]. Freudenburg, W.R. (Wisconsin Univ., Madison, WI (United States)); Carter, L.F.; Willard, W.; Lodwick, D.G.; Hardert, R.A.; Levine, A.G.;
Kroll-Smith, S.; Couch, S.R. Nevada Nuclear Waste Project Office, Carson City, NV (United States). May 1992. 304p. Sponsored by USDOE, Washington, DC (United States). DOE Contract FG08-85NV10461. Order Number DE93013217. Source: OSTI; NTIS; INIS; GPO Dep.

Social impacts of a nuclear waste repository are described. Various case studies are cited such as Rocky Flats Plant, the Feed Materials Production Center, and Love Canal. The social impacts of toxic contamination, mitigating environmental stigma and loss of trust are also discussed.

556 (NWPO-SE-054-92) Expert judgment in assessing radwaste risks: What Nevadans should know about Yucca Mountain: [Final report]. Shrader-Frechette, K. (University of South Florida, Tampa, FL (United States)). Nevada Nuclear Waste Project Office, Carson City, NV (United States). Jun 1992. 225p. Sponsored by USDOE, Washington, DC (United States). DOE Contract FG0885NV10461. Order Number DE93013216. Source: OSTI; NTIS; INIS; GPO Dep.

For phenomena characterized by accurate and largely complete data, quantitative risk assessment (QRA) provides extraordinarily valuable and objective information. However, with phenomena for which the data, models, or probabilities are incomplete or uncertain, QRA may be less useful and more questionable, because its conclusions are typically empirically and theoretically underdetermined. In the face of empirical or theoretical underdetermination, scientists often are forced to make a number of methodological value judgments and inferences about how to estimate and evaluate the associated risks. The purpose of this project is to evaluate instances of methodological value judgments and invalid or imprecise inferences that have occurred in the QRA done for the proposed Yucca Mountain high-level radioactive waste facility. We shall show (1) that questionable methodological value judgments and inferences have occurred in some Yucca Mountain QRA'S; (2) that questionable judgments and inferences, similar to those in the Yucca Mountain studies, have occurred in previous QRA's done for other radiation-related facilities and have likely caused earlier QRA's to err in specific ways; and (3) that, because the value judgments and problems associated with some Yucca Mountain QRA's include repetitions of similar difficulties in earlier studies, therefore the QRA conclusions of some Yucca Mountain analyses are, at best, uncertain.

557 (NWPO-SE-055-92) Institutional trust, information, and risk perceptions: Report of findings of the Las Vegas metropolitan area survey, June 29-July 1, 1992. Mushkatel, A.H. (Arizona State Univ., Tempe, AZ (United States)); Pijawka, K.D. Nevada Nuclear Waste Project Office, Carson City, NV (United States). Sep 1992. 32p. Sponsored by USDOE, Washington, DC (United States). DOE Contract FG08-85NV10461. Order Number DE93013212. Source: OSTI; NTIS; INIS; GPO Dep.

This study reports on the preliminary results of a survey of attitudes and perceptions of Las Vegas area residents regarding the proposed high-level nuclear waste repository. The survey's focus was to examine the various dimensions of trust and confidence in government's efforts to develop the country's nuclear waste repository in Yucca Mountain, Nevada.

558 (NWPO-TN-001-88) A report on high-level nuclear waste transportation: Prepared pursuant to assembly concurrent resolution No. 8 of the 1987 Nevada Legislature. Nevada Nuclear Waste Project Office, Carson 
City, NV (United States). Dec 1988. 163p. Sponsored by USDOE, Washington, DC (United States). DOE Contract FG08-85NV10461. Order Number DE92017707. Source: OSTI; NTIS; INIS; GPO Dep.

This report has been prepared by the staff of the State of Nevada Agency for Nuclear Projects/Nuclear Waste Project Office (NWPO) in response to Assembly Concurrent Resolution No. 8 (ACR 8 ), passed by the Nevada State Legislature in 1987. ACR \& directed the NWPO, in cooperation with affected local governments and the Legislative committee on High-Level Radioactive Waste, to prepare this report which scrutinizes the US Department of Energy's (DOE) plans for transportation of high-level radioactive waste to the proposed yucca Mountain repository, which reviews the regulatory structure under which shipments to a repository would be made and which presents NWPO's plans for addressing high-level radioactive waste transportation issues. The report is divided into three major sections. Section 1.0 provides a review of DOE's statutory requirements, its repository transportation program and plans, the major policy, programmatic, technical and institutional issues and specific areas of concern for the State of Nevada. Section 2.0 contains a description of the current federal, state and tribal transportation regulatory environment within which nuclear waste is shipped and a discussion of regulatory issues which must be resolved in order for the State to minimize risks and adverse impacts to its citizens. Section 3.0 contains the NWPO plan for the study and management of repository-related transportation. The plan addresses four areas, including policy and program management, regulatory studies, technical reviews and studies and institutional relationships. A fourth section provides recommendations for consideration by State and local officials which would assist the State in meeting the objectives of the plan.

559 (NWPO-TN-002-89) Transportation needs assessment: Emergency response section. Nevada Nuclear Waste Project Office, Carson City, NV (United States); Mountain West Research, Las Vegas, NV (United States). May 1989. 588p. Sponsored by USDOE, Washington, DC (United States). DOE Contract FG08-85NV10461. Order Number DE92017709. Source: OSTI; NTIS; INIS; GPO Dep.

The transportation impacts of moving high level nuclear waste (HLNW) to a repository at Yucca Mountain in Nevada are of concern to the residents of the State as well as to the residents of other states through which the nuclear wastes might be transported. The projected volume of the waste suggests that shipments will occur on a daily basis for some period of time. This will increase the risk of accidents, including a catastrophic incident. Furthermore, as the likelihood of repository construction and operation and waste shipments increase, so will the attention given by the national media. This document is not to be construed as a willingness to accept the HLNW repository on the part of the State. Rather it is an initial step in ensuring that the safety and well-being of Nevada residents and visitors and the State's economy will be adequately addressed in federal decision-making pertaining to the transportation of HLNW into and across Nevada for disposal in the proposed repository. The Preferred Transportation System Needs Assessment identifies critical system design elements and technical and social issues that must be considered in conducting a comprehensive transportation impact analysis. Development of the needs assessment and the impact analysis is especially complex because of the absence of information and experience with shipping HLNW and because of the "low probability, high consequence" aspect of the transportation risk.
560 (NWPO-TN-006-90) Probabilistic risk assessment and nuclear waste transportation: A case study of the use of RADTRAN in the 1986 Environmental Assessment for Yucca Mountain. Resnikoff, M. (Radioactive Waste Management Associates, New York, NY (United States)). Nevada Nuclear Waste Project Office, Carson City, NV (United States); Radioactive Waste Management Associates, New York, NY (United States). Dec 1990. 64p. Sponsored by USDOE, Washington, DC (United States). DOE Contract FG08-85NV10461. Order Number DE92017679. Source: OSTI; NTIS; INIS; GPO Dep.

The analysis of the risks of transporting irradiated nuclear fuel to a federal repository, Appendix A of the DOE Environmental Assessment for Yucca Mountain (DOE84), is based on the RADTRAN model and input parameters. The RADTRAN computer code calculates the radiation exposures and health effects under normal or incident-free transport, and over all credible accident conditions. The RADTRAN model also calculates the economic consequences of transportation accidents, though these costs were not included in the Department's Environmental Assessment for the proposed Yucca Mountain repository.

561 (NWPO-TN-007-90) Guidelines on the scope, content, and use of comprehensive risk assessment in the management of high-level nuclear waste transportation. Golding, D. (Clark Univ., Worcester, MA (United States). Center for Technology, Environment, and Development); White, A. Nevada Nuclear Waste Project Office, Carson City, NV (United States). Dec 1990. 45p. Sponsored by USDOE, Washington, DC (United States). DOE Contract FG08-85NV10461. Order Number DE92017678. Source: OSTI; NTIS; INIS; GPO Dep.

This report discusses the scope of risk assessment strategies in the management of the transport of high-level radioactive wastes. In spite of the shortcomings of probabilistic risk assessment(PRA), the Transportation Needs Assessment recommended this as the preferred methodology to assess the risks of high level nuclear waste (HLNW) transportation. A PRA also will need to heed the lessons learned from the development and application of PRA elsewhere, such as in the nuclear power industry. A set of guidelines will aid this endeavor by outlining the appropriate scope, content, and use of a risk assessment which is more responsive to the uncertainties, human-technical interactions, social forces, and iterative relationship with risk management strategies, than traditional PRAS. This more expansive definition, which encompasses but is not totally reliant on rigorous data requirements and quantitative probability estimates, we term Comprehensive Risk Assessment (CRA) Guidelines will be developed in three areas: the limitations of existing methodologies and suggested modifications; CRA as part of a flexible, effective, adaptive risk management system for HLNW transportation; and, the use of CRA in risk communication.

562 (NWPO-TN-010-90) Human and social factors in the transportation of nuclear wastes. Freudenburg, W.R. (Freudenburg and Associates, Middleton, Wisconsin (United States)). Nevada Nuclear Waste Project Office, Carson City, NV (United States). I May 1991. 79p. Sponsored by USDOE, Washington, DC (United States). DOE Contract FG08-85NV10461. Order Number DE92017734. Source: OSTI; NTIS; INIS; GPO Dep.

The main body of this report is a broad-based examination of human and social factors in the transportation of nuclear wastes. It deals with pair interested problems that, 
while familiar to the social science community, appear to have received little attention from the risk assessment community to data: The human and social attenuation of risk estimates, and the organizational amplification of risks. Second, given the special opportunities for learning that are presented by the recent Alaska oil spill, in particular, the Appendix to this report examines the issue of organizational foresight in the context of the Exxon oil spill.

563 (NWPO-TN-011-91-Vol.1) Yucca Mountain transportation routes: Preliminary characterization and risk analysis: Volume 1, Research report. Souleyrette, R.R. II (Nevada Univ., Las Vegas, NV (United States). Transportation Research Center); Sathisan, S.K.; di Bartolo, R. Nevada Nuclear Waste Project Office, Carson City, NV (United States); Nevada Univ., Las Vegas, NV (United States). Transportation Research Center. 31 May 1991. 171p. Sponsored by USDOE, Washington, DC (United States). DOE Contract FG08-85NV10461. (UNLV/TRC/RR91/02-Vol.1). Order Number DE92017892. Source: OSTI; NTIS; INIS; GPO Dep.

In this study, rail and highway routes which may be used for shipments of high-level nuclear waste to a proposed repository at Yucca Mountain, Nevada are characterized. This characterization facilitates three types of impact analysis: comparative study, limited worst-case assessment, and more sophisticated probabilistic risk assessment techniques. Data for relative and absolute impact measures are provided to support comparisons of routes based on selected characteristics. A worst-case scenario assessment is included to determine potentially critical and most likely places for accidents or incidents to occur. The assessment facilitated by the data in this study is limited because impact measures are restricted to the identification of potential areas or persons affected. No attempt is made to quantify the magnitude of these impacts. Most likely locations for accidents to occur are determined relative to other locations within the scope of this study. Independent factors and historical trends used to identify these likely locations are only proxies for accident probability.

564 (NWPO-TN-011-91-Vol.2-3) Yucca Mountain transportation routes: Preliminary characterization and risk analysis: Volume 2, Figures [and] Volume 3, Technical Appendices. Souleyrette, R.R. II (Nevada Univ., Las Vegas, NV (United States). Transportation Research Center); Sathisan, S.K.; di Bartolo, R. Nevada Nuclear Waste Project Office, Carson City, NV (United States); Nevada Univ., Las Vegas, NV (United States). Transportation Research Center. 31 May 1991. 225p. Sponsored by USDOE, Washington, DC (United States). DOE Contract FG0885NV10461. (UNLV/TRC/RR-91/02-Vol.2-3). Order Number DE92017911. Source: OSTI; NTIS; INIS; GPO Dep.

This report presents appendices related to the preliminary assessment and risk analysis for high-level radioactive waste transportation routes to the proposed Yucca Mountain Project repository. Information includes data on population density, traffic volume, ecologically sensitive areas, and accident history.

565

(NWPO-TN-013-91) Organizational management of long-term risks: Implications for risk and safety in the transportation of nuclear wastes. Freudenburg, W.R. (Freudenburg and Associates, Middletown, WI (United States)). Nevada Nuclear Waste Project Office, Carson City, NV (United States). Sep 1991. 79p. Sponsored by USDOE,
Washington, DC (United States). DOE Contract FG0885NV10461. Order Number DE92017708. Source: OSTI; NTIS; INIS; GPO Dep.

The transportation of high-level nuclear waste is often characterized as relatively straightforward at least in terms of hardware; if wastes are to be transported safely, however, it will be necessary to deal not just with hardware, but also with humans. Truly safe operations will require something close to perpetual vigilance, for each and every shipment of nuclear materials, over a period that will span decades of time and an unknown number of political and institutional changes. Nevada has a special relationship to the transportation issue. The state has no commercial nuclear power plants, but if a repository were to be constructed at Yucca Mountain, Nevada would receive all or most of the nation's supply of high-level nuclear waste. The main body of the report is a synthesis of the existing literature on human and social factors in risk management. It deals with a pair of interrelated problems that, while familiar to the social science community, appear to have received little attention to date with respect to the transportation of nuclear wastes: The human and social attenuation of risk estimates, and the organizational amplification of risks. Second, given the special opportunities for learning that are presented by the recent Alaska oil spill, in particular, the Appendix to this report examines the issue of organizational foresight in the context of the Exxon oil spill.

566 (NWPO-TR-011-89) The relationship of the Yucca Mountain repository block to the regional groundwater system: A geochemical model. Matuska, N.A. (Nevada Univ., Reno, NV (United States). Water Resources Center); Hess, J.W. Nevada Nuclear Waste Project Office, Carson City, NV (United States); Nevada Univ., Reno, NV (United States). Water Resources Center. Aug 1989. 149p. Sponsored by USDOE, Washington, DC (United States). DOE Contract FG08-85NV10461. Order Number DE93013204. Source: OSTI; NTIS; INIS; GPO Dep.

Yucca Mountain, in southern Nevada, is being studied by the Department of Energy and the State of Nevada as the site of a high-level nuclear waste repository. Geochemical and isotopic modeling were used in this study to define the relationship of the volcanic tuff aquifers and aquitards to the underlying regional carbonate ground-water system. The chemical evolution of a ground water as it passes through a hypothetical tuffaceous aquifer was developed using computer models PHREEQE, WATEQDR and BALANCE. The tuffaceous system was divided into five parts, with specific mineralogies, reaction steps and temperatures. The initial solution was an analysis of a soil water from Rainier Mesa. The ending solution in each part became the initial solution in the next part. Minerals consisted of zeolites, smectites, authigenic feldspars and quartz polymorphs from described diagentic mineral zones. Reaction steps were ion exchange with zeolites. The solution from the final zone, Part $V$, was chosen as most representative, in terms of $\mathrm{pH}$, element molalities and mineral solubilities, of tuffaceous water. This hypothetical volcanic water from Part $V$ was mixed with water from the regional carbonate aquifer, and the results compared to analyses of Yucca Mountain wells. Mixing and modeling attempts were conducted on wells in which studies indicated upward flow.

567 (NWPO-TR-014-90) Numerical simulation of gas flow through unsaturated fractured rock at Yucca Mountain, Nevada. Cooper, C.A. (Nevada Univ., Las Vegas, NV (United States). Water Resources Center). Nevada 
Nuclear. Waste Project Office, Carson City, NV (United States). Jan 1990. 81p. Sponsored by USDOE, Washington, DC (United States). DOE Contract FG08-85NV10461. Order Number DE93013213. Source: OSTI; NTIS; INIS; GPO Dep.

Numerical analysis is used to identify the physical phenomena associated with barometrically driven gas (air and water vapor) flow through unsaturated fractured rock at Yucca Mountain, Nevada. Results from simple finite difference simulations indicate that for a fractured rock scenario, the maximum velocity of air out of an uncased $10 \mathrm{~cm}$ borehole is $0.002 \mathrm{~m} \mathrm{~s}_{-1}$. An equivalent porous medium (EPM) model was incorporated into a multiphase, multicomponent simulator to test more complex conceptual models. Results indicate that for a typical June day, a diurnal pressure wave propagates about $160 \mathrm{~m}$ into the surrounding Tiva Canyon hydrogeologic unit. Dry air that enters the formation evaporates water around the borehole which reduces capillary pressure. Multiphase countercurrent flow develops in the vicinity of the hole; the gas phase flows into the formation while the liquid phase flows toward the borehole. The effect occurs within $0.5 \mathrm{~m}$ of the borehole. The amount of water vapor leaving the formation during 1 day is $900 \mathrm{~cm}^{3}$. This is less than $0.1 \%$ of the total recharge into the formation, suggesting that the barometric effect may be insignificant in drying the unsaturated zone. However, gas phase velocities out of the borehole $\left(3 \mathrm{~m} \mathrm{~s}^{-1}\right)$, indicating that observed flow rates from wells along the east flank of Yucca Mountain were able to be simulated with a barometric model.

568 (NWPO-TR-016-91) Neotectonics of the southern Amargosa Desert, Nye County, Nevada and Inyo County, California. Donovan, D.E. (Nevada Univ., Reno, NV (United States)). Nevada Nuclear Waste Project Office, Carson City, NV (United States); Nevada Univ., Reno, NV (United States). May 1991. 208p. Sponsored by USDOE, Washington, DC (United States). DOE Contract FG0885NV10461. Order Number DE93018771. Source: OSTI; NTIS; INIS; GPO Dep.

A complex pattern of active faults occurs in the southern Amargosa Desert, southern Nye, County, Nevada. These faults can be grouped into three main fault systems: (1) a NE-striking zone of faults that forms the southwest extension of the left-lateral Rock Valley fault zone, in the much larger Spotted Range-Mine Mountain structural zone, (2) a $\mathrm{N}$-striking fault zone coinciding with a NNW-trending alignment of springs that is either a northward continuation of a fault along the west side of the Resting Spring Range or a $\mathrm{N}$-striking branch fault of the Pahrump fault system, and (3) a NW-striking fault zone which is parallel to the Pahrump fault system, but is offset approximately $5 \mathrm{~km}$ with a left step in southern Ash Meadows. These three fault zones suggest extension is occurring in an E-W direction, which is compatible with the $\sim$ N10W structural grain prevalent in the Death Valley extensional region to the west.

569 (NWPO-TR-018-91) Mesozoic and Cenozoic structural geology of the CP Hills, Nevada Test Site, Nye County, Nevada; and regional implications. Caskey, S.J. (Nevada Univ., Reno, NV (United States)). Nevada Nuclear Waste Project Office, Carson City, NV (United States); Nevada Univ., Reno, NV (United States). Aug 1991. 203p. Sponsored by USDOE, Washington, DC (United States). DOE Contract FG08-85NV10461. Order Number DE93013215. Source: OSTI; NTIS; INIS; GPO Dep.

Detailed mapping and structural analysis of upper Proterozoic and Paleozoic rocks in the CP Hills of the Nevada Test Site, together with analysis of published maps and cross sections and a reconnaissance of regional structural relations indicate that the CP thrust of Barnes and Poole (1968) actually comprises two separate, oppositely verging Mesozoic thrust systems: (1) the west-vergent CP thrust which is well exposed in the CP Hills and at Mine Mountain, and (2) the east-vergent Belted Range thrust located northwest of Yucca Flat. West-vergence of the CP thrust is indicated by large scale west-vergent recumbent folds in both its hangingwall and footwall and by the fact that the $C P$ thrust ramps up section through hangingwall strata toward the northwest. Regional structural relations indicate that the $\mathrm{CP}$ thrust forms part of a narrow sigmoidal belt of westvergent folding and thrusting traceable for over $180 \mathrm{~km}$ along strike. The Belted Range thrust represents earlier Mesozoic deformation that was probably related to the Last Chance thrust system in southeastern California, as suggested by earlier workers. A pre-Tertiary reconstruction of the Cordilieran fold and thrust belt in the region between the NTS and the Las Vegas Range bears a close resemblance to other regions of the Cordillera and has important implications for the development of hinterland-vergent deformation as well as for the probable magnitude of Tertiary extension north of Las Vegas Valley. Subsequent to Mesozoic deformation, the CP Hills were disrupted by at least two episodes of Tertiary extensional deformation: (1) an earlier episode represented by pre-middle Miocene low-angle normal faults, and (2) a later, post-11 Ma episode of high-angle normal faulting. Both episodes of extension were related to regional deformation, the latter of which has resulted in the present basin and range topography of the NTS region.

570 (NWPO-TR-019-92) Review and critique of the US Department of Energy environmental program plan for site characterization for a high-level waste repository at Yucca Mountain, Nevada. Nevada Nuclear Waste Project Office, Carson City, NV (United States). 1992. 65p. Sponsored by USDOE, Washington, DC (United States). DOE Contract FG08-85NV10461. Order Number DE93041147. Source: OSTI; NTIS; INIS; GPO Dep.

This report provides a review and critique of the US Department of Energy (DOE) environmental program plan for site characterization activities at Yucca Mountain which principally addresses compliance with federal and state environmental regulation and to a lesser extent monitoring and mitigation of significant adverse impacts and reclamation of disturbed areas. There are 15 documents which comprise the plan and focus on complying with the environmental requirements of the Nuclear Waste Policy Act, as amended, (NWPA) and with single-media environmental statutes and their regulations. All elements of the plan follow from the 1986 statutory environmental assessment (EA) required by NWPA which concluded that no significant adverse impacts would result from characterization of the Yucca Mountain site. The lack of appropriate environmental planning and review for site characterization at Yucca Mountain points to the need for an oversight function by the State of Nevada. It cannot be assumed that on its own DOE will properly comply with environmental requirements, especially the substantive requirements that comprise the intent of NEPA. Thus, procedures must be established to assure that the environmental interests of the State are addressed in the course of the Yucca Mountain Project. Accordingly, steps will be taken by the State of Nevada to review the soundness and efficacy of the DOE field surveys, monitoring and mitigation activities, reclamation actions, and ecological impact studies that follow from the DOE environmental program plans addressed by this review. 
571 (NWPO-TR-020-93) State of Nevada review of Phase 1 of the INTRAVAL Project. Lehman, L. Lehman (L.) and Associates, Inc., Burnsville, MN (United States). Aug 1992. 9p. Sponsored by USDOE, Washington, DC (United States). DOE Contract FG08-85NV10461. Order Number DE93041148. Source: OSTI; NTIS; INIS; GPO Dep.

The INTRAVAL Project which started in October, 1987 , was designed to be an international cooperation project and is managed by the Swedish Nuclear Power Inspectorate. The project was to undertake the issue of what constitutes a validated model in terms of repository performance assessment. The US Nuclear Regulatory Commission (NRC) in 10CFR60.21 requires an explanation of measures used to support the models utilized in the assessment of pertormance which are included in the License Application. The NRC Nureg 0856, "Final Technical Position on Documentation of Computer Codes for High Level Waste Management" defines the term validation to be, "assurance that a model as embodied in a computer code is a correct representation of the process or system for which it is intended. The notion of validating that a code accurately represents the operational physical processes at a given site has turned out to be a very difficult endeavor. Especially for sites such as Yucca Mountain where the flow regime is poorly known. There is currently no mathematical description of unsaturated flow in fractured - porous media which the majority of the scientific community can support with confidence. Further, all overall performance calculations performed to date by the US DOE assume one dimensional porous flow which enters through the top of Yucca Mountain and makes it way to and through the repository. Not surprisingly these types of calculations lead to the conclusion that little or no release is possible via the groundwater pathway. Quite naturally, the State of Nevada is concerned with these types of calculations, preferring to see something more realistic in terms of conceptual models, fracture pathways, and releases. This concern is carried into the INTRAVAL process because if the DOE is to validate a model of flow at Yucca Mountain within INTRAVAL, the model must be realistic.

572 (ORNL/M-1822) Health and environmental risk-related impacts of actinide burning on high-level waste disposal. Forsberg, C.W. Oak Ridge National Lab., TN (United States). May 1992. 61p. Sponsored by USDOE, Washington, DC (United States). DOE Contract AC0584OR21400. Order Number DE92015564. Source: OSTI; NTIS; INIS; GPO Dep.

The potential health and environmental risk-related impacts of actinide burning for high-level waste disposal were evaluated. Actinide burning, also called waste partitioningtransmutation, is an advanced method for radioactive waste management based on the idea of destroying the most toxic components in the waste. It consists of two steps: (1) selective removal of the most toxic radionuclides from high-level/ spent fuel waste and (2) conversion of those radionuclides into less toxic radioactive materials and/or stable elements. Risk, as used in this report, is defined as the probability of a failure times its consequence. Actinide burning has two potential health and environmental impacts on waste management. Risks and the magnitude of high-consequence repository failure scenarios are decreased by inventory reduction of the long-term radioactivity in the repository. (What does not exist cannot create risk or uncertainty.) Risk may also be reduced by the changes in the waste characteristics, resulting from selection of waste forms after processing, that are superior to spent fuel and which lower the potential of transport of radionuclides from waste form to accessible environment. There are no negative health or environmental impacts to the repository from actinide burning; however, there may be such impacts elsewhere in the fuel cycle.

573 (PB-92-156819/XAB) Fourth report to the U.S. Congress and the U.S. Secretary of Energy from the Nuclear Waste Technical Review Board. Nuclear Waste Technical Review Board, Washington, DC (United States). Dec 1991. 106p. Source: NTIS Prices: PC A06/MF A02; INIS.

Also available from Supt. of Docs. See also PB91. 220467

The Nuciear Waste Technical Review Board (the Board) submitted its Fourth Report as required by the Nuclear Waste Policy Amendments Act of 1987, Public Law 100203. Congress created the Board to evaluate the technical and scientific aspects of the Department of Energy's (DOE) program to manage the permanent disposal of the nation's civilian spent fuel and high-level radioactive waste. Specifically, the Board is evaluating site-characterization activities at Yucca Mountain, Nevada, as well as repository design features that could influence spent fuel packaging and transport activities. As a result of its most recent scientific and technical review of the DOE's civilian radioactive waste disposal program, the Board would like to make several recommendations that it believes will help the DOE in its efforts to characterize the Yucca Mountain site as well as to develop an efficient civilian radioactive waste disposal program. In the report, the Board has suggested that the DOE consider some enhancements to its design approach and schedule for the construction of the exploratory studies facility, the key component to underground site characterization. The Board believes that these enhancements would help in achieving an earlier determination of site suitability, which will require both subsurface and surface-based site characterization. In this way, given adequate funding and the necessary permits, the DOE should be able to progress toward the major milestones of the program in a timely and efficient manner.

574 (PB-92-187616/XAB) Second report to the U.S. Congress and the U.S. Secretary of Energy from the Nuclear Waste Technical Review Board. Nuclear Waste Technical Review Board, Washington, DC (United States). Nov 1990. 90p. Source: NTIS Prices: PC A05/MF A01.

See also PB91-138214 and PB91-220467.

The Nuclear Waste Technical Review Board (Board) herewith submits its second report as required by the Nuclear Waste Policy Amendments Act of 1987, Public Law 100203. Congress created the Board to evaluate the scientific and technical validity of activities undertaken by the Department of Energy (DOE) in its civilian high-level nuclear waste disposal program. The Board is charged with evaluating the DOE's characterization of Yucca Mountain as a potential location for a repository for the permanent disposal of highlevel radioactive waste $(\mathrm{HLW})$. The Board also will evaluate activities relating to the packaging and transportation of HLW. During the seven months since its First Report, the Board pursued the issues it outlined in that report as planned future activities. In the report the Board evaluates its interactions with the DOE and other organizations. It also assesses information from other sources and comments on recent developments at the DOE. At this time, the Board has no specific recommendations that require congressional action. It does, however, make a number of recommendations 
regarding the DOE program for radioactive waste management that are intended to improve ongoing technical work.

575 (PB-93-130615/XAB) Fifth report to the US Congress and the US Secretary of Energy from the Nuclear Waste Technical Review Board. Nuclear Waste Technical Review Board, Washington, DC (United States). Jun 1992. 115p. Source: NTIS Prices: PC A06/MF A02.

Also available from Supt. of Docs. See also PB-92156819 .

The Nuclear Waste Technical Review Board (the Board) herewith submits its Fifth Report as required by the Nuclear Waste Policy Amendments Act of 1987, Public Law 100203. Congress created the Board to evaluate the technical and scientific validity of the Department of Energy's (DOE) program to manage the permanent disposal of the nation's civilian spent fuel and high-level radioactive waste. Specifically, the Board is charged with evaluating the DOE's site-characterization activities at Yucca Mountain, Nevada, as well as activities relating to the design of the repository and to the packaging and transport of spent fuel and highlevel radioactive waste. As in all of the Board's past reports, activities are reviewed and recommendations are presented based primarily on the breakdown of the Board's technical panels. The report is somewhat different, however, in that the Board has chosen to address an issue that it believes has wide-ranging implications for the entire waste management system: the thermal loading of a repository. The thermal-loading strategy used to control the temperatures in a repository will affect the design and long-term performance of the repository, as well as many other aspects of the waste management system, from spent fuel storage through final disposal. It is, therefore, a fundamental decision in the U.S. waste management program.

576 (PNL-6099) Preliminary characterization of risks in the nuclear waste management system based on information in the literature. Daling, P.M. (Pacific Northwest Lab., Richland, WA (United States)); Rhoads, R.E.; Van Luick, A.E.; Fecht, B.A.; Nilson, S.A.; Sevigny, N.L.; Armstrong, G.R.; Hill, D.H.; Rowe, M.; Stern, E. Pacific Northwest Lab., Richland, WA (United States). Jan 1992. 291p. Sponsored by USDOE, Washington, DC (United States). DOE Contract AC06-76RL01830. Order Number DE92007603. Source: OSTI; NTIS; INIS; GPO Dep.

This document presents preliminary information on the radiological and nonradiological risks in the nuclear waste management system. The objective of the study was to (1) review the literature containing information on risks in the nuclear waste management system and (2) use this information to develop preliminary estimates of the potential magnitude of these risks. Information was collected on a broad range of risk categories to assist the US Department of Energy (DOE) in communicating information about the risks in the waste management systems. The study examined all of the portions of the nuclear waste management system currently expected to be developed by the DOE. The scope of this document includes the potential repository, the integral MRS facility, and the transportation system that supports the potential repository and the MRS facility. Relevant literature was reviewed for several potential repository sites and geologic media. A wide range of "risk categories" are addressed in this report: (1) public and occupational risks from accidents that could release radiological materials, (2) public and occupational radiation exposure resulting from routine operations, (3) public and occupational risks from accidents involving hazards other than radioactive materials, and (4) public and occupational risks from exposure to nonradioactive hazardous materials during routine operations. The report is intended to provide a broad spectrum of riskrelated information about the waste management system. This information is intended to be helpful for planning future studies.

577 (SAND-91-0079) Over-the-road tests of nuclear materials package response to normal environments. Gwinn, K.W.; Glass, R.E.; Edwards, K.R. Sandia National Labs., Albuquerque, NM (United States). Dec 1991. 98p. Sponsored by USDOE, Washington, DC (United States). DOE Contract AC04-76DP00789. (TTC-1072). Order Number DE92019767. Source: OSTI; NTIS; INIS; GPO Dep.

In support of the development of American National Standards institute standards for the transport of radioactive materials, Sandia has a program to characterize the normal transport environment. This program includes both analytical modeling of package and trailer responses, and over-theroad tests to measure those responses. This paper presents the results of a series of over-the-road tests performed using Chem-Nuclear equipment in the Barnwell, SC, area. The test events included a variety of road types such as rough concrete, shock events such as railroad grade crossings, and driver responses such as sharp turns. The response of the package and trailer to these events was measured with accelerometers at various locations to determine the inertial loads. Either load cells or strain gages were used to measure tiedown response. These accelerations and loads were measured on systems with flexible and "rigid" tiedowns. The results indicated that while significant accelerations occur on the trailer bed, these do not translate into equivalent loads in either the package or the tiedown system. This indicates that trailer-bed response should not be used in determining the load factor for fatigue calculations of the package components or in determining design loads for tiedowns.

578 (SAND-91-1988C) Developing conceptual models for performance assessment of waste management sites. Kerl, F.A. (New Mexico Univ., Albuquerque, NM (United States). Dept. of Chemical and Nuclear Engineering); Heger, A.S.; Gallegos, D.P. Sandia National Labs., Albuquerque, NM (United States). [1991]. 14p. Sponsored by USDOE, Washington, DC (United States). DOE Contract AC04-76DP00789. (CONF-910435-92: 2. annual American Nuclear Society (ANS) international high level radioactive waste management conference, Las Vegas, NV (United States), 28 Apr - 3 may 1991). Order Number DE92006765. Source: OSTI; NTIS; INIS; GPO Dep.

The conceptual model development process involves making simplifying assumptions about the description and behavior of the natural repository system. To better understand how conceptual models are developed, it is important to explicitly identify and document the process. To investigate the conceptual model development process, conceptualizations of groundwater flow systems for Avra Valley and the potential high-level radioactive waste repository site at Yucca Mountain have been reviewed to identify assumptions. Additionally, a formal expert judgment elicitation has been performed to obtain and document information about the conceptual model development process. The results from both these exercises are represented as a set of assumptions, possible choices for each assumption, and the relationships among the assumptions. From this information, the development of conceptual models can be described as the process by which, for a given site and purpose, choices are made for each of the assumptions dependent upon their 
established relationships. Developing a comprehensive understanding of the conceptual model development process is a step toward addressing the uncertainty associated with conceptual models developed for repository performance assessment. The information presented does provide a significant contribution toward documenting and defining the conceptual model development process.

579 (SAND-91-1993C) Impact of fracture coatings on the transfer of water across fracture faces in unsaturated media. Gallegos, D.P. (Sandia National Labs., Albuquerque, NM (United States)); Thoma, S.G.; Smith, D.M. Sandia National Labs., Albuquerque, NM (United States). [1991]. 6p. Sponsored by USDOE, Washington, DC (United States). DOE Contract AC04-76DP00789. (CONF920430-1: 3. international high level radioactive waste management (IHLRWM) conference, Las Vegas, NV (United States), 12-16 Apr 1992). Order Number DE91018684. Source: OSTI; NTIS; INIS; GPO Dep.

Ground water flow in unsaturated, fractured rock is often assumed to be dominated by the porous matrix component. This is frequently based on the argument that water flowing in the fractures is rapidly imbibed into the rock matrix by capillary suction forces with negligible resistance to uptake at the matrix-fracture interface. However, the existence of a low-permeability mineralized layer or coating at this interface may substantially reduce matrix imbibition and consequently result in fracture-dominated flow. To test this concept, four tuff samples containing natural tractures were obtained from tuff formations in southern Nevada. By performing imbibition experiments into the matrix rock, across a mineralized fracture face and then across a fresh uncoated fracture face, water uptake as a function of time and coating was measured. A relatively simple model has been developed to describe the imbibition behavior. 6 refs.

580 (SAND-91-2266C) Changes in risk perception over time. Gomez, L.S. (Sandia National Labs., Albuquerque, NM (United States)); Jenkins-Smith, H.C.; Miller, K.W. Sandia National Labs., Albuquerque, NM (United States). Jan 1992. 15p. Sponsored by USDOE, Washington, DC (United States). DOE Contract AC04-76DP00789. (CONF-920260-3: American Association for the Advancement of Science (AAAS) annual meeting, Chicago, IL (United States), 7-11 Feb 1992). Order Number DE92011180. Source: OSTI; NTIS; INIS; GPO Dep.

The focus of this paper is on changes in perceptions of the risks associated with nuclear waste management over time. In particular, we are interested in the kinds of change that take place when the management programs, and those who are charged with implementing them, are subject to intensive public debate over an extended period of time. We are undertaken an over-time study of perceived risks in Colorado and New Mexico by implementing sequential random household surveys in each state, timed at six month intervals. This study employs three of these surveys, spanning the period from summer, 1990 to summer, 1991. Using these data, we examine the dynamics that may underlie variations in perceived risks over time. In particular, our analysis is focused on changes in the roles played by (1) basic political orientations (i.e. political ideology) and (2) trust in those who advocate conflicting policy positions.

581 (SAND-92-0472C) Intra-site secure transport vehicle. Plugge, M.; Scott, S. Sandia National Labs., Albuquerque, NM (United States). [1992]. 6p. Sponsored by USDOE, Washington, DC (United States). DOE Contract
AC04-76DP00789. (CONF-9207102-40: Institute of Nuclear Materials Management (INMM) annual meeting, Orlando, FL (United States), 19-22 Jul 1992). Order Number DE92018824. Source: OSTI; NTIS (US Sales Only); GPO Dep.

During the 1980's many facilities involved in handling nuclear material realized a need to enhance safety and security for movement of sensitive materials within their facility, or "intra-site." There have been several prior efforts to improve on-site transportation, including the unique Device Transport Vehicle for the Nevada Test Site. However, there remains a requirement for an improved on-site transporter for a number of other DOE facilities. The requirements for the vehicle are driven by security, safety, and operational concerns. There also is the opportunity to provide a standardized vehicle design. This has many advantages in common validation and certification, training, maintenance, and upgrades. Finally, although the intra-site Secure Transport Vehicle (ISTV) is being designed to address on-site transportation issues at DOE facilities, the vehicle has application to other transportation concerns where enhanced security or improved cargo protection in impact or fire environments is needed.

582 (SAND-92-0556) Evaluation of alternatives for high-level and transuranic radioactive- waste disposal standards. Klett, R.D. (Sandia National Labs., Albuquerque, NM (United States)); Gruebel, M.M. Sandia National Labs., Albuquerque, NM (United States). Dec 1992. 134p. Sponsored by USDOE, Washington, DC (United States). DOE Contract AC04-76DP00789. Order Number DE93006986. Source: OSTI; NTIS; INIS; GPO Dep.

The remand of the US Environmental Protection Agency's long-term performance standards for radioactive-waste disposal provides an opportunity to suggest modifications that would make the regulation more defensible and remove inconsistencies yet retain the basic structure of the original rule. Proposed modifications are in three specific areas: release and dose limits, probabilistic containment requirements, and transuranic-waste disposal criteria. Examination of the modifications includes discussion of the alternatives, demonstration of methods of development and implementation, comparison of the characteristics, attributes, and deficiencies of possible options within each area, and analysis of the implications for performance assessments. An additional consideration is the impact on the entire regulation when developing or modifying the individual components of the radiological standards.

583 (SKB-TR-90-14) Geomorphological and hydrogeological features of the Pocos de Caldas caldera and the Osamu Utsumi mine and Morro do Ferro analogue study sites, Brazil: Pocos de Caldas Report No. 5. Holmes, D.C. (British Geological Survey, Keyworth, Nottingham (United Kingdom)); Pitty, A.E.; Noy, D.J. Brazil; SKB(SE); NAGRA(CH); DOE(GB); DOE(US) collaboration. Swedish Nuclear Fuel and Waste Management Co., Stockholm (Sweden). 1990. 68p. Order Number DE92613489. Source: OSTI; NTIS (US Sales Only); INIS.

The Osamu Utsumi mine and Morro do Ferro study sites lie within the Pocos de Caldas plateau which is roughly circular in outline with a diameter of $35 \mathrm{~km}$ and an area of approximately $800 \mathrm{~km}^{2}$. Its general altitude lies between 1300 and $1600 \mathrm{~m}$. The plateau is the eroded form of a caldera which was initially intruded some 80 million years ago. Geomorphologically, both sites occupy watershed areas adjacent to small streams in the centre of the plateau. 
The climate of the area has a market wet season from November to April and is dry the rest of the year. The streams are ephemeral in their upper reaches, tending to dry up in the dry season as they are fed by a declining base flow. In the wet season they exhibit flash flood fed by highintensity rainfall causing overland flow. The wet season also provides recharge to the groundwater. Natural slopes are steep and the original vegetation was thin forest cover which is now restricted to the valley bottoms; usable slopes have poor quality grass cover used for cattle grazing. The plateau is a stable feature and its surface has been eroding at an average rate of $12 \mathrm{~m}$ per million years over a period of 50 million years. The mine geology is dominantly volcanic to subvolcanic phonolites that have been hydrothermally altered. Fracturing of the rock is extensive. Downward diffusion of oxygen in groundwaters during deep weathering has produced a distinct redox zone seen as a colour change from green/grey to brown/yellow. Morro do Ferro has a more weathered version (laterite/clay) of the same geology penetrated by magnetite breccia dykes. Whilst the area surrounding Morro do Ferro remains untouched, that around the mine has been seriously disturbed by mining activity which has penetrated the water-table. The existing mine has modified groundwater flow patterns and disturbed the movement of oxidising and reducing waters. (au) (47 refs.).

584 (SKB-TR-90-15) Chemical and isotopic composition of groundwaters and their seasonal variability at the OSAMU Utsumi mine and Morro do Ferro analogue study sites, Pocos de Caldas, Brazil: Pocos do Caldas Report No. 6. Nordstrom, D.K. (U.S. Geological Survey, Menlo Park, CA (United States)); Smellie, J.A.T.; Wolf, M. Brazil; SKB(SE); NAGRA(CH); DOE(GB); DOE(US) collaboration. Swedish Nuclear Fuel and Waste Management Co., Stockholm (Sweden). 1990. 122p. Order Number DE92613512. Source: OSTI; NTIS (US Sales Only); INIS.

Groundwaters and a few surface waters were collected over a period of 3 years from two natural analogue sites near Pocos de Caldas, Brazil: the Osamu Utsumi uranium mine and the Morro do Ferro thorium/rare-earth deposit. These were analysed for major constituents, several trace elements, tritium, deuterium and ${ }^{18} \mathrm{O}$, to provide hydrochemical data for the modelling objectives as defined within the natural analogue study programme. The groundwaters are $\mathrm{K}-\mathrm{Fe}-\mathrm{SO}_{4}$ type, which classifies them as a highly unusual composition related to the weathering of a hydrothermally altered, mineralised complex of volcanic to sub-volcanic phonolites. A subset of selected constituents ( $\mathrm{Fe}(\mathrm{II})$, $\mathrm{Fe}$ (total), $\mathrm{SO}_{4}, \mathrm{pH}$, Eh, alkalinity, $\mathrm{F}$ and $\mathrm{U}$ ) was monitored to gain detailed information on the seasonal variability. Seasonal patterns were only apparent from the very shallow groundwater data, but a trend of continuously increasing dissolved solids for the furthest down-gradient sampling point in deep groundwater indicates a growing plume of water affected by pyrite oxidation but without the residual acidity. Tritium and stable isotope measurements indicate that all groundwaters are of meteoric origin and are not affected significantly by evaporation or by water-rock interactions. Recharging groundwaters at both study site demonstrate infiltration of water of less than about 35 years in age, whereas deep groundwaters are below 1 TU (tritium unit) but still contain detectable tritium in most cases. These deeper groundwaters may be interpreted as being 35-60 or more years in age, resulting mainly from an admixture of younger with older groundwaters and/or indicating the influence of subsurface-produced tritium. (au).
585 (SKB-TR-90-19) Microbiological analysis at the Osamu Utsumi mine and Morro do Ferro analogue study sites, Pocos de Caldas, Brazil: Pocos de Caldas Report No. 10. West, J.M. (British Geological Survey, Nottingham (United Kingdom)); Vialta, A.; McKinley, I.G. Brazil; SKB(SE); NAGRA(CH); DOE(GB); DOE(US) collaboration. Swedish Nuclear Fuel and Waste Management Co., Stockholm (Sweden). 1990. 44p. (NAGRA-NTB-90-28; UKDOE-WR-90-050). Order Number DE92613462. Source: OSTI; NTIS (US Sales Only); INIS.

The Pocos de Caldas project is a wide-ranging natural analogue study focussed on a number of areas of concern in the performance assessment of the disposal of radioactive waste. Part of the work has involved characterising microbial populations and their influence in various processes. Core material and groundwaters have been sampled for microbiological content at various depths form boreholes at the Osamu Utsumi open pit uranium mine and Morro do Ferro Th/REE ore body. Microbes were found in all samples but numbers do not appear to be related to depth. Analyses of groundwaters gave higher numbers than with solid material and demonstrated the presence of sulphur cycle bacteria. These observations have been compared with predictions of a model used in performance assessment to calculate the maximum biomass/microbial activity based on constraints set by available nutrients and energy. The main conclusions of this analysis are: 1 . Low microbial activities can be supported by the energy and nutrients supplied by alteration processes at or around the redox front. The maximum annual production of approximately equal to $0.01-0.1 \mathrm{~g}$ biomass (dry) $/ \mathrm{m}^{2}$ of redox front is in reasonable agreement with observed standing populations. 2. The presence of high concentrations of sulphate reducing bacteria around the redox front indicate a complex sulphur geochemistry which may be predominantly microbially catalysed and could explain the nodular form of pitchblende concretions and the presence of secondary pyrite. 3 . There is little trace element mobilisation by organic byproducts and the main role of microbes in this system is to catalyse specific redox reactions. (au).

586 (SKB-TR-90-22) Near-field high-temperature transport: Evidence from the genesis of the Osamu Utsumi uranium mine, Pocos de Caldas alkaline complex, Brazil: Pocos de Caldas Report No. 13. Cathles, L.M. (Cornell Univ., Dept. of Geological Sciences, Ithaca, New York (United States)); Shea, M.E. Brazil; SKB(SE); NAGRA(CH); DOE(GB); DOE(US) collaboration. Swedish Nuclear Fuel and Waste Management Co., Stockholm (Sweden). 1990. 60p. Order Number DE92613490. Source: OSTI; NTIS (US Sales Only); INIS.

The chemical, isotopic and mineralogical alteration which occurred during primary uranium ore deposition at the breccia pipe-hosted Osamu Utsumi mine, Pocos de Caldas, Brazil, was studied as a natural analogue for near-field radionuclide migration. Chemical and isotopic alteration models were combined with finite difference models of the convective cooling of caldera intrusives. Application of the chemical models successfully used to interpret mineralization and alteration at the Osamu Utsumi mine to the hypothetical waste repository shows that even in a worst case scenario (waste emplaced in a permeable host rock with no measures taken to inhibit flow through the repository), the amount of hydrothermal alteration in the hypothetical repository will be about $0.1 \%$ of that in the breccia pipe at the Osamu Utsumi mine. Assuming no barriers to 
uranium mobility, uranium precipitation above the hypothetical repository would be $0.05 \mathrm{ppm}$ (rather than $50 \mathrm{ppm}$ ), hydrothermal alteration $0.03 \mathrm{wt} . \%$ (rather than $30 \mathrm{wt} . \%$ ), etc. The analysis indicates that mineralogical alteration is extremely sensitive to thermodynamic data. Prediction of mineralogical alteration (which may be necessary to predict the migration of radionuclides other than uranium, for example) probably cannot be based directly on even very carefully collected laboratory thermodynamic data. Mineralogical complexities of the system, as well as database uncertainties, will require calibration of the thermodynamic framework against mineralogical alteration observed in the laboratory or field by procedures briefly described. (au).

587 (SKB-TR-91-59, pp. 11-22) Performance assessment perspectives with reference to the proposed repository at Yucca Mountain, Nevada. Murphy, W.M. (Center for Nuclear Waste Regulatory Analyses, San Antonio, TX (USA)). Swedish Nuclear Fuel and Waste Management Co., Stockholm (Sweden). Dec 1991. (CONF9010497-: Technical workshop on near field performance assessment for high-level waste, Madrid (Spain), 15-17 Oct 1990). In Proceedings from the technical workshop on nearfield performance assessment for high-level waste. 190p. Order Number DE92644559. Source: OSTI; NTIS; INIS.

The near-field environment of geologic repositories for high-level nuclear waste (HLW) encompasses the interface between engineered waste containment structures and the geologic surroundings. Near-field fluxes of heat and mass, fields of radiation and stress and the effects of these fluxes and fields on the physical and chemical characteristics of the system are critical to the performance of the geologic repository. The relations among transient and heterogeneous thermal, hydrologic, physical, chemical and radiologic phenomena over the large time and space scales of a geologic repository are incompletely understood. Simplified mathematical and statistical models, which are generally required in present-day performance assessments of HLW systems, can not be expected to represent the complex interactions in detail. These models are justified in part on the basis of conservatism in assumptions and parameters and sensitivity and uncertainty analyses. They must also be supported by comparisons with more detailed theoretical and experimental analyses that are capable of identifying and quantifying significant synergistic effects and assessing the conservatism of the simpler models. The purpose of this paper is to review the general physical and chemical features of the HLW near-field environment. Examples are drawn from selected theoretical, experimental and field analyses of thermal, hydrological, mechanical and chemical phenomena relevant to performance assessments of the proposed repository at Yucca Mountain, Nevada, USA. The consequences of the environmental characteristics for waste isolation and their significance for performance assessments are the focus of other contributions to this volume and will be addressed only generally in this paper. (au) (41 refs.).

588 (SKN-55, pp. 69-86) The Nuclear Waste Technical Review Board - Two years of experience in the US Waste Programme. Do we as reviewers communicate understandably with society?. Deere, D.U. (Nuclear Waste Technical Review Board (United States)). National Board for Spent Nuclear Fuel, Stockholm (Sweden). Feb 1992. (CONF-9109468-: Nuclear waste management review work, Stockhoim (Sweden), 25-26 Sep 1991). In Nuclear waste management review work - part of the decision making process. [149p.] Order Number DE93617548. Source: OSTI; NTIS; INIS.

The Board was established by the U.S. Congress in the Nuclear Waste Policy Amendments Act of 1987. That is the same legislation that directed the U.S. Department of Energy (DOE) to evaluate a site at Yucca Mountain, Nevada, to determine its potential suitability for a repository to hold U.S. civilian spent fuel and some high-level defense waste. The Board is charged with evaluating the technical and scientific validity of nuclear waste disposal activities undertaken by the DOE, including 1 . site-characterization activities, and 2. activities related to the packaging or transport of high-level radioactive waste or spent nuclear fuel. The Board has a full complement of 11 members, who are to be eminent in a field of science or engineering, including environmental sciences. The law stipulates that members shall represent a broad range of scientific and engineering disciplines related to nuclear waste management. The Board is required to report its findings, conclusions, and recommendations to the U.S. Congress and the Secretary of Energy at least twice a year. (au).

589 (TID 29442) Report to the President by the Interagency Review Group on Nuclear Waste Management. Interagency Review Group on Nuclear Waste Management, Washington, DC (United States). Mar 1979. 251p. Source: NTIS, PC A12/MF A01.

This final report presents the findings, policy considerations, and recommendations reached by the IRG. The findings and recommendations reflect the unanimous views of the participating agencies. Independent views of some members and public comments are also included. Technical strategies for high-level and transuranic wastes, and for other waste types, were examined. Institutional issues and management considerations were also taken into account. (DLC)

590 (UCRL-53929-90, pp. 107-108) Evaluation of lead contamination in drillback mudpits using isotopic ratios. Niemeyer, S.; Brown, J. Lawrence Livermore National Lab., CA (United States). 1991. In Nuclear testexperimental science annual report, Fiscal year 1990. 194p. Order Number DE92014082. Source: OSTI; NTIS; INIS.

Evaluation of lead concentrations at the Nevada Test Site is of primary concern because devices are typically emplaced with tons of lead. The premise of this study was that the isotopic composition of the lead loaded with a device at the Nevada Test Site will differ significantly from the lead isotopic composition of the test site rocks. The results indicate that sludge generated by NTS drillback operations does not contain significant amounts of lead from the devices. The diversity of lead isotopic compositon among samples from individual mudpits probably reflects the diversity of natural geologic materials excavated, although contamination from atmospheric aerosols remains possible. 1 ref., 1 fig.

591 (UCRL-CR-106983) LLNL/YMP Waste Container Fabrication and Closure Project: GFY technical activity summary. Babcock and Wilcox Co., Alliance, $\mathrm{OH}$ (United States). Contract Research Div. Oct 1990. 153p. Sponsored by USDOE, Washington, DC (United States). DOE Contract W-7405-ENG-48. Order Number DE92000085. Source: OSTI; NTIS; INIS; GPO Dep.

The Department of Energy's Office of Civilian Radioactive Waste Management (OCRWM) Program is studying Yucca Mountain, Nevada as a suitable site for the first US highlevel nuclear waste repository. Lawrence Livermore National 
Laboratory (LLNL) has the responsibility for designing and developing the waste package for the permanent storage of high-level nuclear waste. This report is a summary of the technical activities for the LLNL/YMP Nuclear Waste Disposal Container Fabrication and Closure Development Project. Candidate welding closure processes were identified in the Phase 1 report. This report discusses Phase 2. Phase 2 of this effort involved laboratory studies to determine the optimum fabrication and closure processes. Because of budget limitations, LLNL narrowed the materiais for evaluation in Phase 2 from the original six to four: Alloy 825, CDA 715, CDA 102 (or CDA 122) and CDA 952. Phase 2 studies focused on evaluation of candidate material in conjunction with fabrication and closure processes.

592 (UCRL-ID-112789) Risk-based screening analysis of ground water contaminated by radionuclides introduced at the Nevada Test Site (NTS). Daniels, J.I. (Lawrence Livermore National Lab., CA (US)); Anspaugh, L.R.; Andricevic, R.; Jacobson, R.L. Lawrence Livermore National Lab., CA (United States). Jun 1993. 29p. Sponsored by USDOE, Washington, DC (United States). DOE Contract W-7405-ENG-48. Order Number DE93016954. Source: OSTI; NTIS; INIS; GPO Dep.

The Nevada Test Site (NTS) is located in the southwestern part of Nevada, about $105 \mathrm{~km}(65 \mathrm{mi})$ northwest of the city of Las Vegas. Underground tests of nuclear weapons devices have been conducted at the NTS since late 1962 and ground water beneath the NTS has been contaminated with radionuclides produced by these tests. This concern prompted this examination of the potential health risk to these individuals from drinking the contaminated ground water either at a location on the NTS (assuming loss of institutional control after $100 \mathrm{y}$ ) or at one offsite (considering groundwater migration). For the purpose of this assessment, a representative mix of the radionuclides of importance and their concentrations in ground water beneath the NTS were identified from measurements of radionuclide concentrations in groundwater samples-of-opportunity collected at the NTS. Transport of radionuclide-contaminated ground water offsite was evaluated using a travel-time-transport approach. At both locations of interest, potential human-health risk was calculated for an individual ingesting radionuclidecontaminated ground water over the course of a 70-y lifetime. Uncertainties about human physiological attributes, as well as about estimates of physical detriment per unit of radioactive material, were quantified and incorporated into the estimates of risk. The maximum potential excess lifetime risk of cancer mortality estimated for an individual at the offsite location ranges from $7 \times 10^{-7}$ to $1 \times 10^{-5}$, and at the onsite location ranges from $3 \times 10^{-3}$ to $2 \times 10^{-2}$. Both the offsite and the onsite estimates of risk are dominated by the lifetime doses from tritium. For the assessment of radionuclides in ground water, the critical uncertainty is their concentration today under the entire NTS.

593 (UCRL-JC-109623) Rock mechanics contributions from defense programs. Heuze, F.E. Lawrence Livermore National Lab., CA (United States). Feb 1992. 24p. Sponsored by USDOE, Washington, DC (United States). DOE Contract W-7405-ENG-48. (CONF-920634 10: 33. US symposium on rock mechanics, Santa $\mathrm{Fe}$, NM (United States), 3-10 Jun 1992). Order Number DE92008061. Source: OSTI; NTIS; INIS; GPO Dep.

An attempt is made at illustrating the many contributions to rock mechanics from US defense programs, over the past 30-plus years. Large advances have been achieved in the technology-base area covering instrumentation, material properties, physical modeling, constitutive relations and numerical simulations. In the applications field, much progress has been made in understanding and being able to predict rock mass behavior related to underground explosions, cratering, projectile penetration, and defense nuclear waste storage. All these activities stand on their own merit as benefits to national security. But their impact is even broader, because they have found widespread applications in the non-defense sector; to name a few: the prediction of the response of underground structures to major earthquakes, the physics of the earth's interior at great depths, instrumentation for monitoring mine blasting, thermo-mechanical instrumentation useful for civilian nuclear waste repositories, dynamic properties of earthquake faults, and transient largestrain numerical modeling of geological processes, such as diapirism. There is not pretense that this summary is exhaustive. It is meant to highlight success stories representative of DOE and DOD geotechnical activities, and to point to remaining challenges.

594 (USGS-OFR-92-130) Ground-water data collected at the Nevada Test Site and vicinity, Nye County, Nevada, water years 1988-89. Wood, D.B. Geological Survey, Carson City, NV (United States). 1992. 66p. Sponsored by USDOE, Washington, DC (United States). DOE Contract Al08-86NV10583. Order Number DE93017646. Source: OSTI; NTIS; INIS; US Geological Survey, Books and OpenFile Reports Section, Federal Center, Box 25425, Denver, CO 80225 (US); GPO Dep.

The US Geological Survey, in support of the US Department of Energy Hydrology/Radionuclide Migration Program, collects and compiles hydrologic and geohydrologic data to aid in characterizing the regional and local ground-water flow systems underlying the Nevada Test Site. This report presents selected ground-water data collected from wells and test holes at and in the vicinity of the Nevada Test Site. Depth-to-water measurements were made at 72 sites and water samples were collected and analyzed for tritium concentrations for 14 sites during the 1988 and 1989 water years. Available historical data for these sites have been included to show the long-term depth-to-water fluctuations and to provide a record of all reported completion depths or open intervals for associated wells and test holes. Depth-to-water measurements show that the altitude of the ground-water surface in the Nevada Test Site area ranged from 1,966 to 6,377 feet above sea level. Depth-to-water measurements were obtained by a combination of wire-line, steel-tape, and iron-horse methods. Tritium concentrations in bailed water samples ranged from -10 to 2,600 picocuries per liter.

595 (USGS-OFR-93-187) A portable vacuum hammer seismic source for use in tunnel environments. Carroll, R.D.; Magner, J.E. Geological Survey, Denver, CO (United States). 1993. 37p. Sponsored by USDOE, Washington, DC (United States). Order Number DE93015498. Source: OSTI; NTIS; US Geological Survey, Books and Open-File Reports Section, Box 25425, Federal Center, Denver, CO 80225 (US); GPO Dep.

Concern for the measurement of seismic refraction velocities in tunnel areas where cables, construction features, and other sensitive structures render the use of dynamite sources unwise, resulted in the design of a vacuum-driven impact system utilizing a $43-\mathrm{kg}(94-\mathrm{lb})$ weight in a $2-\mathrm{m}(6.5-$ $\mathrm{ft}$ tube. The system is portable, quickly assembled and disassembled, and requires only standard electrical power, an air pressure supply, and a laboratory vacuum pump to 
operate. The maximum weight of any component is $84 \mathrm{~kg}$ (185 $\mathrm{lb})$, the remaining components being significantly lighter. Tests in volcanic rock tunnels in Rainier Mesa at the Nevada Test Site indicate maximum energy generated by the system is in the SV wave. When the system was employed at angles other than vertical, a polarized $\mathrm{SH}$ mode was also observed. The hammer was used to obtain velocities in an in-hole survey in a 138-m horizontal hole drilled behind the flat face of the Red Hot chamber after the Red Hot nuclear detonation. A large decrease was observed in compressional velocity compared with pre-event values. Because 20 years have elapsed since the explosion, one cannot separate the effect of ground shock on lowering the velocity from possible effects of destressing around adjacent underground openings over this period.

596 (WINCO-1119) Criticality safety issues associated with the burial of highly enriched nuclear fuel in a geologic repository. Paimer, B. Westinghouse Idaho Nuclear Co., Inc., Idaho Falls, ID (United States). Dec 1992. 25p. Sponsored by USDOE, Washington, DC (United States). DOE Contract AC07-84ID12435. Order Number DE93014824. Source: OSTI; NTIS; INIS; GPO Dep.

The purpose of this study is to provide some basic guidance regarding the criticality safety implications associated with long term burial of highly enriched nuclear fuel in a geologic repository. Generic calculations to determine the distance required to neutronically isolate neighboring fissile regions are reported. Two specific fuels are also addressed, Fort Saint Vrain and Shippingport PWR Core-2 Seed-2 (PWR). These fuels are addressed under both dry and flooded conditions. Fort Saint Vrain fuel contains a uraniumgraphite fuel matrix, is graphite moderated and has a relatively low ${ }^{235} \mathrm{U}$ loading ( $\sim 1 \mathrm{~kg}$ per element). PWR contains a uranium-zirconium fuel matrix, is water moderated, zircaloy clad and has a ${ }^{235} \mathrm{U}$ loading of $\sim 15 \mathrm{~kg}$ per cluster. These two fuels are representative of many of the fuels currently stored at the Idaho Chemical Processing Plant (ICPP). The spent fuel storage system under consideration involves filling cylindrical canisters with spent nuclear fuel. These canisters are then to be placed into a geologic repository. Salt and tuff are the two most likely materials in which the canisters will be buried. Canisters will require sufficient material between them to ensure that the overall reactivity stays within acceptable limits. Fuels will also have to be shown to be critically safe under a variety of conditions. These conditions include flooding and the loss of the physical integrity of the fuel.

597 (WSRC-MS-90-351) Durability study of sodium borosilicate glasses leached in tuff $J-13$ groundwater. Ramsey, W.G. (Clemson Univ., SC (United States)); Taylor, T.D.; Jantzen, C.M. Westinghouse Savannah River Co., Aiken, SC (United States). [1990]. 14p. Sponsored by USDOE, Washington, DC (United States). DOE Contract AC09-89SR18035. (CONF-910430-26: 93. annual meeting and exposition of the American Ceramic Society (ACerS), Cincinnati, OH (United States), 28 Apr - 2 may 1991). Order Number DE92009517. Source: OSTI; NTIS; INIS; GPO Dep.

The relative durability of glasses from the $\mathrm{SiO}_{2}$ $\mathrm{B}_{2} \mathrm{O}_{3}-\mathrm{Na}_{2} \mathrm{O}-\mathrm{Al}_{2} \mathrm{O}_{3}-\mathrm{Fe}_{2} \mathrm{O}_{3}-\mathrm{CaO}$ system in Yucca Mountain groundwater was examined. Six glasses, which encompass the composition range of Savannah River Site high-level waste glass, were leached in the Tuff groundwater from well $\mathrm{J}-13$ and the free energy of hydration durability model was applied to the following sets of data: 4 and 12 week MCC-IP Static Leach Tests; 1,4 , and 12 week Product Consistency
Tests (PCT). Compared to similar tests in deionized water, the $J-13$ groundwater was found to inhibit the glass dissolution rate and $\mathrm{pH}$ excursions. Extended term PCT experiments demonstrated that the relative durability of glasses in J-13 groundwater varied with time. A one week PCT was sufficient to determine the relative durability of the glasses in deionized water.

598 (WSRC-MS-93-143) Code requirements for concrete repository and processing facilities. Hookham, C.J. (Black \& Veatch, Ann Arbor, MI (United States)); Palaniswamy, R. Westinghouse Savannah River Co., Aiken, SC (United States). [1993]. 7p. Sponsored by USDOE, Washington, DC (United States). DOE Contract AC0989SR18035. (CONF-930408-62: International high-level radioactive waste management conference, Las Vegas, NV (United States), 25-29 Apr 1993). Order Number DE93010380. Source: OSTI; NTIS; INIS; GPO Dep.

The design and construction of facilities and structures for the processing and safe long-term storage of low- and highlevel radioactive wastes will likely employ structural concrete. This concrete will be used for many purposes including structural support, shielding, and environmental protection. At the present time, there are no design costs, standards or guidelines for repositories, waste containers, or processing facilities. Recently, the design and construction guidelines contained in American Concrete Institute (ACl), Code Requirements for Nuclear Satety Related Concrete Structures ( $\mathrm{ACl}$ 349), have been cited for low-level waste (LLW) repositories. Conceptual design of various high-level (HLW) repository surface structures have also cited the $\mathrm{ACl}$ 349 Code. However, the present Code was developed for nuclear power generating facilities and its application to radioactive waste repositories was not intended. For low and medium level radioactive wastes, concrete has a greater role and use in processing facilities, engineered barriers, and repository structures. Because of varied uses and performance/safety requirements this review of the current $A C I$ 349 Code document was required to accommodate these special classes of structures.

599 (WSRC-TR-93-0111-Rev.1) Facts and issues of direct disposal of spent fuel: Revision 1. Parks, P.B. Westinghouse Savannah River Co., Aiken, SC (United States). Oct 1993. 135p. Sponsored by USDOE, Washington, DC (United States). DOE Contract AC09-89SR18035. Order Number DE94001176. Source: OSTI; NTIS; INIS; GPO Dep.

This report reviews those facts and issues that affect the direct disposal of spent reactor fuels. It is intended as a resource document for those impacted by the current Department of Energy (DOE) guidance that calls for the cessation of fuel reprocessing. It is not intended as a study of the specific impacts (schedules and costs) to the Savannah River Site (SRS) alone. Commercial fuels, other low enriched fuels, highly enriched defense-production, research, and naval reactor fuels are included in this survey, except as prevented by rules on classification.

600 Dynamic analysis and design considerations for high-level nuclear waste repositories. Hossain, Q.A. (ed.). 443p. American Society of Civil Engineers, New York, NY (US) (1993). (CONF-920866-: American Society of Civil Engineers (ASCE) symposium on dynamic analysis and design considerations, for high-level nuclear waste repositories, San Francisco, CA (United States), 19-20 Aug 1992). 
These proceedings are arranged into six broad categories: general overview of analysis and design; characterization of faulting; characterization of design ground vibratory ground motion; considerations for underground facilities; considerations for surface facilities; and guidelines for instrumentation and monitoring. Discussions are given on the relative merits and inadequacies of state-of-the-art design/analysis practices and methodologies in the seismic and dynamic analysis and design field in relation to highlevel nuclear waste repositories. All papers have been processed for inclusion on the data base.

601 Alligator Rivers Region Research Institute: annual research summary 1989-1990. 78p. Australian Government Publishing Service, Canberra (Australia) (1992).

The basic aim of the research carried out by the Alligator Rivers Region Research Institute is to acquire enough knowledge about the environment of the Alligator Rivers Region to enable control measures to be formulated that will ensure, with the degree of confidence demanded by the community, that a high level of environmental protection can be attained. In this report, summaries are given of progress during 1990/91 on projects within the program. One chapter is devoted to projects within each of the program divisions on Baseline Research, Operational Phase Research, Rehabilitation Research and Techniques Research. 26 tabs., 17 figs.

602 Fish communities in sandy pool of Magela Creek, Alligator Rivers Region: Research Report 9. Woodland, D.J.; Ward, P.J. 81p. Australian Government Publishing Service, Canberra (Australia) (1992).

Physico-chemical conditions, changes in fish communities and characteristics of species populations of eight permanent sandy pools along Magela Creek during the 1981 Dry season are described. Causes of mortality in each species, especially Craterocephalus marianae, were investigated. It is emphasised that in using baseline data to assess the impact of mining and animal communities, it may sometimes be difficult to differentiate natural mortality from mortality resulting from pollution. The aim of this study was to distinguish the most important environmental factors responsible for fish mortality. The study indicates that the mortality was low ( $<50 \%$ of the original population) in most pools. In populations that did suffer high mortality, anoxic conditions may have been an important cause. 67 refs., 36 tabs., 21 figs., ills.

603 A selected GIS bibliography: Technical Memorandum 40. Devonport, C.C. $88 \mathrm{p}$. Australian Government Publishing Service, Canberra (Australia) (1992).

This bibliography has been compiled as part of a collaborative research agreement between the Northern Territory University and the Supervising Scientist for the Alligator. Rivers Region. It contains over 2,000 references to GIS literature which have been selected from books, journals and conference proceedings published from 1987 to the present. The selection is biased to environmental and resource management topics (cf. urban, sociological and facilities management) and specifically aims to provide a reference point for the Geographic Information Systems literature related to environmental risk/hazard assessment associated with activities such as mining. References are in alphabetical order by author and AARNET users can access the bibliography in text format via anonymous ftp from darwin.ntu.edu.au. The data can be provided in other formats or alternative means on request (phone 089466711 , fax 089410460 or email chris at ironwood.ntu.edu.au).

604 Annual Report 1991-1992. 190p. Australian Government Publishing Service, Canberra (Australia) (1992).

Research of the Office of the Supervising Scientist (OSS) is now tending to concentrate more on the problems that will arise with the decommissioning and rehabilitation of the mine sites, and in providing the knowledge that will enable the very stringent rehabilitation goal and objectives for the Ranger mine site that have been established by the Commonwealth and Northern Territory Governments, to be achieved. Since rehabilitation must be designed to achieve objectives, the success of which will not be known for many decades in the case of revegetation, and many hundreds of years in the case of tailings containment, the science underlying the engineering designs must be sufficiently secure to give confidence that those objectives will be achieved. The current OSS research program, presented in the Annual Report modified as necessary as developments unfold, provides a sound scientific base. Whilst the precise nature of the future development of the Ranger site is not known, the Supervising Scientist is confident, given the continued existence of the OSS with its research base in the Alligator Rivers Research Institute, that the knowledge will be available to ensure that the No. 3 ore body and the Jabiluka resource can be developed without damage to the ecosystems of Kakadu National Park. 16 tabs., 22 figs.

605 S. 1138: A bill to amend the Nuclear Waste Policy Act of 1982 to direct the Secretary of Energy to carry out site characterization activities at the Yucca Mountain site in Nevada, and for other purposes, introduced in the US Senate, One Hundred Second Congress, First Session, May 22, 1991. 4p. Government Printing Office, Washington, DC (US) (1991).

This bill was introduced into the US Senate on May 22, 1991 to amend the Nuclear Waste Policy Act of 1982. The purpose of the act is to direct the Secretary of Energy to carry out site characterization activities at the Yucca Mountain site in Nevada in order to determine if the site is acceptable for the storage of radioactive wastes.

606 Alligator Rivers Region Research Institute: annual research summary 1989-1990. 98p. Australian Government Publishing Service, Canberra (Australia) (1991).

The Alligator Rivers Region Research Institute (ARRRI) research activities are associated with an assessment of environmental effect of mining in the region. While emphasis on baseline research is now much reduced, some projects are still necessary because of significant changes in the Magela Creek system, because new areas of proposed mining have been identified (e.g. Coronation Hill) and because the emphasis now being placed on rehabilitation research requires a sound knowledge of the Region's flora. The ARRRI rehabilitation research program has concentrated on the Ranger mine site, principally because it is at a critical planning stage where detailed research information is required. With regard to the development of techniques, research at the Institute has led to the development of specific analytical methods or protocols that can be used in assessing environmental impact. 39 tabs., 42 figs.

607 Proceedings of the conference on shaft drilling technology. vp. Institute of Shaft Drilling Technology, Parker, CO (United States) (1990). (CONF-900565-: Conference on shaft drilling technology, Las Vegas, NV (United States), 2-4 May 1990). 
This book contains the following topics, Market analysis, World-wide operations, Innovative drilling and boring, Raise boring, Shaft lining and fittings, Entry considerations for the Yucca Mountain exploratory shaft facility for potential Radioactive Waste Disposal, Drilling rigs in the coal industry.

608 Cost analysis of spent nuclear fuel management. Robertson, D.L.M. (Fluor Daniel, Irvine, CA (US)); Ford, L.M. pp. 1043-1049 of Proceedings of the American power conference: Economy, efficiency, quality. Volume 55 - 2. Illinois Inst. of Tech., Chicago, IL (US) (1993). pp. 923 (CONF-930433-: 55. annual American power conference, Chicago, IL (United States), 13-15 Apr 1993).

The Department of Energy Civilian Radioactive Waste Management System (CRWMS) is chartered to develop a waste management system for the safe disposal of spent nuclear fuel (SNF) from the 131 nuclear power reactors in the United States and a certain amount of high level waste (HLW) from reprocessing operations. The current schedule is to begin accepting SNF in 1998 for storage at a Monitored Retrievable Storage (MRS) facility. Subsequently, beginning in 2010, the system is scheduled to begin accepting SNF at a permanent geologic repository in 2010 and HLW in 2015. At this time, a MRS site has not been selected. Yucca Mountain, Nevada is currently being evaluated as the candidate site for the repository for permanent geologic disposal of SNF. All SNF, with the possible exception of the SNF from the western reactors, is currently planned to be shipped to or through the MRS site en route to the repository. The repository will operate in an acceptance and performance confirmation phase for a 50 year period beginning in 2010 with an additional nine year closure and five year decontamination and decommissioning period. The MRS has a statutory maximum capacity of 15,000 Metric Tons Uranium (MTU), with a further restriction that it may not store more than $10,000 \mathrm{MTU}$ until the repository begins accepting waste. The repository is currently scheduled to store 63,000 MTU of SNF and an additional 7,000 MTU equivalent of HLW for a total capacity of $70,000 \mathrm{MTU}$. The amended act specified the MRS storage limits and identified Yucca Mountain as the only site to be characterized. Also, an Office of the Nuclear Waste Negotiator was established to secure a voluntary host site for the MRS. The MRS, the repository, and all waste containers/casks will go through a Nuclear Regulatory Commission licensing process much like the licensing process for a nuclear power plant. Environmental assessments and impact statements will be prepared for both the MRS and repository.

609 The role of Geographic Information Systems in the Office of the Supervising Scientist. Riley, S.J. (Office of the Supervising Scientist for the Alligator Rivers Region, Sydney, NSW (Australia)). pp. 92-99 of Proceedings of the GIS and environmental rehabilitation workshop. Devonport, C.C.; Riley, S.J.; Ringrose, S.M. (eds.). Australian Government Publishing Service, Canberra (Australia) (1992). pp. 150 (CONF-9209399-: GIS and environmental rehabilitation workshop, Darwin (Australia), 4-5 Sep 1992).

GIS is a Geographic Information System facility of the Supervising Scientist for the Alligator Rivers Region and the Northern Territory Univ.

A Geographic Information System (GIS), embedded in a Decision Support System linking spatial data bases and biophysical models of the environment, will be an important tool in the design and assessment of rehabilitation of uranium mines in the Alligator Rivers Region. The Office of the Supervising Scientist (OSS) and the Northern Territory of
University are collaborating in the development of GIS and its introduction into rehabilitation planning. The achievements obtained to date are briefly outlined. There is every expectation that the system developed by OSS will be of general use in environmental assessment and management. 33 refs., 1 fig.

610 Overview and status of the U.S. high-level waste program. Peters, F. (Office of Civilian Radioactive Waste Management, U.S. Dept. of Energy (US)). pp. 93-106 of Environmental issues and waste management in energy and minerals production. Yegulalp, T.M.; Kim, K. Battelle Press, Columbus, $\mathrm{OH}$ (United States) (1992). pp. 602 (CONF9008109-: 1 . international conference on environmental issues and waste management in energy and minerals production, Secaucus, NJ (United States), 27-29 Aug 1990).

By passage of the National Waste Policy Act, deep geologic disposal for spent nuclear fuel and high-level radioactive waste was designated by Congress as the permanent, environmentally appropriate means of disposal for the United States. This national decision was consistent with recommendations made 25 years earlier by the National Academy of Sciences, and consistently advocated by knowledgeable scientists in this country and in other nations also faced with the challenge of high-level radioactive waste disposal. This paper reviews the status of the development of a waste disposal site at Yucca mountain, in Nevada.

611 Development of a prototype GIS for risk-hazard assessment. Devonport, $C$. (Northern Territory Univ., Casuarina, NT (Australia). GIS Laboratory). pp. $122-129$ of Proceedings of the GIS and environmental rehabilitation workshop. Devonport, C.C.; Riley, S.J.; Ringrose, S.M. (eds.). Australian Government Publishing Service, Canberra (Australia) (1992). pp. 150 (CONF-9209399-: GIS and environmental rehabilitation workshop, Darwin (Australia), 4-5 Sep 1992).

GIS is a Geographic information System facility of the Supervising Scientist for the Alligator Rivers Region and the Northern Territory Univ.

A collaborative research agreement between the Supervising Scientist for the Alligator Rivers Region (OSS) and the Northern Territory University (NTU) aims to develop and assess a computer-based Geographic Information System (GIS) to integrate terrain and geological data for risk-hazard analysis and modelling. This paper outlines initial design and development of the prototype GIS including the input of trial data of various types. It is recognised that the GIS must be flexible enough to accommodate change and provide a base for a variety of research needs. Such functionality is likely to be provided best by an initially small, generic prototype GIS to which functions and data are added as required. Properties of the prototype identified as critical to its usefulness include integration of different types of data into the system, understanding and accommodating inconsistencies between data sets and the recognition and recording of error. Various types of data (elevation data, maps and images) available at the outset of the project are outlined together with a brief discussion on their source, integration into the database, derivative products and the potential usefulness of, and problems associated with, the different data formats. The analytical possibilities offered by the trial data will be explored next and the results of the first development cycle presented by the end of 1992. Subsequently, additional data will be incorporated into the database, analytical techniques will be used to build models, and user-driven development 
will enable the GIS to begin to support a decision research process. 20 refs.

612 Alternate conceptual model of ground water flow at Yucca Mountain. Lehman, L.L. (L. Lehman and Associates, Inc., Burnsville, MN (US)). pp. 310-320 of Proceedings of high level radioactive waste management: Volume 1. American Nuclear Society, La Grange Park, IL (United States) (1992). pp. 2425 (CONF-920430-: 3. international high level radioactive waste management (IHLRWM) conference, Las Vegas, NV (United States), 1216 Apr 1992).

Attempts to predict the performance of a high-level nuclear waste repository in the United States have lead to the development of alternative conceptual models of the ground water flow field in which the repository will be located. This step has come about because of the large uncertainties involved in predicting the movement of water and radionuclides through an unsaturated fractured rock. Alternative concepts necessitates the use of simplifying assumptions. In this paper the authors examine an alternative conceptual model which utilizes more realistic assumptions of focused recharge in concent with a fractured matrix and nonequilibrium view of ground water flow.

613 Engineered barrier system failure modeling: $A$ statistical approach. Bullen, D.B. (Georgia Inst. of Tech., Atlanta, GA (United States). School of Mechanical Engineering). pp. 401-408 of Proceedings of high level radioactive waste management: Volume 1. American Nuclear Society, La Grange Park, IL (United States) (1992). pp. 2425 (CONF-920430-: 3. international high level radioactive waste management (IHLRWM) conference, Las Vegas, NV (United States), 12-16 Apr 1992).

In this paper a statistical model to calculate the cumulative failure distribution for high-level radioactive waste containers based upon exponential and Weibull distributions is presented. This model has been employed to describe the performance of the engineered barrier system (EBS) as one part of a risk-based performance assessment model of the Yucca Mountain site. The model employs three parameter Weibull distributions to describe a majority of the container failures. Early container failures are described using exponential distributions. Parameter value selections are based upon simple mechanistic submodels describing failure of specific components of the EBS. The impact of EBS performance is demonstrated through the comparison of single barrier and multiple barrier systems.

614 Panel discussion on nuclear waste. pp. 405-426 of Environmental issues and waste management in energy and minerals production. Yegulalp, T.M.; Kim, K. Battelle Press, Columbus, OH (United States) (1992). pp. 602 (CONF-9008109-: 1. international conference on environmental issues and waste management in energy and minerals production, Secaucus, NJ (United States), 27-29 Aug 1990).

This paper covers various aspects of nuclear waste, including: Options for storage of waste; regulations concerning waste disposal; the Yucca Mountain repository project; nuclear waste disposal in the US and Canada.

615 Yucca Mountain digital database. Daudt, C.R. (Purdue Univ., Lafayette, IN (United States). Dept. of Earth and Atmospheric Sciences); Hinze, W.J.; Abrams, C. pp. 442-449 of Proceedings of high level radioactive waste management: Volume 1. American Nuclear Society, La
Grange Park, IL (United States) (1992). pp. 2425 (CONF920430-: 3. international high level radioactive waste management (IHLRWM) conference, Las Vegas, NV (United States), 12-16 Apr 1992).

This paper discusses the Yucca Mountain Digital Database (DDB) which is a digital, PC-based geographical database of geoscience-related characteristics of the proposed high-level waste $(\mathrm{HLW})$ repository site of Yucca Mountain, Nevada. It was created to provide the US Nuclear Regulatory Commission's (NRC) Advisory Committee on Nuclear Waste (ACNW) and its staff with a visual perspective of geological, geophysical, and hydrological features at the Yucca Mountain site as discussed in the Department of Energy's (DOE) pre-licensing reports.

616 Developing conceptual models for performance assessment of waste management sites. Kerl, F.A. (New Mexico Univ., Albuquerque, NM (United States). Dept. of Chemical and Nuclear Engineering); Heger, A.S.; Gallegos, D.P. pp. 502-509 of Proceedings of high level radioactive waste management: Volume 1. American Nuclear Society, La Grange Park, IL (United States) (1992). pp. 2425 DOE Contract AC04-76DP00789. (CONF-920430-: 3. international high level radioactive waste management (IHLRWM) conference, Las Vegas, NV (United States), 12-16 Apr 1992).

The conceptual model development process involves making simplifying assumptions about the description and behavior of the natural repository system. To better understand how conceptual models are developed, it is important to explicitly identify and document the process. To investigate the conceptual model development process, conceptualizations of groundwater flow systems for Avra Valley and the potential high-level radioactive waste repository site at Yucca Mountain have been reviewed to identify assumptions. From this information, the development of conceptual models can be described as the process by which, for a given site and purpose, choices are made for each of the assumptions dependent upon their established relationships. Developing a comprehensive understanding of the conceptual model development process is the first, and probably the most important step toward addressing the uncertainty associated with conceptual models developed for repository performance assessment. Many aspects of the conceptual model development process, however, are subjective, and the results presented here are by no means considered complete. This paper provide a significant contribution toward documenting and defining the conceptual model development process.

617 Perceived risk impacts from siting hazardous waste facilities. Hemphill, R.C. (Argonne National Lab., IL (United States)); Edwards, B.K.; Bassett, G.W. Jr. pp. 582586 of Proceedings of high level radioactive waste management: Volume 1. American Nuclear Society, La Grange Park, IL (United States) (1992). pp. 2425 DOE Contract W-31109-ENG-38. (CONF-920430-: 3. international high level radioactive waste management (HLRWM) conference, Las Vegas, NV (United States), 12-16 Apr 1992).

This paper describes methods for evaluating perceptionbased economic impacts resulting from siting hazardous waste facilities. Socioeconomic impact analysis has devoted increasing attention to the potential implications of changed public perceptions of risk due to an activity or situation. This contrasts with traditional socioeconomic impact analysis, which has been limited to measuring direct and indirect consequences of activities, e.g., the employment effects of 
placing a military base in a specified location. Approaches to estimating economic impacts due to changes in public perceptions are ex ante or ex post. The former predict impacts prior to the construction and operation of a facility, while the later is based on impacts that become evident only when the facility is up and running. The theoretical foundations and practical requirements for demonstrating impacts resulting from the siting of a hazardous facility are described. The theoretical rationale supporting the study of perceived risk research is presented along with discussion of problems that arise in demonstrating the existence and measuring the quantitative importance of economic impacts due to changes in perceived risk. The high-level nuclear waste facility being considered in Nevada is presented as an example in which there is potential for impacts, but where the link between perceived risk and economic conditions has not yet been developed.

618 The Yucca Mountain tours: A test of the familiarity hypothesis. Shepard, N.F. (USDOE Office of Civilian Radioactive Waste Management, Washington, DC (United States)); Champagne, D.L. pp. 593-599 of Proceedings of high level radioactive waste management: Volume 1. American Nuclear Society, La Grange Park, IL (United States) (1992). pp. 2425 (CONF-920430-: 3. international high level radioactive waste management (IHLRWM) conference, Las Vegas, NV (United States), 12-16 Apr 1992).

In 1978, Mderthaner et al. observed that opposition to nuclear facilities was lowest near the facility. This suggested that opposition decreased as familiarity with the facility increased, with distance from the facility as an inverse measure of familiarity. In this paper, the authors analyze data from the literature supporting this hypothesis and examine a poll of 1200 public visitors to the candidate repository site at Yucca Mountain, Nevada, in March through June 1991. The tour poll and independent pools show that most Nevadans support the present scientific investigation of the site while opposing the repository. Among the visitors, support for the investigation increased from 66 to 90 percent, which we attribute to increased familiarity.

619 Needed geologic and seismic rulemaking for HLW repositories. Smith, J.L. (Jay L. Smith Co., Inc., Occidental, CA (US)). pp. 685-690 of Proceedings of high level radioactive waste management: Volume 1. American Nuclear Society, La Grange Park, IL (United States) (1992). pp. 2425 (CONF-920430-: 3. international high level radioactive waste management (IHLRWM) conference, Las Vegas, NV (United States), 12-16 Apr 1992).

This paper reports that informal guidance by the Nuclear Regulatory Commission (NCR) staff to the U.S. Department of Energy (DOE) has indicated that geologic and seismic siting criteria (10 CFR Part 100, Appendix A) for nuclear power plants do not apply to HLW repositories. This is important, particularly for the candidate Yucca Mountain site where quaternary faults exist, because precedents set in nuclear power plant licensing have effectively precluded site suitability if Quaternary faults are present and if consideration must be given to facility design for accommodating fault displacement. Regulations for HLW repositories (10 CFR Part 60) do not preclude site suitability if Quaternary faults are present, but require performance assessment to demonstrate that radionuclide releases to the accessible environment will be acceptably low. Nevertheless, a formal NRC rulemaking should be developed to address the fault-displacement issue specifically, perhaps as an appendix to 10 CFR Part 60.
620 Siting the high level radioactive waste repository in the United States. Tourtellotte, J. pp. 685-699 of Nuclear Inter Jura '91: nuclear law and nuclear energy for the future: Proceedings of the biennial congress of the International Nuclear Law Association (AIDN-INLA), Bath, England, 23-26 September 1991. International Nuclear Law Association, Harwell (United Kingdom) ([1992]). pp. 794 (CONF-910923-: Nuclear Inter Jura '91: biennial conference of the International Nuclear Law Association (INLA) nuclear law and the challenge of the future, Bath (United Kingdom), 22-26 Sep 1991).

For more than twenty-five years after the National Academy of Science issued its 1957 report recommending a Mined Geologic Disposal System ("MGDS") for high level radioactive waste, no substantial progress was made in selecting and siting a repository. The United States Congress attempted to give substantive and procedural direction to the program in the Nuclear Waste Policy Act of 1982. Seeing that very little had been accomplished some five years later, Congress gave further direction and tentatively selected a single site, Yucca Mountain in Nevada, in the Nuclear Waste Policy Act Amendments of 1987. Selection of the Yucca Mountain site created a political conflict between federal and state authorities. Until recently, that conflict stalled the site characterization and evaluation program. Standards development under a polycentric regulatory regime has also been slow and has created a number of technical, legal and policy controversies. The Environmental Protection Agency (EPA), charged with setting radiation protection rules, may be developing regulatory standards which are technically unachievable and, therefore, legally unprovable in a licensing proceeding. The Nuclear Regulatory Commission (NRC), having the responsibility for licensing and setting performance objectives, may be taking an overly conservative approach. This approach could seriously impact the cost and may preclude the ability to reach an affirmative finding on license issuance. The Department of Energy (DOE) has responsibility for siting, construction and operation of the repository. In so doing, DOE must apply both EPA and NRC standards. To the extent that EPA and NRC standards are untimely, poorly defined, unrealistic, inconsistent, and technically or legally unsound, DOE may be forestalled from fulfilling its responsibilities. The US must rethink its approach to siting the high level radioactive waste repository and take realistic, timely action to preserve the nuclear option.

621 Impact of fracture coatings on the transfer of water across fracture faces in unsaturated media. Gallegos, D.P. (Sandia National Labs., Albuquerque, NM (United States)); Thoma, S.G.; Smith, D.M. pp. 738-745 of Proceedings of high level radioactive waste management: Volume 1. American Nuclear Society, La Grange Park, IL (United States) (1992). pp. 2425 DOE Contract AC04-76DP00789. (CONF-920430-: 3. international high level radioactive waste management (IHLRWM) conierence, Las Vegas, NV (United States), 12-16 Apr 1992).

Ground water flow in unsaturated, fractured rock is often assumed to be dominated by the porous matrix component. This is frequently based on the argument that water flowing in the fractures is rapidly imbibed into the rock matrix by capillary suction forces with negligible resistance to uptake at the fracture/matrix interface. However, the existence of a low-permeability mineralized layer or coating at this interface may substantially reduce matrix imbibition and consequently result in fracture-dominated flow. This paper reports that to test this concept, four tuff samples containing natural fractures were obtained from tuff formations in southern 
Nevada. By performing imbibition experiments into the matrix rock, across a mineralized fracture face and then across a fresh uncoated fracture face, water uptake as a function of time and coating was measured. A simple model that combines Darcy's law and the Washburn Equation has been used to describe the imbibition behavior.

622 Introductory remarks for the international highlevel radioactive waste conference technical session on site characterization: Approaches, concepts, concerns. Justus, P.S. (Nuclear Regulatory Commission, Washington, DC (United States). Div. of High-Level Nuclear Waste Management); Stockey, J.R. pp. 746-747 of Proceedings of high level radioactive waste management: Volume 1. American Nuclear Society, La Grange Park, IL (United States) (1992). pp. 2425 (CONF-920430-: 3. international high level radioactive waste management (IHLRWM) conference, Las Vegas, NV (United States), 12-16 Apr 1992).

The U.S. Department of Energy (DOE) is required by the Nuclear Waste Policy Act (NWPA), the Nuclear Waste Policy Amendments Act and Title 10, Code of Federal Regulations, Part 60 (Part 60) to prepare a site characterization plan to obtain the information necessary to determine the suitability of the Yucca Mountain, Nevada Site for a geologic repository. This paper reports that as part of its development of the Site Characterization Plant (SCP), DOE issued a Consultation Draft Site Characterization Plan (CDSCP) for the Yucca Mountain site for the information of the review by the U.S. Nuciear Regulatory Commission (NRC) and the State of Nevada. DOE is to defer shaft sinking until there has been an opportunity for Commission comments to have been solicited and considered by DOE (Part 60.16). Further, DOE conducted an ESF Alternatives Study, in part, to identify and acceptable basis for the design and construction of an ESF at the Yucca Mountain site. The study identified various repository options and configurations e.g., accesses, construction methods, and the identification of preferred locations for accesses and underground facilities based on repository-ESF considerations and the ESF configuration and construction options.

623 Temperature scenarios for a repository at Yucca Mountain. Ross, B. (Disposal Safety, Inc., Washington, DC (United States)). pp. 784-789 of Proceedings of high level radioactive waste management: Volume 1 . American Nuclear Society, La Grange Park, IL (United States) (1992). pp. 2425 (CONF-920430-: 3. international high level radioactive waste management (IHLRWM) conference, Las Vegas, NV (United States), 12-16 Apr 1992).

This paper reports that published calculations of heat transfer around the potential radioactive-waste repository at Yucca Mountain have not treated all mechanisms that might plausibly be significant. This leaves considerable uncertainty in what temperatures might occur. It is not clear whether convection and heat pipe effects could remove a substantial amount of heat. To incorporate these uncertainties in a comprehensive model of repository performance, we defined three scenarios. In the most likely scenario, most waste containers reached a peak temperature of approximately $200^{\circ} \mathrm{C}$. In the other scenarios, most canisters remain at temperatures at or below the boiling point.

624 New approach for regional ground-water modeling in southern Nevada. Turner, A.K. (Dept. of Geology and Geological Engineering, Colorado School of Mines, Golden, CO (US)); Kolm, K.E. pp. $852-858$ of Proceedings of high level radioactive waste management: Volume 1.
American Nuclear Society, La Grange Park, IL (United States) (1992). pp. 2425 (CONF-920430-: 3. international high level radioactive waste management (IHLRWM) conference, Las Vegas, NV (United States), 12-16 Apr 1992).

Three-dimensional Geoscientific Information Systems (GSIS) can assist 3-D ground-water modeling of regional aquifer systems in areas with complex geologic and climatic conditions. In such areas, the complexity of the regional ground-water system frequently requires the use of a 3 dimensional ground-water modeling approach supported by a true 3-dimensional geologic conceptual model. The ground-water system analysis process involves four fundamental modules that are interactive using GSIS: surface and subsurface characterization; hydrogeologic and hydrologic conceptual modeling; ground-water flow and transport modeling; and statistical evaluation and sensitivity analysis. In addition, different ground-water flow and transport models, in either finite-element or finite-difference format, may be used with GSIS. This paper reports that multidisciplinary research team is currently applying this approach for regional modeling efforts in southern Nevada, the site of a proposed high-level nuclear waste repository. Initial studies involve a large area defined as the Death Valley regional ground water basin.

625 Performance assessment for a high-level waste repository at Yucca Mountain. Shaw, R. (Electric Power Research Inst., Palo Alto, CA (United States)); Williams, R.F.; Stepp, J.C.; McGuire, R. pp. 869-873 of Proceedings of high level radioactive waste management: Volume 1. American Nuclear Society, La Grange Park, IL (United States) (1992). pp. 2425 (CONF-920430-: 3. international high level radioactive waste management (IHLRWM) conference, Las Vegas, NV (United States), 12-16 Apr 1992).

This paper reports that the EPRI effort in high-level waste repository performance assessment has added capabilities in several important technical areas, over previous models. Gaseous release of $\mathrm{C}^{14}$ is included, as are human intrusion scenarios. The model uses detailed calculations of precipitation events as a function of climate, along with a specific model of surface infiltration that accounts for ground vegetation and topography. The model also makes time-dependent calculations of hydrologic flow, accounting for changes in climate and flux. heat pulse effects are included, specifically the effect of heat on container performance, the response of the host tuff to high temperatures, and the solubility of waste material as a function of temperature. Specific models are used to calculate a source term as a function of saturated, unsaturated, or wet-drip conditions at the location of waste containers, and element solubility as well as waste dissolution are checked to determine the limiting condition on nuclide solution.

626 A forecasting model of gaming revenues in Clark County, Nevada. Edwards, B. (Argonne National Lab., IL (United States)); Bando, A.; Basset, G.; Rosen, A.; Meenan, C.; Carlson, J. pp. 943-948 of Proceedings of high level radioactive waste management: Volume 1 . American Nuclear Society, La Grange Park, IL (United States) (1992). Pp. 2425 DOE Contract W-31109-ENG-38. (CONF-920430: 3. international high level radioactive waste management (IHLRWM) conference, Las Vegas, NV (United States), 1216 Apr 1992).

This paper describes the Western Area Gaming and Economic Response Simulator (WAGERS), a forecasting model that emphasizes the role of the gaming industry in Clark County, Nevada. It is designed to generate forecasts of 
gaming revenues in Clark County, whose regional economy is dominated by the gaming industry, and identify the exogenous variables that affect gaming revenues. This model will provide baseline forecasts of Clark County gaming revenues in order to assess changes in gaming related economic activity resulting from future events like the siting of a permanent high-level radioactive waste repository at Yucca Mountain.

627 Economic impact of nuclear facilities. Knox, $E$. (USDOE Office of Civilian Radioactive Waste Management, Washington, DC (United States)); Burnison, S. pp. 949-953 of Proceedings of high level radioactive waste management: Volume 1. American Nuclear Society, La Grange Park, IL (United States) (1992). pp. 2425 (CONF-920430-: 3. international high level radioactive waste management (IHLRWM) conference, Las Vegas, NV (United States), 1216 Apr 1992).

This paper reviews empirical analyses of the economic impacts on areas surrounding operating nuclear facilities. Until recently, much of the work that addressed the subject of risk perception and potential impacts of a nuclear waste repository at Yucca Mountain in Nevada claimed that there is the possibility of significant negative economic impacts. This paper adds to the ongoing debate drawing on empirical research compiled at existing nuclear facilities which have had actual operating impacts. This information demonstrates that the economic impacts have not necessarily been negative, in fact, in some cases the impacts have been considered very positive. The economic effects of operating nuclear facilities serves as an important element of analysis for estimating economic impacts of future nuclear sites, including the potential impacts of a high-level, radioactive waste site.

628 Use of annotated outlines to prepare guidance for license applications for the MRS and MGDS. Roberts, J. (USDOE Office of Civilian Radioactive Waste Management, Washington, DC (United States)); Griffin, W.R. pp. 1040-1046 of Proceedings of high level radioactive waste management: Volume 1. American Nuclear Society, La Grange Park, IL (United States) (1992). pp. 2425 (CONF920430-: 3. international high level radioactive waste management (IHLRWM) conference, Las Vegas, NV (United States), 12-16 Apr 1992).

This paper reports that the Office of Civilian Radioactive Waste Management (OCRWM) has embarked on an aggressive program to develop guidance for preparation of the License Applications for the Mined Geological Disposal System (MGDS) and Monitored Retrievable Storage (MRS). The endeavor is a team effort that will utilize personnel and funding from the Office of Systems and Compliance at DOE Headquarters, the MRS Project (i.e., DOE Office of Storage and Transportation) and the Yucca Mountain Project (i.e., DOE Office of Geologic Disposal). The endeavor was initiated in the Spring of 1991. It will continue via an iterative process until License Applications are completed for the MRS and MGDS projects.

629 Modeling fault rupture hazard for the proposed repository at Yucca Mountain, Nevada. Coppersmith, K.J. (Geomatrix Consultants, Inc., San Francisco, CA (United States)); Youngs, R.R. pp. 1142-1150 of Proceedings of high level radioactive waste management: Volume 1 . American Nuclear Society, La Grange Park, IL (United States) (1992). pp. 2425 (CONF-920430-: 3. international high level radioactive waste management (IHLRWM) conference, Las Vegas, NV (United States), 12-16 Apr 1992).
In this paper as part of the Electric Power Research Institute's High Level Waste program, the authors have developed a preliminary probabilistic model for assessing the hazard of fault rupture to the proposed high level waste repository at Yucca Mountain. The model is composed of two parts: the earthquake occurrence model that describes the three-dimensional geometry of earthquake sources and the earthquake recurrence characteristics for all sources in the site vicinity; and the rupture model that describes the probability of coseismic fault rupture of various lengths and amounts of displacement within the repository horizon 350 $m$ below the surface. The latter uses empirical data from normal-faulting earthquakes to relate the rupture dimensions and fault displacement amounts to the magnitude of the earthquake. using a simulation procedure, we allow for earthquake occurrence on all of the earthquake sources in the site vicinity, model the location and displacement due to primary faults, and model the occurrence of secondary faulting in conjunction with primary faulting.

630 Using seals to control flow at Yucca Mountain. Blair, J.A. (TRW Environmental Safety Systems inc., Washington, DC (US)); Stucker, D.; Kumar, P. pp. 1196-1199 of Proceedings of high level radioactive waste management: Volume 1. American Nuclear Society, La Grange Park, IL (United States) (1992). pp. 2425 (CONF-920430-: 3. international high level radioactive waste management (IHLRWM) conference, Las Vegas, NV (United States), 12 16 Apr 1992).

This paper describes how an interpretation of regulations can lead to innovative solutions to the problem of sealing subsurface openings in the highly fractured rock above the water table at Yucca Mountain, Nevada, which is being characterized to determine its suitability for a repository for spent fuel and high level waste. The paper concentrates on the functional requirements for seals as well as the statutory definitions given in 10 CFR Part 60 . Because the main concern of sealing is to prevent the flow of water to the waste packages or radionuclides to the accessible environment, the main strategy for sealing of the proposed repository is to control rather than stop the flow of water. Other functions of seals include the prevention of human intrusion and the control of the flow of gaseous radionuclides. This paper describes the concepts that have thus far been developed for sealing with respect to shafts, ramps, boreholes, and the underground facility rather than detailed numerical analysis and design for seals. The main emphasis of this paper is on the role of regulations in providing flexibility in dealing with a complex, long-term component.

$631{ }^{36} \mathrm{Cl}$ production in situ, and groundwater transport in a uranium ore deposit. Cornett, R.J. (AECL Research, Chalk River, Ontario (Canada)); Andrews, H.R.; Brown, R.M.; Chant, L.A.; Cramer, J.; Davies, W.G.; Greiner, B.F.; Imahori, Y.; Koslowsky, V.T.; McKay, J.W.; Milton, G.M.; Milton, J.D.C. pp. 1276, Paper NUCL 79 of 203rd American Chemical Society national meeting. American Chemical Society, Washington, DC (United States) (1992). pp. 2442 (CONF-920444-: 203. American Chemical Society (ACS) national meeting, San Francisco, CA (United States), 5-10 Apr 1992).

The authors have used AMS to measure ${ }^{36} \mathrm{Cl}$ concentrations produced in situ in ore and in groundwater within the 1.3 billion year old Cigar Lake uranium ore deposit. ${ }^{36} \mathrm{Cl}$ concentrations are up to 300 times higher in the ore zone than in the surrounding aquifer. Based on ${ }^{36} \mathrm{Cl}$ ingrowth, the authors calculate the residence time of water within the ore 
zone to be 100,000 to 300,000 years. Since the geologic setting of this deposit is a very close natural analogue to a proposed nuclear fuel waste repository, this analysis demonstrates that natural geological barriers can effectively isolate mobile radionuclides from an open, regional groundwater flow system over millennia.

632 Variation of the isotopic compositions of xenon and krypton in terrestrial samples. Kuroda, P.K. (Univ. of Arkansas, Fayetteville, AR (United States)); Myers, W.A. pp. 1298, Paper NUCL 157 of 203rd American Chemical Society national meeting. American Chemical Society, Washington, DC (United States) (1992). pp. 2442 (CONF-920444-: 203. American Chemical Society (ACS) national meeting, San Francisco, CA (United States), 5-10 Apr 1992).

Variation in the isotopic composition of krypton in the solar system is just as spectacular, but has not been investigated in as much detail as in the case of xenon isotopes. This is primarily due to the fact that, unlike xenon which has excesses of certain isotopes, due to the decay of ${ }^{129} \mid$ and ${ }^{244} \mathrm{Pu}$, similar excesses from the decay of extinct nuclei are not expected to be found in krypton. Instead, large excesses of both xenon and krypton isotopes from the spontaneous fission of ${ }^{238} \mathrm{U}$ and from the thermal neutron-induced fission of ${ }^{235} \mathrm{U}$ are found in terrestrial samples. An anomalous xenon component whose isotopic composition appears to be a mirror image of that of xenon $H$ was reported to have been found in the Oklo natural reactor. The nature. of this anomalous xenon has remained unexplained for many years, but there now appears to be no need to invoke an exotic substance to explain its isotopic composition.

633 Integrated performance assessment model for waste policy package behavior and radionuclide release. Kossik, R. (Golder Associates, Inc., Redmond, WA (US)); Miller, 1.; Cunnane, M. pp. 1786-1793 of Proceedings of high level radioactive waste management: Volume 1. American Nuclear Society, La Grange Park, IL (United States) (1992). pp. 2425 (CONF-920430-: 3. international high level radioactive waste management (IHLRWM) conference, Las Vegas, NV (United States), 12-16 Apr 1992).

Golder Associates Inc. (GAl) has developed a probabilistic total system performance assessment and strategy evaluation model (RIP) which can be applied in an iterative manner to evaluate repository site suitability and guide site characterization. This paper describes one component of the RIP software, the waste package behavior and radionuclide release model. The waste package component model considers waste package failure by various modes, matrix alteration/dissolution, and radionuclide mass transfer. Model parameters can be described as functions of local environmental conditions. The waste package component model is coupled to component models for far-field radionuclide transport and disruptive events. The model has recently been applied to the proposed repository at Yucca Mountain.

634 Nuclear waste repository program oversight: Strategies of the situs jurisdiction. Niedzielski-Eichner, P.A. (Nye County Policy and Technical Support, Governmental Dynamics, Inc., Fairfax, VA (US)); Holstein, E. pp. 1927-1937 of Proceedings of high level radioactive waste management: Volume 1. American Nuclear Society, La Grange Park, IL (United States) (1992). pp. 2425 (CONF920430-: 3. international high level radioactive waste management (IHLRWM) conference, Las Vegas, NV (United States), 12-16 Apr 1992).
Written as a limited case description of Nye County, Nevada's initiative to engage in oversight and impact monitoring of one of the United State's most complex, expensive, and controversial public works projects, this paper will be valuable for those insights it offers on how a rural local government is confronting the challenges of having the designated repository candidate site for high-level nuclear waste in its jurisdiction. The paper will describe the operating structure of the County's Nuclear Waste Repository Project Office (RPO), and its mission and functions. Repository-related risks and concerns confronting the County will also be discussed. Finally, the basic strategies the RPO has undertaken to ensure that its voice is heard on matters of public health and safety, preservation of the County's environmental and natural resources, and protection from social and economic impacts will be offered.

\section{Diffusion of carbon dioxide and lodine through} Yucca Mountain tuffs: Effects of temperature and moisture content. Bardakci, T. (North Carolina A and T State Univ., Dept. of Chemical Engineering, Greensboro, NC (US)); King, F.G.; Sihgh, A. pp. 1946-1952 of Proceedings of high level radioactive waste management: Volume 1. American Nuclear Society, La Grange Park, IL (United States) (1992). pp. 2425 (CONF-920430-: 3. international high level radioactive waste management (IHLRWM) conference, Las Vegas, NV (United States), 12-16 Apr 1992).

This paper reports that the effective diffusivity of carbon dioxide and iodine was measured for tuff samples from five locations near Yucca Mountain. Samples of $G$ tunnel tuff, lower non-lithophysal zone of Topopah Spring tuff (outcrop sample of the layer right above the proposed repository site layer) and Tiva Canyon tuff samples (proposed repository layer) were studied. A steady state method, using chromatographic analysis, was used to determine the effective diffusivity of $\mathrm{CO}_{2}$ for all tuffs. An unsteady state method was used to determine effective diffusivity for lodine on three tuffs. Empirical correlations are reported for each tuff to correlate the effect of temperature, and moisture content, on the diffusivity of $\mathrm{CO}_{2}$. Effective diffusivity, of all tuffs and both gases, increased with temperature. Effective diffusivity of $\mathrm{CO}_{2}$ decreased as the moisture content increased.

636 Characterization of the Topopah spring and Tiva Canyon tuffs at Yucca Mountain: Effective diffusivities and pore properties. Singh, A. (Chemical Engineering Dept., North Carolina A and T State Univ., Greensboro, NC (US)); llias, S.; Tatterson, G. pp. 1953-1958 of Proceedings of high level radioactive waste management: Volume 1. American Nuclear Society, La Grange Park, IL (United States) (1992). pp. 2425 (CONF-920430-: 3. international high level radioactive waste management (IHLRWM) conference, Las Vegas, NV (United States), 12-16 Apr 1992).

The purpose of this paper is to provide effective diffusivity data which permit the calculation of the amount of diffusion of carbon dioxide and iodine through actual samples of Yucca Mountain tuffs. The effective diffusivity data of carbon dioxide and iodine through the tuff samples were determined using a single pellet high temperature diffusion cell as a function of temperature and sample moisture content. The pore structures of the samples were characterized by using a mercury porosimeter, surface area analyzer, scanning electron microscopy, and helium pycnometer. Effective diffusivity data obtained were of the right order of magnitude. Diffusion took place primarily in the combined Knudsen and bulk diffusion regimes. As expected from these regimes, effective diffusivities varied linearly with temperature in some 
cases and up to the 3.2 power of temperature in other cases. The effective diffusivities were found to be a function of porosity and mean pore radius. Moisture content had little effect on the effective diffusivity data.

637 A Monte Carlo technique to estimate the probability of volcanic dikes. Sheridan, M.F. (Dept. of Geology, Univ. of Buffalo, Buffalo, NY (US)). pp. 2033-2038 of Proceedings of high level radioactive waste management: Volume 1. American Nuclear Society, La Grange Park, IL (United States) (1992). pp. 2425 (CONF-920430-: 3. international high level radioactive waste management (IHLRWM) conference, Las Vegas, NV (United States), 1216 Apr 1992).

This paper discusses estimation of the spatial probability of future volcanic dikes in the vicinity of Yucca Mountain which is based on a computer code using a Monte Carlo simulation. The model for the code incorporates the geometrical aspects of all current hypotheses concerning volcanism in the area. The main functions of the code are to: plot the position of dikes according to input parameters that specify the requisite geometry of the volcanic field and the dikes, calculate the number of dikes that intersect the repository for each simulation, and compute a risk probability function based on field size for the specified field and dike geometries.

638 Conceptual design of a monitored retrievable storage cask employing Yucca Mountain containers. Erwin, C.S. (Nuclear Engineering Program, George W. Woodruff School of Mechanical Engineering, Georgia Inst. of Technology, Atlanta, GA (US)); Jackson, D.R.; Oliver, J.R.; Aljohani, M.S.; Bullen, D.B. pp. 2235-2240 of Proceedings of high level radioactive waste management: Volume 1. American Nuclear Society, La Grange Park, IL (United States) (1992). pp. 2425 (CONF-920430-: 3. international high level radioactive waste management (IHLRWM) conference, Las Vegas, NV (United States), 12-16 Apr 1992).

In this paper a conceptual design of a Monitored Retrievable Storage cask that accepts containers compatible with those currentiy proposed for the deep geologic disposal facility under consideration at the Yucca Mountain site is presented. The proposed cask consists of an outer skin of nickel-based Alloy 825, a boron carbide neutron shield, an additional Alloy 825 structural barrier, a chemical-grade lead gamma shield, and an Alloy 825 inner sleeve. Criticality, thermal, structural, shielding and economic analyses are performed following the determination of the optimum cask configuration. The preliminary design does not violate any technical criteria required for licensing. The economic analysis suggests that a system such as this may be competitive with other dry cask storage options. The significant benefit of this system is the ability to interface directly with the deep geologic disposal facility and thereby limit the handling requirements and the resulting worker radiation exposure.

639 Environmental monitoring for uranium and neptunium at Yucca Mountain. Riggle, K.J. (Univ. of Missouri Research Reactor, Research Park, Columbia, MO (US)). pp. 2323-2330 of Proceedings of high level radioactive waste management: Volume 1. American Nuclear Society, La Grange Park, IL (United States) (1992). pp. 2425 (CONF920430-: 3. international high level radioactive waste management (IHLRWM) conference, Las Vegas, NV (United States), 12-16 Apr 1992).

In this paper Epithermal Neutron Activation Analysis (ENAA) is investigated as an analysis method for uranium and neptunium in environmental samples from Yucca Mountain. The design and construction of a facility for this technique are described. Theoretical improvements in sensitivity for ENAA over thermal Neutron Activation Analysis (NAA) are discussed and compared to experimental results for different sample types. Uranium is analyzed in eight different sample matrices, including samples from Yucca Mountain. To date, neptunium has been studied only in AGV-1 Granite. As predicted by theory, uranium shows a high sensitivity improvement factor (average $=7.76$ ), while neptunium has a factor of only 0.49 . Detection limits for uranium using ENAA range from 6 to $52 \mathrm{ppb}$ (2.6 to $17 \mathrm{ng}$ ). neptunium shows a detection limit of $57 \mathrm{ppb}(6.2 \mathrm{ng})$. Using thermal NAA, neptunium can be analyzed to $35 \mathrm{ppb}$ (3.4 ng).

640 Temporal and spatial distribution of basaltic volcanism in the Pancake and Reveille Ranges north of Yucca Mountain. Foland, K.A. (Ohio State Univ., Columbus, OH (US)); Bergman, S.C. pp. 2366-2371 of Proceedings of high level radioactive waste management: Volume 1 . American Nuclear Society, La Grange Park, IL (United States) (1992). pp. 2425 (CONF-920430-: 3. international high level radioactive waste management (IHLRWM) conference, Las Vegas, NV (United States), 12-16 Apr 1992).

This paper discusses the widespread Late Cenozoic volcanic activity which occurred in Pancake and Reveille Ranges of Nevada overlaps in age and magma composition with analogs near Yucca Mountain and farther south. The volcanism began in the southern part of the Reveille Range as early as about $9 \mathrm{Ma}$ and generally progressed to the northeast, culminating in a number of centers about $0.5 \mathrm{Ma}$ or younger. The basaltic lavas show significant variations in chemical and isotopic composition reflecting mainly differences in magmatic processes. These differences are loosely correlated in both space and time and reflect the changing nature of volcanologic processes which appear to be influenced by the crustal residence intervals of the magmas.

641 Geostatistical methods for site characterization at Yucca Mountain. Istok, J.D. (Oregon State Univ., Corvallis, OR (US)); Flint, A.L. Pp. 47-58 of Disposal of Radioactive Waste. Organisation for Economic Co-operation and Development, Paris (FR) (1991). pp. 334 (CONF-9010214-: Nuclear Energy Agency (NEA) workshop on flow heterogeneity and site evaluation, Paris (France), 22-24 Oct 1990).

Yucca Mountain, Nevada, U.S.A. is being considered as a repository for commercial, high-level nuclear waste. Orie objective of site characterization is to obtain information for numerical models that are used to predict pre-wasteemplacement groundwater travel times. This information will be obtained by analyzing a variety of types of field and laboratory data that can be broadly classified into two groups: hard data consisting of measured values of a quantity, and soft data consisting of guessed values based on qualitative observations and/or subjective interpretation of the available hard data. Hard and soft data can be further classified into three categories: exact, interval, and inequality. The objective of this paper is to review the assumptions and limitations of several geostatistical methods that are potentially useful for analyzing these data to obtain estimates for rock unit contacts, properties, and state variables at Yucca Mountain. 3 Tabs.; 16 Rets.

642 Thorium-230 chronology of natural waters at the Nevada test site. Bakhtiar, S.N. (Reynolds Electrical and Engineering Co., Las Vegas, NV (United States)). pp. 
84, Paper NUCL of American Chemical Society. Division of Nuclear Chemistry and Technology. American Chemical Society, Washington, DC (US) (1991). pp. 30 (CONF9108101-: 4. chemical congress of North America, New York, NY (United States), 25-30 Aug 1991).

Carbon-14 dating was used in the past to estimate the ages of ground water from the Paleozoic aquifer underlying the Nevada Test Site (NTS) and adjacent areas. Grove et al. reported that a generally good correlation existed between the carbon-14 dates and the hydraulic interpretations. The so-called adjusted carbon-14 ages of ten water samples taken from wells and springs at the NTS and adjacent areas vary from -1600 to 23,400 years. It seems, however, the aquifer is heterogeneous and is insufficiently defined to permit detailed predictions of ground water velocities or flow patterns. An alternative dating method measured the concentrations of Th-230, Th-232, U-234, and U-238 in several water samples from the wells and springs, and calculated the Th-230 ages.

643 Validation efforts in modeling flow and transport through partially saturated fractured rock - the Apache leap tuff studies. Rasmussen, T.C. (Arizona Univ., Tucson, AZ (US). Dept. of Hydrology and Water Resources); Evans, D.D.; Nicholson, T.J. pp. 284-291 of Safety Assessment of Radioactive Waste Repositories. Organisation for Economic Co-Operation and Development, Paris (FR) (1991). pp. 668 (CONF-9005117-: GEOVAL '90, Stockholm (Sweden), 14-17 May 1990).

A study designed to assess field and laboratory characterization techniques and to generate data sets for analytic and numeric models of ground-water flow and solute transport in unsaturated fractured rock is described. The generated data sets result from both simple and more complex experiments performed in support of the INTRAVAL program for validation of flow and transport models. Simple experiments focus on interstitial, hydraulic, pneumatic, and thermal properties of 105 oriented rock core segments extracted at selected depths. Additional experiments are being performed on fractured rock blocks as well as on field scales. Data sets incorporating nonisothermal processes are being obtained from core and field experiments. The modeling issues being addressed are scaling effects, spatial heterogeneities, and coupled (e.g., liquid, vapor, thermal, and solute) effects for flow and transport. 14 refs.

644 Natural analogue studies useful in validating regulatory compliance analyses. Alexander, D.H. (Office of Civilian Radioactive Waste Management, Washington DC (US)); Van Luik, A.E. pp. 589-597 of Safety Assessment of Radioactive Waste Repositories. Organisation for Economic Co-operation and Development, Paris (FR) (1991). pp. 668 (CONF-9005117-: GEOVAL '90, Stockholm (Sweden), 1417 May 1990).

The U.S. Department of Energy (the Department) is evaluating the suitability of the Yucca Mountain site, Nevada, as the location for a mined geologic disposal system for highlevel waste and spent nuclear fuel. If the site is found suitable, performance assessment calculations will be used to provide a basis for giving reasonable assurance of regulatory compliance. These performance assessment calculations must be certified, which includes - to the extent practicable - validation using field, laboratory and natural analogue studies. In the Department's published Site Characterization Plan for the Yucca Mountain candidate site numerous proposed studies are listed, some of which include natural analogue studies to obtain information over scales of time and distance not addressable in field and laboratory work. In this paper, the Site Characterization Plan's treatment of natural analogues is examined. Natural analogues in a variety of environments may be useful in terms of identifying and understanding specific processes, but an analogue may be particularly useful if key environmental characteristics are similar to those of the geohydrological setting under consideration for a repository. 2 figs., 8 refs..

645 Sealing performance assessments of bentonite and bentonite/crushed rock plugs. Ouyang, Shoung. Arizona Univ., Tucson, AZ (United States). 1990. 378p. Source: University Microfilms, PO Box 1764, Ann Arbor, MI 48106, Order No.91-11,959.

Bentonite and mixtures of bentonite and crushed rock are potential sealing materials for high level nuclear waste repositories. The materials have been used to form cap layers to reduce infiltration for mined waste tailings and can also be used to construct clay liners for municipal as well as industrial waste managements. American Colloid C/S granular dentonite and Apache Leap tuff have been mixed to prepare samples for laboratory flow testing. Bentonite weight percent and crushed tuff gradation are the major variables studied. The sealing performance assessments include high injection pressure flow tests, polyaxial flow tests, high temperature flow tests, and piping tests. The results indicate that an appropriate composition would have at least $25 \%$ bentonite by weight mixed with well-graded crushed rock. Hydraulic properties of the mixture plugs may be highly anisotropic if significant particle segregation occurs during sample installation and compaction. Temperature has no negative effects on the sealing performance within the test range from room temperature to $60 \mathrm{C}$. The piping damage to the sealing performance is small if the maximum hydraulic gradient does not exceed 120 and 280 for 25 and $35 \%$ bentonite content, respectively. The hydraulic gradients above which flow of bentonite may take place are deemed critical. Analytical work includes the introduction of bentonite occupancy percentage and water content at saturation as two major parameters for the plug design. A permeability model developed is useful for the prediction of permeability in clays. A piping model permits the estimation of critical hydraulic gradient allowed before the flow of bentonite takes place. It can also be used to define the maximum allowable pore diameter of a protective filter layer.

646 Point defects in silicates. Priest, V. Missouri Univ., Columbia, MO (United States). 1989. 95p. Source: University Microfilms, PO Box 1764, Ann Arbor, MI 48106, Order No.90-19,671.

Topaz is a wide band gap insulating crystal with four $\mathrm{Al}_{2} \mathrm{~F}_{2} \mathrm{SiO}_{4}$ formula units per orthorhombic unit cell and containing isolated $\mathrm{SiO}_{4}$ tetrahedron. Electron spin resonance (ESR), UV-VIS spectrophotometry, photoluminescence, and isochronal annealing were used to study the point defects introduced by fast-neutron bombardment or by alpha decay recoils. The superoxide radical is characterized by a single hole-like spin $1 / 2$ signal with principle $g$-values $g_{x x}=2.0055$, $g_{z z}=2.0407$ and the major axis of the defect points along $0.356 \hat{a}+0.152 \hat{b}+0.922 \hat{c}$. The superoxide anneals near $650 \mathrm{C}$. Two polarization dependent absorptions occur in the UV due to the transitions ${ }^{2} \mathrm{I}_{\mathrm{g}} \rightarrow{ }^{2} \mathrm{Il}_{\mathrm{u}}$ and ${ }^{2} \mathrm{II}_{\mathrm{g}} \rightarrow{ }^{2} \Delta_{\mathrm{u}}$. The former has an oscillator strength of 0.06 . The $2.5 \mathrm{eV}$ polarization dependent luminescence is due to the transition ${ }^{2} \|_{g}$ $\rightarrow{ }^{2} \|_{u}$. The ${ }^{2} \Delta_{u} \rightarrow{ }^{2} \|_{u}$ is non-radiative. The doubly occupied dangling silicon bond, the blue center, is characterized by a 
$2 \mathrm{eV}$ polarization dependent absorption and is nonparamagnetic. The transition dipole for this absorption points in the direction $0.93 \hat{a}+0.210 \hat{b}+0.305 \hat{c}$ and the oscillator strength is approximately $2.0 \times 10^{-3}$. The blue center anneals at $500 \mathrm{C}$. This dangling bond defect is one of two models proposed for a similar $2 \mathrm{eV}$ absorption in silica glass. The defects in quartz $\left(\mathrm{SiO}_{2}\right)$ were introduced by the recoil nuclei after alpha decays of uranium, thorium, and their daughters in natural abundances. The accumulating damage provides a geological clock by which the age of the quartz can be found. The sample came from Yucca Flats, Nevada, the proposed site of a nuclear waste dump.

647 Gas phase migration of $\mathrm{C}-14$ through barrier materials applicable for use in a high-level nuclear waste repository located in tuff. Bauer, L.R. Purdue Univ., Lafayette, IN (United States). 1988. 125p. Source: University Microfilms, PO Box 1764, Ann Arbor, MI 48106, Order No.89-11,867.

A study of the movement of ${ }^{14} \mathrm{CO}_{2}$ through proposed barrier media has been conducted. Diffusion coefficients for crushed tuff, bentonite and a $90: 10 \%$ by wt. mixture of crushed tuff and bentonite were measured for two diffusion lengths. The ability of ${ }^{14} \mathrm{CO}_{2}$ to penetrate a microsilicacontaining portland cement mortar proposed for repository use was also examined. The specimens were subjected to uniaxially-applied compressive loads prior to the diffusion tests to simulate the onset of environmentally-induced microcracks. Based on these experiments, the apparent diffusion coefficients for the soil-based media were as follows: crushed tuff, $1.73 \pm 0.26 \times 10^{-2} \mathrm{~cm}^{2} / \mathrm{s}$; bentonite, $1.56 \pm$ $0.61 \times 10^{-2} / \mathrm{s}$; and the crushed tuff/bentonite mixture, 1.77 $\pm 0.13 \times 10^{-2} \mathrm{~cm}^{2} / \mathrm{s}$. These values correspond roughly to breakthrough times of 5 and 10-15 min respectively for the $6.5-$ and $23-\mathrm{cm}$ thicknesses studied. With respect to the mortar studies, the penetration of ${ }^{14} \mathrm{CO}_{2}$ through $1-\mathrm{cm}$ thick microfractured discs was, in all cases, limited to the upper 1 $\mathrm{mm}$ of the cement surfaces. Serial sampling of the diffusion cells and $\mathrm{pH}$ testing of the cement surfaces indicated that the ${ }^{14} \mathrm{CO}_{2}$ was consumed by the reaction of $\mathrm{CO}_{2}$ with free $\mathrm{Ca}(\mathrm{OH})_{2}$ in the cement to form calcite $\left(\mathrm{CaCO}_{3}\right)$. The formation of the calcite apparently acted as a chemical and/or physical barrier to ${ }^{14} \mathrm{CO}_{2}$ migration. Only when a disc was completely fractured could significant penetration of ${ }^{14} \mathrm{CO}_{2}$ be observed. These results may have implications for the ability of a repository to comply with the applicable regulatory release limits for $\mathrm{C}-14$.

648 NRC approves spent-fuel cask for general use: Who needs Yucca Mountain?. Simpson, J. Public Utilities Fortnightly (United States); 131(13): 27-30 (1 Jul 1993).

The Nuclear Regulatory Commission (NRC) on April 7, 1993, added Pacific Sierra Nuclear Associates's (PSNA's) VSC-24 spent-fuel container to its list of approved storage casks. Unlike previously approved designs, however, the cask was made available for use by utilities without sitespecific approval. The VSC-24 (ventilated storage cask) is a 130-ton, 16-foot high vertical storage container composed of a ventilated concrete cask (VCC) housing a steel multiassembly sealed basket (MSB). A third component, a transfer cask (MTC), shields, supports, and protects the MSB during fuel loading and VCC loading operations. The VCC is a cylindrical reinforced-concrete cask 29 inches thick, with a 1.75-inch-thick A 36 steel liner. The cask contains eight vents-four on the top and four on the bottom-to provide for MSB (and fuel rod) cooling. Its concrete shell provides protection against shearing and penetration by tornado projectiles, protects the MSB in the event of a drop or tipover, and is designed to withstand internal temperatures of 350 degrees Farenheit. The VCC is closed with a bolteddown cover of 0.75 -inch-thick A 36 steel. The MSB, which provides the primary boundary for 24 spent fuel rods, is a cylindrical steel shell with a thick shield plug and steel cover plates welded at each end. The shell and covers are constructed from SA 516 Grade 70 pressure vessel steel. Fuel is housed in a basket fabricated from SA 516 Grade 70 sheet steel. Penetrations in the MSB's structural and shield lids allow for vacuum drying and backfilling with helium after fuel loading. Although its manufacturer claims a design life of 50 years, the NRC has licensed the VSC-24 cask for 20 years.

649 Role of organic matter in the Proterozoic Oklo natural fission reactors, Gabon, Africa. Nagy, B. (Univ. of Arizona, Tucson (United States)); Rigali, M.J.; GauthierLafaye, F.; Holliger, P.; Mossman, D.J.; Leventhal, J.S. Geology (United States); 21(7): 655-658 (Jul 1993).

Of the sixteen known Oklo and the Bangombe natural fission reactors (hydrothermally altered elastic sedimentary rocks that contain abundant uraninite and authigenic clay minerals), reactors 1 to 6 at Oklo contain only traces of organic matter, but the others are rich in organic substances. Reactors 7 to 9 are the subjects of this study. These organic-rich reactors may senve as time-tested analogues for anthropogenic nuclear-waste containment strategies. Organic matter helped to concentrate quantities of uranium sufficient to initiate the nuclear chain reactions. Liquid bitumen was generated from organic matter by hydrothermal reactions during nuclear criticality. The bitumen soon became a solid, consisting of polycyclic aromatic hydrocarbons and an intimate mixture of cryptocrystalline graphite, which enclosed and immobilized uraninite and the fissiongenerated isotopes entrapped in uraninite. This mechanism prevented major loss of uranium and fission products from the natural nuclear reactors for 1.2 b.y. 24 refs., 4 figs.

650. Hydrothermal alteration of organic matter in uranium ores, Elliot Lake, Canada: Implications for selected organic-rich deposits. Mossman, D.J. (Mount Allison Univ., Sackville (Canada)); Nagy, B.; Davis, D.W. Geochimica et Cosmochimica Acta (United States); 57(14): 3251-3259 (Jul 1993). Grant A 8295. (CONF-911017-: Annual meeting and exhibition of the Geological Scciety of America (GSA), San Diego, CA (United States), 21-23 Oct 1991).

Organic matter in the uraniferous Matinenda Formation, Elliot Lake, is preserved in the forms of syngenetic kerogen and solid bitumen as it is in many of the Oklo uranium deposits and in the Witwatersrand gold-uranium ores. The Elliot Lake kerogen is a vitrinite-like material considered to be remnants of the Precambrian cyanobacterial mats. The kerogen at Elliot Lake has reflectances (in oil) ranging from $2.63-7.31 \% \mathrm{RO}_{\max }$, high aromaticity, relatively low $(0.41$ 0.60 ) atomic $H / C$ ratios, and it contains cryptocrystalline graphite. Bitumen, present primarily as dispersed globules (up to $0.5 \mathrm{~mm}$ dia.), has reflectances from $0.72-1.32 \%$ $\mathrm{RO}_{\max }$, atomic $\mathrm{H} / \mathrm{C}$ ratios of $0.71-0.81$, and is somewhat less aromatic than the kerogen. Overall similarity in molecular compositions indicates that liquid bitumen was derived from kerogen by processes similar to hydrous pyrolysis. The carbon isotopic composition of kerogen $(-15.62$ to $-24.72 \%)$, and the now solid bitumen $(-25.91$ to $-33.00 \%)$ are compatible with these processes. Despite having been 
subjected to several thermal episodes, ca. 2.45 Ga old kerogen of microbiological origin here survived as testimony of the antiquity of life on Earth. U-Pb isotopic data from discrete kerogen grains at Elliot Lake form a scattered array intersecting concordia at $2130 \pm 100 \mathrm{Ma}$, correspond to the Nipissing event. U-Pb systems were totally reset by this event. Uranium and lead show subsequently partial mobility, the average of which is indicated by the lower concordia intersect of $550 \pm 260 \mathrm{Ma}$. The migrated bitumen contains virtually no uranium and thorium but has a large excess of ${ }^{206} \mathrm{~Pb}$, which indicates that the once liquid bitumen must have acted as a sink for mobile intermediate decay products of ${ }^{238} \mathrm{U}$. Emplacement of the Nipissing diabase may have been responsible for producing the bitumen and, indirectly, for its enrichment in ${ }^{206} \mathrm{~Pb}$ as a result of outgassing of ${ }^{222} \mathrm{Rn}$.

651 Dissolution kinetics of heulandite at $\mathrm{pH} \mathrm{2-12}$ and $25^{\circ} \mathrm{C}$. Ragnarsdottir, K.V. (Univ. of Bristol (GB)). Geochimica et Cosmochimica Acta (United States); 57(11): 2439-2449 (Jun 1993).

Because of their favourable cation exchange reactions; heulandite and clinoptilolite have been suggested as being capable of immobilizing radionuclides and therefore could possibly act as an important barrier for nuclear waste. Recent studies of laboratory-reacted minerals indicate, however, that hydrated surface layers tend to accumulate highly hydrolyzable heavy elements. These hydrated layers may therefore be the most important retardants for radionuclides. The dissolution rate of heulandite depends strongly on $\mathrm{pH}$. Based on silica release, the logarithm of the steady-state dissolution rate at $\mathrm{pH} 2$ is $-13.1 \mathrm{~mol} \mathrm{~cm} \mathrm{~cm}^{-2} \mathrm{~s}^{-1}$. The logarithm of the rate decreases to $-15.8 \mathrm{~mol} \mathrm{~cm}^{-2} \mathrm{~s}^{-1}$ at $\mathrm{pH}$ 7.2 and increases again to $-14.6 \mathrm{~mol} \mathrm{~cm}^{-2} \mathrm{~s}^{-1}$ at $\mathrm{pH} 12.2$. At low pH, Al is released preferentially to silica; but at intermediate and high $\mathrm{pH}$, the release of silica appears to be congruent relative to $\mathrm{Al}$. The change in dissolution rate with $\mathrm{pH}$ indicates that at low $\mathrm{pH}$, the dissolution mechanism is controlled by the detachment of a positively charged $\mathrm{Al}$ species, $>\mathrm{Al}-\mathrm{OH}_{2}{ }^{+}$. Below pH 5 , however, a silica-rich surface layer is formed requiring diffusion through the layer. At intermediate and high $\mathrm{pH}$, it is likely that the dissolution rate is controlled by the detachment of a negatively charged silica species, $>\mathrm{Si}^{-} \mathrm{O}^{-}$. The reaction order of the hydrogen ion under low pH conditions is 0.7 , and the reaction order of the $\mathrm{OH}^{-}$ion is 0.3 at high $\mathrm{pH}$. The measured dissolution rates indicate that a $1 \mathrm{~mm}$ heulandite crystal would dissolve in 300,000 yrs if the solution composition is maintained undersaturated. 75 refs., 11 figs., 3 tabs.

652 2010: America's nuclear waste odyssey. Lowry, D. (Open Univ., Milton Keynes (United Kingdom). Energy and Environmental Research Unit). New Scientist (London) (United Kingdom); 137(1863): 30-33 (6 Mar 1993).

The controversy surrounding the proposal to build a nuclear waste repository beneath Nevada's Yucca mountain is described in this articie. The United States (US) Department of Energy (DOE) has spent billions of dollars studying the site which could hold up to 25,000 tonnes of highly radioactive spent fuel and high-level waste from the US's commercial nuclear power plants. The debate revolves around containment of the waste for DOE's own $\$ 10,000$ year criterion" when the waste will have lost much of its radioactivity. Opponents of the project cite recent earthquakes in the region and evidence of changing watertables within the mountains as reasons to suppose the criterion cannot be met. While Nevada State Government remains adamantly opposed, the new Clinton-Gore administration has yet to decide how the whole nation's interests are best served. (UK).

653 Source parameters of the June 29, 1992 Little Skull Mountain earthquake from complete regional waveforms at a single station. Walter, W.R. (Lawrence Livermore National Lab., CA (US)). Geophysical Research Letters (American Geophysical Union) (United States); 20(5): 403-406 (5 Mar 1993). DOE Contract W-7405-ENG48.

The June 29, 1992, $m_{b}=5.5$, Little Skull Mountain earthquake occurred $20 \mathrm{~km}$ southeast of Yucca Mountain within the boundaries of the Nevada Test Site. This event was recorded at a very broadband station located about $310 \mathrm{~km}$ to the east at Kanab, Utah. Both body and surface waves from this single station were used in a grid search technique for the best fitting double couple moment tensor. The technique minimizes the misfit between reflectivity generated complete synthetic seismograms and the three-component displacement data via a search over the strike, dip and rake of the source. In the passband of 50-15 s period, the grid search results in a well defined, nearly pure normal mechanism with a strike of $35^{\circ}$, a dip of $54^{\circ}$, a rake of $-87^{\circ}$, and a seismic moment of $4.1 \times 10^{17} \mathrm{~N}-\mathrm{m}$. Applying the same technique to the large aftershock on July 5, 1992 the authors obtain a somewhat less well defined minimum with a strike of $358^{\circ}$, a dip of $36^{\circ}$, a rake of $-177^{\circ}$, and a moment of 4.3 $\times 10^{15} \mathrm{~N}$-m. The minimum-compression axes of these mechanisms are consistent with northwest-southeast extension in the Basin and Range. 14 refs., 7 figs.

654 Does multiple land use work - the Ranger example. Cleary, R. (Energy Resources of Australia, Sydney, NSW (Australia)); McNally, P.; Peters, R. ERA Newsletter (Australia); 3(1): 1-6 (Mar 1993). (CONF-9302149-: Outlook' 93: national agricultural and resource outlook conference, Canberra (Australia), 2-4 Feb 1993).

The Ranger uranium mine in the Alligator Rivers Region of the Northern Territory is on Aboriginal land and is surrounded by Kakadu National Park. The Ranger Mine is owned and operated by Energy Resources of Australia Limited (ERA). The issues of environmental performance and impact on traditional Aboriginal have always been key concerns in the planning and operation of the Ranger mine. It is shown that adoption of these priorities, along with efficient mining, have been a large part of ERA's success to date. The Ranger project, its infrastructure and residential community, represents a substantial investment and is a substantial export earner for Australia, as well as a source of revenue for traditional Aboriginals whose land is affected by the development. 1 tab., 2 figs.

655 Some observations on the mechanism of corrosion to be encountered in nuclear waste repositories located in tuffaceous rock. Wilde, M.H. (Ohio State Univ., Columbus, $\mathrm{OH}$ (United States). Fontana Corrosion Centre); Wilde, B.E. Corrosion Science (United Kingdom); 34(3): 433-443 (Mar 1993).

Potentiostatic anodic polarization studies have been conducted in a $\mathrm{J}-13$ simulated nuclear waste repository environment, which was allowed to evaporate to dryness followed by rehydration prior to polarization. The behavior of Type 316L stainiess steel, AISI 1020 carbon steel, Hastelloy $\mathrm{C} 22$ and platinum was compared with that noted previously for a non-baked simulate. The anodic dissolution characteristics of Type $316 \mathrm{~L}$ stainless steel in environments containing $1000 \times \mathrm{Cl}^{-} \mathrm{J}-13$ depend markedly on whether the 
solution is merely a mixture of virgin chemicals or a mixture that has been evaporated to dryness, baked and rehydrated to the same volume. In the non-evaporated environment Type 316L stainless steel pitted severely, and in the evaporated/rehydrated environment a non-corroding type of behavior was observed along with the precipitation of a dense scale. Similar behavior was observed for Hastelloy C22. The polarization curves for carbon steel and platinum were the same as those noted for $316 \mathrm{~L}$ and Hastelloy $\mathrm{C22}$, when conducted in the evaporated/rehydrated environment. $X$-ray diffraction studies indicated that the scale produced in all tests conducted on evaporated/rehydrated solutions was calcium carbonate. Based on the qualitatively similar polarization characteristics of materials having such widely differing corrosion properties, it is concluded that the major factor controlling the anodic charge transfer reaction under these conditions is the formation of a calcium carbonate scale. (Author).

656 Occurrence of naturally enriched ${ }^{235} \mathrm{U}$ : Implications for plutonium behavior in natural environments. Bros, R. (CNRS, Strasbourg (FR)); Gauthier-Lafaye, F.; Stille, P.; Turpin, L.; Holliger, Ph. Geochimica et Cosmochimica Acta (United States); 57(6): 1351-1356 (Mar 1993).

It is generally accepted that uranium and most of the fission products, with the exception of the alkalis, alkaline earths and rare gases, remained in the irradiated uranium oxides during the nuclear reactions that took place $2.0 \mathrm{Ga}$ ago in the Oklo uranium deposit (Gabon). New isotope investigations show that clay minerals from argillaceous rocks neighboring the natural fission reactor 10 at Oklo have depleted ${ }^{235} \mathrm{U}$ with ${ }^{235} \mathrm{U} /{ }^{238} \mathrm{U}$ ratios ranging between 0.00560 and the common natural value of 0.00725 . One sample, however, is enriched in ${ }^{235} \mathrm{U}$ with $a^{235} \mathrm{U} /{ }^{238} \mathrm{U}$ ratio of 0.007682 . Leach experiments of this sample with dilute $1 \mathrm{~N}$ $\mathrm{HCl}$ revealed that the ${ }^{235} \mathrm{U}$ enrichment is actually restricted to the insoluble residue $\left({ }^{235} \mathrm{U} /{ }^{238} \mathrm{U}=0.010511\right)$, whereas the leachate remains depleted in ${ }^{235} \mathrm{U}$. This unique discovery of very enriched uranium, together with samarium, neodymium, rubidium, and strontium isotopic analyses, indicate that a small amount of plutonium could have been more mobile than uranium in the reactor 10 , and it is suggested that plutonium was incorporated in the crystallographic structure of clay minerals such as the chlorites. 28 refs., 3 figs., 1 tab.

657 A dose of HLW reality. Payne, J. Nuclear News (La Grange Park, Illinois) (United States); 36(2): 23 (Feb 1993).

What many people were sure they knew, and some others were fairly confident they knew, was acknowledged by the US Department of Energy in December: A monitored retrievable storage (MRS) facility will not be ready to accept spent fuel by January 31,1998 . A dose of reality has thus been added to the US high-level radioactive waste scene. Perhaps as important as the new reality is the practical, businesslike nature of the DOE's plan. The Department's proposal has the quality of a plan aimed at genuinely solving a problem rather just going through the motions. (In contrast, some readers are familiar with New York State's procedures for siting and licensing a low-level waste facility procedures so labyrinthine that they are much more likely to protect political careers in that state than they are to achieve an LLW site). The DOE has received a lot of criticism - some justified, some not - about its handling of the HLW program. In this instance, it is proposing what many in the industry might have recommended: Make available storage capacity for spent nuclear fuel at existing federal government sites.

658 Nuclear age: Take two?. Davis, E.M. Public Utilities Fortnightly (United States); 131(1): 18-19,29 (1 Jan 1993).

The Energy Policy Act of 1992 removes many institutional obstacles impeding nuclear energy's further development and expansion. Coupled with the important progress being made by the industry in implementing the Nuclear Power Oversight Committee's (NPOC) Strategic Plan for Building New Nuclear Power Plants, the stage is now set for new nuclear plant orders by the mid-1990s, if advanced nuclear plant designs prove by then - as projected - to be competitive with other sources of baseload capacity. Nuclear energy's competitiveness with other energy sources undoubtedly will become increasingly important as the Clinton Administration implements a transition that is expected to shift the Department of Energy's (DOE) focus and priorities to other energy alternatives. Congress overwhelming directive to reform the nuclear plant licensing process, restructure the uranium enrichment enterprise into a business-like corporation, and demonstrate progress toward studying Yucca Mountain as a potential high-level waste site marks the beginning of a new era for nuclear energy in the United States. With the legislative foundation complete, efforts are now concentrating on design and engineering work to allow for an order for an advanced, standardized nuclear energy plant during this decade.

659 Uptake of uranium and thorium series radionuclicies by the waterlily, Nymphaea violacea. Pettersson, H.B.L. (Lund Univ. Teaching Hospital (Sweden). Dept. of Radiation Physics); Hancock, G.; Johnston, A.; Murray, A.S. Journal of Environmental Radioactivity (United Kingdom); 19(2): 85-108 (1993).

The waterlily, Nymphaea violacea, is a major aquatic macrophyte in the waters of the Alligator Rivers Region, Northern Territory, Australia. It is also a traditional Aboriginal diet item, and is considered to be potentially one of the main contributors to the effective dose equivalent arising from consumption of so called bush food in the region. Because of the proximity of the Ranger Uranium Mine (RUM), the activity concentrations of the $\mathrm{U}$ and $\mathrm{Th}$ series radionuclides have been studied in water, sediment and waterlily during different seasons at five sites downstream of the mine site. The objectives of the study were to identify the major source of radionuclide uptake by the plant; i.e. water or sediment; to assess the concentration factorsiratios needed for predicting the radiation exposure of the critical group resulting from any discharge of water to the aquatic environment from the Ranger uranium mine; to estimate the natural radiation exposure of the public arising from consumption of waterlilies. (Author).

660 Nuclear wastes and public trust. Flynn, J. (Decision Research, Eugene, OR (US)); Slovic, P. Forum for Applied Research and Public Policy (United States); 8(1): 92-101 (Spr 1993).

Citing public fear and mistrust, strong opposition to the proposed Yucca Mountain repository site, and less-thanexemplary performance by the Department of Energy (DOE), two private researchers believe present high-level radioactive waste-disposal plans may have to be scrapped. Government and the nuclear industry may have to start over. Policy makers should seek to develop new relationships with communities and states where suitable disposal 
sites exist. These relationships may require that citizen groups and local institutions be given unprecedented authority in locating and operating such facilities. Contrary to popular impressions, there is still time to take a new approach. The US Nuclear Regulatory Commission says present on-site storage arrangements offer a safe alternative for 100 years or more. The sense of immediate crisis and cries for immediate solutions should be calmed and a more considered strategy brought to the public debate. For starters, the researchers propose that the problems of defense waste be separated from the problems of commercial waste. They also suggest that DOE be assigned responsibility for defense waste and a new agency be created to handle high-level commercial waste.

661 Migration of technetium-99 in the alluvial aquifer at the Nevada test site, Nevada. Schroeder, N.C. (Los Alamos National Lab., NM (United States). Isotope and Nuclear Chemistry Div.); Rokop, D.J.; Fabryka-Martin, J.; Morgan, D. Radiochimica Acta (Germany); 60(4): 203-209 (1993).

The Cambric Experiment, under the auspices of the Hydrology/Radionuclide Migration Project, is measuring the migration of radionuclides from the site of an old underground nuclear test. Ten years after the 1965 test, a re-entry well (RNM-1) was drilled into the remnant of the explosion cavity to obtain core and water samples. Pumping water from a satellite well (RNM-2S) $91 \mathrm{~m}$ from the cavity subsequently induced an artificial gradient that has allowed soluble radionuclides to migrate from the cavity. Tritium (HTO) has been observed in the RNM-2S water; its elution has been well characterized. Other radionuclides have also been monitored in water from RNM-2S: ${ }^{36} \mathrm{Cl},{ }^{95} \mathrm{Kr},{ }^{129} \mathrm{l}$, and ${ }^{106} \mathrm{Ru}$. We have recently measured ${ }^{99} \mathrm{Tc}$ at the $10-20 \mathrm{fg} / \mathrm{l}$ level in RNM-2S water. In contrast to the ${ }^{3} \mathrm{H}$ source term, which is essentially entirely available to transport, these results indicate that only $\propto 0.01 \%$ of the ${ }^{99} \mathrm{Tc}$ has escaped from the vitrified rock matrix into the water. The technetium in solution appears to be migrating more slowly than the ${ }^{36} \mathrm{Cl}$ is. Although ${ }^{99}$ Tc's initial breakthrough is similar to that for ${ }^{3} \mathrm{H}$, the migration rate of the ${ }^{99} \mathrm{Tc}$ center of mass appears to slightly exceed that of ${ }^{3} \mathrm{H}$, perhaps as a result of anion exclusion effects. All measured ${ }^{99}$ Tc concentrations are considerably below limits established for public drinking water. (orig.).

662 Volatile and trace element composition of melt inclusions from the Lower Bandelier Tuff - implications for magma chamber processes and eruptive style. Dunbar, N.W. (New Mexico Inst. of Mining and Technology, Socorro (US)); Hervig, R.L. Journal of Geophysical Research (United States); 97: 15 (Oct 1992).

The preeruptive volatile gradient that was present in the magma which produced the Lower Bandelier Tuff (LBT) is determined on the basis of an analysis of the $\mathrm{H}_{2} \mathrm{O}, \mathrm{Cl}$, and $\mathrm{F}$ contents of melt inclusions (Mls) in LBT phenocrysts. The trace element contents of bulk pumice and Mls are measured in order to facilitate interpretation of the pristine nature of the Mis. The data show that there was a large gradient in the $\mathrm{H} 2 \mathrm{O}$ content (hence density) of the magma between an H2O-saturated cap and the body of the chamber. The trace element analysis of the Mls and bulk rocks show that after the water gradient evolved, the chamber underwent about 40 percent eutectic fractional crystallization and was then intruded by a second rhyolitic magma at some time prior to eruption. 75 refs.
663 Using geological information to develop new exploration project for uranium deposits in Southern Africa. Takahashi, Osamu (Power Reactor and Nuclear Fuel Development Corp., Toki, Gifu (Japan). Chubu Works). Donen Giho (PNC Technical Review) (Japan); (83): 70-76 (Sep 1992). (In Japanese).

Unconformity related uranium deposits which contain a large amount of resources with higher grades will be economically superior to other types of deposits. This paper presents the integrated use of geological information, which includes compilation data for the Precambrian geology in southern Africa and selected structural geologic data for some analogues of unconformity related uranium deposit in Canada (e.g. Key Lake deposit in Athabasca Basin) and the Precambrian rock hosted uranium deposit in Africa (e.g. Oklo-Munana, Rossing, Shinkolobwe and Dome deposits). Finally, some favourable geological terrains for unconformity related uranium deposit and the Precambrian rock hosted uranium deposit were selected on the basis of geological information. Further significant discoveries are likely in the following geological terrains. 1. Both the unconformity related and Oklo-Munana type deposits are favourable at (a) and (b). (a) the Lower Proterozoic Eburnian belts which are unconformably overlain by sequences of Kibaran and also the unmetamorphosed sequences in Pan-African. The age and paleoenvironment of the unmetamorphosed sequences in Pan-African is comparable to Kibaran. (b) the unmetamorphosed sequences in Eburnian. 2. The Rossing, Shinkolobwe and Dome type deposits are favourable at the Upper Proterozoic Pan-African Belts. (author).

664 Dissolution and alteration of uraninite under reducing conditions. Janeczek, J. (Dept. of Geology, Univ. of New Mexico, Albuquerque, NM (United States)); Ewing, R.C. Journal of Nuclear Materials (Journal des Materiaux Nucleaires) (Netherlands); : 157-173 (Aug 1992).

The behavior of uraninite under hydrothermal, reducing conditions is discussed on the basis of data in the literature and the authors' investigation of samples from two natural analogue sites: Oklo, Gabon and Cigar Lake, Canada. Uraninite under reducing conditions, in the presence of saline hydrothermal solutions may be altered through dissolution, preferential loss of lead and/or $Y+$ HREE, and coffinitization. Textural features indicative of dissolution or uraninite include embayed grain boundaries, corroded relicts of uraninite embedded in a clay matrix, and replacement of uraninite by clays and sulfides. The alteration textures and phase chemistries at Oklo and Cigar Lake are remarkably similar. Dissolution of uraninite at Cigar Lake and Oklo was associated with the precipitation or illite and was probably caused by saline, uraninite moderately acidic solutions at approximately $200 \mathrm{deg} C$. Increased oxygen fugacity may have occured locally due to release of excess oxygen from uraninite during dissolution or by $\alpha$-radiolysis of the solution. The formation of Pb-rich (up to $18 w t \% \mathrm{~Pb}$, uraninite-l) and Pb-depleted (approximately 7-8 wt\% $\mathrm{Pb}$, uraninite-II) uraninites at both Oklo and Cigar Lake resulted from the loss of $\mathrm{Pb}$ due to predominantly episodic volume diffusion related to regional geologic events. Lead loss was not associated with $U$ mobilization. In addition to uraninite dissolution, coffinitization resulted in $\mathrm{U}, \mathrm{Pb}$ and REE release. (orig.).

665 Measuring the age of the Lathrop Wells volcanic center at Yucca Mountain. Wells, S.G. (Univ. of California, Riverside (United States)); Crowe, B.M.; McFadden, L.D. Science (Washington, D.C.) (United States); 257(5069): 555-556 (24 Jul 1992). 
Turrin et al. argue that conventional $\mathrm{K}-\mathrm{Ar}$ and ${ }^{40} \mathrm{Ar} /{ }^{39} \mathrm{Ar}$ age determinations and paleomagnetic data provide a definitive age assignment of approximatley $136 \mathrm{ka}$ (thousand years ago) to $141 \mathrm{ka}$ for the Lathrop Wells volcanic center with an error of less than 10,000 years. The use of a weighted mean gives age assignments with unrealistically small errors, in that the group age dates range from 20 ka to 947 $k a$. Yet Turrin et al. do not explain why the weighted mean might be more reliable than the conventional mean, nor do they test the validity of the weighted mean method. Specific concerns are as follows. (1) The age determinations are positively skewed with a mean larger than the median. (2) Turrin et al. did not examine the data set with conventional tests for outliers. Evaluation of their data shows that outliers are present where outliers are defined to be more than 1.5 times the interquantile range. (3) Four age determinations were discarded by Turrin et al. in the weighted mean data reduction because of contamination. No systematic criteria were presented for doing so, and recalculation of the data set with these four age determinations yields significantly older values of the weighted mean with larger uncertainty. (4) The regression plots show the presence of influential cases which should have been identified to check for errors and suitability to the data set. (5) There was no discussion of data errors other than analytical. (6) Conventional, whole rock $\mathrm{K}$-Ar data are averaged with the ${ }^{40} \mathrm{Ar} /{ }^{39} \mathrm{Ar}$ to establish final values for the weighted means. However, the whole rock data are not listed. Thus it is not clear whether the data set belongs to the same population as the ${ }^{40} \mathrm{Ar} / 39 \mathrm{Ar}$ data.

666 Update on waste management policies and programmes. Bulletin sur les Dechets Nucleaires (NEA); (7): i-68 (Jul 1992).

This issue gives an update on waste management policies and coordinated research programs for radioactive waste disposal in several countries: Australia, Belgium, Canada, Finland, France, Germany, Japan, Spain, Sweden, Switzerland, United Kingdom, United States. Informations are given on NEA program activities, international projects (INTRAVAL, STRIPA, Alligator Rivers Analogue projects,...), waste management meetings (upcoming and past), recent OECD/NEA waste management publications.

667 Anomalous deuteron to hydrogen ratio in naturally occuring fission reactions and the possibility of deuteron disintegration. Shaheen, M. (Illinois Univ., Urbana, IL (United States)); Ragheb, M. Journal of Radioanalytical and Nuclear Chemistry (Switzerland); 158(2): 323-342 (Apr 1992).

A hypothesis is presented for explaining the experimentally determined anomalous $\mathrm{D} / \mathrm{H}$ ratio observed in the samples from the naturally occuring fission reaction in the Oklo phenomenon. No other explanation has been given, to the best knowledge, for the large difference between the measured $\mathrm{D} / \mathrm{H}$ ratio in the Oklo samples and the expected values in a fission neutron spectrum. A multicomponent system consisting of hydrogen, deuterium, tritium and helium nuclei is considered. An analytical solution is derived and solved using as boundary conditions the experimentally determined value of the $\mathrm{D} / \mathrm{H}$ ratio. The solution of the rate equations for hydrogen and deuteron concentrations, assuming a pure fission process without a deuteron sink term, yields a $\mathrm{D} / \mathrm{H}$ ratio of $445 \mathrm{ppm}$ for a reaction in which the fluence of neutrons is $10^{21} \mathrm{n} / \mathrm{cm}^{2}$. This exceeds the experimentally observed value of $127 \mathrm{ppm}$, and the naturally occuring value of $150 \mathrm{ppm}$. Solving the same rate equations accounting for a deuterium sink term using a hypothesis of deuteron disintegration, and the experimentally observed value of $127 \mathrm{ppm}$ yields a deuteron disintegration constant of $7.47^{\star} 10^{-14} \mathrm{~s}^{-1}$. Deuteron disintegration would provide a neutron source, in addition to the fission neutrons, driving a subcritical chain reaction over an extended period of time. Relationship of the presented hypothesis to the Vlasov theory of an annihilation meteorite impact explosion explaining the experimentally observed anomalous ${ }^{235} \mathrm{U} /{ }^{238} \mathrm{U}$ ratio, and to the suggestion of deuteron disintegration as a possible explanation of some observations of deuterium dissociation in palladium and titanium electrodes is discussed. The tritium andhelium-3 rate equations are further solved under the deuteron disintegration hypothesis and the relationship of the present work to the work by JONES et al. is discussed. (author) 16 refs.; 7 figs.; 2 tabs.

668 Late Quaternary geology of small basaltic volcanic centers, SW USA: Disparity among dating methods and implications for volcanic and geomorphic studies. Wells, S. (Univ. of California, Riverside, CA (United States). Dept. of Earth Sciences); McFadden, L.; Perry, F.; Forman, S.; Crowe, B.; Pothis, J.; Olinger, C. Geological Society of America, Abstracts with Programs (United States); 24(7): A102 (1992). (CONF-921058-: 1992 annual meeting of the Geological Society of America (GSA), Cincinnati, OH (United States), 26-29 Oct 1992).

Evaluation of volcanic hazards near the proposed highlevel radioactive waste repository at Yucca Mountain provides the impetus for a series of detailed field and geochronologic studies of selected small late Quaternary basaltic scoria cones and lava flows in Nevada and California. Two of the most significant results of these studies are: the presence of chronostratigraphic units which indicate multiple eruptions with significant intervals of no activity between events (polycyclic volcanism); and a marked difference between conventional, numerical ages derived from $\mathrm{K}-\mathrm{Ar}$ and Ar-40/Ar-39 methods and numerical, calibrated, and relative ages derived from thermoluminescence, cosmogenic He-3, the degree of soil development, and geomorphology of these volcanic landforms. Soll-bounded unconformities and buried stone pavements define the boundaries of chronostratigraphic units within these small volume basaltic centers. Volcanic centers displaying this type of stratigraphy may appear morphological simple but cannot be considered mongenetic. Recent studies by Perry and Crowe demonstrate that geochemical variations within a single basaltic volcanic center in NV are consistent with several magma batches forming a complex polycyclic volcano. The $\mathrm{K}-\mathrm{Ar}$ and $\mathrm{Ar}-40 / \mathrm{Ar}-39$ ages are 1-2 orders of magnitude older than either TL or cosmogenic $\mathrm{He}-3$ and appear to have insufficient precision to constrain the ages of chronostratigraphic units within polycyclic volcanoes. In contrast, preliminary data indicate the $\pi$ and cosmogenic $\mathrm{He}-3$ dating methods have the ability to resolve the late Quaternary volcanic stratigraphy, and results from these dating methods are consistent with the degree of soil development and geomorphic modification of the volcanic units. $\mathrm{K}-\mathrm{Ar}$ and $\mathrm{Ar}-4 \mathrm{O} /$ Ar-39 dates from these small basaltic volcanic centers have been used to calibrate new Quaternary dating methods, e.g. rock varnish, which in turn have been used to interpret landscape evolution in the SW US.

669 Two-billion-year-old nuclear reactors: Nature goes fission. Curtis, D.B. (Los Alamos National Lab., NM (US)). Transactions of the American Nuclear Society (United States); 66: 239-240 (1992). (CONF-921102-: Joint American Nuclear Society/European Nuclear Society (ANS/ENS) 
international meeting on fifty years of controlled nuclear chain reaction: past, present, and future, Chicago, IL (United States), 15-20 Nov 1992).

Once it was thought that the isotopic composition of natural uranium was invariant. It was thus surprising in 1972 when French scientists observed small but significant deficiencies of the minor isotope ${ }^{235} \mathrm{U}$ in uranium ore. Subsequent investigations traced the isotopically anomalous material to the Oklo mine in the African Republic of Gabon. In the mine, cubic-dekametre-sized pods of rock were found to contain extraordinary concentrations of uranium, as much as $65 \%$, with as little as half the normal isotopic abundance of ${ }^{235} \mathrm{U}$. In these rocks, neodymium was found to be deficient in the premordial isotope ${ }^{142} \mathrm{Nd}$ and enriched in the fission-produced isotopes ${ }^{143-150} \mathrm{Nd}$. The presence of fission products was unambiguous evidence that the ${ }^{235} \mathrm{U}$ deficiencies were the result of sustained nuclear fission. Within the heart of the natural reactors, the fission densities were on the order of $10^{20}$ fissions $/ \mathrm{cm}^{3}$, producing hundreds of megajoules of energy and tens of microwatts of power per gram of rock. Nature had forestalled man's great discovery of energy production by nuclear fission.

670 Migration of radioelements around the new nuclear reactors at Oklo: Analogies with a high-level waste repository. Menet, C. (CEAJDCC, 92 - Fontenayaux-Roses (France)); Menager, M.T.; Petit, J.C. Radiochimica Acta (Germany); 58-59(pt.2): $395-400$ (1992). (CONF-9110152-: 3. international conference on chemistry and migration behaviour of actinides and fission products in the geosphere (MIGRATION-3), Jerez de la Frontera (Spain), 21-25 Oct 1991).

Samples from a new natural reactor of Oklo (zone 10) have been investigated with the aim of specifying possible elemental migrations into its close surroundings. The mineralogy demonstrates the occurrence of a redox front at the boundary of the reactor. We show first that significant migration of rare earths and uranium took place on a decimetric scale around the reactor and that secondary phases (both clay mineral, carbonates filling fissures and accessory minerals such as zircon) are responsible for their subsequent immobilization within the rock. (orig.).

671 Fair rules for siting a high-level nuclear waste repository. Easterling, D. (Univ. of Pennsylvania, Philadelphia (US)). Journal of Policy Analysis and Management (United States); 11 (3): 442-475 (Sum 1992).

Geologic repositories are designed to resolve the evergrowing problem of high-level nuclear waste, but these facilities invite intense local opposition due to the perceived severity of the risks and the possibility of stigma effects. This analysis examines whether the perceived fairness of the siting process affects local residents' support for hosting a repository. In particular, a survey of 1,001 Nevada residents is used to test the hypothesis that an individual's willingness to accept a local repository will increase if he or she is convinced that this is the safest disposal option available. A logistic analysis indicates that beliets regarding relative suitability have an independent effect on the acceptability of a local repository (i.e., Yucca Mountain). The article then considers the question of how to implement an optimizing strategy for siting facilities, comparing an idealized strategy against the original Nuclear Waste Policy Act (NWPA) of 1982 and the Amendments Act of 1987. Although choosing the safest site seems as if it could enhance public acceptance of the repository program, there is currently little prospect of identifying the best option to the high-level waste problem and, as a results, little chance of gaining the public support that is necessary to promote a successful siting outcome. 81 refs., 1 fig., 5 tabs.

672 Thermodynamically derived relationships between the modified Langmuir isotherm and experimental parameters. Polzer, W.L. (Los Alamos National Lab., NM (US)); Beckman, R.J.; Rao, M.G.; Fuentes, H.R. Environmental Science and Technology (United States); 26(9): 1780-1786 (1992).

The modified Langmuir isotherm parameters and the thermodynamic ion-exchange properties are developed from theoretical considerations leading to the derivation of a relationship between the two. For the binary ion-exchange system, the relationship indicates that a unique set of isotherm parameters can be defined by a minimum set of experimental parameters. Those parameters are the solidliquid ratio and the initial concentration of the competing solute in the liquid and exchanger phases. In principle, unique sets of isotherm parameters can be predicted for different conditions from a known set of experimentally determined parameters. The effect of experimental parameters (e.g., solid-liquid ratio and competing solute concentration) on isotherm parameters (e.g., linear $K_{d}$ ) have been documented in the literature. Experimental data are used to illustrate the derived relationships.

673 Perceived risk, stigma, and potential economic impacts of a high-level nuclear waste repository in Nevada. Slovic, P. (Decision Research, Eugene, Oregon (United States)); Layman, M.; Kraus, N.; Flynn, J.; Chaimers, J.; Gesell, G. Risk Analysis (United States); 11(4): 683-696 (Dec 1991).

This study investigates the potential impacts of the proposed nuclear waste repository at Yucca Mountain, Nevada, upon tourism, retirement and job-related migration, and business development in Las Vegas and the state. Adverse impacts may be expected to result from perceptions of risk, stigmatization, and socially amplified reactions to 'unfortunate events' associated with the repository (major and minor accidents, discoveries of radiation releases, evidence of mismanagement, attempts to sabotage or disrupt the facility, etc.). The conceptual underpinnings of risk perception, stigmatization, and social amplification are discussed and empirical data are presented to demonstrate how nuclear images associated with Las Vegas and the State of Nevada might trigger adverse economic effects. The possibility that intense negative imagery associated with the repository may cause significant harm to Nevada's economy can no longer be ignored by serious attempts to assess the risks and impacts of this unique facility. The behavioral processes described here appear relevant as well to the social impact assessment of any proposed facility that produces, uses, transports, or disposes of hazardous materials.

674 Radioactive waste: Finding a safe place. Fairweather, V. Civil Engineering (New York) (United States); 61(4): 48-51 (Apr 1991).

This paper reports on finding a safe place for radioactive wastes. Storing radioactive wastes for thousands of years is a daunting task. U.S. law says we must find a repository for high-level wastes by 2010 , the earliest deadline in the world. Congress has designated Yucca Mountain in Nevada for official site characterization. But the process is immobilized by regulatory, political, legal and technical conflicts. 
675 Temperature effect on diffusion of carbon dioxide through upper layers of Yucca Mountain. Bardakci, Tevfik (North Carolina Agricultural Experiment Station, Raleigh, NC (United States)). Gas Separation and Purification (United Kingdom); 5(1): 11-15 (Mar 1991). Contract 3C-56702; Grant RII-8804227.

The effective diffusivities of carbon dioxide through the Tiva Canyon tuff and the lower lithophysal zone of the Topopah Spring tuff (outcrop samples of the layer above the proposed nuclear repository site layer) were determined using a steady-state method (counter diffusion). The diffusivity of carbon dioxide through the Tiva Canyon and lithophysal zone tuffs increased with temperature. The following correlation was obtained to estimate the effective diffusivity of carbon dioxide through the Tiva Canyon tuff in $\mathrm{cm}^{2} \mathrm{~s}^{-1}$ as a function of temperature $(\mathrm{K}): \mathrm{D}_{\mathrm{e}}=1.22 \times 10^{-2}-3.77 \times 10^{-5} \mathrm{~T}$ $+9.95 \times 10^{-8} \mathrm{~T}^{2}$. The effective diffusivity of carbon dioxide through the lower lithophysal zone of the Topopah Spring tuff (layer right above the proposed repository site) also increased with temperature. For this layer, the following correlation was obtained to estimate the effective diffusivity of carbon dioxide in $\mathrm{cm}^{2} \mathrm{~s}^{-1}$ as a function of temperature $(\mathrm{K})$ : $D_{0}-1.11 \times 10^{-3}+1.25 \times 10^{-5} \mathrm{~T}+1.83 \times 10^{-9} \mathrm{~T}^{2}$. (author).

676 Pressurized grout applications in fractured tuff for containment of radioactive wastes. Crouthamel, D.R. (Arizona Univ., Tucson, AZ (United States). Dept. of Mining and Geological Engineering); Daemen, J.J.K. Geotechnical and Geological Engineering (United Kingdom); 9(1): 53-62 (Mar 1991).

Currently under study by the Department of Energy are the geologic and hydrologic characteristics of the ash-flow deposits under Yucca mountain at the Nevada test site. Of interest at this site is the potential for disposal of high-level radioactive wastes in the unsaturated zone of the densely welded portions of the tuffs. These studies include the performance-assessment of barriers and seals for boreholes, ramps, drifts and shafts at the Yucca mountain site. In-situ tests on standard Type II Portland cement and microfine cement as grout materials have been performed on a similar rock type to Yucca Mountain's near Superior Arizona. The tests were performed in a vertical borehole drilled in highly fractured and densely welded tuff (brown unit of Apache Leap) through a series of pressurized grout applications. Packer flow tests prior to and after each grout application measure the effectiveness of the grout application in reducing the permeability of the rock surrounding the borehole. Overall the grout applications have reduced the permeability of the test hole by three orders of magnitude. (author).

677 Yucca Mountain, a high-level nuclear waste repository over a billion barrel oil field?. Chamberlain, A.K. (Colorado School of Mines, Lakewood (United States)). AAPG Bulletin (American Association of Petroleum Geologists) (United States); 75(3): 551 (Mar 1991). (CONF910403-: Annual meeting of the American Association of Petroleum Geologists (AAPG), Dallas, TX (United States), 7-10 Apr 1991).

New structural models and source rock data suggest that the proposed Yucca Mountain, Nevada, high-level nuclear waste repository lies in the Central Nevada thrust belt. The Central Nevada thrust belt could contain billion-barrel oil fields. The Central Nevada thrust belt coincides with an organic richness fairway and a maturation fairway of Mississippian source rocks that have already produced more than 25 million barrels of oil. Giant thrust-related structures along the thrust belt have yet to be tested. However, new work in the Tempahute Range, which lies between Yucca Mountain and the prolific Grant Canyon field, confirms the thrust belt concept and sheds light on source and reservoir rock quality and thrust belt geometry. Klippen of overmature Mississippian rocks are distinct on maturation maps such as the Diamond Range klippe in central Nevada: Thrust trends suggest that the Eleana Range near Yucca Mountain may be another klippe of overmature rocks over Mississippian source rocks in the oil window. There is a strong possibility that the subthrust source rocks may have generated large quantities of hydrocarbons that may be trapped in large thrust features beneath Yucca Mountain.

678 Manganoan fayalite $\left[(\mathrm{Fe}, \mathrm{Mn})_{2} \mathrm{SiO}_{4}\right]$ : A new occurrence in rhyolitic ash-flow tuff, southwestern Nevada, U.S.A. Mills, J.G. Jr. (Michigan State Univ., East Lansing (United States)); Rose, T.P. American Mineralogist (United States); 76(1-2): 288-292 (Jan-Feb 1991).

Manganoan fayalite is usually found associated with sedimentary iron-manganese ore deposits. Phenocrysts of manganoan fayalite were recently discovered in high-silica rhyolite pumice fragments from the Ammonia Tanks Member of the Timber Mountain Tuff in the Southwestern Nevada Volcanic Field. Twenty-one electron microprobe analyses (major-element oxides, $\mathrm{NiO}, \mathrm{BaO}$ ) are reported for the newly discovered phenocrysts. The slightly zoned phenocrysts range in composition from $\mathrm{Fa}_{63} \mathrm{Fo}_{0} \mathrm{Te}_{37} \mathrm{La} \mathrm{L}_{0.2}$ to $\mathrm{Fa}_{72} \mathrm{Fo}_{0.2} \mathrm{Te}_{28} \mathrm{La}_{0.1}$

679 Technical challenges in the repository program. Isaacs, T.H. (USDOE Office of Civilian Radioactive Waste Management, Washington, DC (United States)). Radioactive Waste Management and the Nuclear Fuel Cycle (Switzerland); 12(1-4): 27-35 (1991). (CONF-8806517-: Nuclear waste management 1988: perspectives on national and international programs and technology, San Diego, CA (United States), 12-16 Jun 1988).

The U.S. Department of Energy (DOE) is conducting a site-characterization program at Yucca Mountain in Nevada to determine whether or not that site would be suitable to host a geologic repository for the disposal of spent nuclear fuel and high-level radioactive waste. Site characterization requires scientists to determine which phenomena or processes can be expected to occur at the site over the 10,000 -year period of required isolation and to assess the expected performance of the repository systems over the required period of containment and isolation. The licensing of the repository also presents some unique technical challenges. The principal challenge will be to demonstrate to the Nuclear Regulatory Commission (NRC) that the repository system - the site, the repository, and the waste package has a high probability of effectively isolating radioactive waste for thousands of years. (author) 2 figs., 5 refs.

680 The siting guidelines, 10 CFR Part 960. Hanlon, C.L. (USDOE Assistant Secretary for Management and Administration, Washington, DC (United States). Office of Civilian Radioactive Waste Management); Lui, A.E. van. Radioactive Waste Management and the Nuclear Fuel Cycle (Switzerland); 12(1-4): 65-76 (1991). (CONF-8806517-: Nuclear waste management 1988: perspectives on national and international programs and technology, San Diego, CA (United States), 12-16 Jun 1988).

The Siting Guidelines, 10 CFR Part 960, have played a major role in the U.S. Department of Energy's (the Department) Office of Civilian Radioactive Waste Management 
siting program since their development and implementation in response to the Nuclear Waste Policy Act of 1982. According to the Act, the Siting Guidelines were applicable to the selection of sites for characterization. The Nuclear Waste Policy Amendments Act of 1987 (the Amendments Act) has selected the Yucca Mountain, Nevada, site for characterization from among those nominated according to the Siting Guidelines. Thus, the Amendments Act has taken the repository program beyond the phase of Siting Guidelines applicability, making the U.S. Nuclear Regulatory Commission's 10 CFR Part 60 the applicable regulation. However, the Department has chosen to make use of aspects of the Siting Guidelines in the Site Characterization Plan for the Yucca Mountain Site. (author) 4 figs., 11 refs.

681 Intergovernmental complexity in nuclear waste disposal policy: The indeterminate role of local government. Herzik, E.B. (Univ. of Nevada, Reno (US)); Mushkatel, A.H. Policy Studies Review (United States); 10(4): 139-151 (Win 1991).

Local governments play a critical, albeit often overlooked, role in nuclear waste disposal policymaking. The centrality of local governments in the policymaking process rests on the simple fact that impacts would be borne disproportionately by local jurisdictions hosting and immediately adjacent to waste disposal sites. This article focuses on the capacity of local jurisdictions in Southern and rural Nevada to absorb and support an undertaking as large and technically complex as the proposed high-level nuclear waste repository. The article also examines the perceptions of local government officials concerning a number of management and policy issues related to the construction and operation of the proposed waste repository.

682 Public opposition to the siting of the high-level nuclear waste repository: The importance of trust. Pijawka, K.D.; Mushkatel, A.H. Policy Studies Review (United States); 10(4): 180-194 (Win 1991).

This paper examines several dimensions of public opposition to the proposed siting of the high-level nuclear waste repository at Yucca Mountain. In order to provide a context for the public's views of the repository in metropolitan Clark County, both governmental studies of the repository siting process are analyzed, as well as elements of the Nuclear Waste Policy Act. This analysis suggests that one potentially key component of the public's opposition to the siting, as well as their perceptions of risk of the facility, may be the result of a lack of trust in the Department of Energy. Empirical analysis of survey data collected in Nevada in 1988 confirms the strong relationship between political trust and repository risk perceptions.

683 U.S. Nuclear Regulatory Commission overview of repository quality assurance. Kennedy, J.E. (Nuclear Regulatory Commission, Washington, DC (United States). Office of Nuclear Material Safety and Safeguards). Radioactive Waste Management and the Nuclear Fuel Cycle (Switzerland); 12(1-4): 227-235 (1991). (CONF-8806517-: Nuclear waste management 1988: perspectives on national and international programs and technology, San Diego, CA (United States), 12-16 Jun 1988).

The U.S. Department of Energy (DOE) is on the threshold of an extensive site characterization program at Yucca Mountain in Nevada to determine if it is a suitable site for the permanent disposal of high-level nuclear waste. Many of the data collection and analysis activities in this program will be the primary basis for a license application to be submitted to the U.S. Nuclear Regulatory Commission (NRC) in 1995, if the site is found to be suitable. The NRC, therefore, requires that these activities be performed under a quality assurance (QA) program to help assure the validity of the data and analyses. There are three major areas of the NRC staff review: (1) developing staff guidance on QA issues; (2) reviewing DOE QA plans and procedures; and (3) observing DOE audits of the implementation of the program. (author) 1 fig., 12 refs.

684 Nevada Nuclear Waste Study Committee: Combating anti-repository-study sentiment. Anderson, H.J. III (Nevada Nuclear Waste Study Committee, Las Vegas (United States)). Transactions of the American Nuclear Society (United States); 63: 353-354 (1991). (CONF-910603-: Annual meeting of the American Nuclear Society (ANS), Orlando, FL (United States), 2-6 Jun 1991).

The Nevada Nuclear Waste Study Committee (NNWSC) consists of 9,000 Nevadans who are interested in seeing the scientific studies of Yucca Mountain continue as the possible location for a high-level nuclear waste repository. The mission of the NNWSC is threefold: (1) to ensure that site characterization of Yucca Mountain proceeds in an orderly and scientific manner - public health and safety must constiiute the primary focus of the study and all questions must be answered completely; (2) to support the efforts of state and local governmental bodies in seeking maximum economic benefits that may be forthcoming from the siting, construction, and/or operation of the proposed repository; and (3) to continue to promote public education and information. The committee has made steady inroads into changing the way many Nevadans view the continued studies of Yucca Mountain.

685 International safeguards concepts for the Yucca Mountain Geological Repository. Case, R.S. (Sandia National Labs., Albuquerque, NM (United States)). Nuclear Materials Management. Annual Meeting Proceedings (United States); 20: 527 (1991). (CONF-910774-: 32. Institute of Nuclear Materials Management (INMM) annual meeting, New Orleans, LA (United States), 28-31 Jul 1991).

This paper reports that the Nuclear Waste Policy Act of 1982 assigns DOE the responsibility to develop a mined geological repository for the long-term storage and isolation from the biosphere of spent civilian nuclear fuel and high level waste from U.S. defense and civilian reprocessing activities. In fulfilling this Congressional mandate, DOE has performed preliminary site characterization on several possible repository sites over the last decade. Recently, Congress delimited site characterization to the site at Yucca Mountain, Nevada for the US's first mined geologic repository. Although the actual repository is not scheduled to begin operation until the first decade of the next century, planning ahead for international safeguards application to the site will allow resolution of issues which arise. This is especially true for geological repositories because of the large amount of material to be safeguarded and the materials' inaccessibility following repository closure. Further, these unique features of geological repositories may require the IAEA to reexamine its present safeguard philosophy with respect to the roles of Containment and Surveillance (C/S) and Material Control and $A c c o u n t a n c y$ ( $M C$ and $A$ ). In light of these issues, a $C / S$ based international safeguard concept for Yucca Mountain has been developed and is presented here, using the DOE's baseline conceptual design of the Yucca Mountain site. 
686 Stable isotopic evidence for a pedogenic origin of carbonates in trench 14 near Yucca Mountain, Nevada. Quade, J. (Univ. of Utah, Salt Lake City (United States)); Cerling, T.E. Science (Washington, D.C.) (United States); 250(4987): 1549-1552 (14 Dec 1990).

Layered carbonate and silica encrust fault fractures exposed in Trench 14 near Yucca Mountain, site of the proposed high-level nuclear waste repository in southern Nevada. Comparison of the stable carbon and oxygen isotopic compositions of the fracture carbonates with those of modern soil carbonates in the area shows that the fracture carbonates are pedogenic in origin and that they likely formed in the presence of vegetation and rainfall typical of a glacial climate. Their isotopic composition differs markedly from that of carbonate associated with nearby springs. The regional water table therefore remained below the level of Trench 14 during the time that the carbonates and silica precipitated, a period probably covering parts of at least the last 300,000 years.

687 Council report finds high-level nuclear waste repository rules 'unrealistic'. Yates, M. Public Utilities Fortnightly (United States); 126(4): 40-41 (16 Aug 1990).

This article reports on a study by the National Research Council that finds that the Department of Energy has established unrealistic rigidity of schedule, of technical requirements definition of each part of the containment system, and in requirements for EPA certification. The result, according to the study, is a unrealistic effort by DOE to provide absolute certainty of the safety of the repository.

688 DOE reassesses civilian radioactive waste management program. Yates, M. Public Utilities Fortnightly (United States); 125(4): 36-38 (15 Feb 1990).

This article reports on the announcement by the Department of Energy (DOE) that the opening of a high-level radioactive nuclear waste repository site will be delayed for seven years. The article discusses DOE's reassessment plan, the restructuring of the Office of Civilian Radioactive Waste Management, site access and evaluation, the Monitored Retrievable Storage Commission proposal, and the industry's response.

689 Nuclear waste policy and politics. Carter, L.J. Forum for Applied Research and Public Policy (United States); 4(3): 5-18 (Fal 1989).

The nation's nuclear waste problem began in 1955 but did not draw widespread public attention until the early 1970 s. It was then that the old Atomic Energy commission got in trouble by prematurely designating a site in Lyons, Kansas, as its first nuclear waste repository. This and several other false starts, coupled with the growing environmental and anti-nuclear movements, thrust the issue to the forefront of national consciousness. in the meantime, growing quantities of waste were accumulating at nuclear power plants across the country, creating mounting pressure for action. Congress acted in 1982 and again in 1987. Its 1987 decision was decisive: stop the nationwide search for a disposal site, and focus all efforts on Yucca Mountain in Nevada. Despite the clear Congressional mandate, the program is again bogged down in controversy, internal conflicts, and bureaucracy. Its future depends on a solution to these problems.
And the solution involves charting some new and innovative paths around political and technical mine fields.

690 Focus shifts from capital to Nevada. Cooper, B.S. (Senate Committee on Energy and Natural Resources, Washington, DC (United States)). Forum for Applied Research and Public Policy (United States); 4(3): 26-28 (Fal 1989).

The nation's long search for a place to store its high-level nuclear wastes has taken a new turn. It has moved from the political quicksands of Capital Hill to the managerial and technical mine fields of Nevada. Questions facing the program now are much less political and far more technical in nature. This is the opinion of the author. This does not mean, however, that the road to success is smoothly paved, DOE will face unique and delicate interactions with NRC and with officials in Nevada but not especially with Congress. The nation will feel its way carefully into the future on this issue he says, adding that further program redirection cannot be ruled out. He also notes that no one has ever constructed and licensed a deep repository, and many of the unique and site-specific design problems cannot be known until site characterization.

691 A view on siting issue from Nevada. Loux, R.R. (Nevada Agency for Nuclear Projects, Carson City (United States)). Forum for Applied Research and Public Policy (United States); 4(3): 29-31 (Fal 1989).

Nevada views its selection as the sole candidate for the nation's high-level nuclear waste repository as an act of political expedience to save a failing program, says the author. He claims that no substantial data exist to suggest the Yucca Mountain site is suitable for a permanent repository. Nevada's elected officials are essentially unanimous in their opposition, and polls show a constant strong majority of citizens against a nuclear waste repository in the state. He adds that the state is committed to taking all necessary legal steps to prevent it.

692 Getting waste program in motion again. Kraft, S.P. Forum for Applied Research and Public Policy (United States); 4(3): 32-35 (Fal 1989).

The nation's electric ratepayers have invested some $\$ 4$ billion since 1983 to finance a nuclear waste storage facility and have little to show for it says the author. DOE's waste management program has been characterized by missed deadlines, schedule delays, bureaucratic entanglements, and lost opportunities he charges. Utilities are concerned by both the lack of progress and DOE's seeming lack of concern for the costs that the delays are imposing on electric utilities and electricity consumers. He believes it is imperative that DOE get the waste management program back on track, and he offers a 5-point strategy to accomplish that objective: strengthen and improve DOE management and operations; proceed aggressively with the start of new sitecharacterization work; restore the monitored retrievable storage option; streamline the licensing process; and determine the suitability of Yucca Mountain as early as possible. 


\title{
Corporate Author Index
}

\begin{abstract}
This index lists the corporate authors responsible for issuing the documents in this publication which are identified primarily by report number. The corporate names are entered in standardized forms as defined in ETDE/PUB-3 (Rev.1), intemational Energy: Research Organizations 1988-1992. Each entry under a corporate name includes the document title and citation number. Three items of information may appear in parentheses: (1) an abbreviation to identify the document type, such as a report; (2) the country of publication, also abbreviated; and (3) the language of the document if non-English (R;CA;In French). Author affiliations are not listed in this index.
\end{abstract}

A

Agapito (J.F.T.) and Associates, Inc., Grand Junction, CO (United States)

Documentation and verification of the SHAFT code: Yucca Mountain Site Characterization Project, 93:235 (R;US)

Documentation and verification of STRES3D, Version 4.0: Yucca Mountain Site Characterization Project, 93:250 (R;US)

HEFF-A user's manual and guide for the HEFF code for thermalmechanical analysis using the boundary-element method: Version 4.1: Yucca Mountain Site Characterization Project 93:223 (R;US)

New three-dimensional far-field potential repository thermomechanical calculations: Yucca Mountain Site Characterization Project, 93:306 (R;US)

Rock mass mechanical property estimations for the Yucca Mountain Site Characterization Project: Yucca Mountain Site Characterization Project, 93:304 (R;US)

American Society of Civil Engineers, New York, NY (United States)

Current plans to characterize the design basis ground motion at the Yucca Mountain, Nevada Site, 93:4 (R;US)

Argonne National Lab., IL (United States)

A forecasting model of gaming revenues in Clark County, Nevada, 93:409 (R;US)

ANL Technical Support Program for DOE Environmental Restoration and Waste Management: Annual report, October 1990-September 1991, 93:402 (R; US)

ANL technical support program for DOE Environmental Restoration and Waste Management: Annual report, October 1991-September 1992, 93:405 (R;US)

Crack growth behavior of candidate waste container materials in simulated underground water, 93:146 (R;US)

Crack-growth-rate testing of candidate waste container materials, 93:145 (R;US)

Dual-energy neutron tomography of water in rock using the Argonne IPNS, 93:411 (R;US)

Effects of radiation exposure on glass alteration in a steam environment, $93: 407$ (R:US)

Elements present in leach solutions from unsaturated spent fuel tests, 93:408 (R;US)

Managing nuclear waste: Social and economic impacts, 93:413 (R;US)

Nuclear technology programs: Semiannual progress report, October 1989-March 1990, 93:401 (R;US)

Nuclear Technology Programs semiannual progress report, October 1990-March 1991, 93:404 (R;US)

Parametric effects on glass reaction in the unsaturated test method, 93:143 (R;US)

Perceived risk impacts from siting hazardous waste facilities, 93:410 (R:US)

Progress in assessing the effect of ionizing radiation on the anticipated waste package environment at the Yucca Mountain potential repository site, $93: 144$ (R;US)

Should high-level nuclear waste be disposed of at geographically dispersed sites?, 93:412 (R;US)

Stress corrosion cracking of candidate waste container materials: Final report, $93: 403$ (R;US)
The reaction of SRL 202 glass in J-13 and DIW, 93:406 (R;US)

Argonne National Lab., IL (United States). Environmental Assessment and Information Sciences Div.

Empirical investigation of the effect of amenities and other factors on business location decisions, $98: 417$ (R;US)

Methodologies for selecting industries for regions and communities: A critical evaluation of the Las Vegas target industry analysis, 93:416 (R;US)

Socioeconomic assessment guidance report: Determining the effects of amenity characteristics on business location decisions, 93:415 (R;US)

Technical evaluation of available state of Nevada survey instruments, 93:418 (R;US)

The role of amenities and other factors in influencing the location of nonmanufacturing industry in the United States, 93:414 (R;US)

Arizona State Univ., Tempe, AZ (United States)

Yucca Mountain socioeconomic project report on the 1987 risk perception telephone surveys, 93:545 (R;US)

Arizona Univ., Tucson, AZ (United States)

Sealing performance assessments of bentonite and bentonite/crushed rock plugs, 93:645 (1;US)

Arizona Univ., Tucson, AZ (United States). Dept. of Hydrology and Water Resources

A survey of hydrothermal modeling related to Yucca Mountain, 93:524 (RA;US)

Apache leap watershed study, 93:516 (RA;US)

Characterization of rock hydrologic properties using model verification, $93: 519$ (RA:US)

Does the wind blow through Yucca Mountain?, 93:366 (RA;US)

Evaluation of tracers for hydrologic studies at Yucca Mountain, 93:526 (RA;US)

Field testing the effectiveness of pumping to remove sulfur hexafluoride traced drilling air from a prototype borehole near superior, Arizona, 93:518 (RA;US)

Flow through nonhomogeneous porous media, 93:525 (RA;US)

Ground water flow through unsaturated fractured rock research needs, 93:521 (RA;US)

Hydrogeologic issues at Yucca Mountain: Findings of a DOE peer review team, 93:513 (RA:US)

Modeling hydrothermal flow in variably saturated, fractured, welded tuff during the prototype engineered barrier system field test of the Yucca Mountain Project, 93:523 (RA;US)

Nonequilibrium fracture-matrix flow during episodic infiltration events in Yucca Mountain, 93:514 (RA;US)

Nonisothermal hydrologic transport study at the Apache Leap Tuff site, 93:515 (RA:US)

Nonisothermal hydrologic transport experimental plan, 93:534 (R;US)

Numerical and laboratory investigations of transient and steadystate flow in a fractured core, 93:520 (RA;US)

Pneumatic permeability measurements in a fractured, partially saturated environment, 93:517 (RA;US)

Technical issues related to groundwater flow and radionuclide transport in unsaturated fractured rock, 93:368 (RA;US)

The composition and $\mathrm{CO}_{2}$ carbon isotope signature of gases from borehole USW UZ-6, Yucca Mountain, Nevada, 93:367 (RA;US)

Use of a submersible pressure outflow cell for determination of moisture characteristic curves on rock core, 93:522 (RA;US) 
Arizona Univ., Tucson, AZ (United States). Dept. of Mining and Geological Engineering

Borehole stability in densely welded tuffs, 93:531 (R;US)

Sealing performance of bentonite and bentonite/crushed rock borehole plugs, $93: 530$ (R;US)

Atomic Energy of Canada Ltd., Pinawa, MB (Canada). Whiteshell Nuclear Research Establishment

Evaluation of copper, aluminum bronze, and copper-nickel container material for the Yucca mountain project, 93:142 (RA;CA)

Babcock and Wilcox $\mathrm{Co}_{a}$, Alliance, $\mathrm{OH}$ (United States). Contract Research Div.

LLNLYMP Waste Container Fabrication and Closure Project: GFY technical activity summary, 93:591 (R;US)

Bechtel National, Inc., San Francisco, CA (United States)

Effects of a potential drop of a shipping cask, a waste container and a bare fuel assembly during waste-handling operations: Yucca Mountain Site Characterization Project, 93:224 (R;US)

Effects of various radiation source characteristics on shielding requirements at the potential Yucca Mountain repository, 93:248 (R;US)

Identification of structures, systems, and components important to safety at the potential repository at Yucca Mountain: Yucca Mountain Site Characterization Project, 93:251 (R;US)

Preclosure radiological safety analysis for accident conditions of the potential Yucca Mountain Repository: Underground facilities: Yucca Mountain Site Characterization Project, 93:234 (R;US)

Preclosure radiological safety analysis for the exploratory shaft facilities: Yucca Mountain Site Characterization Project, 93:246 (R;US)

Probable maximum flood control: Yucca Mountain Site Characterization Project, $93: 232$ (R;US)

Transportation cask decontamination and maintenance at the potential Yucca Mountain repository: Yucca Mountain Site characterization project, 93:247 (R;US)

Brookhaven National Lab., Upton, NY (United States)

Development and evaluation of a performance assessment methodology for analyzing the safety of a geologic repository for high-level radioactive waste, 93:527 (RA;US)

Potential increases in natural radon emissions due to heating of the Yucca Mountain rock mass, 93:212 (R;US)

\section{C}

California Univ., Berkeley, CA (United States)

Effects of actinide burning on waste disposal at Yucca Mountain, 93:446 (R;US)

Carr (Wilfred J.), Wheat Ridge, CO (United States)

Structure in continuously cored, deep drill holes at Yucca Mountain Nevada, with notes on calcite occurrence: Yucca Mountain Site Characterization Project, 93:298 (R;US)

CEA Centre d'Etudes de Fontenay-aux-Roses, 92 (France). Inst. de Protection et de Surete Nucleaire

Hydrogeology and migration in the remote field, $93: 419$ (R;FR;in French)

Chicago Univ., IL (United States). Dept. of Economics

Managing nuclear waste: Social and economic impacts, 93:413 (R;US)

Colorado School of Mines, Golden, CO (United States). Earth Mechanics inst.

Performance prediction of mechanical excavators from linear cutter tests on Yucca Mountain welded tuffs: Yucca Mountain Site Characterization Project, 93:299 (R;US)

Performance predictions for mechanical excavators in Yucca Mountain tuffs: Yucca Mountain Site Characterization Project, 93:297 (R;US)
Commission of the European Communities, Luxembourg (Luxembourg)

Okelobondo Uranium deposit: Regional context, stratigraphy, sedimentology, tectonic and mineralization, 93:465 (RA;XE; In French)

Oklo - natural analogue for transfer processes in a geologica repository: present status of the programme, 93:464 (RA;XE)

Cortest Columbus Technologies, Inc., $\mathrm{OH}$ (United States)

Potentiodynamic polarization studies on candidate container alloys for the Tuff Repository, 93:532 (R;US)

Stress-corrosion-cracking studies on candidate container alloys for the Tuff Repository, 93:533 (R;US)

Cultural Resources Consultants Ltd., Reno, NV (United States)

Native Americans and Yucca Mountain: A revised and updated summary report on research undertaken between 1987 and 1991: Volume 1, $93: 548$ (R;US)

Native Americans and Yucca Mountain: A revised and updated summary report on research undertaken between 1987 and 1991: Volume 2, 93:549 (R;US)

Socioeconomic profiles of native American communities: Yomba Shoshone Reservation, 93:551 (R;US)

Socioeconomic profiles of native American communities: Duckwater Shoshone Reservation, 93:552 (R;US)

Decision Research, Eugene, OR (United States)

Yucca Mountain socioeconomic project report on the 1987 risk perception telephone surveys, 93:545 (R;US)

Disposal Safety, Inc., Washington, DC (United States)

Numerical studies of rock-gas flow in Yucca Mountain: Yucca Mountain Site Characterization Project, 93:296 (R;US)

\section{$\mathbf{E}$}

EG and G Energy Measurements, Inc., Goleta, CA (United States). Santa Barbara Operations

Yucca Mountain Biological Resources Monitoring Program: Annual report, FY91, 93:35 (R;US)

Yucca Mountain biological resources monitoring program: Annual report FY92, $93: 36$ (R;US)

EG and G Energy Measurements, Inc., Las Vegas, NV (United States)

GENISES: A GIS Database for the Yucca Mountain Site Characterization Project, 93:1 (R;US)

Technical data base quarterly report, ApribJune 1992: Yucca Mountain Site Characterization Project, 93:216 (R;US)

Three dimensional visualization in support of Yucca Mountain Site characterization activities, 93:34 (R;US)

Electric Power Research Inst., Palo Alto, CA (United States)

Demonstration of a risk-based approach to high-level waste repository evaluation, Phase 2, 93:461 (R;US)

Reasonableness of human intrusion provisions in EPA's HLW standard, 93:463 (RA; US)

Session II: Gas pathway, 93:462 (RA;US)

\section{$\mathbf{F}$}

Fenix and Scisson, Inc., Tulsa, OK (Unlted States)

Geohydrology of rocks penetrated by test well USW H-6, Yucca Mountain, Nye County, Nevada, 93:390 (R;US)

\section{G}

General Accounting Office, Washington, DC (Unlted States). Resources, Community and Economic Development Div.

Nuclear waste: Quality assurance auditors need access to employee records, $93: 466$ (R;US) 
Nuclear waste: Quarterly report as of March 31, 1990, 93:467 (R; US)

Nuclear waste: Questionable uses of program funds at Lawrence Livermore Lab., 93:468 (R;US)

Nuclear waste: DOE expenditures on the Yucca Mountain Project, 93:469 (R;US)

Geological Survey, Carson City, NV (United States)

Ground-water data collected at the Nevada Test Site and vicinity, Nye County, Nevada, water years 1988-89, 93:594 (R;US)

Streamflow and selected precipitation data for Yucca Mountain and vicinity, Nye County, Nevada, water years 1983-85, 93:389 (R;US)

Geological Survey, Denver, CO (United Siates)

A portable vacuum hammer seismic source for use in tunnel environments, 93:595 (R;US)

A preliminary study of the chemistry of pore water extracted from tuff by one-dimensional compression, 93:363 (R;US)

Assessment of geophysical logs from borehole USW G-2, Yucca Mountain, Nevada, 93:387 (R;US)

Borehole and geohydrologic data for test hole USW UZ-6, Yucca Mountain area, Nye County, Nevada, 93:382 (R;US)

Does localized recharge occur at a discharge area within the ground-water flow system of Yucca Mountain, Nevada?, 93:362 (R;US)

Earthquake-induced water-level fluctuations at Yucca Mountain, Nevada, April 1992, 93:383 (R;US)

Earthquake-induced water-level fluctuations at Yucca Mountain, Nevada, June 1992, 93:388 (R;US)

Geohydrologic data from test holes UE-25 UZ \#4 and UE-25 UZ \#5, Yucca Mountain Area, Nye County, Nevada, 93:372 (R; US)

Geohydrology of rocks penetrated by test well USW H-6, Yucca Mountain, Nye County, Nevada, 93:390 (R;US)

Late quaternary faulting along the Death Valley-Furnace Creek fault system, California and Nevada, 93:369 (R;US)

Photogeologic and kinematic analysis of lineaments at Yucca Mountain, Nevada: Implications for strike-slip faulting and oroclinal bending, $93: 381$ (R;US)

Proposed algorithm for determining the delta intercept of a thermocouple psychrometer curve, 93:386 (R;US)

Results of rock property measurements made on core samples from Yucca Mountain boreholes, Nevada Test Site, Nevada: Part 1, Boreholes UE25A-4, -5, -6, and -7; Part 2, Borehole UE25PNo.1, 93:373 (R;US)

Seismicity and focal mechanisms for the Southern Great Basin of Nevada and California in 1990, 93:376 (R;US)

Seismicity and focal mechanisms for the southern Great Basin of Nevada and California: 1987 through 1989, $93: 379$ (R;US)

Seismicity and focal mechanisms for the southern Great Basin of Nevada and California in 1991, 93:384 (R:US)

Simulated water-level declines caused by withdrawals from wells $J-13$ and J-12 near Yucca Mountain, Nevada, 93:377 (R;US)

US Geological Survey Committee for the Advancement of Science in the Yucca Mountain Project symposium on "Fractures, Hydrology, and Yucca Mountain": Abstracts and summary, 93:375 (R;US)

Water levels in continuously monitored welis in the Yucca Mountain area, Nevada, 1985-88, 93:378 (R; US)

Geological Survey, Lakewood, CO (United States). Water Resources Div.

Characterization of liquid-water percolation in tuffs in the unsaturated zone, Yucca Mountain, Nye County, Nevada, 93:361 (R;US)

Geological Survey, Menlo Park, CA (United States)

Aeromagnetic map of the Beatty quadrangle, Nevada-California, 93:374 (R;US)

Geophysical characterization of mineral and energy resources at Yucca Mountain and vicinity, Nevada, 93:380 (R;US)

Gravity and magnetic data of Fortymile Wash, Nevada Test Site, Nevada, $93: 385$ (R;US)

TURBOSEIS-An interactive program for constructing and editing models of seismic refraction traveltime data using a colorgraphics terminal, 93:371 (R;US)
Geological Survey, Washington, DC (United States)

Geophysical logs and core measurements from forty boreholes at Yucca Mountain, Nevada, 93:370 (R;US)

\section{H}

Howard Univ., Washington, DC (United States)

Summary report on the evaluation of a 1977-1985 edited sorption data base for isotherm modeling, $93: 113$ (R;US)

\section{I}

Industrial Coll. of the Armed Forces, Washington, DC (United States)

High-level nuclear waste disposal: Policy and prognosis. Research report, August 1991-April 1992, 93:400 (R;US)

INTERA, Inc., Las Vegas, NV (United States)

A comparative application of the Repository Integration Program (RIP) to Total System Performance Assessment, 1991, 93:102 (R;US)

Travel to Switzerland for performance assessments for both the low- and intermediate-level and high-level radioactive waste disposal programs being managed and implemented by NAGRA: Foreign trip report, May 2-9, 1993, 93:436 (R;US)

Interagency Review Group on Nuclear Waste Management, Washington, DC (United States)

Report to the President by the Interagency Review Group on Nuclear Waste Management, $93: 589$ (R;US)

\section{$\sqrt{ }$}

Japan Atomic Energy Research Inst., Tokyo (Japan)

Experimental method for determining distribution coefficients of TRU nuclides for evaluating their migration behaviors, 93:476 (R;JP;in Japanese)

Natural analogue studies: Mineral alteration and uranium migration, 93:477 (R;JP;In Japanese)

\section{$\mathbf{L}$}

Lawrence Berkeley Lab., CA (United States)

A gas-phase source term for Yucca Mountain, 93:40 (R;US)

An inverse procedure for estimating the unsaturated hydraulic conductivities of volcanic tuffs, $93: 56$ (R;US)

Conceptual, experimental and computational approaches to support performance assessment of hydrology and chemical transport at Yucca Mountain: Yucca Mountain Site Characterization Project, 93:249 (R;US)

Continued development of a semianalytical solution for two-phase fluid and heat flow in a porous medium, 93:41 (RA;US)

Design of a three-dimensional site-scale model for the unsaturated zone at Yucca Mountain, Nevada, 93:53 (R;US)

Flow and transport in hierarchically fractured systems, 93:61 (R;US)

Geohydrologic data and models of Rainier Mesa and their implications to Yucca Mountain, 93:58 (R;US)

Geological problems in radioactive waste isolation - A world wide review, $93: 497$ (RA;US)

Geotechnical support and topical studies for nuclear waste geologic repositories: Annual report, fiscal year 1989, 93:47 (R;US)

Measured solubilities and speciations of neptunium, plutonium, and americium in a typical groundwater $(\mathrm{J}-13)$ from the Yucca Mountain region: Milestone report 3010-WBS 1.2.3.4.1.3.1, 93:109 (R;US)

Method development and strategy for the characterization of complexly faulted and fractured rhyolitic tuffs, Yucca Mountain, Nevada, $93: 42$ (RA;US) 
Modeling of strongly heat-driven flow processes at a potential high-level nuclear waste repository at Yucca Mountain, Nevada, 93:57 (R;US)

Modeling studies of gas movement and moisture migration at Yucca Mountain, Nevada, 93:44 (RA;US)

Preliminary calculations of release rates of Tc-99, $1-129$, and No237 from spent fuel in a potential repository in tuff, $93: 49$ (R;US)

Preliminary capillary hysteresis simulations for fractured rocks model development and results of simulations, 93:39 (R;US)

Processes, mechanisms, parameters, and modeling approaches for partially saturated flow in soil and rock media: Yucca Mountain Site Characterization Project, 93:233 (R;US)

Radioelements and their occurrence with secondary minerals in heated and unheated tuff at the Nevada Test Site, 93:52 (R;US)

Radionuclide solubility and speciation studies for the Yucca Mountain site characterization project, $93: 55$ (R;US)

Releases from exotic waste packages from partitioning and transmutation, $93: 51$ (R;US)

Semi-analytical treatment of fracture/matrix flow in a dual-porosity simulator for unsaturated fractured rock masses, $93: 54$ (R;US)

Single fracture aperture patterns: Characterization by slit-island fractal analysis, $98: 59$ (R;US)

Solubility and speciation studies for nuclear repository performance assessment, 93:50 (R;US)

Sorptivity of rocks and soils of the van Genuchten-Mualem type, 93:46 (RA;US)

Studies of the mobility of uranium and thorium in Nevada Test Site tuff, 93:498 (RA;US)

The capillary hysteresis model HYSTR: User's guide, $93: 37$ (R;US)

The Nagra-DOE Cooperative Project, 93:499 (R;US)

The role of fautt zones in affecting multiphase flow at Yucca Mountain, 93:60 (R;US)

TOUGH2: A general-purpose numerical simulator for multiphase nonisothermal flows, 93:43 (RA;US)

Variation and correlation of hydrologic properties, 93:45 (RA;US)

Waste-package release rates for site suitability studies, 93:48 (R;US)

\section{Lawrence Livermore National Lab., CA (United States)}

A preliminary guidebook for identifying stratigraphic contacts at the Nevada Test Site, 93:184 (R;US)

A scoping study of water table excursions induced by seismic and volcanic events, 93:163 (R;US)

Alternative strategies: A means for saving money and time on the Yucca Mountain Project, 93:192 (R:US)

ANL Technical Support Program for DOE Environmental Restoration and Waste Management: Annual report, October 1990-September 1991, 93:402 (R;US)

Bibliography of Yucca Mountain Project (YMP) publications at Lawrence Livermore National Laboratory (January 1978 through September 1993), $93: 150$ (R;US)

Characterizing the altered zone at Yucca Mountain: The beginning of a testing strategy, 93:188 (R;US)

Chemical and mineralogical concerns for the use of man-made materials in the post-emplacement environment, 93:176 (R;US)

Corrosion models for predictions of performance of high-leve radioactive-waste containers, $93: 160$ ( $R$; US)

Cost estimate of high-level radioactive waste containers for the Yucca Mountain Site Characterization Project, 93:161 (R;US)

Coupled hydro-geochemical processes and their significance for Yucca Mountain Site Characterization, $93: 197$ (R;US)

Demands placed on waste package performance testing and modeling by some general results on reliability analysis, $93: 181$ (R;US)

Diffusion releases through one and two finite planar zones from a nuclear waste package, 93:167 (R;US)

Drift emplaced waste package thermal response, 93:193 (R;US)

Engineered barrier environment, Yucca Mountain, 93:191 (R;US)

Engineered barrier system -and waste package design concepts for a potential geologic repository at Yucca Mountain, 93:183 (R;US)

EO3/6 V7.0: Geochemical Modeling of Aqueous Systems, 93:147 (CM;US)
EQ3/6 V7.1: Geochemical Modeling of Aqueous Systems, 93:148 (CM;US)

EQ3/6, a software package for geochemical modeling of aqueous systems: Package overview and installation guide (Version 7.0), 93:200 (R;US)

EO3NR, a computer program for geochemical aqueous speciationsolubility calculations: Theoretical manual, user's guide, and related documentation (Version 7.0): Part 3, 93:202 (R;US)

EQ6, a computer program for reaction path modeling of aqueous geochemical systems: Theoretical manual, user's quide, and related documentation (Version 7.0): Part 4, 93:203 (R;US)

EQPT, a data file preprocessor for the EQ3/6 software package: User's guide and related documentation (Version 7.0): Part 2, 93:201 (R;US)

Estimating the time for dissolution of spent fuel exposed to unlimited water, 93:164 (R;US)

Evaluation of lead contamination in drillback mudpits using isotopic ratios, 93:590 (RA;US)

Fabrication and closure development of nuclear waste disposal containers for the Yucca Mountain Project: Status report, 93:186 (R;US)

Field air injection tests to determine the effect of a heat cycle on the permeability of welded tuff, $93: 179$ (R;US)

Incorporation of the capillary hysteresis model HYSTR into the numerical code TOUGH, 93:38 (R;US)

Large-scale in situ heater tests for hydrothermal characterization at Yucca Mountain, 93:195 (R; US)

Modeling fluid-rock interaction at Yucca Mountain, Nevada: A progress report, April 15, 1992, 93:168 (R;US)

Modeling ion exchange in clinoptilolite using the EQ3/6 geochemical modeling code, 93:190 (R;US)

Modeling pitting corrosion damage of high-level radioactive-waste containers, with emphasis on the stochastic approach, 93:169 (R;US)

Physical limits on steam generation by radioactive decay heat, 93:165 (R;US)

Post-closure performance assessment of waste packages for the Yucca Mountain Project, 93:170 (R;US)

Preliminary near-field environment report: Volume 1, Technical bases for EBS design, 93:198 (R;US)

Preliminary near-field environment report: Volume 2, Scientific overview of near-fieid environment and phenomena, 93:199 (R;US)

Prototype heater test of the environment around a simulated waste package, $93: 162$ (R;US)

Rationale for determining MCC spent fuel acquisitions, 93:177 (R;US)

Risk-based screening analysis of ground water contaminated by radionuclides introduced at the Nevada Test Site (NTS), 93:592 (R;US)

Rock mechanics contributions from defense programs, 93:593 (R;US)

Scientific investigation plan for initial engineered barrier system field tests, $93: 171$ (R; US)

Selection of candidate container materials for the conceptual waste package design for a potential high level nuclear waste repository at Yucca Mountain, 93:172 (R;US)

Single-hole in situ thermal probe for hydrothermal characterization at Yucca Mountain, 93:196 (R; US)

Stress corrosion cracking of candidate waste container materials: Final report, $93: 403$ (R;US)

Survey of degradation modes of four nickel-chromiummolybdenum alloys, 93:166 (R;US)

Technical basis and programmatic requirements for laboratory study of hydrological properties of the near-field environment, 93:173 (R;US)

Technical basis and programmatic requirements for Engineered Barrier System Field Tests, $93: 174$ (R;US)

Technical basis and programmatic requirements for large block testing of coupled thermal-mechanical-hydrological-chemical processes, $93: 175$ (R;US)

Technical data base quarterly report, ApribJune 1992: Yucca Mountain Site Characterization Project, 93:216 (R;US) 
Temperature measurements from a horizontal heater test in GTunnel, $93: 178$ (R;US)

The analysis of repository-heat-driven hydrothermal flow at Yucca Mountain, 93:194 (R:US)

The impact of episodic nonequilibrium fracture-matrix flow on geological repository performance, $93: 182$ (R;US)

The impact of episodic nonequilibrium fracture-matrix flow on repository performance at the potential Yucca Mountain site, 93:185 (R;US)

The impact of thermal loading on repository performance at Yucca Mountain, 93:189 (R;US)

The implications of episodic nonequilibrium fracture-matrix flow on site suitability and total system performance, $93: 187$ (R;US)

Thermal performance of a buried nuclear waste storage container storing a hybrid mix of PWR and BWR spent fuel rods: Revision 1, $93: 159$ (R; US)

Thermocouple psychrometer measurements of in situ water potential changes in heated welded tuff, $93: 180$ (R;US)

Lehman (L.) and Associates, Inc., Burnsville, MN (United States) State of Nevada review of Phase 1 of the INTRAVAL Project, 93:571 (R;US)

Los Alamos National Lab., NM (United States)

A strategy for the derivation and use of sorption coefficients in performance assessment calculations for the Yucca Mountain site, 93:105 (RA;US)

A strategy for the derivation and use of sorption coefficients in performance assessment calculations for the Yucca Mountain site, 93:115 (R;US)

A suggested approach toward measuring sorption and applying sorption data to repository performance assessment, $93: 114$ (R;US)

A summary and discussion of hydrologic data from the Calico Hilis nonwelded hydrogeologic unit at Yucca Mountain, Nevada 93:107 (R;US)

Boron adsorption on hematite and clinoptilolite, $93: 490$ (R;US)

Characterization of flow in fractured tuff using computerized tomography, 93:491 (R;US)

Chemical changes associated with zeolitization of the tuffaceous beds of Calico Hills at Yucca Mountain, Nevada, 93:123 (R;US)

Colloid research for the Nevada Test Site, 93:478 (R;US)

Colloid transport code-nuclear user's manual, 93:493 (R;US)

CTCN: Colloid transport code - nuclear: A user's manual, 93:494 (R:US)

Current adsorption models and open issues pertaining to performance assessment, 93:480 (RA;US)

Dependence of radionuclide sorption on sample grinding, surface area, and water composition, 93:127 (R:US)

Diffusion of sorbing and non-sorbing radionuclides, 93:129 (R;US)

Distribution and chemistry of fracture-lining zeolites at Yucca Mountain, Nevada, $93: 134$ (R;US)

Effects of magmatic processes on the potential Yucca Mountain repository: Field and computational studies, 93:135 (R;US)

Equilibrium modeling of the formation of zeolites in fractures at Yucca Mountain, Nevada, 93:133 (R:US)

Evaluation of potential hydrologic tracers in tuffs from Yucca Mountain, Nevada, 93:487 (RA;US)

FEHMN 1.0: Finite element heat and mass transfer code: Revision 1, $93: 103$ (R;US)

Fission product studies in the symmetric mass region, 93:489 (RA;US)

Geochemical evidence for waning magmatism and polycyclic volcanism at Crater Flat, Nevada, 93:1 19 (R;US)

Geologic evaluation of six nonwelded tuff sites in the vicinity of Yucca Mountain, Nevada for a surface-based test facility for the Yucca Mountain Project, 93:108 (R;US)

Geology, drilling, and some hydrologic aspects of seismic hazards program core holes, Los Alamos National Laboratory, New Mexico, $93: 488$ (R;US)

K/AR dating of clinoptilolite, mordenite, and associated clays from Yucca Mountains, Nevada, 93:131 (R;US)

Kinetics of silica-phase transitions, $93: 110$ (R;US)

Laboratory analysis of hydraulic properties of volcanic tuff samples, 93:492 (R;US)
Measured solubilities and speciations of neptunium, plutonium, and americium in a typical groundwater $(\mathrm{J}-13)$ from the Yucca Mountain region: Milestone report 3010 -WBS 1.2.3.4.1.3.1, 93:109 (R;US)

Modeling cation exchange using EQ3/6, $93: 149$ (RA;US)

Natural geis in the Yucca Mountain Area, Nevada, USA, 93:116 (R;US)

Neptunium retardation with tuffs and groundwaters from Yucca Mountain, 93:128 (R;US)

Neptunium( $V$ ) sorption on quartz and albite in aqueous suspension: Annual progress report, 93:495 (R;US)

Physical processes and effects of magmatism in the Yucca Mountain region, $93: 117$ (R;US)

Preliminary assessment of clinoptilolite $\mathrm{K} / \mathrm{Ar}$ results from Yucca Mountain, Nevada: A potential high-level radioactive waste repository site, 93:121 (R;US)

Preliminary conceptual model for mineral evolution in Yucca Mountain, 93:111 (R;US)

Preliminary modeling of moisture movement in the tuff beneath Mortandad Canyon, Los Alamos National Laboratory, 93:496 (R;US)

Proceedings of the DOE/Yucca Mountain Site Characterization Project Radionuclide Adsorption Workshop at Los Alamos National Laboratory, September 11-12, 1990, 93:104 (R;US)

Radionuclide migration laboratory studies for validation of batchsorption data, 93:106 (RA;US)

Radionuclide migration laboratory studies for validation of batch sorption data, 93:118 (R;US)

Recurrence models of volcanic events: Applications to volcanic risk assessment, 93:120 (R;US)

Selected issues on geochemical transport modeling for high-level nuclear waste repository, 93:486 (RA;US)

Sensitivity analysis of integrated radionuclide transport based on a three-dimensional geochemicalgeophysical model, 93:485 (RA;US)

Simulation modeling of the probability of magmatic disruption of the potential Yucca Mountain Site, 93:136 (R;US)

Sorption and porosity heterogeneity: Effects on radionuclide transport, $93: 479$ (RA;US)

Sorption of cesium and strontium by zeolite single crystals, $93: 481$ (RA;US)

Summary report on the evaluation of a 1977-1985 edited sorption data base for isotherm modeling, 93:113 (R;US)

Surface-discharging hydrothermal systems at Yucca Mountain Examining the evidence, 93:125 (R;US)

The importance of zeolites in the potential high-level radioactive waste repository at Yucca Mountain, Nevada, 93:132 (R;US)

The Lathrop Wells volcanic center: Status of field and geochronology studies, $93: 112$ (R;US)

The Lathrop Wells volcanic center: Status of field and geochronology studies, $93: 122$ (R;US)

The quality assurance liaison: Combined technical and quality assurance support, $93: 130$ (R;US)

Transport in unsaturated flow systems using centrifuge techniques, 93:483 (RA; US)

Transport of neptunium through Yucca Mountain tuffs, 93:126 (R;US)

Transport of reactive tracers by unsaturated flow using field and column experiments, 93:482 (RA;US)

Unsaturated transport of inorganic cations in undisturbed soil columns, 93:484 (RA;US)

Water-rock interactions and the $\mathrm{pH}$ stability of groundwater from Yucca Mountain, Nevada, 93:124 (R;US)

\section{M}

Missouri Univ., Columbia, MO (United States)

Environmental monitoring for uranium and neptunium at Yucca Mountain using Epithermal Neutron Activation Analysis, 93:447 (R;US)

Point defects in silicates, 93:646 (I:US) 
Mountain West Research, Las Vegas, NV (United States)

Transportation needs assessment: Emergency response section, 93:559 (R;US)

\section{$\mathbf{N}$}

National Board for Spent Nuclear Fuel, Stockholm (Sweden)

The Nuclear Waste Technical Review Board - Two years of experience in the US Waste Programme. Do we as reviewers communicate understandably with society?, 93:588 (RA;SE)

National Inst. of Standards and Technology (IMSE), Gaithersburg, MD (United States). Metallurgy Div.

Evaluation and compilation of DOE waste package test data: Biannual report, February 1989-July 1989: Volume 7, 93:528 (R;US)

National Inst. of Standards and Technology (MSEL), Gaithersburg, MD (United States). Metallurgy Div.

Evaluation and compilation of DOE waste package test data: Volume 8: Biannual report, August 1989-January 1990, 93:529 (R;US)

National Research Council, Washington, DC (United States). Panel on Coupled Hydrologic/Tectonic/Hydrothermal Systems at Yucca Mountain

Ground water of Yucca Mountain: How high can it rise?: Final report, $93: 511$ (R;US)

Nationale Genossenschaft fuer die Lagerung Radioaktiver Abfaelle (NAGRA), Baden (Switzerland)

Chemical and physical characterisation of suspended particles and colloids in waters from the Osamu Utsumi mine and Morro do Ferro analogue study sites, Pocos de Caldas, Brazil, 93:506 (R;CH)

Geochemical modelling of water-rock interactions at the Osamu Utsumi mine and Morro do Ferro analogue study sites, Pocos de Caldas, Brazil, 93:509 (R;CH)

Isotopic geochemical characterization of selected nepheline syenites and phonolites from the Pocos de Caldas alkaline complex, Minas Gerais, Brazil, 93:503 (R;CH)

Mineralogy, petrology and geochemistry of the Pocos de Caldas analogue study sites, Minas Gerais, Brazil. 1. Osamu Utsumi uranium mine: Pocos de Caldas Report No. 2, 93:501 (R;CH)

Mineralogy, petrology and geochemistry of the Pocos de Caldas analogue study sites, Minas Gerais, Brazil: Il. Morro do Ferro, 93:502 $(\mathrm{R} ; \mathrm{CH})$

Natural radionuclide and stable element studies of rock samples from the Osamu Utsumi mine and Morro do Ferro analogue study sites, Pocos de Caldas, Brazil, $93: 504(\mathrm{R} ; \mathrm{CH})$

Natural series radionuclide and rare-earth element geochemistry of waters from the Osamu Utsumi mine and Morro do Ferro analogue study sites, Pocos de Caldas, Brazil, 93:505 (R;CH)

Testing models of redox front migration and geochemistry at the Osamu Utsumi mine and Morro do Ferro analogue study sites, Pocos de Caldas, Brazil, 93:508 (R;CH)

Testing of geochemical models in the Pocos de Caldas analogue study, 93:507 $(\mathrm{R} ; \mathrm{CH})$

The Pocos de Caldas project: summary and implications for radioactive waste management: Pocos de Caldas report no. 15 , 93:510 (R;CH)

The regional geology, mineralogy and geochemistry of the Pocos de Caldas alkaline caldera complex, Minas Gerais, Brazil, 93:500 (R; $\mathrm{CH})$

Nevada Commission on Nuclear Projects, Carson City, NV (United States)

Report of the State of Nevada Commission on Nuclear Projects, 93:538 (R;US)

Nevada Nuclear Waste Project Office, Carson City, NV (United States)

A report on high-level nuclear waste transportation: Prepared pursuant to assembly concurrent resolution No. 8 of the 1987 Nevada Legislature, 93:558 (R:US)

A structural model analysis of public opposition to a high-level radioactive waste facility, 93:554 (R; US)
Center for Volcanic and Tectonic Studies, Department of Geoscience annual report, October 1, 1989-September 30, 1990 93:541 (R;US)

Evaluation of the geologic relations and seismotectonic stability of the Yucca Mountain area, Nevada Nuclear Waste Site Investigation (NNWSI): Final report, January 1, 1987_June 30, 1988: Volume 1, 93:542 (R; US)

Expert judgment in assessing radwaste risks: What Nevadans should know about Yucca Mountain: [Final report], 93:556 (R;US)

Geothermal evaluation and analysis of the Yucca Mountain Repository, Nevada: Final report, July 1, 1989-December 31, 1989, 93:540 (R;US)

Guidelines on the scope, content, and use of comprehensive risk assessment in the management of high-level nuclear waste transportation, 93:561 (R;US)

Human and social factors in the transportation of nuclear wastes, 93:562 (R;US)

Institutional trust, information, and risk perceptions: Report of findings of the Las Vegas metropolitan area survey, June 29-July 1 1992, 93:557 (R;US)

Mesozoic and Cenozoic structural geology of the CP Hills, Nevada Test Site, Nye County, Nevada; and regional implications, 93:569 (R;US)

Native Americans and state and local governments, $93: 553$ (R;US)

Native Americans and Yucca Mountain: A summary report, 93:544 (R;US)

Native Americans and Yucca Mountain: A revised and updated summary report on research undertaken between 1987 and 1991: Volume 1, $93: 548$ (R;US)

Native Americans and Yucca Mountain: A revised and updated summary report on research undertaken between 1987 and 1991: Volume 2, 93:549 (R;US)

Neotectonics of the southern Amargosa Desert, Nye County, Nevada and inyo County, Calfornia, 93:568 (R;US)

Numerical simulation of gas flow through unsaturated fractured rock at Yucca Mountain, Nevada, 93:567 (R;US)

Organizational management of long-term risks: Implications for risk and safety in the transportation of nuclear wastes, 93:565 (R;US)

Probabilistic risk assessment and nuclear waste transportation: A case study of the use of RADTRAN in the 1986 Environmental Assessment for Yucca Mountain, $93: 560$ (R;US)

Report of the State of Nevada Commission on Nuclear Projects, 93:538 (R;US)

Review and critique of the US Department of Energy environmental program plan for site characterization for a high-level waste repository at Yucca Mountain, Nevada, 93:570 (R;US)

Social impacts of hazardous and nuclear facilities and events: Implications for Nevada and the Yucca Mountain high-level nuclear waste repository: [Final report], $93: 555$ (R;US)

Socioeconomic profiles of Native American communities: Las Vegas Tribes of Paiute Indians, 93:550 (R;US)

Socioeconomic profiles of native American communities: Yomba Shoshone Reservation, 93:551 (R;US)

Socioeconomic profiles of native American communities: Duckwater Shoshone Reservation, 93:552 (R;US)

Southern Nevada residents' views about the Yucca Mountain high-level nuclear waste repository and related issues: $A$ comparative analysis of urban and rural survey data, $93: 547$ (R;US)

The relationship of the Yucca Mountain repository block to the regional ground-water system: A geochemical model, 93:566 (R;US)

Transportation needs assessment: Emergency response section, 93:559 (R;US)

Yucca Mountain program summary of research and technical review activities, July 1988-June 1989, $93: 539$ (R;US)

Yucca Mountain socioeconomic project report on the 1987 risk perception telephone surveys, $93: 545$ (R;US)

Yucca Mountain Socioeconomic Project: The 1991 Nevada State telephone survey: Key findings, $93: 546$ (R;US) 
Yucca Mountain transportation routes: Preliminary characterization and risk analysis: Volume 1, Research report, 93:563 (R;US)

Yucca Mountain transportation routes: Preliminary characterization and risk analysis: Volume 2, Figures [and] Volume 3, Technical Appendices, 93:564 (R;US)

Nevada Univ., Las Vegas, NV (United States)

Quarterly progress report on the DOE Waste Package project at the University of Nevada, Las Vegas, July 1, 1993 through September 30, 1993, 93:17 (R;US)

Reliability modeling of an engineered barrier system, 93:429 (R;US)

Report on task assignment No. 3 for the Waste Package Project: Parts A \& B, ASME pressure vessel codes review for waste package application; Part C, Library search for reliability/failure rates data on low temperature low pressure piping, containers, and casks with long design lives, $93: 12$ (R;US)

Word images as policy instruments: Lessons from the Yucca Mountain Controversey, 93:430 (R;US)

Nevada Univ., Las Vegas, NV (United States). Center for Volcanic and Tectonic Studies

Center for Volcanic and Tectonic Studies, Department of Geoscience annual report, October 1, 1989-September 30, 1990 93:541 (R;US)

Nevada Univ., Las Vegas, NV (United States). Dept. of Civil and Environmental Engineering

Heat pipe effect in porous medium, 93:445 (R;US)

Nevada Univ., Las Vegas, NV (United States). Desert Research Inst.

Yucca Mountain program summary of research and technical review activities, July 1988-June 1989, 93:539 (R;US)

Nevada Univ., Las Vegas, NV (United States). Environmental Research Center

Identification and characterization of conservative organic tracers for use as hydrologic tracers for the Yucca Mountain Site Characterization Study: Progress report, June 1-December 31, 1990, 93:9 (R;US)

Identification and characterization of conservative organic tracers for use as hydrologic tracers for the Yucca Mountain Site Characterization Study: Progress report, January 1, 1991-June 30, 1991, $93: 10$ (R;US)

UNS YMSCP QA support task: Quarterly technical progress report, January 1, 1991-June 30, 1991, 93:11 (R;US)

Nevada Univ., Las Vegas, NV (United States). Harry Reid Center for Environmental Studies

Fingerprinting of ground water by ICP-MS: Progress report, July 1 , 1991-December 31, 1991, 93:13 (R;US)

Identification and characterization of conservative organic tracers for use as hydrologic tracers for the Yucca Mountain Site Characterization Project: Quality Assurance Project Plan: Quarterly technical progress report, January 1, 1993-March 31, 1993, 93:8 (R;US)

Identification and characterization of conservative organic tracers for use as hydrologic tracers for the Yucca Mountain Site Characterization Study: Progress report, July 1, 1991-December 31, 1991, $93: 14$ (R;US)

Identification and characterization of conservative organic tracers for use as hydrologic tracers for the Yucca Mountain Site characterization study: Progress report, April 1, 1993-June 30 , 1993, $93: 15$ (R;US)

Identification of subsurface microorganisms at Yucca Mountain: Fourth quarterly report, $93: 16$ (R;US)

Nevada Univ., Las Vegas, NV (United States). Transportation Research Center

Yucca Mountain transportation routes: Preliminary characterization and risk analysis: Volume 1, Research report, 93:563 (R;US)

Yucca Mountain transportation routes: Preliminary characterization and risk analysis: Volume 2, Figures [and] Volume 3 , Technical Appendices, 93:564 (R;US)
Nevada Univ., Reno, NV (United States)

Mesozoic and Cenozoic structural geology of the CP Hills, Nevada Test Site, Nye County, Nevada; and regional implications, 93:569 (R;US)

Neotectonics of the southern Amargosa Desert, Nye County, Nevada and inyo County, California, 93:568 (R;US)

The Timber Mountain magmato-thermal event: An intense widespread culmination of magmatic and hydrothermal activity at the southwestern Nevada volcanic field, $93: 438$ (R;US)

Nevada Univ., Reno, NV (United States). Center for Neotectonic Studies

Evaluation of the geologic relations and seismotectonic stability of the Yucca Mountain area, Nevada Nuclear Waste Site Investigation (NNWSI): Final report, January 1, 1987-June 30, 1988: Volume 1, 93:542 (R; US)

Evaluation of the geologic relations and seismotectonic stability of the Yucca Mountain Area, Nevada Nuclear Waste Site Investigation (NNWS1): Volume 2, Final report, October 1988, 93:543 (R;US)

Nevada Univ., Reno, NV (United States). Desert Research Inst.

Hydrology/Radionuclide Migration Program and related research activities: FY 1986 progress report, October 1, 1985September $30,1986,93: 437$ (R;US)

Yucca Mountain program summary of research and technical review activities, July 1988-June 1989, $93: 539$ (R;US)

Nevada Univ., Reno, NV (United States). Div. of Earth Sciences

Geothermal evaluation and analysis of the Yucca Mountain Repository, Nevada: Final report, July 1, 1989-December 31, $1989,93: 540$ (R;US)

Nevada Univ., Reno, NV (United States). Water Resources Center

Community Radiation Monitoring Program: Annual report, October 1, 1990-September 30, 1991, 93:442 (R;US)

Estimates of potential radionuclide migration at the Bullion site, 93:443 (R; US)

Groundwater chemistry at the Nevada Test Site: Data and preliminary interpretations, $93: 444$ (R;US)

Hydrogeologic characterization of wells HTH-1, UE18r, UE6e, and HTH-3, Nevada Test Site, 93:441 (R;US)

The relationship of the Yucca Mountain repository block to the regional ground-water system: A geochemical model, 93:566 (R;US)

New Mexico Univ., Albuquerque, NM (United States)

Colloid transport code-nuclear user's manual, $93: 493$ (R;US)

Mineralogy, petrology and whole-rock chemistry of selected mechanical test samples of Yucca Mountain tuffs: Yucca Mountain Site Characterization Project, 93:259 (R;US)

Mineralogy, petrology and whole-rock chemistry data compilation for selected samples of Yucca Mountain tuffs: Yucca Mountain Site Characterization Project, 93:295 (R;US)

Nuclear Energy Agency, 75 - Paris (France)

The international hydrocoin project - Groundwater hydrology modelling strategies for performance assessment of nuclear waste disposal, 93:470 (R;XN)

The international INTRAVAL project. Phase 1 test cases, 93:471 $(R ; X N)$

The International INTRAVAL project. Phase 1 , case 7. The Pocos de Caidas natural analogue: studies of redox front movement, 93:472 (R; XN)

The International INTRAVAL project. Phase 1 case 8: The Alligator rivers natural analogue, 93:473 (R;XN)

Nuclear Regulatory Commission, Washington, DC (United States)

Initial demonstration of the NRC's capability to conduct a performance assessment for a High-Level Waste Repository, 93:512 (R;US)

Nuclear Regulatory Commission, Washington, DC (United States). Div. of High-Level Waste Management

A literature review of coupled thermal-hydrologic-mechanicalchemical processes pertinent to the proposed high-level nuclear waste repository at Yucca Mountain, $93: 537$ (R;US)

Evaluation and compilation of DOE waste package test data: Biannual report, February 1989-July 1989: Volume 7, $93: 528$ (R;US) 
Evaluation and compilation of DOE waste package test data: Volume 8: Biannual report, August 1989-January 1990, 93:529 (R;US)

Regional groundwater modeling of the saturated zone in the vicinity of Yucca Mountain, Nevada: Iterative Performance Assessment, Phase 2, 93:535 (R;US)

Sensitivity and uncertainty analyses applied to one-dimensional radionuclide transport in a layered fractured rock: MULTFRAC Analytic solutions and local sensitivities: Phase 2, Iterative performance assessment: Volume 1, 93:536 (R;US)

Nuclear Regulatory Commission, Washington, DC (United States). Div. of Regulatory Applications

A survey of hydrothermal modeling related to Yucca Mountain, 93:524 (RA;US)

Apache leap watershed study, 93:516 (RA;US)

Borehole stability in densely welded tuffs, 93:531 (R;US)

Characterization of rock hydrologic properties using model verification, 93:519 (RA;US)

Does the wind blow through Yucca Mountain?, 93:366 (RA;US)

Evaluation of tracers for hydrologic studies at Yucca Mountain, 93:526 (RA;US)

Field testing the effectiveness of pumping to remove sulfur hexafluoride traced drilling air from a prototype borehole near superior, Arizona, 93:518 (RA;US)

Flow through nonhomogeneous porous media, 93:525 (RA;US)

Ground water flow through unsaturated fractured rock research needs, $93: 521$ (RA;US)

Hydrogeologic issues at Yucca Mountain: Findings of a DOE peer review team, 93:513 (RA;US)

Modeling hydrothermal flow in variably saturated, fractured, welded tuff during the prototype engineered barrier system field test of the Yucca Mountain Project, 93:523 (RA;US)

Nonequilibrium fracture-matrix flow during episodic infiltration events in Yucca Mountain, 93:514 (RA;US)

Nonisothermal hydrologic transport study at the Apache Leap Tuff site, 93:515 (RA;US)

Nonisothermal hydrologic transport experimental plan, 93:534 (R;US)

Numerical and laboratory investigations of transient and steadystate flow in a fractured core, 93:520 (RA;US)

Pneumatic permeability measurements in a fractured, partially saturated environment, 93:517 (RA;US)

Potentiodynamic polarization studies on candidate container at loys for the Tuff Repository, 93:532 (R;US)

Sealing performance of bentonite and bentonite/crushed rock borehole plugs, $93: 530$ (R;US)

Stress-corrosion-cracking studies on candidate container alloys for the Tuff Repository, 93:533 (R;US)

Technical issues related to groundwater flow and radionuclide transport in unsaturated fractured rock, 93:368 (RA; US)

The composition and $\mathrm{CO}_{2}$ carbon isotope signature of gases from borehole USW UZ-6, Yucca Mountain, Nevada, 93:367 (RA;US)

Use of a submersible pressure outfiow cell for determination of moisture characteristic curves on rock core, 93:522 (RA;US)

Nuclear Regulatory Commission, Washington, DC (United States). Office of Nuclear Regulatory Research

Development and evaluation of a performance assessment methodology for analyzing the safety of a geologic repository for high-level radioactive waste, 93:527 (RA;US)

Nuclear Waste Technical Review Board, Washington, DC (United States)

Fifth report to the US Congress and the US Secretary of Energy from the Nuclear Waste Technical Review Board, 93:575 (R;US)

Fourth report to the U.S. Congress and the U.S. Secretary of Energy from the Nuclear Waste Technical Review Board, 93:573 (R;US)

Second report to the U.S. Congress and the U.S. Secretary of Energy from the Nuclear Waste Technical Review Board, 93:574 (R;US)
Oak Ridge Inst. for Science and Education, TN (United States) Effects of actinide burning on waste disposal at Yucca Mountain, 93:446 (R;US)

Environmental monitoring for uranium and neptunium at Yucca Mountain using Epithermal Neutron Activation Analysis, 93:447 (R;US)

Oak Ridge National Lab., TN (Unlted States)

Heatth and environmental risk-related impacts of actinide burning on high-level waste disposal, 93:572 (R;US)

Office of the Supervising Scientist for the Alligator Rivers Region, Sydney, NSW (Australia)

A selected GIS bibliography: Technical Memorandum 40, 93:603 (B;AU)

Alligator Rivers Region Research Institute: annual research summany 1989-1990, 93:601 (B;AU)

Alligator Rivers Region Research institute: annual research summary 1989-1990, 93:606 (B;AU)

Annual Report 1991-1992, 93:604 (B;AU)

Fish communities in sandy pool of Magela Creek, Alligator Rivers Region: Research Report 9, 93:602 (B;AU)

Pacific Northwest Lab., Richland, WA (United States)

A demonstration of dose modeling at Yucca Mountain, 93:66 (R;US)

An example postclosure risk assessment using the potential Yucca Mountain Site, 93:155 (R;US)

AREST user's guide, PC version, 93:154 (R;US)

AREST: The next generation, 93:157 (R;US)

Characterization of spent fuel approved testing material-ATM-104, 93:151 (R;US)

Characterization of spent fuel approved testing materiaŁATM105, $93: 152$ (R;US)

MSTS - Multiphase Subsurface Transport Simulator theory manual, 93:64 (R;US)

Preliminary characterization of risks in the nuclear waste management system based on information in the literature, 93:576 (R;US)

Preliminary total-system analysis of a potential high-level nuclear waste repository at Yucca Mountain, 93:63 (R;US)

Simulation of two-phase carbon-1.4 transport at Yucca Mountain, Nevada, $93: 65$ (R;US)

SUMO, System performance assessment for a high-level nuclear waste repository: Mathematical models, 93:153 (R;US)

Thermal analysis of Yucca Mountain commercial high-level waste packages, 93:156 (R;US)

Three-dimensional modeling of unsaturated flow in the vicinity of proposed exploratory shaft facilities at Yucca Mountain, Nevada, 93:62 (R;US)

Parsons, Brinckerhoff, Quade and Douglas, Inc., San Francisco, CA (United States)

Waste package emplacement borehole option study: Yucca Mountain Site Characterization Project, 93:236 (R;US)

Pennsylvania Univ., Philadelphia, PA (United States). Wharton School of Finance and Commerce

Yucca Mountain socioeconomic project report on the 1987 risk perception telephone surveys, 93:545 (R;US)

Purdue Univ., Latayette, IN (United States)

Gas phase migration of $\mathrm{C}-14$ through barrier materials applicable for use in a high-level nuclear waste repository located in tuff, 93:647 (l;US) 


\section{$\mathbf{R}$}

Radioactive Waste Management Associates, New York, NY (United States)

Probabilistic risk assessment and nuclear waste transportation: A case study of the use of RADTRAN in the 1986 Environmental Assessment for Yucca Mountain, 93:560 (R;US)

Raytheon Services Nevada, Las Vegas, NV (United States)

Using QA classification to guide design and manage risk, 93:5 (R;US)

RE/SPEC, Inc., Rapid City, SD (United States)

RE/SPEC Inc. technical support to the Repository Technology Program: Summary of activities for September 1, 1988-June 30 , 1992, $93: 432$ (R;US)

Research Triangle Inst., Research Triangle Park, NC (United States)

Yucca Mountain socioeconomic project report on the 1987 risk perception telephone surveys, 93:545 (R;US)

Reynolds Electrical and Engineering Co., Inc., Las Vegas, NV (United States)

Addendum to environmental monitoring plan Nevada Test Site and support facilities, $93: 439$ (R;US)

Estimating the water table under the Radioactive Waste Management Site in Area 5 of the Nevada Test Site: The Dupuit-Forcheimer approximation, 93:428 (R;US)

Evaluation of environmental monitoring thermoluminescent dosimeter locations, $93: 440$ (R:US)

Yucca Mountain Exploratory Studies Facilities: Construction status: Extended summary, 93:100 (R;US)

Risk Engineering, Inc., Golden, CO (United States)

Demonstration of a risk-based approach to high-level waste repository evaluation, Phase 2, 93:461 (R;US)

Rogers and Associates Engineering Corp., Salt Lake City, UT (United States)

Reasonableness of human intrusion provisions in EPA's HLW standard, 93:463 (RA:US)

Session II: Gas pathway, 93:462 (RA;US)

\section{$\mathbf{S}$}

Sandia National Labs., Albuquerque, NM (United States)

A decision analysis of an exploratory studies facility, 93:301 (R;US)

A simplified radionuclide source term for total-system performance assessment: Yucca Mountain Site Characterization Project, 93:260 (R;US)

A study of discrete and continuum joint modeling techniques, 93:271 (R;US)

A working definition of scenario and a method of scenario construction, 93:331 (R;US)

An analysis of a joint shear model for jointed media with orthogonal joint sets: Yucca Mountain Site Characterization Project, 93:245 (R;US)

An approach to validation of thermomechanical models, 93:335 (R;US)

An evaluation of the seismicity of the Nevada Test Site and vicinity: Yucca Mountain Site Characterization Project 93:218 (R:US)

An investigation of the impact of conceptual model uncertainty on the estimated performance of a hypothetical high-level nuclear waste repository site in unsaturated, fractured tuff: Yucca Mountain Site Characterization Project, 93:256 (R;US)

An overview of the Yucca Mountain GlobalRegional Climate Modeling Program, 93:276 (R;US)

Analysis of releases due to drilling at the potential Yucca Mountain repository, 93:336 (R;US)

Analysis of siot cutting methods for the Yucca Mountain heated block test using a compliant-joint model, 93:270 (R;US)

Anisotropy of the Topopah Spring Member Tuff, 93:268 (R;US)

Application of analytical methods for jointed rock as part of a dritt design methodology for the Yucca Mountain Project, 93:240 (R;US)

Applications of performance assessment in support of the Exploratory Studies Facility (ESF) design, $93: 288$ (R;US)
Approach to geologic repository post closure system performance assessment, 93:308 (R; US)

Areal power density: A preliminary examination of underground heat transfer in a potential Yucca Mountain repository and recommendations for thermal design approaches: Yucca Mountain Site Characterization Project, 93:243 (R;US)

Automated waste canister docking and emplacement using a sensor-based intelligent controller: Yucca Mountain Site Characterization Project, 93:262 (R;US)

Calculation of experiment uncertainty in laboratory determination of several geoengineering properties of tuffs from Yucca Mountain, Nevada: Yucca Mountain Site Characterization Project, 93:231 (R;US)

Changes in risk perception over time, $98: 580$ (R;US)

Characterization of porosity in support of mechanical property analysis, 93:313 (R;US)

Comparison of predicted far-field temperatures for discrete and smeared heat sources, 93:332 (R;US)

Comparison of two conceptual models of flow using the TSA, 93:282 (R;US)

Conceptual, experimental and computational approaches to support performance assessment of hydrology and chemical transport at Yucca Mountain: Yucca Mountain Site Characterization Project, 93:249 (R;US)

Design and implementation of the site and engineering properties database: Yucca Mountain Site Characterzation Project, 93:242 (R;US)

Design of an intermediate-scale experiment to validate unsaturated-zone transport models, 93:285 (R;US)

Deterministic geologic processes and stochastic modeling, 93:274 (R;US)

Developing a functioning visualization and analysis system for performance assessment, 93:289 (R;US)

Developing conceptual models for performance assessment of waste management sites, 93:578 (R;US)

Documentation and verification of the SHAFT code: Yucca Mountain Site Characterization Project, 93:235 (R;US)

Documentation and verification of STRES3D, Version 4.0: Yucca Mountain Site Characterization Project, 93.250 (R;US)

Drift design methodology and preliminary application for the Yucca Mountain Site Characterization Project: Yucca Mountain Site Characterization Project, 93:237 (R;US)

Effect of boundary conditions on the strength and deformability of replicas of natural fractures in welded tuff: Data report: Yucca Mountain Site Characterization Project, 93:311 (R;US)

Effect of boundary conditions on the strength and deformability of replicas of natural fractures in welded tuff: Comparison between predicted and observed shear behavior using a graphical method: Yucca Mountain Site Characterization Project, 93:314 (R;US)

Effects of a potential drop of a shipping cask, a waste container and a bare fuel assembly during waste-handling operations: Yucca Mountain Site Characterization Project, 93:224 (R;US)

Effects of various radiation source characteristics on shielding requirements at the potential Yucca Mountain repository, 93:248 (R;US)

Equivalent Energy Density concept: A preliminary reexamination of a technique for equating thermal loads: Yucca Mountain Site Characterization Project, 93:269 (R;US)

Estimating the consequences of significant fracture flow at Yucca Mountain, 93:273 (R;US)

Estimation of the impact of water movement from sewage and settling ponds near a potential high level radioactive waste repository in Yucca Mountain, Nevada: Yucca Mountain Site Characterization Project, 93:267 (R;US)

Estimation of the limitations for surficial water addition above a potential high level radioactive waste repository at Yucca Mountain, Nevada: Yucca Mountain Site Characterization Project, 93:265 (R;US)

Evaluation of alternatives for high-level and transuranic radioactive- waste disposal standards, 93:582 (R;US)

Fault stress analysis for the Yucca Mountain Site Characterization Project, $93: 278$ (R;US) 
Field research program for unsaturated flow and transport experimentation, 93:280 (R;US)

G-tunnel pressurized slot-testing evaluations: Yucca Mountain Site Characterization Project, 93:222 (R;US)

G-Tunnel pressurized slot-testing preparations: Yucca Mountain Site Characterization Project, 93:225 (R;US)

G-Tunnel Welded Tuff Mining Experiment instrumentation evaluations: Yucca Mountain Site Characterization Project, 93:227 (R:US)

Groundwater flow code verification "benchmarking" activity (COVE-2A): Analysis of participants' work, 93:244 (R;US)

HEFF-A user's manual and guide for the HEFF code for thermalmechanical analysis using the boundary-element method: Version 4.1: Yucca Mountain Site Characterization Project, 93:223 (R;US)

Identification of structures, systems, and components important to safety at the potential repository at Yucca Mountain: Yucca Mountain Site Characterization Project, 93:251 (R;US)

Impact of fracture coatings on the transfer of water across fracture faces in unsaturated media, 93:579 (R;US)

Implications of stability analysis for heat transfer at Yucca Mountain, 93:337 (R;US)

Influence of deterministic geologic trends on spatial variability of hydrologic properties in volcanic tuff, $93: 318$ (R;US)

Initial field testing definition of subsurface sealing and backfilling tests in unsaturated tuff: Yucca Mountain Site Characterization Project, 93:307 (R;US)

Instrumentation requirements for the ESF thermomechanical experiments, 93:330 (R;US)

Intra-site secure transport vehicle, 93:581 (R;US)

Investigation of fracture-matrix interaction: Preliminary experiments in a simple system, 93:320 (R;US)

Is it possible to demonstrate compliance with the regulations for high-level-waste repositories?, 93:316 (R;US)

JACBD - A three-dimensional finite element computer program for the nonlinear quasi-static response of solids with the conjugate gradient method: Yucca Mountain Site Characterization Project, 93:219 (R;US)

Linear thermal expansion data for tuffs from the unsaturated zone at Yucca Mountain, Nevada: Yucca Mountain Site Characterization Project, 93:228 (R;US)

LLUVIA-II: A program for two-dimensional, transient flow through partially saturated porous media: Yucca Mountain Site Characterization Project, 93:290 (R;US)

Mineralogy, petrology and whole-rock chemistry of selected mechanical test samples of Yucca Mountain tuffs: Yucca Mountain Site Characterization Project, 93:259 (R;US)

Mineralogy, petrology and whole-rock chemistry data compilation for selected samples of Yucca Mountain tuffs: Yucca Mountain Site Characterization Project, 93:295 (R;US)

MISTY ECHO Tunnel Dynamics Experiment-Data report: Volume 1: Yucca Mountain Site Characterization Project, $93: 238$ (R;US)

MISTY ECHO tunnel dynamics experiment data report: Volume 2 , Appendices: Yucca Mountain Site Characterization Project, 93:239 (R;US)

Modeling gravity-driven fingering in rough-walled fractures using modified percolation theory, 93:328 (R;US)

Modulus dispersion and attenuation in tuff and granite, 93:275 (R;US)

Movement of shaft and drift construction water in Yucca Mountain Nevada: An extended study: Yucca Mountain Site Characterization Project, 93:266 (R;US)

New three-dimensional far-field potential repository thermomechanical calculations: Yucca Mountain Site Characterization Project, 93:306 (R;US)

NORIA-SP: A finite element computer program for analyzing liquid water transport in porous media: Yucca Mountain Site Characterization Project, 93:255 (R;US)

Numerical methods for fluid flow in unsaturated heterogeneous tuff, 93:322 (R;US)

Numerical studies of rock-gas flow in Yucca Mountain: Yucca Mountain Site Characterization Project, 93:296 (R;US)
Over-the-road tests of nuclear materials package response to normal environments, 93:577 (R;US)

PACE-90 water and solute transport calculations for $0.01,0.1$, and $0.5 \mathrm{~mm} / \mathrm{yr}$ infiltration into Yucca Mountain: Yucca Mountain Site Characterization Project, 93:257 (R;US)

Performance prediction of mechanical excavators from linear cutter tests on Yucca Mountain welded tuffs: Yucca Mountain Site Characterization Project, 93:299 (R;US)

Performance predictions for mechanical excavators in Yucca Mountain tuffs: Yucca Mountain Site Characterization Project, 93:297 (R;US)

Pre-waste-emplacement ground-water travel time sensitivity and uncertainty analyses for Yucca Mountain, Nevada: Yucca Mountain Site Characterization Project, 93:305 (R;US)

Preclosure radiological safety analysis for accident conditions of the potential Yucca Mountain Repository: Underground facilities: Yucca Mountain Site Characterization Project, 93:234 (R;US)

Preclosure radiological safety analysis for the exploratory shaft facilities: Yucca Mountain Site Characterization Project, 93:246 (R; US)

Preclosure radiological safety evaluation: Exploratory Studies Facility: Yucca Mountain Site Characterization Project, 93:315 (R;US)

Preclosure seismic hazards and their impact on site suitability of Yucca Mountain, Nevada, 93:291 (R;US)

Prediction of Pseudo relative velocity response spectra at Yucca Mountain for underground nuclear explosions conducted in the Pahute Mesa testing area at the Nevada testing site: Yucca Mountain Site Characterization Project, 93:230 (R;US)

Preliminary characterization of materials for a reactive transport model validation experiment, $93: 334$ (R;US)

Preliminary drift design analyses for nuclear waste repository in tuff, 93:252 (R;US)

Preliminary mapping of surficial geology of Midway Valley Yucca Mountain Project, Nye County, Nevada: Yucca Mountain Site Characterization Project, 93:263 (R;US)

Preliminary numerical modeling for the G-Tunnel welded tuff mining experiment: Yucca Mountain site characterization project, 93:226 (R;US)

Probable maximum flood control: Yucca Mountain Site Characterization Project, 93:232 (R;US)

Procedure development study: Low strain rate and creep experiments: Yucca Mountain Site Characterization Project, 93:261 (R;US)

Processes, mechanisms, parameters, and modeling approaches for partially saturated flow in soil and rock media: Yucca Mountain Site Characterization Project, 93:233 (R;US)

Proposed sealing field tests for a potential high-level radioactive waste repository in unsaturated tuff, 93:286 (R;US)

Quantification of uncertain outcomes from site characterization: Insights from the ESF-AS, $93: 300$ (R;US)

Quasi-linear analysis of water flow in the unsaturated zone at Yucca Mountain, Nevada, USA, 93:258 (R;US)

Recent advances in methods for measuring the dynamic response of geological materials to $100 \mathrm{GPa}, 93: 294$ (R;US)

Recent characterization activities of Midway Valley as a potential repository surface facility site, 93:302 (R;US)

Recent developments in stochastic modeling and upscaling of hydrologic properties in tuff, 93:321 (R; US)

Research program to develop and validate conceptual models for flow and transport through unsaturated, fractured rock: Yucca Mountain Site Characterization Project, 93:253 (R;US)

Retrieval strategy report for a potential high-level nuclear waste repository: Yucca Mountain Site Characterization Project, 93:221 (R;US)

Review of radionuclide source terms used for performanceassessment analyses: Yucca Mountain Site Characterization Project, 93:317 (R;US)

Rock mass mechanical property estimations for the Yucca Mountain Site Characterization Project: Yucca Mountain Site Characterization Project, 93:304 (R;US)

Rock mass mechanical property estimation strategy for the Yucca Mountain Site Characterization Project, 93:329 (R;US) 
Scale dependence of effective media properties, 93:323 (R;US)

Scenario development for performance assessment: Some questions for the near-field modelers, 93:325 (R;US)

Seismic considerations in sealing a potential high-level radioactive waste repository, 93:309 (R;US)

Seismic design of circular-section concrete-lined underground openings: Preclosure performance considerations for the Yucca Mountain Site, 93:303 (R;US)

Sensitivity analyses for total-system performance assessment 93:319 (R; US)

Small-scale behavior of single gravity-driven fingers in an initially dry fracture, 93:326 (R;US)

Statistical analysis of hydrologic data for Yucca Mountain: Yucca Mountain Site Characterization Project, 93:220 (R;US)

Structure in continuously cored, deep drill holes at Yucca Mountain, Nevada, with notes on calcite occurrence: Yucca Mountain Site Characterization Project, 93:298 (R;US)

Summary and evaluation of existing geological and geophysical data near prospective surface facilities in Midway Valley, Yucca Mountain Project, Nye County, Nevada: Yucca Mountain Site Characterization Project, 93:254 (R;US)

Summary of the Exploratory Studies Facility Alternatives Study: Draft, 93:277 (R;US)

Supporting hydration calculations for small- to large-scale seal tests in unsaturated tuff, $93: 287$ (R;US)

Technical data base quarterly report, Aprit-June 1992: Yucca Mountain Site Characterization Project, 93:216 (R;US)

The hydrothermal stability of cement sealing materials in the potential Yucca Mountain high level nuclear waste repository, 93:292 (R;US)

The influence of strain rate and sample inhomogeneity on the moduli and strength of welded tuff, $93: 312$ (R;US)

The most likely groundwater flux through the unsaturated tuff matrix at USW H-1, 93:338 (R;US)

The results of near-field thermal and mechanical calculations of thermal loading schemes, 93:333 (R;US)

The use of sequential indicator simulation to characterize geostatistical uncertainty: Yucca Mountain Site Characterization Project, 93:264 (R;US)

TOSPAC calculations in support of the COVE 2A benchmarking activity: Yucca Mountain Site Characterization Project, 93:229 (R;US)

Total System Performance Assessment Code (TOSPAC): Volume 2, User's guide: Yucca Mountain Site Characterization Project, 93:217 (R;US)

Transportation cask decontamination and maintenance at the potential Yucca Mountain repository: Yucca Mountain Site characterization project, 93:247 (R;US)

Travel to France to attend and participate in the Technical Workshop on Near-Field Performance Assessment: Foreign trip report, May 9-16, 1993, 93:435 (R;US)

Travel to France to report on Waste Management projects at WIPP and Yucca Mountain: Foreign trip report, February 2-8, 1992, 93:434 (R;US)

TSPA 1991: An initial total-system performance assessment for Yucca Mountain: Yucca Mountain Site Characterization Project, 93:293 (R;US)

Uncertainty and sensitivity results for pre-waste-emplacement groundwater travel time, 93:272 (R;US)

Unconfined compression experiments on Topopah Spring Member tuff at $22^{\circ} \mathrm{C}$ and a strain rate of $10^{-9} \mathrm{~s}^{-1}$ : Data report: Yucca Mountain Site Characterization Project, $93: 310$ (R;US)

Use of the iterative solution method for coupled finite element and boundary element modeling: Yucca Mountain Site Characterization Project, 93:324 (R;US)

Use of Wingz spreadsheet as an interface to total-system performance assessment, 93:281 (R;US)

Waste package emplacement borehole option study: Yucca Mountain Site Characterization Project, 93:236 (R;US)

Wetted-region structure in horizontal unsaturated fractures: Water entry through the surrounding porous matrix, 93:283 (R;US)

Wetting front instability in an initially wet unsaturated fracture, 93:327 (R; US)
$X$-ray and visible light transmission as two-dimensional, full-field moisture-sensing techniques: A preliminary comparison, 93:279 (R;US)

Yucce Mountain Project thermal and mechanical codes first benchmark exercise: Part 3, Jointed rock mass analysis: Yucca Mountain Site Characterization Project, 93:241 (R;US)

Yucca Mountain Project total-system performance assessment preliminary analyses: Overview: Draft, $93: 284$ (R;US)

[Symposium for the STRIPA Project]: Foreign trip report, October 10-17, 1992, 93:433 (R;US)

Science Applications International Corp., Las Vegas, NV (United States)

Critical comments on the US Environmental Protection Agency Standards 40 CFR 191, $93: 7$ (R; US)

Current plans to characterize the design basis ground motion at the Yucca Mountain, Nevada Site, 93:4 (R;US)

Nevada commercial spent nuclear fuel transportation experience, 93:69 (R;US)

Report of early site suitability evaluation of the potential repository site at Yucca Mountain, Nevada: Yucca Mountain Site Characterization Project, 93:67 (R;US)

Report of the Peer Review Panel on the early site suitability evaluation of the Potential Repository Site at Yucca Mountain, Nevada: Yucca Mountain Site Characterization Project, 93:68 (R;US)

Technical data management at the Yucca Mountain Site Characterization Project, 93:2 (R;US)

South Carolina State Coll., Orangeburg, SC (United States)

Thermal impact on host rock of geologic repository: Final report, 93:18 (R;US)

Southern States Energy Board, Norcross, GA (United States)

Rail abandonments in the South and their effect on NWPA rail shipments, 93:431 (R;US)

Southwest Research Inst., San Antonio, TX (Uniled States). Center for Nuclear Weste Regulatory Analyses

A literature review of coupled thermal-hydrologic-mechanicalchemical processes pertinent to the proposed high-level nuclear waste repository at Yucca Mountain, 93:537 (R;US)

A survey of hydrothermal modeling related to Yucca Mountain, 93:524 (RA:US)

Apache leap watershed study, 93:516 (RA;US)

Characterization of rock hydrologic properties using model verification, 93:519 (RA;US)

Does the wind blow through Yucca Mountain?, 93:366 (RA;US)

Evaluation of tracers for hydrologic studies at Yucca Mountain, 93:526 (RA;US)

Field testing the effectiveness of pumping to remove sulfur hexafluoride traced drilling air from a prototype borehole near superior, Arizona, 93:518 (RA;US)

Flow through nonhomogeneous porous media, 93:525 (RA;US)

Ground water flow through unsaturated fractured rock research needs, 93:521 (RA:US)

Hydrogeologic issues at Yucca Mountain: Findings of a DOE peer review team, 93:513 (RA;US)

Modeling hydrothermal flow in variably saturated, fractured welded tuff during the prototype engineered barrier system field test of the Yucca Mountain Project, 93:523 (RA;US)

Nonequilibrium fracture-matrix flow during episodic infiltration events in Yucca Mountain, 93:514 (RA;US)

Nonisothermal hydrologic transport study at the Apache Leap Tuff site, 93:515 (RA:US)

Numerical and laboratory investigations of transient and steadystate flow in a fractured core, 93:520 (RA;US)

Pneumatic permeability measurements in a fractured, partially saturated environment, 93:517 (RA; US)

Regional groundwater modeling of the saturated zone in the vicinity of Yucca Mountain, Nevada: Iterative Performance Assessment, Phase 2, 93:535 (R;US)

Sensitivity and uncertainty analyses applied to one-dimensional radionuclide transport in a layered fractured rock: MULTFRAC Analytic solutions and local sensitivities: Phase 2, Iterative performance assessment: Volume 1, 93:536 (R;US)

Technical issues related to groundwater flow and radionuclide transport in unsaturated fractured rock, 93:368 (RA;US) 
The composition and $\mathrm{CO}_{2}$ carbon isotope signature of gases from borehole USW UZ-6, Yucca Mountain, Nevada, 93:367 (RA;US)

Use of a submersible pressure outflow cell for determination of moisture characteristic curves on rock core, 93:522 (RA;US)

Spectra Research Inst., Albuquerque, NM (United States)

TOSPAC calculations in support of the COVE $2 A$ benchmarking activity: Yucca Mountain Site Characterization Project, 93:229 (R;US)

Stantord Univ., CA (United States). Dept. of Civil Engineering

Neptunium( $V$ ) sorption on quart and albite in aqueous suspension: Annual progress report, $93: 495$ (R;US)

Stephens (Daniel B.) and Associates, Inc., Albuquerque, NM (United States)

Laboratory analysis of hydraulic properties of volcanic tuff samples, 93:492 (R;US)

Swedish Nuclear Fuel and Waste Management Co., Stockholm (Sweden)

Chemical and isotopic composition of groundwaters and their seasonal variability at the OSAMU Utsumi mine and Morro do Ferro analogue study sites, Pocos de Caldas, Brazil: Pocos do Catdas Report No. 6, 93:584 (R;SE)

Geomorphological and hydrogeological features of the Pocos de Caldas caldera and the Osamu Utsumi mine and Morro do Ferro analogue study sites, Brazil: Pocos de Caldas Report No. 5, 93:583 (R;SE)

Microbiological analysis at the Osamu Utsumi mine and Morro do Ferro analogue study sites, Pocos de Caldas, Brazil: Pocos de Caldas Report No. 10, $93: 585$ (R;SE)

Near-field high-temperature transport: Evidence from the genesis of the Osamu Utsumi uranium mine, Pocos de Caldas alkaline complex, Brazil: Pocos de Caldas Report No. 13, 93:586 (R;SE)

Performance assessment perspectives with reference to the proposed repository at Yucca Mountain, Nevada, 93:587 (RA;SE)

Solubility and speciation studies for nuclear repository performance assessment, 93:158 (RA;SE)

Swedish Nuclear Power Inspectorate, Stockholm (Sweden)

The International INTRAVAL project. Phase 1 case 8: The Alligator rivers natural analogue, $93: 473(\mathrm{R} ; \mathrm{XN})$

\section{$\mathbf{T}$}

Tennesse Safe Growth Team, Nashville, TN (United States)

Monitored retrievable storage of spent nuclear fuel: Transportation studies: Draft, 93:448 (R; US)

Tennessee Univ., Knoxville, TN (United States). Transportation Center

Monitored retrievable storage of spent nuclear fuel: Transportation studies: Draft, 93:448 (R;US)

Terra Tek, Inc., Salt Lake City, UT (United States)

Characterization of flow in fractured tuff using computerized tomography, 93:491 (R;US)

Texas Univ., EI Paso, TX (United States)

Boron adsorption on hematite and clinoptilolite, 93:490 (R;US)

Summary report on the evaluation of a 1977-1985 edited sorption data base for isotherm modeling, $93: 113$ (R;US)

\section{$\mathbf{U}$}

URS/John A. Blume and Assoclates, Engineers, San Francisco, CA (United States)

Processed seismic motion records from Little Skull Mountain, Nevada earthquake of June 29, 1992, recorded at stations in southern Nevada, $93: 474$ (R;US)

Processed seismic motion records from Little Skull Mountain Nevada earthquake aftershocks of July 5, 1992 and September 13, 1992, recorded at seismic stations in southern Nevada, 93:475 (R;US)

USDOE Office of Civilian Radioactive Waste Management, Washington, DC (Unlted States)

1991 OCRWM bulletin compilation and index, 93:456 (R;US)

Annual report to Congress, 93:454 (R;US)
Annual report to Congress, FY 1992, $93: 460$ (R;US)

DOE's Yucca Mountain studies: What are they? Why are they being done?, 93:24 (R;US)

Office of Civilian Radioactive Waste Management Program Cost and Schedule Baseline: Revision 3, 93:450 (R;US)

Program cost and schedule baseline: Revision 2, 93:449 (R;US)

Progress report on the scientific investigation program for the Nevada Yucca Mountain Site, October 1, 1991-March 31, 1992 Number 6, $93: 27$ (R;US)

Quarterly report on program cost and schedule: Second quarter FY 1992, 93:457 (R;US)

Quarterly report on program cost and schedule, third quarter FY 1992, $93: 458$ (R;US)

Quarterly report on program cost and schedule, fourth quarter $F Y$ 1992, $93: 459$ (R;US)

Site characterization progress report: Yucca Mountain, Nevada, October 1, 1990-March 31, 1991: Number 4, $93: 25$ (R;US)

Site characterization progress report: Yucca Mountain, Nevada, April 1, 1991-September 30, 1991, Number 5: Nuclear Waste Policy Act (Section 113), 93:26 (R;US)

Site characterization progress report: Yucca Mountain, Novada, April 1, 1992-September 30, 1992, Number 7, 93:28 (R;US)

Site characterization progress report: Yucca Mountain, Nevada, October 1, 1992-March 31, 1993, No. 8, $93: 31$ (R;US)

Strategic principles workshops: Discussion drafts and workshop notes, $93: 453$ (R;US)

US Department of Energy Office of Civilian Radioactive Waste Management quarterly report on program cost and schedule: First quarter, FY 1992, 93:455 (R;US)

USDOE Office of Civilian Radioactive Waste Management quarterly report on program cost and schedule: Fourth Quarter, FY 1991, 93:452 (R;US)

Waste Management System Requirements Document: Volume 4 MGDs, Revision 2, $93: 451$ (R;US)

Yucca Mountain Site Characterization Project Plan, $93: 29$ (R;US)

USDOE Office of Civilian Radioactive Waste Management, Washington, DC (United States). Education and Information Div.

DOE's Yucca Mountain studies, 93:30 (R;US)

USDOE Office of Sclentific and Technical Information, Oak Ridge, TN (United States)

Yucca Mountain Site characterization project bibliography, January-June 1992: An Update: Supplement 3, Addendum 1, 93:21 (R:US)

Yucca Mountain Site Characterization Project bibliography, JulyDecember 1992: An update, Supplement 3, Addendum 2: Civilian Radioactive Waste Management Program, 93:22 (R;US)

Yucca Mountain Site characterization project bibliography, January-June 1991: An Update: Supplement 2, Addendum 3 , 93:19 (R;US)

Yucca Mountain Site Characterization Project bibliography, January-June 1991: Supplement 3, 93:20 (R;US)

USDOE Yucca Mountain Site Characterization Project Office, Las Vegas, NV (United States)

DOE's Yucca Mountain studies, 93:30 (R;US)

Nevada commercial spent nuclear fuel transportation experience, 93:69 (R;US)

The Nevada railroad system: Physical, operational, and accident characteristics, $93: 70$ (R;US)

Yucca Mountain Site Characterization Project Technical Data Catalog: Yucca Mountain Site Characterization Project, 93:6 (R;US)

Yucca Mountain Site Characterization Project: Technical data catalog.(quarterly supplement), 93:32 (R;US)

Yucca Mountain Site Characterization Project Technical Data Catalog (quarterly supplement), 93:33 (R;US)

Yucca Mountain Site Characterization Project technical data catalog: Yucca Mountain Site Characterization Project, 93:101 (R;US)

Yucca Mountain Site Characterization Project Technical Data Catalog, $93: 23$ (R;US) 


\section{V}

Vanderbilt Univ., Nashville, TN (United States). Dept. of Civil and Environmental Engineering

Monitored retrievable storage of spent nuclear fuel: Transportation studies: Draft, $93: 448$ (R;US)

\section{W}

Westinghouse Idaho Nuclear Co., Inc., Idaho Falls, ID (United States)

Criticality safety issues associated with the burial of highly enriched nuclear fuel in a geologic repository, 93:596 (R;US)
Westinghouse Savannah River Co., Aiken, SC (United States) Code requirements for concrete repository and processing facilities, 93:598 (R;US)

Durability study of sodium borosilicate glasses leached in tuff $\mathrm{J}-13$ groundwater, 93:597 (R;US)

Facts and issues of direct disposal of spent fuel: Revision 1, 93:599 (R;US) 


\title{
Personal Author Index
}

\begin{abstract}
Authors' surnames are indexed in the form appearing in the publication cited; given names generally have been reduced to initials. For documents with multiple authors, each author name is indexed. The entry for a primary author (first author listed on an abstracted document) includes the full document title and citation number. Entries for other authors provide a cross-reference to the primany author. Also included is information on the document type, country of publication, and the document language listed in parentheses in the format (J;FR;in French and English). Accent marks are not input because of computer alphabetization. Spelling and transliteration follow standard conventions.
\end{abstract}

\section{A}

Abrams, C., See Daudt, C.R., 93:615

Ahola, M., Regional groundwater modeling of the saturated zone in the vicinity of Yucca Mountain, Nevada: Iterative Performance Assessment, Phase 2, 93:535 (R;US)

Ahola, M.P., See Chowdhury, A.H., 93:424

See Manteufel, R.D., 93:537

Alexander, D.H., Natural analogue studies useful in validating regulatory compliance analyses, 93:644 (BA;FR)

Aljohani, M.S., See Erwin, C.S., 93:638

Allan, J., Yucca Mountain Exploratory Studies Facilities: Construction status: Extended summary, 93:100 (R;US)

Allison, T., Methodologies for selecting industries for regions and communities: A critical evaluation of the Las Vegas target in dustry analysis, 93:416 (R;US)

Socioeconomic assessment guidance report: Determining the effects of amenity characteristics on business location decisions, 93:415 (R; US)

The role of amenities and other factors in influencing the location of nonmanufacturing industry in the United States, 93:414 (R;US)

See Calzonetti, F.J., 93:417

Altenhofen, M.K., Thermal analysis of Yucca Mountain commercial high-level waste packages, 93:156 (R;US)

See Engel, D.W., 98:157

Amadei, B., See Wibowo, J., 93:311, 93:314

Amter, S., See Ross, B., 93:296

Ananda, M.M.A., Reliability modeling of an engineered barrier system, 93:429 (R;US)

Anderson, D.R., Travel to France to report on Waste Management projects at WIPP and Yucca Mountain: Foreign trip report, February 2-8, 1992, 93:434 (R;US)

Anderson, H.J. Ill, Nevada Nuclear Waste Study Committee: Combating anti-repository-study sentiment, 93:684 (J;US)

Anderson, l., Apache leap watershed study, 93:516 (RA;US)

Anderson, J.G., Preliminary report: The Little Skull Mountain earthquake, June 29, 1992, 93:365 (BA;US)

Anderson, L.A., Results of rock property measurements made on core samples from Yucca Mountain boreholes, Nevada Test Site, Nevada: Part 1, Boreholes UE25A-4, -5, -6, and -7; Part 2 , Borehole UE25PNo.1, 93:373 (R;US)

Anderton, S., See Kwicklis, E.M., 93:520

Andrews, H.R., See Cornett, R.J., 93:631

Andrews, W.B., See Younker, J.L., 93:67

Andricevic, R., See Daniels, J.I., 93:592

Angell, M.M., See Gibson, J.D., 93:254

See Wesling, J.R., 93:263

Ango, A.M., Okelobondo Uranium deposit: Regional context, stratigraphy, sedimentology, tectonic and mineralization, 93:465 (RA;XE;in French)

Anspaugh, L.R., See Daniels, J.I., 93:592

Apted, M.J., Preliminary calculations of release rates of Tc-99, 1129 , and $\mathrm{Np}-237$ from spent fuel in a potential repository in tuff, 93:49 (R;US)

Armstrong, G.R., See Daling, P.M., 93:576

Arredondo, A., See Stuckless, J.S., 93:368
Asgian, M.I., Documentation and verification of STRES3D, Version 4.0: Yucca Mountain Site Characterization Project, 93:250 (R;US)

\section{$\mathbf{B}$}

Bai, M., See Hardy, M.P., 93:306

Bakhtiar, S.N., Thorium-230 chronology of natural waters at the Nevada test site, 93:642 (BA;US)

Baldwin, D.L., See Guenther, R.J., 93:209

Ballou, L.B., See Younker, J.L., 93:67

Bando, A., See Edwards, B., 93:409, 93:626

Bardakci, T., Diffusion of carbon dioxide and iodine through Yucca Mountain tuffs: Effects of temperature and moisture content, 93:635 (BA:US)

Bardakci, Tevfik, Temperature effect on diffusion of carbon dioxide through upper layers of Yucca Mountain, 93:675 (J;GB)

Barker, L.E., See Lindstrom, F.T., 93:428

Barnard, R.W. Analysis of releases due to drilling at the potential Yucca Mountain repository, 93:336 (R;US)

Performance-assessment comparisons for a repository containing

LWR spent fuel or partitioned/transmutted nuclear waste, 93:351 (BA;US)

Review of radionuclide source terms used for performanceassessment analyses: Yucca Mountain Site Characterization Project, 93:317 (R;US)

Travel to France to attend and participate in the Technical Workshop on Near-Field Performance Assessment: Foreign trip report, May 2 16. 1993, 93:435 (R;US)

TSPA 1991; An initial total-system performance assessment for Yucca Mountain: Yucca Mountain Site Characterization Project, 93:293 (R;US)

Yucca Mountain Project total-system performance assessment preliminary analyses: Overview: Draft, 93:284 (R;US)

Yucca Mountain project total-system performance assessment preliminary analyses: Overview, 93:347 (BA;US)

See Barr, G.E., 93:325

See Dykhuizen, R.C., 93:244

Barr, G.E., A working definition of scenario and a method of scenario construction, 93:331 (R;US)

Scenario development for performance assessment: Some questions for the near-field modelers, 93:325 (R;US)

[Symposium for the STRIPA Project]: Foreign trip report, October 10-17, 1992, 93:433 (R;US)

See Carrigan, C.R., 93:163, 93:211

Bartlett, J., See Gertz, C.P., 93:29

Bartlett, J.W., Technical evaluations necessary for determining site suitability for a high-level waste repository, 93:420 (BA;US)

Basset, G., See Edwards, B., 93:626

Bassett, G., Seө Edwards, B., 93:409

Bassett, G.W. Jr., Should high-level nuclear waste be disposed of at geographically dispersed sites?, $93: 412$ (R;US)

See Hemphill, R.C., 93:410, 98:413, 93:617

Bates, J.K., ANL Technical Support Program for DOE Environmental Restoration and Waste Management: Annual report, October 1990-September 1991, $93: 402$ (R;US) 
ANL technical support program for DOE Environmental Restoration and Waste Management: Annual report, October 1991-September 1992, $93: 405$ (R;US)

See Ebert, W.L., 93:406

See Finn, P.A., $93: 408$

See Woodland, A.B., 93:143

See Wronkiewicz, D.J., $93: 407$

Bauer, L.R., Gas phase migration of C-14 through barrier materials applicable for use in a high-level nuclear waste repository located in tuff, $93: 647$ (1;US)

Bauer, S.J., Fault stress analysis for the Yucca Mountain Site Characterization Project, 93:278 (R;US)

Fault stress analysis for the Yucca Mountain site characterization project, 93:355 (BA;US)

See Costin, L.S., 93:240, 93:241

See Hardy, M.P., 93:213, 93:237, 93:252, 93:306

See Johnson, R.L., 93:226

See Lin, M., 93:304, 93:329

Beavers, J.A., Stress-corrosion-cracking studies on candidate container alloys for the Tuff Repository, 93:533 (R;US)

See Thompson, N.G., 93:532

Beccue, P.C., See Boyle, W.J., 93:300, 93:343

Beck, D.A., See Pabst, M.E., 93:389

Beckett, J., GENISES: A GIS Database for the Yucca Mountain Site Characterization Project, 93:1 (R;US)

Beckman, R.J., See Polzer, W.L., 93:113, 93:672

Becraft, K., See Nitsche, H., 93:55, 93:97

Behl, Y.K., See Sandoval, R.P., 93:276, 93:350

Bellman, R.A. Jr., See Zimmerman, R.M., 93:222, 93:225, $93: 227$

Bennett, T.J., Estimation of near-regional seismic ground motion from underground nuclear explosion tests, 93:423 (BA;US)

Bergman, S.C., See Foland, K.A., 93:640

Bhattacharyya, K.K., Tunnel boring machine applications: Yucca Mountain Exploratory Studies Facility, 93:81 (BA;US)

Biffle, J.H., JAC3D - A three-dimensional finite element computer program for the nonlinear quasi-static response of solids with the conjugate gradient method: Yucca Mountain Site Characterization Project, 93:219 (R:US)

Bingham, F.W., is it possible to demonstrate compliance with the regulations for high-level-waste repositories?, 93:316 (R;US)

See Barnard, R.W., 93:293

Birdsell, K.H., Sensitivity analysis of integrated radionuclide transport based on a three-dimensional geochemicalgeophysical model, 93:485 (RA;US)

See Triay, I.R., $93: 129$

Bish, D., See Carlos, B., 93:134

Bish, D.L., See Chipera, S.J., 93:133

See Vaniman, D.T., 93:132

See WoldeGabriel, G., 93:121

Bixler, N.E., See Carrigan, C.R., 93:211

See Hopkins, P.L., 93:255

Blahnik, D.E., See Guenther, R.J., 93:151, 93:152, 93:209

Blair, J.A., Using seals to control flow at Yucca Mountain, 93:630 (BA;US)

Blanc, P.L., Hydrogeology and migration in the remote field, 93:419 (R;FR;In French)

See Chapuis, A.M., 93:464

Blanchard, M.B., US Department of Energy issue resolution process, 93:80 (BA;US)

See Dobson, D.C. $93: 99$

See Voegele, M.D., $93: 72$

Blejwas, T.E., See Richardson, A.M., 93:214, 93:303

Blink, J.A., See Ruffner, D.J., $93: 193$

Bodvarsson, G.S., See Niemi, A., 93:37, 93:38, 93:39

See Wittwer, C.S., 93:53, 93:74

Se日 Zimmerman, R.W., 93:46, 93:54, 93:56

Bolivar, S.L., The quality assurance liaison: Combined iechnical and quality assurance support, $93: 130$ (R;US)

Boughton, C.J., See Kwicklis, E.M., 93:520

Bourcier, B., See Viani, B., 93:149

Bourcier, W.L., See Bates, J.K., 93:402, 93:405

Bouton, E.H., High-level nuclear waste disposal: Policy and prognosis. Research report, August 1991-April 1992, $93: 400$ (R;US)
Bowlby, W., See Bronzini, M.S., 93:448

Bowman, R.S., Evaluation of potential hydrologic tracers in tuffs from Yucca Mountain, Nevada, 93:487 (RA;US)

Evaluation of tracers for hydrologic studies at Yucca Mountain, 93:526 (RA;US)

Boyd, P.J., See Martin, R.J. III, 93:261, 93:268, 93:310, 93:312

See Price, R.H., 93:313

Boyle, W.J., Quantification of uncertain outcomes from site characterization: Insights from the ESF-AS, 93:300 (R;US)

Quantification of uncertain outcomes from site characterization: Insights from the ESF-AS, 93:343 (BA;US)

Bradley, C.R., See Bates, J.K., 93:402, 93:405

Brechtel, C.E., See Costin, L.S., 93:335

See Hardy, M.P., 93:252

See Lin, M., 93:329

See Pott, J., 93:330

Brickey, D.W., Three dimensional visualization in support of Yucca Mountain Site characterization activities, 93:34 (R;US)

Brikowski, T.H., Estimates of potential radionuclide migration at the Bullion site, $93: 443$ (R;US)

Brocher, T.M., Seismic reflection profiling across Tertiary extensional structures in the eastern Amargosa Desert, southern Nevada, Basin and Range province, 93:398 (J;US)

Brogan, G.E., Late quaternary faulting along the Death ValleyFurnace Creek fault system, California and Nevada, 93:369 (R;US)

Bronzini, M.S., Monitored retrievable storage of spent nuclear fuel: Transportation studies: Draft, 93:448 (R;US)

Bros, R., Occurrence of naturally enriched ${ }^{235} \mathrm{U}$ : Implications for plutonium behavior in natural environments, 93:656 (J;US)

Brown, J., See Niemeyer, S., 93:590

Brown, R.M., See Cornett, R.J., 93:631

Brown, S.R., See Jung, J., 93:271

Broxton, D.E., Chemical changes associated with zeolitization of the tuffaceous beds of Calico Hills at Yucca Mountain, Nevada, 93:123 (R;US)

Geologic evaluation of six nonwelded tuff sites in the vicinity of

Yucca Mountain, Nevada for a surface-based test facility for the Yucca Mountain Project, 93:108 (R;US)

See WoldeGabriel, G., 93:121

Brune, J.N., See Anderson, J.G., 93:365

Bruno, J., Testing of geochemical models in the Pocos de Caldas analogue study, $93: 507(\mathrm{R} ; \mathrm{CH})$

Bruton, C., See Viani, B., 93:149

Bruton, C.J., See Viani, B.E., 93:168, 93:190

Bryant, C., See Siegel, M.D., 93:334

Bryant, E.A., Colloid research for the Nevada Test Site, 93:478 (R;US)

Buchholtz-ten Brink, M., Sorption and porosity heterogeneity: Effects on radionuclide transport, 93:479 (RA;US)

Buck, E.C., See Bates, J.K., 93:402, 93:405

See Ebert, W.L., 93:406

See Finn, P.A., 93:408

Bute, C.G., See Harmsen, S.C., 93:379

Bultard, T.F., See Gibson, J.D., 93:254, 93:302

See Wesling, J.R., 93:263

Bullen, D.B., Engineered barrier system failure modeling: A statistical approach, 93:613 (BA;US)

See Erwin, C.S., 93:638

Bullock, R.L., See DeKlever, R.C., 93:95

Bullock, R.L. Sr., Design considerations for the Yucca Mountain project exploratory shaft facility, $93: 91$ (BA;US)

Burkhardt, D.J., See Luckey, R.R., 93:378

Burnison, S., See Knox, E., 93:627

Burns, R.G., Sorption of cesium and strontium by zeolite single crystals, 93:481 (RA;US)

Burns, W., See Flynn, J., 93:554

Buscheck, T.A., Large-scale in situ heater tests for hydrothermal characterization at Yucca Mountain, 93:195 (R;US)

Modeling hydrothermal flow in variably saturated, fractured, welded tuff during the prototype engineered barrier system field test of the Yucca Mountain Project, 93:523 (RA;US) 
Nonequilibrium fracture-matrix flow during episodic infiltration events in Yucca Mountain, 93:514 (RA;US)

The analysis of repository-heat-driven hydrothermal flow at Yucca Mountain, 93:194 (R;US)

The impact of episodic nonequilibrium fracture-matrix flow on gea logical repository performance, $93: 182$ (R;US)

The impact of episodic nonequilibrium fracture-matrix flow on repository performance at the potential Yucca Mountain site, 93:185 (R;US)

The impact of thermal loading on repository performance at Yucca Mountain, 93:189 (R;US)

The impact of thermal loading on repository performance at Yucca Mountain, 98:205 (BA;US)

See Danko, G., 93:196

See Nitao, J.J., 93:187, 93:204

See Ramirez, A.L., 93:162

Buxbaum, M.E., AREST user's guide, PC version, $98: 154$ (R;US)

Byers, F.M. Jr., See Broxton, D.E., 93:108

Byrne, J., See Lentell, R.L., 98:427

Calzonetti, F.J., Empirical investigation of the effect of amenities and other factors on business location decisions, 93:417 (R;US)

See Allison, T., 93:414

Campbell, K., See Birdsell, K.H., 93:485

Campbell, T.K., See Guenther, R.J., $93: 152$

Canepa, J.A., Proceedings of the DOEYucca Mountain Site Characterization Project Radionuclide Adsorption Workshop at Los Alamos National Laboratory, September 11-12, 1990, 93:104 (R;US)

Cardle, J, See Trabia, MB, 93:12

Carlisle, S., See Hardy, M.P., 93:306

Carlos, B., Distribution and chemistry of fracture-lining zeolites at Yucca Mountain, Nevada, 93:134 (R;US)

Carlos, B.A., See Chipera, S.J., 93:133

Carison, J., See Edwards, B., 93:409, 93:626

Carison, R., See Ramirez, A.L., 93:162

Carnahan, C.L., See Wang, J.S.Y., 93:58

Carns, D.E., See Conary, J.S., $93: 430$

Carpenter, S.A., See Nitsche, H., $93: 55$

Carr, M.D., See Brocher, T.M., 93:398

Carr, W.J., Structure in continuously cored, deep drill holes at Yucca Mountain, Nevada, with notes on calcite occurrence: Yucca Mountain Site Characterization Project, 93:298 (R;US)

Carrigan, C.R., A scoping study of water table excursions induced by seismic and volcanic events, $93: 163$ (R;US)

Potential for water-table excursions induced by seismic events at

Yucca Mountain, Nevada, 93:211 (J;US)

Carroll, R.D., A portable vacuum hammer seismic source for use in tunnel environments, 93:595 (R;US)

Carter, L.F., See Freudenburg, W.R., 93:555

Carter, L.J., Nuclear waste policy and politics, $93: 689$ (J;US)

Case, J.B., Supporting hydration calculations for small- to largescale seal tests in unsaturated tuff, $93: 287$ (R;US)

See Fernandez, J.A., 93:286, 93:307, 93:356

See Tyburski, J.R., 93:357

Case, R.S., Intemational safeguards concepts for the Yucca Mountain Geological Repository, 93:685 (J;US)

Caskey, S.J., Mesozoic and Cenozoic structural geology of the CP Hills, Nevada Test Site, Nye County, Nevada; and regional implications, $93: 569$ (R;US)

Cathles, L.M., Near-field high-temperature transport: Evidence from the genesis of the Osamu Utsumi uranium mine, Pocos de Caldas alkaline complex, Brazil: Pocos de Caldas Report No. 13 93:586 (R;SE)

Cawlfield, D.E., See Lindstrom, F.T., 93:428

Cerling, T.E., See Quade, J., 93:686

Chalmers, J., See Slovic, P., 93:673

Chamberlain, A.K., Yucca Mountain, a high-level nuclear waste repository over a billion barrel oil field?, 93:677 (J;US)

Chamberlain, P.J. Il, See Eslinger, P.W., 93:153
Chambers, W.F., Use of Wingz spreadsheet as an interface to totalsystem performance assessment, 93:281 (R;US)

Use of Wingz spreadsheet as an interface to total-system performance assessment, 93:340 (BA;US)

Chambre, P.L., See Lee, W.W.L., 93:48

See Zwahlen, E.D., 93:40

Champagne, D.L., See Shepard, N.F., 93:618

Champion, D., See Turrin, B.D., 93:399

Chan, P., See Polzer, W.L., 93:113

Chang, S., See Gardner, J.N., 93:488

Channell, J., Reasonableness of human intrusion provisions in EPA's HLW standard, 93:463 (RA;US)

Chant, L.A., See Cornett, R.J., 93:631

Chapman, J.B., Groundwater chemistry at the Nevada Test Site: Data and preliminary interpretations, $93: 444$ (R;US)

See Lyles, B.F., $93: 441$

Chapman, N., The International INTRAVAL project. Phase 1, case 7. The Pocos de Caldas natural analogue: studies of redox front movement, $93: 472(\mathrm{R} ; \mathrm{XN})$

Chapman, N.A., The Pocos de Caldas project: summary and implications for radioactive waste management: Pocos de Caldas report no. $15,93: 510(\mathrm{R} ; \mathrm{CH})$

Chapuis, A.M., Oklo - natural analogue for transfer processes in a geological repository: present status of the programme, $93: 464$ (RA;XE)

Chen, E.P., Analysis of slot cutting methods for the Yucca Mountain heated block test using a compliant-joint model, 93:270 (R;US)

Cheng, W.C., See Siegel, M.D., 93:334

Chesnut, D.A., Characterizing the altered zone at Yucca Mountain: The beginning of a testing strategy, 93:188 (R;US)

Characterizing the altered zone at Yucca Mountain: The beginning of a testing strategy, 93:206 (BA;US)

Demands placed on waste package performance testing and modeling by some general results on reliability analysis, $93: 181$ (R;US)

Physical limits on steam generation by radioactive decay heat, 93:165 (R;US)

See Buscheck, T.A., 93:185

See Nitao, J.J., 93:187, 93:204

Chestnut, D.A., See Buscheck, T.A., 93:182

Chipere, S., See Carlos, B., 93:134

Chipera, S.J., Equilibrium modeling of the formation of zeolites in fractures at Yucca Mountain, Nevada, $93: 133$ (R;US)

See Broxton, D.E., 93:108

See WoldeGabriel, G., 93:121

Chocas, C.S., See Schwartz, B.M., 93:228

See Siegel, M.D., 93:334

Choi, J.S., See Lee, W.W.L., 93:51, 93:207

Chornack, M.P., See Rautman, C.A., 93:318

See Wittwer, C.S., 93:53, 93:74

Chowdhury, A.H., Options for dynamic analyses of underground facilities, 93:424 (BA;US)

See Manteufel, R.D., 93:537

Christy, R.P., See Gertz, C.P., 93:90

Chuchel, B.A., TURBOSEIS-An interactive program for constructing and editing models of seismic refraction traveltime data using a color-graphics terminal, 93:371 (R;US)

Clarke, W., See Russell, E.W., 93:161

Clarke, W.L., See Henshall, G.A., 93:169

Clarke, W.L. Jr., See Van Konynenburg, R.A., $93: 172$

Cleary, R., Does multiple land use work - the Ranger example, 93:654 (J;AU)

Cline, K.M., See Simecka, W.B., 93:3, 93:4

Coates, G., See Dombrowski, T., 93:84

Codell, R., Initial demonstration of the NRC's capability to conduct a performance assessment for a High-Level Waste Repository, 93:512 (R;US)

Codell, R.A., See Gureghian, A.B., 93:536

Conary, J.S., Word images as policy instruments: Lessons from the Yucca Mountain Controversey, 93:430 (R;US)

Conca, J., Transport in unsaturated flow systems using centrifuge techniques, 93:483 (RA;US)

Connelly, M.P., See Rockhold, M.L., 93:62 
Connolly, J.R., Mineralogy, petrology and whole-rock chemistry of selected mechanical test samples of Yucca Mountain tuffs: Yucca Mountain Site Characterization Project, 93:259 (R;US)

Mineralogy, petrology and whole-rock chemistry data compilation for selected samples of Yucca Mountain tuffs: Yucca Mountain Site Characterization Project, 93:295 (R;US)

Conrardy, C.C., See Domian, H.A., 93:186

Cook, N.G.W., See Wang, J.S.Y., 93:58

Cooper, B.S., Focus shifts from capital to Nevada, $93: 690$ (J;US)

Cooper, C.A., Numerical simulation of gas flow through unsaturated fractured rock at Yucca Mountain, Nevada, $93: 567$ (R;US)

Cooper, E.N., Community Radiation Monitoring Program: Annual report, October 1, 1990-September 30, 1991, $93: 442$ (R;US)

Cope, C.M., See Whitfield, M.S. Jr., 93:382

Coppersmith, K.J., Modeling fault rupture hazard for the proposed repository at Yucca Mountain, Nevada, 93:629 (BA;US)

Cornett, R.J., ${ }^{36} \mathrm{Cl}$ production in situ, and groundwater transport in a uranium ore deposit, 93:631 (BA;US)

Costin, L.S., An approach to validation of thermomechanical models, 93:335 (R;US)

Application of analytical methods for jointed rock as part of a drift design methodology for the Yucca Mountain Project, 93:240 (R;US)

Summary of the Exploratory Studies Facility Alternatives Study: Draft, $93: 277$ (R;US)

Summary of the exploratory studies facility alternative study, 93:341 (BA;US)

Yucca Mountain Project thermal and mechanical codes first benchmark exercise: Part 3, Jointed rock mass analysis: Yucca Mountain Site Characterization Project, 93:241 (R;US)

See Chen, E.P., 93:270

See Fewell, M.E., 93:288, 93:344

Couch, S.R., See Freudenburg, W.R., 93:555

Coutinho de Jesus, H., See Miekeley, N., 93:505, 93:506

Cox, B.L., Single fracture aperture patterns: Characterization by slitisland fractal analysis, $93: 59$ (R;US)

Craig, R.W., Geohydrology of rocks penetrated by test well USW H6, Yucca Mountain, Nye County, Nevada, 93:390 (R;US)

Cramer, J., See Cornett, R.J., 93:631

Cross, J.E., Testing models of redox front migration and geochemistry at the Osamu Utsumi mine and Morro do Ferro analogue study sites, Pocos de Caldas, Brazil, 93:508 (R;CH)

See Bruno, J., 93:507

Cross-Smiecinski, A.J., UNS YMSCP QA support task: Quarterly technical progress report, January 1, 1991-June 30, 1991, 93:11 (R;US)

Crouthamel, D.R., Pressurized grout applications in fractured tuff for containment of radioactive wastes, 93:676 (J;GB)

Crowe, B., The Lathrop Wells volcanic center: Status of field and geochronology studies, 93:112 (R;US)

The Lathrop Wells volcanic center: Status of field and geochronology studies, 93:122 (R;US)

The Lathrop Wells volcanic center: Status of field and geochronology studies, 93:137 (BA;US)

See Wells, S., 93:668

Crowe, B.M., Recurrence models of volcanic events: Applications to volcanic risk assessment, 93:120 (R;US)

Simulation modeling of the probability of magmatic disruption of the potential Yucca Mountain Site, 93:136 (R;US)

See Perry, F.V., 93:119, 93:140

See Picard, R., $93: 139$

See Valentine, G.A., 93:117, 93:135, 93:138

See Wells, S.G., 93:665

Cunnane, J.C., See Bates, J.K., 93:402, 93:405

Cunnane, M., See Kossik, R., 93:633 -

Curtis, D.B., Two-billion-year-old nuclear reactors: Nature goes fission, 93:669 (J;US)

See MacKenzie, A.B., 93:504

Czarnecki, J.B., Does localized recharge occur at a discharge area within the ground-water flow system of Yucca Mountain, Nevada?, 93:362 (R;US)

Simulated water-level declines caused by withdrawals from wells $J$ -

13 and J-12 near Yucca Mountain, Nevada, 93:377 (R;US)
Daemen, J.J.K., See Crouthamel, D.R., 93:676

See Fuenkajorn, K., 93:531

See Ouyang, S., 93:530

Daffern, D.D., See Lindstrom, F.T., 93:428

Daily, W., See Ramirez, A.L., 93:162

Daling, P.M., Preliminary characterization of risks in the nuclear waste management system based on information in the literature, 93:576 (R;US)

Daniels, J.I., Risk-based screening analysis of ground water contaminated by radionuclides introduced at the Nevada Test Site (NTS), $93: 592$ (R;US)

Danko, G., Single-hole in situ thermal probe for hydrothermal characterization at Yucca Mountain, 93:196 (R;US)

Dash, Z., See Zyvoloski, G., 93:103

Daudt, C.R., Yucca Mountain digital database, 93:615 (BA;US)

Daveler, S.A., EQPT, a data file preprocessor for the EQ3/6 software package: User's guide and related documentation (Version 7.0): Part 2, 93:201 (R;US)

See Wolery, T.J., 93:203

Davies, W.G., See Cornett, R.J., 93:631

Davis, D.W., See Mossman, D.J., 93:650

Davis, E.M., Nuclear age: Take two?, 93:658 (J;US)

Day, J.L., See Bolivar, S.L., 93:130

De Laeter, J.R., Fission product studies in the symmetric mass region, 93:489 (RA;US)

Deere, D.U., The Nuclear Waste Technical Review Board - Two years of experience in the US Waste Programme. Do we as reviewers communicate understandably with society?, 93:588 (RA;SE)

DeGabriele, C.E., Probable maximum flood control: Yucca Mountain Site Characterization Project, 93:232 (R;US)

Degueldre, $C_{n}$, See Miekeley, N., 93:506

Deinhammer, R.S., See Nitsche, H., 93:97

DeKlever, R., See Lathrop, J., 93:5

DeKlever, R.C., Classification and grading of design products for the Yucca Mountain project, 93:95 (J;US)

Dennis, A.W., See Costin, L.S., 93:277, 93:341

Desvousges, W.H., See Kunreuther, H., 93:545

Devonport, C., Development of a prototype GIS for risk-hazard assessment, 93:611 (BA;AU)

Devonport, C.C., A selected GIS bibliography: Technical Memorandum 40, 93:603 (B;AU)

di Bartolo, R., See Souleyrette, R.R. II, 93:563, 93:564

Diercks, D.R., See Park, J.Y., 93:145, 93:146, 93:403

Dietz, N.L., See Bates, J.K., 93:402, 93:405

DiSilvestro, L.A., See Gibson, J.D., 93:254

Dobson, D.C., Plans for characterization of the potential geologic repository site at Yucca Mountain, Nevada, $93: 99$ (J;US)

Dockery, H.A., See Barnard, R.W., 93:284, 93:293, 93:347

See Barr, G.E., 93:433

Doctor, P.G., An example postclosure risk assessment using the potential Yucca Mountain Site, 93:155 (R;US)

See Eslinger, P.W., 93:360

Dodds, D.J., See Zimmerman, R.M., 93:222, 93:225

Doering, T.W., See Ruffner, D.J., 93:193

Dombrowski, T., Conservative tracers for the $\mathrm{C}$-well hydraulic testing, 93:84 (BA;US)

Identification and characterization of conservative organic tracers for use as hydrologic tracers for the Yucca Mountain Site Characterization Study: Progress report, July 1, 1991-December 31, 1991, 93:14 (R;US)

Identification and characterization of conservative organic tracers for use as hydrologic tracers for the Yucca Mountain Site characterization study: Progress report, April 1, 1993-June 30, 1993, 93:15 (R;US)

Domian, H.A., Fabrication and closure development of nuclear waste disposal containers for the Yucca Mountain Project: Status report, $98: 186$ (R;US)

See Russell, E.W., 93:161

Donovan, D.E., Neotectonics of the southern Amargosa Desert, Nye County, Nevada and Inyo County, California, 93:568 (R;US) 
Doremus, L.A., See Eslinger, P.W., 93:63

Doughty, C., Continued development of a semianalytical solution for two-phase fluid and heat flow in a porous medium, 93:41 (RA;US)

Dozier, B.L., See Lindstrom, F.T., 93:428

Drotning, W.D., Automated waste canister docking and emplacement using a sensor-based intelligent controller: Yucca Mountain Site Characterization Project, 93:262 (R;US)

Ducharme, A.R., See Younker, J.L., 93:67

Dudley, A.L, See Gauthier, J.H., 93:217

Dudley, W.W., See Younker, J.L., 93:67

Duerden, P., The International INTRAVAL project. Phase 1 case 8: The Alligator rivers natural analogue, 93:473 $(R ; X N)$

Duffy, C.J., Kinetics of silica-phase transitions, $93: 110$ (R;US)

Preliminary conceptual model for mineral evolution in Yucca Mountain, $93: 111$ (R;US)

Duguld, J.O., See Pahwa, S.B., 93:308

Dunbar, N.W., Volatile and trace element composition of melt inclusions from the Lower Bandelier Tuff - implications for magma chamber processes and eruptive style, 93:662 (J;US)

Dunn, E., See Barr, G.E., 93:331

Dupree, W.J., See Haupt, R.W., 93:275

Durr, C.L., See Beavers, J.A., 93:533

See Thompson, N.G., 93:532

Dykhuizen, R.C., Groundwater flow code verification "benchmarking" activity (COVE-2A): Analysis of participants' work, 98:244 (R;US)

PACE-90 water and solute transport calculations for $0.01,0.1$, and 0 . $5 \mathrm{~mm} / \mathrm{yr}$ infiltration into Yucca Mountain: Yucca Mountain Site Characterization Project, 93:257 (R;US)

See Eaton, R.R., 93:525

\section{$\mathbf{E}$}

Easterling, D., Fair rules for siting a high-level nuclear waste repository, $98: 671(\mathrm{~J} ; \mathrm{US})$

Easterling, R.G., See Rutherford, B.M., 93:220

Eaton, R.R., Flow through nonhomogeneous porous media, 93:525 (RA;US)

LLUVIA-II: A program for two-dimensional, transient flow through partially saturated porous media: Yucca Mountain Site Characteriza-

tion Project, $93: 290$ (R;US)

See Barnard, R.W., 93:293

See Dykhuizen, R.C., 93:257

See Hopkins, P.L., 93:255

See Sobolik, S.R., 93:266

Ebert, W.L., The reaction of SRL 202 glass in J-13 and DIW, 93:406 (R;US)

See Bates, J.K., 93:402, 93:405

Ebinger, M.H., Water-rock interactions and the $\mathrm{pH}$ stability of groundwater from Yucca Mountain, Nevada, 93:124 (R;US)

Edwards, B., A forecasting model of gaming revenues in Clark County, Nevada, 93:409 (R;US)

A forecasting model of gaming revenues in Clark County, Nevada, 93:626 (BA;US)

Edwards, B.K., See Hemphill, R.C., 93:410, 93:617

Edwards, K.R., See Gwinn, K.W., 93:577

Eggert, K.G., See Birdsell, K.H., 93:485

Eikenberg, J., See Bruno, J., 93:507

Einziger, R.E., See Marschman, S.C., 93:177

Eisenberg, N., See Codell, R., $93: 512$

Ellis, C.B., Implementing the Payments-Equal-To-Taxes (PETT) program in Nevada, 93:88 (BA; US)

Elwood, D.M., See Doctor, P.G., $93: 155$

See Eslinger, P.W., 93:360

Emer, D.F., See Lindstrom, F.T., 93:428

Emery, J.W., See Bates, J.K., 93:402, 93:405

See Finn, P.A., 93:408

Engel, D.W., AREST: The next generation, 93:157 (R;US)

See Buxbaum, M.E., 93:154

See Doctor, P.G., 93:155

See Eslinger, P.W., 93:63, 93:153, 93:360
Erwin, C.S., Conceptual design of a monitored retrievable storage cask employing Yucca Mountain containers, 93:638 (BA;US)

Escalante, E., See Interrante, C.G., 93:528, $93: 529$

Escalier des Orres, P., See Blanc, P.L., 93:419

Eslinger, P.W., Preliminary postclosure risk assessment Yucca mountain, Nevada, candidate repository site, 93:360 (BA;FR; In $F R, E N$ )

Preliminary total-system analysis of a potential high-level nuclear waste repository at Yucca Mountain, 93:63 (R;US)

SUMO, System performance assessment for a high-level nuclear waste repository: Mathematical models, 93:153 (R;US)

See Altenhofen, M.K., 93:156

See Doctor, P.G., 93:155

See Engel, D.W., 93:157

See Miley, T.B., 93:66

See White, M.D., 93:65

Evans, D.D., See Rasmussen, T.C., 93:534, 93:643

Evans, J.R., Teleseismic tomography of the Yucca Mountain region: Volcanism and tectonism, 93:394 (BA;US)

Ewi, See Bates, J.K., 93:402

Ewing, R.C., Søe Janeczek, J., 93:664

\section{$F$}

Fabryka-Martin, J., Sae Schroeder, N.C., 93:661

Fairweather, V., Radioactive waste: Finding a safe place, 93:674 (J;US)

Farmer, J.C., Corrosion models for predictions of performance of high-level radioactive-waste containers, 93:160 (R;US)

Fasano, G.A., See Younker, J.L., 93:67

Fecht, B.A., See Daling, P.M., 93:576

Fehringer, D., See Codell, R., 93:512

Felice, C.W., Characterization of flow in fractured tuff using computerized tomography, $93: 491$ (R;US)

Felton, W., See Pahwa, S.B., 93:308

Feng, X., See Bates, J.K., 93:402, 93:405

Ferarese, J., See Peters, C.A., 93:518

Fernandez, J.A., Initial field testing definition of subsurface sealing and backfilling tests in unsaturated tuff: Yucca Mountain Site Characterization Project, 93:307 (R;US)

Proposed sealing field tests for a potential high-level radioactive waste repository in unsaturated tuff, 93:286 (R;US)

Proposed sealing field tests for a potential high-level radioactive waste repository in unsaturated tuff, 93:356 (BA;US)

Seismic considerations in sealing a potential high-level radioactive waste repository, 93:215 (BA; US)

Seismic considerations in sealing a potential high-level radioactive waste repository, 93:309 (R;US)

See Case, J.B., 93:287

See Tyburski, J.R., 93:357

Ferrigan, P.M.; See Levich, R.A., 93:92

Fewell, M.E., Applications of performance assessment in support of the Exploratory Studies Facility (ESF) design, 93:288 (R;US)

Applications of performance assessment in support of the exploratory studies facility (ESF) design, 93:344 (BA;US)

Estimation of the limitations for surficial water addition above a potential high level radioactive waste repository at Yucca Mountain, Nevada: Yucca Mountain Site Characterization Project, 93:265 (R;US)

See Sobolik, S.R., 93:266, 93:267

Finn, P.A., Elements present in leach solutions from unsaturated spent fuel tests, 93:408 (R;US)

Fish, R.L, See Domian, H.A., 93:186

Fleck, R.J., See Turrin, B.D., 93:399

Flexser, S., Radioelements and their occurrence with secondary minerals in heated and unheated tuff at the Nevada Test Site, 93:52 (R;US)

Radioelements and their occurrence with secondary minerals in heated and unheated tuff at the Nevada test site, 93:82 (BA;US)

See Wollenberg, H.A., 93:498

Fling, L.E., See Rautman, C.A., 93:318 
Flint, A.L., Characterization of rock hydrologic properties using model verification, 93:519 (RA;US)

The influence of scale on calculated sorptivity values from imbibition experiments on welded and nonwelded tuff, 93:397 (BA;FR)

See Flint, L.E., 98:522

See Istok, J.D., 93:641

See Rautman, C.A., 93:274, 93:318, 93:353

See Witwer, C.S., 93:53, $93: 74$

See Zimmerman, R.W., 93:56

Flint, L.E., Use of a submersible pressure outflow cell for determination of moisture characteristic curves on rock core, 93:522 (RA;US)

See Flint, A.L., 93:397, 93:519

See Wittwer, C.S., 93:53, $93: 74$

See Zimmerman, R.W., 93:56

Flores, R., Retrieval strategy report for a potential high-level nuclear waste repository: Yucca Mountain Site Characterization Project, 93:221 (R;US)

Flueck, J.A., See Ananda, M.M.A., 93:429

Flynn, J., A structural model analysis of public opposition to a highlevel radioactive waste facility, 93:554 (R;US)

Nuclear wastes and public trust, 93:660 (J;US)

See Slovic, P., 93:673

Flynn, J.H., Yucca Mountain Socioeconomic Project: The 1991 Nevada State telephone survey: Key findings, 93:546 (R;US)

Foland, K.A., Temporal and spatial distribution of basaltic volcanism in the Pancake and Reveille Ranges north of Yucca Mountain, 93:640 (BA;US)

Folkz, S.D., investigation of fracture-matrix interaction: Preliminary experiments in a simple system, 93:320 (R;US)

Ford, L.M., See Robertson, D.L.M., 93:608

Ford, $W$., Ground water flow through unsaturated fractured rock research needs, 93:521 (RA;US)

See Codell, R., 93:512

Forman, S., See Crowe, B., 93:112, 93:122

See Wells, S., 93:668

Forsberg, C.W., Health and environmental risk-related impacts of actinide burning on high-level waste disposal, 93:572 (R;US)

Fowler, C.S., Native Americans and Yucca Mountain: A summary report, 93:544 (R;US)

Native Americans and Yucca Mountain: A revised and updated summary report on research undertaken between 1987 and 1991:

Volume 1,93:548 (R;US)

Native Americans and Yucca Mountain: A revised and updated summary report on research undertaken between 1987 and 1991:

Volume 2, 93:549 (R; US)

Fox, K.F. Jr., See Brocher, T.M., 93:398

Fraker, A.C., See Interrante, C.G., 93:528, 93:529

Freeze, A., See Stuckless, J.S., 93:368

Freeze, R.A., Hydrogeologic issues at Yucca Mountain: Findings of a DOE peer review team, 93:513 (RA;US)

Freshley, M.D., See Doctor, P.G., 93:155

See Eslinger, P.W., 93:360

See Nichols, W.E. 93:210

See White, M.D., 93:65

Freudenburg, W.R., Human and social factors in the transportation of nuclear wastes, 93:562 (R;US)

Organizational management of long-term risks: Implications for risk and safety in the transportation of nuclear wastes, 93:565 (R;US)

Social impacts of hazardous and nuclear facilities and events: Implications for Nevada and the Yucca Mountain high-level nuclear waste repository: [Final report], 93:555 (R; US)

Frlant, J., See Ozdemir, L., 93:297

Fuenkajorn, K., Borehole stability in densely welded tuffs, 93:531 (R; US)

Fuentes, H.R., See Newman, B.D., 93:141

See Polzer, W.L., 93:113, 93:672

Fumish, M.D., Recent advances in methods for measuring the dynamic response of geological materials to $100 \mathrm{GPa}, 98: 294$ (R;US)

Futa, K., See Peterman, Z.E., 93:393
Gable, C.W., See Valentine, G.A., 93:135

Gainer, G.M., Boron adsorption on hematite and clinoptilolite, 93:490 (R;US)

Gallegos, D.P., An investigation of the impact of conceptual model uncertainty on the estimated performance of a hypothetical highlevel nuclear waste repository site in unsaturated, fractured tuff: Yucca Mountain Site Characterization Project, 93:256 (R;US)

Impact of fracture coatings on the transfer of water across fracture faces in unsaturated media, $93: 579$ (R;US)

Impact of fracture coatings on the transfer of water across fracture faces in unsaturated media, 93:621 (BA;US)

See Kerl, F.A., 93:578, 93:616

Galloway, D., See Karasaki, K., 93:42, 93:395

Gardner, J.N., Geology, drilling, and some hydrologic aspects of seismic hazards program core holes, Los Alamos National Laboratory, New Mexico, 93:488 (R;US)

Gatti, R.C., See Nitsche, H., 98:55, 93:97, 93:109

Gauthier, J.H., Estimating the consequences of significant fracture flow at Yucca Mountain, 93:273 (R;US)

Estimating the consequences of significant fracture flow at Yucca Mountain, $98: 348$ (BA;US)

The most likely groundwater flux through the unsaturated tuff matrix at USW H-1, $93: 338$ (R; US)

TOSPAC calculations in support of the COVE $2 A$ benchmarking activity: Yucca Mountain Site Characterization Project, $93: 229$ (R;US)

Total System Performance Assessment Code (TOSPAC): Volume 2 User's guide: Yucca Mountain Site Characterization Project, 93:217 (R;US)

See Barnard, R.W., 93:293

See Fewell, M.E., 93:265, 93:288, $93: 344$

Gauthier-Lafaye, F., See Bros, R., 98:656

See Nagy, B., 93:649

Gdowski, G.E., Survey of degradation modes of four nickelchromium-molybdenum alloys, $93: 166$ (R;US)

See Farmer, J.C., 93:160

See Van Konynenburg, R.A., 93:172

Geddis, A.M., Preliminary modeling of moisture movement in the tuff beneath Mortandad Canyon, Los Alamos National Laboratory, $93: 496$ (R; US)

Geissman, J., See Crowe, B., 93:112, 93:122

Gerding, T.J., See Bates, J.K., 93:402, 93:405

See Woodland, A.B., 93:143

Gertsch, L., See Gertsch, R., 93:352

See Ozdemir, L., 93:297

Gertsch, R., Performance prediction of mechanical excavators from linear cutter tests on Yucca Mountain welded tuffs: Yucca Mountain Site Characterization Project, 93:299 (R;US)

TBM performance prediction in Yucca Mountain welded tuff from linear cutter tests, 93:352 (BA;US)

Gertz, C.P., Site studies continue at Yucca Mountain in the US, 93:96 (J;GB)

Status of the Yucca Mountain project, 93:93 (BA;US)

The status of Yucca Mountain site characterization activities, 93:79 (BA;US)

U.S. strategy for evaluating the Yucca Mountain, Nevada site, 93:98 $(\mathrm{J} ; \mathrm{CH})$

Underground exploration at Yucca Mountain, $93: 75$ (BA;US)

Update on the Yucca Mountain Project site characterization program, 93:90 (BA:US)

Yucca Mountain: Policy, progress and politics, 93:73 (BA;US)

Yucca Mountain Site Characterization Project Plan, 93:29 (R;US)

Gesell, G., See Slovic, P., 93:673

Ghanem, G.V.A., See Nguyen, V.V., 93:486

Gibson, J.D., Preclosure seismic hazards and their impact on site suitability of Yucca Mountain, Nevada, 93:291 (R;US)

Preclosure seismic hazards and their impact on site suitability of Yucca Mountain, Nevada, $93: 349$ (BA;US)

Recent characterization activities of Midway Valley as a potential repository surface facility site, 93:302 (R;US)

Summary and evaluation of existing geological and geophysical data near prospective surface facilities in Midway Valley, Yucca Mountain 
Project, Nye County, Nevada: Yucca Mountain Site Characterization Project, 93:254 (R;US)

See Wesling, J.R., 93:263

Gil, A.V., Science and students: Yucca Mountain Project's educational outreach and public tour programs, $93: 83$ (BA;US)

Glancy, P.A., See Pabst, M.E., 93:389

Glass, R.E., See Gwinn, K.W., 93:577

Glass, R.J., Laboratory research program to aid in developing and testing the validity of conceptual models for flow and transport through unsaturated porous media, 93:358 (BA;FR)

Modeling gravity-driven fingering in rough-walled fractures using modified percolation theory, $93: 328$ ( $R$; US)

Research program to develop and validate conceptual models for flow and transport through unsaturated, fractured rock: Yucca Mountain Site Characterization Project, 93:253 (R;US)

Wetted-region structure in horizontal unsaturated fractures: Water entry through the surrounding porous matrix, 93:283 (R;US)

See Foltz, S.D., 93:320

See Nicholl, M.J., 93:326, 93:327

S $\theta \theta$ Siegel, M.D., 93:285, 93:354

See Tidwell, V.C., 93:279, 93:280, 93:345

Glassley, W., Coupled hydro-geochemical processes and their significance for Yucca Mountain Site Characterization, 93:197 (R;US)

Glen, J.M., Aeromagnetic map of the Beatty quadrangle, NevadaCalifornia, 93:374 (R;US)

Gnirk, P., See Merkhofer, M.W., 93:301, 93:342

Golding, D., Guidelines on the scope, content, and use of comprehensive risk assessment in the management of high-level nuclear waste transportation, 93:561 (R;US)

Gomberg, J., US Geological Survey Committee for the Advancement of Science in the Yucca Mountain Project symposium on "Fractures, Hydrology, and Yucca Mountain": Abstracts and summary, 93:375 (R;US)

See Anderson, J.G., 93:365

Gomez, L.S., Changes in risk perception over time, $93: 580$ (R;US)

Gong, M., See Bates, J.K., 93:402, 93:405

See Finn, P.A., 93:408

Goodrich, R., See Baver, S.J., 93:278, $93: 355$

Goodrich, R.R., See Asgian, M.I., 93:250

See Hardy, M.P., 93:252, 93:306

Grant, T.A., See Simecka, W.B., 93:3, 93:4

Greiner, B.F., See Cornett, R.J., 93:631

Griffin, W.R., See Robents, J., 93:628

Gross, G.W., See Bowman, R.S., 93:526

Groves, K.R., See Valentine, G.A., 93:135

Gruebel, M.M., See Klett, R.D., $93: 582$

Guenther, R.J., Characterization of spent fuel approved testing material-ATM-104, $98: 151$ (R;US)

Characterization of spent fuel approved testing materia-ATM-105, 98:152 (R;US)

Radionuclide distribution in LWR spent fuel, 93:209 (BA;US)

Gurban, I., See Blane, P.L., 93:419

Gureghian, A.B., Sensitivity and uncertainty analyses applied to one-dimensional radionuclide transport in a layered fractured rock: MULTFRAC -Analytic solutions and local sensitivities: Phase 2, Iterative performance assessment: Volume 1, 93:536 (R:US)

Guzman, A., Pneumatic permeability measurements in a fractured, partially saturated environment, 93:517 (RA;US)

Gwinn, K.W., Over-the-road tests of nuclear materials package response to normal environments, $93: 577$ (R;US)

\section{H}

Hadjlan, A.H., Optimal cost basis for seismic design, 93:426 (BA;US) Hafenrichter, L.D., See Finn, P.A., 93:408

Hall, I.J., See Rutherford, B.M., 93:220

Halsey, W.G., See Henshall, G.A., 93:169

See Van Konynenburg, R.A., 93:172

Hamby, M., Socioeconomic profiles of native American communities: Yomba Shoshone Reservation, 93:551 (R;US)
Socioeconomic profiles of native American communities: Duckwater Shoshone Reservation, 93:552 (R;US)

Hammermeister, D.P., See Loskot, C.L., 93:372

Hancock, G., See Pettersson, H.B.L., 93:659

Hanlon, C.L., The siting guidelines, 10 CFR Part $960,93: 680(\mathrm{~J} ; \mathrm{CH})$

Hansen, K.M., The use of sequential indicator simulation to characterize geostatistical uncertainty: Yucca Mountain Site Characterization Project, 93:264 (R;US)

See Eaton, R.R., 93:525

Hardert, R.A., See Freudenburg, W.R., 93:555

Hardy, M.P., Design of underground repository openings in hard rock to accommodate vibratory ground motions, 93:213 (BA;US)

Drift design methodology and preliminary application for the Yucca Mountain Site Characterization Project: Yucca Mountain Site Characterization Project, 93:237 (R;US)

New three-dimensional far-field potential repository thermomechanical calculations: Yucca Mountain Site Characterization Project, 93:306 (R;US)

Preliminary dritt design analyses for nuclear waste repository in tuff, 93:252 (R;US)

See Asgian, M.I., 93:250

See Bauer, S.J., 93:278, 93:355

See Costin, L.S., 93:240, 93:335

See Lin, M., 93:304, 93:329

Harle, E., See Gil, A.V., 93:83

Harmon, J.E., Nuclear technology programs: Semiannual progress report, October 1989-March 1990, 93:401 (R;US)

Harmsen, S.C., Seismicity and focal mechanisms for the Southern Great Basin of Nevada and California in 1990, 93:376 (R;US)

Seismicity and focal mechanisms for the southern Great Basin of Nevada and California: 1987 through 1989, 93:379 (R;US)

Seismicity and focal mechanisms for the southern Great Basin of Nevada and California in 1991, 93:384 (R; US)

See Anderson, J.G., 93:365

Harrison, D.J., Waste package and engineered barrier system design concepts for the direct disposal of spent fuel in the potential United States repository at Yucca Mountain, Nevada, 93:71 (BA;XA)

Harrison, G.l., See Bronzini, M.S., 93:448

Hart, P.E., See Brocher, T.M., 93:398

Hartman, D.J., Identification of structures, systems, and components important to safety at the potential repository at Yucca Mountain: Yucca Mountain Site Characterization Project, 98:251 (R;US)

Transportation cask decontamination and maintenance at the potential Yucca Mountain repository: Yucca Mountain Site characterization project, $93: 247$ (R;US)

Haupt, R.W., Modulus dispersion and attenuation in tuff and granite, 93:275 (R;US)

See Martin, R.J. III, 93:268

Haworth, A., See Cross, J.E., 93:508

Healy, R.W., See Kwicklis, E.M., 93:520

Heger, A.S., See Kerl, F.A., 98:578, 93:616

Heitland, G.W., See Newbury, C.M., 93:87

See Statler, J., $93: 2$

Hemphill, R., See Bassett, G.W. Jr., $93: 412$

Hemphill, R.C., Managing nuclear waste: Social and economic impacts, $93: 413$ (R;US)

Perceived risk impacts from siting hazardous waste facilities, 93:410 (R;US)

Perceived risk impacts from siting hazardous waste facilities, 98:617 (BA;US)

Henshall, G.A., Modeling pitting corrosion damage of high-level radioactive-waste containers, with emphasis on the stochastic approach, 93:169 (R;US)

Herbst, R.J., See Younker, J.L., 93:67

Herrington, C.C., See Younker, J.L., 93:67

Hertel, E.S. Jr., Areal power density: A preliminary examination of underground heat transfer in a potential Yucca Mountain repository and recommendations for thermal design approaches: Yucca Mountain Site Characterization Project, 93:243 (R;US)

Hervig, R.L., See Dunbar, N.W., 93:662 
Herzik, E.B., Intergovernmental complexity in nuclear waste disposal policy: The indeterminate role of local government, 93:681 (J;US)

Hess, J.W., See Matuska, N.A., 93:566

Heuze, F.E., Dynamic response of tunnels in jointed rocks, $93: 425$ (BA:US)

Rock mechanics contributions from defense programs, 93:593 (R; US)

Hill, D.H., See Daling, P.M., $93: 576$

Hill, R.R., See Hartman, D.J., 93:247

See Smith, D.W., 98:248

Hinkebein, T.E., See Krumhansl, J.L., 93:292, 93:339

Hinze, W.J., See Daudt, C.R., 93:615

Hirschfelder, J., Effects of actinide burning on waste disposal at Yucca Mountain, 93:446 (R;US)

Hitterman, R.L., See Rhodes, E., 93:411

Hoh, J.C., See Bates, J.K., 93:402, 93:405

See Finn, P.A., 93:408

Holland, J.F., The results of near-field thermal and mechanical calculations of thermal loading schemes, $93: 333$ (R;US)

Holliger, P., See Nagy, B., 93:649

Holliger, Ph., See Bros, R., 93:656

Holmes, D.C., Geomorphological and hydrogeological features of the Pocos de Caldas caldera and the Osamu Utsumi mine and Morro do Ferro analogue study sites, Brazil: Pocos de Caldas Report No. 5, $93: 583$ (R;SE)

Holstein, E., See Niedzielski-Eichner, P.A., 93:634

Honda, K.K., See Lum, P.K., 93:474, 93:475

Hookham, C.J., Code requirements for concrete repository and processing facilities, 93:598 (R;US)

Hoover, D.B., See Langenheim, V.E., 93:380

Hopkins, P.L., NORIA-SP: A finite element computer program for analyzing liquid water transport in porous media: Yucca Mountain Site Characterization Project, 93:255 (R;US)

See Dykhuizen, R.C., 93:257

See Eaton, R.R., $93: 290$

See Siegel, M.D., 93:285, 93:354

Hossain, Q.A., Dynamic analysis and design considerations for high-level nuclear waste repositories, 93:600 (B;US)

Hoxie, D.T., Hydrologic modeling and field testing at Yucca mountain, Nevada, 93:396 (BA;FR)

See Younker, J.L., 93:67

Hsiung, Suimin, See Chowdhury, A.H., 93:424

Huddleston, B., See Bronzini, M.S., 93:448

Hudson, M.R., See O'Neill, J.M., 93:381

Hunter, T.O., A conceptual design for a nuclear waste repository at the Yucca Mountain site, 93:359 (BA;US)

See Barr, G.E., 93:433

llias, S., See Singh, A., 93:636

imahori, Y., See Cornett, R.J., 93:631

Interrante, C.G., Evaluation and compilation of DOE waste package test data: Biannual report, February 1989-July 1989: Volume 7 , 93:528 (R;US)

Evaluation and compilation of DOE waste package test data: Volume 8: Biannual report, August 1989-January 1990, $93: 529$ (R;US)

Isaacs, T.H., Technical challenges in the repository program, 93:679 (J:CH)

Istok, J.D., Geostatistical methods for site characterization at Yucca Mountain, 93:641 (BA;FR)

Seө Rautman, C.A., 93:318

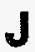

Jackson, D.R., See Erwin, C.S., 93:638

Jackson, M.R. Jr., The Timber Mountain magmato-thermal event: An intense widespread culmination of magmatic and hydrothermal activity at the southwestern Nevada volcanic field, 93:438 (R;US)
Jacobs, G.K., See Jardine, P.M., 93:484

Jacobson, R.L., See Daniels, J.I., 93:592

Jain, $\mathbf{R}_{\text {., }}$ Colloid transport code-nuclear user's manual, 93:493 (R;US)

CTCN: Colloid transport code - nuclear: A user's manual, 93:494 (R;US)

Janeczek, J., Dissolution and alteration of uraninite under reducing conditions, 93:664 (J;NL)

Jantzen, C.M., See Ramsey, W.G., 93:597

Jardine, L.J., See Ma, C.W., 93:234, 93:246

See Short, D.W., 93:183

See Wu, C.L., 93:224

Jardine, P.M., Unsaturated transport of inorganic cations in undisturbed soil columns, 93:484 (RA;US)

Javandel, I., See Wang, J.S.Y., 93:58

Jenkins-Smith, H.C., See Gomez, L.S., 93:580

Jenquin, U.P., See Guenther, R.J., 93:151, 93:152

Johnson, G.L., Thermal performance of a buried nuclear waste storage container storing a hybrid mix of PWR and BWR spent fuel rods: Revision 1, 93:159 (R;US)

See Ruffner, D.J., 93:193

Johnson, J.A., See Pabst, M.E., 93:389

Johnson, R.L., Preliminary numerical modeling for the G-Tunnel welded tuft mining experiment: Yucca Mountain site characterization project, $93: 226$ (R;US)

Johnston, A., See Pettersson, H.B.L., 93:659

Jones, M.A., Hydrology/Radionuclide Migration Program and related research activities: FY 1986 progress report, October 1, 1985-September 30, 1986, 93:437 (R;US)

Jones, M.L., Developing a functioning visualization and analysis system for performance assessment, $93: 289$ (R;US)

Developing a functioning visualization and analysis system for performance assessment, 93:346 (BA;US)

Jones, P., See Krannich, R.S., 93:547

Joseph, M., Heat pipe effect in porous medium, 93:445 (R;US)

See Trabia, M.B., 93:12

Judd, B.R., See Younker, J.L., $93: 76$

Jung, J., A study of discrete and conkinuum joint modeling techniques, 93:271 (R:US)

Justus, P.S., Introductory remarks for the international high-level radioactive waste conference technical session on site characterization: Approaches, concepts, concerns, 93:622 (BA;US)

\section{K}

Kamiyama, Hideo, See Tanaka, Tadao, 93:476

Kaplan, P.G., Pre-waste-emplacement ground-water travel time sensitivity and uncertainty analyses for Yucca Mountain, Nevada: Yucca Mountain Site Characterization Project, 93:305 (R;US)

Uncertainty and sensitivity results for pre-waste-emplacement groundwater travel time, $93: 272$ (R;US)

See Barnard, R.W., 93:293

Karasaki, K., Flow and transport in hierarchically fractured systems 93:61 (R;US)

Method development and strategy for the characterization of complexly faulted and fractured rhyolitic tuffs, Yucca Mountain, Nevada 93:42 (RA;US)

Method development and strategy for the characterization of complexly faulted and fractured rhyolitic tuffs, Yucca Mountain, Nevada, USA, $98: 395$ (BA;FR)

Kess, J., Evaluation of copper, aluminum bronze, and copper-nicke container material for the Yucca mountain project, 93:142 (RA;CA)

Kassner, T.F., See Park, J.Y., 93:403

Keeney, D., See Nitsche, H., 93:55

Kelkar, S., See Zyvoloski, G., 93:103

Kellogg, K.S., See Brogan, G.E., 93:369

Kennedy, J.E., U.S. Nuclear Regulatory Commission overview of repository quality assurance, $93: 683(\mathrm{~J} ; \mathrm{CH})$

Kerl, F.A., Developing conceptual models for performance assessment of waste management sites, 93:578 (R;US) 
Developing conceptual models for performance assessment of waste management sites, 93:616 (BA;US)

Kharaka, Y.K., A preliminary study of the chemistry of pore water extracted from tuff by one-dimensional compression, 93:363 (R;US)

Kibler, J.E., See Nelson, P.H., 93:370

Kiley, M., See Trabia, M.B., $98: 12$

King, F.G., See Bardakci, T., 93:635

King, G.C.P., See Carrigan, C.R., 93:163, 93:211

Kinnison, H.A., See Bronzini, M.S., 93:448

Kinnison, R., Evaluation of environmental monitoring thermoluminescent dosimeter locations, 93:440 (R;US)

Klamerus, L.J., See Hartman, D.J., 93:251

Klavetter, E.A., See Rutherford, B.M., 93:220

Klett, R.D., Evaluation of alternatives for high-level and transuranic radioactive- waste disposal standards, 93:582 (R;US)

Knox, E., Economic impact of nuclear facilities, 93:627 (BA;US)

Kohler, M., Neptunium( $V$ ) sorption on quartz and albite in aqueous suspension: Annual progress report, $93: 495$ (R;US)

Kohout, E., See Bassett, G.W. Jr., $93: 412$

Kohm, S.B., See Ponce, D.A., 93:385

Kolbe, T., See Gardner, J.N., 93:488

Kolm, K.E., See Turner, A.K., 93:624

Koslowsky, V.T., See Cornett, R.J., 93:631

Kossik, R., Integrated performance assessment model for waste policy package behavior and radionuclide release, 93:633 (BA;US)

See Crowe, B.M., 93:136

Koteras, J.R., An analysis of a joint shear model for jointed media with orthogonal joint sets: Yucca Mountain Site Characterization Project, 93:245 (R;US)

Use of the iterative solution method for coupled finite element and boundary element modeling: Yucca Mountain Site Characterization Project, $93: 324$ (R;US)

Kraft, S.P., Getting waste program in motion again, $93: 692$ (J;US)

Krannich, R.S., Southern Nevada residents' views about the Yucca Mountain high-level nuclear waste repository and related issues: A comparative analysis of urban and rural survey data, 93:547 (R;US)

Kraus, N., See Slovic, P., 93:673

Krebs-Jespersen, M.L., Design and implementation of the site and engineering properties database: Yucca Mountain Site Characterzation Project, 93:242 (R;US)

Krishna, P., See Pflum, C.G., 93:7

Kroitoru, L., See Czarnecki, J.B., 93:362

Kroll-Smith, S., See Freudenburg, W.R., 93:555

Krumhansl, J.L., The hydrothermal stability of cement sealing materials in the potential Yucca Mountain high level nuclear waste repository, 93:292 (R;US)

The hydrothermal stability of cement sealing materials in the potential

Yucca Mountain high level nuclear waste repository, 93:339 (BA;US)

Kumar, P., See Blair, J.A., 93:630

Kume, J., Characterization of liquid-water percolation in tuffs in the unsaturated zone, Yucca Mountain, Nye County, Nevada, 93:361 (R;US)

Kunreuther, $H$., Yucca Mountain socioeconomic project report on the 1987 risk perception telephone surveys, 93:545 (R;US)

Kupperman, D.S., See Rhodes, E., 93:411

Kuroda, P.K., Variation of the isotopic compositions of xenon and krypton in terrestrial samples, 93:632 (BA;US)

Kurzmack, M.A., Proposed algorithm for determining the delta intercept of a thermocouple psychrometer curve, 93:386 (R;US)

Kwicklis, E.M., Numerical and laboratory investigations of transient and steady-state flow in a fractured core, 93:520 (RA;US)

LaCount, D.F., See Domian, H.A., 93:186

Ladkany, S.G., Quarterly progress report on the DOE Waste Package project at the University of Nevada, Las Vegas, July 1, 1993 through September 30, 1993, 93:17 (R;US)
Langenheim, V.E., Geophysical characterization of mineral and energy resources at Yucca Mountain and vicinity, Nevada, 93:380 (R;US)

Langford, D.W., See Eslinger, P.W., 93:63

Larkin, E.L., See Gert, C.P., 93:73, 93:79, 93:96

See Gil, A.V., 93:83

Lathrop, J., Using QA classification to guide design and manage risk, 93:5 (R; US)

Latorre, V.R., See Ramirez, A.L., 93:162

Laub, T.W., See Ma, C.W., 93:234

Lauffer, F.C., See Gauthier, J.H., 93:273, 93:348

Layman, M., See Slovic, P., 93:673

Leckie, J.O., See Kohler, M., 93:495

Ledoux, E., See Blanc, P.L., 93:419

Lee, J., See Wu, C.L., $93: 224$

Lee, J.G., See Phillips, J.S., 93:238, 93:239

Lee, K, See Ramirez, A.L., $93: 162$

Lee, K.H., Field air injection tests to determine the effect of a heat cycle on the permeability of welded tuff, $93: 179$ (R;US)

See Apted, M.J., 93:49

Lee, W.W.L., Releases from exotic waste packages from partitioning and transmutation, 93:51 (R;US)

Releases from exotic waste packages from partitioning and transmutation, 93:207 (BA;US)

Waste-package release rates for site suitability studies, $93: 48$ (R;US)

See Apted, M.J., 93:49

See Barnard, R.W., 93:351

See Zwahlen, E.D., 93:40

Lehman, L., State of Nevada review of Phase 1 of the INTRAVAL Project, 93:571 (R;US)

Lehman, L.L., Alternate conceptual model of ground water flow at Yucca Mountain, 93:612 (BA;US)

Leider, H.R., Estimating the time for dissolution of spent fuel exposed to unlimited water, $93: 164$ (R;US)

Lentell, R.L., Geotechnical instrumentation for repository shafts, 93:427 (BA;US)

Leonard, T.M., See Allan, J., $93: 100$

Leventhal, J.S., See Nagy, B., 93:649

Levich, R.A., Stripa: An international cooperative project, 93:92 (BA;US)

Levine, A.G., See Freudenburg, W.R., 93:555

Levitch, R.A., See Long, J.C.S., 93:499

Levy, S.S., Natural gels in the Yucca Mountain Area, Nevada, USA, 93:116 (R;US)

Surface-discharging hydrothermal systems at Yucca Mountain: Examining the evidence, $93: 125$ (R;US)

Lewis, B.D., See Wittwer, C.S., 93:53, $93: 74$

Lewis, LC., See O'Connell, W.J., 93:170

Lichtner, P.C., See Cross, J.E., 93:508

Liddle, R.L., See Bowman, R.S., 93:526

Liebetrau, A.M., See Doctor, P.G., 93:155

See Eslinger, P.W., 93:360

Lin, M., Rock mass mechanical property estimations for the Yucca Mountain Site Characterization Project: Yucca Mountain Site Characterization Project, 93:304 (R;US)

Rock mass mechanical property estimation strategy for the Yucca Mountain Site Characterization Project, 93:329 (R;US)

See Bauer, S.J., 93:278, 93:355

See Hardy, M.P., 93:306

Lin, Ming, See Fernandez, J.A., 93:215, 93:309

Lin, W., Technical basis and programmatic requirements for laboratory study of hydrological properties of the near-field environment, 93:173 (R;US)

Lin, Wunan, Technical basis and programmatic requirements for Engineered Barrier System Field Tests, 93:174 (R;US)

Technical basis and programmatic requirements for large block testing of coupled thermal-mechanical-hydrological-chemical processes, 93:175 (R;US)

Temperature measurements from a horizontal heater test in GTunnel, 93:178 (R;US)

Lin, Wunan, Mao, Nal-hsi, See Ramirez, A.L., $93: 162$ 
Lindstrom, F.T., Estimating the water table under the Radioactive Waste Management Site in Area 5 of the Nevada Test Site: The Dupuit-Forcheimer approximation, $93: 428$ (R;US)

Linsalata, P., See MacKenzie, A.B., 93:504

See Miekeley, N., 93:505

Little, R.L., See Krannich, R.S., 93:547

Lobmeyer, D.H., See Luckey, R.R., 93:378

Lodwick, D.G., See Freudenburg, W.R., 93:555

Loeven, C., A summary and discussion of hydrologic data from the Calico Hills nonwelded hydrogeologic unit at Yucca Mountain, Nevada, 93:107 (R;US)

Lohrstorfer, C., See Guzman, A., 93:517

Long, J.C.S., The Nagra-DOE Cooperative Project, $93: 499$ (R;US)

Long, J.W., See Phillips, J.S., 93:238, 93:239

Lopez, R.M., See Triay, I.R., 93:126, 93:128

Lorenz, J.J., Yucca Mountain Site characterization project bibliography, January-June 1991: An Update: Supplement 2 , Addendum 3, 93:19 (R;US)

Loskot, C.L., Geohydrologic data from test holes UE-25 UZ \#4 and UE-25 UZ \#5, Yucca Mountain Area, Nye County, Nevada, 93:372 (R:US)

See Whitfield, M.S. Jr., 93:382

Loss, R.D., See De Laeter, J.R., 93:489

Loux, R.R., A view on siting issue from Nevada, 93:691 (J;US)

Lowry, D., 2010: America's nuclear waste odyssey, $93: 652$ (J;GB)

Lu, D.L., See Wu, C.L., 93:224

Lu, Ning, See Ross, B., 93:296

Luckey, R.R., Water levels in continuously monitored wells in the Yucca Mountain area, Nevada, 1985-88, 93:378 (R; US)

Lugo, M.A., See Blanchard, M.B., 93:80

Lui, A.E. van, See Hanlon, C.L., 93:680

Luke, B.A., See Phillips, J.S., 93:238, 93:239

Luker, S., See Zimmerman, R.M., 93:222, 93:225

Lum, P.K., Processed seismic motion records from Little Skull Mountain, Nevada earthquake of June 29, 1992, recorded at stations in southern Nevada, $93: 474$ (R;US)

Processed seismic motion records from Little Skull Mountain, Nevada earthquake aftershocks of July 5, 1992 and September 13, 1992, recorded at seismic stations in southern Nevada, 93:475 (R;US)

Lyles, B.F., Hydrogeologic characterization of wells HTH-1, UE18r, UE6e, and HTH-3, Nevada Test Site, 93:441 (R;US)

See Chapman, J.B., 93:444

\section{M}

Ma, C.W., Preclosure radiological safety analysis for accident conditions of the potential Yucca Mountain Repository: Underground facilities: Yucca Mountain Site Characterization Project, 93:234 (R;US)

Preclosure radiological safety analysis for the exploratory shaft facilities: Yucca Mountain Site Characterization Project, 93:246 (R;US)

Macintyre, A.T., See Apted, M.J., 93:49

MacKenzie, A.B., Natural radionuclide and stable element studies of rock samples from the Osamu Utsumi mine and Morro do Ferro analogue study sites, Pocos de Caldas, Brazil, $93: 504$ (R;CH)

Maddix, D.M., See Heuze, F.E. 93:425

Madson, A.A., See Russell, E.W., 93:161

Maest, A.S., See Kharaka, Y.K., 93:363

Magaritz, M., See Czarnecki, J.B., 93:362

Magner, J.E., See Carroll, R.D., 93:595

Mahan, S.A., See Peterman, Z.E., 93:393

Maiya, P.S., See Park, J.Y., 93:403

Mann, K.L., See Zimmerman, R.M., 93:222, 93:225, 93:227

Manteufel, R.D., A literature review of coupled thermal-hydrologicmechanical-chemical processes pertinent to the proposed high-level nuclear waste repository at Yucca Mountain, 93:537 (R;US)

Mao, Nai-hsien, Thermocouple psychrometer measurements of in situ water potential changes in heated welded tuff, 93:180 (R;US)

Margulies, T., See Codell, R., 93:512
Margulies, T.S., See McCartin, T.J., 93:527

Marschman, S.C., Rationale for determining MCC spent fuel acquisitions, 93:177 (R;US)

Marshall, B.D., See Peterman, Z.E., 93:393

Martin, R.J. III, Anisotropy of the Topopah Spring Member Tuff, 93:268 (R:US)

Procedure development study: Low strain rate and creep experiments: Yucca Mountain Site Characterization Project, 93:261 (R;US)

The influence of strain rate and sample inhomogeneity on the moduli and strength of weided tuff, $93: 312$ (R;US)

Unconfined compression experiments on Topopah Spring Member tuff at $22^{\circ} \mathrm{C}$ and a strain rate of $10^{-9} \mathrm{~s}^{-1}$ : Data report: Yucca Mountain Site Characterization Project, 93:310 (R;US)

See Haupt, R.W., $93: 275$

See Price, R.H., 93:313

Martinez, K., See Tidwell, V.C., 93:323

Martinez, M.J., See Dykhuizen, R.C., 93:257

Mattson, S.R., See Younker, J.L., 93:67

Matuska, N.A., The relationship of the Yucca Mountain repository block to the regional ground-water system: A geochemical model, 93:566 (R;US)

Mazer, J.J., See Bates, J.K., 93:402, 93:405

McAninch, M.D., See Domian, H.A., 93:186

McArthur, R.D., See Cooper, E.N., 93:442

McCartin, T., See Codell, R., 93:512

McCartin, T.J., Development and evaluation of a performance assessment methodology for analyzing the safety of a geologic repository for high-level radioactive waste, 93:527 (RA;US)

McCright, R.D., See Farmer, J.C., 93:160

See Henshall, G.A., 93:169

See Van Konynenburg, R.A., $93: 172$

McDonald, E., See Crowe, B., 93:112, 93:122

McDonald, R., See Bhattacharyya, K.K., 93:81

McFadden, L., See Crowe, B., 93:112, 93:122

See Wells, S., 93:668

McFadden, L.D., See Wells, S.G., 93:665

McGrall, B.P., See Engel, D.W., 93:157

McGuire, R., See Shaw, R., 93:625

McGuire, R.K., Demonstration of a risk-based approach to highlevel waste repository evaluation, Phase 2, 93:461 (R;US)

See Swan, F.H., 93:421

McKague, H.L., See Pawloski, G.A., 93:184

McKay, J.W., See Cornet, R.J., 93:631

McKay, W.A., See Lyles, B.F., 93:441

McKinley, I.G., See Bruno, J., 93:507

See Chapman, N.A., 93:510

See Cross, J.E., 93:508

See West, J.M., 93:585

McKinnis, W.B., See Pawloski, G.A., 93:184

McNally, P., See Cleary, R., 93:654

McNutt, R.H., See Nordstrom, D.K., 93:509

Meenan, C., See Edwards, B., 93:409, 93:626

Meijer, A., A strategy for the derivation and use of sorption coefficients in performance assessment calculations for the Yucca Mountain site, 93:105 (RA;US)

A strategy for the derivation and use of sorption coefficients in performance assessment calculations for the Yucca Mountain site, 93:115 (R;US)

See Rogers, P.S.Z., 93:127

See Stuckless, J.S., 93:368

Melke, A., Chemical and mineralogical concerns for the use of manmade materials in the post-emplacement environment, 93:176 (R;US)

Menager, M.T., See Menet, C., 93:670

Mendel, J.E., See Guenther, R.J., 93:151, 93:152, 93:209

Menet, C., Migration of radioelements around the new nuclear reactors at Oklo: Analogies with a high-level waste repository, 93:670 (J;DE)

Merkhofer, M.W., A decision analysis of an exploratory studies facility, 93:301 (R;US)

A decision analysis of an exploratory studies facility, 93:342 (BA;US)

Mertz, C.K., See Flynn, J., 93:554

See Flynn, J.H., 93:546 
Middendorf, D.P., See Bronzini, M.S., 93:448

Miekeley, N., Chemical and physical characterisation of suspended particles and colloids in waters from the Osamu Utsumi mine and Morro do Ferro analogue study sites, Pocos de Caldas, Brazil, 98:506 $(\mathrm{R} ; \mathrm{CH})$

Natural series radionuclide and rare-earth element geochemistry of waters from the Osamu Utsumi mine and Morro do Ferro analogue study sites, Pocos de Caldas, Brazil, 93:505 (R;CH)

See MacKenzie, A.B., 93:504

Miley, T.B., A demonstration of dose modeling at Yucca Mountain, 93:66 (R;US)

See Eslinger, P.W., 93:63, 93:153

Miller, A.J. Jr., See Bronzini, M.S., 93:448

Miller, D.D., See Hartman, D.J., 93:247, 93:251

See Ma, C.W. 93:246

See Smith, D.W., 93:248

Miller, I., See Kossik, R., 93:633

Miller, K.W., See Gomez, L.S., $93: 580$

Miller, W.B.y See Gauthier, J.H., 93:229

Mills, J.G. Jr., Manganoan fayalite $\left[(\mathrm{Fe}, \mathrm{Mn})_{2} \mathrm{SiO}_{4}\right]$ : A new occurrence in rhyolitic ash-flow tuff, southwestern Nevada, U.S.A., 93:678 (J;US)

Milton, G.M., See Cornett, R.J., 93:631

Milton, J.D.C., See Cornett, R.J., 93:631

Mitchell, A.J., See Triay, I.R., 93:106, 93:118, 93:126, 93:128 93:129

Morgan, D., See Schroeder, N.C., 93:661

Morgan, L.E., See Bates, J.K., 93:402, 93:405

Morgenstein, M.E., See Burns, R.G., 93:481

Morley, R., See Crowe, B., 93:112, 93:122, 93:137

Morris, A.P., See Young, S.R., 93:422

Morse, R., See Miekeley, N., 93:505

Mossman, D.J. Hydrothermal alteration of organic matter in uranium ores, Elliot Lake, Canada: Implications for selected organic-rich deposits, 93:650 (J:US)

See Nagy, B., 93:649

Mou, Ching-Hua, Thermal impact on host rock of geologic repository: Final report, 93:18 (R;US)

Mueller, A., See Nitsche, H., 93:97

Muller, D.C., See Nelson, P.H., 93:370

Murakami, Takashi, Natural analogue studies: Mineral alteration and uranium migration, $93: 477$ (R;JP; In Japanese)

Murphy, J.R., See Bennett, T.J., 93:423

Murphy, M.T., See Eslinger, P.W., 93:63

Murphy, W.M., Performance assessment perspectives with reference to the proposed repository at Yucca Mountain, Nevada, 93:587 (RA;SE)

See Stuckless, J.S., 93:368

Murray, A.S., See Pettersson, H.B.L., $93: 659$

Murray, R.C., See Younker, J.L., 93:67

Murrell, M., See Crowe, B., 93:112, 93:122

Mushkatel, A., See Krannich, R.S., 93:547

Mushkatel, A.H., Institutional trust, information, and risk perceptions: Report of findings of the Las Vegas metropolitan area survey, June 29-July 1, 1992, 93:557 (R:US)

See Herzik, E.B., 93:681

See Pijawka, K.D., 93:682

Myers, J., See Krumhansl, J.L., 93:292, 93:339

Myers, W.A., See Kuroda, P.K., 93:632

\section{$\mathbf{N}$}

Nagy, B., Role of organic matter in the Proterozoic Oklo natural fission reactors, Gabon, Africa, 93:649 (J;US)

See Mossman, D.J., 93:650

Narasimhan, T.N., Conceptual, experimental and computational approaches to support performance assessment of hydrology and chemical transport at Yucca Mountain: Yucca Mountain Site Characterization Project, 93:249 (R;US)

See Wang, J.S.Y., 93:233

Neil, D., See Ozdemir, L., 93:297
Nelson, P.H., Assessment of geophysical logs from borehole USW G-2, Yucca Mountain, Nevada, $93: 387$ (R;US)

Geophysical logs and core measurements from forty boreholes at Yucca Mountain, Nevada, 93:370 (R;US)

Neuman, S., See Guzman, A., 93:517

Newbury, C.M., Management of scientific and engineering data collected during site characterization of a potential high-level waste repository, 93:87 (BA;US)

See Statler, J., 93:2

Newman, B.D., An evaluation of lithium sorption isotherms and their application to ground-water transport, $93: 141$ (J:US)

Newton, L., See Bates, J.K., 93:405

Nguyen, H.A., See Nicholl, M.J., 93:326, 93:327

Nguyen, S.N., See Leider, H.R., $93: 164$

Nguyen, V.V., Selected issues on geochemical transport modeling for high-level nuclear waste repository, 93:486 (RA;US)

Nicholl, M.J., Small-scale behavior of single gravity-driven fingers in an initially dry fracture, 93:326 (R;US)

Wetting front instability in an initially wet unsaturated fracture, 93:327 (R;US)

Nichols, W.E., Uncertainty analyses of unsaturated zone travel time at Yucca Mountain, 93:210 (J;US)

See Eslinger, P.W., 93:63

See White, M.D., 93:64

Nicholson, T.J., See Rasmussen, T.C., 93:643

Niedzielski-Eichner, P.A, Nuclear waste repository program oversight: Strategies of the situs jurisdiction, 93:634 (BA;US)

Nielsen, J.K., See Bates, J.K., 93:402, 93:405

Niemeyer, S., Evaluation of lead contamination in drillback mudpits using isotopic ratios, 93:590 (RA;US)

Niemi, A., Incorporation of the capillary hysteresis model HYSTR into the numerical code TOUGH, 93:38 (R;US)

Preliminary capillary hysteresis simulations for fractured rocks model development and results of simulations, $93: 39$ (R;US)

The capillary hysteresis model HYSTR: User's guide, 93:37 (R;US)

Nigg, J., See Kunreuther, H., 93:545

Nilson, S.A., See Daling, P.M., 93:576

Nimick, F.B., Calculation of experiment uncertainty in laboratory determination of several geoengineering properties of tuffs from Yucca Mountain, Nevada: Yucca Mountain Site Characterization Project, 93:231 (R; US)

Ning Lu, See Ross, B., 93:337

Nitao, J.J., The implications of episodic nonequilibrium fracturematrix flow on site suitability and total system performance, 93:187 (R;US)

The implications of episodic nonequilibrium fracture-matrix flow on site suitability and total system performance, 93:204 (BA;US)

See Buscheck, T.A., 93:182, 93:185, 93:189, 93:194, 93:195 93:205, 93:514, 93:523

Nitsche, $H$., Dependence of actinide solubility and speciation on carbonate concentration and ionic strength in groundwater 93:97 (J;DE)

Measured solubilities and speciations of neptunium, plutonium, and americium in a typical groundwater $(\mathrm{J}-13)$ from the Yucca Mountain region: Milestone report 3010-WBS 1.2.3.4.1.3.1, 93:109 (R;US)

Radionuclide solubility and speciation studies for the Yucca Mountain site characterization project, $93: 55$ (R;US)

Solubility and speciation studies for nuclear repository performance assessment, 93:50 (R;US)

Solubility and speciation studies for nuclear repository performance assessment, 93:158 (RA;SE)

Noel, J.S., See Martin, R.J. III, 93:261, 93:310, $93: 312$

Nordstrom, D.K., Chemical and isotopic composition of groundwaters and their seasonal variability at the OSAMU Utsumi mine and Morro do Ferro analogue study sites, Pocos de Caldas, Brazil: Pocos do Caldas Report No. 6, $93: 584$ (R;SE)

Geochemical modelling of water-rock interactions at the Osamu Utsumi mine and Morro do Ferro analogue study sites, Pocos de Caldas, Brazil, 93:509 (R;CH)

Norton, D.L., See Glass, R.J., 93:283

Noy, D.J., See Holmes, D.C., 93:583 
O'Brien, G.M., Earthquake-induced water-level fluctuations at Yucca Mountain, Nevada, April 1992, 93:383 (R;US)

Earthquake-induced water-level fluctuations at Yucca Mountain, Nevada, June 1992, 93:388 (R;US)

O'Connell, W.J., Post-closure performance assessment of waste packages for the Yucca Mountain Project, 93:170 (R;US)

See Apted, M.J., 93:49

See Ueng, Tzou-Shin, 93:167

O'Leary, D.W., See Whitney, J.W., 93:364

O'Neill, J.M., Photogeologic and kinematic analysis of lineaments at Yucca Mountain, Nevada: Implications for strike-slip faulting and oroclinal bending, 93:381 (R;US)

Oldenburg, C.M., On numerical modeling of capillary barriers, 93:94 ( $:$ :US)

Olinger, C., See Wells, S., 93:668

Oliver, H.W., See Langenheim, V.E., 93:380

Oliver, J.R., See Erwin, C.S., 93:638

Osmond, J.K., See MacKenzie, A.B., 93:504

Osmond, K., See Miekeley, N., 93:505

Ott, M.A., See Triay, I.R., 93:106, 93:118, 93:129

Ouderkirk, S.J., See Eslinger, P.W., 93:63

Ouyang, S., Sealing performance of bentonite and bentonite/crushed rock borehole plugs, 93:530 (R;US)

Ouyang, Shoung, Sealing performance assessments of bentonite and bentonite/crushed rock plugs, 93:645 (1;US)

Overly, C.M., See Triay, I.R., 93:126, 93:128

Ozdemir, L., Performance predictions for mechanical excavators in Yucca Mountain tuffs: Yucca Mountain Site Characterization Project, 93:297 (R;US)

See Gertsch, R., 93:299, 93:352

\section{$P$}

Pabst, M.E., Streamflow and selected precipitation data for Yucca Mountain and vicinity, Nye County, Nevada, water years 198385, $93: 389$ (R;US)

Pahwa, S.B., Approach to geologic repository post closure system performance assessment, 93:308 (R; US)

Palaniswamy, R., See Hookham, C.J., 93:598

Palmer, B., Criticality safety issues associated with the burial of highly enriched nuclear fuel in a geologic repository, 93:596 (R;US)

Park, J., See Codell, R., 93:512

Park, J.Y., Crack growth behavior of :candidate waste container materials in simulated underground water, 93:146 (R;US)

Crack-growth-rate testing of candidate waste container materials,

93:145 (R;US)

Stress corrosion cracking of candidate waste container materials: Final report, $93: 403$ (R;US)

Parks, P.B., Facts and issues of direct disposal of spent fuel: Revision 1, 93:599 (R;US)

Parrish, D.K., See Boyle, W.J., 93:300, 93:343

Parsons, M.W., Regulatory considerations in design of the exploratory studies facility, 93:77 (BA;US)

Patera, E.A., See Younker, J.L., 93:67

Patera, E.S., See Levich, R.A., 93:92

Pawloski, G.A., A preliminary guidebook for identifying stratigraphic contacts at the Nevada Test Site, $93: 184$ (R;US)

Payne, J., A dose of HLW reality, 93:657 (J;US)

Peppin, W.A., Evaluation of the geologic relations and seismotectonic stability of the Yucca Mountain Area, Nevada Nuclear Waste Site investigation (NNWS1): Volume 2, Final report, October 1988, 93:543 (R;US)

Perman, R.C., See Gibson, J.D., 93:254

See Wesling, J.R., 93:263

Perry, F., See Crowe, B., 93:112, 93:122

See Wells, S., 93:668

Perry, F.V., Geochemical evidence for waning magmatism and polycyclic volcanism at Crater Flat, Nevada, 93:119 (R;US)
Geochemical evidence for waning magmatism and polycyclic volcanism at Crater Flat, Nevada, 93:140 (BA;US)

See Crowe, B.M., 93:120, 93:136

See Picard, R., 93:139

See Valentine, G.A., 93:117, 93:135, 93:138

Pescatore, $C$., Potential increases in natural radon emissions due to heating of the Yucca Mountain rock mass, 93:208 (BA;US)

Potential increases in natural radon emissions due to heating of the

Yucca Mountain rock mass, $93: 212$ (R;US)

Peterman, Z.E., Strontium isotope geochemistry of calcite fracture fillings in deep core, Yucca Mountain, Nevada: A progress report, 93:393 (BA;US)

Peters, C.A., Field testing the effectiveness of pumping to remove sulfur hexafluoride traced drilling air from a prototype borehole near superior, Arizona, 93:518 (RA;US)

Peters, F., Overview and status of the U.S. high-level waste program, 93:610 (BA;US)

Peters, R., See Cleary, R., 93:654

Peters, R.R., See Gauthier, J.H., 93:217

See Rutherford, B.M., 93:220

Peters, T., See Waber, N., 93:501

Petit, J.C., See Menet, C., 93:670

Petrie, E.H., See Lathrop, J., 93:5

Pettersson, H.B.L., Uptake of uranium and thorium series radionuclides by the waterlily, Nymphaea violacea, 93:659 (J;GB)

Pflum, C.G., Critical comments on the US Environmental Protection Agency Standards 40 CFR 191, 93:7 (R;US)

Phillip, See Bates, J.K., 93:405

Phillips, F., See Stuckless, J.S., 93:368

Phillips, J.S., MISTY ECHO Tunnel Dynamics Experiment-Data report: Volume 1: Yucca Mountain Site Characterization Project, 93:238 (R;US)

MISTY ECHO tunnel dynamics experiment data report: Volume 2 Appendices: Yucca Mountain Site Characterization Project, 93:239 (R;US)

Prediction of Pseudo relative velocity response spectra at Yucca Mountain for underground nuclear explosions conducted in the Pahute Mesa testing area at the Nevada testing site: Yucca Mountain Site Characterization Project, 93:230 (R;US)

Phol, P.I., See Gallegos, D.P., 93:256

Picard, R., Recurrence models of volcanic events: Applications to volcanic risk assessment, 93:139 (BA;US)

See Crowe, B.M., 93:120

Pigford, T.H., See Apted, M.J., 93:49

See Lee, W.W.L., $93: 48$

See Zwahlen, E.D., 93:40

Pijawka, K.D., Public opposition to the siting of the high-level nuclear waste repository: The importance of trust, $93: 682$ (J;US)

See Krannich, R.S., 93:547

See Mushikatel, A.H., 93:557

Pitty, A.E., See Holmes, D.C., 93:583

Platt, E.A., See Ruffner, D.J., 93:193

Plugge, M., Intra-site secure transport vehicle, 93:581 (R;US)

Polo, D. de, See Anderson, J.G., 93:365

Polzer, W.L., Summary report on the evaluation of a 1977-1985 edited sorption data base for isotherm modeling, 93:113 (R;US)

Thermodynamically derived relationships between the modified Langmuir isotherm and experimental parameters, $93: 672$ (J;US)

See Newman, B.D., 93:141

Ponce, D.A., Gravity and magnetic data of Fortymile Wash, Nevada Test Site, Nevada, $93: 385$ (R;US)

See Glen, J.M., 93:374

Porro, l., Transport of reactive tracers by unsaturated flow using field and column experiments, 93:482 (RA;US)

Porto da Silveira, C.L., See Miekeley, N., 93:505, 93:506

Pothis, J., See Wells, S., 93:668

Poths, J., See Crowe, B., 93:112, 93:122

Pott, J., Instrumentation requirements for the ESF thermomechanical experiments, $93: 330$ (R;US)

Price, R.H., Characterization of porosity in support of mechanical property analysis, 93:313 (R;US)

See Haupt, R.W., $93: 275$

See Martin, R.J. III, 93:261, 93:268, 93:310, $93: 312$ 
See Hertel, E.S. Jr., 93:243

\section{$\mathbf{S}$}

Sadeghi, M.M., See Lee, W.W.L., 93:48

Sagar, B., See Ahola, M., 93:535

See Gureghian, A.B., 93:536

See Rockhold, M.L., 93:62

Sandino, A., See Bruno, J., 93:507

Sandoval, R.P., An overview of the Yucca Mountain GlobalRegional Climate Modeling Program, 93:276 (R;US)

An overview of the Yucca Mountain global/regional climate modeling program, 93:350 (BA;US)

Sanjeevan, K., See St. John, C.M., 93:223

Sathisan, S.K., See Souleyrette, R.R. II, 93:563, 93:564

Saunders, R.S., See Bhattacharyya, K.K., 93:81

Savage, M.K., See Anderson, J.G., 93:365

Schelling, F.J., Preclosure radiological safety evaluation: Exploratory Studies Facility: Yucca Mountain Site Characterization Project, $93: 315$ (R;US)

Schimschal, U., See Nelson, P.H., 93:370, 93:387

Schorscher, H.D., The regional geology, mineralogy and geochemistry of the Pocos de Caldas alkaline caldera complex, Minas Gerais, Brazil, 93:500 (R;CH)

See Waber, N., 93:501

Schroeder, N.C., Migration of technetium-99 in the alluvial aquifer at the Nevada test site, Nevada, 93:661 (J;DE)

Schwartz, B.M., Linear thermal expansion data for tuffs from the unsaturated zone at Yucca Mountain, Nevada: Yucca Mountain Site Characterization Project, 93:228 (R;US)

See Nimick, F.B., 93:231

Scott, R.D., See Mackenzie, A.B., 93:504

Scott, S., See Plugge, M., 93:581

Sellin, P., See Bruno, J., 93:507

Serne, R.J., Current adsorption models and open issues pertaining to performance assessment, 93:480 (RA;US)

Sevigny, N.L., See Daling, P.M., 93:576

Shack, W.J., See Park, J.Y., 93:145, 93:146, 93:403

Shatfer, R.J., See Heuze, F.E., 93:425

Shaheen, M., Anomalous deuteron to hydrogen ratio in naturally occuring fission reactions and the possibility of deuteron disintegration, $93: 667(\mathrm{~J} ; \mathrm{HU})$

Sharer, J.C., See Felice, C.W., 93:491

Shaw, $\mathbf{R}$., Performance assessment for a high-level waste repository at Yucca Mountain, 93:625 (BA;US)

Shea, M.E., Isotopic geochemical characterization of selected nepheline syenites and phonolites from the Pocos de Caldas alkaline complex, Minas Gerais, Brazil, 93:503 (R;CH)

See Cathles, L.M., 93:586

See Chapman, N.A., $93: 510$

See Schorscher, H.D., 93:500

Sheats, D.G., Records Management in support of the licensing process for the high level radioactive waste facility, 93:85 (BA;US)

Sheehan, A.F., See Anderson, J.G., 98:365

Shenk, K.J., Radiological environmental monitoring for the Yucca Mountain site, 93:89 (BA;US)

Shepard, N.F., The Yucca Mountain tours: A test of the familiarity hypothesis, 93:618 (BA;US)

Shephard, L.E., See Fewell, M.E., 93:288, 93:344

See Younker, J.L., 93:67

Sheridan, M.F., A Monte Carlo technique to estimate the probability of volcanic dikes, 93:637 (BA;US)

Short, D.W., Engineered barrier system and waste package design concepts for a potential geologic repository at Yucca Mountain, 93:183 (R;US)

Shrader-Frechette, K., Expert judgment in assessing radwaste risks: What Nevadans should know about Yucca Mountain: [Final report], 93:556 (R;US)

Siegel, M.D., Design of an intermediate-scale experiment to validate unsaturated- zone transport models, 93:285 (R;US)

Design of an intermediate-scale experiment to validate unsaturatedzone transport models, 93:354 (BA;US)
Preliminary characterization of materials for a reactive transport model validation experiment, 93:334 (R;US)

Sifre-Soto, C., See Zimmerman, R.M., 93:222, 93:225

Sihgh, A., See Bardakci, T., 93:635

Simecka, W.B., Current plans to characterize the design basis ground motion at the Yucca Mountain, Nevada, site, 93:3 (BA;US)

Current plans to characterize the design basis ground motion at the

Yucca Mountain, Nevada Site, $93: 4$ (R;US)

Simpson, J., NRC approves spent-fuel cask for general use: Who needs Yucca Mountain?, 93:648 (J;US)

Singh, A., Characterization of the Topopah spring and Tiva Canyon tuffs at Yucca Mountain: Effective diffusivities and pore properties, 93:636 (BA;US)

Singh, A.K., See Ananda, M.M.A., 93:429

Sit, R.C., See Ma, C.W., 93:234

Skinner, L.H., See Gauthier, J.H., 93:217

Slemmons, D.B., See Brogan, G.E., 93:369

Slovic, P., Perceived risk, stigma, and potential economic impacts of a high-level nuclear waste repository in Nevada, 93:673 (J;US)

See Flynn, J., 93:554, 93:660

See Flynn, J.H., 93:546

See Kunreuther, H., 93:545

Smellie, J.A.T., See Chapman, N.A., $93: 510$

See Nordstrom, D.K., 93:584

Smith, A.R., See Wollenberg, H.A., 93:498

Smith, D.M., See Gallegos, D.P., 93:579, $93: 621$

Smith, D.W., Effects of various radiation source characteristics on shielding requirements at the potential Yucca Mountain repository, 93:248 (R;US)

Smith, E.l., Center for Volcanic and Tectonic Studies, Department of Geoscience annual report, October 1, 1989-September 30, 1990, $93: 541$ (R;US)

Smith, J.D., See Schelling, F.J., 93:315

Smith, J.L, Needed geologic and seismic rulemaking for HLW repositories, 93:619 (BA;US)

Smith, K.D., See Anderson, J.G., 93:365

Smith, M. III, Seo Evans, J.R., 93:394

Sobolik, S.R., Estimation of the impact of water movement from sewage and settling ponds near a potential high level radioactive waste repository in Yucca Mountain, Nevada: Yucca Mountain Site Characterization Project, 93:267 (R;US)

Movement of shaft and drift construction water in Yucca Mountain, Nevada: An extended study: Yucca Mountain Site Characterization Project, 93:266 (R;US)

See Fewell, M.E., 93:265, 93:288, 93:344

See Foltz, S.D., 93:320

Soden, D.L., See Conary, J.S., 93:430

Soppet, W.K., See Park, J.Y., 93:403

Sorensen, C.D., See Shenk, K.J., 93:89

Souleyrette, R.R. II, Yucca Mountain transportation routes: Preliminary characterization and risk analysis: Volume 1, Research report, 93:563 (R;US)

Yucca Mountain transportation routes: Preliminary characterization and risk analysis: Volume 2, Figures [and] Volume 3, Technical Appendices, 93:564 (R;US)

Spengler, R.W., See Wittwer, C.S., 93:53, 93:74

St. John, C.M., HEFF-A user's manual and guide for the HEFF code for thermal-mechanical analysis using the boundaryelement method: Version 4.1: Yucca Mountain Site Characterization Project, 93:223 (R;US)

See Asgian, M.I., 93:250

St.John, C.M., Documentation and verification of the SHAFT code: Yucca Mountain Site Characterization Project, $93: 235$ (R;US)

Stahl, D., See Harrison, D.J., 93:71

Stammer, R.E. Jr., See Bronzini, M.S., 93:448

Standifer, E.M., See Nitsche, H., 93:97, 93:109

Statler, J., Flow to licensing: Technical data tracking and the Licensing Support System (LSS), 93:86 (BA;US)

Technical data management at the Yucca Mountain Site Characterization Project, 93:2 (R;US)

Stephan, P.M., See Lorenz, J.J., 93:19

Stepp, J.C., See Shaw, R., 93:625 
See Nimick, F.B., 93:231

See Wibowo, J., 93:311, 93:314

Priest, V., Point defects in silicates, $93: 646(1 ;$ US $)$

Prince, J.K., See Shenk, K.J., 93:89

Pruess, K., Modeling of strongly heat-driven flow processes at a potential high-level nuclear waste repository at Yucca Mountain, Nevada, 93:57 (R;US)

TOUGH2: A general-purpose numerical simulator for multiphase nonisothermal flows, $93: 43$ (RA; US)

See Doughty, C., 93:41

See Niemi, A., 93:38

See Oldenburg, C.M., 93:94

See Tsang, Y.W., 93:44, 93:60

Prussin, T., See Nitsche, H., 93:55, 93:97

Puigdomenech, 1., See Nordstrom, D.K., 93:509

Quade, J., Stable isotopic evidence for a pedogenic origin of carbonates in trench 14 near Yucca Mountain, Nevada, 93:686 (J;US)

\section{$\mathbf{R}$}

Ragheb, M., See Shaheen, M., 93:667

Ragnarsdottir, K.V., Dissolution kinetics of heulandite at pH 2-12 and $25^{\circ} \mathrm{C}, 93: 651$ (J;US)

Raimbauk, L., See Blanc, P.L., 93:419

Ramirez, A.L., Prototype heater test of the environment around a simulated waste package, 93:162 (R;US)

See Lin, Wunan, 93:178

Ramsey, W.G., Durability study of sodium borosilicate glasses leached in tuff $\mathrm{J}-13$ groundwater, $93: 597$ (R;US)

Ramspott, L., Session II: Gas pathway, $93: 462$ (RA;US)

Randall, J., See Codell, R., 93:512

Randall, J.D., See McCartin, T.J., 93:527

Rao, M.G., See Polzer, W.L., 93:113, 93:672

Rasmussen, T.C., Nonisothermal hydrologic transport study at the Apache Leap Tuff site, 93:515 (RA;US)

Nonisothermal hydrologic transport experimental plan, 93:534 (R;US) Validation efforts in modeling flow and transport through partially saturated fractured rock - the Apache leap tuff studies, 93:643 (BA;FR)

Rautman, C.A., Deterministic geologic processes and stochastic modeling, 93:274 (R;US)

Deterministic geologic processes and stochastic modeling, 93:353 (BA;US)

Influence of deterministic geologic trends on spatial variability of hydrologic properties in volcanic tuff, $93: 318$ (R;US)

Recent developments in stochastic modeling and upscaling of hydrologic properties in tuff, 93:321 (R;US)

See Broxton, D.E., 93:108

See Tidwell, V.C., 93:280, 93:345

See Wittwer, C.S., 93:53, 93:74

Raymond, R., See Carlos, B., $93: 134$

Read, D., See Bruno, J., 93:507

Reed, D.T., Progress in assessing the effect of ionizing radiation on the anticipated waste package environment at the Yucca Mountain potential repository site, 93:144 (R;US)

Reed, R.L., See Craig, R.W., 93:390

Reimus, P.W., See Doctor, P.G., 93:155

See Eslinger, P.W., 93:360

Resnikoff, M., Probabilistic risk assessment and nuclear waste transportation: A case study of the use of RADTRAN in the 1986 Environmental Assessment for Yucca Mountain, $93: 560$ (R;US)

Revelli, M.A., See Younker, J.L., 93:67

Reynolds, C.G., See Siegel, M.D., 93:334

Rhoads, R.E., See Daling, P.M., 93:576

Rhodes, E., Dual-energy neutron tomography of water in rock using the Argonne IPNS, 93:411 (R;US)

Richards, K., See Stuckless, J.S., 93:368

Richards, K.A., See Flint, A.L., 93:397, 93:519
Richardson, A.M., Seismic design of circular-section concrete-lined underground openings-Preclosure performance considerations for the Yucca Mountain site, 93:214 (BA;US)

Seismic design of circular-section concrete-lined underground openings: Preclosure performance considerations for the Yucca Mountain Site, $93: 303$ (R;US)

See Fernandez, J.A., 93:215, 93:309

Rickertsen, L., See Gertz, C.P., 93:98

Rickertsen, L.D., See Younker, J.L., 93:76

Rigali, M.J., See Nagy, B., 93:649

Riggle, K., Environmental monitoring for uranium and neptunium at Yucca Mountain using Epithermal Neutron Activation Analysis, 93:447 (R;US)

Riggle, K.J., Environmental monitoring for uranium and neptunium at Yucca Mountain, 93:639 (BA;US)

Riley, S.J., The role of Geographic Information Systems in the Office of the Supervising Scientist, 93:609 (BA;AU)

Roberts, J., Use of annotated outlines to prepare guidance for license applications for the MRS and MGDS, 93:628 (BA;US)

Roberts, K., See Nitsche, H., 98:55

Robertson, A.B., See Wibowo, J., 93:311, 93:314

Robertson, D.L.M., Cost analysis of spent nuclear fuel management, 93:608 (BA;US)

Robey, T.H., Numerical methods for fluid flow in unsaturated heterogeneous tuff, $93: 322$ (R;US)

See Barnard, R.W., 93:293

See Rautman, C.A., 93:321

Robinson, B.A., See Triay, I.R., 93:126, 93:128

Robitz, E.S., See Domian, H.A., 93:186

Rockhold, M.L., Three-dimensional modeling of unsaturated flow in the vicinity of proposed exploratory shaft facilities at Yucca Mountain, Nevada, 93:62 (R;US)

Rogers, C.L., See Ellis, C.B., 98:88

Rogers, P.S.Z., Dependence of radionuclide sorption on sample grinding, surface area, and water composition, 93:127 (R;US)

Rokop, D.J., See Schroeder, N.C., 93:661

Ronen, D., See Czarnecki, J.B., 93:362

Rose, T.P., See Mills, J.G. Jr., 93:678

Rosen, A., See Edwards, B., 93:409, 93:626

Rosman, K.J.R., See De Laeter, J.R., $93: 489$

Ross, B., Implications of stability analysis for heat transfer at Yucca Mountain, 93:337 (R;US)

Numerical studies of rock-gas flow in Yucca Mountain: Yucca Mountain Site Characterization Project, 93:296 (R;US)

Quasi-finear analysis of water flow in the unsaturated zone at Yucca Mountain, Nevada, USA, $93: 258$ (R;US)

Temperature scenarios for a repository at Yucca Mountain, 93:623 (BA;US)

Rousseau, J.P., See Kume, J., 93:361

Rowe, M., See Daling, P.M., 93:576

Ruther, D.J., Drift emplaced waste package thermal response, 93:193 (R;US)

See Short, D.W., 98:183

Rundberg, R.S., A suggested approach toward measuring sorption and applying sorption data to repository performance assessment, $93: 114$ (R;US)

Rusco, E., See Hamby, M., 93:551

Rusco, E.R., Native Americans and state and local governments, 93:553 (R;US)

Rusco, M.K., Socioeconomic profiles of Native American communities: Las Vegas Tribes of Paiute Indians, $93: 550$ (R;US)

Russell, E.W., Cost estimate of high-level radioactive waste containers for the Yucca Mountain Site Characterization Project, 93:161 (R;US)

See Domian, H.A., 93:186

Rutherford, B.M., Statistical analysis of hydrologic data for Yucca Mountain: Yucca Mountain Site Characterization Project, 93:220 (R; US)

Ryder, E.E., Comparison of predicted far-field temperatures for discrete and smeared heat sources, 93:332 (R;US)

Equivalent Energy Density concept: A preliminary reexamination of a technique for equating thermal loads: Yucca Mountain Site Characterization Project, 93:269 (R;US) 
See Swan, F.H., 93:421

Stern, E., See Daling. P.M., 93:576

Stetzenbach, K., Fingerprinting of ground water by ICP-MS: Progress report, July 1, 1991 -December 31, $1991,93: 13$ (R;US)

See Dombrowski, T., 93:14, 93:15

Stetzenbach, K.J., Identification and characterization of conservative organic tracers for use as hydrologic tracers for the Yucca Mountain Site Characterization Project: Quality Assurance Project Plan: Quarterly technical progress report, January 1, 1993-March 31, 1993, $93: 8$ (R;US)

Identification and characterization of consenvative organic tracers for use as hydrologic tracers for the Yucca Mountain Site Characterization Study: Progress report, June 1-December 31, 1990, 93:9 (R;US)

Identification and characterization of conservative organic tracers for use as hydrologic tracers for the Yucca Mountain Site Characterization Study: Progress report, January 1, 1991-June 30, 1991, 93:10 (R;US)

See Dombrowski, T., 93:84

Stetzenbach, L.D., Identification of subsurface microorganisms at Yucca Mountain: Fourth quarterly report, $93: 16$ (R;US)

Stevens, A.L., See Costin, L.S., 93:277, 93:341

See Hunter, T.O., 93:359

Steward, S.A., See Bates, J.K., 93:402

Stiffler, P., See Stuckless, J.S., 93:368

Stille, P., See Bros, R., 93:656

Stirewalt, G.L., See Young, S.R., 93:422

Stockey, J.R., See Justus, P.S., 93:622

Stout, R.B., See Leider, H.R., 93:164

See Marschman, S.C., $93: 177$

Streeter, W.S., Waste package emplacement borehole option study: Yucca Mountain Site Characterization Project, 93:236 (R;US)

Strenge, D.L., See Doctor, P.G., 93:155

See Eslinger, P.W., 93:360

Striffler, P., See Peters, C.A., 93:518

Strong, W.R., See Lindstrom, F.T., 93:428

Stucker, D., See Blair, J.A., 93:630

Stuckless, J.S., Technical issues related to groundwater flow and radionuclide transport in unsaturated fractured rock, $93: 368$ (RA;US)

See Peterman, Z.E., 93:393

See Whelan, J.F., 93:392

Sture, S., See Wibowo, J., 93:311, 93:314

Sultivan, T.M., See Pescatore, C., 93:208, 93:212

Sully, M., See Guzman, A., 93:517

Swan, F.H., Assessment of the potential for tectonic fault rupture for high-level nuclear waste repositories, 93:421 (BA;US)

See Gibson, J.D., 93:254, 93:302

See Wesling, J.R., 93:263

\section{$\mathbf{T}$}

Takahashi, Osamu, Using geological information to develop new exploration project for uranium deposits in Southern Africa, 93:663 (J;JP; In Japanese)

Tanaka, Tadao, Experimental method for determining distribution coefficients of TRU nuclides for evaluating their migration behaviors, 93:476 (R;JP; in Japanese)

Tang, X., See Haupt, R.W., 93:275

Tani, B.S., See Wronkiewicz, D.J., 93:407

Tanner, J.E., See Doctor, P.G., 93:155

See Eslinger, P.W., 93:360

Tatterson, G., See Singh, A., 93:636

Taylor, T.D., See Ramsey, W.G., 93:597

Terhune, C.L., See Brogan, G.E., 93:369

Thackston, E.L., See Bronzini, M.S., 93:448

Thamir, F., See Kwicklis, E.M., 93:520

Thoma, S.G., See Gallegos, D.P., 93:579, 93:621

Thomas, L.E., See Guenther, R.J., 93:151, 93:152, 93:209

Thompson, N.G., Potentiodynamic polarization studies on canddate container alloys for the Tuff Repository, 93:532 (R;US)

Thompson, S.L., See Sandoval, R.P., 93:276, 93:350
Thompson, T.W., See Zimmerman, F.M., 93:227

Thornhill, C.K., See Guenther, R.J., 93:151, 93:152

Thorstenson, D.C., The composition and $\mathrm{CO}_{2}$ carbon isotope signature of gases from borehole USW UZ-6, Yucca Mountain, Nevada, 93:367 (RA;US)

Tidwell, V.C., Field research program for unsaturated flow and transport experimentation, 93:280 (R;US)

Field research program for unsaturated flow and transport experimentation, 93:345 (BA;US)

Scale dependence of effective media properties, 93:323 (R;US)

$X$-ray and visible light transmission as two-dimensional, full-field moisture-sensing techniques: A preliminary comparison, 93:279 (R;US)

See Foltz, S.D., 93:320

See Glass, R.J., 93:253

Tourtellotte, J., Siting the high level radioactive waste repository in the United States, 93:620 (BA;GB)

Towse, D., See Ramirez, A.L., 93:162

Trabla, M.B., Report on task assignment No. 3 for the Waste Package Project: Parts A \& B, ASME pressure vessel codes review for waste package application; Part C, Library search for reliability/failure rates data on low temperature low pressure piping, containers, and casks with long design lives, $93: 12$ (R;US)

Travis, B.J., See Birdsell, K.H., 93:485

Treadway, A.H., See Chambers, W.F., 93:281, 93:340

Triay, I.R., Diffusion of sorbing and non-sorbing radionuclides, 93:129 (R;US)

Neptunium retardation with tuffs and groundwaters from Yucca Mountain, 93:128 (R;US)

Radionuclide migration laboratory studies for validation of batchsorption data, 93:106 (RA;US)

Radionuclide migration laboratory studies for validation of batch sorption data, $93: 118$ (R; US)

Transport of neptunium through Yucca Mountain tuffs, $93: 126$ (R;US)

Tsang, C.F., See Wang, J.S.Y., 93:58

Tsang, Y., See Pruess, K., 93:57

Tsang, Y.W., Modeling studies of gas movement and moisture migration at Yucca Mountain, Nevada, 93:44 (RA;US)

The role of fault zones in affecting multiphase flow at Yucca Mountain, 93:60 (R;US)

Turner, A.K., New approach for regional ground-water modeling in southern Nevada, 93:624 (BA;US)

Turner, D.R., See Manteufel, R.D., 93:537

Turpin, L., See Bros, R., 93:656

Turrin, B.D., ${ }^{40} \mathrm{Ar} /{ }^{39} \mathrm{Ar}$ age of the Lathrop Wells Volcanic Center, Yucca Mountain, Nevada, 93:399 (J;US)

Tyburski, J., See Fernandez, J.A., 93:286, 93:356

Tyburski, J.R., Supporting hydration calculations for small- to largescale seal tests in unsaturated tuff, 93:357 (BA;US)

See Case, J.B., 93:287

See Fernandez, J.A., 93:307

Tyler, S.W., See Lyles, B.F., 93:441

\section{$\mathbf{U}$}

Ueng, T.-S., See Apted, M.J., 93:49

Ueng, T.S., See O'Connell, W.J., 93:170

Ueng, Tzou-Shin, Diffusion releases through one and two finite planar zones from a nuclear waste package, $93: 167$ (R;US)

See Lee, K.H., 93:179

See Ramirez, A.L., 93:162

Updegraft, C.D., See Gallegos, D.P., 93:256

\section{$\mathbf{V}$}

Valentine, G., See Crowe, B.M., 98:120

See Picard, R., 93:139

Valentine, G.A., Effects of magmatic processes on the potential Yucca Mountain repository: Field and computational studies, 93:135 (R;US) 
Physical processes and effects of magmatism in the Yucca Mountain region, 93:117 (R;US)

Physical processes and effects of magmatism in the Yucca Mountain region, $93: 138$ (BA;US)

See Crowe, B.M., 93:136

Van Konynenburg, R.A., Selection of candidate container materials for the conceptual waste package design for a potential high level nuclear waste repository at Yucca Mountain, $93: 172$ (R;US)

See Pflum, C.G., 93:7

Van Luick, A.E., See Daling, P.M., 93:576

Van Lulk, A.E., Travel to Switzerland for performance assessments for both the low- and intermediate-level and high-level radioactive waste disposal programs being managed and implemented by NAGRA: Foreign trip report, May 2-9, 1993, 93:436 (R;US)

See Alexander, D.H., 93:644

See Doctor, P.G., 93:155

See Eslinger, P.W., 93:360

Vaniman, D.T., The importance of zeolites in the potential high-level radioactive waste repository at Yucca Mountain, Nevada, 93:132 (R; US)

Verna, B.J., See DeKlever, R.C., 93:95

Vialta, A., See West, J.M., 93:585

Viani, B., Modeling cation exchange using EQ3/6, 93:149 (RA;US

Viani, B.E., Modeling fluid-rock interaction at Yucca Mountain, Nevada: A progress report, April 15, 1992, $93: 168$ (R;US)

Modeling ion exchange in clinoptilolite using the EOS/6 geochemical modeling code, 93:190 (R;US)

Voegele, M.D., Repository development and long-term data observation needs in the Yucca Mountain, Nevada site characterization program, $93: 72(\mathrm{BA} ; \mathrm{XN})$

See Blanchard, M.B., 93:80

See Dobson, D.C., 93:99

See Parsons, M.W., 93:77

See Simecka, W.B., 93:3, 93:4

VonDoemming, J.D., See Tidwell, V.C., 93:323

Vortman, L.J., An evaluation of the seismicity of the Nevada Test Site and vicinity: Yucca Mountain Site Characterization Project, 93:218 (R;US)

\section{W}

Waber, M., Mineralogy, petrology and geochemistry of the Pocos de Caldas analogue study sites, Minas Gerais, Brazil: II. Morro do Ferro, 93:502 (R;CH)

Waber, N., Mineralogy, petrology and geochemistry of the Pocos de Caldas analogue study sites, Minas Gerais, Brazil. I. Osamu Utsumi uranium mine: Pocos de Caldas Report No. 2, 93:501 $(\mathrm{R} ; \mathrm{CH})$

Waddell, S., See Ponce, D.A., 93:385

Wagner, R.A., RE/SPEC Inc. technical support to the Repository Technology Program: Summary of activities for September 1, 1988-June 30, 1992, 93:432 (R;US)

Wagoner, J.L., See Pawloski, G.A., 93:184

Wallmann, P.C., See Crowe, B.M., 93:136

Walter, W.R., Source parameters of the June 29, 1992 Little Skull Mountain earthquake from complete regional waveforms at a single station, 93:653 (J:US)

Walton, O.R., See Heuze, F.E., 93:425

Wang, H.F., See Mao, Nai-hsien, 93:180

Wang, J.S.Y., Geohydrologic data and models of Rainier Mesa and their implications to Yucca Mountain, 93:58 (R;US)

Processes, mechanisms, parameters, and modeling approaches for partially saturated flow in soil and rock media: Yucca Mountain Site Characterization Project, 93:233 (R;US)

Variation and correlation of hydrologic properties, 93:45 (RA;US)

Variations of hydrological parameters of tuff and soil, $93: 78$ (BA;US)

See Cox, B.L., 93:59

See Narasimhan, T.N., 93:249

See Tsang, Y.W., 93:60

Wang, L.M., See Wronkiewicz, D.J., 93:407

Ward, D.B., See Siegel, M.D., 93:285, 93:334, 93:354

Ward, P.J., See Woodland, D.J., 93:602
Watwood, D., See Lin, Wunan, 93:178

See Ramirez, A.L., 93:162

Weed, H.C., See Leider, H.R., 93:164

Weeks, E.P., Does the wind blow through Yucca Mountain?, 93:366 (RA;US)

Wells, S., Late Quaternary geology of small basaltic volcanic centers, SW USA: Disparity among dating methods and implications for volcanic and geomorphic studies, 93:668 (J;US)

See Crowe, B., 93:112, 93:122

Welis, S.G., Measuring the age of the Lathrop Wells volcanic center at Yucca Mountain, 93:665 (J;US)

Wescott, R.G., A survey of hydrothermal modeling related to Yucca Mountain, 93:524 (RA;US)

Wesling, J.R., Preliminary mapping of surficial geology of Midway Valley Yucca Mountain Project, Nye County, Nevada: Yucca Mountain Site Characterization Project, 93:263 (R;US)

See Gibson, J.D., 93:254, 93:302

West, J.M., Microbiological analysis at the Osamu Utsumi mine and Morro do Ferro analogue study sites, Pocos de Caldas, Brazil Pocos de Caldas Report No. 10, 93:585 (R;SE)

Whelan, J.F., Paleohydrologic implications of the stable isotopic composition of secondary calcite within the tertiary volcanic rocks of Yucca Mountain, Nevada, 93:392 (BA:US)

White, A., See Golding, D., 93:561

White, M.D., MSTS - Multiphase Subsurface Transport Simulator theory manual, $93: 64$ (R;US)

Simulation of two-phase carbon-14 transport at Yucca Mountain,

Nevada, 93:65 (R;US)

See Eslinger, P.W., 93:63

Whitfield, M.S. Jr., Borehole and geohydrologic data for test hole USW UZ-6, Yucca Mountain area, Nye County, Nevada, 98:382 (R;US)

Whitney, J.W., Tectonic characterization of a potential high-level nuclear waste repository at Yucca Mountain, Nevada, 93:364 (BA;US)

See O'Neill, J.M., 93:381

Wibowo, J., Effect of boundary conditions on the strength and deformability of replicas of natural fractures in welded tuff: Data report: Yucca Mountain Site Characterization Project, 93:311 (R;US)

Effect of boundary conditions on the strength and deformability of replicas of natural fractures in welded tuff: Comparison between predicted and observed shear behavior using a graphical method: Yucca Mountain Site Characterization Project, 93:314 (R;US)

Wierenga, P.J., See Porro, I., 93:482

Wilde, B.E., See Wilde, M.H., 93:655

Wilde, M.H., Some observations on the mechanism of corrosion to be encountered in nuclear waste repositories located in tuffaceous rock, 93:655 (J;GB)

Wilder, D.G., Alternative strategies: A means for saving money and time on the Yucca Mountain Project, 93:192 (R;US)

Engineered barrier environment, Yucca Mountain, 93:191 (R;US)

Preliminary near-field environment report: Volume 1 , Technical bases for EBS design, 93:198 (R;US)

Preliminary near-field environment report: Volume 2, Scientific overview of near-field environment and phenomena, 93:199 (R;US)

See Buscheck, T.A., 93:195

Wilkey, P.L., See Levich, R.A., 93:92

Willard, W., See Freudenburg, W.R., 93:555

Williams, R.F., See Shaw, R., 93:625

Wilson, M.L., A simplified radionuclide source term for total-system performance assessment: Yucca Mountain Site Characterization Project, 93:260 (R;US)

Comparison of two conceptual models of flow using the TSA, 93:282 (R;US)

Sensitivity analyses for total-system performance assessment, 93:319 (R; US)

See Barnard, R.W., 93:293

See Gauthier, J.H., 93:217, 93:273, 93:348

Witherspoon, P.A., Geological problems in radioactive waste isolation - A world wide review, 93:497 (RA;US)

Wittwer, C.S., Design of a three-dimensional site-scale model for the unsaturated zone at Yucca Mountain, Nevada, 93:53 (R;US) 
Design of a three-dimensional site scale model for the unsaturated zone at Yucca Mountain, Nevada, 93:74 (BA;US)

WoldeGabriel, G., KUR dating of clinoptilolite, mordenite, and associated clays from Yucca Mountains, Nevada, 93:131 (R;US)

Preliminary assessment of clinoptilolite K/Ar results from Yucca Mountain, Nevada: A potential high-level radioactive waste repository site, $93: 121$ (R;US)

Wolery, T.J., EQ3/6 V7.0: Geochemical Modeling Of Aqueous Systems, 98:147 (CM;US)

EQ3/6 V7.1: Geochemical Modeling of Aqueous Systems, 93:148 (CM;US)

EQ3/6, a software package for geochemical modeling of aqueous systems: Package overview and installation guide (Version 7.0), 93:200 (R;US)

EQ3NR, a computer program for geochemical aqueous speciationsolubility calculations: Theoretical manual, user's guide, and related documentation (Version 7.0): Part 3, 93:202 (R;US)

EQ6, a computer program for reaction path modeling of aqueous geochemical systems: Theoretical manual, user's guide, and related documentation (Version 7.0): Part 4, 93:203 (R;US)

See Daveler, S.A., 93:201

Wolf, M., See Nordstrom, D.K., 93:584

Wollenberg, H.A., Studies of the mobility of uranium and thorium in Nevada Test Site tuff, $93: 498$ (RA; US)

See Flexser, S., 93:52, 93:82

See Wang, J.S.Y., $93: 58$

Wood, D.B., Ground-water data collected at the Nevada Test Site and vicinity, Nye County, Nevada, water years 1988-89, 93:594 (R;US)

Wood, V.M., See Burns, R.G., 93:481

Woodland, A.B., Parametric effects on glass reaction in the unsaturated test method, 93:143 (R;US)

Woodland, D.J., Fish communities in sandy pool of Magela Creek, Alligator Rivers Region: Research Report 9, 93:602 (B;AU)

Wronklewicz, D.J., Effects of radiation exposure on glass alteration in a steam environment, $93: 407$ (R;US)

See Bates, J.K., 93:402, 93:405

Wu, C.L., Effects of a potential drop of a shipping cask, a waste container, and a bare fuel assembly during waste-handling operations: Yucca Mountain Site Characterization Project, 93:224 (R;US)

See DeGabriele, C.E., 93:232

Wu, Y.T., See Gureghian, A.B., 93:536

Wunan Lin, Scientific investigation plan for initial engineered barrier system field tests, 93:171 (R;US)

\section{$\mathbf{Y}$}

Yang, I.C., Flow and transport through unsaturated rock: Data from two test holes, Yucca Mountain, Nevada, 93:391 (BA;US)

See Peters, C.A., 93:518

Yates, M., Council report finds high-level nuclear waste repository rules 'unrealistic', 93:687 (J;US)

DOE reassesses civilian radioactive waste management program,

93:688 (J;US)

Yiqiang Zhang, See Ross, B., 93:337

Yong, C., See Poizer, W.L., 93:1 13

Young, S.R., Geometric models of faulting at Yucca Mountain, 93:422 (BA;US)

Youngs, R.R., See Coppersmith, K.J., 93:629

Younker, J.L., Early evaluation of the suitability of the Yucca Mountain site, 93:76 (BA;US)

Report of early site suitability evaluation of the potential repository site at Yucca Mountain, Nevada: Yucca Mountain Site Characterization Project, $93: 67$ (R;US)

See Dobson, D.C., 93:99

See Gertz, C.P., 93:98

\section{$\mathbf{Z}$}

Zavoshy, S.J., See Ma, C.W., 93:234

Zieman, N.B., See Gauthier, J.H., 93:229

Zimmerman, R.M., G-tunnel pressurized slot-testing evaluations: Yucca Mountain Site Characterization Project, 93:222 (R;US)

G-Tunnel pressurized slot-testing preparations: Yucca Mountain Site Characterization Project, 93:225 (R;US)

G-Tunnel Weided Tuff Mining Experiment instrumentation evaluations: Yucca Mountain Site Characterization Project, 93:227 (R;US)

Zimmerman, R.W., An inverse procedure for estimating the unsaturated hydraulic conductivities of volcanic tuffs, 93:56 (R;US)

Semi-analytical treatment of fracture/matrix flow in a dual-porosity simulator for unsaturated fractured rock masses, 93:54 (R;US)

Sorptivity of rocks and soils of the van Genuchten-Mualem type, 93:46 (RA;US)

Zuidema, P., See Long, J.C.S., $93: 499$

Zwahlen, E.D., A gas-phase source term for Yucca Mountain, 93:40 (R;US)

Zyvoloski, G., FEHMN 1.0: Finite element heat and mass transfer code: Revision 1, 93:103 (R;US) 


\section{Subject Index}

This index is arranged by subject descriptors selected from those assigned to each citation in this publication. Subject descriptors are selected from a controlled thesaurus of terms, ETDE/PUB-2(Rev.1), Intemational Energy: Subject Thesaurus. In order to enhance indexing, subject descriptor entries generally consist of a pair of descriptors: a main term and a qualifier term. Each entry includes the full title (which may be foliowed by supplementary descriptive information in parentheses) and the citation number. Additional information given in parentheses indicates the document type (an abbreviation such as B for book), the country of publication (such as DE for Federal Republic of Germany), and the language if non-English.

See references guide users from synonymous terms to the descriptors selected for the concept. See also references indicate subject concepts that are more specific than a particular descriptor. To gain complete subject coverage, all such terms should be reviewed.

\section{A}

ABSORBED DOSES

SEe RADIATION DOSES

ACCIDENTAL INTAKE

See ACCIDENTS

\section{ACCIDENTS}

Nevada commercial spent nuclear fuel transportation experiACTINIDES ence, $93: 69$ (R;US)

See also

\section{AMERICIUM \\ NEPTUNIUM \\ PLUTONIUM \\ THORIUM}

URANIUM

Effects of actinide burning on waste disposal at Yucca Mountain, 93:446 (R;US)

Radionuclide migration laboratory studies for validation of batch-sorption data, 93:106 (RA;US)

Releases from exotic waste packages from partitioning and transmutation, $93: 51$ (R;US)

Releases from exotic waste packages from partitioning and transmutation, 93:207 (BA;US)

\section{ACTINIUM ADDITIONS}

See ALLOYS

AIR

Progress in assessing the effect of ionizing radiation on the anticipated waste package environment at the Yucca Mountain potential repository site, 93:144 (R;US)

\section{AIR FLOW}

Field testing the effectiveness of pumping to remove sulfur hexafluoride traced drilling air from a prototype borehole near superior, Arizona, 93:518 (RA;US)

\section{AIRCRAFT ACCIDENTS}

\section{See ACCIDENTS}

ALBITE

Neptunium( $V$ ) sorption on quartz and albite in aqueous suspension: Annual progress report, 93:495 (R;US)

ALKALINE EARTH ISOTOPES

See also STRONTIUM ISOTOPES

Radionuclide migration laboratory studies for validation of batch-sorption data, 93:106 (RA;US)

ALLOY-50KH4N6G12F2V

See CHROMIUM ALLOYS

ALLOY-79NM

See NICKEL BASE ALLOYS

ALLOY-GMR-235

See NICKEL BASE ALLOYS

ALLOY-HD-8077

See NICKEL BASE ALLOYS

ALLOY-KH2ON8OT

Se日 NICKEL BASE ALLOYS
ALLOY-KHNTTTYU

See NICKEL BASE ALLOYS

ALLOY-M-252

See NICKEL BASE ALLOYS

ALLOY-MA-754

See NICKEL BASE ALLOYS

ALLOY-MM-0011

See NICKEL BASE ALLOYS

ALLOY-WAZ-16

See NICKEL BASE ALLOYS

ALLOYS

See also CHROMIUM ALLOYS

MOLYBDENUM ALLOYS

TITANIUM ALLOYS

Report on task assignment No. 3 for the Waste Package Project: Parts A \& B, ASME pressure vessel codes review for waste package application; Part C, Library search for reliability/failure rates data on low temperature low pressure piping, containers, and casks with long design lives, $93: 12$ (R;US)

ALPHA-BEARING WASTES

Critical comments on the US Environmental Protection Agency Standards 40 CFR 191, 93:7 (R;US)

Criticality safety issues associated with the burial of highly enriched nuclear fuel in a geologic repository, $93: 596$ (R;US)

Evaluation of alternatives for high-level and transuranic radioactive- waste disposal standards, $93: 582$ ( $R$;US)

\section{AMERICAN INDIANS}

Native Americans and Yucca Mountain: A revised and updated summary report on research undertaken between 1987 and 1991: Volume 1, $93: 548$ (R;US)

Native Americans and Yucca Mountain: A revised and updated summary report on research undertaken between 1987 and 1991: Volume 2, 93:549 (R;US)

Native Americans and Yucca Mountain: A summary report, 93:544 (R;US)

Socioeconomic profiles of Native American communities: Las Vegas Tribes of Paiute Indians, 93:550 (R;US)

Socioeconomic profiles of native American communities: Duckwater Shoshone Reservation, 93:552 (R;US)

Socioeconomic profiles of native American communities: Yomba Shoshone Reservation, 93:551 (R;US)

\section{AMERICIUM}

Radionuclide solubility and speciation studies for the Yucca Mountain site characterization project, 93:55 (R;US)

Solubility and speciation studies for nuclear repository performance assessment, $93: 50$ (R; US)

AMERICIUM 241

Experimental method for determining distribution coefficients of TRU nuclides for evaluating their migration behaviors, 93:476 ( $R ; J P ;$ in Japanese)

\section{AMERICIUM COMPOUNDS}

Dependence of actinide solubility and speciation on carbonate concentration and ionic strength in groundwater, $93: 97(\mathrm{~J} ; \mathrm{DE})$ 
AMERICIUM PHOSPHIDES

See AMERICIUM COMPOUNDS

ANALOG SYSTEMS

Natural analogue studies useful in validating regulatory compliance analyses, 93:644 (BA;FR)

ANALYSIS (THERMAL)

See THERMAL ANALYSIS

ANIONS

Diffusion of sorbing and non-sorbing radionuclides (Yucca Mountain Project), 93:129 (R;US)

APERTURES

Single fracture aperture patterns: Characterization by slit-island fractal analysis (Yucca Mountain Project), 93.59 (R;US)

\section{APPARATUS}

See EQUIPMENT

AQUATIC ORGANISMS

See also FISHES

Uptake of uranium and thorium series radionuclides by the waterlily, Nymphaea violacea, $93: 659$ (J;GB)

AQUEOUS SOLUTIONS

EQ3/6 V7.0: Geochemical Modeling of Aqueous Systems, 93:147 (CM;US)

EQ3/6 V7.1: Geochemical Modeling of Aqueous Systems, 93:148 (CM;US)

EQ3/6, a software package for geochemical modeling of aqueous systems: Package overview and installation guide (Version 7.0), 93:200 (R;US)

ASTATINE ADDITIONS

SEe ALLOYS

ATTITUDES OF THE PUBLIC

SOE PUBLIC OPINION

AUSTRALIAN ORGANIZATIONS

Alligator Rivers Region Research Institute: annual research summary 1989-1990, 93:601 (B;AU)

Alligator Rivers Region Research Institute: annual research summary 1989-1990, 93:606 (B;AU)

Annual Report 1991-1992, 93:604 (B;AU)

\section{$\mathbf{B}$}

\section{BENCH-SCALE EXPERIMENTS}

Laboratory research program to aid in developing and testing the validity of conceptual models for flow and transport through unsaturated porous media, 93:358 (BA;FR)

\section{BENTONITE}

Gas phase migration of C-14 through barrier materials applicable for use in a high-level nuclear waste repository located in tuff, 93:647 (i;US)

Sealing performance assessments of bentonite and bentonite/crushed rock plugs, 93:645 (I;US)

Sealing performance of bentonite and bentonite/crushed rock borehole plugs, 93:530 (R;US)

BERKELIUM ADDITIONS

See ALLOYS

BOILING WATER COOLED AND MODERATED REACTOR

SEe BWR TYPE REACTORS

BORATES

- Evaluation of potential hydrologic tracers in tuffs from Yucca Mountain, Nevada, 93:487 (RA;US)

\section{BOREHOLES}

Areal power density: A preliminary examination of underground heat transfer in a potential Yucca Mountain repository and recommendations for thermal design approaches: Yucca Mountain Site Characterization Project (YUCCA MOUNTAIN PROJECT), 93:243 (R;US)

Borehole stability in densely welded tuffs, 93:531 (R;US)

Geophysical logs and core measurements from forty boreholes at Yucca Mountain, Nevada, 93:370 (R;US)

Waste package emplacement borehole option study: Yucca Mountain Site Characterization Project (Yucca Mountain Project), 93:236 (R;US)

\section{BORON}

Boron adsorption on hematite and clinoptilolite, $93: 490$ (R;US)

Transport of reactive tracers by unsaturated flow using field and column experiments, 93:482 (RA;US)

BORON CARBIDES

Conceptual design of a monitored retrievable storage cask employing Yucca Mountain containers, 93:638 (BA;US)

BOROSILICATE GLASS

ANL technical support program for DOE Environmental Restoration and Waste Management: Annual report, October 1991-September 1992, 93:405 (R;US)

Durability study of sodium borosilicate glasses leached in tuff $J$ 13 groundwater, $93: 597$ (R;US)

BOROSILICATES

BRAZIL

See BOROSILICATE GLASS

The regional geology, mineralogy and geochemistry of the Pocos de Caldas alkaline caldera complex, Minas Gerais, Brazil, $93: 500(\mathrm{R} ; \mathrm{CH})$

\section{BROMIDES}

Evaluation of potential hydrologic tracers in tuffs from Yucca Mountain, Nevada, 93:487 (RA;US)

\section{BROMINE}

Preliminary characterization of materials for a reactive transport model validation experiment, $93: 334$ (R;US)

\section{BROMINE BROMIDES}

See BROMINE

\section{BUSINESS}

Empirical investigation of the effect of amenities and other factors on business location decisions, 93:417 (R;US)

Socioeconomic assessment guidance report: Determining the effects of amenity characteristics on business location decisions, 93:415 (R;US)

BWR TYPE REACTORS

Thermal performance of a buried nuclear waste storage container storing a hybrid mix of PWR and BWR spent fuel rods: Revision 1, 93:159 (R;US)

C CODES

CTCN: Colloid transport code - nuclear: A user's manual, 93:494 (R;US)

Colloid transport code-nuclear user's manual, 93:493 (R;US)

CALCITE

Paleohydrologic implications of the stable isotopic composition of secondary calcite within the tertiary volcanic rocks of Yucca Mountain, Nevada, 93:392 (BA;US)

Scenario development for performance assessment: Some questions for the near-field modelers (yucca mountain project), 93:325 (R;US)

CALCIUM

Unsaturated transport of inorganic cations in undisturbed soil columns, 93:484 (RA;US)

CALCULATIONS (2-DIMENSIONAL)

SEe TWO-DIMENSIONAL CALCULATIONS

CALIFORNIA

Late Quaternary geology of small basaltic volcanic centers, SW USA: Disparity among dating methods and implications for volcanic and geomorphic studies, 93:668 (J;US)

CALIFORNIUM ADDITIONS

$$
\text { SeO ALLOYS }
$$

CANADA

Panel discussion on nuclear waste, 93:614 (BA;US)

CANCER

See NEOPLASMS

CANISTERS

SEe CONTAINERS

CAPILLARY FLOW

On numerical modeling of capillary barriers, 93:94 (J;US)

The capillary hysteresis model HYSTR: User's guide, 93:37 (R;US)

Yucca Mountain Site Characterization Project 


\section{CARBON 14}

A gas-phase source term for Yucca Mountain, $93: 40$ (R;US)

Session II: Gas pathway, 93:462 (RA:US)

CARBON 14 COMPOUNDS

Simulation of two-phase carbon-14 transport at Yucca Mountain, Nevada, 93:65 (R;US)

\section{CARBON DIOXIDE}

A gas-phase source term for Yucca Mountain, 93:40 (R;US)

Characterization of the Topopah spring and Tiva Canyon tuffs at Yucca Mountain: Effective diffusivities and pore properties, 93:636 (BA;US)

Diffusion of carbon dioxide and iodine through Yucca Mountain tuffs: Effects of temperature and moisture content, 93:635 (BA;US)

Gas phase migration of $\mathrm{C}-14$ through barrier materials applicable for use in a high-level nuclear waste repository located in tuff, $93: 647$ (i;US)

Temperature effect on diffusion of carbon dioxide through upper layers of Yucca Mountain, 93:675 (J;GB)

\section{CARBON ISOTOPES}

See also CARBON 14

Stable isotopic evidence for a pedogenic origin of carbonates in trench 14 near Yucca Mountain, Nevada, 93:686 (J;US)

\section{CASKS}

See also SPENT FUEL CASKS

A report on high-level nuclear waste transportation: Prepared pursuant to assembly concurrent resolution No. 8 of the 1987 Nevada Legislature, 93:558 (R;US)

Effects of a potential drop of a shipping cask, a waste container, and a bare fuel assembly during waste-handling operations: Yucca Mountain Site Characterization Project (Yucca Mountain Project), 93:224 (R;US)

\section{CATION EXCHANGE CAPACITY}

See ION EXCHANGE

\section{CEMENTS}

See also PORTLAND CEMENT

Pressurized grout applications in fractured tuff for containment of radioactive wastes, 93:676 (J;GB)

Supporting hydration calculations for small- to large-scale seal tests in unsaturated tuff (Yucca Mountain Project), 93:287 (R;US)

Supporting hydration calculations for small- to large-scale seal tests in unsaturated tuff, 93:357 (BA;US)

The hydrothermal stability of cement sealing materials in the potential Yucca Mountain high level nuclear waste repository (Yucca Mountain Project), 93:292 (R;US)

The hydrothermal stability of cement sealing materials in the potential Yucca Mountain high level nuclear waste repository, 93:339 (BA;US)

CENTRAL REGION

See USA

CESIUM

Dependence of radionuclide sorption on sample grinding, surface area, and water composition, $93: 127$ (R;US)

Modeling cation exchange using EQ3/6, 93:149 (RA:US)

Sorption of cesium and strontium by zeolite single crystals, 93:481 (RA:US)

Thermodynamically derived relationships between the modified Langmuir isotherm and experimental parameters, 93:672 ( $\mathrm{J} ; \mathrm{US})$

\section{CESIUM 135}

Sensitivity analysis of integrated radionuclide transport based on a three-dimensional geochemicalgeophysical model, 93:485 (RA:US)

CHEMICAL HEAT PIPES

SeE HEAT PIPES

\section{CHEMICAL REACTIONS}

EQ6, a computer program for reaction path modeling of aqueous geochemical systems: Theoretical manual, user's guide, and related documentation (Version 7.0): Part 4, 93:203 (R;US)

CHLORINE 36

${ }^{36} \mathrm{Cl}$ production in situ, and groundwater transport in a uranium ore deposit, 93:631 (BA;US)
CHLORITE MINERALS

Natural analogue studies: Mineral alteration and uranium migration, $93: 477$ (R;JP;In Japanese)

\section{CHROMIUM}

Transport of reactive tracers by unsaturated flow using field and column experiments, 93:482 (RA;US)

CHROMIUM ALLOYS

Survey of degradation modes of four nickel-chromiummolybdenum alloys, 93:166 (R;US)

CLINOPTILOLITE

KIAR dating of clinoptilolite, mordenite, and associated clays from Yucca Mountains, Nevada, 93:131 (R;US)

Modeling cation exchange using EQ3/6, 93:149 (RA;US)

Modeling fluid-rock interaction at Yucca Mountain, Nevada: A progress report, April 15, 1992, 93:168 (R;US)

Preliminary assessment of clinoptilolite KJAr results from Yucca Mountain, Nevada: A potential high-level radioactive waste repository site, 93:121 (R;US)

Sorption of cesium and strontium by zeolite single crystals, 93:481 (RA;US)

COAL INDUSTRY

Proceedings of the conference on shaft drilling technology, 93:607 (B;US)

COBALT

Thermodynamically derived relationships between the modified Langmuir isotherm and experimental parameters, 93:672 (J:US)

Unsaturated transport of inorganic cations in undisturbed soil columns, 93:484 (RA;US)

COLLOIDS

See also GELS

Chemical and physical characterisation of suspended particles and colloids in waters from the Osamu Utsumi mine and Morro do Ferro analogue study sites, Pocos de Caldas, Brazil, 93:506 (R; $\mathrm{CH})$

Colloid research for the Nevada Test Site, 93:478 (R;US)

COMMUNITIES

Community Radiation Monitoring Program: Annual report, October 1, 1990-September 30, 1991, 93:442 (R;US)

COMPUTER CODES

See also C CODES

E CODES

H CODES

$P$ CODES

$S$ CODES

Groundwater flow code verification "benchmarking" activity (COVE-2A): Analysis of participants' work, 93:244 (R;US)

Supporting hydration calculations for small- to large-scale seal tests in unsaturated tuff, 93:357 (BA;US)

The hydrothermal stability of cement sealing materials in the potential Yucca Mountain high level nuclear waste repository, 93:339 (BA;US)

\section{COMPUTER PROGRAMS}

SEe COMPUTER CODES

COMPUTERIZED SIMULATION

TURBOSEIS-An interactive program for constructing and editing models of seismic refraction traveltime data using a color-graphics terminal, $93: 371$ (R;US)

\section{CONTAINERS}

Soe also CASKS

$$
\text { PRESSURE VESSELS }
$$

\section{Chemical Reactions}

Scientific investigation plan for initial engineered barrier system field tests (Yucca Mountain Project), 93:171 (R;US)

\section{Corrosion}

Corrosion models for predictions of performance of high-level radioactive-waste containers, 93:160 (R;US)

Survey of degradation modes of four nickel-chromiummolybdenum alloys, 93:166 (R;US)

Cracks

Crack growth behavior of candidate waste container materials in simulated underground water, 93:146 (R;US) 
Damage

Analysis of releases due to drilling at the potential Yucca Mountain repository, 93:336 (R;US)

Design

NRC approves spent-fuel cask for general use: Who needs Yucca Mountain?, 93:648 (J;US)

Quarterly progress report on the DOE Waste Package project at the University of Nevada, Las Vegas, July 1, 1993 through September 30, 1993, $93: 17$ (R;US)

Fabrication

Cost estimate of high-level radioactive waste containers for the Yucca Mountain Site Characterization Project (YUCCA MOUNTAIN PROJECT), 93:161 (R;US)

Fabrication and closure development of nuclear waste disposal containers for the Yucca Mountain Project: Status report, 93:186 (R;US)

LLNLYMP Waste Container Fabrication and Closure Project GFY technical activity summary, 93:591 (R;US)

Failures

A gas-phase source term for Yucca Mountain, 93:40 (R;US)

Demands placed on waste package performance testing and modeling by some general results on reliability analysis, 93:181 (R;US)

Post-closure performance assessment of waste packages for the Yucca Mountain Project (Yucca Mountain Project), 93:170 (R;US)

Impact Tests

Effects of a potential drop of a shipping cask, a waste container, and $a$ bare fuel assembly during waste-handling operations: Yucca Mountain Site Characterization Project (Yucca Mountain Project), 93:224 (R;US)

Geohydrologic data and models of Rainier Mesa and their implications to Yucca Mountain (Yucca Mountain Project), 93:58 (R;US)

Using QA classification to guide design and manage risk, 93:5 (R;US)

Licensing

NRC approves spent-fuel cask for general use: Who needs Yucca Mountain?, 93:648 (J;US)

Performance

Waste-package release rates for site suitability studies, $93: 48$ (R;US)

Performance Testing

Demands placed on waste package performance testing and modeling by some general results on reliability analysis, 93:181 (R;US)

Stress Corrosion

Stress corrosion cracking of candidate waste container materials: Final report, 93:403 (R;US)

Stress-corrosion-cracking studies on candidate container alloys for the Tuff Repository, 93:533 (R;US)

System Failure Analysis

Engineered barrier system failure modeling: A statistical approach, 93:613 (BA;US)

Temperature Effects

Thermal performance of a buried nuclear waste storage container storing a hybrid mix of PWR and BWR spent fuel rods: Revision 1, 93:159 (R;US)

\section{CONTAINMENT}

See also CONTAINMENT SYSTEMS

Evaluation and compilation of DOE waste package test data: Biannual report, February 1989-July 1989: Volume 7, 93:528 (R;US)

\section{CONTAINMENT SYSTEMS}

Reliability modeling of an engineered barrier system, 93:429 (R;US)

Seismic considerations in sealing a potential high-level radioactive waste repository, 93:309 (R; US)

\section{CONTROL SYSTEMS}

Automated waste canister docking and emplacement using a sensor-based intelligent controller: Yucca Mountain Site Characterization Project, 93:262 (R;US)

\section{COPPER}

Evaluation of copper, aluminum bronze, and copper-nickel container material for the Yucca mountain project, 93:142 (RA;CA)

\section{COPPER BASE ALLOYS}

Corrosion models for predictions of performance of high-level radioactive-waste containers, 93:160 (R;US)

Evaluation of copper, aluminum bronze, and copper-nickel container material for the Yucca mountain project, 93:142 (RA;CA)

Potentiodynamic polarization studies on candidate container alloys for the Tuff Repository, 93:532 (R;US)

Stress-corrosion-cracking studies on candidate container alloys for the Tuff Repository, 93:533 (R;US)

CORES (DRILL)

See DRILL CORES

\section{DATA BASE MANAGEMENT}

Technical data base quarterly report, Aprit-June 1992: Yucca Mountain Site Characterization Project, 93:216 (R;US)

DATA PROCESSING

EQPT, a data file preprocessor for the EQ3/6 software package: User's guide and related documentation (Version 7.0): Part 2, 93:201 (R;US)

DEBRIS (NUCLEAR)

SeE FISSION PRODUCTS

DEGRADATION (RADIOINDUCED)

See RADIOLYSIS

DESIGN

Classification and grading of design products for the Yucca Mountain project, $93: 95$ (J:US)

Report on task assignment No. 3 for the Waste Package Project: Parts A \& B, ASME pressure vessel codes review for waste package application; Part C, Library search for reliability/failure rates data on low temperature low pressure piping, containers, and casks with long design lives, $93: 12$ (R;US)

\section{DEUTERIUM}

Anomalous deuteron to hydrogen ratio in naturally occuring fission reactions and the possibility of deuteron disintegration, 93:667 (J;HU)

\section{DEUTERONS}

Anomalous deuteron to hydrogen ratio in naturally occuring fission reactions and the possibility of deuteron disintegration, 93:667 (J;HU)

DEVICES

\section{See EQUIPMENT}

DIFFUSION

A gas-phase source term for Yucca Mountain, 93:40 (R;US)

DISSOLUTION

Estimating the time for dissolution of spent fuel exposed to unlimited water, 93:164 (R;US)

\section{DISSOLVED MATERIALS}

SoO SOLUTES

DISSOLVED OXYGEN

See OXYGEN

\section{DOSE RATES}

An example postclosure risk assessment using the potential Yucca Mountain Site, 93:155 (R;US)

DRILL CORES

Influence of deterministic geologic trends on spatial variability of hydrologic properties in volcanic tuff, $98: 318$ (R;US)

Radioelements and their occurrence with secondary minerals in heated and unheated tuff at the Nevada Test Site, 93:52 (R;US)

DRILL HOLES

Soe BOREHOLES

DRILLING

Analysis of releases due to drilling at the potential Yucca Mountain repository, 93:336 (R;US) 
Proceedings of the conference on shaft drilling technology, 93:607 (B;US)

DYMAC SYSTEM

See PLUTONIUM

DYNAMIC MATERIALS ACCOUNTABILITY SYSTEM

See PLUTONIUM

\section{$\mathbf{E}$}

E CODES

EQ3/6 V7.0: Geochemical Modeling Of Aqueous Systems, 93:147 (CM;US)

EQ3/6 V7.1: Geochemical Modeling of Aqueous Systems, 93:148 (CM;US)

\section{EARTHMOVING EQUIPMENT}

Performance prediction of mechanical excavators from linear cutter tests on Yucca Mountain welded tuffs: Yucca Mountain Site Characterization Project, 93:299 (R;US)

\section{EARTHQUAKES}

Modeling tault rupture hazard for the proposed repository at Yucca Mountain, Nevada, 93:629 (BA;US)

Processed seismic motion records from Little Skull Mountain, Nevada earthquake aftershocks of July 5, 1992 and September 13, 1992, recorded at seismic stations in southern Nevada, 93:475 (R;US)

Processed seismic motion records from Little Skull Mountain, Nevada earthquake of June 29,1992, recorded at stations in southern Nevada, 93:474 (R;US)

EFFLUENTS (GASEOUS)

See GASEOUS WASTES

EFFLUENTS (RADIOACTIVE)

See RADIOACTIVE EFFLUENTS

EFFUSION

See DIFFUSION

EINSTEINIUM ADDITIONS

SeE ALLOYS

ELECTRONIC DATA PROCESSING

SEe DATA PROCESSING

EMERGENCIES

SeE ACCIDENTS

\section{EMPLACEMENT}

Waste package emplacement borehole option study: Yucca Mountain Site Characterization Project (Yucca Mountain Project), 93:236 (R:US)

\section{ENGINEERED SAFETY SYSTEMS}

See also CONTAINMENT SYSTEMS

Travel to France to attend and participate in the Technical Workshop on Near-Field Performance Assessment: Foreign trip report, May 9-16, 1993, 93:435 (R;US)

Waste package and engineered barrier system design concepts for the direct disposal of spent fuel in the potential United States repository at Yucca Mountain, Nevada, 93:71 (BA;XA)

\section{ENVIRONMENT}

Science and students: Yucca Mountain Project's educationa outreach and public tour programs, 93:83 (BA;US)

ENVIRONMENTAL EXPOSURE PATHWAY

An example postclosure risk assessment using the potential Yucca Mountain Site, 93:155 (R; US)

ENVIRONMENTAL IMPACTS

A selected GIS bibliography: Technical Memorandum 40 , 93:603 (B;AU)

\section{ENVIRONMENTAL MATERIALS}

Environmental monitoring for uranium and neptunium at Yucca Mountain using Epithermal Neutron Activation Analysis, 93:447 (R:US)

ENVIRONMENTAL PROTECTION AGENCY SeE US EPA

ENVIRONMENTAL TRANSPORT

See also RADIONUCLIDE MIGRATION

MSTS - Multiphase Subsurface Transport Simulator theory manual, 93:64 (R;US)
Technical issues related to groundwater flow and radionuclide transport in unsaturated fractured rock, 93:368 (RA;US)

Validation efforts in modeling flow and transport through partially saturated fractured rock - the Apache leap tuff studies, 93:643

EPA (BA;FR)

See US EPA

EQUIPMENT

See also TUNNELING MACHINES

Performance predictions for mechanical excavators in Yucca Mountain tuffs: Yucca Mountain Site Characterization Project, 93:297 (R:US

UNS YMSCP QA support task: Quarterly technical progress report, January 1, 1991-June 30, 1991, 93:11 (R;US)

ERUPTION

Physical processes and effects of magmatism in the Yucca Mountain region, 93:117 (R:US)

EXCAVATORS

See EARTHMOVING EQUIPMENT

EXCHANGE (HEAT)

SEQ HEAT TRANSFER

EXCHANGE (ION)

SeE ION EXCHANGE

EXPLORATORY WELLS

Preclosure radiological safety analysis for the exploratory shaft facilities: Yucca Mountain Site Characterization Project (Yucca Mountain Project), 93:246 (R;US)

EXPOSURE (RADIATION DOSES)

SE RADIATION DOSES

\section{$\mathbf{F}$}

FACILITIES (NUCLEAR)

SEE NUCLEAR FACILITIES

FACIUTIES (TEST)

SeE TEST FACILITIES

FAILURES

SEe also FRACTURES

A simplified radionuclide source term for total-system performance assessment: Yucca Mountain Site Characterization Project (Yucca Mountain Project:a1), 93:260 (R;US)

FEDERAL REGION I

SEe USA

FEDERAL REGION \|

SEO USA

FEDERAL REGION III

SOE USA

FEDERAL REGION IV

SeE USA

FEDERAL REGION IX

See USA

FEDERAL REGION $V$

SEO USA

FEDERAL REGION VI

SeE USA

FEDERAL REGION VII

Søe USA

FEDERAL REGION VIII

SeO USA

FEDERAL REGION $X$

SeO USA

FINITE ELEMENT METHOD

FEHMN 1.0: Finite element heat and mass transfer code: Revision 1, 93:103 (R;US)

FISHES

Fish communities in sandy pool of Magela Creek, Alligator Rivers Region: Research Report 9, 93:602 (B;AU)

FISSION PRODUCTS

Fission product studies in the symmetric mass region, 93:489 (RA;US)

FISSURED FORMATIONS

SEe FRACTURED RESERVOIRS 


\section{FLASKS}

See CASKS

FLOW (FLUID)

See FLUID FLOW

\section{FLOW MODELS}

Design of an intermediate-scale experiment to validate unsaturated-zone transport models, 93:285 (R;US)

Initial demonstration of the NRC's capability to conduct a performance assessment for a High-Level Waste Repository, 93:512 (R;US)

On numerical modeling of capillary barriers, $93: 94$ (J;US)

The international hydrocoin project - Groundwater hydrology modelling strategies for performance assessment of nuclear waste disposal, $93 ; 470(\mathrm{R} ; \mathrm{XN})$

Uncertainty and sensitivity results for pre-waste-emplacement groundwater travel time, 93:272 (R;US)

\section{FLUID FLOW}

See also CAPILLARY FLOW GAS FLOW

\section{Computer Codes}

Groundwater flow code verification "benchmarking" activity (COVE-2A): Analysis of participants' work, 93:244 (R;US)

\section{H Codes}

Incorporation of the capillary hysteresis model HYSTR into the numerical code TOUGH, 93:38 (R;US)

$L$ Codes

LLUVIA-II: A program for two-dimensional, transient flow through partially saturated porous media: Yucca Mountain Site Characterization Project (Yucca Mountain Project.), 93:290 (R;US)

\section{Mathematical Models}

A survey of hydrothermal modeling related to Yucca Mountain, 93:524 (RA;US)

Characterization of flow in fractured tuff using computerized tomography, $93: 491$ (R;US)

Field research program for unsaturated flow and transport experimentation (Yucca Mountain Project), $93: 280$ (R;US)

Flow through nonhomogeneous porous media, 93:525 (RA;US)

Ground water flow through unsaturated fractured rock research needs, 93:521 (RA;US)

Investigation of fracture-matrix interaction: Preliminary experiments in a simple system (Yucca Mountain Project), 93:320 (R;US)

Wetting front instability in an initially wet unsaturated fracture (Yucca Mountain Project), 93:327 (R;US)

N Codes

Initial demonstration of the NRC's capability to conduct a performance assessment for a High-Level Waste Repository, 93:512 (R:US)

Numerical Analysis

Movement of shaft and drift construction water in Yucca Mountain, Nevada: An extended study: Yucca Mountain Site Characterization Project, 93:266 (R;US)

\section{$P$ Codes}

Three-dimensional modeling of unsaturated flow in the vicinity of proposed exploratory shaft facilities at Yucca Mountain, Nevada, 93:62 (R;US)

\section{$s$ Codes}

Initial demonstration of the NRC's capability to conduct a performance assessment for a High-Level Waste Repository, 93:512 (R;US)

T Codes

Incorporation of the capillary hysteresis model HYSTR into the numerical code TOUGH, 93:38 (R;US)

Initial demonstration of the NRC's capability to conduct a performance assessment for a High-Level Waste Repository, 93:512 (R;US)

Preliminary capillary hysteresis simulations for fractured rocks model development and results of simulations, 93:39 (R;US)

Semi-analytical treatment of fracture/matrix flow in a duat porosity simulator for unsaturated fractured rock masses, 93:54 (R;US)
Total System Performance Assessment Code (TOSPAC): Volume 2, User's guide: Yucca Mountain Site Characterization Project, 93:217 (R;US)

Testing

Evaluation of tracers for hydrologic studies at Yucca Mountain, 93:526 (RA;US)

U Codes

Preliminary modeling of moisture movement in the tuff beneath Mortandad Canyon, Los Alamos National Laboratory, 93:496 (R;US)

$\checkmark$ Codes

Initial demonstration of the NRC's capability to conduct a performance assessment for a High-Level Waste Repository, 93:512 (R;US)

a Codes

AREST: The next generation, 93:157 (R;US)

FLUORINATED ALIPHATIC HYDROCARBONS

Identification and characterization of conservative organic tracers for use as hydrologic tracers for the Yucca Mountain Site characterization study: Progress report, April 1, 1993-June 30, 1993, 93:15 (R:US)

\section{FLUORINATED AROMATIC HYDROCARBONS}

Identification and characterization of conservative organic tracers for use as hydrologic tracers for the Yucca Mountain Site characterization study: Progress report, April 1, 1993-June 30, 1993, 93:15 (R;US)

FORT ST. VRAIN REACTOR

SEO VRAIN REACTOR

FRACTURED FORMATIONS

See FRACTURED RESERVOIRS

FRACTURED RESERVOIRS

TOUGH2: A general-purpose numerical simulator for multiphase nonisothermal flows, 93:43 (RA;US)

\section{FRACTURES}

Pre-waste-emplacement ground-water travel time sensitivity and uncertainty analyses for Yucca Mountain, Nevada: Yucca Mountain Site Characterization Project (yucca mountain project), 93:305 (R;US)

\section{FUEL ASSEMBLIES}

Effects of a potential drop of a shipping cask, a waste container, and a bare fuel assembly during waste-handling operations: Yucca Mountain Site Characterization Project (Yucca Mountain Project), 93:224 (R;US)

\section{FUSION (WELDING)}

Seo WELDING

\section{B}

\section{GAMMA DETECTION}

Effects of various radiation source characteristics on shielding requirements at the potential Yucca Mountain repository, 93:248 (R;US)

\section{GAMMA HEATING}

See RADIATION HEATING

\section{GAS COOLANTS}

See GASES

GAS FLOW

See also AIR FLOW

A gas-phase source term for Yucca Mountain, 93:40 (R;US)

GASEOUS EFFLUENTS

SeE GASEOUS WASTES

GASEOUS WASTES

Session li: Gas pathway, 93:462 (RA;US)

GASES

Soe also AIR

\section{VAPORS}

Does the wind blow through Yucca Mountain?, 93:366 (RA;US) Scale dependence of effective media properties, $93: 323$ (R;US)

The composition and $\mathrm{CO}_{2}$ carbon isotope signature of gases from borehole USW UZ-6, Yucca Mountain, Nevada, 93:367 (RA;US) 
GELS

Natural gels in the Yucca Mountain Area, Nevada, USA, 93:116 (R;US)

GEOCHEMISTRY

AREST: The next generation, $93: 157$ (R;US)

EQ3/6 V7.0: Geochemical Modeling Of Aqueous Systems, 93:147 (CM;US)

EQ3/6 V7.1: Geochemical Modeling of Aqueous Systems, 93:148 (CM;US)

EQ3/6, a software package for geochemical modeling of aqueous systems: Package overview and installation guide (Version 7.0), 93:200 (R;US)

Testing models of redox front migration and geochemistry at the Osamu Utsumi mine and Morro do Ferro analogue study sites, Pocos de Caldas, Brazil, $93: 508$ (R;CH)

GEOISOTHERM

SeO ISOTHERMS

GEOLOGIC FAULTS

Fault stress analysis for the Yucca Mountain Site Characterization Project, 93:278 (R:US)

Late quaternary faulting along the Death Valley-Furnace Creek fault system, California and Nevada, 93:369 (R;US)

GEOLOGIC FISSURES

A study of discrete and continuum joint modeling techniques, 93:271 (R;US)

GEOLOGIC FRACTURES

See also GEOLOGIC FAULTS

A scoping study of water table excursions induced by seismic and volcanic events, 93:163 (R:US)

Apache leap watershed study, 93:516 (RA;US)

Distribution and chemistry of fracture-lining zeolites at Yucca Mountain, Nevada (Yucca Mountain Project), 93:134 (R;US)

Ground water flow through unsaturated fractured rock research needs, 93:521 (RA;US)

impact of fracture coatings on the transfer of water across fracture faces in unsaturated media, 93:621 (BA;US)

Impact of fracture coatings on the transfer of water across fracture faces in unsaturated media, 93:579 (R;US)

Nonequilibrium fracture-matrix flow during episodic infiltration events in Yucca Mountain (Yucca Mountain Project), 93:514 (RA;US)

Nonisothermal hydrologic transport study at the Apache Leap Tuff site, 93:515 (RA;US)

Numerical and laboratory investigations of transient and steadystate flow in a fractured core, 93:520 (RA-US)

Potential increases in natural radon emissions due to heating of the Yucca Mountain rock mass, 93:208 (BA;US)

Technical issues related to groundwater flow and radionuclide transport in unsaturated fractured rock, 93:368 (RA;US)

The impact of thermal loading on repository performance at Yucca Mountain, 93:205 (BA;US)

US Geological Survey Committee for the Advancement of Science in the Yucca Mountain Project symposium on "Fractures, Hydrology, and Yucca Mountain": Abstracts and summary, $93: 375$ (R;US)

[Symposium for the STRIPA Project]: Foreign trip report, October 10-17, 1992, 93:433 (R;US)

GEOLOGIC JOINTS

See GEOLOGIC FISSURES

GEOLOGIC STRATA

Physical processes and effects of magmatism in the Yucca Mountain region, $93: 117$ (R;US)

\section{GEOLOGY}

See also GEOMORPHOLOGY

Deterministic geologic processes and stochastic modeling, 93:274 (R; US)

Developing a functioning visualization and analysis system for performance assessment, 93:346 (BA;US)

GENISES: A GIS Database for the Yucca Mountain Site Characterization Project, 93:1 (R;US)

GEOMORPHOLOGY

Geomorphological and hydrogeological features of the Pocos de Caldas caldera and the Osamu Utsumi mine and Morro do
Ferro analogue study sites, Brazil: Pocos de Caldas Report No. 5, 93:583 (R;SE)

GEOPHYSICAL SURVEYS

A preliminary guidebook for identifying stratigraphic contacts at the Nevada Test Site, 93:184 (R;US)

GLASS

See also BOROSILICATE GLASS

ANL Technical Support Program for DOE Environmental Restoration and Waste Management: Annual report, October 1990-September 1991, 93:402 (R;US)

ANL technical support program for DOE Environmental Restoration and Waste Management: Annual report, October 1991-September 1992, 93:405 (R;US)

AREST: The next generation, 93:157 (R; US)

Effects of radiation exposure on glass alteration in a steam environment, $93: 407$ (R;US)

Parametric effects on glass reaction in the unsaturated test method, 98:143 (R;US)

The reaction of SRL 202 glass in $\mathrm{J}-13$ and DIW, 93:406 (R;US) GLOBAL RISK

See HAZARDS

GRANITES

Modulus dispersion and attenuation in tuff and granite, 93:275 (R;US)

[Symposium for the STRIPA Project]: Foreign trip report, October 10-17, 1992, 93:433 (R;US)

\section{GREAT BASIN}

Seismicity and focal mechanisms for the Southern Great Basin of Nevada and California in 1990, 93:376 (R:US)

Seismicity and focal mechanisms for the southern Great Basin of Nevada and California in 1991, 93:384 (R;US)

Seismicity and focal mechanisms for the southern Great Basin of Nevada and California: 1987 through 1989, 93:379 (R;US)

GREAT LAKES REGION

See USA

GREAT PLAINS

Soe USA

GROUND MOTION

Prediction of Pseudo relative velocity response spectra at Yucca Mountain for underground nuclear explosions conducted in the Pahute Mesa testing area at the Nevada testing site: Yucca Mountain Site Characterization Project (Yucca Mountain Project), 93:230 (R;US)

\section{GROUND WATER}

B Codes

The relationship of the Yucca Mountain repository block to the regional ground-water system: A geochemical model, 93:566 (R;US)

Baseline Ecology

Identification of subsurface microorganisms at Yucca Mountain: Fourth quarterly report, $93: 16$ (R;US)

Chemical Analysis

A preliminary study of the chemistry of pore water extracted from tuff by one-dimensional compression, 93:363 (R;US)

Fingerprinting of ground water by ICP-MS: Progress report, July 1, 1991-December 31, 1991, 93:13 (R;US)

Chemical Composition

Chemical and isotopic composition of groundwaters and their seasonal variability at the OSAMU Utsumi mine and Morro do Ferro analogue study sites, Pocos de Caldas, Brazil: Pocos do Caldas Report No. 6, 93:584 (R;SE)

Conservative tracers for the $\mathrm{C}$-well hydraulic testing, 93:84 (BA;US)

Chemical Reactions

Durability study of sodium borosilicate glasses leached in tuff $\mathrm{J}$. 13 groundwater, $93: 597$ (R:US)

Parametric effects on glass reaction in the unsaturated test method, $93: 143$ (R; US)

Scientific investigation plan for initial engineered barrier system field tests (Yucca Mountain Project), 93:171 (R;US)

The hydrothermal stability of cement sealing materials in the potential Yucca Mountain high level nuclear waste repository (Yucca Mountain Project), 93:292 (R;US) 
The reaction of SRL 202 glass in $J-13$ and DIW, 93:406 (R;US)

\section{Contamination}

An evaluation of lithium sorption isotherms and their application to ground-water transport, 93:141 (J;US)

Risk-based screening analysis of ground water contaminated by radionuclides introduced at the Nevada Test Site (NTS) 93:592 (R;US)

\section{Environmental Transport}

Ground-water data collected at the Nevada Test Site and vicinity, Nye County, Nevada, water years 1988-89, 93:594 (R;US)

\section{Flow Models}

Characterization of liquid-water percolation in tuffs in the unsaturated zone, Yucca Mountain, Nye County, Nevada, 93:361 (R;US)

Design of a three-dimensional site-scale model for the unsaturated zone at Yucca Mountain, Nevada, $93: 53$ (R;US)

Estimating the consequences of significant fracture flow at Yucca Mountain, 93:273 (R;US)

Estimation of the limitations for surficial water addition above a potential high level radioactive waste repository at Yucca Mountain, Nevada: Yucca Mountain Site Characterization Project, 93:265 (R;US)

Potential for water-table excursions induced by seismic events at Yucca Mountain, Nevada, 93:211 (J;US)

Quasi-linear analysis of water flow in the unsaturated zone at Yucca Mountain, Nevada, USA, 93:258 (R;US)

Regional groundwater modeling of the saturated zone in the vicinity of Yucca Mountain, Nevada: Iterative Performance Assessment, Phase 2, 93:535 (R;US)

The international hydrocoin project - Groundwater hydrology modelling strategies for performance assessment of nuclear waste disposal, 93:470 (R;XN)

Uncertainty and sensitivity results for pre-waste-emplacement groundwater travel time, 93:272 (R;US)

Wetted-region structure in horizontal unsaturated fractures: Water entry through the surrounding porous matrix, 93:283 (R;US)

\section{Fluid Flow}

AREST: The next generation, 93:157 (R;US)

Alternate conceptual model of ground water flow at Yucca Mountain, 93:612 (BA;US)

Alternative strategies: A means for saving money and time on the Yucca Mountain Project (Yucca Mountain Project), 93:192 (R;US)

Applications of performance assessment in support of the Exploratory Studies Facility (ESF) design, 93:288 (R;US)

Comparison of two conceptual models of flow using the TSA (Yucca Mountain Project), 93:282 (R;US)

Distribution and chemistry of fracture-lining zeolites at Yucca Mountain, Nevada (Yucca Mountain Project), 93:134 (R;US)

Field research program for unsaturated flow and transport experimentation, 93:345 (BA;US)

Flow and transport through unsaturated rock: Data from two test holes, Yucca Mountain, Nevada, 93:391 (BA;US)

Groundwater flow code verification "benchmarking" activity (COVE-2A): Analysis of participants' work, 93:244 (R;US)

Identification and characterization of conservative organic tracers for use as hydrologic tracers for the Yucca Mountain Site Characterization Study: Progress report, June 1-December 31, 1990, $93: 9$ (R;US)

Identification and characterization of conservative organic tracers for use as hydrologic tracers for the Yucca Mountain Site Characterization Study: Progress report, July 1, 1991December 31, 1991, 93:14 (R;US)

Identification and characterization of conservative organic tracers for use as hydrologic tracers for the Yucca Mountain Site Characterization Study: Progress report, January 1, 1991June $30,1991,93: 10$ (R; US)

Impact of fracture coatings on the transfer of water across fracture faces in unsaturated media, 93:579 (R;US)

Impact of fracture coatings on the transfer of water across fracture faces in unsaturated media, 93:621 (BA;US)
Incorporation of the capillary hysteresis model HYSTR into the numerical code TOUGH, 93:38 (R;US)

Investigation of fracture-matrix interaction: Preliminary experiments in a simple system (Yucca Mountain Project), 93:320 (R:US)

LLUVIA-II: A program for two-dimensional, transient flow through partially saturated porous media: Yucca Mountain Site Characterization Project (Yucca Mountain Project.), 93:290 (R;US)

Large-scale in situ heater tests for hydrothermal characterization at Yucca Mountain (Yucca Mountain Project), 93:195 (R;US)

Modeling gravity-driven fingering in rough-walled fractures using modified percolation theory (Yucca Mountain Project), 93:328 (R;US)

NORIA-SP: A finite element computer program for analyzing liquid water transport in porous media: Yucca Mountain Site Characterization Project (YUCCA MOUNTAIN PROJECT), 93:255 (R;US)

Pre-waste-emplacement ground-water travel time sensitivity and uncertainty analyses for Yucca Mountain, Nevada: Yucca Mountain Site Characterization Project (yucca mountain project), 93:305 (R;US)

Preliminary capillary hysteresis simulations for fractured rocks model development and results of simulations, $93: 39$ (R;US)

Preliminary modeling of moisture movement in the tuff beneath Mortandad Canyon, Los Alamos National Laboratory, 93:496 (R;US)

Preliminary near-field environment report: Volume 1, Technical bases for EBS design (yucca mountain project), 93:198 (R;US)

Processes, mechanisms, parameters, and modeling approaches for partially saturated flow in soil and rock media: Yucca Mountain Site Characterization Project (Yucca Mountain Project.), 93:233 (R;US)

Scenario development for performance assessment: Some questions for the near-field modelers (yucca mountain project), 93:325 (R;US)

Sensitivity analyses for total-system performance assessment (yucca mountain project), 93:319 (R;US)

Sensitivity and uncertainty analyses applied to one-dimensional radionuclide transport in a layered fractured rock: MULTFRAC -Analytic solutions and local sensitivities: Phase 2, Iterative performance assessment: Volume 1, 93:536 (R;US)

Simulated water-level declines caused by withdrawals from wells $\mathrm{J}-13$ and J-12 near Yucca Mountain, Nevada, $93: 377$ (R;US)

The Nagra-DO'E Cooperative Project, 93:499 (R;US)

The implications of episodic nonequilibrium fracture-matrix flow on site suitability and total system performance, 93:187 (R;US)

The most likely groundwater flux through the unsaturated tuff matrix at USW H-1, $93: 338$ (R;US)

The relationship of the Yucca Mountain repository block to the regional ground-water system: A geochemical model, 93:566 (R;US)

Total System Periormance Assessment Code (TOSPAC): Volume 2, User's guide: Yucca Mountain Site Characterization Project, 93:217 (R;US)

US Geological Survey Committee for the Advancement of Science in the Yucca Mountain Project symposium on "Fractures, Hydrology, and Yucca Mountain": Abstracts and summary, $93: 375$ ( $R ;$ US)

Using $Q A$ classification to guide design and manage risk, $93: 5$ (R;US)

Waste-package release rates for site suitability studies, 93:48 (R;US)

Yucca Mountain program summary of research and technical review activities, July 1988-June 1989, 93:539 (R;US)

\section{Interactions}

The hydrothermal stability of cement sealing materials in the potential Yucca Mountain high level nuclear waste repository 93:339 (BA;US)

\section{Mathematical Models}

New approach for regional ground-water modeling in southern Nevada, 93:624 (BA;US) 
Monitoring

Hydrogeologic characterization of wells HTH-1, UE18r, UE6e, and HTH-3, Nevada Test Site, 93:441 (R;US)

\section{P Codes}

The relationship of the Yucca Mountain repository block to the regional ground-water system: A geochemical model, 93:566 (R;US)

$\mathrm{Ph}$ Value

Water-rock interactions and the $\mathrm{pH}$ stability of groundwater from Yucca Mountain, Nevada, 93:124 (R;US)

Quantitative Chemical Analysis

${ }^{36} \mathrm{Cl}$ production in situ, and groundwater transport in a uranium ore deposit, 93:631 (BA;US)

Geochemical modelling of water-rock interactions at the Osamu Utsumi mine and Morro do Ferro analogue study sites, Pocos de Caldas, Brazil, 93:509 (R;CH)

\section{Radionuclide Migration}

Characterizing the altered zone at Yucca Mountain: The beginning of a testing strategy, 93:206 (BA;US)

Colloid research for the Nevada Test Site, 93:478 (R;US)

Deterministic geologic processes and stochastic modeling, 93:353 (BA;US)

Diffusion releases through one and two finite planar zones from a nuclear waste package, 93:167 (R;US)

Elements present in leach solutions from unsaturated spent fuel tests, 93:408 (R;US)

Estimates of potential radionuclide migration at the Bullion site, 93:443 (R;US)

Geohydrologic data and models of Rainier Mesa and their implications to Yucca Mountain (Yucca Mountain Project), 93:58 (R;US)

Initial demonstration of the NRC's capability to conduct a performance assessment for a High-Level Waste Repository, 93:512 (R;US)

Measured solubilities and speciations of neptunium, plutonium, and americium in a typical groundwater $(\mathrm{J}-13)$ from the Yucca Mountain region: Milestone report 3010-WBS 1.2.3.4.1.3.1 (yucca mountain project), 93:109 (R;US)

Post-closure performance assessment of waste packages for the Yucca Mountain Project (Yucca Mountain Project), 93:170 (R;US)

Preliminary near-field environment report: Volume 1, Technical bases for EBS design (yucca mountain project), 93:198 (R; US)

Radionuclide solubility and speciation studies for the Yucca Mountain site characterization project, $93: 55$ (R;US)

Solubility and speciation studies for nuclear repository performance assessment, 93:50 (R;US)

TSPA 1991: An initial total-system performance assessment for Yucca Mountain: Yucca Mountain Site Characterization Project (Yucca Mountain Project), 93:293 (R;US)

Yucca Mountain Project total-system performance assessment preliminary analyses: Overview: Draft, 93:284 (R;US)

Rock-Fluid Interactions

Modeling fluid-rock interaction at Yucca Mountain, Nevada: A progress report, April 15, 1992, 93:168 (R;US)

Water-rock interactions and the $\mathrm{pH}$ stability of groundwater from Yucca Mountain, Nevada, $93: 124$ (R;US)

Soismic Effects

Earthquake-induced water-level fluctuations at Yucca Mountain, Nevada, April 1992, 93:383 (R;US)

\section{W Codes}

The relationship of the Yucca Mountain repository block to the regional ground-water system: A geochemical model, 93:566 (R;US)

Water Chemistry

Groundwater chemistry at the Nevada Test Site: Data and preliminary interpretations, 93:444 (R;US)

The relationship of the Yucca Mountain repository block to the regional ground-water system: A geochemical model, 93:566 (R;US)

\section{H}

\section{H CODES}

HEFF-A user's manual and guide for the HEFF code for thermal-mechanical analysis using the boundary-element method: Version 4.1: Yucca Mountain Site Characterization Project, 93:223 (R;US)

HANDLING (DATA)

SeQ DATA PROCESSING

HAZARDOUS MATERIALS

Perceived risk impacts from siting hazardous waste facilities, 93:617 (BA;US)

HAZARDS

Changes in risk perception over time, $93: 580$ (R;US)

HD 8077

See NICKEL BASE ALLOYS

HEAT EFFECTS

See TEMPERATURE DEPENDENCE

HEAT PIPES

Heat pipe effect in porous medium, 93:445 (R;US)

HEAT TRANSFER

A survey of hydrothermal modeling related to Yucca Mountain, 93:524 (RA;US)

AREST: The next generation, 93:157 (R;US)

FEHMN 1.0: Finite element heat and mass transfer code: Revision 1, 93:103 (R;US)

HEAT TRANSMISSION

SeE HEAT TRANSFER

HEULANDITE

Dissolution kinetics of heulandite at $\mathrm{pH} 2-12$ and $25^{\circ} \mathrm{C}, 93: 651$ (J;US)

\section{HIGH-LEVEL RADIOACTIVE WASTES}

HEFF-A user's manual and guide for the HEFF code for thermal-mechanical analysis using the boundary-element method: Version 4.1: Yucca Mountain Site Characterization Project, 93:223 (R;US)

Supporting hydration calculations for small- to large-scale seal tests in unsaturated tuff (Yucca Mountain Project), 93:287 (R;US)

Containers

Engineered barrier system failure modeling: A statistical approach, 93:613 (BA;US)

Modeling pitting corrosion damage of high-level radioactivewaste containers, with emphasis on the stochastic approach, 93:169 (R;US)

Quarterly progress report on the DOE Waste Package project at the University of Nevada, Las Vegas, July 1, 1993 through September 30, 1993, 93:17 (R;US)

Report on task assignment No. 3 for the Waste Package Project: Parts A \& B, ASME pressure vessel codes review for waste package application; Part C, Library search for reliability/failure rates data on low temperature low pressure piping, containers, and casks with long design lives, 93:12 (R;US)

Containment

Evaluation and compilation of DOE waste package test data: Biannual report, February 1989-July 1989: Volume 7, 93:528 (R;US)

Pressurized grout applications in fractured tuff for containment of radioactive wastes, 93:676 $(\mathrm{J} ; \mathrm{GB})$

Environmental Transport

MSTS - Multiphase Subsurface Transport Simulator theory manual, 93:64 (R;US)

Heat

Nonisothermal hydrologic transport study at the Apache Leap Tuff site, 93:515 (RA; US)

Heat Flux

Characterizing the altered zone at Yucca Mountain: The beginning of a testing strategy, 93:206 (BA;US)

Meetings

Introductory remarks for the international high-level radioactive waste conference technical session on site characterization: Approaches, concepts, concerns, 93:622 (BA;US) 
Nuclear Waste Policy Acts

Overview and status of the U.S. high-level waste program, 93:610 (BA;US)

\section{Packaging}

Quarterly progress report on the DOE Waste Package project at the University of Nevada, Las Vegas, July 1, 1993 through September 30, 1993, 93:17 (R;US)

Waste package and engineered barrier system design concepts for the direct disposal of spent fuel in the potential United States repository at Yucca Mountain, Nevada, 93:71 (BA;XA)

\section{Public Anxiety}

Nuclear wastes and public trust, 93:660 (J;US)

\section{R Codes}

Probabilistic risk assessment and nuclear waste transportation: A case study of the use of RADTAAN in the 1986 Environmental Assessment for Yucca Mountain, 93:560 (R;US)

\section{Radioactive Waste Disposal}

A forecasting model of gaming revenues in Clark County, Nevada, 93:626 (BA;US)

A literature review of coupled thermal-hydrologic-mechanicalchemical processes pertinent to the proposed high-level nuclear waste repository at Yucca Mountain, 93:537 (R;US)

A strategy for the derivation and use of sorption coefficients in performance assessment calculations for the Yucca Mountain site, 93:105 (RA;US)

A survey of hydrothermal modeling related to Yucca Mountain, 93:524 (RA;US)

ANL technical support program for DOE Environmental Restoration and Waste Management: Annual report, October 1991-September 1992, 93:405 (R:US)

An investigation of the impact of conceptual model uncertainty on the estimated performance of a hypothetical high-level nuclear waste repositony site in unsaturated, fractured tuff: Yucca Mountain Site Characterization Project, 93:256 (R;US)

An overview of the Yucca Mountain global/regional climate modeling program, 93:350 (BA;US)

Annual report to Congress, FY 1992, 93:460 (R;US)

Apache leap watershed study, 93:516 (RA;US)

Assessment of the potential for tectonic fault rupture for highlevel nuclear waste repositories, 93:421 (BA;US)

Characterization of rock hydrologic properties using model verification (Yucca Mountain Project), 93:519 (RA;US)

Characterizing the altered zone at Yucca Mountain: The beginning of a testing strategy, 93:188 (R;US)

Characterizing the altered zone at Yucca Mountain: The beginning of a testing strategy, 93:206 (BA;US)

Conceptual, experimental and computational approaches to support performance assessment of hydrology and chemical transport at Yucca Mountain: Yucca Mountain Site Characterization Project, 93:249 (R;US)

Critical comments on the US Environmental Protection Agency Standards 40 CFR 191, 93:7 (R;US)

Current plans to characterize the design basis ground motion at the Yucca Mountain, Nevada, site, 93:3 (BA;US)

DOE's Yucca Mountain studies, $93: 30$ (R;US)

Demonstration of a risk-based approach to high-level waste repository evaluation, Phase 2, 93:461 (R;US)

Design of underground repository openings in hard rock to accommodate vibratory ground motions, 93:213 (BA;US)

Development and evaluation of a performance assessment methodology for analyzing the safety of a geologic repository for high-level radioactive waste, 93:527 (RA;US)

Does the wind blow through Yucca Mountain?, 93:366 (RA;US)

Dynamic analysis and design considerations for high-level nuclear waste repositories, 93:600 (B;US)

Dynamic response of tunnels in jointed rocks, 93:425 (BA;US)

Effects of actinide burning on waste disposal at Yucca Mountain, 93:446 (R;US)

Empirical investigation of the effect of amenities and other factors on business location decisions, 93:417 (R;US)

Estimation of near-regional seismic ground motion from underground nuclear explosion tests, $93: 423$ (BA;US)
Evaluation of tracers for hydrologic studies at Yucca Mountain, 93:526 (RA;US)

Fault stress analysis for the Yucca Mountain site characterization project, 93:355 (BA;US)

Field air injection tests to determine the effect of a heat cycle on the permeability of welded tuff, 93:179 (R;US)

Field testing the effectiveness of pumping to remove sulfur hexafluoride traced driling air from a prototype borehole near superior, Arizona, 93:518 (RA;US)

Flow through nonhomogeneous porous modia, 93:525 (RA;US)

Fourth report to the U.S. Congress and the U.S. Secretary of Energy from the Nuclear Waste Technical Review Board, $93: 573$ (R;US)

Geometric models of faulting at Yucca Mountain, 93:422 (BA;US)

Geotechnical instrumentation for repository shafts, $93: 427$ (BA;US)

Ground water flow through unsaturated fractured rock research needs, 93:521 (RA;US)

Hydrogeologic issues at Yucca Mountain: Findings of a DOE peer review team, 93:513 (RA;US)

Linear thermal expansion data for tuffs from the unsaturated zone at Yucca Mountain, Nevada: Yucca Mountain Site Characterization Project, 93:228 (R;US)

MSTS - Multiphase Subsurface Transport Simulator theory manual, 93:64 (R;US)

Management of scientific and engineering data collected during site characterization of a potential high-level waste repository, 93:87 (BA;US)

Method development and strategy for the characterization of complexly fautted and fractured rhyolitic tuffs, Yucca Mountain, Nevada, USA, 93:395 (BA;FR)

Modeling fault rupture hazard for the proposed repository at Yucca Mountain, Nevada, 93:629 (BA;US)

Modeling hydrothermal flow in variably saturated, fractured, welded tuff during the prototype engineered barrier system field test of the Yucca Mountain Project, 93:523 (RA;US)

Nonequilibrium fracture-matrix flow during episodic infiltration events in Yucca Mountain (Yucca Mountain Project), 93:514 (RA;US)

Nonisothermal hydrologic transport study at the Apache Leap Tuff site, 93:515 (RA;US)

Nuclear waste: Questionable uses of program funds at Lawrence Livermore Lab., 93:468 (R;US)

Numerical and laboratory investigations of transient and steadystate flow in a fractured core, 93:520 (RA;US)

Optimal cost basis for seismic design, 93:426 (BA;US)

Options for dynamic analyses of underground facilities, 93:424 (BA;US)

Overview and status of the U.S. high-level waste program, 93:610 (BA;US)

Perceived risk, stigma, and potential economic impacts of a high-level nuclear waste repository in Nevada, $93: 673$ (J;US)

Performance assessment perspectives with reference to the proposed repository at Yucca Mountain, Nevada, 93:587 (RA;SE)

Preumatic permeability measurements in a fractured, partially saturated environment, 93:517 (RA;US)

Preclosure seismic hazards and their impact on site suitability of Yucca Mountain, Nevada, 93:349 (BA;US)

Preliminary calculations of release rates of Tc-99, 1-129, and $\mathrm{Np}-237$ from spent fuel in a potential repository in tuff, $93: 49$ (R;US)

Preliminary report: The Little Skull Mountain earthquake, June 29, 1992, 93:365 (BA;US)

Releases from exotic waste packages from partitioning and transmutation, 93:207 (BA;US)

Second report to the U.S. Congress and the U.S. Secretary of Energy from the Nuclear Waste Technical Review Board, $93: 574$ (R;US)

Seismic considerations in sealing a potential high-level radioactive waste repository, 93:215 (BA;US) 
Seismic design of circular-section concrete-lined underground openings-Preciosure performance considerations for the Yucca Mountain site, 93:214 (BA;US)

Site characterization progress report: Yucca Mountain, Nevada, April 1, 1992-September 30, 1992, Number 7, 93:28 (R;US)

Siting the high level radioactive waste repository in the United States, 93:620 (BA;GB)

Socioeconomic assessment guidance report: Determining the effects of amenity characteristics on business location decisions, 93:415 (R;US)

Stress-corrosion-cracking studies on candidate container alloys for the Tuff Repository, 93:533 (R;US)

Technical evaluations necessary for determining site suitability for a high-level waste repository, 93:420 (BA;US)

Technical issues related to groundwater flow and radionuclide transport in unsaturated fractured rock, 93:368 (RA;US)

Tectonic characterization of a potential high-level nuclear waste repository at Yucca Mountain, Nevada, 93:364 (BA;US)

Temperature measurements from a horizontal heater test in $G$ Tunnel, $93: 178$ (R;US)

The composition and $\mathrm{CO}_{2}$ carbon isotope signature of gases from borehole USW UZ-6, Yucca Mountain, Nevada, 93:367 (RA;US)

The hydrothermal stability of cement sealing materials in the potential Yucca Mountain high level nuclear waste repository, 93:339 (BA;US)

Thermal impact on host rock of geologic repository: Final report 93:18 (R;US)

Transportation cask decontamination and maintenance at the potential Yucca Mountain repository: Yucca Mountain Site characterization project, 93:247 (R;US)

Travel to France to attend and participate in the Technical Workshop on Near-Field Performance Assessment: Foreign trip report, May 9-16, 1993, 93:435 (R;US)

Uncertainty analyses of unsaturated zone travel time at Yucca Mountain, 93:210 (J;US)

Update on the Yucca Mountain Project site characterization program, 93:90 (BA;US)

Use of a submersible pressure outflow cell for determination of moisture characteristic curves on rock core, 93:522 (RA;US)

Waste package and engineered barrier system design concepts for the direct disposal of spent fuel in the potential United States repository at Yucca Mountain, Nevada, 93:71 (BA;XA)

Yucca Mountain Site Characterization Project Technical Data Catalog, 93:23 (R;US)

Yucca Mountain Site Characterization Project technical data catalog: Yucca Mountain Site Characterization Project, 93:101 (R;US)

Yucca Mountain Site Characterization Project: Technical data catalog,(quarterly supplement), 93:32 (R;US)

\section{Radioactive Waste Facilities}

Proposed sealing field tests for a potential high-level radioactive waste repository in unsaturated tuff, 93:356 (BA;US)

Records Management in support of the licensing process for the high level radioactive waste facility, 93:85 (BA;US)

\section{Radioactive Waste Management}

1991 OCRWM bulletin compilation and index, 93:456 (R;US)

Annual report to Congress, 93:454 (R;US)

Mesozoic and Cenozoic structural geology of the CP Hills, Nevada Test Site, Nye County, Nevada; and regional implications, 93:569 (R;US)

Nevada Nuclear Waste Study Committee: Combating antirepository-study sentiment, 93:684 (J;US)

Yucca Mountain: Policy, progress and politics, 93:73 (BA;US)

Radioactive Waste Processing

The reaction of SRL 202 glass in J-13 and DIW, 93:406 (R;US)

\section{Radioactive Waste Storage}

A decision analysis of an exploratory studies facility, 93:301 (R;US)

ANL Technical Support Program for DOE Environmental Restoration and Waste Management: Annual report, October 1990-September 1991, 93:402 (R;US)
DOE reassesses civilian radioactive waste management program, 93:688 (J;US)

Geological problems in radioactive waste isolation - A world wide review, 93;497 (RA;US)

Radioactive waste: Finding a safe place, $93: 674$ (J;US)

Stable isotopic evidence for a pedogenic origin of carbonates in trench 14 near Yucca Mountain, Nevada, 93:686 (J;US)

Yucca Mountain: Policy, progress and politics, 93:73 (BA;US)

\section{Radlonuclide Migration}

The importance of zeolites in the potential high-level radioactive waste repository at Yucca Mountain, Nevada, $93: 132$ (R;US)

\section{Rail Transport}

Rail abandonments in the South and their effect on NWPA rail shipments, 93:431 (R;US)

The Nevada railroad system: Physical, operational, and accident characteristics (yucca mountain project), 93:70 (R;US)

\section{Risk Assessment}

Organizational management of long-term risks: Implications for risk and safety in the transportation of nuclear wastes, 93:565 (R;US)

\section{Thermal Analysis}

Fifth report to the US Congress and the US Secretary of Energy from the Nuclear Waste Technical Review Board, 93:575 (R;US)

Transport

Organizational management of long-term risks: Implications for risk and safety in the transportation of nuclear wastes, 93:565 (R;US)

\section{Underground Disposal}

2010: America's nuclear waste odyssey, 93:652 (J;GB)

A comparative application of the Repository integration Program (RIP) to Total System Performance Assessment, 1991, 93:102 (R;US)

A demonstration of dose modeling at Yucca Mountain, 93:66 ( $\mathrm{R} ; \mathrm{US}$ )

A simplified radionuclide source term for total-system performance assessment: Yucca Mountain Site Characterization Project (Yucca Mountain Project:a1), 93:260 (R;US)

A structural model analysis of public opposition to a high-level radioactive waste facility, $93: 554$ ( $R ;$ :US)

A summary and discussion of hydrologic data from the Calico Hills nonwelded hydrogeologic unit at Yucca Mountain, Nevada, 93:107 (R;US)

A working definition of scenario and a method of scenario construction (yucca mountain project), 93:331 (R;US)

AREST user's guide, PC version, 93:154 (R;US)

AREST: The next generation, 93:157 (R:US)

Alternative strategies: A means for saving money and time on the Yucca Mountain Project (Yucca Mountain Project), 93:192 (R;US)

An analysis of a joint shear model for jointed media with orthogonal joint sets: Yucca Mountain Site Characterization Project, 93:245 (R;US)

An approach to validation of thermomechanical models, 93:335 (R;US)

An example postclosure risk assessment using the potential Yucca Mountain Site, 93:155 (R;US)

Analysis of releases due to drilling at the potential Yucca Mountain repository, 93:336 (R;US)

Analysis of slot cutting methods for the Yucca Mountain heated block test using a compliant-joint model, 93:270 (R;US)

Anisotropy of the Topopah Spring Member Tuff, 93:268 (R:US)

Applications of performance assessment in support of the EXploratory Studies Facility (ESF) design, 93:288 (R;US)

Areal power density: A preliminary examination of underground heat transfer in a potential Yucca Mountain repository and recommendations for thermal design approaches: Yucca Mountain Site Characterization Project (YUCCA MOUNTAIN PROJECT), 93:243 (R;US)

Assessment of geophysical logs from borehole USW G-2 Yucca Mountain, Nevada, 93:387 (R;US) 
Bibliography of Yucca Mountain Project (YMP) publications at Lawrence Livermore National Laboratory (January 1978 through September 1993), 93:150 (R;US)

Borehole and geohydrologic data for test hole USW UZ-6, Yucca Mountain area, Nye County, Nevada, $93: 382$ (R;US)

Boron adsorption on hematite and clinoptilolite, $93: 490$ (R;US)

Calculation of experiment uncertainty in laboratory determination of several geoengineering properties of tuffs from Yucca Mountain, Nevada: Yucca Mountain Site Characterization Project (Yucca Mountain Project.), 93:231 (R;US)

Center for Volcanic and Tectonic Studies, Department of Geoscience annual report, October 1, 1989-September 30, 1990, 93:541 (R;US)

Characterization of porosity in support of mechanical property analysis (yucca mountain project), $93: 313$ (R;US)

Code requirements for concrete repository and processing facilities, 93:598 (R;US)

Colloid transport code-nuclear user's manual, 93:493 (R;US)

Comparison of predicted far-field temperatures for discrete and smeared heat sources (Yucca Mountain Project), 93:332 (R;US)

Comparison of two conceptual models of flow using the TSA (Yucca Mountain Project), 93:282 (R;US)

Corrosion models for predictions of performance of high-level radioactive-waste containers, 93:160 (R;US)

Cost estimate of high-level radioactive waste containers for the Yucca Mountain Site Characterization Project (YUCCA MOUNTAIN PROJECT), 93:161 (R;US)

Coupled hydro-geochemical processes and their significance for Yucca Mountain Site Characterization (Yucca Mountain Project), 93:197 (R;US)

Criticality safety issues associated with the burial of highly enriched nuclear fuel in a geologic repository, 93:596 (R;US)

Current plans to characterize the design basis ground motion at the Yucca Mountain, Nevada Site, 93:4 (R;US)

Demands placed on waste package performance testing and modeling by some general results on reliability analysis, 93:181 (R;US)

Dependence of radionuclide sorption on sample grinding, surface area, and water composition, 93:127 (R; US)

Diffusion of sorbing and non-sorbing radionuclides (Yucca Mountain Project), 93:129 (R;US)

Distribution and chemistry of fracture-lining zeolites at Yucca Mountain, Nevada (Yucca Mountain Project), 93:134 (R;US)

Documentation and verification of STRES3D, Version 4.0: Yucca Mountain Site Characterization Project, $93: 250$ (R;US)

Documentation and verification of the SHAFT code: Yucca Mountain Site Characterization Project (YUCCA MOUNTAIN PROJECT), 93:235 (R;US)

Drift design methodology and preliminary application for the Yucca Mountain Site Characterization Project: Yucca Mountain Site Characterization Project (YUCCA MOUNTAIN PROJECT), 93:237 (R;US)

Drift emplaced waste package thermal response (Yucca Mountain Project), 93:193 (R;US)

Effect of boundary conditions on the strength and deformability of replicas of natural fractures in welded tuff: Data report: Yucca Mountain Site Characterization Project (yucca mountain project), 93:311 (R;US)

Effect of boundary conditions on the strength and deformability of replicas of natural fractures in welded tuff: Comparison between predicted and observed shear behavior using a graphical method: Yucca Mountain Site Characterization Project (yucca mountain project), 93:314 (R;US)

Effects of a potential drop of a shipping cask, a waste container, and a bare fuel assembly during waste-handling operations: Yucca Mountain Site Characterization Project (Yucca Mountain Project), 93:224 (R;US)

Effects of magmatic processes on the potential Yucca Mountain repository: Field and computational studies, 93:135 (R;US)

Effects of various radiation source characteristics on shielding requirements at the potential Yucca Mountain repository, 93:248 (R;US)
Elements present in leach solutions from unsaturated spent fuel tests, 93:408 (R;US)

Engineered barrier environment, Yucca Mountain, 93:191 (R;US)

Engineered barrier system and waste package design concepts for a potential geologic repository at Yucca Mountain, 93:183 (R;US)

Equilibrium modeling of the formation of zeolites in fractures at Yucca Mountain, Nevada, 93:133 (R;US)

Estimating the consequences of significant fracture flow at Yucca Mountain, 93:273 (R; US)

Estimation of the impact of water movement from sewage and settling ponds near a potential high level radioactive waste repository in Yucca Mountain, Nevada: Yucca Mountain Site Characterization Project, 93:267 (R;US)

Evaluation of alternatives for high-level and transuranic radioactive- waste disposal standards, $93: 582$ (R;US)

Evaluation of the geologic relations and seismotectonic stability of the Yucca Mountain area, Nevada Nuclear Waste Site Investigation (NNWSI): Final report, January 1, 1987-June 30 , 1988: Volume t, 93:542 (R;US)

Expert judgment in assessing radwaste risks: What Nevadans should know about Yucca Mountain: [Final report], 93:556 (R;US)

FEHMN 1.0: Finite element heat and mass transfer code: Revision $1,93: 103$ (R; US)

Fabrication and closure development of nuclear waste disposal containers for the Yucca Mountain Project: Status report, 93:186 (R;US)

Fault stress analysis for the Yucca Mountain Site Characterization Project, 93:278 (R;US)

Field research program for unsaturated flow and transport experimentation (Yucca Mountain Project), 93:280 (R;US)

Flow and transport in hierarchically fractured systems (Yucca Mountain Project), 93:61 (R:US)

Geohydrologic data and models of Rainier Mesa and their implications to Yucca Mountain (Yucca Mountain Project), 93:58 (R; US)

Geohydrologic data from test holes UE-25 UZ \#4 and UE-25 UZ \#5, Yucca Mountain Area, Nye County, Nevada, 93:372 (R;US)

Geologic evaluation of six nonweided tuff sites in the vicinity of Yucca Mountain, Nevada for a surface-based test facility for the Yucca Mountain Project (yucca mountain project), 93:108 (R;US)

Geophysical characterization of mineral and energy resources at Yucca Mountain and vicinity, Nevada, 93:380 (R;US)

Geothermal evaluation and analysis of the Yucca Mountain Repository, Nevada: Final report, July 1, 1989-December 31, 1989, 93:540 (R;US)

Ground water of Yucca Mountain: How high can it rise?: Final report, 93:511 (R;US)

Health and environmental risk-related impacts of actinide burning on high-level waste disposal, 93:572 (R;US)

Identification and characterization of conservative organic tracers for use as hydrologic tracers for the Yucca Mountain Site Characterization Project: Quality Assurance Project Plan: Quarterly technical progress report, January 1, 1993-March 31, 1993, 93:8 (R;US)

Identification and characterization of conservative organic tracers for use as hydrologic tracers for the Yucca Mountain Site characterization study: Progress report, April 1, 1993-june 30, 1993, 93:15 (R;US)

Identification and characterization of conservative organic tracers for use as hydrologic tracers for the Yucca Mountain Site Characterization Study: Progress report, January 1, 1991June 30, 1991, 93:10 (R;US)

Identification and characterization of conservative organic tracers for use as hydrologic tracers for the Yucca Mountain Site Characterization Study: Progress report, July 1, 1991December 31, 1991, 93:14 (R; US)

Identification and characterization of conservative organic tracers for use as hydrologic tracers for the Yucca Mountain Site 
Characterization Study: Progress report, June 1-December 31, 1990, 93:9 (R;US)

Identification of structures, systems, and components important to safety at the potential repository at Yucca Mountain: Yucca Mountain Site Characterization Project (MUCCA MOUNTAIN PROJECT), 93:251 (R;US)

Implications of stability analysis for heat transfer at Yucca Mountain, 93:337 (R;US)

influence of deterministic geologic trends on spatial variability of hydrologic properties in volcanic tuff, 93:318 (R;US)

Initial demonstration of the NRC's capability to conduct a performance assessment for a High-Level Waste Repository, 93:512 (R;US)

Initial field testing definition of subsurface sealing and backfilling tests in unsaturated tuff: Yucca Mountain Site Characterization Project, 93:307 (R;US)

Institutional trust, information, and risk perceptions: Report of findings of the Las Vegas metropolitan area survey, June 29 July $1,1992,93: 557$ (R; US)

Instrumentation requirements for the ESF thermomechanical experiments (Yucca Mountain Project), 93:330 (R;US)

Investigation of fracture-matrix interaction: Preliminary experiments in a simple system (Yucca Mountain Project), 93:320 (R;US)

is it possible to demonstrate compliance with the regulations for high-level-waste repositories?, 93:316 (R;US)

K/AR dating of clinoptilolite, mordenite, and associated clays from Yucca Mountains, Nevada, 93:131 (R;US)

LLNL/YMP Waste Container Fabrication and Closure Project: GFY technical activity summary, 93:591 (R;US)

LLUVIA-II: A program for two-dimensional, transient flow through partially saturated porous media: Yucca Mountain Site Characterization Project (Yucca Mountain Project.), $93: 290$ (R;US)

Large-scale in situ heater tests for hydrothermal characterization at Yucca Mountain (Yucca Mountain Project), 93:195 (R;US)

MISTY ECHO Tunnel Dynamics Experiment-Data report: Volume 1: Yucca Mountain Site Characterization Project (Yucca Mountain Project), 93:238 (R;US)

Managing nuclear waste: Social and economic impacts, 93:413 (R;US)

Measured solubilities and speciations of neptunium, plutonium, and americium in a typical groundwater $(\mathrm{J}-13)$ from the Yucca Mountain region: Milestone report 3010-WBS 1.2.3.4.1.3.1 (yucca mountain project), 93:109 (R;US)

Mineralogy, petrology and whole-rock chemistry data compilation for selected samples of Yucca Mountain tuffs: Yucca Mountain Site Characterization Project, 93:295 (R;US)

Modeling gravity-driven fingering in rough-walled fractures using modified percolation theory (Yucca Mountain Project), 93:328 (R;US)

Modeling of strongly heat-driven flow processes at a potential high-level nuclear waste repository at Yucca Mountain, Nevada, $93: 57$ (R;US)

Movement of shat and drift construction water in Yucca Mountain, Nevada: An extended study: Yucca Mountain Site Characterization Project, 93:266 (R;US)

NORIA-SP: A finite element computer program for analyzing liquid water transport in porous media: Yucca Mountain Site Characterization Project (YUCCA MOUNTAIN PROJECT), 93:255 (R;US)

Native Americans and Yucca Mountain: A summary report, 93:544 (R;US)

Native Americans and state and local governments, 93:553 (R;US)

Neotectonics of the southern Amargosa Desert, Nye County, Nevada and Inyo County, California, 93:568 (R;US)

Neptunium retardation with tuffs and groundwaters from Yucca Mountain (Yucca Mountain Project), 93:128 (R;US)

Nevada commercial spent nuclear fuel transportation experience, 93:69 (R;US)

New three-dimensional far-field potential repository thermomechanical calculations: Yucca Mountain Site Characterization Project (Yucca Mountain Project), 93:306 (R;US)
Nonisothermal hydrologic transport experimental plan, 93:534 (R;US)

Numerical methods for fluid flow in unsaturated heterogeneous tuff, 93:322 (R;US)

Numerical simulation of gas flow through unsaturated fractured rock at Yucca Mountain, Nevada, $93: 567$ (R;US)

PACE-90 water and solute transport calculations for $0.01,0.1$, and $0.5 \mathrm{~mm} / \mathrm{yr}$ infiltration into Yucca Mountain: Yucca Mountain Site Characterization Project, 93:257 (R;US)

Parametric effects on glass reaction in the unsaturated test method, $93: 143$ (R;US)

Performance predictions for mechanical excavators in Yucca Mountain tuffs: Yucca Mountain Site Characterization Project, 93:297 (R;US)

Photogeologic and kinematic analysis of lineaments at Yucca Mountain, Nevada: Implications for strike-slip faulting and oroclinal bending, $93: 381$ (R;US)

Physical limits on steam generation by radioactive decay heat, 93:165 (R;US)

Post-closure performance assessment of waste packages for the Yucca Mountain Project (Yucca Mountain Project), 93:170 (R;US)

Pre-waste-emplacement ground-water travel time sensitivity and uncertainty analyses for Yucca Mountain, Nevada: Yucca Mountain Site Characterization Project (yucca mountain project), 93:305 (R;US)

Preclosure radiological safety analysis for accident conditions of the potential Yucca Mountain Repository: Underground facilities: Yucca Mountain Site Characterization Project (Yucca Mountain Project), 93:234 (R;US)

Preclosure radiological safety analysis for the exploratory shaft facilities: Yucca Mountain Site Characterization Project (Yucca Mountain Project), 93:246 (R;US)

Preclosure seismic hazards and their impact on site suitability of Yucca Mountain, Nevada (Yucca Mountain Project), 93:291 (R;US)

Prediction of Pseudo relative velocity response spectra at Yucca Mountain for underground nuclear explosions conducted in the Pahute Mesa testing area at the Nevada testing site: Yucca Mountain Site Characterization Project (Yucca Mountain Project), 93:230 (R;US)

Preliminary capillary hysteresis simulations for fractured rocks model development and results of simulations, 93:39 (R;US)

Preliminary characterization of materials for a reactive transport model validation experiment, 93:334 (R;US)

Preliminary drift design analyses for nuclear waste repository in tuff (Yucca Mountain Project), 93:252 (R;US)

Preliminary mapping of surficial geology of Midway Valley Yucca Mountain Project, Nye County, Nevada: Yucca Mountain Site Characterization Project, 93:263 (R;US)

Preliminary near-field environment report: Volume 1, Technical bases for EBS design (yucca mountain project), 93:198 (R;US)

Preliminany numerical modeling for the G-Tunnel welded tuff mining experiment: Yucca Mountain site characterization project, 93:226 (R;US)

Preliminary total-system analysis of a potential high-level nuclear waste repository at Yucca Mountain, 93:63 (R;US)

Pressurized grout applications in fractured tuff for containment of radioactive wastes, 93:676 $(\mathrm{J} ; \mathrm{GB})$

Probable maximum flood control: Yucca Mountain Site Characterization Project (Yucca Mountain Project), 93:232 (R;US)

Procedure development study: Low strain rate and creep experiments: Yucca Mountain Site Characterization Project (YUCCA MOUNTAIN PROJECT), 93:261 (R;US)

Proceedings of the DOEYucca Mountain Site Characterization Project Radionuclide Adsorption Workshop at Los Alamos National Laboratory, September 11-12, 1990 (Yucca Mountain Project.), 93:104 (R;US)

Processes, mechanisms, parameters, and modeling approaches for partially saturated flow in soil and rock media: Yucca Mountain Site Characterization Project (Yucca Mountain Project.), 93:233 (R;US) 
Program cost and schedule baseline: Revision 2, 93:449 (R;US)

Progress report on the scientific investigation program for the Nevada Yucca Mountain Site, October 1, 1991-March 31, 1992, Number 6, $93: 27$ (R; US)

Proposed sealing field tests for a potential high-level radioactive waste repository in unsaturated tuff, 93:286 (R;US)

Quarterly progress report on the DOE Waste Package project at the University of Nevada, Las Vegas, July 1, 1993 through September 30, 1993, 93:17 (R;US)

Radioelements and their occurrence with secondary minerals in heated and unheated tuff at the Nevada Test Site, 93:52 (R;US)

Radionuclide solubility and speciation studies for the Yucca Mountain site characterization project, $93: 55$ (R;US)

Rationale for determining MCC spent fuel acquisitions, 93:177 (R;US)

Recent characterization activities of Midway Valley as a potential repository surface facility site, $93: 302$ (R;US)

Regional groundwater modeling of the saturated zone in the vicinity of Yucca Mountain, Nevada: Iterative Performance Assessment, Phase 2, 93:535 (R;US)

Reliability modeling of an engineered barrier system, $93: 429$ (R;US).

Report of early site suitability evaluation of the potential repository site at Yucca Mountain, Nevada: Yucca Mountain Site Characterization Project, 93:67 (R;US)

Report of the Peer Review Panel on the early site suitability evaluation of the Potential Repository Site at Yucca Mountain, Nevada: Yucca Mountain Site Characterization Project, 93:68 (R;US)

Report of the State of Nevada Commission on Nuclear Projects, 93:538 (R;US)

Report on task assignment No. 3 for the Waste Package Project: Parts A \& B, ASME pressure vessel codes review for waste package application; Part C, Library search for reliability/failure rates data on low temperature low pressure piping, containers, and casks with long design lives, $93: 12$ (R;US)

Research program to develop and validate conceptual models for flow and transport through unsaturated; fractured rock: Yucca Mountain Site Characterization Project (YUCCA MOUNTAIN PROJECT), 93:253 (R;US)

Review of radionuclide source terms used for performanceassessment analyses: Yucca Mountain Site Characterization Project, $93: 317$ (R;US)

Rock mass mechanical property estimation strategy for the Yucca Mountain Site Characterization Project (Yucca Mountain Project), 93:329 (R;US)

Rock mass mechanical property estimations for the Yucca Mountain Site Characterization Project: Yucca Mountain Site Characterization Project (Yucca Mountain Project), 93:304 (R;US)

Scenario development for performance assessment: Some questions for the near-field modelers (yucca mountain project), 93:325 (R;US)

Scientific investigation plan for initial engineered barrier system field tests (Yucca Mountain Project), 93:171 (R;US)

Seismic considerations in sealing a potential high-level radioactive waste repository, 93:309 ( $R ; U S$ )

Seismic design of circular-section concrete-lined underground openings: Preclosure performance considerations for the Yucca Mountain Site (Yucca Mountain Project), 93:303 (R;US)

Seismic reflection profiling across Tertiary extensional structures in the eastern Amargosa Desert, southern Nevada, Basin and Range province, 93:398 (J;US)

Seismicity and focal mechanisms for the southern Great Basin of Nevada and California in 1991, 93:384 (R;US)

Seismicity and focal mechanisms for the southern Great Basin of Nevada and California: 1987 through 1989, 93:379 (R;US)

Selection of candidate container materials for the conceptual waste package design for a potential high level nuclear waste repository at Yucca Mountain, $93: 172(\mathrm{R} ; \mathrm{US})$
Semi-analytical treatment of fracture/matrix fiow in a duatporosity simulator for unsaturated fractured rock masses, 93:54 (R;US)

Sensitivity analyses for total-system performance assessment (yucca mountain project), 93:319 (R;US)

Sensitivity and uncertainty analyses applied to one-dimensional radionuclide transport in a layered fractured rock: MULTFRAC - Analytic solutions and local sensitivities: Phase 2 , Iterative performance assessment: Volume 1, $93: 536$ (R;US)

Simulated water-level declines caused by withdrawals from wells $J-13$ and $J-12$ near Yucca Mountain, Nevada, 93:377 (R;US)

Simulation modeling of the probability of magmatic disruption of the potential Yucca Mountain Site, 93:136 (R;US)

Simulation of two-phase carbon-14 transport at Yucca Mountain, Nevada, 93:65 (R;US)

Single fracture aperture patterns: Characterization by slit-island fractal analysis (Yucca Mountain Project), 93:59 (R;US)

Single-hole in situ thermal probe for hydrothermal characterization at Yucca Mountain (Yucca Mountain Project), 93:196 (R;US)

Site characterization progress report: Yucca Mountain, Nevada, April 1, 1991-September 30, 1991, Number 5: Nuclear Waste Policy Act (Section 113), 93:26 (R;US)

Site characterization progress report: Yucca Mountain, Nevada, October 1, 1990-March 31, 1991: Number 4, $93: 25$ (R;US)

Site characterization progress report: Yucca Mountain, Nevada, October 1, 1992-March 31, 1993, No. 8, $93: 31$ (R;US)

Small-scale behavior of single gravity-driven fingers in an initially dry fracture (yucca mountain project), 93:326 (R;US)

Social impacts of hazardous and nuclear facilities and events: Implications for Nevada and the Yucca Mountain high-level nuclear waste repository: [Final report], 93:555 (R;US)

Socioeconomic profiles of Native American communities: Las Vegas Tribes of Paiute Indians, 93:550 (R;US)

Socioeconomic profiles of native American communities: Yomba Shoshone Reservation, 93:551 (R; US)

Southern Nevada residents' views about the Yucca Mountain high-level nuclear waste repository and related issues: A comparative analysis of urban and rural survey data, 93:547 (R;US)

State of Nevada review of Phase 1 of the INTRAVAL Project, 93:571 (R; US)

Statistical analysis of hydrologic data for Yucca Mountain: Yucca Mountain Site Characterization Project, 93:220 (R;US)

Structure in continuously cored, deep drill holes at Yucca Mountain, Nevada, with notes on calcite occurrence: Yucca Mountain Site Characterization Project (Yucca Mountain Project), 93:298 (R;US)

Summary and evaluation of existing geological and geophysical data near prospective surface facilities in Midway Valley, Yucca Mountain Project, Nye County, Nevada: Yucca Mountain Site Characterization Project (Yucca Mountain Project), 93:254 (R;US)

Summary of the Exploratory Studies Facility Alternatives Study: Draft, 93:277 (R;US)

Summary report on the evaluation of a 1977-1985 edited sorption data base for isotherm modeling (yucca mountain project), 93:113 (R;US)

Surface-discharging hydrothermal systems at Yucca Mountain: Examining the evidence, 93:125 (R;US)

Survey of degradation modes of four nickel-chromiummolybdenum alloys, 93:166 (R; US)

TOSPAC calculations in support of the COVE $2 A$ benchmarking activity: Yucca Mountain Site Characterization Project, 93:229 (R;US)

TSPA 1991: An initial total-system performance assessment for Yucca Mountain: Yucca Mountain Site Characterization Project (Yucca Mountain Project), 93:293 (R;US)

Technical basis and programmatic requirements for laboratory study of hydrological properties of the near-field environment 93:173 (R;US) 
Technical basis and programmatic requirements for large block testing of coupled thermal-mechanical-hydrological-chemical processes, 93:175 (R;US)

Technical data base quarterly report, April-June 1992: Yucca Mountain Site Characterization Project, 93:216 (R;US)

The Lathrop Wells volcanic center: Status of field and geochronology studies, $93: 112$ (R;US)

The analysis of repository-heat-driven hydrothermal flow at Yucca Mountain (Yucca Mountain Project), 93:194 (R;US)

The hydrothermal stability of cement sealing materials in the potential Yucca Mountain high level nuclear waste repository (Yucca Mountain Project), 93:292 (R;US)

The implications of episodic nonequilibrium fracture-matrix flow on site suitability and total system performance, 93:187 (R;US)

The most likely groundwater flux through the unsaturated tuff matrix at USW $H-1,93: 338$ (R;US)

The relationship of the Yucca Mountain repository block to the regional ground-water system: A geochemical model, 93:566 (R;US)

The role of fault zones in affecting multiphase flow at Yucca Mountain (Yucca Mountain Project), 93:60 (R;US)

The siting guidelines, 10 CFR Part 960, 93:680 $(\mathrm{J} ; \mathrm{CH})$

The use of sequential indicator simulation to characterize geostatistical uncertainty: Yucca Mountain Site Characterization Project (Yucca Mountain Project.), 93:264 (R;US)

Three dimensional visualization in support of Yucca Mountain Site characterization activities (Yucca Mountain Project), 93:34 (R;US)

Three-dimensional modeling of unsaturated flow in the vicinity of proposed exploratory shaft facilities at Yucca Mountain, Nevada, 93:62 (R;US)

Total System Performance Assessment Code (TOSPAC): Volume 2, User's guide: Yucca Mountain Site Characterization Project, 93:217 (R;US)

Transport of neptunium through Yucca Mountain tuffs, 93:126 (R;US)

Travel to France to report on Waste Management projects at WIPP and Yucca Mountain: Foreign trip report, February $2-8$, 1992, 93:434 (R;US)

U.S. Nuclear Regulatory Commission overview of repository quality assurance, 93:683 $(\mathrm{J} ; \mathrm{CH})$

U.S. strategy for evaluating the Yucca Mountain, Nevada site, 93:98 $(\mathrm{J} ; \mathrm{CH})$

UNS YMSCP QA support task: Quarterly technical progress report, January 1, 1991-June 30, 1991, 93:11 (R;US)

Unconfined compression experiments on Topopah Spring Member tuff at $22^{\circ} \mathrm{C}$ and a strain rate of $10^{-9} \mathrm{~s}^{-1}$ : Data report: Yucca Mountain Site Characterization Project (yucca mountain project), 93:310 (R;US)

Use of Wingz spreadsheet as an interface to total-system performance assessment (Yucca Mountain Project), 93:281 (R;US)

Use of the iterative solution method for coupled finite element and boundary element modeling: Yucca Mountain Site Characterization Project (yucca mountain project), 93:324 (R;US)

Using $Q A$ classification to guide design and manage risk, 93:5 (R;US)

Waste package emplacement borehole option study: Yucca Mountain Site Characterization Project (Yucca Mountain Project), 93:236 (R;US)

Waste-package release rates for site suitability studies, 93:48 (R;US)

Water leveis in continuously monitored wells in the Yucca Mountain area, Nevada, 1985-88, 93:378 (R; US)

Word images as policy instruments: Lessons from the Yucca Mountain Controversey, 93:430 (R;US)

$X$-ray and visible light transmission as two-dimensional, full-field moisture-sensing techniques: A preliminary comparison, 93:279 (R;US)

Yucca Mountain Biological Resources Monitoring Program: Annual report, FY91, $23: 35$ (R;US)

Yucca Mountain Exploratory Studies Facilities: Construction status: Extended summary, 93:100 (R;US)
Yucca Mountain Project total-system performance assessment preliminary analyses: Overview: Draft, 93:284 (R;US)

Yucca Mountain Site Characterization Project Plan, 93:29 (R;US)

Yucca Mountain Site Characterization Project Technical Data Catalog (quarterly supplement), 93:33 (R;US)

Yucca Mountain Site Characterization Project Technical Data Catalog: Yucca Mountain Site Characterization Project (Yucca Mountain Project), 93:6 (R;US)

Yucca Mountain Site Characterization Project bibliography, January-June 1991: Supplement 3, 93:20 (R;US)

Yucca Mountain Socioeconomic Project: The 1991 Nevada State telephone survey: Key findings, 93:546 (R;US)

Yucca Mountain program summary of research and technical review activities, July 1988 June 1989, $93: 539$ (R;US)

Yucca Mountain socioeconomic project report on the 1987 risk perception telephone surveys, 93:545 (R;US)

[Symposium for the STRIPA Project]: Foreign trip report, October 10-17, 1992, 93:433 (R;US)

Underground Storage

Durability study of sodium borosilicate glasses leached in tuff $\mathrm{J}$ 13 groundwater, 93:597 (R;US)

Selected issues on geochemical transport modeling for highlevel nuclear waste repository, 93:486 (RA;US)

\section{Waste Disposal}

High-level nuclear waste disposal: Policy and prognosis. Research report, August 1991-April 1992, $93: 400$ (R;US)

Waste Heat

The impact of thermal loading on repository performance at Yucca Mountain, 93:189 (R;US)

Waste Retrieval

Retrieval strategy report for a potential high-level nuclear waste repository: Yucca Mountain Site Characterization Project, 93:221 (R;US)

Waste Transportation

A report on high-level nuclear waste transportation: Prepared pursuant to assembly concurrent resolution No. 8 of the 1987 Nevada Legislature, 93:558 (R;US)

Guidelines on the scope, content, and use of comprehensive risk assessment in the management of high-level nuclear waste transportation, 93:561 (R;US)

Human and social factors in the transportation of nuclear wastes, 93:562 (R;US)

Probabilistic risk assessment and nuclear waste transportation A case study of the use of RADTRAN in the 1986 Environmental Assessment for Yucca Mountain, 93:560 (R; US)

Transportation needs assessment: Emergency response section, 93:559 (R;US)

Yucca Mountain transportation routes: Preliminary characterization and risk analysis: Volume 1, Research report, 93:563 (R;US)

Yucca Mountain transportation routes: Preliminary characterization and risk analysis: Volume 2, Figures [and] Volume 3 , Technical Appendices, 93:564 (R;US)

HIGHWAYS

See ROADS

HUGENHOLTZ-PINES THEORY

SeO HYDROGEN

HUMAN INTRUSION

Analysis of releases due to drilling at the potential Yucca Mountain repository, 93:336 (R;US)

Reasonableness of human intrusion provisions in EPA's HLW standard, 93:463 (RA;US)

\section{HUMAN POPULATIONS}

An example postclosure risk assessment using the potentia Yucca Mountain Site, 93:155 (R;US)

Community Radiation Monitoring Program: Annual report, October 1, 1990-September 30, 1991, 93:442 (R;US)

Probabilistic risk assessment and nuclear waste transportation: A case study of the use of RADTRAN in the 1986 Environmental Assessment for Yucca Mountain, 93:560 (R;US)

\section{HUMANS}

See HUMAN POPULATIONS 


\section{HUMIDITY}

Thermocouple psychrometer measurements of in situ water potential changes in heated welded tuff, 93:180 (R;US)

\section{HYDROGEN}

Dual-energy neutron tomography of water in rock using the Argonne IPNS, 93:411 (R; US)

\section{HYDROGEN 2}

Se DEUTERIUM

HYDROGEN 3

SEO TRITIUM

HYDROGEN HYDROXIDES

SQO WATER

HYDROLOGY

Characterization of rock hydrologic properties using model verification (Yucca Mountain Project), 93:519 (RA;US)

Coupled hydro-geochemical processes and their significance for Yucca Mountain Site Characterization (Yucca Mountain Project), 93:197 (R;US)

Geomorphological and hydrogeological features of the Pocos de Caldas caldera and the Osamu Utsumi mine and Morro do Ferro analogue study sites, Brazil: Pocos de Caldas Report No. 5, 93:583 (R;SE)

Identification and characterization of conservative organic tracers for use as hydrologic tracers for the Yucca Mountain Site characterization study: Progress report, April 1, 1993-June 30, 1993, 93:15 (R;US)

Statistical analysis of hydrologic data for Yucca Mountain Yucca Mountain Site Characterization Project, 93:220 (R;US)

HYDROXYL IONS

SQB ANIONS

\section{HYPOCENTERS}

Seismicity and focal mechanisms for the Southern Great Basin of Nevada and California in 1990, 93:376 (R;US)

\section{HYSTERESIS}

Preliminary capillary hysteresis simulations for fractured rocks model development and results of simulations, 93:39 (R;US)

\section{I}

\section{INCIDENTS}

SeQ ACCIDENTS

INCOLOY 825

Crack-growth-rate testing of candidate waste container materials, 93:145 (R;US)

Stress corrosion cracking of candidate waste container materials: Final report, $93: 403$ (R; US)

Stress-corrosion-cracking studies on candidate container alloys for the Tuff Repository, 93:533 (R;US)

\section{INCOME}

A forecasting model of gaming revenues in Clark County, Nevada, 93:409 (R;US)

INDIANS (AMERICAN)

Seo AMERICAN INDIANS

INDUSTRIAL SECTOR

SeQ INDUSTRY

INDUSTRY

\section{See also COAL INDUSTRY}

Methodologies for selecting industries for regions and communities: A critical evaluation of the Las Vegas target industry analysis, $93: 416$ (R;US)

The role of amenities and other factors in influencing the location of nonmanufacturing industry in the United States, 93:414 (R;US)

\section{INFORMATION SYSTEMS}

The role of Geographic Information Systems in the Office of the Supervising Scientist, 93:609 (BA;AU)

INSTRUMENTS (MEASURING)

Seo MEASURING INSTRUMENTS

INTERMEDIATE-LEVEL RADIOACTIVE WASTES

Travel to Switzerland for performance assessments for both the low- and intermediate-level and high-level radioactive waste disposal programs being managed and implemented by NAGRA: Foreign trip report, May 2-9, 1993, 93:436 (R;US)

\section{INTERNATIONAL COOPERATION}

Validation efforts in modeling flow and transport through partially saturated fractured rock - the Apache leap tuff studies, 93:643 (BA;FR)

IODIDES

Evaluation of potential hydrologic tracers in tuffs from Yucca Mountain, Nevada, 93:487 (RA; US)

IODINE

Characterization of the Topopah spring and Tiva Canyon tuffs at Yucca Mountain: Effective diffusivities and pore properties, 93:636 (BA;US)

Diffusion of carbon dioxide and iodine through Yucca Mountain tuffs: Effects of temperature and moisture content, 93:635 (BA;US)

IODINE 129

Preliminary calculations of release rates of Tc-99, 1-129, and $\mathrm{Np}-237$ from spent fuel in a potential repository in tuff, $93: 49$ (R;US)

Sensitivity analysis of integrated radionuclide transport based on a three-dimensional geochemical/geophysical model, 93:485 (RA;US)

IODINE IODIDES

See IODINE

ION EXCHANGE

Modeling ion exchange in clinoptilolite using the EQ3/6 geochemical modeling code, 93:190 (R;US)

IONIC REACTIONS

IRON

SEe CHEMICAL REACTIONS

Geochemical modelling of water-rock interactions at the Osamu Utsumi mine and Morro do Ferro analogue study sites, Pocos de Caldas, Brazil, 93:509 (R;CH)

\section{IRON SILICATES}

Manganoan fayalite $\left[(\mathrm{Fe}, \mathrm{Mn})_{2} \mathrm{SiO}_{4}\right]:$ A new occurrence in thyolitic ash-flow tuff, southwestern Nevada, U.S.A., 93:678 (J;US)

ISOTHERM

See ISOTHERMS

ISOTHERMS

Summary report on the evaluation of a 1977-1985 edited sorption data base for isotherm modeling (yucca mountain project), 93:113 (R;US)

\section{K}

\section{KOONGARRA DEPOSIT}

Natural analogue studies: Mineral alteration and uranium migration, 93:477 ( $R ; J P ;$ in Japanese)

\section{KRYPTON ISOTOPES}

Variation of the isotopic compositions of xenon and krypton in terrestrial samples, 93:632 (BA;US)

\section{$\mathbf{L}$}

LABORATORY SCALE EXPERIMENTS

S $\theta$ BENCH-SCALE EXPERIMENTS

LAND FILLS

See SANITARY LANDFILLS

LANDFILLS

See SANITARY LANDFILLS

LANDFORMS

See GEOMORPHOLOGY

LANL

Geology, drilling, and some hydrologic aspects of seismic hazards program core holes, Los Alamos National Laboratory, New Mexico, $93: 488$ (R;US)

LEACHATES

Durability study of sodium borosilicate glasses leached in tuff $\mathrm{J}$ 13 groundwater, $93: 597$ (R;US) 
LEAD

The reaction of SRL 202 glass in $\mathrm{J}-13$ and DIW, $93: 406$ (R;US)

Evaluation of lead contamination in drillback mudpits using isotopic ratios, 93:590 (RA;US)

LEAD MINERALS

See MINERALS

LIGHT WATER COOLED REACTORS

See WATER COOLED REACTORS

LIQUID METAL TEST FACILITIES

SEe TEST FACILITIES

LITHIUM

An evaluation of lithium sorption isotherms and their application to ground-water transport, 93:141 (J;US)

Preliminary characterization of materials for a reactive transport model validation experiment, 93:334 (R;US)

LOCAL GOVERNMENT

Intergovernmental complexity in nuclear waste disposal policy: The indeterminate role of local government, 93:681 (J;US)

LOS ALAMOS NATIONAL LABORATORY See LANL

LOW-LEVEL RADIOACTIVE WASTES

Code requirements for concrete repository and processing facilities, 93:598 (R;US)

Estimating the water table under the Radioactive Waste Management Site in Area 5 of the Nevada Test Site: The Dupuit-Forcheimer approximation, $93: 428$ (R;US)

Travel to Switzerland for performance assessments for both the low- and intermediate-level and high-level radioactive waste disposal programs being managed and implemented by NAGRA: Foreign trip report, May 2-9, 1993, $93: 436$ (R;US)

LWR TYPE REACTORS

SeE WATER COOLED REACTORS

\section{$\mathbf{M}$}

MA 754

See NICKEL BASE ALLOYS

MAGMATISM

Geochemical evidence for waning magmatism and polycyclic volcanism at Crater Flat, Nevada, 93:119 (R;US)

Physical processes and effects of magmatism in the Yucca Mountain region, 93:117 (R;US)

MALIGNANCIES

SEe NEOPLASMS

MARINE VEHICLE ACCIDENTS

SeE ACCIDENTS

MASS TRANSFER

See also ENVIRONMENTAL TRANSPORT

FEHMN 1.0: Finite element heat and mass transfer code: Revision 1, 93:103 (R:US)

MATERIALS (ENVIRONMENTAL)

See ENVIRONMENTAL MATERIALS

MATERIALS (POROUS)

Soe POROUS MATERIALS

MATHEMATICAL MODELS

See also FLOW MODELS

Design of an intermediate-scale experiment to validate unsaturated-zone transport models, 93:285 (R;US)

Developing conceptual models for performance assessment of waste management sites, 93:578 ( $R$;US)

Field research program for unsaturated flow and transport experimentation (Yucca Mountain Project), 93:280 (R;US)

MEASURING INSTRUMENTS

See also NEUTRON ACTIVATION ANALYZERS

Thermocouple psychrometer measurements of in situ water potential changes in heated weided tuff, 93:180 (R;US)

MECHANICAL VIBRATIONS

Over-the-road tests of nuclear materials package response to normal environments, 93:577 (R;US)

MID-ATLANTIC REGION

See USA

Yucca Mountain Site Characterization Project
MIDWEST REGION

SEE USA

MIGRATION (RADIONUCLIDE)

SEe RADIONUCLIDE MIGRATION

MINERALS

See aiso SILICATE MINERALS

A suggested approach toward measuring sorption and applying sorption data to repository performance assessment, $93: 114$ (R;US)

Near-field high-temperature transport: Evidence from the genesis of the Osamu Utsumi uranium mine, Pocos de Caldas alkaline complex, Brazil: Pocos de Caldas Report No. 13, 93:586 (R;SE)

MINES

See aiso URANIUM MINES

Mineralogy, petrology and geochemistry of the Pocos de Caldas analogue study sites, Minas Gerais, Brazil. I. Osamu Utsumi uranium mine: Pocos de Caldas Report No. 2, $93: 501(R ; C H)$

MINING

A selected GIS bibliography: Technical Memorandum 40 , 93:603 (B;AU)

MISCIBILITY

See SOLUBILITY

MISGURNUS

See FISHES

MM-0011

See NICKEL BASE ALLOYS

MODELS (FLOW)

SEe FLOW MODELS

MODELS (MATHEMATICAL)

See MATHEMATICAL MODELS

MOISTURE

Design of a three-dimensional site scale model for the unsaturated zone at Yucca Mountain, Nevada, $93: 74$ (BA:US)

Wetting front instability in an initially wet unsaturated fracture (Yucca Mountain Project), $93: 327$ (R;US)

\section{MOLYBDENUM ALLOYS}

Survey of degradation modes of four nickel-chromiummolybodenum alloys, 93:166 (R;US)

MONITORED RETRIEVABLE STORAGE

Cost analysis of spent nuclear fuel management, 93:608 (BA;US)

Monitored retrievable storage of spent nuclear fuel: Transportation studies: Draft, 93:448 (R;US)

Office of Civilian Radioactive Waste Management Program Cost and Schedule Baseline: Revision 3, 93:450 (R;US)

Use of annotated outlines to prepare guidance for license applications for the MRS and MGDS, 93:628 (BA;US)

MORDENITE

KAR dating of clinoptilolite, mordenite, and associated clays from Yucca Mountains, Nevada, 93:131 (R;US)

\section{$\mathbf{N}$}

NATIONAL ENVIRONMENTAL POLICY ACT

SeE US NATIONAL ENVIRONMENTAL POLICY ACT

\section{NATIONAL GOVERNMENT}

Institutional trust, information, and risk perceptions: Report of findings of the Las Vegas metropolitan area survey, June 29 July 1, 1992, $93: 557$ (R; US)

NATURAL NUCLEAR REACTORS

Soe also OKLO PHENOMENON

Role of organic matter in the Proterozoic Oklo natural fission reactors, Gabon, Africa, 93:649 (J;US)

NEA

Geostatistical methods for site characterization at Yucca Mountain, 93:641 (BA;FR)

NEGATIVE IONS

See ANIONS 


\section{NEOPLASMS}

Risk-based screening analysis of ground water contaminated by radionuclides introduced at the Nevada Test Site (NTS),

NEPA 93:592 (R;US)

\section{See US NATIONAL ENVIRONMENTAL POLICY ACT}

NEPTUNIUM

Dependence of radionuclide sorption on sample grinding, surface area, and water composition, 93:127 (R;US)

Environmental monitoring for uranium and neptunium at Yucca Mountain, 93:639 (BA;US)

Environmental monitoring for uranium and neptunium at Yucca Mountain using Epithermal Neutron Activation Analysis, 93:447 (R;US)

Neptunium retardation with tuffs and groundwaters from Yucca Mountain (Yucca Mountain Project), 93:128 (R;US)

Neptunium(V) sorption on quartz and albite in aqueous suspension: Annual progress report, 93:495 (R;US)

Radionuclide solubility and speciation studies for the Yucca Mountain site characterization project, 93:55 (R;US)

Solubility and speciation studies for nuclear repository performance assessment, 93:50 (R;US)

NEPTUNIUM 237

Preliminary calculations of release rates of $\mathrm{Tc}-99,1-129$, and $\mathrm{Np}-237$ from spent fuel in a potential repository in tuff, $93: 49$ (R;US)

Transport of neptunium through Yucca Mountain tuffs, 93:126 (R;US)

\section{NEPTUNIUM COMPOUNDS}

Dependence of actinide solubility and speciation on carbonate concentration and ionic strength in groundwater, $93: 97(\mathrm{~J} ; \mathrm{DE})$

NEUTRON ACTIVATION ANALYZERS

Environmental monitoring for uranium and neptunium at Yucca Mountain, 93:639 (BA;US)

NEUTRON DETECTION

Effects of various radiation source characteristics on shielding requirements at the potential Yucca Mountain repository, 93:248 (R;US)

NEUTRON HEATING

SEO RADIATION HEATING

\section{NEVADA}

\section{Earthquakes}

Processed seismic motion records from Little Skull Mountain, Nevada earthquake aftershocks of July 5, 1992 and September 13, 1992, recorded at seismic stations in southern Nevada, $93: 475$ (R;US)

Processed seismic motion records from Little Skull Mountain, Nevada earthquake of June 29, 1992, recorded at stations in southern Nevada, $93: 474$ (R;US)

Economic Development

Methodologies for selecting industries for regions and communities: A critical evaluation of the Las Vegas target industry analysis, $93: 416$ (R;US)

Economy

The role of amenities and other factors in influencing the location of nonmanufacturing industry in the United States, $93: 414$ (R;US)

Geologic Faults

Neotectonics of the southern Amargosa Desert, Nye County, Nevada and Inyo County, California, 93.568 (R;US)

Geology

Seismic reflection profiling across Tertiary extensional structures in the eastern Amargosa Desert, southern Nevada, Basin and Range province, $93: 398$ (J;US)

\section{Ground Water}

New approach for regional ground-water modeling in southern Nevada, 93:624 (BA;US)

Magnetic Surveys

Aeromagnetic map of the Beatty quadrangle, Nevada-California, 93:374 (R;US)

Petroleum Deposits

Yucca Mountain, a high-level nuclear waste repository over a billion barrel oil field?, 93:677 (J;US)

\section{Radioactive Waste Disposal}

Perceived risk, stigma, and potential economic impacts of a high-level nuclear waste repository in Nevada, 93:673 (J;US)

Radioactive Waste Facilities

Nuclear waste repository program oversight: Strategies of the situs jurisdiction, 93:634 (BA; US)

Potential for water-table excursions induced by seismic events at Yucca Mountain, Nevada, 93:211 (J;US)

Underground exploration at Yucca Mountain, $93: 75$ (BA;US)

Update on the Yucca Mountain Project site characterization program, 93:90 (BA;US)

Yucca Mountain, a high-level nuclear waste repository over a billion barrel oil field?, 93:677 (J;US)

Seismic Surveys

Seismic reflection profiling across Tertiary extensional structures in the eastern Amargosa Desert, southern Nevada, Basin and Range province, 93:398 (J;US)

State Government

A report on high-level nuclear waste transportation: Prepared pursuant to assembly concurrent resolution No. 8 of the 1987 Nevada Legislature, 93:558 (R;US)

Report of the State of Nevada Commission on Nuclear Projects, 93:538 (R;US)

Stratigraphy

Recent characterization activities of Midway Valley as a potential repository surface facility site, 93:302 (R;US)

Surveys

Technical evaluation of available state of Nevada survey instruments, 93:418 (R;US)

Volcanic Regions

Late Quaternary geology of small basaltic volcanic centers, SW USA: Disparity among dating methods and implications for volcanic and geomorphic studies, 93:668 (J;US)

Manganoan fayalite $\left[(\mathrm{Fe}, \mathrm{Mn})_{2} \mathrm{SiO}_{4}\right]$ : A new occurrence in rhyolitic ash-flow tuff, southwestern Nevada, U.S.A., 93:678 (J;US)

\section{NEVADA TEST STE}

A portable vacuum hammer seismic source for use in tunnel environments, 93:595 (R;US)

A preliminary guidebook for identifying stratigraphic contacts at the Nevada Test Site, 93:184 (R;US)

Addendum to environmental monitoring plan Nevada Test Site and support facilities, 93:439 (R;US)

An evaluation of the seismicity of the Nevada Test Site and vicinity: Yucca Mountain Site Characterization Project, 93:218 (R;US)

Community Radiation Monitoring Program: Annual report, October 1, 1990-September 30, 1991, $93: 442$ (R;US)

Estimating the water table under the Radioactive Waste Management Site in Area 5 of the Nevada Test Site: The Dupuit-Forcheimer approximation, 93:428 (R;US)

Gravity and magnetic data of Fortymile Wash, Nevada Test Site, Nevada, 93:385 (R;US)

Ground-water data collected at the Nevada Test Site and vicinity, Nye County, Nevada, water years 1988-89, 93:594 (R;US)

Groundwater chemistry at the Nevada Test Site: Data and preliminary interpretations, 93:444 (R;US)

Hydrology/Radionuclide Migration Program and related research activities: FY 1986 progress report, October 1 , 1985-September 30, 1986, $93: 437$ (R;US)

Mesozoic and Cenozoic structural geology of the CP Hills, Nevada Test Site, Nye County, Nevada; and regional implications, 93:569 (R; US)

Modeling hydrothermal flow in variably saturated, fractured, welded tuff during the prototype engineered barrier system field test of the Yucca Mountain Project, 93:523 (RA;US)

Risk-based screening analysis of ground water contaminated by radionuclides introduced at the Nevada Test Site (NTS), 93:592 (R;US)

Source parameters of the June 29, 1992 Little Skull Mountain earthquake from complete regional waveforms at a single station, 93:653 (J;US) 


\section{NEW ENGLAND \\ SeO USA}

NICKEL

Preliminary characterization of materials for a reactive transport model validation experiment, 93:334 (R;US)

NICKEL BASE ALLOYS

Conceptual design of a monitored retrievable storage cask employing Yucca Mountain containers, 93:638 (BA; US)

Survey of degradation modes of four nickel-chromiummolybolenum alloys, 93:166 (R;US)

NUCLEAR ACCIDENTS

SoQ ACCIDENTS

NUCLEAR CHEMISTRY

Nuclear Technology Programs semiannual progress report, October 1990-March 1991, 93:404 (R;US)

\section{NUCLEAR CONTROVERSY}

SEQ HAZARDS

NUCLEAR DECAY

HUMAN POPULATIONS

Natural radionuclide and stable element studies of rock samples from the Osamu Utsumi mine and Morro do Ferro analogue study sites, Pocos de Caldas, Brazil, 93:504 (R;CH)

NUCLEAR ENERGY AGENCY

SQQ NEA

NUCLEAR FACILITIES

Seo also NUCLEAR POWER PLANTS

RADIOACTIVE WASTE FACILITIES

Economic impact of nuclear facilities, 93:627 (BA;US)

The Yucca Mountain tours: A test of the familiarity hypothesis, 93:618 (BA;US)

NUCLEAR POWER

Nuclear age: Take two?, 93:658 (J;US)

NUCLEAR POWER PLANTS

NRC approves spent-fuel cask for general use: Who needs Yucca Mountain?, 93:648 (J;US)

NUCLEAR POWER STATIONS

See NUCLEAR POWER PLANTS

NUCLEAR WASTE POLICY ACTS

A view on siting issue from Nevada, 93:691 (J;US)

Focus shifts from capital to Nevada, 93:690 (J;US)

Fourth report to the U.S. Congress and the U.S. Secretary of Energy from the Nuclear Waste Technical Review Boand, 93:573 (R;US)

Implementing the Payments-Equal-To-Taxes (PET) program in Nevada, 93:88 (BA;US)

Nuclear waste policy and politics, 93:689 (U;US)

Nuclear waste: Quarterly report as of March 31, 1990, 93:467 (R;US)

Public opposition to the siting of the high-level nuclear waste repository: The importance of trust, $93: 682$ (J;US)

Records Management in support of the licensing process for the high level radioactive waste facility, 93:85 (BA;US)

S. 1138: A bill to amend the Nuclear Waste Policy Act of 1982 to direct the Secretary of Energy to carry out site characterization activities at the Yucca Mountain site in Nevada, and for other purposes, introduced in the US Senate, One Hundred Second Congress, First Session, May 22, 1991, 93:605 (B;US)

US Department of Energy issue resolution process, $93: 80$ (BA;US)

NUCLEAR WASTES

See RADIOACTIVE WASTES

OIL SHALE WASTE WATER

Soo WASTE WATER

OKLO PHENOMENON

Hydrogeology and migration in the remote field, $93: 419$ (R;FR; In French)

Migration of radioelements around the new nuclear reactors at Oklo: Analogies with a high-level waste repository, 93:670 $(\mathrm{J} ; \mathrm{DE})$
Oklo - natural analogue for transfer processes in a geological repository: present status of the programme, 93:464 (RA;XE)

Two-billion-year-old nuclear reactors: Nature goes fission, 93:669 (J;US)

\section{OPENINGS}

Seo also APERTURES

Seismic design of circular-section concrete-lined underground openings: Preclosure performance considerations for the Yucca Mountain Site (Yucca Mountain Project), 93:303 (R;US)

\section{ORGANIC MATTER}

Hydrothermal alteration of organic matter in uranium ores, Elliot Lake, Canada: Implications for selected organic-rich deposits, 93:650 (J;US)

\section{OXYGEN}

Radioelements and their occurrence with secondary minerals in heated and unheated tuff at the Nevada Test Site, 93:52 (R;US)

OXYGEN EFFECT (RADIOBIOLOGY)

SeO OXYGEN

OXYGEN HYDRIDES

SQQ WATER

\section{OXYGEN ISOTOPES}

Radioelements and their occurrence with secondary minerals in heated and unheated tuff at the Nevada test site, 93:82 (BA;US)

Stable isotopic evidence for a pedogenic origin of carbonates in trench 14 near Yucca Mountain, Nevada, 93;686 (J;US)

\section{P CODES}

Prediction of Pseudo relative velocity response spectra at Yucca Mountain for underground nuclear explosions conducted in the Pahute Mesa testing area at the Nevada testing site: Yucca Mountain Site Characterization Project (Yucca Mountain Project), 93:230 (R;US)

PACIFIC NORTHWEST REGION

SeE USA

PEOPLE

SOQ HUMAN POPULATIONS

\section{PERFORMANCE}

Approach to geologic repository post closure system performance assessment, 93:308 (R;US)

\section{PETROLEUM DEPOSITS}

Yucca Mountain, a high-level nuclear waste repository over a billion barrel oil field?, 93:677 (J;US)

PHOTON DETECTION (GAMMA)

See GAMMA DETECTION

PHYSICAL CHEMISTRY

Nuclear Technology Programs semiannual progress report, OCtober 1990-March 1991, 93:404 (R;US)

Nuclear technology programs: Semiannual progress report, October 1989-March 1990, 93:401 (R;US)

PITTING CORROSION

Modeling pitting corrosion damage of high-level radioactivewaste containers, with emphasis on the stochastic approach 93:169 (R;US)

\section{PLUTONIUM}

Occurrence of naturally enriched ${ }^{235} \mathrm{U}$ : Implications for plutonium behavior in natural environments, 93:656 (J;US)

Solubility and speciation studies for nuclear repository performance assessment, 93:50 (R;US)

PLUTONIUM 238

Experimental method for determining distribution coefficients of TRU nuclides for evaluating their migration behaviors, 93:476 (R;JP;in Japanese)

PLUTONIUM 239

Sorption and porosity heterogeneity: Effects on radionuclide transport, $93: 479$ (RA;US)

PLUTONIUM COMPOUNDS

Dependence of actinide solubility and speciation on carbonate concentration and ionic strength in groundwater, 93:97 (J;DE) 
POISONS (CHEMICAL)

SeQ HAZARDOUS MATERIALS

POLY(VINYLIDENE FLUORIDE)

SeO FLUORINATED ALIPHATIC HYDROCARBONS

POROUS MATERIALS

Colloid transport code-nuclear user's manual, 93:493 (R;US)

Continued development of a semianalytical solution for twophase fluid and heat flow in a porous medium, 93:41 (RA;US)

Design of an intermediate-scale experiment to validate unsaturated-zone transport models, 93:354 (BA;US)

FEHMN 1.0: Finite element heat and mass transfer code: Revision 1, 93:103 (R; US)

NORIA-SP: A finite element computer program for analyzing liquid water transport in porous media: Yucca Mountain Site Characterization Project (YUCCA MOUNTAIN PROJECT), 93:255 (R;US)

PORTLAND CEMENT

Gas phase migration of $\mathrm{C}-14$ through barrier materials applicable for use in a high-level nuclear waste repository located in tuff, $93: 647$ (i;US)

PRESSURE VESSELS

Report on task assignment No. 3 for the Waste Package Project: Parts A \& B, ASME pressure vessel codes review for waste package application; Part C, Library search for reliability/failure rates data on low temperature low pressure piping. containers, and casks with long design lives, $93: 12$ (R;US)

PRESSURIZED WATER COOLED MODERATED REACTOR

SEO PWR TYPE REACTORS

PRESSURIZED WATER REACTORS

SEQ PWR TYPE REACTORS

PROCESSING (DATA)

SOQ DATA PROCESSING

PSYCHROMETRY

Proposed algorithm for determining the delta intercept of a thermocouple psychrometer curve, 93:386 (R;US)

PUBLIC ATTITUDES

SOQ PUBLIC OPINION

PUBLIC OPINION

Changes in risk perception over time, 93:580 (R;US)

PWR TYPE REACTORS

Seo also SHIPPINGPORT REACTOR

Thermal performance of a buried nuclear waste storage container storing a hybrid mix of PWR and BWR spent fuel rods: Revision 1, 93:159 (R;US)

\section{QUARTZ}

Neptunium( $V$ ) sorption on quartz and albite in aqueous suspension: Annual progress report, 93:495 (R;US)

\section{$\mathbf{R}$}

\section{RADIATION BURDEN}

S $\theta$ RADIATION DOSES

\section{RADIATION DOSES}

Probabilistic risk assessment and nuclear waste transportation: A case study of the use of RADTRAN in the 1986 Environmental Assessment for Yucca Mountain, 93:560 (R;US)

RADIATION EXPOSURE (DOSES)

SEO RADIATION DOSES

RADIATION HAZARDS

Preclosure radiological safety evaluation: Exploratory Studies Facility: Yucca Mountain Site Characterization Project, 93:315 (R;US)

RADIATION HEATING

Drift emplaced waste package thermal response (Yucca Mountain Project), 93:193 (R;US)

RADIOACTIVE BIOLOGICAL WASTES

SeO RADIOACTIVE WASTES
RADIOACTIVE EFFLUENTS

Integrated performance assessment model for waste policy package behavior and radionuclide release, 93:633 (BA;US)

Performance-assessment comparisons for a repository containing LWR spent fuel or partitioned/transmutted nuclear waste, 93:351 (BA;US)

Releases from exotic waste packages from partitioning and transmutation, 93:207 (BA;US)

Session II: Gas pathway, 93:462 (RA;US)

RADIOACTIVE GASEOUS WASTES

See GASEOUS WASTES

RADIOACTIVE WASTES

RADIOACTIVE MATERIALS

Seo also FISSION PRODUCTS

RADIOACTIVE WASTES

Intra-site secure transport vehicle, 93:581 (R;US)

RADIOACTIVE WASTE DISPOSAL

Developing a functioning visualization and analysis system for performance assessment, 93:289 (R;US)

Mineralogy, petrology and whole-rock chemistry of selected mechanical test samples of Yucca Mountain tuffs: Yucca Mountain Site Characterization Project, 93:259 (R;US)

Coordinated Research Programs

State of Nevada review of Phase 1 of the INTRAVAL Project, 93:571 (R; US)

The International INTRAVAL project. Phase 1 case 8: The Alligator rivers natural analogue, $93: 473(R ; X N)$

The International INTRAVAL project. Phase 1 test cases, 93:471 $(\mathrm{R} ; \mathrm{XN})$

The International INTRAVAL project. Phase 1, case 7. The Pocos de Caldas natural analogue: studies of redox front movement, $93: 472(\mathrm{R} ; \mathrm{XN})$

The international hydrocoin project - Groundwater hydrology modelling strategies for performance assessment of nuclear waste disposal, 93:470 (R;XN)

Corrosion

Some observations on the mechanism of corrosion to be en countered in nuclear waste repositories located in tuffaceous rock, 93:655 (J;GB)

Data Base Management

Yucca Mountain digital database, 93:615 (BA;US)

Economic Impact

Should high-level nuclear waste be disposed of at geographically dispersed sites?, $93: 412$ (R;US)

Education

Science and students: Yucca Mountain Project's educational outreach and public tour programs, $93: 83$ (BA;US)

Engineered Safety Systems

Travel to France to attend and participate in the Technical Workshop on Near-Field Performance Assessment: Foreign trip report, May 9-16, 1993, 93:435 (R;US)

Engineering

Stripa: An international cooperative project, 93:92 (BA;US)

Environmental Effects

Microbiological analysis at the Osamu Utsumi mine and Morro do Ferro analogue study sites, Pocos de Caldas, Brazil: Pocos de Caldas Report No. 10, 93:585 (R;SE)

Environmental Impacts

Economic impact of nuclear facilities, 93:627 (BA;US)

Environmental Policy

Panel discussion on nuclear waste, 93:614 (BA;US)

Evaluation

Developing conceptual models for performance assessment of waste management sites, 93:616 (BA;US)

Teleseismic tomography of the Yucca Mountain region: Volcanism and tectonism, 93:394 (BA:US)

Travel to Switzerland for performance assessments for both the low- and intermediate-level and high-level radioactive waste disposal programs being managed and implemented by NAGRA: Foreign trip report, May 2-9, 1993, 93:436 (R;US)

Forecasting

Alternate conceptual model of ground water flow at Yucca Mountain, $93: 612$ (BA;US) 


\section{Government Policies}

Panel discussion on nuclear waste, 93:614 (BA;US)

Heat Transfer

Temperature scenarios for a repository at Yucca Mountain, 93:623 (BA;US)

High-Level Radioactive Wastes

The siting guidelines, 10 CFR Part 960, $93: 680(\mathrm{~J} ; \mathrm{CH})$

U.S. Nuclear Regulatory Commission overview of repository quality assurance, $93: 683(\mathrm{~J} ; \mathrm{CH})$

U.S. strategy for evaluating the Yucca Mountain, Nevada site, 93:98 (J;CH)

Hydrology

The implications of episodic nonequilibrium fracture-matrix flow on site suitability and total system performance, 93:204 (BA;US)

Information

DOE's Yucca Mountain studies: What are they? Why are they being done?, $93: 24$ (R;US)

Legal Aspects

The status of Yucca Mountain site characterization activities, 93:79 (BA;US)

Meotings

Proceedings of the conference on shaft drilling technology, 93:607 (B;US)

Performance

The international hydrocoin project - Groundwater hydrology modelling strategies for performance assessment of nuclear waste disposal, 93:470 (R; XN)

Performance Testing

Performance assessment for a high-level waste repository at Yucca Mountain, 93:625 (BA;US)

Political Aspocts

Nuclear waste policy and politics, 93:689 (J;US)

Yucca Mountain: Policy, progress and politics, 93:73 (BA;US)

Pollution Regulations

Panel discussion on nuclear waste, 93:614 (BA;US)

Probabilistic Estimation

Use of Wingz spreadsheet as an interface to total-system performance assessment, 93:340 (BA;US)

Public Anxiety

Nuclear wastes and public trust, $93: 660$ ( $\mathrm{J} ;$ US)

Public Opinion

2010: America's nuclear waste odyssey, 93:652 (J;GB)

Radioactive Waste Facilities

A conceptual design for a nuclear waste repository at the Yucca Mountain site, 93:359 (BA;US)

Hydrologic modeling and field testing at Yucca mountain, Nevada, 93:396 (BA;FR)

RE/SPEC Inc. technical support to the Repository Technology Program: Summary of activities for September 1, 1988-June 30, 1992, $93: 432$ (R;US)

Regulations

Plans for characterization of the potential geologic repository site at Yucca Mountain, Nevada, 93:99 (J;US)

Safeguards

International safeguards concepts for the Yucca Mountain Geological Repository, 93:685 (J;US)

Safoty

Preliminary postclosure risk assessment Yucca mountain, Nevada, candidate repository site, 93:360 (BA;FR; ln FR, EN)

Safety Analysis

Fault stress analysis for the Yucca Mountain site characterization project, 93:355 (BA;US)

Integrated performance assessment model for waste policy package behavior and radionuclide release, 93:633 (BA;US)

Recurrence models of volcanic events: Applications to volcanic risk assessment, 93:139 (BA;US)

Sito Characterization

A decision analysis of an exploratory studies facility, 93:342 (BA;US)

A forecasting model of gaming revenues in Clark County, Nevada, 93:626 (BA;US)
Applications of performance assessment in support of the exploratory studies facility (ESF) design, 93:344 (BA;US)

Characterization of liquid-water percolation in tuffs in the unsaturated zone, Yucca Mountain, Nye County, Nevada, 93:361 (R;US)

DOE's Yucca Mountain studies, 93:30 (R;US)

Economic impact of nuclear facilities, 93:627 (BA;US)

Environmental monitoring for uranium and neptunium at Yucca Mountain using Epithermal Neutron Activation Analysis, 93:447 (R;US)

Fault stress analysis for the Yucca Mountain site characterization project, 93:355 (BA; US)

Fifth report to the US Congress and the US Secretary of Energy from the Nuclear Waste Technical Review Board, 93:575 (R; US)

Geostatistical methods for site characterization at Yucca Mountain, 93:641 (BA;FR)

Identification and characterization of conservative organic tracers for use as hydrologic tracers for the Yucca Mountain Site characterization study: Progress report, April 1, 1993-June 30, 1993, $93: 15$ (R; US)

Integrated performance assessment model for waste policy package behavior and radionuclide release, 93:633 (BA;US)

Method development and strategy for the characterization of complexly faulted and fractured rhyolitic tuffs, Yucca Mountain, Nevada, USA, 93:395 (BA;FR)

Modeling fault rupture hazard for the proposed repository at Yucca Mountain, Nevada, 93:629 (BA;US)

Nuclear waste: DOE expenditures on the Yucca Mountain Project, 93:469 (R;US)

Nuclear waste: Questionable uses of program funds at Lawrence Livermore Lab., 93:468 (R;US)

Overview and status of the U.S. high-level waste program, 93:610 (BA;US)

Preliminary conceptual model for mineral evolution in Yucca Mountain, 93:111 (R;US)

Proposed sealing field tests for a potential high-level radioactive waste repository in unsaturated tuff, 93:356 (BA;US)

Quantification of uncertain outcomes from site characterization: Insights from the ESF-AS, 93:343 (BA;US)

RE/SPEC Inc. technical support to the Repository Technology Program: Summary of activities for September 1, 1988-June 30, 1992, $93: 432$ (R; US)

Recurrence models of volcanic events: Applications to volcanic risk assessment, 93:139 (BA;US)

Regulatory considerations in design of the exploratory studies facility, 93:77 (BA;US)

Site characterization progress report: Yucca Mountain, Nevada, April 1, 1992-September 30, 1992, Number 7, 93:28 (R;US)

Site characterization progress report: Yucca Mountain, Nevada, October 1, 1992-March 31, 1993, No. 8, 93:31 (R;US)

Site studies continue at Yucca Mountain in the US, 93:96 (J;GB)

State of Nevada review of Phase 1 of the INTRAVAL Project, 93:571 (R;US)

Stripa: An international cooperative project, 93:92 (BA;US)

Supporting hydration calculations for small- to large-scale seal tests in unsaturated tuff, 93:357 (BA;US)

Teleseismic tomography of the Yucca Mountain region: Volcanism and tectonism, 93:394 (BA;US)

The international INTRAVAL project. Phase 1 test cases, 93:471 ( $R ; X N)$

Update on the Yucca Mountain Project site characterization program, 93:90 (BA;US)

Using seals to control flow at Yucca Mountain, 93:630 (BA;US)

Yucca Mountain Site Characterization Project bibliography, July-December 1992: An update, Supplement 3, Addendum 2: Civilian Radioactive Waste Management Program, 93:22 (R;US)

Yucca Mountain Site characterization project bibliography, January-June 1992: An Update: Supplement 3, Addendum 1, 93:21 (R;US)

Yucca Mountain: Policy, progress and politics, 93:73 (BA;US) 
Social Impact

Should high-level nuclear waste be disposed of at geographically dispersed sites?, 93:412 (R;US)

Source Terms

Development and evaluation of a performance assessment methodology for analyzing the safety of a geologic repository for high-level radioactive waste, 93:527 (RA;US)

\section{Standards}

Critical comments on the US Environmental Protection Agency Standards 40 CFR 191, 93:7 (R;US)

Evaluation of alternatives for high-level and transuranic USA radioactive- waste disposal standards, $93: 582$ (R;US)

Technical challenges in the repository program, $93: 679(\mathrm{~J} ; \mathrm{CH})$

Underground Disposal

Siting the high level radioactive waste repository in the United States, 93:620 (BA;GB)

Technical challenges in the repository program, $93: 679(\mathrm{~J} ; \mathrm{CH})$

Testing of geochemical models in the Pocos de Caldas analogue study, 93:507 (R;CH)

The Pocos de Caldas project: summary and implications for radioactive waste management: Pocos de Caldas report no. 15, 93:510 (R;CH)

The influence of scale on calculated sorptivity values from imbibition experiments on welded and nonwelded tuff, 93:397 (BA;FR)

Underground Facilities

Nuclear waste: Questionable uses of program funds at Lawrence Livermore Lab., 93:468 (R;US)

Tunnel boring machine applications: Yucca Mountain Exploratory Studies Facility, 93:81 (BA;US)

Yucca Mountain: Policy, progress and politics, 93:73 (BA;US)

Yucca Mountain

Design considerations for the Yucca Mountain project exploratory shaft facility, $93: 91$ (BA;US)

RADIOACTIVE WASTE FACILITIES

Quarterly report on program cost and schedule, fourth quarter FY 1992, $93: 459$ (R;US)

Budgats

Office of Civilian Radioactive Waste Management Program Cost and Schedule Baseline: Revision 3, 93:450 (R;US)

Bullding Materials

Chemical and mineralogical concerns for the use of man-made materials in the post-emplacement environment, 93:176 (R;US)

Cementing

Supporting hydration calculations for small- to large-scale seal tests in unsaturated tuff, 93:357 (BA;US)

Computer Codes

Integrated performance assessment model for waste policy package behavior and radionuclide release, 93:633 (BA;US)

Construction

DOE reassesses civilian radioactive waste management program, 93:688 (J;US)

Nuclear waste: DOE expenditures on the Yucca Mountain Project, 93:469 (R;US)

Preliminary near-field environment report: Volume 1, Technical bases for EBS design (yucca mountain project), 93:198 (R;US)

Tunnel boring machine applications: Yucca Mountain Exploratory Studies Facility, 93:81 (BA;US)

Yucca Mountain Exploratory Studies Facilities: Construction status: Extended summary, 93:100 (R;US)

Cost

Program cost and schedule baseline: Revision 2, $93: 449$ (R;US)

Quarterly report on program cost and schedule, third quarter $F Y$ $1992,93: 458$ (R;US)

Quarterly report on program cost and schedule: Second quarter FY 1992, 93:457 (R;US)

USDOE Office of Civilian Radioactive Waste Management quarterly report on program cost and schedule: Fourth Quarter, FY 1991, 93:452 (R;US)
Data Acquisition Systems

Geotechnical instrumentation for repository shafts, 93:427 (BA;US)

Decision Making

Intergovernmental complexity in nuclear waste disposal policy: The indeterminate role of local government, 93:681 (J;US)

Public opposition to the siting of the high-level nuclear waste repository: The importance of trust, $93: 682$ (J;US)

Decision Tree Analysis

A decision analysis of an exploratory studies facility, 93:301 (R; US)

Decommissioning

An example postclosure risk assessment using the potential Yucca Mountain Site, 93:155 (R;US)

Design

A conceptual design for a nuclear waste repository at the Yucca Mountain site, 93:359 (BA;US)

Current plans to characterize the design basis ground motion at the Yucca Mountain, Nevada Site, 93:4 (R;US)

Design and implementation of the site and engineering properties database: Yucca Mountain Site Characterzation Project 93:242 (R;US)

Design of an intermediate-scale experiment to validate unsaturated-zone transport models, 93:354 (BA;US)

Dritt design methodology and preliminary application for the Yucca Mountain Site Characterization Project: Yucca Mountain Site Characterization Project (YUCCA MOUNTAIN PROJECT), 93:237 (R;US)

Dynamic analysis and design considerations for high-level nuclear waste repositories, 93:600 (B;US)

Nuclear waste repository program oversight: Strategies of the situs jurisdiction, 93:634 (BA;US)

Overview and status of the U.S. high-level waste program, 93:610 (BA;US)

Regulatory considerations in design of the exploratory studies facility, 93:77 (BA;US)

Summary of the Exploratory Studies Facility Alternatives Study: Draft, 93:277 (R;US)

Supporting hydration calculations for small- to large-scale seal tests in unsaturated tuff, 93:357 (BA;US)

US Department of Energy issue resolution process, 93:80 (BA;US)

Underground exploration at Yucca Mountain, 93:75 (BA;US)

Using seals to control flow at Yucca Mountain, 93:630 (BA;US)

Economic Impact

Implementing the Payments-Equal-To-Taxes (PETT) program in Nevada, 93:88 (BA;US)

Perceived risk impacts from siting hazardous waste facilities, 93:410 (R;US)

Environmental Impacts

Environmental monitoring for uranium and neptunium at Yucca Mountain, 93:639 (BA;US)

Nuclear waste repository program oversight: Strategies of the situs jurisdiction, 93:634 (BA; US)

Performance-assessment comparisons for a repository containing LWR spent fuel or partitioned/transmutted nuclear waste, 93:351 (BA;US)

Potential increases in natural radon emissions due to heating of the Yucca Mountain rock mass, 93:208 (BA;US)

Proposed sealing field tests for a potential high-level radioactive waste repository in unsaturated tuff, 93:356 (BA;US)

Radiological environmental monitoring for the Yucca Mountain site, 93:89 (BA;US)

Review and critique of the US Department of Energy environmental program plan for site characterization for a high-level waste repository at Yucca Mountain, Nevada, $93: 570$ (R;US)

Strontium isotope geochemistry of calcite fracture fillings in deep core, Yucca Mountain, Nevada: A progress report 93:393 (BA:US)

The hydrothermal stability of cement sealing materials in the potential Yucca Mountain high level nuclear waste repository, 93:339 (BA;US)

Underground exploration at Yucca Mountain, $93: 75$ (BA;US) 
Yucca Mountain Biological Resources Monitoring Program: Annual report, FY91, 93:35 (R;US)

Field Tests

Hydrologic modeling and field testing at Yucca mountain, Nevada, 93:396 (BA;FR)

Proposed sealing field tests for a potential high-level radioactive waste repository in unsaturated tuff, 93:356 (BA;US)

\section{Flood Control}

Probable maximum flood control: Yucca Mountain Site Characterization Project (Yucca Mountain Project), 93:232 (R;US)

\section{Heat Flow}

TOUGH2: A general-purpose numerical simulator for multiphase nonisothermal flows, 93:43 (RA;US)

Hydrology

Proposed sealing field tests for a potential high-level radioactive waste repository in unsaturated tuff, 93:356 (BA;US)

Information Needs

Flow to licensing: Technical data tracking and the Licensing Support System (LSS), 93:86 (BA;US)

Interagency Cooperation

Intergovernmental complexity in nuclear waste disposal policy: The indeterminate role of local government, 93:681 (J;US)

Public opposition to the siting of the high-level nuclear waste repository: The importance of trust, $93: 682$ (J;US)

\section{Leaching}

Design of an intermediate-scale experiment to validate unsaturated-zone transport models, 93:354 (BA;US)

Deterministic geologic processes and stochastic modeling, 93:353 (BA;US)

Diffusion of carbon dioxide and iodine through Yucca Mountain tuffs: Effects of temperature and moisture content, 93:635 (BA;US)

Releases from exotic waste packages from partitioning and transmutation, 93:207 (BA;US)

Strontium isotope geochemistry of calcite fracture fillings in deep core, Yucca Mountain, Nevada: A progress report, 93:393 (BA;US)

Legal Aspects

Native Americans and Yucca Mountain: A revised and updated summary report on research undertaken between 1987 and 1991: Volume 1, 93:548 (R;US)

Native Americans and Yucca Mountain: A revised and updated summary report on research undertaken between 1987 and 1991: Volume 2, 93:549 (R;US)

Native Americans and Yucca Mountain: A summary report, 93:544 (R:US)

Native Americans and state and local governments, 93:553 (R;US)

License Applications

Use of annotated outlines to prepare guidance for license applications for the MRS and MGDS, 93:628 (BA;US)

Licensing

Flow to licensing: Technical data tracking and the Licensing Support System (LSS), 93:86 (BA;US)

US Department of Energy issue resolution process, 93:80 (BA;US)

Management

A structural model analysis of public opposition to a high-level radioactive waste facility, 93:554 ( $R$; US)

Meetings

Dynamic analysis and design considerations for high-level nuclear waste repositories, 93:600 (B;US)

Multiphase Flow

TOUGH2: A general-purpose numerical simulator for multiphase nonisothermal flows, 93:43 (RA;US)

Performance

A comparative application of the Repository Integration Program (RIP) to Total System Performance Assessment, 1991, 93:102 (R;US)

A working definition of scenario and a method of scenario construction (yucca mountain project), 93:331 (R;US)

Comparison of two conceptual models of flow using the TSA (Yucca Mountain Project), 93:282 (R;US)
Health and environmental risk-related impacts of actinide burn ing on high-level waste disposal, $93: 572$ (R;US)

Preliminary total-system analysis of a potential high-level nuclear waste repository at Yucca Mountain, 93:63 (R;US)

Processes, mechanisms, parameters, and modeling approaches for partially saturated flow in soil and rock media: Yucca Mountain Site Characterization Project (Yucca Mountain Project.), 93:233 (R;US)

SUMO, System performance assessment for a high-level nuclear waste repository: Mathematical models, 93:153 (R;US)

TSPA 1991: An initial total-system performance assessment for Yucca Mountain: Yucca Mountain Site Characterization Project (Yucca Mountain Project), 93:293 (R;US)

Thermal analysis of Yucca Mountain commercial high-level waste packages, 93:156 (R;US)

Use of Wingz spreadsheet as an interface to total-system performance assessment (Yucca Mountain Project), 93:281 (R;US)

Yucca Mountain Project total-system performance assessment preliminary analyses: Overview: Draft, 93:284 (R;US)

Performance Testing

An overview of the Yucca Mountain global/regional climate modeling program, 93:350 (BA; US)

Deterministic geologic processes and stochastic modeling, 93:353 (BA;US)

Developing conceptual models for performance assessment of waste management sites, $93: 578$ (R;US)

integrated performance assessment model for waste policy package behavior and radionuclide release, 93:633 (BA;US)

Performance-assessment comparisons for a repository containing LWR spent fuel or partitioned/transmutted nuclear waste, 93:351 (BA;US)

Underground exploration at Yucca Mountain, $93: 75$ (BA;US)

Permits

Update on the Yucca Mountain Project site characterization program, 93:90 (BA;US)

\section{Planning}

An overview of the Yucca Mountain global/regional climate modeling program, 93:350 (BA;US)

Nuclear waste: Quarterly report as of March 31, 1990, 93:467 (R; US)

\section{Program Management}

Program cost and schedule baseline: Revision 2, 93:449 (R;US)

\section{Public Opinion}

A structural model analysis of public opposition to a high-level radioactive waste facility, $93: 554$ (R;US)

Institutional trust, information, and risk perceptions: Report of findings of the Las Vegas metropolitan area survey, June 29 July 1, 1992, 93:557 (R;US)

Public opposition to the siting of the high-level nuclear waste repository: The importance of trust, $93: 682(\mathrm{~J} ; \mathrm{US})$

Social impacts of hazardous and nuclear facilities and events: Implications for Nevada and the Yucca Mountain high-level nuclear waste repository: [Final report], 93:555 (R;US)

Socioeconomic profiles of Native American communities: Las Vegas Tribes of Paiute Indians, 93:550 (R;US)

Southern Nevada residents' views about the Yucca Mountain high-level nuclear waste repository and related issues: A comparative analysis of urban and rural survey data, 93:547 (R;US)

Technical evaluation of available state of Nevada survey instruments, 98:418 (R;US)

Word images as policy instruments: Lessons from the Yucca Mountain Controversey, $93: 430$ (R; US)

Yucca Mountain socioeconomic project report on the 1987 risk perception telephone surveys, 93:545 (R;US)

Radiation Accidents

Preclosure radiological safety analysis for accident conditions of the potential Yucca Mountain Repository: Underground facilities: Yucca Mountain Site Characterization Project (Yucca Mountain Project), 93:234 (R;US)

Radioactive Waste Management

Characterization of rock hydrologic properties using model verification (Yucca Mountain Project), 93:519 (RA;US) 
Field testing the effectiveness of pumping to remove sulfur hexafluoride traced drilling air from a prototype borehole near superior, Arizona, 93:518 (RA;US)

Flow through nonhomogeneous porous media, 93:525 (RA;US) Hydrogeologic issues at Yucca Mountain: Findings of a DOE peer review team, 93:513 (RA;US)

Modeling hydrothermal flow in variably saturated, fractured, welded tuff during the prototype engineered barrier system field test of the Yucca Mountain Project, 93:523 (RA;US)

Nonequilibrium fracture-matrix flow during episodic infiltration events in Yucca Mountain (Yucca Mountain Project), 93:514 (RA;US)

\section{Recommendations}

Public opposition to the siting of the high-level nuclear waste repository: The importance of trust, $93: 682$ (J;US)

Report of the State of Nevada Commission on Nuclear Projects, 93:538 (R;US)

Records Management

Records Management in support of the licensing process for the high level radioactive waste facility, 93:85 (BA;US)

\section{Regulations}

Is it possible to demonstrate compliance with the regulations for high-level-waste repositories?, 93:316 (R;US)

\section{Risk Assessment}

Expert judgment in assessing radwaste risks: What Nevadans should know about Yucca Mountain: [Final report], 93:556 (R;US)

Potential for water-table excursions induced by seismic events at Yucca Mountain, Nevada, 93:211 (J;US)

Releases from exotic waste packages from partitioning and transmutation, 93:207 (BA:US)

SUMO, System performance assessment for a high-level nuclear waste repository: Mathematical models, 93:153 (R;US)

Technical evaluation of available state of Nevada survey instruments, 93:418 (R;US)

\section{$s$ Codes}

Documentation and verification of STRES3D, Version 4.0 Yucca Mountain Site Characterization Project, $93: 250$ (R;US)

Safety

Identification of structures, systems, and components important to safety at the potential repository at Yucca Mountain: Yucca Mountain Site Characterization Project (YUCCA MOUNTAIN PROJECT), 93:251 (R;US)

\section{Safety Analysis}

Fault stress analysis for the Yucca Mountain site characterization project, 93:355 (BA;US)

Preclosure radiological safety evaluation: Exploratory Studies Facility: Yucca Mountain Site Characterization Project 93:315 (R:US)

Recurrence models of volcanic events: Applications to volcanic risk assessment, 93:139 (BA;US)

\section{Sefety Engineering}

Conceptual design of a monitored retrievable storage cask employing Yucca Mountain containers, 93:638 (BA;US)

Flow to licensing: Technical data tracking and the Licensing Support System (LSS), 93:86 (BA;US)

Preclosure seismic hazards and their impact on site suitability of Yucca Mountain, Nevada, 93:349 (BA;US)

US Department of Energy issue resolution process, 93:80 (BA;US)

Safety Standards

Council report finds high-level nuclear waste repository rules 'unrealistic', 93:687 (J;US)

Radiological environmental monitoring for the Yucca Mountain site, 93:89 (BA:US)

Records Management in support of the licensing process for the high level radioactive waste facility, 93:85 (BA;US)

Using seals to control flow at Yucca Mountain, 93:630 (BA;US)

Sealing Materials

Sealing performance assessments of bentonite and bentonite/crushed rock plugs, 93:645 (1;US)
The hydrothermal stability of cement sealing materials in the potential Yucca Mountain high level nuclear waste repository, 93:339 (BA;US)

Using seals to control flow at Yucca Mountain, 93:630 (BA;US)

\section{Seismic Effects}

Assessment of the potential for tectonic fault rupture for highlevel nuclear waste repositories, 93:421 (BA;US)

Geotechnical instrumentation for repository shafts, $93: 427$ (BA;US)

Optimal cost basis for seismic design, 93:426 (BA;US)

Options for dynamic analyses of underground facilities, 93:424 (BA;US)

Preclosure seismic hazards and their impact on site suitability of Yucca Mountain, Nevada (Yucca Mountain Project), 93:291 (R;US)

Preclosure seismic hazards and their impact on site suitability of Yucca Mountain, Nevada, 93:349 (BA;US)

Seismic Surveys

US Department of Energy issue resolution process, 93:80 (BA;US)

Shaft Excavations

Documentation and verification of the SHAFT code: Yucca Mountain Site Characterization Project (YUCCA MOUNTAIN PROJECT), 93:235 (R; US)

Shielding

Effects of various radiation source characteristics on shielding requirements at the potential Yucca Mountain repository, 93:248 (R;US)

\section{Site Approvals}

Alternative strategies: A means for saving money and time on the Yucca Mountain Project (Yucca Mountain Project), 93:192 (R;US)

Site Characterization

A Monte Carlo technique to estimate the probability of volcanic dikes, 93:637 (BA;US)

A decision analysis of an exploratory studies facility, 93:301 (R;US)

An overview of the Yucca Mountain globalregional climate modeling program, 93:350 (BA;US)

Characterization of the Topopah spring and Tiva Canyon tuffs at Yucca Mountain: Effective diffusivities and pore properties 93:636 (BA:US)

Characterizing the altered zone at Yucca Mountain: The beginning of a testing strategy, 93:206 (BA;US)

Conservative tracers for the $C$-well hydraulic testing, 93:84 (BA;US)

Dependence of actinide solubility and speciation on carbonate concentration and ionic strength in groundwater, 93:97 (J;DE

Design and implementation of the site and engineering properties database: Yucca Mountain Site Characterzation Project 93:242 (R:US)

Design of an intermediate-scale experiment to validate unsaturated-zone transport models, 93:354 (BA;US)

Deterministic geologic processes and stochastic modeling, 93:353 (BA;US)

Diffusion of carbon dioxide and iodine through Yucca Mountain tuffs: Effects of temperature and moisture content, 93:635 (BA;US)

Fault stress analysis for the Yucca Mountain site characterization project, 93:355 (BA;US)

Flow to licensing: Technical data tracking and the Licensing Support System (LSS), 93:86 (BA;US)

Geochemical evidence for waning magmatism and polycyclic volcanism at Crater Flat, Nevada, 93:140 (BA;US)

Geotechnical support and topical studies for nuclear waste geologic repositories: Annual report, fiscal year 1989, 93:47 (R;US)

Implementing the Payments-Equal-To-Taxes (PETT) program in Nevada, 98:88 (BA;US)

Late Quaternary geology of small basaltic volcanic centers, SW USA: Disparity among dating methods and implications for volcanic and geomorphic studies, $93: 668$ (J;US) 
Management of scientific and engineering data collected during site characterization of a potential high-level waste repository, 93:87 (BA;US)

Nuclear waste repository program oversight: Strategies of the situs jurisdiction, 93:634 (BA;US)

Nuclear waste: Quarterly report as of March 31, 1990, 93:467 (R;US)

Overview and status of the U.S. high-level waste program, 93:610 (BA;US)

Paleohydrologic implications of the stable isotopic composition of secondary calcite within the tertiary volcanic rocks of Yucca Mountain, Nevada, 93:392 (BA;US)

Physical processes and effects of magmatism in the Yucca Mountain region, 93:138 (BA;US)

Potential increases in natural radon emissions due to heating of the Yucca Mountain rock mass, 93:208 (BA;US)

Preclosure seismic hazards and their impact on site suitability of Yucca Mountain, Nevada, 93:349 (BA:US)

Progress report on the scientific investigation program for the Nevada Yucca Mountain Site, October 1, 1991-March 31, 1992, Number 6, $93: 27$ (R;US)

Proposed sealing field tests for a potential high-level radioactive waste repository in unsaturated tuff, 93:356 (BA;US)

Radioactive waste: Finding a safe place, 93:674 (J;US)

Radioelements and their occurrence with secondary minerals in heated and unheated tuff at the Nevada test site, 93:82 (BA;US)

Radiological environmental monitoring for the Yucca Mountain site, 93:89 (BA:US)

Records Management in support of the licensing process for the high level radioactive waste facility, 93:85 (BA;US)

Recurrence models of volcanic events: Applications to volcanic risk assessment, 93:139 (BA;US)

Releases from exotic waste packages from partitioning and transmutation, 93:207 (BA;US)

Report of the Peer Review Panel on the early site suitability evaluation of the Potential Repository Site at Yucca Mountain, Nevada: Yucca Mountain Site Characterization Project, 93:68 (R;US)

Review and critique of the US Department of Energy environmental program plan for site characterization for a high-level waste repository at Yucca Mountain, Nevada, 93:570 (R;US)

Science and students: Yucca Mountain Project's educational outreach and public tour programs, 93:83 (BA;US)

Strontium isotope geochemistry of calcite fracture fillings in deep core, Yucca Mountain, Nevada: A progress report, 93:393 (BA;US)

TBM performance prediction in Yucca Mountain weided tuff from linear cutter tests, 93:352 (BA;US)

Technical basis and programmatic requirements for Engineered Barrier System Field Tests, 93:174 (R;US)

Technical evaluations necessary for determining site suitability for a high-level waste repository, 93:420 (BA;US)

Teleseismic tomography of the Yucca Mountain region: Volcanism and tectonism, 93:394 (BA;US)

Temporal and spatial distribution of basaltic volcanism in the Pancake and Reveille Ranges north of Yucca Mountain, 93:640 (BA;US)

The Lathrop Wells volcanic center: Status of field and geochronology studies, 93:137 (BA;US)

UNS YMSCP QA support task: Quarterly technical progress report, January 1, 1991-June 30, 1991, $93: 11$ (R;US)

US Department of Energy issue resolution process, 93:80 (BA;US)

Using seals to control flow at Yucca Mountain, 93:630 (BA;US)

Yucca Mountain Site Characterization Project Plan, 93:29 (R;US)

Yucca Mountain, a high-level nuclear waste repository over a billion barrel oil field?, 93:677 (J;US)

\section{Site Selection}

A view on siting issue from Nevada, 93:691 (J:US)

Empirical investigation of the effect of amenities and other factors on business location decisions, 93:417 (R;US)
Fair rules for siting a high-level nuclear waste repository, 93:671 (J;US)

Focus shifts from capital to Nevada, $93: 690$ (J;US)

Getting waste program in motion again, 93:692 (J;US)

Preliminary near-field environment report: Volume 2, Scientific overview of near-field environment and phenomena, 93:199 (R;US)

Public opposition to the siting of the high-level nuclear waste repository: The importance of trust, $93: 682$ (J;US)

Should high-level nuclear waste be disposed of at geographically dispersed sites?, 93:412 (R;US)

Socioeconomic assessment guidance report: Determining the effects of amenity characteristics on business location decisions, $93: 415$ (R;US)

Thermodynamically derived relationships between the modified Langmuir isotherm and experimental parameters, 93:672 ( $J ;$ US)

Social Impact

Social impacts of hazardous and nuclear facilities and events: Implications for Nevada and the Yucca Mountain high-level nuclear waste repository: [Final report], 93:555 (R;US)

Socio-Economic Factors

Native Americans and Yucca Mountain: A revised and updated summary report on research undertaken between 1987 and 1991: Volume 2, 93:549 (R;US)

Native Americans and Yucca Mountain: A revised and updated summary report on research undertaken between 1987 and 1991: Volume 1, 98:548 (R;US)

Native Americans and Yucca Mountain: A summary report, 93:544 (R:US)

Stability

Dritt design methodology and preliminary application for the Yucca Mountain Site Characterization Project: Yucca Mountain Site Characterization Project (YUCCA MOUNTAIN PROJECT), 93:237 (R;US)

Prediction of Pseudo relative velocity response spectra at Yucca Mountain for underground nuclear explosions conducted in the Pahute Mesa testing area at the Nevada testing site: Yucca Mountain Site Characterization Project (Yucca Moun tain Project), 93:230 (R;US)

Stress Analysis

Fault stress analysis for the Yucca Mountain site characterization project, 93:355 (BA;US)

Systems Analysis

Yucca Mountain Project total-system performance assessment preliminary analyses: Overview: Draft, 93:284 (R;US)

Temperature Measurement

Areal power density: A preliminary examination of underground heat transfer in a potential Yucca Mountain repository and recommendations for thermal design approaches: Yucca Mountain Site Characterization Project (YUCCA MOUNTAIN PROJECT), 93:243 (R;US)

Thermal Stresses

The impact of thermal loading on repository performance at Yucca Mountain, 93:205 (BA;US)

Three-Dimensional Calculations

Fault stress analysis for the Yucca Mountain site characterization project, 93:355 (BA;US)

Tunneling Machines

Tunnel boring machine applications: Yucca Mountain Exploratory Studies Facility, 93:81 (BA;US)

$W$ Codes

Use of Wingz spreadsheet as an interface to total-system performance assessment (Yucca Mountain Project), 93:281 (R;US)

Water Chemistry

Chemical and mineralogical concerns for the use of man-made materials in the post-emplacement environment, 93:176 (R;US)

RADIOACTIVE WASTE MANAGEMENT

See also RADIOACTIVE WASTE DISPOSAL RADIOACTIVE WASTE STORAGE

Nuclear Technology Programs semiannual progress report, $O c$ tober 1990-March 1991, $93: 404$ (R;US) 


\section{Budgets}

Office of Civilian Radioactive Waste Management Program Cost and Schedule Baseline: Revision 3, 93:450 (R;US)

Coordinated Research Programs

Update on waste management policies and programmes, Cost 98:666 $(\mathrm{J} ; \mathrm{XN})$

Quarterly report on program cost and schedule, fourth quarter FY 1992, $98: 459$ (R; US)

US Department of Energy Office of Civilian Radioactive Waste Management quarterly report on program cost and schedule: First quarter, FY 1992, 93:455 (R; US)

USDOE Office of Civilian Radioactive Waste Management quarterly report on program cost and schedule: Fourth Quarter. FY 1991, $93: 452$ (R;US)

Decision Making

Strategic principles workshops: Discussion drafts and workshop notes, $93: 453$ ( $R$; US)

Evaluation

Nuclear wastes and public trust, 93:660 (J;US)

Government Policies

Nuclear wastes and public trust, 93:660 (J;US)

Report to the President by the Interagency Review Group on Nuclear Waste Management, 93:589.(R;US)

Information

1991 OCRWM bulletin compilation and index, 93:456 (R;US)

Information Systems

Technical data management at the Yucca Mountain Site Characterization Project, $93: 2$ (R;US)

Interagency Cooperation

Intergovernmental complexity in nuclear waste disposal policy: The indeterminate role of local government, 93:681 (J;US)

Nea

Update on waste management policies and programmes, 93:666 (J;XN)

Planning

Nuclear waste repository program oversight: Strategies of the situs jurisdiction, 93:634 (BA;US)

Strategic principles workshops: Discussion drafts and workshop notes, 93:453 (R;US)

Waste Management System Requirements Document: Volume 4, MGDs, Revision 2, 93:451 (R;US)

Program Management

Annual report to Congress, $93: 454$ (R;US)

Annual report to Congress, FY 1992, $93: 460$ (R;US)

Public Opinion

Intergovernmental complexity in nuclear waste disposal policy: The indeterminate role of local government, 93:681 (J;US)

Recommendations

Getting waste program in motion again, $93: 692$ (J;US)

Research Programs

Nuclear technology programs: Semiannual progress report, October 1989-March 1990, 93:401 (R;US)

Risk Assessment

Changes in risk perception over time, 93:580 (R;US)

Preliminary characterization of risks in the nuclear waste management system based on information in the literature, 93:576 (R;US)

Schedules

Office of Civilian Radioactive Waste Management Program Cost and Schedule Baseline: Revision 3, 93:450 (R;US)

Us Organizations

The Nuclear Waste Technical Review Board - Two years of experience in the US Waste Programme. Do we as reviewers communicate understandably with society?, 93:588 (RA:SE)

RADIOACTIVE WASTE STORAGE

See also MONITORED RETRIEVABLE STORAGE

${ }^{36} \mathrm{Cl}$ production in situ, and groundwater transport in a uranium ore deposit, 93:631 (BA;US)

High-level nuclear waste disposal: Policy and prognosis. Research report, August 1991-April 1992, 93:400 (R;US)

Needed geologic and seismic rulemaking for HLW repositories, 93:619 (BA;US)
Radioactive waste: Finding a safe place, 93:674 (J;US)

Strategic principles workshops: Discussion drafts and workshop notes, 93:453 (R:US)

Summary of the exploratory studies facility alternative study, 93:341 (BA;US)

Use of annotated outlines to prepare guidance for license applications for the MRS and MGDS, 93:628 (BA;US)

Yucca Mountain: Policy, progress and politics, $93: 73$ (BA;US)

RADIOACTIVE WASTES

See also ALPHA-BEARING WASTES

HIGH-LEVEL RADIOACTIVE WASTES INTERMEDIATE-LEVEL RADIOACTIVE WASTES LOW-LEVEL RADIOACTIVE WASTES RADIOACTIVE EFFLUENTS

Diffusion releases through one and two finite planar zones from a nuclear waste package, 93:167 (R;US)

Estimating the consequences of significant fracture flow at Yucca Mountain, 93;348 (BA;US)

Evaluation and compilation of DOE waste package test data: Volume 8: Biannual report, August 1989-January 1990, 93:529 (R;US)

Fission product studies in the symmetric mass region, $93: 489$ (RA;US)

G-tunnel pressurized slot-testing evaluations: Yucca Mountain Site Characterization Project, 93:222 (R;US)

Integrated performance assessment model for waste policy package behavior and radionuclide release, 93:633 (BA;US)

Laboratory analysis of hydraulic properties of volcanic tuff samples, 93:492 (R;US)

On numerical modeling of capillary barriers, $98: 94$ (J;US)

Over-the-road tests of nuclear materials package response to normal environments, 93:577 (R;US)

Physical processes and effects of magmatism in the Yucca Mountain region, 93:117 (R;US)

Solubility and speciation studies for nuclear repository performance assessment, 93:50 (R;US)

The Nagra-DOE Cooperative Project, 93:499 (R;US)

Yucca Mountain project total-system performance assessment preliminary analyses: Overview, $93: 347$ (BA;US)

RADIOCARBON DATING

See CARBON 14

RADIOISOTOPE MIGRATION

See RADIONUCLIDE MIGRATION

RADIOISOTOPES

${ }^{36} \mathrm{Cl}$ production in situ, and groundwater transport in a uranium ore deposit, 93:631 (BA;US)

A strategy for the derivation and use of sorption coefficients in performance assessment calculations for the Yucca Mountain site, 93:115 (R;US)

A suggested approach toward measuring sorption and applying sorption data to repository performance assessment, 93:114 (R;US)

Estimating the consequences of significant fracture flow at Yucca Mountain, 93:348 (BA;US)

Radionuclide distribution in LWR spent fuel, 93:209 (BA;US)

RADIOLYSIS

AREST: The next generation, 93:157 (R;US)

\section{RADIONUCLIDE MIGRATION}

Bench-Scale Experiments

Radionuclide migration laboratory studies for validation of batch-sorption data, 93:106 (RA;US)

The International INTRAVAL project. Phase 1 test cases, 93:471 $(R ; X N)$

$C$ Codes

CTCN: Colloid transport code - nuclear: A user's manual, 93:494 (R:US)

Computer Calculations

Colloid transport code-nuclear user's manual, 93:493 (R;US)

Computerized Simulation

Hydrogeology and migration in the remote field, $93: 419$ (R;FR;in French)

The International INTRAVAL project. Phase 1 case 8: The Alligator rivers natural analogue, 93:473 $(R ; X N)$ 
Field Tests

The International INTRAVAL project. Phase 1 test cases, 93:471 $(\mathrm{R} ; \mathrm{XN})$

Flow Models

Hydrogeology and migration in the remote field, $93: 419$ (R;FR; in French)

The International INTRAVAL project. Phase 1 case 8: The Alligator rivers natural analogue, $93: 473(R ; X N)$

The International INTRAVAL project. Phase 1 test cases, 93:471 (R;XN)

Ground Water

Natural analogue studies: Mineral alteration and uranium migration, 93:477 (R;JP;in Japanese)

Hydrodynamic Model

Oklo - natural analogue for transfer processes in a geological repository: present status of the programme, 93:464 (RA;XE)

Mathematical Models

Current adsorption models and open issues pertaining to performance assessment, 93:480 (RA;US)

Sensitivity and uncertainty analyses applied to one-dimensional radionuclide transport in a layered fractured rock: MULTFRAC -Analytic solutions and local sensitivities: Phase 2 , Iterative performance assessment: Volume 1, 93:536 (R;US)

\section{Meetings}

Proceedings of the DOEYucca Mountain Site Characterization Project Radionuclide Adsorption Workshop at Los Alamos National Laboratory, September 11-12, 1990 (Yucca Mountain Project.), 93:104 (R;US)

Potential Flow

Colloid research for the Nevada Test Site, $93: 478$ (R;US)

Radioactive Waste Disposal

Solubility and speciation studies for nuclear repository performance assessment, 93:158 (RA;SE)

Redox Reactions

The International INTRAVAL project. Phase 1 , case 7 . The Pocos de Caidas natural analogue: studies of redox front movement, $93: 472(R ; X N)$

Research Programs

Hydrology/Radionuclide Migration Program and related research activities: FY 1986 progress report, October 1 , 1985-September $30,1986,93: 437$ (R;US)

Statistical Models

Geostatistical methods for site characterization at Yucca Mountain, 93:641 (BA;FF)

Time Dependence

Migration of radioelements around the new nuclear reactors at Oklo: Analogies with a high-level waste repository, 93:670 (J;DE)

Uranium

Natural analogue studies: Mineral alteration and uranium migration, 93:477 (R;JP;In Japanese)

a Codes

AREST user's guide, PC version, 93:154 (R;US)

RADIONUCLIDE TRANSFER (IN ENVIRONMENT)

SEe RADIONUCLIDE MIGRATION

RADIONUCLIDES

SOE RADIOISOTOPES

RADIUM ADDITIONS

See ALLOYS

RADON

Potential increases in natural radon emissions due to heating of the Yucca Mountain rock mass, 93:208 (BA;US)

\section{RADON 222}

Potential increases in natural radon emissions due to heating of the Yucca Mountain rock mass, 93:212 (R;US)

\section{RANGER DEPOSIT}

Development of a prototype GIS for risk-hazard assessment, 93:611 (BA;AU)

Does multiple land use work - the Ranger example, 93:654 (J;AU)

Fish communities in sandy pool of Magela Creek, Alligator Rivers Region: Research Report 9, 93:602 (B;AU)

\section{RARE EARTH NUCLEI}

Migration of radioelements around the new nuclear reactors at Oklo: Analogies with a high-level waste repository, 93:670 (J;DE)

\section{RAYLEIGH WAVES}

Modulus dispersion and attenuation in tuff and granite, 93:275 (R;US)

REACTOR SITING

See SITE SELECTION

REGION I

See USA

REGION II

See USA

REGION III

See USA

REGION IV

See USA

REGION IX

See USA

REGION V

See USA

REGION VI

See USA

REGION VII

See USA

REGION VIII

See USA

REGION $X$

See USA

REGULATIONS

Approach to geologic repository post closure system performance assessment, 93:308 (R;US)

Natural analogue studies useful in validating regulatory compliance analyses, 93:644 (BA;FR)

REINFORCED CONCRETE

Code requirements for concrete repository and processing faciiities, 93:598 (R;US)

REMOTE HANDLING EQUIPMENT

Automated waste canister docking and emplacement using a sensor-based intelligent controller: Yucca Mountain Site Characterization Project, 93:262 (R;US)

RESERVOIR ROCK

Sorptivity of rocks and soils of the van Genuchten-Mualem type, 93:46 (RA;US)

Technical basis and programmatic requirements for Engineered Barrier System Field Tests, 93:174 (R;US)

Variation and correlation of hydrologic properties, $93: 45$ (RA;US)

RESIDUES (RADIOACTIVE)

SeE RADIOACTIVE WASTES

RESISTAL

SOe COPPER BASE ALLOYS

RHYOLITES

Estimates of potential radionuclide migration at the Bullion site, 93:443 (R;US)

Method development and strategy for the characterization of complexly faulted and fractured rhyolitic tuffs, Yucca Mountain, Nevada, USA, 93:395 (BA;FR)

RISK ANALYSIS

Søe RISK ASSESSMENT

RISK ASSESSMENT

Development of a prototype GIS for risk-hazard assessment, 93:611 (BA;AU)

Monitored retrievable storage of spent nuclear fuel: Transportation studies: Draft, $93: 448$ (R;US)

Perceived risk impacts from siting hazardous waste facilities, 93:617 (BA;US)

RISKS

See HAZARDS

ROADS

Over-the-road tests of nuclear materials package response to normal environments, 93:577 (R;US) 


\section{ROCK BEDS}

Yucca Mountain Project thermal and mechanical codes first benchmark exercise: Part 3 , Jointed rock mass analysis: Yucca Mountain Site Characterization Project, 93:241 (R;US)

\section{ROCK MECHANICS}

Preliminary numerical modeling for the G-Tunnel welded tuff mining experiment: Yucca Mountain site characterization project, 93:226 (R;US)

Rock mechanics contributions from defense programs, $93: 593$ (R;US)

\section{ROCK-FLUID INTERACTIONS}

EQ6, a computer program for reaction path modeling of aqueous geochemical systems: Theoretical manual, user's guide, and related documentation (Version 7.0): Part 4, 93:203 (R;US)

Modeling fluid-rock interaction at Yucca Mountain, Nevada: $A$ progress report, April 15, 1992, 93:168 (R;US)

Radioelements and their occurrence with secondary minerals in heated and unheated tuff at the Nevada test site, 93:82 (BA;US)

ROCKS

Air Flow

Field testing the effectiveness of pumping to remove sulfur hexafluoride traced drilling air from a prototype borehole near superior, Arizona, 93:518 (RA;US)

Chemical Reactions

Design of an intermediate-scale experiment to validate unsaturated-zone transport modeis, 93:285 (R;US)

Contamination

Evaluation of lead contamination in drillback mudpits using isotopic ratios, 93:590 (RA;US)

Deformation

A study of discrete and continuum joint modeling techniques, 93:271 (R;US)

Environmental Transpori

Sorption and porosity heterogeneity: Effects on radionuclide transport, 93:479 (RA;US)

Equations Of State

Recent advances in methods for measuring the dynamic response of geological materials to $100 \mathrm{GPa}, 93: 294$ (R;US)

Fluid Flow

Comparison of two conceptual models of flow using the TSA (Yucca Mountain Project), 93:282 (R;US)

Flow through nonhomogeneous porous media, 93:525 (RA;US)

Movement of shaft and drift construction water in Yucca Mountain, Nevada: An extended study: Yucca Mountain Site Characterization Project, 93:266 (R;US)

Single fracture aperture patterns: Characterization by slit-island fractal analysis (Yucca Mountain Project), $93: 59$ (R;US)

Three-dimensional modeling of unsaturated flow in the vicinity of proposed exploratory shaft facilities at Yucca Mountain, Nevada, $93: 62$ (R;US)

$X$-ray and visible light transmission as two-dimensional, full-field moisture-sensing techniques: A preliminary comparison, 93:279 (R;US)

Fractures

A working definition of scenario and a method of scenario construction (yucca mountain project), 93:331 (R;US)

Gas Flow

Comparison of two conceptual models of flow using the TSA (Yucca Mountain Project), 93:282 (R;US)

Gaseous Wastes

The composition and $\mathrm{CO}_{2}$ carbon isotope signature of gases from borehole USW UZ-6, Yucca Mountain, Nevada, 93:367 (RA;US)

Geochemistry

Design of an intermediate-scale experiment to validate unsaturated- zone transport models, 93:285 (R;US)

Geologic Fractures

An analysis of a joint shear model for jointed media with orthogonal joint sets: Yucca Mountain Site Characterization Project, 93:245 (R;US)

Impact of fracture coatings on the transfer of water across fracture faces in unsaturated media, 93:621 (BA;US)

\section{Ground Water}

Flow and transport through unsaturated rock: Data from two test holes, Yucca Mountain, Nevada, 93:391 (BA;US)

Heat Transfer

The results of near-field thermal and mechanical calculations of thermal loading schemes (Yucca mountain project), 93:333 (R;US)

Hydraulic Conductivity

Pneumatic permeability measurements in a fractured, partially saturated environment, 93:517 (RA;US)

Use of a submersible pressure outtlow cell for determination of moisture characteristic curves on rock core, 93:522 (RA;US)

Hydrology

Characterization of rock hydrologic properties using model veri fication (Yucca Mountain Project), 93:519 (RA;US)

Mathematical Models

Yucca Mountain Project thermal and mechanical codes first benchmark exercise: Part 3, Jointed rock mass analysis: Yucca Mountain Site Characterization Project, 93:241 (R;US)

Mechanical Properties

G-tunnel pressurized slot-testing evaluations: Yucca Mountain Site Characterization Project, 93:222 (R;US)

Scale dependence of effective media properties, $93: 323$ (R;US)

The results of near-field thermal and mechanical calculations of thermal loading schemes (Yucca mountain project), 93:333 (R;US)

Mineralogy

Thermal impact on host rock of geologic repository: Final report, 93:18 (R;US)

\section{Moisture}

Use of a submersible pressure outflow cell for determination of moisture characteristic curves on rock core, 93:522 (RA;US)

Permeablilty

A scoping study of water table excursions induced by seismic and volcanic events, $93: 163$ (R;US)

Design of an intermediate-scale experiment to validate unsaturated-zone transport models, 93:285 (R;US)

Numerical studies of rock-gas flow in Yucca Mountain: Yucca Mountain Site Characterization Project, 93:296 (R;US)

Technical basis and programmatic requirements for laboratory study of hydrological properties of the near-field environment, 93:173 (R;US)

Physical Properties

Scale dependence of effective media properties, $93: 323$ (R;US)

TBM performance prediction in Yucca Mountain welded tuff from linear cutter tests, 93:352 (BA;US)

Porosity

Design of an intermediate-scale experiment to validate unsaturated-zone transport models, $93: 285$ (R;US)

Pressure Dependence

Recent advances in methods for measuring the dynamic response of geological materials to $100 \mathrm{GPa}, 93: 294$ (R;US)

Radioactive Waste Disposal

A survey of hydrothermal modeling related to Yucca Mountain, 93:524 (RA;US)

Radionuclide Migration

PACE-90 water and solute transport calculations for $0.01,0.1$, and $0.5 \mathrm{~mm} / \mathrm{yr}$ infiltration into Yucca Mountain: Yucca Mountain Site Characterization Project, 93:257 (R;US)

Sensitivity and uncertainty analyses applied to one-dimensional radionuclide transport in a layered fractured rock: MULT. FRAC -Analytic solutions and local sensitivities: Phase 2, Iterative performance assessment: Volume 1, $93: 536$ (R;US)

Rankine-Hugoniot Equations

Recent advances in methods for measuring the dynamic response of geological materials to $100 \mathrm{GPa}, 93: 294$ (R;US)

$s$ Codes

Documentation and verification of STRES3D, Version 4.0 Yucca Mountain Site Characterization Project, 98:250 (R;US)

Sorptive Properties

A strategy for the derivation and use of sorption coefficients in performance assessment calculations for the Yucca Mountain site, $93: 115$ (R;US) 
A suggested approach toward measuring sorption and applying sorption data to repository performance assessment, 93:114 (R;US)

Sorption and porosity heterogeneity: Effects on radionuclide transport, $93: 479$ (RA;US)

Stress Analysis

Yucca Mountain Project thermal and mechanical codes first benchmark exercise: Part 3, Jointed rock mass analysis: Yucca Mountain Site Characterization Project, 93:241 (R;US)

Temperature Effects

Prototype heater test of the environment around a simulated

Testing waste package, 93:162 (R;US)

Thermal impact on host rock of geologic repository: Final report, 93:18 (R;US)

Thermal Analysis

HEFF-A user's manual and quide for the HEFF code for thermal-mechanical analysis using the boundary-element method: Version 4.1: Yucca Mountain Site Characterization Project, 93:223 (R;US)

The results of near-field thermal and mechanical calculations of thermal loading schemes (Yucca mountain project), 93:333 (R;US)

Thermal Expansion

Application of analytical methods for jointed rock as part of a drift design methodology for the Yucca Mountain Project, 93:240 (R;US)

Thermodynamics

Potential increases in natural radon emissions due to heating of the Yucca Mountain rock mass, 93:208 (BA;US)

Thermomechanical Treatments

Instrumentation requirements for the ESF thermomechanical Vents experiments (Yucca Mountain Project), 93:330 (R;US)

Does the wind blow through Yucca Mountain?, 93:366 (RA;US) Wind

Does the wind blow through Yucca Mountain?, 93:366 (RA;US) ROCKY MOUNTAIN REGION

$$
\text { See USA }
$$

\section{$\mathbf{S}$}

\section{$S$ CODES}

Documentation and verification of STRES3D, Version 4.0: Yucca Mountain Site Characterization Project, 93:250 (R;US)

Documentation and verification of the SHAFT code: Yucca Mountain Site Characterization Project (YUCCA MOUNTAIN PROJECT), 93:235 (R;US)

RE/SPEC Inc. technical support to the Repository Technology Program: Summary of activities for September 1, 1988-June SAND $30,1992,93: 432$ (R;US)

Preliminary characterization of materials for a reactive transport model validation experiment, 93:334 (R;US)

\section{SANITARY LANDFILLS}

Sealing performance assessments of bentonite and bentonite/crushed rock plugs, $93: 645$ (1; US)

\section{SAVANNAH RIVER PLANT}

Effects of radiation exposure on glass alteration in a steam environment, 93:407 (R;US)

The reaction of SRL 202 glass in $\mathrm{J}-13$ and DIW, 93:406 (R;US)

\section{SEALING MATERIALS}

Sealing performance assessments of bentonite and bentonite/crushed rock plugs, 93:645 (1;US) .

The hydrothermal stability of cement sealing materials in the potential Yucca Mountain high level nuclear waste repository (Yucca Mountain Project), 93:292 (R;US)

SEALS

sing seals to control flow at Yucca Mountain, 93:630 (BA;US)

Initial field testing definition of subsurface sealing and backfilling tests in unsaturated tuff: Yucca Mountain Site Characterization Project, 93:307 (R;US)
Proposed sealing field tests for a potential high-level radioactive waste repository in unsaturated tuff, 93:286 (R;US)

Sealing performance of bentonite and bentonite/crushed rock borehole plugs, 93:530 (R;US)

Seismic considerations in sealing a potential high-level radioactive waste repository, 93:309 (R;US)

Supporting hydration calculations for small- to large-scale seal tests in unsaturated tuff (Yucca Mountain Project), 93:287 (R;US)

\section{SEISMIC EFFECTS}

TURBOSEIS-An interactive program for constructing and editing models of seismic refraction traveltime data using a color-graphics terminal, $93: 371$ (R;US)

\section{SEISMIC EVENTS}

See also EARTHQUAKES

Recurrence models of volcanic events: Applications to volcanic risk assessment, 93:120 (R;US)

The Lathrop Wells volcanic center: Status of field and geochronology studies, 93:122 (R;US)

\section{SEPARATION PROCESSES}

Nuclear Technology Programs semiannual progress report, October 1990-March 1991, 93:404 (R;US)

Nuclear technology programs: Semiannual progress report, October 1989-March 1990, 93:401 (R;US)

\section{SHAFT EXCAVATIONS}

Design considerations for the Yucca Mountain project exploratory shaft facility, 93:91 (BA;US)

Documentation and verification of the SHAFT code: Yucca Mountain Site Characterization Project (YUCCA MOUNTAIN PROJECT), 93:235 (R;US)

SHIELDING

Conceptual design of a monitored retrievable storage cask employing Yucca Mountain containers, 93:638 (BA;US)

SHIPPINGPORT PRESSURIZED WATER REACTOR

SOE SHIPPINGPORT REACTOR

SHIPPINGPORT REACTOR

Criticality safety issues associated with the burial of highly enriched nuclear fuel in a geologic repository, 93:596 (R;US)

SILICATE MINERALS

See also CHLORITE MINERALS

SMECTITE

ZEOLITES

Point defects in silicates, $93: 646$ (1;US)

SILICON OXIDES

Kinetics of silica-phase transitions, 93:110 (R;US)

Scenario development for performance assessment: Some questions for the near-field modelers (yucca mountain project), 93:325 (R;US)

SITE CHARACTERIZATION

Classification and grading of design products for the Yucca Mountain project, 93:95 (J;US)

$J A C 3 D$ - A three-dimensional finite element computer program for the nonlinear quasi-static response of solids with the conjugate gradient method: Yucca Mountain Site Characterization Project, $93: 219$ (R;US)

Nuclear waste: DOE expenditures on the Yucca Mountain Project, 93:469 (R;US)

Quantification of uncertain outcomes from site characterization: Insights from the ESF-AS, 93:343 (BA; US)

Quantification of uncertain outcomes from site characterization: Insights from the ESF-AS, 93:300 (R;US)

The quality assurance liaison: Combined technical and quality assurance support, 93:130 (R;US)

\section{SITE SELECTION}

Fair rules for siting a high-level nuclear waste repository, 93:671 (J;US)

Natural analogue studies useful in validating regulatory compliance analyses, 93:644 (BA;FR)

SITE SURVEYS

See SITE CHARACTERIZATION

SMECTITE

Parametric effects on glass reaction in the unsaturated test method, $93: 143$ (R;US) 
SODIUM MINERALS

See MINERALS

SOILS

A strategy for the derivation and use of sorption coefficients in performance assessment calculations for the Yucca Mountain site, 93:105 (RA;US)

Modeling studies of gas movement and moisture migration at Yucca Mountain, Nevada, 93:44 (RA;US)

Selected issues on geochemical transport modeling for highlevel nuclear waste repository, 93:486 (RA;US)

Sensitivity analysis of integrated radionuclide transport based on a three-dimensional geochemicalgeophysical model, 93:485 (RA;US)

Transport in unsaturated flow systems using centrifuge techniques, $93: 483$ (RA; US)

Transport of reactive tracers by unsaturated flow using field and column experiments, 93:482 (RA;US)

Unsaturated transport of inorganic cations in undisturbed soil columns, 93:484 (RA;US)

Variations of hydrological parameters of tuff and soil, 93:78 (BA;US)

SOLUBILITY

EQ3NR, a computer program for geochemical aqueous speciation-solubility calculations: Theoretical manual, user's guide, and related documentation (Version 7.0): Part 3, 93:202 (R;US)

SOLUTES

US Geological Survey Committee for the Advancement of Science in the Yucca Mountain Project symposium on "Fractures, Hydrology, and Yucca Mountain": Abstracts and summary, 93:375 (R;US)

\section{SOURCE TERMS}

A simplified radionuclide source term for total-system performance assessment: Yucca Mountain Site Characterization Project (Yucca Mountain Project:a1), 93:260 (R;US)

SOUTH ALLIGATOR DEPOST

The International INTRAVAL project. Phase 1 case 8: The Alligator rivers natural analogue, 93:473 $(\mathrm{R} ; \mathrm{XN})$

\section{SOUTHEAST REGION}

See USA

SOUTHWEST REGION

See USA

\section{SPENT FUEL CASKS}

Conceptual design of a monitored retrievable storage cask employing Yucca Mountain containers, 93:638 (BA;US)

Transportation cask decontamination and maintenance at the potential Yucca Mountain repository: Yucca Mountain Site characterization project, $93: 247$ (R;US)

\section{SPENT FUELS}

Autoradiography

Characterization of spent fuel approved testing materiaŁATM105, 93:152 (R;US)

Bumup

Equivalent Energy Density concept: A preliminary reexamination of a technique for equating thermal loads: Yucca Mountain Site Characterization Project, 93:269 (R;US)

Containers

Evaluation of copper, aluminum bronze, and copper-nickel container material for the Yucca mountain project, 93:142 (RA;CA)

Dissolution

Estimating the time for dissolution of spent fuel exposed to unlimited water, $93: 164$ (R;US)

Electron Microscopy

Characterization of spent fuel approved testing materiał-ATM105, $93: 152$ (R;US)

Characterization of spent fuel approved testing material-ATM104, $93: 151$ (R; US)

Monitored Retrievable Storage

Conceptual design of a monitored retrievable storage cask employing Yucca Mountain containers, 93:638 (BA;US)

Monitored retrievable storage of spent nuclear fuel: Transportation studies: Draft, 93:448 (R;US)
Packaging

Waste package and engineered barrier system design concepts for the direct disposal of spent fuel in the potential United States repository at Yucca Mountain, Nevada, 93:71 (BA;XA)

Radioactive Waste Disposal

Annual report to Congress, FY 1992, $98: 460$ (R;US)

Critical comments on the US Environmental Protection Agency Standards 40 CFR 191, $93: 7$ (R;US)

DOE's Yucca Mountain studies, 93:30 (R;US)

Effects of actinide burning on waste disposal at Yucca Mountain, 93:446 (R;US)

Facts and issues of direct disposal of spent fuel: Revision 1 , 93:599 (R;US)

Waste package and engineered barrier system design concepts for the direct disposal of spent fuel in the potential United States repository at Yucca Mountain, Nevada, 93:71 (BA;XA)

Radioactive Waste Management

Annual report to Congress, 93:454 (R;US)

Radiochemical Analysis

Characterization of spent fuel approved testing material-ATM105, $93: 152$ (R;US)

Characterization of spent fuel approved testing materiał-ATM104, $93: 151$ (R;US)

Radioisotopes

Radionuclide distribution in LWR spent fuel, 93:209 (BA;US)

Rail Transport

Rail abandonments in the South and their effect on NWPA rail shipments, 93:431 (R;US)

Reprocessing

Releases from exotic waste packages from partitioning and transmutation, 93:51 (R;US)

Thermodynamics

Potential increases in natural radon emissions due to heating of the Yucca Mountain rock mass, 93:208 (BA;US)

Underground Disposal

2010: America's nuclear waste odyssey, $93: 652$ (J;GB)

Review of radionuclide source terms used for performanceassessment analyses: Yucca Mountain Site Characterization Project, 93:317 (R;US)

Strategic principles workshops: Discussion drafts and workshop notes, 93:453 (R;US)

Thermal performance of a buried nuclear waste storage container storing a hybrid mix of PWR and BWR spent fuel rods: Revision 1, 93:159 (R;US)

Waste Heat

Equivalent Energy Density concept: A preliminary reexamination of a technique for equating thermal loads: Yucca Mountain Site Characterization Project, 93:269 (R;US)

Waste Transportation

A report on high-level nuclear waste transportation: Prepared pursuant to assembly concurrent resolution No. 8 of the 1987 Nevada Legislature, $93: 558$ (R; US)

Nevada commercial spent nuclear fuel transportation experience, $98: 69$ (R;US)

SPIN-OFF

Søe TECHNOLOGY TRANSFER

STAINLESS STEEL-18-4-1

SeE STAINLESS STEELS

STAINLESS STEEL-19-9DL

See STAINLESS STEELS

STAINLESS STEEL-304L

Crack growth behavior of candidate waste container materials in simulated underground water, 93:146 (R;US)

Crack-growth-rate testing of candidate waste container materials, 93:145 (R;US)

Potentiodynamic polarization studies on candidate container atloys for the Tuff Repository, 93:532 (R;US)

- Stress corrosion cracking of candidate waste container materials: Final report, $93: 403$ (R;US)

Stress-corrosion-cracking studies on candidate container alloys for the Tuff Repository, $93: 533$ (R;US)

The reaction of SRL 202 glass in $\mathrm{J}-13$ and DIW, $93: 406$ (R;US) 


\section{STAINLESS STEEL-316L}

Crack growth behavior of candidate waste container materials in simulated underground water, 93:146 (R;US)

Crack-growth-rate testing of candidate waste container materials, $93: 145$ (R; US)

Stress corrosion cracking of candidate waste container materials: Final report, 93:403 (R;US)

STAINLESS STEELS

Corrosion models for predictions of performance of high-level radioactive-waste containers, $93: 160$ (R;US)

STATE GOVERNMENT

A report on high-level nuclear waste transportation: Prepared pursuant to assembly concurrent resolution No. 8 of the 1987 Nevada Legislature, 93:558 (R;US)

Report of the State of Nevada Commission on Nuclear Projects, 93:538 (R;US)

STEAM

Physical limits on steam generation by radioactive decay heat, 93:165 (R;US)

\section{STEAM COOLANT}

See STEAM

STEEL-00OKH25

SeE STAINLESS STEELS

STEEL-000KH28

See STAINLESS STEELS

STEEL-00KH2ON32T

See STAINLESS STEELS

STEEL-03KH13AG13

Søe STAINLESS STEELS

STEEL-OKH18G8N2T

See STAINLESS STEELS

STEEL-12KH2MV8FB

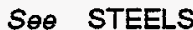

STEEL-12KH2V5FB

Søe STEELS

STEEL-18MNVG

See STEELS

\section{STEELS}

Report on task assignment No. 3 for the Waste Package Project: Parts A \& B, ASME pressure vessel codes review for waste package application; Part C, Library search for reliabitity/failure rates data on low temperature low pressure piping,

STREETS containers, and casks with long design lives, 93:12 (R; US)

See ROADS

STRESSES

Documentation and verification of STRES3D, Version 4.0: Yucca Mountain Site Characterization Project, 93:250 (R;US)

\section{STRONTIUM}

Dependence of radionuclide sorption on sample grinding, surface area, and water composition, 93:127 (R;US)

Modeling cation exchange using EQ3/6, 93:149 (RA;US)

Sorption of cesium and strontium by zeolite single crystals, 93:481 (RA;US)

Thermodynamically derived relationships between the modified Langmuir isotherm and experimental parameters, 93:672 (J;US)

Unsaturated transport of inorganic cations in undisturbed soil columns, 93:484 (RA-US)

STRONTIUM ISOTOPES

Strontium isotope geochemistry of calcite fracture fillings in deep core, Yucca Mountain, Nevada: A progress report, 93:398 (BA;US)

SUBSURFACE STRUCTURES

Seismic design of circular-section concrete-lined underground openings: Preclosure performance considerations for the Yucca Mountain Site (Yucca Mountain Project), 93:303 (R;US)

Use of the iterative solution method for coupled finite element and boundary element modeling: Yucca Mountain Site Characterization Project (yucca mountain project), 93:324 (R;US)

SURVEYS

See also GEOPHYSICAL SURVEYS
Technical evaluation of available state of Nevada survey instruments, 93:418 (R;US)

\section{SYENITES}

Isotopic geochemical characterization of selected nepheline syenites and phonolites from the Pocos de Caldas alkaline complex, Minas Gerais, Brazil, 93:503 $(\mathrm{R} ; \mathrm{CH})$

\section{$\mathbf{T}$}

\section{TECHNETIUM 99}

Migration of technetium-99 in the alluvial aquifer at the Nevada test site, Nevada, 93:661 (J:DE)

Preliminary calculations of release rates of Tc-99, 1-129, and $\mathrm{Np}-237$ from spent fuel in a potential repository in tuff, $93: 49$ (R;US)

Sensitivity analysis of integrated radionuclide transport based on a three-dimensional geochemical/geophysical model, 93:485 (RA;US)

TECHNOLOGY TRANSFER

Stripa: An international cooperative project, $93: 92$ (BA;US)

TEFLON

The reaction of SRL 202 glass in $\mathrm{J}-13$ and DIW, 93:406 (R;US)

TEMPERATURE DEPENDENCE

Coupled hydro-geochemical processes and their significance for Yucca Mountain Site Characterization (Yucca Mountain Project), 93:197 (R;US)

TEMPERATURE EFFECTS

See TEMPERATURE DEPENDENCE

TENNESSEE

Monitored retrievable storage of spent nuclear fuel: Transportation studies: Draft, $93: 448$ (R;US)

TERRESTRIAL ECOSYSTEMS

Yucca Mountain Biological Resources Monitoring Program: Annual report, FY91, 93:35 (R;US)

TEST FACILITIES

Movement of shaft and drift construction water in Yucca Mountain, Nevada: An extended study: Yucca Mountain Site Characterization Project, 93:266 (R;US)

TEST WELLS

SeE EXPLORATORY WELLS

THERMAL ANALYSIS

Analysis of slot cutting methods for the Yucca Mountain heated block test using a compliant-joint model, 93:270 (R:US)

HEFF-A user's manual and guide for the HEFF code for thermal-mechanical analysis using the boundary-element method: Version 4.1: Yucca Mountain Site Characterization Project, 93:223 (R;US)

THERMAL EFFECTS See TEMPERATURE DEPENDENCE

THERMONUCLEAR DEVICES

Evaluation of lead contamination in drillback mudpits using isotopic ratios, 93:590 (RA:US)

THORIUM

Studies of the mobility of uranium and thorium in Nevada Test Site tuff, $93: 498$ (RA;US)

\section{THORIUM ISOTOPES}

Uptake of uranium and thorium series radionuclides by the waterlily, Nymphaea violacea, 93:659 (J;GB)

\section{THORIUM ORES}

Mineralogy, petrology and geochemistry of the Pocos de Caldas analogue study sites, Minas Gerais, Brazil: II. Morro do Ferro, 93:502 (R;CH)

TITANIUM ALLOYS

Selection of candidate container materials for the conceptual waste package design for a potential high level nuclear waste repository at Yucca Mountain, 93:172 (R;US)

TRANSFER (HEAT)

See HEAT TRANSFER

TRANSFER (IN ENVIRONMENT)

SeE RADIONUCLIDE MIGRATION

TRANSFER (MASS)

See MASS TRANSFER 
TRANSMISSION (HEAT)

SEe HEAT TRANSFER

TRANSURANIUM WASTES

See ALPHA-BEARING WASTES

TRTIUM

Anomalous deuteron to hydrogen ratio in naturally occuring fission reactions and the possibility of deuteron disintegration, 93:667 (J;HU)

Evaluation of potential hydrologic tracers in tuffs from Yucca Mountain, Nevada, 93:487 (RA;US)

Ground-water data collected at the Nevada Test Site and vicinity, Nye County, Nevada, water years 1988-89, 93:594 (R;US)

Transport of reactive tracers by unsaturated flow using field and column experiments, 93:482 (RA;US)

TRU WASTES

TUFF

See ALPHA-BEARING WASTES

Arizona

Validation efforts in modeling flow and transport through partially saturated fractured rock - the Apache leap tuff studies, 93:643 (BA;FR)

Chemical Composition

Chemical changes associated with zeolitization of the tuffaceous beds of Calico Hills at Yucca Mountain, Nevada, 93:123 (R;US)

Volatile and trace element composition of melt inclusions from the Lower Bandelier Tuff - implications for magma chamber processes and eruptive style, 93:662 (J;US)

\section{Compiled Data}

Mineralogy, petrology and whole-rock chemistry data compilation for selected samples of Yucca Mountain tuffs: Yucca Mountain Site Characterization Project, 93:295 (R;US)

Mineralogy, petrology and whole-rock chemistry of selected mechanical test samples of Yucca Mountain tuffs: Yucca Mountain Site Characterization Project, 93:259 (R;US)

Compression

A preliminary study of the chemistry of pore water extracted trom tuff by one-dimensional compression, 93:363 (R;US)

Compression Strength

Unconfined compression experiments on Topopah Spring Member tuff at $22^{\circ} \mathrm{C}$ and a strain rate of $10^{-9} \mathrm{~s}^{-1}$ : Data report: Yucca Mountain Site Characterization Project (yucca mountain project), 93:310 (R;US)

Computerized Tomography

Characterization of flow in fractured tuff using computerized tomography, $93: 491$ (R;US)

Cutting

G-Tunnel pressurized slot-testing preparations: Yucca Mountain Site Characterization Project, 93:225 (R;US)

Performance prediction of mechanical excavators from linear cutter tests on Yucca Mountain welded tuffs: Yucca Mountain Site Characterization Project, 93:299 (R;US)

Density

Assessment of geophysical logs from borehole USW G-2, Yucca Mountain, Nevada, 93:387 (R;US)

Diffusion

Temperature effect on diffusion of carbon dioxide through upper layers of Yucca Mountain, 93:675 (J;GB)

\section{Diffusion Barriers}

Diffusion releases through one and two finite planar zones from a nuclear waste package, $93: 167$ (R;US)

\section{Environmental Transport}

Evaluation of potential hydrologic tracers in tuffs from Yucca Mountain, Nevada, 93:487 (RA;US)

Sorption and porosity heterogeneity: Effects on radionuclide transport, 93:479 (RA;US)

Sorption of cesium and strontium by zeolite single crystals, 93:481 (RA;US)

Transport in unsaturated flow systems using centrifuge techniques, 93:483 (RA;US)

\section{Excavation}

Performance predictions for mechanical excavators in Yucca Mountain tuffs: Yucca Mountain Site Characterization Project, 93:297 (R;US)

Preliminary drift design analyses for nuclear waste repository in tuff (Yucca Mountain Project), 93:252 (R;US)

\section{Fluid Flow}

An inverse procedure for estimating the unsaturated hydraulic conductivities of volcanic tuffs, 93:56 (R;US)

Characterization of flow in fractured tuff using computerized tomography, $93: 491$ (R;US)

Comparison of two conceptual models of flow using the TSA (Yucca Mountain Project), 93:282 (R;US)

Flow and transport in hierarchically fractured systems (Yucca Mountain Project), 93:61 (R;US)

Impact of fracture coatings on the transfer of water across fracture faces in unsaturated media, 93:579 (R;US)

Modeling gravity-driven fingering in rough-walled fractures using modified percolation theory (Yucca Mountain Project), 93:328 (R;US)

Modeling hydrothermal flow in variably saturated, fractured, weided tuff during the prototype engineered barrier system field test of the Yucca Mountain Project, 93:523 (RA;US)

Preliminary modeling of moisture movement in the tuff beneath Mortandad Canyon, Los Alamos National Laboratory, 93:496 (R;US)

Processes, mechanisms, parameters, and modeling approaches for partially saturated flow in soil and rock media: Yucca Mountain Site Characterization Project (Yucca Mountain Project.), 93:233 (R;US)

Research program to develop and validate conceptual models for flow and transport through unsaturated, fractured rock: Yucca Mountain Site Characterization Project (YUCCA MOUNTAIN PROJECT), 93:253 (R;US)

Scenario development for performance assessment: Some questions for the near-field modelers (yucca mountain project), 93:325 (R; US)

Simulated water-level declines caused by withdrawais from wells $J-13$ and $J-12$ near Yucca Mountain, Nevada, 93:377 (R;US)

Small-scale behavior of single gravity-driven fingers in an initially dry fracture (yucca mountain project), $93: 326$ (R;US)

Technical basis and programmatic requirements for large block testing of coupled thermal-mechanical-hydrological-chemical processes, 93:175 (R;US)

The impact of episodic nonequilibrium fracture-matrix flow on repository performance at the potential Yucca Mountain site, 93:185 (R;US)

The role of fault zones in affecting multiphase flow at Yucca Mountain (Yucca Mountain Project), 93:60 (R;US)

Three-dimensional modeling of unsaturated flow in the vicinity of proposed exploratory shaft facilities at Yucca Mountain, Nevada, 93:62 (R;US)

$X$-ray and visible light transmission as two-dimensional, full-field moisture-sensing techniques: A preliminary comparison, 93:279 (R;US)

Gas Flow

Numerical simulation of gas flow through unsaturated fractured rock at Yucca Mountain, Nevada, $93: 567$ (R;US)

The role of fault zones in affecting multiphase fiow at Yucca Mountain (Yucca Mountain Project), 93:60 (R;US)

\section{Geologic Faults}

Method development and strategy for the characterization of complexly faulted and fractured rhyolitic tuffs, Yucca Mountain, Nevada, USA, 93:395 (BA;FR)

\section{Geologic Fractures}

Heat pipe effect in porous medium, 93:445 (R;US)

Impact of fracture coatings on the transfer of water across fracture faces in unsaturated media, 93:621 (BA;US)

Method development and strategy for the characterization of complexly faulted and fractured rhyolitic tuffs, Yucca Mountain, Nevada, USA, 93:395 (BA;FR) 
Validation efforts in modeling flow and transport through partially saturated fractured rock - the Apache leap tuff studies, 93:643 (BA;FR)

Heating

Temperature measurements from a horizontal heater test in GTunnel, $93: 178$ (R; US)

Hydraulic Conductivity

An inverse procedure for estimating the unsaturated hydraulic conductivities of volcanic tuffs, 93:56 (R;US)

Estimates of potential radionuclide migration at the Bullion site, 93:443 (R;US)

Method development and strategy for the characterization of complexly fauited and fractured rhyolitic tuffs, Yucca Mountain, Nevada, 93:42 (RA;US)

\section{Hydrology}

Characterization of liquid-water percolation in tuffs in the unsaturated zone, Yucca Mountain, Nye County, Nevada, 93:361 (R;US)

Geohydrology of rocks penetrated by test well USW H-6, Yucca Mountain, Nye County, Nevada, $93: 390$ (R;US)

Recent developments in stochastic modeling and upscaling of hydrologic properties in tuff, $93: 321$ (R;US)

Variations of hydrological parameters of tuff and soil, 93:78 (BA;US)

Hydrothermal Alteration

Surface-discharging hydrothermal systems at Yucca Mountain: Examining the evidence, 93:125 (R;US)

Mechanical Properties

Analysis of slot cutting methods for the Yucca Mountain heated block test using a compliant-joint model, 93:270 (R;US)

Anisotropy of the Topopah Spring Member Tuff, 93:268 (R;US)

Calculation of experiment uncertainty in laboratory determination of several geoengineering properties of tuffs from Yucca Mountain, Nevada: Yucca Mountain Site Characterization Project (Yucca Mountain Project.), 93:231 (R;US)

New three-dimensional far-field potential repository thermomechanical calculations: Yucca Mountain Site Characterization Project (Yucca Mountain Project), 93:306 (R;US)

Rock mass mechanical property estimation strategy for the Yucca Mountain Site Characterization Project (Yucca Mountain Project), 93:329 (R;US)

Rock mass mechanical property estimations for the Yucca Mountain Site Characterization Project: Yucca Mountain Site Characterization Project (Yucca Mountain Project), 93:304 (R;US)

Technical basis and programmatic requirements for large block testing of coupled thermal-mechanical-hydrological-chemical processes, 93:175 (R;US)

Microstructure

The influence of strain rate and sample inhomogeneity on the moduli and strength of welded tuff (yucca mountain project), 93:312 (R;US)

\section{Moisture}

Thermocouple psychrometer measurements of in situ water potential changes in heated welded tuff, 93:180 (R;US)

Permeability

Field air injection tests to determine the effect of a heat cycle on the permeability of welded tuff, 93:179 (R;US)

Recent developments in stochastic modeling and upscaling of hydrologic properties in tuff, 93:321 (R;US)

Sealing performance assessments of bentonite and bentonite/crushed rock plugs, 93:645 (1;US)

Variations of hydrological parameters of tuff and soil, 93:78 (BA;US)

Waste-package release rates for site suitability studies, $93: 48$ (R;US)

Physical Properties

Heat pipe effect in porous medium, 93:445 (R;US)

Laboratory analysis of hydraulic properties of volcanic tuff samples, 93:492 (R;US)

Results of rock property measurements made on core samples from Yucca Mountain boreholes, Nevada Test Site, Nevada:
Part 1, Boreholes UE25A-4, $-5,-6$, and -7; Part 2, Borehole UE25PNo.1, 93:373 (R;US)

\section{Porosity}

Assessment of geophysical logs from borehole USW G-2, Yucca Mountain, Nevada, 93:387 (R;US)

Characterization of porosity in support of mechanical property analysis (yucca mountain project), 93:313 (R;US)

Investigation of fracture-matrix interaction: Preliminary experiments in a simple system (Yucca Mountain Project), 93:320 (R;US)

Recent developments in stochastic modeling and upscaling of hydrologic properties in tuff, 93:321 (R;US)

Semi-analytical treatment of fracture/matrix flow in a dualporosity simulator for unsaturated fractured rock masses, 93:54 (R;US)

Radiation Heating

Drift emplaced waste package thermal response (Yucca Mountain Project), 93:193 (R;US)

Large-scale in situ heater tests for hydrothermal characterization at Yucca Mountain (Yucca Mountain Project), 93:195 (R;US)

Radioactive Waste Disposa!

Some observations on the mechanism of corrosion to be encountered in nuclear waste repositories located in tuffaceous rock, 93:655 (J;GB)

The influence of scale on calculated sorptivity values from imbibition experiments on welded and nonwelded tuff, 93:397 (BA;FR)

Radionuclide Migration

An inverse procedure for estimating the unsaturated hydraulic conductivities of volcanic tuffs, 93:56 (R; US)

Conceptual, experimental and computational approaches to support performance assessment of hydrology and chemical transport at Yucca Mountain: Yucca Mountain Site Characterization Project, 93:249 (R;US)

Diffusion of sorbing and non-sorbing radionuclides (Yucca Mountain Project), 93:129 (R;US)

Engineered barrier environment, Yucca Mountain, 93:191 (R;US)

Field research program for unsaturated flow and transport experimentation (Yucca Mountain Project), 93:280 (R;US)

Gas phase migration of $\mathrm{C}-14$ through barrier materials applicable for use in a high-level nuclear waste repository located in tuff, $93: 647$ (i;US)

Neptunium retardation with tuffs and groundwaters from Yucca Mountain (Yucca Mountain Project), 93:128 (R;US)

Potential increases in natural radon emissions due to heating of the Yucca Mountain rock mass, 93:212 (R;US)

Preliminary calculations of release rates of Tc-99, 1-129, and $\mathrm{Np}-237$ from spent fuel in a potential repository in tuff, $93: 49$ (R;US)

Radionuclide migration laboratory studies for validation of batch sorption data, 93:118 (R;US)

Research program to develop and validate conceptual models for flow and transport through unsaturated, fractured rock: Yucca Mountain Site Characterization Project (YUCCA MOUNTAIN PROJECT), 93:253 (R; US)

Scientific investigation plan for initial engineered barrier system field tests (Yucca Mountain Project), 93:171 (R;US)

Sensitivity and uncertainty analyses applied to one-dimensional radionuclide transport in a layered fractured rock: MULTFRAC -Analytic solutions and local sensitivities: Phase 2, Iterative performance assessment: Volume 1, 93:536 (R;US)

Site characterization progress report: Yucca Mountain, Nevada, October 1, 1990-March 31, 1991: Number 4, 93:25 (R;US)

Studies of the mobility of uranium and thorium in Nevada Test Site tuff, 93:498 (RA;US)

TSPA 1991: An initial total-system performance assessment for Yucca Mountain: Yucca Mountain Site Characterization Project (Yucca Mountain Project), 93:293 (R;US)

Waste-package release rates for site suitability studies, 93:48 (R;US)

Yucca Mountain program summary of research and technical review activities, July 1988-June 1989, 93:539 (R;US) 


\section{Rock Mechanics}

G-Tunnel Welded Tuff Mining Experiment instrumentation evaluations: Yucca Mountain Site Characterization Project, 93:227 (R;US)

G-Tunnel pressurized slot-testing preparations: Yucca Mountain Site Characterization Project, 93:225 (R;US)

Procedure development study: Low strain rate and creep experiments: Yucca Mountain Site Characterization Project (YUCCA MOUNTAIN PROJECT), 93:261 (R;US)

\section{Rock-Fluid Interactions}

Field research program for unsaturated flow and transport experimentation (Yucca Mountain Project), 93:280 (R;US)

Preliminary conceptual model for mineral evolution in Yucca Mountain, 93:111 (R;US)

Pressurized grout applications in fractured tuff for containment of radioactive wastes, 93:676 (J;GB)

Water-rock interactions and the $\mathrm{pH}$ stability of groundwater from Yucca Mountain, Nevada, 93:124 (R;US)

\section{Shear Properties}

Effect of boundary conditions on the strength and deformability of replicas of natural fractures in welded tuff: Comparison between predicted and observed shear behavior using a graphical method: Yucca Mountain Site Characterization Project (yucca mountain project), 93:314 (R;US)

Effect of boundary conditions on the strength and deformability of replicas of natural fractures in welded tuff: Data report: Yucca Mountain Site Characterization Project (yucca mountain project), $93: 311$ (R;US)

New three-dimensional far-field potential repository thermomechanical calculations: Yucca Mountain Site Characterization Project (Yucca Mountain Project), 93:306 (R;US)

\section{Sorptive Properties}

A strategy for the derivation and use of sorption coefficients in performance assessment calculations for the Yucca Mountain site, 93:115 (R;US)

A suggested approach toward measuring sorption and applying sorption data to repository performance assessment, $93: 114$ (R;US)

Dependence of radionuclide sorption on sample grinding, surface area, and water composition, 93:127 (R;US)

Diffusion of sorbing and non-sorbing radionuclides (Yucca Mountain Project), 93:129 (R;US)

Modeling cation exchange using EQ3/6, 93:149 (RA;US)

Neptunium retardation with tuffs and groundwaters from Yucca Mountain (Yucca Mountain Project), 93:128 (R;US)

Proceedings of the DOE/Yucca Mountain Site Characterization Project Radionuclide Adsorption Workshop at Los Alamos National Laboratory, September 11-12, 1990 (Yucca Mountain Project.), 93:104 (R;US)

Radionuclide migration laboratory studies for validation of batch-sorption data, 93:106 (RA;US)

Sorption and porosity heterogeneity: Effects on radionuclide transport, 93:479 (RA;US)

The influence of scale on calculated sorptivity values from imbibition experiments on welded and nonwelded tuff, 93:397 (BA;FR)

Thermodynamically derived relationships between the modified Langmuir isotherm and experimental parameters, 93:672 (J;US)

Stability

Borehole stability in densely welded tuffs, $93: 531$ (R;US)

Temperature Effects

Thermal performance of a buried nuclear waste storage container storing a hybrid mix of PWR and BWR spent fuel rods: Revision 1, 93:159 (R;US)

Temperature Measurement

Temperature measurements from a horizontal heater test in GTunnel, 93:178 (R;US)

\section{Tenslle Properties}

Effect of boundary conditions on the strength and deformability of replicas of natural fractures in welded tuff: Comparison between predicted and observed shear behavior using a graphical method: Yucca Mountain Site Characterization Project (yucca mountain project), 93:314 (R;US)

Effect of boundary conditions on the strength and deformability of replicas of natural fractures in welded tuff: Data report: Yucca Mountain Site Characterization Project (yucca mounTesting tain project), 93:311 (R;US)

Field air injection tests to determine the effect of a heat cycle on the permeability of welded tuff, 93:179 (R;US)

Temperature measurements from a horizontal heater test in GTunnel, 93:178 (R;US)

Thermal Analysis

Analysis of slot cutting methods for the Yucca Mountain heated block test using a compliant-joint model, 93:270 (R;US)

Thermal Cycling

Field air injection tests to determine the effect of a heat cycle on the permeability of welded tuff, 93:179 (R;US)

Thermal Expansion

Calculation of experiment uncertainty in laboratory determination of several geoengineering properties of tuffs from Yucca Mountain, Nevada: Yucca Mountain Site Characterization Project (Yucca Mountain Project.), 93:231 (R;US)

Linear thermal expansion data for tuffs from the unsaturated zone at Yucca Mountain, Nevada: Yucca Mountain Site Characterization Project, 93:228 (R; US)

Waste-Rock Interactions

Transport in unsaturated flow systems using centrifuge techniques, 93:483 (RA; US)

Young Modulus

Modulus dispersion and attenuation in tuff and granite, 93:275 (R;US)

TUMORS

SeO NEOPLASMS

TUNNELING MACHINES

TBM performance prediction in Yucca Mountain welded tuff from linear cutter tests, 93:352 (BA;US)

\section{TUNNELS}

A portable vacuum hammer seismic source for use in tunnel environments, 93:595 (R;US)

Dynamic response of tunnels in jointed rocks, 93:425 (BA;US)

MISTY ECHO Tunnel Dynamics Experiment--Data report: Volume 1: Yucca Mountain Site Characterization Project (Yucca Mountain Project), 93:238 (R;US)

MISTY ECHO tunnel dynamics experiment data report: Volume 2, Appendices: Yucca Mountain Site Characterization Project, 93:239 (R;US)

Use of the iterative solution method for coupled finite element and boundary element modeling: Yucca Mountain Site Characterization Project (yucca mountain project), 93:324 (R;US)

TWO.DIMENSIONAL CALCULATIONS

US Department of Energy issue resolution process, 93:80 (BA;US)

\section{2-DIMENSIONAL CALCULATIONS}

See TWO-DIMENSIONAL CALCULATIONS

\section{UNDERGROUND}

Characterizing the altered zone at Yucca Mountain: The beginning of a testing strategy, $93: 188(R ; U S)$

UNDERGROUND DISPOSAL

Approach to geologic repository post closure system performance assessment, 93:308 (R;US)

Calculation of experiment uncertainty in laboratory determination of several geoengineering properties of tuffs from Yucca Mountain, Nevada: Yucca Mountain Site Characterization Project (Yucca Mountain Project.), 93:231 (R;US)

Geophysical characterization of mineral and energy resources at Yucca Mountain and vicinity, Nevada, 93:380 (R;US)

Report of early site suitability evaluation of the potential repository site at Yucca Mountain, Nevada: Yucca Mountain Site Characterization Project, 93:67 (R;US) 
SUMO, System perfomance assessment for a high-level nuclear waste repository: Mathematical models, 93:153 (R;US)

Socioeconomic profiles of native American communities: Yomba Shoshone Reservation, 93:551 (R;US)

Testing of geochemical models in the Pocos de Caldas analogue study, 93:507 (R;CH)

Use of Wingz spreadsheet as an interface to total-system performance assessment (Yucca Mountain Project), 93:281 (R;US)

Yucca Mountain Socioeconomic Project: The 1991 Nevada State telephone survey: Key findings, 93:546 (R;US)

\section{UNDERGROUND FACILITIES}

See also MINES

$$
\text { TUNNELS }
$$

\section{Construction}

Movement of shaft and drift construction water in Yucca Mountain, Nevada: An extended study: Yucca Mountain Site Characterization Project, 93:266 (R;US)

Contamination Regulations

Reasonableness of human intrusion provisions in EPA's HLW standard, $93: 463$ (RA;US)

Damage

MISTY ECHO Tunnel Dynamics Experiment-Data report: Volume 1: Yucca Mountain Site Characterization Project (Yucca Mountain Project), 93:238 (R;US)

Design

Classification and grading of design products for the Yucca Mountain project, $93: 95$ (J;US)

Equipment

Transportation cask decontamination and maintenance at the potential Yucca Mountain repository: Yucca Mountain Site characterization project, 93:247 (R;US)

Flood Control

Probable maximum flood control: Yucca Mountain Site Characterization Project (Yucca Mountain Project), 93:232 (R;US)

\section{Heat Flow}

The impact of thermal loading on repository performance at Yucca Mountain, 93:189 (R;US)

Mathematical Models

An investigation of the impact of conceptual model uncertainty on the estimated performance of a hypothetical high-level nuclear waste repository site in unsaturated, fractured tuff: Yucca Mountain Site Characterization Project, 93:256 (R;US)

\section{Performance}

An investigation of the impact of conceptual model uncertainty on the estimated performance of a hypothetical high-level nuclear waste repository site in unsaturated, fractured tuff: Yucca Mountain Site Characterization Project, 93:256 (R;US)

Applications of performance assessment in support of the EXploratory Studies Facility (ESF) design, 93:288 (R;US)

Conceptual, experimental and computational approaches to support performance assessment of hydrology and chemical transport at Yucca Mountain: Yucca Mountain Site Characterization Project, 93:249 (R;US)

Demonstration of a risk-based approach to high-level waste repository evaluation, Phase 2, 93:461 (R;US)

Estimation of the impact of water movement from sewage and settling ponds near a potential high level radioactive waste repository in Yucca Mountain, Nevada: Yucca Mountain Site Characterization Project, 93:267 (R;US)

Thermal analysis of Yucca Mountain commercial high-level waste packages, 93:156 (R;US)

Quality Assurance

Classification and grading of design products for the Yucca Mountain project, 93:95 (J;US)

Radioactive Waste Disposal

G-Tunnel pressurized slot-testing preparations: Yucca Mountain Site Characterization Project, 93:225 (R;US)

Radionuclide Migration

Nonisothermal hydrologic transport experimental plan, 93:534 (R;US)

Safety

Identification of structures, systems, and components important to safety at the potential repository at Yucca Mountain: Yucca
Mountain Site Characterization Project (YUCCA MOUNTAIN PROJECT), 93:251 (R; US)

Seals

Sealing performance of bentonite and bentonite/crushed rock borehole plugs, $93: 530$ (R;US)

Seismic Effects

MISTY ECHO Tunnel Dynamics Experiment-Data report: Volume 1: Yucca Mountain Site Characterization Project (Yucca Mountain Project), 93:238 (R;US)

Stability

Application of analytical methods for jointed rock as part of a drift design methodology for the Yucca Mountain Project, 93:240 (R;US)

UNDERGROUND SPACE

Borehole stability in densely welded tuffs, 93:531 (R;US)

MSTS - Multiphase Subsurface Transport Simulator theory manual, 93:64 (R;US)

UNITED STATES OF AMERICA

SOE USA

URANINITES

Dissolution and alteration of uraninite under reducing conditions, 93:664 (J;NL)

URANIUM

Drift emplaced waste package thermal response (Yucca Mountain Project), 93:193 (R;US)

Environmental monitoring for uranium and neptunium at. Yucca Mountain, 93:639 (BA;US)

Environmental monitoring for uranium and neptunium at Yucca Mountain using Epithermal Neutron Activation Analysis, 93:447 (R:US)

Occurrence of naturally enriched ${ }^{235} \mathrm{U}$ : Implications for plutonium behavior in natural environments, 93:656 (J;US)

Studies of the mobility of uranium and thorium in Nevada Test Site tuff, $93: 498$ (RA; US)

URANIUM 235

Anomalous deuteron to hydrogen ratio in naturally occuring fission reactions and the possibility of deuteron disintegration, 93:667 (J;HU)

Sorption and porosity heterogeneity: Effects on radionuclide transport, $93: 479$ (RA;US)

Variation of the isotopic compositions of xenon and krypton in terrestrial samples, 93:632 (BA;US)

\section{URANIUM 238}

Anomalous deuteron to hydrogen ratio in naturally occuring fission reactions and the possibility of deuteron disintegration, 93:667 (J:HU)

Sorption and porosity heterogeneity: Effects on radionuclide transport, 93:479 (RA;US)

Variation of the isotopic compositions of xenon and krypton in terrestrial samples, 93:632 (BA:US)

URANIUM DEPOSITS

See also KOONGARRA DEPOSIT

RANGER DEPOSIT

SOUTH ALLIGATOR DEPOSIT

${ }^{36} \mathrm{Cl}$ production in situ, and groundwater transport in a uranium ore deposit, 93:631 (BA:US)

Okelobondo Uranium deposit: Regional context, stratigraphy, sedimentology, tectonic and mineralization, 93:465 (RA;XE; In French)

URANIUM ISOTOPES

See also URANIUM 235

URANIUM 238

Migration of radioelements around the new nuclear reactors at Oklo: Analogies with a high-level waste repository, 93:670 (J;DE)

Radioelements and their occurrence with secondary minerals in heated and unheated tuff at the Nevada test site, 93:82 (BA;US)

Uptake of uranium and thorium series radionuclides by the waterlily, Nymphaea violacea, $93: 659$ (J:GB)

\section{URANIUM MINES}

Alligator Rivers Region Research Institute: annual research summary 1989-1990, 93:606 (B;AU) 
Alligator Rivers Region Research Institute: annual research summany 1989-1990, 98:601 (B;AU)

Annual Report 1991-1992, 93:604 (B;AU)

Chemical and physical characterisation of suspended particles and colloids in waters from the Osamu Utsumi mine and Morro do Ferro analogue study sites, Pocos de Caldas, Brazil, 93:506 (R;CH)

Geochemical modelling of water-rock interactions at the Osamu Utsumi mine and Morro do Ferro analogue study sites, Pocos de Caldas, Brazil, 93:509 (R;CH)

Natural radionuclide and stable element studies of rock samples from the Osamu Utsumi mine and Morro do Ferro analogue study sites, Pocos de Caldas, Brazil, $93: 504(\mathrm{R} ; \mathrm{CH})$

Natural series radionuclide and rare-earth element geochemistry of waters from the Osamu Utsumi mine and Morro do Ferro analogue study sites, Pocos de Caldas, Brazil, 93:505 (R;CH)

Testing models of redox front migration and geochemistry at the Osamu Utsumi mine and Morro do Ferro analogue study sites, Pocos de Caidas, Brazil, 93:508 (R;CH)

Testing of geochemical models in the Pocos de Caldas analogue study, 93:507 (R;CH)

The Pocos de Caldas project: summary and implications for radioactive waste management: Pocos de Caldas report no. 15 , 93:510 (R;CH)

Uptake of uranium and thorium series radionuclides by the wa terlily, Nymphaea violacea, 93:659 (J;GB)

\section{URANIUM ORES}

Hydrothermal alteration of organic matter in uranium ores, Elliot Lake, Canada: Implications for selected organic-rich deposits, 93:650 (J:US)

Using geological information to develop new exploration project for uranium deposits in Southern Africa, 93:663 (J;JP;In Japanese)

US DOE

See also LANL

\section{NEVADA TEST SITE}

SAVANNAH RIVER PLANT

Nuclear waste: DOE expenditures on the Yucca Mountain Project, 93:469 (R;US)

Nuclear waste: Quality assurance auditors need access to employee records, $93: 466$ (R;US)

Quarterly report on program cost and schedule, fourth quarter FY 1992, 93:459 (R;US)

Quarterly report on program cost and schedule, third quarter $F Y$ 1992, 93:458 (R;US)

Review and critique of the US Department of Energy environmental program plan for site characterization for a high-leve waste repository at Yucca Mountain, Nevada, 93:570 (R;US)

US EPA

Critical comments on the US Environmental Protection Agency Standards 40 CFR 191, 93:7 (R;US)

US GEOLOGICAL SURVEY

SeO US GS

US GS

Late quaternary faulting along the Death Valley-Furnace Creek fault system, California and Nevada, $93: 369$ (R;US)

US MRS PROJECT

A dose of HLW reality, 93:657 (J;US)

US NATIONAL ENVIRONMENTAL POLICY ACT

Overview and status of the U.S. high-level waste program, 93:610 (BA;US)

US NRC

Initial demonstration of the NRC's capability to conduct a performance assessment for a High-Level Waste Repository, 93:512 (R;US)

NRC approves spent-fuel cask for general use: Who needs Yucca Mountain?, 98:648 (J;US)

USA

See also CALIFORNIA

GREAT BASIN

NEVADA

TENNESSEE

Nuclear age: Take two?, 93:658 (J;US)
Overview and status of the U.S. high-level waste program, 93:610 (BA;US)

Panel discussion on nuclear waste, 93:614 (BA;US)

\section{$\mathbf{V}$}

\section{VANADIUM MINERALS}

See MINERALS

VAPORS

See also WATER VAPOR

Modeling of strongly heat-driven flow processes at a potentia high-level nuclear waste repository at Yucca Mountain, Nevada, $93: 57$ (R;US)

VEHICLES

Intra-site secure transport vehicle, 93:581 (R;US)

VESSELS

Soe CONTAINERS

VESSELS (PRESSURE)

SEe PRESSURE VESSELS

VIBRATIONS (MECHANICAL)

SOE MECHANICAL VIBRATIONS

VOLCANIC REGIONS

${ }^{40} \mathrm{Ar}{ }^{\beta 9} \mathrm{Ar}$ age of the Lathrop Wells Volcanic Center, Yucca Mountain, Nevada, 93:399 (J;US)

Geochemical evidence for waning magmatism and polycyclic volcanism at Crater Flat, Nevada, 93:119 (R;US)

Late Quaternary geology of small basaltic volcanic centers, SW USA: Disparity among dating methods and implications for volcanic and geomorphic studies, 93:668 (J;US)

Manganoan fayalite $\left[(\mathrm{Fe}, \mathrm{Mn})_{2} \mathrm{SiO}_{4}\right]:$ A new occurrence in rhyolitic ash-flow tuff, southwestern Nevada, U.S.A., 93:678 (J;US)

Measuring the age of the Lathrop Wells volcanic center at Yucca Mountain, 93:665 (J;US)

The Lathrop Wells volcanic center: Status of field and geochronology studies, 93:122 (R;US)

The Timber Mountain magmato-thermal event: An intense widespread culmination of magmatic and hydrothermal activity at the southwestern Nevada volcanic field, 93:438 (R;US)

\section{VOLCANISM}

A Monte Carlo technique to estimate the probability of volcanic dikes, 93:637 (BA;US)

Geochemical evidence for waning magmatism and polycyclic volcanism at Crater Flat, Nevada, 93:119 (R;US)

Physical processes and effects of magmatism in the Yucca Mountain region, $93: 117$ ( $R$; US)

Recurrence models of voicanic events: Applications to volcanic risk assessment, 93:139 (BA;US)

VOLCANOES

The Lathrop Wells volcanic center: Status of field and geochronology studies, 93:122 (R;US)

The Lathrop Wells volcanic center: Status of field and geochronology studies, $93: 112$ (R;US)

VRAIN REACTOR

Criticality safety issues associated with the burial of highly enriched nuclear fuel in a geologic repository, 93:596 (R;US)

\section{W}

WASTE BURIAL

\section{SeO UNDERGROUND DISPOSAL}

\section{WASTE FORMS}

Health and environmental risk-related impacts of actinide burning on high-level waste disposal, 93:572 (R;US)

Post-closure performance assessment of waste packages for the Yucca Mountain Project (Yucca Mountain Project), 93:170 (R;US)

\section{WASTE TRANSPORTATION}

A report on high-level nuclear waste transportation: Prepared pursuant to assembly concurrent resolution No. 8 of the 1987 Nevada Legislature, 93:558 (R;US) 
Guidelines on the scope, content, and use of comprehensive risk assessment in the management of high-level nuclear waste transportation, 93:561 (R; US)

Probabilistic risk assessment and nuclear waste transportation: A case study of the use of RADTRAN in the 1986 Environmental Assessment for Yucca Mountain, $93: 560$ (R;US)

Transportation needs assessment: Emergency response section, 93:559 (R;US)

Yucca Mountain transportation routes: Preliminary characterization and risk analysis: Volume 2, Figures [and] Volume 3, Technical Appendices, 93:564 (R;US)

Yucca Mountain transportation routes: Preliminary characterization and risk analysis: Volume 1, Research report, 93:563 (R;US)

WASTE WATER

Applications of performance assessment in support of the Exploratory Studies Facility (ESF) design, 93:288 (R;US)

Estimation of the impact of water movement from sewage and settling ponds near a potential high level radioactive waste repository in Yucca Mountain. Nevada: Yucca Mountain Site Characterization Project, 93:267 (R;US)

WASTE-ROCK INTERACTIONS

EQ6, a computer program for reaction path modeling of aqueous geochemical systems: Theoretical manual, user's quide, and related documentation (Version 7.0): Part 4, 93:203 (R;US)

\section{WASTEFORMS}

See WASTE FORMS

WATER

See also GROUND WATER

WASTE WATER

Characterization of flow in fractured tuff using computerized tomography, 93:491 (R;US)

Movement of shaft and drift construction water in Yucca Mountain, Nevada: An extended study: Yucca Mountain Site Characterization Project, 93:266 (R;US)

Radioelements and their occurrence with secondary minerals in heated and unheated tuff at the Nevada test site, 93:82 (BA;US)

Research program to develop and validate conceptual models for flow and transport through unsaturated, fractured rock: Yucca Mountain Site Characterization Project (YUCCA MOUNTAIN PROJECT), 93:253 (R;US)

Strontium isotope geochemistry of calcite fracture fillings in deep core, Yucca Mountain, Nevada: A progress report, 93:393 (BA;US)

Thorium-230 chronology of natural waters at the Nevada test site, 93:642 (BA;US)

Three-dimensional modeling of unsaturated flow in the vicinity of proposed exploratory shaft facilities at Yucca Mountain, Nevada, $93: 62$ (R;US)

WATER COOLANT

SEe WATER

WATER COOLED REACTORS

See also BWR TYPE REACTORS

PWR TYPE REACTORS

Performance-assessment comparisons for a repository containing LWR spent fuel or partitioned/transmutted nuclear waste, 93:351 (BA;US)

Radionuclide distribution in LWR spent fuel, 93:209 (BA;US)

WATER MODERATOR

SEe WATER

WATER SATURATION

The capillary hysteresis model HYSTR: User's guide, 93:37 (R;US)

WATER SOLUTIONS

Søe AQUEOUS SOLUTIONS

WATER TABLES

A scoping study of water table excursions induced by seismic and volcanic events, 93:163 (R;US)

The impact of thermal loading on repository performance at Yucca Mountain, 93:205 (BA;US)

Water levels in continuously monitored wells in the Yucca Mountain area, Nevada, 1985-88, 93:378 (R;US)

\section{WATER VAPOR}

Progress in assessing the effect of ionizing radiation on the anticipated waste package environment at the Yucca Mountain potential repository site, 93:144 (R;US)

WATER WELLS

Earthquake-induced water-level fluctuations at Yucca Mountain, Nevada, June 1992, 98:388 (R;US)

WATERSHEDS

Apache leap watershed study, 93:516 (RA;US)

WAZ 16

Soe NICKEL BASE ALLOYS

WELDING

LLNLYMP Waste Container Fabrication and Closure Project: GFY technical activity summary, $93: 591$ (R;US) WELLS

See also EXPLORATORY WELLS WATER WELLS

Hydrogeologic characterization of wells HTH-1, UE18r, UE6e, and HTH-3, Nevada Test Site, 93:441 (R;US)

WESTERN REGION

Se日 USA

\section{$\mathbf{X}$}

XENON ISOTOPES

Variation of the isotopic compositions of xenon and krypton in terrestrial samples, 93:632 (BA;US)

\section{$\mathbf{Y}$}

YUCCA MOUNTAIN

A decision analysis of an exploratory studies facility, 93:301 (R;US)

Aerial Surveying

Photogeologic and kinematic analysis of lineaments at Yucca Mountain, Nevada: Implications for strike-slip faulting and oroclinal bending, 93:381 (R;US)

Baseline Ecology

Identification of subsurface microorganisms at Yucca Mountain: Fourth quarterly report, 93:16 (R;US)

Boreholes

Flow and transport through unsaturated rock: Data from two test holes, Yucca Mountain, Nevada, 93:391 (BA;US)

Strontium isotope geochemistry of calcite fracture fillings in deep core, Yucca Mountain, Nevada: A progress report, 93:393 (BA;US)

Climate Models

An overview of the Yucca Mountain Global/Regional Climate Modeling Program, 93:276 (R;US)

An ovenview of the Yucca Mountain globalregional climate modeling program, 93:350 (BA;US)

Compiled Data

Yucca Mountain Site Characterization Project Technical Data Catalog (quarterly supplement), 93:33 (R;US)

Data Base Management

Design and implementation of the site and engineering properties database: Yucca Mountain Site Characterzation Project, 93:242 (R;US)

Yucca Mountain digital database, 93:615 (BA;US)

Earthquakes

2010: America's nuclear waste odyssey, 93:652 (J;GB)

Seismicity and focal mechanisms for the southern Great Basin of Nevada and California: 1987 through 1989, 93:379 (R;US)

Environmental Impacts

Review and critique of the US Department of Energy environmental program plan for site characterization for a high-level waste repository at Yucca Mountain, Nevada, 93:570 (R;US)

Environmental Materials

Environmental monitoring for uranium and neptunium at Yucca Mountain using Epithermal Neutron Activation Analysis, 93:447 (R;US) 
G Codes

Three dimensional visualization in support of Yucca Mountain Site characterization activities (Yucca Mountaing Project), 93:34 (R:US)

\section{Gas Flow}

Numerical studies of rock-gas flow in Yucca Mountain: Yucca Cels Mountain Site Characterization Project, 93:296 (R;US)

Natural geis in the Yucca Mountain Area, Nevada, USA, 93:116 (R;US)

Geochemical Surveys

Geochemical evidence for waning magmatism and polycyclic volcanism at Crater Flat, Nevada, 93:140 (BA;US)

Geotechnical support and topical studies for nuclear waste geologic repositories: Annual report, fiscal year 1989, 93:47 (R;US)

Geochem istry

Applications of performance assessment in support of the Exploratory Studies Facility (ESF) design, 93:288 (R;US)

Ceologic Fauits

Fault stress analysis for the Yucca Mountain Site Characterization Project, $93: 278$ (R;US)

The role of fault zones in affecting multiphase flow at Yucca Mountain (Yucca Mountain Project), 93:60 (R;US)

\section{Ceologic Fractures}

Does the wind blow through Yucca Mountain?, 93:366 (RA;US)

Estimating the consequences of significant fracture flow at Yucca Mountain, 93:273 (R; US)

Field testing the effectiveness of pumping to remove sulfur hexafluoride traced drilling air from a prototype borehole near superior, Arizona, 93:518 (RA;US)

Preliminary capillary hysteresis simulations for fractured rocks model development and results of simulations, 93:39 (R;US)

Geologic Models

Developing a functioning visualization and analysis system for performance assessment, 93:289 (R;US)

Geologic Structures

Nonequilibrium fracture-matrix flow during episodic infiltration events in Yucca Mountain (Yucca Mountain Project), 93:514 (RA;US)

Structure in continuously cored, deep drill holes at Yucca Mountain, Nevada, with notes on calcite occurrence: Yucca Mountain Site Characterization Project (Yucca Mountain Project), 93:298 (R;US)

Geologic Surveys

An overview of the Yucca Mountain global/regional climate modeling program, 93:350 (BA;US)

Deterministic geologic processes and stochastic modeling, 93:353 (BA;US)

Geophysical characterization of mineral and energy resources at Yucca Mountain and vicinity, Nevada, 93:380 (R;US)

Geophysical logs and core measurements from forty boreholes at Yucca Mountain, Nevada, $93: 370$ (R;US)

Results of rock property measurements made on core samples from Yucca Mountain boreholes, Nevada Test Site, Nevada: Part 1, Boreholes UE25A-4, -5, -6, and -7; Part 2, Borehole UE25PNo.1, $93: 373$ (R;US)

Streamflow and selected precipitation data for Yucca Mountain and vicinity, Nye County, Nevada, water years 1983-85, 93:389 (R;US)

Summary and evaluation of existing geological and geophysical data near prospective surface facilities in Midway Valley, Yucca Mountain Project, Nye County, Nevada: Yucca Mountain Site Characterization Project (Yucca Mountain Project), 93:254 (R;US)

Geology

An approach to validation of thermomechanical models, 93:335 (R;US)

Assessment of geophysical logs from borehole USW G-2, Yucca Mountain, Nevada, 93:387 (R;US)

Borehole and geohydrologic data for test hole USW UZ-6, Yucca Mountain area, Nye County, Nevada, 93:382 (R;US)

Boron adsorption on hematite and clinoptilolite, 93:490 (R;US)
Characterization of porosity in support of mechanical property analysis (yucca mountain project), $93: 313$ (R;US)

Comparison of predicted far-field temperatures for discrete and smeared heat sources (Yucca Mountain Project), 93:332 (R;US)

Developing a functioning visualization and analysis system for performance assessment, 93:346 (BA;US)

Evaluation of the geologic relations and seismotectonic stability of the Yucca Mountain Area, Nevada Nuclear Waste Site Investigation (NNWSI): Volume 2, Final report, October 1988, 93:543 (R;US)

Evaluation of the geologic relations and seismotectonic stability of the Yucca Mountain area, Nevada Nuclear Waste Site Investigation (NNWS1): Final report, January 1, 1987-June 30, 1988: Volume 1, $93: 542$ (R;US)

Geohydrologic data and models of Rainier Mesa and their implications to Yucca Mountain (Yucca Mountain Project), 93:58 (R;US)

Geologic evaluation of six nonwelded tuff sites in the vicinity of Yucca Mountain, Nevada for a surface-based test facility for the Yucca Mountain Project (yucca mountain project), 93:108 (R;US)

Implications of stability analysis for heat transfer at Yucca Mountain, 93:337 (R;US)

Influence of deterministic geologic trends on spatial variability of hydrologic properties in volcanic tuff, $93: 318$ (R;US)

KIAR dating of clinoptiolite, mordenite, and associated clays from Yucca Mountains, Nevada, 93:131 (R;US)

Modeling of strongly heat-driven flow processes at a potential high-level nuclear waste repository at Yucca Mountain, Nevada, 93:57 (R;US)

Photogeologic and kinematic analysis of lineaments at Yucca Mountain, Nevada: Implications for strike-slip faulting and oroclinal bending, $93: 381$ (R;US)

Scenario development for performance assessment: Some questions for the near-field modelers (yucca mountain project), 93:325 (R;US)

Sensitivity analyses for total-system performance assessment (yucca mountain project), 93:319 (R;US)

The Lathrop Welis volcanic center: Status of field and geochronology studies, 93:112 (R;US)

The analysis of repository-heat-driven hydrothermal flow at Yucca Mountain (Yucca Mountain Project), 93:194 (R;US)

The influence of strain rate and sample inhomogeneity on the moduli and strength of welded tuff (yucca mountain project), 93:312 (R;US)

The most likely groundwater flux through the unsaturated tuff matrix at USW H-1, $93: 338$ (R;US)

The results of near-field thermal and mechanical calculations of thermal loading schemes (Yucca mountain project), 93:333 (R;US)

The use of sequential indicator simulation to characterize geostatistical uncertainty: Yucca Mountain Site Characterization Project (Yucca Mountain Project.), 93:264 (R;US)

Transport of neptunium through Yucca Mountain tuffs, 93:126 (R;US)

Unconfined compression experiments on Topopah Spring Member tuff at $22^{\circ} \mathrm{C}$ and a strain rate of $10^{-9} \mathrm{~s}^{-1}$ : Data report: Yucca Mountain Site Characterization Project (yucca mountain project), 93:310 (R;US)

\section{Geophysical Surveys}

Geotechnical support and topical studies for nuclear waste geologic repositories: Annual report, fiscal year 1989, 93:47 (R;US)

Summary and evaluation of existing geological and geophysical data near prospective surface facilities in Midway Valley, Yucca Mountain Project, Nye County, Nevada: Yucca Mountain Site Characterization Project (Yucca Mountain Project), 93:254 (R;US)

Geothermal Fields

Geothermal evaluation and analysis of the Yucca Mountain Repository, Nevada: Final report, July 1, 1989-December 31, 1989, $93: 540$ (R;US) 
Ground Motion

Current plans to characterize the design basis ground motion at the Yucca Mountain, Nevada Site, 93:4 (R;US)

Preclosure seismic hazards and their impact on site suitability of Yucca Mountain, Nevada (Yucca Mountain Project), 93:291 (R;US)

Prediction of Pseudo relative velocity response spectra at Yucca Mountain for underground nuclear explosions conducted in the Pahute Mesa testing area at the Nevada testing site: Yucca Mountain Site Characterization Project (Yucca Mountain Project), 93:230 (R;US)

\section{Ground Water}

Estimation of the limitations for surficial water addition above a potential high level radioactive waste repository at Yucca Mountain, Nevada: Yucca Mountain Site Characterization Project, 93.265 (R;US)

Field research program for unsaturated flow and transport experimentation, 93:345 (BA;US)

Quasi-linear analysis of water flow in the unsaturated zone at Yucca Mountain, Nevada, USA, 93:258 (R;US)

Simulated water-level declines caused by withdrawals from wells $\mathrm{J}-13$ and J-12 near Yucca Mountain, Nevada, 93:377 (R;US)

Uncertainty and sensitivity results for pre-waste-emplacement groundwater travel time, 93:272 (R;US)

Water-rock interactions and the $\mathrm{pH}$ stability of groundwater from Yucca Mountain, Nevada, 93:124 (R; US)

Hydraulic Conductivity

Conservative tracers for the C-well hydraulic testing, 93:84 (BA;US)

\section{Hydrology}

A summary and discussion of hydrologic data from the Calico Hills nonwelded hydrogeologic unit at Yucca Mountain, Nevada, 93:107 (R:US)

Borehole and geohydrologic data for test hole USW UZ-6, Yucca Mountain area, Nye County, Nevada, 93:382 (R:US)

Boron adsorption on hematite and clinoptilolite, $93: 490$ ( $R ;$ US)

Comparison of predicted far-field temperatures for discrete and smeared heat sources (Yucca Mountain Project), 93:332 (R;US)

Design of a three-dimensional site-scale model for the unsaturated zone at Yucca Mountain, Nevada, 93:53 (R;US)

Does localized recharge occur at a discharge area within the ground-water flow system of Yucca Mountain, Nevada?, 93:362 (R;US)

Earthquake-induced water-level fluctuations at Yucca Mountain, Nevada, April 1992, 93:383 (R;US)

Evaluation of tracers for hydrologic studies at Yucca Mountain, 93:526 (RA;US)

Geohydrologic data and models of Rainier Mesa and their implications to Yucca Mountain (Yucca Mountain Project), 93:58 (R;US)

Geohydrologic data from test holes UE-25 UZ \#4 and UE-25 UZ \#5, Yucca Mountain Area, Nye County, Nevada, 93:372 (R;US)

Geohydrology of rocks penetrated by test well USW H-6, Yucca Mountain, Nye County, Nevada, 93:390 (R;US)

Gravity and magnetic data of Fortymile Wash, Nevada Test Site, Nevada, 93:385 (R;US)

Hydrogeologic issues at Yucca Mountain: Findings of a DOE peer review team, 93:513 (RA;US)

Identification and characterization of conservative organic tracers for use as hydrologic tracers for the Yucca Mountain Site Characterization Study: Progress report, June 1-December 31, 1990, $93: 9$ (R;US)

Identification and characterization of conservative organic tracers for use as hydrologic tracers for the Yucca Mountain Site Characterization Study: Progress report, January 1, 1991June $30,1991,93: 10$ (R;US)

Identification and characterization of conservative organic tracers for use as hydrologic tracers for the Yucca Mountain Site Characterization Project: Quality Assurance Project Plan: Quarterly technical progress report, January 1, 1993-March 31, 1993, 93:8 (R;US)
Identification and characterization of conservative organic tracers for use as hydrologic tracers for the Yucca Mountain Site characterization study: Progress report, April 1, 1993-June 30, 1998, $98: 15$ (R;US)

Identification and characterization of conservative organic tracers for use as hydrologic tracers for the Yucca Mountain Site Characterization Study: Progress report, July 1, 1991December 31, 1991, 93:14 (R;US)

Large-scale in situ heater tests for hydrothermal characterization at Yucca Mountain (Yucca Mountain Project), 93:195 (R;US)

Method development and strategy for the characterization of complexly faulted and fractured rhyolitic tuffs, Yucca Mountain, Nevada, 93:42 (RA;US)

Modeling of strongly heat-driven flow processes at a potential high-level nuclear waste repository at Yucca Mountain, Nevada, 93:57 (R; US)

Proposed algorithm for determining the delta intercept of a thermocouple psychrometer curve, 93:386 (R;US)

Scenario development for performance assessment: Some questions for the near-field modelers (yucca mountain project), 93:325 (R;US)

Sensitivity analyses for total-system performance assessment (yucca mountain project), 93:319 (R;US)

Statistical analysis of hydrologic data for Yucca Mountain: Yucca Mountain Site Characterization Project, 93:220 (R;US)

Streamflow and selected precipitation data for Yucca Mountain and vicinity, Nye County, Nevada, water years 1983-85, 93:389 (R;US)

TOSPAC calculations in support of the COVE 2A benchmarking activity: Yucca Mountain Site Characterization Project, 93:229 (R;US)

Technical basis and programmatic requirements for Engineered Barrier System Field Tests, 93:174 (R;US)

The analysis of repository-heat-driven hydrothermal flow at Yucca Mountain (Yucca Mountain Project), 93:194 (R;US)

The impact of episodic nonequilibrium fracture-matrix flow on geological repository performance, 93:182 (R;US)

The impact of episodic nonequilibrium fracture-matrix flow on repository performance at the potential Yucca Mountain site, 93:185 (R;US)

The impact of thermal loading on repository performance at Yucca Mountain, 93:189 (R;US)

The implications of episodic nonequilibrium fracture-matrix flow on site suitability and total system performance, 93:187 (R;US)

The influence of strain rate and sample inhomogeneity on the moduli and strength of welded tuff (yucca mountain project), 93:312 (R;US)

The most likely groundwater flux through the unsaturated tuff matrix at USW H-1, 93:338 (R;US)

Transport of neptunium through Yucca Mountain tuffs, 93:126 (R;US)

Hydrothermal Systems

Single-hole in situ thermal probe for hydrothermal characterization at Yucca Mountain (Yucca Mountain Project), 93:196 (R;US)

Surface-discharging hydrothermal systems at Yucca Mountain: Examining the evidence, 93:125 (R;US)

I Codes

Three dimensional visualization in support of Yucca Mountain Site characterization activities (Yucca Mountaing Project), 93:34 (R;US)

Information

Technical data base quarterly report, Aprit-June 1992: Yucca Mountain Site Characterization Project, $98: 216$ (R;US)

Legal Aspects

Native Americans and state and local governments, 93:553 (R;US)

Magmatism

Physical processes and effects of magmatism in the Yucca Mountain region, $93: 138$ (BA;US) 
Magnetic Surveys

Geophysical logs and core measurements from forty boreholes at Yucca Mountain, Nevada, 93:370 (R;US)

Maps

Preliminary mapping of surficial geology of Midway Valley Yucca Mountain Project, Nye County, Nevada: Yucca Mountain Site Characterization Project, 93:263 (R;US)

Meetings

US Geological Survey Committee for the Advancement of Science in the Yucca Mountain Project symposium on "Fractures, Hydrology, and Yucca Mountain": Abstracts and summary, 93:375 (R;US)

\section{Mineralogy}

Chemical changes associated with zeolitization of the tuffaceous beds of Calico Hills at Yucca Mountain, Nevada, 93:123 (R;US)

Preliminary conceptual model for mineral evolution in Yucca Mountain, 93:111 (R;US)

Performance Testing

Performance assessment for a high-level waste repository at Yucca Mountain, 93:625 (BA;US)

Yucca Mountain project total-system performance assessment preliminary analyses: Overview, $93: 347$ (BA;US)

Public Opinion

Nevada Nuclear Waste Study Committee: Combating antirepository-study sentiment, 93:684 (J;US)

The Yucca Mountain tours: A test of the familiarity hypothesis, 93:618 (BA;US)

Quality Assurance

Nuclear waste: Quality assurance auditors need access to employee records, 93:466 (R;US)

\section{Radiation Monitoring}

Evaluation of environmental monitoring thermoluminescent dosimeter locations, 93:440 (R;US)

Radiological environmental monitoring for the Yucca Mountain site, 93:89 (BA;US)

Radioactive Waste Disposal

A conceptual design for a nuclear waste repository at the Yucca Mountain site, 93:359 (BA;US)

Characterization of liquid-water percolation in tuffs in the unsaturated zone, Yucca Mountain, Nye County, Nevada, 93:361 (R;US)

DOE's Yucca Mountain studies, 93:30 (R; US)

Design of a three-dimensional site scale model for the unsaturated zone at Yucca Mountain, Nevada, $93: 74$ (BA;US)

Developing a functioning visualization and analysis system for performance assessment, 93:346 (BA:US)

Economic impact of nuclear facilities, 93:627 (BA;US)

Geostatistical methods for site characterization at Yucca Mountain, 93:641 (BA;FR)

Groundwater flow code verification "benchmarking" activity (COVE-2A): Analysis of participants' work, $93: 244$ (R;US)

Heat pipe effect in porous medium, 93:445 (R;US)

Hydrologic modeling and field testing at Yucca mountain, Nevada, 93:396 (BA;FR)

Identification and characterization of conservative organic tracers for use as hydrologic tracers for the Yucca Mountain Site characterization study: Progress report, April 1, 1993-June 30, 1993, 93:15 (R;US)

Laboratory research program to aid in developing and testing the validity of conceptual models for flow and transport through unsaturated porous media, 93:358 (BA;FR)

Method development and strategy for the characterization of complexly faulted and fractured rhyolitic tuffs, Yucca Mountain, Nevada, USA, 93:395 (BA;FR)

Nuclear waste: DOE expenditures on the Yucca Mountain Project, 93:469 (R;US)

Plans for characterization of the potential geologic repository site at Yucca Mountain, Nevada, 93:99 (J;US)

Repository development and long-term data observation needs in the Yucca Mountain, Nevada site characterization program, 93:72 (BA;XN)
S. 1138: A bill to amend the Nuclear Waste Policy Act of 1982 to direct the Secretary of Energy to carry out site characterization activities at the Yucca Mountain site in Nevada, and for other purposes, introduced in the US Senate, One Hundred Second Congress, First Session, May 22, 1991, 93:605 (B;US)

Site characterization progress report: Yucca Mountain, Nevada, October 1, 1992-March 31, 1993, No. 8, 93:31 (R;US)

Temperature scenarios for a repository at Yucca Mountain, 93:623 (BA;US)

The influence of scale on calculated sorptivity values from imbibition experiments on welded and nonwelded tuff, 93:397 (BA;FR)

Uncertainty analyses of unsaturated zone travel time at Yucca Mountain, 93:210 ( $\mathrm{J} ;$ US)

Waste package and engineered barrier system design concepts for the direct disposal of spent fuel in the potential United States repository at Yucca Mountain, Nevada, 93:71 (BA;XA)

Yucca Mountain Site Characterization Project bibliography, July-December 1992: An update, Supplement 3, Addendum 2: Civilian Radioactive Waste Management Program, 93:22 (R;US)

Yucca Mountain Site characterization project bibliography, January-June 1992: An Update: Supplement 3, Addendum $1,93: 21$ (R;US)

Radioactive Waste Facilities

An example postclosure risk assessment using the potential Yucca Mountain Site, 93:155 (R;US)

An overview of the Yucca Mountain globaVregional climate modeling program, 93:350 (BA;US)

Characterization of the Topopah spring and Tiva Canyon tuffs at Yucca Mountain: Effective diffusivities and pore properties, 93:636 (BA;US)

Characterizing the altered zone at Yucca Mountain: The beginning of a testing strategy, 93:206 (BA;US)

Council report finds high-level nuclear waste repository rules 'Unrealistic', 93:687 (J;US)

DOE reassesses civilian radioactive waste management program, 93:688 (J;US)

Design of an intermediate-scale experiment to validate unsaturated-zone transport models, 93:354 (BA;US)

Deterministic geologic processes and stochastic modeling, 93:353 (BA;US)

Diffusion of carbon dioxide and iodine through Yucca Mountain tuffs: Effects of temperature and moisture content, 93:635 (BA;US)

Environmental monitoring for uranium and neptunium at Yucca Mountain, 93:639 (BA;US)

Implementing the Payments-Equal-To-Taxes (PETT) program in Nevada, 93:88 (BA;US)

Late Quaternary geology of small basaltic volcanic centers, SW USA: Disparity among dating methods and implications for volcanic and geomorphic studies, 93:668 (J;US)

Modeling fault rupture hazard for the proposed repository at Yucca Mountain, Nevada, 93:629 (BA;US)

Panel discussion on nuclear waste, 93:614 (BA;US)

Potential increases in natural radon emissions due to heating of the Yucca Mountain rock mass, 93:208 (BA;US)

Preclosure radjological safety evaluation: Exploratory Studies Facility: Yucca Mountain Site Characterization Project, 93:315 (R;US)

Radioelements and their occurrence with secondary minerals in heated and unheated tuff at the Nevada test site, 93:82 (BA;US)

Recurrence models of volcanic events: Applications to volcanic risk assessment, $93: 139$ (BA;US)

Science and students: Yucca Mountain Project's educational outreach and public tour programs, 93:83 (BA;US)

TBM performance prediction in Yucca Mountain welded tuff from linear cutter tests, 93:352 (BA;US)

The Lathrop Wells volcanic center: Status of field and geochronology studies, 93:137 (BA;US) 
The hydrothermal stability of cement sealing materials in the potential Yucca Mountain high level nuclear waste repository, 93:339 (BA;US)

The impact of thermal loading on repository performance at Yucca Mountain, 93:205 (BA;US)

The role of amenities and other factors in influencing the lacation of nonmanufacturing industry in the United States, 93:414 (R;US)

Transportation needs assessment: Emergency response section, 93:559 (R;US)

Tunnel boring machine applications: Yucca Mountain Exploratory Studies Facility, 93:81 (BA;US)

Radioactive Waste Management

Flow to licensing: Technical data tracking and the Licensing Support System (LSS), 93:86 (BA;US)

\section{Radioactive Waste Storage}

Status of the Yucca Mountain project, $93: 93$ (BA;US)

Yucca Mountain biological resources monitoring program: Annual report FY92, 93:36 (R;US)

Radionuclide Migration

Effects of actinide burning on waste disposal at Yucca Mountain, 93:446 (R;US)

Research Programs

DOE's Yucca Mountain studies: What are they? Why are they being done?, 93:24 (R;US)

Risk Assessment

Recurrence models of volcanic events: Applications to volcanic risk assessment, 93:120 (R;US)

Safeguards

International safeguards concepts for the Yucca Mountain Geological Repository, 93:685 (J;US)

Sampling

Conservative tracers for the C-well hydraulic testing, 93:84 (BA;US)

\section{Seismic Effects}

Current plans to characterize the design basis ground motion at the Yucca Mountain, Nevada, site, 93:3 (BA; US)

Design of underground repository openings in hard rock to accommodate vibratory ground motions, 93:213 (BA;US)

Estimation of near-regional seismic ground motion from underground nuclear explosion tests, 93:423 (BA;US)

Seismic considerations in sealing a potential high-level radioactive waste repository, 93:215 (BA;US)

Seismic design of circular-section concrete-lined underground openings-Preclosure performance considerations for the Yucca Mountain site, 93:214 (BA;US)

Selsmicity

Evaluation of the geologic relations and seismotectonic stability of the Yucca Mountain area, Nevada Nuclear Waste Site Investigation (NNWSI): Final report, January 1, 1987-June 30, 1988: Volume 1, 93:542 (R:US)

Evaluation of the geologic relations and seismotectonic stability of the Yucca Mountain Area, Nevada Nuclear Waste Site investigation (NNWS1): Volume 2, Final report, October 1988, 93:543 (R; US)

Seismicity and focal mechanisms for the southern Great Basin of Nevada and California: 1987 through 1989, $93: 379$ (R;US)

\section{Seismology}

Modeling of strongly heat-driven flow processes at a potential high-level nuclear waste repository at Yucca Mountain Nevada, $93: 57$ (R;US)

Photogeologic and kinematic analysis of lineaments at Yucca Mountain, Nevada: Implications for strike-slip faulting and oroclinal bending, 93:381 (R;US)

Structure in continuously cored, deep drill holes at Yucca Mountain. Nevada, with notes on calcite occurrence: Yucca Mountain Site Characterization Project (Yucca Mountain Project), 93:298 (R;US)

Shaft Excavations

Design considerations for the Yucca Mountain project exploratory shaft facility, 93:91 (BA;US)
G-Tunnel Welded Tuff Mining Experiment instrumentation evaluations: Yucca Mountain Site Characterization Project, 93:227 (R;US)

Proceedings of the conference on shaft drilling technology, 93:607 (B;US)

\section{Site Characterization}

A strategy for the derivation and use of sorption coefficients in performance assessment calculations for the Yucca Mountain site, 93:105 (RA;US)

An evaluation of lithium sorption isotherms and their application to ground-water transport, $93: 141$ ( $\mathrm{J} ; \mathrm{US}$ )

Classification and grading of design products for the Yucca Mountain project, $93: 95$ (J;US)

Continued development of a semianalytical solution for twophase fluid and heat flow in a porous medium, 93:41 (RA;US)

Current plans to characterize the design basis ground motion at the Yucca Mountain, Nevada, site, 93:3 (BA;US)

Demonstration of a risk-based approach to high-level waste repository evaluation, Phase 2, 93:461 (R;US)

Design and implementation of the site and engineering properties database: Yucca Mountain Site Characterzation Project, 93:242 (R;US)

Design of an intermediate-scale experiment to validate unsaturated-zone transport models, 93:285 (R;US)

Dynamic response of tunnels in jointed rocks, $93: 425$ (BA;US)

Early evaluation of the suitability of the Yucca Mountain site, 93:76 (BA;US)

Estimation of near-regional seismic ground motion from underground nuclear explosion tests, 93:423 (BA;US)

FEHMN 1.0: Finite element heat and mass transfer code: Revision 1, 93:103 (R;US)

Field research program for unsaturated flow and transport experimentation (Yucca Mountain Project), 93:280 (R;US)

Fourth report to the U.S. Congress and the U.S. Secretary of Energy from the Nuclear Waste Technical Review Board, 93:573 (R;US)

Geometric models of faulting at Yucca Mountain, 93:422 (BA;US)

Hydrogeologic issues at Yucca Mountain: Findings of a DOE peer review team, 93:513 (RA;US)

Introductory remarks for the international high-level radioactive waste conference technical session on site characterization: Approaches, concepts, concerns, 93:622 (BA;US)

JAC3D - A three-dimensional finite element computer program for the nonlinear quasi-static response of solids with the conjugate gradient method: Yucca Mountain Site Characterization Project, 93:219 (R;US)

MSTS - Multiphase Subsurface Transport Simulator theory manual, 93:64 (R;US)

Mineralogy, petrology and whole-rock chemistry data compilation for selected samples of Yucca Mountain tuffs: Yucca Mountain Site Characterization Project, 93:295 (R;US)

Modeling studies of gas movement and moisture migration at Yucca Mountain, Nevada, 93:44 (RA;US)

Movement of shaft and drift construction water in Yucca Mountain, Nevada: An extended study: Yucca Mountain Site Characterization Project, 93:266 (R;US)

Plans for characterization of the potential geologic repository site at Yucca Mountain, Nevada, $93: 99$ (J;US)

Point defects in silicates, 93:646 (1;US)

Preliminary near-field environment report: Volume 2, Scientific overview of near-field environment and phenomena, 93:199 (R;US)

Preliminary report: The Little Skull Mountain earthquake, June 29, 1992, 93:365 (BA:US)

Quantification of uncertain outcomes from site characterization: Insights from the ESF-AS, 93:300 (R;US)

REJSPEC Inc. technical support to the Repository Technology Program: Summary of activities for September 1, 1988-June 30, 1992, $93: 432$ (R;US)

Report of early site suitability evaluation of the potential repository site at Yucca Mountain, Nevada: Yucca Mountain Site Characterization Project, 93:67 (R;US) 
Report of the Peer Review Panel on the early site suitability evaluation of the Potential Repositony Site at Yucca Mountain, Nevada: Yucca Mountain Site Characterization Project, 93:68 (R;US)

Repository development and long-term data observation needs in the Yucca Mountain, Nevada site characterization program, 93:72 (BA;XN)

Review and critique of the US Department of Energy environmental program plan for site characterization for a high-level waste repository at Yucca Mountain, Nevada, 93:570 (R;US)

Second report to the U.S. Congress and the U.S. Secretary of Energy from the Nuclear Waste Technical Review Board, 93:574 (R;US)

Seismicity and focal mechanisms for the Southern Great Basin of Nevada and California in 1990, 93:376 (R;US)

Semi-analytical treatment of fracture/matrix flow in a dualporosity simulator for unsaturated fractured rock masses, 98:54 (R;US)

Site characterization progress report: Yucca Mountain, Nevada, April 1, 1991-September 30, 1991, Number 5: Nuclear Waste Policy Act (Section 113), 93:26 (R;US)

Site characterization progress report: Yucca Mountain, Nevada, April 1, 1992-September 30, 1992, Number 7, $93: 28$ (R;US)

Site characterization progress report: Yucca Mountain, Nevada, October 1, 1990-March 31, 1991: Number 4, $93: 25$ (R;US)

Site characterization progress report: Yucca Mountain, Nevada, October 1, 1992-March 31, 1993, No. 8, $93: 31$ (R;US)

Sorptivity of rocks and soils of the van Genuchten-Mualem type, 93:46 (RA;US)

Technical data base quarterly report, Aprit-June 1992: Yucca Mountain Site Characterization Project, $93: 216$ (R;US)

Tectonic characterization of a potential high-level nuclear waste repository at Yucca Mountain, Nevada, 93:364 (BA;US)

The quality assurance liaison: Combined technical and quality assurance support, $93: 130$ (R;US)

The status of Yucca Mountain site characterization activities, 93:79 (BA;US)

US Geological Survey Committee for the Advancement of Science in the Yucca Mountain Project symposium on "Fractures, Hydrology, and Yucca Mountain": Abstracts and summary, 93:375 (R;US)

Update on the Yucca Mountain Project site characterization program, 93:90 (BA;US)

$X$-ray and visible light transmission as two-dimensional, full-field moisture-sensing techniques: A preliminary comparison, 93:279 (R;US)

Yucca Mountain Site Characterization Project Plan, 93:29 (R;US)

Yucca Mountain Site Characterization Project Technical Data Catalog, $93: 23$ (R;US)

Yucca Mountain Site Characterization Project Technical Data Catalog: Yucca Mountain Site Characterization Project (Yucca Mountain Project), 93:6 (R;US)

Yucca Mountain Site Characterization Project bibliography, January-June 1991: Supplement 3, 93:20 (R;US)

Yucca Mountain Site Characterization Project bibliography, July-December 1992: An update, Supplement 3, Addendum 2: Civilian Radioactive Waste Management Program, 93:22 (R;US)

Yucca Mountain Site Characterization Project technical data catalog: Yucca Mountain Site Characterization Project 93:101 (R;US)

Yucca Mountain Site Characterization Project: Technical data catalog,(quarterly supplement), 93:32 (R;US)

Yucca Mountain Site characterization project bibliography, January-June 1991: An Update: Supplement 2, Addendum 3, 93:19 (R;US)

Yucca Mountain Site characterization project bibliography, January-June 1992: An Update: Supplement 3, Addendum 1, 93:21 (R;US)

Yucca Mountain biological resources monitoring program: Annual report FY92, $93: 36$ (R; US)

Yucca Mountain: Policy, progress and politics, 93:73 (BA;US)

\section{Site Selection}

Methodologies for selecting industries for regions and communities: A critical evaluation of the Las Vegas target industry analysis, 93:416 (R;US)

Statistical Models

The use of sequential indicator simulation to characterize geostatistical uncertainty: Yucca Mountain Site Characterization Project (Yucca Mountain Project.), 93:264 (R;US)

Stratigraphy

Recent characterization activities of Midway Valley as a potential repository surface facility site, 93:302 ( $R ;$; US)

Stress Analysis

Fault stress analysis for the Yucca Mountain site characterization project, 93:355 (BA;US)

T Codes

TOSPAC calculations in support of the COVE 2A benchmarking activity: Yucca Mountain Site Characterization Project, 93:229 (R; US)

Thermal Analysis

Thermal analysis of Yucca Mountain commercial high-level waste packages, 93:156 (R;US)

\section{Time Delay}

Nuclear waste: Quality assurance auditors need access to employee records, 93:466 (R;US)

Tomography

Teleseismic tomography of the Yucca Mountain region: Volcanism and tectonism, 93:394 (BA;US)

Topography

Photogeologic and kinematic analysis of lineaments at Yucca Mountain, Nevada: Implications for strike-slip faulting and oroclinal bending, 93:381 (R;US)

Tutf

Boron adsorption on hematite and clinoptilolite, $93: 490$ (R;US)

Field air injection tests to determine the effect of a heat cycle on the permeability of weided tuff, $93: 179$ (R;US)

Recent developments in stochastic modeling and upscaling of hydrologic properties in tuff, 93:321 (R;US)

Temperature measurements from a horizontal heater test in $G$ Tunnel, 93:178 (R; US)

Wetted-region structure in horizontal unsaturated fractures: Water entry through the surrounding porous matrix, 93:283 (R;US)

Tunneling Machines

TBM performance prediction in Yucca Mountain welded tuff from linear cutter tests, 93:352 (BA;US)

Underground Disposal

Prototype heater test of the environment around a simulated waste package, 93:162 (R;US)

Underground Facilities

Design considerations for the Yucca Mountain project exploratory shaft facility, 93:91 (BA;US)

MISTY ECHO tunnel dynamics experiment data report: Volume 2, Appendices: Yucca Mountain Site Characterization Project. 93:239 (R;US)

Nuclear waste: Questionable uses of program funds at Lawrence Livermore Lab., 93:468 (R;US)

Volcanic Regions

${ }^{40} \mathrm{Ar}{ }^{39} \mathrm{Ar}$ age of the Lathrop Wells Volcanic Center, Yucca Mountain, Nevada, 93:399 (J;US)

Geochemical evidence for waning magmatism and polycyclic volcanism at Crater Flat, Nevada, 93:140 (BA;US)

Measuring the age of the Lathrop Wells volcanic center at Yucca Mountain, 93:665 (J;US)

Volcanic Rocks

Paleohydrologic implications of the stable isotopic composition of secondary calcite within the tertiary volcanic rocks of Yucca Mountain, Nevada, 93:392 (BA;US)

Volcanism

A Monte Carlo technique to estimate the probability of volcanic dikes, 93:637 (BA;US)

Center for Volcanic and Tectonic Studies, Department of Geoscience annual report, October 1,1989-September 30,1990, 93:541 (R;US) 
Effects of magmatic processes on the potential Yucca Mountain repository: Field and computational studies, 93:135 (R;US)

Photogeologic and kinematic analysis of lineaments at Yucca Mountain, Nevada: Implications for strike-slip faulting and oroclinal bending, $93: 381$ ( $R$;US)

Simulation modeling of the probability of magmatic disruption of the potential Yucca Mountain Site, 93:136 (R;US)

Temporal and spatial distribution of basaltic volcanism in the Pancake and Reveille Ranges north of Yucca Mountain, 93:640 (BA:US)

The Lathrop Wells volcanic center: Status of field and geochronology studies, 93:137 (BA;US)

\section{Water Tables}

Ground water of Yucca Mountain: How high can it rise?: Final report, 93:511 (R;US)

Using seals to control flow at Yucca Mountain, 93:630 (BA;US)

Water Wells

Earthquake-induced water-level fluctuations at Yucca Mountain, Nevada, June 1992, 93:388 (R;US)

\section{Well Logging}

Geophysical logs and core measurements from forty boreholes at Yucca Mountain, Nevada, 93:370 (R;US)

\section{$\mathbf{Z}$}

\section{ZEOLITES}

See also CLINOPTILOLITE

HEULANDITE MORDENITE

Distribution and chemistry of fracture-lining zeolites at Yucca Mountain, Nevada (Yucca Mountain Project), 93:134 (R;US)

Equilibrium modeling of the formation of zeolites in fractures at Yucca Mountain, Nevada, 93:133 (R;US)

Modeling ion exchange in clinoptilolite using the EQ3/6 geochemical modeling code, 93:190 (R;US) 


\section{Contract Number Index}

Numbers assigned to DOE contracts announced in documents in this publication are listed. Contract numbers are sorted alphanumerically and list the primary corporate author of the document cited, the citation number, and the report number or other document identification.

Contract No.

AC01-88RW00142

AC02-76CH00016

AC02-89CH10378

AC03-76SF00098

AC04-76DP00789
Abstract No. Report No.

National Research Council, Washington, DC (United States). Panel on Coupled Hydrologic/Tectonic/Hydrothermal Systems at Yucca Mountain 93:511 NRC-98003273

USDOE Yucca Mountain Site Characterization Project Office, Las Vegas, NV (United States)

93:23 DOE/RW/00134-T2 93:101 DOE/RW/00134-T1

INTERA, Inc., Las Vegas, NV (United States)

93:102 DOE/RW/00134-T4 93:436 DOE/FTR-93015807

Brookhaven National Lab., Upton, NY (United States)

93:212 BNL-45042

RE/SPEC, Inc., Rapid City, SD (United States).

93:432 DOE/CH/10378-10

Sandia National Labs., Albuquerque, NM (United States)

93:249 SAND-89-7018

Los Alamos National Lab., NM (United States)

93:109 LA-12562-MS

Lawrence Berkeley Lab., CA (United States)

93:37

93:39

LBL-23591

$93: 40$

LBL-23593

93:47

LBL-28914

93:48

LBL-30043

93:49

LBL-30707

93:50

LBL -31069

$93: 51$

LBL-31181

93:52

LBL-31258

LBL-31666

93:53

$L B L-31799$

93:54

LBL-31975

93:55

$\mathrm{LBL}-32874$

93:56

LBL-33464

LBL-33597

93:57

LBL-33627

$93: 59$

$L B L-33660$

93:60

LBL-33661

93:61

$\angle B L-33663$

93:499

LBL-33662

Lawrence Livermore National Lab., CA (United States)

93:38 LBL-23592

93:94 Journal article

Sandia National Labs., Albuquerque, NM (United States)

93:216

93:217

93:218

93:219
Contract No.

(n)

(1)

Abstract No

93:220

93:221

$93: 222$

93:223

93:224

93:225

93:226

93:227

93:228

93:229

98:230

93:231

93:232

93:233

93:234

93:235

93:236

93:237

93:238

93:239

93:240

93:241

93:242

93:243

93:244

93:245

93:246

93:247

93:248

93:249

93:250

93:251

93:252

93:253

93:254

93:255

93:256

93:257

93:258

93:259

93:260

. 93:261

93:262

93:263

93:264

93:265

93:266

93:267

93:268

93:269

93:270

93:271

93:272

93:273

93:274

93:275

93:276

98:277
Report No.

SAND-87-2380

SAND-87-2777

SAND-87-2778

SAND-87-7075

SAND-87-7082

SAND-88-0585

SAND-88-0810

SAND-88-1331

SAND-88-1581

SAND-88-2730

SAND-88-3032

SAND-88-3164

SAND-88-7051

SAND-88-7054

SAND-88-7061

SAND-88-7065

SAND-88-7124

SAND-89-0837

SAND-89-0972/1

SAND-89-0972/2

SAND-89-1465C

SAND-89-1639

SAND-89-1871

SAND-89-1989

SAND-89-2558

SAND-89-2607

SAND-89-7002

SAND-89-7007

SAND-89-7008

SAND-89-7018

SAND-89-7023

SAND-89-7024

SAND-90-0018C

SAND-90-2261

SAND-90-2491

SAND-90-2542

SAND-90-2882

SAND-90-3165

SAND-90-7052C

SAND-90-7058

SAND-91-0155

SAND-91-0527

SAND-91-0558

SAND-91-0607

SAND-91-0758

SAND-91-0790

SAND-91-0791

SAND-91-0792

SAND-91-0894

SAND-91-1493

SAND-91-1676C

SAND-91-1730C

SAND-91-1788C

SAND-91-1891C

SAND-91-1925C

SAND-91-1926C

SAND-91-1927C

SAND-91-1958C 
Contract No.
Contract No.

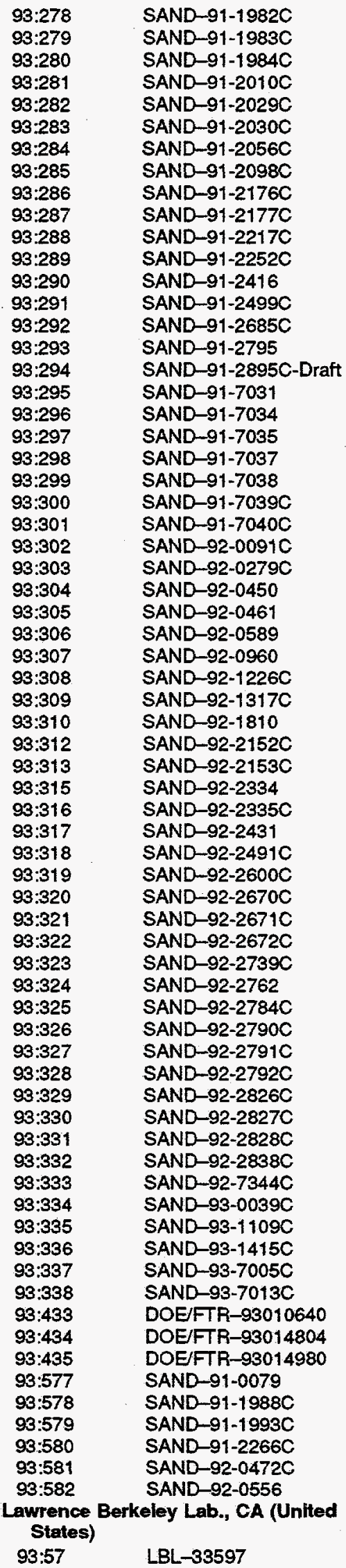

Abstract No. Report No.

Nuclear Regulatory Commission, Washington, DC (United States). Div. of Regulatory Applications

93:525 NUREG/CP-0040

AC04-94AL85000 Sendia National Labs,, Albuquerque, NM (United States)

93:311 SAND-92-1853

93:314 SAND-92-2247

AC05-760R00033 Los Alamos National Lab., NM (United States)

93:496

LA-UR-92-2577

Oak Ridge Inst. for Science and Education, TN (United States)

93:446 DOE/OR/00033-T484

93:447 DOE/OR/00033-T487

AC05-84OR21400 Oak Ridge National Lab., TN (United States)

93:57.2 ORNL/M-1822

Los Alamos National Lab., NM (United States)

93:484 LA-12325-C

AC06-76RL01830 Pacific Northwest Lab., Richland, WA (United States)

93:62

PNL-7474

93:63 PNL-8444

93:64 PNL-8636

93:65 PNL-SA-20324

93:66 PNL-SA-20329

93:151 PNL-5109-104

93:152 PNL-5109-105

93:153 PNL-7581

93:154 PNL-7847

98:155 PNL-8081

93:156 PNL-8327

93:157 PNL-SA-22264

93:576 PNL-6099

93:210 Journal article

AC07-84ID12435 Westinghouse Idaho Nuclear Co., Inc., Idaho Falls, ID (United States)

93:596 WINCO-1119

AC08-83NV10282 Sandia National Labs., Albuquerque, NM (United States)

93:216 DOE/NV/10576-T5

AC08-85NV10384 Nevada Univ., Reno, NV (United States). Desert Research Inst.

93:437 DOE/NV-354

AC08-87NV10576 Sandia National Labs., Albuquerque, NM (United States)

93:216 DOE/NV/10576-T5

Science Applications International Corp., Las Vegas, NV (United States)

93:2 CONF-920849-1

93:4 CONF-920866-7

93:7 DOE/NV/10576-T6

93:67 SAIC $-91 / 8000$

93:68 SAIC-91/8001

93:69 YMP-91-17

USDOE Yucca Mountain Site Characterization Project Office, Las Vegas, NV (United States)

93.6

DOE/NV/10576-T4

93:70 YMP-91-19

AC08-88NV10617 EG and G Energy Measurements, Inc., Las Vegas, NV (United States)

93:1

CONF-9112100-1

Vugraphs

93:34

EGG-10617-1194 
Contract No.

AC08-89NV10630

AC08-89NV10733

AC08-90NV10845

AC08-91NV10833

AC09-89SR18035

Al08-78ET44802

A108-86NV10583

A108-92NV10874
Abstract No. Report No.

EG and $G$ Energy Measurements, Inc. Goleta, CA (United States). Santa Barbara Operations

93:35 EGG-10617-2127

Reynolds Electrical and Engineering Co., Inc., Las Vegas, NV (United States)

93:100 CONF-930408-8

$93: 428$ CONF-921082-2

$93: 439$ DOE/NV/10630-28-Add. 1

$93: 440$ DOE/NV/10630-49

URS/John A. Blume and Associates, Engineers, San Francisco, CA (United States)

$93: 474$

JAB-10733-TM6

$93: 475$ JAB-10733-TM8

Nevada Univ., Reno, NV (United States). Water Resources Center

93:441 DOE/NV/10845-8

$93: 442$ DOE/NV/10845-14

$93: 443$ DOE $N$ V $/ 10845-15$

$93: 444$ DOE/NV/10845-16

Raytheon Services Nevada, Las Vegas, NV (United Stales)

93:5 CONF-930408-69

Westinghouse Savannah River Co., Alken, SC (United States)

93:597

WSRC-MS-90-351

$93: 598$ WSRC-MS-93-143

93.599 WSRC-TR-93-0111-Rev 1

Geological Survey, Denver, CO (United States)

93:372

$93: 373$

USGS-OFR-90-369

93:376

$93: 381$

$93: 382$

USGS-OFR-90-474

USGS-OFR-91-367

USGS-OFR-91-623

USGS/OFR-92-28

$93: 390$

USGSIWRIR-89-4025

Geological Survey, Menlo Park, CA (United States)

93.371

USGS-OFR-89-567A

93:374

USGS-OFR-91-105

93:380

USGS-OFR-91-620

93:385

USGS-OFR-92-343

Geological Survey, Washington, DC (United States)

93:370 USGS/MAP/GP-1001

Sandia National Labs., Albuquerque, NM (United States)

93:274 SAND-91-1925C

Lawrence Berkeley Lab.; CA (United States)

$\begin{array}{ll}93: 37 & \text { LBL-23591 } \\ 93: 53 & \text { LBL-31799 }\end{array}$

93:56 LBL 33464

Lawrence Livermore National Lab., CA (United States)

93:38 LBL-23592 Geological Survey, Carson City, NV
(United States)

93.389 USGS-OFR-93-438

Geological Survey, Carson City, NV (United States)

93:594 USGS-OFR-92-130

Geological Survey, Denver, CO (United States)

93:362

93:363

93:369

93:375

93:377

CONF-920307-89

CONF-920761-15

USGS-BULL-1991

USGS-OFR-91-125

USGS-OFR-91-478
Contract No.

Abstract No. Report No.

$93: 378$

93:379

93:381

93:383

93:384

93:386

93:387

93:388

USGS-OFR-91-493

USGS-OFR-91-572

USGS-OFR-91-623

USGS-OFR-92-137

USGS-OFR-92-340

USGS-OFR-92-490

USGS-OFR-92-572

USGS-OFR-93-73

Geological Survey, Lakewood, CO (United States). Water Resources Div. 93:361 CONF-8904440-1

Geological Survey, Carson Clty, NV (United States)

93:389 USGS-OFR-93-438

FC01-87CH10324

Southern States Energy Board, Norcross, GA (United States)

93:431 DOE/CH/10324-T20

FC08-90NV10872

Nevada Univ., Las Vegas, NV (United States)

93:12

93:17

93:429

DOE/NV/10872-T10

93:430

DOE/NV/10872-T84

CONF-930496-1

Nevada Univ., Las Vegas, NV (United States). Environmental Research Cen ter

93:9

93:10

DOE/NV/10872-T2

93:11

DOENV/10872-T3

Nevada Univ., Las Vegas, NV (United States). Harry Reid Conter for Environmental Studies

93:8

$93: 13$

93:14

93:15

93:16

DOE/NV/10872-8

DOE/NV/10872-T12

DOE/NV/10872-T13

DOE/NV/10872-T68

DOE/NV/10872-T69

Nevada Univ., Las Vegas, NV (United States). Dept. of Civil and Environmental Engineering

93:445 DOE/NV/10872-T57

FC08-90NV10891

Lawrence Livermore National Lab., CA (United States)

93:196 UCRL-JC-112825

FG05-84OR21497

FG05-85OR21555$$
\begin{aligned}
& \text { South Carolina State Col } \\
& \text { SC (United States) }
\end{aligned}
$$

93:18 DOE/OR/21497-1

Tennessee Safe Growth Team, Nashville, TN (United States)

93:448 DOE/OR/21555-T2

FG08-85NV10461

Nevada Univ., Reno, NV (United States)

93:438 DOE/NV/10461-T41

Nevada Nuclear Weste Project Office, Carson City, NV (United States)

93:538 NWPO-GR-1

$93: 539$

93:540

NWPOGR-15

93:541

93:542

NWPO-GR-16

NWPO-GR-20

NWPO-GR-24-Vol.1

NWPO-SE-026-90

93:545 NWPO-SE-036-87

93:546 NWPO-SE-037-91

93:547 NWPO-SE-038-91

93.548

NWPO-SE-038-91

$93: 549$

93:550

NWPO-S

93:551

93:552

93:553

93:554
NWPO-SE- 041-91

NWPO-SE-042-91

NWPO-SE-043-91

NWPO-SE-044-91 
Contract No.

W-31109-ENG-38

W-7405-ENG-36
93:555

$93: 556$

$93: 557$

93:558

98:559

93:560

93:561

93:562

$93: 563$

93:564

93:565

93:566

$93: 567$

93:568

$93: 569$

93:570

Nevada Univ., Reno, NV (United States).

Center for Neotectonic Studies

93:543 NWPO-GR-24-Vol.2

Lehman (L.) and Associates, Inc., Burnsville, MN (United States)

93:571 NWPO-TR-020-93

Argonne National Lab., IL (United States)

93:143 ANL-91/36

93:144 ANLCP-72981

93:145 ANL/CP-75242

93:146 ANL/MCT/CP-75243

98:401 ANL-91/42

93:402 ANL-92-9

93:403 ANL-92/28

93:404 ANL-92/44

98:405 ANL-93/13

93:406 ANLCMT/CP-76238

93:407 ANL/CMT/CP-76240

93:408 ANLCMT/CP-79779

93:409 ANLCP-74094

93:410 ANL/CP-75280

93:411 ANL/CP-76140

93:412 ANLCP-76305

93:413 ANLEAIS/CP-78642

Argonne National Lab., IL (United

States). Environmental Assessment and information Sciences Div.
93:414
$93: 415$
93:416
$93: 417$
93:418
ANLEAIS/TM-41
ANLEAIS/TM-85
ANLEAIS/TM-87
ANLEAIS $/ T M-92$
ANL/EAIS/TM-93

Los Alamos National Lab., NM (United States)

93:103

93:104

93:107

93:108

93:109

93:110

93:111

93:112

93:113

93:114

93:115

93:116

93:117

93:118

93:119

93:120

93:121

93:122

93:123

98:124

93:125
LA-12062-MS-Rev.1

LA-12325-C

LA-12376-MS

LA-12542-MS

LA-12562-MS

LA-12564-MS

LA-12708-MS

LA-SUB-93-51

LA-SUB-93-217

LA-UR-91-3236

LA-UR-91-3747

LA-UR-91-4035

LA-UR-91-4041

LA-UR-92-26

LA-UR-92-329

LA-UR-92-377

LA-UR-92-461

LA-UR-92-534

LA-UR-92-537

LA-UR-92-1194

LA-UR-92-3549
Contract No.

Abstract No. Report No.

93:126

93:127

93:128

$93: 129$

93:130

93:131

$93: 132$

$93: 133$

$93: 134$

93:135

$93: 136$

$93: 478$

$93: 488$

$93: 490$

$93: 491$

$93: 492$

$93: 493$

$93: 494$

93:495

W.7405-ENG-48

Argonne National Lab., IL (United States) 93:144 ANLCP-72981

Babcock and Wilcox Co., Alliance, $\mathrm{OH}$ (United States). Contract Research Div.

93:591 UCRL-CR-106983

Sandia National Labs a Albuquerque, NM (United States)

93:216 DOE/NV/10576-T5

Los Alamos National Lab., NM (United States)

93:479 LA-12325-C

Lawrence Berkeley Lab., CA (United States)

93:51 LBL-31258

Lawrence Livermore National Lab., CA (United States)

93:147

$93: 148$

93:150

93:159

93:160

93:161

93:162

93:163

93:164

93:165

93:166

$93: 167$

93:168

93:169

93:170

93:171

93:172

$93: 173$

$93: 174$

93:175

93:176

93:177

$93: 178$

$93: 179$

93:180

93:181

93:182

93:183

93:184

$93: 185$

93:186

93:187

$98: 188$

93:189

93:190 ESTSC-000324SUN0001 LLNL-94001185 UCID-21414-Rev.1 UCID-21756

UCID-21863

UCRL-101698

UCRL-ID-105340

UCRL-ID-107289

UCRL-ID-108153

UCRL-ID-108330

UCRL-ID-109215

UCRL-ID-109921

UCRL-ID-111624

UCRL-ID-111979

UCRL-ID-112036

UCRL-ID-112058

UCRL-ID-112432

UCRL-ID-112433

UCRL-ID-112834

UCRL-ID-1 13383

UCRL-ID-114148

UCRL-JC-106698

UCRL-JC-106703

UCRL-JC-106752

UCRL-JC-106758

UCRL-JC-106759

UCRL-JC-106916

UCRL-JC-106918

UCRL-JC-107920

UCRL-JC-107985

UCRL-JC-109216

UCRL-JC-109231

UCRL-JC-109232

UCRL-JC-109952
ESTSC-000324SUNOO0O 
Contract No.

Abstract No. Report No.

93:191

93:192

93:193

93:194

93:195

93:196

93:197

93:198

93:199

93:200

93:201

93:202

93:203

93:592

93:593

93:653

\author{
UCRL-JC-110677 \\ UCRL-JC-111652 \\ UCRL-JC-112435 \\ UCRL-JC-112444 \\ UCRL-JC-112445 \\ UCRL-JC-112825 \\ UCRL-JC-114783 \\ UCRL-LR-107476-Vol.1 \\ UCRL-LR-107476-Vol.2 \\ UCRL-MA-1 10662-Pt.1 \\ UCRL-MA-110662-Pt.2 \\ UCRL-MA-110662-Pt.3 \\ UCRL-MA-1 10662-Pt.4 \\ UCRL-ID-112789 \\ UCRL-JC-109623 \\ Journal article
}




\section{Report Number Index}

The report number index consists of the alphanumeric identifiers assigned to report literature as well as patent and conference literature cited in this publication. Entries provide the abstract number; the source(s) of availability of the document; the GPO file prefix for GPO depository library documents; the order number for OSTI and NTIS report ordering purposes; and, if the document was distributed under the DOE distribution program, the category number is shown for paper copy (PC), microfiche (MF), or no distribution (ND). These categories are included to assist DOE librarians in responding to requests for reports in their collections. The index also lists secondary numbers, with the corresponding abstract numbers and cross-references to other identifying numbers.

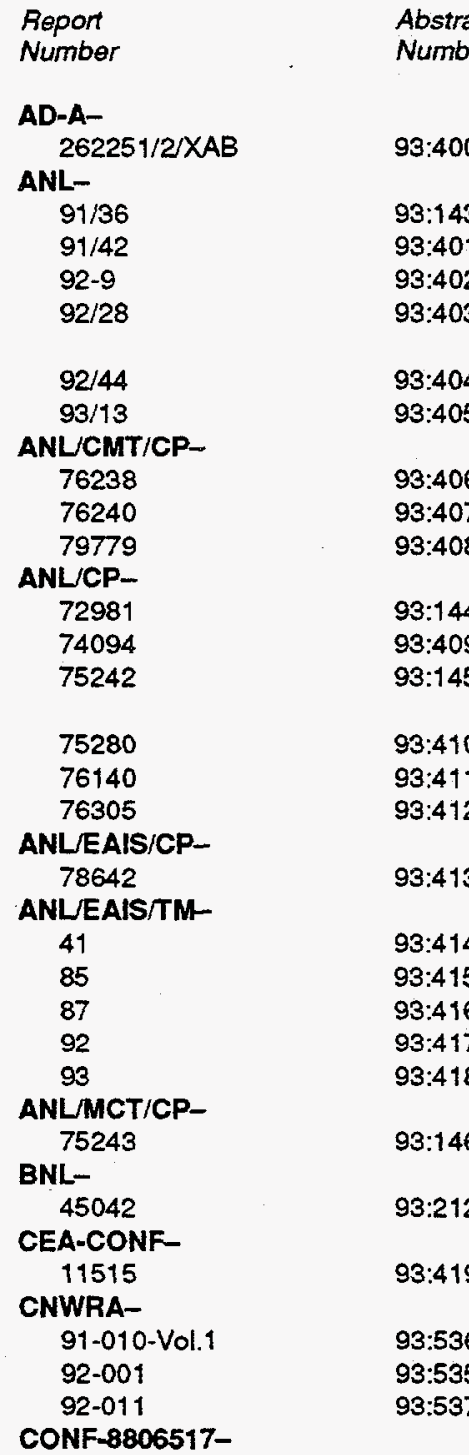

\section{3:98}

$93: 679$

$93: 680$

93:683

CONF-8904440-
Source of

Availability

NTIS Prices: PC A03/MF A01

OST; NTIS; INIS; GPO Dep.

OSTI; NTIS; INIS; GPO Dep.

OSTI; NTIS; INIS; GPO Dep.

OSTI; NTIS; INIS; GPO Dep.

OSTI; NTIS; GPO Dep.

OSTI; NTIS; INIS; GPO Dep.

OSTI; NTIS; INIS; GPO Dep.

OSTI; NTIS; INIS; GPO Dep.

OSTI; NTIS; INIS; GPO Dep.

OSTI; NTIS; INIS; GPO Dep.

OSTI; NTIS; INIS; GPO Dep.

OSTI; NTIS; INIS; GPO Dep.

OSTI; NTIS; INIS; GPO Dep.

OSTI; NTIS; INIS; GPO Dep.

OSTI; NTIS; INIS; GPO Dep.

OSTI; NTIS; INIS; GPO Dep.

OSTI; NTIS; GPO Dep.

OSTI; NTIS; INIS; GPO Dep.

OSTI; NTIS; GPO Dep.

OSTI; NTIS; INIS; GPO Dep.

OSTI; NTIS; INIS; GPO Dep.

OSTI; NTIS; INIS; GPO Dep.

OSTI; NTIS; INIS; GPO Dep.

OSTI; NTIS (US Sales Only); INIS

See NUREG/CR-5917-Vol.1

See NUREG/CR-5890

See NUREG/CR-6021

(Nuclear waste management 1988: perspectives on national and international programs and technology; San Diego, CA (United States); 12-16 Jun 1988)

(F.D. Holland, Jr. North Dakota geological survey symposium; Grand Forks, ND (United States); 14-15 Apr 1989)

OSTI; NTIS; INIS; GPO Dep.

$\begin{array}{lll}\text { E 1.99: } & \text { DE92007578 } & \text { MF-814 } \\ \text { E 1.99: } & \text { DE92013641 } & \text { PC-500 } \\ \text { E 1.99: } & \text { DE92011753 } & \text { MF-814 } \\ \text { E 1.99: } & \text { DE92019239 } & \text { PC-504; } \\ \text { E 1.99: } & \text { DE93007744 } & \text { PC-510 } \\ \text { E 1.99: } & \text { DE93018116 } & \text { MF-814 } \\ \text { E 1.99: } & \text { DE93006405 } & \text { MF-802 } \\ \text { E 1.99: } & \text { DE93006419 } & \text { MF-902 } \\ \text { E 1.99: } & \text { DE94001458 } & \text { MF-814 } \\ & & \\ \text { E 1.99: } & \text { DE92004722 } & \text { MF-810 } \\ \text { E 1.99: } & \text { DE92010900 } & \text { MF-800 } \\ \text { E 1.99: } & \text { DE92007369 } & \text { MF-504; } \\ & & \text { MF-510 } \\ \text { E 1.99: } & \text { DE92016737 } & \text { MF-800 } \\ \text { E 1.99: } & \text { DE92015186 } & \text { MF-403 } \\ \text { E 1.99: } & \text { DE92016399 } & \text { MF-810 } \\ & & \\ \text { E 1.99: } & \text { DE93009953 } & \text { MF-802 } \\ \text { E 1.99: } & \text { DE92009745 } & \text { MF-802 } \\ \text { E 1.99: } & \text { DE93011790 } & \text { MF-802 } \\ \text { E 1.99: } & \text { DE93009908 } & \text { MF-802 } \\ \text { E 1.99: } & \text { DE93011910 } & \text { MF-802 } \\ \text { E 1.99: } & \text { DE93012873 } & \text { MF-802 } \\ \text { E 1.99: } & \text { DE93008648 } & \text { MF-504 } \\ \text { E 1.99: } & \text { DE92007610 } & \text { MF-814 }\end{array}$

$\begin{array}{ll}\text { GPO } & \text { Order } \\ \text { Dep. } & \text { Number }\end{array}$

Distribution

Category

DE94603017 


\section{Revort}

Number

CONF-9004171-

4

CONF-900565-

98:607

CONF-900646-

12

CONF-900832-

CONF-9009454

1

CONF-9009542-

Absts.

CONF-9010497-

1

CONF-910403-

CONF-9104106-

CONF.910430-

26

CONF-910435-

92

CONF-910603-

CONF-910774-

CONF-9109114

10

CONF-9109344-

$93: 258$

$93: 375$

$93: 677$

93:99

93:597

93:684

$93: 685$
Abstract Source of

Number Availability

(International conference on mechanics of jointed and faulted rocks; Vienna (Austria); 18-20 Apr 1990)

See SAND-89-1465C

(Conference on shaft drilling technology; Las Vegas, NV (United States); 2-4 May 1990)

Institute of Shaft Drilling Technology, 6175 Ponderosa, Paker, CO (United States)

(31. US symposium on rock mechanics; Golden, CO (United States); 18-20 Jun 1990)

See SAND-90-0018C

(International conference on water resources in mountainous regions and the 22 nd congress of the International Association of Hydrogeologists; Lausanne (Switzerland); 27 Aug - 1 sep 1990)

See SAND-90-7052C

(DOENucca Mountain site characterization project radionuclide adsorption workshop; Los Alamos, NM (United States); 11-12 Sep 1990)

93:104 See LA-12325-C

(Sorption workshop; Los Alamos, NM (United States); 23 Sep 1990)

See LA-UR-91-3747

(US Geological Survey Committee for the advancement of science conference on fractures, hydrology, and Yucca Mountain; Denver, CO (United States); 13-14 Sep 1990)

See USGS-OFR-91-125

(Technical workshop on near field performance assessment for high-level waste; Madrid (Spain); 15-17 Oct 1990)

See LBL-31181

(Annual meeting of the American Association of Petroleum Geologists (AAPG); Dallas, TX (United States); 7-10 Apr 1991)

(53. annual American power conference; Chicago, IL (United States); 29 Apr - 1 may 1991)

(93. annual meeting and exposition of the American Ceramic Society (ACerS); Cincinnati, $\mathrm{OH}$ (United States); 28 Apr - 2 may 1991)

See WSRC-MS-90-351

(2. annual American Nuclear Society (ANS) international high level radioactive waste management conference; Las Vegas, NV (United Stafes); 28 Apr - 3 may 1991)

See SAND-91-1988C

(Annual meeting of the American Nuclear Society (ANS); Orlando, FL (United States); 2-6 Jun 1991)

32. Institute of Nuclear Materials Management (INMM) annual meeting; New Orleans, LA (United States); 28-31 Jul 1991)

(6. symposium on containment of underground nuclear explosions; Reno, NV (United States); 24-26 Sep 1991)

See UCRL-JC-106918

(Sorption workshop; Los Alamos, NM (United States); 18-22 Sep 1991)

Soe LA-UR-92-26
GPO Order Distribution

Dep. Number Category 


\section{Report}

Number

CONF-910945-

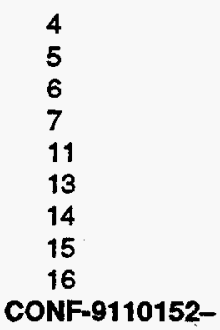

CONF-911017-

CONF-9110263-

1

CONF-911109

4
5

CONF-9111329-

CONF-911202-

10

CONF-9112100-

1-Vugraphs

CONF-920256-

2

CONF-920260-

$$
3
$$

CONF-920307-

67

89

CONF-920430-

1
5
6
8
9
10
103
12
13
15

Abstract

Number

93:183

93:182

93:144

93:145

93:180

93:179

93:178

93:181

93:186

93:97

93:670

93:650

93:114

93:185

93:116

$93: 419$

$93: 292$

$93: 1$

$93: 65$

93:580

93:302

93:362

93:579

93:278

93:300

93:282

93:273

$93: 117$

93:52

93:289

93:272

$93: 281$
Source of

Availability

(Focus '91: nuclear waste packaging; Las Vegas, NV (United States); 29 Sep - 4 oct 1991)

See UCRL-JC-106916

See UCRL-JC-106759

See ANLCP-72981

See ANLCP-75242

See UCRL-JC-106752

See UCRL-JC-106703

See UCRL-JC-106698

See UCRL-JC-106758

See UCRL-JC-107985

(3. international conference on chemistry and migration behaviour of actinides and fission products in the geosphere (MIGRATION-3); Jerez de la Frontera (Spain); 21-25 Oct 1991)

(Annual meeting and exhibition of the Geological Society of America (GSA); San Diego, CA (United States); 21-23 Oct 1991)

(Nuclear Energy Agency (NEA) sorption workshop; Interlacken (Switzerland); 21 Oct 1991)

See LA-UR-91-3236

(Fall meeting of the European Materials Research Society (EMRS); Strasbourg (France); 5-8 Nov 1991)

See UCRL-JC-107920

See LA-UR-91-4035

(SFEN meeting on Oklo phenomenon; Paris (France); 28 Nov 1991)

See CEA-CONF-11515

(Annual fall meeting of the Materials Research Society (MRS); Boston, MA (United States); 2-6 Dec 1991)

See SAND-91-2685C

(GENISES: A geographic information system (GIS) database for the Yucca Mountain Site characterization project; Las Vegas, NV (United States); 16 Dec 1991)

OSTI; NTIS; INIS; GPO Dep.

(National Water Wells Association (NWWA) meeting on solving ground water problems with models; Dallas, TX (United States); 1113 Feb 1992)

See PNL-SA-20324

(American Association for the Advancement of Science (AAAS) annual meeting; Chicago, IL (United States); 7-11 Feb 1992)

See SAND-91-2266C

(Waste management ' 92 ; Tucson, $A Z$ (United States); 1-5 Mar 1992)

See SAND-92-0091C

OSTI; NTIS; INIS; GPO Dep.

(3. international high level radioactive waste management (IHLRWM) conference; Las Vegas, NV (United States); 12-16 Apr 1992)

See SAND-91-1993C

Se日 SAND-91-1982C

See SAND-91-7039C

See SAND-91-2029C

See SAND-91-1891C

See LA-UR-91-4041

See LBL-31666

See SAND-91-2252C

See SAND-91-1788C

Se SAND-91-2010C
GPO

Dep.

Order

Number

Distribution

Category
E 1.99: DE92007905 MF-814

E 1.99: DE92040807

MF-814 


$\begin{array}{ll}\begin{array}{l}\text { Report } \\ \text { Number }\end{array} & \begin{array}{l}\text { Abstract } \\ \text { Number }\end{array} \\ 16 & 93: 285 \\ 19 & 93: 280 \\ 20 \text {-Draft } & 93: 284 \\ 30 & 93: 274 \\ 34 \text {-Draft } & 93: 277 \\ 35 & 93: 291 \\ 36 & 93: 287 \\ 37 & 93: 286 \\ 38 & 93: 288 \\ 40 & 93: 276 \\ 43 & 93: 279 \\ 50 & 93: 34 \\ 51 & 93: 212 \\ 52 & 93: 119 \\ 60 & 93: 189 \\ 64 & 93: 120 \\ 65 & 93: 122 \\ 67 & 93: 188 \\ 68 & 93: 51 \\ 69 & 93: 53 \\ 7-\text { Draft } & 93: 301 \\ 72 & 93: 409 \\ 95 & 93: 187 \\ 98 & 93: 54 \\ \text { CONF-920464- } & \\ & \end{array}$

4

CONF-9205157-

4

CONF-920606-

31

CONF-920633-

1

${ }^{3}$

3

10

CONF-9207102-

40

CONF-920761-

1
2
13
14
15
ONF-9208101-

1

CONF-920849-

$93: 412$

$93: 308$

93:271

93:270

$93: 275$

93:593
Source of

Availability

See SAND-91-2098C

See SAND-91-1984C

See SAND-91-2056C

See SAND-91-1925C

See SAND-91-1958C

See SAND-91-2499C

See SAND-91-2177C

Soe SAND-91-2176C

See SAND-91-2217C

See SAND-91-1927C

See SAND-91-1983C

See EGG-10617-1194

See BNL-45042

See LA-UR-92-329

See UCRL-JC-109232

See LA-UR-92-377

See LA-UR-92-534

See UCRL-JC-109231

See LBL-31258

See LBL-31799

See SAND-91-7040C

See ANLCP-74094

See UCRL-JC-109216

See LBL-31975

(23. annual Pittsburgh conference on modeling and simulation; Pittsburgh, PA (United

States); 30 Apr - 1 may 1992)

See ANLCP-76305

(4. world conference on neutron radiography; San Francisco, CA (United States); $11-14$ May 1992)

93:411 See ANLCP-76140

(American Nuclear Society annual meeting; Boston, MA (United States); 7-12 Jun 1992)

Soe SAND-92-1226C

(International Society for Rock Mechanics fractured and jointed rock masses conference;

Lake Tahoe, CA (United States); 3-5 Jun 1992)

Soe SAND-91-1730C

See SAND-91-1676C

(33. US symposium on rock mechanics; Santa Fe, NM (United States); 3-10 Jun 1992)

See SAND-91-1926C

See UCRL-JC-109623

(Institute of Nuclear Materials Management (INMM) annual meeting; Oriando, FL (United States); 19-22 Jul 1992)

See SAND-92-0472C

(7. water-rock interaction conference; Park City, UT (United States); 9-23 Jul 1992)

See LA-UR-92-461

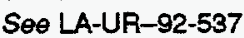

See LA-UR-92-1194

See UCRL-JC-109952

OSTI; NTIS; INIS; GPO Dep.

(International high-level radioactive waste management conference; Las Vegas, NV (United States); 12-16 Aug 1992)

Seo ANL/CP-75280

(16. annual Nuclear Information and Records Management Association symposium: shared information - golden gateway to progress; San Francisco, CA (United States); 30 Aug - 2 sep 1992)

OSTI; NTIS; INIS; GPO Dep.
GPO Order

Dep. Number

Distribution

Category 
Report

Number

CONF-920866-

CONF-921082-

CONF-921101-

CONF-921119

3

CONF-9211191-

CONF-921162-

2-Draft

CONF-9302149

CONF-930408-

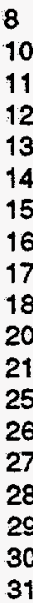

Abstract

Number

93:303

93:309

93:4

$93: 668$

93:125

93:316

$93: 66$

93:406

$93: 407$

$93: 669$

$98: 146$

$93: 126$

98:294

93:654

93:100

93:313

93:331

93:322

93:329

93:330

93:338

93:319

93:326

93:127

93:128

93:129

93:192

93:195

93:325

93:327

93:323

93:334

93:332
Source of

Availability

(American Society of Civil Engineers (ASCE) symposium on dynamic analysis and design considerations, for high-level nuclear waste repositories; San Francisco, CA (United States); 19-20 Aug 1992)

American Society of Civil Engineers, 345 East 47th Street, New York, NY 10017-2398 (US)

See SAND-92-0279C

See SAND-92-1317C

OSTI; NTIS; INIS; GPO Dep.

(1992 annual meeting of the Geological Society of America (GSA); Cincinnati, OH (United States); 26-29 Oct 1992)

(American Institute of Hydrology; Portland, OR (United States); 17-22 Oct 1992)

OSTI; NTIS; INIS; GPO Dep.

(16. Materials Research Society (MRS) fall meeting; Boston, MA (United States); 30 Nov - 5 dec 1992)

See LA-UR-92-3549

See SAND-92-2335C

See PNL-SA-20329

See ANL/CMT/CP-76238

See ANL/CMT/CP-76240

(Joint American Nuclear Society/European Nuclear Society (ANS/ENS) international meeting on fifty years of controlled nuclear chain reaction: past, present, and future; Chicago, IL (United States); 15-20 Nov 1992)

(American Society for Testing and Materials (ASTM) symposium on application of accelerated corrosion tests to life prediction of materials; Miami, FL' (United States); 16-17 Nov 1992)

See ANL/MCT/CP-75243

(Materials Research Society meeting; Austin, TX (United States); 30 Nov 1992)

See LA-UR-93-0071

(Hypenelocity impact symposium; Austin, TX (United States); 17-20 Nov 1992)

Soe SAND-91-2895C-Draft

(Outlook' 93: national agricultural and resource outlook conference; Canberra (Australia); $2-4$ Feb 1993)

(International high-level radioactive waste management conference; Las Vegas, NV (United States); 25-29 Apr 1993)

OSTI; NTIS; INIS; GPO Dep.

See SAND-92-2153C

See SAND-92-2828C

See SAND-92-2672C

See SAND-92-2826C

See SAND-92-2827C

See SAND-93-7013C

See SAND-92-2600C

See SAND-92-2790C

See LA-UR-93-270

See LA-UR-93-436

See LA-UR-93-437

See UCRL-JC-111652

See UCRL-JC-112445

See SAND-92-2784C

See SAND-92-2791C

See SAND-92-2739C

See SAND-93-0039C

See SAND-92-2838C
GPO Order

Dep. Number

Distribution Category

E 1.99: DE93013508

MF-814

E 1.99: DE92013506

MF-702
E 1.99: DE93005704 MF-814 
Report
Number

\begin{tabular}{l}
37 \\
38 \\
39 \\
40 \\
44 \\
48 \\
49 \\
50 \\
51 \\
52 \\
53 \\
54 \\
59 \\
61 \\
62 \\
65 \\
69 \\
70 \\
\hline 0
\end{tabular}

CONF-9304190

\section{1}

CONF-930496-

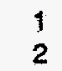

2

CONF-930601-

$\stackrel{6}{\text { CONF-9306100 }}$

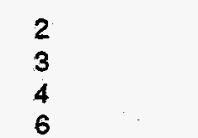

CONF-9306114-

1

CONF-930644-

6

CONF-9309228-

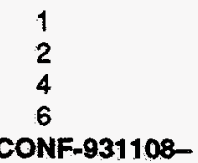

3

CONF-931160-

8

DOE/CH/10324 T2O

DOE/CH/1037810

DOE/FTR-

93010640

93014804

93014980 $\begin{array}{ll}\text { Abstract } & \text { Source of } \\ \text { Number } & \text { Availability }\end{array}$

93:321 S See SAND-92-2671C

$93: 318$

93:337

$93: 333$

98:328

93:61

98:59

93:56

93:499

93:60

93:55

93:413

93:57

93:58

93:598

93:320

93:5

93:157

$93: 430$

93:429

93:196

93:194

93:95

93:191

$93: 132$

93:131

93:133

$93: 134$

$93: 130$

93:312

93:335

93:135

93:197

93:136

$93: 408$

93:336

$93: 431$

93:432

93:433

$93: 434$

93:435

Soe SAND-92-2491C

S $\theta$ SAND-93-7005C

Soe SAND-92-2792C

Se0 LBL-33663

See LBL-33660

See LBL-33464

See LBL-33662

See LBL-33661

See LBL-32874

See LBL-33597

See LBL-33627

See SAND-92-2670C

See PNL-SA-22264 Apr 1993) Jun 1993) Jun 1993)

See LA-UR-93-2326

See LA-UR-93-2254

See LA-UR-93-2761

See LA-UR-93-2882

See LA-UR-93-690

See SAND-92-2152C Sep 1993)

See SAND-93-1109C

See LA-UR-93-3299

See LA-UR-93-3505 3 dec 1993) 14-18 Nov 1993)
See SAND-92-7344C

See ANL/EAIS/CP-78642

See WSRC-MS-93-143

OSTI; NTIS; INIS; GPO Dep.

(Western Social Science Association meeting Corpus Christi, TX (United States); 20-24

OSTI; NTIS; INIS; GPO Dep.

(High-level radioactive waste management; Las Vegas, NV (United States); 25-29 Apr 1993)

OSTI; NTIS; INIS; GPO Dep.

See UCRL-JC-112825

See UCRL-JC-112444

(American Nuclear Society (ANS) annual meeting; San Diego, CA (United States); 20-24

See UCRL-JC-110677

(Zeolite 93: 4th international conference on the occurrence, properties, and utilization of natural zeolites; Boise, ID (United States); 20-28

(17. annual Rocky Mountain quality conference; Denver, CO (United States); 6-8 Jun 1993)

(34. US symposium on rock mechanics; Madison, WI (United States); 27-30 Jun 1993)

(Focus 93: site characterization and model validation; Las Vegas, NV (United States); 26-29

See UCRL-JC-114783

(Fall meeting of the Materials Research Society (MRS); Boston, MA (United States); 29 Nov -

Soe ANLCMT/CP-79779

(American Nuclear Society (ANS) winter meeting; San Francisco, CA (United States);

See SAND-93-1415C

OSTI; NTIS; INIS; GPO DeP.

E 1.99: DE93016317 MF-820

OSTI; NTIS; INIS; GPO Dep.

E 1.99: DE93006069 MF-810

OSTI; NTIS (US Sales Only); GPO Dep.

OSTI; NTIS (US Sales Only); GPO Dep.

OSTI; NTIS (US Sales Only); GPO Dep.
GPO Order

Dep. Number

Distribution

Category

E 1.99: DE93012990 MF-814

E 1.99: DE93019282 MF-814

E 1.99: DE93008149 MF-814

$\begin{array}{lll}\text { E 1.99: } & \text { DE93010640 } & \text { MF-814 } \\ \text { E 1.99: } & \text { DE93014804 } & \text { MF-902 } \\ \text { E 1.99: } & \text { DE } 93014980 & \text { MF-721 }\end{array}$




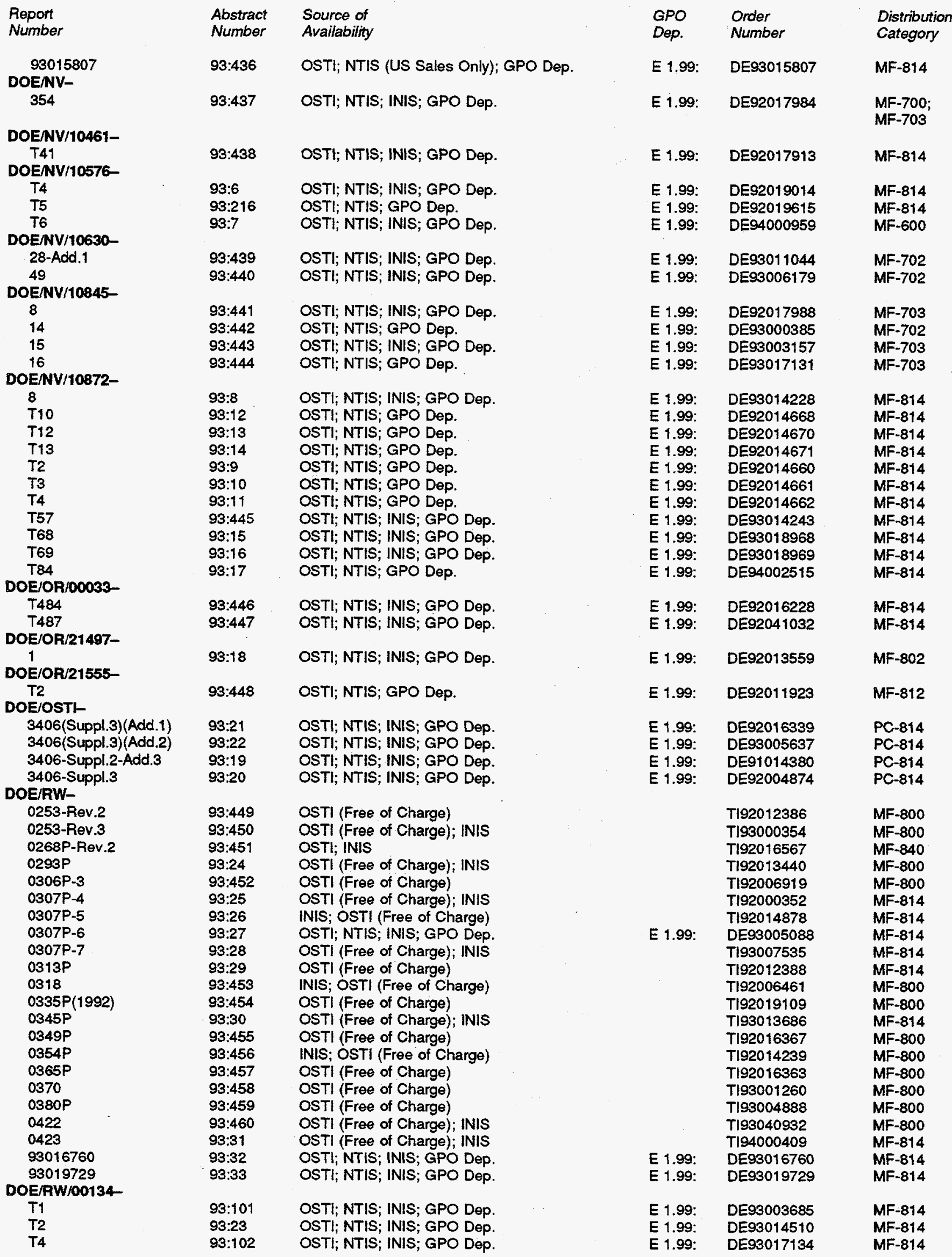




\begin{tabular}{|c|c|c|c|c|c|}
\hline $\begin{array}{l}\text { Report. } \\
\text { Number }\end{array}$ & $\begin{array}{l}\text { Abstract } \\
\text { Number }\end{array}$ & $\begin{array}{l}\text { Source of } \\
\text { Availability }\end{array}$ & $\begin{array}{l}\text { GPO } \\
\text { Dep. }\end{array}$ & $\begin{array}{l}\text { Order } \\
\text { Number }\end{array}$ & $\begin{array}{l}\text { Distribution } \\
\text { Category }\end{array}$ \\
\hline \multicolumn{6}{|l|}{ EGG- } \\
\hline $10617-1194$ & $93: 34$ & OSTI; NTIS; INIS; GPO DeP. & E 1.99: & DE 92007623 & MF-814 \\
\hline $10617-2127$ & $93: 35$ & OSTI; NTIS; INIS; GPO Dep. & E 1.99: & DE92011449 & MF-814 \\
\hline $10617-2195$ & 93:36 & OSTI; NTIS; INIS; GPO Dep. & E 1.99: & DE93018485 & MF-814 \\
\hline \multicolumn{6}{|l|}{ EPRI-TR- } \\
\hline 100384 & $93: 461$ & $\begin{array}{l}\text { EPRI Distribution Center, } 207 \text { Coggins Drive, } \\
\text { PO Box } 23205 \text {, Pleasant Hill, CA } 94523\end{array}$ & & & \\
\hline \multicolumn{6}{|c|}{ 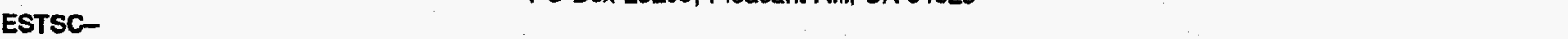 } \\
\hline 000324 SUNO000 & $93: 147$ & ESTSC; Lawrence Livermore National Lab & & & \\
\hline $000324 S U N 0001$ & $93: 148$ & ESTSC; Lawrence Livermore National Lab & & & \\
\hline \multicolumn{6}{|l|}{ GAORCED- } \\
\hline 91-07 & $93: 466$ & $\begin{array}{l}\text { US General Accounting Office, P.O. Box 6015, } \\
\text { Gaithersburg, MD } 20877 \text { (United States) }\end{array}$ & & & \\
\hline $91-55$ & $93: 467$ & $\begin{array}{l}\text { US General Accounting Office, P.O. Box 6015, } \\
\text { Gaithersburg, MD } 20877 \text { (United States) }\end{array}$ & & & \\
\hline $92-157$ & $93: 468$ & $\begin{array}{l}\text { US General Accounting Office, P.O. Box 6015, } \\
\text { Gaithersburg, MD } 20877 \text { (United States) }\end{array}$ & & & \\
\hline \multicolumn{6}{|l|}{ GAO/T-RCED- } \\
\hline $91-37$ & $93: 469$ & $\begin{array}{l}\text { US General Accounting Office, P.O. Box 6015, } \\
\text { Gaithersburg, MD } 20877 \text { (United States) }\end{array}$ & & & \\
\hline \multicolumn{6}{|l|}{ INIS-XN- } \\
\hline 393 & $93: 470$ & OSTI; NTIS (US Sales Only); INIS & & DE93609565 & \\
\hline 415 & $93: 471$ & OSTI; NTIS (US Sales Only); INIS & & DE 93609566 & \\
\hline 418 & $93: 472$ & OSTI; NTIS (US Sales Only); INIS & & DE93609569 & \\
\hline 428 & 93:473 & OSTI; NTIS (US Sales Only); INIS & & DE 93618121 & \\
\hline \multicolumn{6}{|c|}{ 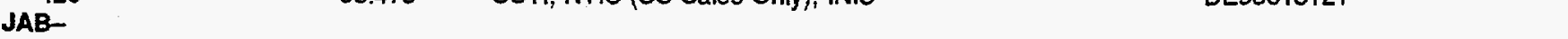 } \\
\hline 10733-TM6 & $93: 474$ & OSTI; NTIS; GPO Dep. & E 1.99: & DE93005849 & MF-703 \\
\hline $\begin{array}{l}\text { 10733-TM8 } \\
\text { JAERLM- }\end{array}$ & $93: 475$ & OSTI; NTIS; GPO Dep. & E 1.99: & DE 93018073 & MF-703 \\
\hline $91-118$ & $93: 476$ & & & & \\
\hline $93-023$ & $\begin{array}{l}93: 4 / 6 \\
93: 477\end{array}$ & $\begin{array}{l}\text { OSTI; NTIS (US Sales Only); INIS } \\
\text { OSTI: NTIS: INIS }\end{array}$ & & DE92750952 & \\
\hline \multicolumn{6}{|c|}{ Uoli, , } \\
\hline 12062-MS-Rev. 1 & $93: 103$ & OSTI; NTIS; INIS; GPO Dep. & E 1.99: & DE92013998 & MF-810 \\
\hline $12301-M S$ & $93: 478$ & OSTI; NTIS; INIS; GPO DeP. & E 1.99: & DE92011870 & MF-940 \\
\hline $12325-\mathrm{C}$ & 93:104 & OSTI; NTIS; INIS; GPO Dep. & E 1.99: & DE 92041241 & MF-510 \\
\hline 12376-MS & 93:107 & OSTI; NTIS; INIS; GPO Dep. & E 1.99: & DE93006097 & MF-814 \\
\hline $12460-M S$ & $93: 488$ & OSTI; NTIS; GPO Dep. & E 1.99: & DE 93011473 & MF-903 \\
\hline $12542-M S$ & $93: 108$ & OSTI; NTIS; INIS; GPO Dep. & E 1.99: & DE 94000698 & MF-814 \\
\hline 12562-MS & $93: 109$ & OSTI; NTIS; INIS; GPO Dep. & E 1.99: & DE 94001566 & $\begin{array}{l}\text { MF-802; } \\
\text { MF-814 }\end{array}$ \\
\hline 12564-MS & $93: 110$ & OSTI; NTIS; INIS; GPO Dep. & E 1.99: & DE98016231 & $\begin{array}{l}\text { MF-802; } \\
\text { MF-814 }\end{array}$ \\
\hline \multicolumn{6}{|l|}{ LA-SUB- } \\
\hline $93-118$ & 93:492 & OSTI; NTIS; GPO Dep. & E 1.99: & DE93012082 & MF-903 \\
\hline $93-185$ & $93: 493$ & OSTI; NTIS; INIS; GPO Dep. & E 1.99: & DE 93018276 & MF-814 \\
\hline $93-217$ & $93: 113$ & OSTI; NTIS; INIS; GPO Dep. & E 1.99: & DE 93040572 & MF-814 \\
\hline $93-231$ & 93:494 & OSTI; NTIS; INIS; GPO Dep. & E 1.99: & DE 93040570 & MF-802 \\
\hline $93-256$ & 93:495 & OSTI; NTIS; INIS; GPO Dep. & E 1.99: & DE 93040587 & MF-814 \\
\hline $93-51$ & $93: 112$ & OSTI; NTIS; INIS; GPO Dep. & E 1.99: & DE93008917 & MF-814 \\
\hline $93-64$ & $93: 490$ & $\begin{array}{l}\text { OSTI; NTIS (documentation only); ESTSC (com- } \\
\text { plete software package), P.O. Box 1020, } \\
\text { Oak Ridge, TN } 37831-1020 ; \text { INIS; GPO Dep. }\end{array}$ & E 1.99: & DE 93008920 & MF-801 \\
\hline $93-83$ & $93: 491$ & OSTI; NTIS; INIS; GPO Dep. & E 1.99: & DE93008910 & $\begin{array}{l}\text { MF-903; } \\
\text { MF-940 }\end{array}$ \\
\hline \multicolumn{6}{|l|}{ LA-UR- } \\
\hline $91-3236$ & $93: 114$ & OSTI; NTIS; INIS; GPO Dep. & E 1.99: & DE92002462 & MF-802 \\
\hline $91-3747$ & $93: 115$ & OSTI; NTIS; INIS; GPO Dep. & E 1.99: & DE92003794 & MF-814 \\
\hline $91-4035$ & $93: 116$ & OSTI; NTIS; INIS; GPO Dep. & E 1.99: & DE92005058 & MF-814 \\
\hline $91-4041$ & $93: 117$ & OSTI; NTIS; INIS; GPO Dep. & E 1.99: & DE92005056 & MF-814 \\
\hline $92-1194$ & $93: 124$ & OSTI; NTIS; INIS; GPO Dep. & E 1.99: & DE 92013548 & MF-814 \\
\hline $92-2577$ & $93: 496$ & OSTI; NTIS; INIS; GPO Dep. & E 1.99: & DE 94000628 & MF-814 \\
\hline $92-26$ & $93: 118$ & OSTI; NTIS; INIS; GPO Dep. & E 1.99: & DE 92007425 & MF- 814 \\
\hline $92-329$ & $93: 119$ & OSTI; NTIS; GPO Dep. & E 1.99: & DE 92007420 & MF-802 \\
\hline $92-3549$ & $93: 125$ & OSTI; NTIS; INIS; GPO Dep. & E 1.99: & DE93003790 & MF-802 \\
\hline $92-377$ & $93: 120$ & OSTI; NTIS; INIS; GPO Dep. & E 1.99: & DE 92008443 & MF-814 \\
\hline $92-461$ & $93: 121$ & OSTI; NTIS; INIS; GPO Dep. & E 1.99: & DE92008473 & MF-814 \\
\hline $92-534$ & $93: 122$ & OSTI; NTIS; INIS; GPO Dep. & E 1.99: & DE92008492 & MF-813 \\
\hline $92-537$ & $93: 123$ & OSTI; NTIS; INIS; GPO Dep. & E 1.99: & DE92008440 & MF-814 \\
\hline
\end{tabular}


Report
Number

93-0071

93-2254

93-2326

93-270

93-2761

93-2882

93-3299

93-3505

93-436

93-437

93-690

LBL-

23591

23592

23593

26224

28613

28914

30043

30707

31069

31181

31258

31666

31799

31975

32874

33464

33597

33627

33660

33661

33662

33663

LLNL-

94001185

NAGRA-NTB90-19

$90-20$

90-21

$90-22$

$90-25$

$90-26$

$90-27$

$90-28$

$90-29$

$90-30$

$90-32$

$90-33$

NDU-ICAF-

92-S9

NRC

93003273

NUREG-

1327

NUREG/CR-

4735-Vol. 7

4735-Vol.8
Abstract Source of

Number Avallability

93:126

93:131

93:132

$93: 127$

93.133

93:134

93:135

$93: 136$

93:128

93:129

93:130

93:37

93:38

93:39

93:233

93:249

93:40

93:47

$93: 48$

$93: 49$

93.50

93:51

$93: 52$

93:53

93:54

93:55

93:56

93:57

93.58

93:59

93:60

93:499

93:61

$93: 150$

$93: 500$

93:501

93:502

93:503

93:504

$93: 505$

$93: 506$

93:585

93:507

93:508

93:509

$93: 510$

$93: 400$

$93: 511$

93:512

93:528

93:529 land land land land land land land
OSTI; NTIS; INIS; GPO Dep.

OSTI; NTIS; INIS; GPO Dep.

OSTI; NTIS; GPO Dep.

OSTI; NTIS; INIS; GPO Dep.

OSTI; NTIS; INIS; GPO Dep.

OSTI; NTIS; INIS; GPO Dep.

OSTI; NTIS; INIS; GPO Dep.

OSTI; NTIS; INIS; GPO Dep.

OSTI; NTIS; INIS; GPO Dep.

OSTI; NTIS; INIS; GPO Dep.

OSTI; NTIS; INIS; GPO Dep.

OSTI; NTIS; INIS; GPO Dep.

OSTI; NTIS; INIS; GPO Dep.

OSTI; NTIS; GPO Dep.

See SAND-88-7054

See SAND-89-7018

OSTI; NTIS; INIS; GPO Dep.

OSTI; NTIS; INIS; GPO Dep.

OSTI; NTIS; INIS; GPO Dep.

OSTI; NTIS; INIS; GPO Dep.

OSTI; NTIS; INIS; GPO Dep.

OSTI; NTIS; INIS; GPO Dep.

OSTI; NTIS; INIS; GPO Dep.

OSTI; NTIS; INIS; GPO Dep.

OSTI; NTIS; INIS; GPO Dep.

OSTI; NTIS; INIS; GPO Dep.

OSTI; NTIS; INIS; GPO Dep.

OSTl; NTIS; INIS; GPO Dep.

OSTI; NTIS; INIS; GPO Dep.

OSTI; NTIS; INIS; GPO Dep.

OSTI; NTIS; INIS; GPO Dep.

OSTI; NTIS; INIS; GPO Dep.

OSTI; NTIS; INIS; GPO Dep.

OSTI; NTIS; INIS; GPO Dep.

Available from Nagra, $\mathrm{CH}-5401$ Baden, Switzer-

Available from Nagra, $\mathrm{CH}-5430$ Wettingen, Switzerland

Available from Nagra, $\mathrm{CH}-5430$ Wettingen, Switzerland

Available from Nagra, CH-5401 Baden, Switzer-

Available from Nagra, $\mathrm{CH}-5401$ Baden, Switzer-

Available from Nagra, $\mathrm{CH}-5430$ Wettingen, Switzerland

Available from Nagra, $\mathrm{CH}-5401$ Baden, Switzer-

See SKB-TR-90-19

Available from Nagra, $\mathrm{CH}-5401$ Baden, Switzer-

Available from Nagra, CH-5401 Baden, Switzer-

Available from Nagra, CH-5401 Baden, Switzer-

Available from Nagra, CH-5430 Wettingen, Switzerland

See AD-A-262251/2/XAB

OSTI; NTIS; INIS; GPO Dep.

E 1.99:

DE93003273

T192014995

T192005176

TI93016057
E 1.99:

E 1.99:

E 1.99:

E 1.99

E 1.99 .

1.99 :

E $1.99:$

E 1.99:

E 1.99:

08106

DE92008051

DE93015280

E 1.99:

1.99 :

E 1.99:

E 1.99:

E 1.99:

E 1.99 :

E 1.99:

1.99:

E 1.99:

1.99:

E 1.99:

1.99.

E 1.99:

E 1.99

E 1.99:

DE92000645

DE94003377

DE92009131

DE92009137

DE92017084

DE92009987

DE 93007659

DE92010459

DE92017022

DE93010444

DE93010421

DE93010450

E93010410

DE93010413

DE93010431

DE93010432

DE93010414

E 1.99:

DE94001185
Distribution

Category

MF-814

MF-814

MF-814

MF-814

MF-814

MF-814

MF-802

MF-814

MF-814

MF-814

MF-802

MF-814

MF-814

MF-814

PC-814

PC-800

PC-814

PC-814

MF-814

MF-812

MF-814

MF-814

MF-814

MF-814

MF-814

MF-814

MF-800

MF-800

MF-814

MF-811

MF -800

MF-814 


$\begin{array}{lll}\begin{array}{l}\text { Report } \\ \text { Number }\end{array} & \begin{array}{l}\text { Abstract } \\ \text { Number }\end{array} & \begin{array}{l}\text { Source of } \\ \text { Availability }\end{array} \\ 5685 & 93: 530 & \text { OSTI NTIS; GPO } \\ 5687 & 93: 531 & \text { OSTI; NTIS; INIS; GPO } \\ 5708 & 93: 532 & \text { OSTI NTIS; INIS; GPO } \\ 5710 & 93: 533 & \text { OSTI; NTIS; INIS; GPO } \\ 5880 & 93: 534 & \text { OSTI; NTIS; INIS; GPO } \\ 5890 & 93: 535 & \text { OSTI; NTIS; INIS; GPO } \\ 5917-\text { Vol.1 } & 93: 536 & \text { OSTI; NTIS; INIS; GPO } \\ 6021 & 93: 537 & \text { OSTI; NTIS; INIS; GPO }\end{array}$

NWPO-GR-

1

15

16

20

24-Vol.1

24-Vol.2

NWPO-SE-

026-90

036-87

$037-91$

038-91

039-91-Vol.1

039-91-Vol.2

040-91

041-91

042-91

043-91

044-91

045-92

054-92

055-92

NWPO-TN-

$001-88$

002-89

006-90

$007-90$

010-90

$011-91-\mathrm{Vol} .1$

$011-91-\mathrm{Vol} .2-3$

$0+3-91$

NWPO-TR-

$011-89$

014-90

016-91

018-91

019-92

020-93

ORNLM-

1822

PB-

92-156819/XAB $\quad 93.573$

92-187616/XAB 93:574

PNL-

93-130615/XAB 93:575

5109-104 93:151

5109-105 93:152

$6099 \quad 93: 576$

7474

7581

7847

$93: 62$

$93: 153$

93:154

$\begin{array}{rl}8081 & 93: 155 \\ 8327 & 93: 156 \\ 8444 & 93: 63 \\ 8636 & 93: 64 \\ \text { PNL-SA- } & \\ 20324 & 93: 65 \\ 20329 & 93: 66\end{array}$
Richiand, WA.
GPO
Order
Dep.
Number
T192019210
T192018776
T192007821
T192015376
T192040954
$T 193002843$
T/93008169
T193019109

Distribution

OSTI; NTIS; INIS; GPO Dep.

OSTI; NTIS; INIS; GPO Dep.

OSTI; NTIS; INIS; GPO Dep.

OSTI; NTIS; INIS; GPO Dep.

OSTI; NTIS; INIS; GPO Dep.

OSTI; NTIS; INIS; GPO Dep.

OSTI; NTIS; INIS; GPO; GPO Dep.

OSTI; NTIS; INIS; GPO Dep.

OSTI; NTIS; INIS; GPO Dep.

OSTI; NTIS; INIS; GPO Dep.

OSTI; NTIS; INIS; GPO Dep.

OSTI; NTIS; INIS; GPO Dep.

OST]; NTIS; INIS; GPO Dep.

OSTI; NTIS; INIS; GPO Dep.

OSTI; NTIS; INIS; GPO Dep.

OSTI; NTIS; INIS; GPO Dep.

OSTI; NTIS; INIS; GPO Dep.

OSTI; NTIS; INIS; GPO Dep.

OSTI; NTIS; INIS; GPO Dep.

OSTI; NTIS; INIS; GPO Dep.

$\begin{array}{ll}\text { E 1.99: } & \text { DE92017833 } \\ \text { E 1.99: } & \text { DE92017893 } \\ \text { E 1.99: } & \text { DE92017904 } \\ \text { E 1.99: } & \text { DE92017912 } \\ \text { E 1.99: } & \text { DE92017901 } \\ \text { E 1.99: } & \text { DE92017902 }\end{array}$

MF-814
MF-814
MF-814
MF-814
MF-814
MF-814

E 1.99: DE92017730

MF-814

E 1.99: DE92017735

E 1.99: DE92017712

E 1.99: DE92017676

E 1.99: DE92017713

E 1.99: DE92017714

E 1.99: DE92017733

E 1.99: DE92017578

E 1.99: DE92017705

E 1.99: DE92017732

E 1.99: DE92017731

E 1.99: DE93013217

E 1.99: DE93013216

E 1.99: DE93013212

MF-814

MF-814

MF-814

MF-814

MF-814

MF-814

MF-814

MF-814

MF-814

MF-814

MF-814

MF-814

MF-814

E 1.99: DE92017707

E 1.99: DE92017709

E 1.99: DE92017679

E 1.99: DE92017678

E 1.99: DE92017734

E 1.99: DE92017892

E 1.99: DE92017911

E 1.99: DE92017708

MF-814

MF-814

MF-814

MF-814

MF-814

MF-814

MF-814

MF-814

E 1.99: DE93013204

E 1.99: DE93013213

E 1.99: DE93018771

E 1.99: DE93013215

E 1.99: DE93041147

E 1.99:

DE93041148

MF-814

MF-814

MF-814

MF-814

MF-814

MF-814

E 1.99: DE92015564

PC-510

PC-810

NTIS Prices: PC A06/MF A02; INIS

NTIS Prices: PC A05/MF A01

NTIS Prices: PC A06/MF A02

OSTI; NTIS; INIS; GPO Dep.

OSTI; NTIS; INIS; GPO Dep.

OSTI; NTIS; INIS; GPO Dep.

OSTI; NTIS; INIS; GPO Dep.

OSTI; NTIS; INIS; GPO Dep.

OSTI (requests by US Government Agencies and Their Contractors). Other requestors should be directed to Battelle Memorial Inst.,

OSTI; NTIS; INIS; GPO Dep.

OSTI; NTIS; INIS; GPO Dep.

OSTI; NTIS; INIS; GPO Dep.

OSTI; NTIS; INIS; GPO Dep.

E 1.99:

DE92006636

MF-802

$M F-802$

E 1.99: DE92007036

E 1.99: DE92007603

E 1.99: DE92012319

E 1.99: DE92041231

MF-810

MF-814

MF-802

OSTI; NTIS; INIS; GPO Dep.

OSTI; NTIS; INIS; GPO Dep.
ND-800

T193003069

$\begin{array}{lll}\text { E 1.99: } & \text { DE92014614 } & \text { MF-814 } \\ \text { E 1.99: } & \text { DE93001775 } & \text { MF-814 } \\ \text { E 1.99: } & \text { DE93007438 } & \text { MF-814 } \\ \text { E 1.99: } & \text { DE93016342 } & \text { MF-814 } \\ \text { E 1.99: } & \text { DE92010496 } & \text { MF-814 } \\ \text { E 1.99: } & \text { DE93005097 } & \text { MF-814 }\end{array}$


Roport

Number

SAIC

$91 / 8000$

91/8001

SAND-

85-0004

86-7006

87-1305

87-2380

87-2777

87-2778

87-7075

87-7082

88-0585

88-0810

88-1331

88-1581

88-2730

88-3032

88-3164

88-7051

88-7054

88-7061

88-7065

88-7124

89-0837

$89-0972 / 1$

89-0972/2

89-1465C

89-1639

89-1871

89-1989

89-2558

89-2607

89-7002

89-7007

89-7008

89-7018

89-7023

89-7024

$90-0018 \mathrm{C}$

90-2261

90-2491

90-2542

90-2882

90-3165

90-7052C

90-7058

91-0079

91-0155

91-0527

91-0558

91-0607

91-0758

91-0790

91-0791

91-0792

91-0894

91-1493

91-1676C

91-1730C

91-1788C

91-1891C

91-1925C

91-1926C

91-1927C

91-1958C

$91-1982 \mathrm{C}$

91-1983C

91-1984C
Abstract Source of

Number Availability

$93: 157$

93:67

93:68

93:217

93:218

93:219

93:220

93:221

93:222

93:223

93:224

93:225

93:226

93:227

93:228

93:229

93:230

93:231

93:232

93:233

93:234

93:235

93:236

93:237

93:238

93:239

93:240

93:241

93:242

93:243

93:244

93:245

93:246

93:247

93:248

93:249

93:250

93:251

93:252

93:253

93:254

93:255

93:256

93:257

93.258

93:259

93:577

93:260

93:261

93:262

93:263

93:264

93:265

93:266

93:267

$93: 268$

93:269

93:270

93:271

93:272

93:273

93.274

93:275

93:276

98:277

93:278

93.279

93:280
OSTI; NTIS; INIS; GPO Dep.

OSTI; NTIS; INIS; GPO Dep. OSTI; NTIS; INIS; GPO Dep.

OSTI; NTIS; INIS; GPO Dep. OSTI; NTIS; INIS; GPO Dep. OSTI; NTIS; INIS; GPO Dep. OSTl; NTIS; INIS; GPO Dep. OSTI; NTIS; INIS; GPO Dep. OSTI; NTIS; INIS; GPO Dep. OSTI; NTIS; INIS; GPO Dep. OSTI; NTIS; INIS; GPO Dep. OSTI; NTIS; INIS; GPO Dep. OSTI; NTIS; INIS; GPO Dep OSTI; NTIS; INIS; GPO Dep. OSTI; NTIS; INIS; GPO Dep. OSTI; NTIS; INIS; GPO Dep. OSTI; NTIS; INIS; GPO Dep. OSTI; NTIS; INIS; GPO Dep. OSTI; NTIS; INIS; GPO Dep. OSTI; NTIS; INIS; GPO Dep. OSTI; NTIS; INIS; GPO Dep. OSTI; NTIS; INIS; GPO Dep. OSTI; NTIS; INIS; GPO Dep. OSTI; NTIS; INIS; GPO Dep. OSTI; NTIS; INIS; GPO Dep. OSTI; NTIS; INIS; GPO Dep. OSTI; NTIS; INIS; GPO Dep. OSTI; NTIS; INIS; GPO Dep. OSTI; NTIS; INIS; GPO Dep. OSTI; NTIS; INIS; GPO Dep OSTI; NTIS; INIS; GPO Dep. OSTI; NTIS; INIS; GPO Dep. OSTI; NTIS; INIS; GPO Dep. OSTI; NTIS; INIS; GPO Dep. OSTI; NTIS; INIS; GPO Dep. OSTI; NTIS; INIS; GPO Dep. OSTI; NTIS; INIS; GPO Dep. OSTI; NTIS; INIS; GPO Dep. OSTI; NTIS; INIS; GPO Dep. OSTI; NTIS; INIS; GPO Dep. OSTI; NTIS; INIS; GPO Dep. OSTI; NTIS; INIS; GPO Dep. OSTI; NTIS; INIS; GPO Dep. OSTI; NTIS; INIS; GPO Dep. OSTI; NTIS; INIS; GPO Dep. OSTI; NTIS; GPO Dep.

OSTI; NTIS; INIS; GPO Dep. OSTI; NTIS; INIS; GPO Dep. OSTI; NTIS; INIS; GPO Dep. OSTI; NTIS; INIS; GPO Dep. OSTI; NTIS; INIS; GPO Dep. OSTI; NTIS; INIS; GPO Dep. OSTI; NTIS; INIS; GPO Dep. OSTI; NTIS; INIS; GPO Dep. OSTI; NTIS; INIS; GPO Dep. OSTI; NTIS; INIS; GPO Dep. OSTI; NTIS; INIS; GPO Dep. OSTI; NTIS; INIS; GPO Dep. OSTI; NTIS; INIS; GPO Dep. OSTI; NTIS; INIS; GPO Dep. OSTI; NTIS; INIS; GPO Dep. OSTI; NTIS; INIS; GPO Dep. OSTI; NTIS; INIS; GPO Dep. OSTI; NTIS; INIS; GPO Dep. OSTI; NTIS; INIS; GPO Dep. OSTI; NTIS; INIS; GPO Dep. OSTI; NTIS; INIS; GPO Dep. OSTI; NTIS; INIS; GPO Dep.

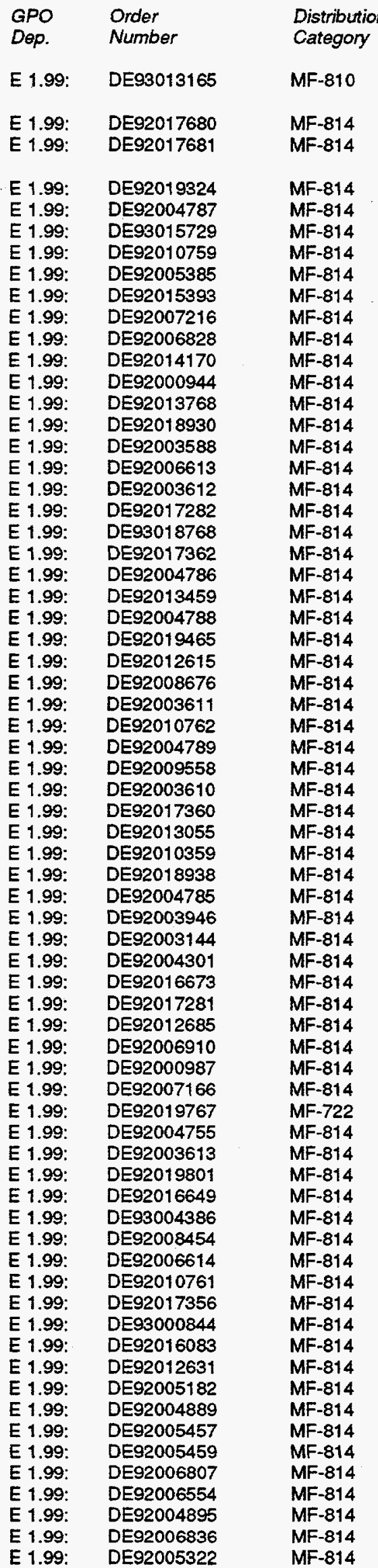




\begin{tabular}{|c|c|c|c|c|c|}
\hline $\begin{array}{l}\text { Report } \\
\text { Number }\end{array}$ & $\begin{array}{l}\text { Abstract } \\
\text { Number }\end{array}$ & $\begin{array}{l}\text { Source of } \\
\text { Availability }\end{array}$ & $\begin{array}{l}\text { GPO } \\
\text { Dep. }\end{array}$ & $\begin{array}{l}\text { Order } \\
\text { Number }\end{array}$ & $\begin{array}{l}\text { Distribution } \\
\text { Category }\end{array}$ \\
\hline $91-1988 \mathrm{C}$ & $.93: 578$ & OSTI; NTIS; INIS; GPO Dep. & E 1.99: & DE92006765 & MF-902 \\
\hline $91-1993 \mathrm{C}$ & $93: 579$ & OSTI; NTIS; INIS; GPO Dep. & E 1.99: & DE 91018684 & MF-810 \\
\hline $91-2010 \mathrm{C}$ & $93: 281$ & OSTI; NTIS; INIS; GPO Dep. & E 1.99: & DE92005179 & MF-814 \\
\hline $91-2029 \mathrm{C}$ & $93: 282$ & OSTI; NTIS; INIS; GPO Dep. & E 1.99: & DE92004890 & MF-814 \\
\hline $91-2030 \mathrm{C}$ & $93: 283$ & OSTI; NTIS; INIS; GPO Dep. & E 1.99: & DE 92005180 & $M F-814$ \\
\hline $91-2056 C$ & $93: 284$ & OSTI; NTIS; INIS; GPO Dep. & E 1.99: & DE 92005320 & MF-814 \\
\hline $91-2098 C$ & $93: 285$ & OSTI; NTIS; INIS; GPO Dep. & E 1.99: & DE92005319 & MF-814 \\
\hline $91-2176 \mathrm{C}$ & $93: 286$ & OSTI: NTIS; INIS; GPO Dep. & E 1.99: & DE92006526 & MF-814 \\
\hline $91-2177 C$ & $93: 287$ & OSTI; NTIS; INIS; GPO Dep. & E 1.99: & DE 92006527 & MF- 814 \\
\hline $91-22170$ & $93: 288$ & OSTI; NTIS; INIS; GPO Dep. & E 1.99: & DE 92006741 & MF-814 \\
\hline $91-2252 \mathrm{C}$ & 98:289 & OSTI; NTIS; INIS; GPO Dep. & E 1.99: & DE 92005183 & MF-814 \\
\hline $91-2266 \mathrm{C}$ & $93: 580$ & OSTI; NTIS; INIS; GPO Dep. & E 1.99: & DE 92011180 & MF-902 \\
\hline $91-2416$ & $93: 290$ & OSTI; NTIS; INIS; GPO Dep. & E 1.99: & DE 93001349 & MF-814 \\
\hline $91-2499 C$ & $93: 291$ & OSTI; NTIS; INIS; GPO Dep. & E 1.99: & DE92006553 & MF-814 \\
\hline $91-2685 C$ & $98: 292$ & OSTI; NTIS; INIS; GPO Dep. & E 1.99: & DE 92004480 & MF-814 \\
\hline $91-2795$ & $93: 293$ & OSTI; NTIS; INIS; GPO Dep. & E 1.99: & DE 92019642 & MF-814 \\
\hline $91-2895 C-D r a f t$ & $93: 294$ & OSTI; NTIS; GPO Dep. & E 1.99: & DE92016791 & MF-700 \\
\hline $91-7031$ & $93: 295$ & OSTI; NTIS; INIS; GPO Dep. & E 1.99: & DE 92005566 & MF-814 \\
\hline $91-7034$ & $93: 296$ & OSTI; NTIS; INIS; GPO Dep. & E 1.99: & DE92010760 & MF-814 \\
\hline $91-7035$ & $93: 297$ & OSTI: NTIS: GPO Dep. & E 1.99: & DE93003232 & MF-814 \\
\hline $91-7037$ & $93: 298$ & OSTI; NTIS; INIS; GPO Dep. & E 1.99: & DE 93006985 & MF-814 \\
\hline $91-7038$ & $93: 299$ & OSTI; NTIS; INIS; GPO Dep. & E 1.99: & DE $930025+3$ & MF-814 \\
\hline $91-7039 \mathrm{C}$ & $93: 300$ & OSTI; NTIS; INIS: GPO Dep. & E 1.99: & DE92004893 & MF-814 \\
\hline $91-7040 \mathrm{C}$ & $93: 301$ & OSTI; NTIS; INIS; GPO Dep. & E 1.99: & DE 92004892 & $M F-814$ \\
\hline $92-0091 \mathrm{C}$ & $93: 302$ & OSTI; NTIS: INIS: GPO Dep. & E 1.99: & DE92011382 & MF-814 \\
\hline $92-0279 \mathrm{C}$ & $93: 303$ & OSTI; NTIS; INIS; GPO Dep. & E 1.99: & DE 92016452 & MF-814 \\
\hline $92-0450$ & $93: 304$ & OSTI; NTIS; INIS; GPO Dep. & E 1.99: & DE 93018522 & MF-814 \\
\hline $92-0461$ & $93: 305$ & OSTI: NTIS: INIS: GPO Dep. & E 1.99: & DE93008082 & MF-814 \\
\hline $92-0472 \mathrm{C}$ & 93:581 & OSTI; NTIS (US Sales Only); GPO Dep. & E 1.99: & DE 92018824 & $\begin{array}{l}\text { MF-706; } \\
\text { MF-722 }\end{array}$ \\
\hline $92-0556$ & $93: 582$ & OSTI; NTIS; INIS; GPO Dep. & E 1.99: & DE93006986 & MF-721 \\
\hline $92-0589$ & 93:306 & OSTI; NTIS; INIS; GPO Dep. & E 1.99: & DE93012451 & MF-814 \\
\hline $92-0960$ & 93:307 & OSTI; NTIS; INIS; GPO Dep. & E 1.99: & DE 93018523 & MF-814 \\
\hline $92-12260$ & $93: 308$ & OSTI; NTIS; INIS; GPO Dep. & E 1.99: & DE 92017043 & MF-814 \\
\hline $92-1317 \mathrm{C}$ & $93: 309$ & OSTI; NTIS; INIS; GPO Dep. & E 1.99: & DE92016499 & MF-814 \\
\hline $92-1810$ & $93: 310$ & OSTI; NTIS; INIS; GPO Dep. & E 1.99: & DE 94000346 & MF-814 \\
\hline $92-1853$ & $93: 311$ & OSTI; NTIS; INIS; GPO Dep. & E 1.99: & DE 94002608 & MF. 814 \\
\hline $92-2152 \mathrm{C}$ & $93: 312$ & OSTI: NTIS: INIS: GPO Dep. & E 1.99: & DE93009626 & MF-814 \\
\hline $92-2153 C$ & $93: 313$ & OSTI; NTIS; INIS; GPO DEP. & E 1.99: & DE93006781 & MF-814 \\
\hline $92-2247$ & $93: 314$ & OSTI; NTIS; INIS; GPO Dep. & E 1.99: & DE 94002609 & MF-814 \\
\hline $92-2334$ & $93: 315$ & OSTI; NTIS; INIS; GPO Dep. & E 1.99: & DE 93018679 & MF-814 \\
\hline $92-2335 \mathrm{C}$ & $93: 316$ & OSTI; NTIS; INIS; GPO Dep. & E 1.99: & DE 93005375 & MF-814 \\
\hline $92-2434$ & $93: 317$ & OSTI: NTIS: INIS: GPO Dep. & E 1.99: & DE93018681 & MF-814 \\
\hline $92-2491 C$ & $93: 318$ & OSTI; NTIS; INIS; GPO Dөp. & E 1.99: & DE 93008354 & MF-814 \\
\hline $92-2600 \mathrm{C}$ & $93: 319$ & OSTI; NTIS: INIS: GPO Dep. & E 199: & DE93006753 & MF-814 \\
\hline $92-2670 \mathrm{C}$ & $93: 320$ & OSTI; NTIS; INIS; GPO Dep. & E 1.99: & DE 93011580 & MF-800 \\
\hline $92-2671 \mathrm{C}$ & $93: 321$ & OSTI; NTIS; INIS; GPO Dep. & E 1.99: & DE 93008358 & MF-814 \\
\hline $92-2672 \mathrm{C}$ & $93: 322$ & OSTI; NTIS; INIS; GPO Dep. & E 1.99: & DE 93006783 & MF-814 \\
\hline $92-2739 \mathrm{C}$ & $93: 323$ & OSTI: NTIS: INIS: GPO DeD. & E 199: & DE 93008408 & MF-814 \\
\hline $92-2762$ & 93:324 & OSTI; NTIS; INIS; GPO Dep. & E 1.99: & DE 93018682 & MF-814 \\
\hline $92-2784 C$ & $93: 325$ & OSTI; NTIS; INIS; GPO Dep. & E 1.99: & DE 93008410 & MF-814 \\
\hline $92-27900$ & $93: 326$ & OSTI: NTIS: INIS: GPO Dep. & E 1.99: & DE 93006765 & MF-814 \\
\hline $92-2791 C$ & $93: 327$ & OSTI; NTIS; INIS; GPO Dep. & E 1.99: & DE 93008409 & MF-814 \\
\hline $92-2792 \mathrm{C}$ & $93: 328$ & OSTI: NTIS: INIS: GPO DeP. & E 1.99: & DE93009636 & MF-814 \\
\hline $92-2826 \mathrm{C}$ & $93: 329$ & OSTI; NTIS; INIS; GPO Dep. & E 1.99: & DE93006771 & MF-814 \\
\hline $92-2827 \mathrm{C}$ & $93: 330$ & OSTI; NTIS; INIS; GPO Dep. & E 1.99: & DE 93006770 & MF-814 \\
\hline $92-2828 \mathrm{C}$ & $93: 331$ & OSTI; NTIS; INIS; GPO Dep. & E 1.99: & DE93006782 & MF-814 \\
\hline $92-2838 \mathrm{C}$ & 93:332 & OSTI; NTIS; INIS; GPO Dep. & E 1.99: & DE 93008406 & MF-814 \\
\hline $92-7344 \mathrm{C}$ & $93: 333$ & OSTI: NTIS: INIS: GPO Dep. & E 1.99: & DE 93008412 & MF-814 \\
\hline $93-0039 \mathrm{C}$ & $93: 334$ & OSTI; NTIS; INIS; GPO Dep. & E 1.99: & DE93008407 & MF-814 \\
\hline $93-1109 \mathrm{C}$ & 93:335 & OSTI: NTIS: GPO Dep. & E 1.99: & DE93018826 & MF-703 \\
\hline $93-1415 \mathrm{C}$ & $93: 336$ & OSTI: NTIS: INIS: GPO Dep. & E 1.99: & DE93017656 & MF-814 \\
\hline $93-7005 \mathrm{C}$ & $93: 337$ & OSTI: NTIS; INIS: GPO Dep. & E 1.99: & DE93008355 & MF-814 \\
\hline $93-7013 \mathrm{C}$ & $93: 338$ & OSTI; NTIS; INIS; GPO Dep. & E 1.99: & DE93006755 & MF-814 \\
\hline \multicolumn{6}{|l|}{ SKB-TR- } \\
\hline $90-10$ & 93:500 & See NAGRA-NTB-90-19 & & & \\
\hline $90-12$ & $93: 502$ & See NAGRA-NTR-90-21 & & & \\
\hline $90-13$ & $93: 503$ & SeO NAGRA-NTB-90-22 & & & \\
\hline $90-14$ & 93:583 & OSTI; NTIS (US Sales Only); INIS & & DE92613489 & \\
\hline $90-15$ & $93: 584$ & OSTI; NTIS (US Sales Only); INIS & & DE 92613512 & \\
\hline
\end{tabular}




\begin{tabular}{|c|c|c|c|c|c|}
\hline $\begin{array}{l}\text { Report } \\
\text { Number }\end{array}$ & $\begin{array}{l}\text { Abstract } \\
\text { Number }\end{array}$ & $\begin{array}{l}\text { Source of } \\
\text { Availability }\end{array}$ & $\begin{array}{l}\text { GPO } \\
\text { Dep. }\end{array}$ & $\begin{array}{l}\text { Order } \\
\text { Number }\end{array}$ & $\begin{array}{l}\text { Distribution } \\
\text { Categony }\end{array}$ \\
\hline $90-16$ & 93:504 & See NAGRA-NTB-90-25 & & . & \\
\hline $90-17$ & 93:505 & See NAGRA-NTB-90-26 & & . & \\
\hline $90-18$ & 93:506 & See NAGRA-NTB-90-27 & & & \\
\hline $90-19$ & 93:585 & OSTI; NTIS (US Sales Only); INIS & & DE92613462 & \\
\hline $90-20$ & 93:507 & See NAGRA-NTB-90-29 & & & \\
\hline $90-21$ & 93.508 & See NAGRA-NTB-90-30 & & & \\
\hline $90-22$ & $93: 586$ & OSTI; NTIS (US Sales Only); INIS & & DE92613490 & \\
\hline $90-23$ & $93: 509$ & See NAGRA-NTB-90-32 & & & \\
\hline $90-24$ & $93: 510$ & See NAGRA-NTB-90-33 & & & \\
\hline \multicolumn{6}{|l|}{ TID 29442} \\
\hline & $93: 589$ & NTIS, PC A12/MF A01 & & & PC-70 \\
\hline \multicolumn{6}{|c|}{ 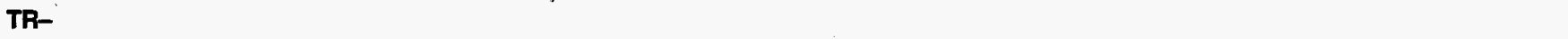 } \\
\hline \multirow{2}{*}{\multicolumn{6}{|c|}{$\pi \mathrm{C}-$}} \\
\hline & & & & & \\
\hline 1072 & $93: 577$ & See SAND-91-0079 & & & \\
\hline \multicolumn{6}{|l|}{ UCB-NE- } \\
\hline 4167 & $93: 40$ & See LBL-28914 & & & \\
\hline \multicolumn{6}{|l|}{ UCID- } \\
\hline 21414-Rev.1 & 93:159 & OSTI; NTIS; INIS; GPO Dep. & E 1.99: & DE92004466 & MF-814 \\
\hline 21756 & 93:160 & OSTI; NTIS; INIS; GPO Dep. & E 1.99: & DE92004467 & MF-814 \\
\hline 21863 & $93: 161$ & OSTI; NTIS; INIS; GPO Dep. & E 1.99: & DE92004628 & MF-814 \\
\hline \multicolumn{6}{|c|}{ - } \\
\hline 101693 & 93:162 & OSTI; NTIS; INIS; GPO Dep. & E 1.99: & DE92005396 & MF-814 \\
\hline \multicolumn{6}{|l|}{ UCRL-CR- } \\
\hline 106983 & 93:591 & OSTI; NTIS; INIS; GPO Dep. & E 1.99: & DE92000085 & MF-814 \\
\hline \multicolumn{6}{|l|}{ UCRL-ID- } \\
\hline 105340 & $93: 163$ & OSTI; NTIS; GPO Dep. & E 1.99: & DE92012395 & MF-802 \\
\hline 107289 & $93: 164$ & OSTI; NTIS; INIS; GPO Dep. & E 1.99: & DE92006660 & MF-814 \\
\hline 108153 & $93: 165$ & OSTI; NTIS; INIS; GPO Dep. & E 1.99: & DE 92004468 & MF-814 \\
\hline 108330 & $93: 166$ & OSTI; NTIS; INIS; GPO Dep. & E 1.99: & DE 92004469 & MF- 814 \\
\hline 109215 & $93: 167$ & OSTI; NTIS; INIS; GPO Dep. & E 1.99: & DE92016744 & MF-814 \\
\hline 109921 & $93: 168$ & OSTI; NTIS; INIS; GPO Dep. & E 1.99: & DE92041080 & MF-814 \\
\hline 111624 & $93: 169$ & OSTI; NTIS; INIS; GPO Dep. & E 1.99: & DE93007743 & MF-814 \\
\hline 111979 & $93: 170$ & OSTI; NTIS; INIS; GPO Dep. & E 1.99: & DE93041100 & MF-814 \\
\hline 112036 & 93:171 & OSTI; NTIS; INIS; GPO Dep. & E 1.99: & DE93008756 & MF-814 \\
\hline 112058 & $93: 172$ & OSTI; NTIS; INIS; GPO Dep. & E 1.99: & DE93008757 & MF-814 \\
\hline 112432 & $93: 173$ & OSTI; NTIS; INIS; GPO Dep. & E 1.99: & DE 94001854 & MF-814 \\
\hline 112433 & $93: 174$ & OSTI; NTIS; INIS; GPO Dep. & E 1.99: & DE 93017958 & MF-814 \\
\hline 112789 & $93: 592$ & OSTI; NTIS; INIS; GPO Dep. & E 1.99: & DE93016954 & MF-903 \\
\hline 112834 & $93: 175$ & OSTI; INIS; NTIS; GPO Dep. & E 1.99: & DE93040441 & MF-814 \\
\hline 113383 & $93: 176$ & OSTI; NTIS; INIS; GPO DeP. & E 1.99: & DE93019212 & MF-804 \\
\hline 114148 & $93: 177$ & OSTI; NTIS; INIS; GPO Dep. & E 1.99: & DE94000351 & MF-814 \\
\hline \multicolumn{6}{|l|}{ UCRLJC } \\
\hline 106693 & $93: 178$ & OSTI; NTIS; INIS; GPO Dep. & E 1.99: & DE92014889 & MF-814 \\
\hline 106703 & $93: 179$ & OSTI; NTIS; INIS; GPO Dep. & E 1.99: & DE92014888 & MF- 814 \\
\hline 106752 & $93: 180$ & OSTI; NTIS; INIS; GPO Dep. & E 1.99: & DE92014884 & MF-814 \\
\hline 106758 & $93: 181$ & OSTI; NTIS; INIS; GPO Dep. & E 1.99: & DE92016156 & MF-802 \\
\hline 106759 & $93: 182$ & OSTI; NTIS; INIS; GPO Dep. & E 1.99: & DE92004673 & MF-814 \\
\hline 106916 & $93: 183$ & OSTI; NTIS; INIS; GPO Dep. & E 1.99: & DE92004657 & MF-814 \\
\hline 106918 & $93: 184$ & OSTI; NTIS; INIS; GPO Dep. & E 1.99: & DE92008074 & MF-703 \\
\hline 107920 & $93: 185$ & OSTI; NTIS; INIS; GPO Dep. & E 1.99: & DE92002764 & MF-814 \\
\hline 107985 & $93: 186$ & OSTI; NTIS; INIS; GPO Dep. & E 1.99: & DE93007507 & MF-814 \\
\hline 109216 & 93:187 & OSTI; NTIS; INIS; GPO Dep. & E 1.99: & DE92014807 & $M F-814$ \\
\hline 109231 & $93: 188$ & OSTI; NTIS; INIS; GPO Dep. & E 1.99: & DE92008930 & MF-814 \\
\hline 109232 & $93: 189$ & OSTI; NTIS; INIS; GPO Dep. & E 1.99: & DE92008080 & $M F-814$ \\
\hline 109623 & $93: 593$ & OSTI; NTIS; INIS; GPO Dep. & E 1.99: & DE92008061 & MF-703 \\
\hline 109952 & $93: 190$ & OSTI; NTIS; INIS; GPO Dep. & E 1.99: & DE92017439 & MF-814 \\
\hline 110677 & 93:191 & OSTI; NTIS; INIS; GPO DEp. & E 1.99: & DE 93009070 & MF-814 \\
\hline 111652 & $93: 192$ & OSTI; NTIS; INIS; GPO Dep. & E 1.99: & DE93008021 & MF-814 \\
\hline 112435 & 93:193 & OSTI; NTIS; INIS; GPO Dep. & E 1.99: & DE 93008020 & MF-814 \\
\hline 112444 & 93:194 & OSTI; NTIS; INIS; GPO Dep. & E 1.99: & DE93009062 & MF-814 \\
\hline 112445 & 93:195 & OSTI; NTIS; INIS; GPO Dep. & E 1.99: & DE 93008022 & MF-814 \\
\hline 112825 & $93: 196$ & OSTI; NTIS; INIS; GPO DeP. & E 1.99: & DE93009063 & MF-814 \\
\hline 114783 & $93: 197$ & OSTI; NTIS; INIS; GPO Dep. & E 1.99: & DE 94002011 & $M F-814$ \\
\hline \multicolumn{6}{|l|}{ UCRL-LR- } \\
\hline $\begin{array}{l}\text { 107476-Vol.1 } \\
\text { 107476-Vol.2 }\end{array}$ & $\begin{array}{l}93: 198 \\
93: 199\end{array}$ & $\begin{array}{l}\text { OSTI; NTIS; INIS; GPO Dep. } \\
\text { OSTI: NTIS: INIS; GPO DeD }\end{array}$ & E 1.99: & DE93014854 & PC-802 \\
\hline
\end{tabular}




\begin{tabular}{|c|c|c|c|c|c|}
\hline $\begin{array}{l}\text { Report } \\
\text { Number }\end{array}$ & $\begin{array}{l}\text { Abstract } \\
\text { Number }\end{array}$ & $\begin{array}{l}\text { Source of } \\
\text { Availability }\end{array}$ & $\begin{array}{l}\text { GPO } \\
\text { Dep. }\end{array}$ & $\begin{array}{l}\text { Order } \\
\text { Number }\end{array}$ & $\begin{array}{l}\text { Distributic } \\
\text { Category }\end{array}$ \\
\hline \multicolumn{6}{|l|}{ UCRL-MA- } \\
\hline 110662-Pt.1 & $93: 200$ & $\begin{array}{l}\text { OSTI; INIS; NTIS (documentation only); ESTSC } \\
\text { (complete software package), P.O. Box } \\
\text { 1020, Oak Ridge, TN 37831-1020; GPO } \\
\text { Dep. }\end{array}$ & E 1.99: & DE93003359 & MF-814 \\
\hline $\begin{array}{l}\text { 110662-Pt.2 } \\
110662-\text { Pt.3 }\end{array}$ & $\begin{array}{l}93: 201 \\
93: 202\end{array}$ & $\begin{array}{l}\text { OSTI; NTIS; INIS; GPO Dep. } \\
\text { OSTI; NTIS; INIS; GPO Dep. }\end{array}$ & $\begin{array}{l}\text { E 1.99: } \\
\text { E 1.99: }\end{array}$ & $\begin{array}{l}\text { DE93005826 } \\
\text { DE93005827 }\end{array}$ & $\begin{array}{l}\text { MF-800 } \\
\text { MF-800 }\end{array}$ \\
\hline 110662-Pt.4 & $93: 203$ & $\begin{array}{l}\text { OSTI; INIS; NTIS (documentation only); ESTSC } \\
\text { (complete software package), P.O. Box } \\
\text { 1020, Oak Ridge, TN } 37831-1020 ; \text { GPO } \\
\text { Dep. }\end{array}$ & E 1.99: & DE 93007118 & MF-814 \\
\hline \multicolumn{6}{|l|}{ UK-DOE-WR- } \\
\hline $90-041$ & $93: 500$ & See NAGRA-NTB-90-19 & & & \\
\hline $90-041$ & $93: 504$ & See NAGRA-NTB-90-25 & & & \\
\hline $90-043$. & $93: 502$ & See NAGRA-NTB-90-21 & & & \\
\hline $90-048$ & $93: 503$ & See NAGRA-NTB-90-22 & & & \\
\hline $90-048$ & $93: 505$ & See NAGRA-NTB-90-26 & & & \\
\hline $90-049$ & 93:506 & See NAGRA-NTB-90-27 & & & \\
\hline $90-050$ & $93: 585$ & See SKB-TR-90-19 & & & \\
\hline $90-051$ & 93:507. & See NAGRA-NTB-90-29 & & & \\
\hline $90-052$ & 93:508 & See NAGRA-NTB-90-30 & & & \\
\hline $90-054$ & $93: 509$ & See NAGRA-NTB-90-32 & & & \\
\hline $90-055$ & $93: 510$ & See NAGRA-NTB-90-33 & & & \\
\hline \multicolumn{6}{|l|}{ UNLV/TRC/RR- } \\
\hline 91/02-Vol.1 & $93: 563$ & See NWPO-TN-011-91-Vol.1 & & & \\
\hline 91/02-Vol.2-3 & $93: 564$ & See NWPO-TN-011-91-Vol.2-3 & & & \\
\hline \multicolumn{6}{|l|}{ USGS-BULL- } \\
\hline 1991 & $93: 369$ & $\begin{array}{l}\text { U.S. Geological Society, Books and OFR Sec- } \\
\text { tion, Federal Center, Box 25425, Denver, CO } \\
80225\end{array}$ & & & ND-814 \\
\hline \multicolumn{6}{|c|}{ CoL } \\
\hline 89-567A & $93: 371$ & $\begin{array}{l}\text { OSTI; NTIS; US Geological Survey, Books and } \\
\text { Open-File Reponts Section, Box 25425, Fed- } \\
\text { eral Center, Denver; CO 80225; GPO Dep. }\end{array}$ & E 1.99: & DE92003698 & MF-802 \\
\hline $90-369$ & $93: 372$ & OSTI; NTIS; GPO Dep. & E 1.99: & DE 93004285 & \\
\hline $90-474$ & $93: 373$ & $\begin{array}{l}\text { OSTI; NTIS; INIS; USGS Books and Open-File } \\
\text { Reports Section, Box } 25425 \text { Federal Center, } \\
\text { Denver, CO 80225; GPO Dep. }\end{array}$ & E 1.99: & DE 92005486 & MF-814 \\
\hline $91-105$ & $93: 374$ & $\begin{array}{l}\text { OSTI; INIS; US Geological Survey, Books and } \\
\text { Open-File Reports Section, Federal Center, } \\
\text { Box 25425, Denver, CO 80225-0425 }\end{array}$ & & T192011882 & MF-814 \\
\hline $91-125$ & $93: 375$ & OSTI; NTIS; INIS; GPO Dep. & E 1.99: & DE94000437 & MF-814 \\
\hline $91-367$ & $93: 376$ & OSTI; NTIS; GPO Dep. & E 1.99: & DE92011869 & \\
\hline $91-478$ & $93: 377$ & OSTI; NTIS; GPO Dep. & E 1.99: & DE93004286 & \\
\hline $91-493$ & 93:378 & $\begin{array}{l}\text { OSTI; NTIS; INIS; GPO; US Geological Survey, } \\
\text { Books and Open-File Reports Section, Box } \\
\text { 25425, Mail Stop 517, Federal Center, Den- } \\
\text { ver, CO 80225-0425; GPO Dep. }\end{array}$ & E 1.99: & DE 93017415 & MF-814 \\
\hline $91-572$ & $93: 379$ & OSTI; NTIS; GPO Dep. & E 1.99: & DE92014882 & MF-703 \\
\hline $91-620$ & $93: 380$ & OSTI; NTIS; GPO Dep. & E 1.99: & DE 92012265 & MF-814 \\
\hline $91-623$ & $93: 381$ & OSTI; NTIS; INIS; GPO Dep. & E 1.99: & DE 93009873 & MF-814 \\
\hline $92-130$ & 93:594 & $\begin{array}{l}\text { OSTI; NTIS; INIS; US Geological Survey, Books } \\
\text { and Open-File Reports Section, Federal } \\
\text { Center, Box 25425, Denver, CO } 80225 \text { (US); } \\
\text { GPO Dep. }\end{array}$ & E 1.99: & DE93017646 & MF-703 \\
\hline $92-137$ & 93:383 & OSTI; NTIS; INIS; GPO; GPO Dep. & E 1.99: & DE92019280 & MF-814 \\
\hline $92-340$ & 93:384 & $\begin{array}{l}\text { OSTI; NTIS; INIS; U.S. Geological Survey, } \\
\text { Books and Open-File Reports Section, Fed- } \\
\text { eral Center, Box 25425, Denver, CO } 80225 ; \\
\text { GPO Dep. }\end{array}$ & E 1.99: & DE93009824 & MF-814 \\
\hline $\begin{array}{l}92-343 \\
92-490\end{array}$ & $\begin{array}{l}93: 385 \\
93: 386\end{array}$ & $\begin{array}{l}\text { OSTI; NTIS; INIS; GPO Dep. } \\
\text { OSTI; NTIS; INIS; U.S. Geological Survey, Box } \\
\text { 25425, MS 517, Denver Federal Center, } \\
\text { Denver, CO } 80225-0425 \text { (US); GPO Dep. }\end{array}$ & $\begin{array}{l}\text { E 1.99: } \\
\text { E 1.99: }\end{array}$ & $\begin{array}{l}\text { DE } 93012727 \\
\text { DE } 93016278\end{array}$ & MF-814 \\
\hline $92-572$ & $93: 387$ & $\begin{array}{l}\text { OSTI; NTIS; INIS; GPO; U.S. Geological Sur- } \\
\text { vey, Books and Open File Reports Section, } \\
\text { Federal Center, Box 25425, Denver, CO } \\
\text { 80225; GPO Dep. }\end{array}$ & E 1.99: & DE93013189 & MF-814 \\
\hline
\end{tabular}




\begin{tabular}{|c|c|c|c|c|c|}
\hline $\begin{array}{l}\text { Report } \\
\text { Number }\end{array}$ & $\begin{array}{l}\text { Abstract } \\
\text { Number }\end{array}$ & $\begin{array}{l}\text { Source of } \\
\text { Availability }\end{array}$ & $\begin{array}{l}\text { GPO } \\
\text { Dep. }\end{array}$ & $\begin{array}{l}\text { Order } \\
\text { Number }\end{array}$ & $\begin{array}{l}\text { Distributic } \\
\text { Category }\end{array}$ \\
\hline $93-187$ & 93:595 & $\begin{array}{l}\text { OSTI; NTIS; US Geological Survey, Books and } \\
\text { Open-File Reports Section, Box 25425, Fed- } \\
\text { eral Center, Denver, CO } 80225 \text { (US); GPO } \\
\text { Dep. }\end{array}$ & E 1.99: & DE 93015498 & MF-703 \\
\hline $\begin{array}{l}93-438 \\
93-73\end{array}$ & $\begin{array}{l}93: 389 \\
93: 388\end{array}$ & $\begin{array}{l}\text { OSTI; NTIS; INIS; GPO Dep. } \\
\text { OSTI; NTIS; INIS; U.S. Geological Survey, Box } \\
\text { 25425, MS 517, Denver Federal Center, } \\
\text { Denver, CO } 80225-0425 \text { (US); GPO Dep. }\end{array}$ & $\begin{array}{l}\text { E 1.99: } \\
\text { E 1.99: }\end{array}$ & $\begin{array}{l}\text { DE94003607 } \\
\text { DE93016279 }\end{array}$ & MF-814 \\
\hline $\begin{array}{l}\text { USGS/MAP/GP- } \\
1001\end{array}$ & $93: 370$ & $\begin{array}{l}\text { U.S.G.S. Open File Service, Box 25425-Denver } \\
\text { Federal Center, Denver, CO } 80225\end{array}$ & & & ND-814 \\
\hline $\begin{array}{l}\text { USGS/OFR- } \\
\text { 92-28 }\end{array}$ & $93: 382$ & $\begin{array}{l}\text { OSTI; INIS; US Geological Survey, Books and } \\
\text { Open-File Reports Section, Federal Center, } \\
\text { Box 25425, Denver, CO } 80225 \text { (United } \\
\text { States) }\end{array}$ & & T193011023 & MF-814 \\
\hline $\begin{array}{l}\text { USGS NRRIR- } \\
89-4025\end{array}$ & $93: 390$ & $\begin{array}{l}\text { OSTI; NTIS; INIS; US Geological Survey, Books } \\
\text { and Open-File Reports Section, Box 250425, } \\
\text { Mail Stop 517, Federal Center, Denver, CO } \\
\text { 80225-0425; GPO Dep. }\end{array}$ & E 1.99: & DE92003375 & MF-814 \\
\hline $\begin{array}{l}\text { WINCO- } \\
1119 \\
\text { WSRC-MS- }\end{array}$ & $93: 596$ & OSTI; NTIS; INIS; GPO Dep. & E 1.99: & DE93014824 & MF-510 \\
\hline $\begin{array}{l}90-351 \\
93-143\end{array}$ & $\begin{array}{l}93: 597 \\
93: 598\end{array}$ & $\begin{array}{l}\text { OSTI; NTIS; INIS; GPO Dep. } \\
\text { OSTI; NTIS; INIS; GPO Dep. }\end{array}$ & $\begin{array}{l}\text { E 1.99: } \\
\text { E 1.99: }\end{array}$ & $\begin{array}{l}\text { DE92009517 } \\
\text { DE93010380 }\end{array}$ & $\begin{array}{l}\text { MF-721 } \\
\text { MF-700 }\end{array}$ \\
\hline $\begin{array}{l}\text { WSRC-TR- } \\
\text { 93-0111-Rev.1 } \\
\text { YMP- }\end{array}$ & $93: 599$ & OSTI; NTIS; INIS; GPO Dep. & E 1.99: & DE94001176 & MF-700 \\
\hline $\begin{array}{l}91-17 \\
91-19\end{array}$ & $\begin{array}{l}93: 69 \\
93: 70\end{array}$ & $\begin{array}{l}\text { OSTI; NTIS; INIS; GPO Dep. } \\
\text { OSTI; NTIS; GPO Dep. }\end{array}$ & $\begin{array}{l}\text { E 1.99: } \\
\text { E 1.99: }\end{array}$ & $\begin{array}{l}\text { DE93017090 } \\
\text { DE93017091 }\end{array}$ & $\begin{array}{l}\text { MF-814 } \\
\text { MF-800 }\end{array}$ \\
\hline
\end{tabular}




\section{Order Number Correlation}

The correlation list is provided for those organizations that file documents by report number but may receive requests by order number. For more information about a document, refer to the Report Number Index.

Order No. Report No.

DE91014380 DOE/OSTI-3406-Suppl.2Add.3

DE91018684 SAND-91-1993C

DE92000085 UCRL-CR-106983

DE92000645 LBL-28914

DE92000944 SAND-88-0810

DE92000987 SAND-90-7052C

DE92002462 LA-UR-91-3236

DE92002764 UCRL-JC-107920

DE92003144 SAND-90-0018C

DE92003375 USGS/WRIR-89-4025

DE92003588 SAND-88-2730

DE92003610 SAND-89-2607

DE92003611 SAND-89-1639

DE92003612 SAND-88-3164

DE92003613 SAND-91-0527

DE 92003698 USGS-OFR-89-567A

DE92003794 LA-UR-91-3747

DE92003946 SAND-89-7024

DE92004301 SAND-90-2261

DE92004466 UCID-21414-Rev.1

DE92004467 UCID-21756

DE92004468 UCRL-ID-108153

DE92004469 UCRL-ID-108330

DE92004480 SAND-91-2685C

DE92004628 UCID-21863

DE92004657 UCRL-JC-106916

DE92004673 UCRL-JC-106759

DE92004722 ANLCP-72981

DE92004755 SAND-91-0155

DE92004785 SAND-89-7023

DE92004786 SAND-88-7065

DE92004787 SAND-86-7006

DE92004788 SAND-89-0837

DE92004789 SAND-89-1989

DE92004874 DOE/OSTI-3406-Suppl.3

DE92004889 SAND-91-1891C

DE92004890 SAND-91-2029C

DE92004892 SAND-91-7040C

DE92004893 SAND-91-7039C

DE92004895 SAND-91-1982C

DE92005056 LA-UR-91-4041

DE92005058 LA-UR-91-4035

DE92005179 SAND-91-2010C

DE92005180 SAND-91-2030C

DE92005182 SAND-91-1788C

DE92005183 SAND-91-2252C

DE92005319 SAND-91-2098C

DE92005320 SAND-91-2056C

DE92005322 SAND-91-1984C

DE92005385 SAND-87-2777

DE92005396 UCRL-101693

DE92005457 SAND-91-1925C

DE92005459 SAND-91-1926C

DE92005486 USGS-OFR-90-474

DE92005566 SAND-91.7031

DE92006526 SAND-91-2176C

DE92006527 SAND-91-2177C

DE92006553 SAND-91-2499C

DE92006554 SAND-91-1958C
Order No. Report No.

DE92006613 SAND-88-3032

DE92006614 SAND-91-0791

DE92006636 PNL-5109-104

DE92006660 UCRL-1D-107289

DE92006741 SAND-91-2217C

DE92006765 SAND-91-1988C

DE92006807 SAND-91-1927C

DE92006828 SAND-87-7082

DE92006836 SAND-91-1983C

DE92006910 SAND-90-3165

DE92007036 PNL-5109-105

DE92007166 SAND-90-7058

DE92007216 SAND-87-7075

DE92007369 ANL/CP-75242

DE92007420 LA-UR-92-329

DE92007425 LA-UR-92-26

DE92007578 ANL-91/36

DE92007603 PNL-6099

DE92007610 BNL-45042

DE92007623 EGG-10617-1194

DE92007905 CONF-9112100-1-Vugraphs

DE92008051 LBL-23592

DE92008061 UCRL-JC-109623

DE92008074 UCRL-JC-106918

DE92008080 UCRL-JC-109232

DE92008106 LBL-23591

DE92008440 LA-UR-92-537

DE92008443 LA-UR-92-377

DE92008454 SAND-91-0790

DE92008473 LA-UR-92-461

DE92008492 LA-UR-92-534

DE92008676 SAND-89-1465C

DE92008930 UCRL-JC-109231

DE92009131. LBL-30707

DE92009137 LBL-31069

DE92009517 WSRC-MS-90-351

DE92009558 SAND-89-2558

DE92009745 ANL/EAIS/TM-41

DE92009987 LBL-31258

DE92010359 SAND-89-7008

DE92010459 LBL-31799

DE92010496 PNL-SA-20324

DE92010759 SAND-87-2380

DE92010760 SAND-91-7034

DE92010761 SAND-91-0792

DE92010762 SAND-89-1871

DE92010900 ANL/CP-74094

DE92011180 SAND-91-2266C

DE92011382 SAND-92-0091C

DE92011449 EGG-10617-2127

DE92011753 ANL-92-9

DE92011869 USGS-OFR-91-367

DE92011870 LA-12301-MS

DE92011923 DOEJOR/21555-T2

DE92012265 USGS-OFR-91-620

DE92012319 PNL-7474

DE92012395 UCRL-ID-105340

DE92012615 SAND-89-0972/2

DE92012631 SAND-91-1730C

DE92012685 SAND-90-2882
Order No. Report No.

DE92013055 SAND-89-7007

DE92013459 SAND-88-7124

DE92013506 CONF-921082-2

DE92013548 LA-UR-92-1194

DE92013559 DOE/OR/21497-1

DE92013641 ANL-91/42

DE92013768 SAND-88-1331

DE92013998 LA-12062-MS-Rev.1

DE92014170 SAND-88-0585

DE92014614 PNL-8081

DE92014660 DOENV/10872-T2

DE92014661 DOE/NV/10872-T3

DE92014662 DOE/NV/10872-T4

DE92014668 DOE/NV/10872-T10

DE 92014670 DOE/NV/10872-T12

DE92014671 DOE/NV/10872-T13

DE92014807 UCRL-JC-109216

DE92014882 USGS-OFR-91-572

DE92014884 UCRL-JC-106752

DE92014888 UCRL-JC-106703

DE92014889 UCRL-JC-106693

DE920151.86 ANL/CP-76140

DE92015393 SAND-87-2778

DE92015564 ORNLM-1822

DE92016083 SAND-91-1676C

DE92016156 UCRL-JC-106758

DE92016228 DOE/OR/00033-T484

DE92016339 DOE/OSTI-

3406(Suppl.3)(Add.1)

DE92016399 ANLCP-76305

DE92016452 SAND-92-0279C

DE92016499 SAND-92-1317C

DE92016649 SAND-91-0607

DE92016673 SAND-90-2491

DE92016737 ANLCP-75280

DE92016744 UCRL-ID-109215

DE92016791 SAND-91-2895C-Draft

DE92017022 LBL-31975

DE92017043 SAND-92-1226C

DE92017084 LBL-31181

DE92017281 SAND-90-2542

DE92017282 SAND-88-7051

DE92017356 SAND-91-0894

DE92017360 SAND-89-7002

DE92017362 SAND-88-7061

DE92017439 UCRL-JC-109952

DE92017578 NWPO-SE-041-91

DE92017676 NWPO-SE-038-91

DE92017678 NWPO-TN-007-90

DE92017679 NWPO-TN-006-90

DE 92017680 SAIC-91/8000

DE92017681 SAIC-91/8001

DE92017705 NWPO-SE-042-91

DE92017707 NWPO-TN-001-88

DE92017708 NWPO-TN-013-91

DE92017709 NWPO-TN-002-89

DE92017712 NWPO-SE-037-91

DE92017713 NWPO-SE-039-91-Vol.1

DE92017714 NWPO-SE-039-91-Vol.2

DE92017730 NWPO-SE-026-90 
Order No. Report No.

DE92017731 NWPO-SE-044-91 DE92017732 NWPO-SE-043-91 DE92017733 NWPO-SE-040-91 DE92017734 NWPO-TN-010-90 DE92017735 NWPO-SE-036-87 DE92017833 NWPO-GR-1 DE92017892 NWPO-TN-011-91-Vol.1

DE92017893 NWPO-GR-15

DE92017901 NWPO-GR-24-Vol.1

DE92017902 NWPO-GR-24-Vol.2

DE92017904 NWPO-GR-16

DE92017911 NWPO-TN-011-91-Vol.2-3

DE92017912 NWPO-GR-20

DE92017913 DOE/NV/10461-T41

DE92017984 DOENNV-354

DE92017988 DOENV/10845-8

DE92018115 CONF-920849-1

DE92018824 SAND-92-0472C

DE92018930. SAND-88-1581

DE92018938 SAND-89-7018

DE92019014 DOENNV/10576-T4

DE92019173 CONF-8904440-1

DE92019239 ANL-92/28

DE92019280 USGS-OFR-92-137

DE92019324 SAND-85-0004

DE92019465 SAND-89-0972/1

DE92019615 DOE/NV/10576-T5

DE92019642 SAND-91-2795

DE92019767 SAND-91-0079

DE92019801 SAND-91-0558

DE92040807 CONF-920307-89

DE92040952 CONF-920761-15

DE92041032 DOE/OR/00033-T487

DE92041080 UCRL-ID-109921

DE92041231 PNL-7581

DE92041241 LA-12325-C

DE92613462 SKB-TR-90-19

DE92613489 SKB-TR-90-14

DE92613490 SKB-TR-90-22

DE92613512 SKB-TR-90-15

DE92750952 JAERI-M-91-118

DE93000385 DOE/NV/10845-14

DE93000844 SAND-91-1493

DE93001349 SAND-91-2416

DE93001775 PNL-8327

DE 93002513 SAND-91-7038

DE93003157 DOE/NV/10845-15

DE93003232 SAND-91-7035

DE93003273 NRC-93003273

DE93003359 UCRL-MA-110662-Pt.1

DE93003685 DOE/RW/00134-Tt

DE93003790 LA-UR-92-3549

DE93004285 USGS-OFR-90-369

DE93004286 USGS-OFR-91-478

DE93004386 SAND-91-0758

DE93005088 DOERWW-0307P-6

DE93005097 PNL-SA-20329

DE93005375 SAND-92-2335C

DE93005637 DOEJOSTI3406(Suppl.3)(Add.2)

DE93005704 CONF-930408-8

DE93005826 UCRL-MA-110662-Pt.2

DE93005827 UCRL-MA-110662-Pt.3

DE93005849 JAB-10733-TM6

DE93006069 DOE/CH/10378-10

DE93006097 LA-12376-MS

DE93006179 DOENV/10630-49

DE93006405 ANLCMT/CP-76238

DE93006419 ANLCMT/CP-76240

DE93006753 SAND-92-2600C

DE93006755 SAND-93-7013C
Order No. Report No.

DE93006765 SAND-92-2790C

DE93006770 SAND-92-2827C

DE93006771 SAND-92-2826C

DE93006781 SAND-92-2153C

DE93006782 SAND-92-2828C

DE93006783 SAND-92-2672C

DE93006985 SAND-91-7037

DE93006986 SAND-92-0556

DE93007118 UCRL-MA-110662-Pt.4

DE93007323 LA-UR-93-437

DE93007324 LA-UR-93-436

DE93007338 LA-UR-93-0071

DE93007371 LA-UR-93-270

DE93007438 PNL-8444

DE93007507 UCRL-JC-107985

DE93007659 LBL-31666

DE93007743 UCRL-ID-111624

DE93007744 ANL-92/44

DE93008020 UCRL-JC-112435

DE93008021 UCRL-JC-111652

DE93008022 UCRL-JC-112445

DE93008082 SAND-92-0461

DE93008149 CONF-930496-1

DE93008354 SAND-92-2491C

DE93008355 SAND-93-7005C

DE93008358 SAND-92-2671C

DE93008406 SAND-92-2838C

DE93008407 SAND-93-0039C.

DE93008408 SAND-92-2739C

DE93008409 SAND-92-2791C

DE93008410 SAND-92-2784C

DE93008412 SAND-92-7344C

DE93008648 ANU/MCT/CP-75243

DE93008725 LA-UR-93-690

DE93008756 UCRL-ID-112036

DE93008757 UCRL-ID-112058

DE93008910 LA-SUB-93-83

DE93008917 LA-SUB-93-51

DE93008920 LA-SUB-93-64

DE93009062 UCRL-JC-112444

DE93009063 UCRL-JC-112825

DE93009070 UCRL-JC-110677

DE93009626 SAND-92-2152C

DE93009636 SAND-92-2792C

DE93009824 USGS-OFR-92-340

DE93009873 USGS-OFR-91-623

DE93009908 ANUEAIS/TM-87

DE93009953 ANUEAIS/CP-78642

DE93010380 WSRC-MS-93-143

DE93010410 LBL-33627

DE93010413 LBL-33660

DE93010414 LBL-33663

DE93010421 LBL-33464

DE93010431 LBL-33661

DE93010432 LBL-33662

DE 93010444 LBL-32874

DE93010450 LBL-33597

DE93010640 DOE/FTR-93010640

DE93011044 DOE/NV/ $10630-28$-Add. 1

DE93011473 LA-12460-MS

DE93011580 SAND-92-2670C

DE93011790 ANUEAIS/TM-85

DE93011910 ANLEAIS/TM-92

DE93012082 LA-SUB-93-118

DE93012451 SAND-92-0589

DE93012727 USGS-OFR-92-343

DE93012873 ANL/EAIS/TM-93

DE93012990 CONF-930408-69

DE93013165 PNL-SA-22264

DE93013189 USGS-OFR-92-572

DE93013204 NWPO-TR-011-89
Order No. Report No.

DE93013212 NWPO-SE-055-92 DE93013213 NWPO-TR-014-90 DE93013215 NWPO-TR-018-91 DE93013216 NWPO-SE-054-92 DE93013217 NWPO-SE-045-92 DE93013508 CONF-920866-7 DE93014228 DOE/NV/10872-8 DE93014243 DOENV/10872-T57 DE93014510 DOE/RW/00134-T2 DE93014804 DOE/FTR-93014804 DE93014824 WINCO-1119 DE93014854 UCRL-LR-107476-Vol.1 DE93014855 UCRL-LR-107476-Vol.2 DE93014980 DOE/FTR-93014980 DE93015280 LBL-23593 DE93015498 USGS-OFR-93-187 DE93015729 SAND-87-1305 DE93015807 DOE/FTR-93015807 DE93016231 LA-12564-MS DE93016278 USGS-OFR-92-490 DE93016279 USGS-OFR-93-73 DE93016317 DOE/CH/10324-T20

DE93016342 PNL-8636 DE93016459 LA-UR-93-2326 DE93016563 LA-UR-93-2254 DE93016760 DOE/RW-93016760 DE93016954 UCRL-ID-112789

DE93017090 YMP-91-17 DE93017091 YMP-91-19 DE93017131 DOENV/10845-16 DE93017134 DOE/RW/00134-T4 DE93017415 USGS-OFR-91-493 DE93017646 USGS-OFR-92-130 DE93017656 SAND-93-1415C DE93017958 UCRL-ID-112433 DE93018073 JAB-10733-TM8 DE93018116 ANL-93/13

DE93018276 LA-SUB-93-185 DE93018290 LA-UR-93-2761 DE93018485 EGG-10617-2195 DE93018522 SAND-92-0450 DE93018523 SAND-92-0960 DE93018679 SAND-92-2334 DE93018681 SAND-92-2431 DE93018682 SAND-92-2762 DE93018768 SAND-88-7054 DE93018771 NWPO-TR-016-91 DE93018826 SAND-93-1109C DE93018968 DOE/NV/10872-T68 DE93018969 DOE/NV/10872-T69 DE93019212 UCRL-ID-113383 DE93019282 CONF-9304190-1 DE93019729 DOE/RW-93019729 DE93040090 LA-UR-93-2882 DE93040441 UCRL-ID-112834 DE93040570 LA-SUB-93-231 DE93040572 LA-SUB-93-217 DE93040587 LA-SUB-93-256 DE93041100 UCRL-ID-111979 DE93041147 NWPO-TR-019-92 DE93041148 NWPO-TR-020-93 DE93609565 INIS-XN-393 DE93609566 INIS-XN-415 DE93609569 INIS-XN-418 DE93618121 INIS-XN-428 DE93797600 JAERI-M-93-023 DE94000346 SAND-92-1810 DE94000351 UCRL-JD-114148 DE94000437 USGS-OFR-91-125 DE94000628 LA-UR-92-2577 DE94000698 LA-12542-MS 
Order No. Report No.

DE94000896 LA-UR-93-3299

DE94000959 DOE/NV/10576-T6

DE94001176 WSRC-TR-93-0111-Rev.1

DE94001185 LLNL-94001185

DE 94001458 ANUCMT/CP-79779

DE94001566 LA-12562-MS

DE94001854 UCRL-ID-112432

DE94002011 UCRL-JC-114783

DE94002515 DOE/NV/10872-T84

DE 94002599 LA-UR-93-3505

DE94002608 SAND-92-1853

DE94002609 SAND-92-2247

DE94003377 LBL-30043

DE94003607 USGS-OFR-93-438

DE94003899 LA-12708-MS

DE94603017 CEA-CONF-11515

T192000352
Order No. Report No.

T192005176

T192006461

T192006919

TI92007821

T192011882

T192012386

T192012388

T192013440

T192014239

T192014878

T192014995

T192015376

T192016363

T192016367

Ti92016567

T192018776

T192019109
NUREG/CR-4735-Vol.7

DOE/RW-0318

DOE $/ R W-0306 \mathrm{P}-3$

NUREG/CR-5708

USGS-OFR-91-105

DOE/RW-0253-Rev.2

DOE'RW-0313P

DOE/RW-0293P

DOE/RW-0354P

DOE/RW-0307P-5

NUREG-1327

NUREG/CR -5710

DOE/RW-0365P

DOE/RW-0349P

DOE/RW-0268P-Rev.2

NUREG/CR-5687

DOE/RW-0335P (1992)
Order No. Report No.

TI92019210

T192040954

T193000354

T/93001260

$\mathrm{T} 193002843$

T193003069

T193004888

T193007535

T198008169

T198011023

T193013686

TI93016057

TI93019109

TI93040932

T194000409

NUREG/CR-5685 NUREG/CR-5880 DOE/RW-0253-Rev.3 DOE $/ R W-0370$ NUREG/CR-5890 PNL-7847 DOE/RW-0380P DOE/RW-0307P-7 NUREG/CR-5917-Vol.1 USGS/OFR-92-28 DOE/RW-0345P NUREG/CR-4735-Vol.8 NUREG/CR-6021 DOE/RW-0422 DOE/RW-0423 


\section{Key Word in Context Index}

A

=Rail

ion of the limitations for surficial water addition =Nuclear waste: Quality assurance auditors need Nevada railroad system: Physical, operational, and $=$ Preclosure radiological safety analysis for =Rationale for determining MCC spent fue mpact of fracture coatings on the transfer of water September 30, 1991, Number 5: Nuclear Waste Policy $=S .1138$ : A bill to amend the Nuclear Waste Policy =Health and environmental risk-related impacts of =Effects of

. . . eptunium at Yucca Mountain using Epithermal Neutron

=Estimation of the limitations for surficial water . . . . Mountain Site Characterization Project Radionuclide . . . . . Mountain Site Characterization Project Radionuclide . . . . Mountain Site Characterization Project Radionuclide . . . . . Mountain Site Characterization Project Radionuclide . . . . Mountain Site Characterization Project Radionuclide . . . . Mountain Site Characterization Project Radionuclide . . . . . Mountain Site Characterization Project Radionuclide . . . . Mountain Site Characterization Project Radionuclide . . . . Mountain Site Characterization Project Radionuclide . . . . Mountain Site Characterization Project Radionuclide . . . . Mountain Site Characterization Project Radionuclide . . . . Mountain Site Characterization Project Radionuclide . . . . Mountain Site Characterization Project Radionuclide =Boron =Proceedings of =US Geological Survey Committee for the

$=$ The role of fault zones in . . . . cords from Little Skull Mountain, Nevada earthquake ... . ritical comments on the US Environmental Protection ..... ngress of the International Nuclear Law Association =Field

$=$ Neptunium $(V)$ sorption on quartz and $=$ Proceedings of the $=$ Proposed mineralogy and geochemistry of the Pocos de Caldas $s$ of the Osamu Utsumi uranium mine, Pocos de Caldas ne syenites and phonolites from the Pocos de Caldas

$=$ Fish communities in sandy pool of Magela Creek International INTRAVAL project. Phase 1 case 8: The dynamic polarization studies on candidate container

s-corrosion-cracking studies on candidate container egradation modes of four nickel-chromium-molybdenum . . . . . eological disposal of spent fuel and high level and =Natural analogue studies: Mineral =Effects of radiation exposure on glass $=$ Characterizing the

$=$ Neotectonics of the southern $=S$. 1138: $A$ bill to

$=$ The role of

=mpirical investigation of the effect of .... essment guidance report: Determining the effects of $=$ Socioeconomic profiles of native =Socioeconomic profiles of Native =Socioeconomic profiles of native $=$ Proceedings of the

=Native

$=$ Native

=Native

=Native abandonments in the South and their effect on NWPA ... . above a potential high level radioactive waste repo . . . . . . access to employee records*

accident characteristics*

accident conditions of the potential Yucca Mountain . . . . . . acquisitions*

across fracture faces in unsaturated media*

Act (Section 113)

Act of 1982 to direct the Secretary of Energy to ca ... . . . actinide burning on high-level waste disposal ${ }_{*}$

actinide burning on waste disposal at Yucca Mountai . . . . . Activation Analysis*

addition above a potential high level radioactive $w$. . . . . . Adsorption Workshop at Los Alamos National Laborato . . . Adsorption Workshop at Los Alamos National Laborato ... Adsorption Workshop at Los Alamos National Laborato . . . Adsorption Workshop at Los Alamos National Laborato . . . Adsorption Workshop at Los Alamos National Laborato . . . Adsorption Workshop at Los Alamos National Laborato . . . Adsorption Workshop at Los Alamos National Laborato . . . Adsorption Workshop at Los Alamos National Laborato . . . Adsorption Workshop at Los Alamos National Laborato . . . Adsorption Workshop at Los Alamos National Laborato . . . Adsorption Workshop at Los Alamos National Laborato . . . Adsorption Workshop at Los Alamos National Laborato . . . Adsorption Workshop at Los Alamos National Laborato . . . adsorption on hematite and clinoptilolite*

advanced cementitious systems: Mechanisms and prope .. Advancement of Science in the Yucca Mountain Projec . . . Aeromagnetic map of the Beatty quadrangle, Nevada-C . . . affecting multiphase flow at Yucca Mountain*

aftershocks of July 5, 1992 and September 13,1992, . . . Agency Standards 40 CFR $191 \%$

AIDN-INLA), Bath, England, 23-26 September 1991 *

air injection tests to determine the effect of a he . . . . . . . . albite in aqueous suspension: Annual progress repor . . . . .

Alfred 0 . Nier symposium on inorganic mass spectrom . . . . algorithm for determining the delta intercept of $a \ldots \ldots$ alkaline caldera complex, Minas Gerais, Brazil*

alkaline complex, Brazil: Pocos de Caldas Report No . . . . . alkaline complex, Minas Gerais, Brazil*

Alligator Rivers Region Research Institute: annual . . . . . . Alligator Rivers Region Research Institute: annual . . . . . . Alligator Rivers Region: Research Report 9*

Alligator rivers natural analoguex

alloys for the Tuff Repository*

alloys for the Tuff Repository*

alloys*

alpha bearing wastes: Proceedings of an internation ..... alteration and uranium migration*

alteration in a steam environment*

altered zone at Yucca Mountain: The beginning of a . . . . . Alternative strategies: A means for saving money an . . . . . Amargosa Desert, Nye County, Nevada and Inyo County . . amend the Nuclear Waste Policy Act of 1982 to direc . . . . . amenities and other factors in influencing the loca . . . . . . . amenities and other factors on business location de ..... amenity characteristics on business location decisi . . . . . . American communities: Duckwater Shoshone Reservatio . . American communities: Las Vegas Tribes of Paiute in . . . . American communities: Yomba Shoshone Reservation* American power conference: Economy, efficiency, qua . . . . Americans and Yucca Mountain: A revised and updated . . . Americans and Yucca Mountain: A revised and updated . . . Americans and Yucca Mountain: A summary report* Americans and state and local governments* 
lities and speciations of neptunium, plutonium, and $=$ Natural

. . aldera and the Osamu Utsumi mine and Morro do Ferro .... . petrology and geochemistry of the Pocos de Caldas ... . . petrology and geochemistry of the Pocos de Caldas . . . aters from the Osamu Utsumi mine and Morro do Ferro ... nalysis at the Osamu Utsumi mine and Morro do Ferro ... ability at the OSAMU Utsumi mine and Morro do Ferro . . . aters from the Osamu Utsumi mine and Morro do Ferro . . . emistry at the Osamu Utsumi mine and Morro do Ferro ... actions at the Osamu Utsumi mine and Morro do Ferro . mples from the Osamu Utsumi mine and Morro do Ferro . . . . esting of geochemical models in the Pocos de Caldas . . . . . oject. Phase 1 case 8: The Alligator rivers natural . . . o oject. Phase 1, case 7. The Pocos de Caldas natural $=$ Sensitivity and uncertainty round-water travel time sensitivity and uncertainty

=Preliminary drift design
=Sensitivity

=Preliminary drift design
=Sensitivity . . . ect total-system performance assessment preliminary .. . uclide source terms used for performance-assessment ... . ide transport in a layered fractured rock: MULTFRAC $=$ Application of $=$ Semi-

=NORIA-SP: A finite element computer program for

$\mathbf{n}$ assessing the effect of ionizing radiation on the ..... Proceedings of an international symposium held in $=$ Single fracture

$s$ phase migration of $\mathrm{C}-14$ through barrier materials =Characterization of spent fuel =Characterization of spent fuel

. . . ea 5 of the Nevada Test Site: The Dupuit-Forcheimer $=E Q 3 / 6$ V7.0: Geochemical Modeling Of $=E Q 3 / 6$ V7.1: Geochemical Modeling of

. ... 6, a computer program for reaction path modeling of $=E Q 3 N R$, a computer program for geochemical =Neptunium $(V)$ sorption on quartz and albite in

\section{... 3/6, a software package for geochemical modeling of}

nergy neutron tomography of water in rock using the No. 3 for the Waste Package Project: Parts A \& B, nuclear waste transportation: Prepared pursuant to a shipping cask, a waste container, and a bare fuel $=$ Expert judgment in $=$ Progress in $=$ Total System Performance ... udy of the use of RADTRAN in the 1986 Environmental =Safety =Safety =Safety =Safety

. . . . tegration Program (RIP) to Total System Performance ty of Yucca Mountain, Nevada: Iterative Performance in the Technical Workshop on Near-Field Performance ... . . of radionuclide source terms used for performance=Probabilistic risk

. . . . . ion and use of sorption coefficients in performance =TSPA 1991: An initial total-system performance on of the NRC's capability to conduct a performance =SUMO, System performance om the technical workshop on near-field performance om the technical workshop on near-field performance =Socioeconomic $=$ Applications of performance $\mathrm{n}$ the scope, content, and use of comprehensive risk =Preliminary

. . . and computational approaches to support performance . . . . . ater hydrology modelling strategies for performance =Proceedings of the Symposium on safety americium in a typical groundwater $(\mathrm{J}-13)$ from the $\ldots . .$. analogue studies: Mineral alteration and uranium $\mathrm{mi}$. . . . . . analogue study sites, Brazil: Pocos de Caldas Repor . . . . . analogue study sites, Minas Gerais, Brazil: II. Mor . . . . . . analogue study sites, Minas Gerais, Brazil. I. Osam . . . . . . analogue study sites, Pocos de Caldas, Brazil

analogue study sites, Pocos de Caldas, Brazil: Poco . . . . . analogue study sites, Pocos de Caldas, Brazil: Poco . . . . analogue study sites, Pocos de Caldas, Brazil* analogue study sites, Pocos de Caldas, Brazil * analogue study sites, Pocos de Caldas, Brazil* analogue study sites, Pocos de Caldas, Brazil* analogue study*

analogue*

analogue: studies of redox front movement*

analyses applied to one-dimensional radionuclide $\mathrm{tr}$. . . . . analyses for Yucca Mountain, Nevada: Yucca Mountain . . . analyses for nuclear waste repository in tuff*

analyses for total-system performance assessment* analyses: Ovenview: Draft.

analyses: Yucca Mountain Site Characterization Proj . . . . . Analytic solutions and local sensitivities: Phase $2 \ldots \ldots$. . analytical methods for jointed rock as part of a $\mathrm{dr}$. . . . . . . analytical treatment of fracture/matrix flow in a $d \ldots \ldots .$. analyzing liquid water transport in porous media: $Y \ldots \ldots$ Anisotropy of the Topopah Spring Member Tuff*

anticipated waste package environment at the Yucca . . . . Antwerp, 19-23 October 1992*

aperture patterns: Characterization by slit-island ...... applicable for use in a high-level nuclear waste re . . . . . . . approved testing materiał-ATM-105*

approved testing materiat-ATM-104*

approximation $\times$

Aqueous Systems*

Aqueous Systems*

equeous geochemical systems: Theoretical manual, us ...

aqueous speciation-solubility calculations: Theoret . . . . . . aqueous suspension: Annual progress report*

aqueous systems: Package overview and installation . . . . Areal power density: A preliminary examination of $u$. . . . . . AREST user's guide, $P C$ version*

AREST: The next generation*

Argonne IPNS*

ASME pressure vessel codes review for waste package ... assembly concurrent resolution No. 8 of the $1987 \mathrm{Ne}$. . . . assembly during waste-handling operations: Yucca Mo . . . . assessing radwaste risks: What Nevadans should know . . . assessing the effect of ionizing radiation on the a ....... Assessment Code (TOSPAC): Volume 2, User's guide: $Y$. . Assessment for Yucca Mountain*

Assessment of Radioactive Waste Repositories*

Assessment of Radioactive Waste Repositories*

Assessment of Radioactive Waste Repositories*

Assessment of Radioactive Waste Repositories*

Assessment of geophysical logs from borehole USW G- . . .

Assessment, 1991*

Assessment, Phase 2*

Assessment: Foreign trip report, May 9-16, 1993*

assessment analyses: Yucca Mountain Site Characteri . . . .

assessment and nuclear waste transportation: A case . . . .

assessment calculations for the Yucca Mountain site*

assessment for Yucca Mountain: Yucca Mountain Site . . .

assessment for a High-Level Waste Repository*

assessment for a high-level nuclear waste repositor . . . . . assessment for high-level waste*

assessment for high-level waste *

assessment guidance report: Determining the effects . . . . . assessment in support of the Exploratory Studies $\mathrm{Fa}$. . . . . assessment in the management of high-level nuclear .... assessment of clinoptilolite KUAr results from Yucc . . . . . . assessment of hydrology and chemical transport at $\dot{Y} \ldots$. assessment of nuclear waste disposal* assessment of radioactive waste repositories* 
$=$ Developing conceptual models for performance $=$ Post-closure performance =Yucca Mountain Project total-system performance =An example postclosure risk ..... nd applying sorption data to repository performance ... geologic repository post closure system performance .... g visualization and analysis system for performance

......s of volcanic events: Applications to volcanic risk =Sensitivity analyses for total-system performance eciation studies for nuclear repository performance . . . adsheet as an interface to total-system performance =Transportation needs -Scenario development for performance local sensitivities: Phase 2, Iterative performance onuclide source term for total-system performance $=$ Travel to Switzerland for performance =Sealing performance $=$ Report on task

. . . . . terization of spent fuel approved testing material. . . . . . terization of spent fuel approved testing material$=$ Modulus dispersion and assessment of waste management sites* assessment of waste packages for the Yucca Mountain . . assessment preliminary analyses: Overview: Draft* assessment using the potential Yucca Mountain Site ${ }^{*}$. . . assessment* assessment* assessment* assessment $*$ assessment* assessment* assessment assessment: Emergency response section* assessment: Some questions for the near-field model . . . . assessment: Volume 1 *

assessment: Yucca Mountain Site Characterization $\mathrm{Pr}$. . . . assessments for both the low- and intermediate-leve . . . . . assessments of bentonite and bentonite/crushed rock . . . . assignment No. 3 for the Waste Package Project: Par . . . ATM-104*

ATM-105*

attenuation in tuff and granite*

Automated waste canister docking and emplacement us ...
. . . . . field testing definition of subsurface sealing and . . . . I drop of a shipping cask, a waste container, and a ... basis and programmatic requirements for Engineered $=$ Engineered $=$ Gas phase migration of $\mathrm{C}-14$ through =Engineered

. . . . . cientific investigation plan for initial engineered $=$ Reliability modeling of an engineered joactive Waste Management Program Cost and Schedule =Program cost and schedule . . . . near-field environment report: Volume 1, Technica ... . smicity and focal mechanisms for the Southern Great ... . smicity and focal mechanisms for the southern Great .... smicity and focal mechanisms for the southern Great . . . . . . lide migration laboratory studies for validation of . . . e e International Nuclear Law Association (AIDN-INLA) . . . . . cal disposal of spent fuel and high level and alpha $=$ Aeromagnetic map of the . . . . ges associated with zeolitization of the tuffaceous . . . . racterizing the altered zone at Yucca Mountain: The $=$ Crack growth =Small-scale

. . . ff: Comparison between predicted and observed shear . . . . . ents of TRU nuclides for evaluating their migration . . . Mountain Project thermal and mechanical codes first $=$ TOSPAC calculations in support of the COVE $2 A$ =Groundwater flow code verification . . . . . . Implications for strike-slip faulting and oroclinal =Sealing performance of =Sealing performance assessments of $=$ Sealing performance of bentonite and =Sealing performance assessments of bentonite and

$=$ Yucca Mountain Site characterization project = Yucca Mountain Site Characterization Project =Yucca Mountain Site characterization project =Yucca Mountain Site Characterization Project =A selected GIS $=S$. 1138: $A$ =Yucca Mountain =Yucca Mountain

. . . . slot cutting methods for the Yucca Mountain heated ..... nical basis and programmatic requirements for large = The relationship of the Yucca Mountain repository . . . . y of Energy from the Nuclear Waste Technical Review ... . y of Energy from the Nuclear Waste Technical Review .... .y of Energy from the Nuclear Waste Technical Review backfilling tests in unsaturated tuff: Yucca Mounta . . . . . . bare fuel assembly during waste-handling operations . . . . Barrier System Field Tests*

barrier environment. Yucca Mountain*

barrier materials applicable for use in a high-leve . . . . . . barrier system and waste package design concepts fo .... barrier system field tests*

barrier system*

Baseline: Revision 3*

baseline: Revision 2*

bases for EBS design*

Basin of Nevada and California in 1990*

Basin of Nevada and California in 1991*

Basin of Nevada and California: 1987 through 1989*

batch sorption data $x$

Bath, England, 23-26 September 1991*

bearing wastes: Proceedings of an international sym . . . . . Beatty quadrangle, Nevada-Californiax

beds of Calico Hills at Yucca Mountain, Nevada*

beginning of a testing strategy*

behavior of candidate waste container materials in ......

behavior of single gravity-driven fingers in an ini . . . . . . .

behavior using a graphical method: Yucca Mountain $S$.... behaviors*

benchmark exercise: Part 3, Jointed rock mass analy ... . benchmarking activity: Yucca Mountain Site Characte . . . . benchmarking" activity (COVE-2A): Analysis of part . . . . . bending $x$

bentonite and bentonite/crushed rock borehole plugs*

bentonite and bentonite/crushed rock plugs*

bentonite/crushed rock borehole plugs*

bentonite/crushed rock plugs×

Bibliography of Yucca Mountain Project (YMP) public . . . .

bibliography, January-June 1991: An Update: Supple . . . . bibliography, January-June 1991: Supplement 3*

bibliography, January-June 1992: An Update: Supple . . . . bibliography, July-December 1992: An update, Suppl . . . . bibliography: Technical Memorandum 40*

bill to amend the Nuclear Waste Policy Act of 1982 . . . . . . Biological Resources Monitoring Program: Annual rep . . . . biological resources monitoring program: Annual rep . . . . . block test using a compliant-joint model×

block testing of coupled thermal-mechanical-hydrolo . . . . . block to the regional ground-water system: A geoche . . . . . Board*

Board*

Board* 
=Assessment of geophysical logs from =Waste package emplacement . . . performance of bentonite and bentonite/crushed rock ... untain boreholes, Nevada Test Site, Nevada: Part 1, =Geophysical logs and core measurements from forty . . asurements made on core samples from Yucca Mountain

$=$ Durability study of sodium =Effect of $=$ Effect of

. . . . tive solution method for coupled finite element and .... HEFF code for thermal-mechanical analysis using the . . . . rro do Ferro analogue study sites, Pocos de Caldas, . . . . rro do Ferro analogue study sites, Pocos de Caldas, .... the Pocos de Caldas alkaline complex, Minas Gerais, . . . . . rro do Ferro analogue study sites, Pocos de Caldas, . . . . rro do Ferro analogue study sites, Pocos de Caldas, . . . . rro do Ferro analogue study sites, Pocos de Caldas, . . . s de Caldas alkaline caldera complex, Minas Gerais, . . . Pocos de Caldas analogue study sites, Minas Gerais, . . . Pocos de Caldas analogue study sites, Minas Gerais, . . . . . rro do Ferro analogue study sites, Pocos de Caldas, . . . umi uranium mine, Pocos de Caldas alkaline complex, . . . . tsumi mine and Morro do Ferro analogue study sites,

. . . . rro do Ferro analogue study sites, Pocos de Caldas, $=1991$ OCRWM

..... stimates of potential radionuclide migration at the $=$ Criticality safety issues associated with the =Thermal performance of a . . . . and environmental risk-related impacts of actinide $=$ Effects of actinide

. . . . . ion of the effect of amenities and other factors on ...... termining the effects of amenity characteristics on .... e storage container storing a hybrid mix of PWR and

Borehole UE25PNo.1*

Borehole and geohydrologic data for test hole USW U . . . .

borehole option study: Yucca Mountain Site Characte ... . borehole plugs*

Boreholes UE25A-4, -5, -6, and -7; Part 2, Borehole . . . . boreholes at Yucca Mountain, Nevada*

boreholes, Nevada Test Site, Nevada: Part 1, Boreho .... Boron adsorption on hematite and clinoptilolite*

borosilicate glasses leached in tuff $\mathrm{J}-13$ groundwat . . . . . boundary conditions on the strength and deformabili . . . . . boundary conditions on the strength and deformabili ..... . boundary element modeling: Yucca Mountain Site Char ... . boundary-element method: Version 4.1: Yucca Mountai . . Brazil*

Brazil*

Brazil*

Brazil*

Brazil*

Brazll*

Brazil*

Brazil. I. Osamu Utsumi uranium mine: Pocos de Cald . . . Brazil: II. Morro do Ferro*

Brazil: Pocos de Caldas Report No. 10*

Brazil: Pocos de Caldas Report No. 13*

Brazil: Pocos de Caldas Report No. 5*

Brazil: Pocos do Caldas Report No. $6 *$

bulletin compilation and index*

Bullion site*

burial of highly enriched nuclear fuel in a geologi . . . . . .

burled nuclear waste storage container storing a hy . . . . . . .

burning on high-level waste disposal*

burning on waste disposal at Yucca Mountain*

business location decisions*

business location decisions*

BWR spent fuel rods: Revision 1 *

. . . . rill holes at Yucca Mountain, Nevada, with notes on =PACE-90 water and solute transport =Supporting hydration

. . . . of sorption coefficients in performance assessment =TOSPAC

=Preliminary

$=$ The results of near-field thermal and mechanical . . . ogram for geochemical aqueous speciation-solubility . . . . . . nal far-field potential repository thermomechanical . . . . ogue study sites, Pocos de Caldas, Brazil: Pocos de .... Pocos de Caldas alkaline complex, Brazil: Pocos de . . . a ais, Brazil. 1. Osamu Utsumi uranium mine: Pocos de . . . . r ro do Ferro analogue study sites, Brazil: Pocos de . . . . ogue study sites, Pocos de Caldas, Brazil: Pocos do . . . eology, mineralogy and geochemistry of the Pocos de ... genesis of the Osamu Utsumi uranium mine, Pocos de .... nepheline syenites and phonolites from the Pocos de .... eralogy, petrology and geochemistry of the Pocos de .... eralogy, petrology and geochemistry of the Pocos de =Testing of geochemical models in the Pocos de . . . . ogical and hydrogeological features of the Pocos de ... nal INTRAVAL project. Phase 1, case 7. The Pocos de $=$ The Pocos de . . . . ications for radioactive waste management: Pocos de .... a and Morro do Ferro analogue study sites, Pocos de .... e and Morro do Ferro analogue study sites, Pocos de . . . . e and Morro do Ferro analogue study sites, Pocos de ... e e and Morro do Ferro analogue study sites, Pocos de .... e and Morro do Ferro analogue study sites, Pocos de .... e and Morro do Ferro analogue study sites, Pocos de . . . . e and Morro do Ferro analogue study sites, Pocos de calcite occurrence: Yucca Mountain Site Characteriz . . . . . 298 Calculation of experiment uncertainty in laboratory ....... calculations for $0.01,0.1$, and $0.5 \mathrm{~mm} / \mathrm{yr}$ infiltra . . . . . calculations for small- to large-scale seal tests $\mathrm{i} \ldots \ldots \ldots$ calculations for the Yucca Mountain sitex

calculations in support of the COVE 2A benchmarking . . . . calculations of release rates of TC-99, $\mid-129$, and . . . . . . calculations of thermal loading schemes*

calculations: Theoretical manual, user's guide, and . . .... . . calculations: Yucca Mountain Site Characterization . . . . . Caldas Report No. 10*

Caldas Report No. 13*

Caldas Report No. 2×

Caldas Report No. 5x

Caldas Report No. 6x

Caldas alkaline caldera complex, Minas Gerais, Braz . . . . .

Caldas alkaline complex, Brazil: Pocos de Caldas Re . . . . .

Caldas alkaline complex, Minas Gerais, Brazil

Caldas analogue study sites, Minas Gerais, Brazil: . . . . . .

Caldas analogue study sites, Minas Gerais, Brazil. . . . . . . Caldas analogue study $\times$

Caldas caldera and the Osamu Utsumi mine and Morro . . .

Caldas natural analogue: studies of redox front mov . . . . .

Caldas project: summary and implications for radioa . . . . .

Caldas report no. 15 -

Caldas, Brazil $\times$

Caldas, Brazil

Caldas, Brazilx

Caldas, Brazil

Caldas, Brazilx

Caldas, Brazil: Pocos de Caldas Report No. 10*

Caldas, Brazil: Pocos do Caldas Report No. 6* 
. . . . and hydrogeological features of the Pocos de Caldas ... . gy and geochemistry of the Pocos de Caldas alkaline . . . . . . ciated with zeolitization of the tuffaceous beds of . . . . summary and discussion of hydrologic data from the ..... along the Death Valley-Furnace Creek fault system, ... chanisms for the Southern Great Basin of Nevada and

... chanisms for the southern Great Basin of Nevada and =Aeromagnetic map of the Beatty quadrangle, Nevadamargosa Desert, Nye County, Nevada and Inyo County, chanisms for the southern Great Basin of Nevada and =Automated waste

of moisture movement in the tuff beneath Mortandad =Initial demonstration of the NRC's $=$ Incorporation of the $=$ The

$=$ Preliminary

$=$ Simulation of two-phase cy Act of 1982 to direct the Secretary of Energy to $=$ The International INTRAVAL project. Phase 1 test $=$ Transportation

=Effects of a potential drop of a shipping ow temperature low pressure piping, containers, and untain Site Characterization Project Technical Data untain Site Characterization Project Technical Data untain Site Characterization Project Technical Data ntain Site Characterization Project: Technical data untain Site Characterization Project technical data $=$ The hydrothermal stability of =Proceedings of advanced $=$ Mesozoic and

$=$ The Lathrop Wells volcanic -The Lathrop Wells volcanic ... the US Environmental Protection Agency Standards $\mathbf{4 0}$ $=$ Chemical and physical .... guidance report: Determining the effects of amenity $=$ Effects of various radiation source . . . . a ailroad system: Physical, operational, and accident

. . . . re review of coupled thermal-hydrologic-mechanical. . . . testing of coupled thermal-mechanical-hydrological. . . . to support performance assessment of hydrology and =Groundwater =Mineralogy, petrology and whole-rock $=$ Distribution and $=A$ preliminary study of the =Mineralogy, petrology and whole-rock =Survey of degradation modes of four nickel=Seismic design of $=A$ forecasting model of gaming revenues in $=$ Using $Q A$

dating of clinoptilolite, mordenite, and associated =An overview of the Yucca Mountain Global/Regional

$=$ Preliminary assessment of =Modeling ion exchange in $=$ Boron adsorption on hematite and =KIAR dating of

$=$ LLNLYMP Waste Container Fabrication and =Fabrication and $=$ Post-

$=$ Approach to geologic repository post $=$ Impact of fracture =Total System Performance Assessment

=CTCN: Colloid transport capillary hysteresis model HYSTR into the numerical $=H E F F-A$ user's manual and guide for the HEFF =Groundwater flow clinoptilolite using the EQ3/6 geochemical modeling =Colloid transport caldera and the Osamu Utsumi mine and Morro do Ferr . . . caldera complex, Minas Gerais, Brazil*

Calico Hills at Yucca Mountain, Nevada*

Calico Hills nonwelded hydrogeologic unit at Yucca . . . . . . California and Nevada*

California in $1990 *$

California in 1991*

California*

California*

California: 1987 through 1989*

canister docking and emplacement using a sensor-bas . . . . Canyon, Los Alamos National Laboratory*

capability to conduct a performance assessment for . . . . . capillary hysteresis model HYSTR into the numerical . . . . . capillary hysteresis model HYSTR: User's guide* capillary hysteresis simulations for fractured rock carbon-14 transport at Yucca Mountain, Nevada* carry out site characterization activities at the $Y \ldots \ldots \ldots$ cases*

cask decontamination and maintenance at the potenti .

cask, a waste container, and a bare fuel assembly $d$

casks with long design lives $\times$

Catalog (quarterly supplement)*

Catalog $\times$

Catalog: Yucca Mountain Site Characterization Proje . . . . . catalog,(quarterly supplement) $\times$

catalog: Yucca Mountain Site Characterization Proje . . . . . cement sealing materials in the potential Yucca Mou . . . . . cementitious systems: Mechanisms and properties. Vo ... Cenozoic structural geology of the CP Hills, Nevada . . . . . Center for Volcanic and Tectonic Studies, Departmen . . . . . center: Status of field and geochronology studies* center: Status of field and geochronology studies* CFR 191*

characterisation of suspended particles and colloid . . . . . . characteristics on business location decisions*

characteristics on shielding requirements at the po . . . . . characteristics .

Chemical and isotopic composition of groundwaters a . . . . Chemical and mineralogical concerns for the use of . . . . Chemical and physical characterisation of suspended . . . . Chemical changes associated with zeolitization of $t$. . . . . . chemical processes pertinent to the proposed high-I . . . . . chemical processes *

chemical transport at Yucca Mountain: Yucca Mountai . . . . chemistry at the Nevada Test Site: Data and prelimi . . . . . chemistry data compilation for selected samples of ..... chemistry of fracture-lining zeolites at Yucca Moun . . . . . . chemistry of pore water extracted from tuff by one- . . . . . . chemistry of selected mechanical test samples of $Y u$. . . . . chromium-molybodenum alloys*

circular-section concrete-lined underground opening . . . . . Clark County, Nevadax

classification to guide design and manage risk*

clays from Yucca Mountains, Nevada*

Climate Modeling Program*

clinoptilolite KAT results from Yucca Mountain, $\mathrm{Ne}$. . . . . . clinoptilolite using the EO3/6 geochemical modeling . . . . . clinoptilolite*

clinoptilolite, mordenite, and associated clays fro . . . . . . . Closure Project: GFY technical activity summary*

closure development of nuclear waste disposal conta . . . . . closure performance assessment of waste packages to ... closure system performance assessment*

coatings on the transfer of water across fracture $f$

Code (TOSPAC): Volume 2, User's guide: Yucca Mour Code (TOSPAC). Volume 2, User's guide: Yucca Mounta. . code - nuclear: A user's manual*

code TOUGH $x$

code for thermal-mechanical analysis using the boun . . . . . code verification "benchmarking" activity (COVE-2 . . . . . . . code $\times$

code-nuclear user's manual× 
$=$ FEHMN 1.0: Finite element heat and mass transfer $=$ Documentation and verification of the SHAFT =Yucca Mountain Project thermal and mechanical Package Project: Parts A \& B, ASME pressure vessel $=A$ strategy for the derivation and use of sorption =Experimental method for determining distribution $=$ Ground - water data $=$ CTCN:

hysical characterisation of suspended particles and . . . . . . hy odels of seismic refraction traveltime data using a =The quality assurance liaison: $=$ Critical =Report of the State of Nevada =US Geological Survey =Fish

..... hodologies for selecting industries for regions and $=$ Socioeconomic profiles of native American =Socioeconomic profiles of Native American =Socioeconomic profiles of native American

... . evel nuclear waste repository and related issues: $\bar{A}$ $=A$

. . . . . ty of replicas of natural fractures in welded tuff:

. . . . II-field moisture-sensing techniques: A preliminary $=1991$ OCRWM bulletin

... Mineralogy, petrology and whole-rock chemistry data =Evaluation and $=$ Evaluation and . Osamu Utsumi uranium mine, Pocos de Caldas alkaline .... es and phonolites from the Pocos de Caldas alkaline .... eochemistry of the Pocos de Caldas alkaline caldera $=$ Is it possible to demonstrate

. . . . ds for the Yucca Mountain heated block test using a =Identification of structures, systems, and $=$ Chemical and isotopic .... orption on sample grinding, surface area, and water =Guidelines on the scope, content, and use of Unconfined

. . . . f pore water extracted from tuff by one-dimensional =Conceptual, experimental and

. . . . . the potential Yucca Mountain repository: Field and =Characterization of flow in fractured tuff using

$=$ Preliminary

$=$ An investigation of the impact of $=$ Research program to develop and validate =Developing =Comparison of two =Selection of candidate container materials for the $=$ Chemical and mineralogical $=$ Code requirements for

=Seismic design of circular-section waste transportation: Prepared pursuant to assembly .... . reclosure radiological safety analysis for accident $=$ Effect of boundary =Effect of boundary $=$ Initial demonstration of the NRC's capability to .... t Yucca Mountain for underground nuclear explosions . . . . . procedure for estimating the unsaturated hydraulic . . . . . nonlinear quasi-static response of solids with the = Estimating the

$=$ TURBOSEIS - An interactive program for

=Yucca Mountain Exploratory Studies Facilities: =Movement of shaft and drift . . . . . ing definition of scenario and a method of scenario preliminary guidebook for identifying stratigraphic $=$ LLNL/YMP Waste

$=$ Stress-corrosion-cracking studies on candidate $=$ Potentiodynamic polarization studies on candidate code: Revision 1*

code: Yucca Mountain Site Characterization Project ${ }^{*}$. . . . . codes first benchmark exercise: Part 3 , Jointed roc . . . . . . codes review for waste package application; Part C, . . . . . coefficients in performance assessment calculations ..... . coetficients of TRU nuclides for evaluating their $m$. . . . . . collected at the Nevada Test Site and vicinity, Nye ...... Colloid research for the Nevada Test Site*

Colloid transport code - nuclear: A user's manual* . . . . . Colloid transport code-nuclear user's manual*

colloids in waters from the Osamu Utsumi mine and $M$. . . . color-graphics terminal*

Combined technical and quality assurance support*

comments on the US Environmental Protection Agency . . . .

Commission on Nuclear Projects $*$

Committee for the Advancement of Science in the Yuc . . . . communities in sandy pool of Magela Creek, Alligato . . . . . communities: A critical evaluation of the Las Vegas ...... communities: Duckwater Shoshone Reservation× communities: Las Vegas Tribes of Paiute Indians* communities: Yomba Shoshone Reservation* Community Radiation Monitoring Program: Annual repo . . . comparative analysis of urban and rural survey data*

comparative application of the Repository Integrati . . . . . . Comparison between predicted and observed shear beh. . . Comparison of predicted far-field temperatures for . . . . . . Comparison of two conceptual models of flow using $t$. . . . . comparison*

compilation and index*

compilation for selected samples of Yucca Mountain . . . . . compilation of DOE waste package test data: Biannua . . . . compilation of DOE waste package test data: Volume . . . . complex, Brazil: Pocos de Caldas Report No. 13*

complex, Minas Gerais, Brazil*

complex, Minas Gerais, Brazil*

compliance with the regulations for high-level-wast . . . . . . compliant-joint model*

components important to safety at the potential rep . . . . . . composition of groundwaters and their seasonal vari . . . . . composition*

comprehensive risk assessment in the management of . . . compression experiments on Topopah Spring Member tu .. compression*

computational approaches to support performance ass ... computational studies :

computerized tomography*

Conceptual, experimental and computational approach . . . . conceptual model for mineral evolution in Yucca Mou . . . . . conceptual model uncertainty on the estimated perfo . . . . . conceptual models for flow and transport through un . . . . . conceptual models for performance assessment of was . . . conceptual models of flow using the TSA*

conceptual waste package design for a potential hig ..... . concerns for the use of man-made materials in the $\mathrm{p}$. . . . . concrete repository and processing facilities*

concrete-lined underground openings: Preclosure per . . . . concurrent resolution No. 8 of the 1987 Nevada Legi . . . . . . conditions of the potential Yucca Mountain Reposito . .... . . conditions on the strength and deformability of rep . . . . . . conditions on the strength and deformability of rep . . . . . . conduct a performance assessment for a High-Level $w$... conducted in the Pahute Mesa testing area at the $\mathrm{Ne} . . .$. conductivities of volcanic tuffs*

conjugate gradient method: Yucca Mountain Site Char . . . . consequences of significant fracture flow at Yucca . . . . . . constructing and editing models of seismic refracti . . . . . . Construction status: Extended summary*

construction water in Yucca Mountain, Nevada: An ex . . . . construction*

contacts at the Nevada Test Site*

Container Fabrication and Closure Project: GFY tech . . . . . container alloys for the Tuff Repository* container alloys for the Tuff Repository* 
Selection of candidate

$=$ Crack growth behavior of candidate waste $=$ Crack-growth-rate testing of candidate waste =Stress corrosion cracking of candidate waste . . . . ermal performance of a buried nuclear waste storage . . . . . . cts of a potential drop of a shipping cask, a waste .... n and closure development of nuclear waste disposa $=$ Cost estimate of high-level radioactive waste ions of performance of high-level radioactive-waste .... gs of a workshop on corrosion of nuclear fuel waste .... . rates data on low temperature low pressure piping . . . . . ng corrosion damage of high-level radioactive-waste

=Risk-based screening analysis of ground water $=$ A study of discrete and $=$ Rock mechanics

$=$ Probable maximum flood

. . . . ng and emplacement using a sensor-based intelligent

. . . . policy instruments: Lessons from the Yucca Mountain $=$ The Nagra-DOE

. . . some hydrologic aspects of seismic hazards program =Geophysical logs and

=Results of rock property measurements made on $=$ Structure in continuously

$$
\begin{array}{r}
= \\
= \\
=\text { Stress } \\
=\text { Modeling pitting } \\
\text { =Proceedings of a workshop on } \\
=\text { Stress- }
\end{array}
$$

. . . ce of Civilian Radioactive Waste Management Program $=$ Program

$=$ Quarterly report on program =Quarterly report on program active Waste Management quarterly report on program active Waste Management quarterly report on program $=$ Quarterly report on program

$=$ Use of the iterative solution method for =A literature review of

. . . . rogrammatic requirements for large block testing of $=$ TOSPAC calculations in support of the er flow code verification "benchmarking" activity =Mesozoic and Cenozoic structural geology of the

=Stress corrosion =Stress-corrosion-

. . . ce for waning magmatism and polycyclic volcanism at . . . . . quaternary faulting along the Death Valley-Furnace =Fish communities in sandy pool of Magela $=$ Procedure development study: Low strain rate and Workshop 2 - Technical basis for EPA HLW disposal .... Workshop 2 - Technical basis for EPA HLW disposal

.... selecting industries for regions and communities: $\bar{A}$

=Review and

=Sealing performance of bentonite and bentonite/ . . . performance assessments of bentonite and bentonite/

. . untain magmato-thermal event: An intense widespread

.... . the delta intercept of a thermocouple psychrometer .... nce prediction of mechanical excavators from linear $=$ Analysis of slot =Fuel

$\ldots . . . r$ injection tests to determine the effect of a heat container materials for the conceptual waste packag . . . . . container materials in simulated underground water ${ }^{*}$. . . . . container materials*

container materials: Final report*

container storing a hybrid mix of PWR and BWR spent . ... . container, and a bare fuel assembly during waste-ha . . . . . containers for the Yucca Mountain Project: Status r . . . . . . containers for the Yucca Mountain Site Characteriza . . . . . containers*

containers $\times$

containers, and casks with long design lives*

containers, with emphasis on the stochastic approac . . . . . contam inated by radionuclides introduced at the Nev . . . . . continuum joint modeling techniques*

contributions from defense programs*

control: Yucca Mountain Site Characterization Proje . . . . . controller: Yucca Mountain Site Characterization $\mathrm{Pr}$. . . . . Controversey*

Cooperative Project*

core holes, Los Alamos National Laboratory, New Mex . . . . core measurements from forty boreholes at Yucca Mou . . . . core samples from Yucca Mountain boreholes, Nevada . . . cored, deep drill holes at Yucca Mountain, Nevada, . . . . . . Corrosion models for predictions of performance of . . . . . corrosion cracking of candidate waste container mat . . . . . . corrosion damage of high-level radioactive-waste co . . . . . corrosion of nuclear fuel waste containers $x$

corrosion-cracking studies on candidate container a . . . . . Cost and Schedule Baseline: Revision $3 *$

Cost estimate of high-level radioactive waste conta . . . . . . cost and schedule baseline: Revision $2 *$

cost and schedule, fourth quarter FY 1992,

cost and schedule, third quarter FY 1992*

cost and schedule: First quarter, FY 1992*

cost and schedule: Fourth Quarter, FY 1991*

cost and schedule: Second quarter FY 1992*

Coupled hydro-geochemical processes and their signi . . . coupled finite element and boundary element modelin . . . . coupled thermal-hydrologic-mechanical-chemical proc . . . . coupled thermal-mechanical-hydrological-chemical pr. . . . . COVE 2A benchmarking activity: Yucca Mountain Site . . . . COVE-2A): Analysis of participants' work*

CP Hills, Nevada Test Site, Nye County, Nevada; and . . . . . Crack growth behavior of candidate waste container . . . . . Crack-growth-rate testing of candidate waste contai . . . . . . cracking of candidate waste container materials: $\mathrm{Fi} \ldots \ldots$. . . cracking studies on candidate container alloys for . . . . . . Crater Flat, Nevada*

Creek fault system, California and Nevada*

Creek, Alligator Rivers Region: Research Report 9*

creep experiments: Yucca Mountain Site Characteriza . . . . criteria*

criteria*

Critical comments on the US Environmental Protectio . . . . critical evaluation of the Las Vegas target industr . . . . . . . Criticality safety issues associated with the buria . . . . . . . critique of the US Department of Energy environment . . . . crushed rock borehole plugs*

crushed rock plugs $x$

CTCN: Colloid transport code - nuclear: A user's m . . . . . . culmination of magmatic and hydrothermal activity $a$. . . . . Current plans to characterize the design basis grou . . . . . . curve*

cutter tests on Yucca Mountain welded tuffs: Yucca . . . . . cutting methods for the Yucca Mountain heated block . . . . cycle 90 conference*

cycle on the permeability of welded tuff* 
plementation of the site and engineering properties $=$ KJAR

=Late quaternary faulting along the $=$ Physical limits on steam generation by radioactive

=Nuclear waste management review work - part of the of amenities and other factors on business location cts of amenity characteristics on business location $=$ Simulated water-level

=Transportation cask $=$ Point

=Rock mechanics contributions from =A working $=$ Initial field testing $=$ Effect of boundary conditions on the strength and $=$ Effect of boundary conditions on the strength and =Survey of =Proposed algorithm for determining the $=$ is it possible to

$=$ Borehole stability in =Equivalent Energy $=$ Areal power

$$
\text { scale }
$$

=A strategy for the =Neotectonics of the southern Amargosa

=Preliminary drift =Using QA classification to guide Mountain repository and recommendations for thermal =Current plans to characterize the =Engineered barrier system and waste package $=$ Dynamic analysis and =Dynamic analysis and =Dynamic analysis and $=$ Dynamic analysis and =Dynamic analysis and =Dynamic analysis and =Dynamic analysis and =Dynamic analysis and =Dynamic analysis and =Dynamic analysis and =Dynamic analysis and =Dynamic analysis and =Dynamic analysis and =Dynamic analysis and $=$ Dynamic analysis and ... ontainer materials for the conceptual waste package .... ow pressure piping, containers, and casks with long . . . . . lytical methods for jointed rock as part of a drift =Seismic

..... . n support of the Exploratory Studies Facility (ESF) ... vironment report: Volume 1, Technical bases for EBS

=Influence of =Research program to

$$
=
$$

. . . . chemistry of pore water extracted from tuff by one-

-New three-

$=J A C B D-A$ three-

=Three-

. . . . ensitivity and uncertainty analyses applied to one- database: Yucca Mountain Site Characterzation Proje . . . . dating of clinoptilolite, mordenite, and associated . . . . . . . Death Valley-Furnace Creek fault system, California . . . . . . decay heat*

decision analysis of an exploratory studies facilit ..... decision making process*

decisions*

decisions*

declines caused by withdrawals from wells $J-13$ and . . . . . decontamination and maintenance at the potential Yu . . . . defects in silicates*

defense programs*

definition of scenario and a method of scenario con .....

definition of subsurface sealing and backfilling te ......

deformabllity of replicas of natural fractures in $w \ldots . .$. .

deformability of replicas of natural fractures in $w \ldots . .$. .

degradation modes of four nickel-chromium-molybdenu . . .

delta intercept of a thermocouple psychrometer cun . . . . .

Demends placed on waste package performance testing . . .

demonstrate compliance with the regulations for hig .....

Demonstration of a risk-based approach to high-leve . . . . .

demonstration of dose modeling at Yucca Mountain*

demonstration of the NRC's capability to conduct $\mathbf{a} \ldots \ldots$ densely welded tuffs*

Density concept: A preliminary reexamination of a $t$. . . . . . density: A preliminary examination of underground $h$. . . . . Dependence of radionuclide sorption on sample grind ... . dependence of effective media properties*

derivation and use of sorption coefficients in perf ....... Desert, Nye County, Nevada and Inyo County, Califor . . . . Design and implementation of the site and engineeri ..... Design of a three-dimensional site-scale model for . . . . . . Design of an intermediate-scale experiment to valid . . . . . . design analyses for nuclear waste repository in tuf . . . . . . design and manage risk*

design approaches: Yucca Mountain Site Characteriza . . . . design basis ground motion at the Yucca Mountain, $\mathrm{N}$... . design concepts for a potential geologic repository . . . . . . design considerations for high-level nuclear waste . . . . . . design considerations for high-level nuclear waste . . . . . . design considerations for high-level nuclear waste ...... design considerations for high-level nuclear waste ..... design considerations for high-level nuclear waste ..... design considerations for high-level nuclear waste $\ldots . .$. design considerations for high-level nuclear waste $\ldots \ldots$. design considerations for high-level nuclear waste $\ldots . .$. design considerations for high-level nuclear waste $\ldots . .$. design considerations for high-level nuclear waste ..... design considerations for high-level nuclear waste . . . . . . design considerations for high-level nuclear waste . . . . . . design considerations for high-level nuclear waste $\ldots . .$. design considerations for high-level nuclear waste . . . . . design considerations for high-level nuclear waste $\ldots . .$. design for a potential high level nuclear waste rep. . . . . . . design lives*

design methodology and preliminary application for ..... design methodology for the Yucca Mountain Project*

design of circular-section concrete-lined undergrou ...... design $*$

design*

Deterministic geologic processes and stochastic mod ... . deterministic geologic trends on spatial variabilit ....... develop and validate conceptual models for flow and ..... Developing a functioning visualization and analysis . . . . . Developing conceptual models for performance assess ... developments in stochastic modeling and upscaling $0 . .$. Diffusion of sorbing and non-sorbing radionuclides ${ }^{*} . . .$. . Diffusion releases through one and two finite plana . . . . . . dimensional compression*

dimensional far-field potential repository thermome . . . . . . dimensional finite element computer program for the . . . . . dimensional modeling of unsaturated flow in the vic . . . . . dimensional radionuclide transport in a layered fra . . . . . . 
$=$ Design of a three$=$ Three $=\mathrm{X}$-ray and visible light transmission as two=LLUVIA-II: A program for two$=$ Facts and issues of . . . . I I to amend the Nuclear Waste Policy Act of 1982 to $=$ Does localized recharge occur at a

=Surface$=$ A study of

$=$ Comparison of predicted far-field temperatures for .... evel nuclear waste be disposed of at geographically $=$ Modulus

=Should high-level nuclear waste be =Simulation modeling of the probability of magmatic =Estimating the time for

$=$ Experimental method for determining $=$ The reaction of SRL 202 glass in $J-13$ and =Automated waste canister $=A$ demonstration of

. . . . ation of environmental monitoring thermoluminescent =Strategic principles workshops: Discussion

=Movement of shaft and $=$ Preliminary of analytical methods for jointed rock as part of a $=$ Structure in continuously cored, deep $=$ Analysis of releases due to $=$ Proceedings of the conference on shaft $=$ Proceedings of the conference on shaft $=$ Geology,

$=$ Modeling gravity-

$=$ Small-scale behavior of single gravity= Modeling of strongly heat-

$=$ The analysis of repository-heat$=$ Effects of a potential ... . . . or of single gravity-driven fingers in an initially . . . . . i-analytical treatment of fracture/matrix flow in a . . . . ioeconomic profiles of native American communities: = Analysis of releases

$=$ Potential increases in natural radon emissions . . . . agement Site in Area 5 of the Nevada Test Site: The $=$ Recent advances in methods for measuring the =MISTY ECHO Tunnel =MISTY ECHO tunnel

=Report of the Peer Review Panel on the $=$ Report of

$=$ Natural series radionuclide and rare-

\section{$=$}

... . . c motion records from Little Skull Mountain, Nevada ... . . c motion records from Little Skull Mountain, Nevada . . . d environment report: Volume 1, Technical bases for $=$ MISTY =MISTY

=Managing nuclear waste: Social and $=$ Excellent and

$=$ Proceedings of the American power conference: =Summary report on the evaluation of a 1977-1985 .... OSEIS-An interactive program for constructing and

=Heat pipe

$=$ Field air injection tests to determine the $=$ Empirical investigation of the =Progress in assessing the $=$ Rail abandonments in the South and their dimensional site-scale model for the unsaturated zo . . . .

dimensional visualization in support of Yucca Mount . . . . . dimensional, full-field moisture-sensing techniques . . . . . . dimensional, transient flow through partially satur . . . . . . . . direct disposal of spent fuel: Revision 1 *

direct the Secretary of Energy to carry out site ch . . . . . . . discharge area within the ground-water flow system . . . . . discharging hydrothermal systems at Yucca Mountain: . . . . discrete and continuum joint modeling techniques* discrete and smeared heat sources*

dispersion and attenuation in tuff and granite*

disposed of at geographically dispersed sites?* disruption of the potential Yucca Mountain Site*

dissolution of spent fuel exposed to unlimited wate . . . . . . Distribution and chemistry of fracture-lining zeoli . . . . . . . . distribution coefficients of TRU nuclides for evalu . . . . . . . DIN*

docking and emplacement using a sensor-based intell . . . . dose modeling at Yucca Mountain*

dosimeter locations*

drafts and workshop notes*

Drift design methodology and preliminary applicatio . . . . . . Drift emplaced waste package thermal response*

drift construction water in Yucca Mountain, Nevada: . . . . . . drift design analyses for nuclear waste repository . . . . . . . drift design methodology for the Yucca Mountain Pro . . . . . . drill holes at Yucca Mountain, Nevada, with notes o . . . . . . . drilling at the potential Yucca Mountain repository* drilling technology*

drilling technology*

drilling, and some hydrologic aspects of seismic ha . . . . . . driven fingering in rough-walled fractures using mo . . . . . driven fingers in an initialiy dry fracture*

driven flow processes at a potential high-level nuc . . . . . . driven hydrothermal flow at Yucca Mountain*

drop of a shipping cask, a waste container, and $a b$. . . . . . dry fracture*

Dual-energy neutron tomography of water in rock usi . . . . . dual-porosity simulator for unsaturated fractured $r$. . . . . . . Duckwater Shoshone Reservation*

due to drilling at the potential Yucca Mountain rep . . . . . . . due to heating of the Yucca Mountain rock mass* Dupuit-Forcheimer approximation*

dynamic response of geological materials to $100 \mathrm{GPa} *$

Dynamics Experiment-Data report: Volume 1: Yucca M . . . dynamics experiment data report: Volume 2, Appendic . . . . dispersed sites?*

\section{E}

early site suitability evaluation of the Potential . . . . . . early site suitability evaluation of the potential . . . . . . . . . earth element geochemistry of waters from the Osamu . . . . Earthquake-induced water-level fluctuations at Yucc . . . . . Earthquake-induced water-level fluctuations at Yucc . . . . . . earthquake aftershocks of July 5, 1992 and Septembe . . . . earthquake of June 29,1992 , recorded at stations i . . . . . . EBS design*

ECHO Tunnel Dynamics Experiment-Data report: Volum . . . ECHO tunnel dynamics experiment data report: Volume . . . economic impacts*

economic nuclear plant performance: NE-Volume 4*

Economy, efficiency, quality. Volume $55-2 *$

edited sorption data base for isotherm modeling*

editing models of seismic refraction traveltime dat . . . . . .

Effect of boundary conditions on the strength and $d . . . .$.

Effect of boundary conditions on the strength and $d . . .$. effect in porous medium*

effect of a heat cycle on the permeability of weide . . . . . . .

effect of amenities and other factors on business $1 . . . . .$.

effect of ionizing radiation on the anticipated was . . . . . .

effect on NWPA rail shipments* 
=Scale dependence of effective media properties*

Effects of a potential drop of a shipping cask, a w . . . . . . .

= Effects of actinide burning on waste disposal at $Y u$......

$=$ Effects of magmatic processes on the potential Yucc .....

$=$ Effects of radiation exposure on glass alteration $i$. . . . . .

$=$ Effects of various radiation source characteristics . . . . . . .

. . conomic assessment guidance report: Determining the $=$ Physical processes and =Parametric

. ceedings of the American power conference: Economy,

=Transportation needs assessment:

=Proceedings of

$=$ Potential increases in natural radon

$=$ Drift

=Waste package

. . . . erns for the use of man-made materials in the post$=$ Pre-waste-

$=$ Uncertainty and sensitivity results for pre-waste$=$ Automated waste canister docking and ar waste: Quality assurance auditors need access to =Technical basis and programmatic requirements for

$=$ Scientific investigation plan for initial $=$ Reliability modeling of an $=$ Design and implementation of the site and .... national Nuclear Law Association (AIDN-INLA), Bath, . . . . . . safety issues associated with the burial of highly . . . . . tructure in horizontal unsaturated fractures: Water . . . . . report: Volume 2, Scientific overview of near-field $=$ Prototype heater test of the

.... Ionizing radiation on the anticipated waste package - Preliminary near-field =Preliminary near-field . . . e use of man-made materials in the post-emplacement ..... f radiation exposure on glass alteration in a steam . . . . . . study of hydrological properties of the near-field =Engineered barrier

$=$ Long-term observation of the geological . . . ion: A case study of the use of RADTRAN in the 1986 $=$ Critical comments on the US

=ANL technical support program for DOE =ANL Technical Support Program for DOE

\section{$=$}

=Addendum to

=Evaluation of

=Review and critique of the US Department of Energy $=$ Proceedings of the GIS and =Proceedings of the GIS and =Health and

. . . able vacuum hammer seismic source for use in tunnel . . . . sts of nuclear materials package response to normal . . . Proceedings: EPRI Workshop 2 - Technical basis for . . . Proceedings: EPRI Workshop 2 - Technical basis for

$=$ The implications of $=$ The impact of The impact of

... g g for uranium and neptunium at Yucca Mountain using =Proceedings: =Proceedings:

$=$ Modeling ion exchange in clinoptilolite using the =EQPT, a data file preprocessor for the effects of amenity characteristics on business loca . . . . . . effects of magmatism in the Yucca Mountain region*

effects on glass reaction in the unsaturated test $m \ldots \ldots$ efficiency, quality. Volume $55-2 *$

Eighteenth water reactor safety information meeting . . . . .

Elements present in leach solutions from unsaturate . . . . . Emergency response section $*$

emerging technologies for hazardous waste managemen . . emissions due to heating of the Yucca Mountain rock . . . . Empirical investigation of the effect of amenities ....... emplaced waste package thermal response*

emplacement borehole option study: Yucca Mountain $S$. . . emplacement environment *

emplacement ground-water travel time sensitivity an ..... emplacement groundwater travel time*

emplacement using a sensor-based intelligent contro . . . . . employee records*

Engineered Barrier System Field Tests*

Engineered barrier environment, Yucca Mountain*

Engineered barrier system and waste package design .... engineered barrier system field tests*

engineered barrier system*

engineering properties database: Yucca Mountain Sit ....

England, 23-26 September $1991 *$

enriched nuclear fuel in a geologic repository*

entry through the surrounding porous matrix*

environment and phenomena*

environment around a simulated waste package*

environment at the Yucca Mountain potential reposit . . . . .

environment report: Volume 1 , Technical bases for $E$. . . . . .

environment report: Volume 2 , Scientific overview 0 ...... environment*

environment*

environment*

environment, Yucca Mountain*

environment: needs and techniques*

Environmental Assessment for Yucca Mountain×

Environmental Protection Agency Standards 40 CFR 19 . . .

Environmentel Restoration and Waste Management: Ann . . Environmental Restoration and Waste Management: Ann . . Environmental issues and waste management in energy .. Environmental issues and waste management in energy . . Environmental issues and waste management in energy ... Environmental monitoring for uranium and neptunium .... environmental monitoring plan Nevada Test Site and ... . . environmental monitoring thermoluminescent dosimete . . . environmental program plan for site characterizatio . . . . . . environmental rehabilitation workshop*

environmental rehabilitation workshop*

environmental risk-related impacts of actinide burn . . . . . . environments*

environments*

EPA HLW disposal criteria*

EPA HLW disposal criteria*

episodic nonequilibrium fracture-matrix flow on sit . . . . . . episodic nonequilibrium fracture-matrix flow on rep . . . . . . episodic nonequilibrium fracture-matrix flow on geo . . . . . . . Epithermal Neutron Activation Analysis*

EPRI Workshop 2 - Technical basis for EPA HLW disp . . . . EPRI Workshop 2 - Technical basis for EPA HLW disp .... EQ3/6 V7.0: Geochemical Modeling Of Aqueous Systems* EQ3/6 V7.1: Geochemical Modeling of Aqueous Systems* EQ3/6 geochemical modeling code*

EQ3/6 software package: User's guide and related do . . . . . EQ3/6, a software package for geochemical modeling .... . EQ3NR, a computer program for geochemical aqueous s ... EQ6, a computer program for reaction path modeling ..... .
446

135

407

248

415

117

143

608

527

408

559

73

212

417

193

236

176

305

272

262

466

174

191

183

171

429

242

620

596

283

199

162

144

198

199

176

407

173

191

72

560

7

405

402

75

610

614

447

439

440

570

611

609

572

595

577

462

463

187

185

182

447

463

462

147

148

190

201

200

202

203 
=Instrumentation requirements for the ... . . ment in support of the Exploratory Studies Facility ... . comes from site characterization: Insights from the $=$ Cost ..... f the impact of conceptual model uncertainty on the

=An inverse procedure for

=Rock mass mechanical property =Rock mass mechanical property ining distribution coefficients of TRU nuclides for

$=$ Geotherma

=Summary report on the

$=$ Technical

=Summary and

=Geologic

...... industries for regions and communities: A critical

... . . . the Peer Review Panel on the early site suitability

=Report of early site suitability

$=\mathrm{An}$

..... risk-based approach to high-level waste repository

$=$ Preclosure radiological safety

. . . unnel Welded Tuff Mining Experiment instrumentation

$=$ G-tunnel pressurized slot-testing

=The Timber Mountain magmato-thermal

... . . er table excursions induced by seismic and volcanic =Recurrence models of volcanic

jal impacts of hazardous and nuclear facilities and =Near-field high-temperature transport: =Geochemical

. . . drothermal systems at Yucca Mountain: Examining the =Preliminary conceptual model for mineral

=Areal power density: A preliminary discharging hydrothermal systems at Yucca Mountain:

$=$ An

=Performance prediction of mechanical $=$ Performance predictions for mechanical

=Modeling ion

=A scoping study of water table

. . . roject thermal and mechanical codes first benchmark =Summary and evaluation of

=Releases from

$=$ Linear thermal

=Nuclear waste: DOE

. . . Nevada commercial spent nuclear fuel transportation $=$ G-Tunnel Welded Tuff Mining =MISTY ECHO Tunnel Dynamics =MISTY ECHO tunnel dynamics $=$ Design of an intermediate-scale $=$ Calculation of

materials for a reactive transport model validation . . . . . erical modeling for the G-Tunnel welded tuff mining

=Conceptual,

=Nonisothermal hydrologic transport =Nuclear testresearch program for unsaturated flow and transport ..... . igation of fracture-matrix interaction: Preliminary
EQPT, a data file preprocessor for the EQ3/6 softwa . . . . equating thermal loads: Yucca Mountain Site Charact . . . . Equilibrium modeling of the formation of zeolites i . . . . . . Equivalent Energy Density concept: A preliminary re . . . . . ESF thermomechanical experiments*

ESF) design*

ESF-AS*

estimate of high-level radioactive waste containers . . . . . estimated performance of a hypothetical high-level . . . . . . Estimates of potential radionuclide migration at th . . . . . . Estimating the consequences of significant fracture . . . . . . Estimating the time for dissolution of spent fuel $\mathrm{e} . \ldots . .$. Estimating the water table under the Radioactive Wa . . . . . estimating the unsaturated hydraulic conductivities . . . . . . Estimation of the impact of water movement from sew . . . . Estimation of the limitations for surficial water a . . . . . . . estimation strategy for the Yucca Mountain Site Cha . . . . . estimations for the Yucca Mountain Site Characteriz . . . . . evaluating their migration behaviors*

Evaluation and compliation of DOE waste package tes .... Evaluation and compilation of DOE waste package tes . . . . Evaluation of alternatives for high-level and trans . . . . . . Evaluation of environmental monitoring thermolumine . . . . Evaluation of the geologic relations and seismotect . . . . . . Evaluation of the geologic relations and seismotect ...... evaluation and analysis of the Yucca Mountain Repos . . . . evaluation of a 1977-1985 edited sorption data bas . . . . . evaluation of available state of Nevada survey inst . . . . . . evaluation of existing geological and geophysical $d . . .$. . evaluation of six nonwelded tuff sites in the vicin ...... evaluation of the Las Vegas target industry analysi . . . . . . evaluation of the Potential Repository Site at Yucc . . . . . . evaluation of the potential repository site at Yucc . . . . . . . evaluation of the seismicity of the Nevada Test Sit . . . . . . evaluation, Phase 2 *

evaluation: Exploratory Studies Facility: Yucca Mou ..... . evaluations: Yucca Mountain Site Characterization P. . . . . evaluations: Yucca Mountain Site Characterization P . . . . . event: An intense widespread culmination of magmati . . . . events*

events: Applications to volcanic risk assessment

events: Implications for Nevada and the Yucca Mount .... Evidence from the genesis of the Osamu Utsumi urani . . . . evidence for waning magmatism and polycyclic volcan . . . . evidence*

evolution in Yucca Mountain*

examination of underground heat transfer in a poten .... Examining the evidence*

example postclosure risk assessment using the poten .... excavators from linear cutter tests on Yucca Mounta ..... . excavators in Yucca Mountain tuffs: Yucca Mountain . . . . Excellent and economic nuclear plant performance: $N$... exchange in clinoptilolite using the EO3/6 geochemi . . . . . excursions induced by seismic and volcanic events $\times$

exercise: Part 3, Jointed rock mass analysis: Yucca .... . . existing geological and geophysical data near prosp . . . . . exotic waste packages from partitioning and transmu . . . . . expansion data for tuffs from the unsaturated zone . . . . . . expenditures on the Yucca Mountain Project* experience*

Experiment instrumentation evaluations: Yucca Mount . . . . Experiment-Data report: Volume 1: Yucca Mountain S . . . . experiment data report: Volume 2, Appendices: Yucca . . . . experiment to validate unsaturated-zone transport ...... experiment uncertainty in laboratory determination . . . . . . experiment*

experiment: Yucca Mountain site characterization pr . . . . . Experimental method for determining distribution co ..... experimental and computational approaches to suppor . . . . experimental plan*

experimental science annual report, Fiscal year 199 . . . . . experimentation*

experiments in a simple system* 
$=$ Unconfined compression . . . mentation requirements for the ESF thermomechanical . . . cedure development study: Low strain rate and creep

=Yucca Mountain

. . . cations of performance assessment in support of the =Summary of the $=$ Preciosure radiological safety evaluation: ing of unsaturated flow in the vicinity of proposed $=$ Preclosure radiological safety analysis for the $=$ A decision analysis of an e spectra at Yucca Mountain for underground nuclear =Estimating the time for dissolution of spent fuel $=$ Effects of radiation xploratory Studies Facilities: Construction status: ft construction water in Yucca Mountain, Nevada: An $=$ A preliminary study of the chemistry of pore water

\section{$=$ LLNLYMP Waste Container}

. . . . . e coatings on the transfer of water across fracture = Yucca Mountain Exploratory Studies =Social impacts of hazardous and nuclear flow in the vicinity of proposed exploratory shatt gical and geophysical data near prospective surface mental monitoring plan Nevada Test Site and support requirements for concrete repository and processing $=$ Perceived risk impacts from siting hazardous waste he potential Yucca Mountain Repository: Underground ..... . iological safety analysis for the exploratory shaft ...... . ce assessment in support of the Exploratory Studies =Summary of the Exploratory Studies

radiological safety evaluation: Exploratory Studies

of Yucca Mountain, Nevada for a surface-based test

of Midway Valley as a potential repository surface

=A decision analysis of an exploratory studies

public opposition to a high-level radioactive waste $=$ The role of amenities and other -Human and social

investigation of the effect of amenities and other pplication; Part C, Library search for reliability/ =New three-dimensional =Comparison of predicted

.... . mary faulting along the Death Valley-Furnace Creek $=$ The role of L Late quaternary ucca Mountain, Nevada: Implications for strike-slip $=$ Geomorphological and hydrogeological

Idas caidera and the Osamu Utsumi mine and Morro do . . . . ical analysis at the Osamu Utsumi mine and Morro do .... I variability at the OSAMU Utsumi mine and Morro do ... y of waters from the Osamu Utsumi mine and Morro do . ock samples from the Osamu Utsumi mine and Morro do ... s in waters from the Osamu Utsumi mine and Morro do . . geochemistry at the Osamu Utsumi mine and Morro do .... interactions at the Osamu Utsumi mine and Morro do . . . . . gue study sites, Minas Gerais, Brazil: II. Morro do . . . . . and participate in the Technical Workshop on Near-

.. rammatic requirements for Engineered Barrier System

... ocesses on the potential Yucca Mountain repository:

$=$ The Lathrop Wells volcanic center: Status of $=$ The Lathrop Wells volcanic center: Status of ment report: Volume 2, Scientific overview of near=Preliminary near$=$ Preliminary near-

experiments on Topopah Spring Member tuff at $22 \ldots \ldots$. experiments*

experiments: Yucca Mountain Site Characterization P . . . . Expert judgment in assessing radwaste risks: What $\mathrm{N} \ldots$. Exploratory Studies Facilities: Construction status . . . . . . Exploratory Studies Facility (ESF) design*

Exploratory Studies Facility Alternatives Study: $\mathrm{Dr}$. . . . . . Exploratory Studies Facility: Yucca Mountain Site C . . . . . exploratory shaft facilities at Yucca Mountain, Nev . . . . . exploratory shaft facilities: Yucca Mountain Site C . . . . . . exploratory studies facility*

explosions conducted in the Pahute Mesa testing are . . . . exposed to unlimited water*

exposure on glass alteration in a steam environment*

Extended summary*

extended study: Yucca Mountain Site Characterizatio . . . . .

extracted from tuff by one-dimensional compression ${ }^{\star}$. . . . .

310

330

261

556

100

288

277

315

62

246

301

230

164

407

100

266

363

\section{$\mathbf{F}$}

Fabrication and Closure Project: GFY technical acti . . . . Fabrication and closure development of nuclear wast . . . . faces in unsaturated media*

Facilities: Construction status: Extended summary*

Facilities and events: Implications for Nevada and

facilities at Yucca Mountain, Nevada*

facilities in Midway Valley, Yucca Mountain Project . . . . . . . 254

facilities*

facilities*

facilities*

facilities: Yúcca Mountain Site Characterization Pr . . . . .

facillties: Yucca Mountain Site Characterization $\operatorname{Pr}$. . . . . .

Facility (ESF) design*

Facility Alternatives Study: Draft×

Facilly: Yucca Mountain Site Characterization Proj . . . . . . tacility for the Yucca Mountain Project*

facility site*

facility $\times$

facility*

factors in influencing the location of nonmanufactu . . . . . factors in the transportation of nuclear wastes $\times$

tactors on business location decisions.

Facts and issues of direct disposal of spent fuel: . . . . . . .

failure rates data on low temperature low pressure ...... .

far-field potential repository themomechanical cal . . . . . . .

far-field temperatures for discrete and smeared hea . . . . . .

Fault stress analysis for the Yucca Mountain Site C . . . . . . fault system, California and Nevada*

fault zones in affecting multiphase flow at Yucca $M$. . . . . . faulting along the Death Valley-Furnace Creek fault . . . . . . . faulting and oroclinal bending*

features of the Pocos de Caldas caldera and the Osa . . . . .

FEHMN 1.0: Finite element heat and mass transfer $\infty \ldots$

Ferro analogue study sites, Brazil: Pocos de Cakdas ..... . Ferro analogue study sites, Pocos de Caldas, Brazil . . . . . Ferro analogue study sites, Pocos de Caldas, Brazil . . . . . Ferro analogue study sites, Pocos de Caldas, Brazil* Ferro analogue study sites, Pocos de Caldas, Brazil* Ferro analogue study sites, Pocos de Caldas, Brazil* Ferro analogue study sites, Pocos de Caldas, Brazil* Ferro analogue study sites, Pocos de Caldas, Brazil* Ferro*

Field Performance Assessment: Foreign trip report, . . . . . Field Tests*

Field air injection tests to determine the effect $0 \ldots \ldots \ldots$ Field and computational studies*

Field research program for unsaturated flow and tra . . . . . field and geochronology studies $\times$

field and geochronology studies*

field environment and phenomena*

field environment report: Volume 1, Technical bases ......

field environment report: Volume 2, Scientific over . . . . . . .

591

186

579

100

555

439

598

410

234

246

288

277

315

108

302

301

554

414

562

417

599

12

306

332

278

369

60

369

381

583

103

583

585

584

505

504

506

508

509

502

435

174

179

135

280

112

122

199

198

199 
atory study of hydrological properties of the near=Near-

. . erformance assessment: Some questions for the nearisible light transmission as two-dimensional, full=Proceedings from the technical workshop on near$=$ Proceedings from the technical workshop on near=New three-dimensional far=Comparison of predicted far=Initial

=Proposed sealing ..... . tigation plan for initial engineered barrier system $=$ The results of near-Hydrogeology and migration in the remote . . . . hermal activity at the southwestern Nevada volcanic

. . . . inary characterization and risk analysis: Volume 2 $=$ EQPT, a data

..... trust, information, and risk perceptions: Report of . . roject: The 1991 Nevada State telephone survey: Key =Modeling gravity-driven

=Small-scale behavior of single gravity-driven $=$ FEHMN 1.0

=Use of the iterative solution method for coupled $=$ NORIA-SP: $A$

$=J A C 3 D-A$ three-dimensional $=$ Diffusion releases through one and two . . uced in the US Senate, One Hundred Second Congress, ment quarterly report on program cost and schedule:

. . Yucca Mountain Project thermal and mechanical codes

. . waning magmatism and polycyclic volcanism at Crater =Probable maximum

$=$ Proceedings of workshop 5: $=$ Proceedings of workshop 5 : $=$ Proceedings of workshop 5: $=$ Proceedings of workshop 5 : $=$ Proceedings of workshop 5: $=$ Proceedings of workshop 5: =Proceedings of workshop 5: $=$ Proceedings of workshop 5 : $=$ Proceedings of workshop 5: $=$ Proceedings of workshop 5: $=$ Proceedings of workshop 5: $=$ Proceedings of workshop 5 : $=$ Proceedings of workshop 5: $=$ Proceedings of workshop 5 $=$ Proceedings of workshop 5 : $=$ Proceedings of workshop 5 : =Proceedings of workshop 5

=Field research program for unsaturated ogram to develop and validate conceptual models for Estimating the consequences of significant fracture The analysis of repository-heat-driven hydrothermal $=$ The role of fault zones in affecting multiphase = Groundwater

=Numerical studies of rock-gas =Semi-analytical treatment of fracture/matrix $=$ Characterization of rs, and modeling approaches for partially saturated $=$ Quasi-linear analysis of wate

=Three-dimensional modeling of unsaturated Numerical methods for fluic e impact of episodic nonequilibrium fracture-matrix e impact of episodic nonequilibrium fracture-matrix ... ications of episodic nonequilibrium fracture-matrix =Modeling of strongly heat-driven e occur at a discharge area within the ground-water LLUVIA-II: A program for two-dimensional, transient =Numerical simulation of gas =Comparison of two conceptual models of =Earthquake-induced water-level fleld environment*

field high-temperature transport: Evidence from the . . . . . . field modelers*

fleld moisture-sensing techniques: A preliminary co . . . . . . field performance assessment for high-level waste* field performance assessment for high-level waste*

field potential repository thermomechanical calcula ...... field temperatures for discrete and smeared heat so . . . . . . field testing definition of subsurface sealing and ........ field tests for a potential high-level radioactive . . . . . . . . field tests*

fleld thermal and mechanical calculations of therma . . . . . . field*

field*

Fith report to the US Congress and the US Secretar . . . . Figures [and] Volume 3 , Technical Appendices*

flle preprocessor for the EQ3/6 software package: $U \ldots .$. . findings of the Las Vegas metropolitan area survey, . . . . . findings*

fingering in rough-walled fractures using modified ..... . Fingerprinting of ground water by ICP-MS: Progress . . . fingers in an initially dry fracture*

Finite element heat and mass transfer code: Revisio ... . . . finite element and boundary element modeling: Yucca . . . . . finite element computer program for analyzing liqui . . . . . . finite element computer program for the nonlinear $q . . .$. . finite planar zones from a nuclear waste package*

gress, Session, May 22, 1991 *

First quarter, FY 1992*

first benchmark exercise: Part 3 , Jointed rock mass . . . . . .

Fish communities in sandy pool of Magela Creek, All . . . . .

Flat, Nevada

flood control: Yucca Mountain Site Characterization . . . . . . Flow and transport in hierarchically fractured syst ....... Flow and transport through unsaturated fractured ro . . . . . . Flow and transport through unsaturated fractured ro . . . . . . Flow and transport through unsaturated fractured ro . . . . . . Flow and transport through unsaturated fractured ro . . . . . . Flow and transport through unsaturated fractured ro . . . . . . Flow and transport through unsaturated fractured ro . . . . . . Flow and transport through unsaturated fractured ro . . . . . . Flow and transport through unsaturated fractured ro . . . . . . Flow and transport through unsaturated fractured ro . . . . . . Flow and transport through unsaturated fractured ro . . . . . . Flow and transport through unsaturated fractured ro . . . . . . Flow and transport through unsaturated fractured ro . . . . . . Flow and transport through unsaturated fractured ro . . . . . . Flow and transport through unsaturated fractured ro . . . . . ; Flow and transport through unsaturated fractured ro . . . . . . Flow and transport through unsaturated fractured ro . . . . . . Flow and transport through unsaturated fractured ro . . . . . . flow and transport experimentation*

flow and transport through unsaturated, fractured $r$. . . . . . flow at Yucca Mountain*

flow at Yucca Mountain*

flow at Yucca Mountain*

flow code verification "benchmarking" activity $(C \ldots . . .$. . flow in Yucca Mountain: Yucca Mountain Site Charact . . . . flow in a dual-porosity simulator for unsaturated $f$. . . . . . flow in fractured tuff using computerized tomograph . . . . . . flow in soil and rock media: Yucca Mountain Site $\mathrm{Ch}$. . . . . flow in the unsaturated zone at Yucca Mountain, Nev . . . . . flow in the vicinity of proposed exploratory shaft ........ flow in unsaturated heterogeneous tuff*

flow on geological repository performance*

flow on repository performance at the potential Yuc . . . . . . flow on site suitability and total system performan . . . . . . . flow processes at a potential high-level nuclear wa . . . . . . flow system of Yucca Mountain, Nevada?*

flow through partially saturated porous media: Yucc . . . . . . flow through unsaturated fractured rock at Yucca Mo . . . . . flow using the TSAx fluctuations at Yucca Mountain, Nevada, April 1992* . . . . . 
$=$ Earthquake-induced water-level $=$ Numerical methods for =Modeling

$=$ The most likely groundwater =Seismicity and =Seismicity and $=$ Seismicity and

\section{.... Site in Area 5 of the Nevada Test Site: The Dupuit-}

. ste Management projects at WIPP and Yucca Mountain:

. al programs being managed and implemented by NAGRA: ical Workshop on Near-Field Performance Assessment $=[$ Symposium for the STRIPA Project] =Equilibrium modeling of the -Geophysical logs and core measurements from =Gravity and magnetic data of =Survey of degradation modes of . . . ment quarterly report on program cost and schedule: ... ion of subsurface microorganisms at Yucca Mountain:

=Quarterly report on program cost and schedule, aperture patterns: Characterization by slit-island =Single =Impact of

. . . . . f fracture coatings on the transfer of water across =Estimating the consequences of significant $f$ single gravity-driven fingers in an initially dry $g$ front instability in an initially wet unsaturated $=$ Distribution and chemistry of $=$ The impact of episodic nonequilibrium $=$ The impact of episodic nonequilibrium $=$ The implications of episodic nonequilibrium $=$ Investigation of =Semi-analytical treatment of ... umerical simulation of gas flow through unsaturated ..... . $x$ flow in a dual-porosity simulator for unsaturated .... one-dimensional radionuclide transport in a layered .... models for flow and transport through unsaturated,

=Preliminary capillary hysteresis simulations for =Flow and transport in hierarchically =Characterization of flow in level nuclear waste repository site in unsaturated, ... Science in the Yucca Mountain Project symposium on ... . . quilibrium modeling of the formation of zeolites in ...... e strength and deformability of replicas of natural ...... e strength and deformability of replicas of natural =Modeling gravity-driven fingering in rough-walled $=$ Wetted-region structure in horizontal unsaturated $=$ Wetting

$=$ Testing models of redox ... Pocos de Caldas natural analogue: studies of redox ..... and visible light transmission as two-dimensional, =Developing a

-Nuclear waste: Questionable uses of program =Late quaternary faulting along the Death Valley... er Jura '91: nuclear law and nuclear energy for the ... ogical Resources Monitoring Program: Annual report, ... . logical resources monitoring program: Annual report fluctuations at Yucca Mountain, Nevada, June 1992*

fluid flow in unsaturated heterogeneous tuff*

fluid-rock interaction at Yucca Mountain, Nevada: A . . . . . . flux through the unsaturated tuff matrix at USW H-1*

focal mechanisms for the Southern Great Basin of Ne

focal mechanisms for the southern Great Basin of Ne

focal mechanisms for the southern Great Basin of $\mathrm{Ne}$. . . . Forcheimer approximation*

forecasting model of gaming revenues in Clark Count . . . . Foreign trip report, February 2-8, 1992*

Foreign trip report, May 2-9, $1993 *$

Foreign trip report, May $9-16,1993 *$

Foreign trip report, October 10-17, 1992*

formation of zeolites in fractures at Yucca Mountai . . . . . . forty boreholes at Yucca Mountain, Nevada*

Fortymile Wash, Nevada Test Site, Nevada*

four nickel-chromium-molybdenum alloys*

Fourth Quarter, FY 1991 *

Fourth quarterly report*

Fourth report to the U.S. Congress and the U.S. Sec . . . . . fourth quarter FY 1992*

fractal analysis*

fracture aperture patterns: Characterization by sli . . . . . . fracture coatings on the transfer of water across $f \ldots \ldots$ fracture faces in unsaturated media*

fracture flow at Yucca Mountain*

fracture*

fracturex

fracture-lining zeolites at Yucca Mountain, Nevada* . . . . . . fracture-matrix flow on geological repository perto . . . . . . . fracture-matrix flow on repository performance at $t . . .$. . fracture-matrix flow on site suitability and total . . . . . . . . fracture-matrix interaction: Preliminary experiment . . . . . . tracture/matrix flow in a dual-porosity simulator $f . . . . .$. fractured rock at Yucca Mountain, Nevada*

frectured rock masses*

fractured rock: MULTFRAC - Analytic solutions and I ..... fractured rock: Yucca Mountain Site Characterizatio . . . . fractured rocks - model development and results of ..... fractured systems*

fractured tuff using computerized tomography*

fractured tuff: Yucca Mountain Site Characterizatio ..... . .

Fractures, Hydrology, and Yucca Mountain": Abstrac . . . . . fractures at Yucca Mountain, Nevada*

tractures in welded tuff: Comparison between predic . . . . fractures in welded tuff: Data report: Yucca Mounta . . . . . tractures using modified percolation theory*

tractures: Water entry through the surrounding poro . . . . . front instability in an initially wet unsaturated $f . . . . .$. front migration and geochemistry at the Osamu Utsum ... . . front movement*

full-field moisture-sensing techniques: A prelimina . . . . . . . functioning visualization and analysis system for $p . . .$. . funds at Lawrence Livermore Lab.*

Furnace Creek fault system, California and Nevada* future: Proceedings of the biennial congress of the ...... FY91*

FY92*

388

322

168

338

376

384

379

428

409

434

436

435

433

133

370

385

166

452

16

573

459

\section{G}

=A forecasting model of =Numerical studies of rock$=$ Numerical simulation of

$=$ Natural

$=$ Physical limits on steam =AREST: The next

field high-temperature transport: Evidence from the

$=\mathrm{EQ3} / 6 \mathrm{~V}$ V 7. gaming revenues in Clark County, Nevada*

Gas phase migration of C-14 through barrier materia ...... gas flow in Yucca Mountain: Yucca Mountain Site Cha . . . . gas flow through unsaturated fractured rock at Yucc . . . . . . gas-phase source term for Yucca Mountain* gels in the Yucca Mountain Area, Nevada, USA* generation by radioactive decay heat* generation*

genesis of the Osamu Utsumi uranium mine, Pocos de . . . GENISES: A GIS Database for the Yucca Mountain Site ... Geochemical Modeling Of Aqueous Systems* 
. . . . . sitory block to the regional ground-water system: $A$

. . . . . ling ion exchange in clinoptilolite using the EQ3/6

$=E 03 / 6$, a software package for

=Testing of

$=$ Coupled hydro

. . . p puter program for reaction path modeling of aqueous

= Testing models of redox front migration and

$=$ The regional geology, mineralogy and $=$ Mineralogy, petrology and

=Mineralogy, petrology and

= Natural series radionuclide and rare-earth element

geochemical aqueous speciation-solubility calculati . . . . . .

geochemical characterization of selected nepheline . . . . . geochemical model*

geochemical modeling code*

geochemical modeling of aqueous systems: Package ov . .

geochemical models in the Pocos de Caldas analogue ... .

geochemical processes and their significance for $Y u$. . . . .

geochemical systems: Theoretical manual, user's gui . . . . geochemistry at the Osamu Utsumi mine and Morro do . . . geochemistry of the Pocos de Caldas alkaline calder . . . . . geochemistry of the Pocos de Caldas analogue study .... . geochemistry of the Pocos de Caldas analogue study . . . . geochemistry of waters from the Osamu Utsumi mine a . . . geochronology studies*

. . . . . Lathrop Wells volcanic center: Status of field and

. . . . . . Lathrop Wells volcanic center: Status of field and uncertainty in laboratory determination of several

$=$ Should high-level nuclear waste be disposed of at

geochronology studies*

geoengineering properties of tuffs from Yucca Mount . . . . . geographically dispersed sites?*

Geohydrologic data and models of Rainier Mesa and t . . . .

Geohydrologic data from test holes UE-25 UZ \#4 and . . . .

$=$ Borehole and

geohydrologic data for test hole USW UZ-6, Yucca Mo . . .

Geohydrology of rocks penetrated by test well USW H . . . .

Geologic evaluation of six nonwelded tuff sites in . . . . . .

$=$ Deterministic

geologic processes and stochastic modeling*

geologic relations and seismotectonic stability of . . . . . .

=Evaluation of the

$=$ Evaluation of the

geologic relations and seismotectonic stability of . . . . . . geologic repositories: Annual report, fiscal year $1 \ldots \ldots$. geologic repository at Yucca Mountain*

geologic repository post closure system performance . . . . . geologic repository*

geologic repository: Final report*

geologic trends on spatial variability of hydrologi . . . . . .

Geology, drilling, and some hydrologic aspects of $s$. . . . . .

geology of Midway Valley Yucca Mountain Project, Ny . . . .

geology of the CP Hills, Nevada Test Site, Nye Coun . . . . .

$=$ Preliminary mapping of surficia

$=$ Mesozoic and Cenozoic structural

$=$ The regional

geology, mineralogy and geochemistry of the Pocos $d$. . . .

Geomorphological and hydrogeological features of th . . . .

Geophysical characterization of mineral and energy . . . . .

Geophysical logs and core measurements from forty b. . . .

geophysical data near prospective surface facilitie ......

=Summary and evaluation of existing geological and

$=$ Assessment of

. . . . er for Volcanic and Tectonic Studies, Department of

$=$ Migration of radionuclides in the

= Migration of radionuclides in the

geophysical logs from borehole USW G-2, Yucca Mount . . .

Geoscience annual report, October 1, 1989-Septembe. . . .

geosphere*

geosphere*

geostatistical uncertainty: Yucca Mountain Site Cha . . . . .

Geotechnical support and topical studies for nuclea . . . . .

Geothermal evaluation and analysis of the Yucca Mou . . . .

Gerais, Brazil*

Gerais, Brazil*

.... es from the Pocos de Caldas alkaline complex, Minas

.... the Pocos de Caldas alkaline caldera complex, Minas

..... of the Pocos de Caldas analogue study sites, Minas

..... of the Pocos de Caldas analogue study sites, Minas

. . . MP Waste Container Fabrication and Closure Project: $=$ GENISES: $A$

$=$ Proceedings of the

$=$ Proceedings of the

$=A$ selected

=Effects of radiation exposure on

$=$ The reaction of SRL 202

=Parametric effects on

Gerais, Brazil

Gerais, Brazil: II. Morro do Ferro*

GIS Database for the Yucca Mountain Site Characteri . . . .

GIS and environmental rehabilitation workshop*

GIS and environmental rehabilitation workshop*

GIS bibliography: Technical Memorandum $40 *$

glass alteration in a steam environment*

glass in J-13 and DIW*

glass reaction in the unsaturated test method*

glasses leached in tuff $\mathrm{J}-13$ groundwater*

$=$ Durability study of sodium borosilicate
$=$ An overview of the Yucca Mountain

Global/Regional Climate Modeling Program*

govemments *

$=$ Native Americans and state and local

. . . . the dynamic response of geological materials to 100

... . . . quasi-static response of solids with the conjugate

=Modulus dispersion and attenuation in tuff and

.... tween predicted and observed shear behavior using a

. . . . . f seismic refraction traveltime data using a color-

=Modeling

=Small-scale behavior of single

GPa*

gradient method: Yucca Mountain Site Characterizati . . . . . granite*

graphical method: Yucca Mountain Site Characterizat .... graphics terminal*

Gravity and magnetic data of Fortymile Wash, Nevada . . . .

gravity-driven fingering in rough-walled fractures . . . . . . gravity-driven fingers in an initially dry fracture*

Great Basin of Nevada and California in 1991* 
$=$ Seismicity and focal mechanisms for the Southern =Seismicity and focal mechanisms for the southern =Dependence of radionuclide sorption on sample

=Current plans to characterize the design basis =Fingerprinting of

-Risk-based screening analysis of

lized recharge occur at a discharge area within the

.... the Yucca Mountain repository block to the regional =Pre-waste-emplacement

=The international hydrocoin project .... of neptunium, plutonium, and americium in a typical =The most tikely

$=$ Water-rock interactions and the $\mathrm{pH}$ stability of =Regional

... . y and sensitivity results for pre-waste-emplacement

.... of sodium borosilicate glasses leached in tuff $\mathrm{J}-13$ =Chemical and isotopic composition of =Neptunium retardation with tuffs and =Crack =Crack-

=Sociceconomic assessment . . . aqueous systems: Package overview and installation ... preprocessor for the EQ3/6 sottware package: User's =Using QA classification to $=H E F F-A$ user's manual and =The capillary hysteresis model HYSTR: User's =AREST user's . . . . solubility calculations: Theoretical manual, user's . . . ous geochemical systems: Theoretical manual, user's formance Assessment Code (TOSPAC): Volume 2, User's A preliminary
Great Basin of Nevada and California in 1990*

376

Great Basin of Nevada and California: 1987 through . . . . . grinding, surface area, and water composition*

Ground water of Yucca Mountain: How high can it ris . . . . . Ground-water data collected at the Nevada Test Site . . . . . ground motion at the Yucca Mountain, Nevada Site* ground water by ICP-MS: Progress report, July 1, $19 \ldots \ldots$. ground water contaminated by radionuclides introduc . . . . . ground-water flow system of Yucca Mountain, Nevada? * ground-water system: A geochemical model*

ground-water travel time sensitivity and uncertaint . . . . . . . Groundwater chemistry at the Nevada Test Site: Data . . . . Groundwater flow code verification "benchmarking" . . . . . . Groundwater hydrology modelling strategies for perf . . . . . groundwater $(\mathrm{J}-13)$ from the Yucca Mountain region: . . . groundwater flux through the unsaturated tuff matri . . . . . . groundwater from Yucca Mountain, Nevada*

groundwater modeling of the saturated zone in the $v \ldots \ldots$ groundwater travel time*

groundwater *

groundwaters and their seasonal variability at the $\ldots \ldots$. groundwaters from Yucca Mountain*

growth behavior of candidate waste container materi . . . . . growth-rate testing of candidate waste container ma ..... . guidance report: Determining the effects of amenity . . . . . . guide (Version 7.0 ) *

guide and related documentation (Version 7.0): Part . . . . . guide design and manage risk*

guide for the HEFF code for thermal-mechanical anal . . . . . gulde*

guide, PC version*

guide, and related documentation (Version 7.0): Par . . . . . guide, and related documentation (Version 7.0): Par . . . . guide: Yucca Mountain Site Characterization Project* guidebook for identifying stratigraphic contacts at . . . . . . . Guidelines on the scope, content, and use of compre . . . . .
379

127

511

594

4
13

592

362

566

305

444

244

470

109

338

124

535

272

597

584

128

146

145

415

200

201

5

223

37

154

202

203

217

184

561

H

$=A$ portable vacuum . . . . . e container, and a bare fuel assembly during waste$=$ Social impacts of $=$ Perceived risk impacts from siting $=$ Proceedings of emerging technologies for =Preciosure seismic . . . . y, drilling, and some hydrologic aspects of seismic

$=$ FEHMN 1.0: Finite element . . . . . . . Id air injection tests to determine the effect of a . . . . ted far-field temperatures for discrete and smeared =Implications of stability analysis for . . . . r density: A preliminary examination of underground .... cal limits on steam generation by radioactive decay =Modeling of strongly

-The analysis of repository. . . . nts and their occurrence with secondary minerals in .... . ysis of slot cutting methods for the Yucca Mountain . . . . measurements of in situ water potential changes in =Temperature measurements from a horizontal $=$ Prototype

$=$ Large-scale in situ . . . . tential increases in natural radon emissions due to $=$ HEFF-A user's manual and guide for the

Boron adsorption on

$=$ Numerical methods for fluid flow in unsaturated =Flow and transport in . . . . apability to conduct a performance assessment for a

=Ground water of Yucca Mountain: How =Geological disposal of spent fuel and hammer seismic source for use in tunnel environment . . . handling operations: Yucca Mountain Site Characteri . . . . . hazardous and nuclear facilities and events: Implic . . . . . . hazardous waste facilities*

hazardous waste management: Volume $1 *$

hazards and their impact on site suitability of Yuc . . . . . . hazards program core holes, Los Alamos National Lab . . . . Health and environmental risk-related impacts of ac . . . . . . Heat pipe effect in porous medium*

heat and mass transfer code: Revision 1 .

heat cycle on the permeability of welded tuff*

heat sources*

heat transfer at Yucca Mountain*

heat transfer in a potential Yucca Mountain reposit . . . . . . . heat*

heat-driven flow processes at a potential high-leve . . . . . . . heat-driven hydrothermal flow at Yucca Mountain*

heated and unheated tuff at the Nevada Test Site*

heated block test using a compliant-joint model*

heated welded tuff*.

heater test in G-Tunnel*

heater test of the environment around a simulated $w \ldots .$.

heater tests for hydrothermal characterization at $Y . \ldots . .$. heating of the Yucca Mountain rock mass*

HEFF code for thermal-mechanical analysis using the . . . . . HEFF-A user's manual and guide for the HEFF code . . . . hemafite and clinoptilolite*

heterogeneous tuff*

hierarchically fractured systems*

High-Level Waste Repository*

High-level nuclear waste disposal: Policy and progn . . . .

high can it rise?: Final report*

high level and alpha bearing wastes: Proceedings of . . . . .
595

224

555

410

73

291

488

572

445

103

179

332

337

243

165

57

194

52

270

180

178

162

195

212

223

223

490

322

61

512

400

511

71 
. . . . the conceptual waste package design for a potential $t$ sealing materials in the potential Yucca Mountain ent from sewage and settling ponds near a potential . . . . . . . . ions for surficial water addition above a potential $=$ Evaluation of alternatives for =Should

.... m nevada residents' views about the Yucca Mountain . . . . . anical-chemical processes pertinent to the proposed $=$ Preliminary total-system analysis of a potentia strongly heat-driven flow processes at a potential

$\ldots . .44$ through barrier materials applicable for use in a $\ldots . .$. inty on the estimated performance of a hypothetical
$=$ SUMO, System performance assessment for a $\ldots .$. inty on the estimated performance of a hypothetical
$=$ SUMO, System performance assessment for a $=$ Retrieval strategy report for a potential ... . nts: Implications for Nevada and the Yucca Mountain $=A$ report on

. . comprehensive risk assessment in the management of $=$ Cost estimate of

. . . . s sments for both the low- and intermediate-level and

. . . . . . structural model analysis of public opposition to a

=Proposed sealing field tests for a potential

$=$ Seismic considerations in sealing a potentia

$=$ The importance of zeolites in the potential

Ar results from Yucca Mountain, Nevada: A potential =Corrosion models for predictions of performance of = Modeling pitting corrosion damage of . . . . . nmental risk-related impacts of actinide burning on =Thermal analysis of Yucca Mountain commercial mental program plan for site characterization for a

=Demonstration of a risk-based approach to ... . I workshop on near-field performance assessment for ..... . to demonstrate compliance with the regulations for $=$ Near-field

. . . . . . . with zeolitization of the tuffaceous beds of Calico

.... . y and discussion of hydrologic data from the Calico = Mesozoic and Cenozoic structural geology of the CP eedings: EPRI Workshop 2 - Technical basis for EPA . . . e edings: EPRI Workshop 2 - Technical basis for EPA $=$ Borehole and geohydrologic data for test =Single-

$=$ Geohydrologic data from test $=$ Structure in continuously cored, deep drill . . . . hydrologic aspects of seismic hazards program core =Temperature measurements from a $=$ Wetted-region structure in $=$ Thermal impact on =Ground water of Yucca Mountain: $=$ Hydrogeologic characterization of wells c characterization of wells HTH-1, UE18r, UE6e, and

. . . or other purposes, introduced in the US Senate, One . . . . . a buried nuclear waste storage container storing a =Supporting

. . . . An inverse procedure for estimating the unsaturated =Laboratory analysis of $=$ Coupled

$=$ The international

. . . . of hydrologic data from the Calico Hills nonwelded =Geomorphological and

=Geology, drilling, and some =Statistical analysis of $=$ A summary and discussion of . . . evelopments in stochastic modeling and upscaling of . . . . . . ministic geologic trends on spatial variability of . . . . . rization of conservative organic tracers for use as ..... rization of conservative organic tracers for use as . . . . . rization of consenvative organic tracers for use as . . . . . rization of conservative organic tracers for use as . . . . rization of conservative organic tracers for use as $=$ Nonisothermal high level nuclear waste repository at Yucca Mounta

high level nuclear waste repository

high level radioactive waste repository in Yucca Mo . . . . . .

high level radioactive waste repository at Yucca Mo . . . . . . .

high-level and transuranic radioactive-waste dispo . . . . . .

high-level nuclear waste be disposed of at geograph . . . . .

high-level nuclear waste repository and related iss . . . . . .

high-level nuclear waste repository at Yucca Mounta . . . . .

high-level nuclear waste repositony at Yucca Mounta . . . . .

high-level nuclear waste repository at Yucca Mounta . . . . .

high-level nuclear waste repository located in tuff*

high-level nuclear waste repository site in unsatur . . . . . . .

high-level nuclear waste repository: Mathematical $m$. . . . .

high-level nuclear waste repository: Yucca Mountain . . . . .

high-level nuclear waste repository: [Final report]*

high-level nuclear waste transportation: Prepared $p$

high-level nuclear waste transportation*

high-level radioactive waste containers for the Yuc . . . . . .

high-level radioactive waste disposal programs bein . . . . . .

high-level radioactive waste facility*

high-level radioactive waste repository in unsatura . . . . .

high-level radioactive waste repository*

high-level radioactive waste repository at Yucca Mo . . . . . .

high-level radioactive waste repository site*

high-level radioactive-waste containers*

high-level radioactive-waste containers, with empha . . . . . .

high-level waste disposal*

high-level waste packages*

high-level waste repository at Yucca Mountain, Neva . . . . .

high-level waste repository evaluation, Phase $2 *$

high-level waste*

high-level waste*

high-level-waste repositories? *

high-temperature transport: Evidence from the genes . . . . . Hills at Yucca Mountain, Nevada*

Hills nonwelded hydrogeologic unit at Yucca Mountai . . . . . Hills, Nevada Test Site, Nye County, Nevada; and re . . . . . HLW disposal criteria*

HLW disposal criteria*

hole USW UZ-6, Yucca Mountain area, Nye County, Nev . . . hole in situ thermal probe for hydrothermal charact . . . . . . holes UE-25 UZ \#4 and UE-25 UZ \#5, Yucca Mountain . . . . holes at Yucca Mountain, Nevada, with notes on calc . . . . . holes, Los Alamos National Laboratory, New Mexico*

horizontal heater test in G-Tunnel*

horizontal unsaturated fractures: Water entry throu . . . . . .

host rock of geologic repository: Final report*

How high can it rise?: Final report*

HTH-1, UE18r, UE6e, and HTH-3, Nevada Test Site*

HTH-3, Nevada Test Site*

Human and social factors in the transportation of $n$. . . . .

Hundred Second Congress, First Session, May 22, 199 . . .

hybrid mix of PWR and BWR spent fuel rods: Revision . . . .

hydration calculations for small- to large-scale se . . . . . . . hydraulic conductivities of volcanic tuffs *

hydraulic properties of voicanic tuff samples*

hydro-geochemical processes and their significance ......

hydrocoin project - Groundwater hydrology modelling . . . .

Hydrogeologic characterization of wells HTH-1, UE18 . . .

hydrogeologic unit at Yucca Mountain, Nevada*

hydrogeological features of the Pocos de Caldas cal . . . . .

Hydrogeology and migration in the remote field*

hydrologic aspects of seismic hazards program core ... .

hydrologic data for Yucca Mountain: Yucca Mountain . . . .

hydrologic data from the Calico Hills nonwelded hyd ..... hydrologic properties in tuff*

hydrologic properties in volcanic tuff $*$

hydrologic tracers for the Yucca Mountain Site Char . . . . .

hydrologic tracers for the Yucca Mountain Site Char ..... . .

hydrologic tracers for the Yucca Mountain Site char .....

hydrologic tracers for the Yucca Mountain Site Char . . . . .

hydrologic tracers for the Yucca Mountain Site Char . . . . .

hydrologic transport experimental plan* 
$=$ A literature review of coupled thermat . . . . d programmatic requirements for laboratory study of $\therefore . .$. large block testing of coupled thermal-mechanical... he Yucca Mountain Project symposium on "Fractures, . . . nal approaches to support performance assessment of $=$ The international hydrocoin project - Groundwater . . . : An intense widespread culmination of magmatic and $=$ Single-hole in situ thermal probe for = Large-scale in situ heater tests for $=$ The analysis of repository-heat-driven =The =Surface-discharging . . . . model uncertainty on the estimated performance of a =incorporation of the capillary $=$ The capillary

$=$ Preliminary capillary

$=$ Incorporation of the capillary hysteresis model $=$ The capillary hysteresis model hydrologic-mechanical-chemical processes pertinent .... hydrological properties of the near-field environme . . . . . hydrological-chemical processes*

Hydrology, and Yucca Mountain": Abstracts and summ .. Hydrology/Radionuclide Migration Program and relate . . . . hydrology and chemical transport at Yucca Mountain: . . . . hydrology modelling strategies for performance asse . . . . hydrothermal activity at the southwestern Nevada vo . . . . hydrothermal characterization at Yucca Mountain* hydrothermal characterization at Yucca Mountain* hydrothermal flow at Yucca Mountain*

hydrothermal stability of cement sealing materials ... . . . hydrothermal systems at Yucca Mountain: Examining t . . . hypothetical high-level nuclear waste repository si ...... hysteresis model HYSTR into the numerical code TOUG . hysteresis model HYSTR: User's guide *

hysteresis simulations for fractured rocks - model . . . . . HYSTR into the numerical code TOUGH*

HYSTR: User's guide*
$=$ Fingerprinting of ground water by

=A preliminary guidebook for $=$ Word

$=$ An investigation of the

$$
\text { =The }
$$

=The

=The

=Estimation of the $=$ Thermal

$=$ Preclosure seismic hazards and their

=Perceived risk

$=$ Health and environmental risk-related

=Social

=Managing nuclear waste: Social and economic

=Design and

.. dioactive waste disposal programs being managed and

..... . cts of hazardous and nuclear facilities and events:

= Organizational management of long-term risks:

. . . . c analysis of lineaments at Yucca Mountain, Nevada:

$=$ The Pocos de Caldas project: summary and =The

... ydrologic data and models of Rainier Mesa and their . . . . Nevada Test Site, Nye County, Nevada; and regional

=The

.... entification of structures, systems, and components $=$ RE/SPEC

$=1991$ OCRWM bulletin compilation and . ve American communities: Las Vegas Tribes of Paiute =The use of sequential =A scoping study of water table excursions =Earthquake=Earthquake-

$=$ Methodologies for selecting ...... ties: A critical evaluation of the Las Vegas target ..... ors in influencing the location of nonmanufacturing ... . . ransport calculations for $0.01,0.1$, and $0.5 \mathrm{~mm} / \mathrm{yr}$

$=$ The role of amenities and other factors in $=$ The influence of strain rate and sample

=Scientific investigation plan for =TSPA 1991: An =Field air

..... of the International Nuclear Law Association (AIDN$=$ Proceedings of the Alfred $\mathrm{O}$. Nier symposium on
ICP-MS: Progress report, July 1, 1991-December 31, . . . Identification of structures, systems, and componen ..... Identification of subsurface microorganisms at Yucc . . . . identifying stratigraphic contacts at the Nevada Te ...... images as policy instruments: Lessons from the Yucc . . . . . Impact of fracture coatings on the transfer of wate . . . . . . . impact of conceptual model uncertainty on the estim ..... impact of episodic nonequilibrium fracture-matrix $f \ldots \ldots$ impact of episodic nonequilibrium fracture-matrix $f \ldots . . .$. impact of thermal loading on repository performance . . . . . impact of water movement from sewage and settling $p . .$. . impact on host rock of geologic repository: Final $r$. . . . . . . impact on site suitability of Yucca Mountain, Nevad . . . . . . impacts from siting hazardous waste facilities *

impacts of actinide burning on high-level waste dis ...... impacts of hazardous and nuclear facilities and eve...... impacts $*$

implementation of the site and engineering properti . . . . . implemented by NAGRA: Foreign trip report, May $2-9$. . . Implications for Nevada and the Yucca Mountain high . . . . Implications for risk and safety in the transportat ....... Implications for strike-slip faulting and oroclinal . . . . . . . . Implications of stability analysis for heat transfe . . . . . . . . implications for radioactive waste management: Poco . . . . implications of episodic nonequilibrium fracture-ma . . . . . . implications to Yucca Mountain* implications*

importance of zeolites in the potential high-level ...... important to safety at the potential repository at . . . . . . . . Inc. technical support to the Repository Technology ....... Incorporation of the capillary hysteresis model HYS . . . . . index*

Indians*

indicator simulation to characterize geostatistical ....... induced by seismic and volcanic events*

induced water-level fluctuations at Yucca Mountain, . . . . . . induced water-level fluctuations at Yucca Mountain, . . . . . . industries for regions and communities: A critical . . . . . . . industry analysis $\times$

Industry in the United States*

Infiltration into Yucca Mountain: Yucca Mountain Si ..... . influencing the location of nonmanufacturing indust ...... inhomogeneity on the moduli and strength of welded .... Initial demonstration of the NRC's capability to co ........ Initial field testing definition of subsurface seal . . . . . . . . initial engineered barrier system field tests*

initial total-system performance assessment for Yuc ..... injection tests to determine the effect of a heat $c \ldots . .$. INLA), Bath, England, 23-26 September 1991* inorganic mass spectrometry* 
..... n of uncertain outcomes from site characterization: =Wetting front

. . I modeling of aqueous systems: Package overview and =Alligator Rivers Region Research =Alligator Rivers Region Research

-G-Tunnel Welded Tuff Mining Experiment .... . ical evaluation of available state of Nevada survey =Word images as policy =A comparative application of the Repository ... nister docking and emplacement using a sensor-based =The Timber Mountain magmato-thermal event: An =Nuclear =Modeling fluid-rock =Investigation of fracture-matrix $=$ Water-rock =Geochemical modelling of water-rock $=$ TURBOSEIS-An

$=$ Report to the President by the =Proposed algorithm for determining the delta =Use of Wingz spreadsheet as an .... d for performance assessments for both the low- and =Design of an

..... istry at the Nevada Test Site: Data and preliminary

=State of Nevada review of Phase 1 of the $=$ The International =The International =The International .... Iysis of ground water contaminated by radionuclides ... . ca Mountain site in Nevada, and for other purposes, $=$ An

. . he southern Amargosa Desert, Nye County, Nevada and =Modeling

$=$ Progress in assessing the effect of ... . utron tomography of water in rock using the Argonne ... . . acture aperture patterns: Characterization by slit.... ation of a 1977-1985 edited sorption data base for

$=$ Chemical and

.... ted zone in the vicinity of Yucca Mountain, Nevada ... . . . nalytic solutions and local sensitivities: Phase 2, =Use of the

mechanical codes first benchmark exercise: Part 3 =An analysis of a joint shear model for =Application of analytical methods for

=Expert

=Nuclear inter

. . . ic Project: The 1991 Nevada State telephone survey: $=$ Photogeologic and

. . . t $t$ in assessing radwaste risks: What Nevadans should
Insights from the ESF-AS*

instability in an initially wet unsaturated fractur ....... installation guide (Version 7.0) \%

Institute: annual research summary 1989-1990*

Institute: annual research summary 1989-1990*

Institutional trust, information, and risk percepti . . . . . . . .

Instrumentation requirements for the ESF thermomech ... instrumentation evaluations: Yucca Mountain Site $\mathrm{Ch}$.... instruments*

instruments: Lessons from the Yucca Mountain Contro . . . Integration Program (RIP) to Total System Performan .... intelligent controller: Yucca Mountain Site Charact . . . . . . intense widespread culmination of magmatic and hydr . . . . Inter Jura ' 91 : nuclear law and nuclear energy for . . . . . . . interaction at Yucca Mountain, Nevada: A progress $r$. . . . . interaction: Preliminary experiments in a simple sy . . . . . . interactions and the $\mathrm{pH}$ stability of groundwater $\mathrm{fr}$. . . . . . . interactions at the Osamu Utsumi mine and Morro do .... interactive program for constructing and editing mo ...... Interagency Review Group on Nuclear Waste Managemen . intercept of a thermocouple psychrometer curve*

interface to total-system performance assessment*

intermediate-level and high-level radioactive waste ...... intermediate-scale experiment to validate unsaturat . . . . . . interpretations*

Intra-site secure transport vehicle*

INTRAVAL Project*

INTRAVAL project. Phase 1 case 8: The Alligator riv . . . . INTRAVAL project. Phase 1 test cases*

INTRAVAL project. Phase 1, case 7 . The Pocos de Cal . . . introduced at the Nevada Test Site (NTS) *

introduced in the US Senate, One Hundred Second Con . . inverse procedure for estimating the unsaturated hy ..... Inyo County, California*

Ion exchange in clinoptilolite using the EQ3/6 geoc ...... ionizing radiation on the anticipated waste package . . . . . . IPNS*

island fractal analysis*

isotherm modeling*

Isolopic geochemical characterization of selected $n$...... isotopic composition of groundwaters and their seas . . . . . Iterative Performance Assessment, Phase $2 *$

lterative performance assessment: Volume $1 *$

Iterative solution method for coupled finite elemen . . . . . . .

\section{J}

JAC3D - A three-dimensional finite element compute . . . . . Jointed rock mass analysis: Yucca Mountain Site Cha . . . . jointed media with orthogonal joint sets: Yucca Mou . . . . . jointed rock as part of a drift design methodology . . . . . . . judgment in assessing radwaste risks: What Nevadans . . . Jura '91: nuclear law and nuclear energy for the fu ......

\section{K}

Key findings*

Kinematic analysis of lineaments at Yucca Mountain, ..... . Kinetics of silica-phase transitions*

know about Yucca Mountain: [Final report]* 219 for

=Technical basis and programmatic requirements for =Supporting hydration calculations for small- to

$$
\text { =The }
$$

=The

the biennial congress of the International Nuclear =Nuclear Inter Jura '91: nuclear
Large-scale in situ heater tests for hydrothermal c . . . . . . . large block testing of coupled thermal-mechanical-h . . . . . . large-scale seal tests in unsaturated tuff*

Lathrop Wells volcanic center: Status of field and . . . . . . . Lathrop Wells volcanic center: Status of field and . . . . . . . Law Association (AIDN-INLA), Bath, England, 23-26 S ... law and nuclear energy for the future: Proceedings ...... 
. . . uclear waste: Questionable uses of program funds at . . . phy of Yucca Mountain Project (YMP) publications at . . . . . lied to one-dimensional radionuclide transport in a $=$ Elements present in $=$ Durability study of sodium borosilicate glasses . . . mbly concurrent resolution No. 8 of the 1987 Nevada =Word images as policy instruments:

$=$ Water

$=$ The quality assurance

... . codes review for waste package application; Part C, $=X$-ray and visible $=$ The most =Estimation of the =Physical

$=$ Photogeologic and kinematic analysis of

$$
\text { =Quasi- }
$$

. . . e erformance prediction of mechanical excavators from =Seismic design of circular-section concrete$=$ Distribution and chemistry of fractureSP: A finite element computer program for analyzing $=$ Characterization of $=A$

. . waste management system based on information in the $=$ Processed seismic motion records from =Processed seismic motion records from . . . ste: Questionable uses of program funds at Lawrence ... cca Mountain Project (YMP) publications at Lawrence ..... sure piping, containers, and casks with long design

$=$ The impact of thermal $\therefore \ldots$ ield thermal and mechanical calculations of thermal .... y reexamination of a technique for equating thermal $=$ Native Americans and state and

... d fractured rock: MULTFRAC -Analytic solutions and =Does

=Geophysical

$=$ Assessment of geophysical =Procedure development study: ...... r reliability/failure rates data on low temperature ... . . . . ibrary search for reliability/failure rates data on . . . . witzerland for performance assessments for both the
Lawrence Livermore Lab.*

Lawrence Livermore National Laboratory (January 197 . . . . layered fractured rock: MULTFRAC -Analytic solutio . . . . . leach solutions from unsaturated spent fuel tests*

leached in tuff $\mathrm{J}-13$ groundwater*

Legislature*

Lessons from the Yucca Mountain Controversey*

levels in continuously monitored wells in the Yucca . . . . . .

liaison: Combined technical and quality assurance $s . .$. .

Library search for reliability/failure rates data $0 . . . . . .$. .

light transmission as two-dimensional, full-field $m$. . . . . . .

Iikely groundwater flux through the unsaturated tur . . . . . .

limitations for surficial water addition above a po ....... .

limits on steam generation by radioactive decay hea . . . . .

lineaments at Yucca Mountain, Nevada: Implications ....

Linear thermal expansion data for tuffs from the un . . . . . .

linear analysis of water flow in the unsaturated zo . . . . . .

linear cutter tests on Yucca Mountain welded tuffs: . . . . . .

lined underground openings: Preclosure performance .... . lining zeolites at Yucca Mountain, Nevada*

liquid water transport in porous media: Yucca Mount . . . . . fiquid-water percolation in tuffs in the unsaturate . . . . . . . .

literature review of coupled thermal-hydrologic-mec . . . . . . literature*

Little Skull Mountain, Nevada earthquake aftershock . . . . .

Little Skull Mountain, Nevada earthquake of June 29 . . . . . Livermore Lab.*

Livermore National Laboratory (January 1978 through . . . . Iives*

LLNLYMP Waste Container Fabrication and Closure Pr . . . LLUVIA-Il: A program for two-dimensional, transient . . . . . . . loading on repository performance at Yucca Mountain* loading schemes:

loads: Yucca Mountain Site Characterization Project* local governments*

local sensitivities: Phase 2 , Iterative performance . . . . . . localized recharge occur at a discharge area within ...... logs and core measurements from forty boreholes at . . . . . logs from borehole USW G-2, Yucca Mountain, Nevada* . . . Low strain rate and creep experiments: Yucca Mounta .... low pressure piping, containers, and casks with lon . . . . . . low temperature low pressure piping, containers, an . . . . . . low- and intermediate-level and high-level radioact . . . . .
468

150

536

408

597

558

430

378

130

12

279

338

265

165

381

228

258

299

303

134

255

361

537

576

475

474

468

150

12

591

290

189

333

269

553

536

362

370

387

261

12

12

436
M

made materials in the post-emplacement environment ${ }^{*} \ldots$ made on core samples from Yucca Mountain boreholes, ... . Magela Creek, Alligator Rivers Region: Research Rep . . . . magmatic and hydrothermal activity at the southwest . . . . . magmatic disruption of the potential Yucca Mountain . . . . . . magmatic processes on the potential Yucca Mountain ... . . magmatism and polycyclic volcanism at Crater Flat, . . . . . magmatism in the Yucca Mountain region*

magmato-thermal event: An intense widespread culmin ... magnetic data of Fortymile Wash, Nevada Test Site, . . . . . maintenance at the potential Yucca Mountain reposit . . . . . . making process*

man-made materials in the post-emplacement environm ... manage risk*

managed and implemented by NAGRA: Foreign trip repo . . Managing nuclear waste: Social and economic impacts* manual and guide for the HEFF code for thermal-mech . . . . manual*

manual*

manual*

manual, user's guide, and related documentation $\mathrm{Ve} . . .$.

manual, user's guide, and related documentation (Ve . . . . . map of the Beatty quadrangle, Nevada-California

mapping of surficial geology of Midway Valley Yucca . . . . . mass analysis: Yucca Mountain Site Characterization . . . . . mass mechanical property estimation strategy for th . . . . . 
$=$ Rock

... edings of the Alfred $O$. Nier symposium on inorganic $=$ FEHMN 1.0: Finite element heat and emissions due to heating of the Yucca Mountain rock I-porosity simulator for unsaturated fractured rock =Characterization of spent fuel approved testing =Characterization of spent fuel approved testing $=$ Gas phase migration of $\mathrm{C}-14$ through barrier =Preliminary characterization of =Selection of candidate container =Crack growth behavior of candidate waste container and mineralogical concerns for the use of man-made =The hydrothermal stability of cement sealing $=$ Over-the-road tests of nuclear . . . . ds for measuring the dynamic response of geological . . . . . ck-growth-rate testing of candidate waste container . . . . ess corrosion cracking of candidate waste container .... . sessment for a high-level nuclear waste repository: . . . . . ikely groundwater flux through the unsaturated tuff $=$ Semi-analytical treatment of fracture

=The impact of episodic nonequilibrium fracture-

=The impact of episodic nonequilibrium fracture-

e implications of episodic nonequilibrium fracture-

... actures: Water entry through the surrounding porous $=$ Probable

$=$ Rationale for determining =Alternative strategies: $A$

$=$ Temperature

=Geophysical logs and core $=$ Results of rock property

=Thermocouple psychrometer

=A suggested approach toward

=Recent advances in methods for

.... p's manual and guide for the HEFF code for thermal$=$ The results of near-field thermal and =Yucca Mountain Project thermal and $=$ Performance prediction of =Performance predictions for $=$ Characterization of porosity in support of $=$ Rock mass $=$ Rock mass

. . . . ogy, petrology and whole-rock chemistry of selected =A literature review of coupled thermal-hydrologic-

rements for large block testing of coupled thermal-

$=$ Rock

$=$ Proceedings of advanced cementitious systems: =Seismicity and focal =Seismicity and focal =Seismicity and focal $=$ Processes,

$=$ Scale dependence of effective $=$ An analysis of a joint shear model for jointed . . . . nsfer of water across fracture faces in unsaturated . . . . . , transient flow through partially saturated porous . . . . gram for analyzing liquid water transport in porous . . . . . . aches for partially saturated flow in soil and rock =Heat pipe effect in porous =Anisotropy of the Topopah Spring nconfined compression experiments on Topopah Spring =A selected GIS bibliography: Technical = Geohydrologic data and models of Rainier . . . erground nuclear explosions conducted in the Pahute

$=$ Use of the iterative solution =Exerimental

$=A$ working definition of scenario and a c effects on glass reaction in the unsaturated test ...... . . mal-mechanical analysis using the boundary-element . . . . . . atic response of solids with the conjugate gradient . . . . icted and observed shear behavior using a graphical mass mechanical property estimations for the Yucca . . . . . mass spectrometry* mass transfer code: Revision $1 *$

mass

masses*

material-ATM-105*

materiaLATM-104*

materials applicable for use in a high-level nuclea . . . . . . .

materials for a reactive transport model validation . . . . . . . .

materials for the conceptual waste package design f . . . . . materials in simulated underground water*

materials in the post-emplacement environment*

materials in the potential Yucca Mountain high leve . . . . . . materials package response to normal environments* materials to $100 \mathrm{GPa} *$

materials*

materials: Final report*

Mathematical models*

matrix at USW $\mathrm{H}-1$ *

matrix flow in a dual-porosity simulator for unsatu . . . . . . . matrix flow on geological repository performance*

matrix flow on repository performance at the potent . . . . . matrix flow on site suitability and total system pe . . . . . . matrix interaction: Preliminary experiments in a si . . . . . . . matrix*

maximum flood control: Yucca Mountain Site Characte . . . . MCC spent fuel acquisitions -

means for saving money and time on the Yucca Mounta . . . Measured solubilities and speciations of neprunium, . . . . . . measurements from a horizontal heater test in G-Tun . . . . measurements from forty boreholes at Yucca Mountain . . . measurements made on core samples from Yucca Mounta . measurements of in situ water potential changes in . . . . . measuring sorption and applying sorption data to re . . . . . measuring the dynamic response of geological materi . . . . mechanical analysis using the boundary-element meth . . . . mechanical calculations of thermal loading schemes* . . . . . mechanical codes first benchmark exercise: Part $3, \ldots .$. mechanical excavators from linear cutter tests on $Y \ldots \ldots$. . . . mechanical excavators in Yucca Mountain tuffs: Yucc .... . mechanical property analysis*

mechanical property estimation strategy for the Yuc . . . . . mechanical property estimations for the Yucca Mount .... . mechanical test samples of Yucca Mountain tuffs: Yu . . . . . mechanical-chemical processes pertinent to the prop . . . . . mechanical-hydrological-chemical processes*

mechanics contributions from defense programs*

Mechanisms and properties. Volume 245×

mechanisms for the Southern Great Basin of Nevada a . . .

mechanisms for the southern Great Basin of Nevada a . . . . mechanisms for the southern Great Basin of Nevada a . . . . mechanisms, parameters, and modeling approaches for . . . media properties*

media with orthogonal joint sets: Yucca Mountain $\mathrm{Si} \ldots \ldots$ mediax

media: Yucca Mountain Site Characterization Project*

media: Yucca Mountain Site Characterization Project*

media: Yucca Mountain Site Characterization Project* medium*

Member Tuff*

Member tuff at $22^{\circ} \mathrm{C}$ and a strain rate of $10 \ldots \ldots \ldots \ldots$ Memorandum 40 *

Mesa and their implications to Yucca Mountain

Mesa testing area at the Nevada testing site: Yucca . . . . . . . Mesozolic and Cenozoic structural geology of the CP . . . . . method for coupled finite element and boundary elem . . . . method for determining distribution coefficients of . . . . . . . method of scenario construction*

method*

method: Version 4.1: Yucca Mountain Site Characteri ... method: Yucca Mountain Site Characterization Projec . . . . method: Yucca Mountain Site Characterization Projec . . . . Methodologies for selecting industries for regions . . . . . 
$=$ Drift design methods for jointed rock as part of a dritt design $=$ Numerical

$=$ Application of analytica $=$ Recent advances in

$=$ Analysis of slot cutting . . . sk perceptions: Report of findings of the Las Vegas Management System Requirements Document: Volume 4,

=Identification of subsurface $=$ Preliminary mapping of surficial geology of $=$ Recent characterization activities of hysical data near prospective surface facilities in =Hydrology/Radionuclide

=Testing modeis of redox front $=$ Estimates of potential radionuclide $n$ coefficients of TRU nuclides for evaluating their =Hydrogeology and $=$ Radionuclide =Gas phase ..... al analogue studies: Mineral alteration and uranium ... groundwater $(\mathrm{J}-13)$ from the Yucca Mountain region: ... onolites from the Pocos de Caldas alkaline complex, ... . . ry of the Pocos de Caldas alkaline caldera complex, ... . . mistry of the Pocos de Caldas analogue study sites, . . . . . mistry of the Pocos de Caldas analogue study sites, . . . lement geochemistry of waters from the Osamu Utsumi ... . ling of water-rock interactions at the Osamu Utsumi . . . ront migration and geochemistry at the Osamu Utsumi . . . ement studies of rock samples from the Osamu Utsumi ..... and their seasonal variability at the OSAMU Utsumi ..... . ticles and colloids in waters from the Osamu Utsumi ... of the Pocos de Caidas caidera and the Osamu Utsumi =Microbiological analysis at the Osamu Utsumi ... idence from the genesis of the Osamu Utsumi uranium . . . . ites, Minas Gerais, Brazil. I. Osamu Utsumi uranium =Natural analogue studies: $=$ Geophysical characterization of $=$ Preliminary conceptual model for $=$ Chemical and

The regional geology, =Radioelements and their occurrence with secondary . ronmental issues and waste management in energy and - ronmental issues and waste management in energy and . ronmental issues and waste management in energy and $=$ G-Tunnel Welded Tuff . . . . . ary numerical modeling for the G-Tunnel welded tuff

\section{$=$}

. . . . ed nuclear waste storage container storing a hybrid . . . . . lute transport calculations for $0.01,0.1$, and 0.5 =Incorporation of the capillary hysteresis $=$ The capillary hysteresis $=$ A structural . . . . . apillary hysteresis simulations for fractured rocks $=$ An analysis of a joint shear =Preliminary conceptual $=$ Design of a three-dimensional site-scale =A forecasting

$=$ An investigation of the impact of conceptual racterization of materials for a reactive transport . . . . . to the regional ground-water system: A geochemical ... mance assessment: Some questions for the near-field $=$ EQ3/6 V7.0: Geochemical . . . . Niew of the Yucca Mountain Global/Regional Climate methodology and preliminary application for the Yuc . . . . . methodology for the Yucca Mountain Project*

methods for fluid flow in unsaturated heterogeneous ..... methods for jointed rock as part of a drift design . . . . . . . methods for measuring the dynamic response of geolo . . . . methods for the Yucca Mountain heated block test us . . . . metropolitan area survey, June 29-July $1,1992 *$

MGDs, Revision 2*

Microbiological analysis at the Osamu Utsumi mine a . . . . microorganisms at Yucca Mountain: Fourth quarterly .... . Midway Valley Yucca Mountain Project, Nye County, N . . . . Midway Valiey as a potential repository surface fac . . . . . . Midway Valley, Yucca Mountain Project, Nye County, . . . . Migration Program and related research activities: . . . . . . Migration of radionuclides in the geosphere*

Migration of radionuclides in the geosphere*

migration and geochemistry at the Osamu Utsumi mine . . . migration at the Bullion site*

migration behaviors*

migration in the remote field*

migration laboratory studies for validation of batc . . . . . .

migration of $\mathrm{C}-14$ through barrier materials applica . . . . . migration*

Milestone report 3010-WBS 1.2.3.4.1.3.1*

Minas Gerais, Brazil*

Minas Gerais, Brazil*

Minas Gerais, Brazil. I. Osamu Utsumi uranium mine: . . . . .

Minas Gerais, Brazil: II. Morro do Ferro*

mine and Morro do Ferro analogue study sites, Pocos ... .

mine and Morro do Ferro analogue study sites, Pocos .... .

mine and Morro do Ferro analogue study sites, Pocos .... .

mine and Morro do Ferro analogue study sites, Pocos .... .

mine and Morro do Ferro analogue study sites, Pocos . . . .

mine and Morro do Ferro analogue study sites, Pocos .... .

mine and Morro do Ferro analogue study sites, Brazi . . . . .

$m$ me and Morro do Ferro analogue study sites, Pocos . . . .

mine, Pocos de Caldas alkaline complex, Brazil: Poc . . . . .

mine: Pocos de Caldas Report No. 2*

Mineral alteration and uranium migration*

mineral and energy resources at Yucca Mountain and . . .

mineral evolution in Yucca Mountain*

mineralogical concerns for the use of man-made mate . . . .

Mineralogy, petrology and geochemistry of the Pocos . . . .

Mineralogy, petrology and geochemistry of the Pocos ... .

Mineralogy, petrology and whole-rock chemistry of $s$.....

Mineralogy, petrology and whole-rock chemistry data . . . . .

mineralogy and geochemistry of the Pocos de Caldas . . . .

minerals in heated and unheated tuff at the Nevada ..... .

minerals production*

minerals production*

minerals production*

Mining Experiment instrumentation evaluations: Yucc . . . . .

mining experiment: Yucca Mountain site characteriza . . . . . .

MISTY ECHO Tunnel Dynamics Experiment-Data report: . . .

MISTY ECHO tunnel dynamics experiment data report: . . .

mix of PWR and BWR spent fuel rods: Revision 1*

$\mathrm{mm} / \mathrm{yr}$ infiltration into Yucca Mountain: Yucca Mount . . . . .

model HYSTR into the numerical code TOUGH*

model HYSTR: User's guide*

model analysis of public opposition to a high-level . . . . . . .

model development and results of simulations*

model for jointed media with orthogonal joint sets: . . . . . . .

model for mineral evolution in Yucca Mountain*

model for the unsaturated zone at Yucca Mountain, N ... .

model of gaming revenues in Clark County, Nevada*

model uncertainty on the estimated performance of a . . . . .

model validation experiment*

model*

model*

modelers*

Modeling Of Aqueous Systems*

Modeling Program*

Modeling fluid-rock interaction at Yucca Mountain, . . . . . . 
$=$ Recent developments in stochastic =Processes, mechanisms, parameters, and $=$ A demonstration of dose ... nds placed on waste package performance testing and . . . . hange in clinoptilolite using the EO3/6 geochemical $=$ Preliminary numerical $=$ Reliability

=EQ6, a computer program for reaction path $=E 03 / 6$, a software package for geochemical =Preliminary =Equilibrium =Simulation

$=$ Regional groundwater $=$ Three-dimensional $=A$ study of discrete and continuum joint $=$ Deterministic geologic processes and stochastic ... . . a hod for coupled finite element and boundary element =Geochemical mational hydrocoin project - Groundwater hydrology ... Research program to develop and validate conceptual =Developing conceptual =Corrosion

=Testing of geochemical $=$ Geohydrologic data and =Comparison of two conceptual =Testing

.... An interactive program for constructing and editing =Recurrence

$=$ An approach to validation of thermomechanical . . . . . experiment to validate unsaturated-zone transport . . . . a high-level nuclear waste repository: Mathematical =Survey of degradation ..... ty-driven fingering in rough-walled fractures using ... ence of strain rate and sample inhomogeneity on the

$=$ Preliminary modeling of . . . . . . e light transmission as two-dimensional, full-field . . . . unvey of degradation modes of four nickel-chromium=Alternative strategies: A means for saving

$=$ Water levels in continuously =Yucca Mountain Biological Resources =Community Radiation $=$ Environmental $=$ Addendum to environmental =Yucca Mountain biological resources $=$ Evaluation of environmental =KAR dating of clinoptilolite, . . cos de Caldas caldera and the Osamu Utsumi mine and . . . ation and geochemistry at the Osamu Utsumi mine and . . . ochemistry of waters from the Osamu Utsumi mine and ... . r seasonal variability at the OSAMU Utsumi mine and .... d colloids in waters from the Osamu Utsumi mine and . . . dies of rock samples from the Osamu Utsumi mine and . . . crobiological analysis at the Osamu Utsumi mine and . . . . ater-rock interactions at the Osamu Utsumi mine and . . . . . das analogue study sites, Minas Gerais, Brazil: II.

.... y modeling of moisture movement in the tuff beneath $=$ The

. . . . rrent plans to characterize the design basis ground =Processed seismic =Processed seismic . . . . ilolite, mordenite, and associated clays from Yucca

=Estimation of the impact of water $=$ Preliminary modeling of moisture . . . . . de Caldas natural analogue: studies of redox front
Modeling gravity-driven fingering in rough-walled $f \quad \ldots \ldots$ Modeling ion exchange in clinoptilolite using the E . . . . . Modeling of Aqueous Systems*

Modeling of strongly heat-driven flow processes at . . . . .

Modeling pitting corrosion damage of high-level rad . . . . . . modeling and upscaling of hydrologic properties in . . . . . . modeling approaches for partially saturated flow in . . . . . . modeling at Yucca Mountain*

modeling by some general results on reliability ana . . . . . modeling code*

modeling for the G-Tunnel welded tuff mining experi . . . . . modeling of an engineered barrier system*

modeling of aqueous geochemical systems: Theoretica . . . modeling of aqueous systems: Package overview and i . . . modeling of moisture movement in the tuff beneath $\mathrm{M}$. . . . modeling of the formation of zeolites in fractures ....... modeling of the probability of magmatic disruption . . . . . modeling of the saturated zone in the vicinity of $Y \ldots \ldots$. . modeling of unsaturated flow in the vicinity of pro . . . . . . modeling techniques*

modeling*

modeling*

modeling: Yucca Mountain Site Characterization Proj . . . . . modelling of water-rock interactions at the Osamu U . . . . . modelling strategies for performance assessment of . . . . . models for flow and transport through unsaturated, . . . . . . models for performance assessment of waste manageme . . models for predictions of performance of high-level . . . . . models in the Pocos de Caldas analogue study*

models of Rainier Mesa and their implications to Yu . . . . . . models of flow using the TSA*

models of redox front migration and geochemistry at . . . . . models of seismic refraction traveltime data using . . . . . . models of volcanic events: Applications to volcanic . . . . . . models*

models*

models*

modes of four nickel-chromium-molybdenum alioys*

modified percolation theory*

modull and strength of welded tuff *

Modulus dispersion and attenuation in tuff and gran . . . . . moisture movement in the tuff beneath Mortandad Can ... moisture-sensing techniques: A preliminary comparis .... molybdenum alloys*

money and time on the Yucca Mountain Project*

Monitored retrievable storage of spent nuclear fuel . . . . . . monitored wells in the Yucca Mountain area, Nevada, . . . . Monitoring Program: Annual report, FY91*

Monitoring Program: Annual report, October 1, 1990- . . . . monitoring for uranium and neptunium at Yucca Mount . . . monitoring plan Nevada Test Site and support facili . . . . . . monitoring program: Annual report FY92*

monitoring thermoluminescent dosimeter locations*

mordenite, and associated clays from Yucca Mountain . . . . Morro do Ferro analogue study sites, Brazil: Pocos . . . . . . Morro do Ferro analogue study sites, Pocos de Calda . . . . Morro do Ferro analogue study sites, Pocos de Calda . . . . Morro do Ferro analogue study sites, Pocos de Calda . . . . Morro do Ferro analogue study sites, Pocos de Calda . . . . Morro do Ferro analogue study sites, Pocos de Calda . . . . Morro do Ferro analogue study sites, Pocos de Calda .... Morro do Ferro analogue study sites, Pocos de Calda .... Morro do Ferro*

Mortandad Canyon, Los Alamos National Laboratory*

most likely groundwater flux through the unsaturate . . . . . . motion at the Yucca Mountain, Nevada Site*

motion records from Little Skull Mountain, Nevada e . . . . .

motion records from Little Skull Mountain, Nevada e . . . . . Mountains, Nevada*

Movement of shaft and drift construction water in $Y$. . . . . movement from sewage and settling ponds near a pote ... movement in the tuff beneath Mortandad Canyon, Los . . . . movement* 
..... radionuclide transport in a layered fractured rock: =MSTS

$=$ The role of fault zones in affecting
MSTS - Multiphase Subsurface Transport Simulator th . . . . MULTFRAC -Analytic solutions and local sensitiviti . . . . . . Multiphase Subsurface Transport Simulator theory ma . . . . multiphase flow at Yucca Mountain*

\section{$\mathbf{N}$}

NAGRA: Foreign trip report, May 2-9, 1993*

Nagre-DOE Cooperative Project*

Native American communities: Las Vegas Tribes of $\mathrm{Pa}$. . .

Native Americans and Yucca Mountain: A revised and . . . .

Native Americans and Yucca Mountain: A revised and . . . .

Native Americans and Yucca Mountain: A summary repo . . .

Native Americans and state and local governments*

=Socioeconomic profiles of

native American communities: Duckwater Shoshone Res . .

native American communities: Yomba Shoshone Reserva . .

Natural analogue studies: Mineral alteration and ur ......

Natural gels in the Yucca Mountain Area, Nevada, US . . . .

Natural radionuclide and stable element studies of ......

Natural series radionuclide and rare-earth element . . . . . .

natural analogue*

natural analogue: studies of redox front movement*

naturel fractures in welded tuff: Comparison betwee . . . .

natural fractures in welded tuff: Data report: Yucc . . . . . . .

natural radon emissions due to heating of the Yucca . . . . . need access to employee records*

Neotectonics of the southern Amargosa Desert, Nye C . . . nepheline syenites and phonolites from the Pocos de . . . . . Neptunium retardation with tuffs and groundwaters $f \ldots .$. . Neptunium(V) sorption on quartz and albite in aqueo ...... neptunium at Yucca Mountain using Epithermal Neutro . . . neptunium through Yucca Mountain tuffs*

neptunium, plutonium, and americium in a typical gr ... . . Neutron Activation Analysis*

neutron tomography of water in rock using the Argon . . . . . Nevadans should know about Yucca Mountain: IFinal $r$. . . . next generation*

nickel-chromium-molybdenum alloys*

Nier symposium on inorganic mass spectrometry*

non-sorbing radionuclides*

nonequilibrium fracture-matrix flow on repository $p . . . .$. nonequilibrium fracture-matrix flow on geological $r$. . . . . nonequilibrium fracture-matrix flow on site suitabi . . . . . Nonisothermal hydrologic transport experimental pla . . . . . nonlinear quasi-static response of solids with the $\ldots . .$. nonmanufecturing industry in the United States*

nonwelded hydrogeologic unit at Yucca Mountain, Nev . . . . nonwelded tuff sites in the vicinity of Yucca Mount ..... NORIA-SP: A finite element computer program for ana . . . . normal environments*

Np-237 from spent fuel in a potential repository in ....... NRC's capability to conduct a performance assessmen .... nuclides for evaluating their migration behaviors*

Numerical methods for fluid flow in unsaturated het . . . . . . Numerical simulation of gas flow through unsaturate . . . . . Numerical studies of rock-gas flow in Yucca Mountai ..... numerical code TOUGH*

numerical modeling for the G-Tunnel welded tuff $\mathrm{min}$. . . .
NWPA rail shipments* on of the capillary hysteresis model HYSTR into the
$=$ Preliminary

$=$ Rail abandonments in the South and their effect on
=Long-term
$=$ Does localized recharge

$=1991$

. . . . sign of circular-section concrete-lined underground =The Nevada railroad system: Physical, ... ner, and a bare fuel assembly during waste-handling

$=$ A structural model analysis of public

. . . . . Identification and characterization of conservative

. . . . . Identification and characterization of conservative observation of the geological environment: needs an . . . . occur at a discharge area within the ground-water $f$. . . . . . OCRWM bulletin compilation and index*

openings: Preclosure performance considerations for .... operational, and accident characteristics*

operations: Yucca Mountain Site Characterization Pr . . . . . opposition to a high-level radioactive waste facili . . . . . . . organic tracers for use as hydrologic tracers for $t$. . . . . . . organic tracers for use as hydrologic tracers for $t$. . . . . . .
72

362

456

303

70

224

554

10

8 
..... Identification and characterization of conservative Identification and characterization of conservative Identification and characterization of conservative

Nevada: Implications for strike-slip faulting and . . . . . . . lysis of a joint shear model for jointed media with $\ldots . .$. groundwaters and their seasonal variability at the .... . suspended particles and colloids in waters from the . . . . . . is of redox front migration and geochemistry at the .... . rare-earth element geochemistry of waters from the =Microbiological analysis at the . . ... hemical modelling of water-rock interactions at the . . . . . cal features of the Pocos de Caldas caldera and the . . . . and stable element studies of rock samples from the . . . . erature transport: Evidence from the genesis of the . . . . . kdas analogue study sites, Minas Gerais, Brazil. 1. . . . . . of 1982 to direct the Secretary of Energy to carry =Quantification of uncertain . . . system performance assessment preliminary analyses: . . or geochemical modeling of aqueous systems: Package . . . . . . near-field environment report: Volume 2, Scientific

$=$

$=$ Report on task assignment No. 3 for the Waste ackage for geochemical modeling of aqueous systems: =Quarterly progress report on the DOE Waste A \& B, ASME pressure vessel codes review for waste =Engineered barrier system and waste didate container materials for the conceptual waste $=$ Waste $\ldots . .$. fect of ionizing radiation on the anticipated waste $=E Q 3 / 6$, a sottware $=$ Demands placed on waste $=$ Waste-

$=$ Over-the-road tests of nuclear materials $=$ Evaluation and compilation of DOE waste $=$ Evaluation and compilation of DOE waste =Drift emplaced waste ..... ne and two finite planar zones from a nuclear waste . . . . . er test of the environment around a simulated waste ..... PT, a data file preprocessor for the EQ3/6 software =Post-closure performance assessment of waste $=$ Releases from exotic waste ... . Iysis of Yucca Mountain commercial high-level waste . . . . for underground nuclear explosions conducted in the . . . of Native American communities: Las Vegas Tribes of =Processes, mechanisms,

- mechanisms, parameters, and modeling approaches for ... . program for two-dimensional, transient flow through . . . o on "benchmarking" activity (COVE-2A): Analysis of =Travel to France to attend and . . . Chemical and physical characterisation of suspended =Releases from exotic waste packages from . . . a ask assignment No. 3 for the Waste Package Project: $=E Q 6$, a computer program for reaction =Single fracture aperture =AREST user's guide, $=$ Report of the =Geohydrology of rocks

$=$ Changes in risk . . . . ntain socioeconomic project report on the 1987 risk =institutional trust information, and risk $=$ Characterization of liquid-water ...... fingering in rough-walled fractures using modified $=$ Total System

. . . . epository Integration Program (RIP) to Total System ..... . n the vicinity of Yucca Mountain, Nevada: Iterative organic tracers for use as hydrologic tracers for $t \ldots \ldots \ldots$ organic tracers for use as hydrologic tracers for $t$. . . . . . . organic tracers for use as hydrologic tracers for $t$. . . . . . . Organizational management of long-term risks: Impli . . . . . oroclinal bending*

orthogonal joint sets: Yucca Mountain Site Characte . . . . OSAMU Utsumi mine and Morro do Ferro analogue study . . Osamu Utsumi mine and Morro do Ferro analogue study . . . Osamu Utsumi mine and Morro do Ferro analogue study . . . Osamu Utsumi mine and Morro do Ferro analogue study . . . Osamu Utsumi mine and Morro do Ferro analogue study . . . Osamu Utsumi mine and Morro do Ferro analogue study . . . Osamu Utsumi mine and Morro do Ferro analogue study . . . Osamu Utsumi mine and Morro do Ferro analogue study . . . Osamu Utsumi uranium mine, Pocos de Caldas alkaline . . . Osamu Utsumi uranium mine: Pocos de Caldas Report N . . out site characterization activities at the Yucca $\mathrm{M}$. . . . . . . outcomes from site characterization: Insights from . . . . . . Overview: Draft* overview and installation guide (Version 7.0)* overview of near-field environment and phenomena* overview of the Yucca Mountain Global/Regional Clim . . . .

PACE-90 water and solute transport calculations for . . . . . .

Package Project: Parts A \& B, ASME pressure vessel . . . . Package overview and installation guide (Version $7 \ldots$. . . . Package project at the University of Nevada, Las Ve . . . . . package application; Part C, Library search for rel . . . . . . . package design concepts for a potential geologic re . . . . . . package design for a potential high level nuclear w . . . . . . . package emplacement borehole option study: Yucca Mo . . . package environment at the Yucca Mountain potential . . . . package for geochemical modeling of aqueous systems . . . package performance testing and modeling by some ge ... package release rates for site suitability studies ${ }^{\star} \ldots . . .$. . package response to normal environments*

package test data: Biannual report, February 1989- . . . . . package test data: Volume 8 : Biannual report, Augus . . . . . . package thermal response $\times$

package*

package*

package: User's guide and related documentation (Ve . . . . packages for the Yucca Mountain Project.

packages from partitioning and transmutation*

packages*

Pahute Mesa testing area at the Nevada testing site . . . . . Paiute Indians*

parameters, and modeling approaches for partially $s$..... Parametric effects on glass reaction in the unsatur . . . . . . partially saturated flow in soil and rock media: $Y u$. . . . . . . partially saturated porous media: Yucca Mountain Si . . . . . participants' work*

participate in the Technical Workshop on Near-Field . . . . particles and colloids in waters from the Osamu Uts .... . partitioning and transmutation*

Parts A \& B, ASME pressure vessel codes review for . . . . . path modeling of aqueous geochemical systems: Theor . . . patterns: Characterization by slit-island fractal a . . . . . . . . PC version*

Peer Review Panel on the early site suitability eva . . . . . . . penetrated by test well USW H-6, Yucca Mountain, Ny . . . . Percelved risk impacts from siting hazardous waste ..... perception over time* percoption telephone surveys*

perceptions: Report of findings of the Las Vegas me . . . . . percolation in tuffs in the unsaturated zone, Yucca ..... percolation theory*

Performance Assessment Code (TOSPAC): Volume 2, Use . Performance Assessment, 1991 *

Performance Assessment, Phase 2* 
.... participate in the Technical Workshop on Near-Field

. . . . the derivation and use of sorption coefficients in =TSPA 1991: An initial total-system

. . . . demonstration of the NRC's capability to conduct a =SUMO, System

.... oceedings from the technical workshop on near-field

... oceedings from the technical workshop on near-field -Applications of

. . . xperimental and computational approaches to support

. . . . c ct - Groundwater hydrology modelling strategies for $=$ Developing conceptual models for

=Post-closure

=Yucca Mountain Project total-system

g sorption and applying sorption data to repository

. . . . . Approach to geologic repository post closure system

=Sensitivity analyses for total-system

ility and speciation studies for nuclear repository

. . . f Wingz spreadsheet as an interface to total-system
=Scenario development for

$\ldots . . f$ Wingz spreadsheet as an interface to total-system
=Scenario development for

. . . . . . lutions and local sensitivities: Phase 2, Iterative

. . . . . implified radionuclide source term for total-system $=$ Travel to Switzerland for =Sealing

=The impact of thermal loading on repository . . . c c nonequilibrium fracture-matrix flow on repository $=$ Thermal

. . . . ct of conceptual model uncertainty on the estimated =Sealing

=Corrosion models for predictions of =Demands placed on waste package ..... brium fracture-matrix flow on geological repository ... . . . re-matrix flow on site suitability and total system =Review of radionuclide source terms used for =Excellent and economic nuclear plant

ests to determine the effect of a heat cycle on the ... ed thermal-hydrologic-mechanical-chemical processes =Mineralogy, =Mineralogy, =Mineralogy, $=$ Mineralogy, $=$ Water-rock interactions and the $=$ The International INTRAVAL project. =State of Nevada review of $=$ The International INTRAVAL project. =The International INTRAVAL project. ... . approach to high-level waste repository evaluation, . . Mountain, Nevada: Iterative Performance Assessment, ... . . . TFRAC -Analytic solutions and local sensitivities: $=$ Simulation of two=Gas $=A$ gas -

$=$ Kinetics of silica-

Scientific overview of near-field environment and characterization of selected nepheline syenites and

$=$ The Nevada railroad system: =Chemical and =Heat

/failure rates data on low temperature low pressure =Modeling $=$ Demands

=Yucca Mountain Site Characterization Project Characterization Project: Quality Assurance Project $=$ Addendum to environmental monitoring $=$ Scientific investigation

.. . f the US Department of Energy environmental program =Nonisothermal hydrologic transport experimental
Performance Assessment: Foreign trip report, May 9- . . . . Performance prediction of mechanical excavators fro . . . . . Performance predictions for mechanical excavators $i$. . . . . performance assessment calculations for the Yucca $M$.... performance assessment for Yucca Mountain: Yucca Mo . . performance assessment for a High-Level Waste Repos . . . performance assessment for a high-level nuclear was . . . . performance assessment for high-level waste*

performance assessment for high-level waste*

performance assessment in support of the Explorator . . . . performance assessment of hydrology and chemical tr . . . . performance assessment of nuclear waste disposal* performance assessment of waste management sites* performance assessment of waste packages for the Yu . . . performance assessment preliminary analyses: Overvi . . . . performance assessment*

performance assessment*

performance assessment*

performance assessment*

performance assessment*

performance assessment*

performance assessment: Some questions for the near . . . performance assessment: Volume 1 *

performance assessment: Yucca Mountain Site Charact . . . performance assessments for both the low- and inter..... . performance assessments of bentonite and bentonite/ . . . . performance at Yucca Mountain*

performance at the potential Yucca Mountain site*

performance considerations for the Yucca Mountain S . . . . performance of a buried nuclear waste storage conta . . . . . performance of a hypothetical high-level nuclear wa . . . . . performance of bentonite and bentonite/crushed rock . . . . performance of high-level radioactive-waste contain . . . . . performance testing and modeling by some general re .... . performance*

pertormance*

performance-assessment analyses: Yucca Mountain Sit . . performance: NE-Volume 4*

permeability of welded tuff*

pertinent to the proposed high-level nuclear waste . . . . . petrology and geochemistry of the Pocos de Caldas a .... . petrology and geochemistry of the Pocos de Caldas a . . . . petrology and whole-rock chemistry data compilation . . . . . petrology and whoie-rock chemistry of selected mech . . . . pH stability of groundwater from Yucca Mountain, Ne . . . . . Phase 1 case 8: The Alligator rivers natural analog . . . . . . Phase 1 of the INTRAVAL Project*

Phase 1 test cases*

Phase 1 , case 7. The Pocos de Caldas natural analog ... . Phase 2×

Phase 2*

Phase 2, Iterative performance assessment: Volume 1 *

phase carbon-14 transport at Yucca Mountain, Nevada*

phase migration of $\mathrm{C}-14$ through barrier materials a . . . . . phase source term for Yucca Mountain*

phase transitions*

phenomena*

phonolites from the Pocos de Caldas alkaline comple ... . Photogeologic and kinematic analysis of lineaments . . . . . Physical limits on steam generation by radioactive ...... Physical processes and effects of magmatism in the .... Physical, operational, and accident characteristics*

physical characterisation of suspended particles an . . . . . pipe effect in porous medium*

piping, containers, and casks with long design live . . . . . . pitting corrosion damage of high-level radioactive- ...... placed on waste package performance testing and mod ... Plan*

Plan: Quarterly technical progress report, January . . . . . . plan Nevada Test Site and support facilities*

plan for initial engineered barrier system field te . . . . . . . . plan for site characterization for a high-level was . . . . . . . . plan $*$ 
$=$ Diffusion releases through one and two finite =Current

$=$ Excellent and economic nuclear . . . . assessments of bentonite and bentonite/crushed rock . . . . . ce of bentonite and bentonite/crushed rock borehole ..... Measured solubilities and speciations of neptunium, . . . . . erro analogue study sites, Pocos de Caldas, Brazil: . . . . ium mine, Pocos de Caldas alkaline complex, Brazil: ... . Minas Gerais, Brazil. I. Osamu Utsumi uranium mine: . . . . ne and Morro do Ferro analogue study sites, Brazil: . . . . egional geology, mineralogy and geochemistry of the . . . . from the genesis of the Osamu Utsumi uranium mine, . . . . . selected nepheline syenites and phonolites from the =Mineralogy, petrology and geochemistry of the =Mineralogy, petrology and geochemistry of the $=$ Testing of geochemical models in the eomorphological and hydrogeological features of the ... nternational INTRAVAL project. Phase 1, case 7. The =The

. . . . and implications for radioactive waste management: ... . tsumi mine and Morro do Ferro analogue study sites, .... . tsumi mine and Morro do Ferro analogue study sites, ... . tsumi mine and Morro do Ferro analogue study sites, .... tsumi mine and Morro do Ferro analogue study sites, ... . tsumi mine and Morro do Ferro analogue study sites, ..... tsumi mine and Morro do Ferro analogue study sites, .... tsumi mine and Morro do Ferro analogue study sites, ... . . erro analogue study sites, Pocos de Caldas, Brazil:

=Potentiodynamic

. . , 1991-September 30, 1991, Number 5: Nuclear Waste =S. 1138: $A$ bill to amend the Nuclear Waste =High-level nuclear waste disposal: $=$ Word images as

$=$ Geochemical evidence for waning magmatism and ... e impact of water movement from sewage and settling $=$ Fish communities in sandy $=A$ preliminary study of the chemistry of $=$ Characterization of

ytical treatment of fracture/matrix flow in a duat$\ldots .$. ytical treatment of fracture/matrix flow in a dual. . . . . nsional, transient flow through partially saturated . . . . . ter program for analyzing liquid water transport in $=$ Heat pipe effect in

=Approach to geologic repository . . . I concerns for the use of man-made materials in the =An example

$=$ Proceedings of the American $=$ Areal

$=$ Streamflow and selected . . . . r rular-section concrete-lined underground openings:

... atural fractures in welded tuff: Comparison between =Comparison of

=Performance

=Performance

$=$ Corrosion models for

$=\mathrm{G}$-Tunnel pressurized slot-testing report on high-level nuclear waste transportation: $=$ EQPT, a data file

$=$ Report to the

liability/failure rates data on low temperature low 3 for the Waste Package Project: Parts A \& B, ASME =G-tunnel =G-Tunnel =Strategic planar zones from a nuclear waste package*

plans to characterize the design basis ground motio . . . . . . plant performance: NE-Volume $4 *$

plugs*

plugs*

plutonium, and americium in a typical groundwater (.... .

Pocos de Caldas Report No. 10*

Pocos de Caldas Report No. 13*

Pocos de Caldas Report No. 2*

Pocos de Caldas Report No. 5*

Pocos de Caldas alkaline caldera complex, Minas Ger . . . .

Pocos de Caldas alkaline complex, Brazil: Pocos de . . . . .

Pocos de Caldas alkaiine complex, Minas Gerais, Bra . . . .

Pocos de Caldas analogue study sites, Minas Gerais, . . . .

Pocos de Caldas analogue study sites, Minas Gerais, . . . .

Pocos de Caldas analogue study*

Pocos de Caldas caldera and the Osamu Utsumi mine a . . .

Pocos de Caldas natural analogue: studies of redox . . . . .

Pocos de Caldas project: summary and implications $f$. . . . .

Pocos de Caldas report no. 15*

Pocos de Caldas, Brazil

Pocos de Caldas, Brazil $x$

Pocos de Caldas, Brazil

Pocos de Caldas, Brazil $\times$

Pocos de Caldas, Brazil

Pocos de Caldas, Brazil: Pocos de Caldas Report No. . . . .

Pocos de Caldas, Brazil: Pocos do Caldas Report No. . . . .

Pocos do Caldas Report No. 6*

Point defects in silicates*

polarization studies on candidate container alloys . . . . .

Policy Act (Section 113)*

Policy Act of 1982 to direct the Secretary of Energ . . . . . .

Policy and prognosis. Research report, August 1991- . . . . .

policy instruments: Lessons from the Yucca Mountain . . . . polycyclic volcanism at Crater Flat, Nevada*

ponds near a potential high level radioactive waste . . . . . . pool of Magela Creek, Alligator Rivers Region: Rese . . . . . pore water extracted from tuff by one-dimensional $c$. . . . . . porosity in support of mechanical property analysis*

porosity simulator for unsaturated fractured rock $m$. . . . . . porous matrix*

porous media: Yucca Mountain Site Characterization . . . . porous media: Yucca Mountain Site Characterization .... . porous medium*

portable vacuum hammer seismic source for use in tu . . . . Post-closure pertormance assessment of waste packag . . . post closure system performance assessment*

post-emplacement environment $\times$

postclosure risk assessment using the potential Yuc . . . . .

Potentiodynamic polarization studies on candidate $c . .$. power conference: Economy, efficiency, quality. Vol . . . . . power density: A preliminary examination of undergr . . . . . precipitation data for Yucca Mountain and vicinity, . . . . . . Preclosure performance considerations for the Yucca . . . . Preclosure radiological safety analysis for acciden . . . . . . Preclosure radiological safety analysis for the exp . . . . . . . Preclosure radiological safety evaluation: Explorat . . . . . . Preclosure seismic hazards and their impact on site . . . . . predicted and observed shear behavior using a graph . . . . predicted far-field temperatures for discrete and s . . . . . . Prediction of Pseudo relative velocity response spe . . . . . . prediction of mechanical excavators from linear cut . . . . . . predictions for mechanical excavators in Yucca Moun .... predictions of performance of high-level radioactiv . . . . . . preparations: Yucca Mountain Site Characterization . . . . . Prepared pursuant to assembly concurrent resolution . . . . . preprocessor for the EQ3/6 software package: User's .... . President by the Interagency Review Group on Nuclea . . . . pressure piping, containers, and casks with long de . . . . . . pressure vessel codes review for waste package appl . . . . pressurized slot-testing evaluations: Yucca Mountai . . . . . pressurized slot-testing preparations: Yucca Mounta . . . . . . principles workshops: Discussion drafts and worksho .... 
-Simulation modeling of the

=Single-hole in situ thermal

$=$ An inverse

. . . . anagement review work - part of the decision making

$=$ Code requirements for concrete repository and

=Socioeconomic

$=$ Socioeconomic

=Socioeconomic

$=$ High-level nuclear waste disposal: Policy and

=Technical basis and

=Technical basis and

$=$ Technical basis and

.... sign and implementation of the site and engineering

. . . . . in stochastic modeling and upscaling of hydrologic

...... eologic trends on spatial variability of hydrologic

. . . . . c requirements for laboratory study of hydrological

.... laboratory determination of several geoengineering

$=$ Laboratory analysis of hydraulic

=Scale dependence of effective media

. . gs of advanced cementitious systems: Mechanisms and

. . . . . aracterization of porosity in support of mechanical

$=$ Rock mass mechanical

=Rock mass mechanical

$=$ Results of rock

=Critical comments on the US Environmental

$=$ Prediction of

...... r determining the detta intercept of a thermocouple $=$ Thermocouple

$=\mathrm{A}$ structural model analysis of

=Bibliography of Yucca Mountain Project (YMP)

. . . . . at the Yucca Mountain site in Nevada, and for other

.... . n high-level nuclear waste transportation: Prepared

.... . ear waste storage container storing a hybrid mix of

$=U$ sing

$=$ UNS YMSCP

$=$ Aeromagnetic map of the Beatty

..... r the Yucca Mountain Site Characterization Project

=Nuclear waste:

$=$ The

.... e quality assurance liaison: Combined technical and

... the American power conference: Economy, efficiency,

.... arterly report on program cost and schedule: Fourth

.... uarterly report on program cost and schedule, third

. . . arterly report on program cost and schedule: Second

. . . . . arterly report on program cost and schedule, fourth

..... uarterly report on program cost and schedule: First

$=$ Neptunium(V) sorption on

. . . I Ifinite element computer program for the nonlinear

=Nuclear waste:

. enario development for performance assessment: Some
Probabilistic risk assessment and nuclear waste tra ....

probability of magmatic disruption of the potential . . . . . . .

Probable maximum flood control: Yucca Mountain Site . . . .

probe for hydrothermal characterization at Yucca Mo . . . . .

Procedure development study: Low strain rate and cr .... .

procedure for estimating the unsaturated hydraulic . . . . . .

process*

Processed seismic motion records from Little Skull . . . . . .

Processed seismic motion records from Little Skull . . . . . . processing facilities*

profiles of Native American communities: Las Vegas . . . . .

profiles of native American communities: Duckwater . . . . .

profiles of native American communities: Yomba Shos . . . .

prognosis. Research report, August 1991-April 1992* . . . .

programmatic requirements for Engineered Barrier Sy . . . .

programmatic requirements for laboratory study of $h$.....

programmatic requirements for large block testing o . . . . .

properties database: Yucca Mountain Site Characterz . . . . properties in tuff*

properties in volcanic tuff*

properties of the near-field environment*

properties of tuffs from Yucca Mountain, Nevada: Yu . . . . . properties of volcanic tuff samples*

properties*

properties. Volume $245 *$

property analysis*

property estimation strategy for the Yucca Mountain .....

property measurements madie on core samples from Yuc . . Protection Agency Standards 40 CFR 191*

Prototype heater test of the environment around a s . . . . .

Pseudo relative velocity response spectra at Yucca . . . . . . psychrometer curve.

psychrometer measurements of in situ water potentia . . . . public opposition to a high-level radioactive waste . . . . . . . publications at Lawrence Livermore National Laborat . . . . purposes, introduced in the US Senate, One Hundred . . . . pursuant to assembly concurrent resolution No. 8 of . . . . PWR and BWR spent fuel rods: Revision $1 *$ property estimations for the Yucca Mountain Site $\mathrm{Ch}$. . . . . .
QA classification to guide design and manage risk*

QA support task: Quarterly technical progress repor . . . . . . quadrangle, Nevada-California*

Quality Assurance Project Plan: Quarterly technical . . . . . .

Quality assurance auditors need access to employee .... quality assurance liaison: Combined technical and q . . . . . quality assurance support*

quality. Volume $55-2 \times$

Quantification of uncertain outcomes from site char ..... Quarter, FY 1991 *

quarter FY 1992*

quarter FY 1992*

quarter FY 1992*

quarter, FY 1992*

quartz and albite in aqueous suspension: Annual pro . . . . .

Quasi-linear analysis of water flow in the unsatura . . . . . . . quasi-static response of solids with the conjugate . . . . . . . quatemary faulting along the Death Valley-Furnace ..... Questionable uses of program funds at Lawrence Live . . . . questions for the near-field modelers*

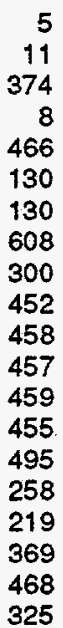

\section{$\mathbf{R}$}

Radiation Monitoring Program: Annual report, Octobe . . . . radiation exposure on glass alteration in a steam $e . . . .$. radiation on the anticipated waste package environm . . . . . radiation source characteristics on shielding requi . . . . . . . radioac tive waste management: Volume 1 *

Radioelements and their occurrence with secondary $m$. . . . 
$=$ Preclosure $=$ Preclosure $=$ Preclosure . . he DOE/Yucca Mountain Site Characterization Project he DOEYucca Mountain Site Characterization Project he DOENucca Mountain Site Characterization Project he DOEYucca Mountain Site Characterization Project he DOEYucca Mountain Site Characterization Project he DOEYucca Mountain Site Characterization Project

. . he DOEYucca Mountain Site Characterization Project

... . he DOE/Yucca Mountain Site Characterization Project he DOENucca Mountain Site Characterization Project he DOENucca Mountain Site Characterization Project he DOENucca Mountain Site Characterization Project he DOEYucca Mountain Site Characterization Project he DOE/Yucca Mountain Site Characterization Project $=$ Hydrology

$=$ Natural series $=$ Natural

$=$ Estimates of potential $=$ Dependence of

$=A$ simplified

=Review of

and uncertainty analyses applied to one-dimensional

= Migration of

= Migration of

screening analysis of ground water contaminated by

$=$ Diffusion of sorbing and non-sorbing =Potential increases in natural

ar waste transportation: A case study of the use of $=$ Expert judgment in assessing

abandonments in the South and their effect on NWPA =The Nevada

=Geohydrologic data and models of $=$ Natural series radionuclide and =Procedure development study: Low strain

$=$ The influence of strain

. . . . . . . pah Spring Member tuff at $22^{\circ} \mathrm{C}$ and a strain $=$ Crack-growth ion; Part C, Library search for reliability/failure =Waste-package release

=Preliminary calculations of release

=Parametric effects on glass

$$
=\text { The }
$$

$=$ EQ6, a computer program for =Preliminary characterization of materials for a

=Eighteenth water

$=$ Does localized

ansfer in a potential Yucca Mountain repository and aftershocks of July 5,1992 and September 13, 1992 , Skull Mountain, Nevada earthquake of June 29, 1992,

$=$ Processed seismic motion

$=$ Processed seismic motion

Quality assurance auditors need access to employee

$=$ Testing models of

7. The Pocos de Caldas natural analogue: studies of =Equivalent Energy Density concept: A preliminary gram for constructing and editing models of seismic =An overview of the Yucca Mountain Global

nship of the Yucca Mountain repository block to the

CP Hills, Nevada Test Site, Nye County, Nevada; and

$=$ Is it possible to demonstrate compliance with the =Proceedings of the GIS and environmental =Proceedings of the GIS and environmental radiological safety analysis for accident condition . . . . . . radiological safety analysis for the exploratory sh . . . . . . . radiological safety evaluation: Exploratory Studies . . . . . . Radionuclide Adsorption Workshop at Los Alamos Nati . . . Radionuclide Adsorption Workshop at Los Alamos Nati . . . Radionuclide Adsorption Workshop at Los Alamos Nati . . . Radionuclide Adsorption Workshop at Los Alamos Nati . . Radionuclide Adsorption Workshop at Los Alamos Nati ... . Radionuclide Adsorption Workshop at Los Alamos Nati . . . Radionuclide Adsorption Workshop at Los Alamos Nati . . . Radionuclide Adsorption Workshop at Los Alamos Nati . . . Radionuclide Adsorption Workshop at Los Alamos Nati . . . Radionuclide Adsorption Workshop at Los Alamos Nati . . . Radionuclide Adsorption Workshop at Los Alamos Nati . . Radionuclide Adsorption Workshop at Los Alamos Nati . . . Radionuclide Adsorption Workshop at Los Alamos Nati . . . Radionuclide Migration Program and related research . . . . Radionuclide migration laboratory studies for valid . . . . . . Redionuclide solubility and speciation studies for . . . . . . . radionuclide and rare-earth element geochemistry of . . . . . radionuclide and stable element studies of rock sam . . . . radionuclide migration at the Bullion site*

radionuclide sorption on sample grinding, surface a . . . . . radionuclide source term for total-system performan . . . . radionuclide source terms used for performance-asse . . . . radionuclide transport in a layered fractured rock: . . . . . . . . radionuclides in the geosphere*

radionuclides in the geosphere $*$

radionuclides introduced at the Nevada Test Site $(N$. . . . radionuclides $\times$

radon emissions due to heating of the Yucca Mountai . . . . RADTRAN in the 1986 Environmental Assessment for Yu . . radwaste risks: What Nevadans should know about Yuc . . . Rail abandonments in the South and their effect on ...... rall shipments×

railroad system: Physical, operational, and acciden . . . . . . Rainier Mesa and their implications to Yucca Mounta . . . . . rare-earth element geochemistry of waters from the . . . . . rate and creep experiments: Yucca Mountain Site Cha ... . rate and sample inhomogeneity on the moduli and str . . . . . rate of $10^{-9} \mathrm{~s}^{-1}$ : Data ................. rate testing of candidate waste container materials*

rates data on low temperature low pressure piping.

rates for site suitability studies $\times$

rates of $\mathrm{Tc}-99,1-129$, and $\mathrm{Np}-237$ from spent fuel $\mathrm{i} . \ldots . .$. Rationale for determining MCC spent fuel acquisitio . . . . . . ray and visible light transmission as two-dimension . . . . . . RE/SPEC Inc. technical support to the Repository Te . . . . . reaction in the unsaturated test method reaction of SRL 202 glass in $\mathrm{J}-13$ and DIWx

reaction path modeling of aqueous geochemical syste .... reactive transport model validation experiment×

reactor safety information meeting. Proceedings: Vo ..... recharge occur at a discharge area within the groun . . . . . recommendations for thermal design approaches: Yucc ... recorded at seismic stations in southern Nevadax

recorded at stations in southern Nevadax

records from Little Skull Mountain, Nevada earthqua . . . . . records from Little Skull Mountain, Nevada earthqua . . . . . records $x$

Recurrence models of volcanic events: Applications . . . . redox front migration and geochemistry at the Osamu . . . . . redox front movement.

reexamination of a technique for equating thermall . . . . . refraction traveltime data using a color-graphics $t$. . . . . . . Regional Climate Modeling Program

Regional groundwater modeling of the saturated zone . . . . regional geology, mineralogy and geochemistry of th . . . . . regional ground-water system: A geochemical model* regional implications* regulations for high-level-waste repositories?* rehabilitation workshop $\times$ rehabilitation workshop 
=Prediction of Pseudo $=$ Waste-package =Preliminary calculations of

$=$ Analysis of $=$ Diffusion

. . . . nce testing and modeling by some general results on .. . . . . ste package application; Part C, Library search for Hydrogeology and migration in the ..... ary conditions on the strength and deformability of ..... ary conditions on the strength and deformability of =Annual

. . . . of Magela Creek, Alligator Rivers Region: Research . . . . udy sites, Pocos de Caldas, Brazil: Pocos de Caldas . . . . de Caldas alkaline complex, Brazil: Pocos de Caldas . . . azil. I. Osamu Utsumi uranium mine: Pocos de Caldas . . . . Ferro analogue study sites, Brazil: Pocos de Caldas . . . u udy sites, Pocos de Caldas, Brazil: Pocos do Caldas

. . . . . itutional trust, information, and risk perceptions:

=Waste Management System rious radiation source characteristics on shielding =Technical basis and programmatic =Code

-Technical basis and programmatic =Technical basis and programmatic =Instrumentation ... of native American communities: Duckwater Shoshone . . . iles of native American communities: Yomba Shoshone =Southern Nevada

. . . portation: Prepared pursuant to assembly concurrent =Yucca Mountain Biological =Geophysical characterization of mineral and energy =Yucca Mountain biological . . ecent advances in methods for measuring the dynamic .... ent computer program for the nonlinear quasi-static $=$ Transportation needs assessment: Emergency $=$ Prediction of Pseudo relative velocity

=Over-the-road tests of nuclear materials package $=$ Drift emplaced waste package thermal ANL Technical Support Program for DOE Environmental ANL technical support program for DOE Environmental $=$ Neptunium =Monitored

$=A$ forecasting model of gaming $=$ Native Americans and Yucca Mountain: A =Native Americans and Yucca Mountain: A e application of the Repository Integration Program =Ground water of Yucca Mountain: How high can it

..... sportation routes: Preliminary characterization and .. . . . sportation routes: Preliminary characterization and . . . . nal management of long-term risks: Implications for Probabilistic

.... nes on the scope, content, and use of comprehensive =An example postclosure .... models of volcanic events: Applications to volcanic =Perceived =Changes in

. . . a Mountain socioeconomic project report on the 1987 =Institutional trust, information, and $=$ Using $Q A$ classification to guide design and manage $=$ Demonstration of a =Health and environmental - Preliminary characterization of =Organizational management of long-term =Expert judgment in assessing radwaste relative velocity response spectra at Yucca Mountai . . . . . . release rates for site suitability studies*

release rates of $\mathrm{Tc}-99, \mathrm{1}-129$, and $\mathrm{Np}-237$ from spen . . . .

Releases from exotic waste packages from partitioni .....

releases due to drilling at the potential Yucca Mou . . . . . . . .

releases through one and two finite planar zones $\mathrm{fr} . . .$.

Reliability modeling of an engineered barrier syste . . . . . . . reliability analysis*

reliability/failure rates data on low temperature $1 \ldots \ldots .$. remote field $*$

replicas of natural fractures in welded tuff: Data . . . . . .

replicas of natural fractures in welded tuff: Compa . . . . . . Report 1991-1992*

Report 9*

Report No. 10*

Report No. 13*

Report No. 2*

Report No. 5*

Report No. 6*

Report of early site suitability evaluation of the $\ldots \ldots \ldots$.

Report of findings of the Las Vegas metropolitan ar . . . . . .

Report of the Peer Review Panel on the early site s . . . . . .

Report of the State of Nevada Commission on Nuclear . . . .

Report on task assignment No. 3 for the Waste Packa .... .

Report to the President by the Interagency Review G . . . . .

Requirements Document: Volume 4, MGDs, Revision 2*

requirements at the potential Yucca Mountain reposi . . . . .

requirements for Engineered Barrier System Field Te . . . . . requirements for concrete repository and processing . . . . . requirements for laboratory study of hydrological $p \ldots \ldots$. requirements for large block testing of coupled the ...... . requirements for the ESF thermomechanical experimen ... . Reservation*

Reservation*

residents' views about the Yucca Mountain high-leve . . . . . resolution No. 8 of the 1987 Nevada Legislature*

Resources Monitoring Program: Annual report, FY91*

resources at Yucca Mountain and vicinity, Nevada*

resources monitoring program: Annual report FY92*

response of geological materials to $100 \mathrm{GPa}$ *

response of solids with the conjugate gradient meth .... response section*

response spectra at Yucca Mountain for underground . . . . response to normal environments*

response*

Restoration and Waste Management: Annual report, Oc . .

Restoration and Waste Management: Annual report, Oc ... . retardation with tuffs and groundwaters from Yucca .....

retrievable storage of spent nuclear fuel: Transpor . . . . . .

Retrieval strategy report for a potential high-leve ....... revenues in Clark County, Nevada*.

revised and updated summary report on research unde ... revised and updated summary report on research unde ... RIP) to Total System Performance Assessment, 1991*

rise?: Final report*

Risk-based screening analysis of ground water conta . . . . . risk analysis: Volume 1, Research report*

risk analysis: Volume 2, Figures [and] Volume $3, \mathrm{Te}_{\mathrm{f}} \ldots \ldots .$. risk and safety in the transportation of nuclear wa . . . . . . . risk assessment and nuclear waste transportation: A . . . . . risk assessment in the management of high-level nuc . . . . . . risk assessment using the potential Yucca Mountain ..... risk assessment*

risk impacts from siting hazardous waste facilities*

risk perception over time*

risk perception telephone surveys*

risk perceptions: Report of findings of the Las Veg . . . . . risk*

risk-based approach to high-level waste repository ...... risk-related impacts of actinide burning on high-le . . . . . . risks in the nuclear waste management system based .... risks: Implications for risk and safety in the tran . . . . . . . risks: What Nevadans should know about Yucca Mounta . . 
$=$ Aliigator

=Alligator ommunities in sandy pool of Magela Creak, Alligator nal INTRAVAL project. Phase 1 case 8: The Alligator =Over-the

\section{$=$}

\section{$=$}

. . . 5: Flow and transport through unsaturated fractured

.... 5: Flow and transport through unsaturated fractured

... . 5: Flow and transport through unsaturated fractured

. . . 5: Flow and transport through unsaturated fractured

.... 5: Flow and transport through unsaturated fractured

. . . 5: Flow and transport through unsaturated fractured

... 5: Flow and transport through unsaturated fractured

... . 5: Flow and transport through unsaturated fractured

... 5: Flow and transport through unsaturated fractured

. . . 5: Flow and transport through unsaturated fractured

. . . . 5: Flow and transport through unsaturated fractured

... . 5: Flow and transport through unsaturated fractured

... 5: Flow and transport through unsaturated fractured

... 5: Flow and transport through unsaturated fractured

... . 5: Flow and transport through unsaturated fractured

... 5: Flow and transport through unsaturated fractured

. . . . 5: Flow and transport through unsaturated fractured =Application of analytical methods for jointed imulation of gas flow through unsaturated fractured .... . . ling performance of bentonite and bentonite/crushed =Mineralogy, petrology and whole=Mineralogy, petrology and whole=Modeling fluid=Water-

=Geochemical modelling of water..... cal codes first benchmark exercise: Part 3 , Jointed . . . . adon emissions due to heating of the Yucca Mountain . . . . . a dual-porosity simulator for unsaturated fractured ..... approaches for partially saturated flow in soil and =Thermal impact on host . . ance assessments of bentonite and bentonite/crushed =Results of

$=$ Natural radionuclide and stable element studies of =Dual-energy neutron tomography of water in =Numerical studies of ..... ional radionuclide transport in a layered fractured ..... r flow and transport through unsaturated, fractured ..... . nary capillary hysteresis simulations for fractured =Geohydrology of

. . . . iner storing a hybrid mix of PWR and BWR spent fuel = Modeling gravity-driven fingering in = Yucca Mountain transportation =Yucca Mountain transportation .... related issues: A comparative analysis of urban and
Rivers Region Research Institute: annual research s . . . . . Rivers Region Research Institute; annual research s . . . . . Rivers Region: Research Report 9* rivers natural analogue*

road tests of nuclear materials package response to ..... Rock mass mechanical property estimations for the $Y$. . . . . Rock mass mechanical property estimation strategy $f$. . . . . Rock mechanics contributions from defense programs* . . . . rock - related to high-level radioactive waste dis . . . . . . . . rock - related to high-level radioactive waste dis . . . . . . . . rock - related to high-level radioactive waste dis . . . . . . . . rock - related to high-level radioactive waste dis . . . . . . . . rock - related to high-level radioactive waste dis . . . . . . . . rock - related to high-level radioactive waste dis . . . . . . . . rock - related to high-level radioactive waste dis . . . . . . . . rock - related to high-level radioactive waste dis . . . . . . . . rock - related to high-level radioactive waste dis . . . . . . . . rock - related to high-level radioactive waste dis . . . . . . . . rock - related to high-level radioactive waste dis . . . . . . . . rock - related to high-level radioactive waste dis . . . . . . . . rock - related to high-level radioactive waste dis . . . . . . . . rock - related to high-level radioactive waste dis . . . . . . . . rock - related to high-level radioactive waste dis . . . . . . . . rock - related to high-level radioactive waste dis . . . . . . . . rock - related to high-level radioactive waste dis . . . . . . . . rock as part of a drift design methodology for the ....... rock at Yucca Mountain, Nevada*

rock borehole plugs*

rock chemistry data compilation for selected sample ..... rock chemistry of selected mechanical test samples ..... rock interaction at Yucca Mountain, Nevada: A progr . . . . . rock interactions and the $\mathrm{pH}$ stability of groundwat . . . . . . . rock interactions at the Osamu Utsumi mine and Morr ... rock mass analysis: Yucca Mountain Site Characteriz . . . . . rock mass $*$

rock masses*

rock media: Yucca Mountain Site Characterization Pr . . . . . rock of geologic repository: Final report*

rock plugs*

rock property measurements made on core samples fro .... rock samples from the Osamu Utsumi mine and Morro $d$. . . rock using the Argonne IPNS*

rock-gas flow in Yucca Mountain: Yucca Mountain Sit . . . . . rock: MULTFRAC -Analytic solutions and local sensi . . . . . rock: Yucca Mountain Site Characterization Project* ..... rocks - model development and results of simulatio . . . . . . . rocks penetrated by test well USW H-6, Yucca Mounta . . . . rods: Revision 1*

rough-walled fractures using modified percolation $\mathrm{t}$. . . . . . routes: Preliminary characterization and risk analy . . . . . . routes: Preliminary characterization and risk analy . . . . . . rural suney data*

\section{$\mathbf{S}$}

$=$ Preclosure radiological $=$ Preclosure radiological $=$ Proceedings of the Symposium on .... of structures, systems, and components important to $=$ Preclosure radiological ..... ement of long-term risks: Implications for risk and =Eighteenth water reactor =Criticality

$=$ Dependence of radionuclide sorption on $=$ The influence of strain rate and =Results of rock property measurements made on core . . . . . . ral radionuclide and stable element studies of rock .... nd whole-rock chemistry of selected mechanical test
Safety Assessment of Radioactive Waste Repositories* Satety Assessment of Radioactive Waste Repositories* Satety Assessment of Radioactive Waste Repositories* Satety Assessment of Radioactive Waste Repositories* safety analysis for accident conditions of the pote ....... safety analysis for the exploratory shaft facilitie ....... safety assessment of radioactive waste repositories* safety at the potential repository at Yucca Mountai. . . . . . . safety evaluation: Exploratory Studies Facility: Yu . . . . . . . safety in the transportation of nuclear wastes* safely information meeting. Proceedings: Volume $1 *$ satety issues associated with the burial of highly . . . . . . sample grinding, surface area, and water compositio . . . . . sample inhomogeneity on the moduli and strength of ..... samples from Yucca Mountain boreholes, Nevada Test . . . samples from the Osamu Utsumi mine and Morro do Fer . . . samples of Yucca Mountain tuffs: Yucca Mountain Sit .... 
... . whole-rock chemistry data compilation for selected ...... y analysis of hydraulic properties of volcanic tuff =Fish communities in .... , parameters, and modeling approaches for partially . . . . . r two-dimensional, transient flow through partially - Regional groundwater modeling of the =Alternative strategies: A means for

$=$ Small-

$=$ Design of an intermediate-

=Large-

$=$ Design of a three-dimensional site-

... . . . porting hydration calculations for small- to large-

$=A$ working definition of

$=A$ working definition of scenario and a method of

. . lian Radioactive Waste Management Program Cost and $=$ Program cost and

$=$ Quarterly report on program cost and

=Quarterly report on program cost and

... ste Management quarterly report on program cost and

... ste Management quarterly report on program cost and =Quarterly report on program cost and

. . . . rmal and mechanical calculations of thermal loading

=Earth

$=$ Earth

-Earth

=Earth

=Earth

$=$ Earth

=Earth

$=$ Earth

=Guidelines on the

$=A$
ased

=Risk-based

ng hydration calculations for small- to large-scale

$=$ Seismic considerations in

$=$ Initial field testing definition of subsurface

=Proposed

$=$ The hydrothermal stability of cement .... view for waste package application; Part C, Library ..... and isotopic composition of groundwaters and their . . . . purposes, introduced in the US Senate, One Hundred =Quarterly report on program cost and schedule:

$=$ Radioelements and their occurrence with $=$ Fourth report to the U.S. Congress and the U.S.

$=$ Fifth report to the US Congress and the US =Second report to the U.S. Congress and the U.S. the Nuclear Waste Policy Act of 1982 to direct the =Intra-site

. . . . scoping study of water table excursions induced by $=$ Preclosure

=Geology, drilling, and some hydrologic aspects of $=$ Processed $=$ Processed

.... tive program for constructing and editing models of $=A$ portable vacuum hammer . . . o of July 5, 1992 and September 13, 1992, recorded at

=An evaluation of the Evaluation of the geologic relations and $=$ Evaluation of the geologic relations and

=Mineralogy, petrology and whole-rock chemistry of =Isotopic geochemical characterization of =Streamfiow and samples of Yucca Mountain tuffs: Yucca Mountain Sit : . . . samples*

sandy pool of Magela Creek, Alligator Rivers Region . . . . . saturated flow in soil and rock media: Yucca Mounta . . . . . saturated porous media: Yucca Mountain Site Charact . . . . saturated zone in the vicinity of Yucca Mountain, N . . . . . saving money and time on the Yucca Mountain Project* Scale dependence of effective media properties*

scale behavior of single gravity-driven fingers in . . . . . . . scale experiment to validate unsaturated-zone tran . . . . . . scale in situ heater tests for hydrothermal charact . . . . . . . scale model for the unsaturated zone at Yucca Mount . . . . . scale seal tests in unsaturated tuff*

Scenario development for performance assessment: So . . . scenario and a method of scenario construction* scenario construction*

Schedule Baseline: Revision 3*

schedule baseline: Revision 2*

schedule, fourth quarter FY 1992*

schedule, third quarter FY 1992*

schedule: First quarter, FY 1992*

schedule: Fourth Quarter, FY 1991 *

schedule: Second quarter FY 1992*

schemes*

Sciences Division annual report $1990 *$

Sclences Division annual report 1990*

Sciences Division annual report $1990 *$

Sciences Division annual report $1990 *$

Sciences Division annual report $1990 *$

Sciences Division annual report $1990 *$

Sciences Division annual report $1990 *$

Sciences Division annual report $1990 *$

scope, content, and use of comprehensive risk asses . . . . .

scoping study of water table excursions induced by ..... .

screening analysis of ground water contaminated by ..... seal tests in unsaturated tuff*

Sealing performance assessments of bentonite and be .... Sealing performance of bentonite and bentonite/crus ..... sealing a potential high-level radioactive waste re . . . . . . . sealing and backfilling tests in unsaturated tuff: . . . . . . . . sealing field tests for a potential high-level radi . . . . . . . . . sealing materials in the potential Yucca Mountain h . . . . . . search for reliability/failure rates data on low te . . . . . . . . . seasonal variability at the OSAMU Utsumi mine and $M$. . . . Second Congress, First Session, May 22, 1991 *

Second quarter FY 1992*

Second report to the U.S. Congress and the U.S. Sec ... secondary minerals in heated and unheated tuff at $t$..... Secretary of Energy from the Nuclear Waste Technica . . . . Secretary of Energy from the Nuclear Waste Technica .... . Secretary of Energy from the Nuclear Waste Technica . . . . Secretary of Energy to carry out site characterizat . . . . . . . secure transport vehicle*

Selsmic considerations in sealing a potential high- . . . . . . Seismic design of circular-section concrete-lined u . . . . . . seismic and volcanic events*

seismic hazards and their impact on site suitabilit . . . . . . . seismic hazards program core holes, Los Alamos Nati . . . . seismic motion records from Little Skull Mountain, . . . . . . seismic motion records from Little Skull Mountain, . . . . . . seismic refraction traveltime data using a color-gr . . . . . . . . seismic source for use in tunnel environments*

seismic stations in southern Nevada*

Seismicity and focal mechanisms for the southern $\mathrm{Gr}$. . . . .

Seismicity and focal mechanisms for the Southern $\mathrm{Gr}$..... .

Seismicity and focal mechanisms for the southern $\mathrm{Gr}$. . . . . seismiclty of the Nevada Test Site and vicinity: Yu . . . . . . seismotectonic stability of the Yucca Mountain Area ...... . seismotectonic stability of the Yucca Mountain area ...... selected GIS bibliography: Technical Memorandum $40^{*} \ldots$ selected mechanical test samples of Yucca Mountain .... selected nepheline syenites and phonolites from the ..... . selected precipitation data for Yucca Mountain and . . . . . . 
. . . . ology and whole-rock chemistry data compilation for =Methodologies for

\section{$=$}

. . . . evada, and for other purposes, introduced in the US . . . . . ansmission as two-dimensional, full-field moisture... . tured rock: MULTFRAC - Analytic solutions and local

$=$ Pre-waste-emplacement ground-water travel time =Uncertainty and . . . ated waste canister docking and emplacement using a $=$ The use of $=$ Natural . . . . . shear model for jointed media with orthogonal joint ... ion of the impact of water movement from sewage and $=$ Estimation of the impact of water movement from $=$ Documentation and verification of the =Movement of

$=$ Proceedings of the conference on =Proceedings of the conference on ..... urated flow in the vicinity of proposed exploratory ... . . . re radiological safety analysis for the exploratory . . . ded tuff: Comparison between predicted and observed $=$ An analysis of a joint . . . . . ects of various radiation source characteristics on ... . donments in the South and their effect on NWPA rail $=$ Effects of a potential drop of a . . . omic profiles of native American communities: Yomba . . . . profiles of native American communities: Duckwater

... judgment in assessing radwaste risks: What Nevadans $=$ Coupled hydro-geochemical processes and their $=$ Estimating the consequences of $=$ Kinetics of =Point defects in

. . . . re-matrix interaction: Preliminary experiments in a

.... behavior of candidate waste container materials in =Prototype heater test of the environment around a

$=$ Numerical

-The use of sequential indicator =Preliminary capillary hysteresis .... fractured rocks - model development and results of =MSTS - Multiphase Subsurface Transport . . . . . . reatment of fracture/matrix flow in a dual-porosity

-Small-scale behavior of $=$ Geologic evaluation of six nonwelded tuff . . dels for performance assessment of waste management . . Osamu Utsumi mine and Morro do Ferro analogue study ... geochemistry of the Pocos de Caldas analogue study ... geochemistry of the Pocos de Caldas analogue study . Osamu Utsumi mine and Morro do Ferro analogue study

. . Osamu Utsumi mine and Morro do Ferro analogue study

. . Osamu Utsumi mine and Morro do Ferro analogue study

. . Osamu Utsumi mine and Morro do Ferro analogue study . Osamu Utsumi mine and Morro do Ferro analogue study OSAMU Utsumi mine and Morro do Ferro analogue study . Osamu Utsumi mine and Morro do Ferro analogue study . . . . . ar waste be disposed of at geographically dispersed $=$ Perceived risk impacts from =Large-scale in $=$ Single-hole in

$=$ Thermocouple psychrometer measurements of in = Geologic evaluation of =Processed seismic motion records from Little $=$ Processed seismic motion records from Little at Yucca Mountain, Nevada: Implications for strike- selected samples of Yucca Mountain tuffs: Yucca Mou . . . . selecting industries for regions and communities: A . . . . . . Selection of candidate container materials for the . . . . . . . Semi-analytical treatment of fracture/matrix flow i . . . . . . . Senate, One Hundred Second Congress, First Session, . . . sensing techniques: A preliminary comparison*

sensitivities: Phase 2, Iterative performance asses . . . . . . Sensitivity analyses for total-system performance a . . . . . . Sensitivity and uncertainty analyses applied to one . . . . . . sensitivity and uncertainty analyses for Yucca Moun . . . . . senslitivity results for pre-waste-emplacement groun . . . . . sensor-based intelligent controller: Yucca Mountain . . . . . . . sequential indicator simulation to characterize geo . . . . . . series radionuclide and rare-earth element geochemi . . . . . sets: Yucca Mountain Site Characterization Project* . . . . . . settling ponds near a potential high level radioact . . . . . . . . sewage and settling ponds near a potential high lev . . . . . . . . SHAFT code: Yucca Mountain Site Characterization Pr . . . . shaft and drift construction water in Yucca Mountai . . . . . . shaft drilling technology*

shaft drilling technology*

shatt facilities at Yucca Mountain, Nevada*

shaft facilities: Yucca Mountain Site Characterizat . . . . . . . shear behavior using a graphical method: Yucca Moun . . . . shear model for jointed media with orthogonal joint . . . . . . shielding requirements at the potential Yucca Mount . . . . . . shipments*

shipping cask, a waste container, and a bare fuel a . . . . .

Shoshone Reservation*

Shoshone Reservation*

Should high-level nuclear waste be disposed of at $\mathrm{g}$. . . . . should know about Yucca Mountain: [Final report]*

significance for Yucca Mountain Site Characterizati . . . . . . significant fracture flow at Yucca Mountain*

silica-phase transitions*

silicates*

simple system $*$

simplified radionuclide source term for total-syste . . . . . . .

Simulated water-level declines caused by withdrawal . . . . . simulated underground water*

simulated waste package.

Simulation modeling of the probability of magmatic . . . . . .

Simulation of two-phase carbon-14 transport at Yuce ..... . simulation of gas flow through unsaturated fracture . . . . . . . simulation to characterize geostatistical uncertain . . . . . . . simulations for fractured rocks - model developmen . . . . . simulations*

Simulator theory manual $*$

simulator for unsaturated fractured rock masses*

Single fracture aperture patterns: Characterization ......

Single-hole in situ thermal probe for hydrothermal . . . . . .

single gravity-driven fingers in an initially dry $f$. . . . . . . .

sites in the vicinity of Yucca Mountain, Nevada for . . . . . . . sites*

sites, Brazil: Pocos de Caldas Report No. 5*

sites, Minas Gerais, Brazil. I. Osamu Utsumi uraniu . . . . . . sites, Minas Gerais, Brazil: II. Morro do Ferro*

sites, Pocos de Caldas, Brazil*

sites, Pocos de Caldas, Brazil*

sites, Pocos de Caldas, Brazil*

sites, Pocos de Caldas, Brazil*

sites, Pocos de Caldas, Brazil *

sites, Pocos de Caldas, Brazil: Pocos do Caldas Rep . . . . .

sites, Pocos de Caldas, Brazil: Pocos de Caldas Rep . . . . . sites?*

siting hazardous waste facilities*

situ heater tests for hydrothermal characterization . . . . . . .

situ thermal probe for hydrothermal characterizatio . . . . . .

situ water potential changes in heated welded tuff ${ }^{*} \ldots \ldots$. .

six nonwelded tuff sites in the vicinity of Yucca $M \ldots \ldots$.

Skull Mountain, Nevada earthquake aftershocks of Ju . . . .

Skull Mountain, Nevada earthquake of June 29, 1992, . . . . slip faulting and oroclinal bending* 
... . gle fracture aperture patterns: Characterization by $=$ Analysis of $=G$-tunnel pressurized $=G-T u n n e l$ pressurized

=Supporting hydration calculations for f predicted far-field temperatures for discrete and = Managing nuclear waste:

Human and =Yucca Mountain

=Yucca Mountain $=$ Durability study of $=E Q 3 / 6, a$

$=E Q P T$, a data file preprocessor for the EQ3/6 modeling approaches for partially saturated flow in ... . . . program for the nonlinear quasi-static response of =Measured

$=$ Radionuclide

. . . omputer program for geochemical aqueous speciation$=$ PACE-90 water and =Use of the iterative ..... rt in a layered fractured rock: MULTFRAC - Analytic $=$ Elements present in leach $=$ Diffusion of

$=$ Diffusion of sorbing and non-

$=A$ suggested approach toward measuring

$=A$ strategy for the derivation and use of . . . . . ary report on the evaluation of a 1977-1985 edited ... . ted approach toward measuring sorption and applying ...... igration laboratory studies for validation of batch $=$ Neptunium(V)

$=$ Dependence of radionuclide Effects of various radiation =A portable vacuum hammer seismic =A gas-phase

$=$ A simplified radionuclide =Review of radionuclide ... . ar-field temperatures for discrete and smeared heat =Rail abandonments in the =Seismicity and focal mechanisms for the

Neotectonics of the $=$ Seismicity and focal mechanisms for the =Seismicity and focal mechanisms for the .... September 13,1992, recorded at seismic stations in ..... arthquake of June 29,1992 , recorded at stations in ..... nation of magmatic and hydrothermal activity at the $=$ NORIA-

$=$ influence of deterministic geologic trends on

$=\mathrm{RE}$

=Solubility and

$=$ Radionuclide solubility and

$=E Q 3 N R$, a computer program for geochemical aqueous

$=$ Measured solubilities and

=Prediction of Pseudo relative velocity response

....s of the Alfred $O$. Nier symposium on inorganic mass

$=$ Proceedings of

$=$ Proceedings of

$=$ Proceedings of

=Rationale for determining MCC

=Geological disposal of =Characterization of =Characterization of

= Estimating the time for dissolution of $s$ of release rates of $\mathrm{Tc}-99, \mathrm{l}-129$, and $\mathrm{Np}-237$ from orage container storing a hybrid mix of PWR and BWR ... . . lements present in leach solutions from unsaturated slit-island fractal analysis*

slot cutting methods for the Yucca Mountain heated . . . . . slot-testing evaluations: Yucca Mountain Site Chara ..... . slot-testing preparations: Yucca Mountain Site Char . . . . . . Small-scale behavior of single gravity-driven finge . . . . . . . small- to large-scale seal tests in unsaturated tuf . . . . . . . smeared heat sources*

Social and economic impacts*

Social impacts of hazardous and nuclear facilities . . . . . . social factors in the transportation of nuclear was . . . . . . Socioeconomic Project: The 1991 Nevada State teleph . . . Socioeconomic assessment guidance report: Determini . . . Socioeconomic profiles of Native American communiti . . . . Socioeconomic profiles of native American communiti . . . . Socioeconomic profiles of native American communiti . . . . socioeconomic project report on the 1987 risk perce . . . . . sodium borosilicate glasses leached in tuff $\mathrm{J}-13 \mathrm{gr}$. . . . . . software package for geochemical modeling of aqueou . . . . software package: User's guide and related document . . . . soil and rock media: Yucca Mountain Site Characteri . . . . . . solids with the conjugate gradient method: Yucca Mo . . . . . solubilities and speciations of neptunium, plutoniu . . . . . . Solubility and speciation studies for nuclear repos . . . . . . solubility and speciation studies for the Yucca Mou . . . . . . . solubility calculations: Theoretical manual, user's . . . . . . . solute transport calculations for $0.01,0.1$, and 0 . . . . . . solution method for coupled finite element and boun . . . . . solutions and local sensitivities: Phase 2 , Iterati . . . . . . . . solutions from unsaturated spent fuel tests* sorbing and non-sorbing radionuclides* sorbing radionuclides*

sorption and applying sorption data to repository $\mathrm{p} . . .$. . sorption coefficients in performance assessment cal . . . . . sorption data base for isotherm modeling*

sorption data to repository performance assessment ${ }^{\star}$... . sorption clata*

sorption on quartz and albite in aqueous suspension . . . . . sorption on sample grinding, surface area, and wate . . . . . source characteristics on shielding requirements at . . . . . . source for use in tunnel environments*

source term for Yucca Mountain.

source term for total-system performance assessment .... source terms used for performance-assessment analys ... sources*

South and their effect on NWPA rail shipments*

Southern Great Basin of Nevada and California in $19 . .$. . Southern Nevada residents' views about the Yucca Mo... . . southern Amargosa Desert, Nye County, Nevada and in . . . southern Great Basin of Nevada and California: 1987 . . . . southern Great Basin of Nevada and California in $19 \ldots .$. southern Nevada*

southern Nevadax

southwestern Nevada volcanic field $x$

SP: A finite element computer program for analyzing .... spatial variability of hydrologic properties in vol ........ SPEC Inc. technical support to the Repository Techn . . . . . speciation studies for nuclear repository performan . . . . . . speciation studies for the Yucca Mountain site char . . . . . . . speciation-solubility calculations: Theoretical man . . . . . . speciations of neptunium, plutonium, and americium . . . . . spectre at Yucca Mountain for underground nuclear e.... . spectrometry*

SPECTRUM ' $90 *$

SPECTRUM ' 90 *

SPECTRUM ' 90 .

spent fuel acquisitions*

spent fuel and high level and alpha bearing wastes: . . . . . .

spent fuel approved testing materia $-A T M-105 *$

spent fuel approved testing material-ATM-104x

spent fuel exposed to unlimited water*

spent fuel in a potential repository in tuffx

spent fuel rods: Revision 1 *

spent fuel tests* 
$=$ Facts and issues of direct disposal of =Nevada commercia $=$ Monitored retrievable storage of $=$ Use of Wingz $=$ The reaction of $=$ Implications of $=$ Borehole

$=$ The hydrothermal

$=$ Water-rock interactions and the $\mathrm{pH}$ uation of the geologic relations and seismotectonic uation of the geologic relations and seismotectonic =Natural radionuclide and . . . comments on the US Environmental Protection Agency ..... h-level and transuranic radioactive- waste disposal ..... location of nonmanufacturing industry in the United . . . e element computer program for the nonlinear quasi. . 5, 1992 and September 13, 1992, recorded at seismic . . . . in, Nevada earthquake of June 29, 1992, recorded at ects of radiation exposure on glass alteration in a $=$ Physical limits on

.... radioactive-waste containers, with emphasis on the $=$ Recent developments in $=$ Deterministic geologic processes and ormance of a buried nuclear waste storage container =Procedure development study: Low $=$ The influence of on Topopah Spring Member tuff at $22^{\circ} \mathrm{C}$ and a

.... hydrocoin project - Groundwater hydrology modelling $=$ Alternative $=$ Rock mass mechanical property estimation

$=$ Retrieva

. . . . zone at Yucca Mountain: The beginning of a testing $=$ A preliminary guidebook for identifying

$=$ Effect of boundary conditions on the $=$ Effect of boundary conditions on the . . . . ain rate and sample inhomogeneity on the moduli and $=$ Documentation and verification of

$=$

$=$ Fault

eaments at Yucca Mountain, Nevada: Implications for $=$ SSymposium for the = Modeling of =Mesozoic and Cenozoic

$=$ Wetted-region $=$ ldentification of =MSTS - Multiphase =identification of $=$ Initial field testing definition of pisodic nonequilibrium fracture-matrix flow on site =Report of the Peer Review Panel on the early site =Report of early site Preclosure seismic hazards and their impact on site =Waste-package release rates for site

. . . . roject bibliography, January-June 1991: An Update: ... . erization Project bibliography, January-June 1991: . . . . roject bibliography, January-June 1992: An Update: . . . o oject bibliography, July-December 1992: An update, ..... erization Project Technical Data Catalog (quarterly ..... rization Project: Technical data catalog, (quarterly

ndence of radionuclide sorption on sample grinding

ng geological and geophysical data near prospective tivities of Midway Valley as a potential repository ..... tes in the vicinity of Yucca Mountain, Nevada for a =Preliminary mapping of spent fuel: Revision $1 *$

spent nuclear fuel transportation experience*

spent nuclear fuel: Transportation studies: Draft

448

sreadsheet as an interface to total-system perform . . . . .

SRL 202 glass in $\mathrm{J}-13$ and DIW*

stability analysis for heat transfer at Yucca Mount . . . . . . . stability in densely welded tuffs*

stability of cement sealing materials in the potent . . . . . . . stability of groundwater from Yucca Mountain, Nevad . . . . . stability of the Yucca Mountain Area, Nevada Nuclea . . . . . stability of the Yucca Mountain area, Nevada Nuclea . . . . stable element studies of rock samples from the Osa . . . . . Standards 40 CFR 191 *

standards:

States*

static response of solids with the conjugate gradie. . . . . . . stations in southern Nevada*

stations in southern Nevada*

Statistical analysis of hydrologic data for Yucca M . . . . . . . steam environment*

steam generation by radioactive decay heat*

stochastic approach*

stochastic modeling and upscaling of hydrologic pro ..... stochastic modeling*

storing a hybrid mix of PWR and BWR spent fuel rods . . . . strain rate and creep experiments: Yucca Mountain $S$.... strain rate and sample inhomogeneity on the moduli .....

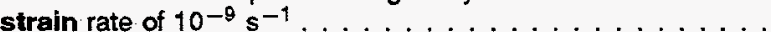
Strategic principles workshops: Discussion drafts a . . . . . . strategies for performance assessment of nuclear wa . . . . strategies: A means for saving money and time on th . . . . strategy for the Yucca Mountain Site Characterizati . . . . . . strategy for the derivation and use of sorption coe . . . . . . . strategy report for a potential high-level nuclear . . . . . . . . strategy*

stratigraphic contacts at the Nevada Test Site*

Streamflow and selected precipitation data for Yucc ..... strength and deformability of replicas of natural $f$....... strength and deformability of replicas of natural $f \ldots \ldots$. . . strength of weided tuff *

STRES3D, Version 4.0: Yucca Mountain Site Character ... Stress corrosion cracking of candidate waste contai . . . . . . Stress-corrosion-cracking studies on candidate cont ..... stress analysis for the Yucca Mountain Site Charact . . . . . strike-slip faulting and oroclinal bending $*$

STRIPA Project]: Foreign trip report, October 10-1 . . . . . . strongly heat-driven flow processes at a potential ...... structural geology of the CP Hills, Nevada Test Sit . . . . . . structural model analysis of public opposition to a . . . . . . . Structure in continuously cored, deep dritl holes a . . . . . . . structure in horizontal unsaturated fractures: Wate . . . . . . structures, systems, and components important to sa . . . . Subsurface Transport Simulator theory manual*

subsurface microorganisms at Yucca Mountain: Fourth ... . subsurface sealing and backfilling tests in unsatur . . . . . . suitability and total system performance*

suitability evaluation of the Potential Repository . . . . . . . sultability evaluation of the potential repository ........ suitability of Yucca Mountain, Nevada* suitability studies *

SUMO, System performance assessment for a high-leve . . . Supplement 2, Addendum 3*

Supplement 3 *

Supplement 3, Addendum 1*

Supplement 3, Addendum 2: Civilian Radioactive Wast . . . supplement)* supplement) $*$

Surface-discharging hydrothermal systems at Yucca $M$. . . . surface area, and water composition

surface facilities in Midway Valley, Yucca Mountain . . . . . . surface facility site*

surtace-based test facility for the Yucca Mountain . . . . . . . surficial geology of Midway Valley Yucca Mountain P......
281

406

337

531

292

124

543

542 
$=$ Estimation of the limitations for ..... ntal unsaturated fractures: Water entry through the . . . . . roject report on the 1987 risk perception telephone $=$ Chemical and physical characterisation of

. . . . ptunium( $V$ ) sorption on quartz and albite in aqueous $=$ Travel to

. . . . geochemical characterization of selected nepheline .... nd programmatic requirements for Engineered Barrier $=$ Total

. . . . . f the Repository Integration Program (RIP) to Total =Waste Management =SUMO,

$=$ Preliminary total$=$ Engineered barrier

. . . . terization of risks in the nuclear waste management . . . . . . c investigation plan for initial engineered barrier .... Developing a functioning visualization and analysis . . . . ur at a discharge area within the ground-water flow =TSPA 1991: An initial total-

= Yucca Mountain Project total-

=Approach to geologic repositony post closure = Sensitivity analyses for total=Use of Wingz spreadsheet as an interface to total-

=A simplified radionuclide source term for total-

fracture-matrix flow on site suitability and total

... . . ix interaction: Preliminary experiments in a simple $=$ Reliability modeling of an engineered barrier

. . . . f faulting along the Death Valley-Furnace Creek fault

... . . . ntain repository block to the regional ground-water $=$ The Nevada railroad

=EQ3/6 V7.0: Geochemical Modeling Of Aqueous =EQ3/6 V7.1: Geochemical Modeling of Aqueous =Surface-discharging hydrothermal

=Flow and transport in hierarchically fractured =Identification of structures,

$=$ Proceedings of advanced cementitious

.. . oftware package for geochemical modeling of aqueous

... m for reaction path modeling of aqueous geochemical surficial water addition above a potential high lev . . . . . . surrounding porous matrix*

surveys*

suspended particles and colloids in waters from the . . . . . suspension: Annual progress report*

Switzerland for performance assessments for both th . . . . . syenites and phonolites from the Pocos de Caldas al . . . . . System Field Tests*

System Performance Assessment Code (TOSPAC): Volume . System Performance Assessment, 1991*

System Requirements Document: Volume 4, MGDs, Revis . System performance assessment for a high-level nucl . . . . system analysis of a potential high-level nuclear w . . . . . . system and waste package design concepts for a pote . . . . system based on information in the literature*

system field tests*

system for performance assessment*

system of Yucca Mountain, Nevada?*

system performance assessment for Yucca Mountain: Y . . .

system performance assessment preliminary analyses: . . . .

system performance assessment*

system performance assessment*

system performance assessment*

system performance assessment: Yucca Mountain Site ... system performance*

system*

system*

system, California and Nevada*

system: A geochemical model*

system: Physical, operational, and accident charact . . . . . .

Systems*

Systems*

systems at Yucca Mountain: Examining the evidence*

systems*

systems, and components important to safety at the ... . . systems: Mechanisms and properties. Volume $245 *$

systems: Package overview and installation guide (V . . . . .

systems: Theoretical manual, user's guide, and rela . . . . .

$\mathbf{T}$

target industry analysis*

Tc-99, 1-129, and Np-237 from spent fuel in a poten . . . . .

technique for equating thermal loads: Yucca Mountai . . . . . techniques*

techniques:

techniques: A preliminary comparison*

technologies for hazardous waste management: Volume .

Technology Program: Summary of activities for Septe . . . .

Technology Programs semiannual progress report, Oct . . .

Technology*

technology programs: Semiannual progress report, Oc ...

technology*

technology

Tectonic Studies, Department of Geoscience annual $r$. . . . telephone survey: Key findings*

telephone surveys*

Temperature measurements from a horizontal heater $t$.... temperature low pressure piping, containers, and ca ...... temperature transport: Evidence from the genesis of . . . . . temperatures for discrete and smeared heat sources* . . . terms used for performance-assessment analyses: Yuc ... Testing models of redox front migration and geochem .... Testing of geochemical models in the Pocos de Calda . . . . testing and modeling by some general results on rel . . . . . . testing area at the Nevada testing site: Yucca Moun . . . . . . testing definition of subsurface sealing and backfi . . . . . . . Testing evaluations: Yucca Mountain Site Characteri . . . . . . testing material-ATM-105*

testing material-ATM-104*

testing of candidate waste container materials*

testing of coupled thermal-mechanical-hydrological- . . . . . . 
$=$ G-Tunnel pressurized slotucted in the Pahute Mesa testing area at the Nevada altered zone at Yucca Mountain: The beginning of a . . . . ic requirements for Engineered Barrier System Field =Proposed sealing field $=$ Large-scale in situ heater dration calculations for small- to large-scale seal $\ldots . . . \mathrm{ng}$ definition of subsurface sealing and backfilling
=Over-the-road .... ng definition of subsurface sealing and backfilling
=Over-the-road .... diction of mechanical excavators from linear cutter
=Field air injection .... sent in leach solutions from unsaturated spent fue ... . on plan for initial engineered barrier system field ction path modeling of aqueous geochemical systems: =MSTS - Multiphase Subsurface Transport Simulator ...... n rough-walied fractures using modified percolation

$=$ The results of near-field =Yucca Mountain Project

1 Yucca Mountain repository and recommendations for $=$ The Timber Mountain magmato=Linear

$=$ The impact of . . . f near-field thermal and mechanical calculations of eliminary reexamination of a technique for equating =Single-hole in situ $=$ Drift emplaced waste package $=A$ literature review of coupled . . . . F-A user's manual and guide for the HEFF code for ... . . . tic requirements for large block testing of coupled . . . . . a algorithm for determining the delta intercept of a =Evaluation of environmental monitoring . . . . . ew three-dimensional far-field potential repository =Instrumentation requirements for the ESF $=$ An approach to validation of =Quarterly report on program cost and schedule, $=$ The

=Estimating the

. . . . Iternative strategies: A means for saving money and

=Pre-waste-emplacement ground-water travel =Changes in risk perception over

. . . esults for pre-waste-emplacement groundwater travel $=$ Proceedings of high level radioac

=Dual-energy neutron

zation of flow in fractured tuff using computerized =Anisotropy of the

=Unconfined compression experiments on

=Total System Performance Assessment Code

tion of the Repository Integration Program (RIP) to

ibrium fracture-matrix flow on site suitability and $=$ Preliminary

=TSPA 1991: An initia

=Yucca Mountain Project

=Sensitivity analyses for

$=$ Use of Wingz spreadsheet as an interface to $=$ A simplified radionuclide source term for . . . . lary hysteresis model HYSTR into the numerical code =A suggested approach conservative organic tracers for use as hydrologic conservative organic tracers for use as hydrologic conservative organic tracers for use as hydrologic conservative organic tracers for use as hydrologic conservative organic tracers for use as hydrologic cation and characterization of conservative organic cation and characterization of conservative organic cation and characterization of conservative organic cation and characterization of conservative organic testing preparations: Yucca Mountain Site Character . . . . testing site: Yucca Mountain Site Characterization . . . . . . testing strategy*

Tests $\times$

tests for a potential high-level radioactive waste . . . . . . . tests for hydrothermal characterization at Yucca Mo . . . . . . tests in unsaturated tuff *

tests in unsaturated tuff: Yucca Mountain Site Char . . . . . . tests of nuclear materials package response to norm . . . . . tests on Yucca Mountain welded tuffs: Yucca Mountai .... tests to determine the effect of a heat cycle on th . . . . . . tests*

tests*

Theoretical manual, user's guide, and related docum . . . . .

Theoretical manual, user's guide, and related docum . . . . . theory manual×

theory

Thermal analysis of Yucca Mountain commercial high- . . . .

Thermal impact on host rock of geologic repository: . . . . . .

Thermal performance of a buried nuclear waste stora . . . . . thermal and mechanical calculations of thermal load ..... thermal and mechanical codes first benchmark exerci ... . . thermal design approaches: Yucca Mountain Site Char . . . . thermal event: An intense widespread culmination of . . . . . thermal expansion data for tuffs from the unsaturat ...... thermal loading on repository performance at Yucca . . . . . thermal loading schemes*

thermal loads: Yucca Mountain Site Characterization ..... . thermal probe for hydrothermal characterization at ..... thermal response*

thermal-hydrologic-mechanical-chemical processes pe ... . thermal-mechanical analysis using the boundary-elem . . . thermal-mechanical-hydrological-chemical processes ${ }^{*}$. . . . Thermocouple psychrometer measurements of in situ $w$... thermocouple psychrometer curve*

thermoluminescent dosimeter locations*

thermomechanical calculations: Yucca Mountain Site . . . thermomechanical experiments*

thermomechanical models

third quarter FY 1992*

Timber Mountain magmato-thermal event: An intense $w$. . . time for dissolution of spent fuel exposed to unlim . . . . . . . time on the Yucca Mountain Project*

time sensitivity and uncertainty analyses for Yucca . . . . . . timex

time*

tive waste management: Volume $1 *$

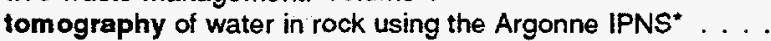
tomography*

Topopah Spring Member Tuff*

Topopah Spring Member tuff at $22^{\circ} \mathrm{C}$ and a st . . . . . . . . TOSPAC calculations in support of the COVE 2A bench ... TOSPAC): Volume 2, User's guide: Yucca Mountain Sit . . . Total System Performance Assessment Code (TOSPAC): . . Total System Performance Assessment, 1991 *

total system performance*

total-system analysis of a potential high-level nuc ....... tolal-system pertormance assessment for Yucca Mount . . . . total-system performance assessment preliminary ana . . . . total-system performance assessment*

total-system performance assessment*

total-system performance assessment: Yucca Mountain . . . TOUGH*

toward measuring sorption and applying sorption dat . . . . . tracers for the Yucca Mountain Site Characterizatio . . . . . tracers for the Yucca Mountain Site Characterizatio . . . . . . tracers for the Yucca Mountain Site Characterizatio . . . . . . tracers for the Yucca Mountain Site Characterizatio . . . . . . tracers for the Yucca Mountain Site characterizatio . . . . . . tracers for use as hydrologic tracers for the Yucca . . . . . . . tracers for use as hydrologic tracers for the Yucca . . . . . . . tracers for use as hydrologic tracers for the Yucca . . . . . . . tracers for use as hydrologic tracers for the Yucca . . . . . . . 
cation and characterization of conservative organic

$=$ Implications of stability analysis for heat

$=$ FEHMN 1.0: Finite element heat and mass . . . . sity: A preliminary examination of underground heat = Impact of fracture coatings on the =LLUVIA-II: A program for two-dimensional, $=$ Kinetics of silica-phase $=X$-ray and visible light . . . . es from exotic waste packages from partitioning and =MSTS - Multiphase Subsurface

=Simulation of two-phase carbon-14 . . . it performance assessment of hydrology and chemica $=$ PACE-90 water and solute =CTCN: Colloid $=$ Colloid

=Nonisothermal hydrologic

=Field research program for unsaturated flow and

$y$ analyses applied to one-dimensional radionuclide $=$ Flow and

. . . element computer program for analyzing liquid water . . . . . . minary characterization of materials for a reactive . . . . . iate-scale experiment to validate unsaturated-zone $=$ Proceedings of workshop 5: Flow and $=$ Proceedings of workshop 5: Flow and $=$ Proceedings of workshop 5: Flow and $=$ Proceedings of workshop 5: Flow and $=$ Proceedings of workshop 5: Flow and $=$ Proceedings of workshop 5: Flow and =Proceedings of workshop 5: Flow and $=$ Proceedings of workshop 5: Flow and $=$ Proceedings of workshop 5: Flow and $=$ Proceedings of workshop 5: Flow and =Proceedings of workshop 5: Flow and $=$ Proceedings of workshop 5: Flow and $=$ Proceedings of workshop 5: Flow and =Proceedings of workshop 5: Flow and $=$ Proceedings of workshop 5: Flow and $=$ Proceedings of workshop 5: Flow and =Proceedings of workshop 5: Flow and develop and validate conceptual models for flow and =Intra-site secure =Near-field high-temperature

. . . . onitored retrievable storage of spent nuclear fuel: $=$ Nevada commercial spent nuclear fuel =Human and social factors in the . . . . . . term risks: Implications for risk and safety in the =Yucca Mountain =Yucca Mountain . . . sment in the management of high-level nuclear waste $=$ Probabilistic risk assessment and nuclear waste $=$ A report on high-level nuclear waste $=$ Evaluation of alternatives for high-level and

=Pre-waste-emplacement ground-wate . . . . ivity results for pre-waste-emplacement groundwater ...... nstructing and editing models of seismic refraction =Influence of deterministic geologic

profiles of Native American communities: Las Vegas gement projects at WIPP and Yucca Mountain: Foreign ams being managed and implemented by NAGRA: Foreign . kshop on Near-Field Performance Assessment: Foreign =[Symposium for the STRIPA Project]: Foreign

method for determining distribution coefficients of =Institutional

.. . mparison of two conceptual models of flow using the

. . . . . emical changes associated with zeolitization of the $=$ MISTY ECHO tracers for use as hydrologic tracers for the Yucca . . . . . . . transfer at Yucca Mountain* transfer code: Revision 1*

transfer in a potential Yucca Mountain repository a . . . . . . transfer of water across fracture faces in unsatura . . . . . . . . transient flow through partially saturated porous $m \ldots \ldots$ transitions*

transmission as two-dimensional, full-field moistur . . . . . . transmutation*

Transport Simulator theory manual*

Transport of neptunium through Yucca Mountain tuffs*

transport at Yucca Mountain, Nevada*

transport at Yucca Mountain: Yucca Mountain Site Ch . . . .

transport calculations for $0.01,0.1$, and $0.5 \mathrm{~mm} / \mathrm{y} \ldots \ldots$

transport code - nuclear: A user's manual*

transport code-nuclear user's manual*

transport experimental plan*

transport experimentation*

transport in a layered fractured rock: MULTFRAC $-A \ldots \ldots$ transport in hierarchically fractured systems*

transport in porous media: Yucca Mountain Site Char . . . . transport model validation experiment*

transport models*

transport through unsaturated fractured rock - rel . . . . . . .

transport through unsaturated fractured rock - rel . . . . . .

transport through unsaturated fractured rock - rel . . . . . . .

transport through unsaturated fractured rock - rel . . . . . . .

transport through unsaturated fractured rock - rel . . . . . . .

transport through unsaturated fractured rock - rel . . . . . . .

transport through unsaturated fractured rock - rel . . . . . . .

transport through unsaturated fractured rock - rel . . . . . . .

transport through unsaturated fractured rock - rel . . . . . . .

transport through unsaturated fractured rock - rel . . . . . . .

transport through unsaturated fractured rock - rel . . . . . . .

transport through unsaturated fractured rock - rel . . . . . . .

transport through unsaturated fractured rock - rel . . . . . . .

transport through unsaturated fractured rock - rel . . . . . .

transport through unsaturated fractured rock - rel . . . . . . .

transport through unsaturated fractured rock - rel . . . . . . .

transport through unsaturated fractured rock - rel . . . . . . .

transport through unsaturated, fractured rock: Yucc . . . . . . transport vehicle*

transport: Evidence from the genesis of the Osamu U . . . . Transportation cask decontamination and maintenance ... . Transportation needs assessment: Emergency response . . Transportation studies: Draft*

transportation experience

transportation of nuclear wastes*

transportation of nuclear wastes*

transportation routes: Preliminary characterization ......

Iransportation routes: Preliminary characterization . . . . . . transportation $*$

transportation: A case study of the use of RADTRAN . . . transportation: Prepared pursuant to assembly concu . . . . transuranic radioactive- waste disposal standards*

Travel to France to attend and participate in the $T$. . . . . .

Travel to France to report on Waste Management proj . . . .

Travel to Switzerland for performance assessments $f$. . . . .

travel time sensitivity and uncertainty analyses to . . . . . . travel $\operatorname{tim} \theta *$

traveltime data using a color-graphics terminal*

trends on spatial variability of hydrologic propert . . . . . . .

Tribes of Paiute Indians*

trip report, February 2-8, 1992*

trip report, May 2-9, 1993*

trip report, May 9-16, 1993.

trip report, October 10-17, 1992*

TRU nuclides for evaluating their migration behavio . . . . . .

trust, information, and risk perceptions: Report of . . . . . . . TSA*

TSPA 1991: An initial total-system performance asse . . . . .

tuffaceous beds of Calico Hills at Yucca Mountain, .......

Tunnel Dynamics Experiment-Data report: Volume 1: . . . .
337

103

243

579

290

110

279

51

64

126

65

249

257

494

493

534

280

536

61

255

334

285

366

516

525

515

513

368

518

524

367

526

521

523

514

522

519

517

520

253

581

586

247

559

448

69

562

565

563

564

561

560

558

582

435

434

436

305

272

371

318

550

434

436

435

433

476

557

282

293

123

238 
=G- Tunnel Welded Tuff Mining Experiment instrumentatio $\ldots$.

=G- Tunnel pressurized slot-testing preparations: Yucca.

$=$ Preliminary numerical modeling for the $G$ -

Tunnel welded tuff mining experiment: Yucca Mountai . . . .

$=A$ portable vacuum hammer seismic source for use in

tunnel dynamics experiment data report: Volume 2, A . . .

$=$ TOSPAC calculations in support of the COVE $2 A$ benchmarking activity: Yucca Mountain Site Chara

\section{$\mathbf{U}$}

$=$ Geohydrologic data from test holes . . . Geohydrologic data from test holes UE-25 UZ \#4 and $=$ Hydrogeologic characterization of wells HTH-1, . . . eholes, Nevada Test Site, Nevada: Part 1, Boreholes ... . Boreholes UE25A-4, -5, -6, and -7; Part 2, Borehole . . . . drogeologic characterization of wells HTH-1, UE18r, =Quantification of

$=$ Sensitivity and . . . . mplacement ground-water travel time sensitivity and $=$ Calculation of experiment =An investigation of the impact of conceptual model ... . . . indicator simulation to characterize geostatistical

ditions of the potential Yucca Mountain Repository: =Areal power density: A preliminary examination of ive velocity response spectra at Yucca Mountain for

=Seismic design of circular-section concrete-lined of candidate waste container materials in simulated ... n: A revised and updated summary report on research $\ldots$ n: A revised and updated summary report on research . . . . . data from the Calico Hills nonwelded hydrogeologic ..... ng the location of nonmanufacturing industry in the . . . . ress report on the DOE Waste Package project at the . . . . . g g the time for dissolution of spent fuel exposed to

=Field research program for $=$ Three-dimensional modeling of $=$ Wetting front instability in an initially wet oceedings of workshop 5: Flow and transport through oceedings of workshop 5: Flow and transport through oceedings of workshop 5: Flow and transport through oceedings of workshop 5: Flow and transport through . . . oceedings of workshop 5: Flow and transport through . . . . oceedings of workshop 5: Flow and transport through . . . oceedings of workshop 5: Flow and transport through . . . oceedings of workshop 5: Flow and transport through . . . oceedings of workshop 5: Flow and transport through . . . oceedings of workshop 5: Flow and transport through . . . oceedings of workshop 5: Flow and transport through . . . oceedings of workshop 5: Flow and transport through . . . oceedings of workshop 5: Flow and transport through ... oceedings of workshop 5: Flow and transport through ... oceedings of workshop 5: Flow and transport through . . . oceedings of workshop 5: Flow and transport through . . . oceedings of workshop 5: Flow and transport through $=$ Numerical simulation of gas flow through . . . . . . acture/matrix flow in a dual-porosity simulator for $=$ Wetted-region structure in horizontal =Numerical methods for fluid flow in $=$ An inverse procedure for estimating the $s$ on the transfer of water across fracture faces in

$=$ Elements present in leach solutions from - Parametric effects on glass reaction in the $=$ The most likely groundwater flux through the
UE-25 UZ \#4 and UE-25 UZ \#5, Yucca Mountain Area, . . . UE-25 UZ \#5, Yucca Mountain Area, Nye County, Neva . . . . UE18r, UE6e, and HTH-3, Nevada Test Site*

UE25A-4, $-5,-6$, and -7 ; Part 2, Borehole UE25PNo.1 * UE25PNo.1*

UE6e, and HTH-3, Nevada Test Site*

uncertain outcomes from site characterization: Insi

Uncertainty and sensitivity results for pre-waste-e . . . . . . . uncertainty analyses applied to one-dimensional rad . . . . . uncertainty analyses for Yucca Mountain, Nevada: Yu . . . . uncertainty in laboratory determination of several . . . . . . uncertainty on the estimated performance of a hypot . . . . . uncertainty: Yucca Mountain Site Characterization P . . . . . Unconfined compression experiments on Topopah Sprin . . . Underground facilities: Yucca Mountain Site Charact . . . . . underground heat transfer in a potential Yucca Moun . . . . . underground nuclear explosions conducted in the Pah . . . . underground openings: Preclosure performance consid . . . underground water*

undertaken between 1987 and 1991: Volume 2* undertaken between 1987 and 1991: Volume 1* unheated tuff at the Nevada Test Site*

unit at Yucca Mountain, Nevada*

United States*

University of Nevada, Las Vegas, July 1, 1993 throu . . . . . unlimited water*

UNS YMSCP QA support task: Quarterly technical prog . . . unsaturated flow and transport experimentation*

unsaturated flow in the vicinity of proposed explor . . . . . . . unsaturated fracture

unseturated fractured rock - related to high-level . . . . . . unsaturated fractured rock - related to high-level . . . . . . . unsaturated fractured rock - related to high-level . . . . . . . unsaturated fractured rock - related to high-level . . . . . . . unsaturated fractured rock - related to high-level . . . . . . unsaturated fractured rock - related to high-level . . . . . . . unsaturated fractured rock - related to high-level . . . . . . . unsaturated fractured rock - related to high-level . . . . . . . unsaturated fractured rock - related to high-level . . . . . . unsaturated fractured rock - related to high-level . . . . . . . unsaturated fractured rock - related to high-level . . . . . . unsaturated fractured rock - related to high-level . . . . . . unsaturated fractured rock - related to high-level . . . . . . unsaturated fractured rock - related to high-level . . . . . . unsaturated fractured rock - related to high-level . . . . . . . unsaturated fractured rock - related to high-level . . . . . . . unsaturated fractured rock - related to high-level . . . . . . . unsaturated fractured rock at Yucca Mountain, Nevad . . . . unsaturated fractured rock masses*

unsaturated fractures: Water entry through the surr . . . . . unsaturated heterogeneous tuff*

unsaturated hydraulic conductivities of volcanic tu ...... unsaturated media

unsaturated spent fuel tests*

unsaturated test method*

unsaturated tuff matrix at USW H-1* 
otential high-level radioactive waste repository in alculations for small- to large-scale seal tests in tion of subsurface sealing and backfilling tests in $=$ Linear thermal expansion data for tuffs from the $=$ Quasi-linear analysis of water flow in the ign of a three-dimensional site-scale model for the ization of liquid-water percolation in tuffs in the conceptual models for flow and transport through

hetical high-level nuclear waste repository site in ign of an intermediate-scale experiment to validate .... zation project bibliography, January - June 1991: An

..... zation project bibliography, January-june 1992: An .... . ation Project bibliography, July-December 1992: An =Native Americans and Yucca Mountain: A revised and $=$ Native Americans and Yucca Mountain: A revised and $=$ Recent developments in stochastic modeling and =Environmental monitoring for =Natural analogue studies: Mineral alteration and port: Evidence from the genesis of the Osamu Utsum . study sites, Minas Gerais, Brazil. I. Osamu Utsumi

... . . itory and related issues: A comparative analysis of

. . . . a file preprocessor for the EQ3/6 software package: = The capillary hysteresis model HYSTR: . tem Performance Assessment Code (TOSPAC): Volume 2, =AREST

... of aqueous geochemical systems: Theoretical manual, . . . . . iation-solubility calculations: Theoretical manual, $=$ HEFF-A

=CTCN: Colloid transport code - nuclear: A =Colloid transport code-nuclear =Nuclear waste: Questionable =Assessment of geophysical logs from borehole nowater flux through the unsaturated tuff matrix at $=$ Geohydrology of rocks penetrated by test well $=$ Borehole and geohydrologic data for test hole atures of the Pocos de Caldas caldera and the Osamu redox front migration and geochemistry at the Osamu able element studies of rock samples from the Osamu ded particles and colloids in waters from the Osamu earth element geochemistry of waters from the Osamu =Microbiological analysis at the Osamu dwaters and their seasonal variability at the OSAMU

I modelling of water-rock interactions at the Osamu e transport: Evidence from the genesis of the Osamu .... e transport: Evidence from the genesis of the Osamu =Geohydrologic data from test holes UE-25 rologic data from test holes UE-25 UZ \#4 and UE-25 =Borehole and geohydrologic data for test hole USW unsaturated tuff $x$

unsaturated tuff

unsaturated tuff: Yucca Mountain Site Characterizat . . . . unsaturated zone at Yucca Mountain, Nevada: Yucca M . . . unseturated zone at Yucca Mountain, Nevada, USA* unsaturated zone at Yucca Mountain, Nevada* unsaturated zone, Yucca Mountain, Nye County, Nevad ... unsaturated, fractured rock: Yucca Mountain Site $\mathrm{Ch}$. . . . . unsaturated, fractured tuff: Yucca Mountain Site Ch ..... unsaturated-zone transport models*

Update: Supplement 2, Addendum 3*

Update: Supplement 3 , Addendum $1 *$

update, Supplement 3, Addendum 2: Civilian Radioact . . . . updated summary report on research undertaken betwe . . updated summary report on research undertaken betwe ... upscaling of hydrologic properties in tuff*

uranium and neptunium at Yucca Mountain using Epith . . . uranium migration

uranium mine, Pocos de Caldas alkaline complex, Bra . . . . uranium mine: Pocos de Caldas Report No. 2*

urban and rural survey data*

USDOE Office of Civilian Radioactive Waste Manageme

User's guide and related documentation (Version $7.0 \ldots \ldots$ User's quide*

User's guide: Yucca Mountain Site Characterization . . . . user's guide, PC version $x$

user's guide, and related documentation (Version 7. . . . . . .

user's guide, and related documentation (Version $7 \ldots . .$.

user's manual and guide for the HEFF code for therm . . . . . user's manual*

user's manual*

uses of program funds at Lawrence Livermore Lab.*

USW G-2, Yucca Mountain, Nevada

USW $\mathrm{H}-1$ *

USW H-6, Yucca Mountain, Nye County, Nevada*

USW UZ-6, Yucca Mountain area, Nye County, Nevada*

Utsumi mine and Morro do Ferro analogue study sites . . . .

Utsumi mine and Morro do Ferro analogue study sites . . . .

Utsumi mine and Morro do Ferro analogue study sites . . . .

Utsumi mine and Morro do Ferro analogue study sites ... . .

Utsumi mine and Morro do Ferro analogue study sites . . .

Utsumi mine and Morro do Ferro analogue study sites . . . .

Utsumi mine and Morro do Ferro analogue study sites . . . .

Utsumi mine and Morro do Ferro analogue study sites ... . .

Utsumi uranium mine, Pocos de Caldas alkaline compl . . . .

Utsumi uranium mine: Pocos de Caldas Report No. 2*

UZ \#4 and UE-25 UZ \#5, Yucca Mountain Area, Nye C . . . .

UZ *5, Yucca Mountain Area, Nye County, Nevada*

UZ-6, Yucca Mountain area, Nye County, Nevadax
286

287

307

228

258

53

361

253

256

285

19

21

22

549

548

321

447

477

586

501

547

452

201

37

217

154

203

202

223

494

493

468

387

338

390

382

583

508

504

506

505

585

584

509

586

501

372

372

382

\section{v}

$=E 03 / 6$

$=E Q 3 / 6$

$=A$ portable

$=$ Research program to develop and

$=$ Design of an intermediate-scale experiment to

ization of materials for a reactive transport mode

=Radionuclide migration laboratory studies for =An approach to

=Preliminary mapping of surficial geology of Midway

$=$ Recent characterization activities of Midway

data near prospective surface facilities in Midway

= Late quaternary faulting along the Death

opic composition of groundwaters and their seasonal

fluence of deterministic geologic trends on spatial = Intra-site secure transport $=$ Prediction of Pseudo relative =Groundwater flow code

$=$ Documentation and

$=$ Documentation and

$=$ Documentation and verification of STRES3D,

77.0: Geochemical Modeling Of Aqueous Systems*

V7.1: Geochemical Modeling of Aqueous Systems*

vacuum hammer seismic source for use in tunnel envi . . .

validate conceptual models for flow and transport t . . . . . .

validate unsaturated-zone transport models*

validation experiment*

validation of batch sorption data*

validation of thermomechanical models*

Valley Yucca Mountain Project, Nye County, Nevada: . . . .

Valley as a potential repository surface facility s . . . . . . . .

Valley, Yucca Mountain Project, Nye County, Nevada: . . . .

Valley-Furnace Creek fault system, California and $N$. . . . .

variability at the OSAMU Utsumi mine and Morro do F . . . .

variability of hydrologic properties in volcanic tu . . . . . . .

vehicle*

velocity response spectra at Yucca Mountain for und . . . . .

verification "benchmarking" activity (COVE-2A): A .......

verification of STRES3D, Version 4.0: Yucca Mountai . . . .

verification of the SHAFT code: Yucca Mountain Site . . . .

Version 4.0: Yucca Mountain Site Characterization P . . . . . 
... hanical analysis using the boundary-element method: . . . . us systems: Package overview and installation guide . . . . are package: User's guide and related documentation ... . cal manual, user's guide, and related documentation . . . . cal manual, user's guide, and related documentation $=$ AREST user's guide, $P C$ . . . . Waste Package Project: Parts A \& B, ASME pressure =Southern Nevada residents $=X$-ray and $=$ Developing a functioning =Three dimensional =Center for $=$ The Lathrop Wells $=$ The Lathrop Wells . . . . dy of water table excursions induced by seismic and =Recurrence models of . . . . nd hydrothermal activity at the southwestern Nevada . . . . c currence models of volcanic events: Applications to =Laboratory analysis of hydraulic properties of on spatial variability of hydrologic properties in ....... imating the unsaturated hydraulic conductivities of .. emical evidence for waning magmatism and polycyclic
Version 4.1: Yucca Mountain Site Characterization P . . . . Version 7.0)*

Version 7.0): Part 2*

Version 7.0): Part 3*

Version 7.0): Part 4*

version*

vessel codes review for waste package application; . . . . viows about the Yucca Mountain high-level nuclear w ...... visible light transmission as two-dimensional, full . . . . . . visualization and analysis system for performance a . . . . . visualization in support of Yucca Mountain Site cha . . . . . . Volcanic and Tectonic Studies, Department of Geosci. . . . . . volcanic center: Status of field and geochronology . . . . . . volcanic center: Status of field and geochronology . . . . . volcanic events

volcanic events: Applications to volcanic risk asse . . . . . volcanic field*

volcanic risk assessment*

volcanic tuff samples*

volcanic tuffs*

volcanism at Crater Flat, Nevada* volcanic tuff*

\section{W}

$=$ Modeling gravity-driven fingering in rough=Geochemical evidence for $=$ Gravity and magnetic data of Fortymile . . . . . and social factors in the transportation of nuclear . . . . . . or risk and safety in the transportation of nuclear . . . . . osal of spent fuel and high level and alpha bearing ..... gion structure in horizontal unsaturated fractures:

=Impact of fracture coatings on the transfer of =Estimation of the limitations for surficia =PACE-90

Fingerprinting of ground lide sorption on sample grinding, surface area, and $x$ Risk-based screening analysis of ground =Ground$=$ A preliminary study of the chemistry of pore Quasi-linear analysis of ..... charge occur at a discharge area within the ground=Movement of shaft and drift construction =Dual-energy neutron tomography of $=$ Estimation of the impact of $=$ Ground

$=$ Characterization of liquid=Thermocouple psychrometer measurements of in situ $=$ Eighteenth

. . . . a Mountain repository block to the regional ground$=$ A scoping study of =Estimating the

. . . . inite element computer program for analyzing liquid $=$ Pre-waste-emplacement ground.... or Yucca Mountain and vicinity, Nye County, Nevada, .... Nevada Test Site and vicinity, Nye County, Nevada, . . . . . waste container materials in simulated underground . . . . . . for dissolution of spent fuel exposed to unlimited $=$ Simulated $=$ Earthquake-induced $=$ Earthquake-induced - Geochemical modelling of . . . . . acterisation of suspended particles and colloids in . . . . radionuclide and rare-earth element geochemistry of ... m the Yucca Mountain region: Milestone report 3010$=$ G-Tunne

$=$ Preliminary numerical modeling for the G-Tunnel . e the effect of a heat cycle on the permeability of $\ldots$ sample inhomogeneity on the moduli and strength of

.... ements of in situ water potential changes in heated

walled fractures using modified percolation theory $\ldots$. . . . . waning magmatism and polycyclic volcanism at Crater . . . . . Wash, Nevada Test Site, Nevadax

wastes*

wastes*

wastes: Proceedings of an international symposium $h \ldots$. Water entry through the surrounding porous matrix*

Water levels in continuously monitored wells in the ......

Water-rock interactions and the pH stability of gro . . . . . . water across fracture faces in unsaturated mediax

water addition above a potential high level radioac . . . . . . . water and solute transport calculations for $0.01,0 \ldots \ldots$. water by ICP-MS: Progress report, July 1, 1991-Dec . . . . water composition*

water contaminated by radionuclides introduced at $\mathrm{t}$. . . . . . water data collected at the Nevada Test Site and vi . . . . . . water extracted from tuff by one-dimensional compre . . . . . water flow in the unsaturated zone at Yucca Mountai .... . water flow system of Yucca Mountain, Nevada?*

water in Yucca Mountain, Nevada: An extended study: . . . . water in rock using the Argonne IPNS*

water movement from sewage and settling ponds near . . . water of Yucca Mountain: How high can it rise?: Fin . . . . water percolation in tuffs in the unsaturated zone,$\ldots \ldots \ldots$ water potential changes in heated welded tuff *

water reactor safety information meeting. Proceedin . . . . . . water system: A geochemical model*

water table excursions induced by seismic and volca . . . . . water table under the Radioactive Waste Management . . . . water transport in porous media: Yucca Mountain Sit . . . . . water travel time sensitivity and uncertainty analy . . . . . . . water years 1983-85*

water years $1988-89 *$

water*

water*

weter-level declines caused by withdrawais from wel ..... water-level fluctuations at Yucca Mountain, Nevada, . . . . . . water-level fluctuations at Yucca Mountain, Nevada, . . . . . . . water-rock interactions at the Osamu Uisumi mine an ...... waters from the Osamu Utsumi mine and Morro do Ferr . . . waters from the Osamu Utsumi mine and Morro do Ferr ... WBS 1.2.3.4.1.3.1\%

Welded Tuff Mining Experiment instrumentation evalu . . . . . welded tuff mining experiment: Yucca Mountain site . . . . . welded tuff,

welded tuff $x$

welded tuff* 
d deformability of replicas of natural fractures in . . . . . d deformability of replicas of natural fractures in $=$ Borehole stability in densely

.... . cavators from linear cutter tests on Yucca Mountain =Geohydrology of rocks penetrated by test

$=$ The Lathrop =The Lathrop

$=$ Hydrogeologic characterization of . . . . . ted water-level declines caused by withdrawals from $=$ Water levels in continuously monitored $=$ Wetting front instability in an initially

$=$ Expert judgment in assessing radwaste risks: =DOE's Yucca Mountain studies: = Mineralogy, petrology and =Mineralogy, petrology and $=$ DOE's Yucca Mountain studies: What are they? . . . e Timber Mountain magmato-thermal event: An intense $=$ Use of

.... to France to report on Waste Management projects at =Simulated water-level declines caused by

=Nuclear waste management review . . . . . . ing" activity (COVE-2A): Analysis of participants' $=A$
Strategic principles

$=L L N L$ =Bibliography of Yucca Mountain Project $=$ UNS ... . ioeconomic profiles of native American communities .... . transport calculations for $0.01,0.1$, and $0.5 \mathrm{~mm} /$

$=$ Distribution and chemistry of fracture-lining $=$ Equilibrium modeling of the formation of $=$ The importance of

$=$ Chemical changes associated with . . . . ee-dimensional site-scale model for the unsaturated . . . . . . si-linear analysis of water flow in the unsaturated ... . ermal expansion data for tuffs from the unsaturated =Characterizing the altered

$=$ Regional groundwater modeling of the saturated ermediate-scale experiment to validate unsaturated...... . iquid-water percolation in tuffs in the unsaturated $\ldots .$. iffusion releases through one and two finite planar $=$ The role of fault welded tuff: Comparison between predicted and obser . . . . welded tuff: Data report: Yucca Mountain Site Chara . . . . . welded tuffs*

welded tuffs: Yucca Mountain Site Characterization ..... well USW H-6, Yucca Mountain, Nye County, Nevada*

Wells volcanic center: Status of field and geochron ....... Wells volcanic center: Status of field and geochron . . . . . . wells HTH-1, UE1 8r, UE6e, and HTH-3, Nevada Test Si . . . wells $J-13$ and $J-12$ near Yucca Mountain, Nevada*

wells in the Yucca Mountain area, Nevada, 1985-88* . . . . . wet unsaturated fracture*

Wetted-region structure in horizontal unsaturated $f . . . .$. Wetting front instability in an initially wet unsat . . . . . . . . What Nevadans should know about Yucca Mountain: [Fi . . . What are they? Why are they being done?*

whole-rock chemistry data compilation for selected ......

whole-rock chemistry of selected mechanical test sa ..... Why are they being done?*

widespread culmination of magmatic and hydrothermal . . . . Wingz spreadsheet as an interface to total-system $p$..... WIPP and Yucca Mountain: Foreign trip report, Fobru . . . . . withdrawals from wells $\mathrm{J}-13$ and $\mathrm{J}-12$ near Yucca Mou . . . Word images as policy instruments: Lessons from the .... work - part of the decision making process* work*

working definition of scenario and a method of scen .... workshops: Discussion drafts and workshop notes*

\section{Y}

YMP Waste Container Fabrication and Closure Project .... YMP) publications at Lawrence Livermore National La . . . . . YMSCP QA support task: Quarterly technical progress .... . Yomba Shoshone Reservation* yr infiltration into Yucca Mountain: Yucca Mountain . . . . . .

314

\section{$\mathbf{Z}$}

zeolites at Yucca Mountain. Nevada

zeolitization of the tuffaceous beds of Calico Hill .......

zone at Yucca Mountain, Nevada* $\ldots . . .$.

zone at Yucca Mountain, Nevada, USA*

zone at Yucca Mountain, Nevada: Yucca Mountain Site . . . . . 228

zone at Yucca Mountain: The beginning of a testing . . . .

zone in the vicinity of Yucca Mountain, Nevada: Ite .......

zone transport modeis $* \quad . . .$.

zone, Yucca Mountain, Nye County, Nevada*

zones from a nuclear waste package* 167

zones in affecting multiphase flow at Yucca Mountai . . . . . . 60 